QA: QA

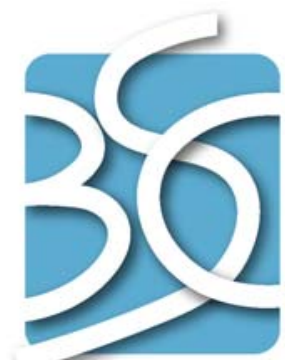

BECHTEL SAIC COMPANYLC

ANL-EBS-MD-000033 REV 05

August 2005

\title{
Engineered Barrier System: Physical and Chemical Environment
}

Prepared for:

U.S. Department of Energy

Office of Civilian Radioactive Waste Management

Office of Repository Development

1551 Hillshire Drive

Las Vegas, Nevada 89134-6321

Prepared by:

Bechtel SAIC Company, LLC

1180 Town Center Drive

Las Vegas, Nevada 89144

Under Contract Number

DE-AC28-01RW12101 


\section{DISCLAIMER}

This report was prepared as an account of work sponsored by an agency of the United States Government. Neither the United States Government nor any agency thereof, nor any of their employees, nor any of their contractors, subcontractors or their employees, makes any warranty, express or implied, or assumes any legal liability or responsibility for the accuracy, completeness, or any third party's use or the results of such use of any information, apparatus, product, or process disclosed, or represents that its use would not infringe privately owned rights. Reference herein to any specific commercial product, process, or service by trade name, trademark, manufacturer, or otherwise, does not necessarily constitute or imply its endorsement, recommendation, or favoring by the United States Government or any agency thereof or its contractors or subcontractors. The views and opinions of authors expressed herein do not necessarily state or reflect those of the United States Government or any agency thereof. 
QA: QA

Engineered Barrier System: Physical and Chemical Environment ANL-EBS-MD-000033 REV 05

August 2005 


\begin{tabular}{c|c|l} 
BSC & $\begin{array}{c}\text { Model Signature Page/Change History } \\
\text { Complete only applicable items. }\end{array}$ & $\begin{array}{l}\text { Page iii } \\
\text { 1. Total Pages: } 476\end{array}$
\end{tabular}

2. Type of Mathematical Model
$\square$ Process Model
Describe Intended Use of Model
The principal intentions of this model and analysis activity are:
- Evaluate the changes in the chemical environment that affect drip shield degradation, waste package degradation, and
radionuclide migration through the invert.
- Provide valid models that will be used for the future integration of EBS thermal, hydrological, and chemical (THC)
processes, which directly support the TSPA model.
Evaluate uncertainties associated with the models.

3. Title

Engineered Barrier System: Physical and Chemical Environment

4. DI (including Rev. No.):

ANL-EBS-MD-000033 REV 05

\begin{tabular}{|l|l|l|}
\hline & Printed Name & Signature \\
\hline $\begin{array}{l}\text { 5. } \text { Originator } \\
\text { Reviewer }\end{array}$ & R. Jarek & Dhomas \\
\hline 7. Checker & W. Downs & K. Gilkerson \\
\hline 8. QER & W. Duffy & E. Hardin \\
\hline 9. Responsible Manager/Lead & &
\end{tabular}

Acknowledgements: Revisions 03 and 04 had significant assistance from David Shields. Revision 02 was originated by Darren Jolley and technically supported by (alphabetically): Russell Jarek, Carlos Jove-Colon, Paul Mariner, and Richard Metcalf.

\begin{tabular}{|l|l|}
\hline \multicolumn{2}{|c|}{ Change History } \\
\hline 12. Revision No. & \multicolumn{1}{|c|}{ 13. Description of Change } \\
\hline REV 00 & Initial Issue. \\
\hline REV 00 ICN 01 & Editorial changes in Response to AP-7.5Q acceptance review. Also corrected DTN in Section \\
& $\begin{array}{l}6.1 .8 . \text { Replaced DTN: GS961108312771.002 with DTN: MO0005PORWATER.000 for } \\
\text { composition of pore water sample in Section 4.1.2.2. Editorial changes throughout. }\end{array}$ \\
\hline
\end{tabular}




\begin{tabular}{|l|l|}
\hline REV 01 & $\begin{array}{l}\text { Revised for no-backfill design, and to include FEPs and IRSR analyses, and to address data } \\
\text { qualification issues in Sections 4 and 5. Thermal-hydrology calculations are taken from } \\
\text { another AMR, and discussions were added for fungal observations from the ECRB and the } \\
\text { prediction of minerals formed by drying waters from THC calculation. Water compositions } \\
\text { were re-calculated using a Pitzer model. }\end{array}$ \\
\hline REV 02 & $\begin{array}{l}\text { Revision to address removal or replacement of non-LA product input (i.e. historical TPO or } \\
\text { other information). }\end{array}$ \\
\hline REV 03 & $\begin{array}{l}\text { Revision to address Regulatory Integration Team comments to enhance transparency. The in- } \\
\text { drift oxygen balance was re-calculated, and model validation was augmented by inclusion of } \\
\text { additional pore water analyses. }\end{array}$ \\
\hline REV 04 & $\begin{array}{l}\text { Revision due to issues from CRs: CR-4290, CR-4713, CR-4961, CR-5673; and from TMRB } \\
\text { decisions: TMRB-2005-007, TMRB-2005-016, TMRB-2005-026 and TMRB-2005-033. All } \\
\text { changes from REV03 ACN01 are incorporated. Changes are indicated by vertical lines. }\end{array}$ \\
\hline REV 05 & DOE Comment Incorporation. Revision addresses CR-6242. \\
\hline
\end{tabular}




\section{CONTENTS}

Page

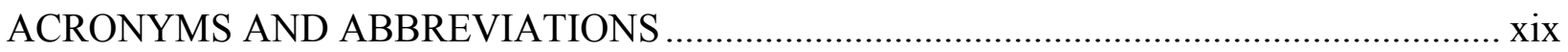

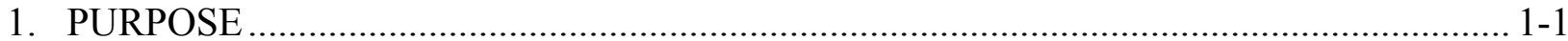

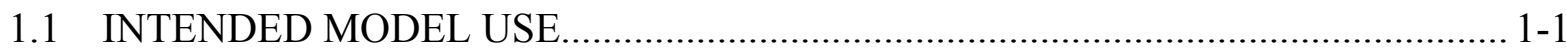

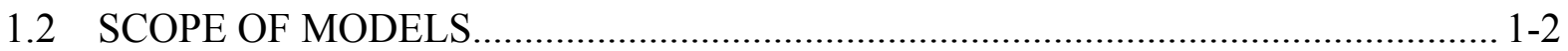

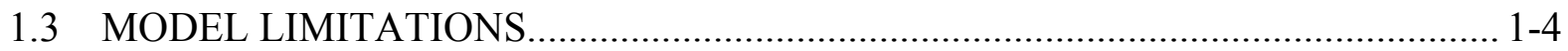

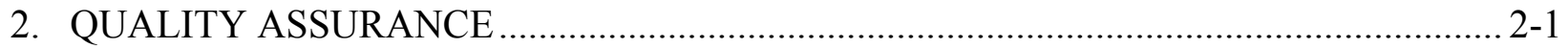

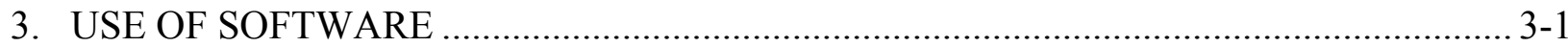

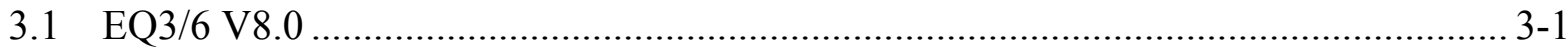

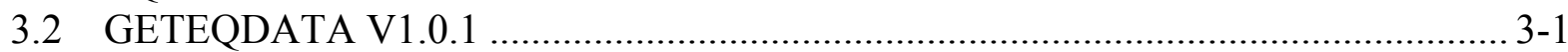

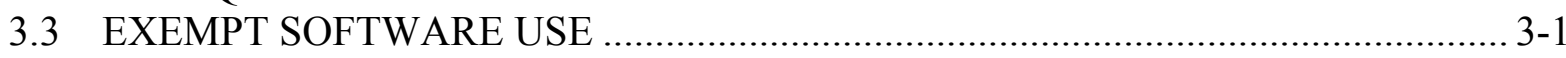

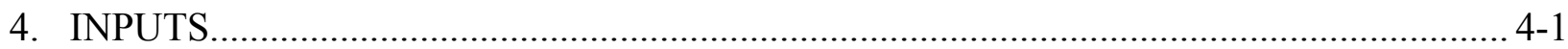

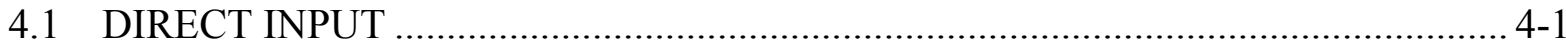

4.1.1 Material Corrosion Rates ........................................................................ 4-1

4.1.2 Committed Low-Alloy or Carbon Steel Materials ............................................ 4-5

4.1.3 Environmental Compositions ................................................................... 4-6

4.1.4 Thermodynamic Databases..................................................................... 4-11

4.1.5 In-Drift Evaporation ........................................................................ 4-12

4.1.6 Stainless Steel Corrosion Chemistry..................................................... 4-12

4.1.7 Inputs Used for Sensitivity Studies...................................................... 4-15

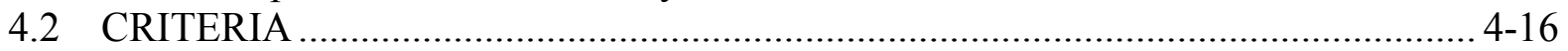

4.2.1 Acceptance Criteria Addressed............................................................. 4-16

4.2.2 Acceptance Criteria Not Addressed......................................................... 4-21

4.3 CODES, STANDARDS, AND REGULATIONS ............................................. 4-22

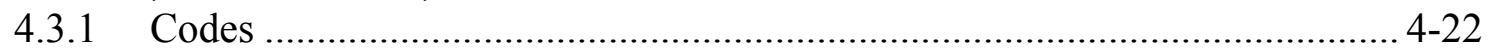

4.3.2 Standards ....................................................................................... 4-22

4.3.3 Level of Accuracy, Precision, and Representativeness of Results ................ 4-23

4.4 INPUTS USED FOR MODEL VALIDATION OR CONFIDENCE BUILDING .... 4-24

4.4.1 Indirect Inputs from the THC Seepage Model........................................... 4-24

4.4.2 Evaporation of Waters to Form Concentrated Brines...................................... 4-24

4.4.3 Chromium Calculation............................................................................ 4-25

4.4.4 Repository Horizon Pore Waters ............................................................ 4-25

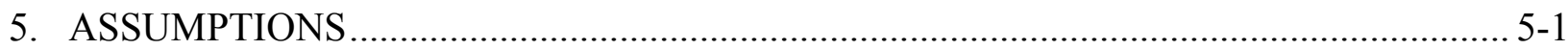

5.1 DISCUSSION OF ASSUMPTIONS IN UPSTREAM DOCUMENTATION ............ 5-1

5.1.1 Standard State of Liquid Phase (Assumption 5.1 of the IDPS Model)............ 5-1

5.1.2 Equilibrium Conditions (Assumption 5.2 of the IDPS Model) ……............... 5-1

5.1.3 Repository Location (Assumption 1 from THC Model) ................................. 5-2

5.1.4 Representative Distribution of Seepage Water Compositions (Assumption 2 from THC Model) ............................................................... 5-3 


\section{CONTENTS (Continued)}

Page

5.2 ASSUMPTIONS INTERNAL TO PHYSICAL AND CHEMICAL ENVIRONMENT MODEL ........................................................................... 5-4

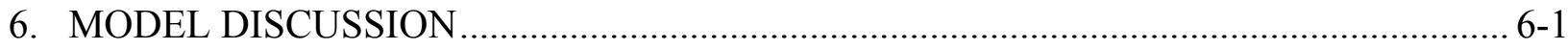

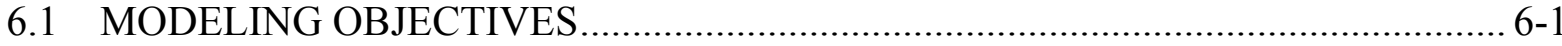

6.2 ENGINEERED BARRIER SYSTEM PHYSICAL AND CHEMICAL ENVIRONMENT CONCEPTUAL MODEL......................................................... 6-3

6.2.1 Integrated Perspective on the Evolution of the Engineered Barrier System Physical and Chemical Environments................................................ 6-3

6.2.2 Evolution of Engineered Barrier System Chemical Environment by Process ....................................................................................... 6-4

6.2.3 Conceptual Description of Engineered Barrier System Chemical Environments by Spatial Location........................................................... 6-7

6.2.4 Engineered Barrier System Physical and Chemical Environment Conceptual Model Locations .

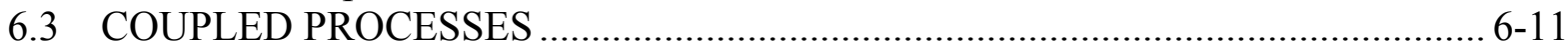

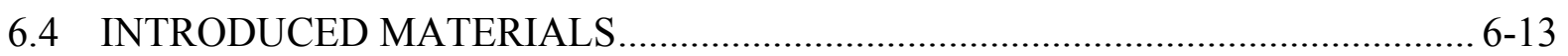

6.4.1 Material Corrosion Rates ....................................................................... 6-14

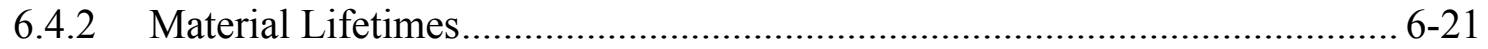

6.5 GEOCHEMICAL MODELING CONSTRAINTS.............................................. 6-23

6.5.1 Mathematical Models Implemented by the Use of EQ3/6 V8.0

Geochemical Modeling Software .......................................................... 6-24

6.5.2 Geochemical Modeling Methodology .................................................. 6-30

6.5.3 Equilibrium versus Kinetics............................................................... 6-30

6.5.4 Engineered Barrier System Geochemical Equilibrium Modeling ................ 6-33

6.5.5 Rationale for Including or Excluding Precipitating Minerals....................... 6-37

6.6 INCOMING SEEPAGE COMPOSITION ANALYSIS ....................................... 6-43

6.6.1 Conceptual Framework Summary for the Seepage Binning Analysis ......... 6-44

6.6.2 Thermal-Hydrological-Chemical Initial Seepage Input (Step 1)................. 6-45

6.6.3 Evaporate Waters to a Common Degree of Concentration (Step 2)............. 6-45

6.6.4 Evaporated Seepage Water Composition Bin Generation (Step 3) .............. 6-48

6.6.5 Choice of Representative Evaporated Seepage Water for Each Bin

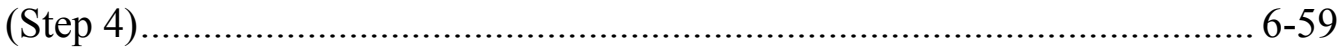

6.6.6 Analysis of THC Model Outputs: Defining Time Sequences of Bins for Seepage Water Composition Time Histories from THC Model Outputs ..................................................................................... 6-61

6.6.7 Impact Analysis Due to Errors Identified during Check Process ................. 6-75

6.7 EVOLUTION OF IN-DRIFT GAS AND TEMPERATURE .............................. 6-79

6.7.1 Oxygen Evaluation ............................................................................ 6-79

6.7.2 Thermal-Hydrological-Chemical Seepage Model Input to In-Drift $\mathrm{CO}_{2}$ Gas Abstraction............................................................................. 6-85

6.7.3 In-Drift $p \mathrm{CO}_{2}$ and Temperature Range for Seepage Evaporation Abstraction 


\section{CONTENTS (Continued)}

Page

6.7.4 THC Seepage Water Equilibrium Gas Pressures......................................... 6-94

6.8 GROUND SUPPORT INTERACTIONS WITH SEEPAGE WATER.................... 6-96

6.8.1 Corrosion Product Concepts ........................................................................... 6-96

6.8.2 Definition of Base Case ........................................................................... 6-102

6.8.3 Modeling Stainless Steel Type 316L and Its Corrosion Rate.................... 6-106

6.8.4 Seepage-Steel Interaction Modeling and Base-Case Limitations ............... 6-108

6.9 IN-DRIFT SEEPAGE EVAPORATION ABSTRACTION ............................. 6-111

6.9.1 Evaporated Seepage Water Inputs ......................................................... 6-111

6.9.2 Temperature and Carbon Dioxide.......................................................... 6-112

6.9.3 No Dilution for Invert Seepage........................................................ 6-116

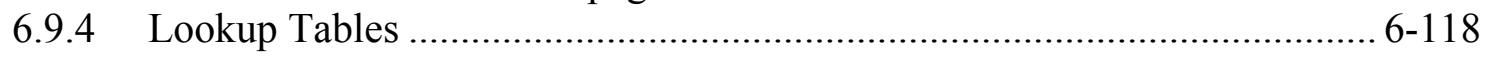

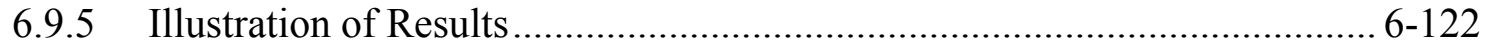

6.10 EVALUATION OF DUST DEPOSITED ON WASTE PACKAGES ................... 6-127

6.11 ALTERNATIVE CONCEPTUAL MODEL …......................................................... 6-130

6.11.1 Alternative Binning Analysis of Evaporated Seepage Waters ................... 6-130

6.12 EVALUATION OF KEY UNCERTAINTIES .................................................. 6-140

6.12.1 Uncertainties and Variabilities in the Inputs from

THC Model Calculations ................................................................... 6-141

6.12.2 Uncertainties in the IDPS Model That Affect Characterization and

Binning of Evaporated Seepage Water Compositions............................. 6-142

6.12.3 Discretization Uncertainty Associated with Seepage

Evaporation Abstraction ........................................................................ 6-143

6.12.4 Factors Showing No Significant Impact on Water Chemistry ................... 6-145

6.12.5 Implementing Abstraction Uncertainties in the TSPA-LA

Lookup Tables .............................................................................. 6-163

6.13 ENGINEERED BARRIER SYSTEM CHEMICAL ENVIRONMENT ................. 6-169

6.13.1 Engineered Barrier System Seepage Chemistry .................................... 6-177

6.13.2 Lookup Table Interpolation for Seepage ................................................. 6-189

6.13.3 Chemical Environments on the Drip Shield and Waste Package ............... 6-189

6.13.4 Chemical Environment in the Invert.................................................... 6-197

6.13.5 Comparison to Corrosion Testing Chemistries........................................ 6-202

6.13.6 Transport-Affected Salt Assemblages ................................................ 6-208

6.14 EVALUATION OF FEATURES, EVENTS, AND PROCESSES ....................... 6-210

6.15 IMPLEMENTATION INSTRUCTIONS FOR THE TSPA-LA MODEL............... 6-212

6.15.1 Implementation of Engineered Barrier System Chemistry on Waste

Package Surfaces: Seepage or "Dripping Scenario"................................. 6-212

6.15.2 Implementation of Engineered Barrier System Chemistry in the Invert ..... 6-215

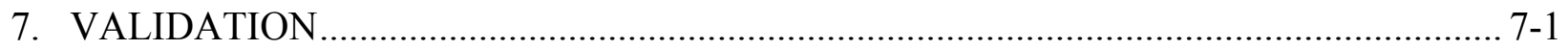

7.1 IN-DRIFT SEEPAGE EVAPORATION ABSTRACTION .................................. 7-2

7.1.1 Comparison of Seepage Evaporation Abstraction to IDPS Model ................. 7-4

7.2 IN-DRIFT GAS MODEL ABSTRACTION …...................................................

7.2.1 Oxygen Fugacity Submodel.................................................................. 7-9 


\section{CONTENTS (Continued)}

Page

7.2.2 Carbon Dioxide Abstraction .................................................................... 7-10

7.3 SUPPLEMENTARY CONFIDENCE BUILDING INFORMATION ..................... 7-12

7.3.1 Binning of Repository-Horizon Pore Waters......................................... 7-12

7.3.2 Confirmation of Binning Variability ......................................................... 7-14

7.3.3 Evaporation of Sierra Nevada Spring Waters to Form

Concentrated Brines........................................................................... 7-26

7.3.4 Comparison of THC Seepage Model with Seepage Binning Analysis ......... 7-29

7.4 VALIDATION SUMMARY …...................................................................... $7-40$

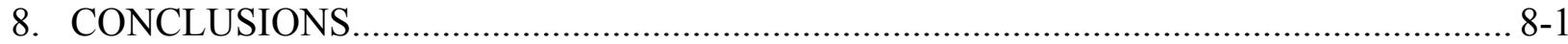

8.1 SUMMARY AND MODEL FINDINGS …...................................................... 8-1

8.2 SUMMARY OF MODEL ABSTRACTION FOR TOTAL SYSTEM PERFORMANCE ASSESSMENT ................................................................... 8-2

8.2.1 Summary of the Total System Performance Assessment Lookup Tables ....... 8-2

8.2.2 Data Tracking Numbers for Data Generated in This Report ......................... 8-4

8.3 ABSTRACTION MODEL UNCERTAINTY AND RESTRICTIONS ................... 8-6

8.4 YUCCA MOUNTAIN REVIEW PLAN CRITERIA ASSESSMENT...................... 8-7

8.4.1 Acceptance Criteria for Quantity and Chemistry of Water Contacting Engineered Barriers and Waste Forms ................................................. 8-7

9. INPUTS AND REFERENCES .......................................................................... 9-1

9.1 DOCUMENTS CITED ............................................................................... 9-1

9.2 CODES, STANDARDS, REGULATIONS, AND PROCEDURES ........................ 9-13

9.3 SOURCE DATA, LISTED BY DATA TRACKING NUMBER ........................... 9-15

9.4 OUTPUT DATA, LISTED BY DATA TRACKING NUMBER …....................... 9-16

9.5 SOFTWARE CODES ........................................................................................ 9-18

APPENDIX A： SUPPORTING FILES ..................................................................... A-1

APPENDIX B: THC SEEPAGE LOOKUP TABLE RESULTS ..........................................1

APPENDIX C: CRITIQUE OF EXCLUDED MINERALS …...........................................

APPENDIX D: QUALIFICATION OF DATA FROM DTN: LL980704605924.035 FOR

INTENDED USE PER LP-SIII.2Q-BSC ................................................ D-1 


\section{FIGURES}

6.1-1. Major EBS Environment Process Flowchart, with Section References

6.2-1. Simplified Chemical Divides Diagram Based on Evaporative Concentration of Dilute Starting Waters to Form a Suite of Naturally Occurring Lake Waters ...... 6-5

6.2-2. Rock Moisture Content as a Function of Temperature as Measured from Neutron Logging of Borehole 79 during the DST Heating Phase.

6.2-3. Schematic Illustration of Locations of Important Interfaces and Fluxes in the Engineered Barrier System

6.4-1. General Location of Engineered Barrier System Components and Materials ......... 6-14

6.4-2. Corrosion Rates for Mild Steel in Water, Plotted as a Function of

Temperature $\left({ }^{\circ} \mathrm{C}\right)$

6.4-3. Relative Material Lifetimes Using the Mean or 50th Percentile, Minimum, and Maximum Corrosion Rates from Table 6.4-8.

6.5-1. Simplified Roadmap of the Process Required to Give a Valid Technical Basis for Mineral Suppression or Inclusion in Geochemical Equilibrium Modeling ....... 6-32

6.6-1. Selected Molal Ratios $(\mathrm{Cl} / \mathrm{N}, \mathrm{Cl} / \mathrm{S}, \mathrm{Cl} / \mathrm{F}, \mathrm{Na} / \mathrm{K}, \mathrm{K} / \mathrm{N}$, and $\mathrm{Na} / \mathrm{C})$ from the Evaporation of the 368 Seepage Waters to $65 \%$ Relative Humidity, Used in the Binning Analysis to Establish Binning Criteria....

6.6-2. Selected Molal Ratios $(\mathrm{Cl} / \mathrm{Na}, \mathrm{Ca} / \mathrm{K}, \mathrm{Ca} / \mathrm{C}, \mathrm{Cl} / \mathrm{C}, \mathrm{Ca} / \mathrm{N})$ and $\mathrm{pH}$ from the Evaporation of the 368 Seepage Waters to $65 \%$ Relative Humidity, Used in the Binning Analysis to Establish Binning Criteria

6.6-3. Mineral Assemblages of the 368 Selected Seepage Waters after Evaporation to $65 \%$ Relative Humidity

6.6-4. Evaporated Water Compositions for All Bins after Evaporation to $65 \%$ Relative Humidity

6.6-5. Evaporated Water Compositions for Bin 1 after Evaporation to $65 \%$ Relative Humidity

6.6-6. Evaporated Water Compositions for Bin 2 after Evaporation to $65 \%$ Relative Humidity

6.6-7. Evaporated Water Compositions for Bin 3 after Evaporation to $65 \%$ Relative Humidity

6.6-8. Evaporated Water Compositions for Bin 4 after Evaporation to $65 \%$ Relative Humidity

6.6-9. Evaporated Water Compositions for Bin 5 after Evaporation to $65 \%$ Relative Humidity

6.6-10. Evaporated Water Compositions for Bin 6 after Evaporation to $65 \%$ Relative Humidity

6.6-11. Evaporated Water Compositions for Bin 7 after Evaporation to $65 \%$ Relative Humidity

6.6-12. Evaporated Water Compositions for Bin 8 after Evaporation to $65 \%$ Relative Humidity

6.6-13. Evaporated Water Compositions for Bin 9 after Evaporation to $65 \%$ Relative Humidity 


\section{FIGURES (Continued)}

Page

6.6-14. Evaporated Water Compositions for Bin 10 after Evaporation to $65 \%$ Relative Humidity

6.6-15. Evaporated Water Compositions for Bin 11 after Evaporation to $65 \%$ Relative Humidity ...................................................................................... 6-58

6.6-16. Bins for Evaporated Crown Seepage: Case w0tf4 .......................................... 6-63

6.6-17. Bins for Evaporated Invert Seepage: Case w0bf4 ........................................ 6-63

6.6-18. Bins for Evaporated Crown Seepage: Case w4tf4 ........................................... 6-64

6.6-19. Bins for Evaporated Invert Seepage: Case w4bf4 .......................................... 6-64

6.6-20. Bins for Evaporated Crown Seepage: Case w5tf4 ............................................ 6-65

6.6-21. Bins for Evaporated Invert Seepage: Case w5bf4 .......................................... 6-65

6.6-22. Bins for Evaporated Invert Seepage: Case w6tf4 .......................................... 6-66

6.6-23. Bins for Evaporated Invert Seepage: Case w6bf4 ........................................ 6-66

6.6-24. Bins for Evaporated Invert Seepage: Case w7tf4 .......................................... 6-67

6.6-25. Bins for Evaporated Invert Seepage: Case w7bf4 .......................................... 6-67

6.6-26. Comparison of Elemental Species Concentrations, N/Cl Ratio and $\mathrm{pH}$

Between the w0 Water (Solid Lines) and the w4 Water (Dashed Lines)

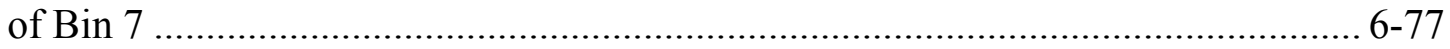

6.7-1. In-Drift Crown Air Fraction from THC Seepage Model for All Five

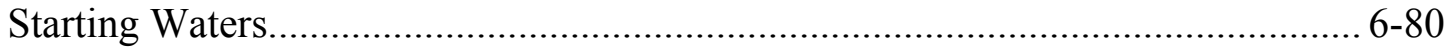

6.7-2. Gas Flux per Axial Meter of Drift per Year .................................................. 6-82

6.7-3. $\quad \mathrm{THC} \mathrm{CO}$ Partial Pressure in the Drift and Near-Drift Environment

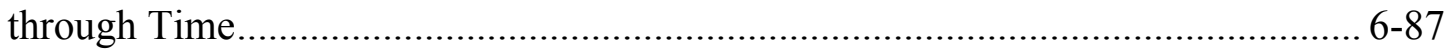

6.7-4. $\mathrm{THC} \mathrm{CO}_{2}$ Partial Pressure in the In-Drift Environment through Time ................. 6-87

6.7-5. Comparison of Temperatures at Various Locations within and

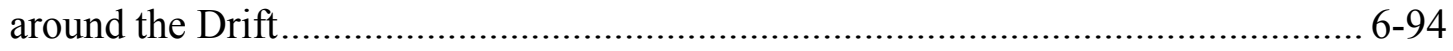

6.8-1. Eh-pH Diagram for Part of the System Fe-C-Si-O-H at $25^{\circ} \mathrm{C}$.............................. 6-98

6.8-2. Eh-pH Diagram for Part of the System Ni-O-H at $25^{\circ} \mathrm{C}$..................................... 6-99

6.8-3. pe-pH Diagram for Aqueous Inorganic Chromium Hydrolysis Species .............. 6-104

6.8-4. EQ3/6 Calculated Chromium Solubility in Equilibrium with $\mathrm{Cr}(\mathrm{OH})_{3}(\mathrm{am})$........ 6-106

6.9-1. Unevaporated Median Seepage Waters Compared to Simulated

Water-Rock Equilibrium .......................................................................... 6-117

6.9-2. Predicted Compositional Evolution During Evaporation of Bin 11 Waters at $70^{\circ} \mathrm{C}$ and $\mathrm{pCO}_{2} 10^{-3}$ bar, versus Relative Humidity ....................................... 6-122

6.9-3. Predicted Compositional Evolution During Evaporation of Bin 11 Waters at $70^{\circ} \mathrm{C}$ and $\mathrm{pCO}_{2} 10^{-3}$ bar, versus Concentration Factor.................................. 6-123

6.9-4. Predicted Concentrations of ANC Species during Evaporative Evolution of Bin 11 Waters at $70^{\circ} \mathrm{C}$ and $p \mathrm{CO}_{2} 10^{-3}$ bar, versus Relative Humidity ................ 6-123

6.9-5. Predicted Concentrations of ANC Species during Evaporative Evolution of Bin 11 Waters at $70^{\circ} \mathrm{C}$ and $p \mathrm{CO}_{2} 10^{-3}$ bar, versus Concentration Factor.............. 6-124

6.9-6. Predicted Mineral Precipitation as Bin 11 Waters Evaporate at $70^{\circ} \mathrm{C}$ and $\mathrm{pCO}_{2} 10^{-3}$ bar, versus Relative Humidity

6.9-7. Predicted Mineral Precipitation as Bin 11 Waters Evaporate at $70^{\circ} \mathrm{C}$ and $p \mathrm{CO}_{2} 10^{-3}$ bar, versus Concentration Factor 


\section{FIGURES (Continued)}

Page

6.9-8. Predicted Compositional Evolution as Bin 11 Waters Are Diluted at $70^{\circ} \mathrm{C}$ and $p \mathrm{CO}_{2} 10^{-3}$ bar, versus Relative Humidity ………..................................... 6-125

6.9-9. Predicted Compositional Evolution as Bin 11 Waters Are Diluted at $70^{\circ} \mathrm{C}$ and $p \mathrm{CO}_{2} 10^{-3}$ bar, versus Dilution Factor ..................................................... 6-126

6.9-10. Predicted Concentrations of ANC Species during Dilution of Bin 11 Waters at $70^{\circ} \mathrm{C}$ and $p \mathrm{CO}_{2} 10^{-3}$ bar, versus Relative Humidity ....................................... 6-126

6.9-11. Predicted Concentrations of ANC Species during Dilution of Bin 11 Waters at $70^{\circ} \mathrm{C}$ and $p \mathrm{CO}_{2} 10^{-3} \mathrm{bar}$, versus Dilution Factor ......................................... 6-127

6.12-1. Uncertainty in Bin $11 \mathrm{Br}^{-}$Concentrations Using Pore-Water Values .................... 6-154

6.12-2. Uncertainty in Bin 11 Ionic Strength Due to Adding $\mathrm{Br}^{-}$..................................... 6-154

6.12-3. Uncertainty in Bin $11 \mathrm{pH}$ Due to Adding $\mathrm{Br}^{-}$................................................. 6-155

6.12-4. Uncertainty in Bin 11 Molar Ratios Due to Adding $\mathrm{Br}^{-}$.................................... 6-155

6.12-5. Variation in Bin 11 Base-Case $\mathrm{pH}$ as a Function of $\mathrm{pCO}_{2} \ldots \ldots \ldots \ldots \ldots \ldots \ldots \ldots \ldots \ldots \ldots . . . . .6 .157$

6.12-6. Variation in Bin 11 Base-Case Ionic Strength as a Function of $p \mathrm{CO}_{2} \ldots \ldots \ldots \ldots \ldots \ldots . . .6-157$

6.12-7. Variation in Bin 11 Base-Case Total Elemental $\mathrm{Cl}$ as a Function of $p \mathrm{CO}_{2} \ldots \ldots \ldots . . .6-158$

6.12-8. Variation in Bin 11 Base-Case Total Elemental $\mathrm{N}$ as a Function of $p \mathrm{CO}_{2} \ldots \ldots \ldots . . . . .6-158$

6.12-9. Comparison of Base-Case EQ6 Results with Those of the Cryolite-

Suppressed Modeling Run ............................................................................... 6-160

6.12-10. Comparison of Base-Case Results to those of the Same Modeling Run with Glaserite Unsuppressed................................................................................... 6-161

6.13-1. Color-Coded Bin History Maps Showing Differences between Crown Seepage and Invert Wicking ........................................................................... 6-171

6.13-2. Aqueous Composition Predictions versus Relative Humidity for All Seepage Evaporation Lookup Tables for Bin 1 ............................................................ 6-178

6.13-3. Aqueous Composition Predictions versus Relative Humidity for All Seepage Evaporation Lookup Tables for Bin 2 ............................................................... 6-179

6.13-4. Aqueous Composition Predictions versus Relative Humidity for All Seepage Evaporation Lookup Tables for Bin 3

6.13-5. Aqueous Composition Predictions versus Relative Humidity for All Seepage Evaporation Lookup Tables for Bin 4 ............................................................. 6-180

6.13-6. Aqueous Composition Predictions versus Relative Humidity for All Seepage Evaporation Lookup Tables for Bin 5 ........................................................... 6-180

6.13-7. Aqueous Composition Predictions versus Relative Humidity for All Seepage Evaporation Lookup Tables for Bin 6 ................................................................ 6-181

6.13-8. Aqueous Composition Predictions versus Relative Humidity for All Seepage Evaporation Lookup Tables for Bin 7 .............................................................. 6-181

6.13-9. Aqueous Composition Predictions versus Relative Humidity for All Seepage Evaporation Lookup Tables for Bin 8 ............................................................. 6-182

6.13-10. Aqueous Composition Predictions versus Relative Humidity for All Seepage Evaporation Lookup Tables for Bin 9 ............................................................. 6-182

6.13-11. Aqueous Composition Predictions versus Relative Humidity for All Seepage Evaporation Lookup Tables for Bin 10 


\section{FIGURES (Continued)}

Page

6.13-12. Aqueous Composition Predictions versus Relative Humidity for All Seepage

Evaporation Lookup Tables for Bin 11 .............................................................. 6-183

6.13-13. Selected Aqueous Molal Ratios Useful for Corrosion Analysis versus

Relative Humidity for All Seepage Evaporation Lookup Tables for All Bins

6.13-14. Flow Diagram Showing Some of the Precipitating Minerals Associated with

Each of the 11 Seepage Bins........................................................................... 6-187

6.13-15. Range of $\mathrm{pH}$ versus Relative Humidity for the Seepage Evaporation Lookup

Tables Representing Bins 3 through 11 ............................................................ 6-188

6.13-16. Range of $\mathrm{pH}$ versus Relative Humidity for the Seepage Evaporation Lookup Tables Representing Bins 1 and 2................................................................... 6-188

6.13-17. Range of F versus Relative Humidity for the Seepage Evaporation Lookup Tables Representing Bins 3 through 11 ........................................................... 6-190

6.13-18. Range of $\mathrm{Cl}$ versus Relative Humidity for the Seepage Evaporation Lookup Tables Representing Bins 3 through 11 .

6.13-19. Range of Cl to N Molal Ratios for the Seepage Evaporation Lookup Tables Representing Bins 3 through 11..................................................................... 6-191

6.13-20. Range of Total Elemental Ca for the Seepage Evaporation Lookup Tables Representing Bins 3 through 11 .

6.13-21. Range of Total Elemental S for the Seepage Evaporation Lookup Tables Representing Bins 3 through 11

6.13-22. Range of Total Elemental C for the Seepage Evaporation Lookup Tables Representing Bins 3 through 11 .

6.13-23. Range of Ionic Strength versus Relative Humidity for the Seepage Evaporation Lookup Tables Representing Bins 3 through $11 . .$.

6.13-24. Mass of Water versus Ionic Strength for the Seepage Evaporation Lookup Tables Representing Bins 3 through 11

6.13-25. Schematic Representation of the Sources of Different Chemical Fluxes into the Invert and Subsequent Radionuclide Release from the Engineered Barrier System

6.13-26. Range of F versus Relative Humidity for the Seepage Evaporation Lookup Tables Representing Bins 1 and 2

6.13-27. Range of $\mathrm{Cl}$ versus Relative Humidity for the Seepage Evaporation Lookup Tables Representing Bins 1 and 2 6-200

6.13-28. Range of Ionic Strength versus Mass of Water $(\mathrm{kg})$ for the Seepage Evaporation Lookup Tables Representing Bins 1 and 2.

6.13-29. Range of Total Elemental Ca for the Seepage Evaporation Lookup Tables Representing Bins 1 and 2

6.13-30. Range of Total Elemental S for the Seepage Evaporation Lookup Tables Representing Bins 1 and 2

6.13-31. Range of Total Elemental C for the Seepage Evaporation Lookup Tables Representing Bins 1 and 2

6.13-32. Relative Humidity at Initial Precipitation of Halite in Median Bin Waters 6-209 


\section{FIGURES (Continued)}

Page

6.15-1. Roadmap for TSPA-LA Implementation of Engineered Barrier System Chemistry on the Waste Package Surface under the "Dripping Scenario"

7.1-1. Seepage Evaporation Abstraction Validation at $56^{\circ} \mathrm{C}, 10^{-3.2} \mathrm{pCO}_{2}$,

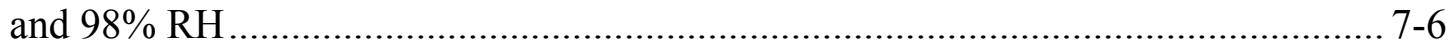

7.1-2. Seepage Evaporation Abstraction Validation at $95.6^{\circ} \mathrm{C}, 10^{-2.4} \mathrm{pCO}_{2}$,

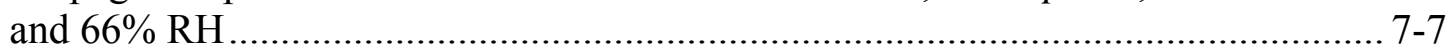

7.2-1. $\quad \mathrm{CO}_{2}$ Gas Abstraction Validation: Log-Linear Interpolation............................... 7-11

7.3-1. $\quad$ Bin $3 \mathrm{pH}, \mathrm{Cl}^{-}$, and $\mathrm{Cl}^{-} / \mathrm{NO}_{3}{ }^{-}$Results ........................................................ 7-17

7.3-2. $\quad$ Bin $4 \mathrm{pH}, \mathrm{Cl}^{-}$, and $\mathrm{Cl}^{-} / \mathrm{NO}_{3}{ }^{-}$Results ........................................................ 7-18

7.3-3. $\quad$ Bin $5 \mathrm{pH}, \mathrm{Cl}^{-}$, and $\mathrm{Cl}^{-} / \mathrm{NO}_{3}{ }^{-}$Results ....................................................... 7-19

7.3-4. Bin $6 \mathrm{pH}, \mathrm{Cl}^{-}$, and $\mathrm{Cl}^{-} / \mathrm{NO}_{3}{ }^{-}$Results ..................................................... 7-20

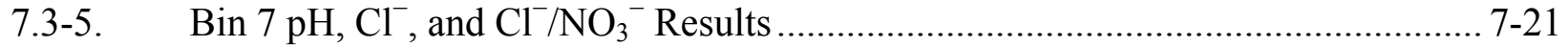

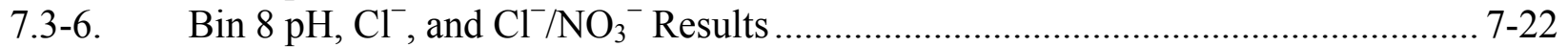

7.3-7. $\quad$ Bin $9 \mathrm{pH}, \mathrm{Cl}^{-}$, and $\mathrm{Cl}^{-} / \mathrm{NO}_{3}{ }^{-}$Results ....................................................... 7-23

7.3-8. $\quad$ Bin $10 \mathrm{pH}, \mathrm{Cl}^{-}$, and $\mathrm{Cl}^{-} / \mathrm{NO}_{3}{ }^{-}$Results ...................................................... 7-24

7.3-9. $\quad$ Bin $11 \mathrm{pH}, \mathrm{Cl}^{-}$, and $\mathrm{Cl}^{-} / \mathrm{NO}_{3}{ }^{-}$Results .................................................... 7-25

7.3-10. Comparison of Results of Evaporation of Typical Sierra Nevada Spring Water at $25^{\circ} \mathrm{C}$ in Equilibrium with Atmospheric $p \mathrm{CO}_{2}$ at $10^{-3.5}$ bar ............................... 7-28

7.3-11. Comparison of THC Seepage $\mathrm{pH}$ with Crown Seepage Water Binning Analysis...................................................................................... 7-32

7.3-12. Comparison of THC Seepage $\mathrm{Ca}^{2+}$ with Binning Analysis for w0bf4 Invert Seepage....................................................................................... 7-33

7.3-13. Comparison of THC Seepage $\mathrm{Mg}^{2+}$ with Binning Analysis for w0tf4 Crown Seepage ........................................................................................ 7-33

7.3-14. Comparison of THC Seepage $\mathrm{Na}^{+}$with Binning Analysis for w4bf4 Invert Seepage...................................................................................... 7-34

7.3-15. Comparison of THC Seepage $\mathrm{Cl}^{-}$with Crown Seepage Water Binning Analysis......................................................................................... 7-35

7.3-16. Comparison of THC Seepage $\mathrm{SiO}_{2}(\mathrm{aq})$ with Abstraction Results for w5bf4 Invert Seepage ..................................................................................... 7-36

7.3-17. Comparison of THC Seepage $\mathrm{HCO}_{3}{ }^{-}$with Binning Analysis for w5tf4 Crown Seepage ......................................................................................... 7-36

7.3-18. Comparison of THC Seepage $\mathrm{SO}_{4}{ }^{2-}$ with Binning Analysis for w6bf4 Invert Seepage ................................................................................. $7-37$

7.3-19. Comparison of THC Seepage $\mathrm{K}^{+}$with Binning Analysis for w6tf4 Crown Seepage ...................................................................................... $7-37$

7.3-20. Comparison of THC Seepage $\mathrm{F}^{-}$with Binning Analysis for w7bf4 Invert Seepage ...................................................................................... $7-38$

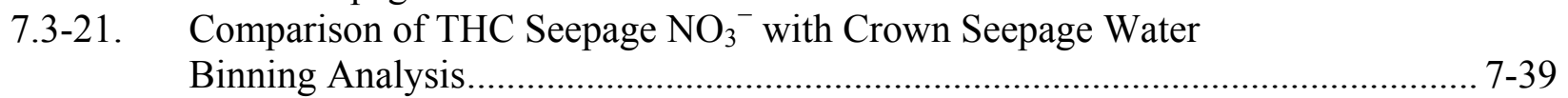

8.2-1. Recommended TSPA-LA Usage Outline for Crown Seepage Evaporation Abstraction ...................................................................................... 8-3 


\section{INTENTIONALLY LEFT BLANK}




\section{TABLES}

4.1-1. Description of Conditions and Sources for Stainless Steel Type 316L Corrosion Rate Data

4.1-2. Description of Conditions and Sources for Low-Alloy or Carbon Steels

Corrosion Rate Data........................................................................................... 4-3

4.1-3. Low-Alloy or Carbon Emplacement Drift Steel Materials and

Size Specifications ……………………........................................................... 4-6

4.1-4. Source Files for Input to Binning Analysis.................................................... 4-7

4.1-5. References for Input Gas Chemistry Analyses ....................................................... 4-7

4.1-6. Time-Varying Inputs for the Gas Flux Calculation in Section 6.7.1 ........................ 4-8

4.1-7. Constant Inputs for Calculations from Section 6.7.1 ............................................... 4-9

4.1-8. Inputs for Calculation of Oxygen Consumption by Within-Package Corrosion Processes ............................................................................................ 4-11

4.1-9. IDPS Model Outputs Used as Inputs .................................................................. 4-12

4.1-10. Dimensional Information for Stainless Steel Type 316L Sheets and

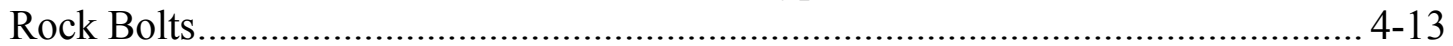

4.1-11. Parameters Used to Analyze Stainless Steel Type 316L Ground Support Corrosion............................................................................................. 4-14

4.1-12. Equilibrium Constants for Dissolution Reactions of Amorphous Chromium(III) Hydroxide and Eskolaite at $25^{\circ} \mathrm{C}$.................................................. 4-14

4.1-13. Pore Water Compositional Data Used to Evaluate the Relative Importance of $\mathrm{Br}$........................................................................................ 4-15

4.4-1. Composition of Sierra Nevada Spring Water Used in Validation Tests for the EBS Seepage Evaporation Model .......................................................................... 4-24

4.4-2. Water Identifications Used in the Binning Analysis............................................... 4-25

6.3-1. Onsager Couplings and Direct Transport Process Fluxes Driven by Temperature, Pressure, Chemical Potential, and Electrical Potential Gradients ..... 6-13

6.4-1. Titanium Grade 16 Corrosion Rates ………………………................................ 6-16

6.4-2. Corrosion Rates of Alloy 22 ............................................................................. 6-17

6.4-3. Corrosion Rates of Copper under Various Environmental Conditions .................... 6-17

6.4-4. Corrosion Rates of Aluminum Alloys in Aqueous Environments........................... 6-18

6.4-5. Atmospheric Corrosion Rates of Aluminum Alloy 6061 ...................................... 6-18

6.4-6. Corrosion Rates of Stainless Steel Type 316L under Various

6.4-7. Corrosion Rates of Carbon and Low-Alloy Steels in Various Environmental Conditions .............................................................................. 6-20

6.4-8. Selected Corrosion Rates of Metallic and Alloy Materials for Use in Engineered Barrier System Chemical Environment Calculations ............................ 6-22

6.5-1. Compositions of Fluoride and Trace Elements in Enhanced Characterization of the Repository Block Pore-Water Samples ………………………………......... 6-38

6.5-2. Mineral Suppressions Used in P\&CE Geochemical Modeling .............................. 6-39

6.5-3. Minerals Allowed to Precipitate in P\&CE Geochemical Modeling ......................... 6-41

6.6-1. Locations and Identification of THC Seepage Water Compositions to Be Binned. 6-46 


\section{TABLES (Continued)}

Page

6.6-2. Additional Mineral Suppressions Included during Evaporation to $65 \%$

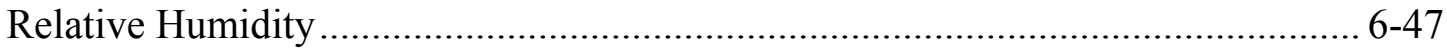

6.6-3. Binning Criteria Answer Key ………………............................................... 6-52

6.6-4. Standard Deviation of In-Drift Water Chemistry at 65\% Relative Humidity, before and after Binning .................................................................................... 6-58

6.6-5. Median Water Identifier and Percentage in Each Bin ......................................... 6-60

6.6-6. Initial Compositions of the 11 Binned THC Seepage Waters ................................. 6-62

6.6-7. Calculated Statistics for All Values within Each Bin $\left(a_{w}=0.65\right) \ldots \ldots \ldots \ldots \ldots \ldots \ldots \ldots \ldots . . . .6-68$

6.6-8. Calculated Statistics for All Values on the Data and Plots Worksheet..................... 6-69

6.6-9. Bin Map for "Water 0" Incoming Seepage Waters ................................................ 6-70

6.6-10. Bin Map for "Water 4" Incoming Seepage Waters ................................................. 6-71

6.6-11. Bin Map for "Water 5" Incoming Seepage Waters ............................................... 6-72

6.6-12. Bin Map for "Water 6" Incoming Seepage Waters ................................................ 6-73

6.6-13. Bin Map for "Water 7" Incoming Seepage Waters ................................................ 6-74

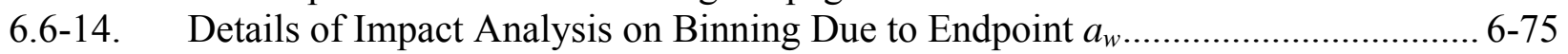

6.6-15. Details of Impact Analysis on $\mathrm{CO}_{2}$ Pressure Correction ........................................ 6-76

6.7-1. Lookup Tables for TSPA-LA Analysis of In-Drift and Invert $p \mathrm{CO}_{2}$ for w0 (HD-PERM) ............................................................................................. 6-88

6.7-2. Lookup Tables for TSPA-LA Analysis of In-Drift and Invert $p \mathrm{CO}_{2}$ for w4

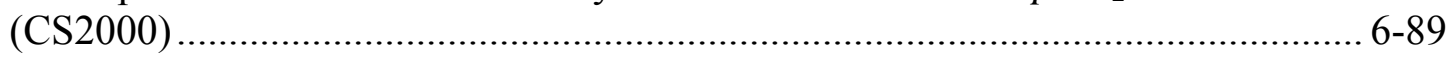

6.7-3. Lookup Tables for TSPA-LA Analysis of In-Drift and Invert $p \mathrm{CO}_{2}$ for w5 (CS1000). $6-90$

6.7-4. Lookup Tables for TSPA-LA Analysis of In-Drift and Invert $p \mathrm{CO}_{2}$ for w6 (SD-9/990)

6.7-5. Lookup Tables for TSPA-LA Analysis of In-Drift and Invert $p \mathrm{CO}_{2}$ for w7 (CS500) $6-92$

6.7-6. Equilibrium Gas Pressure, Temperature, $\mathrm{pH}$, and Ionic Strength from the 11 Bin Waters.

6.8-1. Typical Oxidation-Reduction Reactions and Potential Fe Minerals ....................... 6-97

6.8-2. EQ3/6 Input/Output Files for Stainless Steel Type 316L Corrosion Analysis ...... 6-108

6.8-3. Additional EQ3/6 Mineral Suppressions Included for Seepage Ground Support Interactions

6.8-4. Aqueous Species Suppressions Included for Seepage Ground Support Interactions 6-110

6.8-5. Absolute (Percent Relative) Differences Due to Stainless Steel Type 316L Dissolution in Bin 11 Seepage Water at 100 and 98\% Relative Humidity ........... 6-110

6.9-1. Total EQ3NR Equilibrated Aqueous Elemental Compositions of the 11 Bins ..... 6-113

6.9-2. EQ3NR Equilibrium Speciation of the 11 Bins.................................................. 6-113

6.9-3. List of Species Used to Charge Balance Individual Water Chemistries................. 6-115

6.9-4. EQ3NR Input/Output Files for TSPA-LA Abstraction ....................................... 6-115

6.9-5. Water Activity and $\mathrm{pH}$ of Water-Rock Simulation ............................................. 6-116

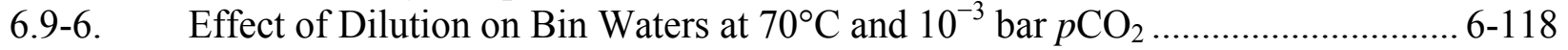

6.9-7. EQ6 Input/Output Files for TSPA-LA Abstraction .............................................. 6-119 


\section{TABLES (Continued)}

Page

6.9-8. Lookup Tables for TSPA-LA Abstraction.

6.9-9. Relative Humidity Boundaries Between Evaporation and Dilution

Lookup Tables

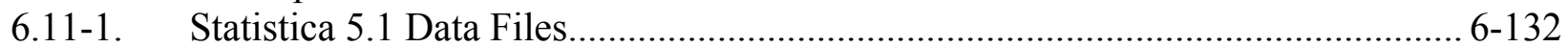

6.11-2. Associated Minerals of Clusters 1 through 11 $6-133$

6.11-3. $\mathrm{pH}$ Statistics for Mineral Clustering and Aqueous Binning .............. 6-134

6.11-4. Al Statistics for Mineral Clustering and Aqueous Binning $6-134$

6.11-5. C Statistics for Mineral Clustering and Aqueous Binning... 6-135

6.11-6. Ca Statistics for Mineral Clustering and Aqueous Binning.... $6-135$

6.11-7. Cl Statistics for Mineral Clustering and Aqueous Binning $6-136$

6.11-8. F Statistics for Mineral Clustering and Aqueous Binning $6-136$

6.11-9. K Statistics for Mineral Clustering and Aqueous Binning .... 6-137

6.11-10. Mg Statistics for Mineral Clustering and Aqueous Binning..... 6-137

6.11-11. N Statistics for Mineral Clustering and Aqueous Binning .... 6-138

6.11-12. Na Statistics for Mineral Clustering and Aqueous Binning... $6-138$

6.11-13. S Statistics for Mineral Clustering and Aqueous Binning.....

6.11-14. Si Statistics for Mineral Clustering and Aqueous Binning....

6.12-1. Estimated Model Uncertainty Ranges for IDPS Model Outputs 6-143

6.12-2. Spreadsheets Containing Log-Transformed Data and Statistics for Each of the Uncertainty RH Locations Evaluated .

6.12-3. Relative Humidity Point with the Most Variability for Bins 1 through 11 for $\mathrm{pH}, \mathrm{Cl}^{-}$, and $\mathrm{Cl}^{-} / \mathrm{NO}_{3}{ }^{-}$.....

6.12-4. Uncertainty Applied to the IDPS Seepage Lookup Tables for $\mathrm{pH}, \mathrm{I}, \mathrm{Cl}^{-}$, and $\mathrm{Cl}^{-} / \mathrm{NO}_{3}{ }^{-}$.....

6.12-5. Base-Case EQ3/6 Input Files for Uncertainty Analysis ........................................146

6.12-6. EQ6 Input/Output Files for Stainless Steel Type 316L Corrosion Rate Uncertainty Case.

6.12-7. Comparison of $\mathrm{pH}$ and Ionic Strength for Corrosion Rate Uncertainty Case............147

6.12-8. EQ3/6 Input/Output Files for Stainless Steel Type 316L Cr(VI)

Uncertainty Case

6.12-9. Comparison of $\mathrm{pH}$ and Ionic Strength for Cr(VI) Uncertainty Case .................... 6-148

6.12-10. EQ3/6 Input/Output Files for Stainless Steel Type 316L Bin 7

Uncertainty Case

6.12-11. Comparison of $\mathrm{pH}$ and Ionic Strength for Bin 7 Uncertainty Case ..................... 6-149

6.12-12. EQ3/6 Input/Output Files for Stainless Steel Type 316 $\mathrm{LCO}_{2}=10^{-2} \mathrm{bar}$ Uncertainty Case

6.12-13. Comparison of $\mathrm{pH}$ and Ionic Strength for $\mathrm{pCO}_{2}=10^{-2}$ bar Uncertainty Case...... 6-149

6.12-14. EQ3/6 Input/Output Files for Stainless Steel Type $316 p \mathrm{CO}_{2}=10^{-4} \mathrm{bar}$ Uncertainty Case....

6.12-15. Comparison of $\mathrm{pH}$ and Ionic Strength for $\mathrm{pCO}_{2}=10^{-4}$ bar Uncertainty Case...... 6-150

6.12-16. $\mathrm{Cl}^{-}$and $\mathrm{Br}^{-}$Data for Pore Waters Collected in the Enhanced Characterization of the Repository Block

6.12-17. Mean, Minimum, and Maximum $\mathrm{Cl}^{-} / \mathrm{Br}^{-}$Ratios Present in Drift Samples. 6-152 


\section{TABLES (Continued)}

6.12-18. Bromide Values Used in EQ3 Input Files.

6.12-19. Bromide Uncertainty Analysis EQ3/6 Input and Output Files

6.12-20. Input and Output Files for Seepage Bin 11 Analysis of $\mathrm{pCO}_{2}$

6.12-21. Traceability Roadmap for Mineral Suppression EQ6 Sensitivity Cases 6-159

6.12-22. Natural Analogue Information for the Inclusion of Minerals Not Reported in Section 6.5 .....

6.12-23. $\mathrm{Cl}^{-} / \mathrm{NO}_{3}{ }^{-}$Molal Ratio for Seepage at the Halite Chemical Divide

6.13-1. Time-Integrated Bin Occurrence for Any Given Crown Seepage Bin (20,000-Year Case)

6.13-2. Time-Integrated Bin Frequency of Occurrence for Any Given Invert Wicking Seepage Bin (20,000-Year Case)

6.13-3. Water Bins Associated with Different Periods in the Repository Thermal History $6-174$

6.13-4. Bin Occurrences for Crown Seepage as a Function of Time 6-175

6.13-5. Bin Occurrence for Invert Seepage as a Function of Time. $6-176$

6.13-6. Summary Table of Precipitating Minerals in Each of the Eleven Bins 6-185

6.13-7. Engineered Barrier System Seepage Lookup Table End-Point Relative Humidity and Brine Evolution.

6.13-8. Target Composition of Standard Test Media Based on Evaporative Concentration of a Dilute Carbonate-Type Water

6.13-9. Evaporated Crown Seepage Water and Corresponding Corrosion Test Solutions 6-205

6.13-10. General Classification of the Brine Types and the Probabilities of Contact 6-206

6.14-1. Included Features, Events, and Processes Addressed in This Report. 6-211

7.3-1. Binning Distribution of Repository-Horizon Pore Waters .................................... 7-13

7.3-2. Temperature and $p \mathrm{CO}_{2}$ Used for Each Bin in the Validation Analysis .................. 7-14

7.3-3. Identified Waters and EQ3/6 Input Filenames Used in the Analysis ................... 7-15

8.2-1. EBS Physical and Chemical Environment Model Output DTNs Derived for Use in the TSPA-LA Model .................................................................................... 8-4

8.2-2. EBS Physical and Chemical Environment Model Supplemental Output DTNs ...... 8-4 


\section{ACRONYMS AND ABBREVIATIONS}

\section{Acronyms}

\begin{tabular}{|c|c|}
\hline ANC & acid neutralizing capacity \\
\hline BSW & basic saturated water \\
\hline $\mathrm{CDF}$ & cumulative distribution function \\
\hline $\mathrm{CR}$ & condition report \\
\hline DRH & deliquescence relative humidity \\
\hline DST & Drift Scale Test \\
\hline DTN & data tracking number \\
\hline EBS & engineered barrier system \\
\hline ESF & Exploratory Studies Facility \\
\hline FEPs & features, events, and processes \\
\hline IDPS & in-drift precipitates/salts \\
\hline IED & information exchange drawing \\
\hline $\mathrm{P} \& \mathrm{CE}$ & physical and chemical environment \\
\hline RH & relative humidity \\
\hline RH & relative humidity (numerical representation) \\
\hline SAW & simulated acidified water \\
\hline SCW & simulated concentrated well water \\
\hline SDW & simulated dilute water \\
\hline SSW & simulated saturated water \\
\hline $\mathrm{THC}$ & thermal-hydrologic-chemical \\
\hline TSPA & total system performance assessment \\
\hline TSPA-LA & total system performance assessment for the license application \\
\hline $\mathrm{UZ}$ & unsaturated zone \\
\hline YMP & Yucca Mountain Project \\
\hline
\end{tabular}




\section{ACRONYMS AND ABBREVIATIONS (Continued)}

\section{Selected Abbreviations}

\begin{tabular}{|c|c|}
\hline $\begin{array}{l}\mathrm{atm} \\
a_{w}\end{array}$ & $\begin{array}{l}\text { atmosphere } \\
\text { thermodynamic activity of water }\end{array}$ \\
\hline Eh & redox potential \\
\hline$I$ & ionic strength \\
\hline $\mathrm{K}$ & Kelvin \\
\hline $\mathrm{kg}$ & kilograms \\
\hline $\mathrm{kg} / \mathrm{L}$ & kilograms per liter \\
\hline $\mathrm{kg} / \mathrm{m}$ & kilograms per meter \\
\hline $\log Q / K$ & saturation index \\
\hline $\begin{array}{l}\mathrm{mg} / \mathrm{L} \\
\mathrm{mg} / \mathrm{m} \\
\mathrm{mm}\end{array}$ & $\begin{array}{l}\text { milligrams per liter } \\
\text { milligrams per meter } \\
\text { millimeter }\end{array}$ \\
\hline $\begin{array}{l}p \mathrm{CO}_{2} \\
\text { pe } \\
\mathrm{pH} \\
\mathrm{ppm}\end{array}$ & $\begin{array}{l}\text { partial pressure of } \mathrm{CO}_{2} \\
\text { electron activity } \\
\text { negative } \log _{10} \text { of hydrogen ion activity } \\
\text { parts per million }\end{array}$ \\
\hline$\mu \mathrm{m}$ & micrometer \\
\hline
\end{tabular}




\section{PURPOSE}

The purpose of this model report is to describe the evolution of the physical and chemical environmental conditions within the waste emplacement drifts of the repository, including the drip shield and waste package surfaces. The resulting seepage evaporation and gas abstraction models are used in the total system performance assessment for the license application (TSPA-LA) to assess the performance of the engineered barrier system and the waste form.

This report develops and documents a set of abstraction-level models that describe the engineered barrier system physical and chemical environment. Where possible, these models use information directly from other reports as input, which promotes integration among process models used for TSPA-LA. Specific tasks and activities of modeling the physical and chemical environment are included in Technical Work Plan for: Near-Field Environment and Transport In-Drift Geochemistry Model Report Integration (BSC 2005 [DIRS 173782], Section 1.2.2). As described in the technical work plan, the development of this report is coordinated with the development of other engineered barrier system reports.

To be consistent with other project documents that address features, events, and processes (FEPs), Table 6.14.1 of the current report includes updates to FEP numbers and FEP subjects for two FEPs identified in the technical work plan (TWP) governing this report (BSC 2005 [DIRS 173782]). FEP 2.1.09.06.0A (Reduction-oxidation potential in EBS), as listed in Table 2 of the TWP (BSC 2005 [DIRS 173782]), has been updated in the current report to FEP 2.1.09.06.0B (Reduction-oxidation potential in Drifts; see Table 6.14-1). FEP 2.1.09.07.0A (Reaction kinetics in EBS), as listed in Table 2 of the TWP (BSC 2005 [DIRS 173782]), has been updated in the current report to FEP 2.1.09.07.0B (Reaction kinetics in Drifts; see Table 6.14-1). These deviations from the TWP are justified because they improve integration with FEPs documents. The updates have no impact on the model developed in this report.

One FEP, indicated as "included" in the TWP, is no longer supported as included in this report. This FEP (FEP 2.1.11.01.0A, Heat Generation in EBS) is listed in Table 2 of the TWP (BSC 2005 [DIRS 173782]). This deviation from the TWP is justified because it improves the accuracy of the FEPs included in this report and used in TSPA-LA. This change has no impact on the model developed in this report.

\subsection{INTENDED MODEL USE}

The principal intentions for the use of this model and analysis are to:

- Predict the potential evolution of in-drift chemical environment for the important parameters that affect drip shield and waste package durability, and control solubility and colloidal stability of radionuclides in the invert

- Provide compositions of gas and water that evolve during seepage evaporation in the drift in the form of lookup tables to TSPA-LA; enables quantification of ionic strength, chloride and nitrate concentration, and $\mathrm{pH}$ as functions of relative humidity $(\mathrm{RH})$, carbon dioxide partial pressure $\left(\mathrm{pCO}_{2}\right)$, and temperature. 
This is accomplished through use of the physical and chemical environment models that consist of a seepage evaporation abstraction model and a gas abstraction model, neither of which are affected by the presence or absence of dust (the effects of dust are described in Section 6.10).

Additionally, there are several in-drift processes that are demonstrated to have no significant effect upon the in-drift seepage chemistry. These include the following:

- Interaction with the stainless steel ground support

- Presence of bromide in seepage water

- Alternative mineral suppressions.

\subsection{SCOPE OF MODELS}

This report focuses on abstractions of evaporated seepage and gas inflow values, based on inputs from the outputs of Drift-Scale THC Seepage Model (BSC 2005 [DIRS 172862]) and Post-Processing Analysis for THC Seepage (BSC 2004 [DIRS 169858]). This report then predicts in-drift aqueous solution compositions due to seepage evaporation using the model developed in In-Drift Precipitates/Salts Model (BSC 2004 [DIRS 169863]).

As seepage waters percolate into the drift, their chemical compositions change by evaporation and mineral precipitation. Evaporation causes dissolved aqueous species concentrations to increase, minerals to precipitate, and the most soluble components to become concentrated in the resulting solution (brine).

Within this model, aqueous and gas-phase chemical speciation calculations use equilibrium and reaction-path modeling of evaporation into highly concentrated brines to determine potential system water compositions (Na-K-H-Mg-Ca-Al-Cl-F-NO $\mathrm{N}_{3}-\mathrm{SO}_{4}-\mathrm{Br}_{-}-\mathrm{CO}_{3}-\mathrm{SiO}_{2}-\mathrm{CO}_{2}-\mathrm{O}_{2}-\mathrm{H}_{2} \mathrm{O}$ ). Model conditions are variable, with temperatures from $25^{\circ} \mathrm{C}$ to more than $140^{\circ} \mathrm{C}$, pressures in the atmospheric range, and relative humidity from 0 to $100 \%$.

Seepage water and gas composition inputs for in-drift chemistry modeling are analyzed from the thermal-hydrologic-chemical (THC) seepage model outputs of time-dependent fracture and matrix water compositions and gas-phase compositions in the host rock (near-field environment) adjacent to the drift wall. An abstraction method is used to generate lookup tables for key measures of possible in-drift water compositions, incorporating the effects of seepage water evaporation as functions of temperature, $\mathrm{RH}$, and $\mathrm{pCO}_{2}$.

This abstraction process includes an analysis that categorizes the possible seepage water compositions into bins. Each bin contains a group of seepage water compositions that yield chemically similar solutions when concentrated by evaporation. A water composition in each bin is identified as a "median water," which serves to approximate all of the water compositions in the group.

In addition to the water composition tables, tables are prepared using THC model output to estimate time-dependent in-drift and invert $\mathrm{pCO}_{2}$ associated with seepage compositions. An appropriate in-drift temperature range is determined by examining time-temperature curves for 
four locations: the waste package surface, the drift wall surface at the crown of the drift, the base of the invert, and within the rock above the crown of the drift.

The evolution of seepage waters is affected by $\mathrm{RH}, p \mathrm{CO}_{2}$, and temperature. Thus, it is necessary to specify these conditions to predict equilibrium chemistries for in-drift aqueous solutions. To accomplish this, lookup tables are prepared to enable selection of predicted water chemistry as a function of seepage or leachate water chemistry (bin number), $\mathrm{RH}, p \mathrm{CO}_{2}$, and temperature.

In addition, the following ancillary analyses are included:

- Evaluation of the corrosion of low-alloy or carbon steel invert materials and its effects on sequestration of oxygen to determine whether there is sufficient flux of oxygen into the drifts to maintain an oxidizing environment throughout the evolution of the engineered barrier system chemical environments

- Evaluation of the corrosion of stainless steel and its effects on the composition of crown seepage waters

- Inclusion of a model to account for the potentially deleterious effects of salt (halite) separation due to transport along waste package surfaces.

In accordance with criteria in Section 4.2, the following relevant condition reports (CRs) tracked by the Corrective Action Program are addressed by this report:

- CR-4290, involving the evaluation of $\mathrm{NaCl}_{-} \mathrm{NaNO}_{3}-\mathrm{KNO}_{3}$ system, which has become extraneous due to removal of the dust deliquescence model (CR-4961 below)

- $\quad \mathrm{CR}-4713$, involving an inconsistency in the $\mathrm{pCO}_{2}$ lookup tables (Section 6.7.2)

- CR-4961, primarily involving revisions to the model validation strategies for seepage evaporation and gas abstractions, and removal of the dust deliquescence abstraction (throughout)

- CR-5673, requiring that the exact operating system used with qualified and exempt software be specified (Sections 3.2 and 3.3).

Finally, other reports that either use the output of this report (directly or through its output DTNs) or are sources to this report are listed below.

Reports using this report:

- In-Package Chemistry Abstraction

- Total System Performance Assessment (TSPA) Model/Analysis for the License Application

- Igneous Intrusion Impacts on Waste Packages and Waste Forms

- Dike/Drift Interactions 
- Engineered Barrier System Features, Events, and Processes

- Dissolved Concentration Limits of Radioactive Elements.

Reports that are sources to this report:

- Post-Processing Analysis for THC Seepage

- Engineered Barrier System Features, Events, and Processes

- Multiscale Thermohydrologic Model

- Drift-Scale THC Seepage Model

- In-Drift Precipitates/Salts Model

- Geochemistry Model Abstraction and Sensitivity Studies for the 21 PWR CSNF Waste Packages

- Probability Analysis of Corrosion Rates for Waste Package Materials

- Analysis of Dust Deliquescence for FEP Screening.

\subsection{MODEL LIMITATIONS}

The TSPA-LA lookup tables quantify the chemical parameters of interest for evaporated THC seepage waters for three sets of $\mathrm{pCO}_{2}\left(10^{-2}, 10^{-3}\right.$, and $10^{-4}$ bar of pressure), multiple temperatures $\left(40^{\circ} \mathrm{C}, 70^{\circ} \mathrm{C}\right.$, and $\left.100^{\circ} \mathrm{C}\right)$, and two-percent relative humidity increments. The main limitations of the physical and chemical environment model involve $p \mathrm{CO}_{2}$ and temperature as inputs to TSPA-LA.

When determining the chemical parameters for evaporated seepage waters under environmental conditions that fall within lookup tables, the parameters are estimated using linear interpolation of temperature and log-linear interpolation of $\mathrm{pCO}_{2}$. Chemistry values are extrapolated for $\mathrm{pH}$, ionic content, chloride, and nitrate if the $\mathrm{pCO}_{2}$ exceeds the range of $1 \times 10^{-4}$ to $1 \times 10^{-2}$ bar established in the lookup tables. Justification for this extrapolation is provided within the $\mathrm{pCO}_{2}$ limits up to $2 \times 10^{-2}$ and down to $1 \times 10^{-5}$ bar (Section 6.12.4.3).

When determining the chemical parameters of evaporated seepage waters for temperatures above $100^{\circ} \mathrm{C}$ and below $40^{\circ} \mathrm{C}$, a limited extrapolation is allowed that uses the limiting values in the $100^{\circ} \mathrm{C}$ or $40^{\circ} \mathrm{C}$ lookup tables, respectively (Section 6.7.3).

If the $R H$ is greater than the highest value in the lookup tables, the highest $R H$ value is used (from dilution tables for crown seepage and evaporation tables for invert; see Sections 6.15.1 and 6.15.2). Explicit consideration of condensation under the drip shield is not addressed by the seepage evaporation abstraction, consistent with its exclusion on the basis of low consequence (BSC 2005 [DIRS 175014], Section 6.2.43).

The lowest $R H$ values at which chemistries are provided in the lookup tables for evaporated seepage water do not always correspond to the final eutectic point for the mixture of salt minerals present (i.e., to dryness). For this reason, if the relative humidity is lower than the 
lowest value in a lookup table, an aqueous system must be considered to persist, and that lowest $R H$ information is used. 


\section{INTENTIONALLY LEFT BLANK}




\section{QUALITY ASSURANCE}

Development of this report and supporting analyses is determined to be subject to the Office of Civilian Radioactive Waste Management quality assurance program (BSC 2005 [DIRS 173782], Section 8). Approved quality assurance procedures identified in the technical work plan (BSC 2005 [DIRS 173782], Section 4) were used to conduct and document the activities described in this report. The technical work plan also identifies the methods used to control the electronic management of data (BSC 2005 [DIRS 173782], Section 8.4) during the analysis and documentation activities.

This report investigates the effect of the in-drift physical and chemical environment on the waste isolation capability of the following safety category barriers that are important to the demonstration of compliance with the postclosure performance objective prescribed in 10 CFR 63.113 [DIRS 173273]:

- Engineered barrier system: drip shield

- Engineered barrier system: waste package

- Engineered barrier system: drift invert (ballast).

The modeling activities of this report provide information that is important to demonstrating compliance with the performance objectives in 10 CFR 63.113 [DIRS 173273]. However, this report does not directly address either engineered or natural barriers as defined in Q-List (BSC 2005 [DIRS 174269]). 


\section{INTENTIONALLY LEFT BLANK}




\section{USE OF SOFTWARE}

The following software was used in the preparation of this report: EQ3/6 V8.0, GETEQDATA V1.0.1, and some exempt software.

\subsection{EQ3/6 V8.0}

EQ3/6 V8.0 (BSC 2003 [DIRS 162228]) is a software package used to perform geochemical modeling computations encompassing fluid-mineral interactions or solution-mineral equilibria in aqueous systems, or both. This software package has two primary codes: EQ3NR and EQ6. The first is for static-system aqueous speciation determination, the second for reaction-path modeling (e.g., precipitation, dissolution, evaporation). These codes are used in this report to model the equilibrium dissolution and precipitation of aqueous species, elemental components, and mineral precipitates associated with evaporated seepage waters in the drift. The program was run on the Windows 98 and 2000 operating systems on a PC platform and its limitations are described in Sections 6.5 and 6.10. The use of this software is consistent with its intended use and within its documented validation range (SNL 2003 [DIRS 162494], Section 1). Hereafter, depending on the general or specific use in the descriptions within this report, the software package will be referred to as EQ3/6, whereas use of a specific code will use the terms EQ3NR (or just EQ3) or EQ6.

\subsection{GETEQDATA V1.0.1}

GETEQDATA V1.0.1 (BSC 2002 [DIRS 173680]) is a software routine that operates as a Microsoft Excel (97 or 2000) macro to post-process data in EQ3NR (*.3o) or EQ6 (*.6o) output files. This program is used in this report to extract specified data from the EQ3/6 output files to generate lookup tables (Excel spreadsheet files). The program was run on the Windows 2000 operating system on a PC platform. This macro is limited by the EQ3/6 output data and performs a specific extraction of data as directed at run time. The use of this software is consistent with its intended use, which is to postprocess the output files from EQ3/6 V8.0 (Section 3.1), and within its qualified range (Jarek 2002 [DIRS 169567], Section 2.1). Hereafter, this code will be referred to as GETEQDATA.

\subsection{EXEMPT SOFTWARE USE}

The following commercial off-the-shelf software (and computer platform indicated) is used in this report to perform basic calculations and statistical operations:

- Microsoft Excel 97 (Windows 95, 98, and 2000)

- Microsoft Excel 2000 (Windows 2000)

- Statistica 5.1 (Windows 98).

Microsoft Excel is used throughout the document. The individual spreadsheets are called out in the section where they were used. The formulas used are identified and described (see Excel's help files) within each spreadsheet. Inputs, if direct, are described in Section 4.1; otherwise Section 6 identifies and discusses the specific data. 
Statistica is only used in Section 6.11.1 and is fully described in that section (e.g., algorithms used; input/output files).

The results obtained from the use of Microsoft Excel and Statistica 5.1 are not dependent on the software program used. The inputs, formulas, and outputs in the Microsoft Excel and Statistica files from the DTNs could be used with other similar software products to reproduce and verify the results. 


\section{INPUTS}

\subsection{DIRECT INPUT}

If not otherwise indicated, data and parameters used in this section are specifically selected for direct use in this model.

Sections 4.1.1 and 4.1.2 identify inputs required to determine the material corrosion rates and committed materials considered for corrosion and resulting oxygen consumption. These inputs are used to estimate the oxygen pressure conditions in the drift. Section 4.1.3 describes the boundary seepage water and associated gas chemistry inputs modeled using the thermodynamic databases specified in Section 4.1.4, both of which are implemented with the in-drift evaporation and salt separation submodels defined in Section 4.1.5. The final two sections describe the inputs used for sensitivity analyses of the effects of stainless steel on seepage water (Section 4.1.6) and the trace component, bromide (Section 4.1.7).

\subsubsection{Material Corrosion Rates}

Committed materials deemed to have no significant impact to oxygen consumption are not included as direct input to these analyses. For example, the low corrosion and degradation activity of titanium and Alloy 22, and the small quantity of copper and aluminum are examples of why these materials will not significantly affect the demand for oxygen. Corrosion rates for low-alloy or carbon steels are direct input required for the oxygen demand calculations (Section 6.7). The inclusion of Stainless Steel Type 316L is for the direct use in the analysis of crown seepage water interactions (Section 6.8) along with inputs from Section 4.1.6.

The sources for these data and brief descriptions are provided in Tables 4.1-1 and 4.1-2 for the atmospheric corrosion of Stainless Steel Type 316L and steam corrosion of carbon or low alloy steels, respectively. The mean aqueous corrosion rates for Stainless Steel Type 316L in salt water are taken from DTN: MO0409SPAACRWP.000 ([DIRS 172059], aqueous-316L.xls, tab "saltwater") as $1.939 \mu \mathrm{m} / \mathrm{yr}$.

Tables 4.1-1 and 4.1-2 list the sources used in the analysis of corrosion rates in this report. The report by Southwell and Bultman (1982 [DIRS 100928]) is considered "established fact" as it is a professional society monograph (The Corrosion Monograph Series). Qualification and justification of the use of the specific corrosion values in DTN: LL980704605924.035 [DIRS 147298] (as listed in Table 4.1-2 and additionally documented in McCright 1998 [DIRS 114637], Section 2.2.6, Supplements 1 and 2) is given in Appendix D of this report and was carried out as described in the data qualification plan included as a facsimile in Section D.7. 
Table 4.1-1. Description of Conditions and Sources for Stainless Steel Type 316L Corrosion Rate Data

\begin{tabular}{|c|c|c|c|c|c|}
\hline Temperature $\left({ }^{\circ} \mathrm{C}\right)$ & $\begin{array}{c}\text { Relative Humidity } \\
(R H)\end{array}$ & $\begin{array}{c}\text { Exposure } \\
\text { Time (years) }\end{array}$ & Note & $\begin{array}{l}\text { Measured Rate } \\
\text { (various units) }\end{array}$ & Source \\
\hline Approximately 27 & Approximately $83 \%$ & 1 & 1 & $<0.3 \mu \mathrm{m}$ loss & \multirow{5}{*}{$\begin{array}{l}\text { Southwell and Bultman } 1982 \\
\text { [DIRS 100928], Table } 64.6\end{array}$} \\
\hline Approximately 27 & Approximately $83 \%$ & 2 & 1 & $<0.3 \mu \mathrm{m}$ loss & \\
\hline Approximately 27 & Approximately $83 \%$ & 4 & 1 & $<0.3 \mu \mathrm{m}$ loss & \\
\hline Approximately 27 & Approximately $83 \%$ & 8 & 1 & $<0.3 \mu \mathrm{m}$ loss & \\
\hline Approximately 27 & Approximately $83 \%$ & 16 & 1 & $<0.3 \mu \mathrm{m}$ loss & \\
\hline Approximately 27 & Approximately $83 \%$ & 1 & 2 & $0 \mathrm{~g} / \mathrm{m}^{2}$ & $\begin{array}{l}\text { Southwell et al. } 1976 \\
\text { [DIRS 100927], Table } 5\end{array}$ \\
\hline Approximately 27 & Approximately $83 \%$ & 2 & 2 & $0 \mathrm{~g} / \mathrm{m}^{2}$ & \multirow{2}{*}{$\begin{array}{l}\text { Alexander et al. } 1961 \\
\text { [DIRS 162265], Table } 2\end{array}$} \\
\hline Approximately 27 & Approximately $83 \%$ & 4 & 2 & $0 \mathrm{~g} / \mathrm{m}^{2}$ & \\
\hline Approximately 27 & Approximately $83 \%$ & 8 & 2 & $0 \mathrm{~g} / \mathrm{m}^{2}$ & \multirow{2}{*}{$\begin{array}{l}\text { Southwell et al. } 1976 \\
\text { [DIRS 100927], Table } 5\end{array}$} \\
\hline Approximately 27 & Approximately $83 \%$ & 16 & 2 & $0 \mathrm{~g} / \mathrm{m}^{2}$ & \\
\hline Approximately 27 & Approximately $83 \%$ & 1 & 3 & $1 \mathrm{~g} / \mathrm{m}^{2}$ & \multirow{12}{*}{$\begin{array}{l}\text { Southwell et al. } 1976 \\
\text { [DIRS 100927], Table } 7\end{array}$} \\
\hline Approximately 27 & Approximately $83 \%$ & 4 & 3 & $7 \mathrm{~g} / \mathrm{m}^{2}$ & \\
\hline Approximately 27 & Approximately $83 \%$ & 16 & 3 & $54 \mathrm{~g} / \mathrm{m}^{2}$ & \\
\hline Approximately 27 & Approximately 83\% & 1 & 3 & $1 \mathrm{~g} / \mathrm{m}^{2}$ & \\
\hline Approximately 27 & Approximately $83 \%$ & 4 & 3 & $4 \mathrm{~g} / \mathrm{m}^{2}$ & \\
\hline Approximately 27 & Approximately $83 \%$ & 16 & 3 & $66 \mathrm{~g} / \mathrm{m}^{2}$ & \\
\hline Approximately 27 & Approximately $83 \%$ & 1 & 2 & $0 \mathrm{~g} / \mathrm{m}^{2}$ & \\
\hline Approximately 27 & Approximately $83 \%$ & 4 & 2 & $0 \mathrm{~g} / \mathrm{m}^{2}$ & \\
\hline Approximately 27 & Approximately $83 \%$ & 16 & 2 & $35 \mathrm{~g} / \mathrm{m}^{2}$ & \\
\hline Approximately 27 & Approximately $83 \%$ & 1 & 2 & $0 \mathrm{~g} / \mathrm{m}^{2}$ & \\
\hline Approximately 27 & Approximately $83 \%$ & 4 & 2 & $0 \mathrm{~g} / \mathrm{m}^{2}$ & \\
\hline Approximately 27 & Approximately 83\% & 16 & 2 & $50 \mathrm{~g} / \mathrm{m}^{2}$ & \\
\hline 15.78 & - & 5 & 4 & 0.0013 mils/yr & \multirow{3}{*}{$\begin{array}{l}\text { Bomberger et al. } 1954 \\
\text { [DIRS 163699], Table II }\end{array}$} \\
\hline 15.31 & - & 5 & 5 & 0 mils/yr & \\
\hline 12.5 & - & 4.92 & 6 & 0.0003 mils $/ y r$ & \\
\hline
\end{tabular}

NOTES: $\quad$ 1. Panama Canal Zone, coastal exposure.

2. Panama Canal Zone, inland exposure.

3. Panama Canal Zone, coastal exposure (Stainless Steel Type 316/316 couple).

4. Kure Beach, NC, shore rack $80 \mathrm{ft}$ from breakers.

5. Kure Beach, NC, main lot $800 \mathrm{ft}$ from breakers.

6. Bridgeport, Connecticut.

Temperatures listed as "approximately $27^{\circ} \mathrm{C}$ " and $\mathrm{RH}$ values listed as "approximately $83 \%$ " are approximated by taking the average value of January through December provided by Southwell and Bultman (1982 [DIRS 100928], Figure 64.1). The actual values of temperature and RH corresponding to each month are not given by these authors, but rather were estimated from the temperature and $\mathrm{RH}$ values at the beginning of each month, and then averaging these values. 
Table 4.1-2. Description of Conditions and Sources for Low-Alloy or Carbon Steels Corrosion Rate Data

\begin{tabular}{|c|c|c|c|}
\hline $\begin{array}{c}\text { Temperature } \\
\left({ }^{\circ} \mathrm{C}\right)\end{array}$ & $\begin{array}{c}\text { Relative Humidity } \\
(R H)\end{array}$ & $\begin{array}{c}\text { Exposure Time } \\
(y r)\end{array}$ & $\begin{array}{c}\text { Rate } \\
(\mu \mathrm{m} / \mathrm{yr})\end{array}$ \\
\hline 90 & Near $100 \%$ & 0.5 & 241.82 \\
\hline 90 & Near $100 \%$ & 0.5 & 321.82 \\
\hline 90 & Near $100 \%$ & 0.5 & 257.97 \\
\hline 90 & Near $100 \%$ & 0.5 & 238.11 \\
\hline 90 & Near $100 \%$ & 0.5 & 195.23 \\
\hline 90 & Near $100 \%$ & 0.5 & 192.02 \\
\hline 90 & Near $100 \%$ & 0.5 & 185.47 \\
\hline 90 & Near $100 \%$ & 0.5 & 228.28 \\
\hline 90 & Near $100 \%$ & 0.5 & 228.04 \\
\hline 90 & Near $100 \%$ & 0.5 & 276.51 \\
\hline 90 & Near $100 \%$ & 0.5 & 175.85 \\
\hline 90 & Near $100 \%$ & 0.5 & 269.12 \\
\hline 90 & Near $100 \%$ & 1 & 342.99 \\
\hline 90 & Near $100 \%$ & 1 & 363.36 \\
\hline 90 & Near $100 \%$ & 1 & 358.68 \\
\hline 90 & Near $100 \%$ & 1 & 423.06 \\
\hline 90 & Near $100 \%$ & 1 & 190.72 \\
\hline 90 & Near $100 \%$ & 1 & 139.58 \\
\hline 90 & Near $100 \%$ & 1 & 133.91 \\
\hline 90 & Near $100 \%$ & 1 & 121.31 \\
\hline 90 & Near $100 \%$ & 1 & 144.45 \\
\hline 90 & Near $100 \%$ & 1 & 132 \\
\hline 90 & Near $100 \%$ & 1 & 146.48 \\
\hline 90 & Near $100 \%$ & 0.53 & 150.33 \\
\hline 90 & Near $100 \%$ & 0.53 & 210.6 \\
\hline 90 & Near $100 \%$ & 0.53 & 313.05 \\
\hline 90 & Near $100 \%$ & 0.53 & 166.22 \\
\hline 90 & Near $100 \%$ & 0.53 & 261.61 \\
\hline 90 & Near $100 \%$ & 0.53 & 203.28 \\
\hline 90 & Near $100 \%$ & 0.53 & 75.29 \\
\hline 90 & Near $100 \%$ & 0.53 & 93.33 \\
\hline 90 & Near $100 \%$ & 0.53 & 102.31 \\
\hline 90 & Near $100 \%$ & 0.53 & 129.12 \\
\hline 90 & Near $100 \%$ & 0.53 & 180.84 \\
\hline 90 & Near $100 \%$ & 0.53 & 218.57 \\
\hline 90 & Near $100 \%$ & 1.01 & 212.81 \\
\hline 90 & Near $100 \%$ & 1.01 & 193.28 \\
\hline 90 & Near $100 \%$ & 1.01 & 272.06 \\
\hline 90 & Near $100 \%$ & 1.01 & 80.15 \\
\hline 90 & Near $100 \%$ & 1.01 & 120.81 \\
\hline 90 & Near $100 \%$ & 1.01 & 168.75 \\
\hline 90 & Near $100 \%$ & 1.01 & 72.96 \\
\hline
\end{tabular}


Table 4.1-2. Description of Conditions and Sources for Low-Alloy or Carbon Steels Corrosion Rate Data (Continued)

\begin{tabular}{|c|c|c|c|}
\hline $\begin{array}{c}\text { Temperature } \\
\left({ }^{\circ} \mathbf{C}\right)\end{array}$ & $\begin{array}{c}\text { Relative Humidity } \\
(\mathbf{R H})\end{array}$ & $\begin{array}{c}\text { Exposure Time } \\
(\mathbf{y r})\end{array}$ & $\begin{array}{c}\text { Rate } \\
(\mu \mathrm{m} / \mathbf{y r})\end{array}$ \\
\hline 90 & Near $100 \%$ & 1.01 & 85.05 \\
\hline 90 & Near $100 \%$ & 1.01 & 87.64 \\
\hline 90 & Near $100 \%$ & 1.01 & 113.86 \\
\hline 90 & Near $100 \%$ & 1.01 & 146.72 \\
\hline 90 & Near 100\% & 1.01 & 220.08 \\
\hline
\end{tabular}

Source: DTN: LL980704605924.035 [DIRS 147298], qualified in Appendix D.

NOTES: Materials tested in simulated concentrated well water (SCW).

See atmospheric.xls (Output DTN: MO0407SPAPCEML.005) for more details of input usage.

Representative low-alloy or carbon steel is considered similar to ASTM A 516/A516M-01 2001 [DIRS 162723], Table 1.

The other sources of direct input for corrosion rates are justified below per the requirements of LP-SIII.10Q-BSC, Models, and are considered qualified for the intended use in this document. The main criteria used for data qualification are corroborating data and technical assessment. Within the scope of the latter criterion, added confidence in the data is given by its publication in peer-reviewed journals and its development in nationally recognized scientific institutions. Descriptions of suitability for intended use for each source are given below:

Alexander, A.L.; Southwell, C.R.; and Forgeson, B.W. 1961 [DIRS 162265]. "Corrosion of Metals in Tropical Environments."

This paper was published in Corrosion, a peer-reviewed journal of the National Association of Corrosion Engineers, and was presented at the 17th annual conference of the National Association of Corrosion Engineers in 1961. The Naval Research Laboratory also published it as NRL Report 5517. The authors from the Naval Research Laboratory performed these experiments using established engineering practices as described in the article. Tests were carried out on materials of specific interest in waste package corrosion (in particular Stainless Steel Type 316) in drift-relevant waters types (dilute and salt/concentrated waters). Two values of Stainless Steel Type 316 corrosion loss, both 0.0 (zero) $\mathrm{g} / \mathrm{m}^{2}$ were taken from Table 2 of this paper, and added to the "316" worksheet in Output DTN: MO0407SPAPCEML.005. These values contribute to the selected mean value. They represent no sample weight loss over twoand four-year durations. The data for Stainless Steel Type 316L in humid air and atmospheric corrosion rates are consistent with and corroborated by the data from the other sources listed in Table 4.1-1 (Output DTN: MO0407SPAPCEML.005, values within "316” worksheet).

Bomberger, H.B.; Cambourelis, P.J.; and Hutchinson, G.E. 1954 [DIRS 163699]. "Corrosion Properties of Titanium in Marine Environments."

This article was published in Journal of the Electrochemical Society, a peer-reviewed journal of a professional society whose area of expertise includes the corrosion of metals. The three Stainless Steel Type 316 values taken from Table II in this article are each the average of three specimens. The values have been added to the "316" worksheet of atmospheric.xls of Output 
DTN: MO0407SPAPCEML.005. The test durations were five years, and four years eleven months. Preparation methods and test conditions are described. The experiments were performed on various materials of specific interest in waste package corrosion in waters of interest (salt/concentrated waters) and atmospheric conditions. The data for Stainless Steel Type 316L humid air and atmospheric corrosion rates are consistent with and corroborated by the data from the other sources listed in Table 4.1-1 and in the "316" worksheet of Output DTN: MO0407SPAPCEML.005.

Southwell, C.R.; Bultman, J.D.; and Alexander, A.L. 1976 [DIRS 100927]. "Corrosion of Metals in Tropical Environments - Final Report of 16-Year Exposures."

This article describes the results of 16-year tests of a wide variety of materials, including copper and Stainless Steel Type 316, in tropical seawater (total and intermittent submersion). The article was published in Materials Performance, an official publication of the Corrosion Society, the National Association of Corrosion Engineers.

Authors from the Naval Research Laboratory performed the tests using established engineering practices. Tests were carried out on materials of specific interest in waste package corrosion (copper and Stainless Steel Type 316) in waters types of interest (dilute and salt/concentrated waters). Coastal and inland corrosion values from Tables 5 and 7 of this article were added to the "316" worksheet of Output DTN: MO0407SPAPCEML.005. The Stainless Steel Type 316 corrosion values are corroborated by and consistent with the other sources listed in the Stainless Steel Type 316L section of Table 4.1-1 and values listed in the output DTN.

\subsubsection{Committed Low-Alloy or Carbon Steel Materials}

Section 6.7.1 estimates to what extent the partial pressure of oxygen might change because of the fast corrosion of low-alloy or carbon steels. This involves a quantitative description of the low-alloy or carbon steel materials that are emplaced within the drift and within a representative waste package (Output DTN: SN0508T0510102.023).

The only significant source of low-alloy or carbon steel within the emplacement drift — excluding the waste package and internal components - is found within the invert structure. These structural elements and their size specifications are listed in Table 4.1-3. Size specifications are used to calculate the surface areas of each component to determine its oxygen demand from corrosion. This is described in Section 6.7 and calculated in this report (Output DTN: SN0508T0510102.023). Some of the minor (in terms of mass) structural components were not included as a simplification, because of nonspecific size specifications and because they account for less than $10 \%$ of the total material. The mass included in Table $4.1-3$ is $982 \mathrm{~kg} / \mathrm{m}$; excluded is $75 \mathrm{~kg} / \mathrm{m}$, determined from weights listed for committed materials (BSC 2004 [DIRS 169776]). 
Table 4.1-3. Low-Alloy or Carbon Emplacement Drift Steel Materials and Size Specifications

\begin{tabular}{|c|c|c|c|}
\hline Component & $\begin{array}{l}\text { Material Conformance } \\
\text { ASTM Manual }\end{array}$ & Type of Material & $\begin{array}{c}\text { Size } \\
\text { Specifications }\end{array}$ \\
\hline Gantry Rails & Carbon Steel Type A759a & Carbon Steel Crane Rails & $135 \mathrm{lb} / \mathrm{yd}$ \\
\hline $\begin{array}{l}\text { Rail Runway Beams with } \\
\text { Stiffeners }\end{array}$ & $\begin{array}{l}\text { Carbon Steel Type A588, } \\
\text { Grade } 50^{\mathrm{b}}\end{array}$ & High-Strength Low-Alloy Steel & W8 $\times 67$ \\
\hline Runway Beam Cap Plates & $\begin{array}{l}\text { Carbon Steel Type A588, } \\
\text { Grade } 50^{\mathrm{b}}\end{array}$ & High-Strength Low-Alloy Steel & PL 1" × 12" \\
\hline Longitudinal Support Beams & $\begin{array}{l}\text { Carbon Steel Type A588, } \\
\text { Grade } 50^{\mathrm{b}}\end{array}$ & High-Strength Low-Alloy Steel & $W 12 \times 35$ \\
\hline $\begin{array}{l}\text { Transverse Beams with } \\
\text { Stiffeners }\end{array}$ & $\begin{array}{l}\text { Carbon Steel Type A588, } \\
\text { Grade } 50^{\mathrm{b}}\end{array}$ & High-Strength Low-Alloy Steel & $W 12 \times 72$ \\
\hline Stub Column & $\begin{array}{l}\text { Carbon Steel Type A588, } \\
{\text { Grade } 52^{\mathrm{b}}}\end{array}$ & High-Strength Low-Alloy Steel & W8 $\times 67$ \\
\hline Base Plates & $\begin{array}{l}\text { Carbon Steel Type A588, } \\
\text { Grade } 50^{\mathrm{b}}\end{array}$ & High-Strength Low-Alloy Steel & $\mathrm{PL} 1 " \times 12 " \times 24 "$ \\
\hline
\end{tabular}

Source: Material ASTM and size specifications indicated in BSC 2004 [DIRS 169776].

${ }^{a}$ ASTM A 759-00 2001 [DIRS 159971], Table 1.

${ }^{\mathrm{b}}$ ASTM A 588/A588M-01 2001 [DIRS 162724], Table 1.

Additional references are necessary to define components that are not plate structures (abbreviated "PL" in Table 4.1-3). The 135-lb/yd gantry rails are defined in Manual of Steel Construction, Allowable Stress Design (AISC 1989 [DIRS 107536], p. 1-113); the "W" size specifications are defined in the same reference in the tables on pp. 1-28 and 1-32. This source is considered to be "Established Fact" as it comes from the American Institute of Steel Construction. The primary purpose of this organization is to standardize steel construction designs.

\subsubsection{Environmental Compositions}

THC Seepage-The seepage water boundary compositions used in the seepage evaporation abstraction and their associated equilibrium $\mathrm{CO}_{2}$ pressure values are listed in DTN: LB0302DSCPTHCS.002 [DIRS 161976]. This DTN consists of five complete drift-scale seepage-coupled THC modeling results, each representing a different starting pore water as described in Drift-Scale THC Seepage Model (BSC 2005 [DIRS 172862]). The THC seepage model output for each water is in Microsoft Excel spreadsheet format:

- CS500/12.0-16.7 (thc6_w7_r.xls)

- CS2000/16.5 (thc6_w4_r.xls)

- CS1000/7.3 (thc6_w5_r.xls)

- SD-9/990.4 (thc6_w6_r.xls)

- HD-PERM water (thc6_w0_r.xls).

These five waters were selected in the source report to represent the spread of available pore-water data and to serve as starting water compositions for the drift-scale THC seepage model. The rationale for the initial selection of these five waters is discussed in Drift-Scale THC Seepage Model (BSC 2005 [DIRS 172862], Section 6.2.2.1). 
Table 4.1-4 lists the THC seepage model outputs used as inputs to the binning analysis in this report (Section 6.6) and identifies these inputs by starting water composition. Throughout the remainder of this report, they will be referred to by their abbreviated water name.

Instructions on how to initially reduce the seepage data to a single time-water sequence from the large set of results is given in Post-Processing Analysis for THC Seepage (BSC 2004 [DIRS 169858], Section 6.2.3.3). These instructions supply 368 water compositions. For crown seepage, this report begins with THC fracture waters in the front region, specifically from "index" number four. For invert seepage, this report begins with THC matrix waters in the front region, again from "index" number four. This information bounds the detailed chemical analysis process in Section 6.6.2.

Table 4.1-4. Source Files for Input to Binning Analysis

\begin{tabular}{|c|c|l|}
\hline $\begin{array}{c}\text { Abbreviated } \\
\text { Water Name }\end{array}$ & Filename & Starting Water Composition \\
\hline w0 & thc6_w0_r.x/s & HD-PERM water (Alcove 5) \\
\hline w4 & thc6_w4_r.x/s & Cross-drift water CS2000/16.5 \\
\hline w5 & thc6_w5_r.xls & Cross-drift water CS1000/7.3 \\
\hline w6 & thc6_w6_r.xls & Borehole water SD-9/990.4 \\
\hline w7 & thc6_w7_r.xls & Cross-drift water CS500/12.0-16.7 \\
\hline
\end{tabular}

Source: DTN: LB0302DSCPTHCS.002 [DIRS 161976].

In-Drift Gas-The files shown in Table 4.1-5 are used as inputs for the in-drift carbon dioxide and oxygen gas analyses in Section 6.7. Used from these files are the time dependencies of volume fraction of $\mathrm{CO}_{2}$, "co2(g)," the total pressure, "Pa," and temperature, "C." These inputs are used within Output DTN: SN0503T0510102.019.

Table 4.1-5. References for Input Gas Chemistry Analyses

\begin{tabular}{|l|c|}
\hline \multicolumn{1}{|c|}{ Filename } & Starting Water Composition \\
\hline thc6_w0_r.xls & HD-PERM water (Alcove 5) \\
thc6_w0_drift_r.xls & \\
\hline thc6_w4_r.xls & Cross-drift water CS2000/16.5 \\
thc6_w4_drift_r.xls & \\
\hline thc6_w5_r.xls & Cross-drift water CS1000/7.3 \\
thc6_w5_drift_r.xls & \\
\hline thc6_w6_r.xls & Borehole water SD-9/990.4 \\
thc6_w6_drift_r.xls & \\
\hline thc6_w7_r.xls & Cross-drift Water CS500/12.0-16.7 \\
thc6_w7_drift_r.xls & \\
\hline
\end{tabular}

Source: DTN: LB0302DSCPTHCS.002 [DIRS 161976].

Gas Flux - The gas flux across the drift wall and into the drift over time is estimated in Section 6.7.1 using output from Drift-Scale THC Seepage Model (BSC 2005 [DIRS 172862]), as listed in Table 4.1-6. The complete set of results in the dataset includes gas flux at the base, side, and crown (DTN: LB0302DSCPTHCS.002 [DIRS 161976], thc6_w0_drift_r.xls). To measure the flux of gas coming into the drift, the largest positive flux value, regardless of its position in the drift (side, base, or crown), is used at each time step in the calculations (Output 
DTN: SN0508T0510102.023, gas flux.xls). Table 4.1-6 summarizes the position in the drift | where the maximum flux occurred, $\mathrm{CO}_{2}$ volume fraction, gas flux, and air-mass fraction.

Table 4.1-6. Time-Varying Inputs for the Gas Flux Calculation in Section 6.7.1

\begin{tabular}{|c|c|c|c|c|}
\hline $\begin{array}{l}\text { Time } \\
(y r s)^{a}\end{array}$ & $\begin{array}{l}\text { Position in Drift } \\
\text { (at the Wall) }\end{array}$ & $\begin{array}{l}\mathrm{CO}_{2}(\mathrm{~g}) \\
\text { Volume } \\
\text { Fraction }\end{array}$ & $\begin{array}{c}\text { Gas Flux } \\
(\mathrm{kg} / \mathrm{s})\end{array}$ & $\begin{array}{l}\text { Air-Mass } \\
\text { Fraction } \\
\end{array}$ \\
\hline 0.0027 & Base & $9.29 \mathrm{E}-04$ & $-5.09 \mathrm{E}-09$ & $9.80 \mathrm{E}-01$ \\
\hline 1 & Side & 1.33E-03 & $2.15 \mathrm{E}-09$ & $9.40 \mathrm{E}-01$ \\
\hline 5 & Side & $1.26 \mathrm{E}-03$ & $4.56 \mathrm{E}-09$ & $9.03 E-01$ \\
\hline 10 & Side & $1.20 \mathrm{E}-03$ & $4.83 \mathrm{E}-09$ & $8.92 \mathrm{E}-01$ \\
\hline 20 & Side & $1.09 \mathrm{E}-03$ & $3.89 \mathrm{E}-09$ & $8.94 \mathrm{E}-01$ \\
\hline 30 & Side & $9.98 \mathrm{E}-04$ & $2.88 \mathrm{E}-09$ & $9.02 \mathrm{E}-01$ \\
\hline 40 & Side & 9.97E-04 & $2.08 \mathrm{E}-09$ & $9.10 \mathrm{E}-01$ \\
\hline 50 & Side & $9.75 \mathrm{E}-04$ & $1.50 \mathrm{E}-09$ & $9.17 \mathrm{E}-01$ \\
\hline 51 & Side & $5.01 \mathrm{E}-04$ & $1.05 \mathrm{E}-07$ & $2.75 \mathrm{E}-01$ \\
\hline 53 & Crown & $2.10 \mathrm{E}-04$ & $1.12 \mathrm{E}-07$ & $9.19 \mathrm{E}-03$ \\
\hline 55 & Side & 1.17E-04 & $2.71 \mathrm{E}-08$ & $2.75 \mathrm{E}-03$ \\
\hline 60 & Crown & $2.58 \mathrm{E}-05$ & $9.51 \mathrm{E}-08$ & $3.49 \mathrm{E}-05$ \\
\hline 75 & Crown & $9.33 \mathrm{E}-05$ & $3.70 \mathrm{E}-08$ & $1.56 \mathrm{E}-03$ \\
\hline 100 & Crown & $2.59 \mathrm{E}-04$ & $2.03 E-08$ & $1.81 \mathrm{E}-02$ \\
\hline 150 & Crown & $5.19 \mathrm{E}-04$ & $2.94 \mathrm{E}-08$ & $5.18 E-02$ \\
\hline 200 & Crown & $5.99 \mathrm{E}-04$ & $5.10 \mathrm{E}-08$ & $6.71 \mathrm{E}-02$ \\
\hline 250 & Crown & $4.92 \mathrm{E}-04$ & $3.52 \mathrm{E}-08$ & $7.04 \mathrm{E}-02$ \\
\hline 300 & Crown & $3.60 \mathrm{E}-04$ & $2.22 \mathrm{E}-08$ & $6.49 \mathrm{E}-02$ \\
\hline 350 & Crown & $2.95 \mathrm{E}-04$ & $1.59 \mathrm{E}-08$ & $5.99 \mathrm{E}-02$ \\
\hline 400 & Crown & $2.95 \mathrm{E}-04$ & $1.31 \mathrm{E}-08$ & $5.37 E-02$ \\
\hline 500 & Crown & $4.46 \mathrm{E}-04$ & $1.12 \mathrm{E}-08$ & $4.31 \mathrm{E}-02$ \\
\hline 600 & Crown & $8.09 E-04$ & 1.07E-08 & $3.96 \mathrm{E}-02$ \\
\hline 650 & Crown & $1.13 \mathrm{E}-03$ & $1.38 \mathrm{E}-08$ & $3.30 \mathrm{E}-02$ \\
\hline 700 & Crown & $1.48 \mathrm{E}-03$ & $1.42 \mathrm{E}-08$ & $3.46 \mathrm{E}-02$ \\
\hline 751 & Crown & $1.87 \mathrm{E}-03$ & 1.36E-08 & $4.02 \mathrm{E}-02$ \\
\hline 790 & Crown & $2.10 \mathrm{E}-03$ & $1.34 \mathrm{E}-08$ & $4.57 \mathrm{E}-02$ \\
\hline 801 & Crown & $2.30 \mathrm{E}-03$ & $1.33 \mathrm{E}-08$ & $4.75 \mathrm{E}-02$ \\
\hline 1,001 & Crown & $4.13 \mathrm{E}-03$ & $1.20 \mathrm{E}-08$ & $9.23 \mathrm{E}-02$ \\
\hline 1,201 & Crown & $5.24 \mathrm{E}-03$ & $1.14 \mathrm{E}-08$ & $1.29 \mathrm{E}-01$ \\
\hline 1,401 & Crown & $6.37 \mathrm{E}-03$ & $9.90 \mathrm{E}-09$ & $1.83 \mathrm{E}-01$ \\
\hline 1,601 & Crown & $7.19 \mathrm{E}-03$ & 8.47E-09 & $2.42 \mathrm{E}-01$ \\
\hline 1,801 & Crown & $7.74 \mathrm{E}-03$ & 7.37E-09 & $2.86 \mathrm{E}-01$ \\
\hline 2,001 & Side & $7.71 \mathrm{E}-03$ & $4.37 \mathrm{E}-08$ & $2.17 \mathrm{E}-01$ \\
\hline 2,202 & Base & $7.94 \mathrm{E}-03$ & $3.29 \mathrm{E}-08$ & $3.01 \mathrm{E}-01$ \\
\hline $2,402^{b}$ & Base & $8.34 \mathrm{E}-03$ & $3.34 \mathrm{E}-08$ & $3.57 \mathrm{E}-01$ \\
\hline 3,002 & Base & 7.94E-03 & $2.80 \mathrm{E}-08$ & $4.84 \mathrm{E}-01$ \\
\hline 5,003 & Base & $6.81 \mathrm{E}-03$ & $2.13 \mathrm{E}-08$ & $7.01 \mathrm{E}-01$ \\
\hline 7,005 & Base & $7.02 \mathrm{E}-03$ & 1.87E-08 & $8.00 \mathrm{E}-01$ \\
\hline 10,007 & Base & $7.15 \mathrm{E}-03$ & $1.67 \mathrm{E}-08$ & $8.73 E-01$ \\
\hline 12,310 & Base & $6.69 \mathrm{E}-03$ & $1.59 \mathrm{E}-08$ & $9.01 \mathrm{E}-01$ \\
\hline
\end{tabular}


Table 4.1-6. Time-Varying Inputs for the Gas Flux Calculation in Section 6.7.1 (Continued)

\begin{tabular}{|c|c|c|c|c|}
\hline $\begin{array}{c}\text { Time } \\
(\mathbf{y r s})^{\mathbf{a}}\end{array}$ & $\begin{array}{c}\text { Position in Drift } \\
\text { (at the Wall) }\end{array}$ & $\begin{array}{c}\mathbf{C O}_{2}(\mathbf{g}) \\
\text { Volume } \\
\text { Fraction }\end{array}$ & $\begin{array}{c}\text { Gas Flux } \\
\text { (kg/s) }\end{array}$ & $\begin{array}{c}\text { Air-Mass } \\
\text { Fraction }\end{array}$ \\
\hline 15,010 & Base & $5.92 \mathrm{E}-03$ & $1.51 \mathrm{E}-08$ & $9.23 \mathrm{E}-01$ \\
\hline 20,013 & Base & $4.59 \mathrm{E}-03$ & $1.42 \mathrm{E}-08$ & $9.46 \mathrm{E}-01$ \\
\hline 27,355 & Base & $3.42 \mathrm{E}-03$ & $1.34 \mathrm{E}-08$ & $9.61 \mathrm{E}-01$ \\
\hline 30,020 & Base & $3.02 \mathrm{E}-03$ & $1.32 \mathrm{E}-08$ & $9.64 \mathrm{E}-01$ \\
\hline 50,035 & Base & $2.24 \mathrm{E}-03$ & $1.24 \mathrm{E}-08$ & $9.74 \mathrm{E}-01$ \\
\hline 77,206 & Base & $1.92 \mathrm{E}-03$ & $1.19 \mathrm{E}-08$ & $9.79 \mathrm{E}-01$ \\
\hline 100,067 & Base & $1.68 \mathrm{E}-03$ & $1.17 \mathrm{E}-08$ & $9.80 \mathrm{E}-01$ \\
\hline
\end{tabular}

Source: DTN: LB0302DSCPTHCS.002 [DIRS 161976], thc6_wO_drift_r.xls, tabs "fractures-ch" and "fractures-th."

a Time is measured in THC from emplacement, with closure occurring at 50 years, see BSC 2004 [DIRS 169858], Section 6.2.3.3.

${ }^{b}$ For time of 2,402 $\mathrm{yr}$ (Base) two values for $\mathrm{CO}_{2}(\mathrm{~g})$ volume fraction exist within DTN: LB0302DSCPTHCS.002 [DIRS 161976], thc6_wO_drift_r.xls, tab "fracture-ch." The higher value $8.34 \mathrm{E}-3$ was chosen over the lower value $8.15 \mathrm{E}-3$.

NOTE: Negative gas flux means flux is away from the drift.

Oxygen Demand-The effects of corrosion of engineered barrier system (EBS) committed materials on the concentration of oxygen in the drift atmosphere through time are evaluated in two ways. One utilizes the THC seepage model output archived in DTN: LB0302DSCPTHCS.002 [DIRS 161976] and its air fraction to calculate the lowest oxygen partial pressure resulting from displacement by thermally generated steam. The second combines the material inputs from Section 4.1.2 with the additional information in Tables 4.1-7 and 4.1-8. For these gas abstraction methodologies, see Section 6.7.1 and calculation results in Output DTN: SN0508T0510102.023.

Table 4.1-7. Constant Inputs for Calculations from Section 6.7.1

\begin{tabular}{|l|c|l|l|}
\hline \multicolumn{1}{|c|}{ Parameter } & Value & $\begin{array}{c}\text { Location in Output } \\
\text { DTN: SN0508T0510102.023 }\end{array}$ & \multicolumn{1}{c|}{ Source } \\
\cline { 1 - 2 } Atomic Weight of $\mathrm{O}$ & $15.9994 \mathrm{~g} / \mathrm{mol}$ & gas flux.xls & Parrington et al. 1996 \\
[DIRS 103896], pp. 62 to 63
\end{tabular}


Table 4.1-7. Constant Inputs for Calculations from Section 6.7.1 (Continued)

\begin{tabular}{|c|c|c|c|}
\hline Parameter & Value & $\begin{array}{l}\text { Location in Output } \\
\text { DTN: SN0508T0510102.023 }\end{array}$ & Source \\
\hline $\begin{array}{l}\text { Cross-Sectional Area at } \\
\text { Wall (Crown and Side) }\end{array}$ & $0.3605 \mathrm{~m}^{2}$ & \multirow[t]{2}{*}{ gas flux.xls } & \multirow{2}{*}{$\begin{array}{l}\text { DTN: LB0302DSCPTHCS.002 } \\
\text { [DIRS 161976], } \\
\text { thc6_w0_drift_r.xIs, tab "notes" }\end{array}$} \\
\hline $\begin{array}{l}\text { Cross-Sectional Area at } \\
\text { Wall (Base) }\end{array}$ & $0.5417 \mathrm{~m}^{2}$ & & \\
\hline Drift Diameter & $5.5 \mathrm{~m}$ & gas flux.xls & $\begin{array}{l}\text { BSC } 2005 \text { [DIRS 173498], } \\
\text { Figure } 1\end{array}$ \\
\hline $\begin{array}{l}\text { 21-PWR Waste Package } \\
\text { Length }\end{array}$ & $5.0244 \mathrm{~m}$ & Oxygen Demand.xls & BSC 2005 [DIRS 173501], Table 1 \\
\hline $\begin{array}{l}\text { Spacing between Waste } \\
\text { Packages }\end{array}$ & $0.1 \mathrm{~m}$ & Oxygen Demand.xls & BSC 2004 [DIRS 168489], Table 1 \\
\hline $\begin{array}{l}\text { Density of Carbon or } \\
\text { Low-Alloy Steels } \\
\end{array}$ & $7.85 \mathrm{~g} / \mathrm{cm}^{3}$ & Oxygen Demand.xls & ASME 1995 [DIRS 151765], p. 67 \\
\hline $\begin{array}{l}\text { Composition of Carbon or } \\
\text { Low-Allow Steel (Carbon } \\
\text { Steel Type A } 516 \text { Grade 55) }\end{array}$ & $\begin{array}{l}\text { C } 0.22 \text { max; } \\
\text { Mn } 0.6 \text { to } 1.20 ; \\
\text { P } 0.035 \text { max; } \\
\text { S } 0.035 \text { max; } \\
\text { Si } 0.13 \text { to } 0.45 ; \\
\text { Fe remainder }\end{array}$ & Oxygen Demand.xls & $\begin{array}{l}\text { ASTM A 516/A 516M-012001 } \\
\text { [DIRS 162723], Table } 1\end{array}$ \\
\hline $\begin{array}{l}\text { Atmospheric Pressure at } \\
\text { the Repository Elevation }\end{array}$ & $\begin{array}{c}89,112 \mathrm{~Pa} \\
\text { (rounded to } \\
0.89 \text { bar) }\end{array}$ & Air fraction.xIs & $\begin{array}{l}\text { BSC } 2004 \text { [DIRS 169862], } \\
\text { Appendix XIX }\end{array}$ \\
\hline
\end{tabular}

Data from the two non-project sources (ASME 1995 [DIRS 151765] and ASTM A516/A 516M-01 2001 [DIRS 162723]) are considered to be established fact as they are published standards for commonly used engineering materials.

The surface areas for in-package components of A516 material are also needed in Section 6.7.1.2 in order to determine an accurate oxygen demand due to corrosion. These are determined from the mass and thickness data available from an information exchange drawing (BSC 2005 [DIRS 173501], Table 3) as presented in Table 4.1-7. The calculation of surface area is contained within Output DTN: SN0508T0510102.023 (Oxygen Demand.xls, tab "Surface Areas Carbon Steel"). 
Table 4.1-8. Inputs for Calculation of Oxygen Consumption by Within-Package Corrosion Processes

\begin{tabular}{|c|c|c|c|c|}
\hline Components & $\begin{array}{c}\text { Mass } \\
(\mathrm{kg})\end{array}$ & Quantity & $\begin{array}{c}\text { Total Mass of } \\
\text { Component } \\
(\mathrm{kg})\end{array}$ & $\begin{array}{c}\text { Minimum } \\
\text { Thickness } \\
\text { (cm) }\end{array}$ \\
\hline $\begin{array}{l}\text { Carbon Steel Type A516 Basket } \\
\text { Side Guide }\end{array}$ & $2.49 \mathrm{E}+01$ & 16 & $3.98 \mathrm{E}+02$ & \multirow[t]{6}{*}{0.9525} \\
\hline $\begin{array}{l}\text { Carbon Steel Type A516 Basket } \\
\text { Side Guide Stiffener }\end{array}$ & $6.15 \mathrm{E}-01$ & 32 & 1.97E+01 & \\
\hline $\begin{array}{l}\text { Carbon Steel Type A516 Basket } \\
\text { End Side Guide }\end{array}$ & $3.27 \mathrm{E}+01$ & 32 & $1.05 E+03$ & \\
\hline $\begin{array}{l}\text { Carbon Steel Type A516 Basket } \\
\text { End Side Guide Stiffener }\end{array}$ & $1.38 \mathrm{E}+00$ & 64 & $8.83 E+01$ & \\
\hline $\begin{array}{l}\text { Carbon Steel Type A516 Basket } \\
\text { Corner Guide }\end{array}$ & $4.01 \mathrm{E}+01$ & 16 & $6.42 \mathrm{E}+02$ & \\
\hline $\begin{array}{l}\text { Carbon Steel Type A516 Basket } \\
\text { Corner Guide Stiffener }\end{array}$ & $2.07 \mathrm{E}+00$ & 32 & $6.62 E+01$ & \\
\hline $\begin{array}{l}\text { Carbon Steel Type A516 Fuel } \\
\text { Basket Tube }\end{array}$ & $1.59 \mathrm{E}+02$ & 21 & 3.34E+03 & 0.47625 \\
\hline
\end{tabular}

Source: BSC 2005 [DIRS 173501], Table 3.

NOTE: All data listed here are used in Section 6.7.1 and in Output DTN: SN0508T0510102.023, Oxygen Demand.xls.

\subsubsection{Thermodynamic Databases}

The following two datasets have been developed by the Yucca Mountain Project (YMP) for geochemical modeling calculations using EQ3/6 (BSC 2003 [DIRS 162228]):

- data0.ymp.R2: This database is found in DTN: MO0302SPATHDYN.000 [DIRS 161756]. It does not contain Pitzer parameters, and is used in Sections 6.7 and 6.8 for analyses involving transition metals. This database was originated in the report by the Steinborn et al. (2003 [DIRS 161956]), and qualified in Qualification of Thermodynamic Data for Geochemical Modeling of Mineral-Water Interactions in Dilute Systems (BSC 2004 [DIRS 171916]). This extensive database is usable for ionic strength up to one molal and temperatures up to $300^{\circ} \mathrm{C}$ (with restrictions; see BSC 2004 [DIRS 171916], Section 7).

- data0.ypf.R0: This database is found in DTN: SN0302T0510102.002 [DIRS 162572]. Its development is documented in In-Drift Precipitates/Salts Model (IDPS model; BSC 2004 [DIRS 169863], Attachment I). The database constitutes part of the IDPS model and is used for EQ3/6 Pitzer-type calculations, including those which support the seepage evaporation abstraction. It includes updated equilibrium constants (e.g., $\log (K), \Delta H, \Delta G$, and $S$ ) and Pitzer interaction parameters for temperatures above $25^{\circ} \mathrm{C}$ and additional mineral phases (including zeolites, clays, cement phases, and minerals associated with salt deposits). 


\subsubsection{In-Drift Evaporation}

In-Drift Precipitates/Salts Model (BSC 2004 [DIRS 169863]) is documented independently of this model report. The IDPS model, its assumptions (Section 5.1), and validation are a direct feed into this model. Additionally, In-Drift Precipitates/Salts Model (BSC 2004 [DIRS 169863]) is the report that developed DTN: MO0303SPAMEQ36.000 [DIRS 162549] listed in Table 4.1-9. Refer to that report (BSC 2004 [DIRS 169863]) for model development specifics.

The model validation range for the current IDPS model is for temperatures up to $140^{\circ} \mathrm{C}$ and $R H$ from 0 to 100\% (BSC 2004 [DIRS 169863], Section 1; and Section 7.5.3), excepting that deliquescence $R H$ is not validated for predictions below $40 \%$. This report acknowledges these ranges and always remains bound by them.

The second DTN listed in Table 4.1-9 (DTN: MO0312SPAESMUN.002 [DIRS 166329]) is developed in In-Drift Precipitates/Salts Model (BSC 2004 [DIRS 169863], Section 8.4) and is used as input for the geochemical model uncertainties quantified in this report (Section 6.12).

Table 4.1-9. IDPS Model Outputs Used as Inputs

\begin{tabular}{|l|l|}
\hline \multicolumn{1}{|c|}{ Source DTN } & \multicolumn{1}{c|}{ Description } \\
\hline MO0303SPAMEQ36.000 & General Formats for EQ3/6 Input Files \\
[DIRS 162549] & Simulating the In-Drift Precipitates/Salts Model \\
\hline $\begin{array}{l}\text { MO0312SPAESMUN.002 } \\
\text { [DIRS 166329] }\end{array}$ & $\begin{array}{l}\text { Estimated Model Uncertainties in the In-Drift } \\
\text { Precipitates/Salts Model }\end{array}$ \\
\hline
\end{tabular}

Halite Precipitation-In order to determine the highest relative humidity at which precipitation of halite may occur, two sources are examined: DTN: LL031106231032.007 [DIRS 170605] (ExptDRHCalcsKracekRev00c.xls) and a study by Greenspan (1977 [DIRS 104945], Table 2). Results are discussed in Section 6.13.6 and contained in Output DTN: SN0403T0503404.001.

Greenspan's (1977 [DIRS 104945]) report is from Journal of Research of the National Bureau of Standards, 81A. The author is a highly recognized individual in this field of work and worked for the National Bureau of Standards. The National Bureau of Standards is a federal agency that establishes the standards used in measuring the physical properties of substances; therefore, the report by Greenspan (1977 [DIRS 104945]) is regarded as established fact due to its publication source and author.

\subsubsection{Stainless Steel Corrosion Chemistry}

This section provides inputs to Section 6.8, which examines the chemical impact of the steel ground support system and its resulting corrosion products on seepage waters entering the drift. The current design for drift ground support calls for using stainless steel sheets and rock bolts (BSC 2005 [DIRS 173498], Figure 1), and the design specified this as Stainless Steel Type 316L (BSC 2004 [DIRS 169058], Note 4). Stainless Steel Type 316L is the specific material used for modeling the corrosion-seepage water interaction. The metallic elements contained within Stainless Steel Type 316L are presented here along with seepage condition parameters and new chromium solid species. 
Design Specifications-The relevant dimensional information for the ground support sheets and rock bolts is presented in Table 4.1-10.

Table 4.1-10. Dimensional Information for Stainless Steel Type 316L Sheets and Rock Bolts

\begin{tabular}{|l|c|l|}
\hline \multicolumn{1}{|c|}{ Parameter } & Value & \multicolumn{1}{c|}{ Sources } \\
\hline Sheet Thickness & $3 \mathrm{~mm}$ & BSC 2005 [DIRS 173498], Figure 1 \\
\hline Rock Bolt Component & $\begin{array}{c}10 \text { Bolts/Row } \\
3.0-\mathrm{m} \mathrm{long}\end{array}$ & BSC 2005 [DIRS 173498], Figure 1 \\
\hline Rock Bolt Outer Diameter & $54 \mathrm{~mm}$ & BSC 2003 [DIRS 164101], Table 3 \\
\hline Rock Bolt Thickness & $3 \mathrm{~mm}$ & BSC 2004 [DIRS 169058], Note 2 \\
\hline Rock Bolt Row Spacing & $1.25 \mathrm{~m}$ & BSC 2005 [DIRS 173498], Figure 1 \\
\hline
\end{tabular}

${ }^{a}$ The source for rock bolt outer diameter is BSC 2003 [DIRS 164101], a superseded information exchange drawing (IED). The outer diameter of the rock bolts is not provided in the revised design data in the superseding IED (BSC 2005 [DIRS 173498]). Therefore, the value of 54-mm diameter is retained here and justified for use because of the lack of this information in the superseding IED (BSC 2005 [DIRS 173498]).

${ }^{b}$ The source for rock bolt thickness is BSC 2004 [DIRS 169058], a superseded IED. The rock bolt thickness is not provided in the revised design data in the superseding IED (BSC 2005 [DIRS 173498]). Therefore, the value of 3-mm thickness is retained here and justified for use because of the lack of this information in the superseding IED (BSC 2005 [DIRS 173498]).

As was noted previously, the material composition of both the perforated "Bernold" sheets and the rock bolts is contained within ASTM A 276-03 [DIRS 165006], Section 4.3.2, as indicated on the justified historical source D\&E/PA/C IED Subsurface Facilities Committed Materials (BSC 2004 [DIRS 169058], Note 4); this is Stainless Steel Type 316L.

Condition Parameters-The calculation for Stainless Steel Type 316L corrosion is performed in Sections 6.8.3 and 6.8.4. Table 4.1-11 summarizes the specific inputs utilized to analyze the degree of corrosion as a function of time.

Infiltration Rates-Infiltration rates are used as input (see Table 4.1-11) in Section 6.8 to determine how much water per year is available to react with the stainless steel. These infiltration rates are taken from DTN: LB0302DSCPTHCS.002 [DIRS 161976], this being consistent with the usage of many other inputs from Drift-Scale THC Seepage Model (BSC 2005 [DIRS 172862], infiltration rates in Section 4.1.1.2). The infiltration rates used as inputs to the THC seepage model are qualified for use in this report to maintain consistency with the incorporation of that model's outputs. 
Table 4.1-11. Parameters Used to Analyze Stainless Steel Type 316L Ground Support Corrosion

\begin{tabular}{|c|c|c|c|}
\hline Parameter & Value & Units & Source \\
\hline $\begin{array}{l}\text { Stainless Steel Type } \\
\text { 316L Density }\end{array}$ & 7.98 & $\mathrm{~g} / \mathrm{cm}^{3}$ & ASTM G 1-90 1999 [DIRS 103515], Table X1.1 \\
\hline $\begin{array}{l}\text { Composition of } \\
\text { Stainless Steel Type } \\
\text { 316L }\end{array}$ & $\begin{array}{l}\mathrm{Fe}-65.545^{\mathrm{a}} \\
\mathrm{Cr}-16.0 \text { to } 18.0(17 \mathrm{avg}) \\
\mathrm{Ni}-10.0 \text { to } 14.0(12 \mathrm{avg}) \\
\mathrm{Mo}-2.00 \text { to } 3.00(2.5 \mathrm{avg}) \\
\mathrm{Mn}-2.00, \mathrm{Si}-0.75 \\
\mathrm{~N}-0.10, \mathrm{P}-0.045 \\
\mathrm{C}-0.03, \mathrm{~S}-0.03\end{array}$ & wt $\%$ & $\begin{array}{l}\text { ASTM A 240/A 240M-02a } 2002 \text { [DIRS 162720], } \\
\text { Table } 1\end{array}$ \\
\hline $\begin{array}{l}\text { Time-Dependent } \\
\text { Infiltration Rates }\end{array}$ & $\begin{array}{l}6,16,25 \text { (incrementing at } \\
600 \text { and } 2,000 \text { years) }\end{array}$ & $\mathrm{mm} / \mathrm{yr}$ & DTN: LB0302DSCPTHCS.002 [DIRS 161976] \\
\hline $\begin{array}{l}\text { Fracture Transition } \\
\text { Time from Dry to Wet } \\
\text { Drift Wall Conditions } \\
\text { for the Value }\end{array}$ & Approximately 2,000 & $\mathrm{yr}$ & $\begin{array}{l}\text { DTN: LB0302DSCPTHCS.002 [DIRS 161976], } \\
\text { thc6_w\#_r.xls, tab "distance" }\end{array}$ \\
\hline
\end{tabular}

${ }^{a}$ The weight percent of Fe was calculated from Table 1 of ASTM A 240/A 240M-02a [DIRS 162720] by subtracting all alloying elements from 100 . When a range is given, the average of that range is used in Output DTN: SN0312T0510102.013, DegradationMolality.zip, tab "Composition."

Chromium Solids-The inclusion of an amorphous chromium(III) hydroxide mineral species is required to model the effects of corrosion on incoming seepage waters; otherwise, there is no controlling solid phase available for $\mathrm{Cr}$ in the data0.ymp.R2 database (DTN: MO0302SPATHDYN.000 [DIRS 161756]). The rationale for selecting the amorphous chromium hydroxide mineral species is discussed in Section 6.8.2. In addition, the formation reaction for the mineral Eskolaite $\left(\mathrm{Cr}_{2} \mathrm{O}_{3}\right)$ in the current non-Pitzer database has been recast to match that described in the source for the thermodynamic data for amorphous chromium hydroxide. The solubility parameters are listed in Table 4.1-12.

The article by Ball and Nordstrom (1998 [DIRS 163015]), the source for these added chromium solids, contains the directly relevant data as exemplified by this reference's title, "Critical Evaluation and Selection of Standard State Thermodynamic Properties for Chromium Metal and its Aqueous Ions, Hydrolysis Species, Oxides, and Hydroxides." This particular article is a comprehensive review of chromium metal and its aqueous species, drawing information from many sources with as much corroboration as available. It is published in Journal of Chemical and Engineering Data, a peer-reviewed journal with rigorous screening processes, and authored by well-known experts in this field. Dr. Nordstrom has over thirty publications in the field of geochemistry, examining unique groundwaters both natural and contaminated. Therefore, this source is considered qualified for its intended use within this report.

Table 4.1-12. Equilibrium Constants for Dissolution Reactions of Amorphous Chromium(III) Hydroxide and Eskolaite at $25^{\circ} \mathrm{C}$

\begin{tabular}{|c|c|c|l|l|}
\hline Reaction & Parameter & Value & \multicolumn{1}{|c|}{ Source } & Used in Output DTN \\
\hline $\mathrm{Cr}(\mathrm{OH})_{3}(\mathrm{am})+3 \mathrm{H}^{+} \leftrightarrow \mathrm{Cr}^{3+}+3 \mathrm{H}_{2} \mathrm{O}$ & $\log (K)$ & 9.35 & $\begin{array}{l}\text { Ball and Nordstrom 1998 } \\
\text { [DIRS 163015], Table 8 }\end{array}$ & $\begin{array}{l}\text { SN0312T0510102.013, } \\
\text { Cr-database.txt }\end{array}$ \\
\hline $\mathrm{Cr}_{2} \mathrm{O}_{3}+6 \mathrm{H}^{+} \leftrightarrow 2 \mathrm{Cr}^{3+}+3 \mathrm{H}_{2} \mathrm{O}$ & $\log (K)$ & 8.52 & $\begin{array}{l}\text { Ball and Nordstrom 1998 } \\
\text { [DIRS 163015], Table 8 }\end{array}$ & \\
\hline
\end{tabular}




\subsubsection{Inputs Used for Sensitivity Studies}

In the THC seepage model, bromide $\left(\mathrm{Br}^{-}\right)$is a trace component that is not modeled. Because halides are of concern to corrosion modeling, it is important to know to what levels they will concentrate. As $\mathrm{Br}^{-}$is not a modeled species, no direct output for $\mathrm{Br}^{-}$concentration is available. Measured pore water $\mathrm{Br}^{-}$concentrations listed in Table 4.1-13 are used in Section 6.12.4 to estimate the uncertainty that the presence of $\mathrm{Br}^{-}$adds to the evaporated seepage water composition.

Table 4.1-13. Pore Water Compositional Data Used to Evaluate the Relative Importance of $\mathrm{Br}$

\begin{tabular}{|c|c|c|c|c|}
\hline & Local Sample Name $^{a}$ & SPC Number ${ }^{b}$ & $\mathrm{Cl} \mathrm{mg/L}$ & $\mathrm{Br} \mathrm{mg} / \mathrm{L}$ \\
\hline 1 & ECRB-SYS-CS400/3.8-4.3/UC & SPC00554610 & 29 & $<1$ \\
\hline 2 & ECRB-SYS-CS400/5.6-6.2/UC & SPC00554611 & 21 & $<1$ \\
\hline 3 & ECRB-SYS-CS600/3.6-4.0/UC & SPC00554612 & 22 & $<1$ \\
\hline 4 & ECRB-SYS-CS1000/7.3-7.7/UC & SPC00554613 & 21 & $<1$ \\
\hline 5 & ECRB-SYS-CS750/6.2-6.5/UC & SPC00554614 & 73 & $<1$ \\
\hline 6 & ECRB-SYS-CS2150/5.5-6.1/UC & SPC00554615 & 27 & $<0.2$ \\
\hline 7 & ECRB-SYS-CS900/5.4-5.9/UC & SPC00554616 & 37 & $<0.2$ \\
\hline 8 & ECRB-SYS-CS850/5.1-5.6/UC & SPC00554617 & 32 & $<0.2$ \\
\hline 9 & SD-9/990.4-991.7/UC & SPC00554618 & 23 & $<0.2$ \\
\hline 10 & ECRB-SYS-CS900/3.5-4.1/UC & SPC00554619 & 53 & 0.3 \\
\hline 11 & ECRB-SYS-CS1000/12.9-14.0/UC & SPC00554620 & 22 & $<0.1$ \\
\hline 12 & ECRB-SYS-CS450/5.3-6.0/UC & SPC00554621 & 66 & 0.4 \\
\hline 13 & ECRB-SYS-CS2300/4.3-4.9/UC & SPC00554622 & 23 & $<0.1$ \\
\hline 14 & ECRB-SYS-CS500/12.0-16.7/UC & SPC00554800 & 54 & 0.4 \\
\hline 15 & ECRB-SYS-CS2000/16.5-21.1/UC & SPC00554801 & 26 & $<0.2$ \\
\hline 16 & ECRB-SYS-CS2000/16.3-16.5/UC & SPC00554802 & 24 & $<0.2$ \\
\hline 17 & ECRB-SYS-CS950/5.2-5.3/UC & SPC00554803 & 19 & $<0.2$ \\
\hline 18 & ECRB-SYS-CS950/4.8-5.5/UC & SPC00554804 & 30 & $<0.2$ \\
\hline 19 & SD-9/991.7-992.1/UC & SPC00554805 & 26 & 0.1 \\
\hline 20 & ECRB-SYS-CS1250/5.0-5.7/UC & SPC00554806 & 50 & 0.2 \\
\hline 21 & ECRB-SYS-CS1250/3.4-4.0/UC & SPC00554807 & 25 & ND \\
\hline 22 & SD-9/670.5-670.6/UC & SPC00554808 & 46 & 0.3 \\
\hline 23 & ECRB-SYS-CS800/4.9-5.6/UC & SPC00554809 & 20 & ND \\
\hline
\end{tabular}


Table 4.1-13. Pore Water Compositional Data Used to Evaluate the Relative Importance of $\mathrm{Br}$ (Continued)

\begin{tabular}{|c|l|c|c|c|}
\hline & \multicolumn{1}{|c|}{ Local Sample Name $^{\mathbf{a}}$} & SPC Number $^{\mathbf{b}}$ & Cl mg/L & Br mg/L \\
\hline 24 & ECRB-SYS-CS700/5.5-5.8/UC & SPC00554810 & 64 & $<0.1$ \\
\hline 25 & NRG-7/7A/839.3-839.8/UC & SPC00554811 & 31 & 0.1 \\
\hline
\end{tabular}

Source: DTN: GS020408312272.003 [DIRS 160899].

a This name encodes the borehole number (e.g., ECRB-SYS-CS1000), core interval in feet (e.g., 12.9-14.0), and the pore water extraction method (e.g., UC is ultra centrifuge).

$\mathrm{b}$ This is the sample identification number used internally to U.S. Geological Survey and its lab notebooks.

NOTE: ND indicates "not determined."

The direct input DTN source for the data in Table 4.1-13 (DTN: GS020408312272.003 [DIRS 160899]) contains data for other dissolved constituents that are used as indirect input for validation (Table 4.4-2). This is an acceptable use of this DTN source because the validation is based upon the major aqueous ion chemistries used in the binning criteria (Section 6.6) that do not include any of the direct input bromide data.

Section 6.6.7.3 evaluates selection of the median water for Bin 7 of the seepage evaporation abstraction, based on the THC seepage model run using the w0 starting water, instead of the w4 starting water. The trends in the localized corrosion model sensitivity to concentrations of chloride and nitrate (BSC 2004 [DIRS 169984], Section 8.1) are used in the justification.

\subsection{CRITERIA}

The technical work plan (BSC 2005 [DIRS 173782], Section 3.4) states the following acceptance criteria relevant to this report:

This work will satisfy the requirements of AP-16.1Q, Condition Reporting and Resolution, to enable closure of the CRs identified in Section 1.2, and any other relevant CRs which may be generated by the Corrective Action Program.

Additionally, the requirements for models and analyses presented in this report are provided by Project Requirements Document (Canori and Leitner 2003 [DIRS 166275], pp. 3 to 15), which is based on 10 CFR 63.113 and 63.114 [DIRS 173273] requirements. More specific acceptance criteria exist in Yucca Mountain Review Plan, Final Report (NRC 2003 [DIRS 163274]) and are presented and addressed in Section 8.4 to supplement or clarify citation of Project Requirements Document (Canori and Leitner 2003 [DIRS 166275]).

\subsubsection{Acceptance Criteria Addressed}

The following criteria are from Yucca Mountain Review Plan, Final Report (NRC 2003 [DIRS 163274], Section 2.2.1.3.3.3), which is based on meeting the requirements of 10 CFR 63.114(a)-(c) and (e)-(g) [DIRS 173273]. 


\section{Acceptance Criterion 1-System Description and Model Integration Are Adequate}

(1) Total system performance assessment adequately incorporates important design features, physical phenomena, and couplings, and uses consistent and appropriate assumptions throughout the quantity and chemistry of water contacting engineered barriers and waste forms abstraction process;

(2) The abstraction of the quantity and chemistry of water contacting engineered barriers and waste forms uses assumptions, technical bases, data, and models that are appropriate and consistent with other related DOE abstractions. For example, the assumptions used for the quantity and chemistry of water contacting engineered barriers and waste forms are consistent with the abstractions of "Degradation of Engineered Barriers" (Section 2.2.1.3.1); "Mechanical Disruption of Engineered Barriers" (Section 2.2.1.3.2); "Radionuclide Release Rates and Solubility Limits" (Section 2.2.1.3.4); "Climate and Infiltration" (Section 2.2.1.3.5); and "Flow Paths in the Unsaturated Zone" (Section 2.2.1.3.6). The descriptions and technical bases provide transparent and traceable support for the abstraction of quantity and chemistry of water contacting engineered barriers and waste forms;

(3) Important design features, such as waste package design and material selection, backfill, drip shield, ground support, thermal loading strategy, and degradation processes, are adequate to determine the initial and boundary conditions for calculations of the quantity and chemistry of water contacting engineered barriers and waste forms;

(4) Spatial and temporal abstractions appropriately address physical couplings (thermalhydrological-mechanical-chemical). For example, DOE evaluates the potential for focusing of water flow into drifts, caused by coupled thermal-hydrologicalmechanical-chemical processes;

(5) Sufficient technical bases and justification are provided for total system performance assessment assumptions and approximations for modeling coupled thermalhydrological-mechanical-chemical effects on seepage and flow, the waste package chemical environment, and the chemical environment for radionuclide release. The effects of distribution of flow on the amount of water contacting the engineered barriers and waste forms are consistently addressed, in all relevant abstractions;

(6) The expected ranges of environmental conditions within the waste package emplacement drifts, inside of breached waste packages, and contacting the waste forms and their evolution with time are identified. These ranges may be developed to include:

(i) Effects of the drip shield and backfill on the quantity and chemistry of water (e.g., the potential for condensate formation and dripping from the underside of the shield);

(ii) Conditions that promote corrosion of engineered barriers and degradation of waste forms; 
(iii) Irregular wet and dry cycles;

(iv) Gamma-radiolysis; and

(v) Size and distribution of penetrations of engineered barriers;

(7) The model abstraction for quantity and chemistry of water contacting engineered barriers and waste forms is consistent with the detailed information on engineered barriers design and other engineered features. For example, consistency is demonstrated for:

(i) Dimensionality of the abstractions;

(ii) Various design features and site characteristics; and

(iii) Alternative conceptual approaches.

Analyses are adequate to demonstrate that no deleterious effects are caused by design or site features that DOE does not take into account in this abstraction;

(8) Adequate technical bases are provided, including activities such as independent modeling, laboratory or field data, or sensitivity studies, for inclusion of any thermalhydrologic-mechanical-chemical couplings and features, events, and processes;

(9) Performance-affecting processes that have been observed in thermal-hydrologic tests and experiments are included into the performance assessment. For example, the U.S. Department of Energy either demonstrates that liquid water will not reflux into the underground facility or incorporates refluxing water into the performance assessment calculation, and bounds the potential adverse effects of alteration of the hydraulic pathway that result from refluxing water;

(10) Likely modes for container corrosion (Section 2.2.1.3.1 of the Yucca Mountain Review Plan) are identified and considered in determining the quantity and chemistry of water entering the engineered barriers and contacting waste forms. For example, the model abstractions consistently address the role of parameters, such as $\mathrm{pH}$, carbonate concentration, and the effect of corrosion on the quantity and chemistry of water contacting engineered barriers and waste forms;

(12) Guidance in NUREG-1297 (Altman et al. 1988 [DIRS 103597]) and NUREG-1298 (Altman et al. 1988 [DIRS 103750]), or other acceptable approaches, is followed.

\section{Acceptance Criterion 2-Data Are Sufficient for Model Justification}

(1) Geological, hydrological, and geochemical values used in the license application are adequately justified. Adequate description of how the data were used, interpreted, and appropriately synthesized into the parameters is provided; 
(2) Sufficient data were collected on the characteristics of the natural system and engineered materials to establish initial and boundary conditions for conceptual models of thermal-hydrological-mechanical-chemical coupled processes, that affect seepage and flow and the engineered barriers chemical environment;

(4) Sufficient information to formulate the conceptual approach(es) for analyzing water contact with the drip shield, engineered barriers, and waste forms is provided;

\section{Acceptance Criterion 3-Data Uncertainty Is Characterized and Propagated Through the Model Abstraction}

(1) Models use parameter values, assumed ranges, probability distributions, and bounding assumptions that are technically defensible, reasonably account for uncertainties and variabilities, and do not result in an under-representation of the risk estimate;

(2) Parameter values, assumed ranges, probability distributions, and bounding assumptions used in the total system performance assessment calculations of quantity and chemistry of water contacting engineered barriers and waste forms are technically defensible and reasonable, based on data from the Yucca Mountain region (e.g., results from large block and drift-scale heater and niche tests), and a combination of techniques that may include laboratory experiments, field measurements, natural analog research, and process-level modeling studies;

(3) Input values used in the total system performance assessment calculations of quantity and chemistry of water contacting engineered barriers (e.g., drip shield and waste package) are consistent with the initial and boundary conditions and the assumptions of the conceptual models and design concepts for the Yucca Mountain site. Correlations between input values are appropriately established in the DOE total system performance assessment. Parameters used to define initial conditions, boundary conditions, and computational domain in sensitivity analyses involving coupled thermal-hydrological-mechanical-chemical effects on seepage and flow, the waste package chemical environment, and the chemical environment for radionuclide release, are consistent with available data. Reasonable or conservative ranges of parameters or functional relations are established;

(4) Adequate representation of uncertainties in the characteristics of the natural system and engineered materials is provided in parameter development for conceptual models, process-level models, and alternative conceptual models. DOE may constrain these uncertainties using sensitivity analyses or conservative limits. For example, DOE demonstrates how parameters used to describe flow through the EBS bound the effects of backfill and excavation-induced changes;

\section{Acceptance Criterion 4-Model Uncertainty Is Characterized and Propagated Through the Model Abstraction}

(1) Alternative modeling approaches of FEPs are considered and are consistent with available data and current scientific understanding, and the results and limitations are appropriately considered in the abstraction; 
(2) Alternative modeling approaches are considered and the selected modeling approach is consistent with available data and current scientific understanding. A description that includes a discussion of alternative modeling approaches not considered in the final analysis and the limitations and uncertainties of the chosen model is provided;

(3) Consideration of conceptual model uncertainty is consistent with available site characterization data, laboratory experiments, field measurements, natural analog information and process-level modeling studies; and the treatment of conceptual model uncertainty does not result in an under-representation of the risk estimate;

(4) Adequate consideration is given to effects of thermal-hydrological-mechanicalchemical coupled processes in the assessment of alternative conceptual models. These effects may include:

(i) Thermal-hydrologic effects on gas, water, and mineral chemistry;

(ii) Effects of microbial processes on the engineered barriers chemical environment and the chemical environment for radionuclide release;

(iii) Changes in water chemistry that may result from the release of corrosion products from the engineered barriers and interactions between engineered materials and ground water; and

(iv) Changes in boundary conditions (e.g., drift shape and size) and hydrologic properties, relating to the response of the geomechanical system to thermal loading.

\section{Acceptance Criterion 5-Model Abstraction Output Is Supported by Objective Comparisons}

(1) The models implemented in this total system performance assessment abstraction provide results consistent with output from detailed process level models and/or empirical observations (laboratory and field-testing and/or natural analogs);

(2) Abstracted models for coupled thermal-hydrological-mechanical-chemical effects on seepage and flow and the engineered barriers chemical environment, as well as on the chemical environment for radionuclide release, are based on the same assumptions and approximations demonstrated to be appropriate for process-level models or closely analogous natural or experimental systems. For example, abstractions of processes, such as thermally induced changes in hydrological properties, or estimated diversion of percolation away from the drifts, are adequately justified by comparison to results of process-level modeling, that are consistent with direct observations and field studies; and

(3) Accepted and well-documented procedures are used to construct and test the numerical models that simulate coupled thermal-hydrological-mechanical-chemical effects on seepage and flow, engineered barriers chemical environment, and the chemical environment for radionuclide release. Analytical and numerical models are 
appropriately supported. Abstracted model results are compared with different mathematical models, to judge robustness of results.

\subsubsection{Acceptance Criteria Not Addressed}

The subcriteria from "Quantity and Chemistry of Water Contacting Engineered Barriers and Waste Forms" in Yucca Mountain Review Plan, Final Report (NRC 2003 [DIRS 163274], Section 2.2.1.3.3.3) are based on meeting the requirements of 10 CFR 63.114(a)-(c) and (e)-(g) [DIRS 173273]) but are not addressed within this report. The specific subcriteria, followed by reasoning for their exclusion, are presented here.

\section{Acceptance Criterion 1-System Description and Model Integration Are Adequate}

(11) The abstraction of in-package criticality or external-to-package criticality, within the emplacement drift, provides an adequate technical basis for screening these events. If either event is included in the assessment, then the U.S. Department of Energy uses acceptable technical bases for selecting the design criteria that mitigate the potential impact of in-package criticality on repository performance; identifies the features, events, and processes that may increase the reactivity of the system inside the waste package; identifies the configuration classes and configurations that have potential for nuclear criticality; and includes changes in thermal conditions and degradation of engineered barriers in the abstraction of the quantity and chemistry of water contacting engineered barriers and waste forms;

Issues involving criticality are not addressed in this report.

\section{Acceptance Criterion 2-Data Are Sufficient for Model Justification}

(3) Thermo-hydrologic tests were designed and conducted with the explicit objectives of observing thermal-hydrologic processes for the temperature ranges expected for repository conditions and making measurements for mathematical models. Data are sufficient to verify that thermal-hydrologic conceptual models address important thermal-hydrologic phenomena;

This report is not used for design or conduct of thermal-hydrologic testing. Information on predicted thermal-hydrologic conditions in the repository is obtained from other reports (e.g., BSC 2005 [DIRS 173944]).

(5) Sufficient data are provided to complete a nutrient- and energy-inventory calculation, if it has been used to justify the inclusion of the potential for microbial activity affecting the engineered barrier chemical environment and the chemical environment for radionuclide release. As necessary, data are adequate to support determination of the probability for microbially influenced corrosion and microbial effects, such as production of organic byproducts and microbially enhanced dissolution of the high-level radioactive waste glass form.

This report involves no microbial activity calculations and therefore uses no data regarding nutrient or energy inventory. 


\section{Acceptance Criterion 3-Data Uncertainty Is Characterized and Propagated Through the Model Abstraction}

(5) If criticality is included in the total system performance assessment, then the U.S. Department of Energy uses an appropriate range of input parameters for calculating the effective neutron multiplication factor;

Issues involving criticality are not addressed within this report.

(6) Where sufficient data do not exist, the definition of parameter values and conceptual models is based on other appropriate sources, such as expert elicitation conducted in accordance with NUREG-1563 (Kotra et al. 1996 [DIRS 100909]).

This report had no need for expert elicitation (peer review) for basis of parameter values or conceptual models. This would be performed, if required, as directed by LP-SIII.10Q-BSC, Section 5.3.2(c)(4).

\section{Acceptance Criterion 4-Model Uncertainty Is Characterized and Propagated Through the Model Abstraction}

(5) If the U.S. Department of Energy uses an equivalent continuum model for the total system performance assessment abstraction, the models produce conservative estimates of the effects of coupled thermal-hydrologic-mechanical-chemical processes on calculated compliance with the postclosure public health and environmental standards.

This report contains no specifics on TSPA-continuum modeling for coupled thermal-hydrologicmechanical-chemical processes.

\subsection{CODES, STANDARDS, AND REGULATIONS}

\subsubsection{Codes}

This model documentation was prepared to comply with the U.S. Nuclear Regulatory Commission high-level waste rule (10 CFR Part 63 [DIRS 173273]). Subparts of this rule applicable to data include Subpart B, Section 15 (Site Characterization) and Subpart E, Section 114 (Requirements for Performance Assessment). The Subpart applicable to models is also Subpart E, Section 114. The sections applicable to FEPs are 10 CFR 63.114(d), (e), and (f) [DIRS 173273].

\subsubsection{Standards}

The following standards are applicable to this report as they have been used as direct input in subsections of Section 4.1. The specific use of each standard is listed below with that standard's reference.

- ASTM A 240/A240M-02a 2002 [DIRS 162720], Standard Specification for Chromium and Chromium-Nickel Stainless Steel Plate, Sheet, and Strip for Pressure 
Vessels and for General Applications, was used to determine the chemical composition of the material to be used in the fabrication of the ground support (Stainless Steel Type 316L, Table 4.1-11).

- ASTM A 276-03 2003 [DIRS 165006], Standard Specification for Stainless Steel Bars and Shapes, was used to determine the chemical composition of the Stainless Steel Type 316L material to be used in the fabrication of the perforated sheets for the ground support.

- ASTM A 516/A516M-01 2001 [DIRS 162723], Standard Specification for Pressure Vessel Plates, Carbon Steel, for Moderate- and Lower-Temperature Service, was used to determine the chemical composition of the material to be used in the fabrication of the basket for the waste package.

- ASTM A 588/A588M-01 2001 [DIRS 162724], Standard Specification for High-Strength Low-Alloy Structural Steel with 50ksi [345Mpa] Minimum Yield Point to 4-in. [100-mm] Thick, was used to determine the chemical composition of the material to be used in the fabrication of the invert-transverse beams with stiffeners, invert-longitudinal support beams, invert-stiffener brackets, invert-base plates, invert-structural bolts, and the rail runway beams, cap plate, and guide beams for the gantry rail assembly.

- ASTM A 759-00 [DIRS 159971], Standard Specification for Carbon Steel Crane Rails, was used to determine the chemical composition of the material to be used in the fabrication of the gantry rail for the gantry rail assembly.

- ASTM G 1-90 (1999) [DIRS 103515], Standard Practice for Preparing, Cleaning, and Evaluating Corrosion Test Specimens, was used to provide steel density input found in Tables 4.1-7 and 4.1-12.

\subsubsection{Level of Accuracy, Precision, and Representativeness of Results}

The accuracy, precision, and representativeness of results are provided for by justifying the selection of the input data used, expressing the range of uncertainty and variability of the model and analyses parameters, and indicating the range of applicability for which the results apply. The representativeness of direct inputs used by the models described in this report is discussed in Section 4.1. The level of accuracy for predictions of the chemical environment is addressed in Section 6: specifically, equilibrium versus kinetics (Section 6.5.2), mineral suppression (Section 6.5.5), basis for binning of seepage compositions (Section 6.6), effects from ground support materials (Section 6.8), evaluation of alternative conceptual models (Section 6.11), lookup table interpolation (Section 7.2.2), and other validation issues that pertain to accuracy (Section 7). Numerical precision is not a significant concern for thermochemical modeling of the in-drift environment, although convergence of EQ3/6 runs is addressed in Section 6.5. Uncertainty in model output is addressed and represented explicitly in the feeds to TSPA-LA (Sections 6.12 and 6.15). 


\subsection{INPUTS USED FOR MODEL VALIDATION OR CONFIDENCE BUILDING}

This section summarizes the indirect inputs used for model validation (Section 7).

\subsubsection{Indirect Inputs from the THC Seepage Model}

For confidence building in Sections 7.3.2 and 7.3.4, and not model validation, the 368 THC water compositions are compared to their median bin history results in Section 6.6. Note that these same data are used as direct input (Section 4.1.3). Five complete drift-scale seepage THC modeling results, taken from Drift-Scale THC Seepage Model (BSC 2005 [DIRS 172862]), represent the sources of seepage water entering the drift (DTN: LB0302DSCPTHCS.002 [DIRS 161976]). Due to the large amount of information contained within this DTN, specific values are not cited here (Table 4.1-13).

For validation of the gas abstraction $\left(\mathrm{CO}_{2}\right.$ partial pressure) in Section 7.2.2, additional detailed output from a THC seepage model run is used. These supplemental THC gas modeling data containing more time-detailed data are taken from DTN: LB0506DSCPTHCS.001 [DIRS 174149] and its time.dat file for starting water w0.

\subsubsection{Evaporation of Waters to Form Concentrated Brines}

To provide additional confidence in the use of the IDPS model, a classic model presented by Garrels and McKenzie (1967 [DIRS 123636]) for the evaporation of Sierra Nevada spring water is used. The EBS model simulates evaporation and concentration of these waters by a factor of 1,000, and the results are compared against the original results of Garrels and McKenzie (1967 [DIRS 123636]). Table 4.4-1 provides the initial spring water composition used in this validation test. Figure 4 from the study by Garrels and McKenzie (1967 [DIRS 123636]) has been reproduced as Figure 7.3-10 for comparison against the EBS model results.

Table 4.4-1. Composition of Sierra Nevada Spring Water Used in Validation Tests for the EBS Seepage Evaporation Model

\begin{tabular}{|l|c|c|}
\hline \multicolumn{1}{|c|}{ Parameter } & ppm & mol/L $\times \mathbf{1 0}^{\mathbf{4}}$ \\
\hline $\mathrm{SiO}_{2}$ & 24.6 & 4.1 \\
\hline $\mathrm{Ca}$ & 10.4 & 2.6 \\
\hline $\mathrm{Mg}$ & 1.7 & 0.71 \\
\hline $\mathrm{Na}$ & 5.95 & 2.59 \\
\hline $\mathrm{K}$ & 1.57 & 0.4 \\
\hline $\mathrm{HCO}_{3}$ & 54.6 & 8.95 \\
\hline $\mathrm{SO}_{4}$ & 2.38 & 0.25 \\
\hline $\mathrm{Cl}$ & 1.06 & 0.16 \\
\hline $\mathrm{pH}$ & \multicolumn{2}{|c|}{6.8} \\
\hline lonic Strength & \multicolumn{2}{|c|}{$0.0013 \mathrm{~mol} / \mathrm{L}$} \\
\hline
\end{tabular}

Source: Garrels and McKenzie 1967 [DIRS 123636], Table VI.

NOTE: At $25^{\circ} \mathrm{C}$ and $p \mathrm{CO}_{2}=10^{-3.5}$ bar. 


\subsubsection{Chromium Calculation}

Figure 2 from the study by Rai et al. (1987 [DIRS 163369]) has been used to qualify the $\mathrm{Cr}(\mathrm{OH})_{3}(\mathrm{am})$ solubility $\log (\mathrm{K})$ value obtained from Ball and Nordstrom (1998 [DIRS 163015], Table 8), and as given in Table 4.1-12 (Section 4.1.6). This figure from Rai et al. (1987 [DIRS 163369], Figure 2) is incorporated into Figure 6.8-4.

\subsubsection{Repository Horizon Pore Waters}

Repository Horizon Pore Waters-Starting water chemistry compositions used to model the evaporation of repository horizon pore waters are archived in five separate DTNs and one report. Table 4.4-2 provides the pore water sample identification numbers and source DTNs. The water samples chosen for the analysis are those that originated from the stratigraphic rock units located at the depth of the repository horizon. These rock units in the Topopah Spring Tuff include the upper lithophysal (Tptpul), middle nonlithophysal (Tptpmn), lower lithophysal (Tptpll), and lower nonlithophysal (Tptpln). In addition, the pore water samples must include $\mathrm{pH}$ measurements in their analyses. Other pore water samples archived in the listed DTNs (Table 4.4-2) are not included in the analysis, as they do not meet these criteria. These pore waters and their resulting chemical distributions are used to support validation of the selection of the five starting THC pore waters (Section 7.2.3). Throughout the remainder of this report, the waters will be referred to by their abbreviated name (Table 4.4-2).

Table 4.4-2. Water Identifications Used in the Binning Analysis

\begin{tabular}{|c|l|l|}
\hline $\begin{array}{c}\text { Abbreviated } \\
\text { Water Name }\end{array}$ & \multicolumn{1}{|c|}{$\begin{array}{c}\text { Starting Water Composition } \\
\text { Sample Identification }\end{array}$} & \multicolumn{1}{c|}{ Source } \\
\hline ecrb1 & ECRB-SYS-CS400/5.6-6.2/UC & DTN: GS020408312272.003 [DIRS 160899] \\
\hline ecrb2 & ECRB-SYS-CS450/5.3-6.0/UC & DTN: GS020408312272.003 [DIRS 160899] \\
\hline ecrb3 & ECRB-SYS-CS500/12.0-16.7/UC & DTN: GS020408312272.003 [DIRS 160899] \\
\hline ecrb4 & ECRB-SYS-CS600/3.6-4.0/UC & DTN: GS020408312272.003 [DIRS 160899] \\
\hline ecrb5 & ECRB-SYS-CS750/6.2-6.5/UC & DTN: GS020408312272.003 [DIRS 160899] \\
\hline ecrb6 & ECRB-SYS-CS800/4.9-5.6/UC & DTN: GS020408312272.003 [DIRS 160899] \\
\hline ecrb7 & ECRB-SYS-CS850/5.1-5.6/UC & DTN: GS020408312272.003 [DIRS 160899] \\
\hline ecrb8 & ECRB-SYS-CS900/3.5-4.1/UC & DTN: GS020408312272.003 [DIRS 160899] \\
\hline ecrb9 & ECRB-SYS-CS900/5.4-5.9/UC & DTN: GS020408312272.003 [DIRS 160899] \\
\hline ecrb10 & ECRB-SYS-CS950/4.8-5.5/UC & DTN: GS020408312272.003 [DIRS 160899] \\
\hline ecrb11 & ECRB-SYS-CS950/5.2-5.3/UC & DTN: GS020408312272.003 [DIRS 160899] \\
\hline ecrb12 & ECRB-SYS-CS1000/11.1-11.6/UC & DTN: GS031008312272.008 [DIRS 166570] \\
\hline ecrb13 & ECRB-SYS-CS1000/12.9-14.0/UC & DTN: GS020408312272.003 [DIRS 160899] \\
\hline ecrb14 & ECRB-SYS-CS1000/5.4-6.1/UC & DTN: GS031008312272.008 [DIRS 166570] \\
\hline ecrb15 & ECRB-SYS-CS1000/7.3-7.7/UC & DTN: GS020408312272.003 [DIRS 160899] \\
\hline ecrb16 & ECRB-SYS-CS1100/3.7-3.8/UC & DTN: GS030408312272.002 [DIRS 165226] \\
\hline ecrb17 & ECRB-SYS-CS1250/3.4-4.0/UC & DTN: GS020408312272.003 [DIRS 160899] \\
\hline ecrb18 & ECRB-SYS-CS1500/10.0-12.1./CU & DTN: GS020808312272.004 [DIRS 166569] \\
\hline ecrb19 & ECRB-SYS-CS2000/16.3-16.5/UC & DTN: GS020408312272.003 [DIRS 160899] \\
\hline ecrb20 & ECRB-SYS-CS2000/16.5-21.1/UC & DTN: GS020408312272.003 [DIRS 160899] \\
\hline ecrb21 & ECRB-SYS-CS-2000/3.95-4.1/UC & DTN: GS031008312272.008 [DIRS 166570] \\
\hline ecrb22 & ECRB-SYS-CS2150/5.5-6.1/UC & DTN: GS020408312272.003 [DIRS 160899] \\
\hline ecrb23 & ECRB-SYS-CS2250/5.2-5.6/UC & DTN: GS020808312272.004 [DIRS 166569] \\
\hline & &
\end{tabular}


Table 4.4-2. Water Identifications Used in the Binning Analysis (Continued)

\begin{tabular}{|c|l|l|}
\hline $\begin{array}{c}\text { Abbreviated } \\
\text { Water Name }\end{array}$ & \multicolumn{1}{|c|}{$\begin{array}{c}\text { Starting Water Composition } \\
\text { Sample Identification }\end{array}$} & \multicolumn{1}{c|}{ Source } \\
\hline ecrb24 & ECRB-SYS-CS2300/4.3-4.9/UC & DTN: GS020408312272.003 [DIRS 160899] \\
\hline ecrb25 & ECRB-SYS-CS2300/6.1-6.7/UC & DTN: GS020808312272.004 [DIRS 166569] \\
\hline esfsad1 & ESF-SAD-GTB\#1/194.2-195.2/UC & DTN: GS020808312272.004 [DIRS 166569] \\
\hline esfsad2 & ESF-SAD-GTB\#1/195.4-196.7/UC & DTN: GS020808312272.004 [DIRS 166569] \\
\hline esfther1 & ESF-THERMALK-017/26.5-26.9/UC & DTN: GS031008312272.008 [DIRS 166570] \\
\hline esfther2 & ESF-THERMALK-017/22.9-23.0/UC & DTN: GS031008312272.008 [DIRS 166570] \\
\hline nrg1 & NRG-7/7A/839.3-839.8/UC & DTN: GS020408312272.003 [DIRS 160899] \\
\hline sd9-1 & SD-9/990.4-991.7/UC & DTN: GS020408312272.003 [DIRS 160899] \\
\hline sd9-2 & SD-9/1184.0-1184.2/UC & DTN: GS020808312272.004 [DIRS 166569] \\
\hline sd9-3 & SD-9/1184.7-1184.8/UC & DTN: GS030408312272.002 [DIRS 165226] \\
\hline sd9-4 & SD-9/1184.8-1185.0/UC & DTN: GS020808312272.004 [DIRS 166569] \\
\hline sd9-5 & SD-9/1236.4-1236.8/UC & DTN: GS020808312272.004 [DIRS 166569] \\
\hline sd9-6 & SD-9/1275.6-1276.0/UC & DTN: GS020808312272.004 [DIRS 166569] \\
\hline sd9-7 & SD-9/1330.4-1330.7/UC & DTN: GS020808312272.004 [DIRS 166569] \\
\hline esfperm2 & ESF-HD-PERM-2/30.1-30.5 & DTN: MO0005PORWATER.000 [DIRS 150930] \\
\hline esfperm3 & ESF-HD-PERM-3/34.8-35.1 & DTN: MO0005PORWATER.000 [DIRS 150930] \\
\hline permavg & ESF-HD-PERM-AVG & BSC 2005 [DIRS 172862], Table 6.2-1 \\
\hline
\end{tabular}

\footnotetext{
a Average of pore water analyses ESF-HD-PERM-2/30.1-30.5 and ESF-HD-PERM-3/34.8-35.1.
} 


\section{ASSUMPTIONS}

This section addresses the assumptions built into the engineered barrier system physical and chemical environment model and those passed into it from upstream documentation that may have significant impact on the results of this model.

\subsection{DISCUSSION OF ASSUMPTIONS IN UPSTREAM DOCUMENTATION}

The assumptions listed in the two primary modeling reports that feed this model were reviewed and evaluated for their potential consequences. The two reports are:

- Drift-Scale THC Seepage Model (BSC 2005 [DIRS 172862], Section 5)

- In-Drift Precipitates/Salts Model (BSC 2004 [DIRS 169863], Section 5).

Those assumptions having a potentially significant impact are addressed below.

\subsubsection{Standard State of Liquid Phase (Assumption 5.1 of the IDPS Model)}

Assumption: Liquid phase is at standard state.

Basis: As discussed in In-Drift Precipitates/Salts Model (BSC 2004 [DIRS 169863], Section 5.1), an aqueous solution at standard state has an equilibrium relative humidity equivalent to the activity of water in the aqueous solution. Standard state in this sense implies that the water-air interface is flat (i.e., that the boundary between water and air is a plane) and that the behavior of the water molecule $\left(\mathrm{H}_{2} \mathrm{O}\right)$ is not influenced by solid surfaces in contact with the water. Adsorption and air-water interface curvature, such as the curvature of menisci caused by capillary forces, create nonstandard-state conditions with respect to vapor pressure and equilibrium relative humidity near the air-water interface (Walton 1994 [DIRS 127454]; Koorevaar et al. 1983 [DIRS 125329], pp. 67 to 68).

For the IDPS model, nonstandard-state aqueous solutions are not considered. Only dissolved salts and temperature are considered to affect liquid-vapor equilibrium. The small amounts of water held in double layers and adsorbed to solid surfaces have negligible roles in radionuclide transport and waste package corrosion due to their near immobility. Water held by the surface tension effects of capillarity is more mobile than water in double layers or adsorbed to solids; however, even capillary forces under very dry conditions (in the range of negative 500 meters water pressure head) have a limited effect on $\mathrm{H}_{2} \mathrm{O}$ activity in solution (Walton 1994 [DIRS 127454], pp. 3,480 to 3,481 ).

Confirmation Status: No further confirmation is required. Because of this limited effect, uncertainties due to the assumption that the liquid phase in the IDPS model is at standard state are negligible compared to the more-sizable uncertainties in the IDPS model and model inputs.

Use in the Model: This assumption is used throughout.

\subsubsection{Equilibrium Conditions (Assumption 5.2 of the IDPS Model)}

Assumption: The system is in a state of local metastable equilibrium. All aqueous and gas constituents in the model achieve and maintain local equilibrium, and most mineral phases achieve and maintain local equilibrium upon saturation. Several slow-forming and unlikely 
minerals identified in In-Drift Precipitates/Salts Model (BSC 2004 [DIRS 169863], Section 5.2) will not precipitate upon saturation or supersaturation. The model can be used, however, to make steady-state nonequilibrium predictions with respect to relative humidity, provided the appropriate inputs are used.

Basis: Most chemical reactions included in the model occur rapidly compared to the modeling timeframe. Redox reactions, which generally are not rapid, are not included in the model. Similarly, certain mineral precipitation reactions are not expected to be rapid enough to occur to a considerable degree for the anticipated applications of the model. Mineral precipitation reactions that fall into this category are suppressed, as explained in In-Drift Precipitates/Salts Model (BSC 2004 [DIRS 169863], Section 6.6.2.6.4), permitting the formation of metastable mineral phases in the model.

Highly soluble nitrate and chloride salts, which are direct inputs into TSPA-LA, rapidly deliquesce, dissolve, and precipitate, and are well approximated by equilibrium modeling. As seepage changes rather slowly with time, its most recent compositions will rapidly dominate and overcome any preexisting mineral formation influence. For this reason, kinetic properties of various mineral phases need not be explicitly included in the model during drying and rewetting cycles.

Confirmation Status: No further confirmation is required because mineral precipitation reactions that fall into this category are suppressed, as explained in In-Drift Precipitates/Salts Model (BSC 2004 [DIRS 169863]), permitting the formation of metastable mineral phases in the model.

Use in the Model: This assumption is used throughout.

\subsubsection{Repository Location (Assumption 1 from THC Model)}

Assumption: The THC model results, calculated for a repository in the Tptpll lithologic unit, are applicable to all lithologies intersected by the repository drifts.

Basis: There are three bases for this assumption:

- Model simulations in an earlier version of the THC model, as alternate conceptual models (BSC 2005 [DIRS 172862], Section 6.3), modeled drifts located within the Tptpmn and Tptpll lithologic units and show that the lithology had little effect on predicted water chemistries. Although the Ttptmn simulations are not repeated with the current THC model, which uses different input parameters and differs in some ways from the earlier model, these simulations provide confidence that the current model results are applicable over the stratigraphic section intersected by the repository.

- The repository horizon within the Topopah Spring Tuff (including the Tptpll, Tptpul, Tptpmn, and Tptpln units) is relatively uniform in composition. Peterman and Cloke (2002 [DIRS 162576]) analyzed twenty core samples, in duplicate, from the cross drift within the four lithologic units constituting the repository level. All samples were compositionally similar with respect to major oxides and trace elements (Peterman and Cloke 2002 [DIRS 162576], Table 4), and normative mineral compositions (Peterman and Cloke 2002 [DIRS 162576], Table 5, Figure 4, p. 692). 
Samples vary by only $2 \%$ in $\mathrm{SiO}_{2}$ concentration, and plot as a tight cluster in the rhyolite field on the chemical rock classification diagram for igneous rocks $\left(\mathrm{SiO}_{2}\right.$ plotted against $\mathrm{Na}_{2} \mathrm{O}+\mathrm{K}_{2} \mathrm{O}$ ) (Peterman and Cloke 2002 [DIRS 162576], Figure 3, Table 4, p. 687). The tight clustering also indicates that the effect of localized mineral heterogeneity on large-scale rock compositions, due to the presence of minerals which precipitated from the vapor phase during cooling of the tuff, and low-temperature minerals, such as calcite and amorphous $\mathrm{SiO}_{2}$ (opal), is insignificant (Peterman and Cloke 2002 [DIRS 162576], pp. 695 to 696).

- The five starting waters used in the THC seepage model simulations were chosen to represent the entire range of available pore water compositions, and include pore waters from three of the four repository-level lithologic units (Tptpmn, Tptpll, and Tptpul) (BSC 2005 [DIRS 172862], Section 6.2.2.1).

Confirmation Status: No further confirmation is required because the variability in chemistries that are provided in the other lithologies are of the same order of magnitude or less than the variability in chemistry provided by the range of pore water compositions. This assumption allows the TSPA-LA model to implement the lookup tables derived in Section 6.9.3.

Use in the Model: This assumption is used throughout.

\subsubsection{Representative Distribution of Seepage Water Compositions (Assumption 2 from THC Model)}

Assumption: THC model runs using the five starting waters adequately represent all possible seepage waters.

Basis: The five starting waters were chosen from available measured pore water compositions for repository-level lithologic units. These waters cover the spread of measured compositions (BSC 2005 [DIRS 172862], Figure 6.2-4). However, pore water samples are not available from all possible locations in the repository, and available data can only be assumed to be representative of all water chemistries actually present in the repository units. This assumption is supported in part by the chemical similarity of the four TSw lithostratigraphic units that will host the repository, as described in the previous assumption. Reaction with these rocks should homogenize many reactive mineral species and make large variations in the concentrations of nonconservative aqueous species (i.e., those that are unreactive and nonvolatile) from any single unit unlikely. This assumption is borne out by the available data (BSC 2005 [DIRS 172862], Figure 6.2-4); when the five starting waters were originally chosen, only about half the data were available (BSC 2005 [DIRS 172862], Figure 6.2-4). Pore water samples collected more recently fall within the range of the previous data and cluster in a similar fashion.

Confirmation Status: No further confirmation is required because the range of input waters is representative of the waters in the host rock.

Use in the Model: This assumption is used throughout but is explicitly referenced in Section 6.13.4. 


\subsection{ASSUMPTIONS INTERNAL TO PHYSICAL AND CHEMICAL ENVIRONMENT MODEL}

No additional assumptions have been identified in this report. 


\section{MODEL DISCUSSION}

\subsection{MODELING OBJECTIVES}

The main purpose of the engineered barrier system (EBS) physical and chemical environment (P\&CE) abstractions is to predict the evolution of the environment in the disposal drifts in response to the chemical and physical processes shaping that environment following repository closure. The chemical conditions can affect drip shield and waste package corrosion, radionuclide solubility, and colloidal stability. The conceptual model (Section 6.2) for the evolution of water chemistry in the EBS includes the consideration of seepage evaporation effects, interactions with engineered materials, deliquescence, and reactions with in-drift gases.

In general, Section 6 can be divided into three major areas of focus: 1) a set of screening analyses conducted to evaluate the effects of introduced materials on the EBS geochemical environment; 2) models developed and abstracted, with uncertainties, for use by the total system performance assessment for the license application (TSPA-LA) in evaluating engineered barrier performance and radionuclide mobility (Figure 6.1-1); and 3) additional sensitivity studies and alternative conceptual models.

One of the screening analyses provided in Section 6 consists of evaluating predominate engineered material types, compositions, and corrosion rates (Section 6.4). Section 6.4 presents corrosion rates for iron steel and alloy materials. Once the rates have been determined, most of the materials are screened out as having little potential to affect the chemical environment.

Of the introduced materials, the rock bolts and the perforated stainless steel sheets are the engineered items that could react with, and affect the chemical composition of, potential seepage before it makes contact with the drip shield or waste package outer barrier. These two items are made of stainless steel and their potential interactions with seepage water are evaluated in Section 6.8 .

Also included in the screening analyses is an evaluation of the effect of the degradation of introduced materials on the in-drift gas composition (particularly $\mathrm{O}_{2}$; see Section 6.7.1). This analysis investigates whether corrosion of the introduced low-alloy or carbon steel has the potential to affect one of the main boundary conditions established for the model calculations (oxidizing conditions will be maintained in the drift).

Section 6.6 takes the seepage chemistry output of Drift-Scale THC Seepage Model (BSC 2005 [DIRS 172862]), referred to in this report as the thermal-hydrologic-chemical (THC) model or THC seepage model, and performs an analysis to evaluate the smallest set of boundary condition water compositions that capture the full range of variability for use as input to the in-drift seepage evaporation analysis.

In the remainder of Section 6, two abstraction models are developed:

- Lookup tables containing the estimated partial pressure of $\mathrm{CO}_{2}$ in the drift through time (gas abstraction, Section 6.7.2) 
- An abstraction model to represent the evolution of in-drift water compositions that result from evaporation of seepage (seepage evaporation abstraction, Section 6.9).

Figure 6.1-1 diagrams the main process steps that generate the abstractions and lookup tables feeding the TSPA-LA model.

\section{Development and Output of Seepage Evaporation and Gas Abstraction Models}

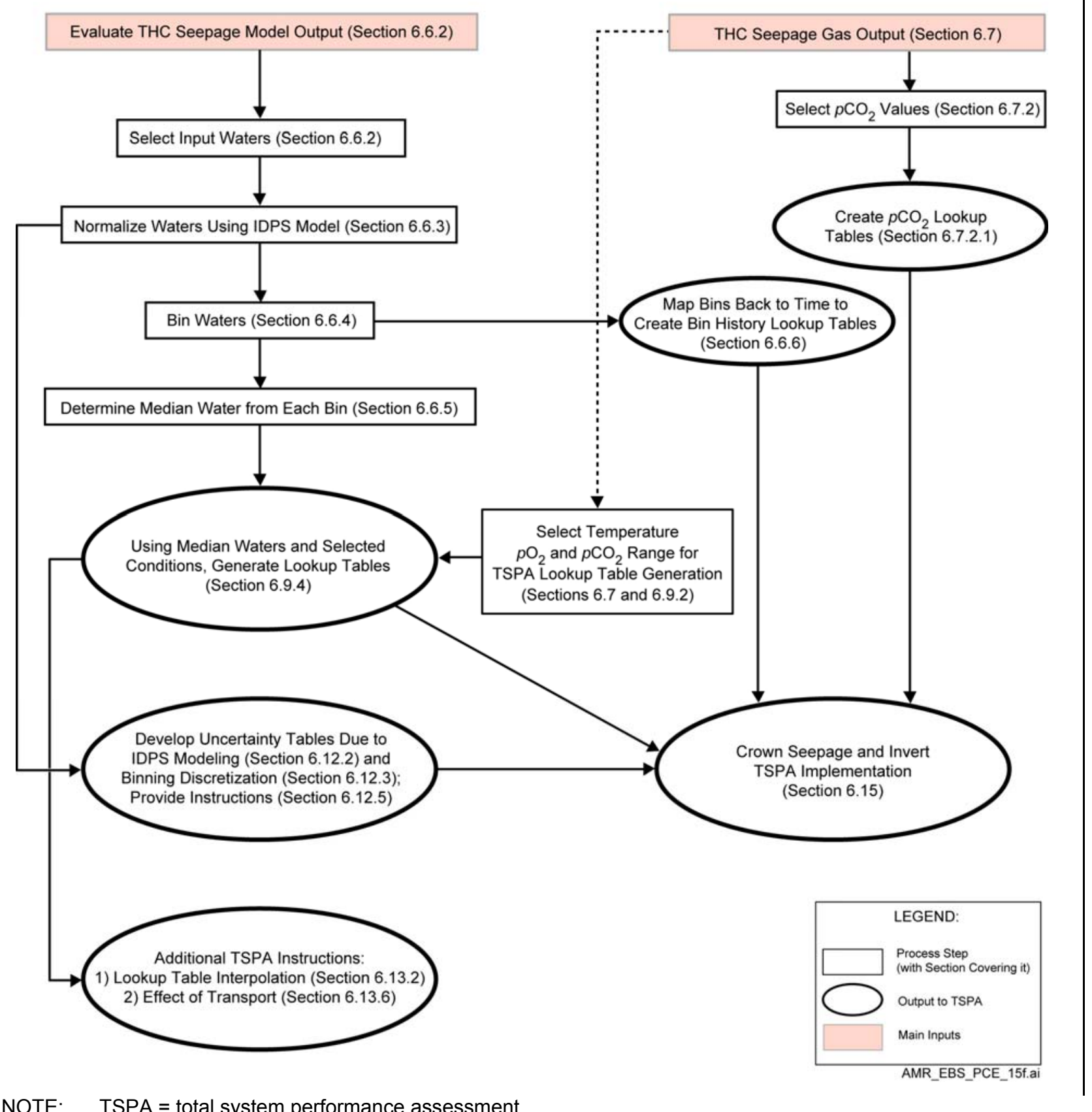

NOTE: $\quad$ TSPA $=$ total system performance assessment.

Figure 6.1-1. Major EBS Environment Process Flowchart, with Section References 
The main software tool used in the development of the seepage evaporation abstraction is EQ3/6 V8.0 (BSC 2003 [DIRS 162228]). Section 6.5 discusses the mathematics used by the EQ3/6 calculations and some of the modeling constraints required to produce the model results used in developing the lookup tables for seepage. The main process modeling tool used by these calculations is the in-drift precipitates/salts (IDPS) model, as presented in In-Drift Precipitates/Salts Model (BSC 2004 [DIRS 169863]).

Sections 6.12 and 6.13 summarize the results of the modeling calculations. Section 6.12 details the uncertainties associated with key outputs as determined from the IDPS model and the development of the lookup tables. Section 6.12 also documents several additional sensitivity analyses, including:

- Use of alternate mineral suppressions

- Model sensitivity to carbon dioxide partial pressure

- The presence of bromine in seepage

- Variations in the geochemical model for stainless steel-seepage interactions.

Section 6.13 summarizes and discusses the model results in terms of the potential environmental conditions on waste packages, drip shields, and in the invert. That section also discusses the potential evolution of brines, the controlling mineral phases for each brine type, and the types of water that could contact waste packages, drip shields, and the invert. Finally, there are specific instructions important to the TSPA to ensure the lookup tables can be properly implemented in the TSPA-LA model. These instructions are located primarily in Section 6.15, and describe the seepage evaporation abstraction model as two sets of location-dependent look-up tables:

- Implementation of seepage evaporation abstraction on the waste package

- Instructions for the seepage evaporation abstraction for the invert.

The Instructions for implementing uncertainty in each of these locations are given in Section 6.12.5. Some discussion on the implementation of interpolation and extrapolation between the lookup tables is provided in Section 6.13. Alternative conceptual models and features, events, and processes (FEPs) are discussed in Sections 6.11 and 6.14, respectively.

\subsection{ENGINEERED BARRIER SYSTEM PHYSICAL AND CHEMICAL ENVIRONMENT CONCEPTUAL MODEL}

\subsubsection{Integrated Perspective on the Evolution of the Engineered Barrier System Physical and Chemical Environments}

The EBS environments are important to repository performance to the extent that they help determine engineered barrier component degradation rates, quantities and species of mobilized radionuclides, and transport rates for radionuclides and fluids through the drift into the unsaturated zone (UZ). The drip shield and the waste package outer barrier are the principal performance-related engineered barrier components that initially prevent water contact with waste forms and determine fluid transport paths. The EBS chemical environment affects radionuclide solubility and colloid stability in the invert, which affect the mobile radionuclide 
source term for transport. Fluid transport paths and rates, coupled with the source term, determine radionuclide transport rates to the $\mathrm{UZ}$.

The main purpose of this report is to:

- Evaluate the potential evolution of the in-drift chemical environment for the important parameters that affect drip shield and waste package durability, and control solubility and colloidal stability of radionuclides in the invert by:

1. Providing TSPA-LA the lookup tables for potential geochemical conditions on the waste package and drip shield, where concentrated brines could potentially form through the evaporation of crown seepage waters

2. Providing TSPA-LA the lookup tables for potential geochemical conditions in the invert, which may be used to determine the solubility and colloidal stability of radionuclides.

The evolution of the EBS environment is discussed in terms of processes (Section 6.2.2) and spatial locations (Section 6.2.3). Descriptions by process are often independent of exact spatial location in the drift. On the other hand, descriptions by spatial location may encompass multiple processes taking place within meters of each other within the drift. In-Drift Precipitates Salts Model (BSC 2004 [DIRS 169863]) also discusses many of these same concepts and processes.

\subsubsection{Evolution of Engineered Barrier System Chemical Environment by Process}

The following discussion conceptualizes potential seepage, evaporation, dust deposition, and the influence of thermal-hydrologic and relative humidity changes over time on the chemical environment within the drift.

\subsubsection{Seepage}

Surface waters, originating as surface precipitation and snow melt, gradually make their way downward through fractures and the matrix of the tuffaceous rocks in the UZ to the level of the drift. During the initial radioactive decay heating pulse (extending approximately 2,000 years after the permanent closure of the repository), areas near the drift rise in temperature above $96^{\circ} \mathrm{C}$, the boiling point of water for the drift elevation (Figure 6.7-5). This heating pulse drives away water as steam, resulting in some parts of the drift that do not have macroscale liquid water available for chemical reactions. This process is important because it limits aqueous corrosion on the waste package and drip shield. The process also limits the water available to transport soluble and colloidal radionuclides from the waste form.

After the maximum temperature in the drift is reached during the radioactive decay heat pulse, water can potentially flow into the drift and onto the engineered barriers from the host rock. A result of seepage during and after the heat pulse is evaporation and deposition of minerals on the surface of the waste package and drip shield. This can also cause a separation of components from the aqueous phase during transport to the invert (Section 6.13.6). 
Depending on the percolation fluxes and saturation levels, the contact between the host rock and invert crushed tuff can allow water to imbibe into the invert through the permeable tuff matrix.

\subsubsection{Chemical Divides}

As seepage waters make their way into the drift, their chemical composition changes by evaporation and mineral precipitation. When minerals (including salts) precipitate, the relative concentrations of remaining dissolved components change. This effect is a result of chemical divides encountered and mineral precipitates from natural waters. Drever (1988 [DIRS 118564], p. 235) explains the chemical divide:

Whenever a binary salt is precipitated during evaporation, and the effective ratio of the two ions in the salt is different from the ratio of these ions in solution, further evaporation will result in an increase in the concentration of the ion present in greater relative concentration in solution and a decrease in the concentration of the ion present in lower relative concentration.

There are three initial geochemical divides for natural lakes (Figure 6.2-1). These geochemical divides largely control the types of waters that can develop by evaporation.

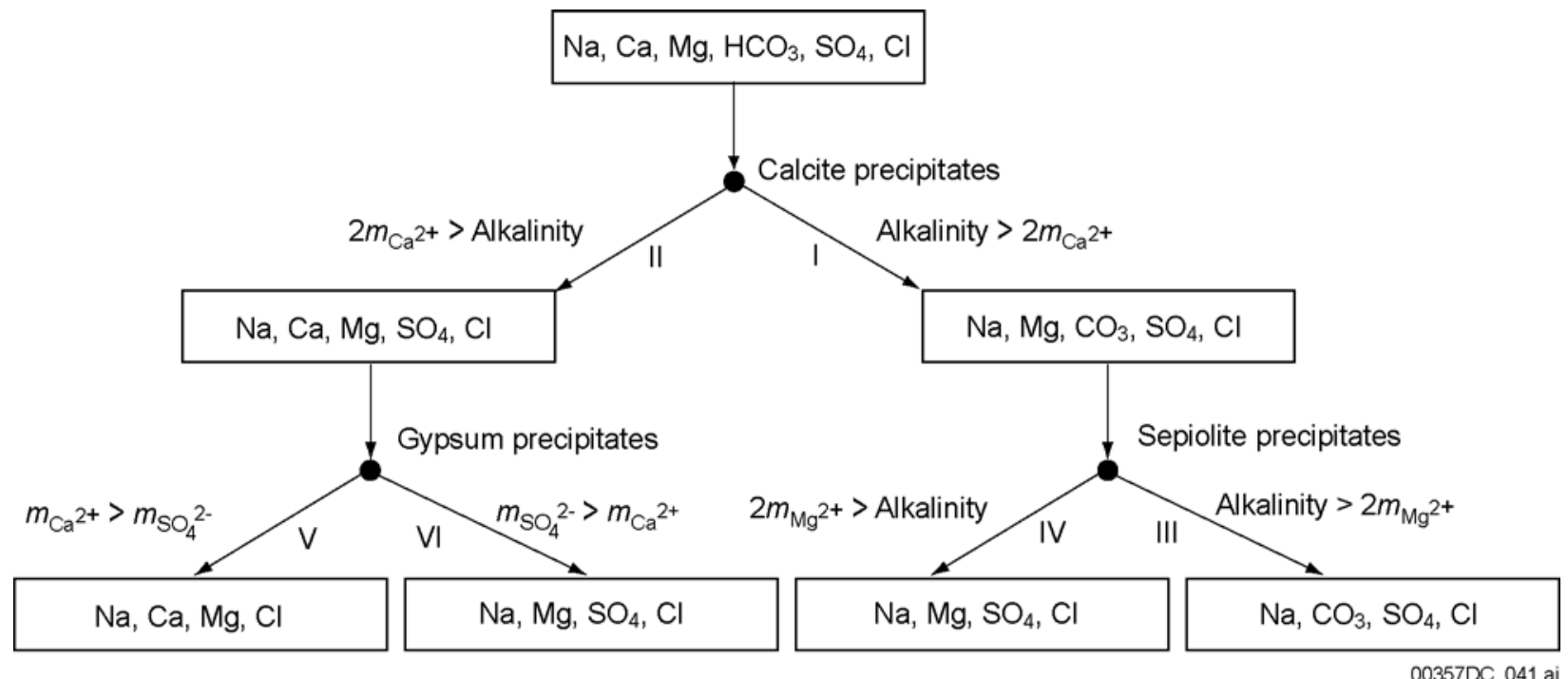

Source: Drever 1988 [DIRS 118564], p. 236. Note that Drever identifies dolomite or another Mg-bearing carbonate as a possible alternative to sepiolite in this diagram.

Figure 6.2-1. Simplified Chemical Divides Diagram Based on Evaporative Concentration of Dilute Starting Waters to Form a Suite of Naturally Occurring Lake Waters

In the seepage evaporation abstraction, potential seepage waters are grouped based on the composition of the concentrated brines that form upon evaporation and after they have passed through these chemical divides (Section 6.6). In accordance with geochemical divide theory, the water composition changes due to the sequence of minerals that precipitate from solution. That sequence is a function of the initial water composition, the thermal conditions, and the gas composition. Evaporation to concentrated brines is simulated using geochemical speciation 
calculations (Sections 6.5 and 6.6). These modeling results provide the suite of concentrated brine compositions that could potentially form on the waste package and drip shield.

Analogous evaporite minerals are commonly found on desert playa lakes in Nevada as the result of evaporative concentrations of relatively dilute and low-solute content rainwater and snowmelt (Papke 1976 [DIRS 162274], Table 1). For these reasons, model calculation runs simulating the evaporation of Sierra snowmelt were carried out to build confidence in the EQ6 Pitzer brine evaporation modeling (Section 7.3.3). In addition, the presence of the same evaporite minerals in Nevada playas provides corroboration for the mineral assemblages predicted by EQ3/6 evaporative concentration computer simulations (Table 6.13-1).

\subsubsection{Dust Deposition}

During construction, ventilation, and waste package emplacement, and after sealing the primary entrances to the repository, dust will accumulate in the drift. Dust on the drip shields and waste packages is of concern for its potential influence on corrosion.

Dust is deposited initially from the tuff bedrock during excavation and construction of the repository. In addition, ventilation will carry surface dust into the drifts. Surface dust may contain natural evaporite minerals, blown in from the surrounding countryside and playas, possibly from up to hundreds of kilometers away (Reheis et al. 2002 [DIRS 163132]). Some excavation dust may contain small amounts of bromide, which has been used as a tracer in construction waters at Yucca Mountain. The effect of bromide on the expected chemical environment is evaluated in Section 6.12.4.2.

Information on the general characteristics of atmospheric dust, on relevant atmospheric processes, and on dust from desert playas in Nevada, has been summarized in Environment on the Surfaces of Drip Shield and Waste Package Outer Barrier (BSC 2004 [DIRS 161237], Section 6.7.2.8) and in Analysis of Dust Deliquescence for FEP Screening (BSC 2005 [DIRS 175058], Sections 4.1.2 and 6.1.4). In general, nitrate and ammonia are important components of atmospheric dust, primarily due to their production in the upper atmosphere. Nitrate salts are recognized as an important component of atmospheric dusts and aerosols, and their properties (including deliquescence) are considered important to the understanding of certain weather and climatic phenomena. Anthropogenic sources add to the nitrate burden of atmospheric dust. The extent to which playa dusts are incorporated within atmospheric dust is uncertain. Nitrate minerals are not commonly described as components of surficial playa salts, so playas are not considered a significant source of nitrate in atmospheric dust.

\subsubsection{Determining the Range of Temperature for the Seepage Evaporation Abstraction}

Drift-Scale THC Seepage Model (BSC 2005 [DIRS 172862], Figures 6.5-4, 6.5-6, and 6.5-7) shows thermal seepage constraints that indicate there can be no seepage at drift temperatures above about $100^{\circ} \mathrm{C}$ due to the presence of a vaporization barrier (i.e., the liquid saturation levels fall sharply towards zero). In addition to this limitation, the results of the Drift Scale Test (DST) corroborate the absence of macroscale liquid water available in the host rock at temperatures much above about $100^{\circ} \mathrm{C}$ (Figure 6.2-2). Figure 6.2-2 shows the observed relationship of in situ 
moisture content with temperature, from neutron logging for the DST, in borehole 79 (February 1998 to December 2001).

Literature data and measured laboratory core-sample saturations (Flint 1998 [DIRS 100033], pp. 32 to 33) are in close agreement with observations from the DST (Figure 6.2-2), and show that at $60^{\circ} \mathrm{C}$ and $65 \%$ relative humidity, rock saturation becomes low enough that liquid flow essentially stops and vapor transport predominates. In measuring volumetric water content, Flint (1998 [DIRS 100033], pp. 32 to 38) used the standard drying heat of $105^{\circ} \mathrm{C}$, which is normally considered to remove most pore waters, but noted that "some, but not all, water was removed from the zeolites, clays, and pore spaces." The literature surveyed by Flint (1998 [DIRS 100033], p. 38) suggests that most of the water released from $105^{\circ} \mathrm{C}$ to $180^{\circ} \mathrm{C}$ is from thermal dehydration of zeolites, clays, and interstitial waters. These constraints indicate that the seepage evaporation abstraction should be made applicable for temperatures from ambient (approximately $25^{\circ} \mathrm{C}$ ) to around $105^{\circ} \mathrm{C}$. Specific temperatures for abstraction are determined in Section 6.7.3.

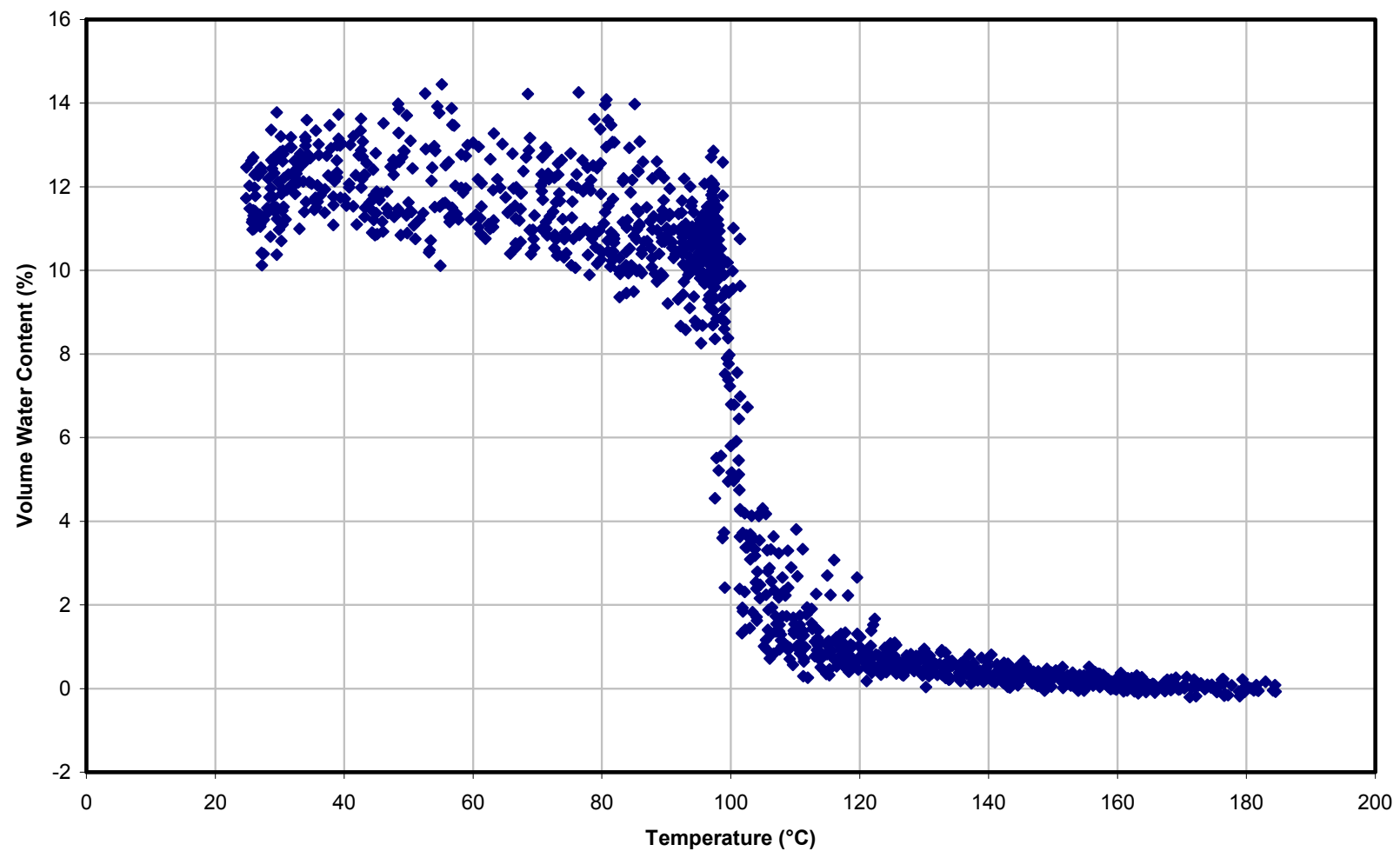

Source: DTN: MO0406SEPTVDST.000 [DIRS 170616], 79_complete.xIs.

Figure 6.2-2. Rock Moisture Content as a Function of Temperature as Measured from Neutron Logging of Borehole 79 during the DST Heating Phase

\subsubsection{Conceptual Description of Engineered Barrier System Chemical Environments by Spatial Location}

Figure 6.2-3 depicts several representative locations along a vertical flow path from the crown of the drift to the base of the invert where the chemical compositions of water and gas can directly affect degradation rates of the engineered barrier components, quantities and species of 
mobilized radionuclides, and transport rates for radionuclides and fluids through the drift into the UZ. It is at these locations that performance-related water compositions may change (to concentrated brines in some instances) due to the processes described previously.

Waste forms are contained in metal waste packages. These packages lie on pallets that rest on a flat invert composed of crushed host rock and metal beams. Titanium alloy drip shields, resting on the invert, cover the waste packages. Drip shields divert entering water, preventing it from contacting the waste packages. If a drip shield is breached, it only partially shields the waste packages from potential seepage water. Waste packages may be breached by corrosion, which may lead to degradation of the waste forms and release of radionuclides to the invert.

Several processes potentially affect the in-drift chemical environments and are relevant to performance assessment:

- Gas, water, and EBS materials interactions (Sections 6.4 through 6.10, and 6.13)

- Evaporation of water and condensation of water vapor (Sections 6.9 and 6.10)

- Salts precipitation and dissolution (Sections 6.9, 6.10, and 6.13.6).

When conditions for seepage exist, seepage water enters the drift by gravity (i.e., by dripping; see Figure 6.2-3). The composition of this water is influenced by reactions with ground support materials (e.g., rock bolts, and other ground support components) and with gases in the host rock. The water then falls through the air gap above the drip shield where further reaction with in-drift gases occurs. Interactions with ground support materials and reactions with gases are considered to be part of Location 1 (Figure 6.2-3).

After passing through the air gap above the drip shield, the water contacts the surface of the drip shield (Figure 6.2-3, Location 2) where it is diverted away from the waste package. On the drip shield, water evaporation, salt precipitation, transport related phase separation, and aqueous solution formation by rewetting and deliquescence of precipitated salts can occur. As long as it is intact, the drip shield will divert water fluxes around the waste packages to the invert and the UZ.

If the drip shield is breached (e.g., by uniform corrosion), seepage water can pass through the breaches and contact the surface of the waste package (Figure 6.2-3, Location 3) where it is diverted to the invert unless the waste package is breached. Potential evaporation, condensation, transport separation, and chemical processes at the surface of the waste package are the same as those for the drip shield. Aqueous solutions can initiate corrosion and corrosion products can further alter the water composition.

Water that passes through breaches in the waste package will contact the waste forms (Figure 6.2-3, Location 4). As the cladding and waste forms degrade, radionuclides will be mobilized in the water as dissolved or colloidal species. Further discussion of these issues is provided in In-Package Chemistry Abstraction (BSC 2005 [DIRS 174583]), Dissolved Concentration Limits of Radioactive Elements (BSC 2005 [DIRS 174566]), and Waste Form and In-drift Colloids-Associated Radionuclide Concentrations: Abstraction and Summary (BSC 2004 [DIRS 170025]). 
Advection and diffusion in flowing water and condensed water films can transport radionuclide-containing species through breaches in the waste package to the invert (Figure 6.2-3, Location 5).

Water can enter the invert (Figure 6.2-3, Location 5) from:

- Direct seepage

- Diversion by the drip shield

- Diversion by the waste package

- Flow from the waste package

- Imbibition or wicking from the host rock (not shown in Figure 6.2-3).

The composition of waters entering the invert (Figure 6.2-3, Location 5) determines the stable concentrations of dissolved and colloidal radionuclides, based on solubility and colloid stability models (BSC 2005 [DIRS 174566]; BSC 2004 [DIRS 170025]).

\subsubsection{Engineered Barrier System Physical and Chemical Environment Conceptual Model Locations}

The P\&CE model can be summarized by a discussion of the locations identified in the conceptual model (Figure 6.2-3). The model can be described as a series of either mixing or reaction cells that are found at the various spatial locations along the flow path, as discussed in Section 6.2.2. The various process model calculations documented or reported in Sections 6.4 through 6.10 use these reaction cells. Outputs from these sections are applied to other existing models, such as in-drift colloids and radionuclide solubility in the invert. The following subsections describe the development, application, and use of the P\&CE model calculations. The actual flow and transport calculations that determine the flux and diversion within the in-drift environment can be found in EBS Radionuclide Transport Abstraction (BSC 2005 [DIRS 173433], Section 6.5.1.1).

\subsubsection{Flux into Drift}

The first step in developing the P\&CE model is the selection of the incoming gas and water compositions for potential seepage entering through the crown of drift, as described in Section 6.6. Water compositions representing fluids wicking into the invert for the same spatial and boundary conditions are also provided for direct input into Location 5.

\subsubsection{Location 1 (Drift Wall and Air Gap)}

Potential seepage water and gas chemistries can be modified by interactions with rock bolts and steel sheets, or directly flow (drip) onto the surface of the drip shield (Location 2). In general, potential seepage water interactions with the corrosion products themselves should not significantly alter the major ion composition of the water entering the drift. To support this, sensitivity analyses of the effects of chromium released during the corrosion of Stainless Steel Type 316L have been conducted (Section 6.8). 


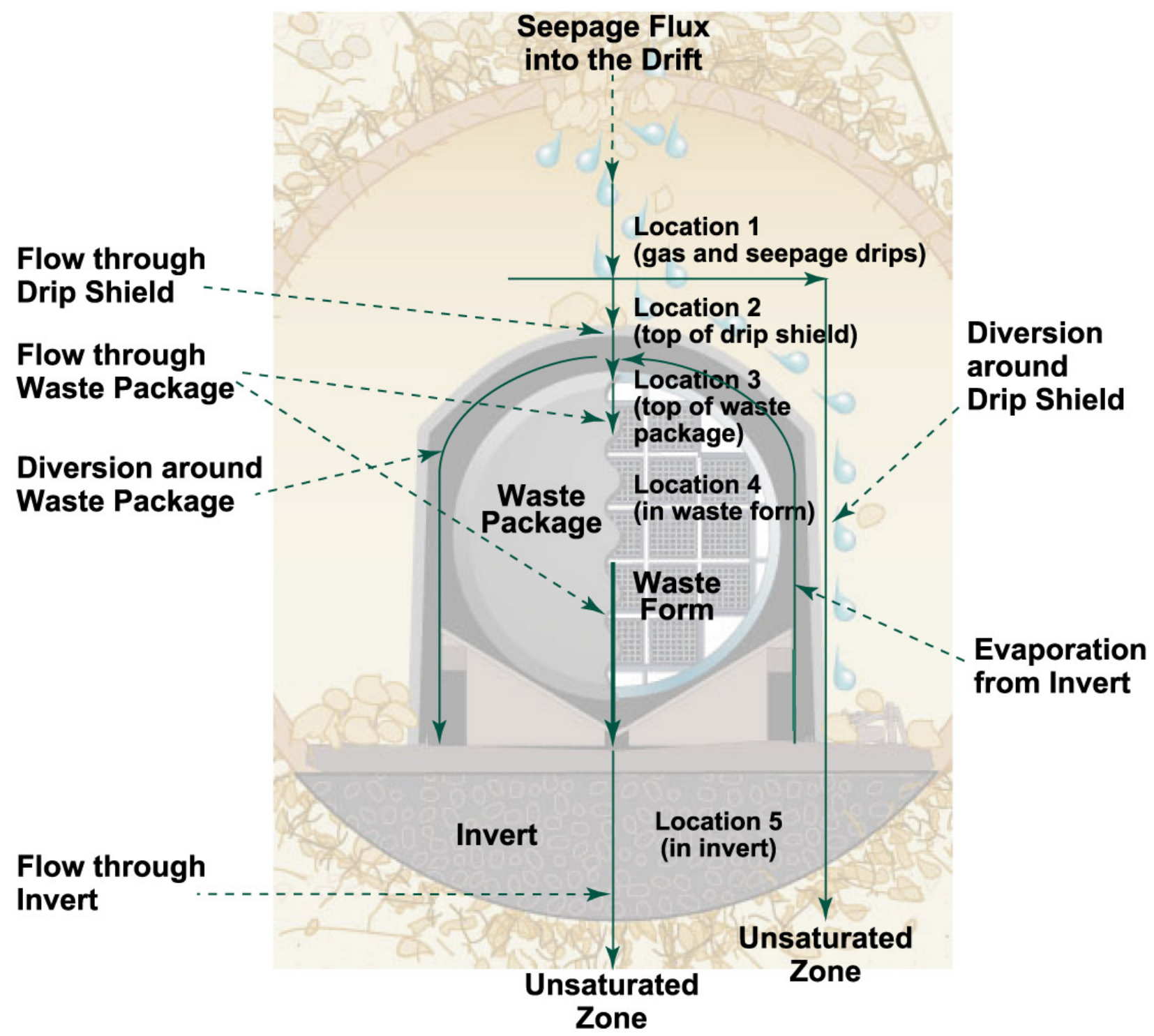

NOTE: Not shown is the wicking of water into the invert from the host rock.

abq0063G265.ai

Figure 6.2-3. Schematic Illustration of Locations of Important Interfaces and Fluxes in the Engineered Barrier System

\subsubsection{Location 2 (Surface of the Drip Shield)}

A portion of the water coming from Location 1 may be diverted directly to the invert (Location 5) by the drip shield, or it may undergo evaporative processes, be influenced by any biofilms present, or react with dust and debris sitting on the drip shield. These fluids could flow onto the surface of the waste package (Location 3), but could only flow into the package (Location 4) if a pathway becomes available. The effects of evaporative processes on the potential seepage composition are modeled and discussed in Sections 6.9 and 6.13. These process model results are the primary source of chemistry for fluids contacting the waste package. 
The corrosion products associated with the drip shield are not expected to adversely effect the compositions of any waters flowing off or through the drip shield due to the very slow corrosion rates for titanium and to the insoluble nature of titanium oxides (Section 6.4.2). For the same reasons, removal or addition of trace elements by sorption or dissolution processes associated with the active corrosion of the alloy is not considered.

\subsubsection{Location 3 (Surface of the Waste Package)}

Although the composition of the waste package alloy differs from that of the drip shield, it too is highly corrosion-resistant (Section 6.4.2), and the processes occurring at Location 2 are also applicable to this location.

\subsubsection{Location 4 (Inside Waste Package)}

This portion of the conceptual process is documented in other reports such as Summary of In-Package Chemistry Abstraction (BSC 2005 [DIRS 174583]). The results of the model developed in that report are used as input into Location 5.

\subsubsection{Location 5 (Invert)}

The in-drift colloids model and the radionuclide solubility model require compositional parameters for water in the invert, as discussed in Section 6.13. Three incoming water sources are considered: from Locations 2 or 3 (i.e., potential seepage was modified by evaporative processes and diverted around the waste package), from Location 4, and waters wicking directly into the invert. These are provided to the TSPA-LA (Sections 6.13 and 6.15) in order to evaluate radionuclide solubility and colloid stability in the TSPA model for the invert.

\subsection{COUPLED PROCESSES}

Coupled processes are those in which two or more physical and chemical processes simultaneously interact to produce a result, or in which a process is affected by physical and chemical variables at the same time. The coupled processes considered in the TSPA are those that have been found to have a potentially significant effect on dose calculations.

The relative importance of different coupled processes, formally classified as FEPs, is discussed briefly in Section 6.14 and documented in more detail in various FEPs reports (BSC 2005 [DIRS 175014], Section 6.2.60). These reports contain straightforward screening arguments if the FEP is excluded from further consideration, or a description of the TSPA disposition if it is included. The rationale for exclusion may be based upon regulatory requirements, low probability of occurrence, or low consequence in terms of impact on calculated dose.

Coupled processes are incorporated into the P\&CE model implicitly through inputs from the THC-coupled seepage model. This report describes the chemical processes at various locations in the drift that are influenced by processes (including coupled processes) in the host rock (BSC 2005 [DIRS 172862]; BSC 2005 [DIRS 173944]); an abstraction methodology that produces a chemical environment dependent upon drip shield and waste package surface temperature and humidity; and reaction with gas-phase $\mathrm{CO}_{2}$ and precipitation, and possible 
deliquescence, of soluble salts. Explicit consideration was given to the chemical interactions of potential crown seepage and ground support materials (Section 6.8).

Onsager Coupled Processes-Coupled processes involving diffusion and diffusion-like processes (e.g., heat conduction) can be described in terms of the Onsager processes, which are represented by a matrix of first-order relationships (Table 6.3-1). These are fundamental processes that can occur even if the associated physical or chemical properties of the medium are temporally or spatially invariant. Onsager couplings are driven indirectly by gradients of thermodynamic state variables (e.g., temperature, pressure, chemical potential, and electrical potential) that affect chemical transport in aqueous solution. Direct transport processes are driven by the same thermodynamic-state variables in well-known relations such as Fourier's Law, Darcy's Law, Fick's Laws, and Ohm's Law. Diffusive processes dominate in Onsager-coupled processes.

Direct processes lie along the main diagonal of the table, and indirect coupled processes are off-diagonal. The existence of indirect processes is generally known from controlled experiments. Phenomenological coefficients relating gradients and fluxes for indirect coupled processes are not generally known for geologic media. Nevertheless, the indirect coupled processes shown in Table 6.3-1 are not significant to performance of the repository because the magnitudes of the associated potential gradients or fluxes in the host rock are too small. The direct processes including Darcy flow and Fickian diffusion overwhelm the indirect processes. These direct processes are included in the models used for TSPA-LA. Some of the indirect Onsager-coupled processes listed in Table 6.3-1, such as chemical osmosis (observed in clays or zeolites) or the sedimentation current in response to heating the host rock (static potentials in the host rock), have been observed at Yucca Mountain. However, the effects of these processes are relatively small, and not important to various aspects of repository performance, including the environment in which metal barriers might corrode and the possible migration of radionuclides from breached packages.

The possible effect of coupled processes (relevant to the Onsager process) on radionuclide migration has been discussed and evaluated (BSC 2005 [DIRS 175014], Section 6.2.60). The conclusion was reached that the off-diagonal processes are unimportant. The on-diagonal processes are either accounted for in current modeling for TSPA or are excluded. That determination is applicable to the effect of such processes acting on the chemical environment to which metal barriers are exposed. For example, no significant pressure gradients (sufficient to support significant off-diagonal type fluxes as included in Table 6.3-1) are expected between the drift wall and the waste package outer barrier, either radially or along the length of the drift (see the treatment of pressure in BSC 2005 [DIRS 172862]). Similarly, electrical potentials affecting the chemical environment are minimal and insufficient to drive associated off-diagonal fluxes. Temperature- and chemical-potential gradients are principal drivers for the in-drift chemical environment. Existing models incorporate the relevant effects, which are more often dominated by vapor-liquid equilibrium than condensed-phase transport effects. Osmotic equilibrium in particular is dominated by vapor-liquid equilibrium, as represented by deliquescence of salts. The same effect is controlling when a drop of seepage water falls from the drift wall onto a metal barrier surface (drip shield or waste package outer barrier). The drop re-equilibrates to new conditions of temperature (higher) and relative humidity (lower). Salt separation effects may occur on a metal barrier surface owing to several factors, including temperature and $\mathrm{RH}$ 
gradients on that surface and even in the absence of such gradients due to the flow of aqueous solution down a sloping surface while precipitated solids remain behind at the point of precipitation. However, vapor-liquid equilibrium at any point along such gradients or flow paths is a strong determinant of what results at any such point.

Lastly, it is worth pointing out that the Onsager framework of addressing coupled processes is nothing more than that, a framework. Other equivalent approaches can be taken that include the relevant effects. Consider for example, diffusion of solutes in aqueous solution in the case in which the system of interest includes a temperature gradient. Instead of referring to the "Soret" effect, a treatment that explicitly expresses the diffusion coefficients as temperature-dependent quantities could be used. Furthermore, Table 6.3-1 could be expanded to include the effects of analogous potential gradients, such as a gravitational potential gradient.

Table 6.3-1. Onsager Couplings and Direct Transport Process Fluxes Driven by Temperature, Pressure, Chemical Potential, and Electrical Potential Gradients

\begin{tabular}{|l|l|l|l|l|}
\cline { 2 - 5 } \multicolumn{1}{c|}{} & \multicolumn{1}{c|}{ Temperature } & \multicolumn{1}{c|}{ Pressure } & \multicolumn{1}{c|}{ Chemical Potential } & \multicolumn{1}{c|}{ Electrical Potential } \\
\cline { 2 - 5 } Heat Flux & $\begin{array}{l}\text { Fourier's Law: heat } \\
\text { flow in a temperature } \\
\text { gradient }\end{array}$ & $\begin{array}{l}\text { Thermal filtration: } \\
\text { heat flow in a } \\
\text { pressure gradient }\end{array}$ & $\begin{array}{l}\text { Dufour effect: heat flow } \\
\text { in a density gradient }\end{array}$ & $\begin{array}{l}\text { Peltier effect: heat flow } \\
\text { in a voltage gradient }\end{array}$ \\
\hline Volume Flux & $\begin{array}{l}\text { Thermal osmosis: } \\
\text { volume flow in a } \\
\text { temperature gradient }\end{array}$ & $\begin{array}{l}\text { Darcy's Law: } \\
\text { volume flow in a } \\
\text { pressure gradient }\end{array}$ & $\begin{array}{l}\text { Chemical osmosis: } \\
\text { volume flow in a } \\
\text { concentration gradient }\end{array}$ & $\begin{array}{l}\text { Electro-osmosis: volume } \\
\text { flow in a voltage gradient }\end{array}$ \\
\hline Mass Flux & $\begin{array}{l}\text { Soret effect: particle } \\
\text { flow in a temperature } \\
\text { gradient }\end{array}$ & $\begin{array}{l}\text { Reverse osmosis: } \\
\text { mass flow in a } \\
\text { pressure gradient }\end{array}$ & $\begin{array}{l}\text { Fick's Law: mass flow } \\
\text { in a concentration } \\
\text { gradient }\end{array}$ & $\begin{array}{l}\text { Electrophoresis: mass } \\
\text { flow in a voltage gradient }\end{array}$ \\
\hline Electrical & $\begin{array}{l}\text { Seebeck effect: } \\
\text { electrical current in a } \\
\text { temperature gradient }\end{array}$ & $\begin{array}{l}\text { Streaming current: } \\
\text { electrical current in a } \\
\text { pressure gradient }\end{array}$ & $\begin{array}{l}\text { Sedimentation current: } \\
\text { electrical current in a } \\
\text { density gradient }\end{array}$ & $\begin{array}{l}\text { Ohm's Law: current } \\
\text { flow in a voltage } \\
\text { gradient }\end{array}$ \\
\hline
\end{tabular}

Source: Carnahan 1987 [DIRS 138706], p. 2.

NOTE: Onsager couplings and direct transport processes are along the diagonal in bold type. The Onsager couplings are important only when aqueous, liquid, or solid diffusion dominates over advection.

\subsection{INTRODUCED MATERIALS}

Figure 6.4-1 illustrates the general configuration of materials introduced into a repository drift. As the figure shows, the current emplacement drift configuration contains no cementitious materials. The materials that are emplaced are expected to undergo chemical and physical changes, and they may affect the in-drift chemical environment.

This section analyzes the corrosion rate and relative lifetime of the primary introduced materials in the current repository design. This information is used later to establish boundary conditions, modeling constraints, and potential effects on the in-drift environment. In general, waste package and drip shield material longevity is evaluated in documentation such as WAPDEG Analysis of Waste Package and Drip Shield Degradation (BSC 2004 [DIRS 169996]). Evolution of the in-package materials is evaluated in In-Package Chemistry Abstraction (BSC 2005 [DIRS 174583]). 
The chemical effects and corrosion rates of other introduced materials are evaluated within this document. The low-alloy or carbon steels are found to be the only significant contributor to the oxygen mass balance calculations associated with the evolution of the in-drift gaseous environment (Section 6.7). Alloy 22 and titanium material corrosion rates are only presented here to demonstrate their insignificant effect upon the in-drift environment. The analyses in this section are also used to determine the extent of effect on seepage chemistry as it pertains to the interaction with the ground support (e.g., Stainless Steel Type 316L corrosion in Section 6.8).

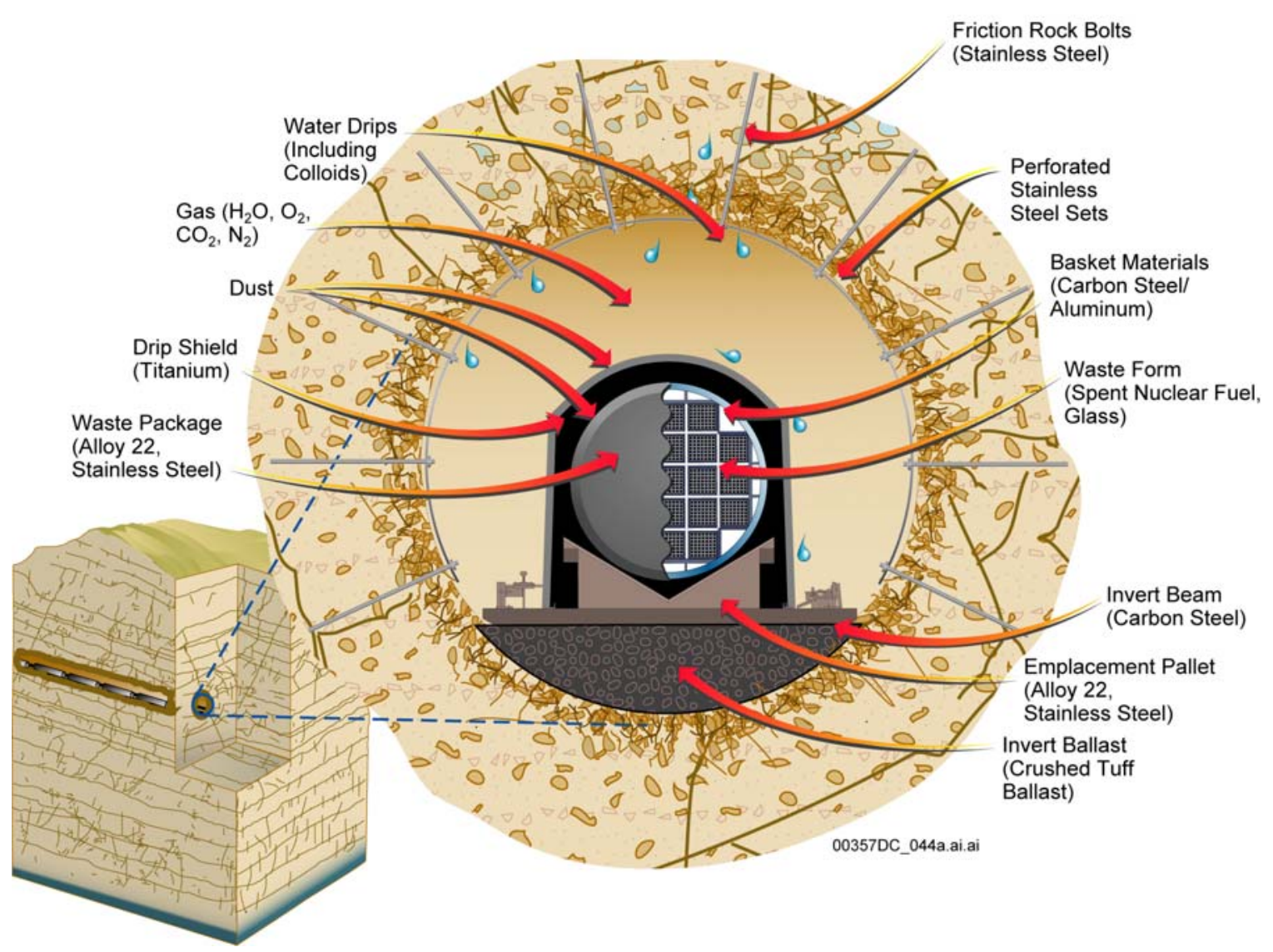

Figure 6.4-1. General Location of Engineered Barrier System Components and Materials

\subsubsection{Material Corrosion Rates}

In the following sections and tables, general corrosion rates under a variety of environmental conditions are discussed. These include corrosion rates determined under humid air and immersed conditions. Titanium and Alloy 22 corrosion rates are taken directly as those used by other project documents.

For other materials, a set of experimental work for the project was carried out using three waters, referred to as simulated dilute water (SDW), simulated concentrated water (SCW), and simulated acidified water (SAW), respectively (McCright 1998 [DIRS 114637]). The SDW simulates J-13 well water at $10 \times$ concentration to account for minor effects of water evaporation and boiling. 
SCW simulates J-13 well water concentrated $1,000 \times$ to account for long-term water evaporation and boiling in the repository environment. SAW represents J-13 well water that has been acidified and concentrated, which is intended to simulate the effect of possible microbial metabolic products. Corrosion tests were run on samples immersed in these waters, and in the humid air generated above these waters upon heating. Further information on these simulated solutions is provided by McCright (1998 [DIRS 114637]).

The corrosion of metals in the atmosphere is primarily controlled by temperature, relative humidity, and chemistry. Many other parameters can affect corrosion rates, including time of wetness, rainfall, fog, and hours of sunlight, but these are not discussed here as such parameters are not available to describe the in-drift environment. Temperatures and relative humidity values are presented in the tables below. However, details of chemistry are not available in many cases. Note that the tables in this document capture the data as it exists within each data source as opposed to providing a consistent number of significant figures. In the case of reporting values from $\mathrm{EQ} 3 / 6$ calculated data, rounding is usually done to three significant figures.

The most corrosive environments are typically the marine and industrial atmospheres, which represent corrosion under conditions of high humidity, of metal covered with a salt crust, or in the presence of high concentrations of atmospheric contaminants.

In the case of pooled water in or on materials, those values indicated by "freshwater" and "saltwater" are used for the corrosion rate. The freshwater rates are representative of those solutions that are dilute, such as lake water and J-13 well water. The saltwater rates are for ocean water with an average chloride content of approximately 17,000 ppm (Forgeson et al. 1958 [DIRS 159343]), and are used when the natural waters have been concentrated due to evaporation or contact with engineered materials. Modifications to these definitions will be discussed for each individual material in the following sections.

\subsubsection{Titanium}

Because a stable oxide film $\left(\mathrm{TiO}_{2}\right)$ forms quickly upon exposure to oxygen, titanium is generally resistant to corrosion. This is shown in Table 6.4-1, which lists the corrosion rates of titanium (Grade 16) determined for the dripping water case in General Corrosion and Localized Corrosion of the Drip Shield (BSC 2004 [DIRS 169845], Table 17). These general corrosion rates of the outer surface of the drip shield are represented by a cumulative distribution function (CDF) generated by combining the Long Term Corrosion Test Facility 1-year weight-loss samples and the crevice samples from experimental results (BSC 2004 [DIRS 169845], Section 6.5.5). The minimum corrosion rate is taken as the lowest corrosion rate that is greater than zero for the CDF. The maximum corrosion rate is given as the corrosion rate that is closest to the 95th percentile for the CDF. The minimum, maximum, and 50th percentile of the CDF are shown in Tables 6.4-1 (in bold) and 6.4-8. 
Table 6.4-1. Titanium Grade 16 Corrosion Rates

\begin{tabular}{|c|c|c|}
\hline Sample & Corrosion Rate $(\mu \mathrm{m} / \mathrm{yr})$ & $\begin{array}{c}\text { Cumulative Distribution } \\
\text { Function (CDF) }\end{array}$ \\
\hline 1 & $0.00 \mathrm{E}+00$ & $0.00 \mathrm{E}+00$ \\
\hline 2 & 4.18E-03 (minimum) & 1.43E-01 \\
\hline 3 & 7.91E-03 & $1.79 \mathrm{E}-01$ \\
\hline 4 & 7.91E-03 & $2.14 \mathrm{E}-01$ \\
\hline 5 & 7.92E-03 & $2.50 \mathrm{E}-01$ \\
\hline 6 & $7.99 \mathrm{E}-03$ & $2.86 \mathrm{E}-01$ \\
\hline 7 & $1.60 \mathrm{E}-02$ & $3.21 \mathrm{E}-01$ \\
\hline 8 & $1.61 \mathrm{E}-02$ & $3.57 \mathrm{E}-01$ \\
\hline 9 & $1.65 \mathrm{E}-02$ & $3.93 \mathrm{E}-01$ \\
\hline 10 & $2.10 \mathrm{E}-02$ & $4.29 \mathrm{E}-01$ \\
\hline 11 & $2.36 \mathrm{E}-02$ & 4.64E-01 \\
\hline 12 & 2.37E-02 (50th percentile) & $5.00 \mathrm{E}-01$ \\
\hline 13 & $2.40 \mathrm{E}-02$ & $5.36 \mathrm{E}-01$ \\
\hline 14 & $2.53 \mathrm{E}-02$ & $5.71 \mathrm{E}-01$ \\
\hline 15 & $4.00 \mathrm{E}-02$ & $6.07 \mathrm{E}-01$ \\
\hline 16 & $4.26 \mathrm{E}-02$ & $6.43 \mathrm{E}-01$ \\
\hline 17 & $4.29 \mathrm{E}-02$ & $6.79 \mathrm{E}-01$ \\
\hline 18 & $5.15 \mathrm{E}-02$ & $7.14 \mathrm{E}-01$ \\
\hline 19 & $6.34 \mathrm{E}-02$ & $7.50 \mathrm{E}-01$ \\
\hline 20 & $6.50 \mathrm{E}-02$ & $7.86 \mathrm{E}-01$ \\
\hline 21 & $7.15 \mathrm{E}-02$ & $8.21 \mathrm{E}-01$ \\
\hline 22 & 7.92E-02 & 8.57E-01 \\
\hline 23 & $8.22 \mathrm{E}-02$ & 8.93E-01 \\
\hline 24 & $1.12 \mathrm{E}-01$ & $9.29 \mathrm{E}-01$ \\
\hline 25 & 1.13E-01 (maximum) & $9.64 \mathrm{E}-01$ \\
\hline 26 & $3.19 \mathrm{E}-01$ & $1.00 \mathrm{E}+00$ \\
\hline
\end{tabular}

Source: BSC 2004 [DIRS 169845], Table 17.

NOTE: Corrosion rates converted to $\mu \mathrm{m} / \mathrm{yr}$ from $\mathrm{mm} / \mathrm{yr}$.

\subsubsection{Alloy 22}

Corrosion rates for Alloy 22 given here are consistent with those determined in General Corrosion and Localized Corrosion of Waste Package Outer Barrier (BSC 2004 [DIRS 169984], Section 6.4.3.4), which presents a base-case temperature-dependent general corrosion model that determines general corrosion rates of Alloy 22 based on an Arrhenius relation in logarithmic form (BSC 2004 [DIRS 169984], Equation 6-25). This does not account for any microbial activity, which can only increase the corrosion rate on a localized scale. The effect on mass corroded by microbial activity is small, and implemented in TSPA by increasing the general corrosion rate by up to a factor of two (BSC 2004 [DIRS 169984], Section 6.4.5). The calculated model output is presented as a general corrosion rate CDF at different temperatures (BSC 2004 [DIRS 169984], Figure 6-26; DTN: MO0409MWDUGCMW.000 [DIRS 171714]). Table 6.4-2 provides the 5th, 50th, and 95th percentile results of the corrosion rate $\mathrm{CDF}$ for Alloy 22 at $25^{\circ} \mathrm{C}, 50^{\circ} \mathrm{C}, 75^{\circ} \mathrm{C}, 100^{\circ} \mathrm{C}, 125^{\circ} \mathrm{C}$, and $150^{\circ} \mathrm{C}$. Table $6.4-8$ provides 
these same results but for $25^{\circ} \mathrm{C}, 100^{\circ} \mathrm{C}$, and $150^{\circ} \mathrm{C}$ only. The corrosion rate results in Tables 6.4-2 and 6.4-8 have been converted from $\mathrm{nm} / \mathrm{yr}$ to $\mu \mathrm{m} / \mathrm{yr}$.

Table 6.4-2. Corrosion Rates of Alloy 22

\begin{tabular}{|c|c|c|c|}
\hline Temperature $\left({ }^{\circ} \mathbf{C}\right)$ & 5th Percentile $(\boldsymbol{\mu m} / \mathbf{y r})$ & 50th Percentile $(\boldsymbol{\mu m} / \mathbf{y r})$ & 95th Percentile $(\boldsymbol{\mu m} / \mathbf{y r})$ \\
\hline 25 & 0.0005 & 0.0024 & 0.0058 \\
\hline 50 & 0.0011 & 0.0053 & 0.0131 \\
\hline 75 & 0.0021 & 0.0106 & 0.0262 \\
\hline 100 & 0.0039 & 0.0193 & 0.0477 \\
\hline 125 & 0.0065 & 0.0326 & 0.0805 \\
\hline 150 & 0.0104 & 0.0518 & 0.1278 \\
\hline
\end{tabular}

Source: DTN: MO0409MWDUGCMW.000 [DIRS 171714]' Base Case GC Rate CDF.xls, tab "Base Case GC Rate."

\subsubsection{Copper Alloy}

The summary of corrosion rates for copper under different environmental conditions is presented in Table 6.4-3. Under outdoor conditions, the main factors influencing corrosion of copper are relative humidity and concentration of aerosol particles (Sequeira 2000 [DIRS 162970]).

Table 6.4-3. Corrosion Rates of Copper under Various Environmental Conditions

\begin{tabular}{|c|c|c|c|}
\hline Environment & $\begin{array}{c}\text { Maximum } \\
(\mu \mathrm{m} / \mathrm{yr})\end{array}$ & $\begin{array}{c}\text { Mean } \\
(\mu \mathrm{m} / \mathrm{yr})\end{array}$ & $\begin{array}{c}\text { Minimum } \\
(\mu \mathrm{m} / \mathrm{yr})\end{array}$ \\
\hline $90^{\circ} \mathrm{C}, \mathrm{J}-13$ Steam, near $100 \%$ relative humidity & 4.15 & 2.86 & 1.67 \\
\hline $95^{\circ} \mathrm{C}$ to $100^{\circ} \mathrm{C}, \mathrm{J}-13$ Steam, near $100 \%$ relative humidity & 6.60 & 4.79 & 3.15 \\
\hline $150^{\circ} \mathrm{C}, \mathrm{J}-13$ Steam, near $100 \%$ relative humidity & 1.78 & 1.09 & 0.46 \\
\hline $90^{\circ} \mathrm{C}$, Soln 7 steam, near $100 \%$ relative humidity $(1,000 \mathrm{ppm} \mathrm{Cl})$ & 5.90 & 1.60 & 0.39 \\
\hline Marine Atmosphere ( $70 \%$ to $83 \%$ relative humidity) & 4.14 & 1.68 & 0.43 \\
\hline Marine Atmosphere ( $60 \%$ to $70 \%$ relative humidity) & 1.38 & 1.33 & 1.27 \\
\hline Rural Atmosphere (wet: $69.5 \%$ to $83 \%$ relative humidity) & 2.01 & 0.94 & 0.42 \\
\hline Rural Atmosphere (dry: $39 \%$ relative humidity) & 0.13 & 0.13 & 0.13 \\
\hline Industrial Atmosphere ( $65 \%$ to $68 \%$ relative humidity) & 1.90 & 1.50 & 1.30 \\
\hline Urban Atmosphere (74\% relative humidity) & 1.40 & 1.22 & 1.04 \\
\hline
\end{tabular}

Source: DTN: MO0312SPAPCEML.003 [DIRS 167409], atmospheric.xls, tab "copper."

\subsubsection{Aluminum Alloy}

Measured aqueous corrosion rates for aluminum alloy are presented in Table 6.4-4. Aluminum differs from other metals in that the main corrosion behavior is a form of localized corrosion called pitting. Because pitting does not allow for easy determination of material lifetimes, pitting weight loss data for aluminum are converted to general rates for use in this report. 
Table 6.4-4. Corrosion Rates of Aluminum Alloys in Aqueous Environments

\begin{tabular}{|c|c|c|c|}
\hline Environment & $\begin{array}{c}\text { Maximum } \\
(\mu \mathrm{m} / \mathbf{y r})\end{array}$ & $\begin{array}{c}\text { Mean } \\
(\mu \mathrm{m} / \mathbf{y r})\end{array}$ & $\begin{array}{c}\text { Minimum } \\
(\mu \mathrm{m} / \mathbf{y r})\end{array}$ \\
\hline Freshwater & 36.93 & 12.95 & 0.40 \\
\hline Saltwater & 110.91 & 9.69 & 0.12 \\
\hline
\end{tabular}

Source: DTN: MO0409SPAACRWP.000 [DIRS 172059], aluminum2.xIs, tab "range."

Atmospheric data on the corrosion of aluminum alloy come from Corrosion (ASM International 1987 [DIRS 103753], Tables 8 and 11) and can be found in Table 6.4-5. The minimum value comes from 20-year atmospheric corrosion data, the median value from 10-year atmospheric corrosion data, and the maximum from the highest value of atmospheric corrosion.

Table 6.4-5. Atmospheric Corrosion Rates of Aluminum Alloy 6061

\begin{tabular}{|c|c|c|}
\hline $\begin{array}{c}\text { Maximum Rate } \\
(\mu \mathrm{m} / \mathrm{yr})\end{array}$ & $\begin{array}{c}\text { Median Rate } \\
(\mu \mathrm{m} / \mathrm{yr})\end{array}$ & $\begin{array}{c}\text { Minimum Rate } \\
(\mu \mathrm{m} / \mathrm{yr})\end{array}$ \\
\hline 0.422 & 0.35 & 0.076 \\
\hline
\end{tabular}

Source: ASM International 1987 [DIRS 103753], Tables 8 and 11.

\subsubsection{Stainless Steel Type 316L}

In relatively uncontaminated but open environments, such as rural atmospheres or steam produced from dilute solutions such as J-13 well water, the corrosion rate for Stainless Steel Type $316 \mathrm{~L}$ is slow. The data, mostly originating from non-sterile and open environment, inherently includes any increased corrosion rate due to microbial influences. However, when the atmosphere contains contaminants, such as chlorides, the corrosion rate rises significantly (Table 6.4-6). Chloride contamination can come from exposure to marine environments or concentrated underground waters. The amount of corrosion depends on the distance of the test specimen from the chloride source (i.e., the tide line), showing that the more chlorides an environment contains, the more corrosive it will be.

The two values in bold type in Table 6.4-6 below are used in the calculations to determine the effect of Stainless Steel Type 316L ground support degradation upon crown seepage water (Section 6.8). 
Table 6.4-6. Corrosion Rates of Stainless Steel Type 316L under Various Environmental Conditions

\begin{tabular}{|c|c|c|c|}
\hline Environment & $\begin{array}{c}\text { Maximum } \\
(\mu \mathrm{m} / \mathrm{yr})\end{array}$ & $\begin{array}{c}\text { Mean } \\
(\mu \mathrm{m} / \mathrm{yr})\end{array}$ & $\begin{array}{c}\text { Minimum } \\
(\mu \mathrm{m} / \mathrm{yr})\end{array}$ \\
\hline $100^{\circ} \mathrm{C} \mathrm{J}-13$ Steam $^{a}$ & 0.099 & 0.099 & 0.099 \\
\hline $150^{\circ} \mathrm{C} \mathrm{J}-13$ Steam $^{a}$ & 0.064 & 0.064 & 0.064 \\
\hline Marine Atmosphere $^{a}$ & 0.517 & $0.113^{b}$ & 0.000 \\
\hline Industrial Atmosphere ${ }^{a}$ & 0.014 & 0.008 & 0.000 \\
\hline Rural Atmosphere $^{a}$ & 0.00 & 0.00 & 0.00 \\
\hline $207^{\circ} \mathrm{C}$ Brine Steam ${ }^{a}$ & 53 & 49.67 & 48 \\
\hline $29.5^{\circ} \mathrm{C}$ Freshwater $^{\mathrm{c}}$ & 0.0475 & 0.0083 & 0.0007 \\
\hline $50^{\circ} \mathrm{C}$ Freshwater ${ }^{\mathrm{C}}$ & 0.2286 & 0.1614 & 0.1016 \\
\hline $70^{\circ} \mathrm{C}$ Freshwater ${ }^{\mathrm{c}}$ & 0.2540 & 0.2413 & 0.2286 \\
\hline $80^{\circ} \mathrm{C}$ Freshwater $^{\mathrm{C}}$ & 0.2794 & 0.2141 & 0.1090 \\
\hline $90^{\circ} \mathrm{C}$ Freshwater $^{\mathrm{C}}$ & 0.2540 & 0.2032 & 0.1524 \\
\hline $100^{\circ} \mathrm{C}$ Freshwater ${ }^{\mathrm{C}}$ & 0.5100 & 0.3247 & 0.0370 \\
\hline $26.7^{\circ} \mathrm{C}$ Saltwater ${ }^{\mathrm{C}}$ & 14.787 & $1.939^{b}$ & 0.0014 \\
\hline
\end{tabular}

${ }^{a}$ DTN: MO0312SPAPCEML.003 [DIRS 167409], atmospheric.xls.

b This item's source, Table 4.1-1, provides values that are qualified for intended use in Appendix D, and calculated in Output DTN: MO0407SPAPCEML.005.

c DTN: MO0409SPAACRWP.000 [DIRS 172059], aqueous-316L.xIs.

\subsubsection{Carbon and Low-Alloy Steels}

The corrosion rates for carbon and low-alloy steels in different environments are shown in Table 6.4-7. Thus far, no specific data have been located for corrosion at $25^{\circ} \mathrm{C}$ of Carbon Steel Type A516, but in terms of composition it is a carbon or low-alloy steel ( $>98 \%$ iron, Table $4.1-7$ ) and is considered equivalent to any other carbon/low-alloy steel for corrosion purposes. Under subaerial exposure, the highest corrosion rate of approximately $1,057 \mu \mathrm{m} / \mathrm{yr}$ comes from a steel sample sitting directly on the beach at Cape Kennedy, Florida. This sample was fully exposed to constant sea spray and is an indication of how salt buildup may affect the corrosion of metals. The lowest rate $(0.40 \mu \mathrm{m} / \mathrm{yr})$ comes from a rural atmosphere at a relative humidity below $60 \%$. These two values show how the corrosion rate for these steels can greatly differ depending on the atmospheric environment. Both of these examples originate from non-sterile and open environments, and therefore inherently include any increased corrosion rate due to microbial influences.

Aqueous corrosion rates of carbon and mild steels are much lower than marine or industrial atmospheric corrosion rates. Temperature effects are also different. In atmospheric corrosion, there is generally a direct correlation between temperature and corrosion rate. However, in aqueous environments, corrosion at $60^{\circ} \mathrm{C}$ is greater than that at $90^{\circ} \mathrm{C}$. This is corroborated by Brasher and Mercer (1968 [DIRS 100883]), who measured the relationship between corrosion and temperature (Figure 6.4-2). As shown in the worksheet titled "rate vs. temperature" in DTN: MO0409SPAACRWP.000 [DIRS 172059], the highest corrosion rates occur at $60^{\circ} \mathrm{C}$. The corrosion rate decreases with either increasing or decreasing temperature from this value (i.e., corrosion rates for $25^{\circ} \mathrm{C}$ and $90^{\circ} \mathrm{C}$ will be lower than the $60^{\circ} \mathrm{C}$ rates). As can be seen from Figure 6.4-2, the rates for the mild steel are within the same range as those for Carbon Steel Type 
A516 as provided by McCright (1998 [DIRS 114637]). The data plotted in Figure 6.4-2 show that in corrosion for mild steel, the rates at $25^{\circ} \mathrm{C}$ are slightly lower than those at $90^{\circ} \mathrm{C}$.

Table 6.4-7. Corrosion Rates of Carbon and Low-Alloy Steels in Various Environmental Conditions

\begin{tabular}{|c|c|c|c|}
\hline Environment & $\begin{array}{c}\text { Maximum } \\
(\mu \mathrm{m} / \mathrm{yr})\end{array}$ & $\begin{array}{c}\text { Mean } \\
(\mu \mathrm{m} / \mathrm{yr})\end{array}$ & $\begin{array}{c}\text { Minimum } \\
(\mu \mathrm{m} / \mathrm{yr})\end{array}$ \\
\hline $60^{\circ} \mathrm{C}-\mathrm{SDW}$ near $100 \% \mathrm{RH}^{\mathrm{a}}$ & 74.25 & 41.97 & 18.60 \\
\hline $90^{\circ} \mathrm{C}-\mathrm{SDW}$ near $100 \% \mathrm{RH}^{\mathrm{a}}$ & 135.26 & 63.60 & 22.69 \\
\hline $60^{\circ} \mathrm{C}-\mathrm{SCW}$ near $100 \% \mathrm{RH}^{\mathrm{a}}$ & 360.78 & 177.16 & 76.38 \\
\hline $90^{\circ} \mathrm{C}-\mathrm{SCW}$ near $100 \% \mathrm{RH}^{\mathrm{b}}$ & $423.06^{\mathrm{b}}$ & $195.44^{\mathrm{b}}$ & $72.96^{b}$ \\
\hline $\begin{array}{l}\text { Marine Atmosphere } \\
(80 \% \text { relative humidity and over })^{a}\end{array}$ & 851.09 & 153.33 & 9.87 \\
\hline Marine Atmosphere ( $70 \%$ to $80 \%$ relative humidity $)^{a}$ & $1,057.18$ & 101.94 & 6.39 \\
\hline Industrial Atmosphere (Over $80 \%$ relative humidity) ${ }^{a}$ & 123.00 & 102.5 & 85.50 \\
\hline Industrial Atmosphere $\left(70 \%\right.$ to $80 \%$ relative humidity) ${ }^{a}$ & 137.80 & 46.28 & 12.55 \\
\hline Industrial Atmosphere ( $60 \%$ to $70 \%$ relative humidity) ${ }^{a}$ & 164.54 & 20.58 & 3.77 \\
\hline Semi-Industrial Atmosphere (over $80 \%$ relative humidity) ${ }^{a}$ & 171.70 & 119.93 & 75.3 \\
\hline Semi-Industrial Atmosphere $(60 \% \text { to } 70 \% \text { relative humidity })^{a}$ & 60.88 & 35.23 & 17.33 \\
\hline Rural Atmosphere (over $80 \%$ relative humidity) ${ }^{a}$ & 60.10 & 39.19 & 21.60 \\
\hline Rural Atmosphere $\left(70 \%\right.$ to $79 \%$ relative humidity) ${ }^{a}$ & 59.00 & 26.63 & 10.68 \\
\hline Rural Atmosphere $(60 \% \text { to } 69 \% \text { relative humidity })^{a}$ & 75.50 & 19.37 & 3.93 \\
\hline Rural Atmosphere (less than $60 \%$ relative humidity) ${ }^{a}$ & 38.67 & 13.86 & 0.40 \\
\hline Urban Atmosphere $(70 \% \text { to } 80 \% \text { relative humidity })^{a}$ & 68.70 & 34.81 & 10.76 \\
\hline Urban Atmosphere $(60 \% \text { to } 70 \% \text { relative humidity })^{a}$ & 93.70 & 38.71 & 7.12 \\
\hline Urban Atmosphere (below $60 \%$ relative humidity) ${ }^{a}$ & 29.16 & 11.09 & 0.70 \\
\hline $60^{\circ} \mathrm{C}-\mathrm{SDW}^{\mathrm{C}}$ & 106.93 & 77.43 & 65.77 \\
\hline $90^{\circ} \mathrm{C}-\mathrm{SDW}^{\mathrm{C}}$ & 88.68 & 51.80 & 29.53 \\
\hline $60^{\circ} \mathrm{C}-\mathrm{SCW}^{\mathrm{c}}$ & 14.36 & 10.61 & 6.77 \\
\hline $90^{\circ} \mathrm{C}-\mathrm{SCW}^{\mathrm{C}}$ & 9.35 & 6.84 & 3.69 \\
\hline
\end{tabular}

a DTN: MO0312SPAPCEML.003 [DIRS 167409], atmospheric.xIs, tab "lab results (100\%RH)."

b This item's source (DTN: LL980704605924.035) is qualified for intended use in Appendix D and calculated in Output DTN: MO0407SPAPCEML.005, atmospheric.xls, tab "mild-structural-carbon steel."

c DTN: MO0409SPAACRWP.000 [DIRS 172059], aqueous-A516.xls. 


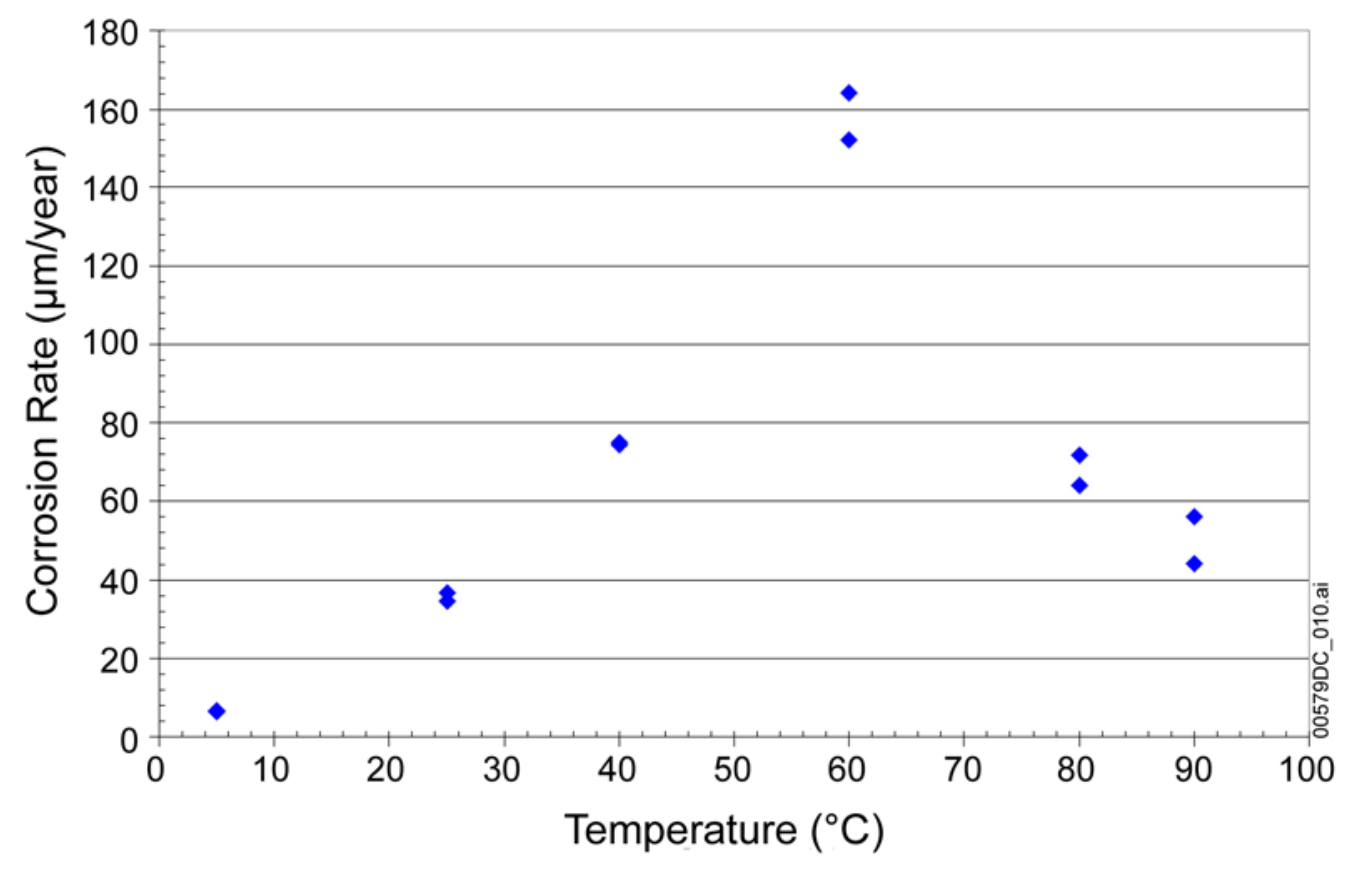

Source: DTN: MO0409SPAACRWP.000 [DIRS 172059], aqueous - A516.xIs.

Figure 6.4-2. Corrosion Rates for Mild Steel in Water, Plotted as a Function of Temperature $\left({ }^{\circ} \mathrm{C}\right)$

\subsubsection{Material Lifetimes}

The expected lifetime of the introduced materials in the repository will be influenced by environmental parameters such as temperature, relative humidity, and available oxygen. Due to the variability of the in-drift environment, the corrosion rates are compiled into Table 6.4-8 by finding the maximum corrosion rate to represent each of the rate categories (maximum or 95\%, mean or $50 \%$, and minimum or $5 \%$ ) for aqueous and atmospheric conditions. The "Comments" column in Table 6.4-8 indicates the conditions under which the corrosion occurred.

The materials that corrode away within a few hundred years (the low-alloy carbon steel) will consume oxygen at the greatest rate and form oxides that will settle in the drift. It is anticipated that the remaining materials will last long enough to potentially interact with crown seepage water entering the drift and possibly influence the chemistry of those waters.

The long-lasting component most likely to interact with crown seepage is the stainless steel ground support along the crown of the drift, and this interaction is explicitly analyzed in Section 6.8 and found to have an insignificant impact on water chemistry.

The analysis in Section 6.8 uses the Stainless Steel Type $316 \mathrm{~L}$ mean corrosion rates of $0.113 \mu \mathrm{m} / \mathrm{yr}$ (steam and atmospheric) and $1.939 \mu \mathrm{m} / \mathrm{yr}$ (fresh or salt water) from Table 6.4-8 as direct input for the analysis of Stainless Steel Type 316L in Section 6.8.3. The availability of oxygen, as decreased by corrosion in the drift, is addressed in Section 6.7. The mean corrosion rate of $195.44 \mu \mathrm{m} / \mathrm{yr}$ for carbon or low alloy steels (Table 6.4-8) is used as direct input for calculating the availability of oxygen in Section 6.7. 
Table 6.4-8. Selected Corrosion Rates of Metallic and Alloy Materials for Use in Engineered Barrier System Chemical Environment Calculations

\begin{tabular}{|c|c|c|c|c|c|c|}
\hline Material & $\begin{array}{c}\text { Environmental } \\
\text { Conditions }\end{array}$ & $\begin{array}{c}\text { Maximum } \\
\text { Corrosion } \\
\mu \mathrm{m} / \mathrm{yr}\end{array}$ & $\begin{array}{c}\text { Mean } \\
\text { or 50th } \\
\text { Percentile } \\
\text { Corrosion } \\
\mu \mathrm{m} / \mathrm{yr} \\
\end{array}$ & $\begin{array}{c}\text { Minimum } \\
\text { Corrosion } \\
\mu \mathrm{m} / \mathrm{yr}\end{array}$ & Reference & Comments \\
\hline $\begin{array}{l}\text { Titanium } \\
\text { (Grade 16) }\end{array}$ & $\begin{array}{l}\text { Water Dripping } \\
\text { Case (Seepage } \\
\text { Environment) }\end{array}$ & 0.113 & 0.0237 & 0.00418 & Table $6.4-1$ & 50th percentile corrosion used, not the mean \\
\hline Alloy 22 & $25^{\circ} \mathrm{C}$ & 0.0058 & 0.0024 & 0.0005 & Table 6.4-2 & 50th percentile corrosion used, not the mean \\
\hline Alloy 22 & $100^{\circ} \mathrm{C}$ & 0.0477 & 0.0193 & 0.0039 & Table $6.4-2$ & 50th percentile corrosion used, not the mean \\
\hline Alloy 22 & $150^{\circ} \mathrm{C}$ & 0.1278 & 0.0518 & 0.0104 & Table 6.4-2 & 50th percentile corrosion used, not the mean \\
\hline Copper Alloy & $\begin{array}{l}\text { Steam and } \\
\text { Atmospheric }\end{array}$ & 6.60 & 4.79 & 3.15 & Table 6.4-3 & $\mathrm{J}-13$ steam, $95^{\circ} \mathrm{C}$ to $100^{\circ} \mathrm{C}$, near $100 \% \mathrm{RH}$ \\
\hline Aluminum Alloy & $\begin{array}{l}\text { Fresh/Salt } \\
\text { Water }\end{array}$ & 110.91 & 12.95 & 0.4 & Table 6.4-4 & Saltwater for maximum, fresh water for mean and minimum \\
\hline $\begin{array}{l}\text { Stainless Steel } \\
\text { Type 316L }\end{array}$ & $\begin{array}{l}\text { Steam and } \\
\text { Atmospheric }\end{array}$ & 0.517 & $0.113^{a}$ & 0.099 & Table 6.4-6 & $\begin{array}{l}\text { Marine atm for maximum and mean and } 100^{\circ} \mathrm{C} \mathrm{J} 13 \text { steam } \\
\text { for minimum (data for } 207^{\circ} \mathrm{C} \text { brine steam not included) }\end{array}$ \\
\hline $\begin{array}{l}\text { Stainless Steel } \\
\text { Type 316L }\end{array}$ & $\begin{array}{l}\text { Fresh/Salt } \\
\text { Water }\end{array}$ & 14.787 & $1.939^{b}$ & 0.2286 & Table 6.4-6 & $\begin{array}{l}26.7^{\circ} \mathrm{C} \text { saltwater for maximum and mean and } 70^{\circ} \mathrm{C} \\
\text { freshwater for minimum }\end{array}$ \\
\hline $\begin{array}{l}\text { Carbon or Low } \\
\text { Alloy Steels }\end{array}$ & $\begin{array}{l}\text { Steam and } \\
\text { Atmospheric }\end{array}$ & $1,057.18$ & $195.44^{\mathrm{a}}$ & 85.5 & Table 6.4-7 & $\begin{array}{l}\text { Maximum marine atm } 70 \text { to } 80 \% \mathrm{RH} \text {, mean } \mathrm{SCW} 90^{\circ} \mathrm{C} \\
\text { steam, and minimum industrial atm. Over } 80 \% \mathrm{RH}\end{array}$ \\
\hline $\begin{array}{l}\text { Carbon or Low } \\
\text { Alloy Steels }\end{array}$ & Simulated Water & 106.93 & 77.43 & 65.77 & Table 6.4-7 & $60^{\circ} \mathrm{C} \mathrm{SDW}$ for all \\
\hline
\end{tabular}

Sources: DTN: MO0312SPAPCEML.003 [DIRS 167409] (indirect only) and MO0409SPAACRWP.000 [DIRS 172059]; only bolded items are used further as direct input. Source for titanium corrosion rates is BSC 2004 [DIRS 169845; Table 17]. Source for Alloy 22 corrosion rates is DTN: MO0409MWDUGCMW.000; [DIRS 171714] Base Case GC Rate CDF.xls, tab "Base Case GC Rate."

a Item's source is qualified for modeling use (Appendix D); contained within the Output DTN: MO0407SPAPCEML.005.

b DTN: MO0409SPAACRWP.000 [DIRS 172059], aqueous-316L.xIs, tab "saltwater." 
Figure 6.4-3 shows the mean (or 50th percentile), minimum, and maximum lifetimes of materials listed in Table 6.4-8. These material lifetimes are presented on a per centimeter basis as that distance is an excellent proxy for general material thickness, within an order of magnitude. Specifically, material lifetimes were hand calculated by dividing $10,000 \mu \mathrm{m} / \mathrm{cm}$ conversion by the mean or 50th percentile, minimum, and maximum corrosion rates $(\mu \mathrm{m} / \mathrm{yr})$ for each material given in Table 6.4-8. For example, the minimum corrosion rate for titanium (Grade 16) given in Table $6.4-8$ is $0.00418 \mu \mathrm{m} / \mathrm{yr}$; thus, by dividing $10,000 \mu \mathrm{m} / \mathrm{cm}$ by $0.00418 \mu \mathrm{m} / \mathrm{yr}$, the maximum lifetime for titanium is calculated to be approximately $2.392 \times 10^{6} \mathrm{yr} / \mathrm{cm}$ of material.

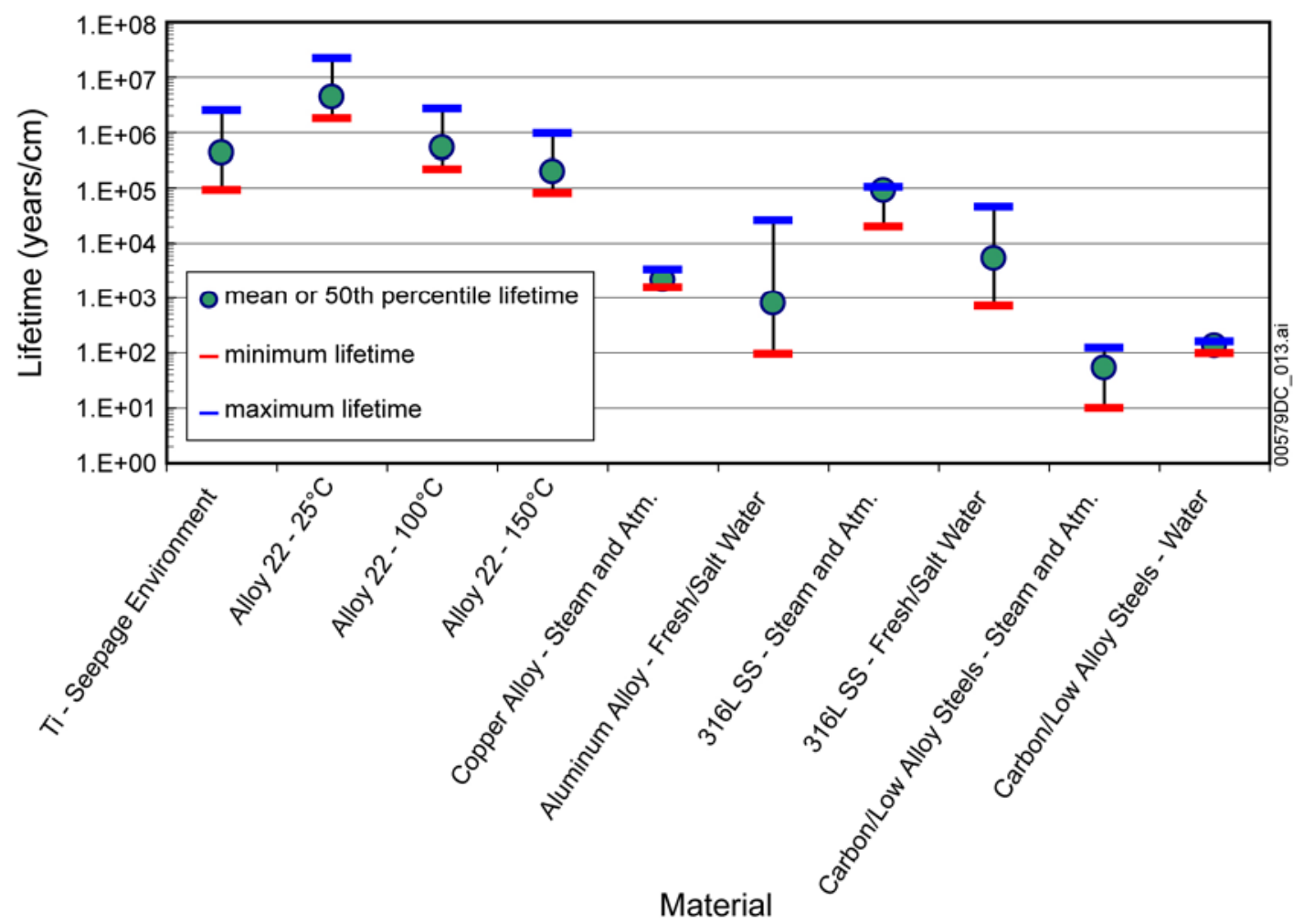

Figure 6.4-3. Relative Material Lifetimes Using the Mean or 50th Percentile, Minimum, and Maximum Corrosion Rates from Table 6.4-8.

As can be seen by Figure 6.4-3, the mean lifetime values for carbon or low-alloy steels in a steam and atmospheric environment is over one order of magnitude less than any other material. This comparison leads to the conclusion that for modeling of oxygen consumption, due to and proportional to corrosion, the most significant consumption from low-alloy or carbon steels will lead to a reasonable approximation of the total oxygen demand. The oxygen balance calculation based upon this is performed in Section 6.7.1.

\subsection{GEOCHEMICAL MODELING CONSTRAINTS}

This section summarizes the main set of mathematical models used in this report and establishes a modeling framework for developing equilibrium-type geochemical models in systems under metastable or partial equilibrium. This section can be thought of as a supplement to the conceptual model outlined in Section 6.2. It is also intended to demonstrate the importance of 
mineral and species suppression (i.e., the way equilibrium models are used to predict chemical conditions in metastable systems), which is a fundamental modeling concept of this report. Some sensitivity studies discussing the uncertainties associated with this concept are further evaluated in Section 6.12.4.

\subsubsection{Mathematical Models Implemented by the Use of EQ3/6 V8.0 Geochemical Modeling Software}

Geochemical modeling constraints are imposed by the primary geochemical modeling software used in this report, EQ3/6 V8.0 (BSC 2003 [DIRS 162228]). This software is composed of two independent codes: EQ3NR and EQ6. Both of these are described in general terms in the following subsections, much of which is derived from Software User's Manual EQ3/6 Version 8.0 (SNL 2003 [DIRS 162494], Appendices B and D). The reader is referred to the EQ3/6 software users manual for a more detailed explanation of the concepts discussed in the following paragraphs.

\subsubsection{EQ3NR: Speciation-Solubility Modeling of Aqueous Systems}

EQ3NR (BSC 2003 [DIRS 162228]; see Section 3.1) is an equilibrium speciation-solubility code for aqueous systems. As such, given sufficient data for a chemical species to characterize a specific aqueous system, it computes a model of the solution that consists of two principal parts: the distribution of species in the solution and a set of saturation indices $(S I=\log Q / K)$ for various reactions of interest. The saturation indices measure the degree of disequilibrium of corresponding solution-mineral reactions. They provide a means for evaluating solubility controls on natural waters. For example, at equilibrium the $\mathrm{SI}=0$, but under close to equilibrium conditions where a series of related fluids all have a given mineral SI value close to zero, it is probable that this mineral is present and partial equilibrium with this mineral is maintained as the solutions evolve in composition.

EQ3NR (BSC 2003 [DIRS 162228]; see Section 3.1) is not a specific computerized geochemical model, but a software code that is useful in evaluating many different conceptual geochemical models, which are defined by the contents of a supporting thermodynamic data file (from which there are now several to choose, including data0.ymp.R2 and data0.ypf.R0) and by other user-defined inputs and constraints in the EQ3NR input file. The supporting thermodynamic data files differ not only in terms of data values but also, more importantly, in terms of the identities of the components and chemical species represented, and in terms of the general approaches used in the estimation of activity coefficients. Because of various limitations (such as the use of the Pitzer model for estimation of activity coefficients), some problems may require the use of only certain data files, while others can be treated using any of the available data files.

Although speciation-solubility models are commonly used as a means of testing whether heterogeneous reactions are in a state of thermodynamic equilibrium, they often just assume that all reactions occurring in aqueous solution are in such a state. Reactions most likely to be in disequilibrium are redox reactions or reactions for the formation or dissociation of large complexes that are more like small polymers, such as $\left(\mathrm{UO}_{2}\right)_{3}(\mathrm{OH})_{7}^{-}$. Speciation-solubility 
models are better used when they are employed to test the degree of disequilibrium of these kinds of reactions than when these are assumed to be in equilibrium.

An equilibrium speciation-solubility model cannot, by itself, predict how aqueous solution composition will change in response to rock-water interactions. Nevertheless, this type of modeling can be a powerful tool for elucidating such interactions when it is applied to a family of related waters. Such a family might be a set of spring waters issuing from the same geologic formation, a sequence of groundwater samples taken along an underground flow path, or a sequence of water samples taken in the course of a rock-water interactions experiment in the laboratory. Jenne (1981 [DIRS 162479]) reviews several studies of this kind. Particularly interesting are the Nordstrom and Jenne (1977 [DIRS 162480]) study of fluorite solubility equilibria in geothermal waters and the Nordstrom et al. (1979 [DIRS 162508]) study of controls on the concentration of iron in acid mine waters. EQ3NR (BSC 2003 [DIRS 162228]; see Section 3.1) offers many options for the input file description of a given water chemistry's composition. Consequently, the code can be used in a variety of ways.

Many of the descriptive parameters of interest can be either model inputs or outputs. For example, the $\mathrm{pH}$ of a buffer solution can be calculated from the buffer recipe by adjusting the hydrogen ion concentration to satisfy charge balance. Alternatively, adjusting the concentration of a buffer component to satisfy the charge balance is a means of computing the complete recipe for a buffer having a desired $\mathrm{pH}$. Some possible model inputs may be constraints, as in specifying equilibrium with one or more specified mineral phases.

\subsection{Input Constraints, Governing Equations, and Outputs}

Aqueous speciation models can be constructed to satisfy a variety of combinations of possible input constraints and governing equations. The input constraints may include:

- Total (analytical) concentrations

- An electrical balance requirement

- Mass balance

- Free ion concentrations

- Aqueous species activities

- $\mathrm{pH}$

- Eh

- pe

- Oxygen pressure

- Phase equilibrium requirements

- Homogeneous equilibria

- Run-specific values for equilibrium constants.

The governing equations are the corresponding mathematical expressions, such as the mass-balance equation and the charge-balance equation.

The choice of governing equations in large part depends on which parameters are to be inputs to the model, and which are to be outputs. This, in turn, is a function of what data on a given water are available, what form they are in, and what constraints the modeler would like to use. 
Chemical analysis mainly provides a set of values for the so-called total concentrations of dissolved components. The analytical value for an ion such as calcium is an example. It does not discriminate between the various calcium species in solution, but rather estimates the dissolved calcium contributed by all of them. This leads to a mass-balance equation of the form:

$$
m_{\mathrm{T}, \mathrm{Ca}}=m_{\mathrm{Ca}^{2+}}+m_{\mathrm{CaOH}^{-}}+m_{\mathrm{CaCO}_{3}(\mathrm{aq})}+m_{\mathrm{CaHCO}_{3}{ }^{+}}+\ldots
$$

where $m_{T, C a}$ is the total or analytical concentration (on the molal scale) and $m_{i}$ is the molality of any individual chemical species contributing to the mass balance. The summations must be weighted by the appropriate stoichiometric equivalences; for example, in the case of $\mathrm{F}^{-}$:

$$
m_{T, F}=m_{F^{-}}+m_{H F(a q)}+2 m_{H_{2} F_{2}(a q)}+2 m_{H_{2}^{-}}+3 m_{A l F_{3}(a q)}+\ldots
$$

The total concentration is the most common type of input parameter to an aqueous speciation model. Therefore, the most common governing equation is the mass balance constraint. As will be seen, there are situations in which a total concentration is replaced by another type of input such as the use of the input flag "heterogeneous equilibrium," where an aqueous concentration can be calculated from a gas pressure. In these cases, the mass-balance constraint is replaced by a different governing equation, and the total concentration becomes something to be calculated (an output parameter). Charge balance is also a common governing concept that will either calculate the apparent charge imbalance or force the aqueous solution to maintain electrical balance. Large charge imbalance errors indicate there may be incomplete or erroneous chemical analysis or a misinterpretation of reported analytical results.

Mathematically, there is no reason to discriminate among ion pairs (and ion triplets, etc.) and complexes. For some investigators, the term "ion pair" implies a species in which an anion is separated from a cation by an unbroken hydration sheath about the latter, whereas the term "complex" implies direct contact and perhaps some degree of covalent bonding. Other investigators use these terms interchangeably. It is a general presumption in cases of geochemical interest that the concentrations of ion pairs and complexes are governed by thermodynamic equilibrium.

Each case of this equilibrium can be represented by a mass-action equation for the dissociation of the ion pair or complex. As an example, the calcium sulfate ion pair dissociates according to the reaction:

$$
\mathrm{CaSO}_{4}(a q)=\mathrm{Ca}^{2+}+\mathrm{SO}_{4}^{2-}
$$

where " $=$ " is used as the sign for a reversible chemical reaction. The corresponding mass-action equation is:

$$
\mathrm{K}_{\mathrm{CaSO}_{4}(a q)}=\frac{a_{\mathrm{Ca}^{2+}} a_{\mathrm{SO}_{4}^{2-}}}{a_{\mathrm{CaSO}_{4}(a q)}}
$$


where $K$ is the equilibrium constant and $a_{i}$ represents the thermodynamic activity of each species. This may also be written in logarithmic form:

$$
\log \mathrm{K}_{\mathrm{CaSO}_{4}(\mathrm{aq})}=\log a_{\mathrm{Ca}^{2+}}+\log a_{\mathrm{SO}_{4}^{2-}}-\log a_{\mathrm{CaSO}_{4}(\mathrm{aq})}
$$

The thermodynamic activity is related to the molal concentration by the relation:

$$
a_{i}=m_{i} \gamma_{i}
$$

where $\gamma_{i}$ is the activity coefficient, a function of the composition of the aqueous solution. As the solution approaches infinite dilution, the value of $\gamma_{i}$ for each species approaches unity. The user, in the EQ3/6 input calculation file, chooses the set of equations for computing the activity coefficients of aqueous species. The requisite supporting data are on the EQ3/6 database file. The activity of pure mineral phases is specified to be at unity.

\subsection{Activity Coefficient Models of Aqueous Species}

The thermodynamic activities $\left(a_{i}\right)$ of aqueous solute species are usually defined on the basis of molalities. Thus, they can be described by the product of their molal concentrations $\left(m_{i}\right)$ and molal activity coefficients $\left(\gamma_{i}\right)$, as shown in Equation 6.5-6.

The thermodynamic activity of the water $\left(a_{w}\right)$ is always defined on a mole-fraction basis. Thus, it can be described analogously by the product of the mole fraction of water $\left(x_{w}\right)$ and its mole-fraction activity coefficient $\left(\lambda_{w}\right)$ :

$$
a_{w}=x_{w} \lambda_{w}
$$

The activity coefficients, in reality, are complex functions of the composition of the aqueous solution. In electrolyte solutions, the activity coefficients are influenced mainly by electrical interactions. Much of their behavior can be correlated in terms of the ionic strength, defined by:

$$
I=\frac{1}{2} \sum_{i} m_{i} z_{i}^{2}
$$

where the summation is over all aqueous solute species and $z_{i}$ is the electrical charge. However, the use of the ionic strength as a means of correlating and predicting activity coefficients has a very limited range of usefulness (e.g., in the mean-salt method used by Garrels and Christ 1965 [DIRS 144877], pp. 58 to 60). A comparison between the mean-salt method of Garrels and Christ and the classical Debye-Hückel activity model (Garrels and Christ 1965 [DIRS 144877], Figure 2.15 , p. 63) shows a reasonable agreement up to an ionic strength of 0.05 to 0.1 depending on the ion. In general, model equations that express the dependence of activity coefficients on solution composition only in terms of the ionic strength are restricted in applicability to dilute solutions. 
The three basic options for computing the activity coefficients of aqueous species in EQ3/6 calculations are models based on the Davies (1962 [DIRS 162482]) equation, the Hückel equation, also known as the "B-dot" equation (Helgeson 1969 [DIRS 137246]), and Pitzer's equations (1973 [DIRS 152738]; 1975 [DIRS 152740]; 1979 [DIRS 119530]; 1987 [DIRS 162481]). The first two models, owing to limitations on accuracy, are only useful in dilute solutions (generally up to ionic strengths of 1 molal, although extension for specific application is possible). The third basic model is useful in highly concentrated as well as dilute solutions, but is limited in terms of the components that can be accurately treated, as defined by the input database. Calculations of relevance to this report were performed with either B-dot or Pitzer activity models.

With regard to temperature and pressure dependence, all of the following models are parameterized along the standard $\mathrm{EQ} 3 / 6$ curve, which is 1.013 bar up to $100^{\circ} \mathrm{C}$ and the steam-liquid water equilibrium curve at higher temperatures.

All EQ3/6 calculations in this report, with the exception of the calculations performed in Section 6.8, use the Pitzer activity model, the usual formulation of which implies (in the absence of other action) a nonstandard "Pitzer" $\mathrm{pH}$ scale. However, the results of this report are presented in terms of National Bureau of Standards $\mathrm{pH}$. The primary users of the output of this model are using its calculated $\mathrm{pH}$ values to represent input parameters to models established on laboratory measurements using National Bureau of Standards $\mathrm{pH}$ standards. The same measurement standard is true for values of $\mathrm{pH}$ input into EQ3/6 calculations (if a scale for $\mathrm{pH}$ output is chosen, any $\mathrm{pH}$ input is thought to be on the same scale). This $\mathrm{pH}$ scale conversion is done internal to EQ3/6 software (BSC 2003 [DIRS 162228]) following the discussion outlined in Software User's Manual EQ3/6 Version 8.0 (SNL 2003 [DIRS 162494], Attachment B, Equation B-99).

\subsubsection{EQ6: Reaction-Path and Single-Point Modeling}

EQ6 computations can first be broken down into "single-point" thermodynamic equilibrium calculations and irreversible mass transfer reaction-path calculations. A single-point thermodynamic calculation is essentially just the special case of a reaction path with no steps (e.g., used when precipitating supersaturated phases or making a temperature jump). Reaction paths may be calculated for titrations, irreversible reaction in closed systems, and irreversible reaction in certain well-defined types of open systems (e.g., a fluid-centered flow-through open system). Such calculations may be in reaction progress mode (time independent) or time mode (explicit kinetic or time dependent), depending on the rate law being implemented.

EQ6 (BSC 2003 [DIRS 162228]; see Section 3.1) uses separate methodologies for treating intrinsically algebraic equations and intrinsically differential equations. The former govern the thermodynamic calculations, and the latter consist of rate laws for irreversible processes. This numerical decoupling makes it possible to perform thermodynamic calculations, given the necessary inputs of total number of moles of components, the temperature, and the pressure, independently of the integration of rate equations. This decoupling permits making "singlepoint" thermodynamic equilibrium calculations, such as temperature jump problems, in which rate equations do not appear. 
In EQ6 reaction-path models, the two types of equations are coupled in the mathematically formal sense, but the solution of each is performed semi-independently. Each calculation type is performed alternately, the output of one becoming the input to the next execution of the other. For example, in moving a step forward in reaction progress $(\xi)$, rate equations are integrated. This defines new values for the temperature, pressure, and total number of moles of the components, which are inputs to the following thermodynamic calculation. This, in turn, gives a new distribution of species from which values may be calculated for the rates of the irreversible processes at the new point. If accuracy tests on the ordinary differential equation integration are satisfied, these rate values are used in making the next integration step. Otherwise, the step size may be cut until those tests are satisfied.

When the rate chosen to constrain an irreversible process is a relative rate $\left(d \xi_{j} / d \xi\right)$, the rate function is either a constant or a simple function of the overall reaction progress variable $(\xi)$. When EQ6 (BSC 2003 [DIRS 162228]; see Section 3.1) operates in the mode of arbitrary kinetics (all irreversible processes constrained by relative rate expressions; no time variable in the model), these rates can be integrated by simple closed-form expressions. It is, therefore, possible to take arbitrarily large step sizes, subject only to the following conditions.

In the case of closed and open system calculations, the rate of an irreversible reaction is set to zero when the corresponding thermodynamic driving force, the affinity, is no longer positive. Affinities are outputs of the thermodynamic calculations. EQ6 (BSC 2003 [DIRS 162228]; see Section 3.1) locates the point of reaction progress where the affinity goes to zero. If the corresponding reactant is a mineral, this means that the aqueous solution has reached saturation. The code then changes the status of the reactant to inactive (meaning it is effectively removed from the set of reactants) and any remaining mass of the reactant is moved into the equilibrium system. Titration calculations are very similar to closed-system calculations, but the rate of an irreversible reaction is not set to zero when saturation is reached, and the remaining reactant mass continues to be added to the equilibrium system according to the rate law.

The rate of an irreversible reaction rate also becomes zero when the associated "reactant" becomes exhausted, no matter what kind of system model the code is dealing with. The user specifies how much of a reactant is available at the start of the calculation run. The code then finds the point of reaction progress at which exhaustion occurs.

\subsection{Constraints on Thermodynamic Calculations}

The following thermodynamic constraints are enforced in EQ6 calculations:

- Mass balance

- Charge balance

- Law of mass action

- Activity coefficients of aqueous species

- Activity coefficients of solid solution components

- Saturation indices and affinities.

Details on each of these can be found in Software User's Manual EQ3/6 Version 8.0 (SNL 2003 [DIRS 162494], Appendix D1.2). 


\subsection{Constraints on Reaction Path Calculations}

The following reaction path constraints are enforced in EQ6 calculations:

- Reaction progress variable $(\xi)$, which is a measure of the extent to which a reaction has proceeded

- Reaction rates and time for each irreversible reaction as a function for either the relative rate or the absolute rate

- Rate laws programmed into EQ6: relative rate, partial equilibrium, transition-state theory, and linear rate.

Details on each of these can be found in Software User's Manual EQ3/6 Version 8.0 (SNL 2003 [DIRS 162494], Appendix D1.3).

\subsubsection{Geochemical Modeling Methodology}

Generally, a reaction path geochemical equilibrium model is constructed using the steps outlined in Figure 6.5-1. First, a conceptual model is defined where the chemical system and state are defined. This system and state are tested and investigated to produce results. Those results are compared with independent experimental, natural analogue, or other modeling data to ensure that the model is representative of the system and state to be analyzed.

Decisions about mineral suppression or inclusion require:

- A reasonable understanding of mineralogy and petrology

- A well-researched conceptual model

- An understanding of how to develop a reaction-path model using software codes like EQ3/6 (Wolery 1992 [DIRS 100836]; Wolery and Daveler 1992 [DIRS 100097]), PHREEQC (Parkhurst 1995 [DIRS 142177]), or MINTEQA2 (HydroGeoLogic and Allison Geoscience Consultants 1999 [DIRS 158974])

- An understanding of how to ensure that confidence exists in the model and that model uncertainty has been appropriately addressed.

The following subsection contains a brief summary of the kinetics versus equilibrium relations rationale that must be considered in the selection of mineral phases for the model. Bethke (1996 [DIRS 162270]), Smith and Missen (1991 [DIRS 161602]), and Van Zeggeren and Storey (1970 [DIRS 161603]) provide more-detailed discussions concerning modeling methodology aspects.

\subsubsection{Equilibrium versus Kinetics}

Bethke (1996 [DIRS 162270], Chapter 2) reports two main types of equilibrium end states that are important to recognize in reaction path modeling: complete and metastable equilibrium. In 
complete equilibrium, the chemical state of the system attains stable equilibrium such that there is no chemical potential to drive any net chemical reaction. Usually, when an equilibrium model is first constructed, the first-order model (Figure 6.5-1) is allowed to go to complete equilibrium. When the initial system is constrained based on the end equilibrium state by determining variables such as the temperature, dissolved aqueous concentrations, quantity of given minerals in the system, or the fugacities of any gases, the calculation results in a fluid saturated with respect to the stable equilibrium mineral assemblage for the system.

Once this first-order model is constructed, the boundary conditions and the conceptual model are evaluated to determine whether various states of metastable equilibrium should be taken into account (Section 6.5.5). The first-order model is then refined to account for these effects. For example, if the model predicts the complete equilibrium state to include minerals that do not occur in the actual system, this may imply that a metastable equilibrium situation exists in the actual system.

Metastable equilibrium occurs when one or more chemical reactions proceed toward equilibrium at a rate that is so small on the time scale of interest that the system does not reflect the consequences of reaction with that phase. In this case, the system can be considered not to include the reaction(s) involving that mineral. Such reactions are commonly heterogeneous reactions involving mineral precipitation. That is, the nucleation or growth of the mineral is subject to kinetic barriers that are large enough to preclude, or allow only negligible progress of, the reaction. In such a case, the mineral that should exert an equilibrium compositional constraint is supplanted by another, less stable, phase that is not kinetically constrained from forming and growing.

In other words, mineral suppression is used in equilibrium calculations to represent, in a simple manner, the fact that some solid phases are kinetically inhibited from precipitating or dissolving under equilibrium conditions in certain environments (e.g., quartz precipitation at low temperature). Because of the kinetic constraints, the chemical constituents commonly controlled by the inhibited solid phase are controlled instead, if at all, by a somewhat less-stable phase that reaches its metastable equilibrium rapidly compared to the inhibited phase. Inclusion of the explicit kinetic approaches would handle mineral dissolution or precipitation directly, but for simpler equilibrium calculations this is commonly handled by suppressing the occurrence of a mineral phase in the model to represent the kinetic barrier and to achieve the same result found in real systems. Suppression of minerals, therefore, is a practical tool in being able to define the end-state equilibrium of a modeled system or to use an equilibrium-type model to mimic the effect of kinetic processes without having to know actual details about the kinetic rates of dissolution or precipitation. 


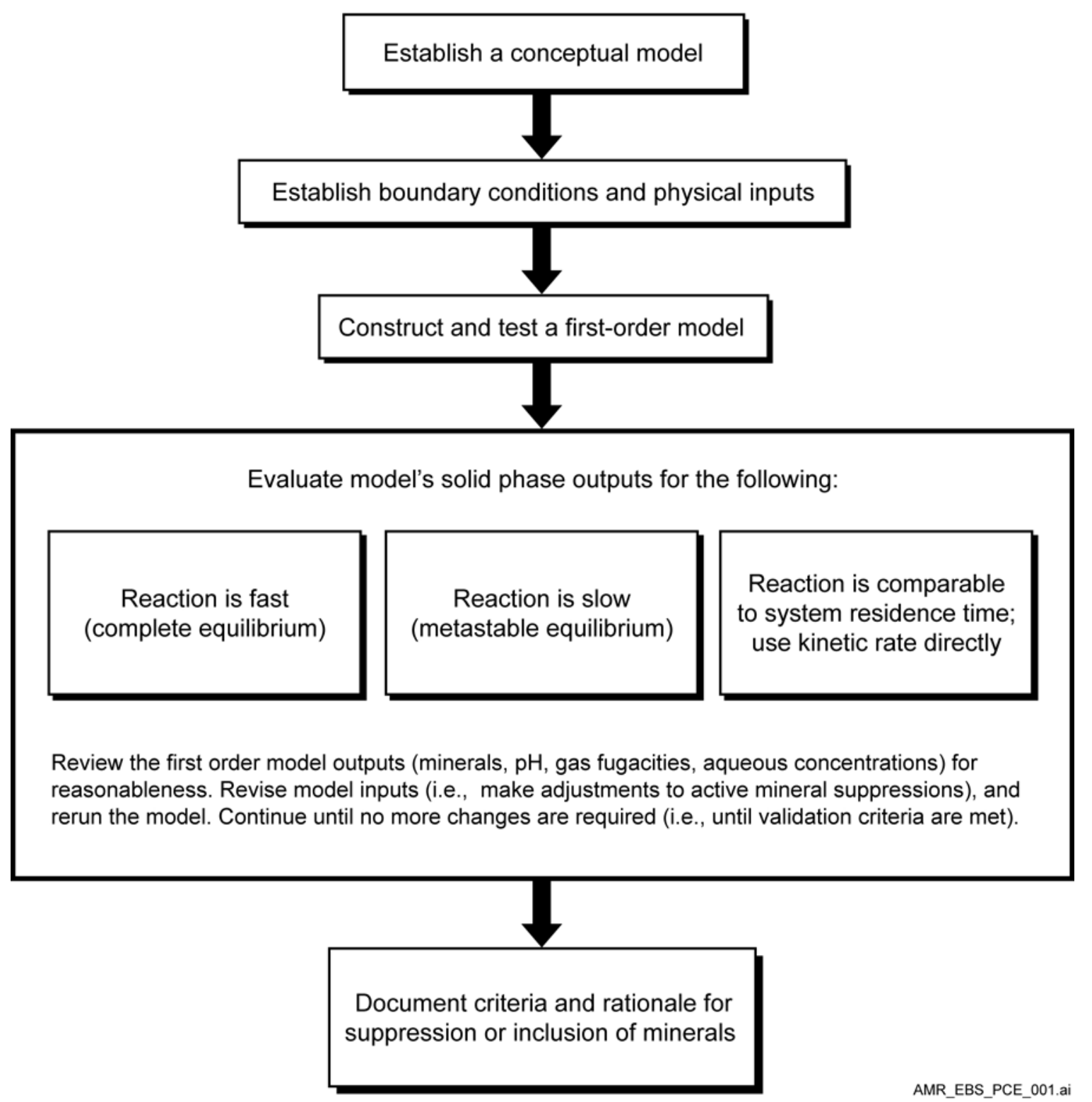

NOTE: A first order model is a model that accounts for complete equilibrium (i.e., no metastable equilibrium or kinetic controls) with no active mineral suppressions.

Figure 6.5-1. Simplified Roadmap of the Process Required to Give a Valid Technical Basis for Mineral Suppression or Inclusion in Geochemical Equilibrium Modeling

Partial equilibrium and local equilibrium are specific cases or subsets of metastable equilibrium that can have relevance to a given geochemical problem. Partial equilibrium (also known as heterogeneous equilibrium) is defined by Wolery and Daveler (1992 [DIRS 100097]) such that some (usually most) reactions are in a state of equilibrium, while others, usually few in number and representing heterogeneous processes such as mineral dissolution or precipitation, are not. For example, the fluid in sandstone might be in equilibrium itself but may not be in equilibrium with the mineral grains in the sandstone or with just some of the grains. Local equilibrium, which is sometimes called mosaic equilibrium (i.e., temperature, mineralogy, or fluid chemistry 
vary across the system of interest), can be thought of as a system that is open to groundwater flow (Bethke 1996 [DIRS 162270], p. 12). In this idealized flow through system, the aqueous phase moves over or through several different mineral assemblages and the water reacts with each of these and achieves some degree of equilibrium on the local scale with each assemblage, even though each location is at a different equilibrium state comparatively. All of these various types of equilibrium conditions can be combined into a single model, depending on the conceptual model.

Kinetics can be combined into reaction path modeling because the equilibrium point of a reaction is the point at which dissolution and precipitation rates balance. Bethke (1996 [DIRS 162270], Chapter 2) indicates that kinetic reactions fall into three groups:

- Those in which reaction rates are so slow relative to the period of interest that the reaction can be ignored (i.e., accounting for metastable equilibrium). This slow reaction rate group commonly corresponds to what mineral suppression is used to represent.

- Those fast enough to maintain equilibrium (accounting for complete equilibrium).

- All other reactions that do not fall into the first two groups. These "other reactions" are the only reactions that require a kinetic description.

\subsubsection{Engineered Barrier System Geochemical Equilibrium Modeling}

The equilibrium reaction path models used by the P\&CE model are designed to predict long-term chemical processes within a potential repository drift. Although short-term occurrences (such as seepage water falling onto the drip shield) can cause transitory divergence from the conceptualized state of metastable equilibrium, an equilibrium approach is adopted because it provides valuable insight into long-term processes. This modeling provides the exposure conditions needed by General Corrosion and Localized Corrosion of Waste Package Outer Barrier (BSC 2004 [DIRS 169984], Section 6.4.4); specifically, these are $\mathrm{pH}$, and chloride and nitrate ion concentrations.

An equilibrium reaction-path model, such as that implemented using the EQ6 (BSC 2003 [DIRS 162228]; see Section 3.1), relies on a thermodynamic database that contains standardstate thermochemical parameters of the different chemical species in a system to determine the chemical reaction equilibria as functions of the changing conditions. In addition to the homogeneous reactions that occur within each phase (e.g., water, gas, solid), there are heterogeneous reactions that involve more than one phase, such as mineral precipitation and degassing of volatile constituents from the aqueous phase. Most of the reactions in the equilibrium models employed by the P\&CE model are rapid relative to the timeframe of the modeling period; therefore, most reactions are allowed to reach equilibrium. However, there are many minerals in the thermodynamic database that will not form under the expected conditions of the repository. These minerals predominantly include those that require high pressures or very high temperatures to achieve the kinetic rates of formation that would produce a significant mass within the modeling time frame. Other minerals that could be excluded from consideration are those that form during the oxidation of pyrite or other sulfide minerals, which form only under redox conditions that will not occur in the repository (Section 6.7.1). 
The pressure in the repository is expected to remain near atmospheric, and the temperature at the drift wall is not expected to rise above $200^{\circ} \mathrm{C}$ (Figure 6.7-5). These conditions limit those minerals in the database that can realistically be expected to form at a significant rate. As discussed previously, an equilibrium model ignores the use of kinetic rates; it predicts the most stable mineral phases at equilibrium, except when the user suppresses (i.e., rules out) those minerals. When precipitation is suppressed for a mineral, the equilibrium model does not allow the mineral to precipitate, resulting in a condition of supersaturation with respect to that phase. In this way, the equilibrium model can incorporate simplified kinetic constraints as metastable equilibrium conditions. Current conceptualization of postclosure drift conditions allows for conditions in the repository to be essentially dry. Any seepage entering the drift would be subject to conditions in which the relative humidity or activity of water would fall below one. Therefore, evaporative processes are expected to dominate during the evolution of in-drift seepage.

\subsubsection{Modeling of Mineral Precipitation}

The Pitzer thermodynamic database (data0.ypf.R0 in DTN: SN0302T0510102.002 [DIRS 162572]) currently includes more than 220 minerals, but only a small fraction of these have been suppressed in the modeling run calculations evaluated to date. It is unnecessary to identify a priori which of the more than 220 minerals should be suppressed for these calculations. The limited range of chemical compositions of the waters likely to occur within the drift dictates that a majority of the more than 220 minerals will never achieve a chemical potential favoring precipitation. This point is demonstrated by the results to date. So far, over 368 different observed and predicted water compositions at Yucca Mountain have been evaporated to dryness using EQ3/6 V8.0 (BSC 2003 [DIRS 162228]) and the new Pitzer database (Section 6.6), yet fewer than 40 minerals have become saturated or supersaturated with respect to the aqueous composition. Thus, it is not necessary to categorize the remaining 180-plus minerals according to their potential for precipitating under drift conditions.

Having some sort of simple criteria to appropriately suppress or include the approximately 40 minerals that have become saturated in the engineered barrier system models being developed for TSPA-LA facilitates determining the end equilibrium state in a model. Six criteria have been developed to assist in determining the rationale for suppression or inclusion in the models to account for the kinetic or metastable equilibrium arguments stated previously. These six criteria are listed in the following paragraphs.

Criterion 1-Is the mineral of interest beyond or outside the defined chemical system of the model?

If the mineral lies outside or beyond the defined chemical system of the model, there is no reason to include the mineral. For example, while modeling mineral formation at low temperatures and pressures (near ambient), any mineral could be excluded that was known to form only at high temperatures or pressures.

Individuals trained in mineralogy or petrology can readily make these determinations. Example reference sources, used to make these decisions when combined with expert judgment, are Klein and Hurlbut's Manual of Mineralogy (1985 [DIRS 105907]), Kerr's Optical Mineralogy 
(1977 [DIRS 161606]), and Roberts et al.'s Encyclopedia of Minerals, 2nd Ed. (1990 [DIRS 107105]), or any similar reference source that discusses the petrology or mineralogy of a given system or analogue system.

If a mineral is not included in the database, it is, in effect, suppressed. The formation conditions applicable to the great majority of the over 3,000 minerals listed by Roberts et al. (1990 [DIRS 107105]) lie outside the physiochemical boundaries of the repository system. Most of these can be excluded because they contain trace or minor elements of no interest to repository operations, or have been addressed through studies of corrosion and radionuclide solubility. Table $\mathrm{C}-1$ in Appendix $\mathrm{C}$ provides details on an additional 709 minerals that are not in data0.ymp.R2 or data0.ypf.R0; these minerals are not included in the current modeling effort for various reasons as detailed in Table $\mathrm{C}-1$.

Criterion 2-Is the mineral of interest likely or unlikely to precipitate because of kinetic controls?

Langmuir (1997 [DIRS 100051]) provides a general rule of thumb for determining the need for a kinetic description of mineral dissolution or precipitation. When a reaction is irreversible or its rate is comparable to, or slower than, the system residence time (i.e., the half-life is greater than or equal to the residence time), a kinetic rate is needed to describe the state of reaction. When this rule of thumb is met and kinetic data are available, the data are used directly. Often, however, rate data are not available for the system being modeled, or it is much simpler to invoke a state of metastable equilibrium and use a mineral suppression to simplify the model. Therefore, a modeler will make a mineral suppression that mimics the conceptualized state of metastable or localized equilibrium. As an example, one of the most common mineral suppressions used in geochemical modeling is that of considering the kinetic rates of reaction for amorphous silica, quartz, or one of its polymorphs (tridymite and chalcedony). In general, amorphous precipitates will tend to form first, and then a process of mineral recrystallization will take place (Langmuir 1997 [DIRS 100051], p. 55). Therefore, the metastable phase that would generally be used in a reaction path model for quartz would be amorphous silica. If the conceptual model were to account for a longer system residence time or higher temperatures, the modeler would allow quartz or one of its polymorphs to precipitate. For iron oxides, it would be expected that either goethite or ferrihydrite would form first, depending on temperature and relative humidity. Ferrihydrite recrystallizes relatively quickly to form goethite or hematite, which may persist for eons.

Criterion 3-Is analytical or natural analogue information available that warrants the inclusion or exclusion of the mineral?

Commonly, when performing geochemical modeling, information or data are found by researching the relevant literature used to develop the conceptual model. This information often comes from analytical data or natural analogue information, and warrants the suppression or inclusion of minerals that could be dispositioned differently based on Criteria 1 and 2 . This allows for inclusion of minerals that could form due to some unknown kinetic constraint that has not been accounted for directly in the model. 
Although care is taken in constructing and attempting to "validate" a model as it is developed, conceptual model or thermodynamic database uncertainty must still be addressed. Therefore, three additional criteria are included to allow evaluation of the effect of mineral suppressions on model results.

Criterion 4-Do minerals need to be suppressed or included to test overall model uncertainty or sensitivity due to reported uncertainty in the supporting literature, database, or conceptual model?

Criterion 5-Does the suppression or inclusion of minerals that are highly uncertain drive the resulting chemical output to a more or less conservative modeling result?

Criterion 6-Do other minerals that are in a database provide an adequate surrogate or proxy for the mineral?

Certainly, Criteria 4 through 6 are not applicable to the normal types of mineral dispositions in models. However, they are of great use when conducting sensitivity studies or handling modeling uncertainties.

Although the six criteria are written to address mineral suppressions, they can and should be used to document the suppression of any aqueous species of concern (Table 6.8-4).

\subsubsection{Modeling of Trace Elements}

The term "trace" used in reference to solutes in natural water cannot be precisely defined. Commonly, the term is used for substances that occur in concentrations less than $1.0 \mathrm{mg} / \mathrm{L}$ (Hem 1985 [DIRS 115670], pp. 129 to 130). Trace elements from the natural system that are potentially present in the in-drift seepage waters that have been identified and considered for affects on the waste package and drip shield environments are lead $(\mathrm{Pb})$, arsenic (As), and mercury $(\mathrm{Hg})$. The chemical composition of the rhyolite tuff that makes up the repository horizon is well characterized and essentially uniform (Peterman and Cloke 2002 [DIRS 162576]). Compositions of pore waters extracted from the tuff at the repository horizon have been characterized for trace element concentration. Table 6.5-1 shows the composition of selected minor and trace elements in the pore waters extracted from cores collected in the Enhanced Characterization of the Repository Block Cross Drift. As can be seen from Table 6.5-1, $\mathrm{Pb}$ and $\mathrm{Hg}$ concentrations and more than one third of the arsenic concentrations are below the detection limits.

Fluoride, trace elements in seepage, and elements in introduced materials that are normally considered as trace species in natural waters may be important to certain in-drift processes, yet not be significant contributors to the major ion geochemistry. Most analyses presented to date have focused on the chemical reactions among major constituents because these are considered to be the primary system drivers controlling the in-drift environmental conditions. Bruno et al. (1998 [DIRS 110969]) also conclude in their studies of trace metals in natural systems that good characterization of the site mineralogy and a sound understanding of the main geochemical driving forces (i.e., bulk chemistry) are needed to further investigate the reactions of trace species; that is, the trace species will only have a small effect upon the bulk chemistry (e.g., $\mathrm{pH}$, ionic strength, or major cation-anion concentrations). 
Fluoride and bromide are explicitly included in the analyses and discussions of Sections 6.6, 6.12, and 6.13. The potential impacts of fluoride on corrosion processes have also been evaluated and found to not significantly enhance the general corrosion of the drip shield under repository conditions (BSC 2004 [DIRS 169845], Section 8.3). Chromium and iron, considered major constituents of introduced materials in the drift, and trace element bromide in the seepage waters entering the drift, are specifically considered in Sections 6.8 and 6.12.4.2, respectively.

\subsubsection{Rationale for Including or Excluding Precipitating Minerals}

Table 6.5-2 provides a listing of the minerals that have been suppressed in the IDPS and P\&CE models; Table 6.5-3 provides a listing of the minerals that precipitated during modeling run calculations. In each case, a rationale for the decision to suppress or include each mineral is provided. In addition to the rationale listed in Tables 6.5-2 and 6.5-3, which are used to strengthen model confidence, each engineered barrier system model is independently validated against natural analogue data or experimental results, to ensure that the model is an appropriate representation. Minerals that are present in the thermodynamic database but did not precipitate during model development were not included in Table 6.5-3.

Relevant natural analogues for the IDPS and P\&CE conceptual models are saline lakes and playa deposits; the evaporite mineral assemblages that form in those environments are documented by Eugster and Hardie (1978 [DIRS 100743]) and Papke (1976 [DIRS 162274]). These minerals should reflect the mineral assemblages that could form in the low-temperature, low-pressure, in-drift environment, where the activity of water is below one and the solution compositions are comparable. These analogues are used, in conjunction with the model boundary conditions in the low-temperature, low-pressure, in-drift environment, to strengthen the mineral suppression and inclusion rationale listed in Tables 6.5-2 and 6.5-3. 
Table 6.5-1. Compositions of Fluoride and Trace Elements in Enhanced Characterization of the Repository Block Pore-Water Samples

\begin{tabular}{|c|c|c|c|c|c|c|c|c|c|c|c|c|c|}
\hline Sample Designation & $\mathbf{F}$ & $\mathrm{Br}$ & Mn & Co & $\mathrm{Zn}$ & $\mathbf{R b}$ & $\mathrm{Sr}$ & As & Mo & $\mathrm{Ba}$ & $\mathrm{Hg}$ & $\mathrm{Pb}$ & U \\
\hline ECRB-SYS-CS400/3.8-4.3/UC & 3.7 & $<1$ & 410 & $<2.5$ & $<100$ & 41 & 3,580 & 8 & 13 & 420 & $<1.0$ & $<2.0$ & 6.9 \\
\hline ECRB-SYS-CS400/5.6-6.2/UC & 1.7 & $<1$ & 43 & $<2.5$ & $<100$ & 30 & 1,480 & $<6.0$ & 4.8 & $<30$ & $<1.0$ & $<2.0$ & $<0.3$ \\
\hline ECRB-SYS-CS600/3.6-4.0/UC & 2 & $<1$ & 39 & $<2.5$ & $<100$ & 16 & 1,750 & $<6.0$ & 5.3 & $<30$ & $<1.0$ & $<2.0$ & 0.5 \\
\hline ECRB-SYS-CS1000/7.3-7.7/UC & 3.4 & $<1$ & 23 & $<2.5$ & $<100$ & 21 & 1,040 & $<6.0$ & 5.3 & $<30$ & $<1.0$ & $<2.0$ & 0.8 \\
\hline ECRB-SYS-CS750/6.2-6.5/UC & 1.2 & $<1$ & 54 & $<2.5$ & $<100$ & 22 & 1,160 & $<6.0$ & 6.2 & $<30$ & $<1.0$ & $<2.0$ & 10.3 \\
\hline ECRB-SYS-CS2150/5.5-6.1/UC & 5.3 & $<0.2$ & 38 & $<1.3$ & $<100$ & 16 & 1,110 & 5.7 & 8.9 & $<15$ & $<1.0$ & $<1.0$ & 4.1 \\
\hline ECRB-SYS-CS900/5.4-5.9/UC & 1.7 & $<0.2$ & 77 & $<1.3$ & $<100$ & 12 & 1,980 & 5.4 & 7.4 & $<15$ & $<1.0$ & $<1.0$ & 0.3 \\
\hline ECRB-SYS-CS850/5.1-5.6/UC & 2.9 & $<0.2$ & 14 & $<1.3$ & $<100$ & 9.3 & 1,150 & 8.3 & 13 & $<15$ & $<1.0$ & $<1.0$ & 2.7 \\
\hline ECRB-SYS-CS900/3.5-4.1/UC & 2 & 0.3 & 470 & 1.1 & $<50$ & 20 & 4,090 & 3.4 & 9.5 & $<15$ & $<1.0$ & $<1.0$ & 1.2 \\
\hline ECRB-SYS-CS1000/12.9-14.0/UC & 2 & $<0.1$ & 47 & $<1.0$ & $<40$ & 24 & 1,110 & 5.4 & 11 & 61 & $<1.0$ & $<1.0$ & 6.9 \\
\hline ECRB-SYS-CS450/5.3-6.0/UC & 1.1 & 0.4 & 100 & $<1.0$ & 40 & 32 & 1,240 & 5.7 & 5.1 & 46 & $<1.0$ & $<1.0$ & 0.1 \\
\hline ECRB-SYS-CS2300/4.3-4.9/UC & 1.7 & $<0.1$ & 260 & $<2.5$ & $<100$ & 22 & 590 & $<6.0$ & 14 & 29 & $<1.0$ & $<2.0$ & 7.6 \\
\hline ECRB-SYS-CS500/12.0-16.7/UC & 4.8 & 0.4 & 26 & $<2.5$ & $<100$ & 20 & 1,100 & 7.6 & 14 & $<30$ & $<1.0$ & $<2.0$ & 2.5 \\
\hline ECRB-SYS-CS2000/16.5-21.1/UC & 11 & $<0.2$ & 58 & $<1.3$ & $<100$ & 33 & 1,390 & 5.9 & 22 & $<20$ & $<1.0$ & $<1.0$ & 22.7 \\
\hline ECRB-SYS-CS2000/16.3-16.5/UC & 6 & $<0.2$ & 130 & $<1.3$ & $<100$ & 22 & 1,260 & $<3.0$ & 22 & $<15$ & $1.2^{\mathrm{a}}$ & $<1.0$ & 11.3 \\
\hline ECRB-SYS-CS950/5.2-5.3/UC & 1.9 & $<0.2$ & 62 & $<1.8$ & $<100$ & 10 & 1,240 & 4 & 3.4 & $<25$ & $<1.0$ & $<1.6$ & $<0.2$ \\
\hline ECRB-SYS-CS950/4.8-5.5/UC & 4.9 & $<0.2$ & 130 & $<1.3$ & $<100$ & 11 & 2,070 & 3.9 & 4.8 & $<15$ & $<1.0$ & $<1.0$ & 0.2 \\
\hline ECRB-SYS-CS1250/5.0-5.7/UC & 3 & 0.2 & 18 & $<1.3$ & $<50$ & 22 & 480 & 11 & 22 & 42 & $<1.0$ & $<1.0$ & 15 \\
\hline ECRB-SYS-CS1250/3.4-4.0/UC & 2.1 & M & 200 & $<1.0$ & 50 & 29 & 1,390 & $<8.0$ & 8 & 150 & $<1.0$ & $<1.0$ & 3.6 \\
\hline ECRB-SYS-CS800/4.9-5.6/UC & 1.6 & $\mathrm{M}$ & 34 & $<1.0$ & $<25$ & 12 & 1,140 & 6.7 & 6.3 & 36 & $<1.0$ & $<1.0$ & 0.9 \\
\hline ECRB-SYS-CS700/5.5-5.8/UC & 6.2 & $<0.1$ & 330 & $<7.5$ & $<300$ & 22 & 2,970 & $<18$ & 18 & 72 & $<2.5$ & $<6.0$ & 6.1 \\
\hline
\end{tabular}

Source: DTN: GS020408312272.003 [DIRS 160899].

${ }^{a}$ Greater than $200 \mathrm{ppb}$ tungsten in sample, resulting in possible interference for $\mathrm{Hg}$.

NOTE: $\mathrm{F}$ and $\mathrm{Br}$ are in $\mathrm{mg} / \mathrm{L}$, all others are $\mu \mathrm{g} / \mathrm{L} ; \mathrm{M}$ indicates not measured. 
Table 6.5-2. Mineral Suppressions Used in P\&CE Geochemical Modeling

\begin{tabular}{|c|c|c|c|c|}
\hline Mineral & Formula & $\begin{array}{l}\text { Criteria } \\
\text { Selected }\end{array}$ & Rationale & References \\
\hline $\begin{array}{l}\text { Cristobalite } \\
\text { (alpha) }\end{array}$ & $\mathrm{SiO}_{2}$ & Criterion 2 & $\begin{array}{l}\text { Cristobalite is } \\
\text { thermodynamically stable } \\
\text { at temperatures greater } \\
\text { than } 1,470^{\circ} \mathrm{C} \text {. At standard } \\
\text { temperatures and } \\
\text { pressures, cristobalite will } \\
\text { slowly convert to quartz. }\end{array}$ & $\begin{array}{l}\text { Krauskopf 1979 } \\
\text { [DIRS 105909], } \\
\text { Figure 14-1, Table } \\
6.4 .4-1\end{array}$ \\
\hline Dolomite & $\mathrm{CaMg}\left(\mathrm{CO}_{3}\right)_{2}$ & Criterion 2 & $\begin{array}{l}\text { Although dolomite is a } \\
\text { common mineral in } \\
\text { evaporite deposits from } \\
\text { springs derived from } \\
\text { carbonate and tuffaceous } \\
\text { waters in southern } \\
\text { Nevada at Yucca } \\
\text { Mountain, its growth } \\
\text { mechanism is slow when } \\
\text { compared to the } \\
\text { precipitation calcite, opal } \\
\text { and Mg-bearing minerals, } \\
\text { such as sepiolite. }\end{array}$ & $\begin{array}{l}\text { Vaniman et al. } 1992 \\
\text { [DIRS 107066], } \\
\text { Table 6.4.4-1 }\end{array}$ \\
\hline Glaserite & $\mathrm{NaK}_{3}\left(\mathrm{SO}_{4}\right)_{2}$ & Criterion 4 & $\begin{array}{l}\text { Although glaserite is a } \\
\text { mineral that is expected to } \\
\text { form in evaporitic type } \\
\text { deposits, at the time } \\
\text { modeling runs for this } \\
\text { document were initiated, } \\
\text { the thermodynamic data } \\
\text { for glaserite being } \\
\text { considered for inclusion in } \\
\text { the Pitzer database was in } \\
\text { question. }\end{array}$ & $\begin{array}{l}\text { This mineral was } \\
\text { suppressed, subject } \\
\text { to sensitivity } \\
\text { analysis (see } \\
\text { Section } 6.12 .4 .4 \text { for } \\
\text { results of the } \\
\text { sensitivity analysis) }\end{array}$ \\
\hline Magnesite & $\mathrm{MgCO}_{3}$ & Criterion 4 & $\begin{array}{l}\text { Magnesite is commonly } \\
\text { associated with } \\
\text { metamorphic mineral } \\
\text { assemblages, such as } \\
\text { serpentine. There are } \\
\text { instances where } \\
\text { magnesite is associated } \\
\text { with salt deposits, yet it is } \\
\text { uncertain that it can form } \\
\text { under standard } \\
\text { temperatures and } \\
\text { pressures as magnesite } \\
\text { could be associated with } \\
\text { the diagenesis of buried } \\
\text { salt deposits. }\end{array}$ & $\begin{array}{l}\text { Kerr } 1977 \\
\text { [DIRS 161606] } \\
\text { Eugster and Hardie } \\
1978 \text { [DIRS 100743] } \\
\text { This mineral would } \\
\text { be suppressed, } \\
\text { subject to sensitivity } \\
\text { analysis (see } \\
\text { Section } 6.12 .4 .4 \text { for } \\
\text { results of the } \\
\text { sensitivity analysis) }\end{array}$ \\
\hline
\end{tabular}


Table 6.5-2. Mineral Suppressions Used in P\&CE Geochemical Modeling (Continued)

\begin{tabular}{|c|c|c|c|c|}
\hline Mineral & Formula & $\begin{array}{l}\text { Criteria } \\
\text { Selected }\end{array}$ & Rationale & References \\
\hline $\begin{array}{l}\text { Maximum } \\
\text { Microcline }\end{array}$ & $\mathrm{KAISi}_{3} \mathrm{O}_{8}$ & Criterion 1 & $\begin{array}{l}\text { Microcline is generally } \\
\text { associated with the } \\
\text { formation of granite, } \\
\text { syenite, and gneiss. } \\
\text { Although it is often found } \\
\text { as a common mineral in } \\
\text { sandstone or arkose, the } \\
\text { occurrence in these } \\
\text { instances is detrital. }\end{array}$ & $\begin{array}{l}\text { Kerr } 1977 \\
\text { [DIRS 161606], } \\
\text { p. } 306, \text { Table } \\
6.4 .4-1\end{array}$ \\
\hline Quartz & $\mathrm{SiO}_{2}$ & Criterion 2 & $\begin{array}{l}\text { Literature evidence } \\
\text { suggests that amorphous } \\
\text { silica is at metastable } \\
\text { equilibrium with respect to } \\
\text { quartz at low } \\
\text { temperatures and } \\
\text { pressures. This is also } \\
\text { evidenced by the } \\
\text { precipitation of opal-A (an } \\
\text { amorphous silica phase) } \\
\text { as opposed to quartz in } \\
\text { evaporated carbonate and } \\
\text { tuffaceous waters of } \\
\text { southern Nevada. }\end{array}$ & $\begin{array}{l}\text { Langmuir 1997 } \\
\text { [DIRS 100051] } \\
\text { Vaniman et al. } 1992 \\
\text { [DIRS 107066], } \\
\text { Table 6.4.4-1 }\end{array}$ \\
\hline Talc & $\mathrm{Mg}_{3} \mathrm{Si}_{4} \mathrm{O}_{10}(\mathrm{OH})_{2}$ & Criterion 1 & $\begin{array}{l}\text { Talc is characteristically } \\
\text { associated with low-grade } \\
\text { metamorphic rock and } \\
\text { hydrothermal alteration of } \\
\text { ultramafic rocks. }\end{array}$ & $\begin{array}{l}\text { Kerr } 1977 \\
\text { [DIRS 161606], } \\
\text { Table 6.4.4-1 }\end{array}$ \\
\hline $\begin{array}{l}\text { Ca-saponite } \\
\text { Mg-saponite } \\
\text { Na-saponite } \\
\text { H-saponite } \\
\text { K-saponite }\end{array}$ & $\begin{array}{l}\mathrm{Ca}_{0.165} \mathrm{Mg}_{3} \mathrm{Al}_{0.33} \\
\mathrm{Si}_{3.67} \mathrm{O}_{10}(\mathrm{OH})_{2} \\
\mathrm{Mg}_{3.165} \mathrm{Al}_{0.33} \mathrm{Si}_{3.67} \mathrm{O}_{10}(\mathrm{OH})_{2} \\
\mathrm{Na}_{0.33} \mathrm{Mg}_{3} \mathrm{Al}_{0.33} \\
\mathrm{Si}_{3.67} \mathrm{O}_{10}(\mathrm{OH})_{2} \\
\mathrm{H}_{0.33} \mathrm{Mg}_{3} \mathrm{Al}_{0.33} \\
\mathrm{Si}_{3.67} \mathrm{O}_{10}(\mathrm{OH})_{2} \\
\mathrm{~K}_{0.33} \mathrm{Mg}_{3} \mathrm{Al}_{0.33} \\
\mathrm{Si}_{3.67} \mathrm{O}_{10}(\mathrm{OH})_{2}\end{array}$ & Criterion 1 & $\begin{array}{l}\text { Saponite is a } \\
\text { montmorillonite or } \\
\text { smectite clay. Smectite } \\
\text { clays are commonly } \\
\text { associated with fracture } \\
\text { linings at Yucca Mountain. } \\
\text { However, saponitic clays } \\
\text { are associated with the } \\
\text { weathering of basalt and } \\
\text { not rhyolitic tuffs. } \\
\text { Saponite does not } \\
\text { generally form } \\
\text { independently from its } \\
\text { associated parent } \\
\text { material, nor does it } \\
\text { precipitate independently } \\
\text { in soil environments. }\end{array}$ & $\begin{array}{l}\text { Krauskopf 1979 } \\
\text { [DIRS 105909] } \\
\text { Carlos et al. 1995 } \\
\text { [DIRS 105213] } \\
\text { Deer et al. 1966 } \\
\text { [DIRS 162338] } \\
\text { Borchardt 1989 } \\
\text { [DIRS 156639] }\end{array}$ \\
\hline
\end{tabular}


Table 6.5-3. Minerals Allowed to Precipitate in P\&CE Geochemical Modeling

\begin{tabular}{|c|c|c|c|c|}
\hline Mineral & Formula & $\begin{array}{l}\text { Criteria } \\
\text { Selected }\end{array}$ & Rationale & References \\
\hline Calcite & $\mathrm{CaCO}_{3}$ & Criterion 3 & $\begin{array}{l}\text { Calcite is a common evaporite mineral } \\
\text { formed from evaporated waters of } \\
\text { southern Nevada. }\end{array}$ & $\begin{array}{l}\text { Vaniman et al. } 1992 \\
\text { [DIRS 107066] }\end{array}$ \\
\hline \multirow[t]{2}{*}{$\mathrm{SiO}_{2}(\mathrm{am})$} & \multirow[t]{2}{*}{$\mathrm{SiO}_{2}$} & \multirow[t]{2}{*}{ Criterion 2} & \multirow{2}{*}{$\begin{array}{l}\text { Literature evidence suggests that } \\
\text { amorphous silica is at metastable } \\
\text { equilibrium with respect to quartz at } \\
\text { low temperatures and pressures. This } \\
\text { is also evidenced by precipitation of } \\
\text { opal-A as opposed to quartz in } \\
\text { evaporated carbonate and tuffaceous } \\
\text { waters of southern Nevada. }\end{array}$} & $\begin{array}{l}\text { Langmuir } 1997 \\
\text { [DIRS 100051] }\end{array}$ \\
\hline & & & & $\begin{array}{l}\text { Vaniman et al. } 1992 \\
\text { [DIRS 107066] }\end{array}$ \\
\hline Fluorite & $\mathrm{CaF}_{2}$ & Criterion 3 & $\begin{array}{l}\text { Fluorite is associated with evaporite } \\
\text { deposits in Nevada playas. }\end{array}$ & $\begin{array}{l}\text { Papke } 1976 \\
\text { [DIRS 162274], Tables } 1 \\
\text { and 6.4.4-1 }\end{array}$ \\
\hline \multirow[t]{3}{*}{ Sepiolite } & \multirow[t]{3}{*}{$\mathrm{Mg}_{4} \mathrm{Si}_{6} \mathrm{O}_{15}(\mathrm{OH})_{2} \bullet 6 \mathrm{H}_{2} \mathrm{O}$} & \multirow[t]{3}{*}{ Criterion 3} & \multirow{3}{*}{$\begin{array}{l}\text { The precipitation of sepiolite is } \\
\text { common in conjunction with calcite } \\
\text { precipitation in calcrete deposits. } \\
\text { Sepiolite is a common fracture-lining } \\
\text { mineral above the basil vitrophyre of } \\
\text { the Topopah Spring Member at Yucca } \\
\text { Mountain. Sepiolite is also known to } \\
\text { commonly form on evaporation of } \\
\text { either carbonate-source or tuff-source } \\
\text { waters in southern Nevada. }\end{array}$} & $\begin{array}{l}\text { Hay and Wiggens } 1980 \\
\text { [DIRS 162281] }\end{array}$ \\
\hline & & & & $\begin{array}{l}\text { Carlos et al. } 1995 \\
\text { [DIRS 105213] }\end{array}$ \\
\hline & & & & $\begin{array}{l}\text { Vaniman et al. } 1992 \\
\text { [DIRS 107066] }\end{array}$ \\
\hline \multirow[t]{2}{*}{ Celadonite } & \multirow[t]{2}{*}{$\mathrm{KMgAISi}_{4} \mathrm{O}_{10}(\mathrm{OH})_{2}$} & \multirow[t]{2}{*}{ Criterion 3} & \multirow{2}{*}{$\begin{array}{l}\text { Although its occurrence is generally } \\
\text { associated with hydrothermally altered } \\
\text { mafic volcanic rocks and with illite- } \\
\text { chlorite minerals, celadonite is also } \\
\text { found as an authigenic silicate mineral } \\
\text { in saline, alkaline, and nonmarine } \\
\text { environments such as playa deposits. }\end{array}$} & $\begin{array}{l}\text { Li et al. } 1997 \\
\text { [DIRS 159034] }\end{array}$ \\
\hline & & & & $\begin{array}{l}\text { Hay et al. } 1966 \\
\text { [DIRS 105965] }\end{array}$ \\
\hline Thenardite & $\mathrm{Na}_{2} \mathrm{SO}_{4}$ & Criterion 3 & $\begin{array}{l}\text { Thenardite is associated with evaporite } \\
\text { deposits in Nevada playas. }\end{array}$ & $\begin{array}{l}\text { Papke } 1976 \text { [DIRS 162274], } \\
\text { Table } 1\end{array}$ \\
\hline \multirow[t]{2}{*}{ Halite } & \multirow[t]{2}{*}{$\mathrm{NaCl}$} & \multirow[t]{2}{*}{ Criterion 3} & \multirow[t]{2}{*}{$\begin{array}{l}\text { Halite is associated with evaporite } \\
\text { deposits in Nevada playas. }\end{array}$} & $\begin{array}{l}\text { Papke } 1976 \text { [DIRS 162274], } \\
\text { Table } 1\end{array}$ \\
\hline & & & & $\begin{array}{l}\text { Kerr } 1979 \text { [DIRS 161606], } \\
\text { p. 221, Table 6.4.4-1 }\end{array}$ \\
\hline \multirow[t]{2}{*}{ Huntite } & \multirow[t]{2}{*}{$\mathrm{CaMg}_{3}\left(\mathrm{CO}_{3}\right)_{4}$} & \multirow[t]{2}{*}{ Criterion 3} & \multirow[b]{2}{*}{$\begin{array}{l}\text { Huntite is a Mg carbonate mineral } \\
\text { associated with cave and evaporite } \\
\text { deposits as well as with meteoric (low- } \\
\text { temperature) dissolution, and re- } \\
\text { precipitation of calcite, dolomite, or } \\
\text { magnesite. Huntite will precipitate } \\
\text { instead of calcite when } \mathrm{Mg}^{2+} \text { is } \\
\text { concentrated in solutions with respect } \\
\text { to } \mathrm{Ca}^{2+} \text { due to evaporative processes. }\end{array}$} & Faust 1953 [DIRS 162282] \\
\hline & & & & $\begin{array}{l}\text { Walling et al. } 1995 \\
\text { [DIRS 162283], p. } 360\end{array}$ \\
\hline Sellaite & $\mathrm{MgF}_{2}$ & Criterion 3 & $\begin{array}{l}\text { Sellaite is the } \mathrm{Mg} \text { analogue to fluorite } \\
\text { that forms in evaporite deposits. }\end{array}$ & $\begin{array}{l}\text { Palache et al. } 1951 \\
\text { [DIRS 162280], pp. } 37 \text { to } 39\end{array}$ \\
\hline \multirow[t]{2}{*}{ Gypsum } & \multirow[t]{2}{*}{$\mathrm{CaSO}_{4} \cdot 2 \mathrm{H}_{2} \mathrm{O}$} & \multirow[t]{2}{*}{ Criterion 3} & \multirow[t]{2}{*}{$\begin{array}{l}\text { Gypsum is associated with evaporite } \\
\text { deposits in Nevada playas. }\end{array}$} & $\begin{array}{l}\text { Papke } 1976 \text { [DIRS 162274], } \\
\text { Table } 1\end{array}$ \\
\hline & & & & $\begin{array}{l}\text { Kerr } 1979 \text { [DIRS 161606], } \\
\text { p. 221, Table 6.4.4-1 }\end{array}$ \\
\hline
\end{tabular}


Table 6.5-3. Minerals Allowed to Precipitate in P\&CE Geochemical Modeling (Continued)

\begin{tabular}{|c|c|c|c|c|}
\hline Mineral & Formula & $\begin{array}{l}\text { Criteria } \\
\text { Selected }\end{array}$ & Rationale & References \\
\hline Glauberite & $\mathrm{Na}_{2} \mathrm{Ca}\left(\mathrm{SO}_{4}\right)_{2}$ & Criterion 3 & $\begin{array}{l}\text { Glauberite is associated with evaporite } \\
\text { deposits in Nevada playas. }\end{array}$ & $\begin{array}{l}\text { Papke } 1976 \\
\text { [DIRS 162274], Table } 1\end{array}$ \\
\hline Niter & $\mathrm{KNO}_{3}$ & Criterion 3 & $\begin{array}{l}\text { Niter is associated with evaporite } \\
\text { deposits in Nevada playas. }\end{array}$ & $\begin{array}{l}\text { Papke } 1976 \\
\text { [DIRS 162274], Table } 1\end{array}$ \\
\hline Sylvite & $\mathrm{KCl}$ & Criterion 3 & $\begin{array}{l}\text { Sylvite is associated with evaporite } \\
\text { deposits in Nevada playas. }\end{array}$ & $\begin{array}{l}\text { Papke } 1976 \\
\text { [DIRS 162274], Table } 1 \\
\text { Kerr } 1979 \text { [DIRS 161606], } \\
\text { p. } 221\end{array}$ \\
\hline Arcanite & $\mathrm{K}_{2} \mathrm{SO}_{4}$ & Criterion 3 & $\begin{array}{l}\text { Arcanite is a very soluble mineral } \\
\text { belonging to the Mascagnite group and } \\
\text { can be precipitated in the laboratory } \\
\text { from the slow evaporation of water } \\
\text { solutions. This mineral is related to } \\
\text { thenardite and should have similar } \\
\text { properties. }\end{array}$ & $\begin{array}{l}\text { Palache et al. } 1951 \\
\text { [DIRS 162280], pp. } 398 \text { to } \\
400\end{array}$ \\
\hline Soda Niter & $\mathrm{NaNO}_{3}$ & Criterion 3 & $\begin{array}{l}\text { Soda Niter is associated with evaporite } \\
\text { deposits in Nevada playas. }\end{array}$ & $\begin{array}{l}\text { Papke } 1976 \\
\text { [DIRS 162274], Table } 1\end{array}$ \\
\hline Carnallite & $\mathrm{KMgCl}_{3} \cdot 6 \mathrm{H}_{2} \mathrm{O}$ & Criterion 3 & $\begin{array}{l}\text { Carnallite is associated with evaporite } \\
\text { deposits in Nevada playas. }\end{array}$ & $\begin{array}{l}\text { Papke } 1976 \\
\text { [DIRS 162274], Table } 1 \\
\text { Kerr } 1979 \text { [DIRS 161606], } \\
\text { p. } 221\end{array}$ \\
\hline $\begin{array}{l}\text { Pentasalt } \\
\text { (Gorgeyite) }\end{array}$ & $\mathrm{K}_{2} \mathrm{Ca}_{5}\left(\mathrm{SO}_{4}\right)_{6} \bullet \mathrm{H}_{2} \mathrm{O}$ & Criterion 3 & $\begin{array}{l}\text { Gorgeyite occurs in association with } \\
\text { glauberite, halite, and polyhalite in salt } \\
\text { deposits. }\end{array}$ & $\begin{array}{l}\text { Fleischer and } \\
\text { Efremov } 1954 \\
\text { [DIRS 162312] }\end{array}$ \\
\hline Syngenite & $\mathrm{K}_{2} \mathrm{Ca}\left(\mathrm{SO}_{4}\right)_{2} \bullet \mathrm{H}_{2} \mathrm{O}$ & Criterion 3 & $\begin{array}{l}\text { Syngenite is associated with salt } \\
\text { deposits (especially halite) and } \\
\text { precipitates in cavities created by } \\
\text { volcanic action. It precipitates at room } \\
\text { temperatures from solutions that } \\
\text { contain } \mathrm{K}_{2} \mathrm{SO}_{4} \text {. }\end{array}$ & $\begin{array}{l}\text { Palache et al. } 1951 \\
\text { [DIRS 162280], pp. } 442 \\
\text { to } 444\end{array}$ \\
\hline Anhydrite & $\mathrm{CaSO}_{4}$ & Criterion 3 & $\begin{array}{l}\text { Anhydrite is associated with evaporite } \\
\text { deposits in Nevada playas. }\end{array}$ & $\begin{array}{l}\text { Papke } 1976 \\
\text { [DIRS 162274], Table } 1 \\
\text { Kerr } 1979 \text { [DIRS 161606], } \\
\text { p. } 221\end{array}$ \\
\hline Natrite & $\mathrm{Na}_{2} \mathrm{CO}_{3}$ & Criterion 3 & $\begin{array}{l}\text { Natrite is a highly soluble carbonate } \\
\text { mineral associated with shortite, } \\
\text { pirssonite, and gaylussite. These three } \\
\text { minerals are also associated with the } \\
\text { precipitation of trona, calcite, and } \\
\text { montmorillonite and are found in clay } \\
\text { beds that have deposited in borax } \\
\text { lakes. }\end{array}$ & $\begin{array}{l}\text { Fleischer and Pabst } 1983 \\
\text { [DIRS 162284] } \\
\text { Palache et al. 1951 } \\
\text { [DIRS 162280] }\end{array}$ \\
\hline Trona & $\mathrm{Na}_{3} \mathrm{H}\left(\mathrm{CO}_{3}\right)_{2} \bullet 2 \mathrm{H}_{2} \mathrm{O}$ & Criterion 3 & $\begin{array}{l}\text { Trona is associated with evaporite } \\
\text { deposits in Nevada playas. }\end{array}$ & \begin{tabular}{|l} 
Papke 1976 \\
[DIRS 162274], Table 1
\end{tabular} \\
\hline Burkeite & $\mathrm{Na}_{6} \mathrm{CO}_{3}\left(\mathrm{SO}_{4}\right)_{2}$ & Criterion 3 & $\begin{array}{l}\text { Burkeite is a saline mineral associated } \\
\text { with } \mathrm{Na}-\mathrm{CO}_{3}-\mathrm{SO}_{4}-\mathrm{Cl} \text { brines. }\end{array}$ & $\begin{array}{l}\text { Eugster and Hardie } 1978 \\
\text { [DIRS 100743], Table } 3\end{array}$ \\
\hline
\end{tabular}


Table 6.5-3. Minerals Allowed to Precipitate in P\&CE Geochemical Modeling (Continued)

\begin{tabular}{|l|l|l|l|l|}
\hline Mineral & \multicolumn{1}{|c|}{ Formula } & \multicolumn{1}{c|}{$\begin{array}{c}\text { Criteria } \\
\text { Selected }\end{array}$} & \multicolumn{1}{c|}{ Rationale } & \multicolumn{1}{c|}{ References } \\
\hline Stellerite & $\mathrm{Ca}_{2} \mathrm{Al}_{4} \mathrm{Si}_{14} \mathrm{O}_{36} \bullet 14 \mathrm{H}_{2} \mathrm{O}$ & Criterion 3 & $\begin{array}{l}\text { Stellerite is a zeolite mineral commonly } \\
\text { associated with fracture linings at } \\
\text { Yucca Mountain. }\end{array}$ & $\begin{array}{l}\text { Carlos et al. 1995 } \\
\text { [DIRS 105213] }\end{array}$ \\
\hline Phillipsite & $\begin{array}{l}\mathrm{K}_{0.7} \mathrm{Na}_{0.7} \mathrm{Ca}_{1.1} \mathrm{Al}_{3.6} \mathrm{Si}_{12.4} \\
\mathrm{O}_{32} \bullet 12.6 \mathrm{H}_{2} \mathrm{O}\end{array}$ & Criterion 3 & $\begin{array}{l}\text { Phillipsite is a zeolite mineral } \\
\text { commonly associated with evaporite } \\
\text { deposits. }\end{array}$ & $\begin{array}{l}\text { Hay et al. 1966 } \\
\text { [DIRS 105965] }\end{array}$ \\
\hline Kieserite & $\mathrm{MgSO}_{4} \bullet \mathrm{H}_{2} \mathrm{O}$ & Criterion 3 & $\begin{array}{l}\text { Kieserite is an evaporite mineral } \\
\text { commonly found in salt deposits. Often } \\
\text { it is associated with halite or carnallite. }\end{array}$ & $\begin{array}{l}\text { Palache et al. 1951 } \\
\text { [DIRS 162280], pp. 477 } \\
\text { to 479 }\end{array}$ \\
\hline
\end{tabular}

\subsection{INCOMING SEEPAGE COMPOSITION ANALYSIS}

The seepage water and gas compositional inputs for in-drift chemistry modeling are obtained from THC model outputs of time-dependent seepage water and gas-phase compositions in the host rock (near field environment) adjacent to the drift wall. A discussion of the model used to derive these compositions is presented in Drift-Scale THC Seepage Model (BSC 2005 [DIRS 172862]). The THC seepage model is based on a specific design basis thermal load and thermal decay rate, which are a function of repository loading and ventilation (BSC 2005 [DIRS 172862], Section 4.1.7).

A time-history of seepage water compositions is calculated with the THC model for each of five compositions of pore water in the host rock, located far enough away from the drifts, at any given time interval, for liquid water presence. The THC model does not assign the probabilities of occurrence for each of the five seepage water compositions due to the small number of samples collected from the range in lithologic units. The number of water samples collected does not support a detailed statistical definition of probability of pore fluid occurrence because of the multivariate nature of water compositions ( $~ 10$ or more variables) and, in part, because the samples are from a variety of lithostratigraphic units. As such, the water compositions were chosen to span the range of variation and taken to be equally probable. Given the manner in which these are used (defining five separate THC cases each based on a single water composition) and the fact that the natural system will in reality integrate the effects of multiple pore fluid compositions simultaneously, these equal weights are expected to overestimate the range of water compositions expected to result in the real system.

The five thermal-hydrologic-chemical cases ensure that the full range of compositional evolution possible in the actual system has been captured, with the full set of results tending to overemphasize the end-member values. Thus, the water compositions extracted from the results of these five thermal-hydrologic-chemical cases represent the full range of potential compositions of seepage. A Piper plot of all available samples (BSC 2005 [DIRS 172862], Figure 6.2-4) shows that the five samples generally encompass the spread in pore-water compositions from the repository units. Those five pore-water compositions are designated as (BSC 2005 [DIRS 172862], Section 6.2.2.1): 
- $\mathrm{w} 0=$ HD-Perm water (Alcove 5)

- $\mathrm{w} 4=$ Cross-drift water CS2000/16.5

- $\mathrm{w} 5=$ Cross-drift water CS1000/7.3

- $\mathrm{w} 6=$ Borehole water SD-9/990.4

- $\mathrm{w} 7=$ Cross-drift water CS500/12.0.

The results of this model are reduced by further analysis from where Post-Processing Analysis for THC Seepage (BSC 2004 [DIRS 169858]) left off, as described in this section, to capture the time- and temperature-dependent changes in drift boundary conditions.

\subsubsection{Conceptual Framework Summary for the Seepage Binning Analysis}

The composition of water potentially seeping into the drift is a primary influence on the type of brine produced after evaporation. For example, if the alkalinity of the water is more than twice the calcium concentration (molar basis), the water will tend to evolve during evaporation into a carbonate-rich brine (Eugster and Hardie 1978 [DIRS 100743], p. 244). As evaporation continues, other chemical divides will be encountered as different phases precipitate (e.g., see Figure 6.2-1). Nitrate is not necessarily conserved in a system that contains organics; however, the results of the in-drift microbial communities model concludes (BSC 2004 [DIRS 169991], Section 7.1), "Because of the oxic environment, denitrification is inhibited. Significant microbial consumption of nitrate will not occur." In the end, the composition of the resulting brine will depend heavily on the original ratios of dissolved components.

As described in Section 4.1.3, each of the five THC model runs produce time histories of changing water compositions for the grid blocks of a numerical grid representing the host rock around the drift. Manipulation of the numerical model output produces time histories at 72 locations and 50 discrete points in time over the 100,000-year modeling period. To capture the more rapid fluctuations at early times, these points in time are roughly log-normally distributed over the time period (i.e., durations between these points increase with time). In total, there are approximately 3,600 discrete water chemistries per THC output. Thus, the inputs listed in Table 4.1-4 contain 18,000 $(5 \times 72 \times 50)$ water chemistries. These are reduced down to 368 water chemistries using the selection process as defined within Post-Processing Analysis for THC Seepage (BSC 2004 [DIRS 169858], Section 6.2.3.3).

Further reduction of that number of input water compositions is required to enable a tractable seepage evaporation abstraction using the IDPS process model. Four analysis steps are required to reduce the THC results. That sequence of steps is repeated for each of the five THC cases (w0, w4, w5, w6, and w7). The five steps are as follows:

- Step 1: Obtain the THC seepage model output for the five starting-water compositions as instructed by the post-processing THC report (BSC 2004 [DIRS 169858]) (Section 6.6.2).

- Step 2: Use the IDPS model (BSC 2004 [DIRS 169863]) to calculate compositions that result from the seepage waters evaporation identified in Step 1 to a common water activity equal to 0.65 . Having passed through many chemical divides, this step allows the characterization of the seepage compositions by chemical properties of the waters 
they yield when concentrated by evaporation, the in-drift process of concern (Section 6.6.3).

- Step 3: Sort the evaporated seepage water compositions from Step 2 into groups that exhibit similar chemical characteristics, placing into a single bin those evaporated seepage water compositions from Step 1. The result is a set of evaporated seepage water composition bins, each populated with compositions that yield chemically similar solutions after they are concentrated by evaporation (Section 6.6.4).

- Step 4: Identify the median water composition in each bin and use it as an approximation of all the evaporated seepage water compositions within the bin (Section 6.6.5).

\subsubsection{Thermal-Hydrological-Chemical Initial Seepage Input (Step 1)}

The method described in Post-Processing Analysis for THC Seepage (BSC 2004 [DIRS 169858], Section 6.2.3.3) selects a set of 368 water compositions that are used to represent the seepage boundary conditions to the drift for the five starting water THC cases. The THC product output files containing the inventory of possible seepage waters are listed in Table 4.1-4. The set of 368 water compositions is used as a direct input boundary condition to this analysis. These water selections are listed in Table 6.6-1 and provide a summary of the seepage water inputs. The two right-hand columns in Table 6.6-1 give the points in time (which also coincide with the filenames) that were used.

\subsubsection{Evaporate Waters to a Common Degree of Concentration (Step 2)}

The seepage water compositions from the THC model identified in Step 1 vary over time not only in terms of the molal ratios of the dissolved constituents, but also in terms of the absolute concentrations of these constituents. To group these THC seepage water compositions into bins containing relatively homogeneous water types, these waters are normalized (based on same activity of water) to reflect the compositions of water by evaporating them to a common activity of water.

The IDPS model (BSC 2004 [DIRS 169863]) is used to calculate normalized seepage water compositions resulting from evaporation of the more than 300 waters identified in Step 1. This approach accounts for the effects of nearly all chemical divides important to a particular water. Other methods, such as dividing each concentration by the ionic strength, cannot accurately reveal the likely brine endpoint for a given water, which is important to establishing corrosion rates germane to performance assessment. As determined by the IDPS model evaporations, the waters evolve during evaporation to several different brine types, most commonly nitrate brines, chloride brines, and their combinations. An activity of water of 0.65 was chosen as the common endpoint of these evaporation runs (at equilibrium, the water activity is equivalent to the relative humidity) because this is the lowest approximate value at which all runs are above the deliquescence point.

The EQ3/6 program input files used in the IDPS model evaporation calculations are generated according to the protocol outlined in In-Drift Precipitates/Salts Model (BSC 2004 [DIRS 169863]) using the EQ3/6 program template files found in DTN: MO0303SPAMEQ36.000 [DIRS 162549]. Temperature, $\mathrm{pH}$, carbon dioxide partial 
pressure, and concentrations of dissolved components tracked in the THC model are taken directly from the THC model output, except for Fe. The predominate iron species $\left(\mathrm{Fe}^{3+}\right)$ is excluded as it is a relatively insoluble $\left(<2 \times 10^{-10}\right.$ molal $)$ species and of no consequence to the evaporated brine composition. Electrical balancing is performed using the aqueous component whose molality (mole/kg solvent) would be least affected on a percentage basis. The minerals suppressed in these calculation runs are discussed in Section 6.5.5. In addition to the list of minerals provided in Table 6.5-2, three additional minerals (albite, k-feldspar, and celadonite) that were not originally included in the IDPS model mineral suppression list, are suppressed in a few of the calculation runs.

Table 6.6-1. Locations and Identification of THC Seepage Water Compositions to Be Binned

\begin{tabular}{|c|c|c|c|c|}
\hline $\begin{array}{l}\text { Starting Water } \\
\text { Composition }\end{array}$ & $\begin{array}{l}\text { Worksheet: } \\
\text { Quadrant: } \\
\text { Zone: } \\
\text { Index: }\end{array}$ & Case Abbreviation & $\begin{array}{c}\text { Points in } \\
\text { Time Specific } \\
\text { to Case } \\
\end{array}$ & $\begin{array}{c}\text { Points in Time Common to All } \\
\text { Cases }^{a}\end{array}$ \\
\hline \multirow[t]{2}{*}{$\begin{array}{l}\text { HD-PERM water } \\
\text { (Alcove 5) } \\
\text { thc6_w0_r.xls }\end{array}$} & $\begin{array}{l}\text { "fractures-ch" } \\
\text { "Top" } \\
\text { "Front" } \\
\text { "4" }\end{array}$ & w0tf4 & \multirow[t]{2}{*}{$\begin{array}{l}789 \\
12,310\end{array}$} & \multirow{8}{*}{$\begin{array}{l}10,51,53,55,60,75,100, \\
150,200,250,300,350,400,500, \\
600,650,700,750,800, \\
1,000,1,200,1,400,1,601,1,801, \\
2,001,2,201,2,401,3,002,5,003, \\
7,004,10,006,15,010,20,013, \\
50,034\end{array}$} \\
\hline & $\begin{array}{l}\text { "matrix-ch" } \\
\text { "Base" } \\
\text { "Front" } \\
\text { "4" }\end{array}$ & w0bf4 & & \\
\hline \multirow[t]{2}{*}{$\begin{array}{l}\text { Cross-drift water } \\
\text { CS2000/16.5 } \\
\text { thc6_w4_r.xls }\end{array}$} & $\begin{array}{l}\text { "fractures-ch" } \\
\text { "Top" } \\
\text { "Front" } \\
\text { "4" }\end{array}$ & w4tf4 & \multirow[t]{2}{*}{$\begin{array}{l}804 \\
2,597 \\
12,597\end{array}$} & \\
\hline & $\begin{array}{l}\text { "matrix-ch" } \\
\text { "Base" } \\
\text { "Front" } \\
\text { "4" }\end{array}$ & w4bf4 & & \\
\hline \multirow[t]{2}{*}{$\begin{array}{l}\text { Cross-drift water } \\
\text { CS1000/7.3 } \\
\text { thc6_w5_r.xls }\end{array}$} & $\begin{array}{l}\text { "fractures-ch" } \\
\text { "Top" } \\
\text { "Front" } \\
\text { "4" }\end{array}$ & w5tf4 & \multirow[t]{2}{*}{$\begin{array}{l}784 \\
2,392 \\
12,304\end{array}$} & \\
\hline & $\begin{array}{l}\text { "matrix-ch" } \\
\text { "Base" } \\
\text { "Front" } \\
\text { "4" }\end{array}$ & w5bf4 & & \\
\hline \multirow[t]{2}{*}{$\begin{array}{l}\text { Borehole water } \\
\text { SD-9/990.4 } \\
\text { thc6_w6_r.xls }\end{array}$} & $\begin{array}{l}\text { "fractures-ch" } \\
\text { "Top" } \\
\text { "Front" } \\
\text { "4" }\end{array}$ & w6tf4 & \multirow[t]{2}{*}{$\begin{array}{l}865 \\
3,048 \\
13,053\end{array}$} & \\
\hline & $\begin{array}{l}\text { "matrix-ch" } \\
\text { "Base" } \\
\text { "Front" } \\
\text { "4" }\end{array}$ & w6bf4 & & \\
\hline
\end{tabular}


Table 6.6-1. Locations and Identification of THC Seepage Water Compositions to Be Binned (Continued)

\begin{tabular}{|l|l|l|l|l|}
\hline $\begin{array}{c}\text { Starting Water } \\
\text { Composition }\end{array}$ & $\begin{array}{c}\text { Worksheet: } \\
\text { Quadrant: } \\
\text { Zone: } \\
\text { Index: }\end{array}$ & Case Abbreviation & $\begin{array}{c}\text { Points in } \\
\text { Time Specific } \\
\text { to Case }\end{array}$ & $\begin{array}{c}\text { Points in Time Common to All } \\
\text { Cases }^{\text {a }}\end{array}$ \\
\hline $\begin{array}{l}\text { Cross-drift water } \\
\text { CS500/12.0 } \\
\text { thc6_w7_r.xls }\end{array}$ & $\begin{array}{l}\text { "fractures-ch" } \\
\text { "Top" } \\
\end{array}$ & "Front" & & 784, \\
& "4" & & 2,591, & \\
\cline { 2 - 4 } & "matrix-ch" & w7bf4 & & \\
& "Base" & & & \\
& "Front" & & & \\
\hline
\end{tabular}

Source: Starting water compositions: DTN: LB0302DSCPTHCS.002 [DIRS 161976].

a Some values differ by -1 from the values in DTN: LB0302DSCPTHCS.002 [DIRS 161976] due to rounding errors.

NOTE: EQ3 and EQ6 input and output filenames are the same as the points in time with the extensions *.3i, 3o, $6 i$, and 6o, respectively, and are archived in Output DTNs: MO0303MWDSCMAB.000 (EQ3) and MO0303MWDEBSSM.000 (EQ6).

The rationale for suppression of these three minerals is included in Table 6.6-2. These suppressions are also made in the modeling runs listed in Section 6.9. The pressure of carbon dioxide is set at the volume fraction value provided by the THC model output (Section 6.6.7.2), and that of oxygen is set at the approximate atmospheric value of $10^{-0.7}$ (Table 4.1-7 and Section 6.7). The model runs are set to stop evaporation when the activity of water reaches 0.65 (evaporations start with $a_{w} \approx 1.0$ ).

Table 6.6-2. Additional Mineral Suppressions Included during Evaporation to 65\% Relative Humidity

\begin{tabular}{|c|c|c|c|c|}
\hline Mineral & Formula & $\begin{array}{l}\text { Criteria } \\
\text { Selected }\end{array}$ & Rationale & References \\
\hline Albite & $\mathrm{NaAlSi}_{3} \mathrm{O}_{8}$ & Criterion 2 & $\begin{array}{l}\text { Albite is a common mineral in felsic volcanic } \\
\text { and plutonic rocks. It can also form in low- } \\
\text { grade metamorphic greenschist facies. It } \\
\text { forms at normal pressures at temperatures } \\
\text { around } 700^{\circ} \mathrm{C} \text {. The formation of albite is } \\
\text { kinetically retarded at low temperatures. }\end{array}$ & $\begin{array}{l}\text { Frye } 1981 \\
\text { [DIRS 161804], p. } 538 \\
\text { Deer et al. 1992 } \\
\text { [DIRS 163286], p. } 401\end{array}$ \\
\hline K-feldspar & $\mathrm{KAISi}_{3} \mathrm{O}_{8}$ & Criterion 2 & $\begin{array}{l}\text { K-feldspars such as sanidine and microcline } \\
\text { are commonly found in plutonic rocks and } \\
\text { pegmatites and are found in gneisses. } \\
\text { K-feldspars generally form at temperatures } \\
\text { between } 700^{\circ} \mathrm{C} \text { and } 500^{\circ} \mathrm{C} \text {. The formation } \\
\text { of K-feldspar is kinetically retarded at } \\
\text { diagenetic temperatures }\left(\leq 200^{\circ} \mathrm{C}\right) \text {. The } \\
\text { formation of } \mathrm{K} \text {-feldspar in low-temperature } \\
\text { metamorphic rocks is common but } \\
\text { typically } \geq 200^{\circ} \mathrm{C} \text {. }\end{array}$ & $\begin{array}{l}\text { Frye } 1981 \\
\text { [DIRS 161804], pp. } 669 \\
\text { to } 670 \\
\text { Deer et al. 1992 } \\
\text { [DIRS } 163286 \text { ], } \\
\text { Figure } 130\end{array}$ \\
\hline Celadonite & $\begin{array}{l}\mathrm{KMgAISi}_{4} \\
\mathrm{O}_{10}(\mathrm{OH})_{2}\end{array}$ & Criterion 2 & $\begin{array}{l}\text { Celadonite is a mica mineral similar to } \\
\text { glauconite that occurs mostly in basalts. } \\
\text { The occurrences are in vesicles or as } \\
\text { replacements of ferromagnesian } \\
\text { constituents. }\end{array}$ & $\begin{array}{l}\text { Deer et al. } 1992 \\
\text { [DIRS 163286], p. } 297\end{array}$ \\
\hline
\end{tabular}


Table 6.6-1 lists the input and output files generated for use in EQ3/6 calculations, along with the DTNs in which the files are archived. The filenames correspond to the year for which the water composition prediction is documented by the THC model. The full set of input and output files is included in Output DTNs: MO0303MWDSCMAB.000 and MO0303MWDEBSSM.000.

\subsubsection{Evaporated Seepage Water Composition Bin Generation (Step 3)}

The final equilibration results from each output file, as listed in Table 6.6-1 and archived in Output DTN: MO0303MWDEBSSM.000, are tabulated using the GETEQDATA software (BSC 2002 [DIRS 173680]) to create Final Checked EBS Seepage Binning Abstraction Rev 4.xls. This spreadsheet is archived in Output DTN: MO0508SPAEBSCB.001 and contains the following output variables: $\mathrm{pH}$, activity of water $\left(a_{w} \approx 0.65\right)$, ionic strength $(I)$, total molalities of the aqueous constituents, and cumulative log moles of minerals precipitated. In addition, formulas are added to calculate various molar ratios and the hydrogen ion activity, and several graphs are inserted to illustrate the variability in the outputs and calculations (Figures 6.6-1 to 6.6-3). These graphs are ordered primarily by the five different starting waters, and then each of those outputs ordered by time. This information is needed before the waters can be grouped by similarity.

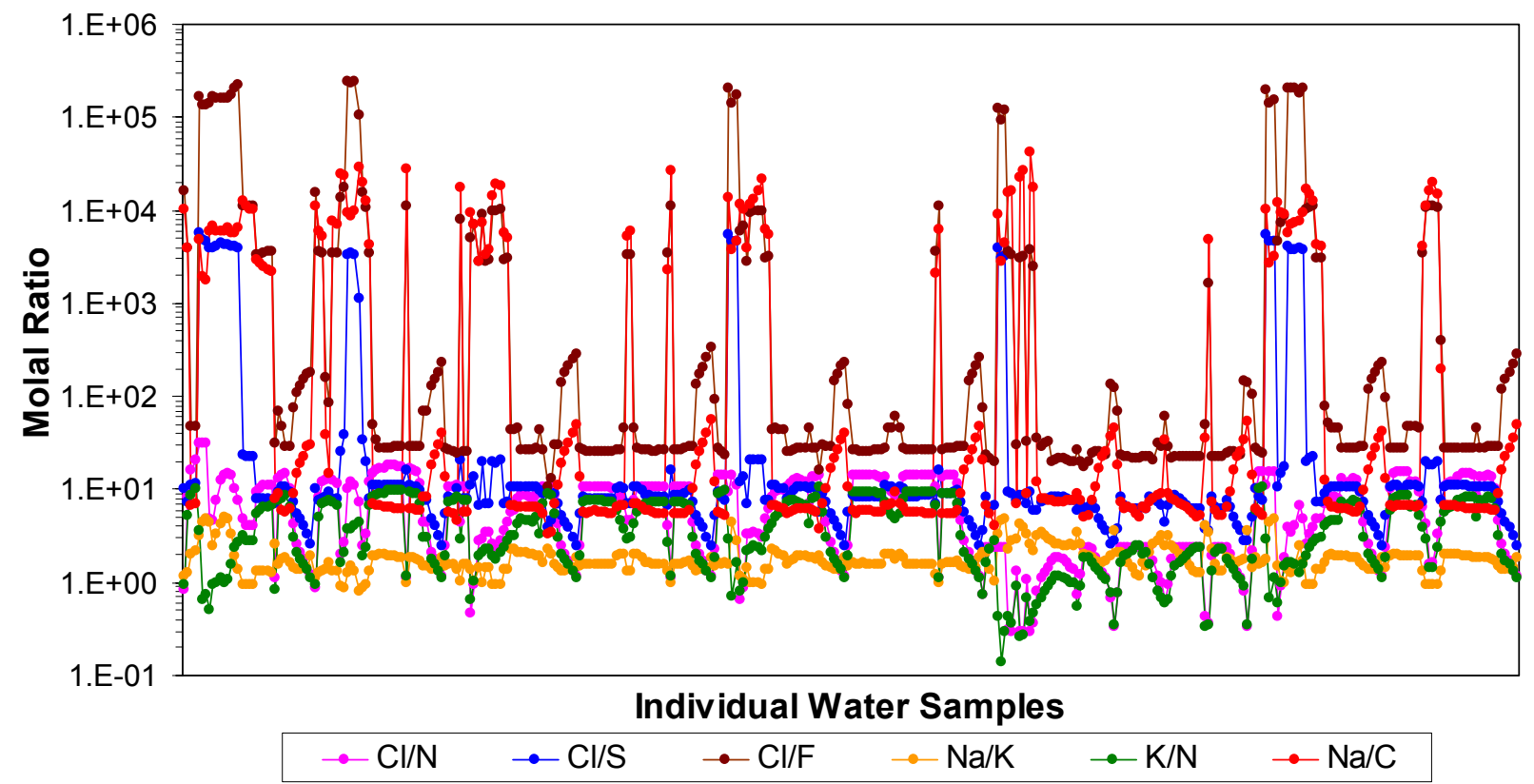

Source: Output DTN: MO0508SPAEBSCB.001.

Figure 6.6-1. Selected Molal Ratios (Cl/N, Cl/S, Cl/F, Na/K, K/N, and Na/C) from the Evaporation of the 368 Seepage Waters to $65 \%$ Relative Humidity, Used in the Binning Analysis to Establish Binning Criteria 


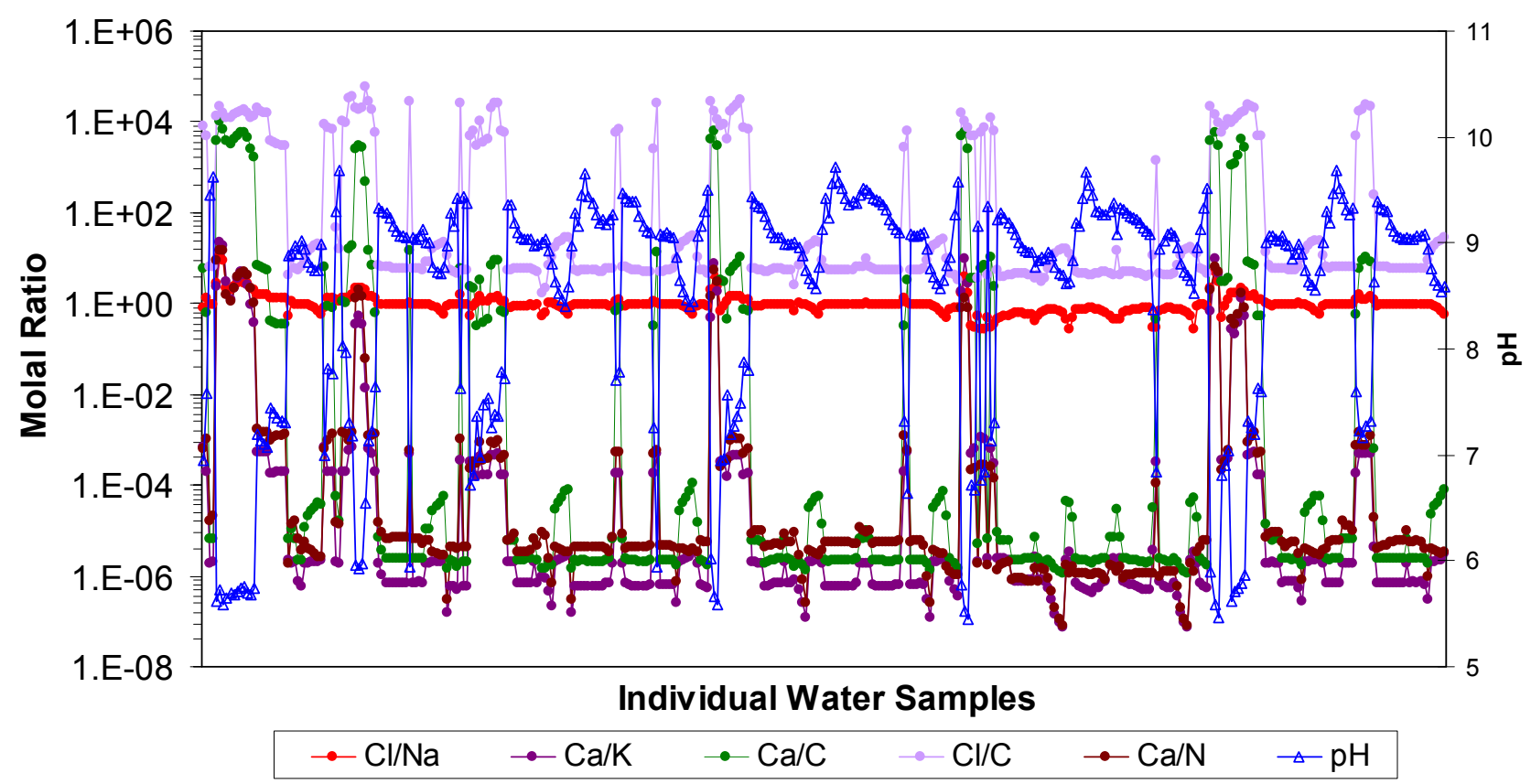

Source: Output DTN: MO0508SPAEBSCB.001.

Figure 6.6-2. Selected Molal Ratios $(\mathrm{Cl} / \mathrm{Na}, \mathrm{Ca} / \mathrm{K}, \mathrm{Ca} / \mathrm{C}, \mathrm{Cl} / \mathrm{C}, \mathrm{Ca} / \mathrm{N})$ and $\mathrm{pH}$ from the Evaporation of the 368 Seepage Waters to $65 \%$ Relative Humidity, Used in the Binning Analysis to Establish Binning Criteria 

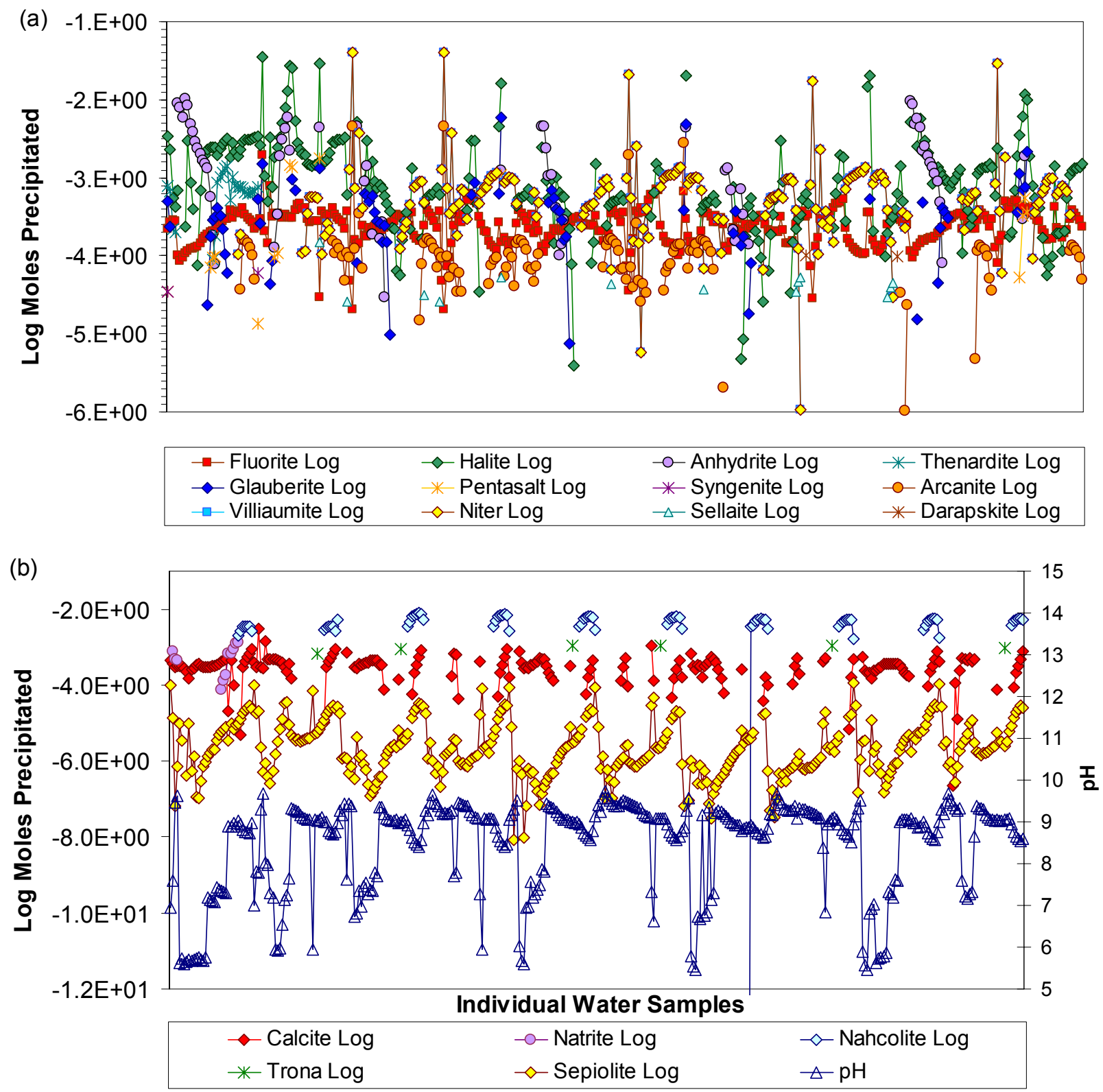

Source: Output DTN: MO0508SPAEBSCB.001.

Figure 6.6-3. Mineral Assemblages of the 368 Selected Seepage Waters after Evaporation to 65\% Relative Humidity

Binning of the evaporated seepage water compositions identified in Step 1 is accomplished by group sorting, such that all the evaporated seepage waters in a group yield chemically similar solution compositions after they are concentrated by evaporation. Eight characteristic properties are identified for determining that chemical similarity. They are defined in such a way that they yield low intra-bin composition ranges compared with the composition ranges existing among all of the waters. 
The evaporated waters are binned based on the following eight criteria, evaluated as their total elemental aqueous concentrations:

- Total aqueous Ca molality $>0.01$ molal?

- If yes, the water evaporatively evolves on the calcium side of the calcite and gypsum chemical divides, resulting in brine that is depleted of carbonate and sulfate (Figure 6.2-1). These brines also tend to have neutral to acidic $\mathrm{pH}$.

- Total aqueous $\mathrm{CO}_{3}$ molality $<0.1$ molal?

- If no, $\mathrm{Ca}$ is likely depleted by the precipitation of calcite. In some cases, $\mathrm{Ca}$ and $\mathrm{CO}_{3}$ have low concentrations, so this criterion further divides brines with Ca molality less than 0.1 molal. Waters having low concentrations of both of these components tend to maintain a neutral $\mathrm{pH}$ as they evaporate.

- Total aqueous Ca molality $>$ total aqueous Na molality?

- This criterion segregates Bin 1 and Bin 2 waters.

- Total aqueous Ca molality $>$ total aqueous K molality?

- This criterion segregates Bin 2 and Bin 3 waters. Without this criterion, $\mathrm{K}$ and $\mathrm{Ca}$ would have large variability ranges in a combined $2+3$ bin.

- Total aqueous $\mathrm{NO}_{3}$ molality $>$ total aqueous $\mathrm{CO}_{3}$ molality?

- This criterion segregates Bin 9 and Bin 11 waters. Without this criterion, a combined $9+11$ bin would have larger variations within the bin, especially for $\mathrm{NO}_{3}$.

- Total aqueous F molality $<0.1$ molal?

- This criterion distinguishes waters in Bin 6 from Bin 9 and waters in Bin 8 from Bin 10. Without this criterion, combined $6+9$ and $8+10$ bins would have larger variabilities within the bins.

- Total aqueous F molality $<0.03$ molal?

- This criterion distinguishes waters in Bin 7 from Bin 8. Without this criterion, a combined $7+8$ bin would have much larger variability within the bin for many of the components.

- Total aqueous $\mathrm{SO}_{4}$ molality $>1$ molal?

- This criterion distinguishes waters in Bin 6 from Bin 8 and waters in Bin 9 from Bin 10. Waters remaining high in sulfate will be quite low in calcium (Figure 6.2-1). Without this criterion, combined $6+8$ and $9+10$ bins would have larger variabilities within the bins for many output parameters. 
Columns containing "if/then/else" formulas are added to the spreadsheet to facilitate responding to each criterion for each water. Waters having identical answers to the questions listed in Table 6.6-3 are placed in the same bin. Eleven bins are similarly defined.

Table 6.6-3. Binning Criteria Answer Key

\begin{tabular}{|c|c|c|c|c|c|c|c|c|}
\hline Bin & $\mathbf{C a}>\mathbf{0 . 0 1}$ & $\mathbf{C O}_{3}<\mathbf{0 . 1 m}$ & $\mathbf{C a}>\mathbf{N a}$ & $\mathbf{C a} \mathbf{K}$ & $\mathbf{N O}_{3}>\mathbf{C O}_{\mathbf{3}}$ & $\mathbf{F}<\mathbf{0 . 1 m}$ & $\mathbf{F}<\mathbf{0 . 0 3}$ & $\mathbf{S O}_{\mathbf{4}}>\mathbf{1 m}$ \\
\hline 1 & yes & yes & yes & yes & yes & yes & yes & no \\
\hline 2 & yes & yes & no & yes & yes & yes & yes & no \\
\hline 3 & yes & yes & no & no & yes & yes & yes & no \\
\hline 4 & no & yes & no & no & yes & yes & yes & no \\
\hline 5 & no & yes & no & no & yes & yes & yes & yes \\
\hline 6 & no & no & no & no & yes & yes & no & no \\
\hline 7 & no & no & no & no & yes & yes & yes & yes \\
\hline 8 & no & no & no & no & yes & yes & no & yes \\
\hline 9 & no & no & no & no & yes & no & no & no \\
\hline 10 & no & no & no & no & yes & no & no & yes \\
\hline 11 & no & no & no & no & no & no & no & no \\
\hline
\end{tabular}

Source: Output DTN: MO0508SPAEBSCB.001.

Results are provided in Final Checked EBS Seepage Binning Abstraction Rev 4.xls (Output DTN: MO0508SPAEBSCB.001). These results are also shown for all water compositions within each of the eleven bins. Figures 6.6-5 through 6.6-15 show the water compositions for each bin separately. A comparison of these plots with the previous plots showing all of the evaporated water compositions before binning (Figures 6.6-1 to 6.6-3) illustrates that the binning process is successful in grouping waters with similar compositions in the same bin. The $\mathrm{pH}$ results are especially salient, as $\mathrm{pH}$ is not an explicit binning criterion. The $\mathrm{pH}$ covers a wide range in the initial waters, and is well segregated into the resulting bins as shown in Figure 6.6-4.

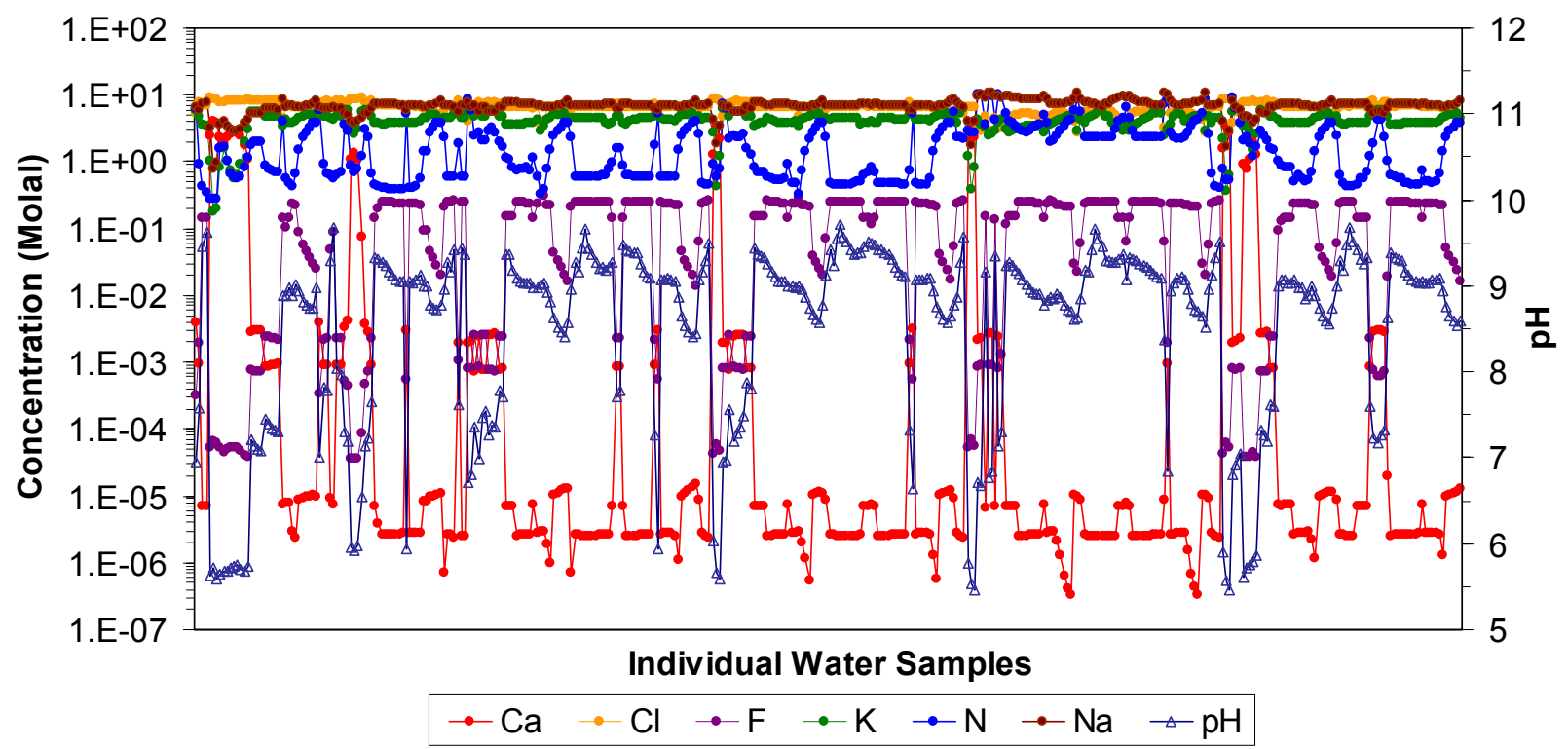

Source: Output DTN: MO0508SPAEBSCB.001.

Figure 6.6-4. Evaporated Water Compositions for All Bins after Evaporation to 65\% Relative Humidity 


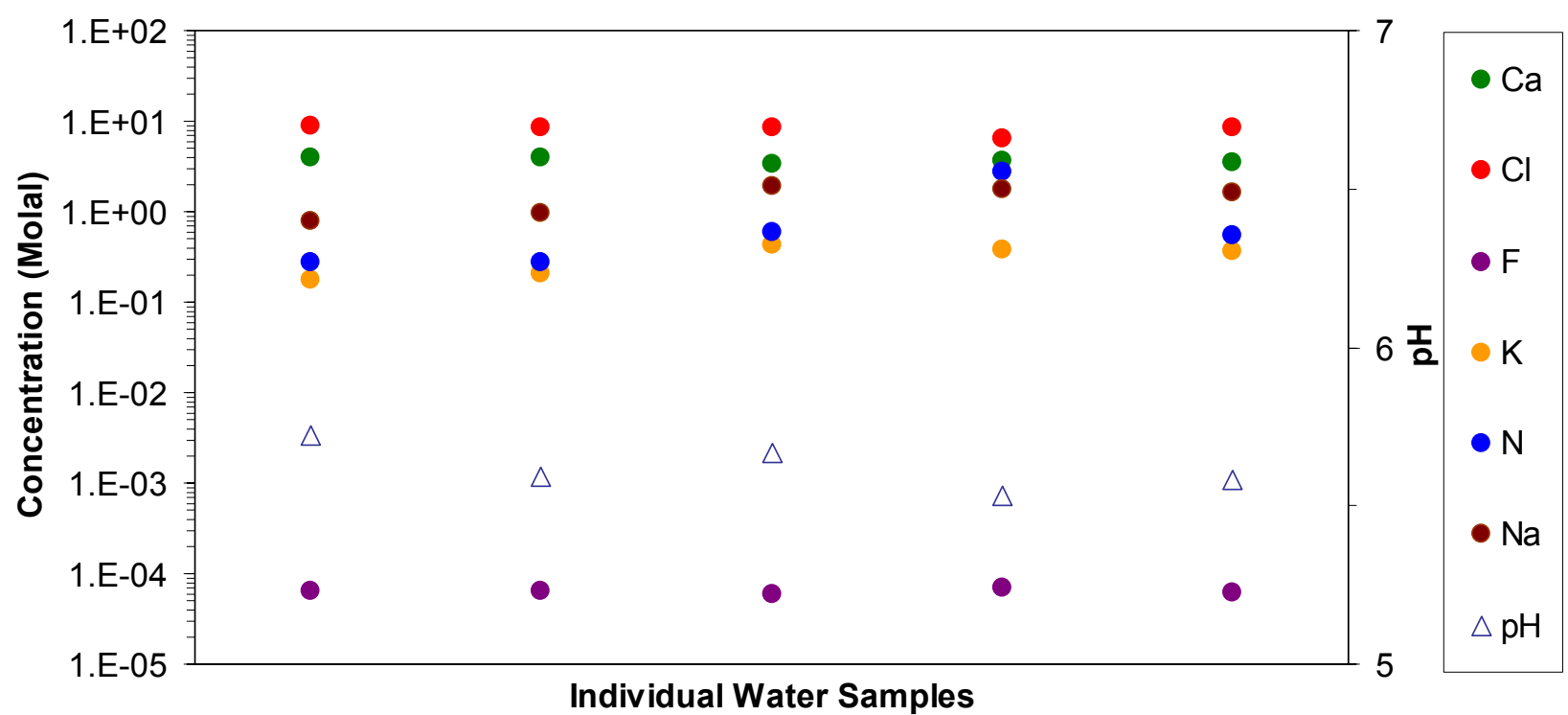

Source: Output DTN: MO0508SPAEBSCB.001.

NOTE: Individual compositions are grouped vertically by data points.

Figure 6.6-5. Evaporated Water Compositions for Bin 1 after Evaporation to 65\% Relative Humidity

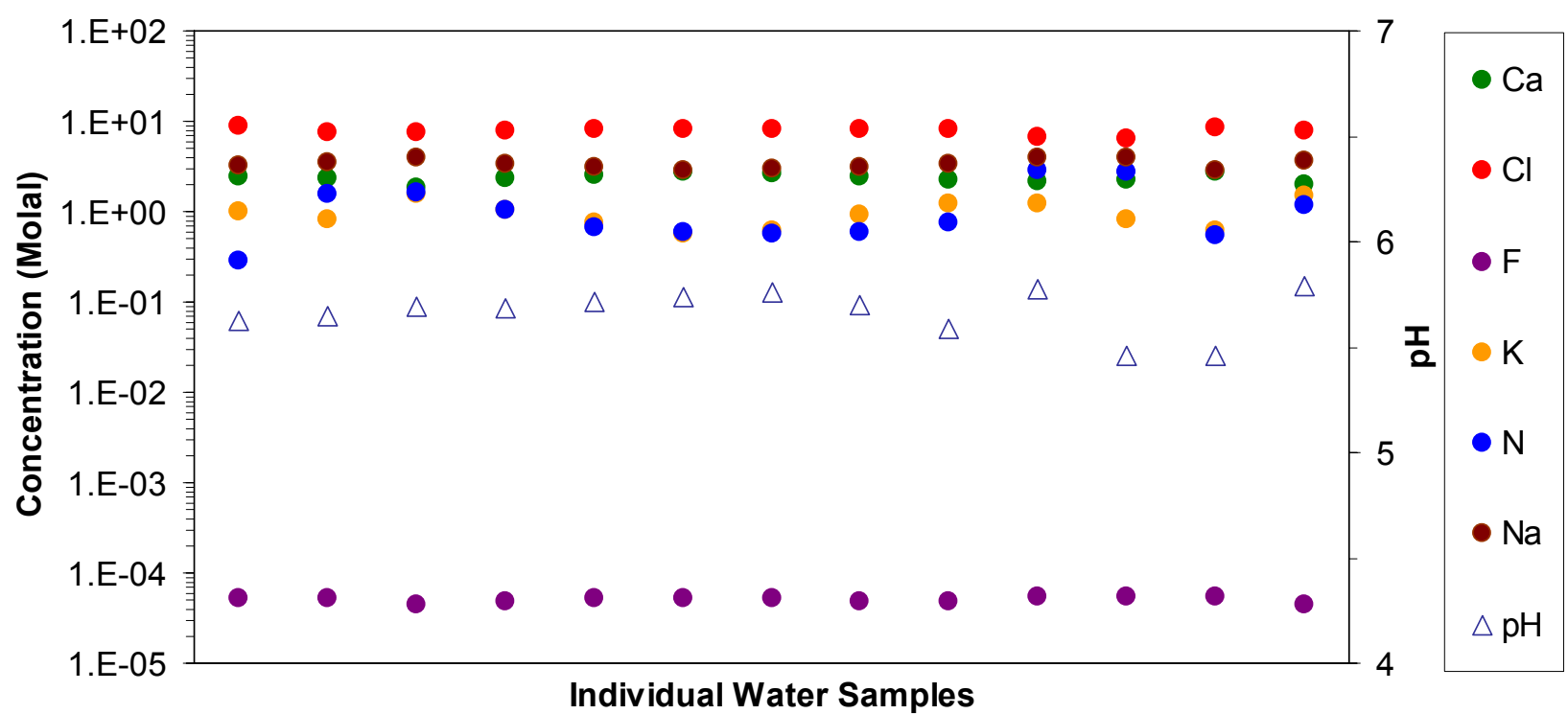

Source: Output DTN: MO0508SPAEBSCB.001.

NOTE: Individual compositions are grouped vertically by data points.

Figure 6.6-6. Evaporated Water Compositions for Bin 2 after Evaporation to 65\% Relative Humidity 


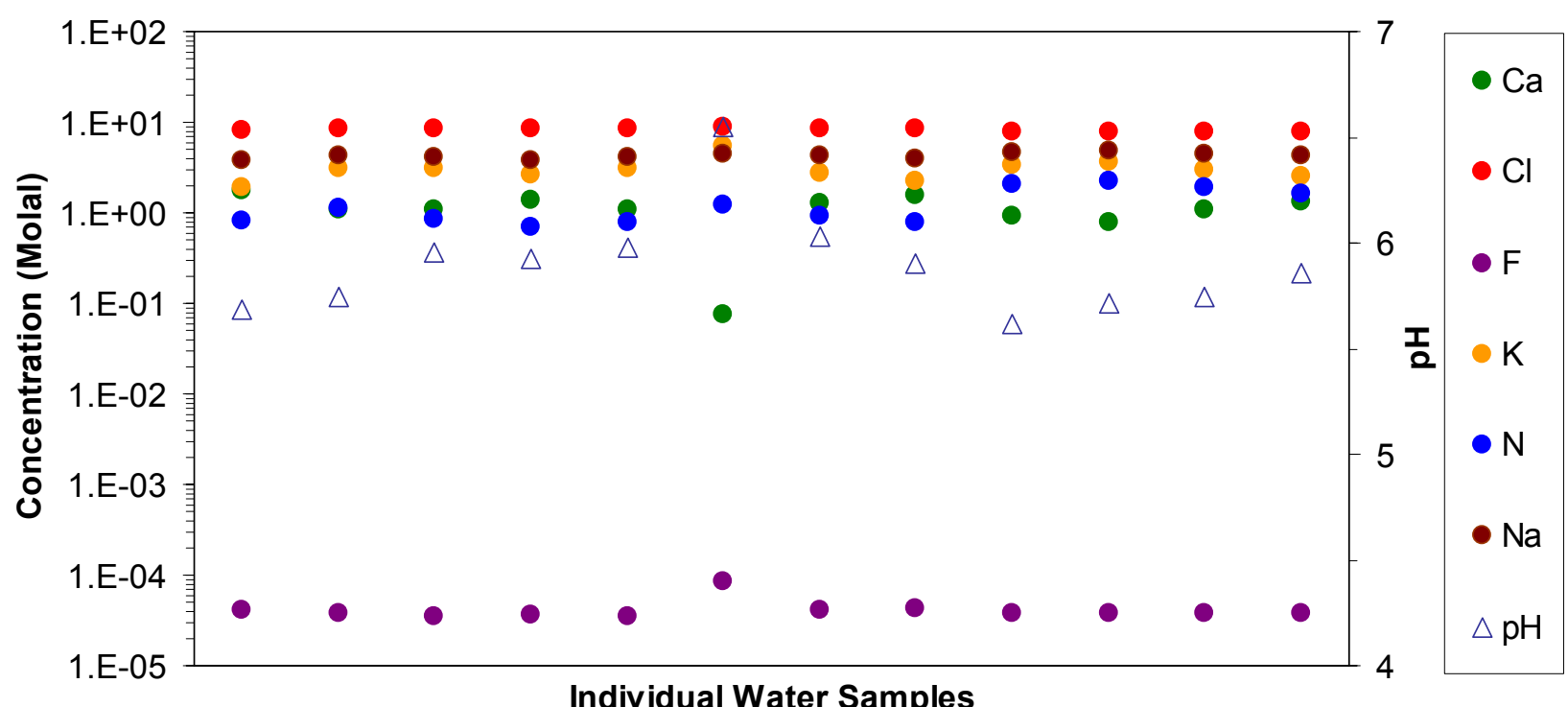

Source: Output DTN: MO0508SPAEBSCB.001.

NOTE: Individual compositions are grouped vertically by data points.

Figure 6.6-7. Evaporated Water Compositions for Bin 3 after Evaporation to 65\% Relative Humidity

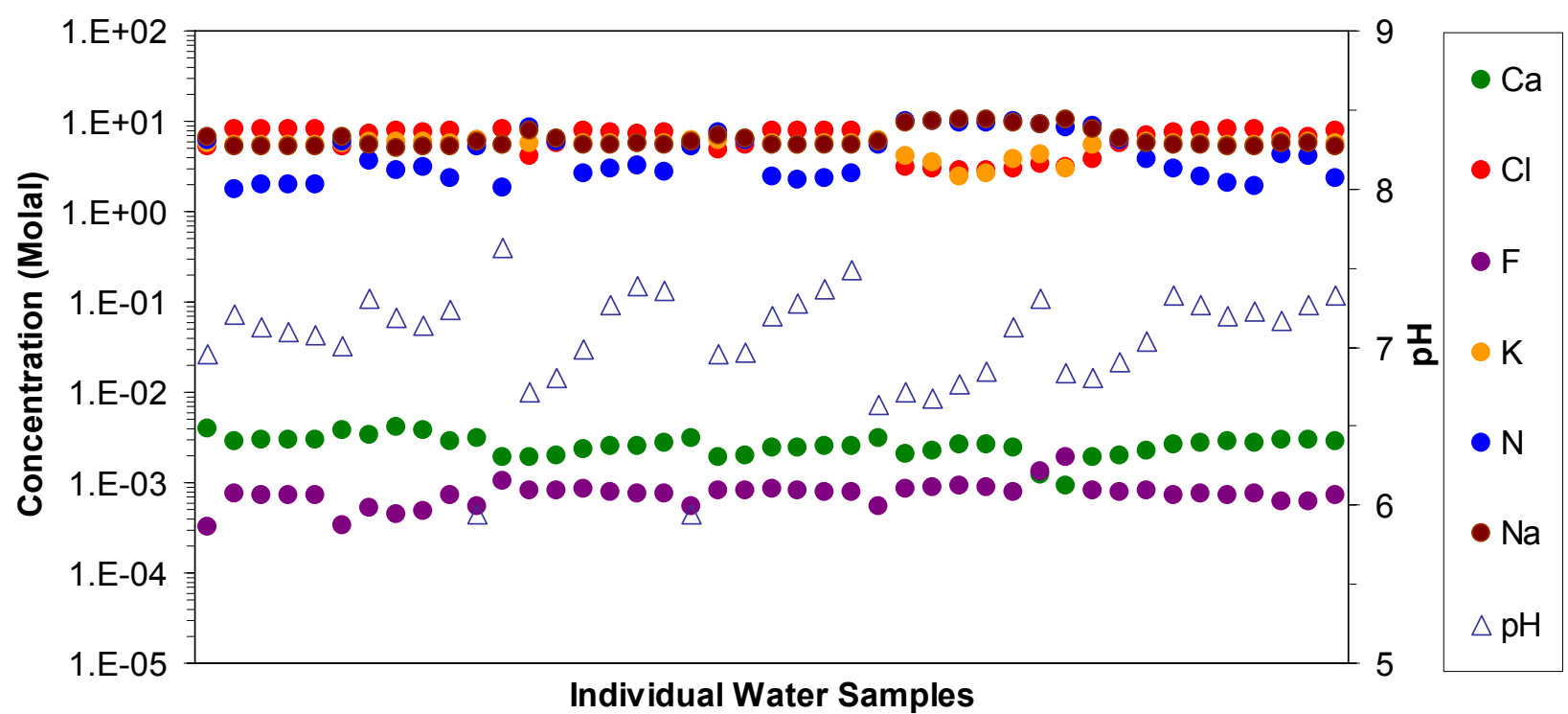

Source: Output DTN: MO0508SPAEBSCB.001.

NOTE: Individual compositions are grouped vertically by data points.

Figure 6.6-8. Evaporated Water Compositions for Bin 4 after Evaporation to 65\% Relative Humidity 


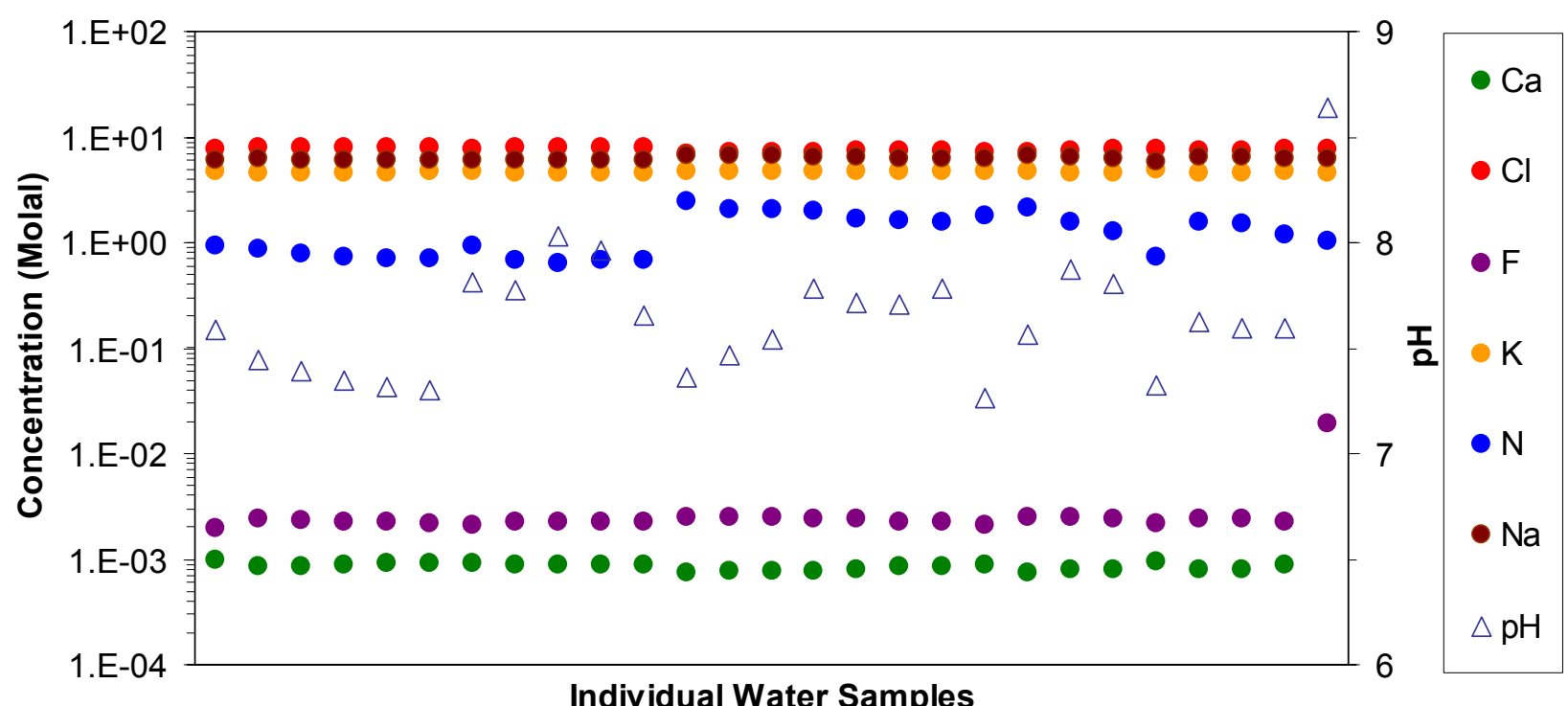

Source: Output DTN: MO0508SPAEBSCB.001.

NOTE: Individual compositions are grouped vertically by data points.

Figure 6.6-9. Evaporated Water Compositions for Bin 5 after Evaporation to 65\% Relative Humidity

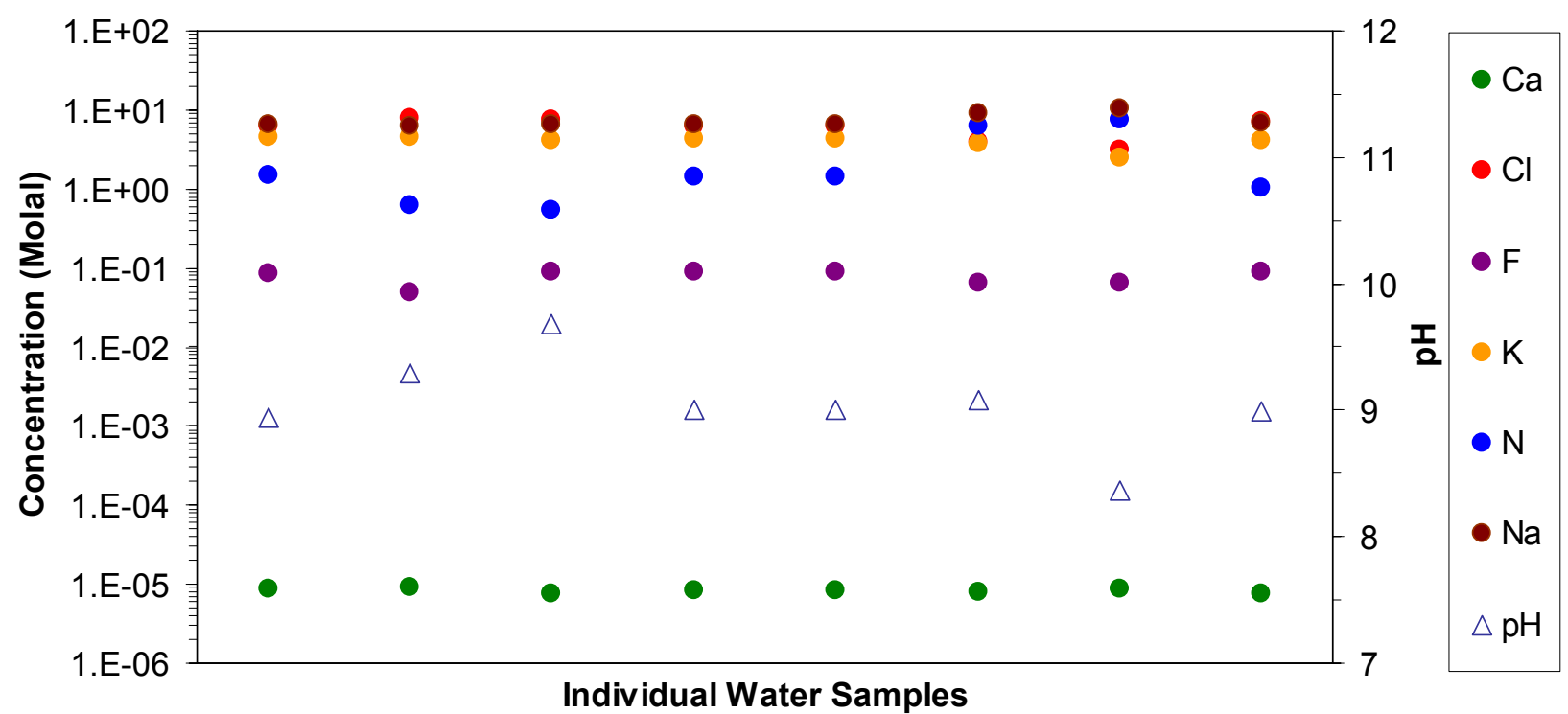

Source: Output DTN: MO0508SPAEBSCB.001.

NOTE: Individual compositions are grouped vertically by data points.

Figure 6.6-10. Evaporated Water Compositions for Bin 6 after Evaporation to 65\% Relative Humidity 


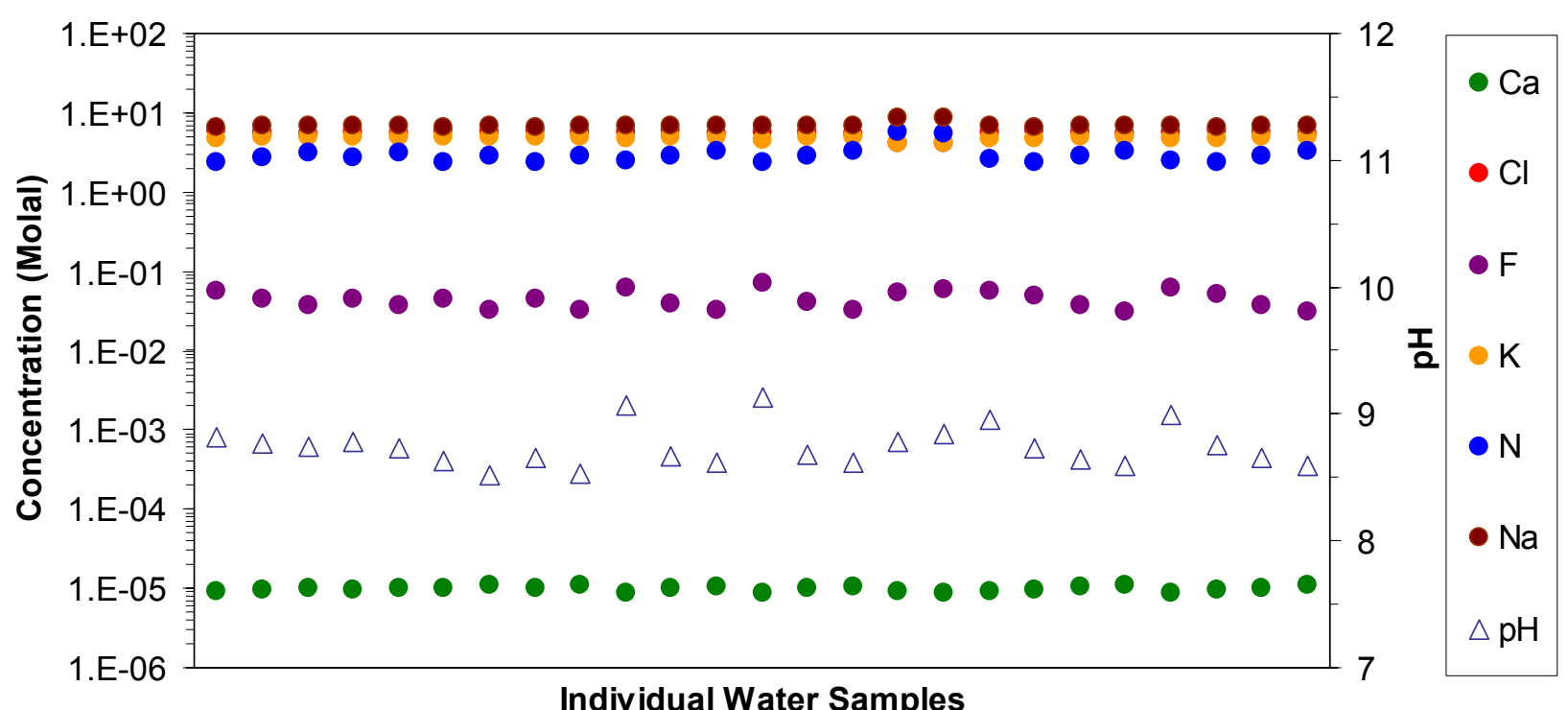

Source: Output DTN: MO0508SPAEBSCB.001.

NOTE: Individual compositions are grouped vertically by data points.

Figure 6.6-11. Evaporated Water Compositions for Bin 7 after Evaporation to $65 \%$ Relative Humidity

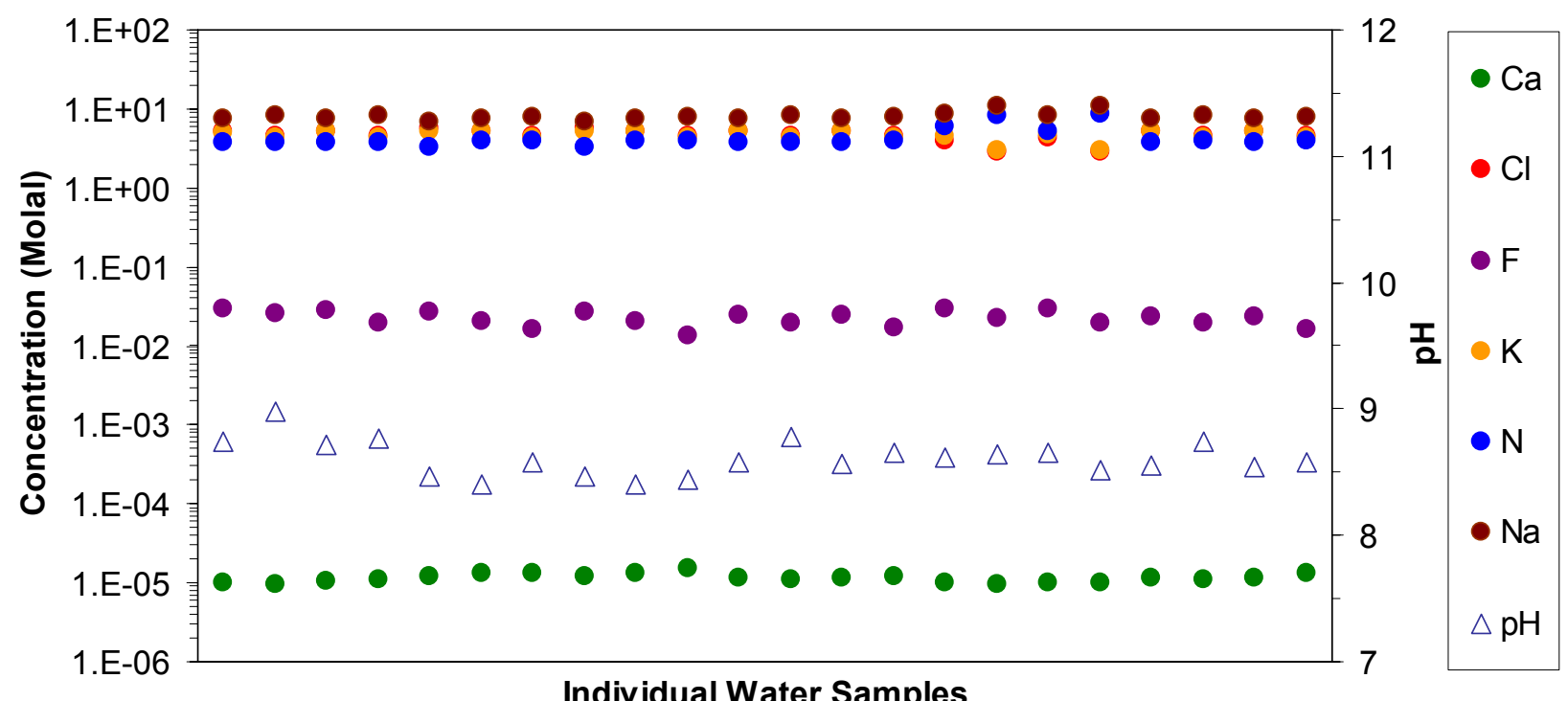

Individual Water Samples

Source: Output DTN: MO0508SPAEBSCB.001.

NOTE: Individual compositions are grouped vertically by data points.

Figure 6.6-12. Evaporated Water Compositions for Bin 8 after Evaporation to 65\% Relative Humidity 


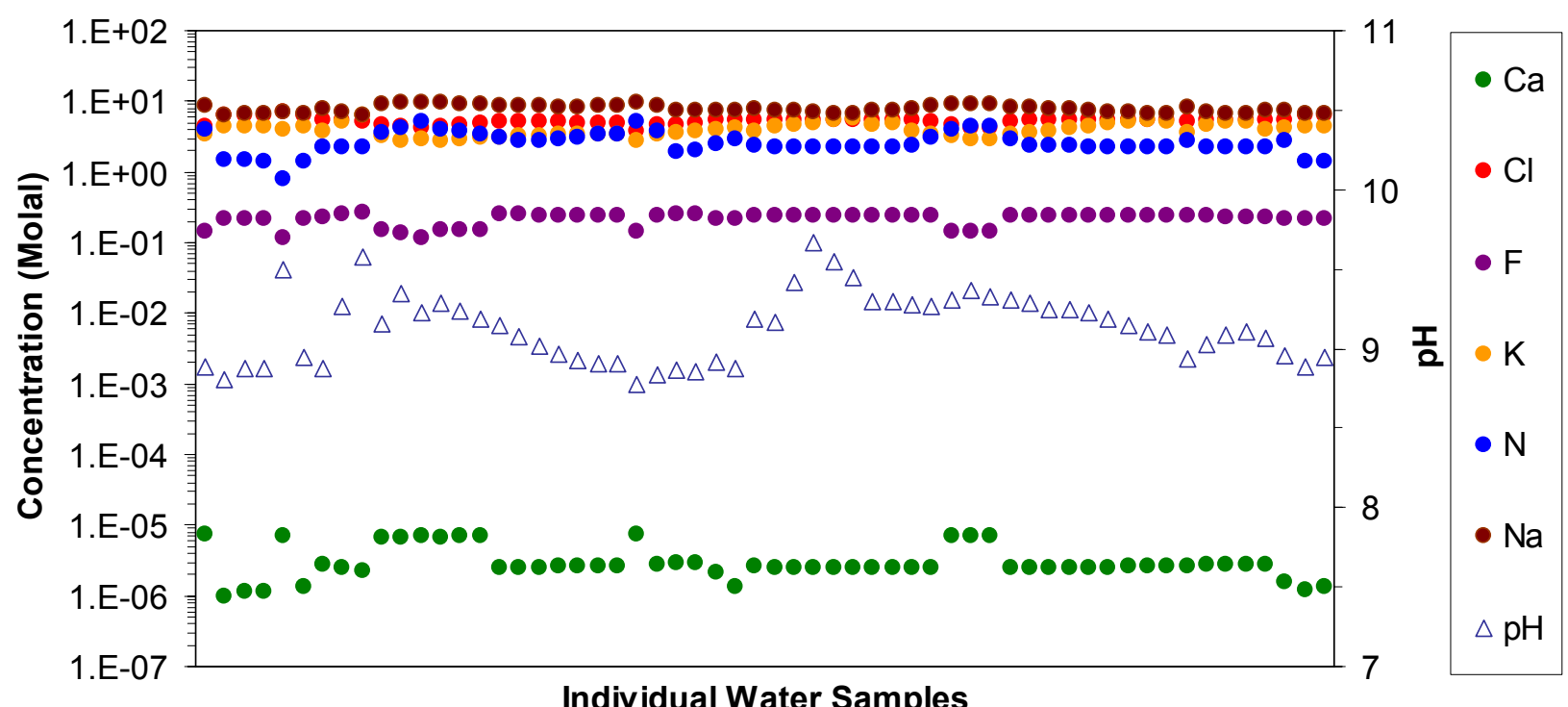

Source: Output DTN: MO0508SPAEBSCB.001.

NOTE: Individual compositions are grouped vertically by data points.

Figure 6.6-13. Evaporated Water Compositions for Bin 9 after Evaporation to $65 \%$ Relative Humidity

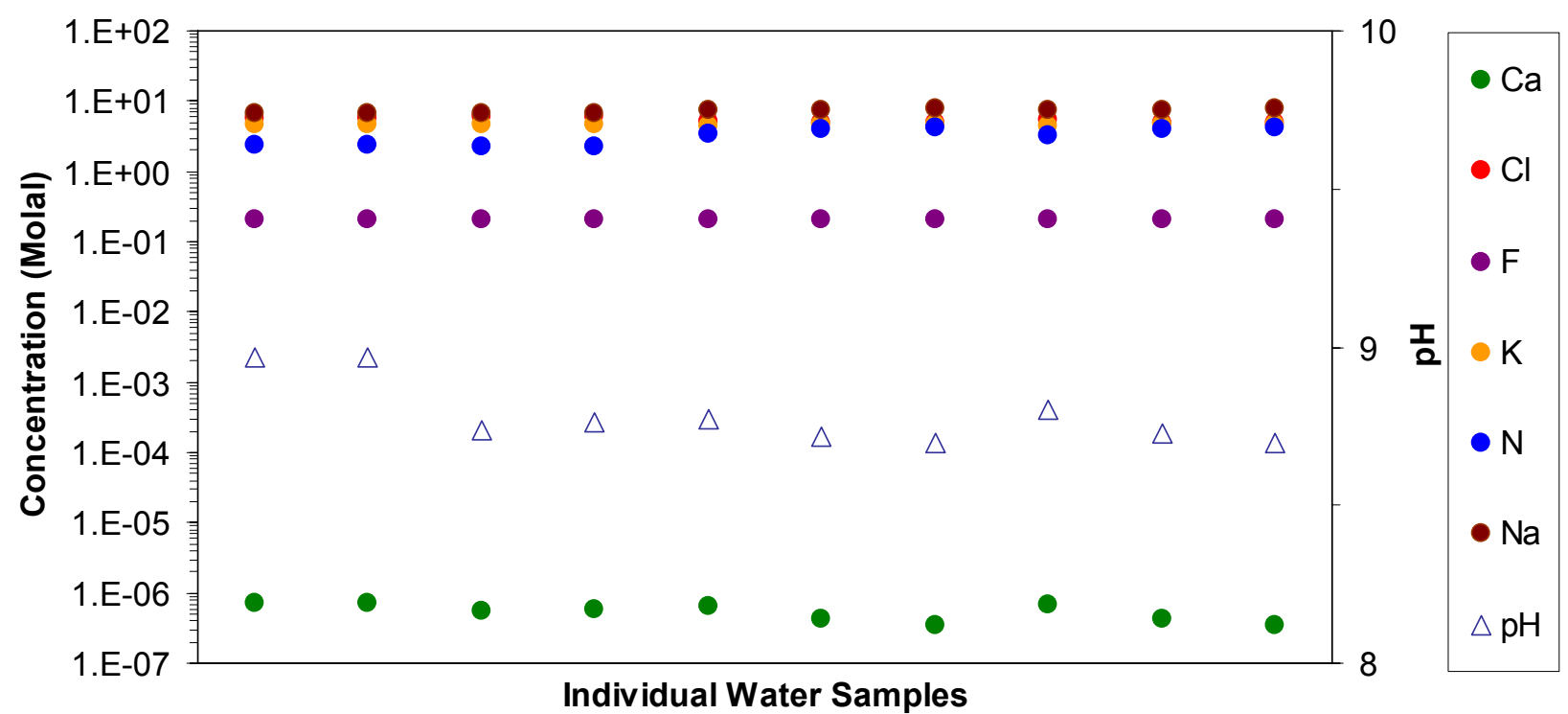

Source: Output DTN: MO0508SPAEBSCB.001.

NOTE: Individual compositions are grouped vertically by data points.

Figure 6.6-14. Evaporated Water Compositions for Bin 10 after Evaporation to 65\% Relative Humidity 


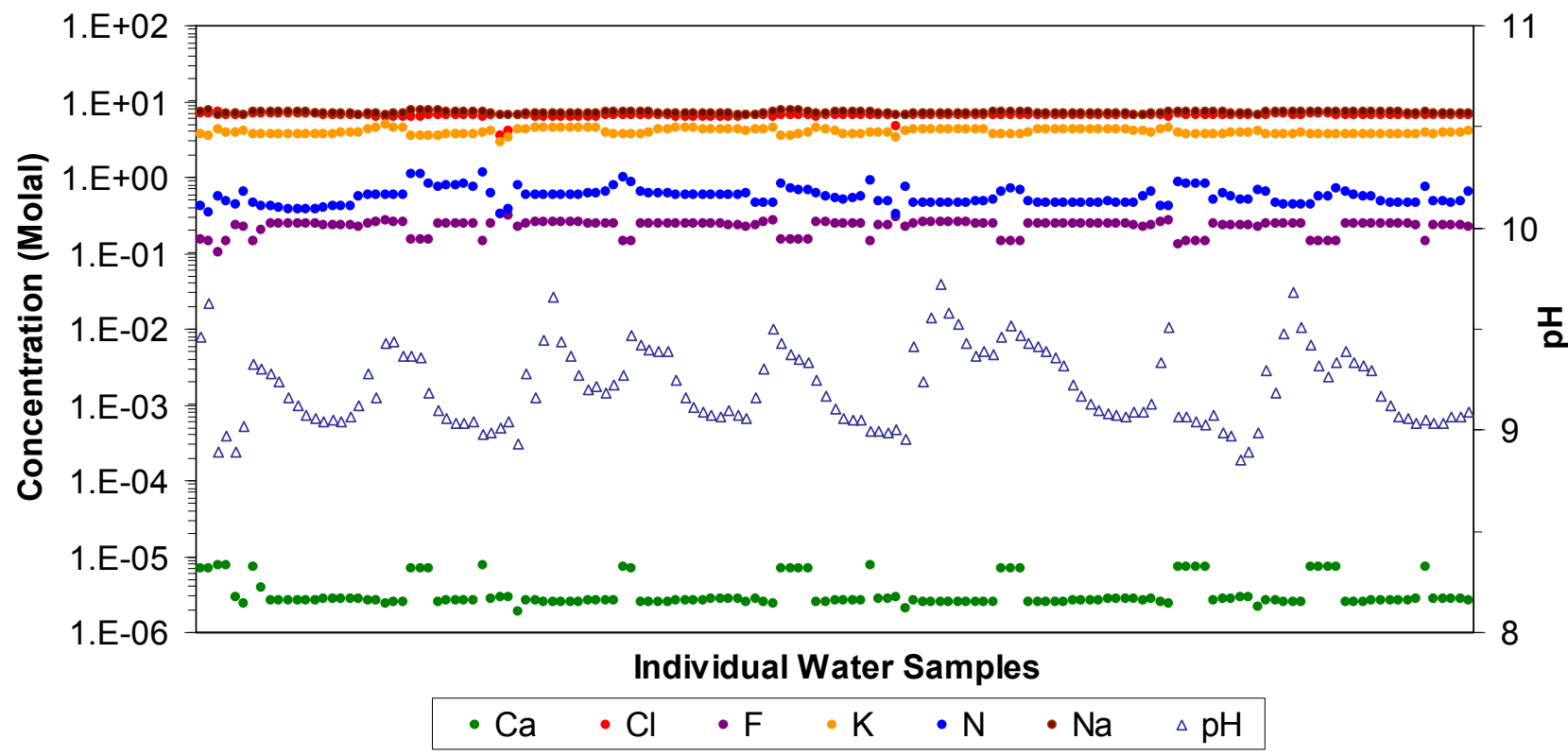

Source: Output DTN: MO0508SPAEBSCB.001.

NOTE: Individual compositions are grouped vertically by data points.

Figure 6.6-15. Evaporated Water Compositions for Bin 11 after Evaporation to 65\% Relative Humidity

Binning Efficacy-The effectiveness of the binning process is measured by how well it reduces the variability of important chemical parameters. Table 6.6-4 demonstrates that the binning procedure was effective in segregating the water chemistries. For example, the overall standard deviation in $\mathrm{pH}$ of all $65 \%$ relative humidity waters is 1.12 , while the average of the standard deviations of those waters in their eleven bins is 0.20 (nearly a factor of 6 decrease in the standard deviation). Binning is also very effective for calcium (reduced deviation by factor of 7), and somewhat effective for segregating chloride and nitrate (near a factor of 2 reduction in deviation).

Table 6.6-4. Standard Deviation of In-Drift Water Chemistry at 65\% Relative Humidity, before and after Binning

\begin{tabular}{|l|r|c|c|c|c|}
\hline Bin & $\begin{array}{c}\text { Waters } \\
\text { (n) }\end{array}$ & $\begin{array}{c}\text { Standard } \\
\text { Deviation } \\
\text { of } \mathbf{~ p H}\end{array}$ & $\begin{array}{c}\text { Standard } \\
\text { Deviation of Ca } \\
\text { (molal) }\end{array}$ & $\begin{array}{c}\text { Standard } \\
\text { Deviation of Cl } \\
\text { (molal) }\end{array}$ & $\begin{array}{c}\text { Standard } \\
\text { Deviation of } \text { NO }_{3} \\
\text { (molal) }\end{array}$ \\
\hline Bin 1 & 5 & 0.08 & 0.29 & 0.92 & 1.05 \\
\hline Bin 2 & 13 & 0.11 & 0.28 & 0.68 & 0.83 \\
\hline Bin 3 & 12 & 0.24 & 0.42 & 0.4 & 0.56 \\
\hline Bin 4 & 43 & 0.34 & $<0.01$ & 1.87 & 2.79 \\
\hline Bin 5 & 27 & 0.29 & $<0.01$ & 0.32 & 0.56 \\
\hline Bin 6 & 8 & 0.37 & $<0.01$ & 1.65 & 2.73 \\
\hline Bin 7 & 25 & 0.16 & $<0.01$ & 0.5 & 0.81 \\
\hline Bin 8 & 22 & 0.14 & $<0.01$ & 0.73 & 1.43 \\
\hline Bin 9 & 58 & 0.22 & $<0.01$ & 0.61 & 0.91 \\
\hline
\end{tabular}


Table 6.6-4. Standard Deviation of In-Drift Water Chemistry at 65\% Relative Humidity, before and after Binning (Continued)

\begin{tabular}{|l|c|c|c|c|c|}
\hline \multicolumn{1}{|c|}{ Bin } & $\begin{array}{c}\text { Waters } \\
\text { (n) }\end{array}$ & $\begin{array}{c}\text { Standard } \\
\text { Deviation } \\
\text { of pH }\end{array}$ & $\begin{array}{c}\text { Standard } \\
\text { Deviation of Ca } \\
\text { (molal) }\end{array}$ & $\begin{array}{c}\text { Standard } \\
\text { Deviation of Cl } \\
\text { (molal) }\end{array}$ & $\begin{array}{c}\text { Standard } \\
\text { Deviation of } \text { NO }_{3} \\
\text { (molal) }\end{array}$ \\
\hline Bin 10 & 10 & 0.1 & $<0.01$ & 0.5 & 0.85 \\
\hline Bin 11 & 145 & 0.19 & $<0.01$ & 0.39 & 0.15 \\
\hline $\begin{array}{l}\text { Average } \\
\text { Bins 1 to 11 }\end{array}$ & 368 & 0.2 & 0.09 & 0.78 & 1.15 \\
\hline $\begin{array}{l}\text { All Waters, } \\
\text { no binning }\end{array}$ & 368 & 1.12 & 0.63 & 1.21 & 1.94 \\
\hline
\end{tabular}

A second binning approach that uses characteristic properties of precipitating mineral assemblages to sort and generate the bins has also been evaluated. This approach is considered an alternative conceptual model and is documented in Section 6.11.

\subsubsection{Choice of Representative Evaporated Seepage Water for Each Bin (Step 4)}

A median evaporated seepage water composition for each bin is chosen to represent all evaporated seepage water compositions in that bin. Table 6.6-5 provides the median water identifiers for each of the eleven bins defined in Section 6.6.4, and Table 6.6-6 provides the median evaporated seepage water compositions for each bin. A description of the method for that process is as follows. All 368 unevaporated seepage water compositions corresponding to the evaporated waters binned in Step 3 are sorted by bin and copied into separate bin worksheets (e.g., "Bin 11 abstract", "Bin 10 abstract," etc.). This information is found in the data and plots worksheet in Final Checked EBS Seepage Binning Abstraction Rev 4.xls (Output DTN: MO0508SPAEBSCB.001). These worksheets are used to determine a representative median water for each bin, as well as individual bin statistics. In so doing, the analysis further reduces from 368 to 11 the set of representative evaporated seepage waters. These 11 water compositions are then used as inputs into the seepage evaporation abstraction calculations performed in Section 6.9. 
Table 6.6-5. Median Water Identifier and Percentage in Each Bin

\begin{tabular}{|c|c|c|c|c|}
\hline \multicolumn{3}{|c|}{ Water Compositions } & \multirow[b]{2}{*}{ Number of Waters } & \multirow{2}{*}{$\begin{array}{c}\% \text { of All Evaporated Waters } \\
\text { Represented }\end{array}$} \\
\hline Case & Water & Filename & & \\
\hline Bin 1 & w7bf4 & 75.60 & 5 & 1.36 \\
\hline Bin 2 & w0bf4 & 250.60 & 13 & 3.53 \\
\hline Bin 3 & w0bf4 & 650.60 & 12 & 3.26 \\
\hline Bin 4 & w4bf4 & 600.60 & 43 & 11.68 \\
\hline Bin 5 & w7tf4 & 300.60 & 27 & 7.34 \\
\hline $\operatorname{Bin} 6$ & w0tf4 & 7004.60 & 8 & 2.17 \\
\hline $\operatorname{Bin} 7$ & w4bf4 & 10006.60 & 25 & 6.79 \\
\hline Bin 8 & w5tf4 & 20013.60 & 22 & 5.98 \\
\hline Bin 9 & w6tf4 & 51.60 & 58 & 15.76 \\
\hline Bin 10 & w5bf4 & 10006.60 & 10 & 2.72 \\
\hline Bin 11 & w4tf4 & 300.60 & 145 & 39.40 \\
\hline
\end{tabular}

Source: Output DTN: MO0508SPAEBSCB.001.

The selected bin chemistry is as close to the median chemistry (within the bin) as can be obtained without actually using the median, minimum, and maximum values calculated in each bin for each independent aqueous species. This approach is designed to maintain consistency with the evaporated EQ6 results, because the starting water used in the EQ3/6 evaluation is a specific time-dependent result from the THC model. In addition, this approach maintains charge balance (sum of cations versus anions), which is important in evaporation calculations.

Median Water-A methodology is used to determine the median water from each of the 11 bins. Internal Excel functions are used to determine the statistical rank (1 through 12) for each set of twelve parameters (i.e., $\mathrm{pH}, \mathrm{Al}, \mathrm{C}, \mathrm{Ca}, \mathrm{Cl}, \mathrm{F}, \mathrm{K}, \mathrm{Mg}, \mathrm{N}, \mathrm{Na}, \mathrm{S}$, and $\mathrm{Si}$ ) among all the waters in an individual bin. A median water is selected by determining which waters contain the median value for each parameter, and then using the COUNTIF function, and then summing the number of these median value parameters captured by each water in the bin. If two waters of a single bin contain equivalent numbers of median value parameters, then the number of "near median" values (parameter values on either side of the median) are next considered, with the water containing the greatest number of these then being designated as the median water to represent the bin. Table 6.6-5 lists the water selection results of the median water for each bin.

In addition, the distribution of all waters is calculated among the bins by counting the total number of waters contained within each bin and determining the percentage of waters represented in each bin; these results are also shown in Table 6.6-5. Bin 11 contains the largest number of waters and thus is the most likely median water. Bins 4, 9, and 11 make up the composition of over $66 \%$ of all of the waters. Each of the EQ6 filenames listed in Table 6.6-5 were mapped back to the values found on the THC spreadsheets listed in Table 6.6-1 to create Table 6.6-6 which contains the 11 complete starting water compositions and associated partial pressures of carbon dioxide.

Within each of the 11 "bin abstract" worksheets, the median, minimum, maximum standard deviation $(\sigma)$, and two standard deviations $(2 \sigma)$ are calculated. Table 6.6-7 contains the individual parameter statistics for each bin, which, when compared to similar statistics for data 
shown on the data and plots worksheet, indicate that the within-bin statistics are generally much smaller than the entire group of data (Table 6.6-8).

\subsubsection{Analysis of THC Model Outputs: Defining Time Sequences of Bins for Seepage Water Composition Time Histories from THC Model Outputs}

In this section, each THC model realization (time history of seepage water compositions) is related to the evaporated seepage water bin median compositions in the form of a time-sequence. For simplicity, the term "bin," henceforth, refers to the median composition for a bin, as well as to its contents, and the term "bin map" refers to time sequences of evaporated seepage water bin median compositions related to a THC model realization.

The bin maps for THC outputs are generated using the bin definitions given in Section 6.6.4 and the THC output time defined in Section 6.6.2 (Step 1). The following bin-mapping process was applied to each of the ten combinations of water composition parameter (QUADR, ZONE, and INDEX) values, and worksheets (fractures-ch and matrix-ch) from THC model outputs (defined in Section 6.6.2, Step 1; summarized in Table 6.6-1):

1. Define a time interval around each of the THC output time values that are identified in Step 1 of the binning process (Section 6.6.2 and fourth and fifth columns of Table 6.6-1) for each of the combinations described above (e.g., the combination for case w0tf4). Begin and end the time intervals approximately midway between adjacent time values. For example, in Table 6.6-9 (applicable to water w0) for the THC output time value of 800 years (in EQ6 output filename 800.60), the time interval begins at 794.5 years (between 789 and 800 years) and ends at 900 years (between 800 and 1,000 years).

2. Assign to that time interval the bin (bin median composition) that contains the seepage water composition from the THC output at the output time around which the time interval was defined. For example, in Table 6.6-9, Bin 11 is assigned to time interval 794.5 up to, not including, 900 years for crown seepage (Quadrant $=$ Top), because the THC seepage water output composition for case w0tf4 at 800 years (EQ6 output filename 800.6) is placed into Bin 11 during the binning process.

3. Sequentially repeat items 1 and 2, directly above, for each THC output time.

Each combination is given a case abbreviation in the third column of Table 6.6-1. The first, second, and last periods for each case are special cases. The bin assigned to the 10-year output represents the period from 0 years up to (but not including) 50 years. The 51-year output is binned for the period from 50 up to 52 years. Lastly, the 50,034-year output is binned for the period from $35,023.5$ up to 100,000 years.

Tables 6.6-9 through 6.6-13 provide the maps for each THC seepage water used in the binning analysis. The graphic plots of Figures 6.6-16 through 6.6-25 compare the binning assignments to the evaporated THC outputs. These figures graphically illustrate that the bins cover the changes in chemistry at $65 \%$ relative humidity through time. For example, peaks and valleys in the chemistry output correspond to a visible change in assigned bins. 
Table 6.6-6. Initial Compositions of the 11 Binned THC Seepage Waters

\begin{tabular}{|c|c|c|c|c|c|c|c|c|c|c|c|}
\hline Species & Bin 1 & $\operatorname{Bin} 2$ & Bin 3 & Bin 4 & Bin 5 & $\operatorname{Bin} 6$ & $\operatorname{Bin} 7$ & Bin 8 & $\operatorname{Bin} 9$ & Bin 10 & Bin 11 \\
\hline $\begin{array}{c}\text { Water I } \\
\text { File Name }\end{array}$ & $\begin{array}{c}\text { w7bf4 I } \\
75.60\end{array}$ & $\begin{array}{l}\text { w0bf4 I } \\
250.60\end{array}$ & $\begin{array}{l}\text { w0bf4 I } \\
650.60\end{array}$ & $\begin{array}{l}\text { w4bf4 I } \\
600.60\end{array}$ & $\begin{array}{l}\text { w7tf4 I } \\
300.60\end{array}$ & $\begin{array}{c}\text { w0tf4 I } \\
7004.60 \\
\end{array}$ & $\begin{array}{c}\text { w4bf4 I } \\
10006.60\end{array}$ & $\begin{array}{c}\text { w5tf4 I } \\
20013.60\end{array}$ & $\begin{array}{c}\text { w6tf4 I } \\
51.60\end{array}$ & $\begin{array}{c}\text { w5bf4 / } \\
10006.60\end{array}$ & $\begin{array}{l}\text { w4tf4 I } \\
300.60\end{array}$ \\
\hline $\mathrm{T}\left({ }^{\circ} \mathrm{C}\right)$ & 111.9 & 109.1 & 104.3 & 104.9 & 95.62 & 65.13 & 56.34 & 40.18 & 91.78 & 56.34 & 95.61 \\
\hline $\mathrm{pH}$ & 7.407 & 7.583 & 7.615 & 7.896 & 7.634 & 7.695 & 7.768 & 7.94 & 8.139 & 7.815 & 7.759 \\
\hline $\mathrm{Ca}^{2+}$ & $1.75 \mathrm{E}-02$ & $6.49 \mathrm{E}-03$ & $2.14 \mathrm{E}-03$ & $1.08 \mathrm{E}-03$ & 1.36E-03 & $4.20 \mathrm{E}-04$ & $4.46 \mathrm{E}-04$ & 5.73E-04 & $7.24 \mathrm{E}-05$ & $3.52 E-04$ & 3.34E-04 \\
\hline $\mathrm{Mg}^{2+}$ & $1.70 \mathrm{E}-05$ & $2.95 \mathrm{E}-06$ & 4.13E-06 & $5.75 \mathrm{E}-07$ & 1.13E-05 & $4.82 \mathrm{E}-05$ & $5.52 \mathrm{E}-05$ & $8.51 \mathrm{E}-05$ & $2.54 \mathrm{E}-07$ & $4.31 \mathrm{E}-05$ & $6.34 \mathrm{E}-06$ \\
\hline $\mathrm{Na}^{+}$ & $3.89 \mathrm{E}-03$ & $2.63 \mathrm{E}-03$ & $2.67 \mathrm{E}-03$ & $1.26 \mathrm{E}-03$ & 5.53E-03 & $8.09 \mathrm{E}-03$ & $7.65 \mathrm{E}-03$ & $7.31 \mathrm{E}-03$ & $4.27 \mathrm{E}-03$ & $6.82 \mathrm{E}-03$ & $4.80 \mathrm{E}-03$ \\
\hline $\mathrm{Cl}^{-}$ & $2.01 \mathrm{E}-02$ & $5.02 \mathrm{E}-03$ & $3.35 \mathrm{E}-03$ & 1.03E-03 & $3.28 \mathrm{E}-03$ & $3.32 \mathrm{E}-03$ & 7.44E-04 & $5.61 \mathrm{E}-04$ & 7.34E-04 & $6.00 \mathrm{E}-04$ & 1.30E-03 \\
\hline $\mathrm{SiO}_{2}(\mathrm{aq})$ & $9.42 \mathrm{E}-03$ & 7.42E-03 & $6.96 \mathrm{E}-03$ & $7.38 \mathrm{E}-03$ & 1.22E-02 & $2.90 \mathrm{E}-03$ & $2.46 \mathrm{E}-03$ & $1.79 \mathrm{E}-03$ & $4.15 \mathrm{E}-03$ & $2.47 \mathrm{E}-03$ & 1.19E-02 \\
\hline $\mathrm{HCO}_{3}^{-}$ & 5.57E-05 & $9.06 \mathrm{E}-05$ & $1.95 \mathrm{E}-04$ & 1.64E-04 & $4.18 \mathrm{E}-04$ & $2.93 \mathrm{E}-03$ & $6.72 \mathrm{E}-03$ & $6.92 \mathrm{E}-03$ & $2.04 \mathrm{E}-03$ & $5.74 \mathrm{E}-03$ & 1.13E-03 \\
\hline $\mathrm{SO}_{4}^{2-}$ & 8.87E-03 & 4.89E-03 & $1.50 \mathrm{E}-03$ & $5.88 \mathrm{E}-04$ & 1.77E-03 & $1.21 \mathrm{E}-03$ & 4.12E-04 & $3.55 \mathrm{E}-04$ & 1.18E-04 & $3.80 \mathrm{E}-04$ & $7.29 \mathrm{E}-04$ \\
\hline $\mathrm{K}^{+}$ & $8.68 \mathrm{E}-04$ & $5.40 \mathrm{E}-04$ & $5.00 \mathrm{E}-04$ & $2.38 \mathrm{E}-04$ & $8.68 \mathrm{E}-04$ & $6.25 \mathrm{E}-04$ & 4.67E-04 & $2.76 \mathrm{E}-04$ & $5.02 \mathrm{E}-04$ & 4.17E-04 & $7.50 \mathrm{E}-04$ \\
\hline $\mathrm{AlO}_{2}$ & $3.27 \mathrm{E}-08$ & $7.08 \mathrm{E}-08$ & $5.02 \mathrm{E}-08$ & 9.97E-08 & 8.03E-10 & $5.36 \mathrm{E}-09$ & 3.62E-09 & $1.50 \mathrm{E}-09$ & $6.09 \mathrm{E}-08$ & 4.03E-09 & \begin{tabular}{|l|}
$1.42 \mathrm{E}-09$ \\
\end{tabular} \\
\hline $\mathrm{F}^{-}$ & 1.93E-04 & $2.46 \mathrm{E}-04$ & $3.48 \mathrm{E}-04$ & $4.28 \mathrm{E}-04$ & $1.00 \mathrm{E}-03$ & $8.26 \mathrm{E}-04$ & $7.81 \mathrm{E}-04$ & $6.43 \mathrm{E}-04$ & 9.77E-04 & $8.61 \mathrm{E}-04$ & 1.38E-03 \\
\hline $\mathrm{NO}_{3}{ }^{-}$ & $1.30 \mathrm{E}-03$ & $5.46 \mathrm{E}-04$ & $1.83 \mathrm{E}-04$ & $1.33 \mathrm{E}-04$ & $2.22 \mathrm{E}-04$ & $1.04 \mathrm{E}-04$ & $6.87 \mathrm{E}-05$ & 3.97E-05 & $3.10 \mathrm{E}-04$ & $4.25 \mathrm{E}-05$ & 1.26E-04 \\
\hline $\mathrm{CO}_{2}(\mathrm{~g})$ (bar) & $3.89 \mathrm{E}-04$ & 4.93E-04 & $1.04 \mathrm{E}-03$ & $4.88 \mathrm{E}-04$ & 1.88E-03 & 7.06E-03 & 1.19E-02 & $6.34 \mathrm{E}-03$ & $2.94 \mathrm{E}-03$ & $9.19 \mathrm{E}-03$ & 4.06E-03 \\
\hline $\log \mathrm{CO}_{2}(\mathrm{~g})$ & -3.410 & -3.307 & -2.984 & -3.312 & -2.726 & -2.151 & -1.926 & -2.198 & -2.532 & -2.037 & -2.392 \\
\hline
\end{tabular}

Source: Output DTN: MO0508SPAEBSCB.001

NOTE: Unless otherwise marked, units are in molal. Species are those designated by THC model output in DTN: LB0302DSCPTHCS.002 [DIRS 161976]. 


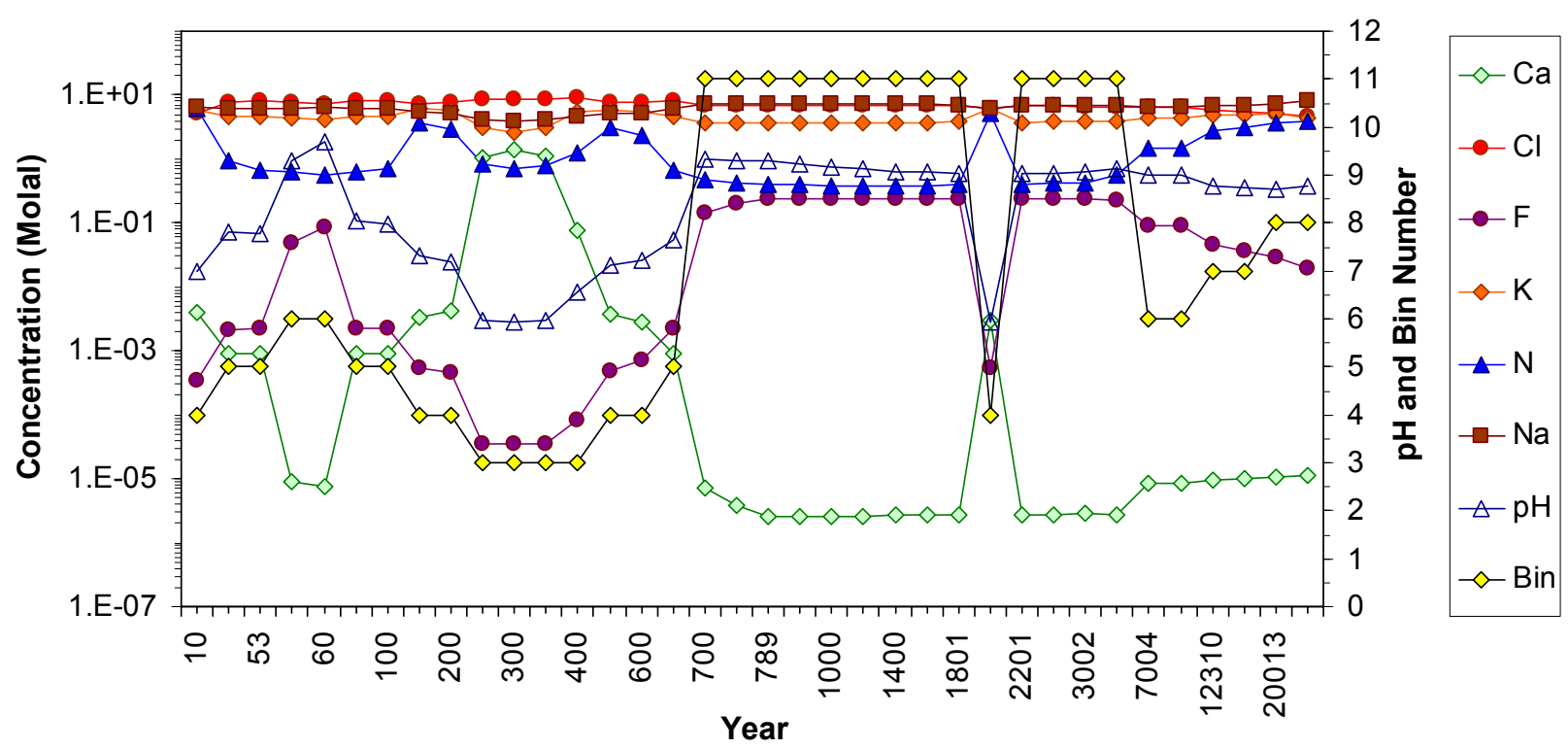

Source: Output DTN: MO0508SPAEBSCB.001.

Figure 6.6-16. Bins for Evaporated Crown Seepage: Case w0tf4

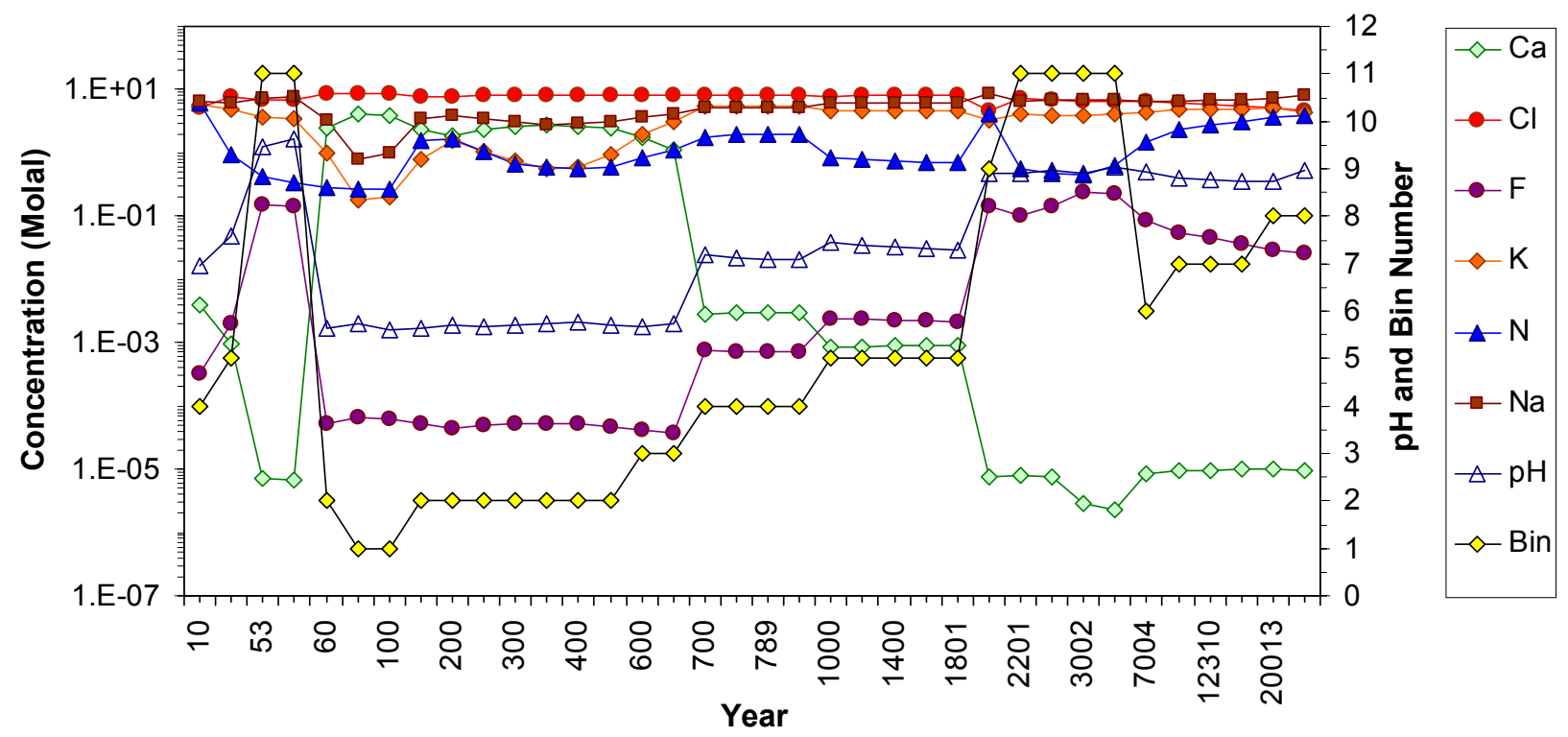

Source: DTN: Output MO0508SPAEBSCB.001.

Figure 6.6-17. Bins for Evaporated Invert Seepage: Case w0bf4 


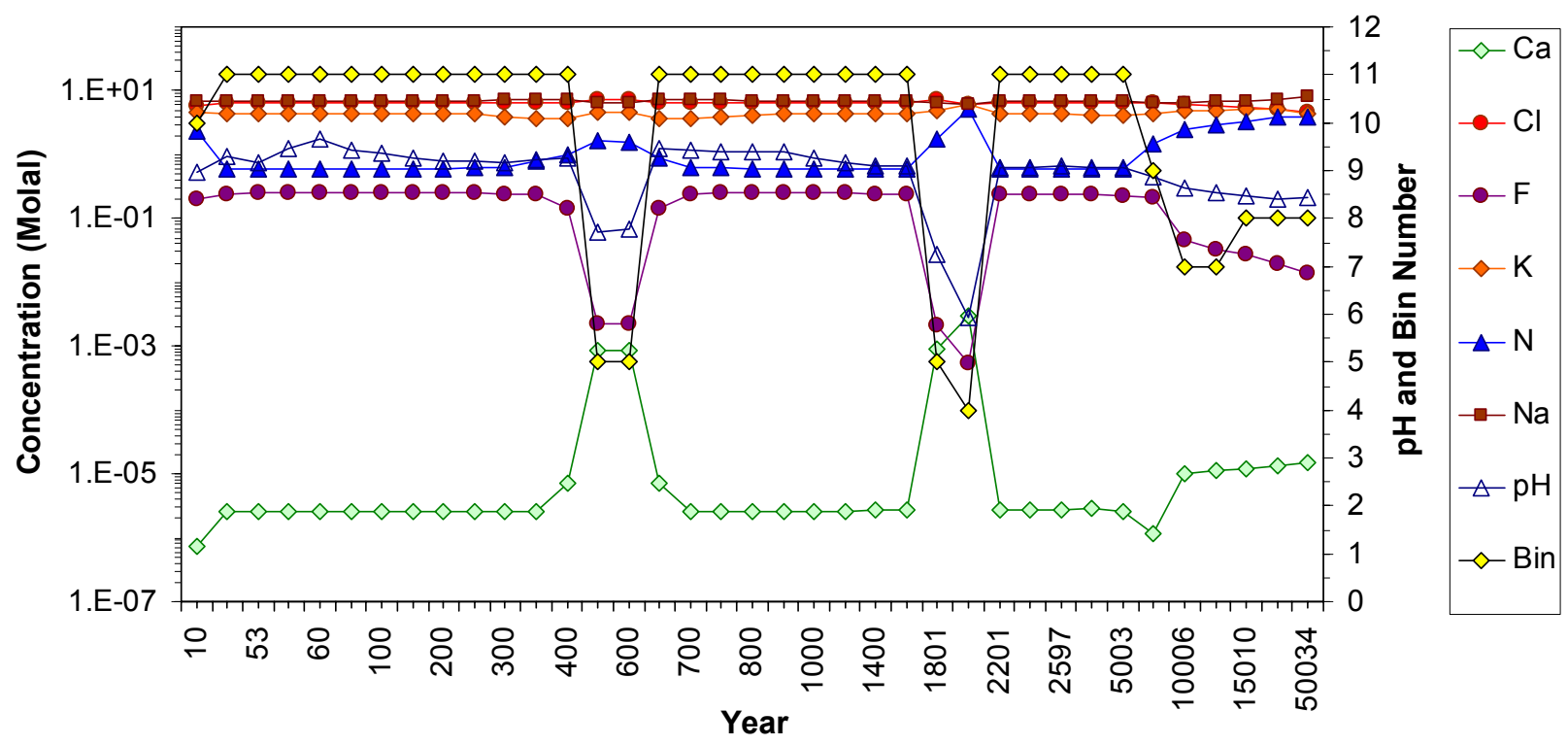

Source: Output DTN: MO0508SPAEBSCB.001.

Figure 6.6-18. Bins for Evaporated Crown Seepage: Case w4tf4

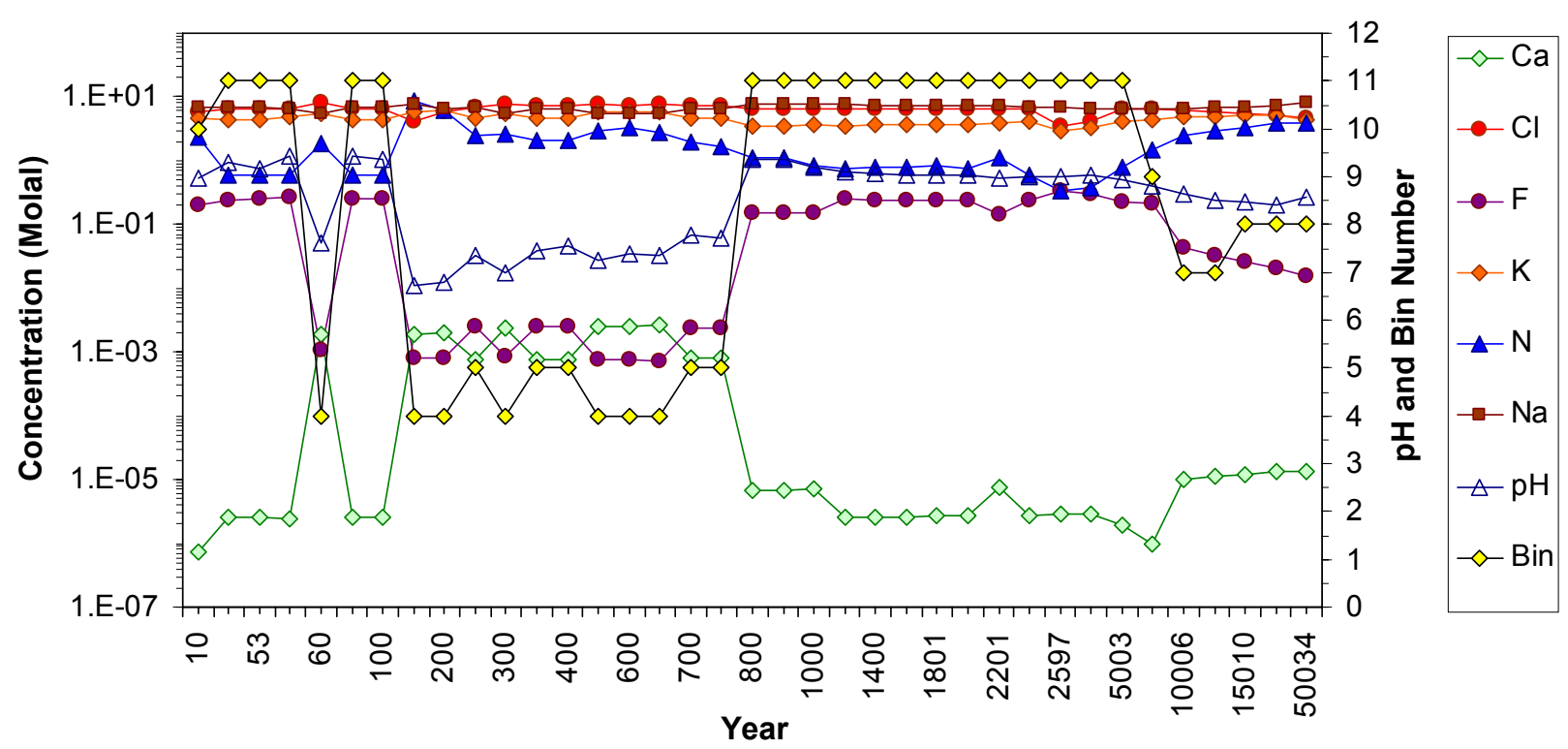

Source: Output DTN: MO0508SPAEBSCB.001.

Figure 6.6-19. Bins for Evaporated Invert Seepage: Case w4bf4 


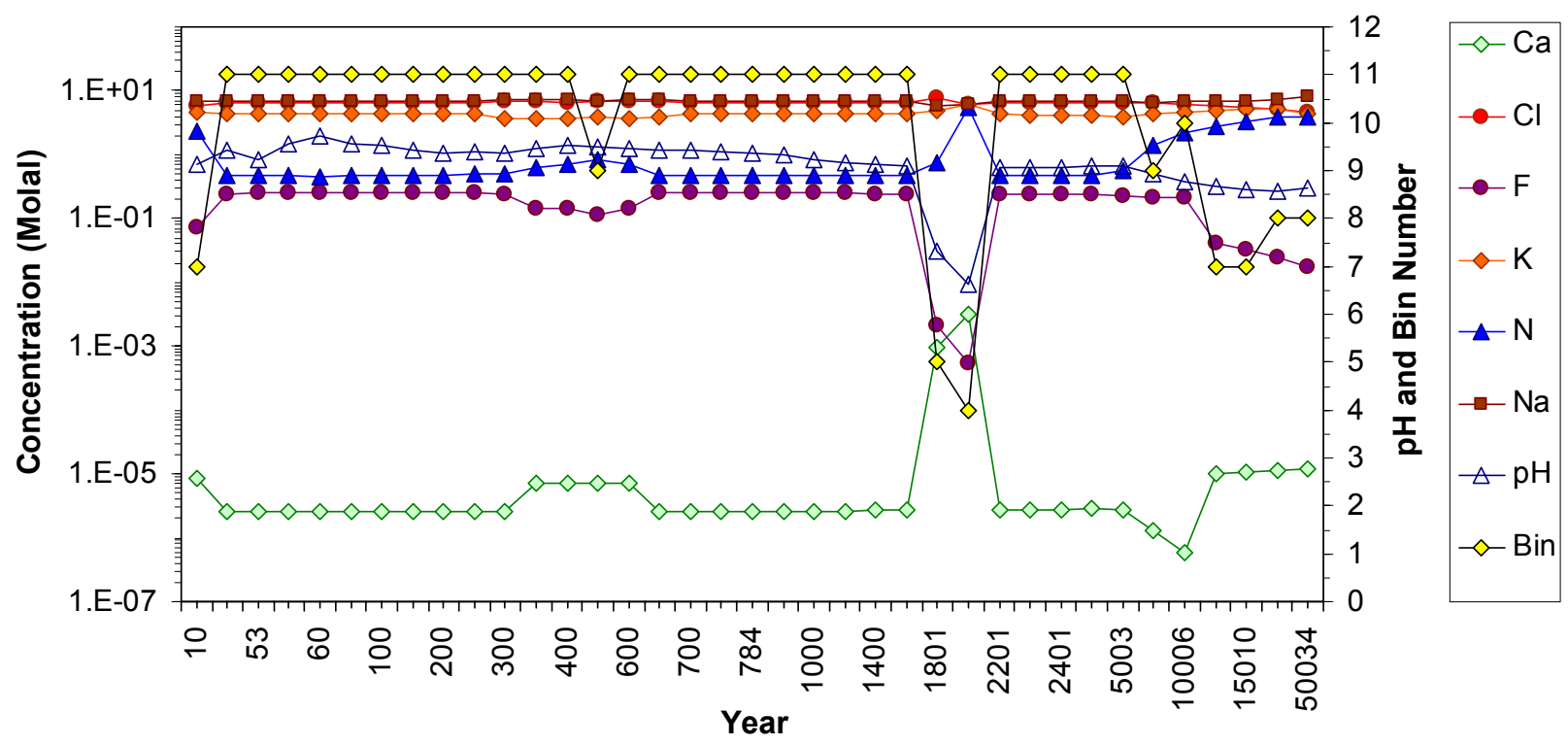

Source: Output DTN: MO0508SPAEBSCB.001.

Figure 6.6-20. Bins for Evaporated Crown Seepage: Case w5tf4

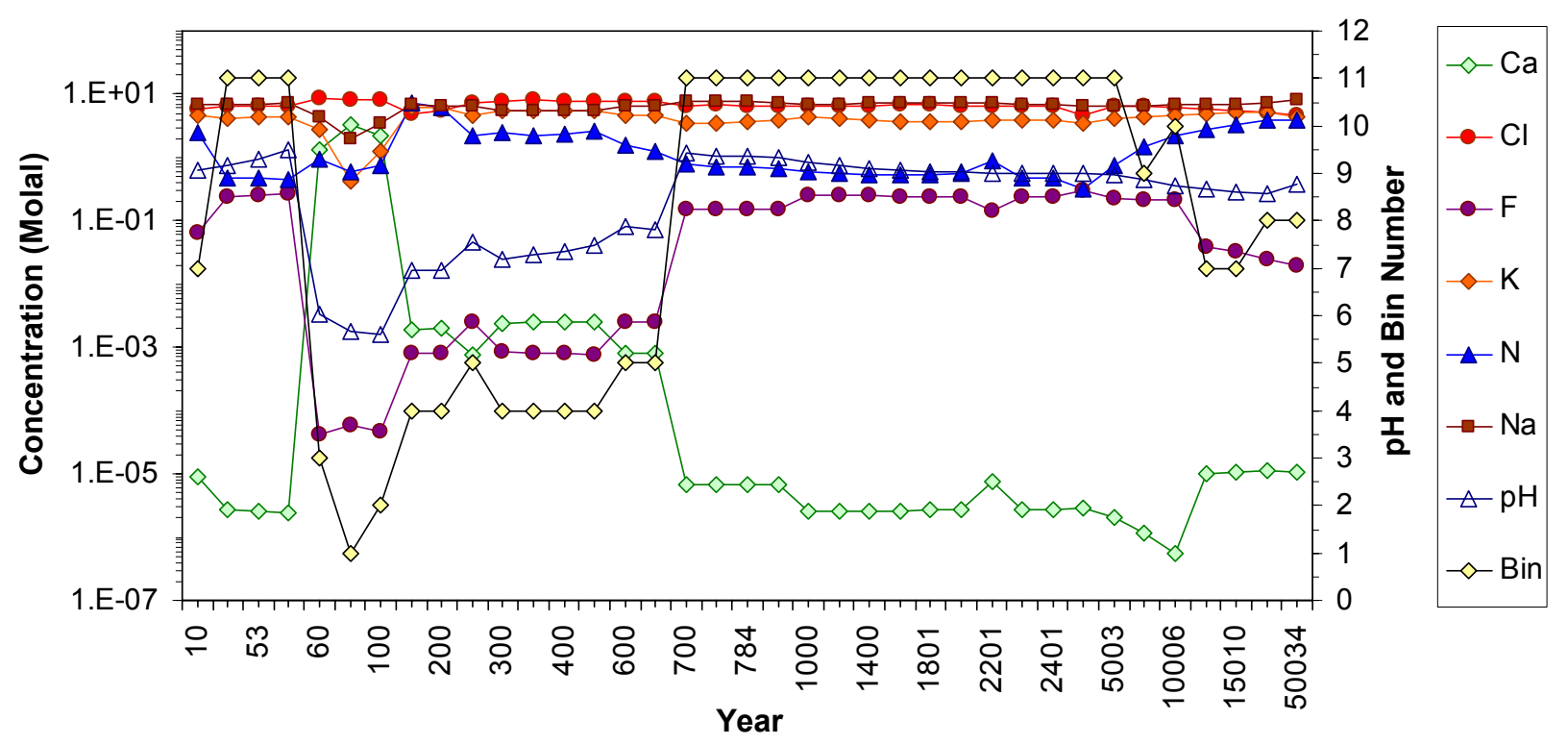

Source: Output DTN: MO0508SPAEBSCB.001.

Figure 6.6-21. Bins for Evaporated Invert Seepage: Case w5bf4 


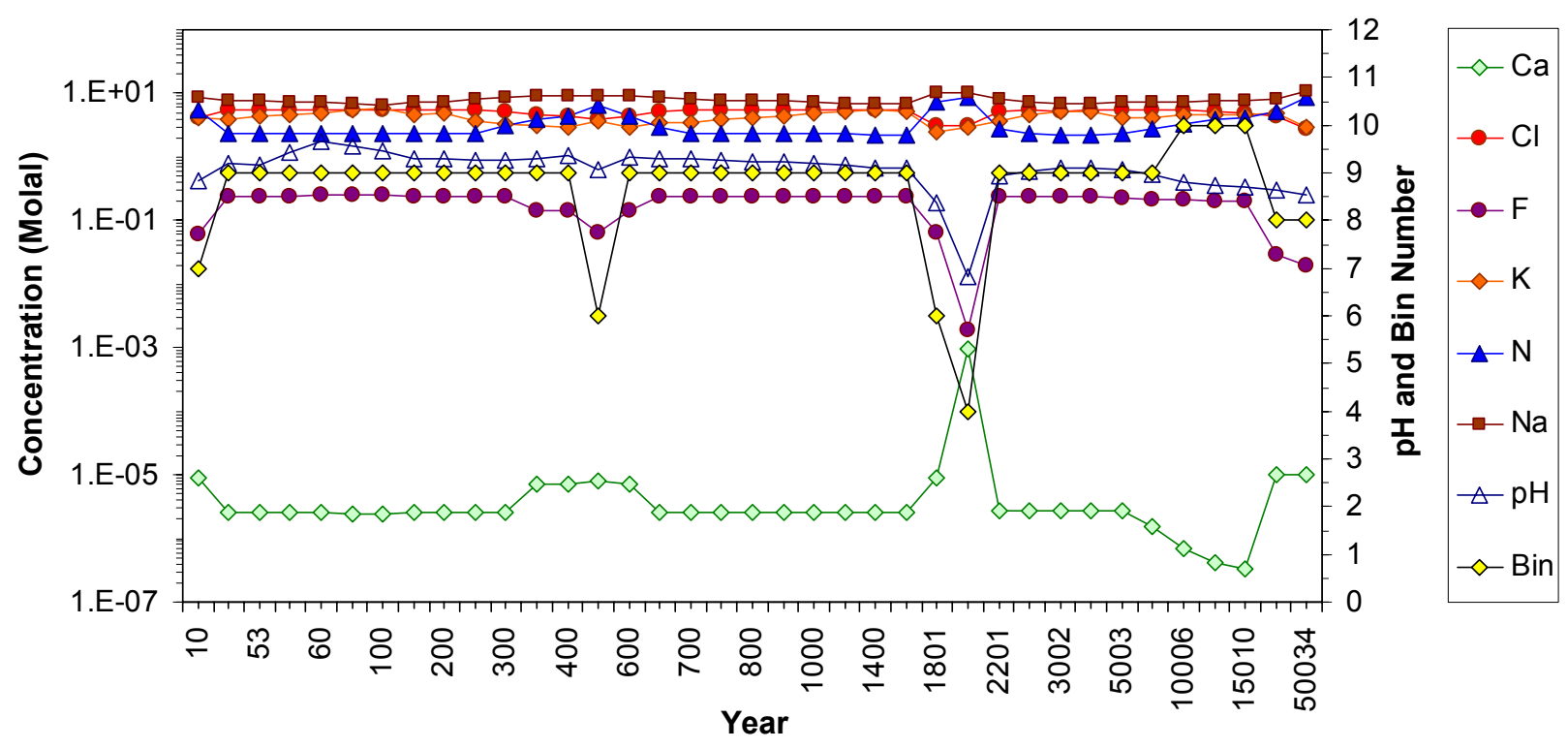

Source: Output DTN: MO0508SPAEBSCB.001.

Figure 6.6-22. Bins for Evaporated Invert Seepage: Case w6tf4

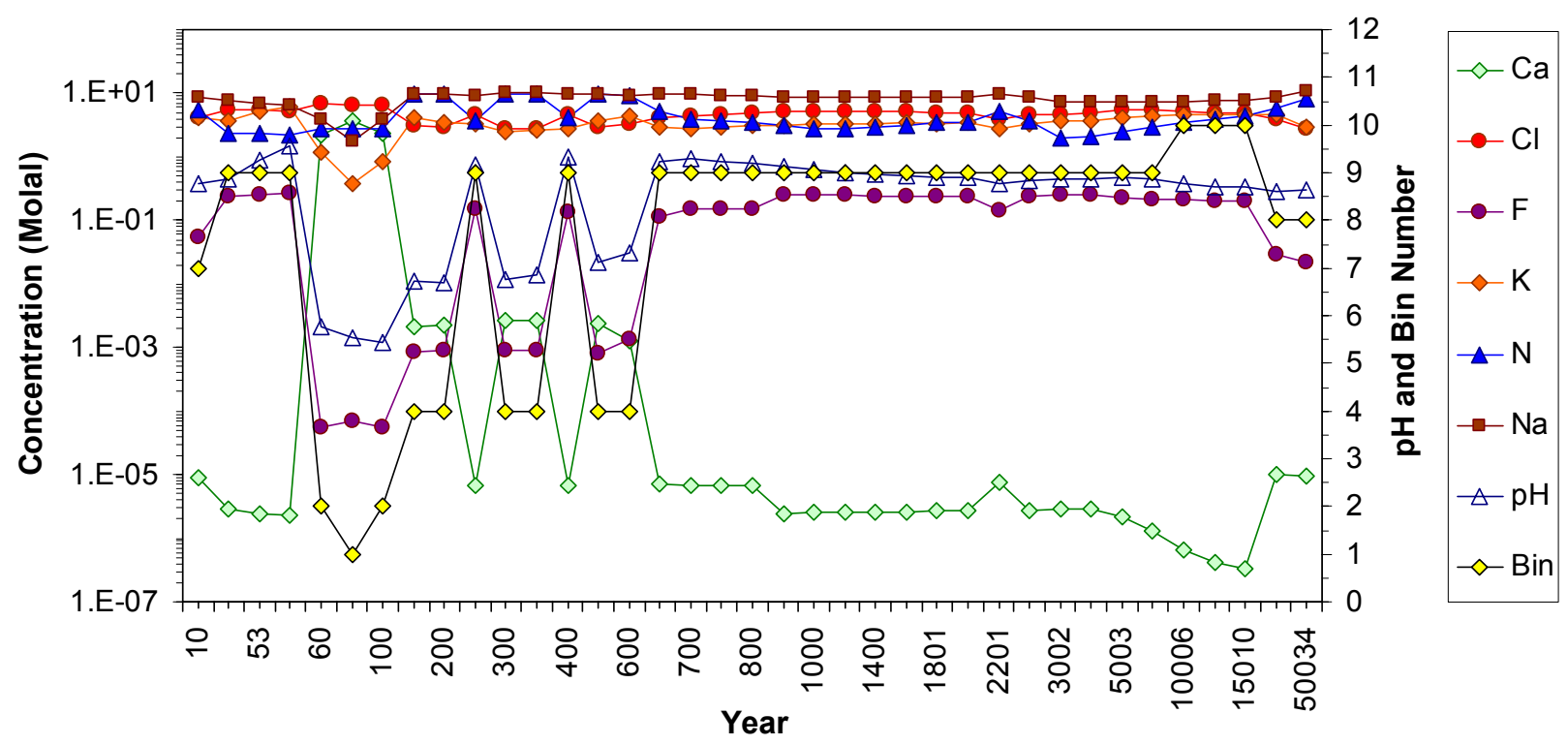

Source: Output DTN: MO0508SPAEBSCB.001.

Figure 6.6-23. Bins for Evaporated Invert Seepage: Case w6bf4 


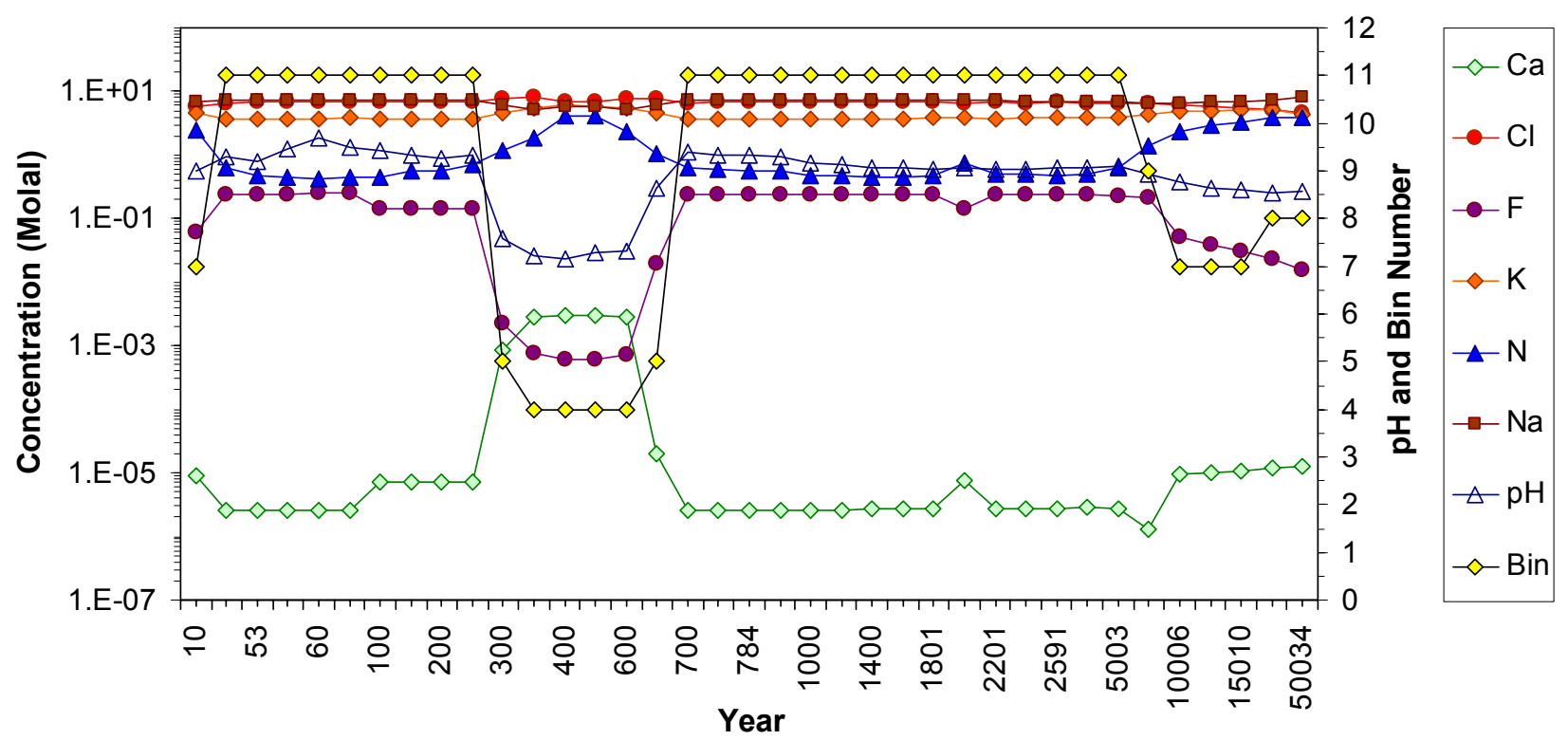

Source: Output DTN: MO0508SPAEBSCB.001.

Figure 6.6-24. Bins for Evaporated Invert Seepage: Case w7tf4

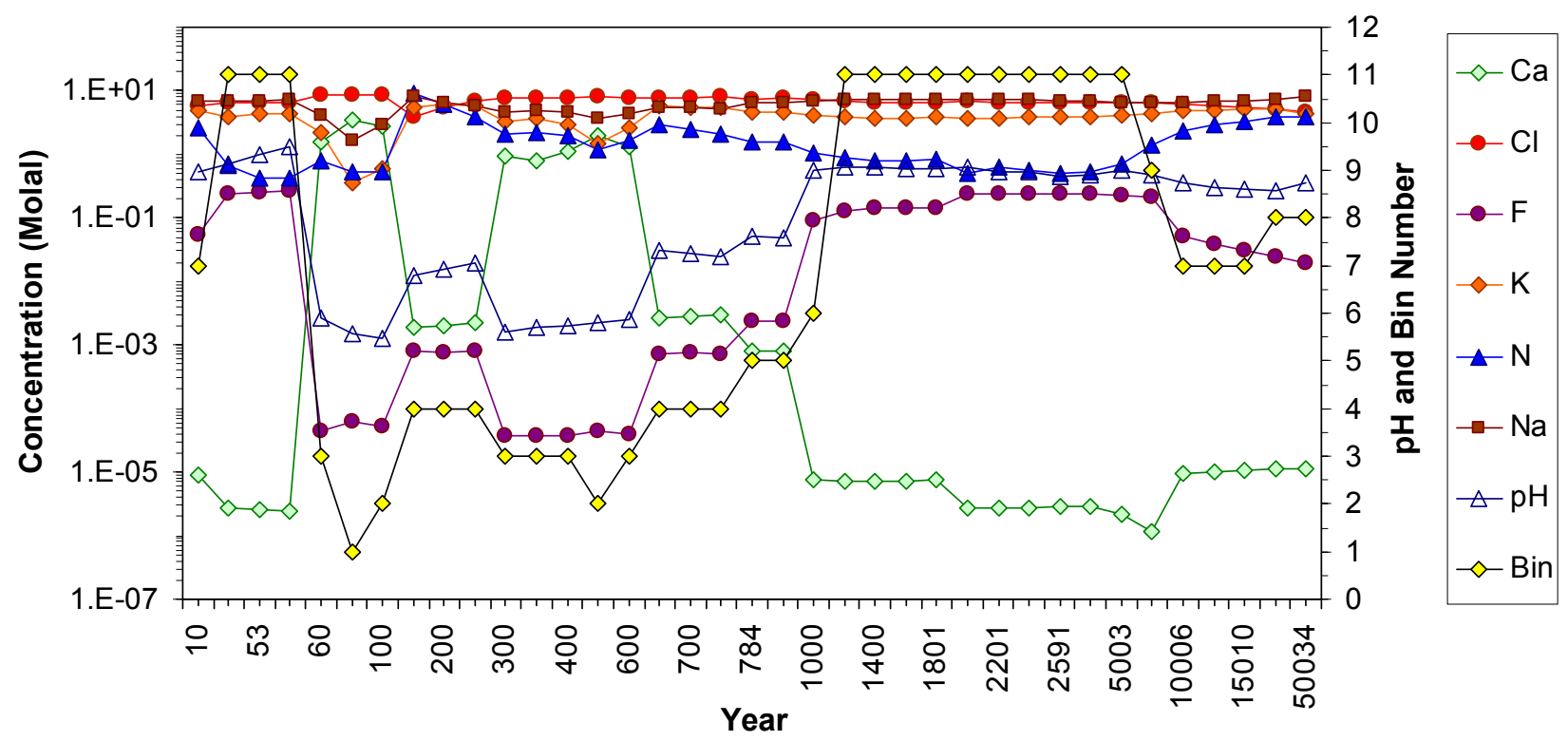

Source: Output DTN: MO0508SPAEBSCB.001.

Figure 6.6-25. Bins for Evaporated Invert Seepage: Case w7bf4 
Table 6.6-7. Calculated Statistics for All Values within Each Bin $\left(a_{w}=0.65\right)$

\begin{tabular}{|c|c|c|c|c|c|c|c|c|c|c|c|c|c|c|c|}
\hline Bin & tatistic & pH & I & Al & C & $\mathrm{Ca}$ & $\mathrm{Cl}$ & $\mathbf{F}$ & $\mathrm{K}$ & $\mathrm{Mg}$ & $\mathbf{N}$ & $\mathrm{Na}$ & S & Si & $\mathrm{Cl}^{-} / \mathrm{NO}_{3}^{-}$ \\
\hline \multirow{5}{*}{1} & Median & 5.59 & $8 \mathrm{E}+01$ & $20 \mathrm{E}-12$ & $54 \mathrm{E}-04$ & $3 E+00$ & $3 \mathrm{E}+00$ & $31 \mathrm{E}-05$ & $54 \mathrm{E}-01$ & $6 \mathrm{E}-04$ & $45 \mathrm{E}-01$ & $3 \mathrm{E}+00$ & $34 \mathrm{E}-03$ & $48 \mathrm{E}-03$ & $\overline{11}$ \\
\hline & Min & 5.53 & $3 \mathrm{E}+01$ & $E-12$ & -04 & $2 E+00$ & $2 \mathrm{E}+00$ & $2 E-05$ & $6 \mathrm{E}-01$ & $4 \mathrm{E}-04$ & $3 E-01$ & & 03 & & \\
\hline & $\operatorname{Max}$ & 5.72 & $30 \mathrm{E}+01$ & $\mathrm{EE}-12$ & E-04 & $11 \mathrm{E}+00$ & $1 \mathrm{E}+00$ & $9 \mathrm{E}-05$ & $4.25 \mathrm{E}-01$ & $27 \mathrm{E}-03$ & $75 \mathrm{E}+00$ & & $12 \mathrm{E}-03$ & & \\
\hline & $\sigma$ & 08 & E-01 & -13 & -05 & -01 & -01 & EE-06 & $E-01$ & & $E+00$ & & & & \\
\hline & $2 \sigma$ & 15 & $93 \mathrm{E}-01$ & $4 \mathrm{E}-13$ & $E-04$ & $76 \mathrm{E}-01$ & $84 \mathrm{E}+00$ & $7 \mathrm{E}-06$ & $25 \mathrm{E}-01$ & & $E+00$ & & $2.55 \mathrm{E}-04$ & -04 & \\
\hline \multirow{5}{*}{2} & Median & 5.69 & $1.15 \mathrm{E}+01$ & $2.32 \mathrm{E}-12$ & $74 \mathrm{E}-04$ & $2.38 \mathrm{E}+00$ & $8.30 \mathrm{E}+00$ & $5.20 \mathrm{E}-05$ & $9.28 \mathrm{E}-01$ & $1.32 \mathrm{E}-03$ & $7.62 \mathrm{E}-01$ & $3.41 \mathrm{E}+00$ & $1.93 \mathrm{E}-03$ & $2.20 \mathrm{E}-03$ & $9 \mathrm{E}+01$ \\
\hline & Min & 5.46 & \begin{tabular}{|l|}
$1.11 \mathrm{E}+01$ \\
\end{tabular} & \begin{tabular}{|l|}
$1.33 \mathrm{E}-12$ \\
\end{tabular} & \begin{tabular}{|l|}
$4.32 \mathrm{E}-04$ \\
\end{tabular} & $1.86 \mathrm{E}+00$ & $6.54 \mathrm{E}+00$ & \begin{tabular}{|l|l|}
$4.41 \mathrm{E}-05$ \\
\end{tabular} & \begin{tabular}{|l|}
$5.74 \mathrm{E}-01$ \\
\end{tabular} & $4.66 \mathrm{E}-04$ & 2.84E-01 & $2.82 \mathrm{E}+00$ & $1.58 \mathrm{E}-03$ & $1.90 \mathrm{E}-03$ & \\
\hline & Max & \begin{tabular}{|l|}
5.79 \\
\end{tabular} & $1.17 \mathrm{E}+01$ & $3.76 \mathrm{E}-12$ & $8.94 \mathrm{E}-04$ & $2.75 \mathrm{E}+00$ & $8.83 \mathrm{E}+00$ & $5.51 \mathrm{E}-05$ & $1.58 \mathrm{E}+00$ & $2.49 \mathrm{E}-03$ & $2.83 \mathrm{E}+00$ & $3.98 \mathrm{E}+00$ & $2.03 \mathrm{E}-03$ & $3.00 \mathrm{E}-03$ & \\
\hline & $\sigma$ & 0.11 & $1.98 \mathrm{E}-01$ & $7.15 \mathrm{E}-13$ & \begin{tabular}{|l|}
$1.52 \mathrm{E}-04$ \\
\end{tabular} & $2.75 \mathrm{E}-01$ & $6.77 \mathrm{E}-01$ & $3.50 \mathrm{E}-06$ & \begin{tabular}{|l|}
$3.32 \mathrm{E}-01$ \\
\end{tabular} & $5.87 \mathrm{E}-04$ & $8.35 \mathrm{E}-01$ & $4.13 \mathrm{E}-01$ & $1.29 \mathrm{E}-04$ & $3.16 \mathrm{E}-04$ & \\
\hline & $2 \sigma$ & 0.22 & $3.97 \mathrm{E}-01$ & $1.43 \mathrm{E}-12$ & $3.03 \mathrm{E}-04$ & $5.51 \mathrm{E}-01$ & $1.35 \mathrm{E}+00$ & $6.99 \mathrm{E}-06$ & $6.64 \mathrm{E}-01$ & 1.17E-03 & $1.67 \mathrm{E}+00$ & $8.27 \mathrm{E}-01$ & $2.58 \mathrm{E}-04$ & $6.31 \mathrm{E}-04$ & 1.55 \\
\hline \multirow{5}{*}{3} & Median & 5.88 & $1.08 \mathrm{E}+01$ & $1.09 \mathrm{E}-12$ & $4.55 \mathrm{E}-04$ & $1.10 \mathrm{E}+00$ & $8.42 \mathrm{E}+00$ & $3.79 \mathrm{E}-05$ & $3.00 \mathrm{E}+00$ & $1.26 \mathrm{E}-03$ & $1.02 \mathrm{E}+00$ & $4.24 \mathrm{E}+00$ & $2.07 \mathrm{E}-03$ & $2.29 \mathrm{E}-03$ & \\
\hline & Min & 5.62 & $1.03 \mathrm{E}+01$ & $9.46 \mathrm{E}-14$ & $1.56 \mathrm{E}-04$ & $7.49 \mathrm{E}-02$ & $7.74 \mathrm{E}+00$ & $3.56 \mathrm{E}-05$ & $1.93 \mathrm{E}+00$ & & $7.05 \mathrm{E}-01$ & +00 & $1.54 \mathrm{E}-03$ & $E-03$ & \\
\hline & $\operatorname{Max}$ & 6.55 & $1.10 \mathrm{E}+01$ & $3.54 \mathrm{E}-12$ & $8.21 \mathrm{E}-04$ & $1.74 \mathrm{E}+00$ & $8.95 \mathrm{E}+00$ & $8.47 \mathrm{E}-05$ & $5.55 \mathrm{E}+00$ & $2.50 \mathrm{E}-03$ & $2.26 \mathrm{E}+00$ & $E+00$ & \begin{tabular}{|l|}
$8.07 \mathrm{E}-03$ \\
\end{tabular} & $3.27 \mathrm{E}-03$ & \\
\hline & $\sigma$ & 0.24 & & & 04 & 4.2 & & 05 & & & & & -03 & & \\
\hline & $2 \sigma$ & \begin{tabular}{|l|}
0.49 \\
\end{tabular} & & & 04 & 01 & & -05 & 00 & & +00 & & -03 & -03 & \\
\hline \multirow{5}{*}{4} & Media & 7.13 & +01 & -13 & -04 & -03 & +00 & -04 & +00 & 06 & +00 & 00 & 01 & -03 & \\
\hline & Min & 5.94 & +01 & 15 & 54 & 04 & +00 & 04 & 00 & 57 & -00 & 00 & 01 & 04 & \\
\hline & Max & 7.62 & +01 & & -03 & 03 & & & & & & & & & \\
\hline & $\sigma$ & 0.34 & $1.02 \mathrm{E}+00$ & $2.78 \mathrm{E}-13$ & -04 & $6.45 \mathrm{E}-04$ & $1.87 \mathrm{E}+00$ & \begin{tabular}{|l|}
$2.50 \mathrm{E}-04$ \\
\end{tabular} & \begin{tabular}{|c|}
$9.45 \mathrm{E}-01$ \\
\end{tabular} & $8.23 \mathrm{E}-05$ & $E+00$ & $1.69 \mathrm{E}+00$ & $9.58 \mathrm{E}-02$ & -03 & \\
\hline & $2 \sigma$ & 0.68 & $2.04 \mathrm{E}+00$ & $5.56 \mathrm{E}-13$ & $6.30 \mathrm{E}-04$ & $1.29 \mathrm{E}-03$ & $3.74 \mathrm{E}+00$ & $5.00 \mathrm{E}-04$ & $1.89 \mathrm{E}+00$ & 1.65E-04 & $5.59 \mathrm{E}+00$ & $3.38 \mathrm{E}+00$ & $1.92 \mathrm{E}-01$ & E-03 & 2. \\
\hline \multirow{5}{*}{5} & Medial & 7.60 & $1.20 \mathrm{E}+01$ & \begin{tabular}{|l|}
$1.26 \mathrm{E}-13$ \\
\end{tabular} & $1.53 \mathrm{E}-03$ & 8.57E-04 & $7.71 \mathrm{E}+00$ & \begin{tabular}{|l|}
$2.29 \mathrm{E}-03$ \\
\end{tabular} & 4.67E+00 & -07 & $1.20 \mathrm{E}+00$ & $E+00$ & $1.02 \mathrm{E}+00$ & -03 & 6.3 \\
\hline & Min & 7.26 & $1.17 \mathrm{E}+01$ & $5.79 \mathrm{E}-14$ & 7.97E-04 & $2.00 \mathrm{E}-05$ & $6.98 \mathrm{E}+00$ & $1.98 \mathrm{E}-03$ & $4.60 \mathrm{E}+00$ & $3.63 \mathrm{E}-08$ & $6.30 \mathrm{E}-01$ & $5.93 \mathrm{E}+00$ & $1.00 \mathrm{E}+00$ & $5 \mathrm{E}-03$ & 2.8 \\
\hline & Max & 8.64 & $1.25 \mathrm{E}+01$ & $3.44 \mathrm{E}-13$ & $3.19 \mathrm{E}-02$ & $9.78 \mathrm{E}-04$ & $8.04 \mathrm{E}+00$ & $1.91 \mathrm{E}-02$ & $4.92 \mathrm{E}+00$ & 7.68E-06 & $2.46 \mathrm{E}+00$ & $6.77 \mathrm{E}+00$ & $1.13 \mathrm{E}+00$ & $2.45 \mathrm{E}-02$ & $1.28 \mathrm{E}+01$ \\
\hline & $\sigma$ & 0.29 & $2.49 \mathrm{E}-01$ & $8.09 \mathrm{E}-14$ & $5.84 \mathrm{E}-03$ & 1.72E-04 & 3.23E-01 & $3.24 \mathrm{E}-03$ & $6.75 \mathrm{E}-02$ & 2.37E-06 & 5.63E-01 & 2.39E-01 & 2.83E-02 & 3.95E-03 & $3.34 \mathrm{E}+00$ \\
\hline & $2 \sigma$ & 0.58 & $4.97 \mathrm{E}-01$ & $1.62 \mathrm{E}-13$ & $1.17 \mathrm{E}-02$ & $3.44 \mathrm{E}-04$ & $6.46 \mathrm{E}-01$ & $6.48 \mathrm{E}-03$ & 1.35E-01 & $4.75 \mathrm{E}-06$ & $1.13 \mathrm{E}+00$ & $4.77 \mathrm{E}-01$ & $5.66 \mathrm{E}-02$ & E-03 & $6.68 \mathrm{E}+00$ \\
\hline \multirow{5}{*}{6} & Median & 9.01 & $1.24 \mathrm{E}+01$ & $1.18 \mathrm{E}-13$ & $5.03 \mathrm{E}-01$ & $8.47 \mathrm{E}-06$ & $6.36 \mathrm{E}+00$ & $8.67 \mathrm{E}-02$ & $4.30 \mathrm{E}+00$ & $6.72 \mathrm{E}-08$ & $1.45 \mathrm{E}+00$ & $6.63 \mathrm{E}+00$ & $8.53 \mathrm{E}-01$ & $4.45 \mathrm{E}-02$ & $4.37 \mathrm{E}+00$ \\
\hline & Min & \begin{tabular}{|l|}
8.37 \\
\end{tabular} & $1.18 \mathrm{E}+01$ & 1.13E-14 & $1.64 \mathrm{E}-01$ & $7.54 \mathrm{E}-06$ & $3.17 \mathrm{E}+00$ & $4.91 \mathrm{E}-02$ & $2.51 \mathrm{E}+00$ & 2.59E-09 & \begin{tabular}{|l|}
$5.55 \mathrm{E}-01$ \\
\end{tabular} & $6.28 \mathrm{E}+00$ & $7.99 \mathrm{E}-01$ & $2.03 \mathrm{E}-02$ & $4.26 \mathrm{E}-01$ \\
\hline & Max & \begin{tabular}{|l|}
9.68 \\
\end{tabular} & $1.40 \mathrm{E}+01$ & $2.37 \mathrm{E}-13$ & $7.96 \mathrm{E}-01$ & $9.05 \mathrm{E}-06$ & $7.79 \mathrm{E}+00$ & $9.15 \mathrm{E}-02$ & $4.49 \mathrm{E}+00$ & $4.35 \mathrm{E}-07$ & $7.43 \mathrm{E}+00$ & $1.04 \mathrm{E}+01$ & $9.30 \mathrm{E}-01$ & $2.46 \mathrm{E}-01$ & $1.34 \mathrm{E}+01$ \\
\hline & $\sigma$ & 0.37 & $8.46 \mathrm{E}-01$ & $9.15 \mathrm{E}-14$ & 2.52E-01 & $5.58 \mathrm{E}-07$ & $1.65 \mathrm{E}+00$ & 1.63E-02 & 6.66E-01 & 1.91E-07 & $2.73 \mathrm{E}+00$ & $1.52 \mathrm{E}+00$ & $4.38 \mathrm{E}-02$ & 7.78E-02 & $4.87 \mathrm{E}+00$ \\
\hline & $2 \sigma$ & 0.73 & $1.69 \mathrm{E}+00$ & $1.83 \mathrm{E}-13$ & $5.04 \mathrm{E}-01$ & $1.12 \mathrm{E}-06$ & $3.29 \mathrm{E}+00$ & $3.26 \mathrm{E}-02$ & $1.33 \mathrm{E}+00$ & $3.83 \mathrm{E}-07$ & $5.46 \mathrm{E}+00$ & $3.04 \mathrm{E}+00$ & $8.75 \mathrm{E}-02$ & 1.56E-01 & $9.75 \mathrm{E}+00$ \\
\hline \multirow{5}{*}{7} & Median & 8.73 & $1.32 \mathrm{E}+01$ & \begin{tabular}{|l|}
$3.94 \mathrm{E}-15$ \\
\end{tabular} & 3.51E-01 & 1.00E-05 & $5.83 \mathrm{E}+00$ & 4.42E-02 & $4.90 \mathrm{E}+00$ & 1.30E-06 & $2.81 \mathrm{E}+00$ & $6.81 \mathrm{E}+00$ & $1.24 \mathrm{E}+00$ & 8.04E-03 & $2.08 \mathrm{E}+00$ \\
\hline & Min & 8.52 & $1.28 \mathrm{E}+01$ & \begin{tabular}{|l|}
$2.71 \mathrm{E}-15$ \\
\end{tabular} & $2.57 \mathrm{E}-01$ & $8.59 \mathrm{E}-06$ & $4.08 \mathrm{E}+00$ & $3.12 \mathrm{E}-02$ & $4.15 \mathrm{E}+00$ & $3.64 \mathrm{E}-07$ & $2.33 \mathrm{E}+00$ & $6.59 \mathrm{E}+00$ & $1.03 \mathrm{E}+00$ & $5.57 \mathrm{E}-03$ & $7.31 \mathrm{E}-01$ \\
\hline & Max & 9.13 & $1.42 \mathrm{E}+01$ & $5.87 \mathrm{E}-15$ & $6.49 \mathrm{E}-01$ & $1.11 \mathrm{E}-05$ & $6.11 \mathrm{E}+00$ & $7.08 \mathrm{E}-02$ & $5.06 \mathrm{E}+00$ & $2.31 \mathrm{E}-06$ & $5.59 \mathrm{E}+00$ & $8.59 \mathrm{E}+00$ & $1.41 \mathrm{E}+00$ & $2.00 \mathrm{E}-02$ & $2.60 \mathrm{E}+00$ \\
\hline & $\sigma$ & 0.16 & 3.72E-01 & 1.08E-15 & 1.06E-01 & $7.70 \mathrm{E}-07$ & 5.03E-01 & $1.15 \mathrm{E}-02$ & $2.40 \mathrm{E}-01$ & $5.78 \mathrm{E}-07$ & $8.14 \mathrm{E}-01$ & $4.96 \mathrm{E}-01$ & $1.17 \mathrm{E}-01$ & $4.00 \mathrm{E}-03$ & $4.80 \mathrm{E}-01$ \\
\hline & $2 \sigma$ & 0.32 & $7.44 \mathrm{E}-01$ & $2.15 \mathrm{E}-15$ & $2.11 \mathrm{E}-01$ & $1.54 \mathrm{E}-06$ & $1.01 \mathrm{E}+00$ & $2.30 \mathrm{E}-02$ & $4.81 \mathrm{E}-01$ & $1.16 \mathrm{E}-06$ & $1.63 \mathrm{E}+00$ & 9.93E-01 & $2.34 \mathrm{E}-01$ & $7.99 \mathrm{E}-03$ & $9.60 \mathrm{E}-01$ \\
\hline
\end{tabular}


Table 6.6-7. Calculated Statistics for All Values within Each Bin $\left(a_{w}=0.65\right)$ (Continued)

\begin{tabular}{|c|c|c|c|c|c|c|c|c|c|c|c|c|c|c|c|}
\hline Bin & & $\mathrm{pH}$ & 1 & Al & C & $\mathrm{Ca}$ & $\mathrm{Cl}$ & $\mathbf{F}$ & K & Mg & $\mathbf{N}$ & $\mathrm{Na}$ & $\mathbf{S}$ & Si & $\mathrm{O}_{3}^{-}$ \\
\hline & & 58 & & 15 & & & & & +00 & & $6 \mathrm{E}+00$ & & & & \\
\hline & |IVIIn & 8 & & & & & & & & & & & & & \\
\hline & Max & 8.98 & & & & & & & & & & & & & \\
\hline & o & 0.14 & & & & & & & & & & & & & \\
\hline & 20 & 0.28 & & & & & & & & & & & & & \\
\hline & & 9.15 & & & & & & & & & & & & & \\
\hline & Min & 8.78 & & & & & & & & & & & & & \\
\hline & Max & 9.66 & & & & & 0 & & 00 & & & & & & \\
\hline & $\sigma$ & 0.22 & & & & & & & & & & & & & -00 \\
\hline & $2 \sigma$ & 0.43 & 00 & 11 & & & & & 00 & & & & & & 00 \\
\hline & Med & 8.75 & 01 & $E-14$ & & & 0 & & -00 & & & & & & $E+00$ \\
\hline & Min & 8.70 & +01 & -15 & & & 00 & & +00 & & 00 & & & & $E+00$ \\
\hline & Max & 8.97 & $38 \mathrm{E}+01$ & $49 \mathrm{E}-14$ & $06 \mathrm{E}-01$ & $29 \mathrm{E}-07$ & $6.08 \mathrm{E}+00$ & -01 & $E+00$ & & $.25 \mathrm{E}+00$ & $80 \mathrm{E}+00$ & 1.32 & -02 & $.74 \mathrm{E}+00$ \\
\hline & $\sigma$ & 0.1 & $2 \mathrm{E}-01$ & $33 \mathrm{E}-15$ & $77 \mathrm{E}$ & 07 & 4.981 & & -02 & & & & & & $78 \mathrm{E}-01$ \\
\hline & $2 \sigma$ & 0.2 & $24 \mathrm{E}-01$ & $66 \mathrm{E}-15$ & $55 \mathrm{E}-01$ & -07 & 9.96 & & -02 & & +00 & -01 & & -03 & $.36 \mathrm{E}+00$ \\
\hline & $\mathrm{Mec}$ & 9.17 & & & & & & & & & & & & & \\
\hline & Min & 8.85 & & & & & & & & & & & & & \\
\hline & Max & 9.72 & & & & & & & & & & & & & \\
\hline & 0 & 0.19 & & & & & & & -01 & & & & & -02 & \\
\hline & 20 & 0.38 & 44E-01 & 42E-14 & .70E-01 & 3.63E-06 & \begin{tabular}{|l|}
$7.86 \mathrm{E}-01$ \\
\end{tabular} & 8.44E-02 & $6.60 \mathrm{E}-01$ & -07 & -01 & \begin{tabular}{|l|}
$5.23 \mathrm{E}-01$ \\
\end{tabular} & $1.54 \mathrm{E}-01$ & $1.11 \mathrm{E}-01$ & $63 \mathrm{E}$ \\
\hline
\end{tabular}

Source: Output DTN: MO0508SPAEBSCB.001.

NOTE: All units, except $\mathrm{pH}$ and $\mathrm{Cl}^{-} / \mathrm{NO}_{3}{ }^{-}$, are in molal.

Table 6.6-8. Calculated Statistics for All Values on the Data and Plots Worksheet

\begin{tabular}{|c|c|c|c|c|c|c|c|c|c|c|c|c|c|c|}
\hline Statistic & $\mathrm{pH}$ & I & Al & C & $\mathrm{Ca}$ & $\mathrm{Cl}$ & $\mathbf{F}$ & $\mathrm{K}$ & Mg & $\mathbf{N}$ & $\mathrm{Na}$ & $\mathbf{S}$ & Si & $\mathrm{Cl}^{-} / \mathrm{NO}_{3}^{-}$ \\
\hline Median & 8.98 & $1.27 \mathrm{E}+01$ & $1.08 \mathrm{E}-13$ & $1.04 \mathrm{E}+00$ & $6.93 \mathrm{E}-06$ & $6.53 \mathrm{E}+00$ & $1.48 \mathrm{E}-01$ & $4.29 \mathrm{E}+00$ & $2.04 \mathrm{E}-07$ & $1.25 \mathrm{E}+00$ & $6.93 \mathrm{E}+00$ & $6.96 \mathrm{E}-01$ & $3.79 \mathrm{E}-02$ & $5.66 \mathrm{E}+00$ \\
\hline Min & 5.46 & $1.03 \mathrm{E}+01$ & $6.86 \mathrm{E}-16$ & $1.56 \mathrm{E}-04$ & $3.39 \mathrm{E}-07$ & $2.80 \mathrm{E}+00$ & $3.56 \mathrm{E}-05$ & $1.76 \mathrm{E}-01$ & $1.16 \mathrm{E}-09$ & $2.73 \mathrm{E}-01$ & $7.83 \mathrm{E}-01$ & $1.54 \mathrm{E}-03$ & $8.22 \mathrm{E}-04$ & $2.93 \mathrm{E}-01$ \\
\hline $\operatorname{Max}$ & 9.72 & $1.49 \mathrm{E}+01$ & $1.16 \mathrm{E}-10$ & $2.06 \mathrm{E}+00$ & $4.01 \mathrm{E}+00$ & $8.95 \mathrm{E}+00$ & $3.34 \mathrm{E}-01$ & $6.25 \mathrm{E}+00$ & $2.50 \mathrm{E}-03$ & $9.90 \mathrm{E}+00$ & $1.07 \mathrm{E}+01$ & $1.87 \mathrm{E}+00$ & $3.01 \mathrm{E}-01$ & $3.18 \mathrm{E}+01$ \\
\hline$\sigma$ & 1.12 & $8.88 \mathrm{E}-01$ & $6.07 \mathrm{E}-12$ & $5.39 \mathrm{E}-01$ & $6.34 \mathrm{E}-01$ & $1.21 \mathrm{E}+00$ & $1.08 \mathrm{E}-01$ & $1.09 \mathrm{E}+00$ & $3.89 \mathrm{E}-04$ & $1.94 \mathrm{E}+00$ & $1.41 \mathrm{E}+00$ & $3.81 \mathrm{E}-01$ & $6.51 \mathrm{E}-02$ & $5.72 \mathrm{E}+00$ \\
\hline $2 \sigma$ & 2.23 & $1.78 \mathrm{E}+00$ & $1.21 \mathrm{E}-11$ & $1.08 \mathrm{E}+00$ & $1.27 \mathrm{E}+00$ & $2.42 \mathrm{E}+00$ & $2.17 \mathrm{E}-01$ & $2.17 \mathrm{E}+00$ & $7.78 \mathrm{E}-04$ & $3.87 \mathrm{E}+00$ & $2.82 \mathrm{E}+00$ & \begin{tabular}{|l|}
$7.61 \mathrm{E}-01$ \\
\end{tabular} & $1.30 \mathrm{E}-01$ & $1.14 \mathrm{E}+01$ \\
\hline
\end{tabular}


Table 6.6-9. Bin Map for "Water 0" Incoming Seepage Waters

\begin{tabular}{|c|c|c|c|c|}
\hline Start (yr) & End (yr) & $\begin{array}{l}\text { Bin for } \\
\text { Invert } \\
\text { Seepage } \\
\text { (w0bf4) }\end{array}$ & $\begin{array}{l}\text { Bin for } \\
\text { Crown } \\
\text { Seepage } \\
\text { (w0tf4) }\end{array}$ & $\begin{array}{c}\text { EQ6 } \\
\text { Output } \\
\text { Filename }\end{array}$ \\
\hline 0 & 50 & 4 & 4 & 10.60 \\
\hline 50 & 52 & 5 & 5 & 51.60 \\
\hline 52 & 54 & 11 & 5 & 53.60 \\
\hline 54 & 57.5 & 11 & 6 & 55.60 \\
\hline 57.5 & 67.5 & 2 & 6 & 60.60 \\
\hline 67.5 & 87.5 & 1 & 5 & 75.60 \\
\hline 87.5 & 125 & 1 & 5 & 100.60 \\
\hline 125 & 175 & 2 & 4 & 150.60 \\
\hline 175 & 225 & 2 & 4 & 200.60 \\
\hline 225 & 275 & 2 & 3 & 250.60 \\
\hline 275 & 325 & 2 & 3 & 300.60 \\
\hline 325 & 375 & 2 & 3 & 350.60 \\
\hline 375 & 450 & 2 & 3 & 400.60 \\
\hline 450 & 550 & 2 & 4 & 500.60 \\
\hline 550 & 625 & 3 & 4 & 600.60 \\
\hline 625 & 675 & 3 & 5 & 650.60 \\
\hline 675 & 725 & 4 & 11 & 700.60 \\
\hline 725 & 769.5 & 4 & 11 & 750.60 \\
\hline 769.5 & 794.5 & 4 & 11 & 789.60 \\
\hline 794.5 & 900 & 4 & 11 & 800.60 \\
\hline 900 & 1,100 & 5 & 11 & 1000.60 \\
\hline 1,100 & 1,300 & 5 & 11 & 1200.60 \\
\hline 1,300 & $1,500.5$ & 5 & 11 & 1400.60 \\
\hline $1,500.5$ & 1,701 & 5 & 11 & 1601.60 \\
\hline 1,701 & 1,901 & 5 & 11 & 1801.60 \\
\hline 1,901 & 2,101 & 9 & 4 & 2001.60 \\
\hline 2,101 & 2,301 & 11 & 11 & 2201.60 \\
\hline 2,301 & $2,701.5$ & 11 & 11 & 2401.60 \\
\hline $2,701.5$ & $4,002.5$ & 11 & 11 & 3002.60 \\
\hline $4,002.5$ & $6,003.5$ & 11 & 11 & 5003.60 \\
\hline $6,003.5$ & 8,505 & 6 & 6 & 7004.60 \\
\hline 8,505 & 11,158 & 7 & 6 & 10006.60 \\
\hline 11,158 & 13,660 & 7 & 7 & 12310.60 \\
\hline 13,660 & $17,511.5$ & 7 & 7 & 15010.60 \\
\hline $17,511.5$ & $35,023.5$ & 8 & 8 & 20013.60 \\
\hline $35,023.5$ & 100,000 & 8 & 8 & 50034.60 \\
\hline
\end{tabular}

Source: Output DTN: MO0508SPAEBSCB.001.

NOTE: Start time is inclusive; end time is exclusive. 
Table 6.6-10. Bin Map for "Water 4" Incoming Seepage Waters

\begin{tabular}{|c|c|c|c|c|}
\hline Start (yr) & End (yr) & $\begin{array}{l}\text { Bin for } \\
\text { Invert } \\
\text { Seepage } \\
\text { (w4bf4) }\end{array}$ & $\begin{array}{l}\text { Bin for } \\
\text { Crown } \\
\text { Seepage } \\
\text { (w4tf4) }\end{array}$ & $\begin{array}{c}\text { EQ6 } \\
\text { Output } \\
\text { Filename }\end{array}$ \\
\hline 0 & 50 & 10 & 10 & 10.60 \\
\hline 50 & 52 & 11 & 11 & 51.60 \\
\hline 52 & 54 & 11 & 11 & 53.60 \\
\hline 54 & 57.5 & 11 & 11 & 55.60 \\
\hline 57.5 & 67.5 & 4 & 11 & 60.60 \\
\hline 67.5 & 87.5 & 11 & 11 & 75.60 \\
\hline 87.5 & 125 & 11 & 11 & 100.60 \\
\hline 125 & 175 & 4 & 11 & 150.60 \\
\hline 175 & 225 & 4 & 11 & 200.60 \\
\hline 225 & 275 & 5 & 11 & 250.60 \\
\hline 275 & 325 & 4 & 11 & 300.60 \\
\hline 325 & 375 & 5 & 11 & 350.60 \\
\hline 375 & 450 & 5 & 11 & 400.60 \\
\hline 450 & 550 & 4 & 5 & 500.60 \\
\hline 550 & 625 & 4 & 5 & 600.60 \\
\hline 625 & 675 & 4 & 11 & 650.60 \\
\hline 675 & 725 & 5 & 11 & 700.60 \\
\hline 725 & 775 & 5 & 11 & 750.60 \\
\hline 775 & 802 & 11 & 11 & 800.60 \\
\hline 802 & 902 & 11 & 11 & 804.60 \\
\hline 902 & 1,100 & 11 & 11 & 1000.60 \\
\hline 1,100 & 1,300 & 11 & 11 & 1200.60 \\
\hline 1,300 & $1,500.5$ & 11 & 11 & 1400.60 \\
\hline $1,500.5$ & 1,701 & 11 & 11 & 1601.60 \\
\hline 1,701 & 1,901 & 11 & 5 & 1801.60 \\
\hline 1,901 & 2,101 & 11 & 4 & 2001.60 \\
\hline 2,101 & 2,301 & 11 & 11 & 2201.60 \\
\hline 2,301 & 2,499 & 11 & 11 & 2401.60 \\
\hline 2,499 & $2,799.5$ & 11 & 11 & 2597.60 \\
\hline $2,799.5$ & $4,002.5$ & 11 & 11 & 3002.60 \\
\hline $4,002.5$ & $6,003.5$ & 11 & 11 & 5003.60 \\
\hline $6,003.5$ & 8,505 & 9 & 9 & 7004.60 \\
\hline 8,505 & $11,301.5$ & 7 & 7 & 10006.60 \\
\hline $11,301.5$ & $13,803.5$ & 7 & 7 & 12597.60 \\
\hline $13,803.5$ & $17,511.5$ & 8 & 8 & 15010.60 \\
\hline $17,511.5$ & $35,023.5$ & 8 & 8 & 20013.60 \\
\hline $35,023.5$ & 100,000 & 8 & 8 & 50034.60 \\
\hline
\end{tabular}

Source: Output DTN: MO0508SPAEBSCB.001.

NOTE: Start time is inclusive; end time is exclusive. 
Table 6.6-11. Bin Map for "Water 5" Incoming Seepage Waters

\begin{tabular}{|c|c|c|c|c|}
\hline Start (yr) & End (yr) & $\begin{array}{l}\text { Bin for } \\
\text { Invert } \\
\text { Seepage } \\
\text { (w5bf4) }\end{array}$ & $\begin{array}{l}\text { Bin for } \\
\text { Crown } \\
\text { Seepage } \\
\text { (w5tf4) }\end{array}$ & $\begin{array}{c}\text { EQ6 } \\
\text { Output } \\
\text { Filename } \\
\end{array}$ \\
\hline 0 & 50 & 7 & 7 & 10.60 \\
\hline 50 & 52 & 11 & 11 & 51.60 \\
\hline 52 & 54 & 11 & 11 & 53.60 \\
\hline 54 & 57.5 & 11 & 11 & 55.60 \\
\hline 57.5 & 67.5 & 3 & 11 & 60.60 \\
\hline 67.5 & 87.5 & 4 & 11 & 75.60 \\
\hline 87.5 & 125 & 2 & 11 & 100.60 \\
\hline 125 & 175 & 4 & 11 & 150.60 \\
\hline 175 & 225 & 4 & 11 & 200.60 \\
\hline 225 & 275 & 5 & 11 & 250.60 \\
\hline 275 & 325 & 4 & 11 & 300.60 \\
\hline 325 & 375 & 4 & 11 & 350.60 \\
\hline 375 & 450 & 4 & 11 & 400.60 \\
\hline 450 & 550 & 4 & 9 & 500.60 \\
\hline 550 & 625 & 5 & 11 & 600.60 \\
\hline 625 & 675 & 5 & 11 & 650.60 \\
\hline 675 & 725 & 11 & 11 & 700.60 \\
\hline 725 & 767 & 11 & 11 & 750.60 \\
\hline 767 & 792 & 11 & 11 & 784.60 \\
\hline 792 & 900 & 11 & 11 & 800.60 \\
\hline 900 & 1,100 & 11 & 11 & 1000.60 \\
\hline 1,100 & 1,300 & 11 & 11 & 1200.60 \\
\hline 1,300 & $1,500.5$ & 11 & 11 & 1400.60 \\
\hline $1,500.5$ & 1,701 & 11 & 11 & 1601.60 \\
\hline 1,701 & 1,901 & 11 & 5 & 1801.60 \\
\hline 1,901 & 2,101 & 11 & 4 & 2001.60 \\
\hline 2,101 & $2,296.5$ & 11 & 11 & 2201.60 \\
\hline $2,296.5$ & $2,396.5$ & 11 & 11 & 2392.60 \\
\hline $2,396.5$ & $2,701.5$ & 11 & 11 & 2401.60 \\
\hline $2,701.5$ & $4,002.5$ & 11 & 11 & 3002.60 \\
\hline $4,002.5$ & $6,003.5$ & 11 & 11 & 5003.60 \\
\hline $6,003.5$ & 8,505 & 9 & 9 & 7004.60 \\
\hline 8,505 & 11,155 & 10 & 10 & 10006.60 \\
\hline 11,155 & 13,657 & 7 & 7 & 12304.60 \\
\hline 13,657 & $17,511.5$ & 7 & 7 & 15010.60 \\
\hline $17,511.5$ & $35,023.5$ & 8 & 8 & 20013.60 \\
\hline $35,023.5$ & 100,000 & 8 & 8 & 50034.60 \\
\hline
\end{tabular}

Source: Output DTN: MO0508SPAEBSCB.001.

NOTE: Start time is inclusive; end time is exclusive. 
Table 6.6-12. Bin Map for "Water 6" Incoming Seepage Waters

\begin{tabular}{|c|c|c|c|c|}
\hline Start (yr) & End (yr) & $\begin{array}{l}\text { Bin for } \\
\text { Invert } \\
\text { Seepage } \\
\text { (w6bf4) }\end{array}$ & $\begin{array}{l}\text { Bin for } \\
\text { Crown } \\
\text { Seepage } \\
\text { (w6tf4) }\end{array}$ & $\begin{array}{c}\text { EQ6 } \\
\text { Output } \\
\text { Filename } \\
\end{array}$ \\
\hline 0 & 50 & 7 & 7 & 10.60 \\
\hline 50 & 52 & 9 & 9 & 51.60 \\
\hline 52 & 54 & 9 & 9 & 53.60 \\
\hline 54 & 57.5 & 9 & 9 & 55.60 \\
\hline 57.5 & 67.5 & 2 & 9 & 60.60 \\
\hline 67.5 & 87.5 & 1 & 9 & 75.60 \\
\hline 87.5 & 125 & 2 & 9 & 100.60 \\
\hline 125 & 175 & 4 & 9 & 150.60 \\
\hline 175 & 225 & 4 & 9 & 200.60 \\
\hline 225 & 275 & 9 & 9 & 250.60 \\
\hline 275 & 325 & 4 & 9 & 300.60 \\
\hline 325 & 375 & 4 & 9 & 350.60 \\
\hline 375 & 450 & 9 & 9 & 400.60 \\
\hline 450 & 550 & 4 & 6 & 500.60 \\
\hline 550 & 625 & 4 & 9 & 600.60 \\
\hline 625 & 675 & 9 & 9 & 650.60 \\
\hline 675 & 725 & 9 & 9 & 700.60 \\
\hline 725 & 775 & 9 & 9 & 750.60 \\
\hline 775 & 832.5 & 9 & 9 & 800.60 \\
\hline 832.5 & 932.5 & 9 & 9 & 865.60 \\
\hline 932.5 & 1,100 & 9 & 9 & 1000.60 \\
\hline 1,100 & 1,300 & 9 & 9 & 1200.60 \\
\hline 1,300 & $1,500.5$ & 9 & 9 & 1400.60 \\
\hline $1,500.5$ & 1,701 & 9 & 9 & 1601.60 \\
\hline 1,701 & 1,901 & 9 & 6 & 1801.60 \\
\hline 1,901 & 2,101 & 9 & 4 & 2001.60 \\
\hline 2,101 & 2,301 & 9 & 9 & 2201.60 \\
\hline 2,301 & $2,701.5$ & 9 & 9 & 2401.60 \\
\hline $2,701.5$ & 3,025 & 9 & 9 & 3002.60 \\
\hline 3,025 & $4,025.5$ & 9 & 9 & 3048.60 \\
\hline $4,025.5$ & $6,003.5$ & 9 & 9 & 5003.60 \\
\hline $6,003.5$ & 8,505 & 9 & 9 & 7004.60 \\
\hline 8,505 & $11,529.5$ & 10 & 10 & 10006.60 \\
\hline $11,529.5$ & $14,031.5$ & 10 & 10 & 13053.60 \\
\hline $14,031.5$ & $17,511.5$ & 10 & 10 & 15010.60 \\
\hline $17,511.5$ & $35,023.5$ & 8 & 8 & 20013.60 \\
\hline $35,023.5$ & 100,000 & 8 & 8 & 50034.60 \\
\hline
\end{tabular}

Source: Output DTN: MO0508SPAEBSCB.001.

NOTE: Start time is inclusive; end time is exclusive. 
Table 6.6-13. Bin Map for "Water 7" Incoming Seepage Waters

\begin{tabular}{|c|c|c|c|c|}
\hline Start (yr) & End (yr) & $\begin{array}{c}\text { Bin for } \\
\text { Invert } \\
\text { Seepage } \\
\text { (w7bf4) }\end{array}$ & $\begin{array}{l}\text { Bin for } \\
\text { Crown } \\
\text { Seepage } \\
\text { (w7tf4) }\end{array}$ & $\begin{array}{c}\text { EQ6 } \\
\text { Output } \\
\text { Filename }\end{array}$ \\
\hline 0 & 50 & 7 & 7 & 10.60 \\
\hline 50 & 52 & 11 & 11 & 51.60 \\
\hline 52 & 54 & 11 & 11 & 53.60 \\
\hline 54 & 57.5 & 11 & 11 & 55.60 \\
\hline 57.5 & 67.5 & 3 & 11 & 60.60 \\
\hline 67.5 & 87.5 & 1 & 11 & 75.60 \\
\hline 87.5 & 125 & 2 & 11 & 100.60 \\
\hline 125 & 175 & 4 & 11 & 150.60 \\
\hline 175 & 225 & 4 & 11 & 200.60 \\
\hline 225 & 275 & 4 & 11 & 250.60 \\
\hline 275 & 325 & 3 & 5 & 300.60 \\
\hline 325 & 375 & 3 & 4 & 350.60 \\
\hline 375 & 450 & 3 & 4 & 400.60 \\
\hline 450 & 550 & 2 & 4 & 500.60 \\
\hline 550 & 625 & 3 & 4 & 600.60 \\
\hline 625 & 675 & 4 & 5 & 650.60 \\
\hline 675 & 725 & 4 & 11 & 700.60 \\
\hline 725 & 767 & 4 & 11 & 750.60 \\
\hline 767 & 792 & 5 & 11 & 784.60 \\
\hline 792 & 900 & 5 & 11 & 800.60 \\
\hline 900 & 1,100 & 6 & 11 & 1000.60 \\
\hline 1,100 & 1,300 & 11 & 11 & 1200.60 \\
\hline 1,300 & $1,500.5$ & 11 & 11 & 1400.60 \\
\hline $1,500.5$ & 1,701 & 11 & 11 & 1601.60 \\
\hline 1,701 & 1,901 & 11 & 11 & 1801.60 \\
\hline 1,901 & 2,101 & 11 & 11 & 2001.60 \\
\hline 2,101 & 2,301 & 11 & 11 & 2201.60 \\
\hline 2,301 & 2,496 & 11 & 11 & 2401.60 \\
\hline 2,496 & $2,796.5$ & 11 & 11 & 2591.60 \\
\hline $2,796.5$ & $4,002.5$ & 11 & 11 & 3002.60 \\
\hline $4,002.5$ & $6,003.5$ & 11 & 11 & 5003.60 \\
\hline $6,003.5$ & 8,505 & 9 & 9 & 7004.60 \\
\hline 8,505 & 11,301 & 7 & 7 & 10006.60 \\
\hline 11,301 & 13,803 & 7 & 7 & 12596.60 \\
\hline 13,803 & $17,511.5$ & 7 & 7 & 15010.60 \\
\hline $17,511.5$ & $35,023.5$ & 8 & 8 & 20013.60 \\
\hline $35,023.5$ & 100,000 & 8 & 8 & 50034.60 \\
\hline
\end{tabular}

Source: Output DTN: MO0508SPAEBSCB.001.

NOTE: Start time is inclusive; end time is exclusive. 


\subsubsection{Impact Analysis Due to Errors Identified during Check Process}

The binning process has been developed to facilitate an evaluation of whether any new input (such as a new THC seepage model output) would require a new type of chemistry (i.e., a new bin) that this analysis has not investigated. Only if a potential water falls outside a defined bin area is reanalysis of potential seepage compositions necessary. The 11 bins are designed to cover a broad range of possible water chemistry within the drift. Likewise, if an error is found in the calculated chemistries, and an analysis of the error finds that the corrected chemistry falls within the same bin, then there is no real impact to the chemistries within that bin (i.e., the predicted evolution of the chemistry in the bin does not change), so the current median water is still sufficient to represent the corrected water.

During the check process (LP-SIII.10Q-BSC, Section 5.4.3), two errors in the binning analysis were discovered. The first dealt with four of the 368 input waters not being completely normalized to an activity of water equaling 0.65 . This occurred when the number of iterations EQ6 (BSC 2003 [DIRS 162228]; see Section 3.1) was allowed to perform was set too low for the calculation to reach the desired activity of water $\left(a_{w}\right)$. The second error occurred when the $\mathrm{pCO}_{2}$ inputs used from the five THC seepage model outputs were not converted from dimensionless volume fractions to partial pressures in bars. Thus, the volume fractions in the model runs used for the binning process were treated as if they were partial pressures in bars. The impact evaluation of these two errors resulted in no changes to the assigned bins; therefore, these errors have no impact on the lookup tables developed in Section 6.9. The details of the impact analyses are documented in Sections 6.6.7.1 and 6.6.7.2..

In addition, a discrepancy in the water compositions used to represent the median water for Bin 7 was discovered during checking of Rev. 05 of this report. Another water composition from Bin 7 was selected instead, and used to develop the abstraction lookup tables for use in TSPA. The differences between the water compositions in question are evaluated, and the abstraction output is justified, in Section 6.6.7.3.

\subsubsection{Endpoint $a_{w}$}

Table 6.6-14 lists the files that do not normalize to an $a_{w}$ of 0.65 and the results of the recalculation down to an $a_{w}$ of 0.65 .

Table 6.6-14. Details of Impact Analysis on Binning Due to Endpoint $a_{w}$

\begin{tabular}{|l|c|c|c|c|}
\hline \multicolumn{1}{|c|}{ Water/File Name $^{\mathbf{a}}$} & $\begin{array}{c}\text { Initial Endpoint } \\
\mathbf{a}_{\mathbf{w}}\end{array}$ & Initial Bin $^{\mathbf{b}}$ & New Endpoint $\mathbf{a}_{w}{ }^{\mathbf{c}}$ & New Bin $^{\mathbf{c}}$ \\
\hline W4bf4 2597.6o & 0.72 & 11 & 0.65 & 11 \\
\hline W4bf4 3002.6o & 0.706 & 11 & 0.65 & 11 \\
\hline W5bf4 3002.6o & 0.695 & 11 & 0.65 & 11 \\
\hline W6bf4 3002.6o & 0.675 & 9 & 0.65 & 9 \\
\hline
\end{tabular}

a Output DTN: MO0303MWDEBSSM.000.

b Output DTN: MO0508SPAEBSCB.001, Final Checked EBS THC Seepage Binning Abstraction Rev 4.xls.

c Output DTN: MO0508SPAEBSCB.001, Bin Abstraction Rerun.xls. 
These four files were rerun to the correct water activity and the binning criteria discussed in Section 6.6.4 were reapplied. All of the waters fell within the original bins. Therefore, there was no impact to the lookup tables developed in Section 6.9. All recalculated EQ6 files and the rebinning spreadsheet (Bin Abstraction Rerun.xls) are archived in Output DTN: MO0508SPAEBSCB.001.

\subsubsection{2 $\quad \mathrm{CO}_{2}$ Pressure Correction}

To evaluate the impact of the error in units for the pressure of $\mathrm{CO}_{2}$, the median waters that are determined to represent the eleven bins were rerun with corrected $p \mathrm{CO}_{2}$. The pressure was corrected by multiplying the original volume fractions by the approximate average total atmospheric pressure at Yucca Mountain of between 0.88 and 0.89 bar (archived in Output DTN: SN0503T0510102.019, THC_CO2_Look-up.xls, tab "Total Gas Data"). This action converts the volume fractions to partial pressures in bars.

After reapplying the binning criteria discussed in Section 6.6.4, all of the waters fall within the same bin as the original calculation runs (Table 6.6-15), showing that the error in the $\mathrm{CO}_{2}$ values has no effect on the binning analysis. All recalculated EQ6 files and the rebinning spreadsheet (Bin Abstraction Rerun.xls) are archived in Output DTN: MO0508SPAEBSCB.001.

Table 6.6-15. Details of Impact Analysis on $\mathrm{CO}_{2}$ Pressure Correction

\begin{tabular}{|c|c|c|c|c|}
\hline Water/File Name $^{a}$ & $\begin{array}{c}\text { Initial } \log _{\text {Value }^{b}} \mathrm{CO}_{2} \\
\end{array}$ & Initial Bin ${ }^{b}$ & $\begin{array}{c}\text { Corrected } \log \mathrm{CO}_{2} \\
\text { Value }^{\mathrm{c}}\end{array}$ & New Bin \\
\hline W7bf4/75.6o & -3.41 & 1 & -3.466 & 1 \\
\hline W0bf4/250.6o & -3.307 & 2 & -3.363 & 2 \\
\hline W0bf4/650.60 & -2.984 & 3 & -3.040 & 3 \\
\hline W4bf4/600.6o & -3.312 & 4 & -3.368 & 4 \\
\hline W7tf4/300.6o & -2.726 & 5 & -2.782 & 5 \\
\hline W0tf4/7004.6o & -2.151 & 6 & -2.207 & 6 \\
\hline W4bf4/10006.6o & -1.926 & 7 & -1.982 & 7 \\
\hline W5tf4/20013.6o & -2.198 & 8 & -2.254 & 8 \\
\hline W6tf4/51.6o & -2.532 & 9 & -2.589 & 9 \\
\hline W5bf4/10006.6o & -2.037 & 10 & -2.093 & 10 \\
\hline W4tf4/300.6o & -2.392 & 11 & -2.448 & 11 \\
\hline
\end{tabular}

a Output DTN: MO0303MWDEBSSM.000.

b Output DTN: MO0508SPAEBSCB.001, Final Checked EBS THC Seepage Binning Abstraction Rev 4.xls.

c Output DTN: MO0508SPAEBSCB.001, Bin Abstraction Reruns.xls.

\subsubsection{Bin 7 Median Water Selection}

The THC seepage model output water composition used for Bin 7 of the seepage evaporation abstraction was determined during checking not to be the same median-bin water composition from the selection process described in Section 6.6.5. During development of the abstraction lookup tables (during preparation of Rev. 02 of this report), the EQ3NR input file Bin07.3i (see Output DTN: MO0304MWDSAB11.001) was constructed for use in generating the lookup tables. For this input file the composition of a different water from Bin 7, not the median-bin water, was used. The water composition used was from the THC seepage model run with the w0 
starting water, whereas the median water for Bin 7 is from the model run with the w4 starting water. Both compositions correspond to the base-front location, and 10,006 years. The impact of this selection is evaluated here and found to be insignificant for application of the results to TSPA.

First, and most important, the erroneously selected w0 water chemistry is from Bin 7, and all the waters in that group have similar characteristics. For example, Bin 7 is a low-calcium and high-carbonate bin (see Table 6.6-3), and both the w0 and w4 waters in question show that during evaporative concentration, calcium concentrations decrease due to Ca-carbonate precipitation, and the effect is substantially complete during evaporation from near $100 \%$ down to approximately $98 \% \mathrm{RH}$.

Comparison of $\mathrm{pH}$ is used in this evaluation as an important, and more general indicator of similarity between the $\mathrm{w} 0$ and $\mathrm{w} 4$ waters in question. The $\mathrm{pH}$ is affected by mineral precipitation as well as aqueous speciation. Figure 6.6-26 includes the comparison of the evolution of $\mathrm{pH}$ during simulation of the evaporative concentration of the two waters. The responses are very similar and differ by only $0.2 \mathrm{pH}$ units, which is less than the binning uncertainty range of $0.28 \mathrm{pH}$ for Bin 7 (Table 6.12-4), and insignificant compared to the IDPS model uncertainty of $1 \mathrm{pH}$ unit (Table 6.12-1). The data for this comparison come from the evaporation at the originating $\mathrm{THC}$ conditions, both at a temperature of $56.3^{\circ} \mathrm{C}$ and only slightly different $p \mathrm{CO}_{2}$ levels ( -2.12 and $-1.93 \log p \mathrm{CO}_{2}$ for $\mathrm{w} 0$ and $\mathrm{w} 4$, respectively).

Comparison of the other major aqueous species elemental concentrations $(\mathrm{Cl}, \mathrm{K}, \mathrm{N}, \mathrm{Na})$ and the $\mathrm{N} / \mathrm{Cl}$ ratio is also considered in this justification - especially $\mathrm{Cl}$ (as chloride), $\mathrm{N}$ (as nitrate) and their ratio, as these are output for TSPA to determine the potential for localized corrosion on the waste package outer barrier. Figure 6.6-26 shows these chemical comparisons as functions of water activity.

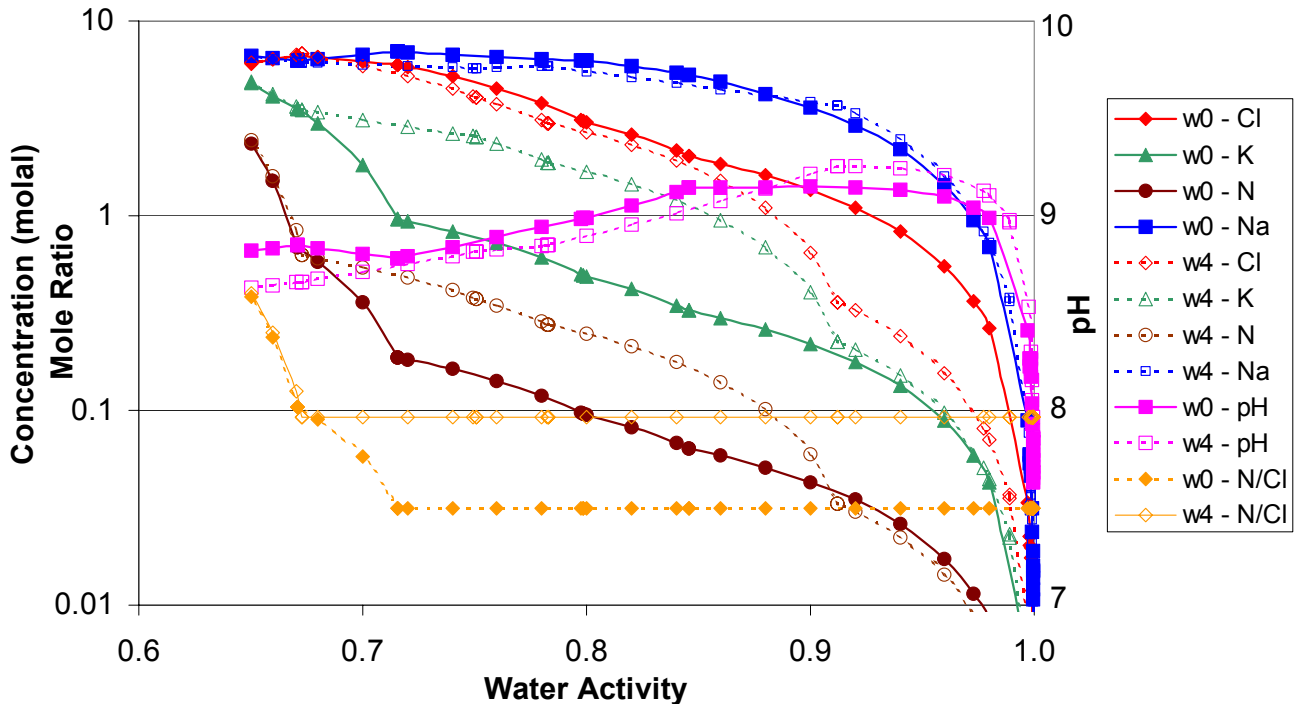

Source: Output DTN: MO0303MWDEBSSM.000, two files named 10006.6o from WO_THCabstractionRH65_6i_6o_ files.zip and W4_THCabstractionRH65_6i_6o_files.zip, in path ending /bf4/RH65.

Figure 6.6-26. Comparison of Elemental Species Concentrations, N/Cl Ratio and $\mathrm{pH}$ Between the w0 Water (Solid Lines) and the w4 Water (Dashed Lines) of Bin 7 
Very similar sodium concentrations are observed throughout the evaporative evolution. While differences approach 0.5 log units for potassium, they converge at low water activies as their brine chemistries are quite similar. Also, the aqueous $\mathrm{N}$ (all nitrate) concentrations are different because of the higher nitrate concentration present in the w4 starting water (thus, the erroneous selection produces waters with less nitrate). The $\mathrm{Cl}$ concentrations (all chloride) for w4 water begin lower than those of the w0 water, as explained by their different starting $\mathrm{Cl} / \mathrm{NO}_{3}$ ratios of 10.3 and 31.7, for w4 and w0, respectively. As with the other chemical species, both $\mathrm{Cl}$ and $\mathrm{N}$ converge near $65 \% \mathrm{RH}$ as the same salt mineral saturations control these concentrations.

The principal differences in the evolution of the w0 and w4 waters used to represent Bin 7 are in the precipitation of nahcolite and halite. Both waters evolve to alkaline, carbonate-type brines. The w4 water precipitates nahcolite $\left(\mathrm{NaHCO}_{3}\right)$ starting at water activity of approximately 0.91, while the w0 water precipitates less nahcolite, starting at water activity of approximately 0.85 . While nahcolite precipitation is occurring at this stage of the evaporative evolution of water w4, the concentrations of other, conservative species (represented by $\mathrm{N}, \mathrm{Cl}$, and $\mathrm{K}$ ) increase more as a function of the water activity. Halite precipitates from the w0 water starting at a water activity of approximately 0.72 , while the w4 water precipitates less halite, starting at water activity of approximately 0.67. While halite precipitation is occurring at this stage of the evaporative evolution of water w0, the concentrations of other, conservative species (represented by $\mathrm{N}$ and K) increase more as a function of the water activity. The evaporative endpoints for both waters are nearly identical, but the reaction paths differ in respect to the relative amounts of these precipitates formed. All of the precipitates formed during evaporation of both waters are qualitatively identical.

In conclusion, the only important difference between the composition of the w0 chemistry used in output for TSPA and the w4 one that was selected in Section 6.6.5 for use, is that the w0 water has an initial three-fold greater chloride to nitrate ratio. The presence of nitrate tends to inhibit localized corrosion, and the chloride-nitrate ratio is used as a parameter in the localized corrosion model (BSC 1005 [DIRS 169984], Section 8.1). The smaller nitrate concentration in the w0 water, compared to the w4 water in question, increases the likelihood that seepage waters could initiate localized corrosion. On this basis, use of the w0 base-front water chemistry at 10,006 years is justified as the Bin 7 median water for the TSPA abstraction. 


\subsection{EVOLUTION OF IN-DRIFT GAS AND TEMPERATURE}

The purposes of this section are:

- To analyze oxygen demand in the drift. This determines the potential (given the large masses of introduced materials in the drift) for the development of oxygen-deficient conditions.

- To establish the expected range of $\mathrm{pCO}_{2}$ through time and derive lookup tables for this parameter for the TSPA-LA.

- To establish the expected range of in-drift temperatures, for use in developing lookup tables.

- To report values of trace gas pressure in equilibrium with the initial THC seepage waters used as inputs to this model.

\subsubsection{Oxygen Evaluation}

Two evaluations of the in-drift oxygen are reported here as part of the gas abstraction model. The first is a simple examination of the THC seepage model results that are used to directly calculate in-drift oxygen partial pressure and accounts for air displacement resulting from thermal water-vapor generation. The second involves a steady-state rate balance calculation that estimates oxygen partial pressure by balancing the oxygen flux (supply as given by the THC seepage model) with oxygen consumption rate due to corrosion.

\subsubsection{THC Air Fraction}

The in-drift fraction of air is available in the THC seepage model Output DTN: LB0302DSCPTHCS.002 [DIRS 161976] within the five files titled thc6_w\#_drift_r.xls (where \# is 0 and 4 through 7) and under tab "fracture-th," columns labeled "Xair Crown." These are plotted together in Figure 6.7-1.

The minimum value from all available air fraction data, at all drift wall locations (crown, side, and base) is $3.5 \times 10^{-5}$ (unit less air fraction). Multiply that by the resulting oxygen fraction (multiply air fraction by 0.21 fraction of oxygen in air; Table 4.1-7) and the pressure at the repository level (rounded to 0.89 bar; Table $4.1-7$ ) to obtain a THC seepage model minimum oxygen content of $6.5 \times 10^{-6}$ bar (for these results see Output DTN: SN0508T0510102.023, Air fraction.xls). 


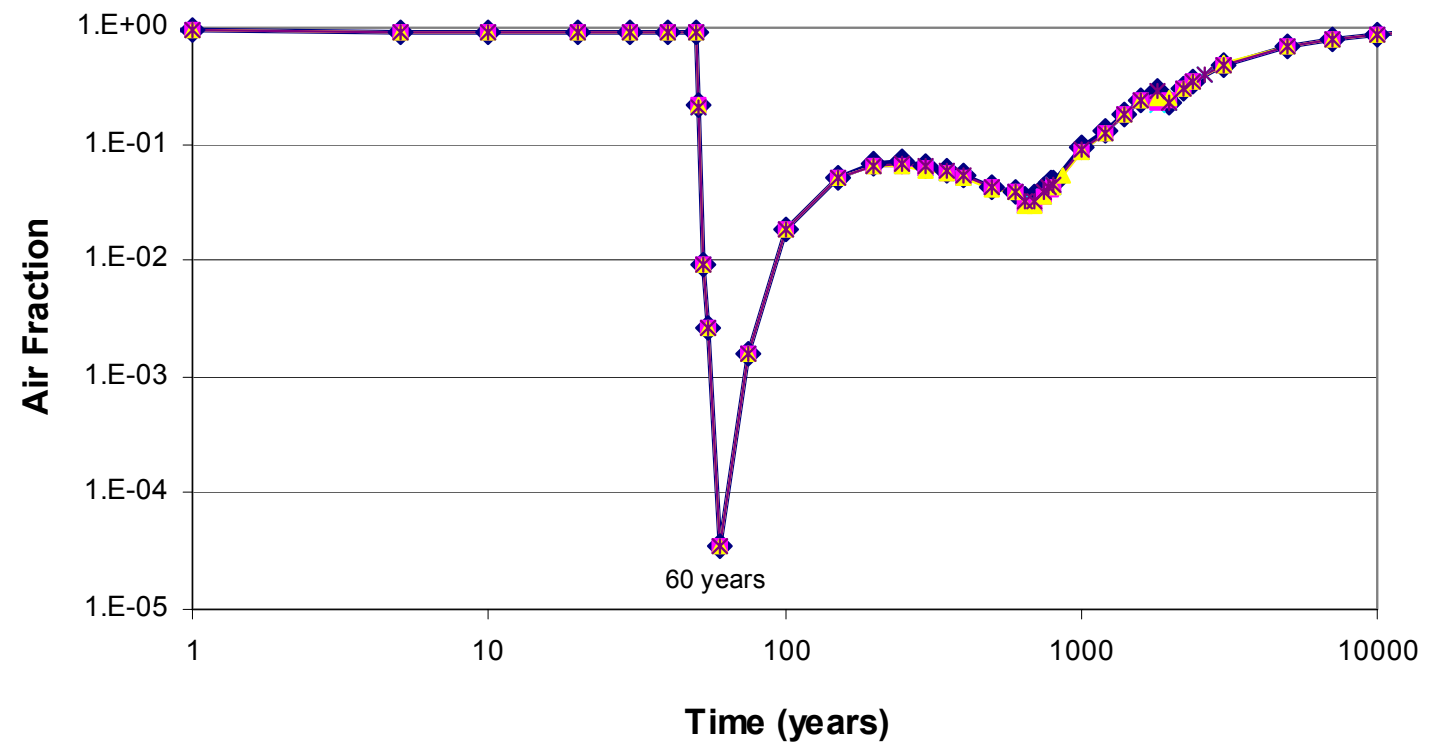

Source: DTN: LB0302DSCPTHCS.002 [DIRS 161976].

Figure 6.7-1. In-Drift Crown Air Fraction from THC Seepage Model for All Five Starting Waters

\subsubsection{Mass Balance: Flux versus Corrosion Consumption}

A steady-state rate balance, based on one-meter length of drift, is calculated to determine the potential for the development of molecular oxygen deficient conditions in the drift. The calculation involves (1) an estimate of molecular oxygen supply flux into the drift through the walls and along the axis of the drift, and (2) estimates of atomic oxygen consumption due to corrosion of the emplaced materials at corrosion rates specified in Section 6.4. Oxygen consumption due to microbial activity is expected to be low compared to oxygen consumption due to corrosion. Similar to the discussion in Evaluation of Potential Impacts of Microbial Activities on Drift Chemistry (BSC 2004 [DIRS 169991], Section 6.5.1 and Equation 6-4) with impact upon $\mathrm{CO}_{2}$ generation as compared to flux, $\mathrm{O}_{2}$ consumption (the same reaction generating $\mathrm{CO}_{2}$ ) will be much less than the oxygen flux.

The estimate of molecular oxygen flux (the supply rate) begins with calculating the gas flux across the drift wall and into the drift, based on results from Drift-Scale THC Seepage Model (BSC 2005 [DIRS 172862]). The THC model presents values of flux into (or out of) the drift at the crown, side, and base of the drift at each time step (Output DTN: SN0508T0510102.023, gas flux.xls, tab "fractures-th," Columns Titled "Gflux"). The total flux is estimated by selecting the greatest inward flux to one-quarter of the drift wall and assuming outward flux through the opposite quarter, and zero flux along the two adjacent quarters. This is an underestimation of the actual flux that might be expected in a three-dimensional drift because of the axial transport of gas (i.e., water vapor and air) between warmer and cooler areas, and between parts of the drift where corrosion is active and where it is not. For corrosion of invert steel, and especially for corrosion of carbon steel within breached waste packages, the consumptive reactions do not occur everywhere simultaneously. 
The molecular oxygen flux is calculated using the following values (DTN: LB0302DSCPTHCS.002 [DIRS 161976], thc6_w0_drift_r.xls):

- Gas flux at the crown, base, and side of the drift

- Mass fraction of air in the gas (with the remainder being water vapor)

- Volume fraction of $\mathrm{CO}_{2}$ in the gas

- The surface area of the drift wall for which the gas-flux calculation was performed.

The following inputs are also needed (as listed in Tables 4.1-7 and 4.1-8):

- The volume fraction of oxygen, nitrogen, and argon in the Earth's atmosphere (Weast and Astle 1979 [DIRS 102865], p. F-211)

- The atomic weights of the elements (Parrington et al. 1996 [DIRS 103896], pp. 62 to 63 )

- The 5.5-m diameter of an emplacement drift (BSC 2005 [DIRS 173498])

- Size specifications of emplacement drift invert steel materials (see Table 4.1-3)

- 21-PWR waste package length and separation distances

- Surface area and density of 21-PWR low-alloy steel components.

The resulting gas-flux rates are plotted in Figure 6.7-2, which shows the molar $\mathrm{O}_{2}$ and $\mathrm{CO}_{2}$ gas fluxes into the drift per year per lineal meter of drift (Output DTN: SN0508T0510102.023, gas flux.xls). The flux drop at 50 years is due to the thermally generated water vapor displacing air outward from the drifts. At 2,000 years, the gas flux increases, which also causes the $\mathrm{O}_{2}$ and $\mathrm{CO}_{2}$ to increase. This increase coincides with the temperature dropping significantly below $100^{\circ} \mathrm{C}$ (approximately $91^{\circ} \mathrm{C}$ ) and, with the return of the liquid saturation in the rock, to values similar to pre-emplacement levels (Figures 6.5-3, 6.5-6, and 6.5-7; BSC 2005 [DIRS 172862]).

In order to perform a steady-state estimate of the oxygen partial pressure, an average oxygen flux rate was selected. Examination of Figure 6.7-2, especially for 50 through approximately 200 or 300 years, resulted in the selection of a value of $3 \mathrm{~mol} / \mathrm{yr}$ per meter of drift for the oxygen flux. It is noted that the oxygen flux available after about 2,000 years increases by an order of magnitude from this $3 \mathrm{~mol} / \mathrm{yr}$ level.

The rate equation for oxygen supply is then simply:

$$
\frac{d\left[\mathrm{O}_{2}\right]}{d t}=k_{s}
$$

where $k_{s}$ is the constant supply rate $\left(\mathrm{mol} \mathrm{O}_{2}\right.$ per year). 


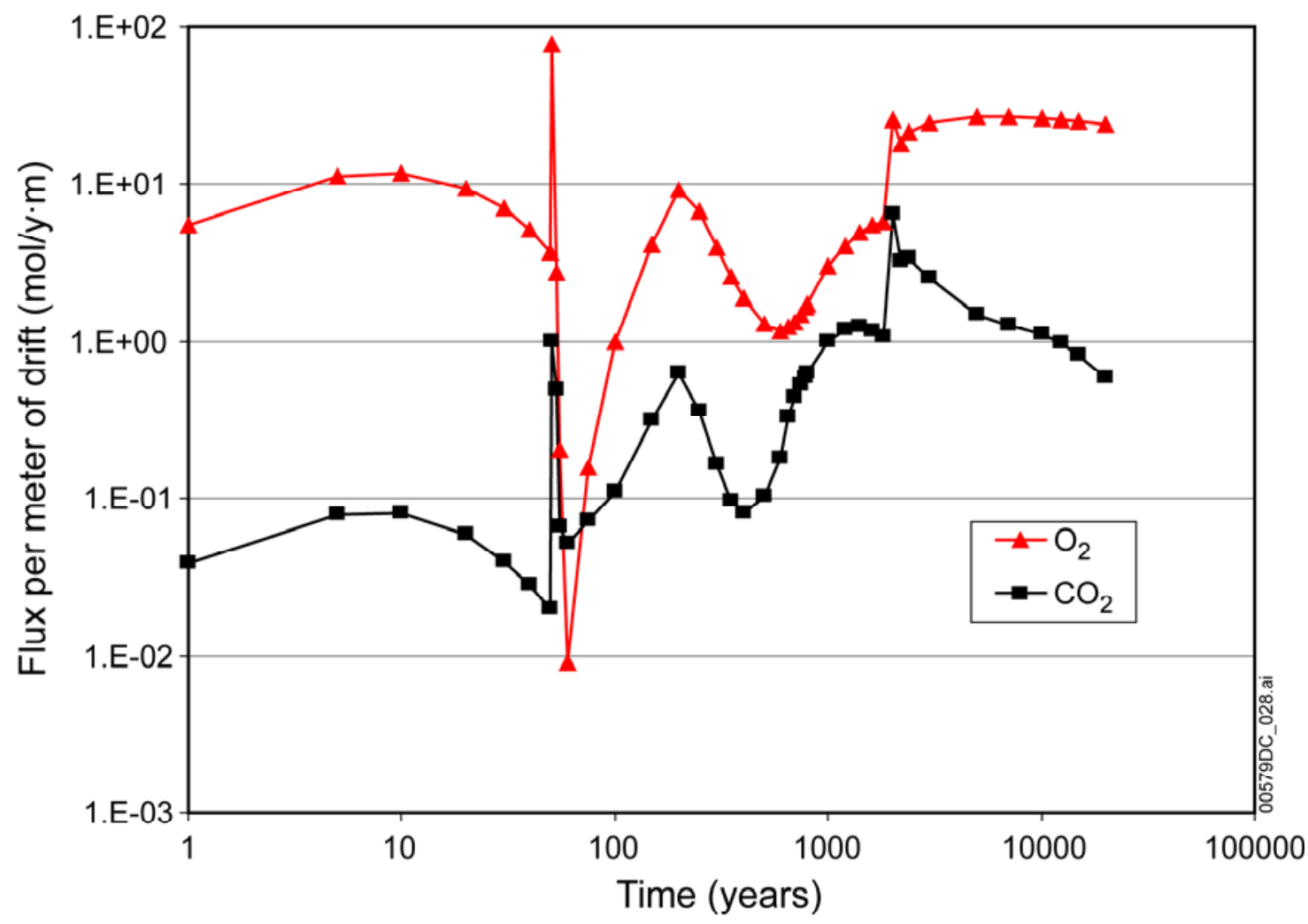

Source: Output DTN: SN0508T0510102.023.

Figure 6.7-2. Gas Flux per Axial Meter of Drift per Year

The conceptual basis for a corrosion consumption rate of oxygen is from a corrosion study by Jovancicevic and Bockris (1986 [DIRS 168509]) that explicitly investigated its dependence upon oxygen pressure. In that source's conclusion section (Jovancicevic and Bockris 1986 [DIRS 168509], p. 1805), the authors state, "In respect to $\mathrm{O}_{2}$, the reaction order on both surfaces [bare and passive iron] is 1." A reaction order of one in this case means that consumption of oxygen by corrosion of steel is linearly dependent upon its partial pressure. The partial pressures investigated ranged from 1 atmosphere down to $10^{-2}$ atmospheres. As this limitation is likely due to the diffusion limit of oxygen in reaching the surface, it is not expected ever to decrease its oxygen reaction order; i.e., for oxygen-driven corrosion limited by diffusion, the reaction rate cannot decrease its slope or "bottom out." The corrosion of iron itself could be observed to lose its oxygen dependence or even increase, but that would be due to another mechanism not limited by oxygen diffusion and not consuming gas-phase oxygen.

The reaction can be expressed as the consumptive rate equation that is a function of the exposed surface area:

$$
-\frac{d\left[\mathrm{O}_{2}\right]}{d t}=k_{c} * p\left(\mathrm{O}_{2}\right) * S A
$$

where $k_{c}$ is the consumption rate constant and $S A$ is the exposed surface area. This dependence is observed to be very linear with oxygen pressure and deviation from linearity at 
sub-atmospheric levels shows lower corrosion activity occurring (Jovancicevic and Bockris 1986 [DIRS 168509], Figure 6). Therefore, this strict linear dependence will result in overestimation of oxygen consumption and predict a lower oxygen pressure than might actually be expected. This is a reasonable approach as the results are for screening out the potential for anoxic conditions to occur within the drift.

The next step in the steady-state balance is to calculate the resulting oxygen pressure due to two cases where low-alloy steels in the introduced materials may corrode:

- Corrosion of materials outside of the waste package

- Corrosion of commercial waste packages (21-PWR).

Consideration is only given to the carbon or low-alloy steel components. This is because of their large mass and dominant corrosion rate (Table 6.4-8), making the carbon/low-alloy steels the only materials to consume oxygen at a significant rate due to corrosion.

A ratio of 1.5 moles of oxygen atoms per mole of iron is based on the formation of ferric iron as a solid or aqueous product, which can be seen in the reaction:

$$
\frac{4}{3} \mathrm{Fe}(\mathrm{s})+\mathrm{O}_{2}+2 \mathrm{H}_{2} \mathrm{O} \rightarrow \frac{4}{3} \mathrm{Fe}^{3+}+4 \mathrm{OH}^{-}
$$

This ratio is also a maximum for iron oxidation, and therefore consumes the most oxygen.

The principle of the steady-state analysis is that the consumption and production of the species are equivalent such that the rate of change for oxygen pressure is zero. This is calculated by summing the supply (Equation 6.7-1) and consumption (Equation 6.7-2) equations to give:

$$
p\left(\mathrm{O}_{2}\right)=-\frac{k_{s}}{k_{c} * S A}
$$

Dimensional analysis of the rate constants is the last item required to obtain a numeric solution. Note that the "per meter of drift" is removed from all units as it cancels. Units for $k_{s}$ are mole $\mathrm{O}_{2}$ per year; for $k_{c}$ they are mole $\mathrm{O}_{2}$ per year per $\mathrm{cm}^{2}$ per atmospheric partial pressure of $\mathrm{O}_{2}$, or:

$$
\frac{\mathrm{molO}_{2}}{\mathrm{yr} .} \cdot \frac{1}{\mathrm{~cm}^{2}} \cdot \frac{1}{p^{\circ}\left(\mathrm{O}_{2}\right)}
$$

Measured corrosion penetration rates are available for carbon or low-alloy steel used in the drift (Table 6.4-8), and $k_{c}$ is recast to utilize this type of rate. To convert to the unit of mole Fe per year per $\mathrm{cm}^{2}$, the stoichiometry of Equation 6.7-3 is included, incorporating the fact that the corrosion measurements were all performed at or near atmospheric partial pressures of oxygen, $p^{\circ}\left(\mathrm{O}_{2}\right)$ :

$$
k_{c}=\frac{3 \mathrm{molO}_{2}}{4 \mathrm{molFe}} \frac{k_{c}{ }^{\prime}}{p^{\circ}\left(\mathrm{O}_{2}\right)}
$$


where $k_{c}{ }^{\prime}$ now has simplified units of mole Fe per year per $\mathrm{cm}^{2}$. Making this substitution for the $k_{\mathrm{c}}$ rate, Equation 6.7-4 becomes:

$$
p\left(\mathrm{O}_{2}\right)=\frac{4}{3} \frac{p^{\circ}\left(\mathrm{O}_{2}\right) \cdot k_{s}}{k_{c}{ }^{\prime} \cdot S A}
$$

Invert Material Corrosion-The materials inside the waste package are not expected to corrode until the corrosion-resistant (Alloy 22) outer shell is breached, which is unlikely until after the end of the regulatory period. However, the corrosion of materials in the waste package is included in the oxygen consumption calculations as an upper bound of oxygen consumption. Using the size specifications for the invert and gantry rails from Table 4.1-3 to determine the surface area (Output DTN: SN0508T0510102.023, Oxygen Demand.xls, tab "Invert Surface Areas") and the corrosion rate for low-alloy or carbon steel (mean steam and atmospheric) listed in Table 6.4-8 (justified within Section 4.1.2), the oxygen consumption rate due to corrosion of all low-alloy or carbon steel materials outside the waste package is calculated (Output DTN: SN0508T0510102.023, Oxygen Demand.xls, tab “Invert O2 Consumption”).

The iron corrosion rate (for $k_{c}{ }^{\prime}$ ) is first converted from the $195 \mu \mathrm{m} /$ year value in Table 6.4-8 to the value of $2.75 \times 10^{-3} \mathrm{~mol}$ per year per $\mathrm{cm}^{2}$. Then, with calculated surface areas and $k_{s}$ of $3 \mathrm{~mol} / \mathrm{yr}$, implementation of Equation 6.7-7 is straightfoward. The results indicate that due to corrosion of steel in the invert and gantry rails, the oxygen pressure may drop to approximately $2.7 \times 10^{-3}$ bar (Output DTN: SN0508T0510102.023, Oxygen Demand.xls, tab "Invert O2 Consumption").

Waste Package Material Corrosion-Once the waste package itself is breached, materials in the package may begin to undergo oxygen-mediated corrosion. Oxygen partial pressure is modeled with the conservative simplification that an entire drift consisting of 21-PWR waste packages that have ruptured simultaneously. Using the waste package length and spacing in Table 4.1-7, and the mass and material thickness data in Table 4.1-8 for the 21-PWR internal low-alloy/carbon steel materials, the surface area per meter of drift available for corrosion is determined. Briefly, the calculation of the surface areas for the Carbon Steel Type A516 fuel basket tube and Carbon Steel Type A516 guides is done using the formula (surface area) = (mass/density)*(1/thickness)*(2), where 2 in the formula accounts for two sides and mass is multiplied by 1,000 to convert to grams. This surface area within a 21 -PWR package is divided by its effective length in the drift (waste package length plus separation distance, Table 4.1-7; see Output DTN: SN0508T0510102.023, Oxygen Demand.xls, tabs "Surface Areas Carbon Steel" and "21-PWR Surface Area"). Then, oxygen consumption rates are calculated as before using Equation 6.7-7 and the steady-state partial pressure of oxygen estimated (Output DTN: SN0508T0510102.023, Oxygen Demand.xls, tab "21-PWR O2 Consumption"). Although of high surface area, the waste material itself was not considered in this modeling as it is encased in Zircaloy; this will prevent all the fuel from being exposed at the same time. This example involving the entire failure of a drift containing only the 21-PWR waste packages leads to a lower oxygen pressure of $6.6 \times 10^{-4}$ bar. 


\subsubsection{Comparison to Important Redox Couples}

All of the oxygen levels from Sections 6.7.1.1 and 6.7.1.2 are still significantly above those required to produce anoxic conditions. To demonstrate this, three EQ3/6 calculations are performed to determine the following:

- Nitrate/nitrite equivalence-point oxygen pressure

- Approximate ferric/ferrous iron equivalence-point oxygen pressure

- Various redox species present at the minimum drift oxygen pressure.

These calculations are contained in the Output DTN: SN0508T0510102.023 in the input/output files, corresponding to the list above: no2no3.3i/.3o, fe2fe3.3i/.3o, and minoxy.3i/.3o.

The nitrate-nitrite couple was calculated using the Pitzer thermodynamic database (DTN: SN0302T0510102.002 [DIRS 162572]). Setting both nitrate and nitrite equal to molality of 0.01 , charge balanced by sodium, the equilibrium oxygen pressure is determined to be at $2.7 \times 10^{-28}$ bar.

The ferric-ferrous couple was calculated using the data0.ymp.R2 B-dot database (DTN: MO0302SPATHDYN.000 [DIRS 161756]) because the Pitzer database is not validated for iron speciation. The species $\mathrm{HFeO}(\mathrm{aq})$ and $\mathrm{Fe}^{2+}$ represent iron in the +3 and +2 valences, respectively. A concentration for each was selected near the equivalence point, to estimate the associated oxygen fugacity or pressure. For $\mathrm{HFeO}_{2}(\mathrm{aq})=4.3 \times 10^{-11}$ and $\mathrm{Fe}^{2+}=3.3 \times 10^{-11}$, the resulting oxygen pressure is $1.4 \times 10^{-54}$ bar.

An alternate analysis is to compare the calculated quantity of redox species found at the lowest reasonably expected oxygen pressure from the determinations in Sections 6.7.1.1 and 6.7.1.2. This is at the THC seepage model's minimum air fraction result at $6.5 \times 10^{-6}$ bar. The results using the data0.ymp.R2 B-dot database show that at such an oxygen pressure, with $\mathrm{Fe}^{3+}$ species at the $10^{-10}$ molal level, the $\mathrm{Fe}^{2+}$ is less than the $10^{-22}$ molal. Aqueous hydrogen peroxide is in the same range at $2 \times 10^{-21}$ molal.

The three comparisons all indicate that the minimum oxygen pressures expected within the in-drift environment are sufficient to prevent anoxic conditions from occurring and generating reduced aqueous species.

\subsubsection{Thermal-Hydrological-Chemical Seepage Model Input to In-Drift $\mathrm{CO}_{2}$ Gas Abstraction}

The $\mathrm{pCO}_{2}$ and temperature in the drift environment can affect chemical processes, such as radionuclide solubility. As an illustration, the uranium concentration in equilibrium with schoepite $\left(\mathrm{UO}_{3} \cdot 2 \mathrm{H}_{2} \mathrm{O}\right)$ is shown to be at least ten times higher for $\mathrm{pCO}_{2}=10^{-2}$ bar compared to $p \mathrm{CO}_{2}=0$ bar for $\mathrm{pH}>7$ (Langmuir 1997 [DIRS 100051], Figure 13.5). Section 6.7.2.1 provides the lookup tables for in-drift and invert $\mathrm{pCO}_{2}$ values, which correspond to the seepage compositions presented in Section 6.6.5. Section 6.7.3 determines the range of values of $\mathrm{pCO}_{2}$ and temperature for construction of water chemistry lookup tables presented in Section 6.9.4. 


\subsubsection{TSPA-LA Lookup Tables for Drift and Invert $p \mathrm{CO}_{2}$}

In conjunction with the seepage binning and bin maps presented in Section 6.6.6 (Tables 6.6-9 to 6.6-13), the TSPA-LA requires lookup tables to define the $\mathrm{pCO}_{2}$ within the drift and invert for each of the five THC cases.

These lookup tables (Tables 6.7-1 to 6.7-5) are prepared using the ten THC seepage model files listed in Table 4.1-5 and discussed in Section 4.1.3. The tables are found in THC_CO2_Look-up.xls (archived in Output DTN: SN0503T0510102.019). The input files thc6_XX_drift_r.xls (where "XX" stands for the abbreviated water name) from DTN: LB0302DSCPTHCS.002 [DIRS 161976] are the source of the in-drift and invert values; and the file types thc6_XX_r.xls are the source for the in-rock values used for comparison only.

The in-drift values are represented by the $\mathrm{pCO}_{2}$ values at the crown location from worksheet "fracture-ch." The invert values are represented by the $\mathrm{pCO}_{2}$ values at the base location taken from worksheet "matrix-ch." Additionally, for the w0 starting water, the input DTN worksheets contain an extra entry at 2,400 years; the second entry at this time is deleted from the output DTN data. The input files contain the volume fraction data for carbon dioxide and the total pressure at that location as functions of time. The product of these two values gives $\mathrm{pCO}_{2}$.

The $\mathrm{pCO}_{2}$ values are plotted as a log-function of time in Figures 6.7-3 and 6.7-4. Figure 6.7-3 contains all the values including those from within the rock, whereas Figure 6.7-4 contains only the in-drift values for clarity. The atmospheric $\mathrm{CO}_{2}$ content (Weast 1984 [DIRS 106170], p. F-157) is also plotted for reference purposes. Both figures show the $\mathrm{pCO}_{2}$ values for various spatial locations, namely, within the drift, in the rock near the drift wall crown, and near the base of the invert. Validation of this $\mathrm{CO}_{2}$ gas abstraction is performed in Section 7.2.2. 


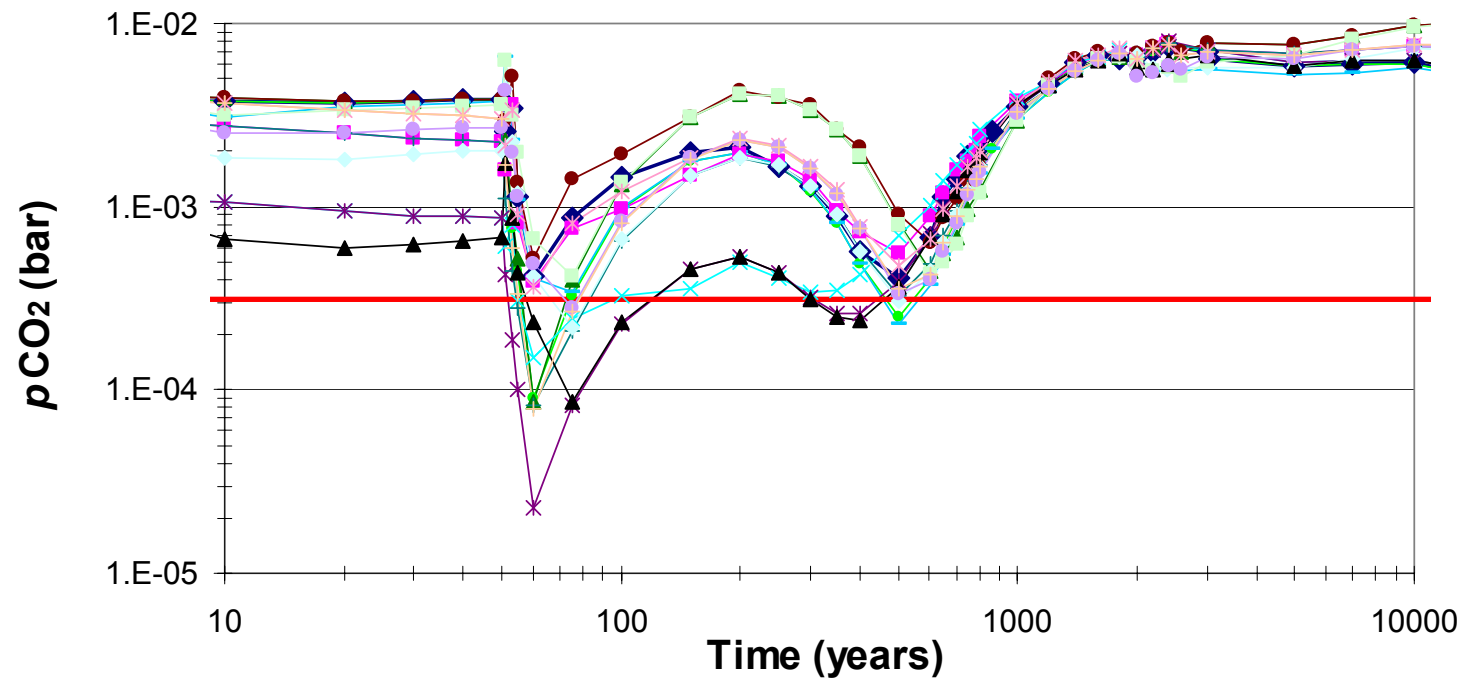

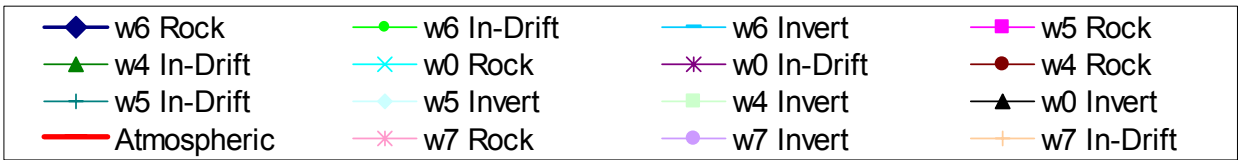

Source: Output DTN: SN0503T0510102.019.

NOTES: See Table 4.1-4 for abbreviated water names of labels in the legend.

Figure 6.7-3. $\mathrm{THC} \mathrm{CO}_{2}$ Partial Pressure in the Drift and Near-Drift Environment through Time

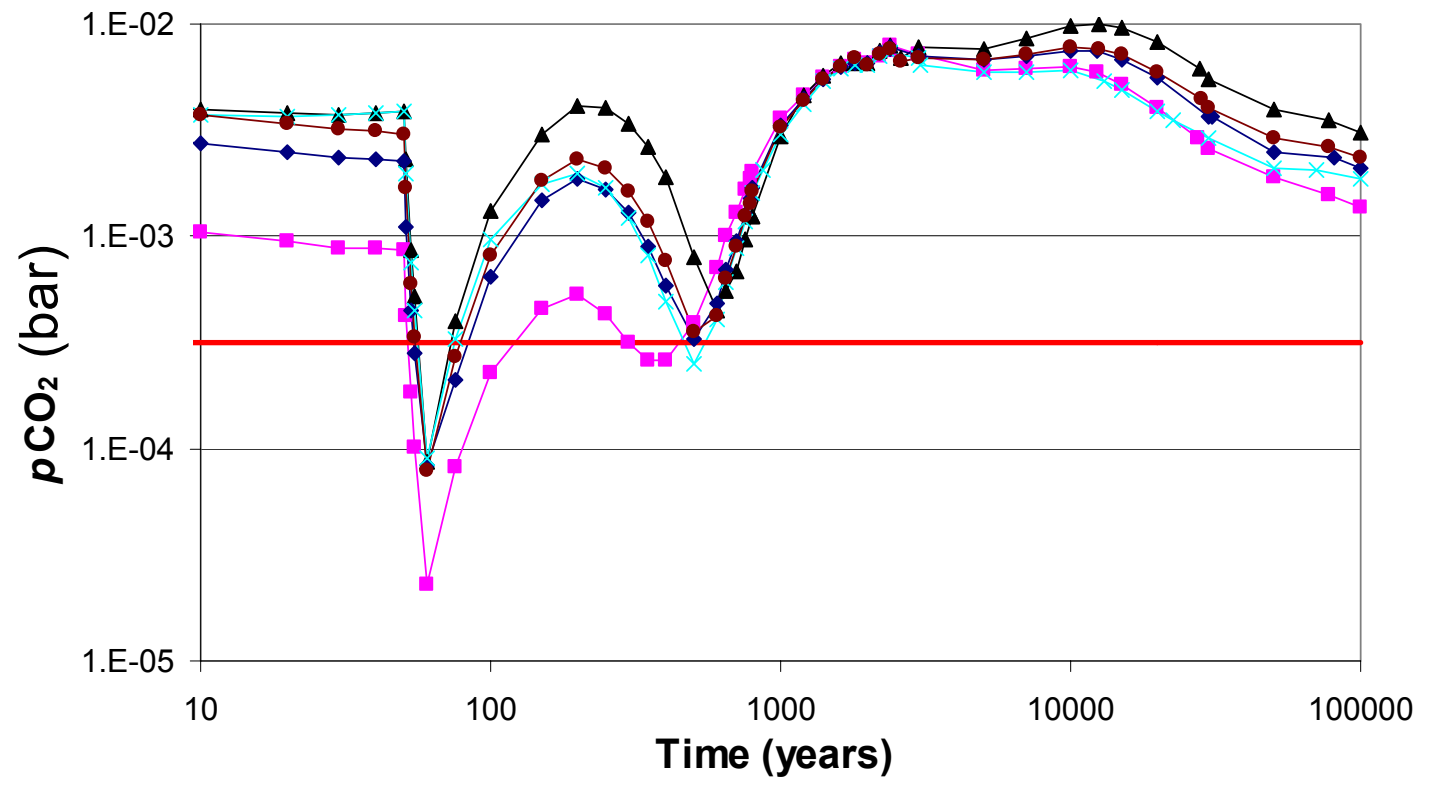

- w0 In-Drift $\_$w4 In-Drift $\bullet$ w5 In-Drift $\longrightarrow$ w6 In-Drift $\longrightarrow$ Atmospheric $\longrightarrow$ w7 In-Drift

Source: Output DTN: SN0503T0510102.019.

NOTE: See Table 4.1-4 for abbreviated water names of labels in the legend.

Figure 6.7-4. $\mathrm{THC} \mathrm{CO}_{2}$ Partial Pressure in the In-Drift Environment through Time 
Table 6.7-1. Lookup Tables for TSPA-LA Analysis of In-Drift and Invert $p \mathrm{CO}_{2}$ for w0 (HD-PERM)

\begin{tabular}{|c|c|c|}
\hline \multirow{2}{*}{$\frac{\text { w0 (HD-PERM) }}{\text { Year }}$} & \multicolumn{2}{|c|}{ Partial Pressure $\mathrm{CO}_{2}(\mathrm{~g})$ (bar) } \\
\hline & Drift & Invert \\
\hline 0.00 & $8.22 \mathrm{E}-04$ & 7.77E-04 \\
\hline 1.00 & $1.21 \mathrm{E}-03$ & $2.02 E-03$ \\
\hline 5.00 & $1.12 \mathrm{E}-03$ & $1.04 \mathrm{E}-03$ \\
\hline 10.01 & $1.05 E-03$ & $6.65 E-04$ \\
\hline 20.01 & $9.51 \mathrm{E}-04$ & $5.89 E-04$ \\
\hline 30.02 & $8.82 E-04$ & $6.16 \mathrm{E}-04$ \\
\hline 40.02 & $8.80 \mathrm{E}-04$ & $6.53 \mathrm{E}-04$ \\
\hline 50.00 & $8.61 \mathrm{E}-04$ & $6.85 E-04$ \\
\hline 51.03 & $4.25 \mathrm{E}-04$ & $1.74 \mathrm{E}-03$ \\
\hline 53.04 & $1.86 \mathrm{E}-04$ & $8.64 \mathrm{E}-04$ \\
\hline 55.04 & $1.01 \mathrm{E}-04$ & $4.34 \mathrm{E}-04$ \\
\hline 60.04 & $2.29 E-05$ & $2.36 \mathrm{E}-04$ \\
\hline 75.05 & $8.25 E-05$ & $8.60 \mathrm{E}-05$ \\
\hline 100.07 & $2.29 E-04$ & $2.34 \mathrm{E}-04$ \\
\hline 150.10 & $4.58 \mathrm{E}-04$ & $4.60 \mathrm{E}-04$ \\
\hline 200.13 & $5.28 \mathrm{E}-04$ & $5.30 \mathrm{E}-04$ \\
\hline 250.17 & $4.34 \mathrm{E}-04$ & $4.35 \mathrm{E}-04$ \\
\hline 300.20 & $3.18 \mathrm{E}-04$ & $3.12 \mathrm{E}-04$ \\
\hline 350.24 & $2.60 \mathrm{E}-04$ & $2.49 \mathrm{E}-04$ \\
\hline 400.27 & $2.60 \mathrm{E}-04$ & $2.40 \mathrm{E}-04$ \\
\hline 500.35 & $3.93 E-04$ & 3.67E-04 \\
\hline 600.39 & $7.12 \mathrm{E}-04$ & $6.80 \mathrm{E}-04$ \\
\hline 650.43 & 9.97E-04 & $9.06 \mathrm{E}-04$ \\
\hline 700.47 & $1.30 \mathrm{E}-03$ & $1.21 \mathrm{E}-03$ \\
\hline 750.51 & $1.65 E-03$ & $1.57 \mathrm{E}-03$ \\
\hline 789.87 & $1.85 \mathrm{E}-03$ & $1.82 \mathrm{E}-03$ \\
\hline 800.55 & $2.02 E-03$ & 1.97E-03 \\
\hline 1000.67 & $3.63 E-03$ & $3.58 \mathrm{E}-03$ \\
\hline 1200.79 & $4.61 \mathrm{E}-03$ & $4.62 E-03$ \\
\hline 1400.94 & $5.60 \mathrm{E}-03$ & $5.57 \mathrm{E}-03$ \\
\hline 1601.06 & $6.32 \mathrm{E}-03$ & $6.32 \mathrm{E}-03$ \\
\hline 1801.21 & $6.81 \mathrm{E}-03$ & $6.79 \mathrm{E}-03$ \\
\hline 2001.33 & $6.51 \mathrm{E}-03$ & $5.71 \mathrm{E}-03$ \\
\hline 2201.52 & $7.10 \mathrm{E}-03$ & 5.57E-03 \\
\hline 2401.64 & $7.49 E-03$ & $5.95 E-03$ \\
\hline 3002.00 & $7.20 \mathrm{E}-03$ & $6.65 E-03$ \\
\hline 5003.49 & $6.08 \mathrm{E}-03$ & $5.93 E-03$ \\
\hline 7004.69 & $6.22 \mathrm{E}-03$ & $6.23 E-03$ \\
\hline 10006.70 & $6.31 \mathrm{E}-03$ & $6.26 \mathrm{E}-03$ \\
\hline 12310.20 & $5.90 \mathrm{E}-03$ & $5.83 \mathrm{E}-03$ \\
\hline 15010.10 & $5.21 \mathrm{E}-03$ & $5.16 \mathrm{E}-03$ \\
\hline 20013.30 & $4.02 E-03$ & $3.95 E-03$ \\
\hline
\end{tabular}

Source: Output DTN: SN0503T0510102.019. 
Table 6.7-2. Lookup Tables for TSPA-LA Analysis of In-Drift and Invert $p \mathrm{CO}_{2}$ for w4 (CS2000)

\begin{tabular}{|c|c|c|}
\hline \multirow{2}{*}{$\frac{\text { w4 (CS2000) }}{\text { Year }}$} & \multicolumn{2}{|c|}{ Partial Pressure $\mathrm{CO}_{2}(\mathrm{~g})$ (bar) } \\
\hline & Drift & Invert \\
\hline 0.00 & $3.01 \mathrm{E}-03$ & $2.86 \mathrm{E}-03$ \\
\hline 1.00 & $3.75 \mathrm{E}-03$ & $5.18 \mathrm{E}-03$ \\
\hline 5.00 & $4.11 \mathrm{E}-03$ & $4.06 \mathrm{E}-03$ \\
\hline 10.01 & $3.97 \mathrm{E}-03$ & $3.13 E-03$ \\
\hline 20.01 & $3.79 \mathrm{E}-03$ & $3.35 \mathrm{E}-03$ \\
\hline 30.02 & $3.75 \mathrm{E}-03$ & $3.47 \mathrm{E}-03$ \\
\hline 40.02 & $3.82 \mathrm{E}-03$ & $3.56 \mathrm{E}-03$ \\
\hline 50.00 & $3.87 \mathrm{E}-03$ & $3.64 \mathrm{E}-03$ \\
\hline 51.03 & $2.31 \mathrm{E}-03$ & $6.22 \mathrm{E}-03$ \\
\hline 53.04 & $8.59 \mathrm{E}-04$ & $3.15 E-03$ \\
\hline 55.04 & $5.25 \mathrm{E}-04$ & 1.97E-03 \\
\hline 60.04 & $8.70 \mathrm{E}-05$ & $6.64 \mathrm{E}-04$ \\
\hline 75.05 & $3.97 \mathrm{E}-04$ & $4.15 \mathrm{E}-04$ \\
\hline 100.07 & $1.32 \mathrm{E}-03$ & $1.35 \mathrm{E}-03$ \\
\hline 150.10 & $3.05 \mathrm{E}-03$ & $3.08 \mathrm{E}-03$ \\
\hline 200.13 & $4.09 \mathrm{E}-03$ & $4.12 \mathrm{E}-03$ \\
\hline 250.17 & $4.01 \mathrm{E}-03$ & $4.02 \mathrm{E}-03$ \\
\hline 300.20 & $3.37 \mathrm{E}-03$ & $3.38 \mathrm{E}-03$ \\
\hline 350.24 & $2.63 \mathrm{E}-03$ & $2.64 \mathrm{E}-03$ \\
\hline 400.27 & $1.89 \mathrm{E}-03$ & $1.88 \mathrm{E}-03$ \\
\hline 500.35 & $8.05 E-04$ & $7.99 \mathrm{E}-04$ \\
\hline 600.39 & $4.50 \mathrm{E}-04$ & $4.28 \mathrm{E}-04$ \\
\hline 650.43 & $5.54 \mathrm{E}-04$ & $5.00 \mathrm{E}-04$ \\
\hline 700.47 & $6.80 \mathrm{E}-04$ & $6.28 \mathrm{E}-04$ \\
\hline 750.51 & $9.65 \mathrm{E}-04$ & $8.82 \mathrm{E}-04$ \\
\hline 800.55 & $1.24 \mathrm{E}-03$ & 1.17E-03 \\
\hline 804.22 & $1.24 \mathrm{E}-03$ & $1.18 \mathrm{E}-03$ \\
\hline 1000.67 & $2.98 \mathrm{E}-03$ & $2.94 \mathrm{E}-03$ \\
\hline 1200.79 & $4.63 \mathrm{E}-03$ & $4.61 \mathrm{E}-03$ \\
\hline 1400.94 & $5.69 \mathrm{E}-03$ & $5.64 \mathrm{E}-03$ \\
\hline 1601.06 & $6.48 \mathrm{E}-03$ & $6.44 \mathrm{E}-03$ \\
\hline 1801.21 & $6.55 \mathrm{E}-03$ & $6.56 \mathrm{E}-03$ \\
\hline 2001.33 & $6.60 \mathrm{E}-03$ & $6.19 \mathrm{E}-03$ \\
\hline 2201.52 & $7.47 \mathrm{E}-03$ & $5.55 \mathrm{E}-03$ \\
\hline 2401.64 & $7.89 \mathrm{E}-03$ & $5.71 \mathrm{E}-03$ \\
\hline 2597.46 & $6.96 \mathrm{E}-03$ & $5.14 \mathrm{E}-03$ \\
\hline 3002.00 & $7.82 \mathrm{E}-03$ & $6.08 \mathrm{E}-03$ \\
\hline 5003.49 & $7.63 \mathrm{E}-03$ & $6.66 \mathrm{E}-03$ \\
\hline 7004.69 & $8.55 \mathrm{E}-03$ & $8.27 \mathrm{E}-03$ \\
\hline 10006.70 & $9.87 \mathrm{E}-03$ & $9.60 \mathrm{E}-03$ \\
\hline 12597.90 & $1.01 \mathrm{E}-02$ & $9.90 \mathrm{E}-03$ \\
\hline 15010.10 & $9.63 \mathrm{E}-03$ & $9.57 \mathrm{E}-03$ \\
\hline 20013.30 & $8.19 \mathrm{E}-03$ & $8.21 \mathrm{E}-03$ \\
\hline
\end{tabular}

Source: Output DTN: SN0503T0510102.019. 
Table 6.7-3. Lookup Tables for TSPA-LA Analysis of In-Drift and Invert $p \mathrm{CO}_{2}$ for w5 (CS1000)

\begin{tabular}{|c|c|c|}
\hline \multirow{2}{*}{$\frac{\text { w5 (CS1000) }}{\text { Year }}$} & \multicolumn{2}{|c|}{ Partial Pressure $\mathrm{CO}_{2}(\mathrm{~g})$ (bar) } \\
\hline & Drift & Invert \\
\hline 0.00 & $3.01 \mathrm{E}-03$ & $2.88 \mathrm{E}-03$ \\
\hline 1.00 & $3.73 \mathrm{E}-03$ & 4.07E-03 \\
\hline 5.00 & $3.00 \mathrm{E}-03$ & $2.45 \mathrm{E}-03$ \\
\hline 10.01 & $2.75 \mathrm{E}-03$ & $1.85 \mathrm{E}-03$ \\
\hline 20.01 & $2.50 \mathrm{E}-03$ & $1.82 \mathrm{E}-03$ \\
\hline 30.02 & $2.35 \mathrm{E}-03$ & $1.94 \mathrm{E}-03$ \\
\hline 40.02 & $2.31 \mathrm{E}-03$ & $2.01 \mathrm{E}-03$ \\
\hline 50.00 & $2.26 \mathrm{E}-03$ & $2.03 E-03$ \\
\hline 51.03 & $1.12 \mathrm{E}-03$ & $4.38 \mathrm{E}-03$ \\
\hline 53.04 & $4.47 \mathrm{E}-04$ & $2.24 \mathrm{E}-03$ \\
\hline 55.04 & $2.82 \mathrm{E}-04$ & $1.19 \mathrm{E}-03$ \\
\hline 60.04 & $8.33 \mathrm{E}-05$ & $4.20 \mathrm{E}-04$ \\
\hline 75.05 & $2.10 \mathrm{E}-04$ & $2.20 \mathrm{E}-04$ \\
\hline 100.07 & $6.49 \mathrm{E}-04$ & $6.63 E-04$ \\
\hline 150.10 & $1.47 \mathrm{E}-03$ & $1.48 \mathrm{E}-03$ \\
\hline 200.13 & $1.85 \mathrm{E}-03$ & $1.86 \mathrm{E}-03$ \\
\hline 250.17 & $1.67 \mathrm{E}-03$ & $1.68 \mathrm{E}-03$ \\
\hline 300.20 & $1.29 \mathrm{E}-03$ & $1.29 \mathrm{E}-03$ \\
\hline 350.24 & $9.04 \mathrm{E}-04$ & $9.02 \mathrm{E}-04$ \\
\hline 400.27 & $5.82 \mathrm{E}-04$ & $5.72 \mathrm{E}-04$ \\
\hline 500.35 & $3.27 \mathrm{E}-04$ & $3.05 E-04$ \\
\hline 600.39 & $4.86 \mathrm{E}-04$ & $4.48 \mathrm{E}-04$ \\
\hline 650.43 & $7.01 \mathrm{E}-04$ & $6.32 E-04$ \\
\hline 700.47 & $9.52 \mathrm{E}-04$ & 8.99E-04 \\
\hline 750.51 & $1.28 \mathrm{E}-03$ & $1.22 \mathrm{E}-03$ \\
\hline 784.70 & $1.52 \mathrm{E}-03$ & $1.48 \mathrm{E}-03$ \\
\hline 800.55 & $1.70 \mathrm{E}-03$ & $1.65 \mathrm{E}-03$ \\
\hline 1000.67 & $3.36 \mathrm{E}-03$ & $3.28 \mathrm{E}-03$ \\
\hline 1200.79 & $4.40 \mathrm{E}-03$ & $4.41 \mathrm{E}-03$ \\
\hline 1400.94 & $5.49 \mathrm{E}-03$ & $5.50 \mathrm{E}-03$ \\
\hline 1601.06 & $6.30 \mathrm{E}-03$ & $6.34 \mathrm{E}-03$ \\
\hline 1801.21 & $6.50 \mathrm{E}-03$ & $6.51 \mathrm{E}-03$ \\
\hline 2001.33 & $6.59 \mathrm{E}-03$ & $6.68 \mathrm{E}-03$ \\
\hline 2201.52 & $7.33 \mathrm{E}-03$ & $5.69 \mathrm{E}-03$ \\
\hline 2392.40 & $7.66 \mathrm{E}-03$ & $5.60 \mathrm{E}-03$ \\
\hline 2401.64 & $7.75 \mathrm{E}-03$ & $5.69 \mathrm{E}-03$ \\
\hline 3002.00 & $7.11 \mathrm{E}-03$ & $5.76 \mathrm{E}-03$ \\
\hline 5003.49 & $6.78 \mathrm{E}-03$ & $5.78 \mathrm{E}-03$ \\
\hline 7004.69 & $7.10 \mathrm{E}-03$ & $6.44 \mathrm{E}-03$ \\
\hline 10006.70 & $7.55 \mathrm{E}-03$ & $7.25 \mathrm{E}-03$ \\
\hline 12304.20 & $7.42 \mathrm{E}-03$ & $7.22 \mathrm{E}-03$ \\
\hline 15010.10 & $6.83 \mathrm{E}-03$ & $6.75 \mathrm{E}-03$ \\
\hline 20013.30 & $5.59 \mathrm{E}-03$ & $5.55 \mathrm{E}-03$ \\
\hline
\end{tabular}

Source: Output DTN: SN0503T0510102.019. 
Table 6.7-4. Lookup Tables for TSPA-LA Analysis of In-Drift and Invert $p \mathrm{CO}_{2}$ for w6 (SD-9/990)

\begin{tabular}{|c|c|c|}
\hline \multirow{2}{*}{$\begin{array}{c}\text { w6 (SD-9/990) } \\
\text { Year }\end{array}$} & \multicolumn{2}{|c|}{ Partial Pressure $\mathrm{CO}_{2}(\mathrm{~g})$ (bar) } \\
\hline & Drift & Invert \\
\hline 0.00 & $3.03 E-03$ & $2.93 E-03$ \\
\hline 1.00 & $3.36 \mathrm{E}-03$ & $5.58 \mathrm{E}-03$ \\
\hline 5.00 & $3.81 \mathrm{E}-03$ & $3.97 E-03$ \\
\hline 10.01 & $3.77 \mathrm{E}-03$ & $3.11 \mathrm{E}-03$ \\
\hline 20.01 & $3.69 \mathrm{E}-03$ & $3.54 \mathrm{E}-03$ \\
\hline 30.02 & $3.73 \mathrm{E}-03$ & $3.61 \mathrm{E}-03$ \\
\hline 40.02 & $3.82 \mathrm{E}-03$ & $3.69 \mathrm{E}-03$ \\
\hline 50.00 & $3.88 \mathrm{E}-03$ & $3.76 \mathrm{E}-03$ \\
\hline 51.03 & $1.99 \mathrm{E}-03$ & $6.50 \mathrm{E}-03$ \\
\hline 53.04 & $7.56 \mathrm{E}-04$ & $2.30 \mathrm{E}-03$ \\
\hline 55.04 & $4.48 \mathrm{E}-04$ & 1.09E-03 \\
\hline 60.04 & 9.07E-05 & 4.07E-04 \\
\hline 75.05 & $3.26 \mathrm{E}-04$ & $3.40 \mathrm{E}-04$ \\
\hline 100.07 & $9.72 \mathrm{E}-04$ & $9.92 E-04$ \\
\hline 150.10 & $1.76 \mathrm{E}-03$ & $1.77 \mathrm{E}-03$ \\
\hline 200.13 & $1.98 \mathrm{E}-03$ & 1.99E-03 \\
\hline 250.17 & $1.69 \mathrm{E}-03$ & $1.69 \mathrm{E}-03$ \\
\hline 300.20 & $1.22 \mathrm{E}-03$ & $1.23 E-03$ \\
\hline 350.24 & $8.07 \mathrm{E}-04$ & $8.08 \mathrm{E}-04$ \\
\hline 400.27 & $4.89 \mathrm{E}-04$ & $4.84 \mathrm{E}-04$ \\
\hline 500.35 & $2.50 \mathrm{E}-04$ & $2.28 \mathrm{E}-04$ \\
\hline 600.39 & $4.10 \mathrm{E}-04$ & $3.76 \mathrm{E}-04$ \\
\hline 650.43 & $6.09 \mathrm{E}-04$ & $5.43 E-04$ \\
\hline 700.47 & $8.76 \mathrm{E}-04$ & $8.01 \mathrm{E}-04$ \\
\hline 750.51 & $1.18 \mathrm{E}-03$ & $1.13 \mathrm{E}-03$ \\
\hline 800.55 & $1.60 \mathrm{E}-03$ & $1.53 E-03$ \\
\hline 865.34 & $2.08 \mathrm{E}-03$ & $2.06 \mathrm{E}-03$ \\
\hline 1000.67 & $3.04 \mathrm{E}-03$ & $3.02 E-03$ \\
\hline 1200.79 & $4.22 \mathrm{E}-03$ & $4.23 E-03$ \\
\hline 1400.94 & $5.38 \mathrm{E}-03$ & $5.34 \mathrm{E}-03$ \\
\hline 1601.06 & $6.21 \mathrm{E}-03$ & $6.20 \mathrm{E}-03$ \\
\hline 1801.21 & $6.41 \mathrm{E}-03$ & $6.47 \mathrm{E}-03$ \\
\hline 2001.33 & $6.47 \mathrm{E}-03$ & $6.57 \mathrm{E}-03$ \\
\hline 2201.52 & $7.05 \mathrm{E}-03$ & $5.43 \mathrm{E}-03$ \\
\hline 2401.64 & $7.41 \mathrm{E}-03$ & $5.46 \mathrm{E}-03$ \\
\hline 3002.00 & $6.95 \mathrm{E}-03$ & $5.56 \mathrm{E}-03$ \\
\hline 3048.54 & $6.38 \mathrm{E}-03$ & $5.56 \mathrm{E}-03$ \\
\hline 5003.49 & $5.92 \mathrm{E}-03$ & $5.21 \mathrm{E}-03$ \\
\hline 7004.69 & $5.98 \mathrm{E}-03$ & $5.39 \mathrm{E}-03$ \\
\hline 10006.70 & $6.06 \mathrm{E}-03$ & $5.77 \mathrm{E}-03$ \\
\hline 13053.70 & $5.42 \mathrm{E}-03$ & $5.26 \mathrm{E}-03$ \\
\hline 15010.10 & $4.92 \mathrm{E}-03$ & $4.84 \mathrm{E}-03$ \\
\hline 20013.30 & $3.88 \mathrm{E}-03$ & $3.88 E-03$ \\
\hline
\end{tabular}

Source: Output DTN: SN0503T0510102.019. 
Table 6.7-5. Lookup Tables for TSPA-LA Analysis of In-Drift and Invert $p \mathrm{CO}_{2}$ for w7 (CS500)

\begin{tabular}{|c|c|c|}
\hline \multirow{2}{*}{$\frac{\text { w7 (CS500) }}{\text { Year }}$} & \multicolumn{2}{|c|}{ Partial Pressure $\mathrm{CO}_{2}(\mathrm{~g})$ (bar) } \\
\hline & Drift & Invert \\
\hline 0.00 & $3.12 \mathrm{E}-03$ & $3.53 E-03$ \\
\hline 1.00 & $4.73 \mathrm{E}-03$ & $5.11 \mathrm{E}-03$ \\
\hline 5.00 & $4.04 \mathrm{E}-03$ & $3.30 \mathrm{E}-03$ \\
\hline 10.01 & $3.72 \mathrm{E}-03$ & $2.50 \mathrm{E}-03$ \\
\hline 20.01 & $3.38 \mathrm{E}-03$ & $2.52 E-03$ \\
\hline 30.02 & $3.19 \mathrm{E}-03$ & $2.63 E-03$ \\
\hline 40.02 & $3.12 \mathrm{E}-03$ & $2.68 \mathrm{E}-03$ \\
\hline 50.00 & $3.04 \mathrm{E}-03$ & $2.70 \mathrm{E}-03$ \\
\hline 51.03 & 1.69E-03 & $4.35 \mathrm{E}-03$ \\
\hline 53.04 & 5.97E-04 & 1.97E-03 \\
\hline 55.04 & 3.36E-04 & $1.14 \mathrm{E}-03$ \\
\hline 60.04 & $7.83 \mathrm{E}-05$ & $4.87 E-04$ \\
\hline 75.05 & $2.69 \mathrm{E}-04$ & $2.81 \mathrm{E}-04$ \\
\hline 100.07 & $8.20 \mathrm{E}-04$ & 8.37E-04 \\
\hline 150.10 & $1.82 \mathrm{E}-03$ & $1.84 \mathrm{E}-03$ \\
\hline 200.13 & $2.30 \mathrm{E}-03$ & $2.31 \mathrm{E}-03$ \\
\hline 250.17 & $2.10 \mathrm{E}-03$ & $2.10 \mathrm{E}-03$ \\
\hline 300.20 & 1.63E-03 & 1.63E-03 \\
\hline 350.24 & 1.17E-03 & $1.16 \mathrm{E}-03$ \\
\hline 400.27 & 7.66E-04 & $7.62 \mathrm{E}-04$ \\
\hline 500.35 & $3.55 \mathrm{E}-04$ & 3.37E-04 \\
\hline 600.39 & $4.25 \mathrm{E}-04$ & $3.95 E-04$ \\
\hline 650.43 & 6.34E-04 & $5.66 \mathrm{E}-04$ \\
\hline 700.47 & 8.95E-04 & 8.19E-04 \\
\hline 750.51 & $1.24 \mathrm{E}-03$ & $1.16 \mathrm{E}-03$ \\
\hline 784.28 & $1.42 \mathrm{E}-03$ & $1.38 \mathrm{E}-03$ \\
\hline 800.55 & $1.64 \mathrm{E}-03$ & $1.56 \mathrm{E}-03$ \\
\hline 1000.67 & $3.28 \mathrm{E}-03$ & $3.25 \mathrm{E}-03$ \\
\hline 1200.79 & 4.37E-03 & 4.37E-03 \\
\hline 1400.94 & $5.55 \mathrm{E}-03$ & $5.50 \mathrm{E}-03$ \\
\hline 1601.06 & $6.30 \mathrm{E}-03$ & $6.33 E-03$ \\
\hline 1801.21 & 6.91E-03 & $6.88 \mathrm{E}-03$ \\
\hline 2001.33 & $6.45 \mathrm{E}-03$ & $5.17 \mathrm{E}-03$ \\
\hline 2201.52 & $7.26 \mathrm{E}-03$ & $5.41 \mathrm{E}-03$ \\
\hline 2401.64 & 7.62E-03 & $5.81 \mathrm{E}-03$ \\
\hline 2591.83 & $6.73 \mathrm{E}-03$ & $5.62 \mathrm{E}-03$ \\
\hline 3002.00 & $6.99 \mathrm{E}-03$ & $6.60 \mathrm{E}-03$ \\
\hline 5003.49 & $6.76 \mathrm{E}-03$ & $6.38 \mathrm{E}-03$ \\
\hline 7004.69 & 7.17E-03 & 7.17E-03 \\
\hline 10006.70 & 7.74E-03 & 7.56E-03 \\
\hline 12596.40 & 7.67E-03 & $7.56 \mathrm{E}-03$ \\
\hline 15010.10 & 7.18E-03 & $7.12 \mathrm{E}-03$ \\
\hline 20013.30 & $5.91 \mathrm{E}-03$ & $5.89 E-03$ \\
\hline
\end{tabular}

Source: Output DTN: SN0503T0510102.019. 


\subsubsection{In-Drift $p \mathrm{CO}_{2}$ and Temperature Range for Seepage Evaporation Abstraction}

The intent of the in-drift seepage evaporation abstraction (Section 6.9) is to use the 11 selected seepage boundary condition water compositions (Section 6.6) and analyze the resulting water compositions after evaporation or dilution using the in-drift precipitates salts model to generate lookup tables for use in the TSPA-LA. For the evaporation calculations, ranges of temperature and carbon dioxide pressure are needed to capture the effects of these parameters on the evaporative evolution.

To determine the $p \mathrm{CO}_{2}$ range, $p \mathrm{CO}_{2}$ values presented in THC_CO2_Look-up.xls, tab "Total Gas Data" (Output DTN: SN0503T0510102.019) were statistically analyzed using the built-in functions in the Microsoft Excel software application. The overall pressure ranges from a maximum of $1.01 \times 10^{-2}$ bar (CS2000, in-drift) to a minimum of $2.29 \times 10^{-5}$ bar (HD-Perm, in-drift). The majority of values fall between $1.0 \times 10^{-4}$ and $1.0 \times 10^{-2}$ bar, with only seven values below $1.0 \times 10^{-4}$ bar and one above $1.0 \times 10^{-2}$ bar. Based on these statistics, the three values selected for use are $1.0 \times 10^{-2}, 1.0 \times 10^{-3}$, and $1.0 \times 10^{-4}$ bar of carbon dioxide and encompass about $99 \%$ of the range of $p \mathrm{CO}_{2}$ levels. Sensitivity cases have been run using a larger range of $p \mathrm{CO}_{2}$ (Section 6.12.4.3) to demonstrate that an extended range can be reached by extrapolation.

The in-drift THC modeled temperature range (Figure 6.7-5) is constructed using the following four time-temperature curves: the waste package node, the drift wall surface at the crown of the drift, the base of invert, and within the rock above the crown of the drift (Output DTN: SN0503T0510102.019, THC_CO2_Look-up.xls). The plotted curves of Figure 6.7-5 indicate that the minimum temperature in the drift after 20,000 years is approximately $40^{\circ} \mathrm{C}$. This is reasonable when compared to the entire range of waste package temperatures given in Multiscale Thermohydrologic Model (BSC 2005 [DIRS 173944], Figure 6.3-53a), which range from about 30 to $70^{\circ} \mathrm{C}$ at 10,000 years.

The maximum in-drift temperature can be as great as approximately $180^{\circ} \mathrm{C}$ on the waste package surface and $150^{\circ} \mathrm{C}$ at the drift wall during the peak thermal pulse (BSC 2005 [DIRS 173944], Figure 6.3-2). An evaluation of the THC model output in Figure 6.7-5 shows that only in the period from 50 to almost 2,000 years are the temperatures above $100^{\circ} \mathrm{C}$; this is the time when liquid water available for macroscale reaction is limited by the temperature pulse in the drift (Figure 6.2-2). This is consistent with the mean infiltration case results presented in Multiscale Thermohydrologic Model (BSC 2005 [DIRS 173944], Figure 6.3-59a). Accurate modeling is also limited to temperatures of approximately $100^{\circ} \mathrm{C}$ or less because of the limits imposed by the boiling point at the elevation of the drift, uncertainties in the boiling point elevation due to concentration of pore-water salts, and temperature limitations on the applicability of some thermodynamic data in the data0.yfp database (DTN: SN0302T0510102.002 [DIRS 162572]). Therefore, an upper calculation limit of $100^{\circ} \mathrm{C}$ is within an acceptable range limit to consider evaporated seepage water chemistries of calculated uncertainty.

For the infrequent and brief events where seepage occurs onto surfaces slightly above $100^{\circ} \mathrm{C}$, the results at $100^{\circ} \mathrm{C}$ are used as an extrapolation. At most, when the drift wall cools through $100^{\circ} \mathrm{C}$, the waste package temperatures are at or below $110^{\circ} \mathrm{C}$ (BSC 2005 [DIRS 173944], Figure 6.3-14). The effect of this higher temperature extrapolation on the equilibrium seepage 
modeling will be upon the $\log (K)$ values. The solubilities of the most soluble minerals of relevance at such temperatures typically increase and thereby nullify any net effect upon the relative seepage composition. Therefore, extrapolation above $100^{\circ} \mathrm{C}$ to the temperature of the waste package is reasonable.

With these upper and lower bounds, the midpoint between these two bounding points is selected $\left(70^{\circ} \mathrm{C}\right)$. The three temperatures $\left(40,70\right.$, and $\left.100^{\circ} \mathrm{C}\right)$ are used to construct the lookup tables for use in the analyses described in the following section and for the construction of the lookup tables for the TSPA-LA.

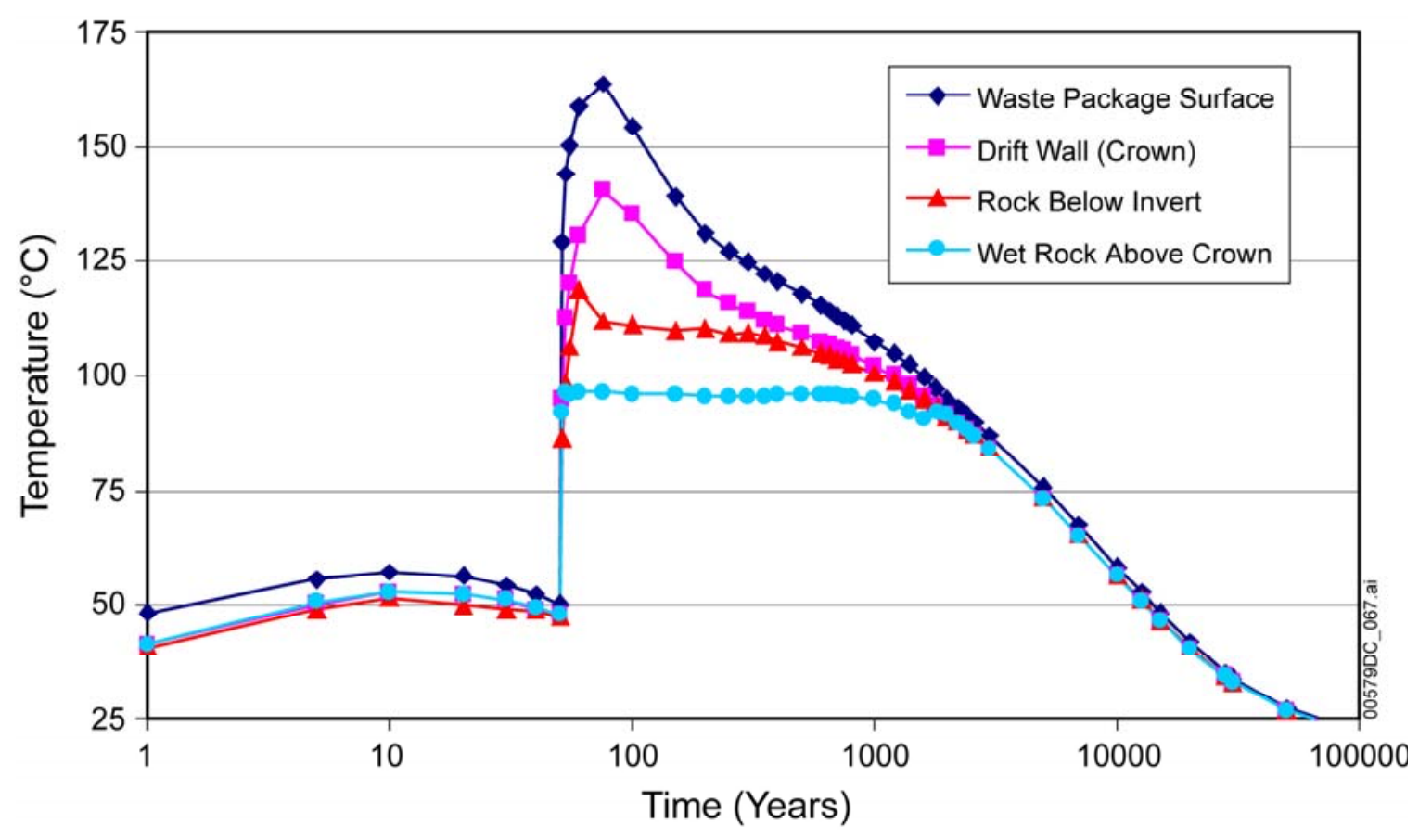

Source: Output DTN: SN0503T0510102.019.

Figure 6.7-5. Comparison of Temperatures at Various Locations within and around the Drift

\subsubsection{THC Seepage Water Equilibrium Gas Pressures}

EQ3 calculations are run to equilibrate and speciate the water compositions of the 11 bin waters in Section 6.6 (Table 6.6-6). The resulting water compositions and the corresponding gas pressures are provided in Table 6.7-6.

The complete set of EQ3 calculated pressure values from all 368 THC waters identified by Table 6.6-1 (rather than the subset presented in Table 6.7-6) can be extracted from the calculated EQ3 output (".3o") files archived in Output DTN: MO0303MWDSCMAB.000 using the GETEQDATA (BSC 2002 [DIRS 173680]) data extraction tool. 
Table 6.7-6. Equilibrium Gas Pressure, Temperature, $\mathrm{pH}$, and lonic Strength from the 11 Bin Waters

\begin{tabular}{|c|c|c|c|c|c|c|c|c|c|c|c|}
\hline & $\sin 01.30$ & in02.3o & 3in03.3o & Bin04.3o & Bin05.3o & Bin06.3o & Bin07.3o & Bin08.3o & Bin09.3o & Bin10.30 & Bin11.3o \\
\hline Temp $\left({ }^{\circ} \mathrm{C}\right)$ & 112 & 109 & 104 & 105 & 95.6 & 65.1 & 56.3 & 40.2 & 91.8 & 56.3 & 95.6 \\
\hline $\mathrm{pH}$ & 7.41 & 58 & 7.62 & 7.9 & 7.63 & 7.7 & 7.75 & 7.94 & 8.14 & 7.82 & 7.76 \\
\hline$I$ (molal) & $4.93 \mathrm{E}-02$ & $2.05 \mathrm{E}-02$ & $74 \mathrm{E}-03$ & $4.92 \mathrm{E}-03$ & $1.13 \mathrm{E}-02$ & $1.12 \mathrm{E}-02$ & $1.24 \mathrm{E}-02$ & $9.77 \mathrm{E}-03$ & $5.10 \mathrm{E}-03$ & $8.71 \mathrm{E}-03$ & $7.06 \mathrm{E}-03$ \\
\hline $\mathrm{H}_{2} \mathrm{O}(\mathrm{g})^{\mathrm{a}}$ & 1.77E-01 & 1.34E-01 & $6.07 \mathrm{E}-02$ & $7.56 \mathrm{E}-02$ & $-6.92 \mathrm{E}-02$ & $-6.02 \mathrm{E}-01$ & $-7.77 \mathrm{E}-01$ & $-1.13 E+00$ & $-1.30 \mathrm{E}-01$ & $-7.77 \mathrm{E}-01$ & $-6.91 \mathrm{E}-02$ \\
\hline $\mathrm{O}_{2}(\mathrm{~g})^{\mathrm{a}}$ & $-7.00 \mathrm{E}-01$ & $-7.00 \mathrm{E}-01$ & $-7.00 \mathrm{E}-01$ & $-7.00 \mathrm{E}-01$ & $-7.00 \mathrm{E}-01$ & $-7.00 \mathrm{E}-01$ & $-7.00 \mathrm{E}-01$ & $-7.00 \mathrm{E}-01$ & $-7.00 \mathrm{E}-01$ & $-7.00 \mathrm{E}-01$ & $-7.00 \mathrm{E}-01$ \\
\hline $\mathrm{CO}_{2}(\mathrm{~g})^{\mathrm{a}}$ & $-3.47 E+00$ & $-3.36 E+00$ & $-3.05 E+00$ & $-3.38 \mathrm{E}+00$ & $-2.78 E+00$ & $-2.21 \mathrm{E}+00$ & $-2.18 \mathrm{E}+00$ & $-2.25 E+00$ & $-2.59 \mathrm{E}+00$ & $-2.10 \mathrm{E}+00$ & $-2.45 \mathrm{E}+00$ \\
\hline $\mathrm{HF}(\mathrm{g})^{\mathrm{a}}$ & $-9.82 E+00$ & $-9.91 \mathrm{E}+00$ & $-9.91 \mathrm{E}+00$ & $-1.01 \mathrm{E}+01$ & $-9.69 E+00$ & $-1.07 \mathrm{E}+01$ & $-1.11 \mathrm{E}+01$ & $-1.19 \mathrm{E}+01$ & $-1.03 E+01$ & $-1.11 \mathrm{E}+01$ & $-9.67 E+00$ \\
\hline $\mathrm{HCl}(\mathrm{g})^{a}$ & $-1.23 E+01$ & $-1.32 E+01$ & $-1.35 E+01$ & $-1.43 E+01$ & $-1.38 E+01$ & $-1.49 \mathrm{E}+01$ & $-1.53 E+01$ & $-1.69 E+01$ & $-1.51 \mathrm{E}+01$ & $-1.61 E+01$ & $-1.43 \mathrm{E}+01$ \\
\hline $\mathrm{HNO}_{3}(\mathrm{~g})^{\mathrm{a}}$ & $-1.38 \mathrm{E}+01$ & $-1.44 \mathrm{E}+01$ & $-1.51 \mathrm{E}+01$ & $-1.55 \mathrm{E}+01$ & $-1.53 E+01$ & $-1.67 E+01$ & $-1.70 \mathrm{E}+01$ & $-1.82 \mathrm{E}+01$ & $-1.57 \mathrm{E}+01$ & $-1.75 E+01$ & $-1.56 \mathrm{E}+01$ \\
\hline $\mathrm{NO}_{3}(\mathrm{~g})^{\mathrm{a}}$ & $-2.40 \mathrm{E}+01$ & $-2.46 \mathrm{E}+01$ & $-2.54 E+01$ & $-2.58 \mathrm{E}+01$ & $-2.58 \mathrm{E}+01$ & $-2.80 \mathrm{E}+01$ & $-2.87 E+01$ & $-3.04 E+01$ & $-2.64 E+01$ & $-2.91 \mathrm{E}+01$ & $-2.62 \mathrm{E}+01$ \\
\hline $\mathrm{H}_{2}(\mathrm{~g})^{\mathrm{a}}$ & $-2.99 \mathrm{E}+01$ & $-3.02 E+01$ & $-3.08 E+01$ & $-3.07 E+01$ & $-3.17 \mathrm{E}+01$ & $-3.53 E+01$ & $-3.65 E+01$ & $-3.88 \mathrm{E}+01$ & $-3.21 \mathrm{E}+01$ & $-3.65 E+01$ & $-3.17 E+01$ \\
\hline $\mathrm{N}_{2} \mathrm{O}_{5}(\mathrm{~g})^{\mathrm{a}}$ & $-3.28 E+01$ & $-3.40 E+01$ & $-3.53 E+01$ & $-3.61 E+01$ & $-3.57 E+01$ & $-3.84 \mathrm{E}+01$ & $-3.92 E+01$ & $-4.16 \mathrm{E}+01$ & $-3.66 \mathrm{E}+01$ & $-4.01 E+01$ & $-3.64 E+01$ \\
\hline
\end{tabular}

Source: Output DTN: MO0304SPAA11GC.000.

a Units are log pressure relative to 1 bar. 


\subsection{GROUND SUPPORT INTERACTIONS WITH SEEPAGE WATER}

This section evaluates the impact on incoming THC seepage water chemistry from interactions with prevalent components of the ground support system and invert and their corrosion products. The materials of interest have been tabulated in Table 4.1-10, and are composed of carbon steels and Stainless Steel Type 316L (also see in-drift schematic Figure 6.4-1). Based upon the short lifetime estimates of carbon or low-alloy steels in the humid environments expected after closure, on the order of $50 \mathrm{yrs} / \mathrm{cm}$ relative lifetime (Figure 6.4-3), any effects of carbon steel on seepage chemistry are short-lived and are not further considered. Also, all carbon steels are located in or on the invert below the waste package. In contrast, Stainless Steel Type 316L has a significantly longer lifetime (relative per-cm lifetime on the order of 5,000 years; Figure 6.4-3) and is located over the crown of the drift, and therefore its effects upon the seepage water composition are considered.

Specifically the current design uses stainless steel (BSC 2005 [DIRS 173498], Figure 1), and the superseded design calls specifically for Stainless Steel Type 316L perforated sheets and rock bolts (BSC 2004 [DIRS 169058]; Table 4.1-10) to be used for the drift ground support system. Therefore, the elemental components of this steel are discussed, and the material is examined in detail with respect to its corrosion/precipitation and subsequent effect upon seepage water chemistry. The results presented here show that the Stainless Steel Type 316L corrosion process - the release of aqueous species and formation of corrosion products - has only negligible effect on the composition of incoming seepage waters.

\subsubsection{Corrosion Product Concepts}

Corrosion of the ground support materials is modeled as occurring by direct oxygen and proton consumption and can be generalized in Equation 6.8-1:

$$
\mathrm{M}_{(s)}+\frac{n}{4} \mathrm{O}_{2(\mathrm{~g})}+n \mathrm{H}^{+} \rightarrow \mathrm{M}^{n+}{ }_{(a q)}+\frac{n}{2} \mathrm{H}_{2} \mathrm{O}
$$

If this process alone occurs, the $\mathrm{pH}$ in the aqueous phase must increase. However, the magnitude of this effect is dependent upon the disposition of the metal ion released. If the ion is highly soluble, then the oxidation reaction shown in Equation 6.8-1 will dominate, and the $\mathrm{pH}$ of the seepage water will rise. However, if it is of low solubility then the resulting precipitation reaction must be accounted for. Typically, this reaction involves the formation of a hydroxide or oxide (or combined oxyhydroxide). A general metal-hydroxide formation reaction can be represented as shown in Equation 6.8-2:

$$
\mathrm{M}^{n+}{ }_{(a q)}+n \mathrm{H}_{2} \mathrm{O} \rightarrow \mathrm{M}(\mathrm{OH})_{n(s)}+n \mathrm{H}^{+}
$$

This has the effect of releasing as many hydrogen ions as were consumed during corrosion, thereby negating any effect upon the water chemistry $\mathrm{pH}$. This is also the general case for oxide formation, shown by Equation 6.8-3: 


$$
\mathrm{M}^{n+}(a q)+\frac{n}{2} \mathrm{H}_{2} \mathrm{O} \rightarrow \mathrm{MO}_{\mathrm{n} / 2(s)}+n \mathrm{H}^{+}
$$

The following subsections will discuss the three primary metals comprising Stainless Steel Type 316L (Fe, Ni, and $\mathrm{Cr}$ ), which account for greater than $90 \%$ of this alloy by weight.

\subsubsection{Iron $(\mathrm{Fe})$}

Iron in the natural environment exists in two oxidation states. Fe(II) is the soluble form, but is not stable under the redox conditions in the drift (i.e., consistently oxic $p \mathrm{O}_{2}$, Section 6.7). Fe(III) primarily forms insoluble oxides and oxyhydroxides (e.g., $\mathrm{Fe}_{2} \mathrm{O}_{3}$ and $\mathrm{FeOOH}$, respectively); its solubility product ranges from $10^{-36}$ to $10^{-42}$ at $25^{\circ} \mathrm{C}$ and $\mathrm{pH}>3$ based on the Pitzer thermodynamic database (DTN: SN0302T0510102.002 [DIRS 162572]), and it is increasingly soluble with lower $\mathrm{pH}$ values (Pankow 1991 [DIRS 105952], p. 231).

Table 6.8-1 shows the typical oxidation-reduction reactions for iron aqueous species and minerals. The Eh-pH diagram for iron plotted in Figure 6.8-1 shows that Fe(III) oxyhydroxides are the stable phase at the relatively high oxidation potentials expected at Yucca Mountain. The stability of the various forms of iron hydroxides and oxyhydroxides increases from amorphous $\mathrm{Fe}(\mathrm{OH})_{3}$ to goethite to hematite $\left(\mathrm{Fe}_{2} \mathrm{O}_{3}\right)$ at $25^{\circ} \mathrm{C}$ (Stumm and Morgan 1981 [DIRS 100829], p. 434). However, predicting if goethite or hematite will be present in a given system is difficult, because geochemical conditions may favor nucleation and growth of one or the other phase, and because goethite may persist metastably for millions of years, as the conversion of goethite to hematite can be very slow (Krauskopf 1979 [DIRS 105909], p. 208). However, in soils, goethite tends to form at low temperatures (in cool or temperate climate zones), at high $\mathrm{H}_{2} \mathrm{O}$ activity, and with higher organic matter contents. The hematite-to-goethite ratio usually increases with increasing soil temperature (Schwertmann and Taylor 1995 [DIRS 105959], pp. 398 to 400). The $\mathrm{pH}$ also plays a role in the preferred formation of the two phases. Goethite is favored in soils with low $\mathrm{pH}$ (3 to 7), whereas hematite is favored above $\mathrm{pH} 7$ (Schwertmann and Taylor 1995 [DIRS 105959], pp. 401 to 402). However, if a small amount of titanium is present $(<0.05$ mol fraction) in the solution, it inhibits hematite formation and favors the formation of goethite (Fitzpatrick et al. 1978 [DIRS 105795]).

Table 6.8-1. Typical Oxidation-Reduction Reactions and Potential Fe Minerals

\begin{tabular}{|c|c|c|}
\hline Reaction & $\begin{array}{c}\text { Oxidation } \\
\text { State }\end{array}$ & Minerals Formed \\
\hline $\begin{array}{l}2 \mathrm{Fe}^{2+}+1 / 2 \mathrm{O}_{2}+2 \mathrm{H}_{2} \mathrm{O}=\mathrm{Fe}_{2} \mathrm{O}_{3}+4 \mathrm{H}^{+} \\
\mathrm{Fe}_{3} \mathrm{O}_{4}+2 \mathrm{H}^{+}=\mathrm{Fe}_{2} \mathrm{O}_{3}+\mathrm{Fe}^{2+}+\mathrm{H}_{2} \mathrm{O} \\
2 \mathrm{FeOOH}+2 \mathrm{H}^{+}+1 / 2 \mathrm{O}_{2}=\mathrm{Fe}_{2} \mathrm{O}_{3}+\mathrm{Fe}^{2+}+2 \mathrm{H}_{2} \mathrm{O}\end{array}$ & 3 & Hematite $\left(\alpha-\mathrm{Fe}_{2} \mathrm{O}_{3}\right)$ \\
\hline $\begin{array}{l}\mathrm{Fe}^{2+}+1 / 4 \mathrm{O}_{2}+3 / 2 \mathrm{H}_{2} \mathrm{O}=\mathrm{FeOOH}+2 \mathrm{H}^{+} \\
\mathrm{Fe}_{3} \mathrm{O}_{4}+\mathrm{H}^{+}+1 / 2 \mathrm{O}_{2}=\mathrm{Fe}_{2} \mathrm{O}_{3}+\mathrm{FeOOH}\end{array}$ & 3 & Goethite $(\alpha-\mathrm{FeOOH})$ \\
\hline $3 \mathrm{Fe}^{2+}+1 / 2 \mathrm{O}_{2}+3 \mathrm{H}_{2} \mathrm{O}=\mathrm{Fe}_{3} \mathrm{O}_{4}+6 \mathrm{H}^{+}$ & 2.67 & Magnetite $\left(\mathrm{Fe}_{3} \mathrm{O}_{4}\right)$ \\
\hline
\end{tabular}

Source: Designed for Fe minerals using Tebo et al. 1997 [DIRS 105960], Table 2, as an example.

Given the slow rate of hematite formation, its suppression by high humidity conditions, and the presence of large quantities of titanium, goethite is expected to be the prevalent iron corrosion 
species for the period of regulatory interest. However, it is important to note that there is only a difference of $<0.5 \log$ units between the solubility of goethite and hematite, so, for modeling purposes, the choice of mineral has little impact.

Other minerals that could potentially form, based on the geochemical system at Yucca Mountain, are $\mathrm{Fe}$ carbonates and Fe-rich silicates. Given the low-temperature conditions, the iron would most likely be incorporated into a solid solution of smectite clay (nontronite).

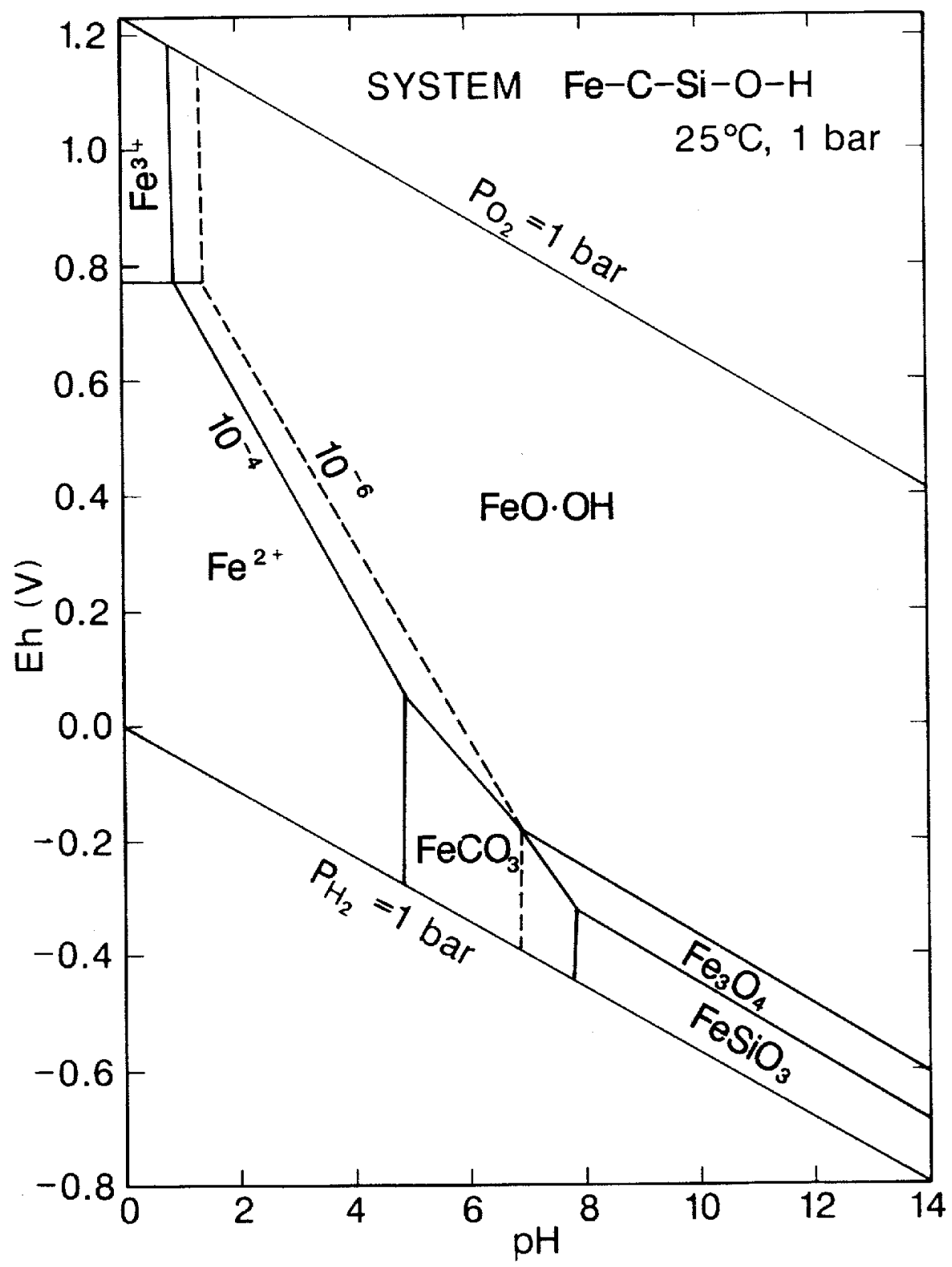

Source: Brookins 1988 [DIRS 105092].

NOTE: Approximated activities for dissolved species are: $\mathrm{Fe}=10^{-6}, \mathrm{Si}=10^{-3}, \mathrm{C}=10^{-3}$. Goethite and magnetite are considered Fe(III) solid phases.

Figure 6.8-1. Eh-pH Diagram for Part of the System Fe-C-Si-O-H at $25^{\circ} \mathrm{C}$ 


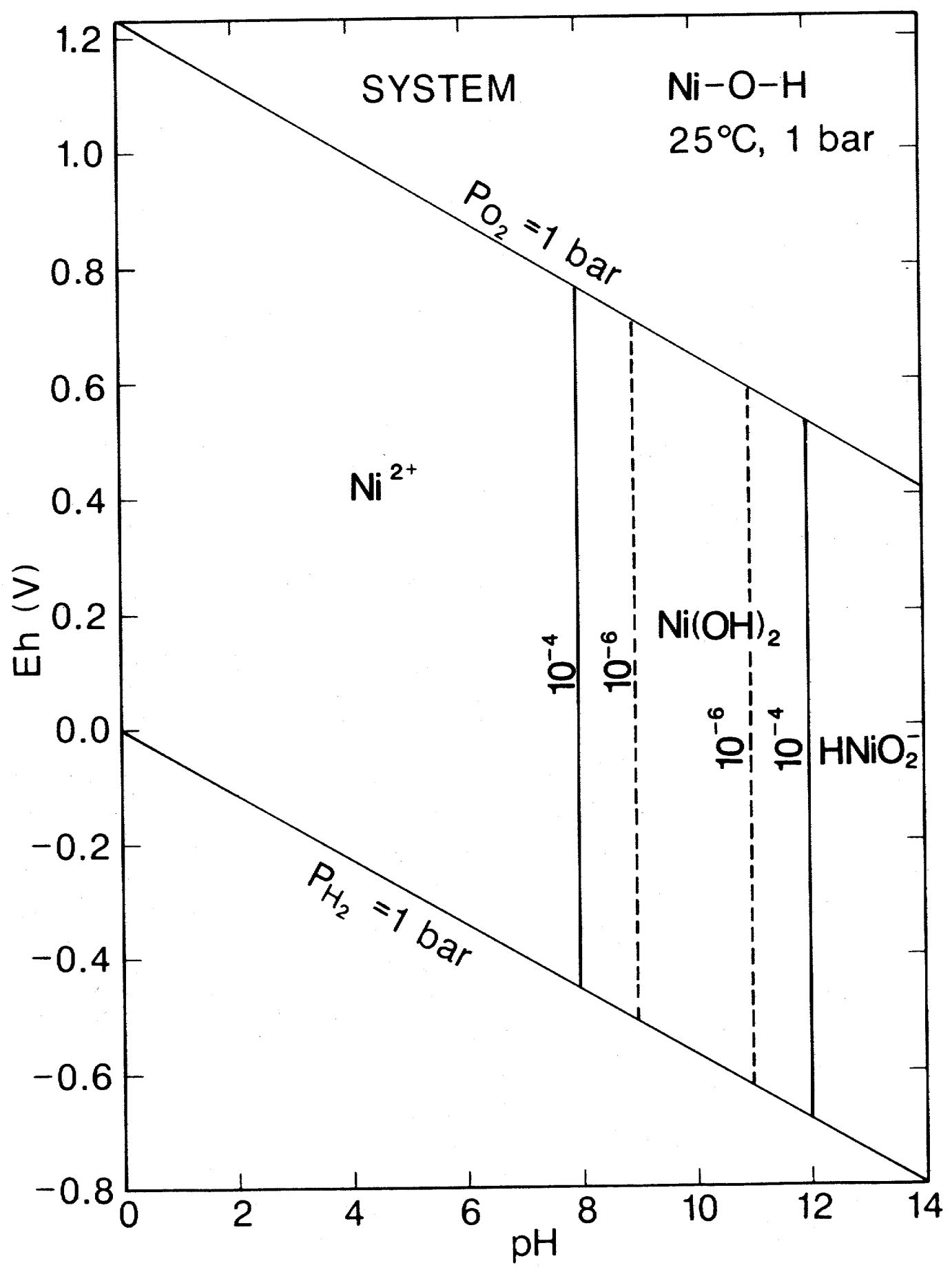

Source: Brookins 1988 [DIRS 105092].

NOTE: Estimated activity for $\mathrm{Ni}=10^{-4}, 10^{-6}$.

Figure 6.8-2. Eh-pH Diagram for Part of the System Ni-O-H at $25^{\circ} \mathrm{C}$ 


\subsubsection{Nickel (Ni)}

Only Ni(II) occurs at ambient environmental conditions. The higher oxidation states occur rarely and, even in those cases, it is not clear whether it is the ligand rather than the metal atom that is oxidized (Cotton and Wilkinson 1988 [DIRS 105732], p. 741). No other oxidation state would be expected under repository environmental conditions once $\mathrm{Ni}$ is released by oxidation of the metal alloys.

Once the $\mathrm{Ni}$ is released into an aqueous environment under oxidizing conditions, nickel hydroxides $\left[\mathrm{Ni}(\mathrm{OH})_{2}\right]$ are stable in a $\mathrm{pH}$ range between 8 and 12 (Figure 6.8-2). Otherwise, either the $\mathrm{Ni}^{2+}$ ion or the $\mathrm{HNiO}_{2}{ }^{-}$ions are in solution, indicating that nickel is relatively soluble under neutral-acidic conditions and under relatively alkaline conditions (Garrels and Christ 1990 [DIRS 144877], pp. 244 to 245).

Nickel tends to substitute for iron and manganese in solid phases, and tends to be coprecipitated as $\mathrm{Ni}(\mathrm{OH})_{2}$ with both iron oxides and manganese oxides (Hem 1985 [DIRS 115670]; Hem et al. 1989 [DIRS 105854]). Nickel will also adsorb to clays, iron and manganese oxides, and organic matter (McLean and Bledsoe 1992 [DIRS 108954]).

\subsubsection{Chromium (Cr)}

Unless otherwise indicated, the source of the following summary was taken from Natural Attenuation of Hexavalent Chromium in Ground Water and Soils (Palmer and Puls 1994 [DIRS 108991]).

Chromium exists in oxidation states ranging from +6 to -2 ; however, only the +6 and the +3 oxidation states are commonly encountered in the environment (refer to $\mathrm{Eh} / \mathrm{pH}$ diagram in Figure 6.8-3). $\mathrm{Cr}(\mathrm{VI})$ exists in solution as the monomeric ions $\mathrm{H}_{2} \mathrm{CrO}_{4}{ }^{\mathrm{o}}, \mathrm{HCrO}_{4}{ }^{-}$(bichromate), and $\mathrm{CrO}_{4}{ }^{2-}$ (chromate), or as the dimeric ion $\mathrm{Cr}_{2} \mathrm{O}_{7}{ }^{2-}$ (dichromate). The relative concentration of each of these species depends on both the $\mathrm{pH}$ of the chromium-laden water and the total concentration of $\mathrm{Cr}(\mathrm{VI})$.

Significant concentrations of $\mathrm{H}_{2} \mathrm{CrO}_{4}{ }^{\circ}$ only occur at $\mathrm{pH} \leq 1$. Above $\mathrm{pH} 6.5, \mathrm{CrO}_{4}{ }^{2-}$ generally dominates. Below $\mathrm{pH} 6.5, \mathrm{HCrO}_{4}{ }^{-}$dominates when $\mathrm{Cr}(\mathrm{VI})$ concentrations are low $(<30 \mathrm{mM})$, but $\mathrm{Cr}_{2} \mathrm{O}_{7}{ }^{2-}$ becomes significant when concentrations are greater than $1 \mathrm{mM}$, and may even dominate when the total $\mathrm{Cr}(\mathrm{VI})$ concentrations are greater than $30 \mathrm{mM}$.

In the $\mathrm{Cr}(\mathrm{III})-\mathrm{H}_{2} \mathrm{O}$ system, $\mathrm{Cr}(\mathrm{III})$ exists predominantly as $\mathrm{Cr}^{3+}$ below a $\mathrm{pH}$ of 3.5. With increasing $\mathrm{pH}$, hydrolysis of $\mathrm{Cr}^{3+}$ yields $\mathrm{Cr}(\mathrm{OH})^{2+}, \mathrm{Cr}(\mathrm{OH})_{2}{ }^{+}, \mathrm{Cr}(\mathrm{OH})_{3}{ }^{0}$, and $\mathrm{Cr}(\mathrm{OH})_{4}{ }^{-}$ (corresponding to the species $\mathrm{Cr}^{3+}, \mathrm{CrOH}^{2+}, \mathrm{CrO}^{+}, \mathrm{HCrO}_{2}(\mathrm{aq})$, and $\mathrm{CrO}_{2}^{-}$, respectively, in data0.R2.ymp). From under slightly acidic through alkaline conditions, $\mathrm{Cr}(\mathrm{III})$ can precipitate as an amorphous chromium hydroxide. Amorphous $\mathrm{Cr}(\mathrm{OH})_{3}$ can crystallize to $\mathrm{Cr}(\mathrm{OH})_{3} \cdot 3 \mathrm{H}_{2} \mathrm{O}$ or $\mathrm{Cr}_{2} \mathrm{O}_{3}$ (eskolaite) depending upon conditions. In the presence of $\mathrm{Fe}(\mathrm{III})$, trivalent chromium can precipitate as a solid solution, $\mathrm{Fe}_{\mathrm{x}} \mathrm{Cr}_{1-\mathrm{x}}(\mathrm{OH})_{3}$, with a lower solubility (Sass and Rai 1987 [DIRS 105957], Figure 1). If the $\mathrm{pH}$ of the system is between 6 and 12, the aqueous solubility of $\mathrm{Cr}$ (III) should be less than $1 \mu$ mole/L. In addition, when the $\mathrm{pH}$ of the groundwater is greater than $4, \mathrm{Cr}$ (III) coprecipitates with the Fe(III) in a solid solution with the general composition 
$\mathrm{Cr}_{\mathrm{x}} \mathrm{Fe}_{1-\mathrm{x}}(\mathrm{OH})_{3}$ (Sass and Rai 1987 [DIRS 105957], pp. 2,228 to 2,229; Amonette and Rai 1990 [DIRS 105701]). This should limit the concentration of $\mathrm{Cr}$ (III) to less than $10^{-6}$ molar, in the $\mathrm{pH}$ range from 6 through 12 .

$\mathrm{Cr}(\mathrm{VI})$ is a strong oxidant and is reduced in the presence of electron donors. A common electron donor that could be present in the repository is ferrous iron. This reaction is very fast on the time scales of interest for most environmental problems, with the reaction going to completion in about five minutes even in the presence of dissolved oxygen (Eary and Rai 1988 [DIRS 105784]). When the $\mathrm{pH}$ is greater than 10, the rate of oxidation for $\mathrm{Fe}(\mathrm{II})$ by dissolved oxygen will exceed the rate of oxidation by Cr(VI) (Eary and Rai 1988 [DIRS 105784]).

Efficient $\mathrm{Cr}(\mathrm{VI})$ reduction in the presence of stainless steel, iron oxides, iron-containing silicates, and organic matter has been observed in several experiments. The reduction of $\mathrm{Cr}(\mathrm{VI})$ in the presence of hematite $\left(\mathrm{Fe}_{2} \mathrm{O}_{3}\right)$ was demonstrated by Eary and Rai (1989 [DIRS 105788]). They attribute the reduction to the presence of a small amount of an $\mathrm{FeO}$ component in the hematite. They also suggest that the reaction occurs in solution after the $\mathrm{FeO}$ component has been solubilized. Reduction by biotite occurs when potassium ions are released to solution and $\mathrm{Fe}^{3+}$ ions are adsorbed onto the surface of the biotite. Potassium ions are released to maintain charge balance in the biotite structure. Reduction seems to occur even in oxygenated solutions. Lastly, experiments by Smith and Purdy (1995 [DIRS 162976], Abstract) addressing corrosion of Stainless Steel Type 316L and chromium speciation show that "Oxidation of chromium(III) to chromium(VI) was negligible at room temperature and only became significant in hot concentrated nitric acid. The rate of reduction of chromium(VI) back to chromium(III) by reaction with stainless steel or oxalic acid was found to be much greater than the rate of the reverse oxidation reaction."

Humic and fulvic acids are often associated with reduction by organic matter. The rate of reduction of $\mathrm{Cr}(\mathrm{VI})$ by the humic and fulvic acids will decrease with increasing $\mathrm{pH}$. It increases with increasing initial $\mathrm{Cr}(\mathrm{VI})$ concentration and increases as the concentration of soil humic substances increases. At neutral $\mathrm{pH}$, complete reduction of $\mathrm{Cr}(\mathrm{VI})$ may take many weeks. Sedlak and Chan (1997 [DIRS 105964]) studied the reaction of Cr(VI) with Fe(II) with respect to temperature and $\mathrm{pH}$ and determined that the reduction of $\mathrm{Cr}(\mathrm{VI})$ occurred on the time scale of minutes to months in sediments, soils, and waters that contained ferrous iron. Similar experiments conducted in $\mathrm{NaCl}, \mathrm{NaClO}_{4}$, and seawater solutions showed a parabolic dependence on $\mathrm{pH}$, and the influences of temperature, ionic strength, and reductant concentration showed various linearly dependent effects on reduction (Pettine et al. 1998 [DIRS 105955]). In low-temperature soil environments that have been contaminated with chromate-laden solutions, $\mathrm{KFe}_{3}\left(\mathrm{CrO}_{4}\right)_{2}(\mathrm{OH})_{6}$ has been shown to precipitate and can reduce the amount of $\mathrm{Cr}(\mathrm{VI})$ in groundwater (Baron and Palmer 1996 [DIRS 105730]). This mineral, analogous to the sulfate mineral jarosite, is stable in oxidizing environments between a $\mathrm{pH}$ of 2 and 6 .

Oxidation of $\mathrm{Cr}$ (III) to $\mathrm{Cr}$ (VI) is achieved in three ways. The first requires dissolved oxygen, the second requires either manganese dioxide $\left(\mathrm{MnO}_{2}\right)$ (Eary and Rai 1987 [DIRS 105780]) or manganite (MnOOH) (Johnson and Xyla 1991 [DIRS 105878]), and the third requires using hot concentrated nitric acid (Smith and Purdy 1995 [DIRS 162976]). Eary and Rai (1987 [DIRS 105780], p. 1,188) found that dissolved oxygen is not an especially effective or likely way to oxidize $\mathrm{Cr}(\mathrm{III})$. However, interaction with manganese dioxide has been 
demonstrated to increase as $\mathrm{pH}$ decreases and the ratio of surface area to solution volume increases. Eary and Rai (1987 [DIRS 105780]) developed an empirical rate law for the oxidation of $\mathrm{Cr}$ (III) by $\beta-\mathrm{MnO}_{2}$ (pyrolusite). For manganite, the rate law has been determined to be independent of $\mathrm{pH}$ and ionic strength; however, it proceeds slower in the presence of organic ligands (Johnson and Xyla 1991 [DIRS 105878]).

Sorption of $\mathrm{Cr}(\mathrm{VI})$ onto goethite has been demonstrated to be a surface complexation mechanism dependent on $\mathrm{pH}$. However, on magnetite, the mechanism has been determined to be reductive precipitation onto Fe(II) surface sites (Deng et al. 1996 [DIRS 105778]). Competition between common anionic groundwater ions $\left(\mathrm{CO}_{2}(\mathrm{~g}), \mathrm{H}_{4} \mathrm{SiO}_{4}\right.$, and $\left.\mathrm{SO}_{4}{ }^{2-}\right)$ and the $\mathrm{CrO}_{4}{ }^{2-}$ ion is known to occur, where the adsorption of $\mathrm{CrO}_{4}{ }^{2-}$ onto amorphous iron oxides was suppressed between 50 to $80 \%$ (Zachara et al. 1987 [DIRS 105963]).

\subsubsection{Definition of Base Case}

Base Case for Stainless Steel Type 316L — This is defined by the following:

- Material (sheets and rock bolts of Stainless Steel Type 316L) and dimensions as defined by IED Subsurface Facilities Ground Support Configuration (BSC 2005 [DIRS 173498], Figure 1), D\&E/PA/C IED Subsurface Facilities Committed Materials (BSC 2004 [DIRS 169058]), and Repository Design Project, Repository/PA IED Emplacement Drift Committed Materials (2) (BSC 2003 [DIRS 164101], Table 3) (see Section 4.1.6 and Table 4.1-10 for details)

- "Bin 11" unevaporated seepage water (analyzed in Section 6.6.6; results in Output DTN: MO0304MWDSAB11.001), as it is the most prevalent chemistry for this stainless steel corrosion period (51 to 5,000 years; Table 6.13-3)

- Oxidation corrosion products that include $\mathrm{Fe}(\mathrm{III})$ and $\mathrm{Cr}(\mathrm{III})$

- Primary controlling mineral phases for stainless steel corrosion products: goethite and amorphous chromium hydroxide

- Temperature of $25^{\circ} \mathrm{C}$ and pressure of $\mathrm{CO}_{2}$ and $\mathrm{O}_{2}$ at $10^{-3}$ and $10^{-0.7}$ bar, respectively

- Corrosion rates for Stainless Steel Type 316L based on Output DTN: MO0407SPAPCEML.005 (Section 6.8.3).

The "maximum of the means" corrosion value for Stainless Steel Type 316L (Table 6.4-8) is used as the "Mean" to represent a relatively fast corrosion rate. As these corrosion rates are, in most experiments, based on weight loss, they include the effects of localized corrosion (if any) that occur during the experiments.

Interaction with Bin 11 seepage water is chosen because this is the most prevalent chemistry to exist during the period over which corrosion of stainless steel ground supports will occur (51 to 5,000 years; Table 6.13-3), and dominates four of the five seepage water compositions shown 
in Tables 6.6-9 through 6.6-13. Bin 7 seepage water was selected as a sensitivity case in Section 6.12.4.

An Fe(III) phase has been selected as a corrosion end product that may influence seepage water chemistry because $\mathrm{Fe}(\mathrm{III})$, as opposed to $\mathrm{Fe}(\mathrm{II})$, is the oxidation state that would form under the relatively oxidizing conditions (atmospheric $\mathrm{O}_{2}$ concentrations leading to significant dissolved oxygen content) and mild $\mathrm{pH}$ ranges of the seepage waters. The plotted diagram of Figure 6.8-1 shows that in the $\mathrm{pH}$ range of 6 through 9 , with an $\mathrm{O}_{2}$-fixed Eh range of $\sim 0.8$ through $\sim 0.6$ volts, the $\mathrm{Fe}(\mathrm{III})$ species are dominant.

Selection of $\mathrm{Cr}(\mathrm{III})$ over that of the more soluble $\mathrm{Cr}(\mathrm{VI})$ species is based on experimentally observed corrosion products, and on the kinetics and conditions required to obtain the fully oxidized Cr(VI) state (Smith and Purdy 1995 [DIRS 162976]). Smith and Purdy's (1995 [DIRS 162976], Figure 6) examination of the actual chromium speciation as a result of corrosion of Stainless Steel Type 316L demonstrated a predominance of the less soluble $\mathrm{Cr}(\mathrm{III})$ species, except under the conditions of hot concentrated nitric acid $\left(111^{\circ} \mathrm{C}\right.$ and $>7$ molar $\left.\mathrm{HNO}_{3}\right)$. Other groups performing oxidation experiments, conducted under more ambient conditions, examined the oxidation of $\mathrm{Cr}(\mathrm{III})$ to $\mathrm{Cr}(\mathrm{VI})$ by dissolved oxygen. The experiments of Eary and Rai (1987 [DIRS 105780], p. 1,188) were performed from $\mathrm{pH} 4.0$ to 12.5 without the detection of $\mathrm{Cr}(\mathrm{VI})$ formation in 24 days. Additionally, observed disequilibrium of dissolved oxygen in water corresponds to the much more rapidly reacting $\mathrm{O}_{2}-\mathrm{H}_{2} \mathrm{O}_{2}$ couple (Langmuir 1997 [DIRS 100051], Figure 11.5). The Eh values for this couple in the $\mathrm{pH}$ range from 6 to 9 are in the range of $\sim 0.6$ down to $\sim 0.4$ volts, corresponding to the $\mathrm{Cr}$ (III) field of Figure $6.8-3$. However, $\mathrm{Cr}(\mathrm{VI})$ is examined as a sensitivity case in Section 6.12.4. 


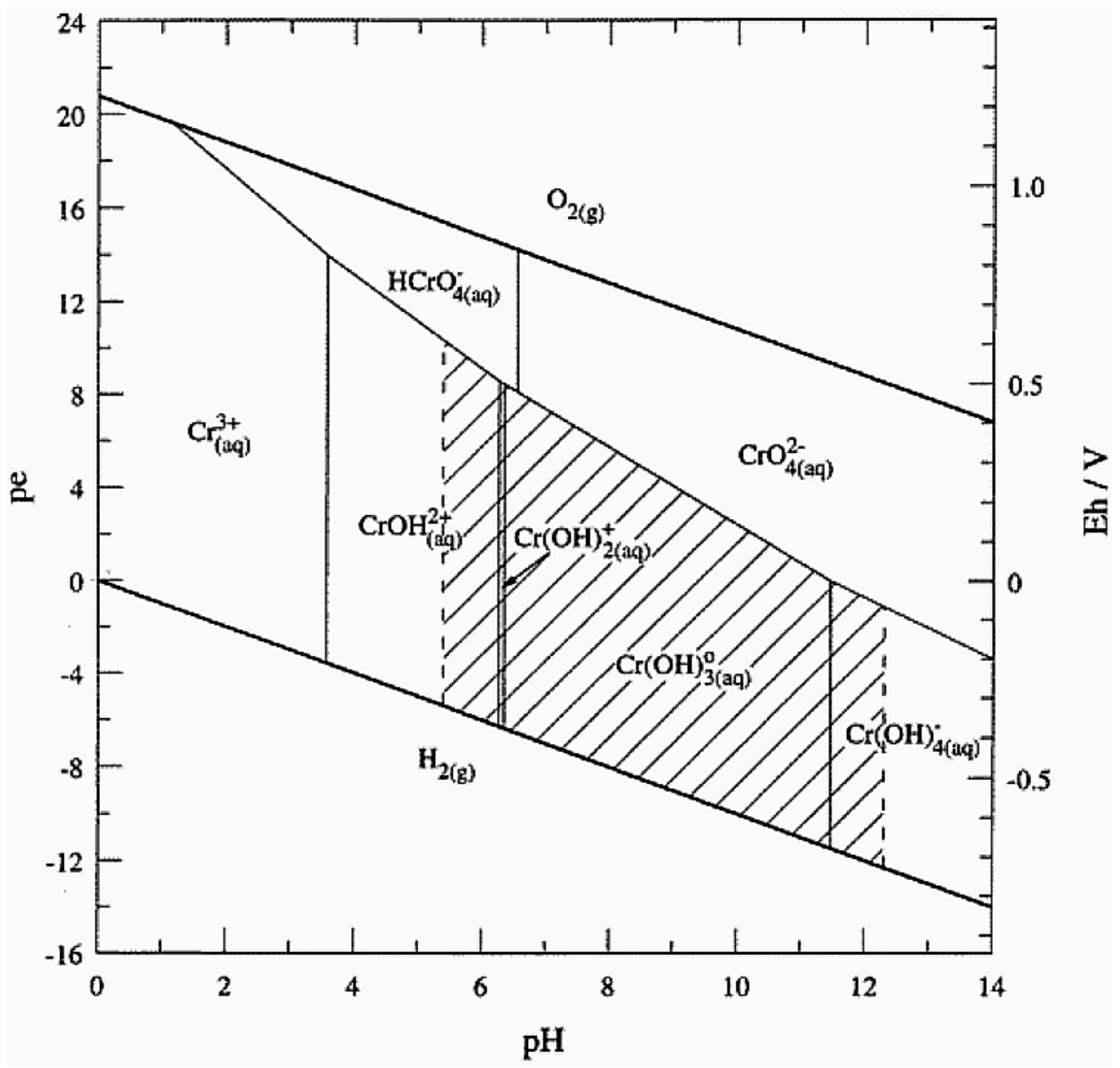

Source: Ball and Nordstrom 1998 [DIRS 163015].

NOTE: Eh units in volts $(\mathrm{V})$ not $\mathrm{Eh} / \mathrm{V}$ as shown on the figure. Hatched area indicates predominance region for $\mathrm{Cr}(\mathrm{OH})_{3}(\mathrm{~s})$.

Figure 6.8-3. pe-pH Diagram for Aqueous Inorganic Chromium Hydrolysis Species

Chromium Solid and Aqueous Species-After determining that the most common aqueous chromium oxidation state will be $\mathrm{Cr}$ (III) (and not $\mathrm{Cr}(\mathrm{VI})$; Section 6.8.1.3), all Cr(VI) related species are suppressed in the EQ3/6 chemical model calculations. Detailed examination of the remaining $\mathrm{Cr}(\mathrm{III})$ aqueous species is performed with respect to the solubility controlling chromium phase.

Based on the review article by Ball and Nordstrom (1998 [DIRS 163015]) of the original work by Rai et al. (1987 [DIRS 163369]), the amorphous chromium hydroxide $\left[\mathrm{Cr}(\mathrm{OH})_{3}\right]$ was selected as the solubility limiting phase for $\mathrm{Cr}(\mathrm{III})$. The solubility constant was taken from the report by Ball and Nordstrom (1998 [DIRS 163015], Table 8). This constant at $25^{\circ} \mathrm{C}$ is used as a modification to data0.ymp.R2 (DTN: MO0302SPATHDYN.000 [DIRS 161756]). In addition, 
Rai et al. (1987 [DIRS 163369], p. 345) reiterate a previous review of literature (Rai and Zachara 1984 [DIRS 107060]) concluding that the $\mathrm{Cr}$ (III) solubility-controlling solids are thought to be either $\mathrm{Cr}(\mathrm{OH})_{3}$ or $\mathrm{Cr}(\mathrm{III})$ coprecipitated with $\mathrm{Fe}$ oxides and hydroxides. This amorphous chromium phase end-member solubility represents a conservative upper solubility, as there exists a well-characterized solid solution of chromium(III)-iron(III) hydroxide with solubility decreasing as the iron content increases (Sass and Rai 1987 [DIRS 105957]).

Five aqueous species in the EQ3/6 data input files are suppressed from the data0.ymp.R2 database (DTN: MO0302SPATHDYN.000 [DIRS 161756]) prior to finalizing the model runs: three have undesired oxidation states $(+6$ and +5$)$ and the other two were recently characterized as relatively unimportant polynuclear $\mathrm{Cr}$ (III) species (these aqueous suppressions are listed in Table 6.8-4). The polynuclear species in the data0.ymp.R2 database (DTN: MO0302SPATHDYN.000 [DIRS 161756]) are derived from the thermodynamic data compiled by Baes and Mesmer (1976 [DIRS 157860]). More recent experimental analysis by Rai et al. (1987 [DIRS 163369]) has cast doubt upon the importance of these polynuclear Cr(III) species, which the thermodynamic data (Baes and Mesmer 1976 [DIRS 157860]) predict as becoming the dominant aqueous species at $\mathrm{pH}<6$. This has the effect of raising the solubility of $\mathrm{Cr}(\mathrm{OH})_{3}$ "unrealistically high and is completely at odds with the long-known descriptive solubility of $\mathrm{Cr}(\mathrm{OH})_{3}(\mathrm{~s})$ " (Rai et al. 1987 [DIRS 163369], p. 346).

The remaining $\mathrm{Cr}$ (III) aqueous species are based upon thermodynamic estimates by Shock et al. (1997 [DIRS 127953]), who based their estimations upon the enthalpy of $\mathrm{Cr}^{3+}$ determined by Dellien et al. (1976 [DIRS 151392]). Though differing in their water content from the comprehensive review speciation equations of Ball and Nordstrom (1998 [DIRS 163015], Table 10) (e.g., $\mathrm{CrO}^{+}$in the database and not $\mathrm{Cr}(\mathrm{OH})_{2}{ }^{+}$), the species are retained unaltered as they represent the same basic species and make no numerical difference in calculation of formation constants using them. With the remaining aqueous chromium(III) species and the solubility constant of amorphous chromium(III) hydroxide (Ball and Nordstrom 1998 [DIRS 163015], Table 8) that resulted from the experimental work by Rai et al. (1987 [DIRS 163369]), the solubility of the amorphous chromium(III) hydroxide is calculated as a function of $\mathrm{pH}$ (4 through 13). The results of these calculations are compared to the Rai et al. (1987 [DIRS 163369], Figure 2) results plotted in Figure 6.8-4.

In this comparison, the detection limit reported by Rai et al. (1987 [DIRS 163369]) probably overestimates solubility in the $\mathrm{pH}$ range of 6 through 11. Their raw data show measurements well below their detection limits with values approaching those of the calculations (e.g., approximately $4 \times 10^{-9}$ molar aqueous $\mathrm{Cr}$ in Rai et al. 1987 [DIRS 163369], Figure 2), compared to a calculated $3.6 \times 10^{-9} \mathrm{~mol} / \mathrm{kg} \mathrm{H}_{2} \mathrm{O}$ at $\mathrm{pH}=9$ shown in the Figure $6.8-4$ plot. At these concentrations the solution density is very close to $1.0 \mathrm{gm} / \mathrm{cm}^{3}$, making molar (mol/liter) and molal $\left(\mathrm{mol} / \mathrm{kg} \mathrm{H}_{2} \mathrm{O}\right)$ units virtually equivalent.

This favorable comparison provides an independent confirmation of the remaining unsuppressed chromium(III) aqueous species in the data0.ymp.R2 database (DTN: MO0302SPATHDYN.000 [DIRS 161756]), which were derived from independent thermodynamic data sources, as they reproduce chromium(III) solubility based on the $\log (K)$ value of the hydroxide $\left(\mathrm{Cr}(\mathrm{OH})_{3}(\mathrm{am})\right)$ obtained from Ball and Nordstrom (1998 [DIRS 163015]) (derived from Rai et al. 1987 [DIRS 163369]). 


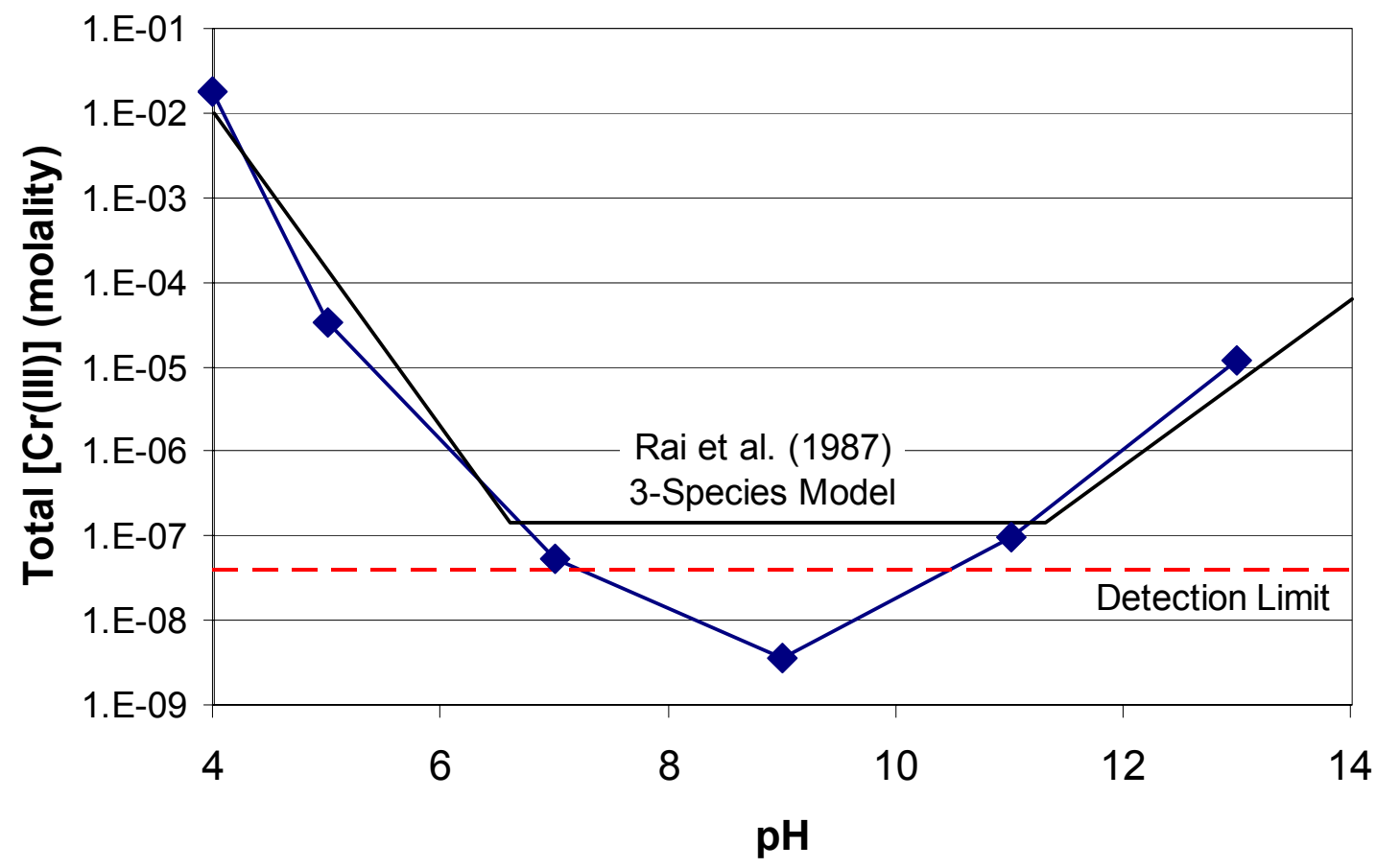

Source: Output DTN: SN0312T0510102.013.

NOTE: Diamonds with lines compared to the three-species model of Rai et al. (1987 [DIRS 163369], Figure 2, solid lines) with their detection limit shown by the dashed line.

Figure 6.8-4. EQ3/6 Calculated Chromium Solubility in Equilibrium with $\mathrm{Cr}(\mathrm{OH})_{3}(\mathrm{am})$

Limitations - The base case is limited to supporting calculations at $25^{\circ} \mathrm{C}$, because the primary mineral phase that controls $\mathrm{Cr}(\mathrm{III})$ solubility, $\mathrm{Cr}(\mathrm{OH})_{3}$, has its solubility defined only at this temperature (Rai et al. 1987 [DIRS 163369]). Rai et al. (1987 [DIRS 163369], Figure 4) only show that at $90^{\circ} \mathrm{C}$ the solubility of the $\mathrm{Cr}(\mathrm{OH})_{3}$ solid decreases, lowering the concentration of aqueous $\mathrm{Cr}(\mathrm{III})$ species by about two orders of magnitude. $\mathrm{A}^{\mathrm{CO}_{2}}$ pressure of $10^{-3}$ bar was chosen to be consistent with the median value from the ranges used for in-drift seepage evaporation (Section 6.9). Other pressure values of $10^{-2}$ and $10^{-4}$ bar are examined to evaluate model uncertainty in Section 6.12.4.

\subsubsection{Modeling Stainless Steel Type 316L and Its Corrosion Rate}

The development of this analysis begins with a review of the standard specifications for Stainless Steel Type 316L, as determined by the American Society for Testing and Materials standard (ASTM A 240/A 240M-02a 2002 [DIRS 162720], Table 1). This specification establishes weight-percentage values or limits or ranges for the various compositional elements. When ranges are specified, mean values are used to calculate the balance of Fe as 65.5 percent by weight (Output DTN: SN0312T0510102.013, DegradationMolality.xls, sheet "Composition"). This compares to 17 percent $\mathrm{Cr}$ by weight, resulting in a molar ratio of $\mathrm{Fe}$ : $\mathrm{Cr}$ of 3.59:1.0 (Output DTN: SN0312T0510102.013, sheet "degradation") that is rounded off to $3.6: 1.0$ and implemented in the modified data0.YMP.R2 EQ3/6 database file (original database DTN: MO0302SPATHDYN.000 [DIRS 161756]) as a fictitious mineral species titled Stainless Steel Type 316L. 
The fictive stainless steel species, whose molecular formula is $\mathrm{Fe}_{3.6} \mathrm{Cr}_{1.0}$, is defined by the dissociation reaction:

$$
1.0 \mathrm{SS} 316 \mathrm{~L}+13.8 \mathrm{H}^{+}+3.45 \mathrm{O}_{2}(\mathrm{~g}) \rightarrow 1.0 \mathrm{Cr}^{3+}+3.6 \mathrm{Fe}^{3+}+6.9 \mathrm{H}_{2} \mathrm{O}
$$

The reaction is not shown as being reversible because stainless steel will never precipitate. This is achieved operationally by providing an arbitrarily large solubility $\log (K)$ value of 266 . The database text inserted into data0.YMP.R2 is also in Output DTN: SN0312T0510102.013 (Cr-database.zip).

The corrosion rate of Stainless Steel Type 316L controls the quantity of corrosion product and the extent to which corrosion affects the unevaporated crown seepage water chemistry. The corrosion rate was estimated by determining the mean quantity of Stainless Steel Type 316L ground support over a one square meter section of drift wall. This quantity includes the stainless steel sheets and rock bolts from IED Subsurface Facilities Ground Support Configuration (BSC 2005 [DIRS 173498]). A step-function for the corrosion rate was used to approximate the transition from dry to wet drift-wall conditions, which is estimated to occur around 2,000 years after emplacement as shown by the THC model results (DTN: LB0302DSCPTHCS.002 [DIRS 161976]). Seepage amounts, represented directly by the infiltration rates, were also taken from the THC spreadsheets (DTN: LB0302DSCPTHCS.002 [DIRS 161976], from "notes" sheet).

The rate of corrosion during the hot, dry period (up to 2,000 years after closure) was taken as $0.113 \mu \mathrm{m} / \mathrm{yr}$, from the "316L SS" "Steam and atmospheric" "Mean" rate contained in Table 6.4-8 (Output DTN: MO0407SPAPCEML.005). At 2,000 plus years, a larger "fresh/salt water" corrosion rate was applied. The corrosion rate selected for wet conditions was $1.9391 \mu \mathrm{m} / \mathrm{yr}$, listed under Material "316L SS," "fresh/salt water," in Table 6.4-8 (Output DTN: MO0407SPAPCEML.005). To obtain the quantity (moles) of corroded steel in one year, the calculation multiplies the surface area by the corrosion rate, factoring in the density of Stainless Steel Type 316L (ASTM 1999 [DIRS 103515]) and its compositional makeup (ASTM 2002 [DIRS 162720]). This mole quantity of iron and chromium, as the amount released by corrosion per year, is then combined with the percolation flux calculated by the THC seepage model (DTN: LB0302DSCPTHCS.002 [DIRS 161976], sheet "notes") to generate a final molal quantity for input into the EQ3/6 speciation calculations.

These spreadsheet calculations, which are included in DegradationMolality.xls (Output DTN: SN0312T0510102.013, DegradationMolality.zip), provide a value for the corrosion rate in moles per year per square meter of the Stainless Steel Type 316L ground support.

A parametric sensitivity to this corrosion rate, with an increase in corrosion by a factor of 10 , is examined in Section 6.12.4.1. This increased corrosion rate more than accounts for any uncertainty in the corrosion rate (mostly due to the uniqueness of the in-drift environment), as well as any detrimental microbial activity that may exist. Those parametric results support the conclusions of this analysis in Section 6.8.4.3. 


\subsubsection{Seepage-Steel Interaction Modeling and Base-Case Limitations}

Details of the calculation runs and results are supplied in the following subsections, concluding with a discussion on the limitations of this base-case model.

\subsubsection{EQ3/6 Model Runs}

The analysis for stainless steel ground support interaction with unevaporated seepage water | consists of the following sequential EQ3/6 calculation runs:

1. Initial EQ3NR speciation of Bin 11 seepage water (Output DTN: MO0304MWDSAB11.001) with trace quantities of " $\mathrm{Fe}^{2+}$ " $\left(10^{-30}\right.$ molal) and " $\mathrm{Cr}^{3+"}$ ( $\left(10^{-20}\right.$ molal $)$ added; output pickup file from this feeds into items 2 and 3

2. EQ6 evaporation to $98 \%$ relative humidity of the Bin 11 water for basis of comparison

3. EQ6 "titration" run dissolving fictive Stainless Steel Type 316L mineral by corrosion quantity; output second half of pickup file from this feeds into item 4

4. EQ6 evaporation to $98 \%$ relative humidity of the steel corrosion product containing Bin 11 water.

The input and output files associated with these four EQ3/6 calculation runs are listed in Table 6.8-2 and are documented in Output DTN: SN0312T0510102.013.

Table 6.8-2. EQ3/6 Input/Output Files for Stainless Steel Type 316L Corrosion Analysis

\begin{tabular}{|c|c|c|c|}
\hline Run & Input File Names & Output File Names & Pickup File Names \\
\hline 1 & Bin11.3i & bin11.3o & bin11.3p \\
\hline 2 & Bin11e.6i & bin11e.6o & bin11e.6p \\
\hline 3 & ssbin11.6i & ssbin11.6o & ssbin11.6p \\
\hline 4 & ssbin11e.6i & ssbin11e.6o & - \\
\hline
\end{tabular}

Source: Output DTN: SN0312T0510102.013, Base case.zip.

\subsubsection{Mineral and Aqueous Suppressions}

The mineral suppressions include those identified in Section 6.6.2.6.4 of In-Drift Precipitates/Salts Analysis (BSC 2004 [DIRS 169863]; also see Table 6.5-2 in the current report) and the three minerals identified in Table 6.6-2 (Albite, K-feldspar, and Celadonite). Due to the presence of ferric and chromium species, additional suppressions are required for these calculation runs, and more silica species are suppressed as they saturated before amorphous silica in the $25^{\circ} \mathrm{C}$ calculation runs. These extra mineral suppressions and the bases for their suppression are listed in Table 6.8-3. 
Table 6.8-3. Additional EQ3/6 Mineral Suppressions Included for Seepage Ground Support Interactions

\begin{tabular}{|c|c|c|c|c|}
\hline Mineral & Formula & $\begin{array}{c}\text { Criteria } \\
\text { Selected }\end{array}$ & Rationale & References \\
\hline Tridymite & $\mathrm{SiO}_{2}$ & Criterion 2 & $\begin{array}{l}\text { Tridymite forms at temperatures from about } \\
700^{\circ} \mathrm{C} \text { to } 1,470^{\circ} \mathrm{C} \text {. }\end{array}$ & $\begin{array}{l}\text { Deer et al. } 1992 \\
\text { [DIRS 163286], } \\
\text { p. } 465\end{array}$ \\
\hline Chalcedony & $\mathrm{SiO}_{2}$ & Criterion 6 & $\begin{array}{l}\text { Modeling choice uses amorphous silica to } \\
\text { control the silica phase and provide } \\
\text { adequate conservatism. }\end{array}$ & Table C-1 \\
\hline Coesite & $\mathrm{SiO}_{2}$ & Criterion 2 & $\begin{array}{l}\text { Coesite is a high-pressure } \mathrm{SiO}_{2} \text { phase }(>35 \\
\text { kbar) that will not form at atmospheric } \\
\text { pressures. }\end{array}$ & $\begin{array}{l}\text { Deer et al. } 1992 \\
\text { [DIRS 163286], } \\
\text { p. } 466\end{array}$ \\
\hline Cristobalite (beta) & $\mathrm{SiO}_{2}$ & Criterion 2 & $\begin{array}{l}\text { Cristobalite forms at temperatures from } \\
330^{\circ} \mathrm{C} \text { to } 440^{\circ} \mathrm{C} \text {; beta quartz transforms into } \\
\text { beta cristobalite at } 1,027^{\circ} \mathrm{C} \text { and above } 650 \\
\text { bar. }\end{array}$ & $\begin{array}{l}\text { Deer et al. } 1992 \\
\text { [DIRS } 163286] \\
\text { pp. } 465 \text { to } 466\end{array}$ \\
\hline Hematite & $\mathrm{Fe}_{2} \mathrm{O}_{3}$ & Criterion 3 & $\begin{array}{l}\text { Over long time frames, hematite is more } \\
\text { stable than goethite, and the temperatures in } \\
\text { the drift are elevated enough to warrant the } \\
\text { precipitation of hematite; however, if small } \\
\text { amounts of Ti are present in solution, } \\
\text { hematite is inhibited and goethite forms. } \\
\text { Therefore, due to the large amount of } \\
\text { titanium being emplaced in the repository } \\
\text { drift, hematite will be suppressed (see } \\
\text { discussion in Section 6.8.1.1). }\end{array}$ & $\begin{array}{l}\text { Stumm and } \\
\text { Morgan 1981 } \\
\text { [DIRS 100829], } \\
\text { p. } 434 \\
\text { Fitzpatrick et al. } \\
1978 \\
\text { [DIRS 105795] }\end{array}$ \\
\hline Eskolaite & $\mathrm{Cr}_{2} \mathrm{O}_{3}$ & Criterion 2 & $\begin{array}{l}\text { Eskolaite is a common chromium mineral } \\
\text { that may precipitate from a cooling magma. } \\
\text { Although details of its liquid precipitation } \\
\text { curves are still emerging, present data } \\
\text { shows that } 0.5 \text { to } 1.0 \% \text { by mass of eskolaite } \\
\text { precipitates in the range from } 1,000^{\circ} \mathrm{C} \text { to } \\
1,150^{\circ} \mathrm{C} \text {, and it is likely to begin precipitation } \\
\text { above } 920^{\circ} \mathrm{C} \text { at atmospheric pressures. }\end{array}$ & $\begin{array}{l}\text { Perez et al. } 2001 \\
\text { [DIRS 163030], } \\
\text { p. } 4-31 \\
\text { Hrma et al. } 2001 \\
\text { [DIRS 163031], } \\
\text { Table } 3.14, \\
\text { p. } 3.27\end{array}$ \\
\hline Chromite & $\mathrm{FeCr}_{2} \mathrm{O}_{4}$ & Criterion 2 & $\begin{array}{l}\text { Chromite is a spinel mineral that is one of the } \\
\text { earliest minerals to form in a cooling magma. } \\
\text { It may also occur in some metamorphic } \\
\text { rocks. It does not form from aqueous } \\
\text { solutions near or below } 100^{\circ} \mathrm{C} \text {. }\end{array}$ & $\begin{array}{l}\text { Frye } 1981 \\
\text { [DIRS 161804], } \\
\text { p. } 581\end{array}$ \\
\hline Magnesiochromite & $\mathrm{MgCr}_{2} \mathrm{O}_{4}$ & Criterion 2 & $\begin{array}{l}\text { Magnesiochromite is a spinel mineral similar } \\
\text { to chromite. }\end{array}$ & $\begin{array}{l}\text { Frye } 1981 \\
\text { [DIRS 161804], } \\
\text { p. } 581\end{array}$ \\
\hline
\end{tabular}

NOTE: The criteria used to include suppression of a mineral are defined in Section 6.5.4.

In calculation run 2 (Table 6.8-2), the zeolite clinoptilolite-K (0.015 Fe content) is also suppressed, because trace amounts of Fe cause numerical EQ6 calculation run instabilities. This suppression is removed for calculation runs 3 and 4, and this zeolite does not form.

The suppression of a set of aqueous species is also deemed necessary from these seepage-steel interaction runs and is described in Table 6.8-4. Reasons for these suppressions range from incorrect oxidation states to overly stable polymeric aqueous species. 
Table 6.8-4. Aqueous Species Suppressions Included for Seepage Ground Support Interactions

\begin{tabular}{|c|c|c|c|c|}
\hline $\begin{array}{l}\text { EQ3/6 Aqueous } \\
\text { Species }\end{array}$ & Formula & $\begin{array}{l}\text { Criteria } \\
\text { Selected }\end{array}$ & Rationale & Reference(s) \\
\hline Chromate & $\mathrm{CrO}_{4}{ }^{2-}$ & Criteria 3 & $\begin{array}{l}\text { Oxidation of the initial } \mathrm{Cr}(\mathrm{III}) \text { corrosion } \\
\text { species to this } \mathrm{Cr}(\mathrm{VI}) \text { basis species is } \\
\text { very slow in the absence of strong } \\
\text { oxidizing agent or extreme temperature } \\
\text { and } \mathrm{pH} \text { conditions. }\end{array}$ & $\begin{array}{l}\text { Eary and Rai } 1987 \\
\text { [DIRS 105780], } \\
\text { p. } 1188 \\
\text { Smith and Purdy } 1995 \\
\text { [DIRS 162976], } \\
\text { Abstract }\end{array}$ \\
\hline $\mathrm{CrO}_{3} \mathrm{Cl}^{-}$ & $\mathrm{CrO}_{3} \mathrm{Cl}^{-}$ & Criteria 3 & $\mathrm{Cr}(\mathrm{VI})$ species, see above. & As above \\
\hline $\mathrm{CrO}_{4}{ }^{3-}$ & $\mathrm{CrO}_{4}{ }^{3-}$ & Criteria 3 & $\begin{array}{l}\text { Metastable } \operatorname{Cr}(\mathrm{V}) \text { species, not } \\
\text { observable under near-equilibrium } \\
\text { conditions. }\end{array}$ & $\begin{array}{l}\text { Niki } 1985 \\
\text { [DIRS 163728], p. } 460\end{array}$ \\
\hline $\mathrm{Cr}_{2}(\mathrm{OH})_{2}^{4+}$ & $\mathrm{Cr}_{2}(\mathrm{OH})_{2}^{4+}$ & Criteria 3 & $\begin{array}{l}\text { Previous studies that determined the } \\
\text { polymeric species used in the } \\
\text { database are overly stable. "The } \\
\text { polymeric species of Cr(III) are } \\
\text { generally absent in solutions at room } \\
\text { temperature." }\end{array}$ & $\begin{array}{l}\text { Rai et al. } 1987 \\
\text { [DIRS } 163369 \text { ], } \\
\text { pp. } 345 \text { to } 346\end{array}$ \\
\hline $\mathrm{Cr}_{3}(\mathrm{OH})_{4}{ }^{5+}$ & $\mathrm{Cr}_{3}(\mathrm{OH})_{4}{ }^{5+}$ & Criteria 3 & As above & As above \\
\hline
\end{tabular}

\subsubsection{Result of Introducing Stainless Steel Type 316L to Bin 11}

The effect of dissolving the fictive Stainless Steel Type 316L species into Bin 11 water is negligible. Bin 11 water, with and without the $4.7 \times 10^{-3}$ moles of Stainless Steel Type 316L added, has only two differences in the water chemistries and then only at the 6th significant digit (ionic strength and total molality of carbon). This is shown in 316SS-base.xls (Output DTN: SN0312T0510102.013) under the heading "Dissolution of SS316L into Bin 11 water." The effect of Stainless Steel Type 316L dissolution in the Bin 11 crown seepage water is summarized in Table 6.8-5. Values in this table represent the values calculated with the Stainless Steel Type 316L dissolution, minus the values of pure Bin 11 seepage waters, as determined at 100 and $98 \%$ relative humidity. The largest differences are less than $0.1 \%$.

The results of sensitivity analyses (Section 6.12.4.1) do not conflict, with the exception of the $\mathrm{pH}$-affecting case where $\mathrm{Cr}(\mathrm{VI})$ is allowed to form.

Table 6.8-5. Absolute (Percent Relative) Differences Due to Stainless Steel Type 316L Dissolution in Bin 11 Seepage Water at 100 and $98 \%$ Relative Humidity

\begin{tabular}{|c|c|c|c|c|c|}
\hline $\mathbf{R H}(\%)$ & $\Delta \mathbf{p H}$ & $\Delta$ (lonic Strength) & $\Delta$ (Cl molal) & $\Delta$ (Si molal) & $\Delta$ (C molal) \\
\hline 100 & 0.0001 & $1.5 \mathrm{E}-6(2 \mathrm{E}-2)$ & $3.6 \mathrm{E}-7(3 \mathrm{E}-2)$ & $1.7 \mathrm{E}-8(8 \mathrm{E}-4)$ & $3.6 \mathrm{E}-7(3 \mathrm{E}-2)$ \\
\hline 98 & -0.0001 & $-3.9 \mathrm{E}-4(-0.05)$ & $-1.1 \mathrm{E}-4(-0.06)$ & $-2.5 \mathrm{E}-5(-0.07)$ & $-6.1 \mathrm{E}-5(-0.05)$ \\
\hline
\end{tabular}

Source: Output DTN: SN0312T0510102.013 (316SS-base.xls within Base case.zip). 
There are no significant differences in the amounts of the mineral phases that exist in Stainless Steel Type 316L interacted and pure Bin 11 water at either 100 or $98 \%$ relative humidity; those minerals are: fluorite, sepiolite, and $\mathrm{SiO}_{2}(\mathrm{am})$. Goethite and $\mathrm{Cr}(\mathrm{OH})_{3}(\mathrm{am})$ are found only in the Stainless Steel Type 316L interacted water. Several trace $\left(<10^{-8}\right.$ moles $)$ solid species are found only in one or the other of the waters; these consist of nontronite ( $\mathrm{Ca}$ and $\mathrm{K}$ derivatives), erionite, and stellerite.

\subsubsection{Limitations to Base-Case Results}

Though there are several limitations discussed below, none are likely to affect the results of this section so much as to change the conclusion that stainless steel corrosion does not impact water chemistry.

Usage of only iron and chromium is considered a valid surrogate representation of stainless steel (encompassing approximately $85 \%$ by weight of total stainless steel composition), but is nonetheless a limitation. The next most abundant element is nickel at approximately $12 \%$ by weight. As nickel is more soluble than iron(III) or chromium(III) in mildly acidic conditions, it may be expected to affect $\mathrm{pH}$ slightly. However, not accounting for the nickel species is conservative as its inclusion would result in slightly higher $\mathrm{pH}$ solutions that are less likely to induce localized corrosion on the waste package outer barrier (BSC 2004 [DIRS 169984], Figure 6-50). The higher $\mathrm{pH}$ results from the dissolution of metallic $\mathrm{Ni}$ to $\mathrm{Ni}^{2+}$ with consumption of $\mathrm{H}^{+}$during the corrosion process (see reaction in Equation 6.8-1) without the corresponding production of $\mathrm{H}^{+}$during Ni-hydroxide precipitation (Equation 6.8-2). Note as well that this is a self-limiting process; due to higher $\mathrm{Ni}^{2+}$ aqueous species concentrations and higher $\mathrm{pH}$, the solubility of $\mathrm{Ni}^{2+}$ decreases and more aqueous $\mathrm{Ni}(\mathrm{OH})_{2}$ and solid are formed.

The temperature of $25^{\circ} \mathrm{C}$ imposed by the $\mathrm{Cr}(\mathrm{III})$ solubility data is a limitation. Direct comparisons of the effect of the corrosion products on the unevaporated seepage waters at operational temperatures are not possible. This is conservative because Rai et al. (1987 [DIRS 163369], Figure 4) show decreasing solubility with increasing temperatures.

The analysis run calculations are restricted to using the non-Pitzer database data0.ymp.R2 (DTN: MO0302SPATHDYN.000 [DIRS 161756]) and the B-dot activity model. Available Pitzer interaction parameters for $\mathrm{Cr}(\mathrm{III})$ species are limited, and the available pool was not deemed reliable enough to be implemented at this time.

\subsection{IN-DRIFT SEEPAGE EVAPORATION ABSTRACTION}

In-drift water compositions resulting from heating and evaporation of seepage are calculated with the IDPS process model (BSC 2004 [DIRS 169863]). This model includes the chemical influence of the in-drift atmosphere. Calculated outputs from the IDPS model are abstracted in the form of lookup tables for use as inputs to TSPA-LA calculations.

\subsubsection{Evaporated Seepage Water Inputs}

Section 6.6 essentially takes a large number of time-dependent THC model output compositions and reduces it by binning to eleven representative compositions. This section proceeds from 
those eleven original THC chemistries and creates the abstraction based upon them at various environmental relative humidity, temperature, and $\mathrm{pCO}_{2}$ conditions.

The 11 EQ3 input files with THC model output compositions (associated with the EQ6 output files listed in Table 6.6-5, archived in Output DTN: MO0303MWDSCMAB.000) were copied and renamed (Bins 1 through 11), and three additional mineral suppression inputs are added (Table 6.6-2). These 11 EQ3 $3 \mathrm{i}$ input files are run and the results archived in Output DTN: MO0304MWDSAB11.001. Data from the $11 \mathrm{EQ3}$ 3o output files are extracted using GETEQDATA (BSC 2002 [DIRS 173680]) to produce 11 bin EQ3 gas and water extract.xls (archived in Output DTN: MO0304SPAA11GC.000). This spreadsheet is then used to produce Tables 6.9-1 and 6.9-2. These tables represent the EQ3NR equilibration and charge balancing of the 11 chemistries listed in Table 6.6-6. EQ3NR (BSC 2003 [DIRS 162228]; see Section 3.1) is used only to equilibrate the solution with respect to all aqueous species. It does not equilibrate the solutions with respect to minerals and gases. Subsequent EQ6 calculation runs are used for mineral and gas-phase equilibration. Table 6.9-3 lists the species that are used to charge balance the 11 bin compositions. As noted in Section 6.6.3, charge balancing is done on the least affected species, consistent with Section 6.6.3.1 of In-Drift Precipitates/Salts Model (BSC 2004 [DIRS 169863]). Comparison of Table 6.9-1 with the inputs found in Table 6.6-6 show that performing a charge balance does not impact the concentration of the given ion in the starting water.

The EQ3NR input and output files for the median bin waters that define the starting compositions of the 11 incoming THC seepage waters (Table 6.6-6) are documented in Output DTN: MO0304MWDSAB11.001 and are listed in Table 6.9-4.

\subsubsection{Temperature and Carbon Dioxide}

Temperature and carbon dioxide pressure are varied to capture their effects on the compositional evolution of the bin waters during evaporation. Three values are chosen for each parameter, as described in Section 6.7.3. For temperature, the values are $40^{\circ} \mathrm{C}, 70^{\circ} \mathrm{C}$, and $100^{\circ} \mathrm{C}$. The $p \mathrm{CO}_{2}$ values are $10^{-2}, 10^{-3}$, and $10^{-4}$ bar. Each temperature is run for each $\mathrm{CO}_{2}$ pressure, resulting in nine combinations for each bin water. The input values for temperature and $p \mathrm{CO}_{2}$ are defined in the EQ6 input files of the IDPS model. These input files are based on the EQ6 input file templates of DTN: MO0303MWDIOJ13.000 [DIRS 162841]. The EQ3NR pickup files identified in Table 6.9-4 provide the bottom halves of the EQ6 input files. 
Table 6.9-1. Total EQ3NR Equilibrated Aqueous Elemental Compositions of the 11 Bins

\begin{tabular}{|c|c|c|c|c|c|c|c|c|c|c|c|}
\hline & Bin01.3o & Bin02.3o & Bin03.3o & Bin04.3o & Bin05.3o & Bin06.3o & Bin07.3o & Bin08.3o & Bin09.3o & Bin10.3o & Bin11.3o \\
\hline Temp $\left({ }^{\circ} \mathrm{C}\right)$ & 112 & 109 & 104 & 105 & 95.6 & 65.1 & 56.3 & 40.2 & 91.8 & 56.3 & 95.6 \\
\hline $\mathrm{pH}$ & 7.41 & 7.58 & 7.62 & 7.90 & 7.63 & 7.7 & 7.75 & 7.94 & 8.14 & 7.82 & 7.76 \\
\hline (I) & 4.93E-02 & $2.05 \mathrm{E}-02$ & $9.74 \mathrm{E}-03$ & $4.92 E-03$ & $1.13 E-02$ & $1.12 \mathrm{E}-02$ & $1.24 \mathrm{E}-02$ & $9.77 \mathrm{E}-03$ & $5.10 \mathrm{E}-03$ & $8.71 \mathrm{E}-03$ & $7.06 \mathrm{E}-03$ \\
\hline Al & 3.27E-08 & $7.08 \mathrm{E}-08$ & $5.02 \mathrm{E}-08$ & $9.97 \mathrm{E}-08$ & $8.03 \mathrm{E}-10$ & $5.36 \mathrm{E}-09$ & $3.71 \mathrm{E}-09$ & $1.50 \mathrm{E}-09$ & $6.09 \mathrm{E}-08$ & 4.03E-09 & 1.42E-09 \\
\hline C & $5.57 \mathrm{E}-05$ & $9.06 \mathrm{E}-05$ & $1.95 \mathrm{E}-04$ & $1.64 \mathrm{E}-04$ & $4.18 \mathrm{E}-04$ & $2.93 \mathrm{E}-03$ & $4.15 \mathrm{E}-03$ & $6.92 \mathrm{E}-03$ & $2.04 \mathrm{E}-03$ & $5.74 \mathrm{E}-03$ & $1.13 \mathrm{E}-03$ \\
\hline $\mathrm{Ca}$ & $1.75 \mathrm{E}-02$ & $6.48 \mathrm{E}-03$ & $2.15 \mathrm{E}-03$ & $1.09 \mathrm{E}-03$ & 1.36E-03 & $4.20 \mathrm{E}-04$ & $6.40 \mathrm{E}-04$ & $5.73 E-04$ & $7.24 \mathrm{E}-05$ & $3.52 \mathrm{E}-04$ & 3.34E-04 \\
\hline $\mathrm{Cl}$ & $2.01 \mathrm{E}-02$ & $5.02 \mathrm{E}-03$ & $3.35 \mathrm{E}-03$ & $1.03 E-03$ & $3.28 \mathrm{E}-03$ & $3.32 \mathrm{E}-03$ & 3.33E-03 & $5.61 \mathrm{E}-04$ & 7.34E-04 & $6.00 \mathrm{E}-04$ & $1.30 \mathrm{E}-03$ \\
\hline$F$ & $1.93 E-04$ & $2.46 \mathrm{E}-04$ & $3.48 \mathrm{E}-04$ & $4.28 \mathrm{E}-04$ & $1.00 \mathrm{E}-03$ & $8.26 \mathrm{E}-04$ & $6.73 \mathrm{E}-04$ & $6.43 E-04$ & $9.77 \mathrm{E}-04$ & $8.61 \mathrm{E}-04$ & $1.38 \mathrm{E}-03$ \\
\hline K & 8.68E-04 & $5.40 \mathrm{E}-04$ & $5.00 \mathrm{E}-04$ & $2.38 \mathrm{E}-04$ & $8.68 \mathrm{E}-04$ & $6.25 \mathrm{E}-04$ & $5.37 \mathrm{E}-04$ & $2.76 \mathrm{E}-04$ & $5.02 \mathrm{E}-04$ & 4.17E-04 & $7.50 \mathrm{E}-04$ \\
\hline $\mathrm{Mg}$ & $1.70 \mathrm{E}-05$ & $2.95 \mathrm{E}-06$ & $4.13 \mathrm{E}-06$ & $5.75 \mathrm{E}-07$ & 1.13E-05 & $4.82 \mathrm{E}-05$ & $6.94 \mathrm{E}-05$ & $8.51 \mathrm{E}-05$ & $2.54 \mathrm{E}-07$ & $4.31 \mathrm{E}-05$ & $6.34 \mathrm{E}-06$ \\
\hline $\mathrm{N}$ & $1.30 \mathrm{E}-03$ & $5.46 \mathrm{E}-04$ & $1.83 \mathrm{E}-04$ & $1.33 \mathrm{E}-04$ & $2.22 \mathrm{E}-04$ & $1.04 \mathrm{E}-04$ & $1.05 \mathrm{E}-04$ & $3.97 \mathrm{E}-05$ & $3.10 \mathrm{E}-04$ & $4.25 \mathrm{E}-05$ & $1.26 \mathrm{E}-04$ \\
\hline $\mathrm{Na}$ & $3.89 \mathrm{E}-03$ & $2.63 E-03$ & $2.67 \mathrm{E}-03$ & $1.26 \mathrm{E}-03$ & $5.46 \mathrm{E}-03$ & $8.08 \mathrm{E}-03$ & $8.75 \mathrm{E}-03$ & $7.30 \mathrm{E}-03$ & 4.27E-03 & $6.81 \mathrm{E}-03$ & $4.72 \mathrm{E}-03$ \\
\hline$S$ & $8.87 \mathrm{E}-03$ & $4.89 \mathrm{E}-03$ & $1.50 \mathrm{E}-03$ & $5.88 \mathrm{E}-04$ & 1.77E-03 & $1.21 \mathrm{E}-03$ & $1.22 \mathrm{E}-03$ & $3.55 \mathrm{E}-04$ & $1.18 \mathrm{E}-04$ & $3.80 \mathrm{E}-04$ & $7.29 \mathrm{E}-04$ \\
\hline $\mathrm{Si}$ & $9.42 \mathrm{E}-03$ & $7.42 \mathrm{E}-03$ & $6.96 \mathrm{E}-03$ & $7.38 \mathrm{E}-03$ & $1.22 \mathrm{E}-02$ & $2.90 \mathrm{E}-03$ & $2.35 \mathrm{E}-03$ & $1.79 \mathrm{E}-03$ & $4.15 \mathrm{E}-03$ & $2.47 \mathrm{E}-03$ & $1.19 \mathrm{E}-02$ \\
\hline
\end{tabular}

Source: Output DTN: MO0304SPAA11GC.000.

$\stackrel{i}{=}$

NOTE: All units, except temperature and $\mathrm{pH}$, are in molal.

Table 6.9-2. EQ3NR Equilibrium Speciation of the 11 Bins

\begin{tabular}{|c|c|c|c|c|c|c|c|c|c|c|c|}
\hline Species & in01.3o & in02.3o & in03.3o & in04.3o & in05.3o & in06.3o & $\sin 07.30$ & $\sin 08.30$ & Bin09.3o & Bin10.3o & Bin11.3o \\
\hline $\mathrm{Cl}^{-}$ & $01 \mathrm{E}-02$ & $02 \mathrm{E}-03$ & $35 \mathrm{E}-03$ & $1.03 \mathrm{E}-03$ & $3.28 \mathrm{E}-03$ & $3.32 \mathrm{E}-03$ & $3.33 \mathrm{E}-03$ & $5.61 \mathrm{E}-04$ & 7.34E-04 & $6.00 \mathrm{E}-04$ & $0 E-03$ \\
\hline & $3 \mathrm{E}-02$ & $70 \mathrm{E}-03$ & & & & & & & & & \\
\hline & & & & & & & & & & & \\
\hline so & -03 & 03 & & 01 & & 03 & 03 & & & & \\
\hline & & & & & & & & & & & \\
\hline $\mathrm{Na}^{+}$ & $E-03$ & & & & & $08 \mathrm{E}-03$ & & & & & \\
\hline $\mathrm{NO}_{3}$ & $\mathrm{E}-03$ & -04 & -04 & 1.33E-04 & $2.22 \mathrm{E}-04$ & 04E-04 & $05 E-04$ & 97E-05 & $\mathrm{E}-04$ & $E-05$ & $\mathrm{E}-04$ \\
\hline $\mathrm{K}^{+}$ & $8 \mathrm{E}-04$ & 40E-04 & $.00 \mathrm{E}-04$ & $2.38 \mathrm{E}-04$ & $8.68 E-04$ & $6.25 \mathrm{E}-04$ & & & & & $\mathrm{E}-04$ \\
\hline $\mathrm{HSiC}$ & $3.97 \mathrm{E}-04$ & 3.95E-04 & $3.62 \mathrm{E}$ & $6.82 \mathrm{E}-04$ & & & & & & & \\
\hline$F^{-}$ & $93 \mathrm{E}-04$ & $2.46 \mathrm{E}-04$ & $348 \mathrm{~F}-04$ & $4.28 \mathrm{E}-04$ & & $25 \mathrm{E}-04$ & & & & & -03 \\
\hline $\mathrm{O}_{2}$ & & & & & & & & & & & $E-04$ \\
\hline $\mathrm{HCC}$ & $2 \mathrm{E}-05$ & $7.30 \mathrm{E}-05$ & & 1.47E-04 & $3.82 \mathrm{E}-04$ & $80 \mathrm{E}-03$ & $3.97 \mathrm{E}-03$ & $.68 \mathrm{E}-03$ & 3 & $E-03$ & $07 \mathrm{E}-03$ \\
\hline $\mathrm{OH}^{-}$ & $3 \mathrm{E}-0$ & & & & & & & & & & $.00 \mathrm{E}-05$ \\
\hline $\mathrm{CaO}$ & & & & & & & & & & & \\
\hline $\mathrm{Mg}^{2}$ & & & & & & & & & & & \\
\hline $\mathrm{CaHCC}$ & $6.95 \mathrm{E}-06$ & $5.43 \mathrm{E}-06$ & $5.30 \mathrm{E}-06$ & $2.83 \mathrm{E}-06$ & $6.19 \mathrm{E}-06$ & $9.87 \mathrm{E}-06$ & $1.91 \mathrm{E}-05$ & $2.68 \mathrm{E}-05$ & $1.88 \mathrm{E}-06$ & $1.56 \mathrm{E}-05$ & $4.85 \mathrm{E}-06$ \\
\hline
\end{tabular}


Table 6.9-2. EQ3NR Equilibrium Speciation of the 11 Bins (Continued)

\begin{tabular}{|c|c|c|c|c|c|c|c|c|c|c|c|c|}
\hline \multirow{8}{*}{ 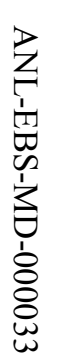 } & Species & Bin01.3o & Bin02.3o & Bin03.3o & Bin04.3o & Bin05.3o & Bin06.3o & Bin07.3o & Bin08.3o & Bin09.3o & Bin10.3o & Bin11.3o \\
\hline & $\mathrm{CaCO}_{3}(\mathrm{aq})$ & $6.04 \mathrm{E}-06$ & 7.42E-06 & $8.15 \mathrm{E}-06$ & $8.66 \mathrm{E}-06$ & $9.06 \mathrm{E}-06$ & 1.17E-05 & $2.13 \mathrm{E}-05$ & $3.16 \mathrm{E}-05$ & $8.97 \mathrm{E}-06$ & $2.10 \mathrm{E}-05$ & $9.85 \mathrm{E}-06$ \\
\hline & $\mathrm{CO}_{2}(\mathrm{aq})$ & $3.34 \mathrm{E}-06$ & 4.37E-06 & $9.28 \mathrm{E}-06$ & 4.37E-06 & $1.83 \mathrm{E}-05$ & $9.30 \mathrm{E}-05$ & $1.15 \mathrm{E}-04$ & $1.32 \mathrm{E}-04$ & $2.95 \mathrm{E}-05$ & $1.39 \mathrm{E}-04$ & $3.90 \mathrm{E}-05$ \\
\hline & $\mathrm{CO}_{3}{ }^{2-}$ & $2.05 \mathrm{E}-07$ & $4.01 \mathrm{E}-07$ & $8.72 \mathrm{E}-07$ & $1.28 \mathrm{E}-06$ & $2.02 \mathrm{E}-06$ & $1.54 \mathrm{E}-05$ & $2.34 \mathrm{E}-05$ & $4.91 \mathrm{E}-05$ & $2.96 \mathrm{E}-05$ & $3.64 \mathrm{E}-05$ & $7.02 \mathrm{E}-06$ \\
\hline & $\mathrm{MgOH}^{+}$ & $1.42 \mathrm{E}-07$ & $3.73 \mathrm{E}-08$ & $5.41 \mathrm{E}-08$ & $1.71 \mathrm{E}-08$ & $9.05 \mathrm{E}-08$ & $6.85 \mathrm{E}-08$ & $5.89 \mathrm{E}-08$ & $3.52 \mathrm{E}-08$ & $5.92 \mathrm{E}-09$ & $4.55 E-08$ & $7.49 \mathrm{E}-08$ \\
\hline & $\mathrm{NaF}(\mathrm{aq})$ & $1.21 \mathrm{E}-07$ & 1.19E-07 & $1.80 \mathrm{E}-07$ & $1.13 \mathrm{E}-07$ & $9.46 \mathrm{E}-07$ & $8.18 \mathrm{E}-07$ & $6.45 \mathrm{E}-07$ & $4.42 \mathrm{E}-07$ & $7.52 \mathrm{E}-07$ & $6.67 \mathrm{E}-07$ & 1.19E-06 \\
\hline & $\mathrm{HSO}_{4}^{-}$ & 1.16E-07 & $6.44 \mathrm{E}-08$ & $2.17 \mathrm{E}-08$ & $5.46 \mathrm{E}-09$ & $2.13 \mathrm{E}-08$ & $5.27 \mathrm{E}-09$ & $3.51 \mathrm{E}-09$ & $4.22 \mathrm{E}-10$ & 4.94E-10 & $9.90 \mathrm{E}-10$ & $7.65 \mathrm{E}-09$ \\
\hline & $\mathrm{H}^{+}$ & $4.94 \mathrm{E}-08$ & $3.14 \mathrm{E}-08$ & $2.72 \mathrm{E}-08$ & $1.38 \mathrm{E}-08$ & $2.67 \mathrm{E}-08$ & $2.26 \mathrm{E}-08$ & $2.02 \mathrm{E}-08$ & $1.28 \mathrm{E}-08$ & $7.93 \mathrm{E}-09$ & $1.69 \mathrm{E}-08$ & $1.93 E-08$ \\
\hline \multirow{9}{*}{ 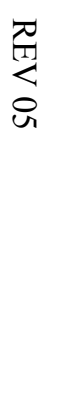 } & $\mathrm{AlO}_{2}^{-}$ & $3.27 \mathrm{E}-08$ & $7.08 \mathrm{E}-08$ & $5.02 \mathrm{E}-08$ & $9.97 \mathrm{E}-08$ & $8.03 E-10$ & $5.36 \mathrm{E}-09$ & $3.71 \mathrm{E}-09$ & $1.50 \mathrm{E}-09$ & $6.09 \mathrm{E}-08$ & $4.03 E-09$ & $1.42 \mathrm{E}-09$ \\
\hline & $\mathrm{MgHCO}_{3}{ }^{+}$ & $7.58 \mathrm{E}-09$ & $2.89 \mathrm{E}-09$ & 1.13E-08 & $1.58 \mathrm{E}-09$ & $5.73 \mathrm{E}-08$ & $1.18 \mathrm{E}-06$ & $2.12 \mathrm{E}-06$ & $3.96 \mathrm{E}-06$ & 7.27E-09 & $1.96 \mathrm{E}-06$ & $1.00 \mathrm{E}-07$ \\
\hline & $\mathrm{MgCO}_{3}(\mathrm{aq})$ & 1.49E-09 & $9.14 \mathrm{E}-10$ & $4.16 \mathrm{E}-09$ & $1.15 \mathrm{E}-09$ & $2.13 \mathrm{E}-08$ & $4.46 \mathrm{E}-07$ & $8.15 \mathrm{E}-07$ & $1.85 \mathrm{E}-06$ & $9.03 \mathrm{E}-09$ & $9.05 \mathrm{E}-07$ & $5.15 E-08$ \\
\hline & $\mathrm{NO}_{2}{ }^{-}$ & $5.53 \mathrm{E}-13$ & $1.71 \mathrm{E}-13$ & $3.68 \mathrm{E}-14$ & $2.89 \mathrm{E}-14$ & $2.13 \mathrm{E}-14$ & $5.03 E-16$ & $1.94 \mathrm{E}-16$ & $1.08 \mathrm{E}-17$ & $2.08 \mathrm{E}-14$ & $7.82 \mathrm{E}-17$ & $1.20 \mathrm{E}-14$ \\
\hline & $\mathrm{AlO}^{+}$ & $5.40 \mathrm{E}-14$ & $6.57 \mathrm{E}-14$ & $5.22 \mathrm{E}-14$ & $2.69 \mathrm{E}-14$ & $1.33 \mathrm{E}-15$ & $5.16 \mathrm{E}-14$ & $5.58 \mathrm{E}-14$ & $3.58 \mathrm{E}-14$ & $1.23 \mathrm{E}-14$ & $4.37 \mathrm{E}-14$ & $1.29 \mathrm{E}-15$ \\
\hline & $\mathrm{AlOH}^{2+}$ & $1.49 \mathrm{E}-17$ & $1.07 \mathrm{E}-17$ & $7.87 \mathrm{E}-18$ & $1.85 \mathrm{E}-18$ & $2.75 \mathrm{E}-19$ & $3.24 \mathrm{E}-17$ & $4.88 \mathrm{E}-17$ & $4.71 \mathrm{E}-17$ & $8.01 \mathrm{E}-19$ & $3.06 \mathrm{E}-17$ & $1.83 E-19$ \\
\hline & $\mathrm{Al}^{3+}$ & $1.93 \mathrm{E}-21$ & $6.81 \mathrm{E}-22$ & $4.43 \mathrm{E}-22$ & 4.29E-23 & $2.41 \mathrm{E}-23$ & 1.16E-20 & $2.63 \mathrm{E}-20$ & $3.90 \mathrm{E}-20$ & $2.11 \mathrm{E}-23$ & $1.25 \mathrm{E}-20$ & $1.05 \mathrm{E}-23$ \\
\hline & $\mathrm{ClO}_{4}{ }^{-}$ & $9.85 \mathrm{E}-24$ & $2.13 \mathrm{E}-24$ & $1.18 \mathrm{E}-24$ & $3.73 \mathrm{E}-25$ & $8.53 \mathrm{E}-25$ & $2.63 \mathrm{E}-25$ & $1.82 \mathrm{E}-25$ & $1.48 \mathrm{E}-26$ & $1.65 \mathrm{E}-25$ & $3.27 \mathrm{E}-26$ & $3.37 \mathrm{E}-25$ \\
\hline & $\mathrm{H}_{2}(\mathrm{aq})$ & $9.65 \mathrm{E}-34$ & $4.76 \mathrm{E}-34$ & $1.43 \mathrm{E}-34$ & $1.82 \mathrm{E}-34$ & $1.75 \mathrm{E}-35$ & $3.83 \mathrm{E}-39$ & $2.56 \mathrm{E}-40$ & $1.25 \mathrm{E}-42$ & $6.56 \mathrm{E}-36$ & $2.56 \mathrm{E}-40$ & $1.75 \mathrm{E}-35$ \\
\hline \multirow[b]{2}{*}{$\stackrel{i}{I}$} & $\mathrm{NH}_{3}(\mathrm{aq})$ & $1.44 \mathrm{E}-49$ & $1.54 \mathrm{E}-50$ & $8.51 \mathrm{E}-52$ & $4.76 \mathrm{E}-52$ & $4.72 \mathrm{E}-53$ & 8.89E-59 & $1.56 \mathrm{E}-60$ & $1.65 \mathrm{E}-64$ & $5.05 E-54$ & $5.45 \mathrm{E}-61$ & $2.03 E-53$ \\
\hline & $\mathrm{NH}_{4}{ }^{+}$ & 1.05E-49 & $8.13 E-51$ & $4.86 \mathrm{E}-52$ & 1.32E-52 & $3.89 \mathrm{E}-53$ & $2.91 \mathrm{E}-58$ & $7.48 \mathrm{E}-60$ & $1.33 E-63$ & $1.48 \mathrm{E}-54$ & $2.19 \mathrm{E}-60$ & $1.21 \mathrm{E}-53$ \\
\hline
\end{tabular}

Source: Output DTN: MO0304SPAA11GC.000.

NOTE: All units are in molal. 
Table 6.9-3. List of Species Used to Charge Balance Individual Water Chemistries

\begin{tabular}{|l|l|}
\hline \multicolumn{1}{|c|}{ Bin } & \multicolumn{1}{c|}{ Charge-Balanced lon } \\
\hline Bin 1 & $\mathrm{Ca}^{2+}$ \\
\hline Bin 2 & $\mathrm{Ca}^{2+}$ \\
\hline Bin 3 & $\mathrm{Ca}^{2+}$ \\
\hline Bin 4 & $\mathrm{Ca}^{2+}$ \\
\hline Bin 5 & $\mathrm{Na}^{+}$ \\
\hline Bin 6 & $\mathrm{Na}^{+}$ \\
\hline Bin 7 & $\mathrm{Na}^{+}$ \\
\hline Bin 8 & $\mathrm{Na}^{+}$ \\
\hline Bin 9 & $\mathrm{Na}^{+}$ \\
\hline Bin 10 & $\mathrm{Na}^{+}$ \\
\hline Bin 11 & $\mathrm{Na}^{+}$ \\
\hline
\end{tabular}

Source: Output DTN: MO0304MWDSAB11.001.

Table 6.9-4. EQ3NR Input/Output Files for TSPA-LA Abstraction

\begin{tabular}{|l|c|c|c|}
\hline \multicolumn{1}{|c|}{ Bin } & Input File Names & Output File Names & Pickup File Names \\
\hline Bin 1 & bin01.3i & bin01.3o & bin01.3p \\
\hline Bin 2 & bin02.3i & bin02.3o & bin02.3p \\
\hline Bin 3 & bin03.3i & bin03.3o & bin03.3p \\
\hline Bin 4 & bin04.3i & bin04.3o & bin04.3p \\
\hline Bin 5 & bin05.3i & bin05.3o & bin05.3p \\
\hline Bin 6 & bin06.3i & bin06.3o & bin06.3p \\
\hline Bin 7 & bin07.3i & bin07.3o & bin07.3p \\
\hline Bin 8 & bin08.3i & bin08.3o & bin08.3p \\
\hline Bin 9 & bin09.3i & bin09.3o & bin09.3p \\
\hline Bin 10 & bin10.3i & bin10.3o & bin10.3p \\
\hline Bin 11 & bin11.3i & bin11.3o & bin11.3p \\
\hline
\end{tabular}

Source: Output DTN: MO0304MWDSAB11.001.

To cover the range of expected in-drift relative humidity values for crown seepage, the bin waters are evaporated to or below a water activity of 0.65 and diluted by a factor of 100 . The starting bin waters are sufficiently dilute that they represent solutions in equilibrium with relative humidity between 99.9 and $99.99 \%$. Dilution of water vapor is simulated for potential relative humidity values higher than the equilibrium relative humidity values of the starting bin water, but only for crown seepage and not the invert (see Section 6.9.3). Thus, for each temperature and $\mathrm{pCO}_{2}$ combination, two EQ6 input files are generated, one for evaporation and one for dilution. The resulting EQ6 input and output data files for the bin waters are listed in Table 6.9-7 and documented in Output DTN: MO0304MWDEBSSA.000. The file nomenclature is ??c\#t\%\$.6i or $6 o$, where:

- "??" is the two-digit bin number $(01,02$, etc.)

- "\#” is 2,3 , or 4 for pressure of $\mathrm{CO}_{2}$ equal to $10^{-2}, 10^{-3}$, or $10^{-4}$ bar, respectively

- "\%" is 4,7 , or 1 for temperature equal to $40^{\circ} \mathrm{C}, 70^{\circ} \mathrm{C}$, or $100^{\circ} \mathrm{C}$, respectively, and

- " $\$$ " is " $\mathrm{e}$ " or " $\mathrm{c}$ " for evaporation or dilution. 
For example, file $01 c 2 t 1 c .6 i$ is the EQ6 input file for bin 1 dilution at $100^{\circ} \mathrm{C}$ and a pressure of $\mathrm{CO}_{2}$ of $10^{-2}$ bar.

\subsubsection{No Dilution for Invert Seepage}

The modeling of evaporated seepage waters in the invert does not require the use of any of the dilution tables. Consideration of the local environmental conditions within the invert, where the water will be primarily contained within the pore structure of the invert rock, will limit the extent to which dilution can become important, i.e., nearly pure carbonated water will not form. This is in contrast to the relatively smooth and initially mineral-free surface on the waste package where crown seepage may reside and can dilute to match the local relative humidity conditions.

To demonstrate the reasonableness of not including invert dilution, a comparison is made between the unevaporated median water chemistries and those of pure water in equilibrium with rock minerals. EQ3/6 modeling calculations are performed at the nine lookup table temperature and $\mathrm{pCO}_{2}$ conditions (Output DTN: SN0505T0510102.020, Water-Rock.zip in path "Calcs〉"). The only input required for this analysis is the Pitzer database data0.ypf.R0 (DTN: SN0302T0510102.002 [DIRS 162572]).

These EQ3/6 calculations determine the expected ranges of water activity and $\mathrm{pH}$ possible for a very dilute seepage water in continuous contact with invert rock. This is modeled with saturation with respect to both calcite and amorphous silica. A strong dependence is found with $p \mathrm{CO}_{2}$ and a weaker dependence upon temperature, as seen in Table 6.9-5.

Table 6.9-5. Water Activity and pH of Water-Rock Simulation

\begin{tabular}{|c|c|c|c|}
\hline \multicolumn{5}{|c|}{ Relative Humidity (Water Activity $\times 100 \%)$} \\
\hline & -4 & -3 & $\mathbf{- 2}$ \\
\hline Temperature & $\mathbf{- 4}\left(\mathbf{C O O}_{2}\right)$ \\
\hline $\mathbf{4 0} \mathbf{C}$ & 99.9925 & 99.9914 & 99.9876 \\
\hline $\mathbf{7 0}^{\circ} \mathbf{C}$ & 99.9891 & 99.9894 & 99.9874 \\
\hline $\mathbf{1 0 0}^{\circ} \mathbf{C}$ & 99.9843 & 99.9858 & 99.9851 \\
\hline \multicolumn{5}{|c|}{ pH (NBS) } \\
\hline $\mathbf{4 0}^{\circ} \mathbf{C}$ & 8.5072 & 7.924 & 7.2785 \\
\hline $\mathbf{7 0}^{\circ} \mathbf{C}$ & 8.3567 & 7.8804 & 7.2678 \\
\hline $\mathbf{1 0 0}^{\circ} \mathbf{C}$ & 8.2007 & 7.8034 & 7.2627 \\
\hline
\end{tabular}

Source: Output DTN: SN0505T0510102.020, HumidityUpperLimit.xls.

These water-rock results are now compared to unevaporated median bin water results at these same temperature and $\mathrm{pCO}_{2}$ conditions. These unevaporated median bin water $\mathrm{RH}$ values come from the highest RH values available from the TSPA-LA lookup table evaporation outputs in Output DTN: MO0304SPACSALT.000. These highest relative humidity values are summarized in that DTN in the file Evap_Look-up-Tables.zip, in RH MAP.xls, and compared to Table 6.9-5 RH results in Figure 6.9-1. This comparison does not include Bin 1, which has an unevaporated RH ranging from 99.915 to $99.921 \%$. Exclusion of Bin 1 from this comparison is justified because it only occurs in some of the seepage bin histories from 67.5 through 125 years 
(17.5 through 75 years postclosure) while the drift is undergoing rapid heating and the invert will not experience these high RH levels.

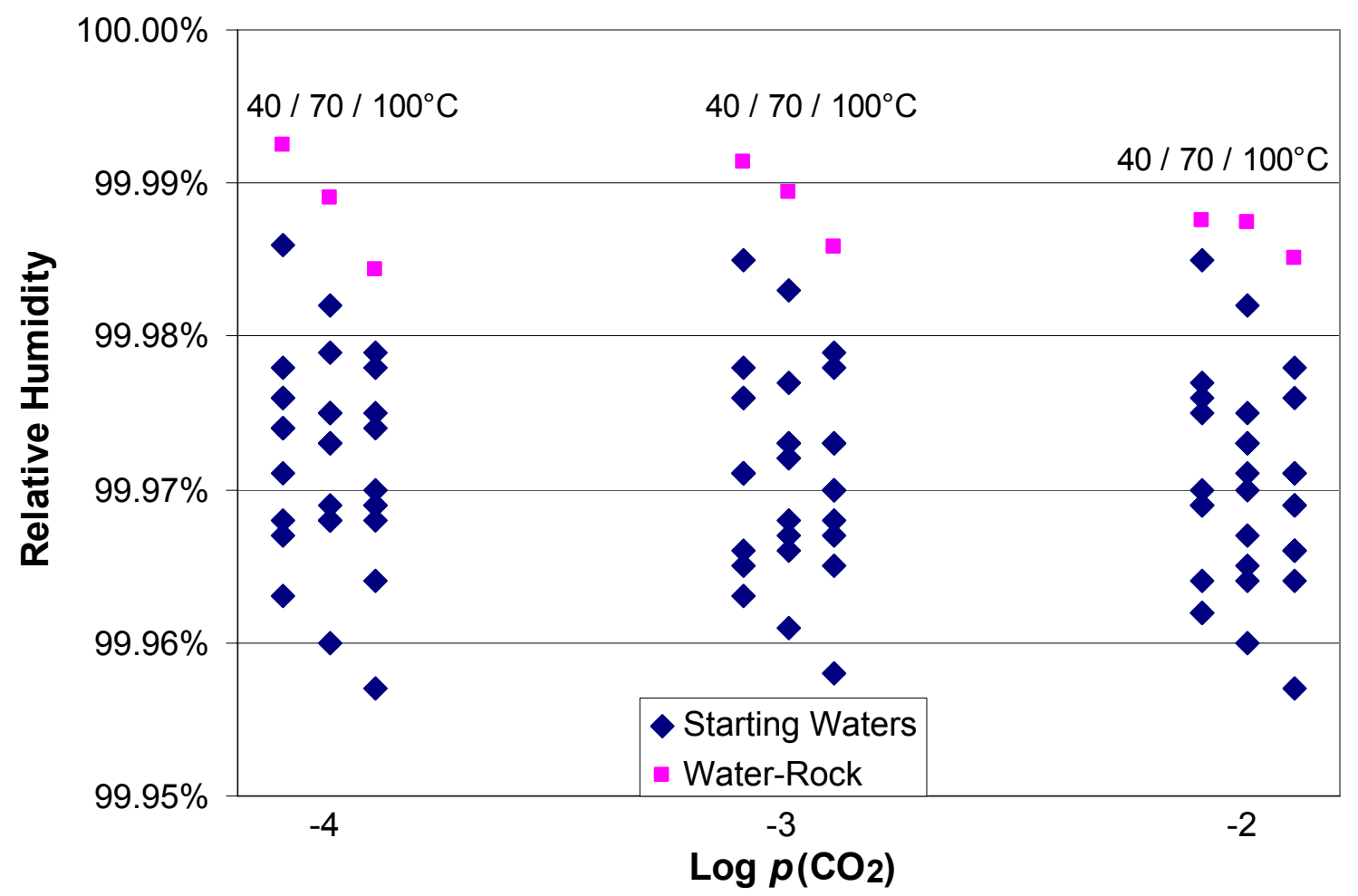

Sources: Output DTNs: SN0505T0510102.020 and MO0304SPACSALT.000 (Evap_Look-up-Tables.zip, RH MAP.XIS).

NOTE: The three temperatures are separated along the $\mathrm{x}$-axis, but are exactly $-4,-3$ or $-2 \log \left(p \mathrm{CO}_{2}\right)$.

Figure 6.9-1. Unevaporated Median Seepage Waters Compared to Simulated Water-Rock Equilibrium

The difference between the approximate mean of the median waters at $99.97 \% \mathrm{RH}$ to the water-rock simulated water at and just below $99.99 \% \mathrm{RH}$ is examined further. The files in Output DTN: MO0304SPACSALT.000, Cond_Look-up-Tables.zip, contains the result of dilution on the median bin water chemistries. Specifically, Bin 10 waters, with an unevaporated $\mathrm{RH}$ of $99.972 \%$ at $70^{\circ} \mathrm{C}$ and $10^{-3} \mathrm{pCO}_{2}$, dilute nearly four-fold to $99.991 \% \mathrm{RH}$ (Output DTN: MO0304SPACSALT.000, 10c3t7c.xls.xls). Similarly, Bin 11 waters at 99.973\% RH dilute four-fold to attain a 99.989\% RH (Output DTN: MO0304SPACSALT.000, $11 c 3 t 7 c . x l s . x l s)$.

The effects of this factor of four dilution, or concentration factor of $1 / 4$, is primarily to decrease the ionic strength by approximately a factor of four. Also, as shown in Table $6.9-6$ at $70^{\circ} \mathrm{C}$ and $p \mathrm{CO}_{2}$ of $10^{-3}$, a decrease of the $\mathrm{pH}$ is on average 0.38 , and at most by just over half a $\mathrm{pH}$ unit (for Bin 5). 
Table 6.9-6. Effect of Dilution on Bin Waters at $70^{\circ} \mathrm{C}$ and $10^{-3}$ bar $p \mathrm{CO}_{2}$

\begin{tabular}{|c|c|c|c|c|c|c|c|c|c|c|}
\hline pH & Bin 2 & Bin 3 & Bin 4 & Bin 5 & Bin 6 & Bin 7 & Bin 8 & Bin 9 & Bin 10 & Bin 11 \\
\hline Unevaporated & 7.441 & 7.620 & 7.750 & 7.790 & 8.309 & 8.431 & 8.736 & 8.363 & 8.671 & 8.151 \\
\hline $\begin{array}{c}\text { Diluted to } \\
\text { 99.99\% RH }\end{array}$ & $7.0485^{\mathrm{a}}$ & 7.194 & 7.547 & 7.235 & 7.927 & 8.072 & 8.414 & 8.053 & $8.295^{\mathrm{a}}$ & 7.665 \\
\hline Difference & 0.3925 & 0.426 & 0.203 & 0.555 & 0.382 & 0.359 & 0.322 & 0.310 & 0.376 & 0.486 \\
\hline
\end{tabular}

Source: Output DTN: MO0304SPACSALT.000, Cond_Look-up-Tables.zip, files \#\#c3t7c.xls, where \#\# is 02 through 11. The difference row is hand calculated.

a For Bins 2 and 10, the diluted value is a hand-calculated average taken from the pH values that are above and below $99.99 \% \mathrm{RH}$.

If calcite saturation is maintained within these diluted bin waters, as interaction with rock minerals would provide, the $\mathrm{pH}$ for all bin waters would begin to approach 7.88 under these same conditions (Table 6.9-5).

\subsubsection{Lookup Tables}

The abstracted results of the evaporation and dilution calculations that are provided as direct input into TSPA-LA calculations are summarized in a set of lookup tables documented in Output DTN: MO0304SPACSALT.000, and modified for TSPA-LA direct use in Output DTN: MO0310SPAPCEGS.000 as described by Section 8.2.1. These lookup tables, listed in Table 6.9-8, include stated boundary conditions, abstracted output, and results of supplemental calculations. Each evaporation or dilution lookup table corresponds to one of the IDPS model output files identified in Table 6.9-7. Each row in these tables provides output parameter values as the water incrementally evolves due to evaporation or dilution, given the defined boundary conditions. Each value is defined by a unique equilibrium relative humidity, concentration factor, and relative evaporation rate.

The general lookup table format and the calculations placed in the lookup tables are developed and described in In-Drift Precipitates/Salts Model (BSC 2004 [DIRS 169863], Sections 6.6.3.5 and 6.7.3). The first three columns of these tables are supplemental spreadsheet calculations for concentration factor $(C F)$, relative evaporation rate $(Q e / Q s)$, and dilution factor $(D F)$. The next column is the equilibrium $R H$, calculated by multiplying the activity of water (in column $\mathrm{K}$ ) by $100 \%$. The rest of the columns are filled with selected output data using GETEQDATA (BSC 2002 [DIRS 173680]). Columns E through H show reaction progress and the boundary conditions for the starting water (i.e., the temperature and the pressures of oxygen and carbon dioxide). Columns I through $\mathrm{X}$ show reaction progress, $\mathrm{pH}$, ionic strength, mass of $\mathrm{H}_{2} \mathrm{O}$ in the reactor, and the total concentrations of the aqueous components. Columns $\mathrm{Y}$ through AL present reaction progress, mass of $\mathrm{H}_{2} \mathrm{O}$, and the concentrations of potential acid-neutralizing species. Finally, columns AM through BD show the amounts of minerals accumulated. 
Table 6.9-7. EQ6 Input/Output Files for TSPA-LA Abstraction

\begin{tabular}{|c|c|c|}
\hline Bin & Input File Names & Output File Names \\
\hline 1 & $\begin{array}{lll}01 c 2 t 1 e .6 i, & 01 c 3 t 1 e .6 i, & 01 c 4 t 1 e .6 i \\
01 c 2 t 4 e .6 i, & 01 c 3 t 4 e .6 i, & 01 c 4 t 4 e .6 i \\
01 c 2 t 7 e .6 i, & 01 c 3 t 7 e .6 i, & 01 c 4 t 7 e .6 i \\
01 c 2 t 1 c .6 i, & 01 c 3 t 1 c .6 i, & 01 c 4 t 1 c .6 i \\
01 c 2 t 4 c .6 i, & 01 c 3 t 4 c .6 i, & 01 c 4 t 4 c .6 i \\
01 c 2 t 7 c .6 i, & 01 c 3 t 7 c .6 i, & 01 c 4 t 7 c .6 i\end{array}$ & $\begin{array}{lll}01 c 2 t 1 e .6 o, & 01 c 3 t 1 e .6 o, & 01 c 4 t 1 e .6 o \\
01 c 2 t 4 e .6 o & 01 c 3 t 4 e .6 o, & 01 c 4 t 4 e .6 o \\
01 c 2 t 7 e .6 o & 01 c 3 t 7 e .6 o, & 01 c 4 t 7 e .6 o \\
01 c 2 t 1 c .6 o, & 01 c 3 t 1 c .6 o, & 01 c 4 t 1 c .6 o \\
01 c 2 t 4 c .6 o, & 01 c 3 t 4 c .6 o, & 01 c 4 t 4 c .6 o \\
01 c 2 t 7 c .6 o, & 01 c 3 t 7 c .6 o, & 01 c 4 t 7 c .6 o\end{array}$ \\
\hline 2 & $\begin{array}{lll}02 c 2 t 1 e .6 i, & 02 c 3 t 1 e .6 i, & 02 c 4 t 1 e .6 i \\
02 c 2 t 4 e .6 i, & 02 c 3 t 4 e .6 i, & 02 c 4 t 4 e .6 i \\
02 c 2 t 7 e .6 i, & 02 c 3 t 7 e .6 i, & 02 c 4 t 7 e .6 i \\
02 c 2 t 1 c .6 i, & 02 c 3 t 1 c .6 i, & 02 c 4 t 1 c .6 i \\
02 c 2 t 4 c .6 i, & 02 c 3 t 4 c .6 i, & 02 c 4 t 4 c .6 i \\
02 c 2 t 7 c .6 i, & 02 c 3 t 7 c .6 i, & 02 c 4 t 7 c .6 i\end{array}$ & $\begin{array}{lll}02 c 2 t 1 e .6 o, & 02 c 3 t 1 e .6 o, & 02 c 4 t 1 e .6 o \\
02 c 2 t 4 e .6 o, & 02 c 3 t 4 e .6 o, & 02 c 4 t 4 e .6 o \\
02 c 2 t 7 e .6 o, & 02 c 3 t 7 e .6 o, & 02 c 4 t 7 e .6 o \\
02 c 2 t 1 c .6 o, & 02 c 3 t 1 c .6 o, & 02 c 4 t 1 c .6 o \\
02 c 2 t 4 c .6 o, & 02 c 3 t 4 c .6 o, & 02 c 4 t 4 c .6 o \\
02 c 2 t 7 c .6 o, & 02 c 3 t 7 c .6 o, & 02 c 4 t 7 c .6 o\end{array}$ \\
\hline 3 & $\begin{array}{lll}03 c 2 t 1 e .6 i, & 03 c 3 t 1 e .6 i, & 03 c 4 t 1 e .6 i, \\
03 c 2 t 4 e .6 i, & 03 c 3 t 4 e .6 i, & 03 c 4 t 4 e .6 i \\
03 c 2 t 7 e .6 i, & 03 c 3 t 7 e .6 i, & 03 c 4 t 7 e .6 i \\
03 c 2 t 1 c .6 i, & 03 c 3 t 1 c .6 i, & 03 c 4 t 1 c .6 i \\
03 c 2 t 4 c .6 i, & 03 c 3 t 4 c .6 i, & 03 c 4 t 4 c .6 i \\
03 c 2 t 7 c .6 i, & 03 c 3 t 7 c .6 i, & 03 c 4 t 7 c .6 i\end{array}$ & $\begin{array}{lll}03 c 2 t 1 e .6 o, & 03 c 3 t 1 e .6 o, & 03 c 4 t 1 e .6 o \\
03 c 2 t 4 e .6 o, & 03 c 3 t 4 e .6 o, & 03 c 4 t 4 e .6 o \\
03 c 2 t 7 e .6 o, & 03 c 3 t 7 e .6 o, & 03 c 4 t 7 e .6 o \\
03 c 2 t 1 c .6 o, & 03 c 3 t 1 c .6 o, & 03 c 4 t 1 c .6 o \\
03 c 2 t 4 c .6 o, & 03 c 3 t 4 c .6 o, & 03 c 4 t 4 c .6 o \\
03 c 2 t 7 c .6 o, & 03 c 3 t 7 c .6 o, & 03 c 4 t 7 c .6 o\end{array}$ \\
\hline 4 & $\begin{array}{lll}04 c 2 t 1 e .6 i, & 04 c 3 t 1 e .6 i, & 04 c 4 t 1 e .6 i \\
04 c 2 t 4 e .6 i, & 04 c 3 t 4 e .6 i, & 04 c 4 t 4 e .6 i \\
04 c 2 t 7 e .6 i, & 04 c 3 t 7 e .6 i, & 04 c 4 t 7 e .6 i \\
04 c 2 t 1 c .6 i, & 04 c 3 t 1 c .6 i, & 04 c 4 t 1 c .6 i \\
04 c 2 t 4 c .6 i, & 04 c 3 t 4 c .6 i, & 04 c 4 t 4 c .6 i \\
04 c 2 t 7 c .6 i, & 04 c 3 t 7 c .6 i, & 04 c 4 t 7 c .6 i\end{array}$ & $\begin{array}{lll}04 c 2 t 1 e .6 o, & 04 c 3 t 1 e .6 o, & 04 c 4 t 1 e .6 o \\
04 c 2 t 4 e .6 o, & 04 c 3 t 4 e .6 o, & 04 c 4 t 4 e .6 o \\
04 c 2 t 7 e .6 o, & 04 c 3 t 7 e .6 o, & 04 c 4 t 7 e .6 o \\
04 c 2 t 1 c .6 o, & 04 c 3 t 1 c .6 o, & 04 c 4 t 1 c .6 o \\
04 c 2 t 4 c .6 o, & 04 c 3 t 4 c .6 o, & 04 c 4 t 4 c .6 o \\
04 c 2 t 7 c .6 o, & 04 c 3 t 7 c .6 o, & 04 c 4 t 7 c .6 o\end{array}$ \\
\hline 5 & $\begin{array}{lll}05 c 2 t 1 e .6 i, & 05 c 3 t 1 e .6 i, & 05 c 4 t 1 e .6 i \\
05 c 2 t 4 e .6 i, & 05 c 3 t 4 e .6 i, & 05 c 4 t 4 e .6 i \\
05 c 2 t 7 e .6 i, & 05 c 3 t 7 e .6 i, & 05 c 4 t 7 e .6 i \\
05 c 2 t 1 c .6 i, & 05 c 3 t 1 c .6 i, & 05 c 4 t 1 c .6 i \\
05 c 2 t 4 c .6 i, & 05 c 3 t 4 c .6 i, & 05 c 4 t 4 c .6 i \\
05 c 2 t 7 c .6 i, & 05 c 3 t 7 c .6 i, & 05 c 4 t 7 c .6 i\end{array}$ & $\begin{array}{lll}05 c 2 t 1 e .6 o, & 05 c 3 t 1 e .6 o, & 05 c 4 t 1 e .6 o \\
05 c 2 t 4 e .6 o, & 05 c 3 t 4 e .6 o, & 05 c 4 t 4 e .6 o \\
05 c 2 t 7 e .6 o, & 05 c 3 t 7 e .6 o, & 05 c 4 t 7 e .6 o \\
05 c 2 t 1 c .6 o, & 05 c 3 t 1 c .6 o, & 05 c 4 t 1 c .6 o \\
05 c 2 t 4 c .6 o, & 05 c 3 t 4 c .6 o, & 05 c 4 t 4 c .6 o \\
05 c 2 t 7 c .6 o, & 05 c 3 t 7 c .6 o, & 05 c 4 t 7 c .6 o\end{array}$ \\
\hline 6 & $\begin{array}{lll}06 c 2 t 1 e .6 i, & 06 c 3 t 1 e .6 i, & 06 c 4 t 1 e .6 i \\
06 c 2 t 4 e .6 i, & 06 c 3 t 4 e .6 i, & 06 c 4 t 4 e .6 i \\
06 c 2 t 7 e .6 i, & 06 c 3 t 7 e .6 i, & 06 c 4 t 7 e .6 i \\
06 c 2 t 1 c .6 i, & 06 c 3 t 1 c .6 i, & 06 c 4 t 1 c .6 i \\
06 c 2 t 4 c .6 i, & 06 c 3 t 4 c .6 i, & 06 c 4 t 4 c .6 i \\
06 c 2 t 7 c .6 i, & 06 c 3 t 7 c .6 i, & 06 c 4 t 7 c .6 i\end{array}$ & $\begin{array}{lll}06 c 2 t 1 e .6 o, & 06 c 3 t 1 e .6 o, & 06 c 4 t 1 e .6 o \\
06 c 2 t 4 e .6 o, & 06 c 3 t 4 e .6 o, & 06 c 4 t 4 e .6 o \\
06 c 2 t 7 e .6 o, & 06 c 3 t 7 e .6 o, & 06 c 4 t 7 e .6 o \\
06 c 2 t 1 c .6 o, & 06 c 3 t 1 c .6 o, & 06 c 4 t 1 c .6 o \\
06 c 2 t 4 c .6 o, & 06 c 3 t 4 c .6 o, & 06 c 4 t 4 c .6 o \\
06 c 2 t 7 c .6 o, & 06 c 3 t 7 c .6 o, & 06 c 4 t 7 c .6 o\end{array}$ \\
\hline 7 & $\begin{array}{lll}07 c 2 t 1 e .6 i, & 07 c 3 t 1 e .6 i, & 07 c 4 t 1 e .6 i \\
07 c 2 t 4 e .6 i, & 07 c 3 t 4 e .6 i, & 07 c 4 t 4 e .6 i \\
07 c 2 t 7 e .6 i, & 07 c 3 t 7 e .6 i, & 07 c 4 t 7 e .6 i \\
\text { 07c2t1c.6i, } & 07 c 3 t 1 c .6 i, & 07 c 4 t 1 c .6 i \\
\text { 07c2t4c.6i, } & 07 c 3 t 4 c .6 i, & 07 c 4 t 4 c .6 i \\
07 c 2 t 7 c .6 i, & 07 c 3 t 7 c .6 i, & 07 c 4 t 7 c .6 i\end{array}$ & $\mid \begin{array}{lll}07 c 2 t 1 e .6 o, & 07 c 3 t 1 e .6 o, & 07 c 4 t 1 e .6 o \\
07 c 2 t 4 e .6 o, & 07 c 3 t 4 e .6 o, & 07 c 4 t 4 e .6 o \\
07 c 2 t 7 e .6 o, & 07 c 3 t 7 e .6 o, & 07 c 4 t 7 e .6 o \\
07 c 2 t 1 c .6 o, & 07 c 3 t 1 c .6 o, & 07 c 4 t 1 c .6 o \\
07 c 2 t 4 c .6 o, & 07 c 3 t 4 c .6 o, & 07 c 4 t 4 c .6 o \\
07 c 2 t 7 c .6 o, & 07 c 3 t 7 c .6 o, & 07 c 4 t 7 c .6 o\end{array}$ \\
\hline 8 & $\begin{array}{lll}08 c 2 t 1 e .6 i, & 08 c 3 t 1 e .6 i, & 08 c 4 t 1 e .6 i \\
08 c 2 t 4 e .6 i, & 08 c 3 t 4 e .6 i, & 08 c 4 t 4 e .6 i \\
08 c 2 t 7 e .6 i, & 08 c 3 t 7 e .6 i, & 08 c 4 t 7 e .6 i \\
08 c 2 t 1 c .6 i, & 08 c 3 t 1 c .6 i, & 08 c 4 t 1 c .6 i \\
08 c 2 t 4 c .6 i, & 08 c 3 t 4 c .6 i, & 08 c 4 t 4 c .6 i \\
08 c 2 t 7 c .6 i, & 08 c 3 t 7 c .6 i, & 08 c 4 t 7 c .6 i\end{array}$ & $\begin{array}{lll}08 c 2 t 1 e .6 o, & 08 c 3 t 1 e .6 o, & 08 c 4 t 1 e .6 o \\
08 c 2 t 4 e .6 o, & 08 c 3 t 4 e .6 o, & 08 c 4 t 4 e .6 o \\
08 c 2 t 7 e .6 o, & 08 c 3 t 7 e .6 o, & 08 c 4 t 7 e .6 o \\
08 c 2 t 1 c .6 o, & 08 c 3 t 1 c .6 o, & 08 c 4 t 1 c .6 o \\
08 c 2 t 4 c .6 o, & 08 c 3 t 4 c .6 o, & 08 c 4 t 4 c .6 o \\
08 c 2 t 7 c .6 o, & 08 c 3 t 7 c .6 o, & 08 c 4 t 7 c .6 o\end{array}$ \\
\hline
\end{tabular}


Table 6.9-7. EQ6 Input/Output Files for TSPA-LA Abstraction (Continued)

\begin{tabular}{|c|c|c|}
\hline Bin & Input File Names & Output File Names \\
\hline 9 & $\begin{array}{lll}09 c 2 t 1 e .6 i, & 09 c 3 t 1 e .6 i, & 09 c 4 t 1 e .6 i \\
09 c 2 t 4 e .6 i, & 09 c 3 t 4 e .6 i, & 09 c 4 t 4 e .6 i \\
09 c 2 t 7 e .6 i, & 09 c 3 t 7 e .6 i, & 09 c 4 t 7 e .6 i \\
09 c 2 t 1 c .6 i, & 09 c 3 t 1 c .6 i, & 09 c 4 t 1 c .6 i \\
\text { 09c2t4c.6i, } & 09 c 3 t 4 c .6 i, & 09 c 4 t 4 c .6 i \\
09 c 2 t 7 c .6 i, & 09 c 3 t 7 c .6 i, & 09 c 4 t 7 c .6 i\end{array}$ & $\begin{array}{lll}09 c 2 t 1 e .6 o, & 09 c 3 t 1 e .6 o, & 09 c 4 t 1 e .6 o \\
09 c 2 t 4 e .6 o, & 09 c 3 t 4 e .6 o, & 09 c 4 t 4 e .6 o \\
09 c 2 t 7 e .6 o, & 09 c 3 t 7 e .6 o, & 09 c 4 t 7 e .6 o \\
09 c 2 t 1 c .6 o, & 09 c 3 t 1 c .6 o, & 09 c 4 t 1 c .6 o \\
09 c 2 t 4 c .6 o, & 09 c 3 t 4 c .6 o, & 09 c 4 t 4 c .6 o \\
09 c 2 t 7 c .6 o, & 09 c 3 t 7 c .6 o, & 09 c 4 t 7 c .6 o\end{array}$ \\
\hline 10 & $\begin{array}{l}\text { 10c2t1e.6i, 10c3t1e.6i, 10c4t1e.6i, } \\
\text { 10c2t4e.6i, 10c3t4e.6i, 10c4t4e.6i, } \\
\text { 10c2t7e.6i, 10c3t7e.6i, 10c4t7e.6i, } \\
\text { 10c2t1c.6i, 10c3t1c.6i, 10c4t1c.6i, } \\
\text { 10c2t4c.6i, 10c3t4c.6i, 10c4t4c.6i, } \\
\text { 10c2t7c.6i, 10c3t7c.6i, 10c4t7c.6i }\end{array}$ & 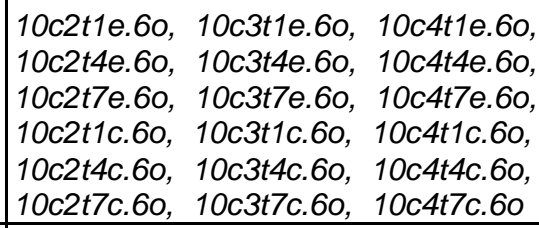 \\
\hline 11 & 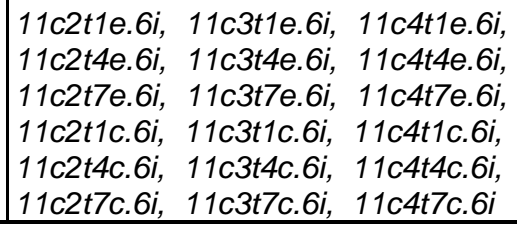 & 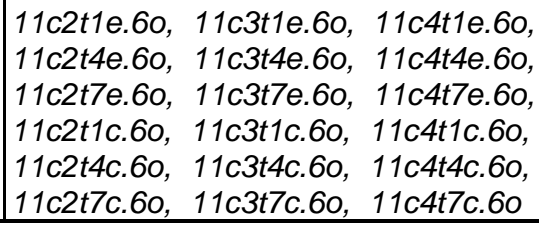 \\
\hline
\end{tabular}

Source: Output DTN: MO0304MWDEBSSA.000.

Table 6.9-8. Lookup Tables for TSPA-LA Abstraction

\begin{tabular}{|c|c|c|}
\hline Bin & Evaporation Lookup Tables & Dilution Lookup Tables \\
\hline 1 & 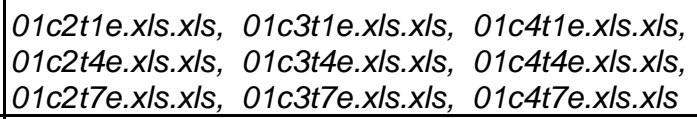 & 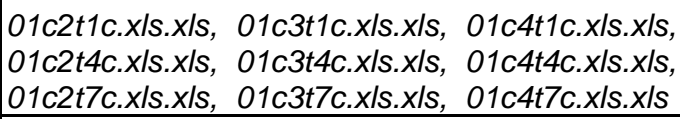 \\
\hline 2 & $\begin{array}{lll}02 c 2 t 1 e . x I s . x I s, & 02 c 3 t 1 e . x I s . x I s, & 02 c 4 t 1 e . x I s . x I s \\
02 c 2 t 4 e . x I s . x I s, & 02 c 3 t 4 e . x I s . x I s, & 02 c 4 t 4 e . x I s . x I s \\
02 c 2 t 7 e . x I s . x I s, & 02 c 3 t 7 e . x I s . x I s, & 02 c 4 t 7 e . x I s . x I s\end{array}$ & $\begin{array}{lll}02 c 2 t 1 c . x I s . x I s, & 02 c 3 t 1 c . x I s . x I s, & 02 c 4 t 1 c . x I s . x I s \\
02 c 2 t 4 c . x I s . x I s, & 02 c 3 t 4 c . x I s . x I s, & 02 c 4 t 4 c . x I s . x I s \\
02 c 2 t 7 c . x I s . x I s, & 02 c 3 t 7 c . x I s . x I s, & 02 c 4 t 7 c . x I s . x I s\end{array}$ \\
\hline 3 & $\begin{array}{lll}03 c 2 t 1 e . x I s . x I s, & 03 c 3 t 1 e . x I s . x I s, & 03 c 4 t 1 e . x I s . x I s \\
03 c 2 t 4 e . x I s . x I s, & 03 c 3 t 4 e . x I s . x I s, & 03 c 4 t 4 e . x I s . x I s \\
03 c 2 t 7 e . x I s . x I s, & 03 c 3 t 7 e . x I s . x I s, & 03 c 4 t 7 e . x I s . x I s\end{array}$ & $\begin{array}{lll}03 c 2 t 1 c . x I s . x I s, & 03 c 3 t 1 c . x I s . x I s, & 03 c 4 t 1 c . x I s . x I s \\
\text { 03c2t4c.xIs.xIs, } & 03 c 3 t 4 c . x I s . x I s, & 03 c 4 t 4 c . x I s . x I s, \\
03 c 2 t 7 c . x I s . x I s, & 03 c 3 t 7 c . x I s . x I s, & 03 c 4 t 7 c . x I s . x I s \\
\end{array}$ \\
\hline 4 & $\begin{array}{lll}04 c 2 t 1 e . x I s . x I s, & 04 c 3 t 1 e . x I s . x I s, & 04 c 4 t 1 e . x I s . x I s \\
04 c 2 t 4 e . x I s . x I s, & 04 c 3 t 4 e . x I s . x I s, & 04 c 4 t 4 e . x I s . x I s \\
04 c 2 t 7 e . x I s . x I s, & 04 c 3 t 7 e . x I s . x I s, & 04 c 4 t 7 e . x I s . x I s\end{array}$ & $\begin{array}{lll}04 c 2 t 1 c . x I s . x I s, & 04 c 3 t 1 c . x I s . x I s, & 04 c 4 t 1 c . x I s . x I s \\
04 c 2 t 4 c . x I s . x I s, & 04 c 3 t 4 c . x I s . x I s, & 04 c 4 t 4 c . x I s . x I s \\
04 c 2 t 7 c . x I s . x I s, & 04 c 3 t 7 c . x I s . x I s, & 04 c 4 t 7 c . x I s . x I s\end{array}$ \\
\hline 5 & $\begin{array}{lll}05 c 2 t 1 e . x I s . x I s, & 05 c 3 t 1 e . x I s . x I s, & 05 c 4 t 1 e . x I s . x I s \\
05 c 2 t 4 e . x I s . x I s, & 05 c 3 t 4 e . x I s . x I s, & 05 c 4 t 4 e . x I s . x I s \\
05 c 2 t 7 e . x I s . x I s, & 05 c 3 t 7 e . x I s . x I s, & 05 c 4 t 7 e . x I s . x I s\end{array}$ & 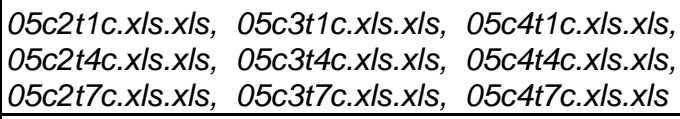 \\
\hline 6 & $\begin{array}{lll}06 c 2 t 1 e . x I s . x I s, & 06 c 3 t 1 e . x I s . x I s, & 06 c 4 t 1 e . x I s . x I s \\
06 c 2 t 4 e . x I s . x I s, & 06 c 3 t 4 e . x I s . x I s, & 06 c 4 t 4 e . x I s . x I s \\
06 c 2 t 7 e . x I s . x I s, & 06 c 3 t 7 e . x I s . x I s, & 06 c 4 t 7 e . x I s . x I s\end{array}$ & $\begin{array}{lll}06 c 2 t 1 c . x I s . x I s, & 06 c 3 t 1 c . x I s . x I s, & 06 c 4 t 1 c . x I s . x I s \\
06 c 2 t 4 c . x I s . x I s, & 06 c 3 t 4 c . x I s . x I s, & 06 c 4 t 4 c . x I s . x I s \\
06 c 2 t 7 c . x I s . x I s, & 06 c 3 t 7 c . x I s . x I s, & 06 c 4 t 7 c . x I s . x I s\end{array}$ \\
\hline 7 & $\begin{array}{lll}\text { 07c2t1e.xls.xIs, } 07 c 3 t 1 e . x I s . x I s, & 07 c 4 t 1 e . x I s . x I s \\
07 c 2 t 4 e . x I s . x I s, & 07 c 3 t 4 e . x I s . x I s, & 07 c 4 t 4 e . x I s . x I s \\
07 c 2 t 7 e . x I s . x I s, & 07 c 3 t 7 e . x I s . x I s, & 07 c 4 t 7 e . x I s . x I s\end{array}$ & 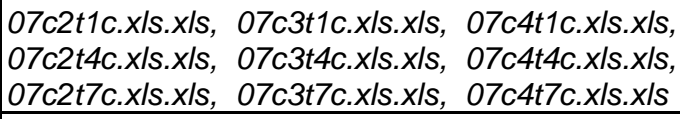 \\
\hline 8 & $\begin{array}{lll}08 c 2 t 1 e . x I s . x I s, & 08 c 3 t 1 e . x I s . x I s, & 08 c 4 t 1 e . x I s . x I s \\
08 c 2 t 4 e . x I s . x I s, & 08 c 3 t 4 e . x I s . x I s, & 08 c 4 t 4 e . x I s . x I s \\
08 c 2 t 7 e . x I s . x I s, & 08 c 3 t 7 e . x I s . x I s, & 08 c 4 t 7 e . x I s . x I s\end{array}$ & 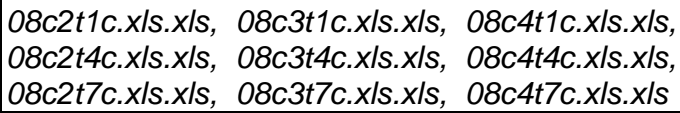 \\
\hline
\end{tabular}


Table 6.9-8. Lookup Tables for TSPA-LA Abstraction (Continued)

\begin{tabular}{|c|c|c|}
\hline Bin & Evaporation Lookup Tables & Dilution Lookup Tables \\
\hline 9 & $\begin{array}{l}\text { 09c2t1e.xls.xIs, 09c3t1e.xls.xIs, 09c4t1e.xIs.xIs, } \\
\text { 09c2t4e.xIs.xIs, 09c3t4e.xIs.xIs, 09c4t4e.xIs.xIs, } \\
\text { 09c2t7e.xIs.xIs, 09c3t7e.xIs.xIs, 09c4t7e.xIs.xIs }\end{array}$ & 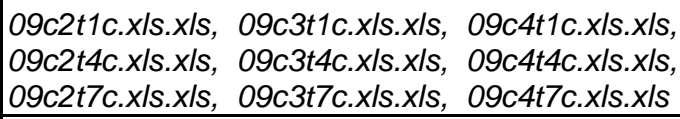 \\
\hline 10 & $\begin{array}{l}\text { 10c2t1e.xIs.xIs, 10c3t1e.xls.xIs, 10c4t1e.xIs.xIs, } \\
\text { 10c2t4e.xls.xIs, 10c3t4e.xls.xIs, 10c4t4e.xIs.xIs, } \\
\text { 10c2t7e.xls.xIs, 10c3t7e.xIs.xIs, 10c4t7e.xIs.xIs }\end{array}$ & 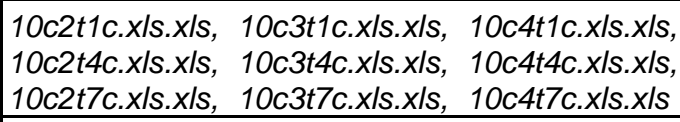 \\
\hline 11 & $\begin{array}{l}11 c 2 t 1 e . x I s . x I s, 11 c 3 t 1 e . x I s . x I s, 11 c 4 t 1 e . x I s . x I s \\
11 c 2 t 4 e . x I s . x I s, 11 c 3 t 4 e . x I s . x I s, 11 c 4 t 4 e . x I s . x I s \\
11 c 2 t 7 e . x I s . x I s, 11 c 3 t 7 e . x I s . x I s, 11 c 4 t 7 e . x I s . x I s\end{array}$ & 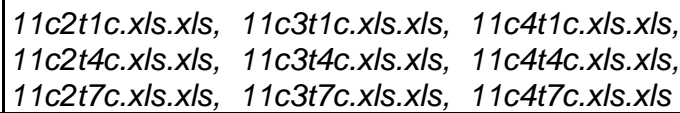 \\
\hline
\end{tabular}

Source: Output DTN: MO0304SPACSALT.000.

NOTE: $\quad$ TSPA-LA modelers should use DTN: MO0310SPAPCEGS.000 as the source for the lookup tables as discussed in Section 8.2.1. The filenames in DTN: MO0310SPAPCEGS.000 do not carry the extra ".xls."

The values in the lookup tables may be used to define response surfaces so that interpolations and extrapolations $\left(\mathrm{pCO}_{2}\right.$ parameter only; Section 6.12.4.3) may be obtained for more precise input values not provided in the tables. Table 6.9-9 displays the maximum equilibrium relative humidity value in the evaporation lookup table for a given boundary condition at or below which the information remains valid. If the equilibrium relative humidity used for crown seepage exceeds this maximum value, then the corresponding dilution lookup table is used instead.

Table 6.9-9. Relative Humidity Boundaries Between Evaporation and Dilution Lookup Tables

\begin{tabular}{|c|c|c|c|c|c|c|c|c|c|}
\hline \multirow[b]{2}{*}{ Bin } & \multicolumn{3}{|c|}{$10^{-2} \mathrm{pCO}_{2}$ (bar) } & \multicolumn{3}{|c|}{$10^{-3} \mathrm{pCO}_{2}$ (bar) } & \multicolumn{3}{|c|}{$10^{-4} \mathrm{pCO}_{2}$ (bar) } \\
\hline & $40^{\circ} \mathrm{C}$ & $70^{\circ} \mathrm{C}$ & $100^{\circ} \mathrm{C}$ & $40^{\circ} \mathrm{C}$ & $70^{\circ} \mathrm{C}$ & $100^{\circ} \mathrm{C}$ & $40^{\circ} \mathrm{C}$ & $70^{\circ} \mathrm{C}$ & $100^{\circ} \mathrm{C}$ \\
\hline 1 & $99.916 \%$ & $99.915 \%$ & $99.921 \%$ & $99.917 \%$ & $99.915 \%$ & $99.921 \%$ & $99.917 \%$ & $99.915 \%$ & $99.921 \%$ \\
\hline 2 & $99.962 \%$ & $99.960 \%$ & $99.957 \%$ & $99.963 \%$ & $99.961 \%$ & $99.958 \%$ & $99.963 \%$ & $99.960 \%$ & $99.957 \%$ \\
\hline 3 & $99.975 \%$ & $99.973 \%$ & $99.969 \%$ & $99.976 \%$ & $99.973 \%$ & $99.970 \%$ & $99.976 \%$ & $99.973 \%$ & $99.970 \%$ \\
\hline 4 & $99.985 \%$ & $99.982 \%$ & $99.978 \%$ & $99.985 \%$ & $99.983 \%$ & $99.979 \%$ & $99.986 \%$ & $99.982 \%$ & $99.978 \%$ \\
\hline 5 & $99.970 \%$ & $99.967 \%$ & $99.964 \%$ & $99.971 \%$ & $99.968 \%$ & $99.965 \%$ & $99.971 \%$ & $99.968 \%$ & $99.964 \%$ \\
\hline 6 & $99.964 \%$ & $99.965 \%$ & $99.966 \%$ & $99.966 \%$ & $99.967 \%$ & $99.968 \%$ & $99.968 \%$ & $99.969 \%$ & $99.969 \%$ \\
\hline 7 & $99.962 \%$ & $99.964 \%$ & $99.966 \%$ & $99.965 \%$ & $99.966 \%$ & $99.967 \%$ & $99.967 \%$ & $99.968 \%$ & $99.968 \%$ \\
\hline 8 & $99.969 \%$ & $99.971 \%$ & $99.971 \%$ & $99.971 \%$ & $99.972 \%$ & $99.973 \%$ & $99.974 \%$ & $99.975 \%$ & $99.974 \%$ \\
\hline 9 & $99.977 \%$ & $99.975 \%$ & $99.976 \%$ & $99.978 \%$ & $99.977 \%$ & $99.978 \%$ & $99.978 \%$ & $99.979 \%$ & $99.979 \%$ \\
\hline 10 & $99.969 \%$ & $99.970 \%$ & $99.971 \%$ & $99.971 \%$ & $99.972 \%$ & $99.973 \%$ & $99.974 \%$ & $99.975 \%$ & $99.975 \%$ \\
\hline 11 & $99.976 \%$ & $99.973 \%$ & $99.969 \%$ & $99.976 \%$ & $99.973 \%$ & $99.970 \%$ & $99.976 \%$ & $99.973 \%$ & $99.969 \%$ \\
\hline
\end{tabular}

Source: Output DTN: MO0304SPACSALT.000, RH MAP.xIs, tab "Sheet 1." 


\subsubsection{Illustration of Results}

Figures 6.9-2 through 6.9-7 graphically illustrate the results with plots of values from the 11c3t7e.xls.xls lookup table. These are Bin 11 evaporation results at a temperature of $70^{\circ} \mathrm{C}$ and a $\mathrm{pCO}_{2}$ of $10^{-3}$ bar. Figures 6.9-2 and 6.9-3 plot the total elemental aqueous concentrations and $\mathrm{pH}$ as a function of relative humidity and concentration factor. Figures 6.9-4 and 6.9-5 plot the acid neutralizing capacity (ANC) (ANC in this case represents those species that contribute to or influence the $\mathrm{pH}$ ) aqueous species concentrations and $\mathrm{pH}$ as a function of relative humidity and concentration factor. Figures 6.9-6 and 6.9-7 plot pH, the fixed $\mathrm{CO}_{2}$ and $\mathrm{O}_{2}$ pressures, and the moles of minerals precipitated from one kilogram of incoming water as a function of relative humidity and concentration factor.

Results of the corresponding dilution lookup table (11c3t7c.xls.xls) are displayed in Figures 6.9-8 through 6.9-11. The first two figures show plots of the total elemental aqueous concentrations and $\mathrm{pH}$ as a function of relative humidity and dilution factor. The last two plot the ANC aqueous species concentrations and $\mathrm{pH}$ as a function of relative humidity and dilution factor. The results from the remainder of the lookup tables are provided in Appendix B.

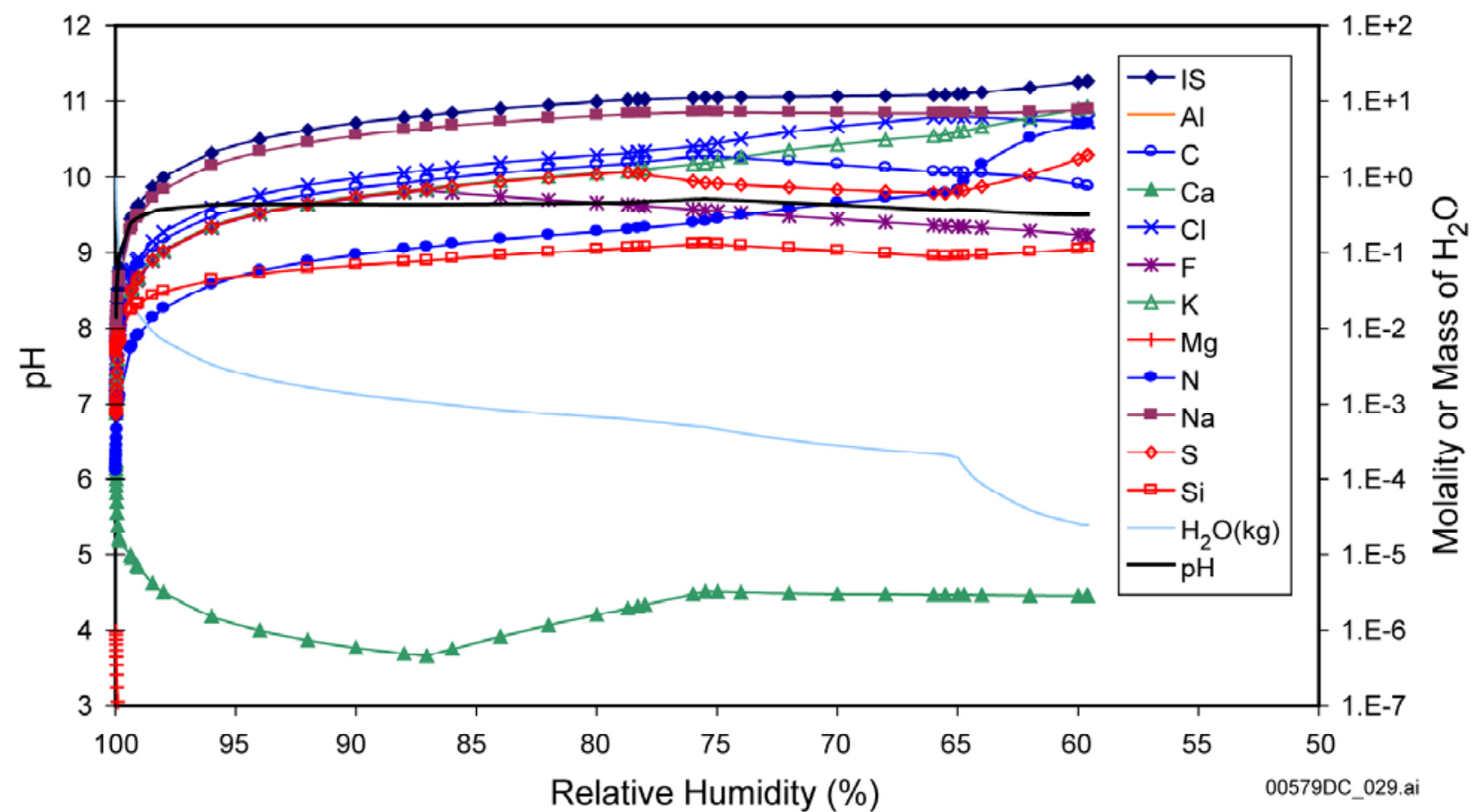

Source: Output DTN: MO0304SPACSALT.000.

NOTE: $\quad$ IS = ionic strength.

Figure 6.9-2. Predicted Compositional Evolution During Evaporation of Bin 11 Waters at $70^{\circ} \mathrm{C}$ and $\mathrm{pCO}_{2} 10^{-3}$ bar, versus Relative Humidity 


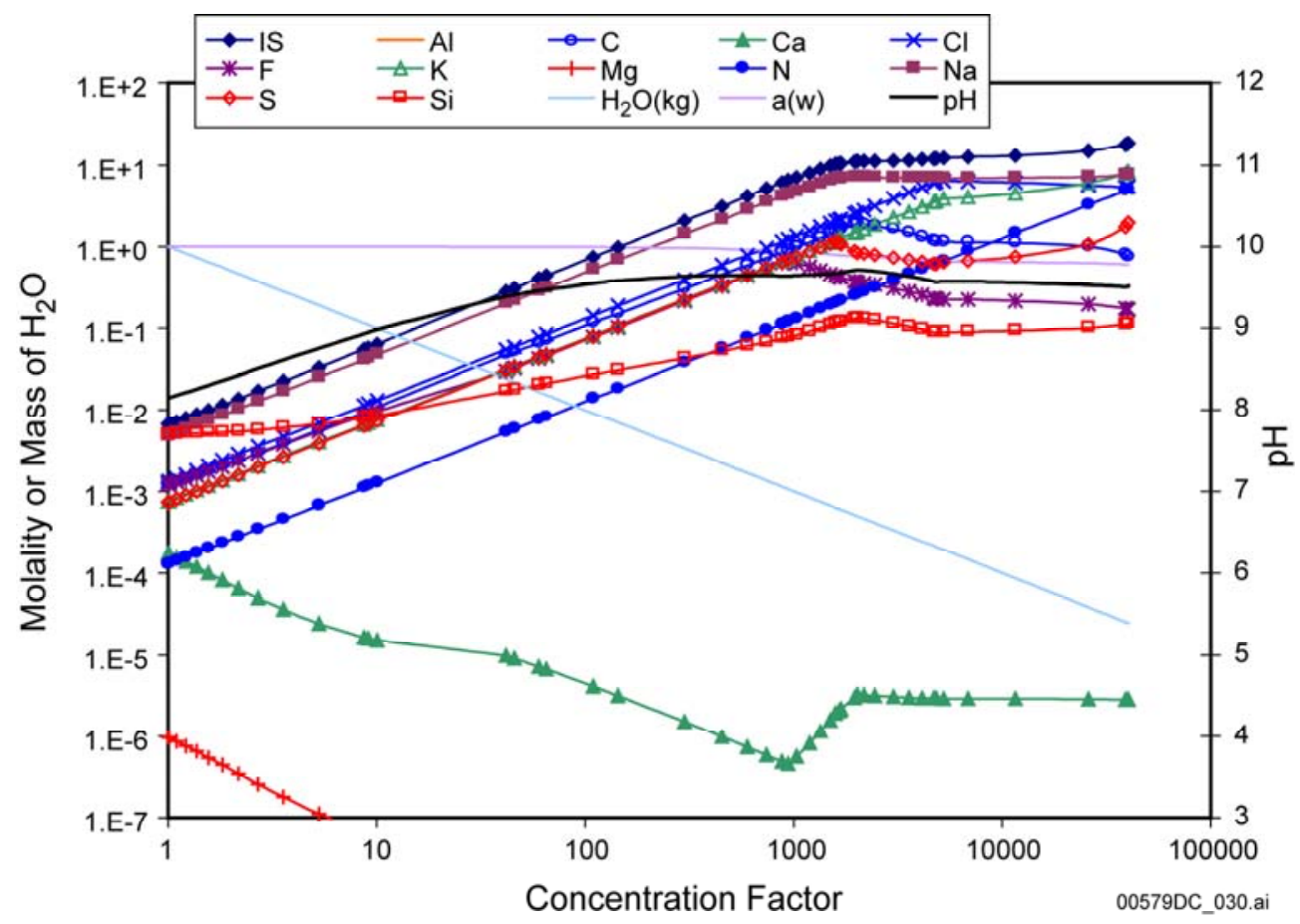

Source: Output DTN: MO0304SPACSALT.000.

Figure 6.9-3. Predicted Compositional Evolution During Evaporation of Bin 11 Waters at $70^{\circ} \mathrm{C}$ and $\mathrm{pCO}_{2} 10^{-3}$ bar, versus Concentration Factor

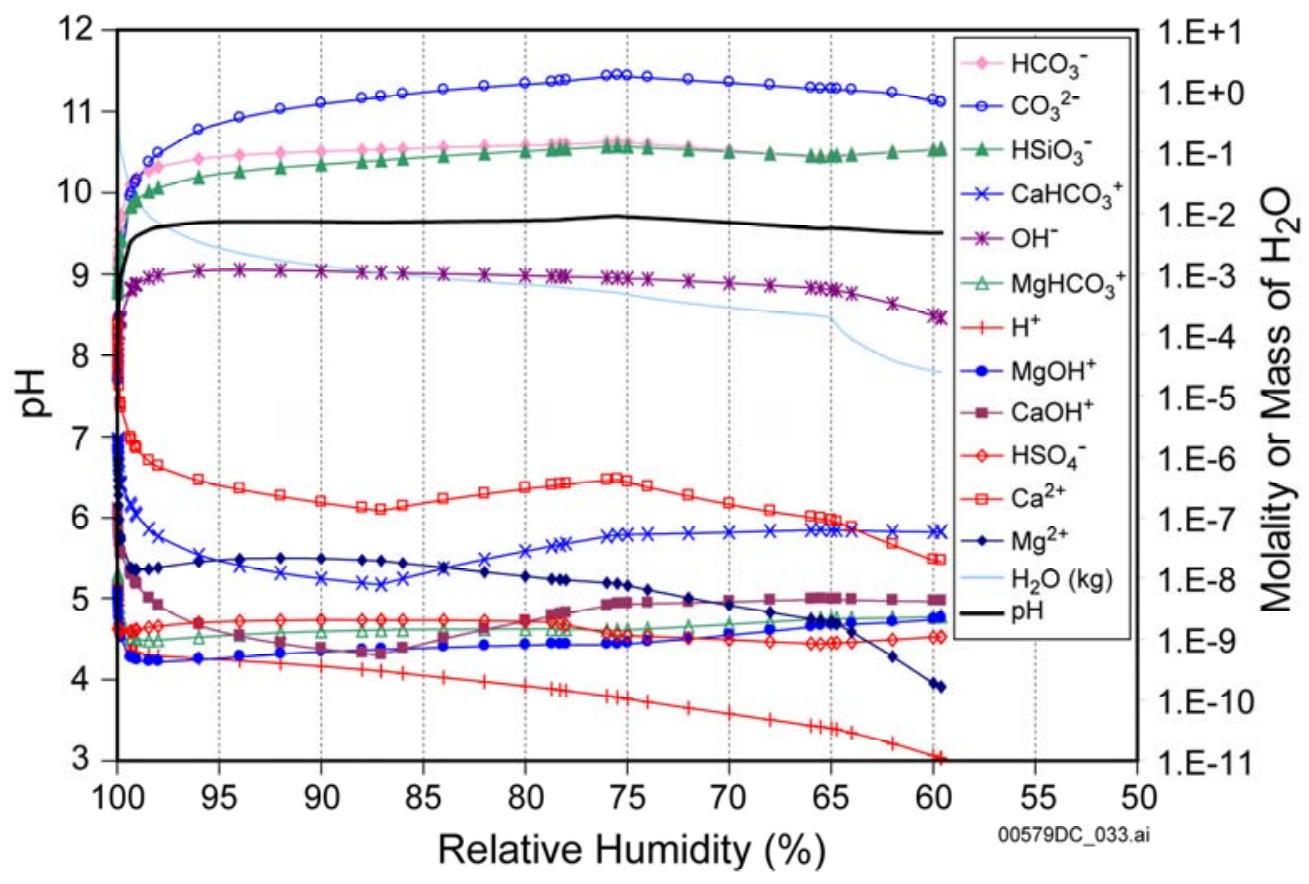

Source: Output DTN: MO0304SPACSALT.000.

Figure 6.9-4. Predicted Concentrations of ANC Species during Evaporative Evolution of Bin 11 Waters at $70^{\circ} \mathrm{C}$ and $p \mathrm{CO}_{2} 10^{-3}$ bar, versus Relative Humidity 


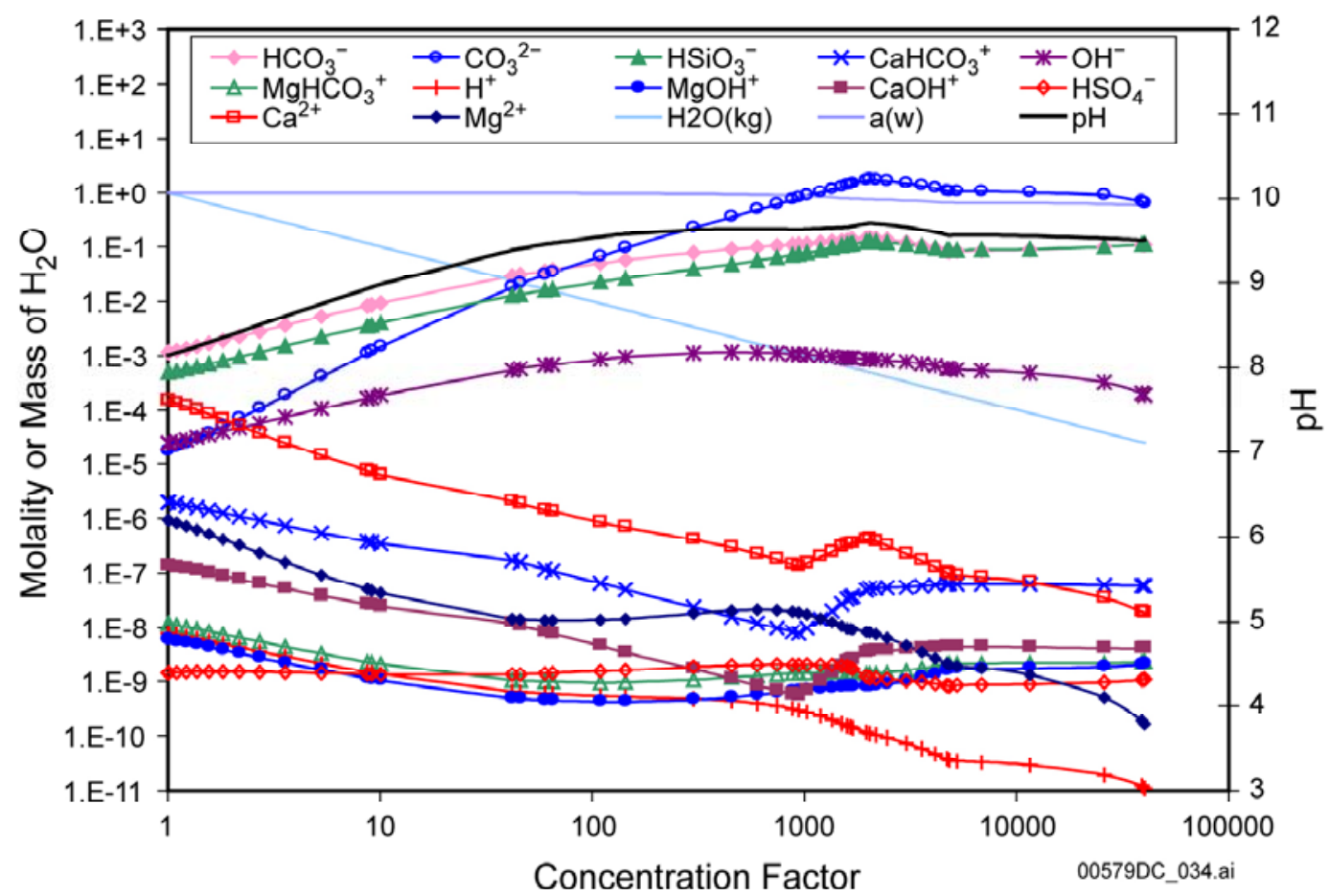

Source: Output DTN: MO0304SPACSALT.000.

Figure 6.9-5. Predicted Concentrations of ANC Species during Evaporative Evolution of Bin 11 Waters at $70^{\circ} \mathrm{C}$ and $p \mathrm{CO}_{2} 10^{-3}$ bar, versus Concentration Factor

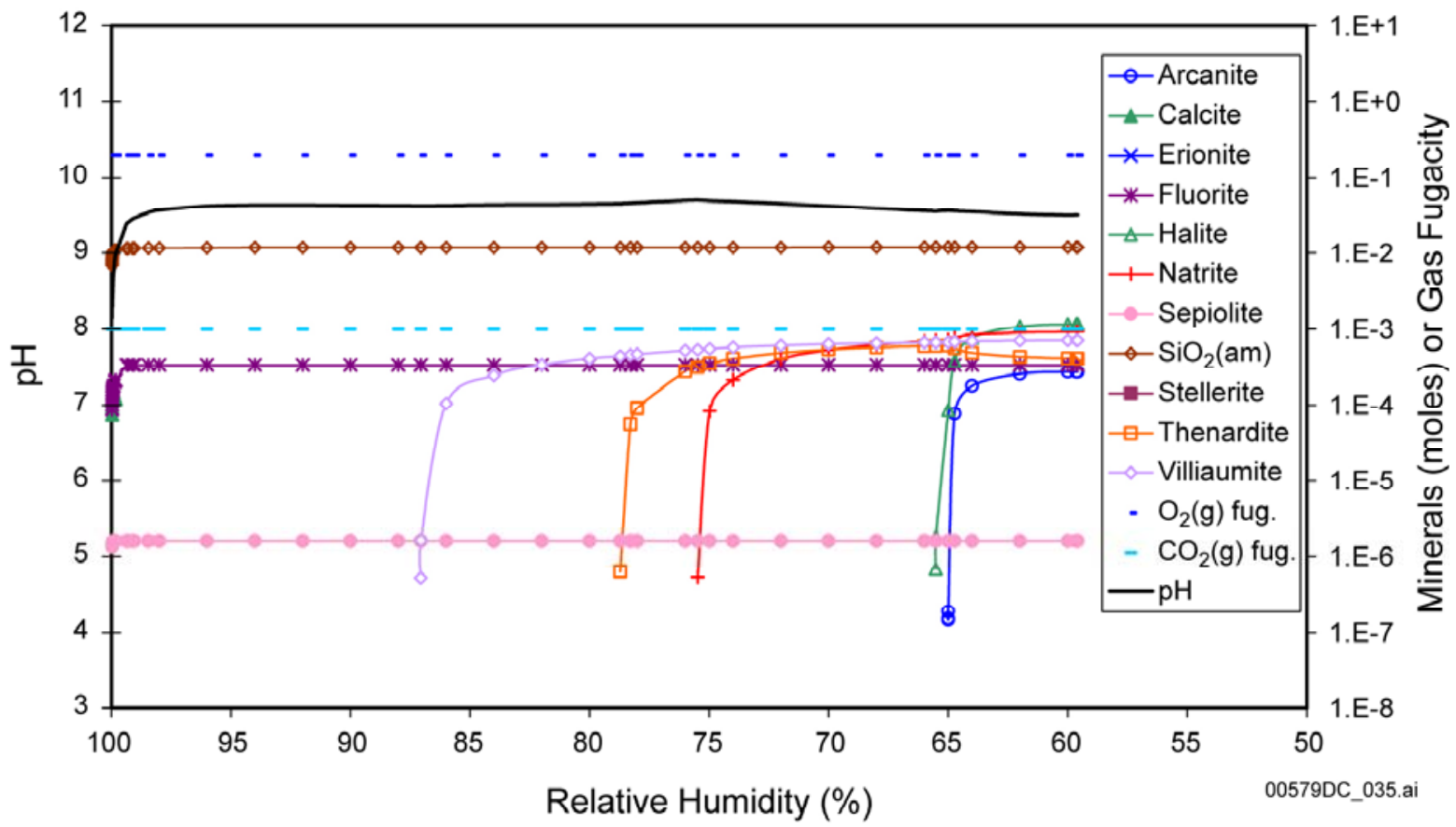

Source: Output DTN: MO0304SPACSALT.000.

Figure 6.9-6. Predicted Mineral Precipitation as Bin 11 Waters Evaporate at $70^{\circ} \mathrm{C}$ and $p \mathrm{CO}_{2} 10^{-3}$ bar, versus Relative Humidity 


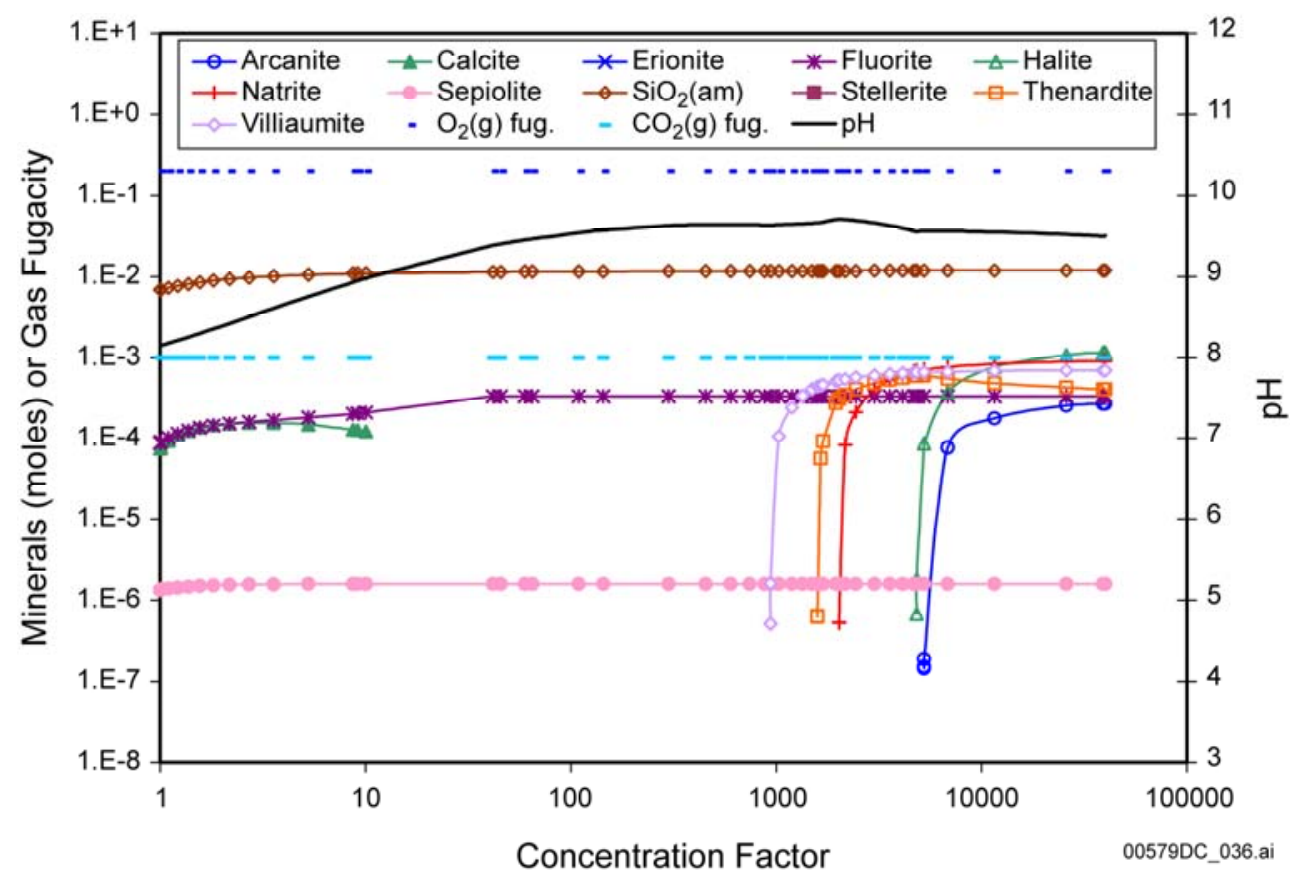

Source: Output DTN: MO0304SPACSALT.000.

Figure 6.9-7. Predicted Mineral Precipitation as Bin 11 Waters Evaporate at $70^{\circ} \mathrm{C}$ and $p \mathrm{CO}_{2} 10^{-3}$ bar, versus Concentration Factor

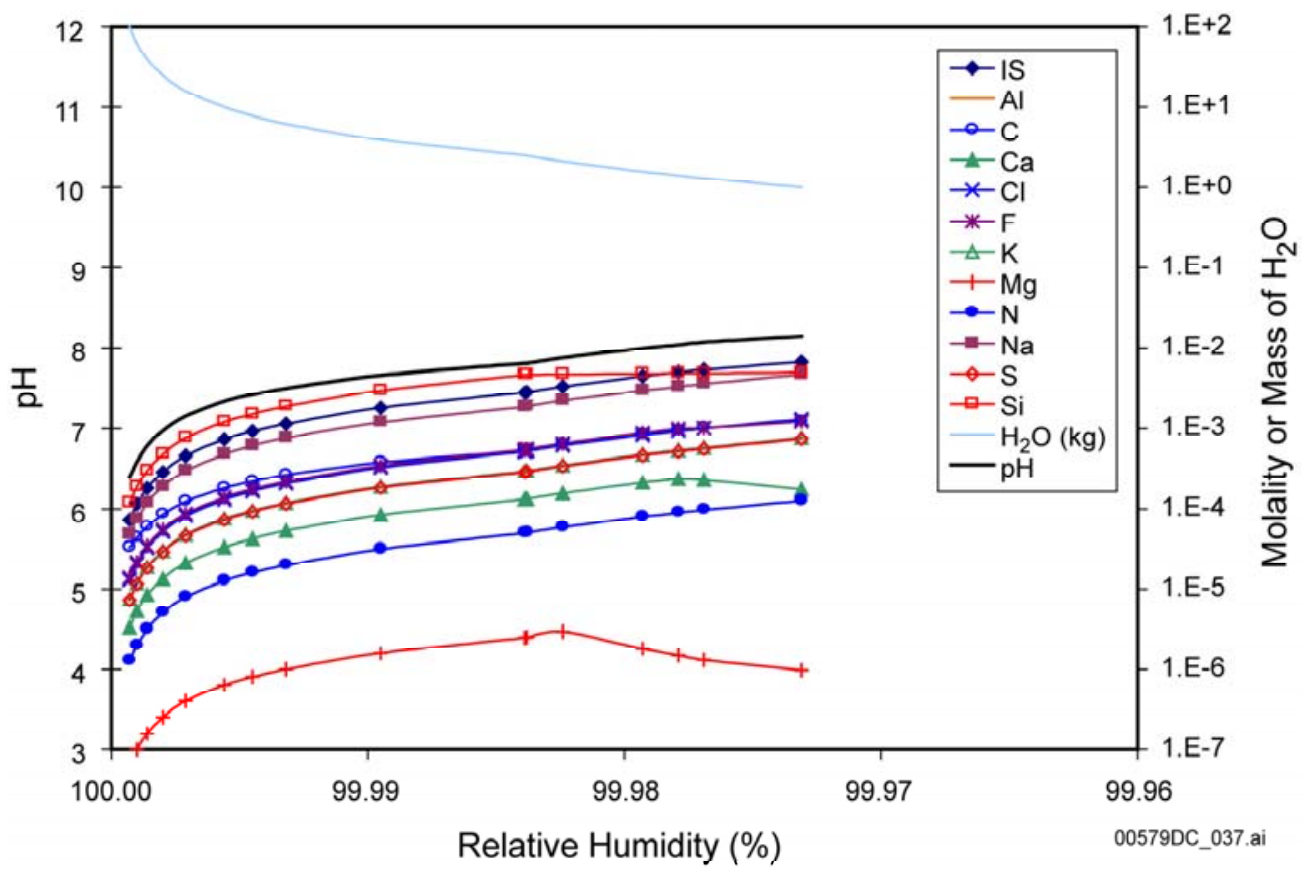

Source: Output DTN: MO0304SPACSALT.000.

NOTE: IS = ionic strength.

Figure 6.9-8. Predicted Compositional Evolution as Bin 11 Waters Are Diluted at $70^{\circ} \mathrm{C}$ and $\mathrm{pCO}_{2} 10^{-3}$ bar, versus Relative Humidity 


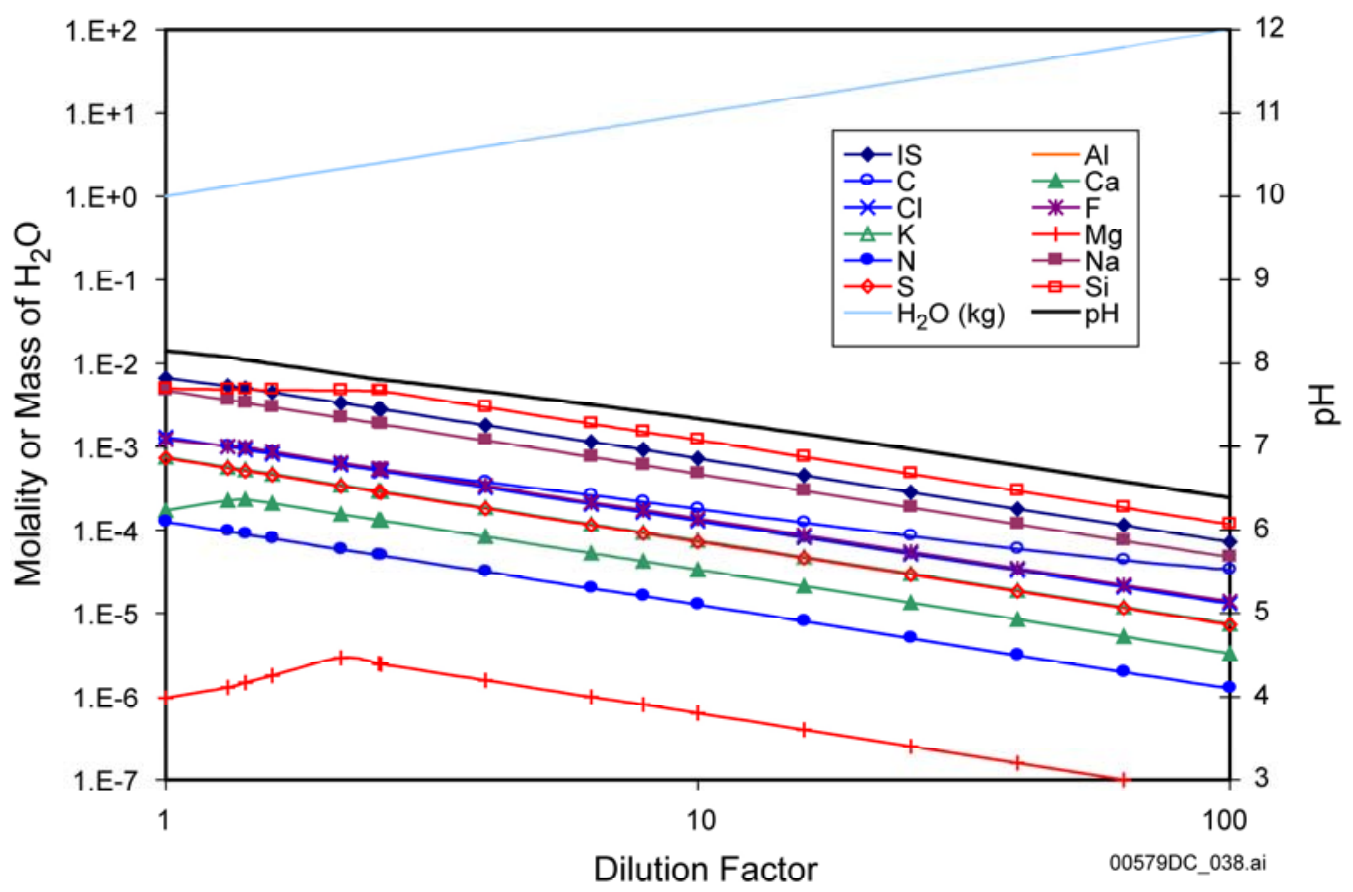

Source: Output DTN: MO0304SPACSALT.000.

Figure 6.9-9. Predicted Compositional Evolution as Bin 11 Waters Are Diluted at $70^{\circ} \mathrm{C}$ and $\mathrm{pCO}_{2} 10^{-3}$ bar, versus Dilution Factor

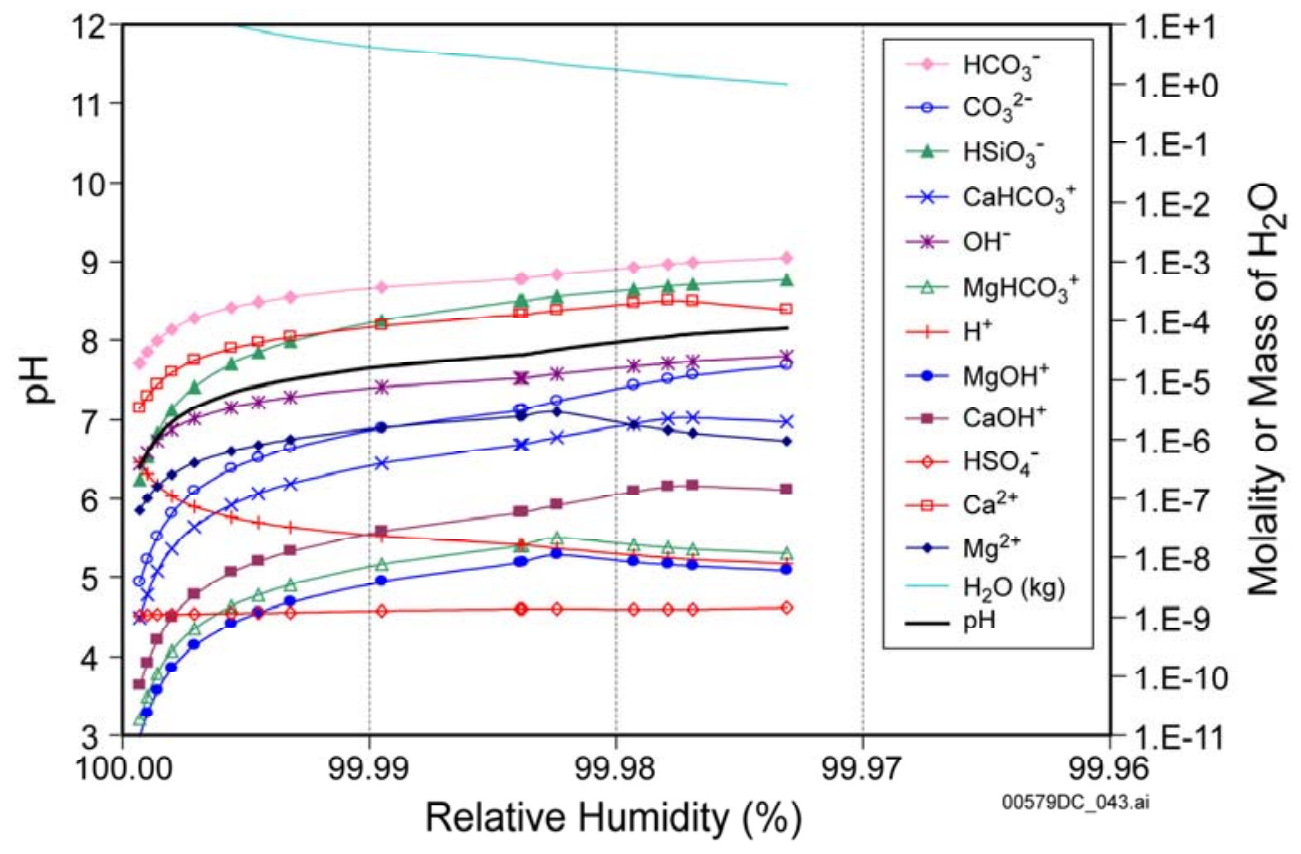

Source: Output DTN: MO0304SPACSALT.000.

Figure 6.9-10. Predicted Concentrations of ANC Species during Dilution of Bin 11 Waters at $70^{\circ} \mathrm{C}$ and $\mathrm{pCO}_{2} 10^{-3}$ bar, versus Relative Humidity 


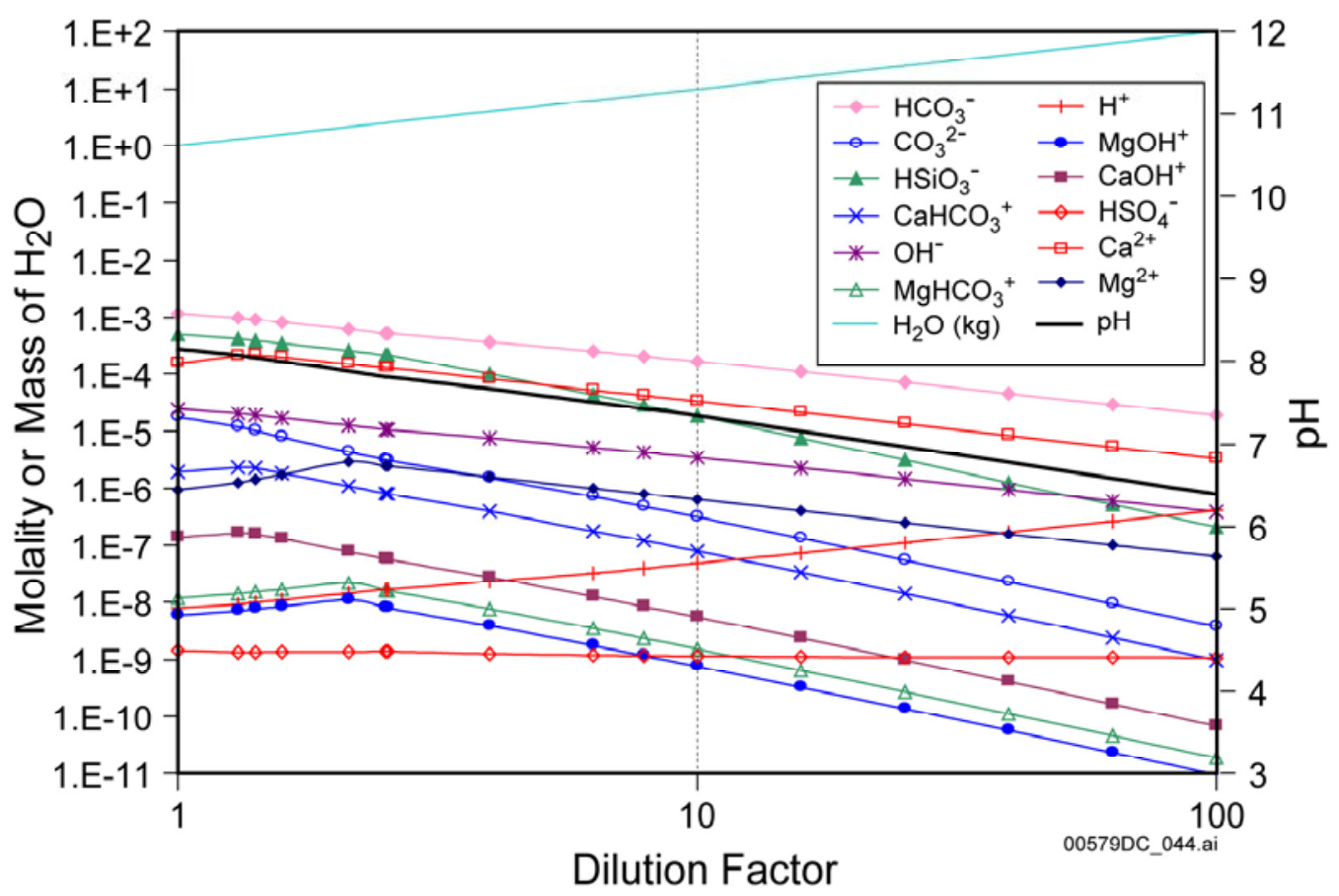

Source: Output DTN: MO0304SPACSALT.000.

Figure 6.9-11. Predicted Concentrations of ANC Species during Dilution of Bin 11 Waters at $70^{\circ} \mathrm{C}$ and $\mathrm{pCO}_{2} 10^{-3}$ bar, versus Dilution Factor

\subsection{EVALUATION OF DUST DEPOSITED ON WASTE PACKAGES}

The following is a summary of the report Analysis of Dust Deliquescence for FEP Screening (BSC 2005 [DIRS 175058]). This brief summary describes the general conclusions of the dust screening analysis that has led to the decision to screen out localized corrosion caused by deliquescence of dust (BSC 2005 [DIRS 175058], Section 7.1.5). The reader is referred to the source document for additional information.

Small amounts of dust will be deposited on the surfaces of waste packages in drifts at Yucca Mountain during the operational and the preclosure ventilation periods. Salts present in the dust will deliquesce as the waste packages cool and relative humidity in the drifts increases. The report (BSC 2005 [DIRS 175058], Sections 6.4 and 6.5) evaluates the potential for brines formed by dust deliquescence to initiate and sustain localized corrosion that results in failure of the waste package outer barrier and early failure of the waste package. These arguments have been used to show that dust deliquescence-induced localized or crevice corrosion of the waste package outer barrier (Alloy 22) is of low consequence with respect to repository performance (BSC 2005 [DIRS 175058], Section 1.1).

Measured atmospheric and underground dust compositions are the basis of thermodynamic modeling and experimental studies to evaluate the likelihood of brine formation and persistence, the volume of brines that may form, and the relative corrosivity of the initial deliquescent brines and of brines modified by processes on the waste package surface (BSC 2005 [DIRS 175058], 
Sections 6.1 and 6.2). In addition, the report (BSC 2005 [DIRS 175058], Section 6.5) evaluates several mechanisms that could inhibit or stifle localized corrosion should it initiate.

The dust compositions considered include both tunnel dust samples from Yucca Mountain, National Airfall Deposition Program rainout data, and other literature information on atmospheric aerosols (BSC 2005 [DIRS 175058], Sections 6.1.1 through 6.1.3). Included for consideration is the decomposition of ammonium salts, a process that could affect dust composition prior to deliquescence. Ammonium chlorides, nitrates, and even sulfates decompose readily into ammonia and acid gasses, and will be lost from the surface of the waste package prior to deliquescence (BSC 2005 [DIRS 175058], Section 6.1.2.3).

Arguments are developed using a logic-tree approach, based upon that presented by Apted et al. (2005 [DIRS 172858]) evaluating the potential importance of localized corrosion by high-temperature deliquescent brines. Expanding on this approach, Analysis of Dust Deliquescence for FEP Screening (BSC 2005 [DIRS 175058]) considers a wider range of dust and brine compositions, conditions, and arguments. In order for dust deliquescence to cause failure of the waste package, each of the following propositions must be affirmative (BSC 2005 [DIRS 175058], Section 7.1):

1) Can multiple-salt deliquescent brines form at elevated temperature? Yes. Some important salt phases in the dust (e.g., ammonium salts) will decompose into gaseous components prior to deliquescence. However, other salts in the dust are stable, and form eutectic assemblages that can deliquesce at temperatures much higher than the individual salt components. For most single-salt phases (nitrates, chlorides, and carbonates) boiling points at one atmosphere are limited to temperatures below $120^{\circ} \mathrm{C}$-boiling points of saturated salt solutions represent the maximum temperature of deliquescence at a given pressure. Multi-salt mixtures always boil at higher temperatures than the individual salt components. The boiling points for important salt assemblages predicted to occur on the waste package surface have been investigated experimentally. The two-salt mixture $\mathrm{NaCl}+\mathrm{KNO}_{3}$ boils at a maximum temperature of $134^{\circ} \mathrm{C}$ and the three-salt mixture, $\mathrm{NaCl}+\mathrm{KNO}_{3}+\mathrm{NaNO}_{3}$, at over $190^{\circ} \mathrm{C}$. By inference, the four-salt mixture, $\mathrm{NaCl}+\mathrm{KNO}_{3}+\mathrm{NaNO}_{3}+\mathrm{Ca}\left(\mathrm{NO}_{3}\right)_{2}$, must also deliquesce at temperatures above $190^{\circ} \mathrm{C}$.

2) If brines form at elevated temperature, will they persist? Sometimes. Brines on the waste package surface will degas acid phases- $\mathrm{HCl}$ and $\mathrm{HNO}_{3}$ - which can result in precipitation of less deliquescent salts and dryout. High-temperature calcium and magnesium chloride brines degas rapidly and dry out, precipitating non-deliquescent hydroxide-chloride phases. All predicted deliquescent brine compositions are unstable in the drift environment and will degas acid phases, leading to an increase in $\mathrm{pH}$, increases in the $\mathrm{NO}_{3}{ }^{-} / \mathrm{Cl}^{-}$ratio, precipitation of less deliquescent salts, and, if sufficient degassing occurs, resulting in dryout. Reactions with low-solubility minerals in the dust (silicates, sulfates) may also lead to dryout, by modifying cation concentrations in the brine (specifically, divalent cations are removed) and changing the deliquescent salt assemblage. However, for most brines, kinetics of acid degassing and mineral reactions are slow, and dryout is unlikely. 
3) If deliquescent brines persist, are they corrosive? No. Brines that form at elevated temperature by dust deliquescence are near-neutral to alkaline $\mathrm{pH}$, nitrate-rich and chloride-poor, and are therefore benign with respect to initiation of localized corrosion. Based on thermodynamic principles, brines that form beyond the temperature limits of available thermodynamic models are constrained to be even more nitrate-rich. New, higher-temperature data indicate that general corrosion mechanisms do not change up to temperatures of $220^{\circ} \mathrm{C}$, suggesting that nitrate inhibition of localized corrosion may continue to be effective at elevated temperatures. Processes occurring after deliquescence, including acid degassing and reactions with silicate minerals, do not result in corrosive brines. Acid degassing has beneficial effects, increasing the $\mathrm{NO}_{3}{ }^{-} / \mathrm{Cl}^{-}$ratio of the remaining solution, and even small degrees of degassing will result in increases in the brine $\mathrm{pH}$, to values ranging from near-neutral to alkaline. Brine interactions with silicate minerals may also buffer the $\mathrm{pH}$ to near-neutral or slightly alkaline values, and may lead to dryout by precipitation of a less deliquescent salt assemblage.

4) If deliquescent brines are potentially corrosive, will they initiate localized corrosion? No. Potential dust deposition on waste packages in the drift has been quantified, and brines generated by dust deliquescence will be limited in volume. Physical isolation of salt minerals in the dust may inhibit formation of eutectic brines, further decreasing deliquescent brine volumes. Capillary and surface tension effects in the dust are likely to reduce surface contact or inhibit brine flow into pores or crevices. Characterization of dust porosity indicates that a typical dimension of about one micron characterizes the capillary response of the dust. This dimension suggests that brine flow through the dust will be inhibited and that pores or crevices on the metal surface would have to have similar dimension in order to compete successfully for the brine. Also, predicted deliquescent brine volumes, represented as layer thicknesses or droplets on the waste package, are too small to support differences in $\mathrm{O}_{2}$ concentration required to develop the separate anodic and cathodic zones required for initiation of localized corrosion.

5) Once initiated, will localized corrosion penetrate the waste package outer barrier? No. The process of crevice corrosion requires that water be consumed by redox reactions in both the anodic and cathodic regions of the corrosion cell. As corrosion products accumulate in the cell, cathodic limitation will occur from decreased availability of reaction sites where secondary products precipitate, and potentially from decreased availability of oxygen and water if the required transport pathways are restricted. As with many other materials, localized or crevice corrosion penetration of Alloy 22 is best described by a power rate law. Laboratory data clearly show that stifling of crevice corrosion in Alloy 22 occurs. In addition, physical sequestration of brine in the porous corrosion products will inhibit further corrosion. Given the small volumes of brine involved, corrosion products would have to be nearly nonporous not to volumetrically deplete the brine by capillary retention. Finally, the consumption of brine components, especially chloride, by incorporation into corrosion products, may decrease brine corrosivity or lead to brine dryout.

The arguments presented in Analysis of Dust Deliquescence for FEP Screening (BSC 2005 [DIRS 175058]) show that brines formed by deliquescence of tunnel and atmospheric dust compositions are chemically benign with respect to corrosion. Processes that act to modify them 
on the waste package surface are beneficial with respect to corrosivity. Should corrosive brines form, scale factors related to brine volume will inhibit initiation of localized corrosion. Finally, should corrosion initiate, several processes will act to limit or stifle it before waste package breach.

\subsection{ALTERNATIVE CONCEPTUAL MODEL}

Within the P\&CE model, submodels are discussed and developed; these models are the seepage evaporation abstraction and gas abstraction. One alternative conceptual model is investigated for the seepage binning analysis, as discussed in the following subsection. No alternative conceptual model for the gas abstraction model is presented in this document and is not necessary for the following reason:

- In-Drift Gas - The in-drift gas abstraction is consistent with the chemistry of the incoming seepage compositions as provided by Drift-Scale THC Seepage Model (BSC 2005 [DIRS 172862]); for a discussion of alternative models of THC processes, see Section 6.3 of that report. Analyses have shown that the repository is likely to remain an oxygen-rich environment throughout the repository lifetime (see Section 6.7.1 of the current report).

\subsubsection{Alternative Binning Analysis of Evaporated Seepage Waters}

This alternative model discusses the reduction of THC seepage waters based on clustering the waters by their identity and amount of precipitated carbonates, chlorides, nitrates, and sulfates present upon evaporation to dryness, rather than binning by aqueous elemental concentrations. This is a purely statistical analysis upon which the conclusions are based; no direct comparisons are made between the chemistries and populations of the binning analysis to this alternative methodology. Conclusions are based upon how well each method lowers the chemical uncertainty.

Results of the alternative conceptual model are summarized in Section 6.11.1.2. The effectiveness of each approach was evaluated using the standard deviation as a percent of the mean (the coefficient of variation) for each bin. The mean value of the coefficient of variation is lower for the aqueous binning case for $\mathrm{pH}$ and for the five solutes $\mathrm{Ca}^{2+}, \mathrm{F}^{-}, \mathrm{NO}_{3}{ }^{-}, \mathrm{SO}_{4}{ }^{-}$, and $\mathrm{SiO}_{2}$, and is lower for the mineral clustering for the six solutes $\mathrm{AlO}_{2}{ }^{-}, \mathrm{CO}_{3}{ }^{2-}, \mathrm{Cl}^{-}, \mathrm{K}^{+}, \mathrm{Mg}^{2+}$, and $\mathrm{Na}^{+}$.

However, $\mathrm{pH}, \mathrm{Ca}^{2+}, \mathrm{NO}_{3}{ }^{-}$, and $\mathrm{Cl}^{-}$are of primary importance when evaluating and determining corrosive properties and corrosion rates for the TSPA-LA. Aqueous binning gives a lower uncertainty (mean coefficient of variation) for all of these except $\mathrm{Cl}^{-}$. Furthermore, the mean coefficient of variation for $\mathrm{Cl}^{-}$in aqueous binning is only $0.24 \%$ higher than for mineral clustering (Table 6.11-7). Additionally, $\mathrm{F}^{-}$and $\mathrm{SO}_{4}{ }^{2-}$ can be inhibitors or enhancers of corrosion and it is desirable to have the least amount of uncertainty for these species, as with $\mathrm{pH}, \mathrm{Ca}^{2+}$, $\mathrm{NO}_{3}{ }^{-}$, and $\mathrm{Cl}^{-}$. Aqueous binning gives less uncertainty (mean coefficient of variation) for both $\mathrm{F}^{-}$and $\mathrm{SO}_{4}{ }^{2-}$. Based on these findings it was decided to use aqueous binning in the $\mathrm{P} \& \mathrm{CE}$ model. 
In this alternative evaporated seepage water analysis, the output mineralogy extracted from the EQ6 calculation runs (Table 6.6-1) is used, instead of binning based on aqueous chemistry as discussed in Sections 6.6.4 and 6.6.5. The "normalized" mineral assemblages are used to classify or define a group of resulting output waters. The approach presented below relies entirely on the statistical analysis of the "normalized" output without considering any other geochemical parameters. If successful, the statistically based method will analytically determine the best binning criteria to use for defining the bins. However, the intra-bin variances produced using this alternative method are generally larger than those reported in Section 6.6, so this alternative binning model will not be used.

In the analysis outlined in the following section, two terms are frequently used: bins and clusters. A bin is defined as a group of THC model output waters with similar physical or chemical characteristics (Section 6.6.4), which appear to be from related geochemical groups, as determined by chemical divides or mineralogy of precipitates. A cluster is defined as "a group of THC model precipitated minerals," which is not chosen by physical or chemical criteria (as in "binning") but is instead chosen using "cluster analysis" in the Statistica 5.1 software.

\subsubsection{Clustering Based on Mineralogy}

The analysis begins by taking the mineral data from each EQ3/6 output from the spreadsheet EBS THC Seepage Binning Abstraction REV 4.xls developed in Section 6.6.4 and archived in Output DTN: MO0508SPAEBSCB.001. For this analysis, only data from the carbonate, chloride, nitrate, and sulfate phases are used; the silicate and fluoride minerals are excluded from the clustering investigation. The mineral phases used for the clustering case are:

- anhydrite $\left(\mathrm{CaSO}_{4}\right)$

- $\operatorname{arcanite}\left(\mathrm{K}_{2} \mathrm{SO}_{4}\right)$

- calcite $\left(\mathrm{CaCO}_{3}\right)$

- darapskite $\left(\mathrm{Na}_{3} \mathrm{NO}_{3} \mathrm{SO}_{4} \cdot \mathrm{H}_{2} \mathrm{O}\right)$

- glauberite $\left(\mathrm{Na}_{2} \mathrm{Ca}\left(\mathrm{SO}_{4}\right)_{2}\right)$

- halite $(\mathrm{NaCl})$

- nahcolite $\left(\mathrm{NaHCO}_{3}\right)$

- natrite $\left(\mathrm{Na}_{2} \mathrm{CO}_{3}\right)$

- niter $\left(\mathrm{KNO}_{3}\right)$

- pentasalt $\left(\mathrm{K}_{2} \mathrm{SO}_{4} \cdot 5 \mathrm{CaSO}_{4} \cdot \mathrm{H}_{2} \mathrm{O}\right)$

- thenardite $\left(\mathrm{Na}_{2} \mathrm{SO}_{4}\right)$

- trona $\left(\mathrm{Na}_{3} \mathrm{HCO}_{3} \mathrm{CO}_{3} \cdot \mathrm{H}_{2} \mathrm{O}\right)$.

Values for the selected minerals (moles precipitated) are cut and pasted from EBS THC Seepage Binning Abstraction REV 4.xls into a Statistica 5.1 data spreadsheet (NewQminbin.STA, archived in Output DTN: MO0310SPAPCEAC.002). This is the main data file from which the cluster analysis is developed. These data are binned using a "K-means cluster analysis." In cluster sampling, clusters of individual units are chosen at random, and all units in the chosen clusters are measured (Gilbert 1987 [DIRS 163705], p. 23). In a K-means cluster analysis, the user is allowed to select the number of clusters to form. Eleven clusters have been chosen for the model simply because 11 bins are used in the aqueous binning analysis; thus, a more direct comparison 
can be made between the uncertainty of the solute concentrations (including $\mathrm{pH}$ ) in the waters of the 11 bins with the uncertainty of the solute concentration in the waters of the 11 clusters comprising this mineral-based analysis. For the cluster analysis, output data are saved in Statistica 5.1 files (Table 6.11-1). All 368 waters (called case numbers by Statistica 5.1) from EBS THC Seepage Binning Abstraction REV 4.xls are assigned a cluster (1 through 11) by cluster analysis in Statistica 5.1. For each specified cluster, case numbers are determined by checking the Statistica 5.1 output files WATERS OF CLUSTER NO 1.SCR to WATERS OF CLUSTER NO 11.SCR (archived in Output DTN: MO0310SPAPCEAC.002). The mean and standard deviation are then calculated for each solute concentration and $\mathrm{pH}$ to determine the uncertainty for each cluster (Output DTN: MO0310SPAPCEAC.002: New Mineral Binning Stats2.xls). These uncertainties are then compared to the uncertainty of the 11-bin aqueous analysis by determining the mean coefficient of variation for both the mineral clustering and aqueous binning for each solute and $\mathrm{pH}$ (Tables 6.11-3 to 6.11-14). The associated precipitated minerals (excluding silicates and fluorides) for each of the 11 clusters are given in Table 6.11-2.

Table 6.11-1. Statistica 5.1 Data Files

\begin{tabular}{|l|}
\hline 11-Cluster Model \\
\hline NewQminbin.STA \\
\hline WATERS OF CLUSTER NO 1.SCR to WATERS OF CLUSTER NO 11.SCR \\
\hline
\end{tabular}

Source: Output DTN: MO0310SPAPCEAC.002.

\subsubsection{Results}

Results shown in Tables 6.11-3 to 6.11-14 indicate that the coefficients of variation are lower for aqueous binning in 6 cases and lower for mineral clustering in 6 cases. The mean value of the coefficients of variation is smaller for the solute species $\mathrm{Ca}^{2+}, \mathrm{F}^{-}, \mathrm{NO}_{3}{ }^{-}, \mathrm{SO}_{4}, \mathrm{SiO}_{2}$, and $\mathrm{pH}$ in the 11-bin aqueous analysis. The mean value of the coefficient of variations is smaller for $\mathrm{AlO}_{2}$, $\mathrm{CO}_{3}, \mathrm{Cl}^{-}, \mathrm{K}^{+}, \mathrm{Mg}^{2+}$, and $\mathrm{Na}$ for the 11-cluster mineral case. On the basis of these results, where $\mathrm{pH}, \mathrm{Ca}^{2+}, \mathrm{NO}_{3}^{-}, \mathrm{F}^{-}$, and $\mathrm{SO}_{4}$ uncertainties (mean coefficient of variations) are lower for the aqueous binning case and the $\mathrm{Cl}$ uncertainty (mean coefficient of variation) is very similar, the mineral clustering approach has been discarded in favor of the aqueous composition binning approach. However, because the results are similar, the alternative method corroborates the chosen method. 
Table 6.11-2. Associated Minerals of Clusters 1 through 11

\begin{tabular}{|c|c|c|c|c|c|c|c|c|c|c|c|}
\hline Mineral & Cluster 1 & Cluster 2 & Cluster 3 & Cluster 4 & Cluster 5 & Cluster 6 & Cluster 7 & Cluster 8 & Cluster 9 & Cluster 10 & Cluster 11 \\
\hline Anhydrite & - & - & - & - & - & - & - & $x$ & - & - & - \\
\hline Arcanite & $x$ & $x$ & - & - & - & $x$ & $x$ & - & $x$ & $x$ & $x$ \\
\hline Calcite & - & - & $x$ & - & $x$ & $x$ & - & $x$ & $x$ & - & $x$ \\
\hline \begin{tabular}{|l|} 
Darapskite \\
\end{tabular} & - & - & - & - & - & - & - & - & - & - & $x$ \\
\hline Glauberite & - & - & - & - & - & $x$ & - & $x$ & - & - & - \\
\hline Halite & $x$ & - & $x$ & - & - & $x$ & $x$ & $x$ & $x$ & - & $x$ \\
\hline Nahcolite & - & $x$ & - & - & - & $x$ & $x$ & - & $x$ & - & $x$ \\
\hline Natrite & - & $x$ & $x$ & $x$ & $x$ & $x$ & $x$ & - & - & $x$ & - \\
\hline Niter & - & - & - & - & - & - & - & - & - & - & $x$ \\
\hline Pentasalt & - & - & - & - & - & - & - & $x$ & - & - & - \\
\hline Thenardite & $x$ & $x$ & $x$ & - & $x$ & $x$ & $x$ & - & $x$ & $x$ & $x$ \\
\hline Trona & $x$ & - & - & - & - & - & - & - & - & $x$ & - \\
\hline
\end{tabular}

Source: Output DTN: MO0310SPAPCEAC.002, New Mineral Binning Stats2.xls. 
Table 6.11-3. pH Statistics for Mineral Clustering and Aqueous Binning

\begin{tabular}{|c|c|c|c|c|c|c|c|c|c|}
\hline \multicolumn{5}{|c|}{ pH by Mineral Clustering } & \multicolumn{5}{|c|}{ pH by Aqueous Binning } \\
\hline Cluster & \begin{tabular}{|c|} 
Waters \\
(n)
\end{tabular} & Mean & $\begin{array}{l}\text { Standard } \\
\text { Deviation } \\
\end{array}$ & $\begin{array}{c}\text { Coefficient } \\
\text { of Variation } \\
(\%)\end{array}$ & Bin & \begin{tabular}{|c|} 
Waters \\
(n)
\end{tabular} & Mean & \begin{tabular}{|c|} 
Standard \\
Deviation \\
\end{tabular} & $\begin{array}{c}\text { Coefficient } \\
\text { of Variation } \\
(\%)\end{array}$ \\
\hline Cluster 1 & 4 & 9.09 & 0.02 & 0.26 & Bin 1 & 5 & 5.62 & 0.08 & 1.35 \\
\hline Cluster 2 & 6 & 9.27 & 0.19 & 2.10 & Bin 2 & 13 & 5.66 & 0.11 & 1.91 \\
\hline Cluster 3 & 80 & 9.15 & 0.17 & 1.88 & Bin 3 & 12 & 5.89 & 0.24 & 4.14 \\
\hline Cluster 4 & 12 & 9.23 & 0.22 & 2.43 & Bin 4 & 43 & 7.05 & 0.34 & 4.80 \\
\hline Cluster 5 & 32 & 9.24 & 0.18 & 1.97 & Bin 5 & 27 & 7.64 & 0.29 & 3.82 \\
\hline Cluster 6 & 45 & 8.22 & 0.78 & 9.54 & Bin 6 & 8 & 9.05 & 0.37 & 4.04 \\
\hline Cluster 7 & 24 & 8.86 & 0.10 & 1.15 & Bin 7 & 25 & 8.74 & 0.16 & 1.81 \\
\hline Cluster 8 & 73 & 6.51 & 0.71 & 10.84 & Bin 8 & 22 & 8.61 & 0.14 & 1.63 \\
\hline Cluster 9 & 36 & 8.70 & 0.19 & 2.15 & Bin 9 & 58 & 9.13 & 0.22 & 2.36 \\
\hline Cluster 10 & 46 & 9.29 & 0.18 & 1.97 & Bin 10 & 10 & 8.79 & 0.10 & 1.17 \\
\hline Cluster 11 & 10 & 8.67 & 0.15 & 1.77 & Bin 11 & 145 & 9.21 & 0.19 & 2.05 \\
\hline \multicolumn{4}{|r|}{ Mean: } & 3.28 & \multicolumn{4}{|c|}{ 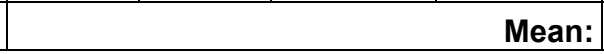 } & 2.64 \\
\hline
\end{tabular}

Source: Output DTN: MO0310SPAPCEAC.002, New Mineral Binning Stats2.xls.

Table 6.11-4. Al Statistics for Mineral Clustering and Aqueous Binning

\begin{tabular}{|c|c|c|c|c|c|c|c|c|c|}
\hline \multicolumn{5}{|c|}{ Al (Total) by Mineral Clustering } & \multicolumn{5}{|c|}{ Al (Total) by Aqueous Binning } \\
\hline Cluster & $\begin{array}{c}\text { Waters } \\
(\mathrm{n})\end{array}$ & $\begin{array}{c}\text { Mean } \\
\text { (molal) }\end{array}$ & $\begin{array}{c}\text { Standard } \\
\text { Deviation } \\
\text { (molal) } \\
\end{array}$ & $\begin{array}{c}\text { Coefficient } \\
\text { of Variation } \\
(\%)\end{array}$ & Bin & \begin{tabular}{|c}
$\begin{array}{c}\text { Waters } \\
\text { (n) }\end{array}$ \\
\end{tabular} & $\begin{array}{c}\text { Mean } \\
\text { (molal) }\end{array}$ & \begin{tabular}{|c|}
$\begin{array}{c}\text { Standard } \\
\text { Deviation } \\
\text { (molal) }\end{array}$ \\
\end{tabular} & \begin{tabular}{|c} 
Coefficient \\
of Variation \\
$(\%)$
\end{tabular} \\
\hline Cluster 1 & 4 & 2.13E-14 & $1.62 \mathrm{E}-15$ & 7.57 & Bin 1 & 5 & 3.26E-12 & $2.22 \mathrm{E}-13$ & 6.81 \\
\hline Cluster 2 & 6 & $1.22 \mathrm{E}-13$ & 6.49E-14 & 53.13 & Bin 2 & 13 & 2.52E-12 & 7.15E-13 & 28.36 \\
\hline Cluster 3 & 80 & 1.25E-13 & $6.43 E-14$ & 51.52 & Bin 3 & 12 & 1.15E-12 & $9.64 \mathrm{E}-13$ & 83.90 \\
\hline Cluster 4 & 12 & $9.96 \mathrm{E}-12$ & 3.34E-11 & 335.89 & Bin 4 & 43 & $3.28 \mathrm{E}-13$ & $2.78 \mathrm{E}-13$ & 84.62 \\
\hline Cluster 5 & 32 & $1.31 \mathrm{E}-13$ & 7.11E-14 & 54.46 & Bin 5 & 27 & $1.66 \mathrm{E}-13$ & 8.09E-14 & 48.63 \\
\hline Cluster 6 & 45 & $1.61 \mathrm{E}-13$ & $1.04 \mathrm{E}-13$ & 64.81 & Bin 6 & 8 & 1.10E-13 & 9.15E-14 & 83.18 \\
\hline Cluster 7 & 24 & $1.51 \mathrm{E}-14$ & $1.09 \mathrm{E}-14$ & 71.83 & Bin 7 & 25 & $4.11 \mathrm{E}-15$ & 1.08E-15 & 26.19 \\
\hline Cluster 8 & 73 & 1.05E-12 & 1.15E-12 & 108.82 & Bin 8 & 22 & 1.33E-15 & $6.66 \mathrm{E}-16$ & 50.25 \\
\hline Cluster 9 & 36 & $4.05 \mathrm{E}-15$ & $2.59 \mathrm{E}-15$ & 64.06 & Bin 9 & 58 & $2.18 \mathrm{E}-12$ & 1.52E-11 & 698.63 \\
\hline Cluster 10 & 46 & 9.54E-14 & $3.23 \mathrm{E}-14$ & 33.90 & Bin 10 & 10 & $9.78 \mathrm{E}-15$ & 3.33E-15 & 34.06 \\
\hline Cluster 11 & 10 & 6.92E-16 & $4.62 \mathrm{E}-18$ & 0.67 & Bin 11 & 145 & 1.00E-13 & $4.21 \mathrm{E}-14$ & 41.88 \\
\hline \multicolumn{4}{|r|}{ Mean: } & 76.97 & \multicolumn{4}{|c|}{ Mean: } & 107.87 \\
\hline
\end{tabular}

Source: Output DTN: MO0310SPAPCEAC.002, New Mineral Binning Stats2.xIs.

NOTE: $\quad \mathrm{Al}^{3+}$ considered present as $\mathrm{AlO}_{2}$. 
Table 6.11-5. C Statistics for Mineral Clustering and Aqueous Binning

\begin{tabular}{|c|c|c|c|c|c|c|c|c|c|}
\hline \multicolumn{5}{|c|}{ C (Total) by Mineral Clustering } & \multicolumn{5}{|c|}{ C (Total) by Aqueous Binning } \\
\hline Cluster & $\begin{array}{c}\text { Waters } \\
\text { (n) }\end{array}$ & $\begin{array}{c}\text { Mean } \\
\text { (molal) }\end{array}$ & $\begin{array}{c}\text { Standard } \\
\text { Deviation } \\
\text { (molal) }\end{array}$ & $\begin{array}{c}\text { Coefficient } \\
\text { of Variation } \\
(\%)\end{array}$ & Bin & $\begin{array}{c}\text { Waters } \\
(\mathrm{n})\end{array}$ & $\begin{array}{c}\text { Mean } \\
\text { (molal) }\end{array}$ & $\begin{array}{c}\text { Standard } \\
\text { Deviation } \\
\text { (molal) }\end{array}$ & $\begin{array}{c}\text { Coefficient } \\
\text { of Variation } \\
(\%)\end{array}$ \\
\hline Cluster 1 & 4 & 1.15E+00 & $9.50 \mathrm{E}-03$ & 0.82 & Bin 1 & 5 & 5.37E-04 & 8.67E-05 & 16.15 \\
\hline Cluster 2 & 6 & $1.32 \mathrm{E}+00$ & $1.58 \mathrm{E}-01$ & 11.95 & Bin 2 & 13 & $6.04 \mathrm{E}-04$ & $1.52 \mathrm{E}-04$ & 25.12 \\
\hline Cluster 3 & 80 & 1.13E+00 & 4.41E-02 & 3.89 & Bin 3 & 12 & $5.02 \mathrm{E}-04$ & $1.84 \mathrm{E}-04$ & 36.55 \\
\hline Cluster 4 & 12 & $1.29 \mathrm{E}+00$ & 8.25E-02 & 6.40 & Bin 4 & 43 & $5.04 \mathrm{E}-04$ & $3.15 E-04$ & 62.43 \\
\hline Cluster 5 & 32 & 1.19E+00 & $1.71 \mathrm{E}-01$ & 14.37 & Bin 5 & 27 & 2.81E-03 & $5.84 \mathrm{E}-03$ & 208.21 \\
\hline Cluster 6 & 45 & $2.62 \mathrm{E}-01$ & 3.86E-01 & 147.17 & Bin 6 & 8 & 5.07E-01 & $2.52 \mathrm{E}-01$ & 49.71 \\
\hline Cluster 7 & 24 & $6.63 \mathrm{E}-01$ & 2.85E-01 & 42.98 & Bin 7 & 25 & $3.71 \mathrm{E}-01$ & 1.06E-01 & 28.50 \\
\hline Cluster 8 & 73 & $5.24 \mathrm{E}-04$ & 2.62E-04 & 50.02 & Bin 8 & 22 & 2.08E-01 & $3.28 \mathrm{E}-02$ & 15.82 \\
\hline Cluster 9 & 36 & 3.57E-01 & $1.68 \mathrm{E}-01$ & 46.98 & Bin 9 & 58 & $1.10 \mathrm{E}+00$ & $2.12 \mathrm{E}-01$ & 19.33 \\
\hline Cluster 10 & 46 & $1.25 \mathrm{E}+00$ & 1.34E-01 & 10.72 & Bin 10 & 10 & $4.03 \mathrm{E}-01$ & 7.77E-02 & 19.26 \\
\hline Cluster 11 & 10 & 1.92E-01 & 3.64E-02 & 18.93 & Bin 11 & 145 & $1.18 \mathrm{E}+00$ & 1.35E-01 & 11.43 \\
\hline \multicolumn{4}{|r|}{ Mean: } & 32.20 & \multicolumn{4}{|r|}{ Mean: } & 44.77 \\
\hline
\end{tabular}

Source: Output DTN: MO0310SPAPCEAC.002, New Mineral Binning Stats2.xls.

NOTE: $\quad \mathrm{C}^{4+}$ considered present as $\mathrm{CO}_{3}{ }^{2-}$.

Table 6.11-6. Ca Statistics for Mineral Clustering and Aqueous Binning

\begin{tabular}{|c|c|c|c|c|c|c|c|c|c|}
\hline \multicolumn{5}{|c|}{$\mathrm{Ca}^{2+}$ by Mineral Clustering } & \multicolumn{5}{|c|}{$\mathrm{Ca}^{2+}$ by Aqueous Binning } \\
\hline Cluster & $\begin{array}{c}\text { Waters } \\
\text { (n) }\end{array}$ & $\begin{array}{c}\text { Mean } \\
\text { (molal) }\end{array}$ & $\begin{array}{c}\text { Standard } \\
\text { Deviation } \\
\text { (molal) }\end{array}$ & $\begin{array}{c}\text { Coefficient } \\
\text { of Variation } \\
(\%)\end{array}$ & Bin & $\begin{array}{c}\text { Waters } \\
\text { (n) }\end{array}$ & $\begin{array}{c}\text { Mean } \\
\text { (molal) }\end{array}$ & $\begin{array}{c}\text { Standard } \\
\text { Deviation } \\
\text { (molal) }\end{array}$ & $\begin{array}{c}\text { Coefficient } \\
\text { of Variation } \\
(\%)\end{array}$ \\
\hline Cluster 1 & 4 & $2.69 \mathrm{E}-06$ & $4.98 \mathrm{E}-08$ & 1.85 & Bin 1 & 5 & $3.66 \mathrm{E}+00$ & $2.88 \mathrm{E}-01$ & 7.87 \\
\hline Cluster 2 & 6 & $2.49 \mathrm{E}-06$ & $1.23 \mathrm{E}-07$ & 4.93 & Bin 2 & 13 & $2.37 E+00$ & $2.75 \mathrm{E}-01$ & 11.63 \\
\hline Cluster 3 & 80 & $4.25 \mathrm{E}-06$ & $2.15 \mathrm{E}-06$ & 50.58 & Bin 3 & 12 & $1.12 \mathrm{E}+00$ & $4.24 \mathrm{E}-01$ & 37.87 \\
\hline Cluster 4 & 12 & $2.60 \mathrm{E}-06$ & $1.28 \mathrm{E}-07$ & 4.91 & Bin 4 & 43 & $2.63 \mathrm{E}-03$ & $6.45 \mathrm{E}-04$ & 24.54 \\
\hline Cluster 5 & 32 & 3.00E-06 & 1.26E-06 & 42.04 & $\operatorname{Bin} 5$ & 27 & 8.20E-04 & 1.72E-04 & 20.97 \\
\hline Cluster 6 & 45 & $4.95 \mathrm{E}-04$ & $4.24 \mathrm{E}-04$ & 85.51 & Bin 6 & 8 & $8.31 \mathrm{E}-06$ & $5.58 \mathrm{E}-07$ & 6.72 \\
\hline Cluster 7 & 24 & 1.21E-06 & 7.20E-07 & 59.66 & Bin 7 & 25 & 9.88E-06 & 7.70E-07 & 7.80 \\
\hline Cluster 8 & 73 & $8.58 \mathrm{E}-01$ & $1.20 \mathrm{E}+00$ & 140.33 & Bin 8 & 22 & 1.15E-05 & 1.38E-06 & 11.97 \\
\hline Cluster 9 & 36 & 1.03E-05 & $1.22 \mathrm{E}-06$ & 11.81 & Bin 9 & 58 & 3.33E-06 & $1.98 \mathrm{E}-06$ & 59.49 \\
\hline Cluster 10 & 46 & 2.62E-06 & 1.07E-07 & 4.09 & Bin 10 & 10 & $5.46 \mathrm{E}-07$ & $1.55 \mathrm{E}-07$ & 28.40 \\
\hline Cluster 11 & 10 & 1.16E-05 & $1.75 \mathrm{E}-06$ & 15.10 & Bin 11 & 145 & $3.51 \mathrm{E}-06$ & 1.81E-06 & 51.66 \\
\hline \multicolumn{4}{|r|}{ Mean: } & 38.25 & \multicolumn{4}{|r|}{ Mean: } & 24.45 \\
\hline
\end{tabular}

Source: Output DTN: MO0310SPAPCEAC.002, New Mineral Binning Stats2.xls. 
Table 6.11-7. Cl Statistics for Mineral Clustering and Aqueous Binning

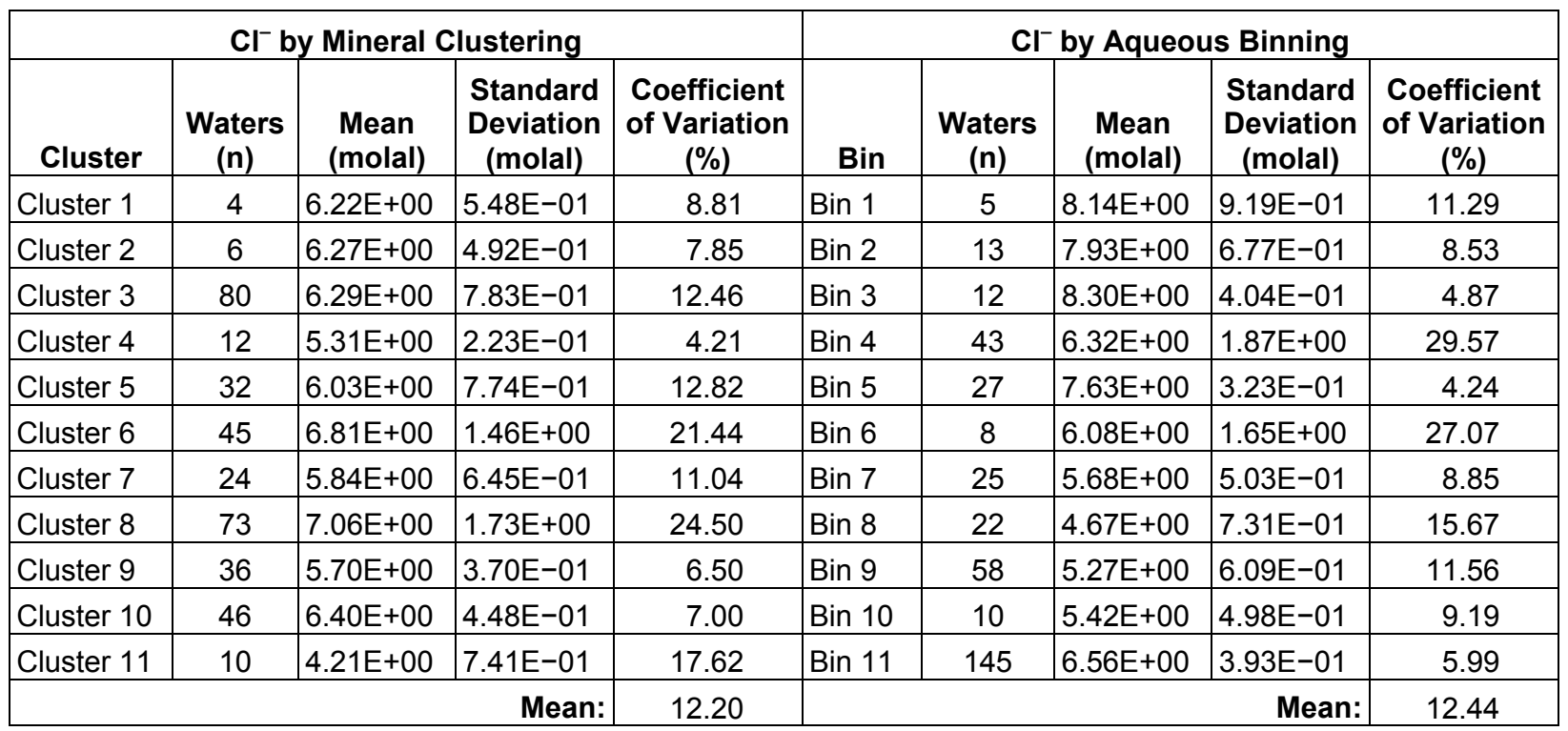

Source: Output DTN: MO0310SPAPCEAC.002, New Mineral Binning Stats2.xls.

Table 6.11-8. F Statistics for Mineral Clustering and Aqueous Binning

\begin{tabular}{|c|c|c|c|c|c|c|c|c|c|}
\hline \multicolumn{5}{|c|}{$\mathrm{F}^{-}$by Mineral Clustering } & \multicolumn{5}{|c|}{$\mathrm{F}^{-}$by Aqueous Binning } \\
\hline Cluster & $\begin{array}{c}\text { Waters } \\
\text { (n) }\end{array}$ & $\begin{array}{l}\text { Mean } \\
\text { (molal) }\end{array}$ & $\begin{array}{c}\text { Standard } \\
\text { Deviation } \\
\text { (molal) }\end{array}$ & $\begin{array}{c}\text { Coefficient } \\
\text { of Variation } \\
(\%)\end{array}$ & Bin & $\begin{array}{c}\text { Waters } \\
\text { (n) }\end{array}$ & $\begin{array}{l}\text { Mean } \\
\text { (molal) }\end{array}$ & $\begin{array}{c}\text { Standard } \\
\text { Deviation } \\
\text { (molal) }\end{array}$ & $\begin{array}{c}\text { Coefficient } \\
\text { of Variation } \\
(\%)\end{array}$ \\
\hline Cluster 1 & 4 & $2.24 \mathrm{E}-01$ & $5.25 \mathrm{E}-04$ & 0.23 & Bin 1 & 5 & $6.36 \mathrm{E}-05$ & $4.18 \mathrm{E}-06$ & 6.58 \\
\hline Cluster 2 & 6 & $2.52 \mathrm{E}-01$ & 1.47E-02 & 5.83 & Bin 2 & 13 & $5.07 \mathrm{E}-05$ & $3.50 \mathrm{E}-06$ & 6.89 \\
\hline Cluster 3 & 80 & 2.07E-01 & $4.51 \mathrm{E}-02$ & 21.77 & Bin 3 & 12 & $4.23 \mathrm{E}-05$ & $1.36 \mathrm{E}-05$ & 32.15 \\
\hline Cluster 4 & 12 & $2.44 \mathrm{E}-01$ & $6.94 \mathrm{E}-03$ & 2.84 & Bin 4 & 43 & 7.66E-04 & $2.50 \mathrm{E}-04$ & 32.64 \\
\hline Cluster 5 & 32 & $2.39 \mathrm{E}-01$ & $3.27 \mathrm{E}-02$ & 13.71 & Bin 5 & 27 & $2.94 \mathrm{E}-03$ & $3.24 \mathrm{E}-03$ & 110.06 \\
\hline Cluster 6 & 45 & $3.98 \mathrm{E}-02$ & $5.25 \mathrm{E}-02$ & 131.75 & Bin 6 & 8 & $7.83 \mathrm{E}-02$ & $1.63 \mathrm{E}-02$ & 20.81 \\
\hline Cluster 7 & 24 & $2.17 \mathrm{E}-01$ & $9.52 \mathrm{E}-03$ & 4.39 & Bin 7 & 25 & $4.49 \mathrm{E}-02$ & $1.15 \mathrm{E}-02$ & 25.59 \\
\hline Cluster 8 & 73 & 4.71E-04 & $4.03 E-04$ & 85.49 & Bin 8 & 22 & $2.26 \mathrm{E}-02$ & $4.79 \mathrm{E}-03$ & 21.18 \\
\hline Cluster 9 & 36 & $4.24 \mathrm{E}-02$ & $1.91 \mathrm{E}-02$ & 45.01 & Bin 9 & 58 & 2.19E-01 & $4.11 \mathrm{E}-02$ & 18.82 \\
\hline Cluster 10 & 46 & $2.51 \mathrm{E}-01$ & $1.25 \mathrm{E}-02$ & 4.99 & Bin 10 & 10 & 2.09E-01 & $2.71 \mathrm{E}-03$ & 1.30 \\
\hline Cluster 11 & 10 & 1.89E-02 & $3.42 \mathrm{E}-03$ & 18.06 & Bin 11 & 145 & $2.26 \mathrm{E}-01$ & $4.22 \mathrm{E}-02$ & 18.71 \\
\hline \multicolumn{4}{|r|}{ Mean: } & 30.37 & & & & Mean: & 26.79 \\
\hline
\end{tabular}

Source: Output DTN: MO0310SPAPCEAC.002, New Mineral Binning Stats2.xls. 
Table 6.11-9. K Statistics for Mineral Clustering and Aqueous Binning

\begin{tabular}{|c|c|c|c|c|c|c|c|c|c|}
\hline \multicolumn{5}{|c|}{$\mathrm{K}^{+}$by Mineral Clustering } & \multicolumn{5}{|c|}{$\mathrm{K}^{+}$by Aqueous Binning } \\
\hline Cluster & $\begin{array}{c}\text { Waters } \\
\text { (n) }\end{array}$ & $\begin{array}{c}\text { Mean } \\
\text { (molal) }\end{array}$ & $\begin{array}{c}\text { Standard } \\
\text { Deviation } \\
\text { (molal) }\end{array}$ & $\begin{array}{c}\begin{array}{c}\text { Coefficient } \\
\text { of Variation } \\
(\%)\end{array} \\
\end{array}$ & Bin & $\begin{array}{c}\text { Waters } \\
\text { (n) }\end{array}$ & $\begin{array}{c}\text { Mean } \\
\text { (molal) }\end{array}$ & $\begin{array}{c}\text { Standard } \\
\text { Deviation } \\
\text { (molal) }\end{array}$ & $\begin{array}{c}\text { Coefficient } \\
\text { of Variation } \\
(\%)\end{array}$ \\
\hline Cluster 1 & 4 & $4.01 \mathrm{E}+00$ & 3.04E-02 & 0.76 & Bin 71 & 5 & $3.11 \mathrm{E}-01$ & 1.13E-01 & 36.29 \\
\hline Cluster 2 & 6 & $4.74 \mathrm{E}+00$ & 7.92E-01 & 16.70 & Bin 2 & 13 & $9.75 \mathrm{E}-01$ & 3.32E-01 & 34.08 \\
\hline Cluster 3 & 80 & $3.62 \mathrm{E}+00$ & 2.42E-01 & 6.69 & Bin 3 & 12 & $3.07 E+00$ & $9.15 \mathrm{E}-01$ & 29.78 \\
\hline Cluster 4 & 12 & $5.06 \mathrm{E}+00$ & $5.35 \mathrm{E}-01$ & 10.58 & Bin 4 & 43 & $5.38 \mathrm{E}+00$ & $9.45 \mathrm{E}-01$ & 17.57 \\
\hline Cluster 5 & 32 & $3.94 \mathrm{E}+00$ & 4.02E-01 & 10.19 & $\operatorname{Bin} 5$ & 27 & $4.69 E+00$ & $6.75 \mathrm{E}-02$ & 1.44 \\
\hline Cluster 6 & 45 & $4.33 \mathrm{E}+00$ & $5.96 \mathrm{E}-01$ & 13.76 & Bin 6 & 8 & $4.05 E+00$ & $6.66 \mathrm{E}-01$ & 16.44 \\
\hline Cluster 7 & 24 & $4.39 \mathrm{E}+00$ & 2.35E-01 & 5.35 & Bin 7 & 25 & $4.85 \mathrm{E}+00$ & $2.40 \mathrm{E}-01$ & 4.96 \\
\hline Cluster 8 & 73 & $3.87 \mathrm{E}+00$ & $2.13 \mathrm{E}+00$ & 54.99 & Bin 8 & 22 & $4.61 \mathrm{E}+00$ & 6.63E-01 & 14.39 \\
\hline Cluster 9 & 36 & $4.94 \mathrm{E}+00$ & 2.16E-01 & 4.37 & Bin 9 & 58 & $4.03 E+00$ & 8.45E-01 & 20.99 \\
\hline Cluster 10 & 46 & $4.31 \mathrm{E}+00$ & 2.15E-01 & 4.98 & Bin 10 & 10 & $4.59 \mathrm{E}+00$ & 4.66E-02 & 1.02 \\
\hline Cluster 11 & 10 & $4.05 \mathrm{E}+00$ & $5.89 \mathrm{E}-01$ & 14.53 & Bin 11 & 145 & $3.98 \mathrm{E}+00$ & 3.30E-01 & 8.30 \\
\hline \multicolumn{4}{|r|}{ Mean: } & 12.99 & \multicolumn{4}{|c|}{ Mean: } & 16.84 \\
\hline
\end{tabular}

Source: Output DTN: MO0310SPAPCEAC.002, New Mineral Binning Stats2.xls.

Table 6.11-10. Mg Statistics for Mineral Clustering and Aqueous Binning

\begin{tabular}{|c|c|c|c|c|c|c|c|c|c|}
\hline \multicolumn{5}{|c|}{$\mathrm{Mg}^{2+}$ by Mineral Clustering } & \multicolumn{5}{|c|}{$\mathrm{Mg}^{2+}$ by Aqueous Binning } \\
\hline Cluster & $\begin{array}{c}\text { Waters } \\
\text { (n) }\end{array}$ & $\begin{array}{c}\text { Mean } \\
\text { (molal) }\end{array}$ & $\begin{array}{c}\text { Standard } \\
\text { Deviation } \\
\text { (molal) }\end{array}$ & $\begin{array}{c}\text { Coefficient } \\
\text { of Variation } \\
(\%)\end{array}$ & Bin & $\begin{array}{c}\text { Waters } \\
\text { (n) }\end{array}$ & $\begin{array}{c}\text { Mean } \\
\text { (molal) }\end{array}$ & $\begin{array}{c}\text { Standard } \\
\text { Deviation } \\
\text { (molal) }\end{array}$ & $\begin{array}{c}\text { Coefficient } \\
\text { of Variation } \\
(\%)\end{array}$ \\
\hline Cluster 1 & 4 & $2.20 \mathrm{E}-07$ & $1.89 \mathrm{E}-08$ & 8.56 & Bin 1 & 5 & 8.38E-04 & 3.55E-04 & 42.40 \\
\hline Cluster 2 & 6 & $6.95 \mathrm{E}-08$ & $9.94 \mathrm{E}-08$ & 143.07 & Bin 2 & 13 & 1.39E-03 & 5.87E-04 & 42.27 \\
\hline Cluster 3 & 80 & $6.28 \mathrm{E}-08$ & $6.17 \mathrm{E}-08$ & 98.31 & Bin 3 & 12 & 1.30E-03 & 7.39E-04 & 57.05 \\
\hline Cluster 4 & 12 & $6.70 \mathrm{E}-08$ & 8.30E-08 & 123.87 & Bin 4 & 43 & $2.16 \mathrm{E}-05$ & 8.23E-05 & 381.32 \\
\hline Cluster 5 & 32 & 4.87E-08 & $6.35 \mathrm{E}-08$ & 130.48 & Bin 5 & 27 & $2.09 \mathrm{E}-06$ & 2.37E-06 & 113.35 \\
\hline Cluster 6 & 45 & 1.36E-06 & $2.06 \mathrm{E}-06$ & 151.46 & Bin 6 & 8 & 1.66E-07 & $1.91 \mathrm{E}-07$ & 115.42 \\
\hline Cluster 7 & 24 & $4.21 \mathrm{E}-07$ & 8.96E-08 & 21.30 & Bin 7 & 25 & 1.26E-06 & $5.78 \mathrm{E}-07$ & 45.93 \\
\hline Cluster 8 & 73 & 5.30E-04 & 7.37E-04 & 139.01 & Bin 8 & 22 & $2.72 \mathrm{E}-06$ & 1.21E-06 & 44.52 \\
\hline Cluster 9 & 36 & 1.67E-06 & $1.05 \mathrm{E}-06$ & 62.59 & Bin 9 & 58 & 1.16E-07 & $1.65 \mathrm{E}-07$ & 141.39 \\
\hline Cluster 10 & 46 & $5.50 \mathrm{E}-08$ & $6.03 E-08$ & 109.72 & Bin 10 & 10 & 4.30E-07 & 8.62E-08 & 20.03 \\
\hline Cluster 11 & 10 & $2.80 \mathrm{E}-06$ & $1.45 \mathrm{E}-06$ & 51.55 & Bin 11 & 145 & 7.29E-08 & 8.18E-08 & 112.26 \\
\hline \multicolumn{4}{|r|}{ Mean: } & 94.54 & & & & Mean: & 101.45 \\
\hline
\end{tabular}

Source: Output DTN: MO0310SPAPCEAC.002, New Mineral Binning Stats2.xls. 
Table 6.11-11. N Statistics for Mineral Clustering and Aqueous Binning

\begin{tabular}{|c|c|c|c|c|c|c|c|c|c|}
\hline \multicolumn{5}{|c|}{$\mathrm{NO}_{3}{ }^{-}$by Mineral Clustering } & \multicolumn{5}{|c|}{$\mathrm{NO}_{3}{ }^{-}$by Aqueous Binning } \\
\hline Cluster & $\begin{array}{c}\text { Waters } \\
(\mathrm{n})\end{array}$ & $\begin{array}{c}\text { Mean } \\
\text { (molal) }\end{array}$ & $\begin{array}{c}\text { Standard } \\
\text { Deviation } \\
\text { (molal) }\end{array}$ & $\begin{array}{c}\text { Coefficient } \\
\text { of Variation } \\
(\%)\end{array}$ & Bin & $\begin{array}{c}\text { Waters } \\
(\mathrm{n})\end{array}$ & $\begin{array}{c}\text { Mean } \\
\text { (molal) }\end{array}$ & $\begin{array}{c}\text { Standard } \\
\text { Deviation } \\
\text { (molal) } \\
\end{array}$ & $\begin{array}{c}\text { Coefficient } \\
\text { of Variation } \\
(\%)\end{array}$ \\
\hline Cluster 1 & 4 & $1.01 \mathrm{E}+00$ & $8.44 \mathrm{E}-01$ & 83.35 & Bin 1 & 5 & $8.88 \mathrm{E}-01$ & $1.05 \mathrm{E}+00$ & 118.66 \\
\hline Cluster 2 & 6 & $8.46 \mathrm{E}-01$ & 6.79E-01 & 80.26 & Bin 2 & 13 & $1.16 \mathrm{E}+00$ & $8.35 \mathrm{E}-01$ & 72.23 \\
\hline Cluster 3 & 80 & $1.22 \mathrm{E}+00$ & $1.22 \mathrm{E}+00$ & 99.31 & Bin 3 & 12 & $1.25 \mathrm{E}+00$ & $5.58 \mathrm{E}-01$ & 44.56 \\
\hline Cluster 4 & 12 & $2.25 E+00$ & $9.52 \mathrm{E}-02$ & 4.24 & Bin 4 & 43 & $4.76 \mathrm{E}+00$ & $2.79 \mathrm{E}+00$ & 58.72 \\
\hline Cluster 5 & 32 & $1.32 \mathrm{E}+00$ & $9.88 \mathrm{E}-01$ & 74.85 & Bin 5 & 27 & $1.28 \mathrm{E}+00$ & $5.63 \mathrm{E}-01$ & 43.89 \\
\hline Cluster 6 & 45 & $2.02 \mathrm{E}+00$ & $1.92 \mathrm{E}+00$ & 95.30 & Bin 6 & 8 & $2.55 \mathrm{E}+00$ & $2.73 \mathrm{E}+00$ & 106.79 \\
\hline Cluster 7 & 24 & $2.25 \mathrm{E}+00$ & $1.15 \mathrm{E}+00$ & 51.00 & Bin 7 & 25 & $3.00 \mathrm{E}+00$ & $8.14 \mathrm{E}-01$ & 27.17 \\
\hline Cluster 8 & 73 & $3.28 \mathrm{E}+00$ & $2.83 \mathrm{E}+00$ & 86.25 & Bin 8 & 22 & $4.37 E+00$ & $1.43 \mathrm{E}+00$ & 32.69 \\
\hline Cluster 9 & 36 & $2.93 E+00$ & $6.74 \mathrm{E}-01$ & 23.00 & Bin 9 & 58 & $2.70 \mathrm{E}+00$ & 9.15E-01 & 33.89 \\
\hline Cluster 10 & 46 & $5.13 E-01$ & $7.58 \mathrm{E}-02$ & 14.78 & Bin 10 & 10 & $3.22 \mathrm{E}+00$ & $8.54 \mathrm{E}-01$ & 26.50 \\
\hline Cluster 11 & 10 & $4.78 \mathrm{E}+00$ & $1.92 \mathrm{E}+00$ & 40.21 & Bin 11 & 145 & $5.71 \mathrm{E}-01$ & $1.52 \mathrm{E}-01$ & 26.63 \\
\hline \multicolumn{4}{|r|}{ Mean: } & 59.32 & & & & Mean: & 53.79 \\
\hline
\end{tabular}

Source: Output DTN: MO0310SPAPCEAC.002, New Mineral Binning Stats2.xIs.

NOTE: $\quad \mathrm{N}^{5+}$ considered present as $\mathrm{NO}_{3}{ }^{-}$.

Table 6.11-12. Na Statistics for Mineral Clustering and Aqueous Binning

\begin{tabular}{|c|c|c|c|c|c|c|c|c|c|}
\hline \multicolumn{5}{|c|}{$\mathrm{Na}+$ by Mineral Clustering } & \multicolumn{5}{|c|}{$\mathrm{Na}+$ by Aqueous Binning } \\
\hline Cluster & $\begin{array}{c}\text { Waters } \\
\text { (n) }\end{array}$ & $\begin{array}{c}\text { Mean } \\
\text { (molal) }\end{array}$ & $\begin{array}{c}\text { Standard } \\
\text { Deviation } \\
\text { (molal) }\end{array}$ & $\begin{array}{c}\text { Coefficient } \\
\text { of Variation } \\
(\%)\end{array}$ & Bin & \begin{tabular}{|c} 
Waters \\
$(\mathrm{n})$
\end{tabular} & $\begin{array}{c}\text { Mean } \\
\text { (molal) }\end{array}$ & $\begin{array}{c}\text { Standard } \\
\text { Deviation } \\
\text { (molal) }\end{array}$ & $\begin{array}{c}\text { Coefficient } \\
\text { of Variation } \\
(\%)\end{array}$ \\
\hline Cluster 1 & 4 & $6.94 \mathrm{E}+00$ & $3.21 \mathrm{E}-01$ & 4.62 & Bin 1 & 5 & $1.41 \mathrm{E}+00$ & $5.00 \mathrm{E}-01$ & 35.51 \\
\hline Cluster 2 & 6 & $6.75 \mathrm{E}+00$ & $1.94 \mathrm{E}-01$ & 2.87 & Bin 2 & 13 & $3.38 \mathrm{E}+00$ & 4.13E-01 & 12.21 \\
\hline Cluster 3 & 80 & $7.58 \mathrm{E}+00$ & $6.74 \mathrm{E}-01$ & 8.89 & Bin 3 & 12 & $4.24 \mathrm{E}+00$ & $3.22 \mathrm{E}-01$ & 7.60 \\
\hline Cluster 4 & 12 & $6.97 \mathrm{E}+00$ & $2.52 \mathrm{E}-01$ & 3.61 & Bin 4 & 43 & $6.47 \mathrm{E}+00$ & $1.69 \mathrm{E}+00$ & 26.14 \\
\hline Cluster 5 & 32 & $7.44 \mathrm{E}+00$ & $5.08 \mathrm{E}-01$ & 6.83 & Bin 5 & 27 & $6.28 \mathrm{E}+00$ & $2.39 \mathrm{E}-01$ & 3.80 \\
\hline Cluster 6 & 45 & $7.00 \mathrm{E}+00$ & $1.19 \mathrm{E}+00$ & 17.02 & Bin 6 & 8 & $7.38 \mathrm{E}+00$ & $1.52 \mathrm{E}+00$ & 20.58 \\
\hline Cluster 7 & 24 & $7.00 \mathrm{E}+00$ & $4.38 \mathrm{E}-01$ & 6.25 & Bin 7 & 25 & $6.97 \mathrm{E}+00$ & $4.96 \mathrm{E}-01$ & 7.12 \\
\hline Cluster 8 & 73 & $5.21 \mathrm{E}+00$ & $2.10 \mathrm{E}+00$ & 40.43 & Bin 8 & 22 & $8.02 \mathrm{E}+00$ & 9.77E-01 & 12.19 \\
\hline Cluster 9 & 36 & $6.95 \mathrm{E}+00$ & $2.89 \mathrm{E}-01$ & 4.16 & Bin 9 & 58 & $7.82 \mathrm{E}+00$ & $9.65 \mathrm{E}-01$ & 12.35 \\
\hline Cluster 10 & 46 & $6.87 \mathrm{E}+00$ & $9.80 \mathrm{E}-02$ & 1.43 & Bin 10 & 10 & $7.26 \mathrm{E}+00$ & $4.34 \mathrm{E}-01$ & 5.97 \\
\hline Cluster 11 & 10 & $8.60 \mathrm{E}+00$ & $1.10 \mathrm{E}+00$ & 12.84 & Bin 11 & 145 & $7.08 \mathrm{E}+00$ & $2.61 \mathrm{E}-01$ & 3.69 \\
\hline \multicolumn{4}{|r|}{ Mean: } & 9.90 & & & & Mean: & 13.38 \\
\hline
\end{tabular}

Source: Output DTN: MO0310SPAPCEAC.002, New Mineral Binning Stats2.xIs. 
Table 6.11-13. S Statistics for Mineral Clustering and Aqueous Binning

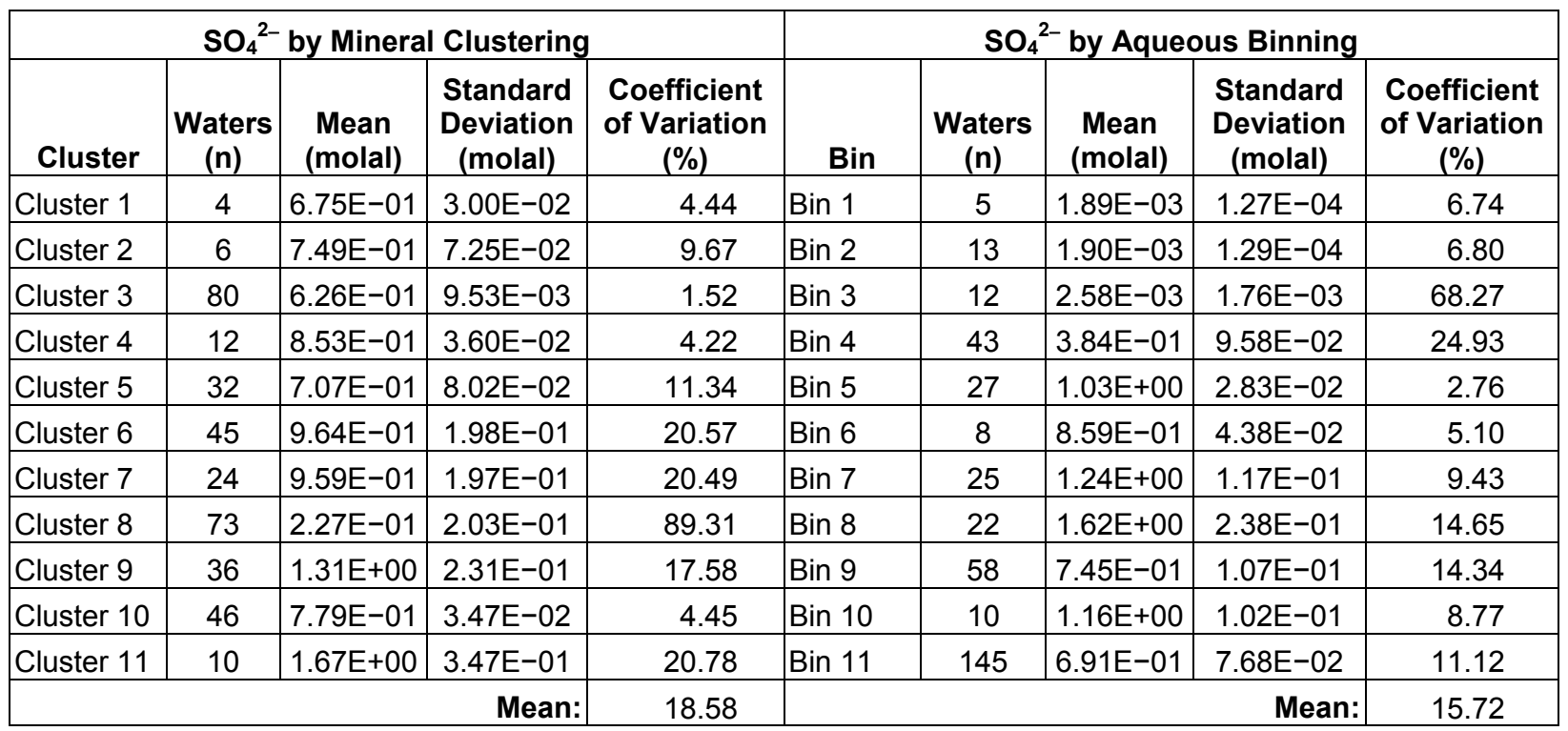

Source: Output DTN: MO0310SPAPCEAC.002, New Mineral Binning Stats2.xls.

NOTE: $\quad \mathrm{S}^{7+}$ considered present as $\mathrm{SO}_{4}{ }^{2-}$.

Table 6.11-14. Si Statistics for Mineral Clustering and Aqueous Binning

\begin{tabular}{|c|c|c|c|c|c|c|c|c|c|}
\hline \multicolumn{5}{|c|}{$\mathrm{SiO}_{2}$ by Mineral Clustering } & \multicolumn{5}{|c|}{$\mathrm{SiO}_{2}$ by Aqueous Binning } \\
\hline Cluster & $\begin{array}{c}\text { Waters } \\
(\mathrm{n})\end{array}$ & $\begin{array}{c}\text { Mean } \\
\text { (molal) }\end{array}$ & \begin{tabular}{|c|} 
Standard \\
Deviation \\
(molal)
\end{tabular} & $\begin{array}{c}\text { Coefficient } \\
\text { of Variation } \\
(\%)\end{array}$ & Bin & $\begin{array}{c}\text { Waters } \\
(\mathrm{n})\end{array}$ & $\begin{array}{c}\text { Mean } \\
\text { (molal) }\end{array}$ & $\begin{array}{c}\text { Standard } \\
\text { Deviation } \\
\text { (molal) }\end{array}$ & \begin{tabular}{|c}
$\begin{array}{c}\text { Coefficient } \\
\text { of Variation } \\
(\%)\end{array}$ \\
\end{tabular} \\
\hline Cluster 1 & 4 & $3.63 E-02$ & $2.00 \mathrm{E}-03$ & 5.51 & Bin 1 & 5 & $1.42 \mathrm{E}-03$ & $1.86 \mathrm{E}-04$ & 13.14 \\
\hline Cluster 2 & 6 & 1.30E-01 & $9.81 \mathrm{E}-02$ & 75.67 & Bin 2 & 13 & $2.26 \mathrm{E}-03$ & $3.16 \mathrm{E}-04$ & 13.97 \\
\hline Cluster 3 & 80 & $9.13 E-02$ & $4.71 \mathrm{E}-02$ & 51.61 & Bin 3 & 12 & $2.33 E-03$ & $5.22 \mathrm{E}-04$ & 22.40 \\
\hline Cluster 4 & 12 & 1.18E-01 & 7.69E-02 & 65.12 & Bin 4 & 43 & $3.49 E-03$ & $1.26 \mathrm{E}-03$ & 35.96 \\
\hline Cluster 5 & 32 & $1.13 E-01$ & $4.84 \mathrm{E}-02$ & 42.83 & Bin 5 & 27 & $6.08 \mathrm{E}-03$ & $3.95 \mathrm{E}-03$ & 65.00 \\
\hline Cluster 6 & 45 & $4.61 \mathrm{E}-02$ & 7.57E-02 & 164.06 & Bin 6 & 8 & $7.71 \mathrm{E}-02$ & $7.78 \mathrm{E}-02$ & 100.86 \\
\hline Cluster 7 & 24 & 1.79E-02 & 7.77E-03 & 43.28 & Bin 7 & 25 & $9.58 \mathrm{E}-03$ & $4.00 \mathrm{E}-03$ & 41.72 \\
\hline Cluster 8 & 73 & $2.94 \mathrm{E}-03$ & $1.21 \mathrm{E}-03$ & 41.25 & Bin 8 & 22 & $4.16 \mathrm{E}-03$ & $1.18 \mathrm{E}-03$ & 28.36 \\
\hline Cluster 9 & 36 & $8.95 \mathrm{E}-03$ & $5.51 \mathrm{E}-03$ & 61.58 & Bin 9 & 58 & 1.03E-01 & 7.03E-02 & 67.99 \\
\hline Cluster 10 & 46 & 1.12E-01 & $5.92 \mathrm{E}-02$ & 52.71 & Bin 10 & 10 & 1.07E-02 & $2.49 \mathrm{E}-03$ & 23.16 \\
\hline Cluster 11 & 10 & $3.50 \mathrm{E}-03$ & 1.04E-03 & 29.69 & Bin 11 & 145 & $9.70 \mathrm{E}-02$ & $5.56 \mathrm{E}-02$ & 57.33 \\
\hline \multicolumn{4}{|r|}{ Mean: } & 57.57 & \multicolumn{4}{|c|}{ Mean: } & 42.72 \\
\hline
\end{tabular}

Source: Output DTN: MO0310SPAPCEAC.002, New Mineral Binning Stats2.xls.

NOTE: $\mathrm{Si}^{4+}$ considered present as $\mathrm{SiO}_{2}$. 


\subsection{EVALUATION OF KEY UNCERTAINTIES}

There are three primary inputs to the P\&CE model, and each has uncertainty associated with it. These inputs are the:

- Composition of seepage water entering the drift. A set of potential seepage waters is selected as input from the suite of possible water compositions from the THC model, as determined by Post-Processing Analysis for THC Seepage (BSC 2004 [DIRS 169858]), and uncertainty in these water compositions is propagated into the P\&CE model. Additional uncertainty is associated with the binning analysis used within this model report (Section 6.6) to further reduce the water compositions to 11 representative waters.

- In-Drift Precipitates/Salts Model (BSC 2004 [DIRS 169863]) and its associated databases (thermodynamic data, modeling assumptions, and other technical information not specific to the site) used in the geochemical modeling of seepage water evaporation that produces the model output.

- Composition and flux of in-drift gases. The atmosphere in the drift, in particular the partial pressure of $\mathrm{CO}_{2}$, will affect in-drift water compositions, especially $\mathrm{pH}$.

These inputs are used in the P\&CE model to estimate the compositions of potential in-drift waters, which in turn are used in the TSPA-LA to evaluate drip shield and waste package corrosion, radionuclide solubility, and colloid stability. The following five parameters are extracted from the P\&CE model output as the seepage evaporation abstraction model and passed as direct input to the TSPA-LA:

- Chloride ion concentration

- Nitrate ion concentration

- Chloride to nitrate ion molar ratio

- Ionic strength

- $\mathrm{pH}$.

Of the three P\&CE model inputs, two have uncertainties that must be propagated into the parameters that are passed to the TSPA-LA: the composition of evaporated seepage waters and the IDPS model. The remaining one, the composition of the in-drift atmosphere, has been screened out. Potential factors affecting composition and flux of in-drift gases, including oxygen consumption by corrosion of the committed materials, are evaluated in Section 6.7. The effects of corrosion are negligible with respect to a continuous presence of an oxidizing environment (Section 6.7.1). Uncertainties in $\mathrm{pCO}_{2}$ concentrations are found to be implicitly propagated by the use of the THC seepage inputs through the five starting water variations, as explained in Section 6.12.1. Thus, uncertainties in the in-drift $p \mathrm{CO}_{2}$ input are propagated to TSPA-LA feeds by the random selection of the starting water and associated gas composition lookup tables.

The effects of corrosion of engineered materials on the water chemistry is evaluated in Section 6.8, and found to be of low consequence. Thus, minor changes in repository design and the amounts of engineered materials have no effect on model uncertainty. 
In the following sections, the ranges and distributions of the relevant uncertainties are developed, and implementation guidance is provided for propagating these uncertainties into the TSPA-LA parameter feeds.

\subsubsection{Uncertainties and Variabilities in the Inputs from THC Model Calculations}

The incoming seepage evaporation abstraction and gas abstraction models, presented respectively in Sections 6.9 and 6.7, incorporate a range of effects due to uncertainties and variability in the THC model by including all five THC model starting water compositions (w0, w4, w5, w6, and w7) into the lookup tables. The choice of input water compositions covers the natural variability of pore-water compositions in the repository units, so the relative spread in predicted water compositions, and in the $\mathrm{CO}_{2}$ partial pressures in equilibrium with them, is in most cases larger than the spread introduced by THC model and model input uncertainties. Drift-Scale THC Seepage Model (BSC 2005 [DIRS 172862]) offers the following insights:

- On initial pore-water and pore-gas chemistry (BSC 2005 [DIRS 172862], Section 6.2.2.1, p. 6-15):

"The choice of input water composition must also consider the natural variability of pore-water compositions in the repository units. This natural variability is illustrated in Figure 6.2-4."

"Given these considerations, several initial water compositions have been selected for use in the current THC seepage model based on the following criteria:

(1) Capture the spread of pore-water compositions shown in Figure 6.2-4 and include, to the extent practicable, waters that may yield different end-brine compositions..."

- On evaluation of model result uncertainty (BSC 2005 [DIRS 172862], Section 6.6.2, p. 6-128):

"In this study, the spread in predicted concentrations of aqueous species and $\mathrm{CO}_{2}$ (i.e., Figures 6.5-11 to 6.5-20 and 6.5-24 to 6.5-37) is related to:

- The natural variability of input water compositions (Sections 6.2.2.1)

- The various investigated model conceptualizations (vapor-pressure model, drift location, stratigraphic columns, open versus closed drift wall) (Table 6.6-1)

- Ranges of input parameters other than water composition (in this case infiltration rates and $\mathrm{CO}_{2}$ diffusion coefficients) (Section 6.5.4).

The relative spread caused by the variability of input water compositions (computed as standard deviation) is shown as a function of time in Table 6.6-2. This spread is up to approximately one order of magnitude and in many cases much less. The spread overlaps with, and in most cases is larger than, the spread 
introduced by use of the different model conceptualizations and ranges of other input data considered (compare Figures 6.5-24a through 6.5-37a to Figures 6.5$24 \mathrm{~b}$ through 6.5-37b). This is quantitatively demonstrated in Post-Processing Analysis for THC Seepage (BSC 2004 [DIRS 169858])."

- On modeled coupled processes and uncertainty (BSC 2005 [DIRS 172862], Section 8.1, p. 8-2):

"These THC Seepage Model simulations covered a wide range of the most important uncertainties, and the range of results obtained is represented by the principal source of uncertainty, which is the natural variability in input water composition. In the spread of simulation results corresponding to the range of input water composition, the uncertainties in predicted concentrations of aqueous species and of $\mathrm{CO}_{2}$ gas are estimated to approximately one order of magnitude or less (Section 6.6.2)."

\subsubsection{Uncertainties in the IDPS Model That Affect Characterization and Binning of Evaporated Seepage Water Compositions}

The IDPS model is used to predict the changing compositions of potential seepage waters as they evolve by evaporation to concentrated brines (BSC 2004 [DIRS 169863], Section 1). Using the IDPS process model, the output of this model is a set of lookup tables that describe the chemical compositions of evaporated seepage waters as a function of relative humidity. As relative humidity decreases, the degree of evaporation or concentration increases, which in turn causes an increase in the salinity of these waters. The output parameters used in TSPA-LA are $\mathrm{pH}$, ionic strength $(I)$, the total concentrations of chloride and nitrate, and the $\mathrm{Cl}^{-} / \mathrm{NO}_{3}{ }^{-}$ratio. The uncertainty in the values of these output parameters due to model uncertainty is addressed in this section. Model uncertainties result from uncertainties in the selected seepage boundary conditions (seepage binning analysis), process model equations (IDPS Pitzer process model), the choice of mineral suppressions, and constraints in the thermodynamic database.

The uncertainty that is readily quantifiable and useful to the TSPA-LA is the uncertainty in the $\mathrm{P} \& \mathrm{CE}$ model output parameter values for $\mathrm{pH}$, ionic strength, total concentrations of chloride and nitrate, and the $\mathrm{Cl}^{-} / \mathrm{NO}_{3}{ }^{-}$ratio. The IDPS model uncertainty contributes to this, and is determined by comparing IDPS model evaporation predictions to experimentally measured data.

The overall IDPS model uncertainty in these outputs is quantified in In-Drift Precipitates/Salts Model (BSC 2004 [DIRS 169863], Section 7.5) and is reproduced here in Table 6.12-1. Note that deliquescence relative humidity (DRH) uncertainty is no longer used (Section 6.10).

The uncertainty values for $I$ and $\mathrm{Cl}^{-}$are in units of log molal, whereas for the $\mathrm{Cl}^{-} / \mathrm{NO}_{3}{ }^{-}$ratio the uncertainty is for the $\log$ of the molal ratio and is therefore unitless. The units for $\mathrm{pH}$ uncertainty are in their native $\mathrm{pH}$ units. It is noted that $\mathrm{Cl}^{-}, \mathrm{NO}_{3}{ }^{-}$and $\mathrm{Cl}^{-} / \mathrm{NO}_{3}{ }^{-}$are not simultaneously independent parameters. 
Table 6.12-1. Estimated Model Uncertainty Ranges for IDPS Model Outputs

\begin{tabular}{|l|l|c|c|c|c|c|}
\hline \multicolumn{1}{|c|}{ Parameter } & \multicolumn{1}{|c|}{ Units } & $\begin{array}{c}\text { RH Range } \\
\mathbf{1 0 0 \%} \text { to } 85 \%\end{array}$ & $\begin{array}{c}\text { RH Range } \\
\mathbf{8 5 \%} \text { to } \mathbf{6 5 \%}\end{array}$ & $\begin{array}{c}\text { RH Range } \\
\mathbf{6 5 \%} \text { to } \mathbf{6 0} \%\end{array}$ & $\begin{array}{c}\text { RH Range } \\
\mathbf{6 0 \%} \text { to } \mathbf{4 0 \%}\end{array}$ & $\begin{array}{c}\text { RH Range } \\
\mathbf{4 0 \%} \text { to } \mathbf{0 \%}\end{array}$ \\
\hline $\mathrm{pH}$ & $\mathrm{pH}$ units & \pm 1 & \pm 1 & \pm 1 & \pm 2 & \pm 2 \\
\hline lonic Strength & log molal & \pm 0.1 & $0^{\mathrm{a}}$ & $0^{\mathrm{a}}$ & $0^{\mathrm{a}}$ & $0^{\mathrm{a}}$ \\
\hline $\mathrm{Cl}^{-}$ & log molal & \pm 0.0 & \pm 0.2 & \pm 0.5 & \pm 0.7 & \pm 0.7 \\
\hline $\mathrm{Cl}^{-} / \mathrm{NO}_{3}{ }^{-}$ & $\begin{array}{l}\text { log molal ratio } \\
\text { (unitless) }\end{array}$ & \pm 0.0 & \pm 0.2 & \pm 0.5 & \pm 0.7 & \pm 1 \\
\hline $\mathrm{DRH}$ & \%RH units & \pm 5 & \pm 10 & \pm 10 & $\pm 10^{\mathrm{b}}$ & $\pm 15^{\mathrm{c}}$ \\
\hline
\end{tabular}

Source: DTN: MO0312SPAESMUN.002 [DIRS 166329].

${ }^{a}$ At $\mathrm{RH}<85 \%$, ionic strength exceeds 3 molal, which is far above the critical ionic strength where colloids are stable and above which dissolved concentration limit uncertainty imposes no limit.

${ }^{b}$ Exceptions:

1. Predicted $\mathrm{DRH}$ for $\mathrm{Ca}\left(\mathrm{NO}_{3}\right)_{2}$ is 20 to $25 \% \mathrm{RH}$ units higher than data: error not conservative.

1. Predicted $\mathrm{DRH}$ for $\mathrm{Ca}\left(\mathrm{NO}_{3}\right)_{2}$ is 20 to $25 \% \mathrm{RH}$ units higher than data.

NOTE: These uncertainties are defined as uniform distributions encompassing approximately $95 \%$ probability. Uncertainties between $85 \% \mathrm{RH}$ and $40 \% \mathrm{RH}$ are based primarily on ternary systems involving $\mathrm{Na}, \mathrm{K}$, and Ca. Uncertainties below $40 \%$ are primarily based on binary and ternary systems involving $\mathrm{Mg}$ and $\mathrm{Ca}$.

\subsubsection{Discretization Uncertainty Associated with Seepage Evaporation Abstraction}

This section examines the uncertainty tied to the seepage evaporation abstraction, where the variability in each of the bins is considered to quantify the largest amount of uncertainty possible within a bin during the evaporative process. The variability is examined at four different relative humidity (or activity of water) conditions: unevaporated, $98 \%, 85 \%$, and $65 \%$. These four snapshot modeling points represent locations that capture the effects of major chemical divides that may occur, such as the precipitation of calcite and halite. At the four locations along the evaporative pathway, the objective is to see where the variability is reasonable, and yet greatest within the bin. The largest amount of variability along this pathway is the uncertainty that can be applied to any given parameter on IDPS seepage chemistry lookup tables. The probability distribution for the within-bin uncertainty is defined to be log-uniform. This uniform distribution is used because the probability of realizing an extreme value is higher than it is for triangular or normal (truncated Gaussian) distributions; thereby resulting in a wider range of seepage compositions considered. A uniform distribution is also generally apparent from Figures 6.6-5 through 6.6-15.

The bin histories for each water (Tables 6.6-9 through 6.6-13) were mapped back to the five unevaporated THC seepage model time history chemistries (Table 6.6-1) in New Non Evaporated Binning Statistics02.xls, which is archived in Output DTN: MO0310SPAEBSUE.002. The standard functions of Excel (median, minimum, maximum, standard deviations: $\sigma$ and $2 \sigma$ ) were used to calculate the linear statistics. This is done to determine the variability within the bins before the chemistries were evaporated. The variability of the unevaporated waters was not included in estimates of binning variability because it decreases rapidly as the waters are "normalized" by even small degrees of evaporation. However, the unevaporated water compositional information is used in Section 7.3.4. 
For the 98 and $85 \%$ relative humidity conditions, the spreadsheets listed in Table 6.12-2 were developed to show the variability of seepage water chemistry due to evaporation to brine water activities corresponding to 98 and 85\% RH. The associated EQ6 input and output files for these two spreadsheets are archived in Output DTN: MO0310SPAEBSSB.002. Recalculating the EQ6 input files listed in Table 6.6-1 at 98 and 85\% relative humidity generates the EQ6 input files used in this calculation. Data for $65 \% \mathrm{RH}$ in Seepage Evaporation Bin log statistics.xls comes from the original binning spreadsheet (Output DTN: MO0508SPAEBSCB.001, Final Checked EBS THC Seepage Binning Abstraction REV 4.xls) documented in Section 6.6.4. GETEQDATA (BSC 2002 [DIRS 173680]) was used to extract the final evaporated result from each output file. Standard Excel functions (median, minimum, maximum, standard deviation: $\sigma)$ are used to calculate the statistics to determine the variability within the bins after the chemistries were evaporated. The extracted output variables, found on the "Data \& Plots" worksheet in both spreadsheets, include $\mathrm{pH}$, activity of water $\left(a_{w} \approx 0.98\right.$ or 0.85$)$, ionic strength (I), and total molalities of the log aqueous constituents (Al, C, Ca, Cl, F, K, Mg, N, Na, S, and $\mathrm{Si})$. The waters in the "Data \& Plots" worksheet are sorted by bin and the chemistries for each of the 11 bins were copied into separate bin worksheets. Two standard deviations $(2 \sigma)$ are considered reasonable for an estimate of the $95 \%$ distribution about the mean for log-normally distributed log-chemistries. Table 6.12-2. Spreadsheets Containing Log-Transformed Data and Statistics for Each of the Uncertainty RH Locations Evaluated

\begin{tabular}{|c|l|}
\hline RH Location (\%) & \multicolumn{1}{c|}{ Spreadsheet Name } \\
\hline 98 & $98 \%$ RH Seepage Evaporation Bin log statistics.xls \\
\hline 85 & $85 \%$ RH Seepage Evaporation Bin log statistics.xls \\
\hline 65 & Seepage Evaporation Bin log statistics.xls \\
\hline
\end{tabular}

Source: Output DTN: SN0508T0510102.024.

A review of the $65 \% \mathrm{RH}$ data indicated that in many instances the uncertainty values were skewed because the evaporative evolution had passed beyond the halite divide, causing larger uncertainty than should be present for the uncertainty caused by bin or lookup table variability. Therefore, only the data from 98 and 85\% RH were used to develop Tables 6.12-3 and 6.12-4. Table 6.12-3 provides the relative humidity location (e.g., 98 or $85 \% \mathrm{RH}$ ) with the most uncertainty (largest $2 \sigma$ value). Only the uncertainties for the parameters of interest to the TSPA-LA are presented in the following tables; uncertainties for all other species of interest can be found in the spreadsheets listed in Table 6.12-2. Ionic strength is not included in this table as its uncertainty is only considered at $98 \% \mathrm{RH}$ (ionic strength is above $1 \mathrm{M}$ at this $\mathrm{RH}$ ). This is because the ionic strength $(I)$ values will only be utilized by the TSPA-LA when $I$ is less than $3 \mathrm{M}$ (e.g., for colloid stability modeling, the colloids are unstable when $I>0.05 \mathrm{M}$ ) (BSC 2004 [DIRS 170025], Section 6.3.1 and Table 6-12). 
Table 6.12-3. Relative Humidity Point with the Most Variability for Bins 1 through 11 for $\mathrm{pH}^{-} \mathrm{Cl}^{-}$, and $\mathrm{Cl}^{-} / \mathrm{NO}_{3}{ }^{-}$

\begin{tabular}{|c|c|c|c|c|c|c|c|c|c|c|c|}
\hline Species & Bin 1 & Bin 2 & Bin 3 & Bin 4 & Bin 5 & Bin 6 & Bin 7 & Bin 8 & Bin 9 & Bin 10 & Bin 11 \\
\hline $\mathrm{pH}$ & 85 & 98 & 85 & 85 & 85 & 98 & 85 & 98 & 98 & 85 & 85 \\
\hline $\mathrm{Cl}^{-}$ & 98 & 98 & 98 & 98 & 98 & 98 & 98 & 98 & 98 & 85 & 98 \\
\hline $\mathrm{Cl}^{-} / \mathrm{NO}_{3}^{-}$ & $85 / 98$ & $85 / 98$ & $85 / 98$ & $85 / 98$ & $85 / 98$ & $85 / 98$ & $85 / 98$ & $85 / 98$ & $85 / 98$ & $85 / 98$ & $85 / 98$ \\
\hline
\end{tabular}

NOTES: lonic strength was only considered at the $98 \% \mathrm{RH}$ level.

The $\mathrm{Cl}^{-} / \mathrm{NO}_{3}{ }^{-}$ratio is the same for $85 \%$ and $98 \% \mathrm{RH}$.

Given the $2 \sigma$ statistics presented in the spreadsheets in Table 6.12-2 and the RH location where the most variability lies (Table 6.12-3), Table 6.12-4 has been developed to give the uncertainty that can be applied to any given discrete parameter used in the TSPA-LA.

Table 6.12-4. Uncertainty Applied to the IDPS Seepage Lookup Tables for $\mathrm{pH}, I_{,} \mathrm{Cl}^{-}$, and $\mathrm{Cl}^{-} / \mathrm{NO}_{3}{ }^{-}$

\begin{tabular}{|l|l|l|l|l|l|l|l|l|l|l|l|}
\hline \multicolumn{1}{|c|}{ Species } & Bin 1 & Bin 2 & Bin 3 & Bin 4 & Bin 5 & Bin 6 & Bin 7 & Bin 8 & Bin 9 & Bin 10 & Bin 11 \\
\hline$\pm \mathrm{pH}$ & 0.13 & 0.25 & 0.42 & 0.65 & 0.49 & 0.77 & 0.28 & 0.33 & 0.46 & 0.12 & 1.05 \\
\hline$\pm \log \mathrm{I}^{\mathrm{a}}$ & 0.04 & 0.06 & 0.03 & 0.08 & 0.07 & 0.11 & 0.04 & 0.04 & 0.07 & 0.03 & 0.05 \\
\hline$\pm \log \mathrm{Cl}^{-}$ & 0.13 & 0.10 & 0.03 & 0.30 & 0.13 & 0.17 & 0.48 & 0.50 & 0.38 & 0.11 & 0.43 \\
\hline$\pm \log \mathrm{Cl}^{-} / \mathrm{NO}_{3}{ }^{-}$ & 0.92 & 0.67 & 0.43 & 1.10 & 0.57 & 0.97 & 0.56 & 0.73 & 0.53 & 0.75 & 0.32 \\
\hline
\end{tabular}

Source: Output DTN: MO0311SPAEPMUT.000.

${ }^{\text {a }}$ Based on $98 \% \mathrm{RH}$ results only.

NOTE: Uncertainty based on $2 \sigma$ values.

The use of uncertainty on the $\log$ of $\mathrm{Cl}^{-} / \mathrm{NO}_{3}{ }^{-}$is implemented in order to account for correlation between these two species. This is done rather than passing along an independent nitrate uncertainty value that is not related to the variability in chloride. One of the strongest correlations exists in Bin 9 at $98 \%$, where the $\log$ nitrate uncertainty $2 \sigma$ value is 0.72 (from calculations within Output DTN: SN0508T0510102.024) compared to the $\log \mathrm{Cl}^{-} / \mathrm{NO}_{3}{ }^{-} 2 \sigma$ value of 0.53 (Table 6.12-4). This is a way to implement correlation because, for example, if the $\log$ chloride value goes to an extreme value low $(-0.38$ for Bin 9$)$, the log nitrate will not exceed outside the $\log \mathrm{Cl}^{-} / \mathrm{NO}_{3}{ }^{-}$range (maximum difference of +0.53 ). Conversely, using nitrate uncertainty instead could result in an extreme $\log \mathrm{Cl}^{-} / \mathrm{NO}_{3}{ }^{-}$ratio difference of 1.10 $\left(\log \mathrm{NO}_{3}{ }^{-} 2 \sigma\right.$ value of 0.72 plus $\log \mathrm{Cl}^{-}$of 0.38 ). Section 6.12.5.3 provides specific TSPA-LA implementation instructions.

\subsubsection{Factors Showing No Significant Impact on Water Chemistry}

Several potential sources of perturbation to the predicted water chemistries contained within the lookup tables have been evaluated in sensitivity studies. These include:

- Degradation of stainless steel in the ground support material

- Inclusion of bromide in the evaporated seepage water compositions 
- Lookup table extrapolation as a function of $\mathrm{pCO}_{2}$

- Use of alternate mineral suppressions.

Analyses performed on the first two of these sources demonstrate that there is no increase in overall model uncertainty, except in the case where $\mathrm{Cr}(\mathrm{VI})$ is designated as the stable chromium oxidation state. For $p \mathrm{CO}_{2}$, it is shown that extrapolation outside the lookup table values $\left(p \mathrm{CO}_{2}\right.$ at $10^{-2}, 10^{-3}$, and $10^{-4}$ bar) is valid within the modeling error, with the only significant effect upon $\mathrm{pH}$ being $\sim 0.15 \mathrm{pH}$ units at $\mathrm{pCO}_{2}=2 \times 10^{-2}$ bar, which is the highest $\mathrm{pCO}_{2}$ found in the lookup tables. Alternate mineral suppressions are also examined, and in general are found to have no significant effect upon lookup table values, with the largest deviation being approximately $0.2 \mathrm{pH}$ units.

These studies show that variations due to these factors are well within the model uncertainty ranges and demonstrate that any additional errors caused by their exclusion from the lookup table calculations are subsumed by other modeling uncertainties (see Section 6.12.5.2 for uncertainty values determined for the TSPA-LA lookup tables).

For the calculations produced in this section, a general base case is selected. This is done to characterize the uncertainty that is possible within the preceding model calculations. This case represents the commonly recurring (based on actual number of data points available) evaporated seepage water bin (Bin 11 in Table 6.6-5). The base-case files are listed in Table 6.12-5.

Table 6.12-5. Base-Case EQ3/6 Input Files for Uncertainty Analysis

\begin{tabular}{|c|c|}
\hline $\begin{array}{c}\text { Seepage Water } \\
\text { Bin 11EQ3 Input File }\end{array}$ & $\begin{array}{c}\text { Seepage Water } \\
\text { Bin 11EQ6 }^{\text {Input File }}\end{array}$ \\
\hline bin11.3i & $11 c 3 t 7 e .6 i$ \\
\hline
\end{tabular}

${ }^{a}$ Output DTN: MO0304MWDSAB11.001.

${ }^{b}$ Output DTN: MO0304MWDEBSSA.000.

\subsubsection{Degradation of Stainless Steel in Ground Support Components}

A range of possible sources of uncertainty in the seepage with ground support analysis for Stainless Steel Type 316L is examined here. All but one source were found to have no effect on the values of the lookup table results, with all deviations less than 0.04 for $\mathrm{pH}$ and 0.01 molal for ionic strength. Use of $\mathrm{Cr}(\mathrm{VI})$ resulted in a large drop in $\mathrm{pH}$ (to 2.7 unevaporated) and increased ionic strength by 0.56 molal when evaporated. Comparisons are primarily made to the base-case scenario of evaporated seepage waters, whose files are labeled as "Run" number 2 in Table 6.8-2. Some of the uncertainty cases required their own "base-case" calculation run for comparative purposes, included in Sections 6.12.4.1.3 through 6.12.4.1.4, due to changes in their basic chemical parameters (e.g., $p \mathrm{CO}_{2}$ ).

All calculation runs utilized a modified data0.YMP.R2 thermodynamic database as was described in Section 6.8.3; this modification is contained in Cr-database.zip within Output DTN: SN0312T0510102.013. 


\subsection{Alternate Corrosion Rates}

A sensitivity analysis has been performed with a corrosion rate ten times greater than the base-case value. This higher corrosion rate is investigated to evaluate the base-case model results and determine the effect upon seepage water chemistries. This analysis is implemented by increasing the fictive Stainless Steel Type 316L species dissolved into the Bin 11 crown seepage water by a factor of ten, resulting in the addition of $4.7 \times 10^{-2}$ moles of Stainless Steel Type 316L. Table 6.12-6 shows the EQ6 input/output files generated for this uncertainty case. The bottom half of the pickup file from ssbin11.6p is used as the bottom half of the subsequent ssbin11e.6i evaporation run.

Table 6.12-6. EQ6 Input/Output Files for Stainless Steel Type 316L Corrosion Rate Uncertainty Case

\begin{tabular}{|c|c|c|}
\hline Input File Names & Output File Names & Pickup File Names \\
\hline SSBin11.6i & ssbin11.60 & ssbin11.6p \\
\hline ssbin11e.6i & ssbin11e.6o & - \\
\hline
\end{tabular}

Source: Output DTN: SN0312T0510102.013, Uncertainties.zip.

NOTE: These files are in directory: ICor Rate.

The calculated results of this uncertainty run are compared with the bounding base-case model; the results are summarized in Table 6.12-7. There is no calculable difference in the aqueous water chemistry.

Table 6.12-7. Comparison of $\mathrm{pH}$ and Ionic Strength for Corrosion Rate Uncertainty Case

\begin{tabular}{|c|c|c|c|c|c|c|}
\hline \multirow{2}{*}{$\mathbf{R H}(\%)$} & \multicolumn{2}{|c|}{ Uncertainty Case } & \multicolumn{2}{c|}{ Base Case } & \multicolumn{2}{c|}{ Difference } \\
\cline { 2 - 7 } & $\mathbf{p H}$ & $\boldsymbol{I}$ (molal) & $\mathbf{p H}$ & $\boldsymbol{I}$ (molal) & $\mathbf{p H}$ & $\boldsymbol{I}$ (molal) \\
\hline 100 & 7.880 & 0.00606 & 7.879 & 0.00605 & 0.001 & 0.00001 \\
\hline 98 & 9.462 & 0.7313 & 9.462 & 0.7312 & 0.000 & 0.0001 \\
\hline
\end{tabular}

Source: Output DTN: SN0312T0510102.013, Uncertainties.zip, UncertaintyCases.xls, sheet "Corrosion Rate."

\subsubsection{2 $\operatorname{Cr}(\mathrm{VI})$}

A sensitivity analysis is performed to examine the impact on seepage water chemistry resulting from the formation of $\mathrm{Cr}(\mathrm{VI})$, which could occur under extremely oxidizing conditions. As this case requires a completely new speciation from that of the base case, an EQ3NR calculation run is required and its pickup file is used as the bottom half of the calculated EQ6 Stainless Steel Type 316L dissolution run. Also, the bottom half of the pickup file from ssbin11.6p is used as the bottom half of the subsequent calculated ssbin11e.6i evaporation run. Table 6.12-8 contains the EQ3/6 filenames for this uncertainty case.

The results of this uncertainty run are also compared with the bounding base case and are summarized in Table 6.12-9. Unlike the other stainless steel sensitivity cases, dramatic changes are seen in the predicted $\mathrm{pH}$ and ionic strength. This is directly due to the production of five protons for every $\mathrm{Cr}(\mathrm{III})$ converted to $\mathrm{Cr}(\mathrm{VI}) \mathrm{O}_{4}{ }^{2-}$, which exceeds the acid neutralizing capacity of the seepage water from $\mathrm{CO}_{2}(\mathrm{~g})$ buffering. As discussed in Section 6.8.3, it is unlikely that $\mathrm{Cr}(\mathrm{VI})$ will significantly contribute to the in-drift chemical environment. 
Table 6.12-8. EQ3/6 Input/Output Files for Stainless Steel Type 316L Cr(VI) Uncertainty Case

\begin{tabular}{|c|c|c|}
\hline Input File Names & Output File Names & Pickup File Names \\
\hline bin11.3i & bin11.3o & bin11.3p \\
\hline SSBin11.6i & ssbin11.6o $11.6 p$ \\
\hline ssbin11e.6i & ssbin11e.6o & - \\
\hline
\end{tabular}

Source: Output DTN: SN0312T0510102.013, Uncertainties.zip.

NOTE: These files are in directory: $\mathrm{ICr}(\mathrm{VI})$.

Table 6.12-9. Comparison of $\mathrm{pH}$ and lonic Strength for $\mathrm{Cr}(\mathrm{VI})$ Uncertainty Case

\begin{tabular}{|c|c|c|c|c|c|c|}
\hline \multirow{2}{*}{ RH } & \multicolumn{2}{|c|}{ Uncertainty Case } & \multicolumn{2}{c|}{ Base Case } & \multicolumn{2}{c|}{ Difference } \\
\cline { 2 - 7 } & $\mathbf{p H}$ & $\boldsymbol{I}$ (molal) & $\mathbf{p H}$ & $\boldsymbol{I}$ (molal) & $\mathbf{p H}$ & $\boldsymbol{I}$ (molal) \\
\hline 100 & 2.7281 & 0.00922 & 7.879 & 0.00605 & -5.1509 & 0.00317 \\
\hline 98 & 1.7107 & 1.28679 & 9.462 & 0.7312 & -7.7514 & 0.5556 \\
\hline
\end{tabular}

Source: Output DTN: SN0312T0510102.013, Uncertainties.zip, UncertaintyCases.xls, sheet "Cr(VI)."

NOTE: $\quad$ I = ionic strength.

\subsection{Bin 7 Seepage}

Another unevaporated crown seepage water has been examined to determine whether a different starting water chemistry would affect the Stainless Steel Type 316L interactions. Bin 7 (Output DTN: MO0304MWDSAB11.001) was chosen because it represents seepage water that is likely to enter the repository during relatively long periods (i.e., 10,000 years; Tables 6.6-9 through 6.6-13), thus being appropriate given the potentially long lifetimes of stainless steel.

The EQ3/6 input, output, and pickup files are listed in Table 6.12-10. Because a different starting water composition is used, the EQ3NR speciation was rerun by replacing the water chemistry description in file Bin11.3i (Section 6.8.4.1) with the descriptions residing in Bin 7. The rest of the procedure is identical to that used for the base-case calculation runs described in Section 6.8.4.1.

Table 6.12-10. EQ3/6 Input/Output Files for Stainless Steel Type 316L Bin 7 Uncertainty Case

\begin{tabular}{|c|c|c|}
\hline Input File Names & Output File Names & Pickup File Names \\
\hline Bin07.3i & bin07.3o & bin07.3p \\
\hline Bin07e.6i & bin07e.6o & ssbin07.6p $p$ \\
\hline SSBin07.6i & ssbin07.6o & - \\
\hline Ssbin07E.6i & sssbin07e.6o & \\
\hline
\end{tabular}

Source: Output DTN: SN0312T0510102.013, Uncertainties.zip.

NOTE: These files are in directory: $\mid B i n$.

The results of this uncertainty calculation run are compared with the pure Bin 7 seepage water evaporation results; these results are summarized in Table 6.12-11. As with the base-case Bin 11 seepage water, there is effectively no change in the aqueous water chemistry caused by stainless steel corrosion and corrosion product formation in this case. 
Table 6.12-11. Comparison of $\mathrm{pH}$ and lonic Strength for Bin 7 Uncertainty Case

\begin{tabular}{|c|c|c|c|c|c|c|}
\hline \multirow{2}{*}{$\mathbf{R H}$} & \multicolumn{2}{|c|}{ Uncertainty Case } & \multicolumn{2}{c|}{ Base Case } & \multicolumn{2}{c|}{ Difference } \\
\cline { 2 - 7 } & $\mathbf{p H}$ & $\boldsymbol{I}$ (molal) & $\mathbf{p H}$ & $\boldsymbol{I}$ (molal) & $\mathbf{p H}$ & $\boldsymbol{I}$ (molal) \\
\hline 100 & 8.240 & 0.0110 & 8.240 & 0.0110 & 0.000 & 0.0000 \\
\hline 98 & 9.520 & 0.7283 & 9.520 & 0.7284 & 0.000 & -0.0001 \\
\hline
\end{tabular}

Source: Output DTN: SN0312T0510102.013, Uncertainties.zip, UncertaintyCases.xls, sheet "Bin 07."

NOTE: $\quad I=$ ionic strength.

\subsubsection{4 $\quad \mathrm{CO}_{2}$ Pressures}

Two additional pressures for $\mathrm{CO}_{2}$ gas are examined as uncertainty cases; these are taken at $10^{-2}$ and $10^{-4}$ bar. These pressure uncertainty calculation runs are compared to the pure Bin 11 water chemistries calculated at the same $\mathrm{pCO}_{2}$.

The EQ3/6 input, output and pickup files are listed in Table 6.12-12 for the uncertainty case. As a different starting water pressure of $\mathrm{CO}_{2}$ is used, the EQ3NR speciation is rerun and the resulting pickup file bin11.3p is attached to the bottom half of the two EQ6 calculation runs: Bin11e.6i and SSBin11.6i for the pure Bin 11 evaporation and SS316L/Bin 11 mixing calculation runs, respectively. The bottom half of the pickup file ssbin11.6p is used by the evaporation EQ6 calculation run ssbin11E.6i.

Table 6.12-12. EQ3/6 Input/Output Files for Stainless Steel Type 316 $p \mathrm{CO}_{2}=10^{-2}$ bar Uncertainty Case

\begin{tabular}{|c|c|c|}
\hline Input File Names & Output File Names & Pickup File Names \\
\hline Bin11.3i & bin11.30 & bin11.3p \\
\hline Bin11e.6i & bin11e.60 & bin11e.6p \\
\hline SSBin11.6i & ssbin11.6o & ssbin11.6p \\
\hline ssbin11E.6i & ssbin11e.6o & - \\
\hline
\end{tabular}

Source: Output DTN: SN0312T0510102.013.

NOTE: These files are in directory: IPCO2 -2.

The results of the pressure uncertainty calculation run at $10^{-2}$ bar are compared with the evaporation of pure Bin 11 water results at the same $\mathrm{pCO}_{2}$, summarized in Table 6.12-13. There is no significant change in the predicted water chemistry caused by stainless steel corrosion and corrosion product formation at this higher $\mathrm{pCO}_{2}$.

Table 6.12-13. Comparison of $\mathrm{pH}$ and lonic Strength for $\mathrm{pCO}_{2}=10^{-2}$ bar Uncertainty Case

\begin{tabular}{|c|c|c|c|c|c|c|}
\hline \multirow{2}{*}{ RH } & \multicolumn{2}{|c|}{ Uncertainty Case } & \multicolumn{2}{c|}{ Base Case } & \multicolumn{2}{c|}{ Difference } \\
\cline { 2 - 7 } & $\mathbf{p H}$ & $\boldsymbol{I}$ (molal) & $\mathbf{p H}$ & $\boldsymbol{I}$ (molal) & $\mathbf{p H}$ & $\boldsymbol{I}$ (molal) \\
\hline 100 & 6.898 & 0.00606 & 6.898 & 0.00605 & 0.000 & 0.00000 \\
\hline 98 & 8.741 & 0.7015 & 8.741 & 0.7012 & 0.000 & 0.0003 \\
\hline
\end{tabular}

Source: Output DTN: SN0312T0510102.013, Uncertainties.zip, UncertaintyCases.xls, sheet "PCO2=-2."

NOTE: $\quad I=$ ionic strength. 
The EQ3/6 input, output, and pickup files for the case with the $p \mathrm{CO}_{2}$ set at $10^{-4}$ bar are listed in Table 6.12-14. Because a different starting pressure of $\mathrm{CO}_{2}$ is used, the EQ3NR speciation was redone and the resulting pickup file bin11.3p was fed to the bottom half of the two EQ6 calculation runs: Bin11e.6i and SSBin11.6i for the pure Bin 11 evaporation and SS316L/Bin 11 mixing calculation runs, respectively. Again, the bottom half of the pickup file ssbin11.6p is used by the evaporation EQ6 calculation run, ssbin11E.6i.

Table 6.12-14. EQ3/6 Input/Output Files for Stainless Steel Type $316 \mathrm{pCO}_{2}=10^{-4}$ bar Uncertainty Case

\begin{tabular}{|c|c|c|}
\hline Input File Names & Output File Names & Pickup File Names \\
\hline Bin11.3i & bin11.3o & bin11.3p \\
\hline Bin11e.6i & bin11e.6o $11 e .6 p$ \\
\hline SSBin11.6i & ssbin11.6o & ssbin11.6p \\
\hline ssbin11E.6i & ssbin11e.6o & - \\
\hline
\end{tabular}

Source: Output DTN: SN0312T0510102.013, Uncertainties.zip.

NOTE: These files are in directory: IPCO2 -4.

The results of this pressure uncertainty calculation run at $10^{-4}$ bar are compared with the pure unevaporated Bin 11 seepage water evaporation results at the same $\mathrm{pCO}_{2}$; these are summarized in Table 6.12-15. There is no significant change in the water chemistry caused by stainless steel corrosion and corrosion product formation at this lower $\mathrm{CO}_{2}$ pressure.

Table 6.12-15. Comparison of $\mathrm{pH}$ and lonic Strength for $\mathrm{pCO}_{2}=10^{-4}$ bar Uncertainty Case

\begin{tabular}{|c|l|l|l|l|l|l|}
\hline \multirow{2}{*}{ RH } & \multicolumn{2}{|c|}{ Uncertainty Case } & \multicolumn{2}{c|}{ Base Case } & \multicolumn{2}{c|}{ Difference } \\
\cline { 2 - 7 } & $\mathbf{p H}$ & $I$ (molal) & $\mathbf{p H}$ & $\boldsymbol{I}$ (molal) & $\mathbf{p H}$ & $\boldsymbol{I}$ (molal) \\
\hline 100 & 8.726 & 0.00600 & 8.726 & 0.00600 & 0.000 & 0.00000 \\
\hline 98 & 9.957 & 0.7088 & 9.957 & 0.7089 & 0.000 & -0.0002 \\
\hline
\end{tabular}

Source: Output DTN: SN0312T0510102.013, Uncertainties.zip, UncertaintyCases.xls, sheet "PCO2=-4."

NOTE: $I=$ ionic strength.

\subsubsection{Evaporative Concentration of Bromide}

The starting pore water compositions provided by the U.S. Geological Survey (DTN: GS020408312272.003 [DIRS 160899]), which are used as chemical inputs into the THC seepage analysis, give trace quantities of many chemical components including $\mathrm{Br}^{-}$. Bromide is a halide species that behaves conservatively in aqueous solutions, much like $\mathrm{Cl}^{-}$, and will tend to concentrate in solution upon evaporation. Because total aqueous $\mathrm{Br}^{-}$is not a modeled species in the IDPS seepage evaporation abstraction model, no direct model output for $\mathrm{Br}^{-}$concentration is available. However, because halides are of concern to corrosion modeling, it is important to know to what level bromide would concentrate if present in the initial water. This sensitivity study investigates the evaporative concentration of $\mathrm{Br}^{-}$in seepage waters. The results show that the concentration of $\mathrm{Br}^{-}$is small compared to the total halide concentrations. Therefore, the seepage compositions as presented in the lookup tables are adequate for the present application. 


\subsection{Conceptual Framework}

The calculation presented here compares the evaporative concentration of $\mathrm{Br}^{-}$as a function of the $\mathrm{Cl}^{-} / \mathrm{Br}^{-}$ratio in the starting pore-water compositions to the base-case seepage analysis bin file listed in Table 6.12-5.

\subsection{Calculation Set Up}

Three bounding evaporation cases are developed by altering the unevaporated seepage water base-case EQ3 input file (bin11.3i; see Table 6.12-5) through the addition of $\mathrm{Br}^{-}$to the starting water composition. The $\mathrm{Cl}^{-} / \mathrm{Br}^{-}$ratio is calculated for samples collected at locations along the drift, as shown in Table 6.12-16 (from DTN: GS020408312272.003 [DIRS 160899]).

The concentration of $\mathrm{Cl}^{-}$in each sample is divided by the value of $\mathrm{Br}^{-}$(both in units of $\mathrm{mg} / \mathrm{L}$ ) to obtain the $\mathrm{Cl}^{-} / \mathrm{Br}^{-}$ratio. For concentrations of $\mathrm{Br}^{-}$below the detection limit, the value of $\mathrm{Br}$ used for the calculation is one half of the detection limit and is indicated in the column labeled "Br ${ }^{-} \mathrm{mg} / \mathrm{L}^{\mathrm{a}}$." From the ratios calculated, the mean, maximum, and minimum values are obtained using the built-in functions in Excel from Cl_BrREV2.xls (Table 6.12-17; Output DTN: MO0505MWDEBSCP.000).

The ratios found from this calculation are then used to calculate the amount of bromide to be added to the base-case 3 i file (bin11.3i; Table 6.12-5). By dividing the chloride constraint value in Bin $11\left(1.30 \times 10^{-3} \mathrm{~mol}\right)$ from the base-case 3i file (bin11.3i; Table 6.12-5) by the $\mathrm{Cl}^{-} / \mathrm{Br}^{-}$ ratio, as calculated in Cl_BrREV2.xls (Output DTN: MO0505MWDEBSCP.000), three bromide concentrations are obtained as presented in Table 6.12-18.

Each $\mathrm{Br}^{-}$value found in Table 6.12-18 is then inserted into the base-case EQ3 input file and run in EQ3 using the data0.ypf.R0 Pitzer database file (DTN: SN0302T0510102.002 [DIRS 162572]), generating the EQ3 input and output files listed in Table 6.12-19. Once the new values for $\mathrm{Br}^{-}$are added to the three $3 \mathrm{i}$ files, they are run using EQ3 v8.0. The pickup files replaced the bottom half of the base-case $6 \mathrm{i}$ file. Then, the $6 \mathrm{i}$ files are run at three temperatures $\left(40^{\circ} \mathrm{C}, 70^{\circ} \mathrm{C}\right.$, and $\left.100^{\circ} \mathrm{C}\right)$ using EQ6 (BSC 2003 [DIRS 162228]; see Section 3.1) to obtain the final results of the alternate evaporation reaction. Lookup tables are generated using GETEQDATA (BSC 2002 [DIRS 173680]) to compare the results of the three $\mathrm{Br}^{-}$added evaporation runs to the base case.

Table 6.12-16. $\mathrm{Cl}^{-}$and $\mathrm{Br}^{-}$Data for Pore Waters Collected in the Enhanced Characterization of the Repository Block

\begin{tabular}{|c|l|c|c|c|c|c|}
\hline & \multicolumn{1}{|c|}{ Local Sample Name } & SPC Number & $\begin{array}{c}\mathrm{Cl}^{-} \\
\mathbf{m g} / \mathbf{L}\end{array}$ & $\begin{array}{c}\mathrm{Br}^{-} \\
\mathbf{m g} / \mathbf{L}\end{array}$ & $\begin{array}{c}\mathrm{Br}^{-} \\
\mathbf{m g} / \mathbf{L}^{\mathbf{a}}\end{array}$ & $\begin{array}{c}\mathrm{Cl}^{-} / \mathrm{Br}^{-} \\
\text {ratio }^{-}\end{array}$ \\
\hline 1 & ECRB-SYS-CS400/3.8-4.3/UC & SPC00554610 & 29 & $<1$ & 0.5 & 58 \\
\hline 2 & ECRB-SYS-CS400/5.6-6.2/UC & SPC00554611 & 21 & $<1$ & 0.5 & 42 \\
\hline 3 & ECRB-SYS-CS600/3.6-4.0/UC & SPC00554612 & 22 & $<1$ & 0.5 & 44 \\
\hline 4 & ECRB-SYS-CS1000/7.3-7.7/UC & SPC00554613 & 21 & $<1$ & 0.5 & 42 \\
\hline 5 & ECRB-SYS-CS750/6.2-6.5/UC & SPC00554614 & 73 & $<1$ & 0.5 & 146 \\
\hline 6 & ECRB-SYS-CS2150/5.5-6.1/UC & SPC00554615 & 27 & $<0.2$ & 0.1 & 270 \\
\hline 7 & ECRB-SYS-CS900/5.4-5.9/UC & SPC00554616 & 37 & $<0.2$ & 0.1 & 370 \\
\hline
\end{tabular}


Table 6.12-16. $\mathrm{Cl}^{-}$and $\mathrm{Br}^{-}$Data for Pore Waters Collected in the Enhanced Characterization of the Repository Block (Continued)

\begin{tabular}{|c|l|l|c|c|c|c|}
\hline \multicolumn{1}{|c|}{ Local Sample Name } & SPC Number & $\begin{array}{c}\mathbf{C l}^{-} \\
\mathbf{m g} / \mathbf{L}\end{array}$ & $\begin{array}{c}\mathrm{Br}^{-} \\
\mathbf{m g} / \mathbf{L}\end{array}$ & $\begin{array}{c}\mathbf{B r}^{-} \\
\mathbf{m g}^{-} \mathbf{L}^{\mathbf{a}}\end{array}$ & $\begin{array}{c}\mathbf{C l}^{-} / \mathrm{Br}^{-} \\
\mathbf{r a t i o}\end{array}$ \\
\hline 8 & ECRB-SYS-CS850/5.1-5.6/UC & SPC00554617 & 32 & $<0.2$ & 0.1 & 320 \\
\hline 9 & SD-9/990.4-991.7/UC & SPC00554618 & 23 & $<0.2$ & 0.1 & 230 \\
\hline 10 & ECRB-SYS-CS900/3.5-4.1/UC & SPC00554619 & 53 & 0.3 & 0.3 & 177 \\
\hline 11 & ECRB-SYS-CS1000/12.9-14.0/UC & SPC00554620 & 22 & $<0.1$ & 0.05 & 440 \\
\hline 12 & ECRB-SYS-CS450/5.3-6.0/UC & SPC00554621 & 66 & 0.4 & 0.4 & 165 \\
\hline 13 & ECRB-SYS-CS2300/4.3-4.9/UC & SPC00554622 & 23 & $<0.1$ & 0.05 & 460 \\
\hline 14 & ECRB-SYS-CS500/12.0-16.7/UC & SPC00554800 & 54 & 0.4 & 0.4 & 135 \\
\hline 15 & ECRB-SYS-CS2000/16.5-21.1/UC & SPC00554801 & 26 & $<0.2$ & 0.1 & 260 \\
\hline 16 & ECRB-SYS-CS2000/16.3-16.5/UC & SPC00554802 & 24 & $<0.2$ & 0.1 & 240 \\
\hline 17 & ECRB-SYS-CS950/5.2-5.3/UC & SPC00554803 & 19 & $<0.2$ & 0.1 & 190 \\
\hline 18 & ECRB-SYS-CS950/4.8-5.5/UC & SPC00554804 & 30 & $<0.2$ & 0.1 & 300 \\
\hline 19 & SD-9/991.7-992.1/UC & SPC00554805 & 26 & 0.1 & 0.1 & 260 \\
\hline 20 & ECRB-SYS-CS1250/5.0-5.7/UC & SPC00554806 & 50 & 0.2 & 0.2 & 250 \\
\hline 21 & ECRB-SYS-CS1250/3.4-4.0/UC & SPC00554807 & 25 & NM & - & - \\
\hline 22 & SD-9/670.5-670.6/UC & SPC00554808 & 46 & 0.3 & 0.3 & 153 \\
\hline 23 & ECRB-SYS-CS800/4.9-5.6/UC & SPC00554809 & 20 & NM & - & - \\
\hline 24 & ECRB-SYS-CS700/5.5-5.8/UC & SPC00554810 & 64 & $<0.1$ & 0.05 & 1280 \\
\hline 25 & NRG-7/7A/839.3-839.8/UC & SPC00554811 & 31 & 0.1 & 0.1 & 310 \\
\hline
\end{tabular}

Source: DTN: GS020408312272.003 [DIRS 160899].

a The value of bromide actually used for further analysis.

NOTES: "NM" = not measured.

Table 6.12-17. Mean, Minimum, and Maximum $\mathrm{Cl}^{-} / \mathrm{Br}^{-}$Ratios Present in Drift Samples

\begin{tabular}{|c|c|}
\hline Parameter & $\mathrm{Cl}^{-} / \mathrm{Br}^{-}$ \\
\hline Mean & 267 \\
\hline Min & 42 \\
\hline Max & 1280 \\
\hline
\end{tabular}

Source: Output DTN: MO0505MWDEBSPC.000, SeepageBrSensitivityStudy.zip, Cl_BrREV2.xIs.

Table 6.12-18. Bromide Values Used in EQ3 Input Files

\begin{tabular}{|c|c|}
\hline Parameter & Bromide Constraint Value (molal) \\
\hline Median & $4.87 \mathrm{E}-06$ \\
\hline Low & $1.02 \mathrm{E}-06$ \\
\hline High & $3.10 \mathrm{E}-05$ \\
\hline
\end{tabular}

Source: Output DTN: MO0505MWDEBSPC.000, SeepageBrSensitivityStudy.zip, Cl_BrREV2.xls. 
Table 6.12-19. Bromide Uncertainty Analysis EQ3/6 Input and Output Files

\begin{tabular}{|c|c|c|c|}
\hline File Type & High $\mathrm{Br}^{-}$ & Median $\mathrm{Br}^{-}$ & Low $\mathrm{Br}^{-}$ \\
\hline EQ3 Input File Name & B11Mxbr.3i & NewB11Avgbr.3i & B11Mnbr.3i \\
\hline EQ3 Output File Name & b11mxbr.3o & newb11av.3o & b11mnbr.3o \\
\hline Pickup File Name & $b 11 m \times b r .3 p$ & newb11av.3p & b11mnbr.3p \\
\hline EQ6 Input File Name & $\begin{array}{l}\text { B11Mxbr.6i } \\
11 M \times b r 1.6 i \\
11 M \times b r 4.6 i\end{array}$ & $\begin{array}{c}\text { NewB11Avgbr.6i } \\
\text { NewB11Avgbr1.6i } \\
\text { NewB11Avgbr4.6i }\end{array}$ & $\begin{array}{l}\text { B11Mnbr.6i } \\
11 M n b r 1.6 i \\
11 M n b r 4.6 i\end{array}$ \\
\hline EQ6 Output File Name & $\begin{array}{l}b 11 m \times b r .60 \\
11 m \times b r 1.60 \\
11 m \times b r 4.60 \\
\end{array}$ & $\begin{array}{l}\text { newb11av.6o } \\
\text { newb11av1.6o } \\
\text { newb11av4.6o }\end{array}$ & $\begin{array}{l}\text { b11mnbr.6o } \\
11 \mathrm{mnbr} 1.60 \\
11 \mathrm{mnbr} 4.60 \\
\end{array}$ \\
\hline Lookup Table File Name & bin11mxbrLT.xls & Bin11avgbrLT.xIs & bin11mnbrLT.xls \\
\hline
\end{tabular}

Source: Output DTN: MO0505MWDEBSPC.000, within SeepageBrSensitivityStudy.zip.

\subsection{Results of Bromide in Evaporated Seepage Waters}

Figure 6.12-1 depicts the total $\mathrm{Br}^{-}$concentration as the seepage water is evaporated; when added to the starting waters in concentrations found in the pore waters, $\mathrm{Br}^{-}$concentration is used as input to the THC seepage analysis. Concentrations of $\mathrm{Br}^{-}$can become large as evaporation progresses and brines become more and more concentrated. Below relative humidity of approximately $70 \%$, the results start to show the temperature dependency of $\mathrm{KBr}$ saturation; higher $\mathrm{Br}^{-}$concentrations tend to be possible at lower temperatures. At very low relative humidity, the $\mathrm{Br}^{-}$concentrations in solution can become rather high, on the order of 1 to 3 molal. At the lowest lookup table $\mathrm{RH}$ of $65 \%$, the maximum $\mathrm{Br}^{-}$concentration is 0.4 molal, and is typically much lower.

Also shown in this section are the effects of $\mathrm{Br}^{-}$addition on predicted ionic strength and $\mathrm{pH}$ (Figures 6.12-2 and 6.12-3). Over the entire RH range examined, the presence of $\mathrm{Br}^{-}$in solution causes no noticeable change in the predicted $\mathrm{pH}$ values. The effect on ionic strength is small but increases with evaporation. It is greatest at low relative humidity, where the uncertainty can be as large as 1 to 5 molal. At $65 \% \mathrm{RH}$, only the $40^{\circ} \mathrm{C}$ data show a significant deviation. In the high $\mathrm{Br}$ case, the predicted ionic strength is lowered by approximately 1 molal (approximately $8 \%$ relative). 


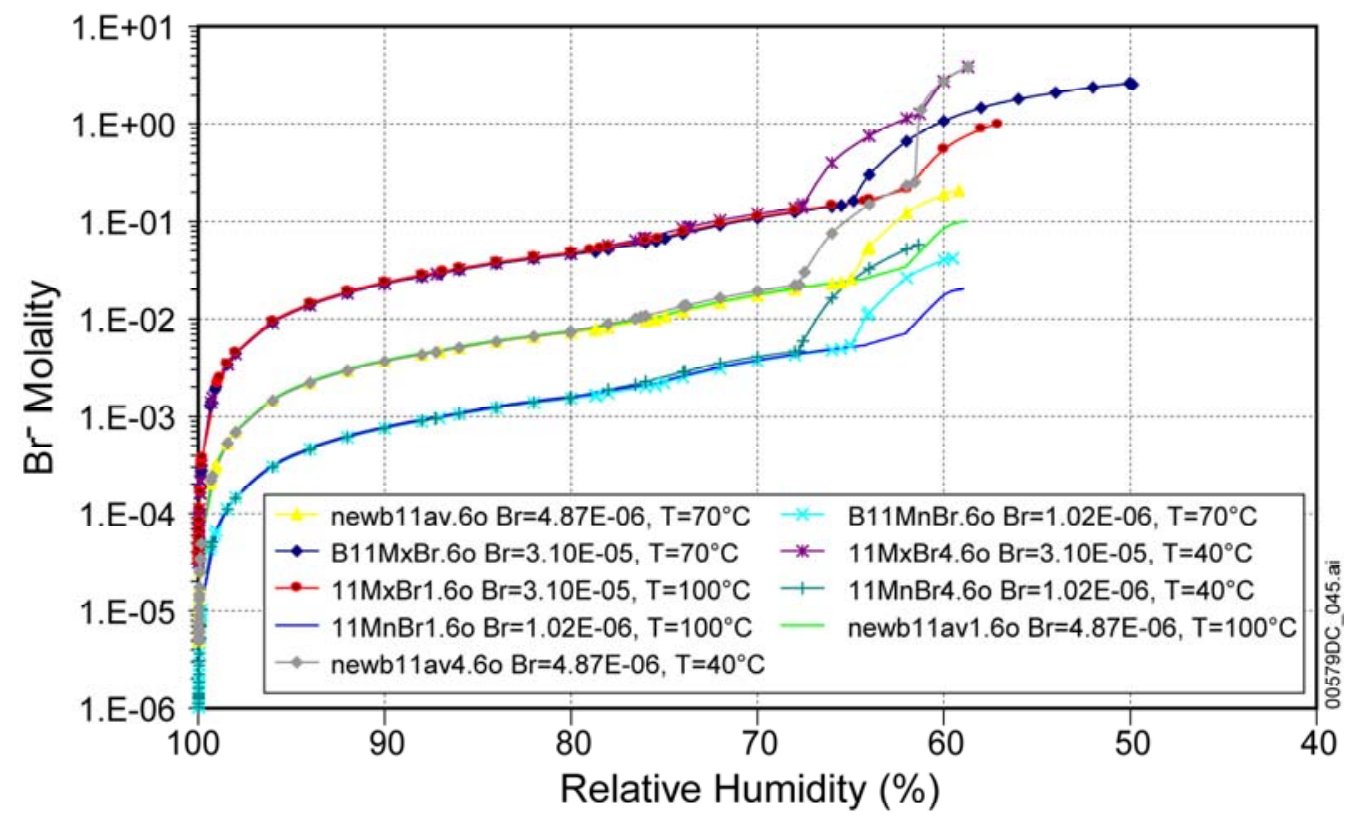

Source: Output DTN: MO0505MWDEBSPC.000, SeepageBrSensitivityStudy.zip, B11brMoalt revised.xls. NOTE: $\quad \mathrm{T}=$ temperature.

Figure 6.12-1. Uncertainty in Bin $11 \mathrm{Br}^{-}$Concentrations Using Pore-Water Values

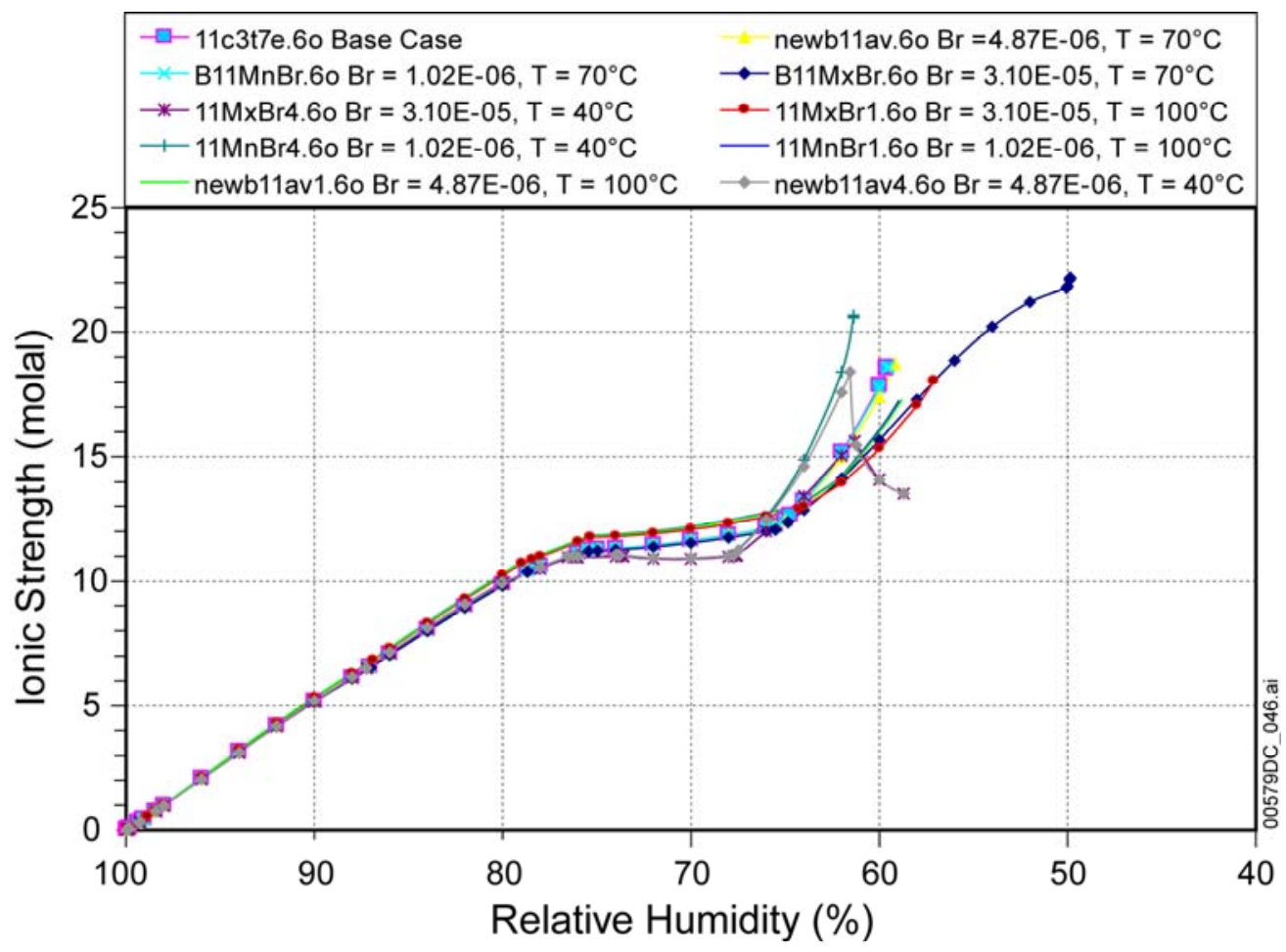

Source: Output DTN: MO0505MWDEBSPC.000, SeepageBrSensitivityStudy.zip, B11brMoalt revised.xls. NOTE: $\quad T=$ temperature.

Figure 6.12-2. Uncertainty in Bin 11 lonic Strength Due to Adding $\mathrm{Br}^{-}$ 


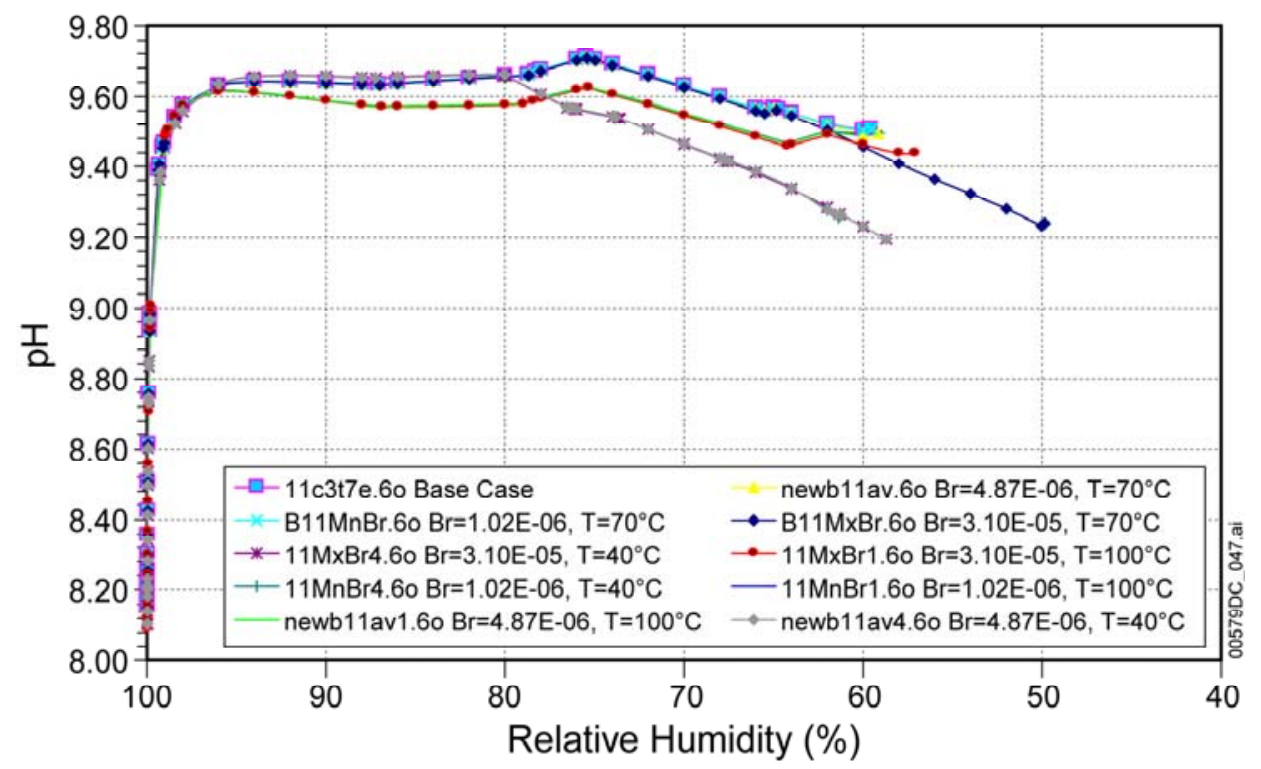

Source: Output DTN: MO0505MWDEBSPC.000, SeepageBrSensitivityStudy.zip, B11brMoalt revised.xls.

NOTE: $\quad \mathrm{T}=$ temperature.

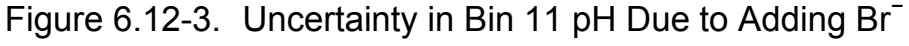

Figure 6.12-4 shows the effect on molar ratios that are of importance to waste package corrosion. The ratios only deviate significantly at lower relative humidity, where there would be an increase in halide concentration with respect to $\mathrm{NO}_{3}{ }^{-}$and $\mathrm{SO}_{4}{ }^{2-}$, and these are below the lowest $\mathrm{RH}$ values reported in the TSPA-LA lookup table and, therefore, of negligible impact.

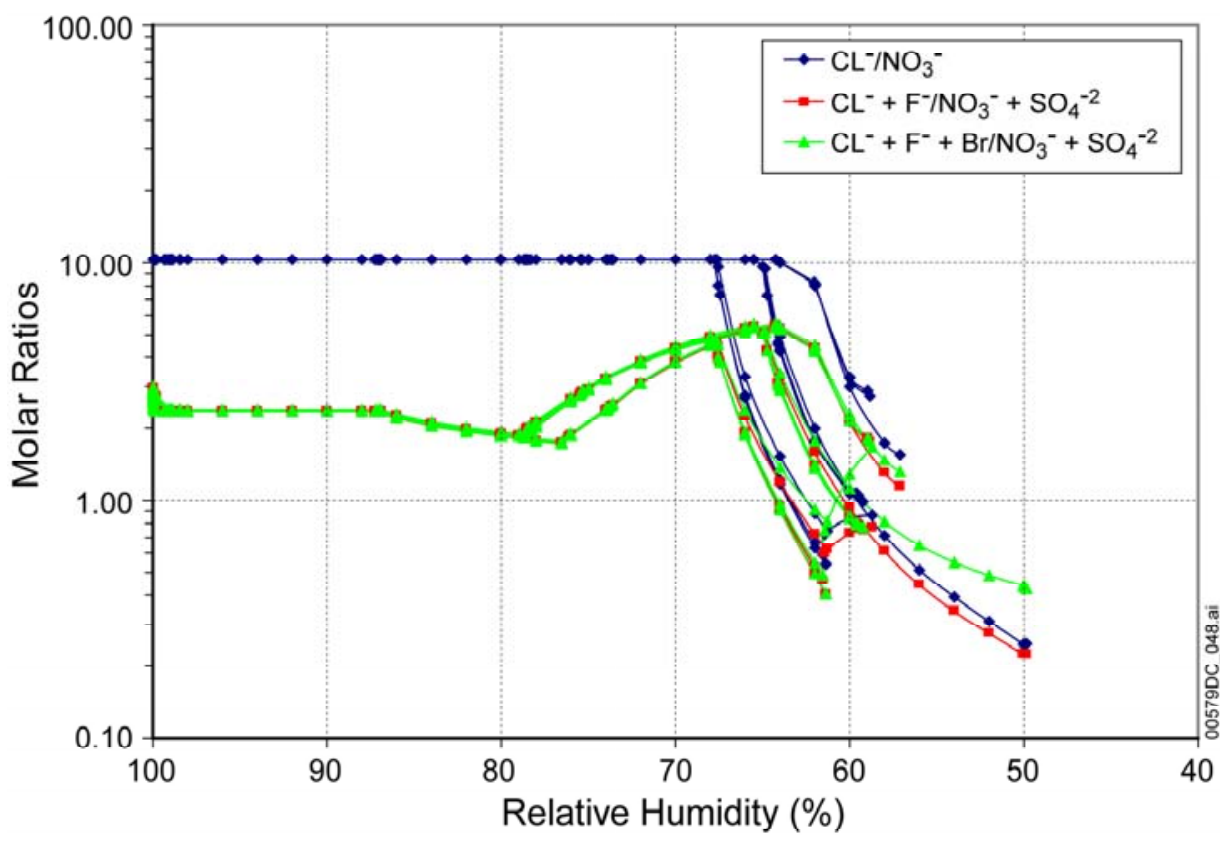

Source: Output DTN: MO0505MWDEBSPC.000, SeepageBrSensitivityStudy.zip, B11brMoalt revised.xls.

Figure 6.12-4. Uncertainty in Bin 11 Molar Ratios Due to Adding $\mathrm{Br}^{-}$ 


\subsubsection{Extrapolating $p \mathrm{CO}_{2}$ Values beyond Lookup Tables}

As discussed in Section 6.13.2, extrapolation can be made when $\mathrm{pCO}_{2}$ is outside the given range of the EBS seepage lookup tables. This sensitivity study gives the predictive range to which the lookup tables can be extrapolated. Results indicate that valid linear extrapolation as a function of $\mathrm{pCO}_{2}$ can be performed for values of ionic strength, and chloride and nitrogen (mostly nitrate) concentrations, and $\log$ scale extrapolations for $\mathrm{pH}$.

\subsection{Calculation Framework}

Two calculation cases are run for each of the base-case files (Table 6.12-11) to bound the effects of the possible range of $\mathrm{pCO}_{2}$. Based on the total possible range of in-drift $p \mathrm{CO}_{2}\left(1.75 \times 10^{-2}\right.$ to $2.29 \times 10^{-5} \mathrm{~atm}$ ) discussed in Section 6.7.3, there is a possibility that the lookup tables used in the TSPA-LA model could be outside the $10^{-2}$ to $10^{-4}$ bar range specified for the creation of the seepage lookup tables (Section 6.9). A sensitivity calculation run is made using $p \mathrm{CO}_{2}=10^{-5}$ bar and a sensitivity run using $p \mathrm{CO}_{2}=10^{-1}$ bar. These input and output files are listed in Table 6.12-20 for the seepage water.

Table 6.12-20. Input and Output Files for Seepage Bin 11 Analysis of $p \mathrm{CO}_{2}$

\begin{tabular}{|c|c|c|}
\hline $\mathbf{p C O}$ & Input Files & Output Files \\
\hline $10^{-1} \mathrm{bar}$ & $11 c 1 t 7 e .6 i$ & $11 c 1 t 7 e .60$ \\
\hline $10^{-5} \mathrm{bar}$ & $11 c 5 t 7 e .6 i$ & $11 c 5 t 7 e .60$ \\
\hline
\end{tabular}

Source: Output DTN: MO0505MWDEBSPC.000, seepage_pco2uncertcalcs.zip.

\subsection{Seepage Water Results}

GETEQDATA (BSC 2002 [DIRS 173680]) has been used to extract the appropriate output data from the output files. The resulting Seepage $\mathrm{CO}_{2}$ uncert.xls is used to create Figures 6.12-5 through 6.12-8. This spreadsheet is archived in Output DTN: MO0505MWDEBSPC.000, in the file SeepageBrSensitivityStudy.zip.

Figure 6.12-5 shows the variation in $\mathrm{pH}$ when $\mathrm{pCO}_{2}$ gas values fall outside the normal range of the provided lookup tables. The trend is about half a $\mathrm{pH}$ unit increase for every order of magnitude decrease in $\mathrm{pCO}_{2}$ below $10^{-4}$ bar, and nearly one $\mathrm{pH}$ unit decrease when increasing $p \mathrm{CO}_{2}$ above $10^{-2}$ bar. High-pressure $\mathrm{pCO}_{2}$ extrapolation of $\mathrm{pH}$ could result in an additional error of nearly half a $\mathrm{pH}$ unit, but only at this extreme $\mathrm{pCO}_{2}$ of $10^{-1}$ bar. This error would at most scale log linearly with $p \mathrm{CO}_{2}$ and, therefore, at $p \mathrm{CO}_{2}=2 \cdot 10^{-2}$ bar (high end of in-drift range); this error can be at most $0.15 \mathrm{pH}$ and thus small compared to total uncertainty.

For ionic strength and nitrate, there is only a small dependence upon $\mathrm{pCO}_{2}$ and only at low $\mathrm{RH}$ (Figures 6.12-6 and 6.12-8). Chloride, however, shows some linearly predictable trends. The values at $10^{-1}$ bar show more variation, as the predictable trends are not as uniform (Figure 6.12-7). These trends are strongly associated with the activity at which calcite and halite precipitate. 


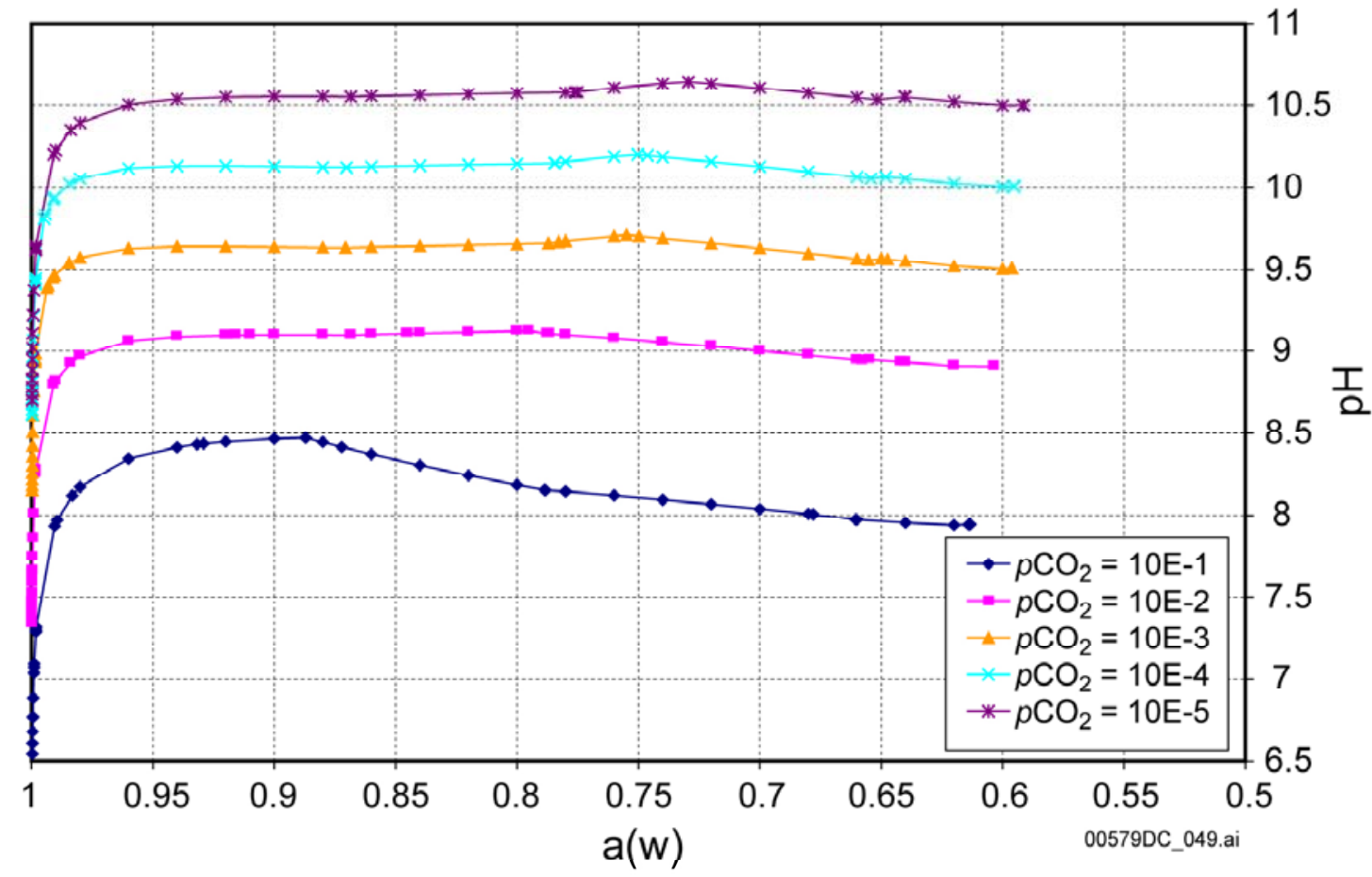

Source: Output DTN: MO0505MWDEBSPC.000, seepage_pco2uncertcalcs.zip, Seepage CO2 uncert.xls.

Figure 6.12-5. Variation in Bin 11 Base-Case $\mathrm{pH}$ as a Function of $\mathrm{pCO}_{2}$

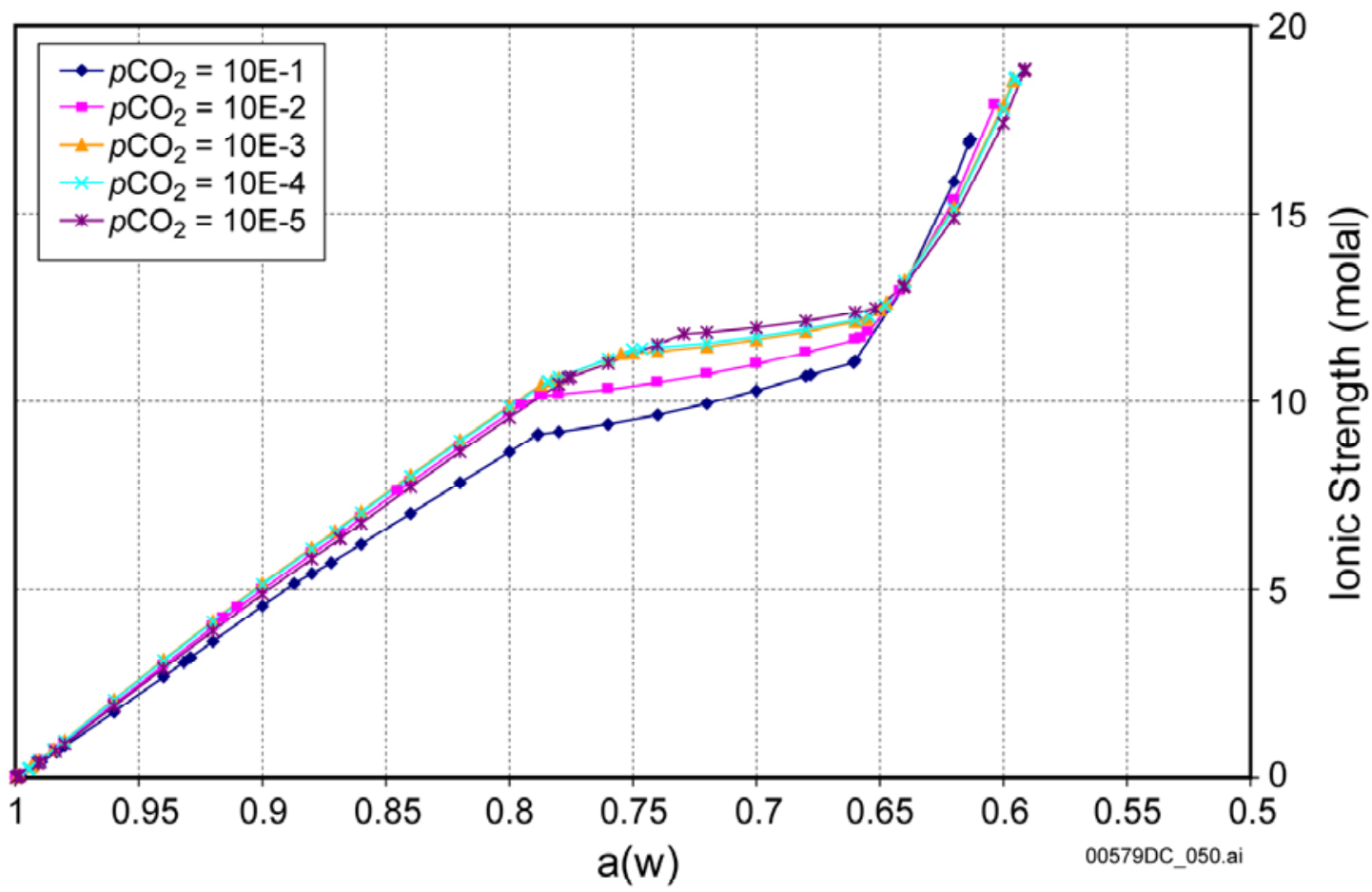

Source: Output DTN: MO0505MWDEBSPC.000, seepage_pco2uncertcalcs.zip, Seepage CO2 uncert.xls.

Figure 6.12-6. Variation in Bin 11 Base-Case lonic Strength as a Function of $p \mathrm{CO}_{2}$ 


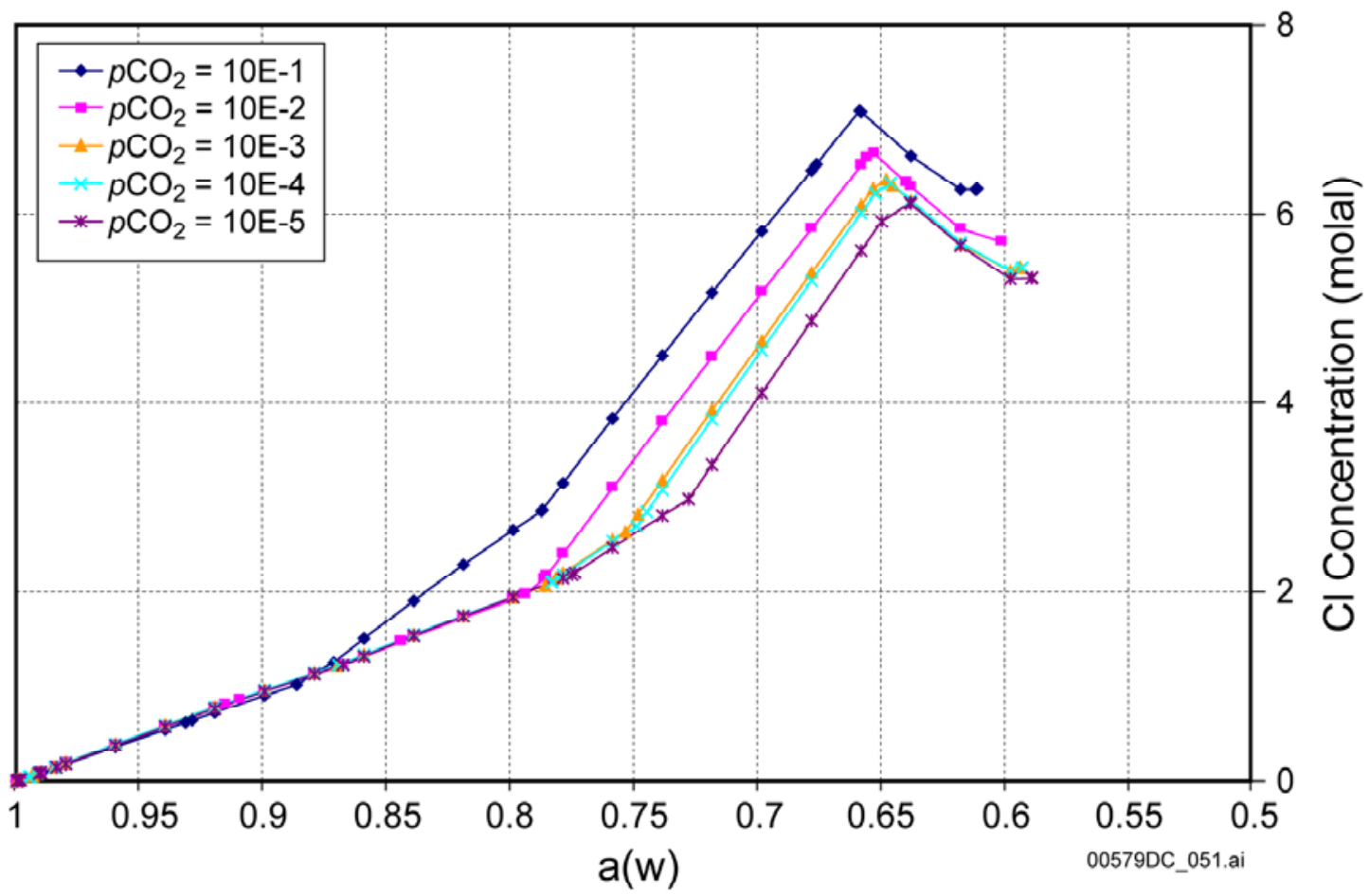

Source: Output DTN: MO0505MWDEBSPC.000, seepage_pco2uncertcalcs.zip, Seepage CO2 uncert.xls.

Figure 6.12-7. Variation in Bin 11 Base-Case Total Elemental $\mathrm{Cl}$ as a Function of $p \mathrm{CO}_{2}$

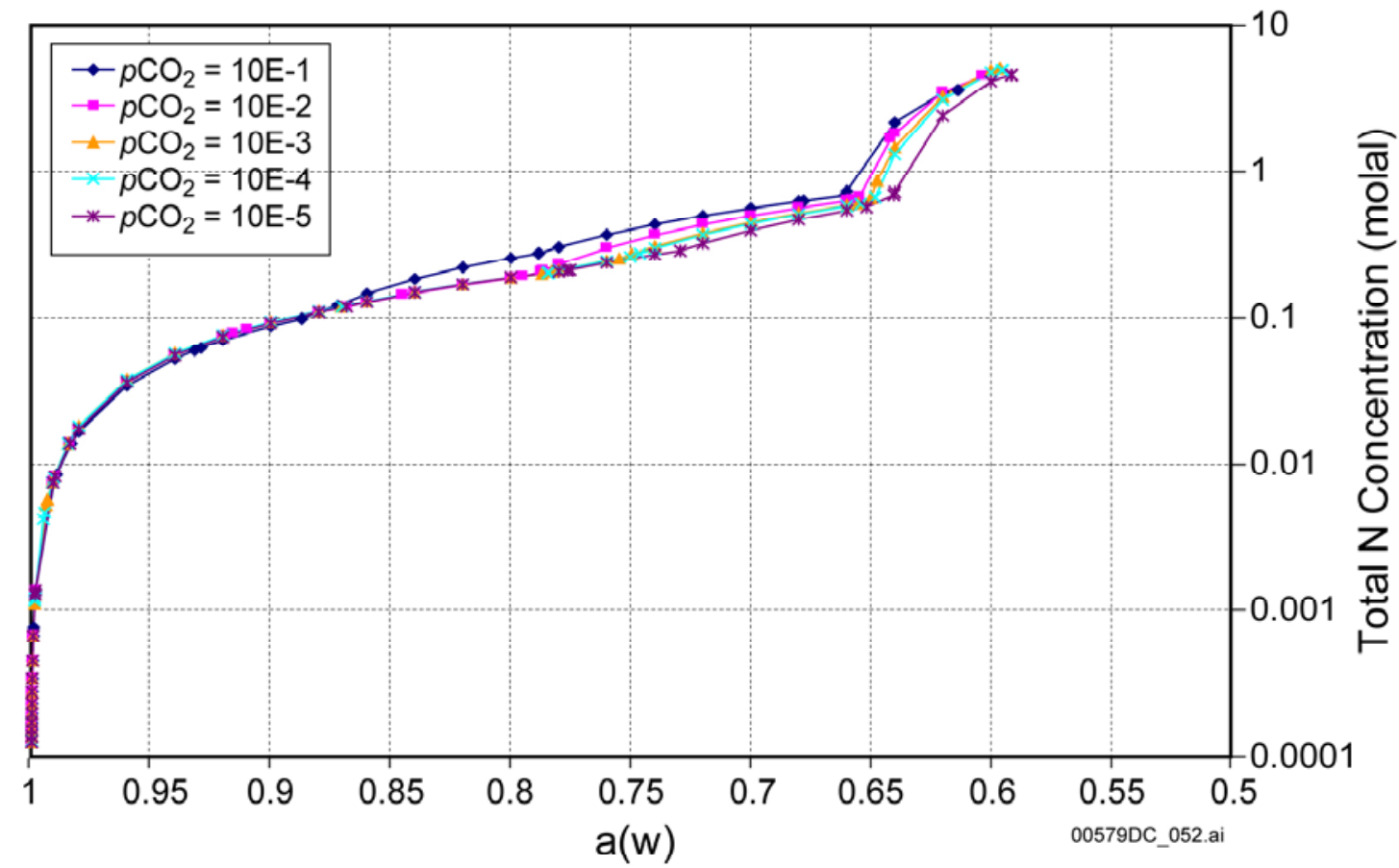

Source: Output DTN: MO0505MWDEBSPC.000, seepage_pco2uncertcalcs.zip, Seepage CO2 uncert.xIs.

Figure 6.12-8. Variation in Bin 11 Base-Case Total Elemental $\mathrm{N}$ as a Function of $p \mathrm{CO}_{2}$ 


\subsubsection{Mineral Suppressions}

Three minerals cryolite, glaserite, and magnesite have been identified as candidates for sensitivity studies to document the impact of mineral suppressions on the analyses in this report (Table 6.5-2). This is based on their inclusion or exclusion in the thermodynamic modeling approach that is used, as discussed in Section 6.5.

Table 6.12-21 documents the base-case input files and associated output files used to investigate the suppression or inclusion of these minerals. The base-case input file is modified by either including or removing the mineral in the "Alter/Suppress Options" input block of the EQ6 *.6i data file. The results are extracted into a Microsoft Excel spreadsheet using GETEQDATA (BSC 2002 [DIRS 173680]). This spreadsheet (Mineral Suppressions Rev 2.xls, archived in Output DTN: MO0505MWDEBSPC.000, MineralSuppressions.zip) is used to create the figures and determine the results shown in the following subsections.

Table 6.12-21. Traceability Roadmap for Mineral Suppression EQ6 Sensitivity Cases

\begin{tabular}{|c|c|c|c|}
\hline Suppression Case & Base-Case Input File & Altered Input File & Output file \\
\hline Cryolite & $11 c 2 t 4 e .6 i$ (Table 6.9-7) & 11crysup.6i & $11 \mathrm{crysup.60}$ \\
\hline Glaserite & $11 \mathrm{c} 3 t 7 e .6 I$ (Table 6.12-5) & $11 \mathrm{glas} .6 \mathrm{i}$ & $11 \mathrm{glas.60}$ \\
\hline Magnesite & $11 \mathrm{c} 3 \mathrm{t} 7 \mathrm{e} .6 \mathrm{I}$ (Table 6.12-5) & $11 \mathrm{mag} .6 \mathrm{i}$ & $11 \mathrm{mag} .60$ \\
\hline
\end{tabular}

Source: Output DTN: MO0505MWDEBSPC.000, MineralSuppressions.zip.

\subsection{Cryolite}

In the modeling work performed to establish the mineral suppression tables (Tables 6.5-2 and 6.6-2), cryolite did not precipitate; therefore, it was not suppressed when creating the seepage lookup tables (Sections 6.5, 6.6, and 6.9), yet it precipitated in a few cases (Table 6.13-6). Cryolite $\left(\mathrm{Na}_{3} \mathrm{AlF}_{6}\right)$ is a halide mineral that is associated with pegmatite veins in granite and gneiss (Palache et al. 1951 [DIRS 162280], p. 113); it commonly forms at higher temperature and pressure conditions not relevant to the repository and would have normally been suppressed on this basis. However, during the literature review that was performed, cryolite was also found to precipitate in fluid inclusions where the end-member solutions are Na-K-Ca-Cl$\mathrm{HCO}_{3}$ brines. The minerals associated with cryolite in these fluid inclusions are nahcolite, halite, sylvite, and fluorite (Buhn and Rankin 1999 [DIRS 163753]). These minerals are commonly found in evaporite deposits and are present in many of the lookup table results as precipitates. The naturally occurring association with common evaporite minerals would justify the inclusion of cryolite as a potential precipitate in the modeled system. Therefore, this sensitivity analysis was conducted to determine the potential impact to the lookup tables.

Total aqueous concentrations for $\mathrm{Na}, \mathrm{Al}$, and $\mathrm{F}$ are shown in Figure 6.12-9. Also plotted are $\mathrm{pH}$ and moles of cryolite precipitated in the base-case results. Figure 6.12-9 also shows that, with the exception of Al concentrations, there is no major impact to the base-case files from the precipitation of cryolite. The Al concentrations are affected by approximately two orders of magnitude, but because $\mathrm{Al}$ concentrations are less than $10^{-10}$ molal, the $\mathrm{pH}$ and other parameters of interest are unaffected. 


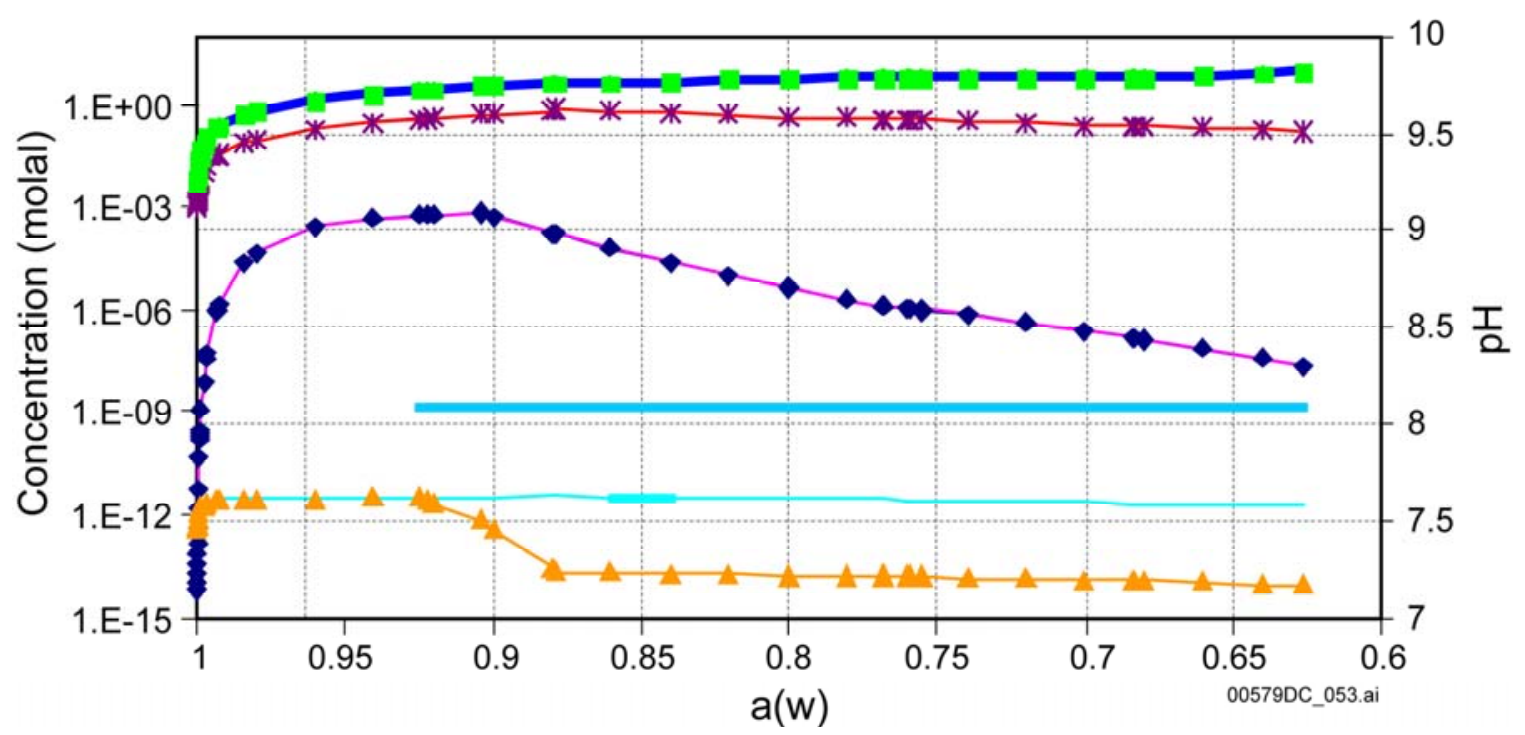

$$
\begin{array}{|lll|}
\hline \rightarrow \text { Base Case } \mathrm{pH} & -\mathrm{pH} \text { - Cryolite Suppressed } & - \text { Base Case Al } \\
- \text { Al-Cryolite Suppressed } & \rightarrow-\text { Base Case F } & - \text { F - Cryolite Suppressed } \\
- \text { Base Case } \mathrm{Na} & -\mathrm{Na} \text { - Cryolite Suppressed } & - \text { Base Case Cryolite (moles) } \\
\hline
\end{array}
$$

Source: Output DTN: MO0505MWDEBSPC.000; MineralSuppressions.zip, Mineral Suppressions Rev 2.xls.

Figure 6.12-9. Comparison of Base-Case EQ6 Results with Those of the Cryolite-Suppressed Modeling Run

\subsection{Glaserite}

As reported in Table 6.5-2, glaserite $\left(\mathrm{NaK}_{3}\left(\mathrm{SO}_{4}\right)_{2}\right)$ is suppressed due to the uncertain nature of the values reported in the data0.ypf.RO thermodynamic database. This sensitivity calculation run documents the potential changes that could occur if glaserite is allowed to precipitate in the analyses. The data0.ypf.RO database includes two sets of data; the set that was used is the single $25^{\circ} \mathrm{C} \log (K)$ value of -3.8027 . Therefore, the modeling calculation runs at $70^{\circ} \mathrm{C}$ are not fully representative, but do indicate the potential changes to the output results that could occur with inclusion.

Figure 6.12-10 shows the comparative results of the base case with the inclusion of glaserite for $\mathrm{pH}, \mathrm{S}, \mathrm{Na}$, and K (Output DTN: MO0505MWDEBSPC.000, MineralSuppressions.zip). The largest change is the difference in endpoint water activity. With the glaserite present, the endpoint of the calculated model run is lowered by about $12 \%$. The $\mathrm{pH}$ change is less than half a unit when the base-case model ends. The aqueous solute concentrations do not vary much (at most approximately $0.3 \log$ units). The $\mathrm{pH}$ shift at the lowest water activity used in the lookup tables $\left(\mathrm{a}_{\mathrm{w}}=0.65\right)$ is just under $0.2 \mathrm{pH}$ units. 

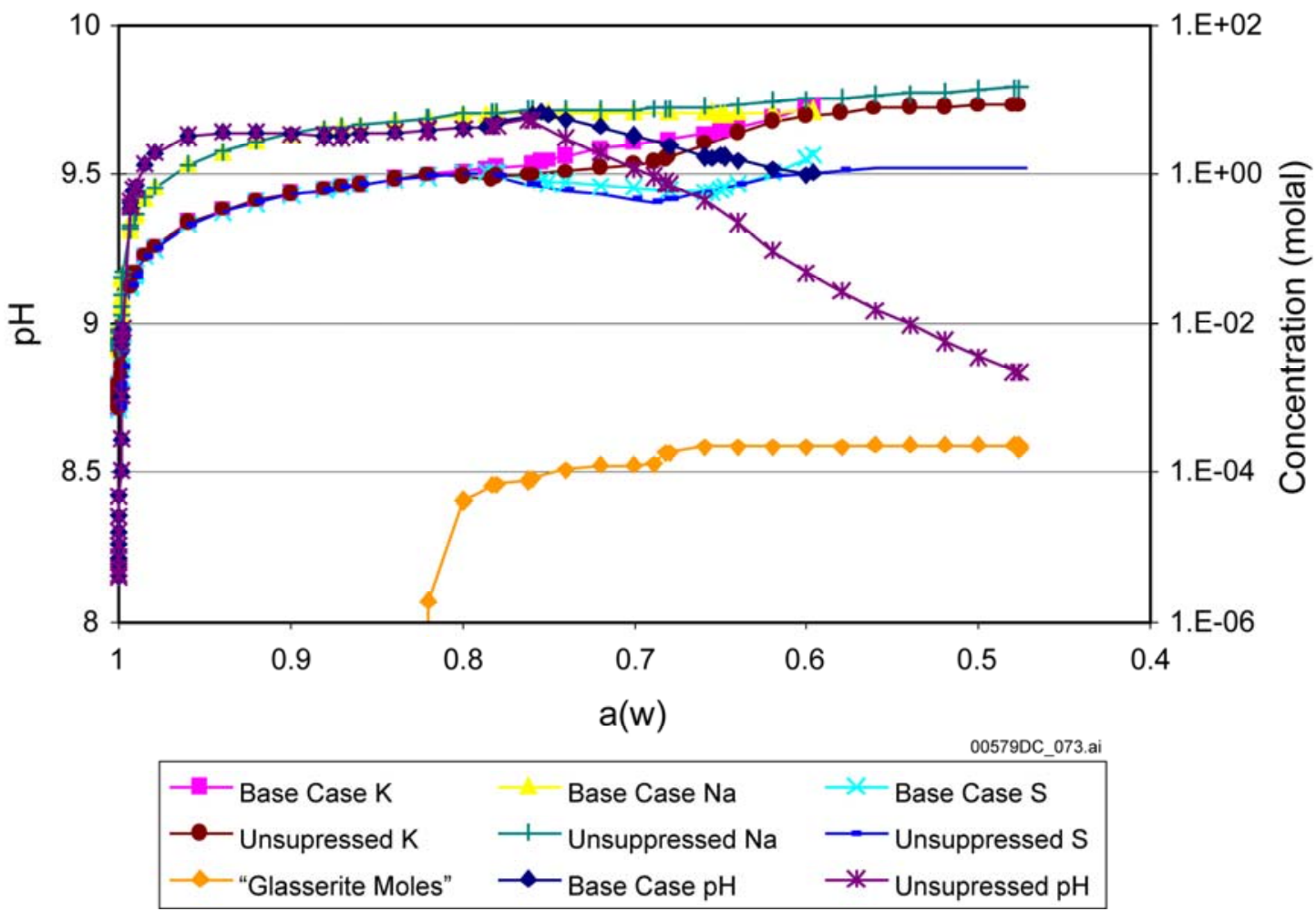

Source: Output DTN: MO0505MWDEBSPC.000, MineralSuppressions.zip, Mineral Suppressions Rev 2.xls.

Figure 6.12-10. Comparison of Base-Case Results to those of the Same Modeling Run with Glaserite Unsuppressed

\subsection{Magnesite}

As reported in Table 6.5-2, according to Eugster and Hardie (1978 [DIRS 100743]) magnesite can be associated with salt deposits. However, it is uncertain whether it is associated with the diagenesis of salt deposits at temperatures and pressures higher than $100^{\circ} \mathrm{C}$ and 1 atmosphere, respectively, or with lower temperatures and pressures such as those anticipated in the repository. The sensitivity analysis is conducted to evaluate the possible effects to the model results. The results indicate that even with the inclusion of magnesite in the modeling calculation run, it does not precipitate in the base-case file. Therefore, with this limited sensitivity study, it is concluded that there is no impact to the results.

\subsubsection{Mineral Precipitation}

Supplemental to the information found in Tables 6.5-2 and 6.5-3, Table 6.12-22 includes natural analogue information and the mineral inclusion (or suppression) criteria as discussed in Section 6.5.5. As indicated, all the minerals listed in Tables 6.5-3 and 6.12-22 have analogue information that allows for their precipitation in the P\&CE model, and the information here corroborates the minerals that are precipitating in the model.

Cryolite was included in the seepage modeling runs but has analogue information that suggests mineral suppression indicated in EQ3/6 calculations could be warranted. It may be possible for cryolite to precipitate under repository conditions. 
Section 6.12.4.4.1 documents an uncertainty calculation that indicates that a suppression of cryolite has virtually no impact on the seepage lookup table results except for the aluminum output (Figure 6.12-9). This portion of the output can be affected by two orders of magnitude as the water activity decreases. Cryolite formation is predicted in some of the lookup tables representing bins 9, 10, and 11. As shown in Figure 6.12-9, the impact is not significant since the aluminum concentrations are less than $10^{-10}$ molal, thereby having no effect on the bulk chemistry.

Table 6.12-22. Natural Analogue Information for the Inclusion of Minerals Not Reported in Section 6.5

\begin{tabular}{|c|c|c|c|c|}
\hline $\begin{array}{l}\text { Mineral Name } \\
\text { (if available) }\end{array}$ & Formula & $\begin{array}{l}\text { Criteria } \\
\text { Selected }\end{array}$ & Rationale & References \\
\hline \multirow[t]{2}{*}{ Calcium nitrate } & $\mathrm{Ca}\left(\mathrm{NO}_{3}\right)_{2}$ & Criterion 3 & Less-hydrated phase of nitrocalcite. & See below \\
\hline & $\mathrm{Ca}\left(\mathrm{NO}_{3}\right)_{2}: 3 \mathrm{H}_{2} \mathrm{O}$ & Criterion 3 & Less-hydrated phase of nitrocalcite. & See below \\
\hline Nitrocalcite & $\mathrm{Ca}\left(\mathrm{NO}_{3}\right)_{2}: 4 \mathrm{H}_{2} \mathrm{O}$ & Criterion 3 & $\begin{array}{l}\text { Water-soluble salt associated with niter } \\
\text { deposits in caves and lake beds. }\end{array}$ & $\begin{array}{l}\text { Palache et al. } 1951 \\
\text { [DIRS 162280], } \\
\text { pp. } 306 \text { to } 307\end{array}$ \\
\hline Erionite & $\begin{array}{l}\mathrm{K}_{1.5} \mathrm{Na}_{0.9} \mathrm{Ca}_{0.9} \\
\mathrm{Al}_{4.2} \mathrm{Si}_{13.8} \mathrm{O}_{36} \\
13 \mathrm{H}_{2} \mathrm{O}\end{array}$ & Criterion 3 & $\begin{array}{l}\text { Zeolite mineral known to form in } \\
\text { sedimentary saline, non-marine } \\
\text { environments. }\end{array}$ & $\begin{array}{l}\text { Frye } 1981 \\
\text { [DIRS 161804], } \\
\text { p. } 524 \\
\text { Hay } 1966 \\
\text { [DIRS 105965], } \\
\text { Table } 4\end{array}$ \\
\hline Nahcolite & $\mathrm{NaHCO}_{3}$ & Criterion 3 & $\begin{array}{l}\text { Associated with trona and other playa or } \\
\text { salt bed minerals. }\end{array}$ & $\begin{array}{l}\text { Palache et al. } 1951 \\
\text { [DIRS 162280], } \\
\text { p. } 135\end{array}$ \\
\hline Pirssonite & $\begin{array}{l}\mathrm{Na}_{2} \mathrm{Ca}\left(\mathrm{CO}_{3}\right)_{2}: \\
2 \mathrm{H}_{2} \mathrm{O}\end{array}$ & Criterion 3 & $\begin{array}{l}\text { Associated with trona and thenardite and } \\
\text { found in clays in dry lake beds. }\end{array}$ & $\begin{array}{l}\text { Palache et al. } 1951 \\
\text { [DIRS 162280], } \\
\text { p. } 233\end{array}$ \\
\hline $\begin{array}{l}\text { Potassium } \\
\text { bromide }\end{array}$ & $\mathrm{KBr}$ & Criterion 3 & $\begin{array}{l}\text { Deliquescent mineral that maintains a } \\
\text { saturated solution at } 84 \% \mathrm{RH} \text { at } 20^{\circ} \mathrm{C} \\
\text { and } 69 \% \mathrm{RH} \text { at } 100^{\circ} \mathrm{C} \text {. }\end{array}$ & $\begin{array}{l}\text { Weast } 1984 \\
\text { [DIRS 106170], } \\
\text { p. E-42 }\end{array}$ \\
\hline Kalicinite & $\mathrm{KHCO}_{3}$ & Criterion 3 & Associated with trona. & $\begin{array}{l}\text { Palache et al. } 1951 \\
\text { [DIRS 162280], } \\
\text { p. } 136\end{array}$ \\
\hline Brucite & $\mathrm{Mg}(\mathrm{OH})_{2}$ & Criterion 3 & $\begin{array}{l}\text { Associated with contact metamorphosed } \\
\text { limestone in association with calcite, } \\
\text { dolomite, and magnesite. This would be } \\
\text { analogous to calcite alteration on the } \\
\text { surface of the hot waste packages. In } \\
\text { the modeling runs brucite only forms in } \\
\text { one dust leachate lookup table at } 100^{\circ} \mathrm{C} \text {. } \\
\text { Brucite is also found in crystalline } \\
\text { limestone, the chief component of which } \\
\text { is calcite. }\end{array}$ & $\begin{array}{l}\text { Frye } 1981 \\
\text { [DIRS 161804], } \\
\text { p. } 568 \\
\text { Klein and Hurlbut } \\
1977 \text { [DIRS 105907], } \\
\text { p. } 316\end{array}$ \\
\hline Darapskite & $\begin{array}{l}\mathrm{Na}_{3}\left(\mathrm{NO}_{3}\right)\left(\mathrm{SO}_{4}\right): \\
\mathrm{H}_{2} \mathrm{O}\end{array}$ & Criterion 3 & $\begin{array}{l}\text { Associated soda-niter, niter, halite, and } \\
\text { anhydrite. Also occurs in nitrate and } \\
\text { sulfate deposits. }\end{array}$ & $\begin{array}{l}\text { Palache et al. } 1951 \\
\text { [DIRS 162280], } \\
\text { p. } 310\end{array}$ \\
\hline
\end{tabular}


Table 6.12-22. Natural Analogue Information for the Inclusion of Minerals Not Reported in Section 6.5 (Continued)

\begin{tabular}{|l|l|c|l|l|}
\hline $\begin{array}{c}\text { Mineral Name } \\
\text { (if available) }\end{array}$ & \multicolumn{1}{|c|}{ Formula } & $\begin{array}{c}\text { Criteria } \\
\text { Selected }\end{array}$ & \multicolumn{1}{|c|}{ Rationale } & \multicolumn{1}{c|}{ References } \\
\hline Thermonatrite & $\mathrm{Na}_{2} \mathrm{CO}_{3}: \mathrm{H}_{2} \mathrm{O}$ & Criterion 3 & $\begin{array}{l}\text { Associated with trona and found as an } \\
\text { efflorescence on soil in arid regions and } \\
\text { as a deposit from saline lakes. }\end{array}$ & $\begin{array}{l}\text { Palache et al. 1951 } \\
\text { [DIRS 162280], } \\
\text { p. 224 }\end{array}$ \\
\hline Villiaumite & $\mathrm{NaF}$ & Criterion 3 & $\begin{array}{l}\text { Deliquescent mineral that maintains a } \\
\text { saturated solution at 96\% } \mathrm{RH} \text { at 100 }\end{array}$ & $\begin{array}{l}\text { Weast 1984 } \\
\text { [DIRS 106170], } \\
\text { p. E-42 }\end{array}$ \\
\hline
\end{tabular}

NOTE: $\quad$ Criteria described in Section 6.5.4.1; briefly, Criterion 3 means analytical or analogue information is available to support inclusion or exclusion of mineral.

\subsubsection{Implementing Abstraction Uncertainties in the TSPA-LA Lookup Tables}

EBS chemical environments abstractions are documented for use by the TSPA-LA in the form of lookup tables identified in Sections 6.7 and 6.9 Seepage evaporation and dilution lookup tables are archived in Output DTN: MO0304SPACSALT.000.

The subsequent sections provide details on the determination of uncertainties and guidelines for their treatment by TSPA-LA.

\subsubsection{Uncertainties That Are Negligible and Not Included}

Degradation of stainless steel in ground support components, inclusion of bromide, limited extrapolation of $\mathrm{pCO}_{2}$ values outside the range of the lookup tables, and alternate mineral suppressions are all shown to have a negligible effect on the uncertainties in EBS chemical environment abstractions. Evidence for the relative insignificance of those processes is presented in Section 6.12.4.

\subsubsection{Uncertainty Distributions for TSPA-LA Lookup Tables}

As shown in Tables 6.12-1 and 6.12-4, uncertainty in the model output stems from two sources, IDPS model uncertainty and the uncertainty due to binning (or lookup table) variability. These two types of uncertainty have to be accounted for in the TSPA-LA. First the IDPS model uncertainties in chemical parameters relevant to the TSPA-LA are summarized in Table 6.12-1. Second are the binning uncertainties for the seepage analysis found in Table 6.12-4. Both of these apply when using the seepage evaporation abstraction from this report.

\subsubsection{Specific Guidance for TSPA-LA Implementation}

The lookup tables summarizing evaporated seepage water chemistries must be implemented in the TSPA-LA with the associated uncertainties. Carbon dioxide partial pressure lookup tables, as taken from the THC model results, are shown in Tables 6.7-1 through 6.7-5 and are archived in Output DTN: SN0503T0510102.019. Seepage lookup tables are archived in Output DTN: MO0304SPACSALT.000 (DTN: MO0310SPAPCEGS.000 for TSPA-LA use). 
Quantification of the uncertainties in parameters that will feed the TSPA-LA is developed above and includes the following parameters:

- Ionic strength

- Chloride concentration

- Chloride to nitrate ratio

- $\mathrm{pH}$.

Nitrate uncertainty is calculated using the chloride and chloride-to-nitrate ratio uncertainties to account for any correlation, as discussed in the following paragraphs.

The lookup table results presented in Section 6.13 (Figure 6.13-19) indicate that, in all cases, once the halite divide is crossed, the $\mathrm{Cl}^{-} / \mathrm{NO}_{3}{ }^{-}$ratio can only decrease. These results indicate that, at relative humidity below the halite divide, a limit can be placed on the uncertainty of this value. In most lookup table cases, the sylvite divide further ensures this limit. Table 6.12-23 is a compilation of the $\mathrm{Cl}^{-} / \mathrm{NO}_{3}{ }^{-}$ratio at the halite divide for all simulations. This table was created by extracting the relevant information from the lookup table contained in Output DTN: MO0304SPACSALT.000 (DTN: MO0310SPAPCEGS.000 for TSPA-LA use), and calculating the ratios.

Because distinct water compositions are provided in the lookup tables along an evolutionary evaporative path using the IDPS model, any uncertainty distribution selected at the beginning of the evaporative path can be maintained throughout any given TSPA-LA model realization.

Table 6.12-23. $\mathrm{Cl}^{-} / \mathrm{NO}_{3}{ }^{-}$Molal Ratio for Seepage at the Halite Chemical Divide

\begin{tabular}{|c|c|c|c|c|}
\hline $\begin{array}{l}\text { Bin } \\
\text { Number }\end{array}$ & $\operatorname{Temp}\left({ }^{\circ} \mathrm{C}\right)$ & $\begin{array}{l}\mathrm{pCO}_{2} \\
\text { (bar) }\end{array}$ & $\begin{array}{c}\text { Halite Divide } \mathrm{Cl}^{-} / \mathrm{NO}_{3}{ }^{-} \\
\text {Molal Ratio }\end{array}$ & $\begin{array}{c}\text { Halite Divide } \mathrm{Log} \mathrm{Cl}^{-} / \mathrm{NO}_{3}{ }^{-} \\
\text {Molal Ratio }\end{array}$ \\
\hline \multirow[t]{9}{*}{1} & 70 & 0.0001 & 15.46 & 1.19 \\
\hline & 40 & 0.0001 & 15.46 & 1.19 \\
\hline & 100 & 0.0001 & 15.46 & 1.19 \\
\hline & 70 & 0.001 & 15.46 & 1.19 \\
\hline & 40 & 0.001 & 15.46 & 1.19 \\
\hline & 100 & 0.001 & 15.46 & 1.19 \\
\hline & 70 & 0.01 & 15.46 & 1.19 \\
\hline & 40 & 0.01 & 15.46 & 1.19 \\
\hline & 100 & 0.01 & 15.46 & 1.19 \\
\hline \multirow[t]{9}{*}{2} & 70 & 0.0001 & 9.19 & 0.96 \\
\hline & 40 & 0.0001 & 9.19 & 0.96 \\
\hline & 100 & 0.0001 & 9.19 & 0.96 \\
\hline & 70 & 0.001 & 9.19 & 0.96 \\
\hline & 40 & 0.001 & 9.19 & 0.96 \\
\hline & 100 & 0.001 & 9.19 & 0.96 \\
\hline & 70 & 0.01 & 9.19 & 0.96 \\
\hline & 40 & 0.01 & 9.19 & 0.96 \\
\hline & 100 & 0.01 & 9.19 & 0.96 \\
\hline
\end{tabular}


Table 6.12-23. $\mathrm{Cl}^{-} / \mathrm{NO}_{3}{ }^{-}$Molal Ratio for Seepage at the Halite Chemical Divide (Continued)

\begin{tabular}{|c|c|c|c|c|}
\hline $\begin{array}{c}\text { Bin } \\
\text { Number }\end{array}$ & $\operatorname{Temp}\left({ }^{\circ} \mathrm{C}\right)$ & $\begin{array}{l}\mathrm{pCO}_{2} \\
\text { (bar) }\end{array}$ & $\begin{array}{c}\text { Halite Divide } \mathrm{Cl}^{-} / \mathrm{NO}_{3}{ }^{-} \\
\text {Molal Ratio }\end{array}$ & $\begin{array}{c}\text { Halite Divide } \mathrm{Log} \mathrm{Cl}^{-} / \mathrm{NO}_{3}^{-} \\
\text {Molal Ratio }\end{array}$ \\
\hline \multirow[t]{9}{*}{3} & 70 & 0.0001 & 18.30 & 1.26 \\
\hline & 40 & 0.0001 & 18.30 & 1.26 \\
\hline & 100 & 0.0001 & 18.30 & 1.26 \\
\hline & 70 & 0.001 & 18.30 & 1.26 \\
\hline & 40 & 0.001 & 18.30 & 1.26 \\
\hline & 100 & 0.001 & 18.30 & 1.26 \\
\hline & 70 & 0.01 & 18.30 & 1.26 \\
\hline & 40 & 0.01 & 18.30 & 1.26 \\
\hline & 100 & 0.01 & 18.30 & 1.26 \\
\hline \multirow[t]{9}{*}{4} & 70 & 0.0001 & 7.74 & 0.89 \\
\hline & 40 & 0.0001 & 7.74 & 0.89 \\
\hline & 100 & 0.0001 & 7.74 & 0.89 \\
\hline & 70 & 0.001 & 7.74 & 0.89 \\
\hline & 40 & 0.001 & 7.74 & 0.89 \\
\hline & 100 & 0.001 & 7.74 & 0.89 \\
\hline & 70 & 0.01 & 7.74 & 0.89 \\
\hline & 40 & 0.01 & 7.74 & 0.89 \\
\hline & 100 & 0.01 & 7.74 & 0.89 \\
\hline \multirow[t]{9}{*}{5} & 70 & 0.0001 & 14.77 & 1.17 \\
\hline & 40 & 0.0001 & 14.77 & 1.17 \\
\hline & 100 & 0.0001 & 14.77 & 1.17 \\
\hline & 70 & 0.001 & 14.77 & 1.17 \\
\hline & 40 & 0.001 & 14.77 & 1.17 \\
\hline & 100 & 0.001 & 14.77 & 1.17 \\
\hline & 70 & 0.01 & 14.77 & 1.17 \\
\hline & 40 & 0.01 & 14.77 & 1.17 \\
\hline & 100 & 0.01 & 14.77 & 1.17 \\
\hline \multirow[t]{9}{*}{6} & 70 & 0.0001 & 31.91 & 1.50 \\
\hline & 40 & 0.0001 & 31.91 & 1.50 \\
\hline & 100 & 0.0001 & 31.91 & 1.50 \\
\hline & 70 & 0.001 & 31.91 & 1.50 \\
\hline & 40 & 0.001 & 31.91 & 1.50 \\
\hline & 100 & 0.001 & 31.91 & 1.50 \\
\hline & 70 & 0.01 & 31.91 & 1.50 \\
\hline & 40 & 0.01 & 31.91 & 1.50 \\
\hline & 100 & 0.01 & 31.91 & 1.50 \\
\hline \multirow[t]{6}{*}{7} & 70 & 0.0001 & 31.70 & 1.50 \\
\hline & 40 & 0.0001 & 31.70 & 1.50 \\
\hline & 100 & 0.0001 & 31.70 & 1.50 \\
\hline & 70 & 0.001 & 31.70 & 1.50 \\
\hline & 40 & 0.001 & 31.70 & 1.50 \\
\hline & 100 & 0.001 & 31.70 & 1.50 \\
\hline
\end{tabular}


Table 6.12-23. $\mathrm{Cl}^{-} / \mathrm{NO}_{3}{ }^{-}$Molal Ratio for Seepage at the Halite Chemical Divide (Continued)

\begin{tabular}{|c|c|c|c|c|}
\hline $\begin{array}{c}\text { Bin } \\
\text { Number }\end{array}$ & Temp $\left({ }^{\circ} \mathrm{C}\right)$ & $\begin{array}{l}\mathrm{pCO}_{2} \\
\text { (bar) }\end{array}$ & $\begin{array}{c}\text { Halite Divide } \mathrm{Cl}^{-} / \mathrm{NO}_{3}{ }^{-} \\
\text {Molal Ratio }\end{array}$ & $\begin{array}{c}\text { Halite Divide Log } \mathrm{Cl}^{-} / \mathrm{NO}_{3}{ }^{-} \\
\text {Molal Ratio }\end{array}$ \\
\hline \multirow{3}{*}{$\begin{array}{c}7 \\
\text { (cont.) }\end{array}$} & 70 & 0.01 & 31.70 & 1.50 \\
\hline & 40 & 0.01 & 31.70 & 1.50 \\
\hline & 100 & 0.01 & 31.70 & 1.50 \\
\hline \multirow[t]{9}{*}{8} & 70 & 0.0001 & 14.12 & 1.15 \\
\hline & 40 & 0.0001 & 14.12 & 1.15 \\
\hline & 100 & 0.0001 & 14.12 & 1.15 \\
\hline & 70 & 0.001 & 14.12 & 1.15 \\
\hline & 40 & 0.001 & 14.12 & 1.15 \\
\hline & 100 & 0.001 & 14.12 & 1.15 \\
\hline & 70 & 0.01 & 14.12 & 1.15 \\
\hline & 40 & 0.01 & 14.12 & 1.15 \\
\hline & 100 & 0.01 & 14.12 & 1.15 \\
\hline \multirow[t]{9}{*}{9} & 70 & 0.0001 & 2.37 & 0.37 \\
\hline & 40 & 0.0001 & 2.37 & 0.37 \\
\hline & 100 & 0.0001 & 2.37 & 0.37 \\
\hline & 70 & 0.001 & 2.37 & 0.37 \\
\hline & 40 & 0.001 & 2.37 & 0.37 \\
\hline & 100 & 0.001 & 2.37 & 0.37 \\
\hline & 70 & 0.01 & 2.37 & 0.37 \\
\hline & 40 & 0.01 & 2.37 & 0.37 \\
\hline & 100 & 0.01 & 2.37 & 0.37 \\
\hline \multirow[t]{9}{*}{10} & 70 & 0.0001 & 14.11 & 1.15 \\
\hline & 40 & 0.0001 & 14.11 & 1.15 \\
\hline & 100 & 0.0001 & 14.11 & 1.15 \\
\hline & 70 & 0.001 & 14.11 & 1.15 \\
\hline & 40 & 0.001 & 14.11 & 1.15 \\
\hline & 100 & 0.001 & 14.11 & 1.15 \\
\hline & 70 & 0.01 & 14.11 & 1.15 \\
\hline & 40 & 0.01 & 14.11 & 1.15 \\
\hline & 100 & 0.01 & 14.11 & 1.15 \\
\hline \multirow[t]{9}{*}{11} & 70 & 0.0001 & 10.31 & 1.01 \\
\hline & 40 & 0.0001 & 10.31 & 1.01 \\
\hline & 100 & 0.0001 & 10.31 & 1.01 \\
\hline & 70 & 0.001 & 10.31 & 1.01 \\
\hline & 40 & 0.001 & 10.31 & 1.01 \\
\hline & 100 & 0.001 & 10.31 & 1.01 \\
\hline & 70 & 0.01 & 10.31 & 1.01 \\
\hline & 40 & 0.01 & 10.31 & 1.01 \\
\hline & 100 & 0.01 & 10.31 & 1.01 \\
\hline
\end{tabular}

Source: Output DTN: MO0311SPAEPMUT.000, halite divide ratio for seepage.xls. 
Implementation of Ionic Strength and Chloride Concentration Uncertainties - Quantifying and implementing uncertainties for the chemical parameters of ionic strength and chloride concentration are to be carried out as explained in the steps directly below. The two distributions for ionic strength and chloride concentration $\left(\left[\mathrm{Cl}^{-}\right]\right.$) should be co-varied using same-scaled random uncertainty factor (i.e., the two parameters can use the same sampled distribution), as the ionic strength directly depends upon the often-dominant chloride concentration.

1. Look up the appropriate parameter value (ionic strength or $\left[\mathrm{Cl}^{-}\right]$) from the relevant TSPA-LA lookup table for seepage. Convert this value to its $\log _{10}$-base quantity; this becomes the value for which the subsequent distribution will be developed.

2. Create a uniform parameter uncertainty range that extends from the $\log _{10}$-base quantity calculated in Step 1 by adding and subtracting the parameter binning uncertainty (Table 6.12-4) for each parameter.

3. Randomly choose a parameter value within this range (thereby producing a log-uniform probability of occurrence) to obtain the $\log \left[\mathrm{Cl}^{-}\right]$or ionic strength that includes the binning uncertainty.

4. Combine the $\left[\mathrm{Cl}^{-}\right]$or ionic strength log value from Step 3, which includes the binning uncertainty, with the model uncertainty by adding and subtracting the model uncertainty tabulated as a function of RH in Table 6.12-1. This will establish upper and lower bounds for the log $\left[\mathrm{Cl}^{-}\right]$and ionic strength.

5. Randomly choose a parameter value within this range (thereby producing a log-uniform probability of occurrence) to obtain the $\log \left[\mathrm{Cl}^{-}\right]$or ionic strength that includes both binning uncertainty and model variability.

6. Take the adjusted uncertainty log value and convert this back to nonlog units, if required.

Implementation of Chloride-Nitrate Ratio Uncertainties-Quantifying uncertainties for the chemical parameter of chloride to nitrate concentration is to be carried out as explained in the steps below:

1. Using the $\left[\mathrm{Cl}^{-}\right]$and $\left[\mathrm{NO}_{3}^{-}\right]$concentrations from the lookup table determinations (without uncertainty), compute the chloride-to-nitrate ratio without uncertainty. Next, convert this value to its $\log _{10}$-base quantity. This becomes the nominal value for which the subsequent distribution will be developed.

2. Create a uniform parameter uncertainty range that extends from the $\log _{10}$-base quantity calculated in Step 1 by adding and subtracting the bin uncertainty from Table 6.12-4 to account for bin uncertainty.

3. Randomly choose a parameter value within this range (thereby producing a log-uniform probability of occurrence) to obtain a $\mathrm{Cl}^{-} / \mathrm{NO}_{3}{ }^{-}$ratio that includes the binning uncertainty. Note the difference between this step and the nominal log $\mathrm{Cl}^{-} / \mathrm{NO}_{3}{ }^{-}$ratio (Step 1). Call this difference delta because it will be used in Step 4 to 
adjust the theoretical log upper limit for $\mathrm{Cl}^{-} / \mathrm{NO}_{3}{ }^{-}$. Delta can be a positive or negative value.

4. From the $\mathrm{Cl}^{-} / \mathrm{NO}_{3}{ }^{-}$halite divide molal ratio lookup table (Table 6.12-23), find the nominal theoretical upper limit as a function of bin, temperature, and $p \mathrm{CO}_{2}$. Adjust this upper limit for binning uncertainty by adding the delta determined in Step 3.

5. Combine the $\mathrm{Cl}^{-} / \mathrm{NO}_{3}{ }^{-} \log$ value from Step 3, which includes the binning uncertainty, with the model uncertainty by adding and subtracting the log of the model uncertainty tabulated as a function of $\mathrm{RH}$ in Table 6.12-1. This will establish a lower and a preliminary upper bound for the $\log \mathrm{Cl}^{-} / \mathrm{NO}_{3}{ }^{-}$ratio.

6. Compare the preliminary upper bound established in Step 5 with the theoretical upper bound established in Step 4. If the upper bound of Step 4 is more than the value of Step 5, then set the final log upper bound to equal the value of Step 5. If the value of Step 4 is less than the value of Step 5, use the theoretical upper limit of Step 4 as the final value for the log upper bound.

7. Sample randomly from the range of $\log \mathrm{Cl}^{-} / \mathrm{NO}_{3}{ }^{-}$ratio established in Steps 5 and 6 to obtain a value that includes both binning and modeling uncertainties (i.e., log uniform distribution). If the preferred ratio is nitrate to chloride $\left(\mathrm{NO}_{3}{ }^{-} / \mathrm{Cl}^{-}\right)$, proceed with the negative value of this resulting $\log _{10}$-base quantity. Convert this $\log _{10}$-base quantity back to a ratio of non log units, if required.

Calculation of Nitrate Concentration That Includes Uncertainty - To obtain a consistent and correlated nitrate concentration value, it must be calculated from the two previously determined chemical conditions of chloride concentration and chloride to nitrate ratio.

1. Take the value for the chloride concentration and divide it by the chloride to nitrate ratio, where both of these values have already been adjusted to their uncertainty ranges.

Implementation of pH Uncertainties - Quantifying and implementing uncertainties for the $\mathrm{pH}$ is to be carried out as explained in the steps directly below. This will yield a uniform distribution centered on the $\mathrm{pH}$ value initially selected from the TSPA-LA lookup table.

1. Choose the appropriate $\mathrm{pH}$ value from the relevant TSPA-LA lookup table. This will become the nominal $\mathrm{pH}$ value for a subsequent distribution to be developed for this parameter.

2. Create a uniform parameter uncertainty range that extends from the nominal $\mathrm{pH}$ in Step 1 by adding and subtracting the bin uncertainty from Table 6.12-4.

3. Randomly select a value from the range established in Step 2 to produce a $\mathrm{pH}$ adjusted for binning uncertainty. 
4. Create a uniform parameter uncertainty range that extends from the $\mathrm{pH}$ in Step 3, which includes binning uncertainty, by adding and subtracting the model uncertainty of Table 6.12-1.

5. Randomly select a value from the range established in Step 4 to produce a $\mathrm{pH}$ adjusted for both binning and modeling uncertainty.

\subsection{ENGINEERED BARRIER SYSTEM CHEMICAL ENVIRONMENT}

The engineered barrier system chemical environment analyses focus on a quantitative description of $\mathrm{pH}$, ionic strength (I), and major ionic and elemental compositions of waters in contact with the waste package, the drip shield, and the invert. The brines that form by evaporative concentration from the crown seepage over time can potentially affect localized corrosion rates on the waste package and drip shield, and influence radionuclide mobility in the invert. Corrosion of the Alloy 22 forming the waste package may lead to premature release of radionuclides from the waste form. Elemental ratios such as $\mathrm{Cl} / \mathrm{N}$ are important in assessing the potential for localized corrosion of the waste package in the EBS environment (BSC 2004 [DIRS 169984], Figure 6-1; BSC 2004 [DIRS 169845]). Acidic or alkaline pH values of water in the invert can enhance the solubility of radionuclides. The ionic strength of water in the invert will control the mobility of colloidal material transporting sorbed radionuclides.

In addition, dust that accumulates on waste packages or drip shields during the operational and ventilation time periods may contain soluble salts, which will cause water condensation if the in-drift humidity is higher than the minimum deliquescent point of the salts. The resulting brine solutions are not significant to degradation of the waste package outer barrier, as discussed in Section 6.10.

This section summarizes the results of the P\&CE model described in this document, establishing the magnitude and range of chemical variables in the processes involved, and establishing the foundation for the TSPA-LA modeling approach for the EBS environment.

Two terms, widely used in this document, are defined again here to ensure that the reader understands the material presented in this section. "Bin" is defined as a group of THC seepage waters with physical and chemical characteristics (Section 6.6.4) that fall within a single geochemical group as determined by chemical divides (or precipitated minerals) upon evaporative analysis. A "bin history" is defined as the discretized version of the evolution curves (Section 6.6.6) of the five THC seepage analysis starting water compositions, for both invert and crown seepage waters, in which the water compositions at each time interval are mapped to the compositional bins to which they belong. It is these analyses that are used to generate the seepage evaporation abstraction model in Section 6.9.

As calculated in Section 6.8.4, the quantifiable effects of Stainless Steel Type 316L active corrosion on seepage water for $\mathrm{pH}$ and ionic strength are insignificant at $100 \%$ relative humidity and negligible at $98 \%$ relative humidity. Based on these results and the results of the uncertainty calculations presented in Section 6.12.4, it has been concluded that active corrosion of the ground support will not appreciably influence the composition of the seepage waters in the drift. 
Figure 6.13-1 has been created from the bin history maps from the analysis results in Section 6.6.6. This work is documented in the spreadsheet Time integration20013.xls (Output DTN: MO0312SPAPCESA.002). Figure 6.13-1 shows the bin history maps for each of the five waters in a color-coded scheme. Also calculated in this spreadsheet is the time-integrated bin frequency of occurrence for waters entering the crown of the drift and the invert, which does not represent the TSPA implementation but is provided for discussion purposes. The frequency of occurrence is calculated by determining the relative percent of time each bin occurs for the five different waters. The relative weighting for a bin at a given time step is calculated by dividing the time step by the total length of the time interval examined. By totaling the relative weighting of the individual time steps according to bin, the percent of time the waters from each bin occur is calculated for each of the five different starting waters. This total is, for the specified time interval of 20,000 years, the time-integrated frequency of occurrence percentage for each bin, for the five different waters entering the crown of the drift and the invert.

It is immediately evident in Figure 6.13-1 that Bins 9 and 11 predominate during and after heating, with w6 dominated by Bin 9. Looking back to the binning criteria summarized in Table 6.6-3, the only difference between bins 9 and 11 is that Bin 9 has $\mathrm{NO}_{3}{ }^{-}>\mathrm{CO}_{3}{ }^{2-}$ (total carbonate) and Bin 11 does not. The native median water for Bin 9 begins with more than three times the nitrate of Bin 11 (Table 6.6-6); however, it also has almost twice as much total carbonate. Looking at the statistics of the waters at $65 \% \mathrm{RH}$ (Table 6.6-7), it is evident that though both bins have essentially the same carbonate levels and $\mathrm{pH}$, Bin 9 has a median nitrate (or elemental "N") level four times that of Bin 11. This clearly distinguishes their chemistries in a manner relevant to TSPA-LA with regard to chloride and nitrate concentrations.

Additionally, evaporated seepage waters dominated by both Bins 9 through 11 follow a similar evolution during their time histories at 65\% RH (see "Final Checked EBS THC Seepage Binning Abstraction REV 4.xls.xls" (Output DTN: MO0508SPAEBSCB.001). Calcite is usually present at the initial time step then absent (excluding w0) during most the remaining water time histories (fluorite being the calcium phase precipitating) until the later time steps (year 7004 or after), then calcite precipitates again, likely due to the water re-equilibrating with the surrounding rock. The $\mathrm{pH}$ conditions for waters in Bins 9 through 11 are also similar (approximately 9.0 to 9.5) throughout the time histories, but are often significantly different from those waters residing in other bins (approximately 6.0 to 9.0). Furthermore, waters residing in these lower $\mathrm{pH}$ conditions, in bins other than 9 through 11, are usually characterized by calcite precipitation throughout the time histories. 

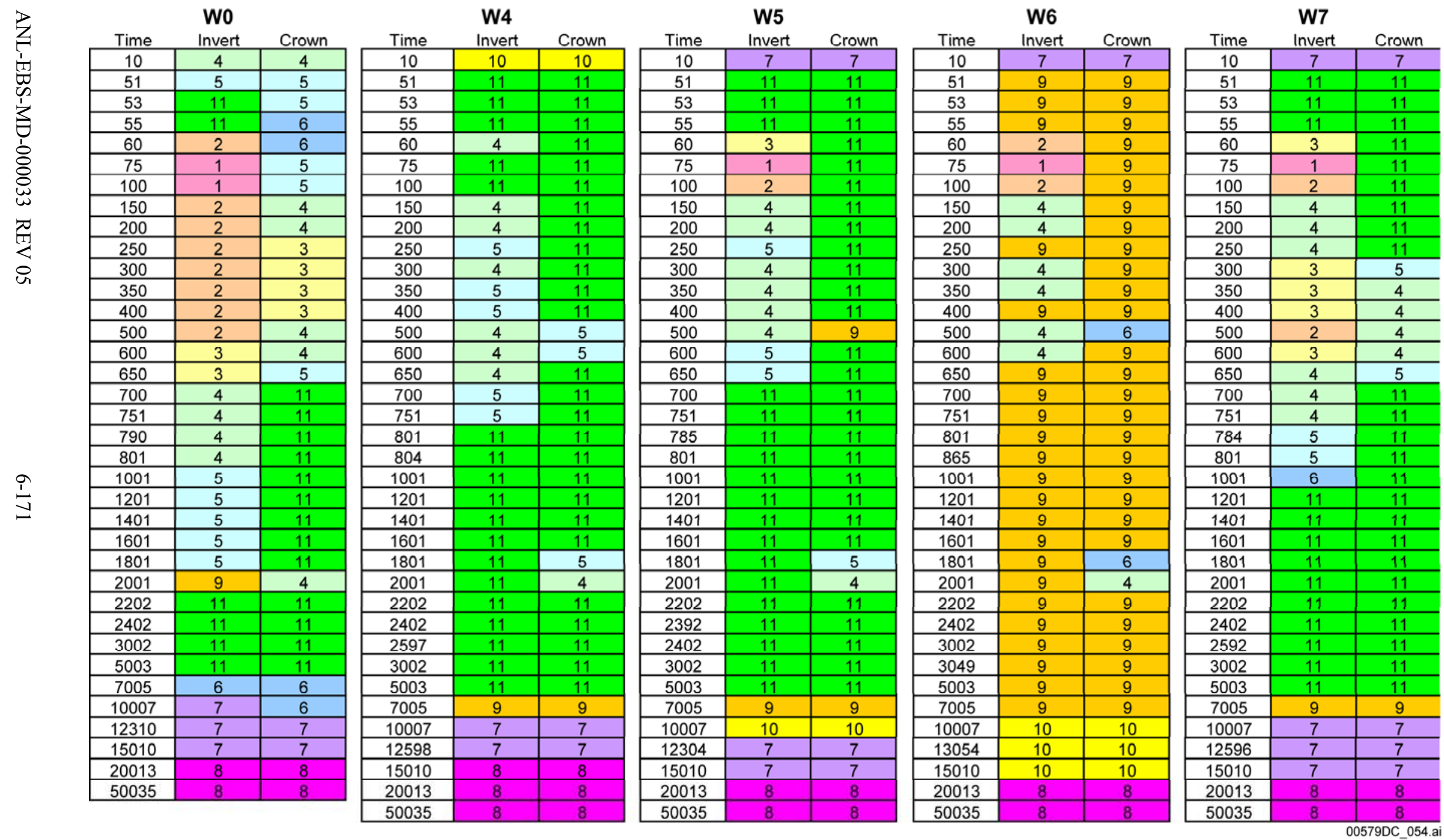

Source: Output DTN: MO0312SPAPCESA.002.

Figure 6.13-1. Color-Coded Bin History Maps Showing Differences between Crown Seepage and Invert Wicking 
The bin history maps show the composition of most-likely seepage waters - the liquid water existing closest to the drift in any given time step. They do not necessarily represent water present as seepage. At early times (less than approximately 1,800 years), when temperatures exceed the boiling point of water at the drift wall, the vaporization barrier effect should prevent water from entering the drift. In these early time steps, the most proximal liquid water may be meters into the drift wall. Only after drift-wall temperatures have cooled below boiling will the given compositions correspond to seepage.

The resulting time-integrated bin occurrences for a 50-year preclosure period and first 19,950 years after closure are shown in Tables 6.13-1 (crown seepage waters) and 6.13-2 (invert wicking waters), where each of the five starting waters is equally likely to occur and the normalized values reflect the sum total of all five starting waters. (These probabilities represent the percent of time that each bin water is expected to enter the drift at the given location. For instance, in the first 20,000 years, if w0 is the chosen starting water, Bin 3 water will be present at the drift crown for $1.12 \%$ of the time, or 224 years. However, since all five waters are equally probable, Bin 3 water will be present at the crown, on the average, for $0.22 \%$ of the time, or 44 years. These probabilities are only applicable for the time interval 0 to 20,000 years, as the bin occurrences are not randomly distributed through time; see Figure 6.13-1.)

Table 6.13-1. Time-Integrated Bin Occurrence for Any Given Crown Seepage Bin (20,000-Year Case)

\begin{tabular}{|c|c|c|c|c|c|c|c|}
\hline Water & $\begin{array}{l}\text { w0 } \\
\text { (\%) }\end{array}$ & $\begin{array}{l}\text { w4 } \\
\text { (\%) }\end{array}$ & $\begin{array}{l}\text { w5 } \\
\text { (\%) }\end{array}$ & $\begin{array}{l}\text { w6 } \\
\text { (\%) }\end{array}$ & $\begin{array}{l}\text { w7 } \\
\text { (\%) }\end{array}$ & $\begin{array}{c}\text { Sum } \\
(\%)\end{array}$ & $\begin{array}{c}\text { Norm } \\
(\%)\end{array}$ \\
\hline Bin 1 & 0.00 & 0.00 & 0.00 & 0.00 & 0.00 & 0.00 & 0.00 \\
\hline Bin 2 & 0.00 & 0.00 & 0.00 & 0.00 & 0.00 & 0.00 & 0.00 \\
\hline Bin 3 & 1.12 & 0.00 & 0.00 & 0.00 & 0.00 & 1.12 & 0.22 \\
\hline Bin 4 & 2.62 & 1.00 & 1.00 & 1.00 & 1.50 & 7.12 & 1.42 \\
\hline $\operatorname{Bin} 5$ & 0.56 & 1.87 & 1.00 & 0.00 & 0.50 & 3.93 & 0.79 \\
\hline $\operatorname{Bin} 6$ & 25.82 & 0.00 & 0.00 & 1.50 & 0.00 & 27.32 & 5.46 \\
\hline Bin 7 & 31.75 & 26.48 & 32.01 & 0.25 & 45.25 & 135.74 & 27.15 \\
\hline Bin 8 & 12.50 & 31.03 & 12.50 & 12.50 & 12.50 & 81.02 & 16.20 \\
\hline Bin 9 & 0.00 & 12.50 & 13.00 & 39.75 & 12.50 & 77.75 & 15.55 \\
\hline Bin 10 & 0.00 & 0.25 & 13.24 & 45.00 & 0.00 & 58.49 & 11.70 \\
\hline Bin 11 & 25.63 & 26.88 & 27.25 & 0.00 & 27.75 & 107.50 & 21.50 \\
\hline Sum & 100.00 & 100.00 & 100.00 & 100.00 & 100.00 & 500.00 & 100.00 \\
\hline
\end{tabular}

Source: Output DTN: MO0312SPAPCESA.002.

NOTES: w0 through w7 refer to the starting THC seepage chemistry inputs as listed in Table 4.1-4.

Time-integrated frequency of occurrence is calculated for discussion purposes only and is not implemented in TSPA. 
Table 6.13-2. Time-Integrated Bin Frequency of Occurrence for Any Given Invert Wicking Seepage Bin $(20,000-$ Year Case $)$

\begin{tabular}{|c|c|c|c|c|c|c|c|}
\hline Water & $\begin{array}{c}\text { w0 } \\
\text { (\%) }\end{array}$ & $\begin{array}{c}\text { w4 } \\
\mathbf{( \% )}\end{array}$ & $\begin{array}{c}\text { w5 } \\
\text { (\%) }\end{array}$ & $\begin{array}{c}\text { w6 } \\
\text { (\%) }\end{array}$ & $\begin{array}{c}\text { w7 } \\
\text { (\%) }\end{array}$ & $\begin{array}{c}\text { Sum } \\
\text { (\%) }\end{array}$ & $\begin{array}{c}\text { Norm } \\
\text { (\%) }\end{array}$ \\
\hline Bin 1 & 0.29 & 0.00 & 0.10 & 0.10 & 0.10 & 0.59 & 0.12 \\
\hline $\operatorname{Bin} 2$ & 2.17 & 0.00 & 0.19 & 0.24 & 0.69 & 3.29 & 0.66 \\
\hline $\operatorname{Bin} 3$ & 0.62 & 0.00 & 0.05 & 0.00 & 1.30 & 1.97 & 0.39 \\
\hline $\operatorname{Bin} 4$ & 1.37 & 1.92 & 1.87 & 1.87 & 1.46 & 8.50 & 1.70 \\
\hline $\operatorname{Bin} 5$ & 5.01 & 1.37 & 0.87 & 0.00 & 0.66 & 7.92 & 1.58 \\
\hline $\operatorname{Bin} 6$ & 12.50 & 0.00 & 0.00 & 0.00 & 1.00 & 13.50 & 2.70 \\
\hline $\operatorname{Bin} 7$ & 45.00 & 26.48 & 32.01 & 0.25 & 45.25 & 148.99 & 29.80 \\
\hline $\operatorname{Bin} 8$ & 12.50 & 31.03 & 12.50 & 12.50 & 12.50 & 81.02 & 16.20 \\
\hline $\operatorname{Bin} 9$ & 1.00 & 12.50 & 12.50 & 40.04 & 12.50 & 78.53 & 15.71 \\
\hline $\operatorname{Bin} 10$ & 0.00 & 0.25 & 13.24 & 45.00 & 0.00 & 58.49 & 11.70 \\
\hline $\operatorname{Bin} 11$ & 19.53 & 26.45 & 26.66 & 0.00 & 24.54 & 97.18 & 19.44 \\
\hline Sum & 100.00 & 100.00 & 100.00 & 100.00 & 100.00 & 500.00 & 100.00 \\
\hline
\end{tabular}

Source: Output DTN: MO0312SPAPCESA.002.

NOTE: $\quad$ w0 through w7 refer to the THC seepage chemistry inputs as listed in Table 4.1-4.

Time-integrated frequency of occurrence is calculated for discussion purposes only and is not implemented in TSPA.

The results in Table 6.13-1 show that, for the drift crown, the frequency of occurrence of waters from Bins 1 and 2 coming in contact with the waste package and drip shield is zero. The bin waters most likely to be present as crown seepage through the critical time period (701 to 7,000 years), when the repository is cooling down, are Bins 4, 9, and 11, with waters from Bins 5 and 6 present in lesser amounts of time. For the invert, during 701 to 7,000 years, waters from Bins 4, 5, 9, and 11 are dominant, with small amounts of time when Bin 6 water is most likely. However, from 7,001 to 20,000 years at both the crown and the invert, waters from Bins 7 and 8 are the most likely bins, with Bin 10 waters also occurring in both the crown and the invert, and Bin 6 only in the crown. For periods beyond 20,000 years, only Bin 8 waters will be present.) Only during the high-temperature period (from 51 to 700 years) do the more corrosive Bin 1, 2, and 3 waters potentially enter the repository, with Bin 3 water possibly occurring in the crown and the invert, and Bin 1 and 2 waters possibly occurring in the invert. This high temperature period is precisely the time when there is the least potential for liquid water to enter the drift, due to the heat energy generated within the waste packages. These observations have been included in Table 6.13-3, which associates the bins with five general periods of repository time, associated with general thermal or operational constraints. (They include the preclosure period ( 0 years to 50 years), the boiling period (51 to 700 years), a hot period (701 to 2,000 years), a cool-down period (2,001 to 7,000 years), and a return to ambient period (7,001 to 20,000) years. Although the chemistry is similar, the hot and cool-down periods are generally separated by a short, chemically distinct period that is shown in the bin histories (Tables 6.6-9 through 6.6-13 and Figure 6.13-1) and the analysis of the THC seepage model (Figures 6.6-16 through 6.6-25).) 
Table 6.13-3. Water Bins Associated with Different Periods in the Repository Thermal History

\begin{tabular}{|c|c|c|c|c|c|}
\hline Water Location & $\begin{array}{l}0 \text { to } 50 \text { years } \\
\text { (Preclosure) }\end{array}$ & $\begin{array}{l}51 \text { to } 700 \text { years } \\
\text { (Boiling) }\end{array}$ & $\begin{array}{l}701 \text { to } 2,000 \\
\text { years (Hot) }\end{array}$ & $\begin{array}{c}2,001 \text { to } 5,000 \\
\text { years (Cool } \\
\text { Down) }\end{array}$ & $\begin{array}{c}5,001 \text { to } 20,000 \\
\text { years (Return to } \\
\text { Ambient) }\end{array}$ \\
\hline Crown & $4,7,10$ & $3,4,5,6,9,11$ & $4,5,6,9,11$ & $6, \mathbf{9}, \mathbf{1 1}$ & $6,7,8,9,10$ \\
\hline Invert & $4,7,10$ & $1,2,3,4,5,9,11$ & $4,5,6,9,11$ & $6,9,11$ & $6,7,8,9,10$ \\
\hline
\end{tabular}

NOTE: Bins marked in bold are the most likely for each period, based on Figure 6.13-1.

At the edges of the repository, the duration of the heat pulse will be much shorter. The net effect of this distance on the "center of repository" results reported in this section would be to shorten the boiling and hot periods and result in reaching the cool-down period sooner (Table 6.13-3 for the associated bins).

In addition to the time integrated bin frequency of occurrences previously discussed, a second discrete probability distribution is also presented. This approach looks at the frequency of occurrence of the waters from any given bin at any given time.

As described in Section 6.6, the analysis of the THC model incoming seepage waters resulted in the definition of eleven groups of waters based on water type. Single median waters were chosen from these groups (or bins) to represent the bin in the analysis. Bin histories were developed to mimic the incoming water compositions predicted by the THC model as the most likely waters to seep into the drift.

Because there were five THC model runs, each with a different starting water composition (w0, w4, w5, w6, and w7), five bin histories are mapped for the crown seepage and five bin histories are mapped for the invert seepage (Section 6.6.6). These five THC starting water compositions are determined to be equally probable. Therefore, each bin has a $0,20,40,60,80$, or $100 \%$ frequency of occurring in the TSPA-LA model at any given time.

Bin occurrences are calculated for the crown and invert seepage for the time intervals defined in the bin histories. They are presented in Tables 6.13-4 and 6.13-5. Time intervals are approximated where noted in the tables. Approximations have been made where time intervals did not exactly match between bin histories. 
Table 6.13-4. Bin Occurrences for Crown Seepage as a Function of Time

\begin{tabular}{|c|c|c|c|c|c|c|c|c|c|c|c|c|}
\hline Start (yr) & End (yr) & Bin 1 & Bin 2 & Bin 3 & Bin 4 & Bin 5 & Bin 6 & Bin 7 & Bin 8 & Bin 9 & Bin 10 & Bin 11 \\
\hline 0.0 & 30.5 & - & - & - & $20 \%$ & - & - & $60 \%$ & - & - & $20 \%$ & - \\
\hline 30.5 & 52.0 & - & - & - & - & $20 \%$ & - & - & - & $20 \%$ & - & $60 \%$ \\
\hline 52.0 & 54.0 & - & - & - & - & $20 \%$ & - & - & - & $20 \%$ & - & $60 \%$ \\
\hline 54.0 & 57.5 & - & - & - & - & - & $20 \%$ & - & - & $20 \%$ & - & $60 \%$ \\
\hline 57.5 & 67.5 & - & - & - & - & - & $20 \%$ & - & - & $20 \%$ & - & $60 \%$ \\
\hline 67.5 & 87.5 & - & - & - & - & $20 \%$ & - & - & - & $20 \%$ & - & $60 \%$ \\
\hline 87.5 & 125.0 & - & - & - & - & $20 \%$ & - & - & - & $20 \%$ & - & $60 \%$ \\
\hline 125.0 & 175.0 & - & - & - & $20 \%$ & - & - & - & - & $20 \%$ & - & $60 \%$ \\
\hline 175.0 & 225.0 & - & - & - & $20 \%$ & - & - & - & - & $20 \%$ & - & $60 \%$ \\
\hline 225.0 & 275.0 & - & - & $20 \%$ & - & - & - & - & - & $20 \%$ & - & $60 \%$ \\
\hline 275.0 & 325.0 & - & - & $20 \%$ & - & $20 \%$ & - & - & - & $20 \%$ & - & $40 \%$ \\
\hline 325.0 & 375.0 & - & - & $20 \%$ & $20 \%$ & - & - & - & - & $20 \%$ & - & $40 \%$ \\
\hline 375.0 & 450.0 & - & - & $20 \%$ & $20 \%$ & - & - & - & - & $20 \%$ & - & $40 \%$ \\
\hline 450.0 & 550.0 & - & - & - & $40 \%$ & $20 \%$ & $20 \%$ & - & - & $20 \%$ & - & - \\
\hline 550.0 & 625.0 & - & - & - & $40 \%$ & $20 \%$ & - & - & - & $20 \%$ & - & $20 \%$ \\
\hline 625.0 & 675.0 & - & - & - & - & $40 \%$ & - & - & - & $20 \%$ & - & $40 \%$ \\
\hline 675.0 & 725.0 & - & - & - & - & - & - & - & - & $20 \%$ & - & $80 \%$ \\
\hline 725.0 & 775.0 & - & - & - & - & - & - & - & - & $20 \%$ & - & $80 \%$ \\
\hline 775.0 & 900.0 & - & - & - & - & - & - & - & - & $20 \%$ & - & $80 \%$ \\
\hline 900.0 & $1,100.0$ & - & - & - & - & - & - & - & - & $20 \%$ & - & $80 \%$ \\
\hline $1,100.0$ & $1,300.0$ & - & - & - & - & - & - & - & - & $20 \%$ & - & $80 \%$ \\
\hline $1,300.0$ & $1,500.5$ & - & - & - & - & - & - & - & - & $20 \%$ & - & $80 \%$ \\
\hline $1,500.5$ & $1,701.0$ & - & - & - & - & - & - & - & - & $20 \%$ & - & $80 \%$ \\
\hline $1,701.0$ & $1,901.0$ & - & - & - & - & $40 \%$ & $20 \%$ & - & - & - & - & $40 \%$ \\
\hline $1,901.0$ & $2,101.0$ & - & - & - & $80 \%$ & - & - & - & - & - & - & $20 \%$ \\
\hline $2,101.0$ & $2,301.0$ & - & - & - & - & - & - & - & - & $20 \%$ & - & $80 \%$ \\
\hline $2,301.0$ & $2,701.5$ & - & - & - & - & - & - & - & - & $20 \%$ & - & $80 \%$ \\
\hline $2,701.5$ & $4,002.5$ & - & - & - & - & - & - & - & - & $20 \%$ & - & $80 \%$ \\
\hline $4,002.5$ & $6,003.5$ & - & - & - & - & - & - & - & - & $20 \%$ & - & $80 \%$ \\
\hline $6,003.5$ & $8,505.0$ & - & - & - & - & - & $20 \%$ & - & - & $80 \%$ & - & - \\
\hline $8,505.0$ & $11,289.0^{a}$ & - & - & - & - & - & $20 \%$ & $40 \%$ & - & - & $40 \%$ & - \\
\hline $11,289.0^{\mathrm{a}}$ & $13,791.0^{a}$ & - & - & - & - & - & - & $80 \%$ & - & - & $20 \%$ & - \\
\hline $13,791.0^{a}$ & $17,511.5$ & - & - & - & - & - & - & $60 \%$ & $20 \%$ & - & $20 \%$ & - \\
\hline $17,511.5$ & $35,023.5$ & - & - & - & - & - & - & - & $100 \%$ & - & - & - \\
\hline $35,023.5$ & $100,000.0$ & - & - & - & - & - & - & - & $100 \%$ & - & - & - \\
\hline
\end{tabular}

Source: Table 6.13-1.

${ }^{a}$ Approximated time interval cutoff to accommodate all bin histories. 
Table 6.13-5. Bin Occurrence for Invert Seepage as a Function of Time

\begin{tabular}{|c|c|c|c|c|c|c|c|c|c|c|c|c|}
\hline Start (yr) & End (yr) & Bin 1 & $\operatorname{Bin} 2$ & Bin 3 & Bin 4 & Bin 5 & $\operatorname{Bin} 6$ & $\operatorname{Bin} 7$ & Bin 8 & Bin 9 & Bin 10 & Bin 11 \\
\hline 0.0 & 30.5 & - & - & - & $20 \%$ & - & - & $60 \%$ & - & - & $20 \%$ & - \\
\hline 30.5 & 52.0 & - & - & - & - & $20 \%$ & - & - & - & $20 \%$ & - & $60 \%$ \\
\hline 52.0 & 54.0 & - & - & - & - & - & - & - & - & $20 \%$ & - & $80 \%$ \\
\hline 54.0 & 57.5 & - & - & - & - & - & - & - & - & $20 \%$ & - & $80 \%$ \\
\hline 57.5 & 67.5 & - & $40 \%$ & $40 \%$ & $20 \%$ & - & - & - & - & - & - & - \\
\hline 67.5 & 87.5 & $60 \%$ & - & - & $20 \%$ & - & - & - & - & - & - & $20 \%$ \\
\hline 87.5 & 125.0 & $20 \%$ & $60 \%$ & - & - & - & - & - & - & - & - & $20 \%$ \\
\hline 125.0 & 175.0 & - & $20 \%$ & - & $80 \%$ & - & - & - & - & - & - & - \\
\hline 175.0 & 225.0 & - & $20 \%$ & - & $80 \%$ & - & - & - & - & - & - & - \\
\hline 225.0 & 275.0 & - & $20 \%$ & - & $20 \%$ & $40 \%$ & - & - & - & $20 \%$ & - & - \\
\hline 275.0 & 325.0 & - & $20 \%$ & $20 \%$ & $60 \%$ & - & - & - & - & - & - & - \\
\hline 325.0 & 375.0 & - & $20 \%$ & $20 \%$ & $40 \%$ & $20 \%$ & - & - & - & - & - & - \\
\hline 375.0 & 450.0 & - & $20 \%$ & $20 \%$ & $20 \%$ & $20 \%$ & - & - & - & $20 \%$ & - & - \\
\hline 450.0 & 550.0 & - & $40 \%$ & - & $60 \%$ & - & - & - & - & - & - & - \\
\hline 550.0 & 625.0 & - & - & $40 \%$ & $40 \%$ & $20 \%$ & - & - & - & - & - & - \\
\hline 625.0 & 675.0 & - & - & $20 \%$ & $40 \%$ & $20 \%$ & - & - & - & $20 \%$ & - & - \\
\hline 675.0 & 725.0 & - & - & - & $40 \%$ & $20 \%$ & - & - & - & $20 \%$ & - & $20 \%$ \\
\hline 725.0 & $767.0^{a}$ & - & - & - & $40 \%$ & $20 \%$ & - & - & - & $20 \%$ & - & $20 \%$ \\
\hline $767.0^{\mathrm{a}}$ & $792.0^{a}$ & - & - & - & $20 \%$ & $20 \%$ & - & - & - & $20 \%$ & - & $40 \%$ \\
\hline $792.0^{\mathrm{a}}$ & 900.0 & - & - & - & $20 \%$ & $20 \%$ & - & - & - & $20 \%$ & - & $40 \%$ \\
\hline 900.0 & $1,100.0$ & - & - & - & - & $20 \%$ & $20 \%$ & - & - & $20 \%$ & - & $40 \%$ \\
\hline $1,100.0$ & $1,300.0$ & - & - & - & - & $20 \%$ & - & - & - & $20 \%$ & - & $60 \%$ \\
\hline $1,300.0$ & $1,500.5$ & - & - & - & - & $20 \%$ & - & - & - & $20 \%$ & - & $60 \%$ \\
\hline $1,500.5$ & $1,701.0$ & - & - & - & - & $20 \%$ & - & - & - & $20 \%$ & - & $60 \%$ \\
\hline $1,701.0$ & $1,901.0$ & - & - & - & - & $20 \%$ & - & - & - & $20 \%$ & - & $60 \%$ \\
\hline $1,901.0$ & $2,101.0$ & - & - & - & - & - & - & - & - & $40 \%$ & - & $60 \%$ \\
\hline $2,101.0$ & $2,301.0$ & - & - & - & - & - & - & - & - & $20 \%$ & - & $80 \%$ \\
\hline $2,301.0$ & $2,701.5$ & - & - & - & - & - & - & - & - & $20 \%$ & - & $80 \%$ \\
\hline $2,701.5$ & $4,002.5$ & - & - & - & - & - & - & - & - & $20 \%$ & - & $80 \%$ \\
\hline $4,002.5$ & $6,003.5$ & - & - & - & - & - & - & - & - & $20 \%$ & - & $80 \%$ \\
\hline $6,003.5$ & $8,505.0$ & - & - & - & - & - & $20 \%$ & - & - & $80 \%$ & - & - \\
\hline $8,505.0$ & $11,228.3^{a}$ & - & - & - & - & - & - & $60 \%$ & - & - & $40 \%$ & - \\
\hline $11,228.3^{a}$ & $13,730.3^{a}$ & - & - & - & - & - & - & $80 \%$ & - & - & $20 \%$ & - \\
\hline $13,730.3^{\mathrm{a}}$ & $17,511.5$ & - & - & - & - & - & - & $60 \%$ & $20 \%$ & - & $20 \%$ & - \\
\hline $17,511.5$ & $35,023.5$ & - & - & - & - & - & - & - & $100 \%$ & - & - & - \\
\hline $35,023.5$ & $100,000.0$ & - & - & - & - & - & - & - & $100 \%$ & - & - & - \\
\hline
\end{tabular}

Source: Table 6.13-1.

${ }^{a}$ Approximated time interval cutoff to accommodate all bin histories. 


\subsubsection{Engineered Barrier System Seepage Chemistry}

Section 6.9 describes the development of seepage evaporation model lookup tables that represent the $\mathrm{pH}, \mathrm{I}$, and chemical compositions ( $\mathrm{Ca}, \mathrm{Na}, \mathrm{K}, \mathrm{Mg}, \mathrm{Al}, \mathrm{F}, \mathrm{S}, \mathrm{Si}, \mathrm{N}, \mathrm{Cl}$, and $\mathrm{C}$ ) of crown seepage and seepage wicking into the invert. Appendix B contains figures that show the various chemical parameters as a function of relative humidity and concentration factor as well as the results from the 99 individual evaporation lookup tables. The results from the lookup tables are summarized as follows:

- Section 6.13.1.1 describes the distribution of starting waters that would define which set of bin history maps could be used at any given time.

- Section 6.13.1.2 discusses what these lookup tables represent and the ranges of outputs associated with these tables.

\subsubsection{Engineered Barrier System Seepage Chemistry Constraints}

The THC seepage model output (input to this report, Table 4.1-4) is calculated at a discrete location in the repository associated with the Topopah Spring tuff lower lithophysal zone (Tptpll) (BSC 2005 [DIRS 172862]). The assumption is made for this report, as discussed in Section 5.1.4, that the starting waters taken from the THC model, and therefore their subsequent abstraction, can be applied throughout the repository as representing the full range of possible evaporated seepage water chemistries.

The five starting waters selected for use as input to the THC seepage model represent the range of chemistries in the plotted data. Therefore, each of the five starting waters (w0, w4, w5, w6, and w7) is assigned a $20 \%$ frequency of being selected as the starting water for a given realization. Confidence in this representation is enhanced in Section 7.3.1. The selection of a starting water also dictates the bin history that a given model realization uses. The bin histories are located in Section 6.6.6 (Tables 6.6-9 through 6.6-13). Selecting a starting water also establishes what the starting $\mathrm{pCO}_{2}$ lookup table is for a given model realization. These lookup tables are found in Section 6.7.2.1 (Tables 6.7-1 through 6.7-5). The bin history maps and $p \mathrm{CO}_{2}$ lookup tables are produced from two source locations: crown fractures for the in-drift and invert matrix for the invert.

In-drift temperatures and relative humidity are calculated in Multiscale Thermohydrologic Model (BSC 2005 [DIRS 173944]). The model results presented here are generalized, and results are discussed in terms of ranges. Aside from the overall calculated ranges, specific ranges are discussed in Sections 6.13.3 and 6.13.4 for the five periods that are reported in Table 6.13-3. This provides the reader with compositional trends through time.

\subsubsection{Engineered Barrier System Seepage Chemistry Response Surface Ranges}

The seepage evaporation lookup tables developed and described in Section 6.9 are combined into one large lookup table to assess the overall ranges of model outputs. This combined lookup table, documented in Output DTN: MO0304SPACPSLT.000, defines 11 multidimensional response surfaces, one for each of the representative bin seepage waters. From these response surfaces, IDPS model outputs can be interpolated for water temperatures ranging from $40^{\circ} \mathrm{C}$ 
to $100^{\circ} \mathrm{C}$, partial pressures of $\mathrm{CO}_{2}$ from $10^{-4}$ to $10^{-2}$ bar, and relative humidity in the drift from 0 to $100 \%$ (Output DTN: MO0505SEPSEEPA.000).

Figures 6.13-2 through 6.13-12 show the seepage evaporation lookup tables for each of the 11 bins. These figures are meant only to illustrate the general output trends. The actual values are provided in the specific lookup tables listed in Table 6.9-8. For each bin, there are nine evaporation runs represented, one for each combination of temperature $\left(40^{\circ} \mathrm{C}, 70^{\circ} \mathrm{C}\right.$, and $\left.100^{\circ} \mathrm{C}\right)$ and $\mathrm{pCO}_{2}\left(10^{-4}, 10^{-3}\right.$, and $10^{-2}$ bar $)$.

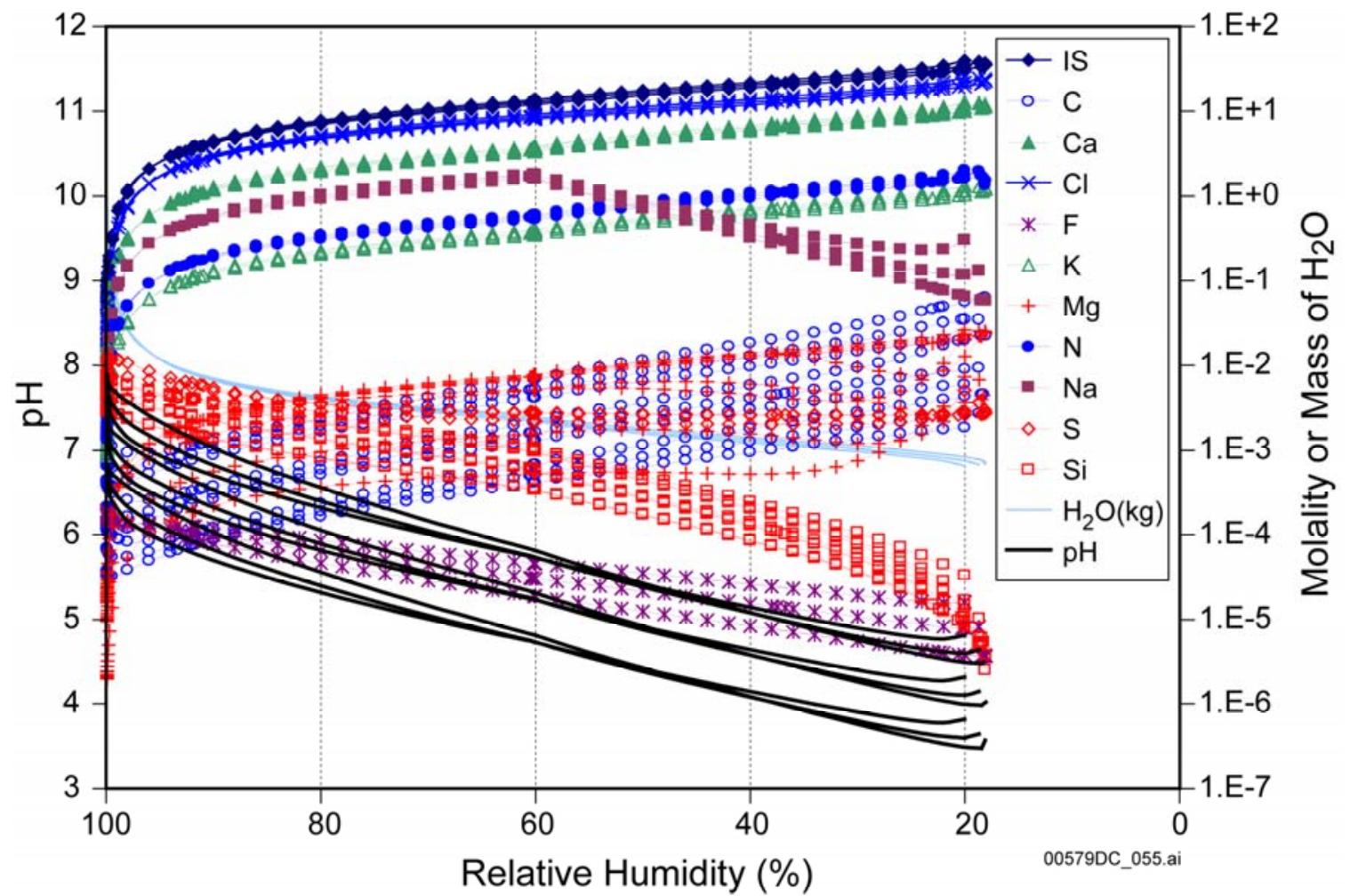

Source: Output DTN: MO0304SPACPSLT.000.

NOTE: $\quad$ IS = ionic strength.

Figure 6.13-2. Aqueous Composition Predictions versus Relative Humidity for All Seepage Evaporation Lookup Tables for Bin 1 


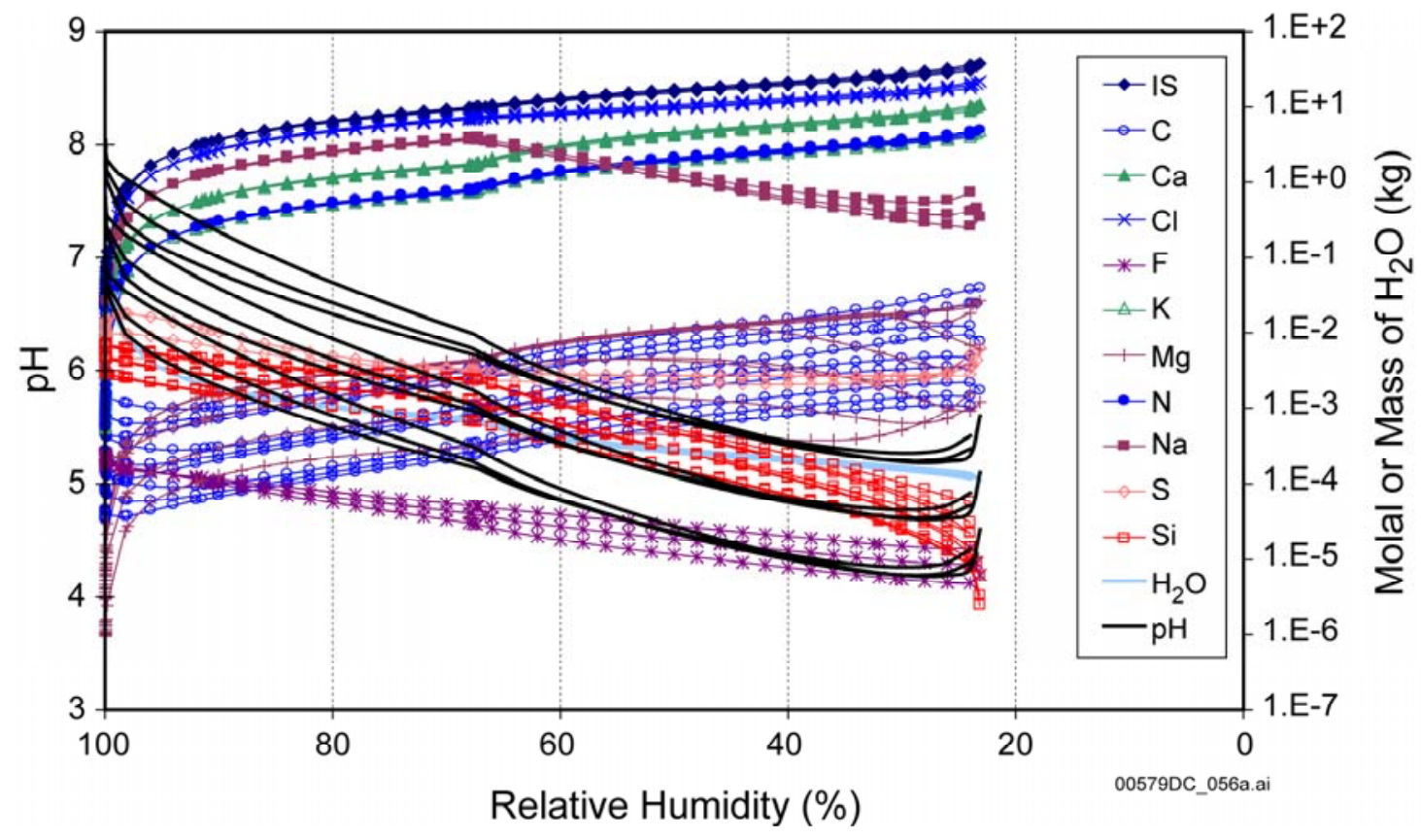

Source: Output DTN: MO0304SPACPSLT.000.

NOTE: $\quad$ IS = ionic strength.

Figure 6.13-3. Aqueous Composition Predictions versus Relative Humidity for All Seepage Evaporation Lookup Tables for Bin 2

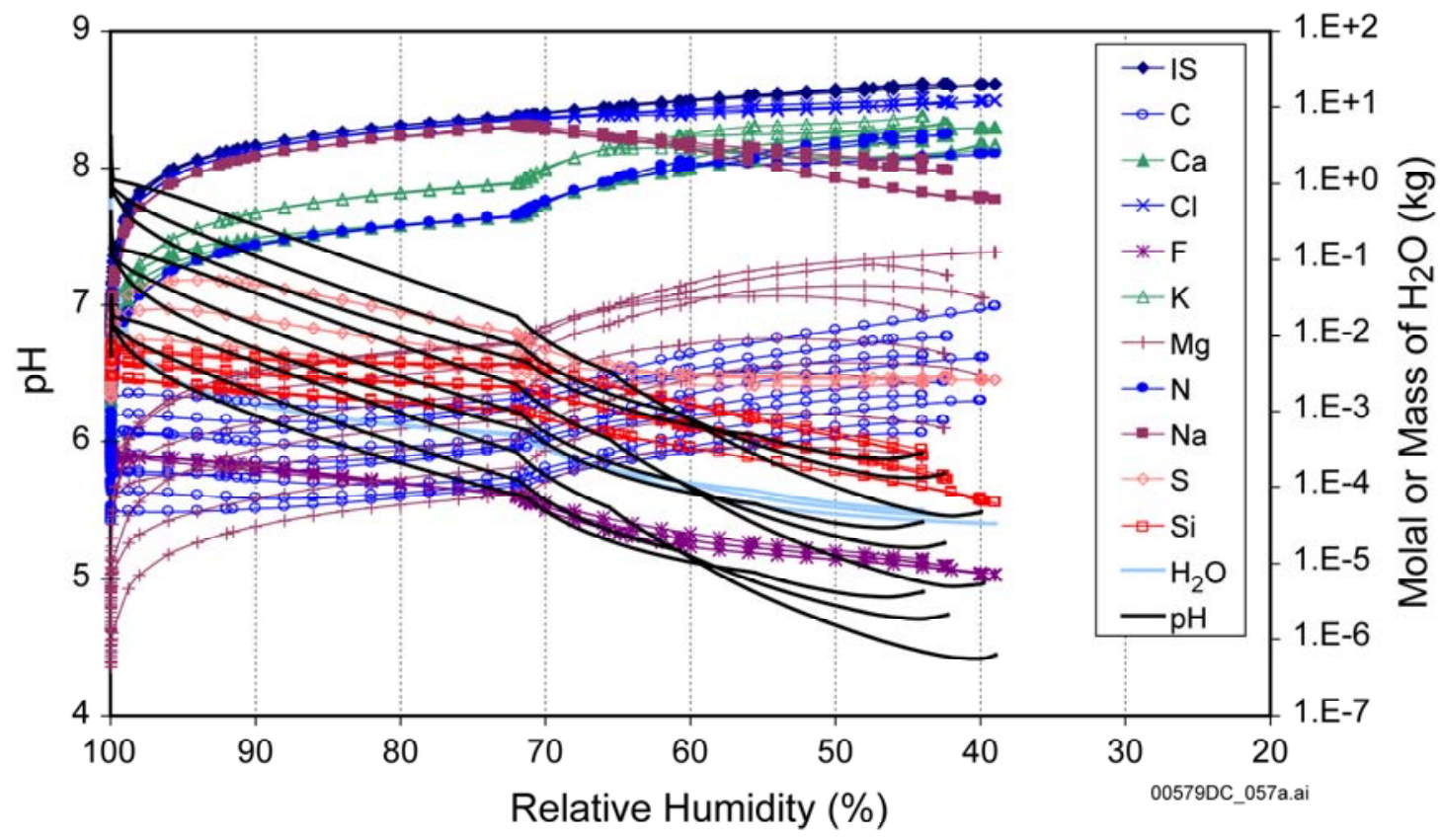

Source: Output DTN: MO0304SPACPSLT.000.

NOTE: IS = ionic strength.

Figure 6.13-4. Aqueous Composition Predictions versus Relative Humidity for All Seepage Evaporation Lookup Tables for Bin 3 


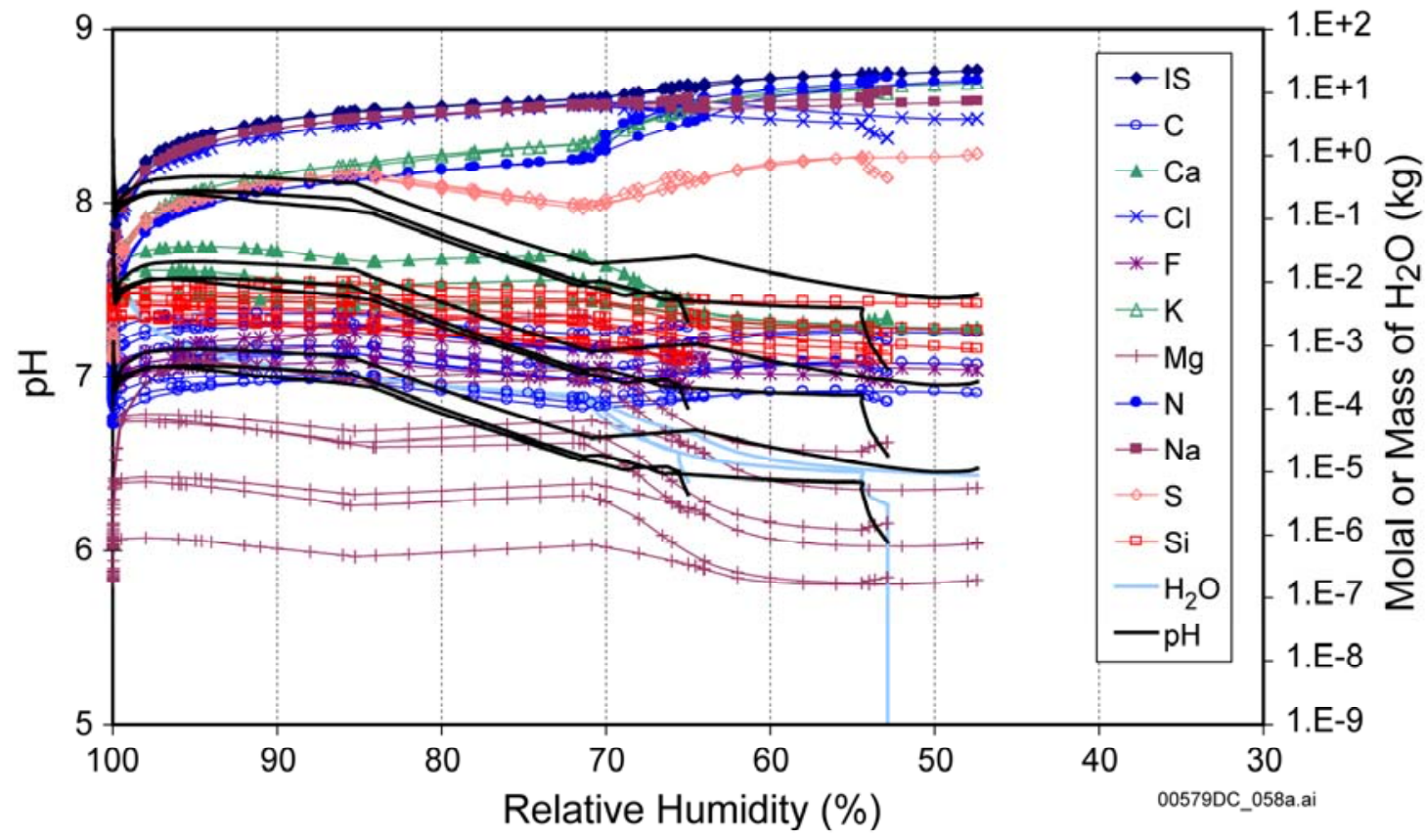

Source: Output DTN: MO0304SPACPSLT.000.

NOTE: $\quad$ IS = ionic strength.

Figure 6.13-5. Aqueous Composition Predictions versus Relative Humidity for All Seepage Evaporation Lookup Tables for Bin 4

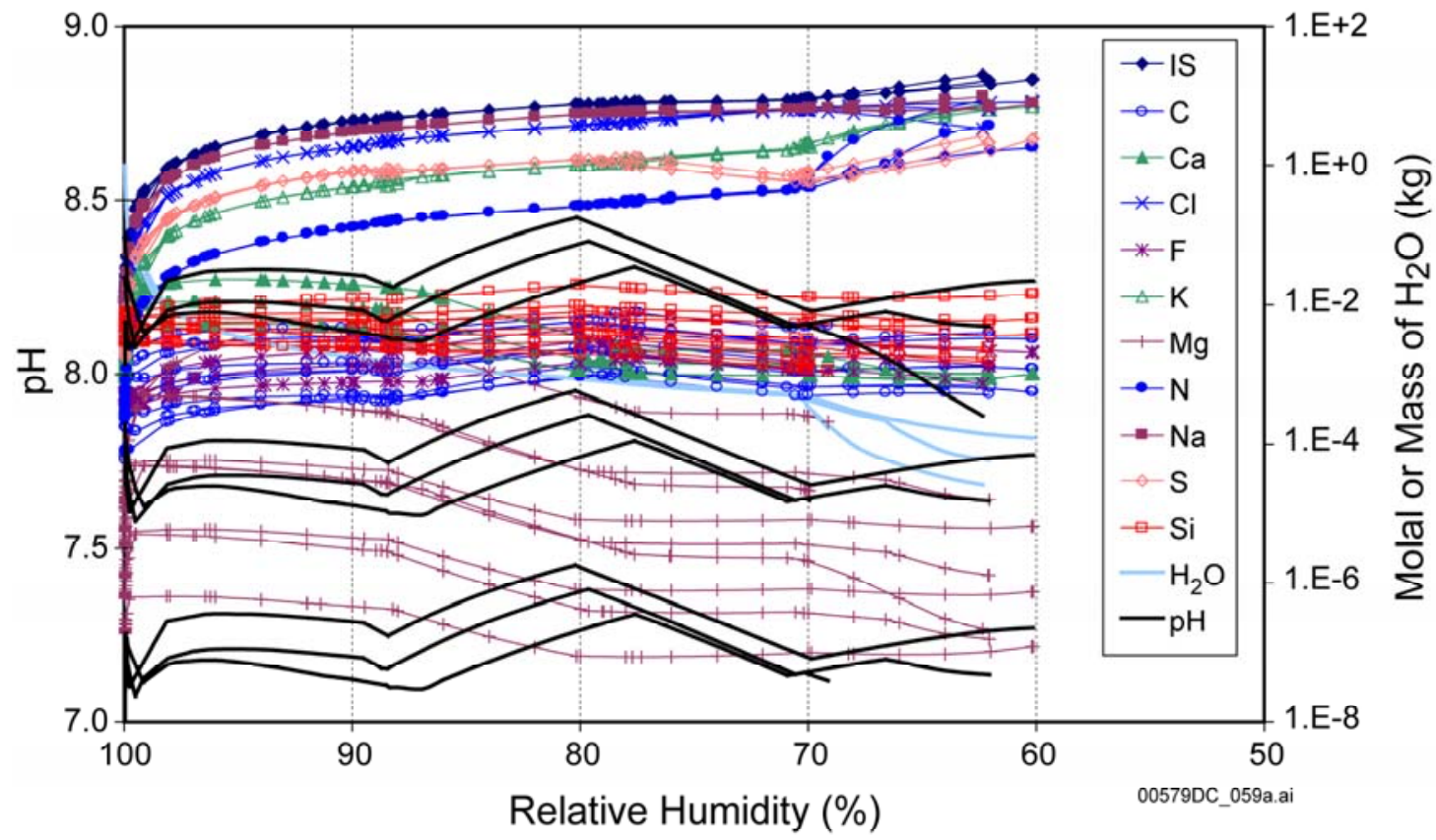

Source: Output DTN: MO0304SPACPSLT.000.

NOTE: $\quad$ IS = ionic strength.

Figure 6.13-6. Aqueous Composition Predictions versus Relative Humidity for All Seepage Evaporation Lookup Tables for Bin 5 


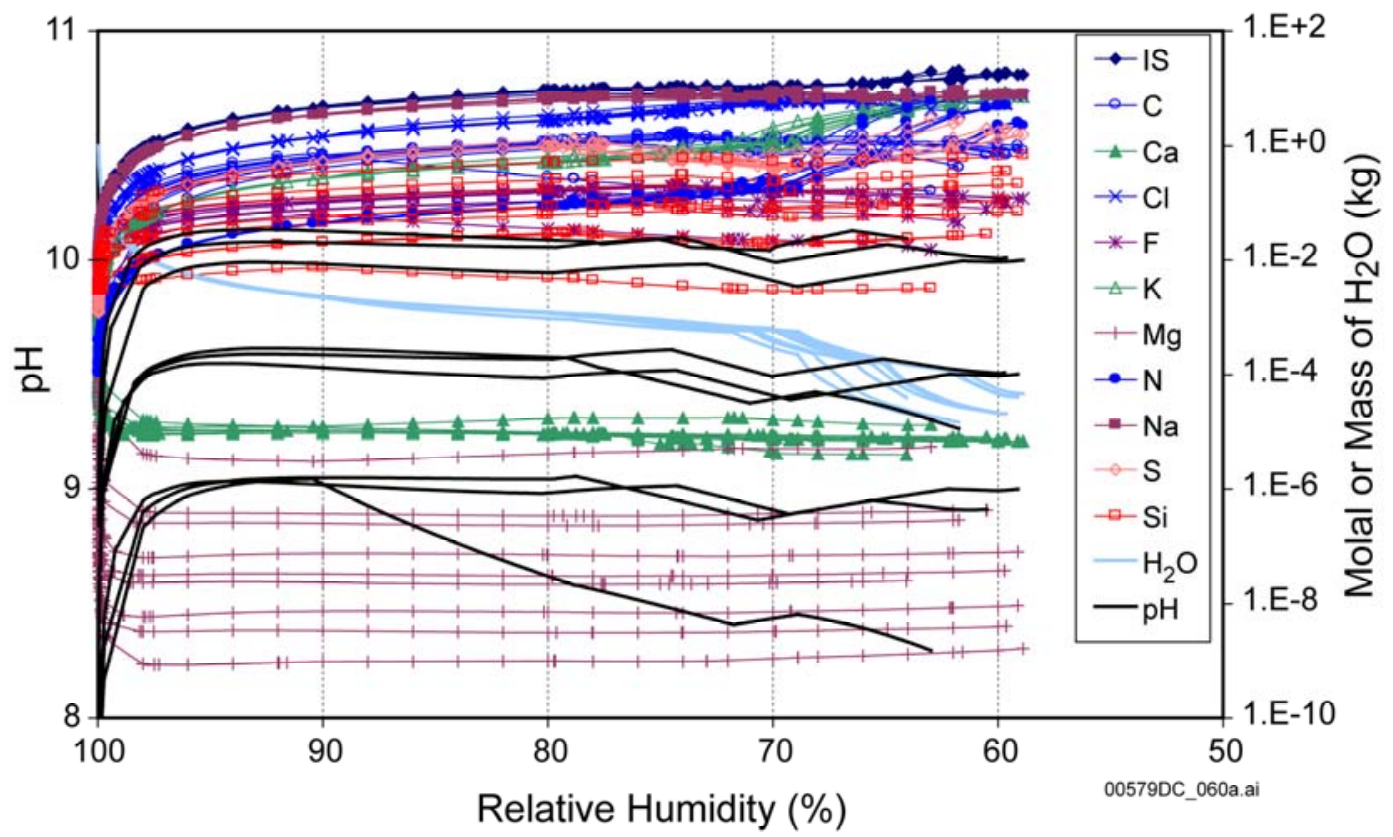

Source: Output DTN: MO0304SPACPSLT.000.

NOTE: $\quad$ IS = ionic strength.

Figure 6.13-7. Aqueous Composition Predictions versus Relative Humidity for All Seepage Evaporation Lookup Tables for Bin 6

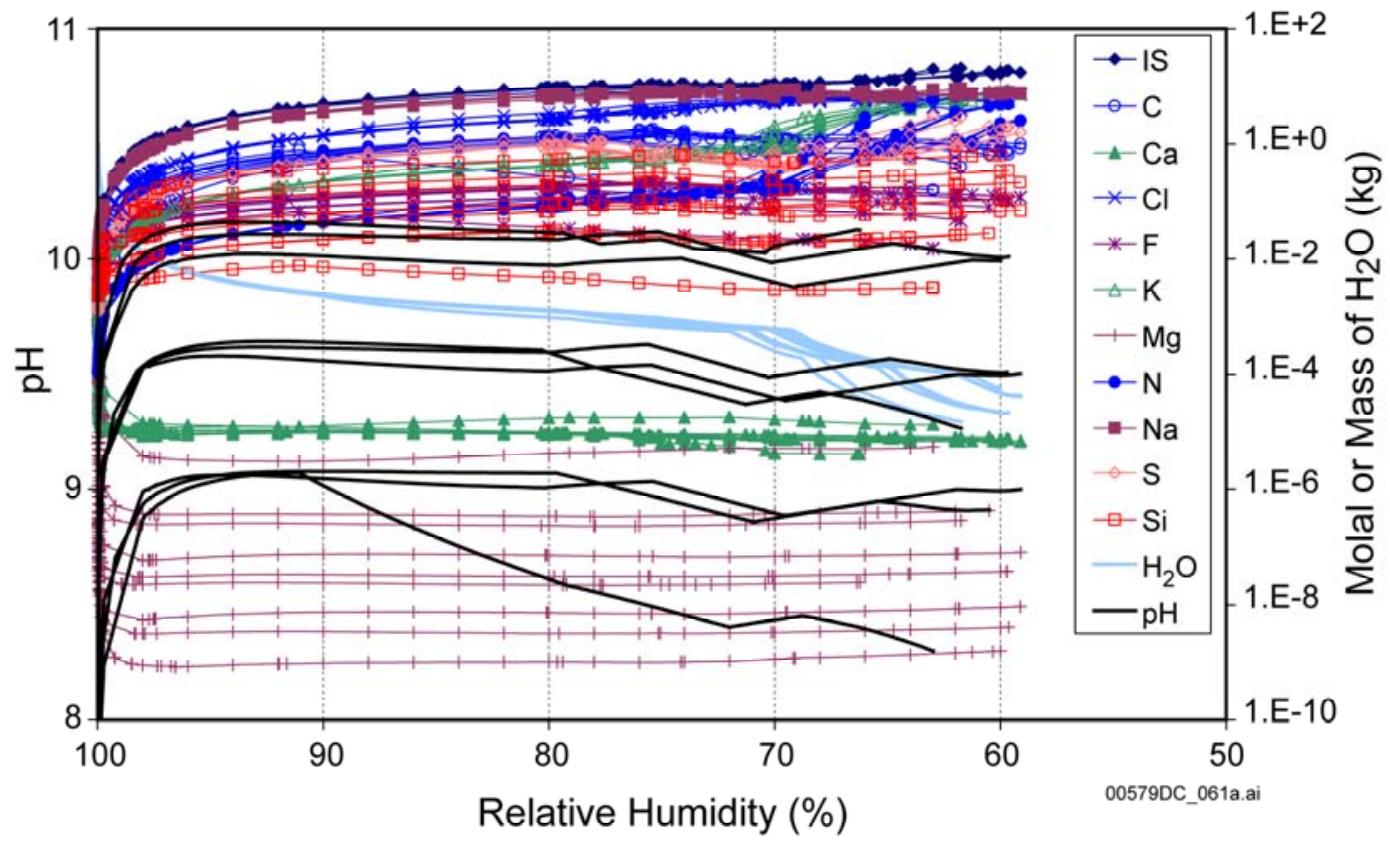

Source: Output DTN: MO0304SPACPSLT.000.

NOTE: $\quad$ IS = ionic strength.

Figure 6.13-8. Aqueous Composition Predictions versus Relative Humidity for All Seepage Evaporation Lookup Tables for Bin 7 


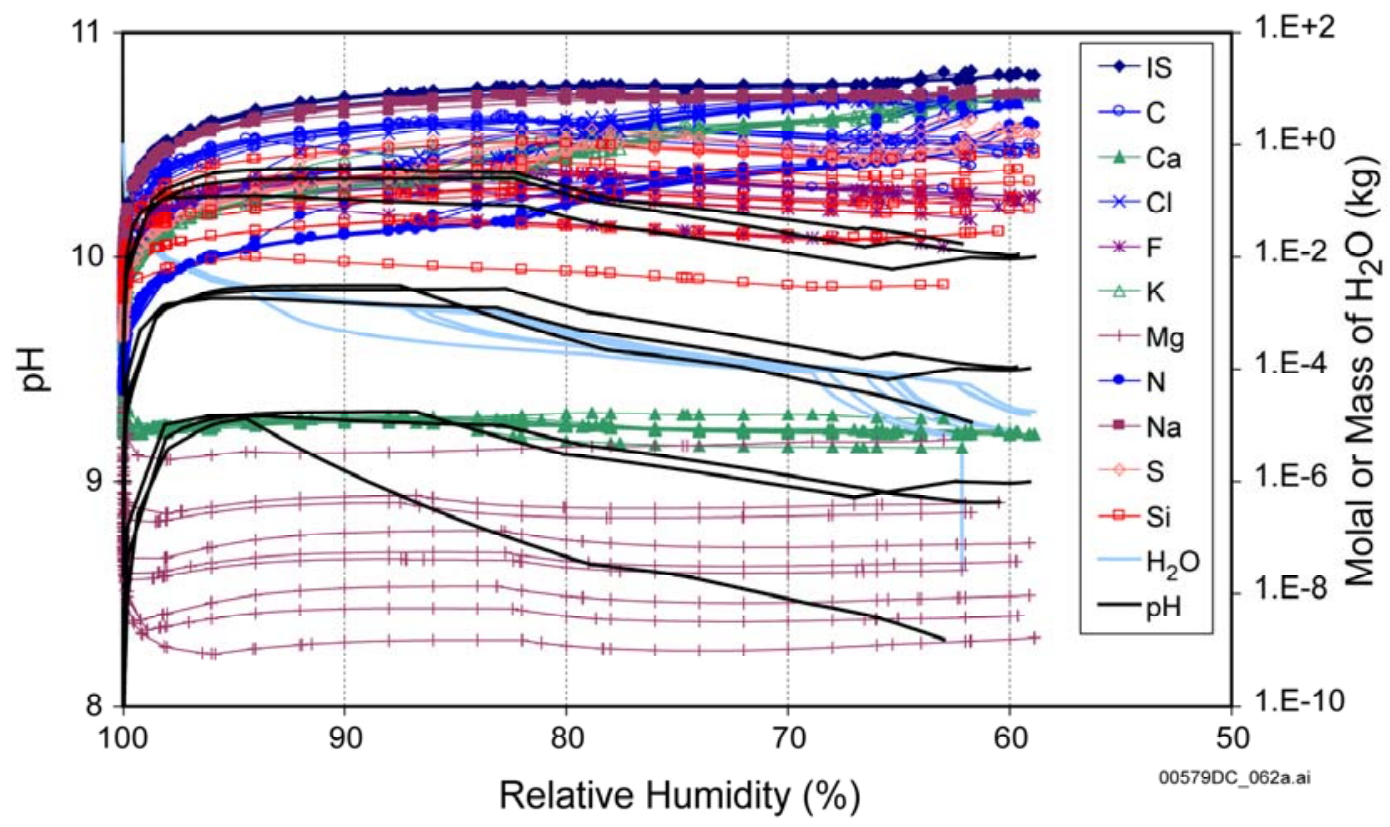

Source: Output DTN: MO0304SPACPSLT.000.

NOTE: $\quad$ IS = ionic strength.

Figure 6.13-9. Aqueous Composition Predictions versus Relative Humidity for All Seepage Evaporation Lookup Tables for Bin 8

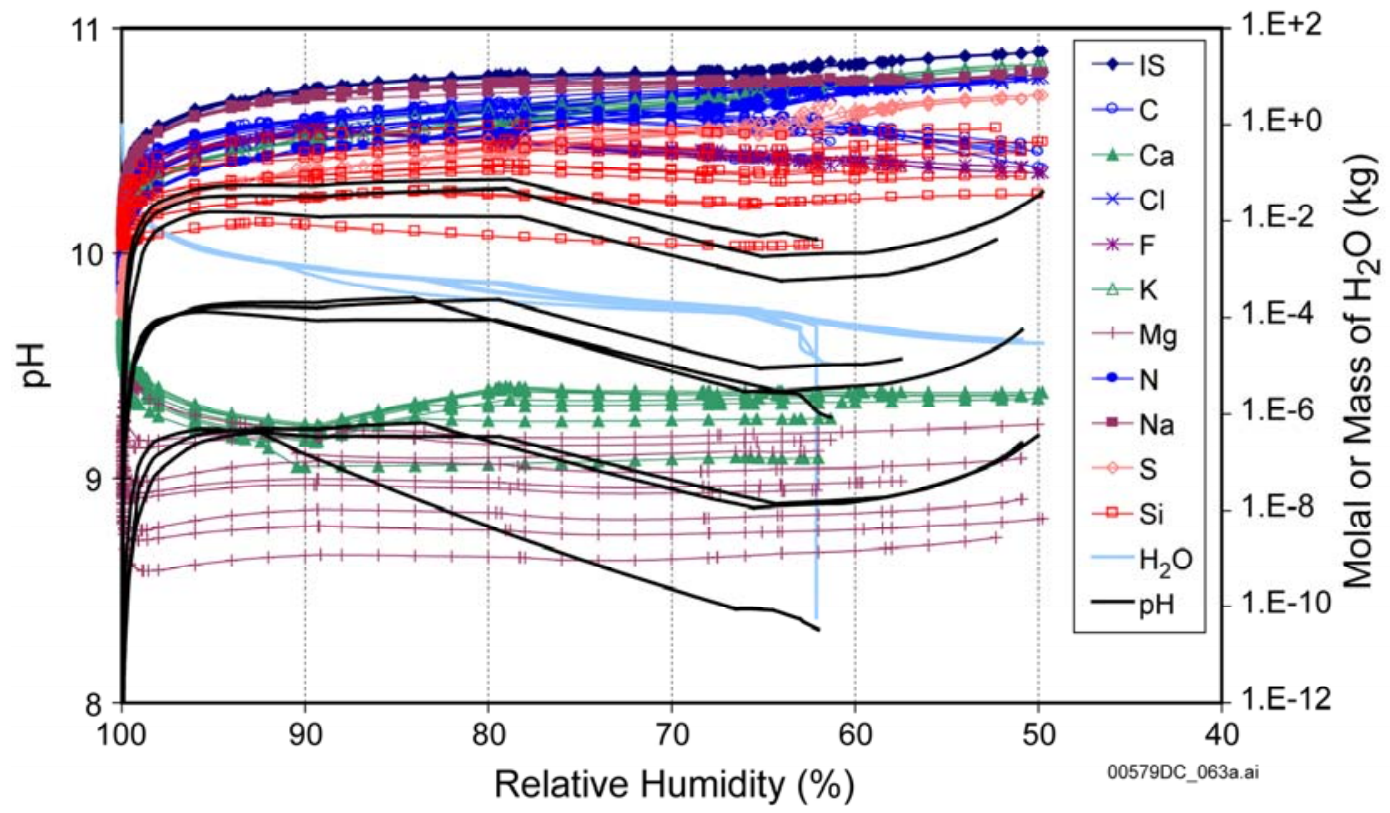

Source: Output DTN: MO0304SPACPSLT.000.

NOTE: $\quad$ IS = ionic strength.

Figure 6.13-10. Aqueous Composition Predictions versus Relative Humidity for All Seepage Evaporation Lookup Tables for Bin 9 


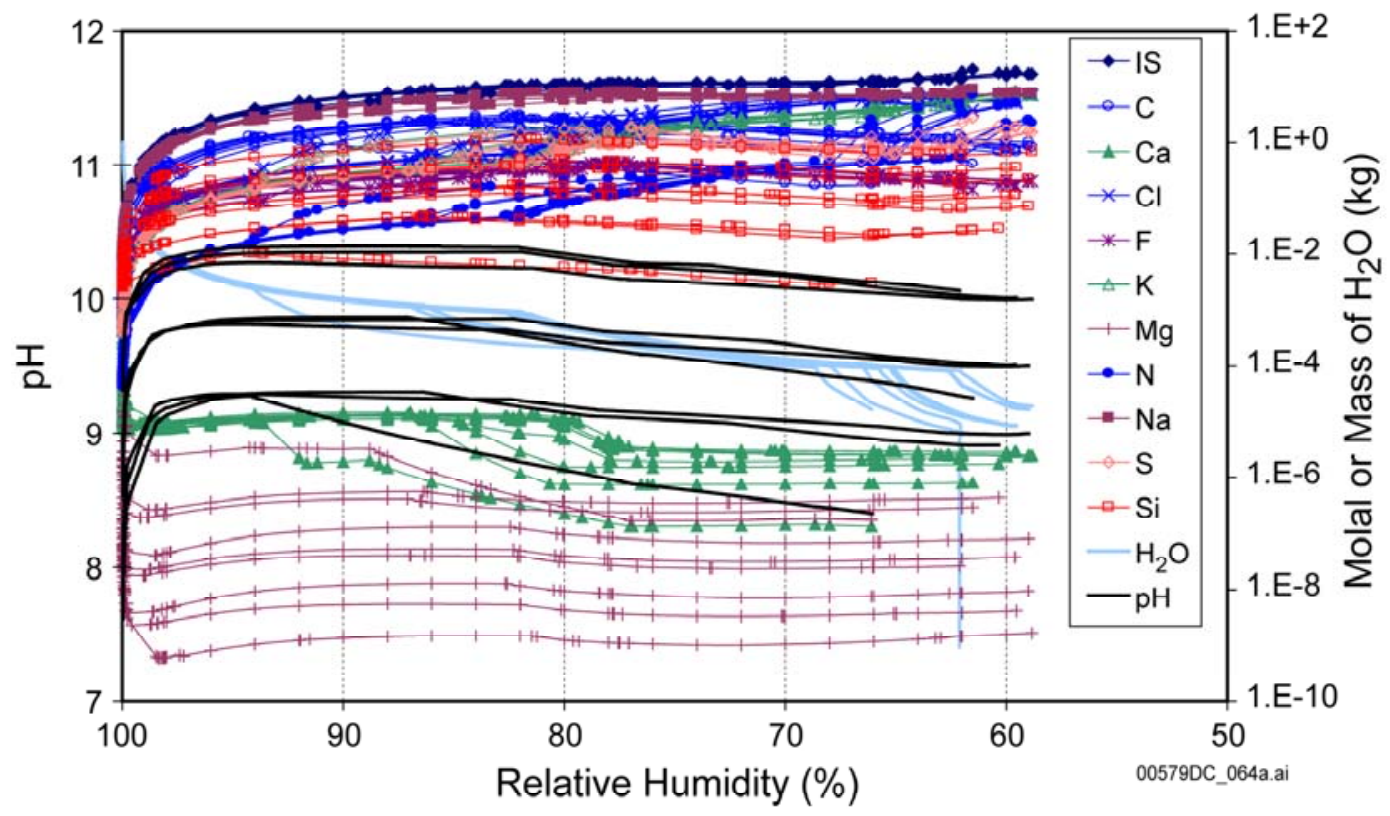

Source: Output DTN: MO0304SPACPSLT.000.

NOTE: $\quad$ IS = ionic strength.

Figure 6.13-11. Aqueous Composition Predictions versus Relative Humidity for All Seepage Evaporation Lookup Tables for Bin 10

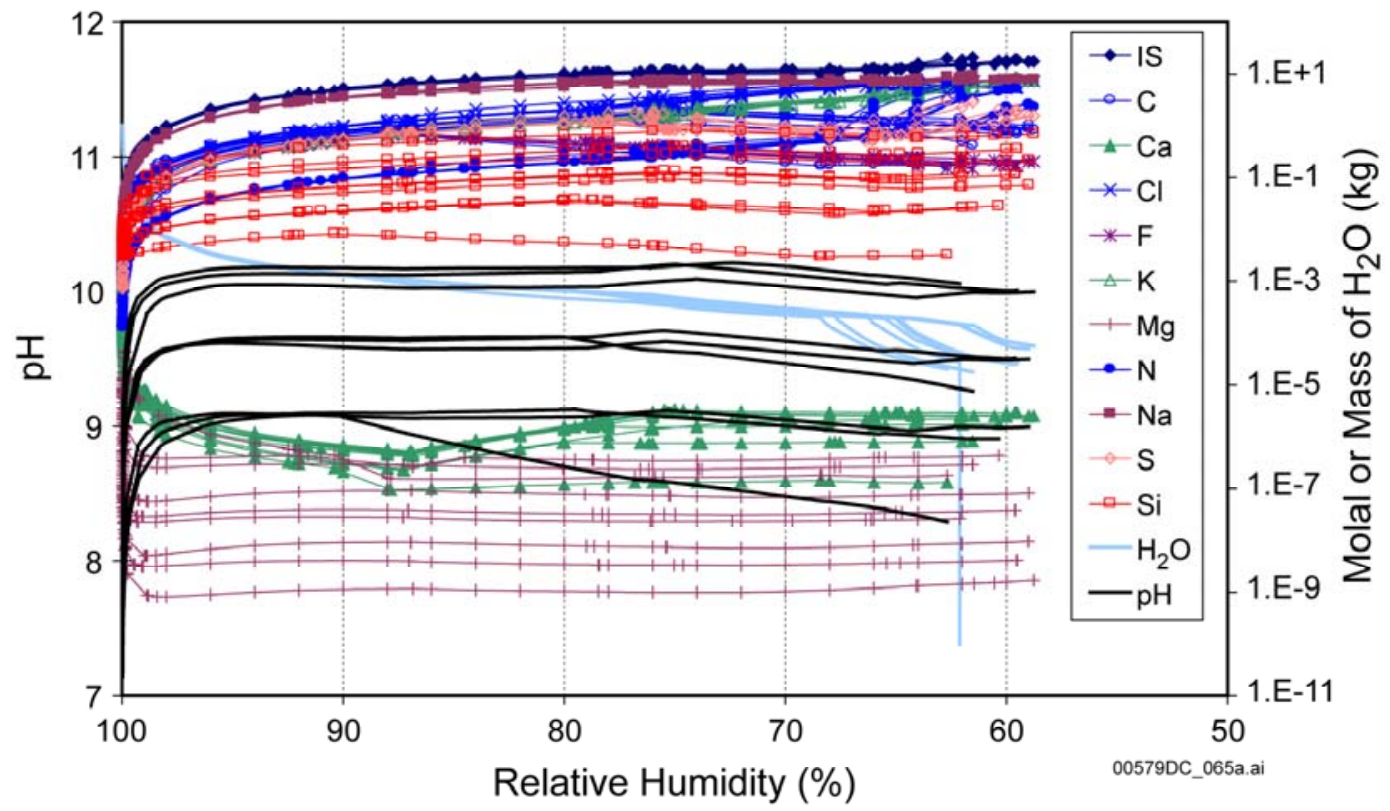

Source: Output DTN: MO0304SPACPSLT.000.

NOTE: $\quad$ IS = ionic strength.

Figure 6.13-12. Aqueous Composition Predictions versus Relative Humidity for All Seepage Evaporation Lookup Tables for Bin 11 
The combination of the nine individual lookup tables for each bin represents a response surface for the chemistry in that bin, so they suggest the potential ranges of outputs for the ranges of inputs simulated. These figures provide the entire range of values for each compositional variable. However, in the TSPA-LA simulations, the potential range of values is constrained to a single evolution path for each variable by the choice of $p \mathrm{CO}_{2}$ and temperature. The predicted relative humidity will further constrain the possible value of each parameter to a narrow range on each curve.

For example, the Bin 1 results shown in Figure 6.13-2 indicate that $\mathrm{pH}$ values could vary from 7 or 8 to 3.5 for the ranges of temperature, $p \mathrm{CO}_{2}$, and relative humidity modeled. However, according to the bin maps in Section 6.6.6, Bin 1 water only occurs in the invert between 57.5 years and 125 years. During this period, the temperature will be high and the $\mathrm{CO}_{2}$ pressure and relative humidity will be relatively low. The most likely Bin 1 output values used in the TSPA-LA will correspond to those predicted at low relative humidity for the high-temperature, low- $\mathrm{CO}_{2}$ pressure simulation $(01 c 4 t 1 e)$. The $\mathrm{pH}$ curve that corresponds to this case in Figure 6.13-2 is that with the highest $\mathrm{pH}$ values at a relative humidity of less than $35 \%$. Consequently, if the relative humidity is less than $60 \%$ during this time period, which is reasonable, then the most likely $\mathrm{pH}$ range for the TSPA-LA Bin 1 output is approximately 5 to 6 , a much smaller range than the $\mathrm{pH}$ response surface represented in Figure 6.13-2.

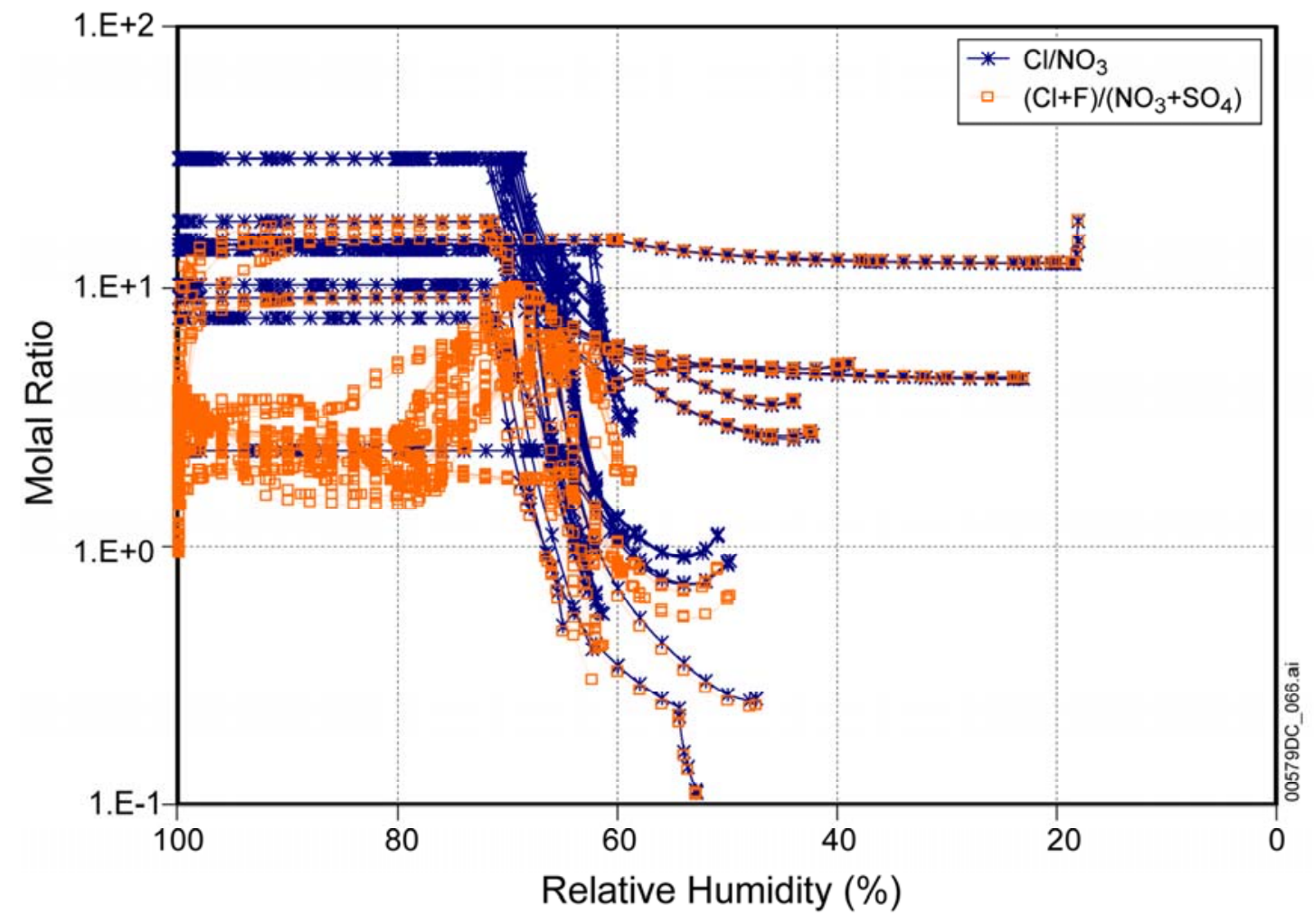

Source: Output DTN: MO0304SPACPSLT.000.

Figure 6.13-13. Selected Aqueous Molal Ratios Useful for Corrosion Analysis versus Relative Humidity for All Seepage Evaporation Lookup Tables for All Bins 
Figure 6.13-13 displays the all-bin response surface for two molar ratios: $\mathrm{Cl}^{-} / \mathrm{NO}_{3}{ }^{-}$which is potentially important to corrosion, and $\left(\mathrm{Cl}^{-}+\mathrm{F}^{-}\right) /\left(\mathrm{NO}_{3}{ }^{-}+\mathrm{SO}_{4}{ }^{2-}\right)$, which provides information on additional ions that potentially inhibit corrosion. As is the case for the response surfaces for the individual components displayed in the previous figures in this section, the ranges for the ratios relevant to TSPA-LA in any given time step are much smaller than the ranges plotted. In other words, many of the points plotted in Figure 6.13-13 (perhaps a majority, based on an extrapolation of the analysis in the previous paragraph) have a TSPA-LA frequency of | occurrence that approaches zero.

\subsubsection{Evaporative Brine Precipitate Mineralogy and Chemical Divide Phenomena}

Each lookup table developed in Section 6.9 has an associated precipitating mineral assemblage. Mineral precipitation as a function of relative humidity and degree of evaporative concentration is presented for each individual lookup table in Appendix B. Table 6.13-6 summarizes the characteristic mineral assemblages for each of the 11 bins.

Table 6.13-6. Summary Table of Precipitating Minerals in Each of the Eleven Bins

\begin{tabular}{|c|c|c|c|}
\hline Bin & $\begin{array}{c}\text { Precipitating } \\
\text { Minerals at the } \\
\text { Start of EQ6 Runs }\end{array}$ & $\begin{array}{c}\text { Additional Precipitating Minerals } \\
\text { (Roman Numerals Represent the } \\
\text { Precipitation Sequence) }\end{array}$ & Occurrence Notes \\
\hline Bin 1 & $\mathrm{SiO}_{2}(\mathrm{am})$, Stellerite & $\begin{array}{l}\text { Fluorite (I), Calcite (II), Anhydrite } \\
\text { (III), Sepiolite (IV), Halite (V), } \\
\mathrm{Ca}\left(\mathrm{NO}_{3}\right)_{2}\left(\mathrm{VI}_{\mathrm{a}}\right), \mathrm{Ca}\left(\mathrm{NO}_{3}\right)_{2}: 3 \mathrm{H}_{2} \mathrm{O} \\
\left(\mathrm{VI}_{\mathrm{b}}\right), \mathrm{Ca}\left(\mathrm{NO}_{3}\right)_{2}: 4 \mathrm{H}_{2} \mathrm{O}\left(\mathrm{VI}_{\mathrm{c}}\right)\end{array}$ & $\begin{array}{l}\text { Sepiolite does not form at } p \mathrm{CO}_{2}=10^{-2} \text {; calcium } \\
\text { nitrates are strongly temperature dependant; } \\
a=100^{\circ} \mathrm{C} ; \mathrm{b}=70^{\circ} \mathrm{C} ; \mathrm{c}=40^{\circ} \mathrm{C} \text {. }\end{array}$ \\
\hline Bin 2 & $\mathrm{SiO}_{2}(\mathrm{am})$, Stellerite & $\begin{array}{l}\text { Calcite (I), Fluorite (II), Anhydrite } \\
\text { (III), Sepiolite (IV), Halite (V), Soda } \\
\text { Niter (VI) }\end{array}$ & Soda niter only forms at $40^{\circ} \mathrm{C}$. \\
\hline Bin 3 & Stellerite, $\mathrm{SiO}_{2}(\mathrm{am})$ & $\begin{array}{l}\text { Fluorite (I), Calcite (II), Anhydrite } \\
\text { (III), Sepiolite (IV), Halite (V), } \\
\text { Sylvite (VI), Niter (VII) }\end{array}$ & $\begin{array}{l}\mathrm{SiO}_{2}(\mathrm{am}) \text { in one lookup table did not form at the } \\
\text { start of the run; niter only forms at } 40^{\circ} \mathrm{C} \text {. }\end{array}$ \\
\hline Bin 4 & $\mathrm{SiO}_{2}(\mathrm{am})$, Stellerite & $\begin{array}{l}\text { Calcite (I), Fluorite (II), Anhydrite } \\
\text { (III), Sepiolite (IV), Phillipsite (V), } \\
\text { Glauberite (VI), Halite (VII), } \\
\text { Pentasalt (VIII), Erionite (IX), Niter } \\
(\mathrm{X})\end{array}$ & $\begin{array}{l}\text { Zeolite minerals evolve in this bin in the following } \\
\text { general manner: stellerite to phillipsite to erionite; } \\
\text { niter does not show up in the } 100^{\circ} \mathrm{C} \text { simulations } \\
\text { tables; erionite does not show up in the } 40^{\circ} \mathrm{C} \\
\text { modeling runs. }\end{array}$ \\
\hline Bin 5 & $\begin{array}{l}\mathrm{SiO}_{2}(\mathrm{am}), \text { Stellerite, } \\
\text { Fluorite }\end{array}$ & $\begin{array}{l}\text { Calcite (I), Sepiolite (II), Glauberite } \\
\text { (III), Thenardite (IV), Erionite (V), } \\
\text { Halite (VI), Syngenite (VII), Niter } \\
\text { (VIII) }\end{array}$ & $\begin{array}{l}\text { Syngenite does not form at } 100^{\circ} \mathrm{C} \text {; niter only } \\
\text { forms in the } 40^{\circ} \mathrm{C}, p \mathrm{CO}_{2}=10^{-4} \text { modeling runs. }\end{array}$ \\
\hline Bin 6 & $\begin{array}{l}\text { Stellerite, Calcite, } \\
\text { Sepiolite }\end{array}$ & $\begin{array}{l}\mathrm{SiO}_{2}(\mathrm{am})(\mathrm{I}), \text { Fluorite }(\mathrm{II}), \text { Erionite } \\
(\mathrm{III}), \text { Thenardite }(\mathrm{IV}), \text { Halite }(\mathrm{V}), \\
\text { Arcanite }(\mathrm{VI}), \text { Natrite }(\mathrm{VII}) \text {, } \\
\text { Nahcolite }(\mathrm{VII}) \text {, [Pirssonite, } \\
\text { Burkeite, Trona] }(\mathrm{VII})\end{array}$ & $\begin{array}{l}\text { Calcite and sepiolite do not precipitate at the start } \\
\text { of the run in one model simulation }(06 c 2 t 4 e) ; \\
\text { natrite does not form at } 40^{\circ} \mathrm{C} \text {; nahcolite does not } \\
\text { form at } 100^{\circ} \mathrm{C} \text { or at } p \mathrm{CO}_{2}=10^{-4} \text {; burkeite, } \\
\text { pirssonite, and trona only form at } 40^{\circ} \mathrm{C} \text { and } \\
p^{\circ} \mathrm{CO}_{2}=10^{-4} \text {. }\end{array}$ \\
\hline Bin 7 & $\begin{array}{l}\text { Calcite, Sepiolite, } \\
\text { Stellerite }\end{array}$ & $\begin{array}{l}\mathrm{SiO}_{2}(\mathrm{am})(\mathrm{I}), \text { Fluorite }(\mathrm{II}), \text { Erionite } \\
(\mathrm{III}) \text {, Thenardite }(\mathrm{IV}), \text { Halite }(\mathrm{V}), \\
\text { Arcanite }(\mathrm{VI}) \text {, Natrite }\left(\mathrm{VII}_{\mathrm{a}}\right), \\
\text { Nahcolite }(\mathrm{VII}) \text {, [Pirssonite, } \\
\text { Burkeite, Trona] }\left(\mathrm{VII}_{\mathrm{c}}\right)\end{array}$ & $\begin{array}{l}\text { Calcite and sepiolite do not precipitate at the start } \\
\text { of the run in one model simulation }(07 c 2 t 4 e) \text {; } \\
\text { stellerite does not precipitate at start of run in two } \\
\text { of the three } 100^{\circ} \mathrm{C} \text { runs; natrite does not form at } \\
40^{\circ} \mathrm{C} \text {; nahcolite does not form at } 100^{\circ} \mathrm{C} \text { or at } \\
p \mathrm{CO}_{2}=10^{-4} \text {; burkeite, pirssonite, and trona only } \\
\text { form at } 40^{\circ} \mathrm{C} \text { and } p \mathrm{CO}_{2}=10^{-4} \text {. }\end{array}$ \\
\hline
\end{tabular}


Table 6.13-6. Summary Table of Precipitating Minerals in Each of the Eleven Bins (Continued)

\begin{tabular}{|c|c|c|c|}
\hline Bin & $\begin{array}{c}\text { Precipitating } \\
\text { Minerals at the } \\
\text { Start of EQ6 Runs }\end{array}$ & $\begin{array}{c}\text { Additional Precipitating Minerals } \\
\text { (Roman Numerals Represent the } \\
\text { Precipitation Sequence) }\end{array}$ & Occurrence Notes \\
\hline Bin 8 & Calcite, Sepiolite & $\begin{array}{l}\text { Stellerite }(\mathrm{I}), \mathrm{SiO}_{2}(\mathrm{am})(\mathrm{II}) \text {, Erionite } \\
(\mathrm{III}) \text {, Fluorite }(\mathrm{IV}) \text {, Natrite }\left(\mathrm{V}_{\mathrm{a}}\right) \text {, } \\
\text { Nahcolite }\left(\mathrm{V}_{\mathrm{b}}\right), \text { [Pirssonite, Trona, } \\
\text { Burkeite, Niter] }\left(\mathrm{V}_{\mathrm{c}}\right) \text {, Thenardite } \\
(\mathrm{VI}), \text { Halite }(\mathrm{VII}) \text {, Arcanite (VIII) }\end{array}$ & $\begin{array}{l}\text { Sepiolite does not form at the start in one model } \\
\text { run }(08 c 2 t 4 e) \text {; stellerite does not form at all in } \\
\text { three modeling runs; natrite does not form at } \\
40^{\circ} \mathrm{C} \text {, nahcolite does not form at } 100^{\circ} \mathrm{C} \text { or at } \\
p \mathrm{CO}_{2}=10^{-4} ; \text { burkeite, pirssonite, niter, and trona } \\
\text { only form at } 40^{\circ} \mathrm{C} \text { and } p \mathrm{CO}_{2}=10^{-4} \text {. When these } \\
\text { four minerals form, thenardite does not. }\end{array}$ \\
\hline Bin 9 & Stellerite & $\begin{array}{l}\text { Calcite (I), Sepiolite }(\mathrm{II}), \mathrm{SiO}_{2}(\mathrm{am}) \\
(\mathrm{III}), \text { Fluorite }(\mathrm{IV}), \text { Erionite }(\mathrm{V}), \\
\text { Villiaumite }(\mathrm{VI}), \text { Natrite }(\mathrm{VII}), \\
\text { [Nahcolite, Sellaite, Cryolite] }(\mathrm{VII}) \text {, } \\
\text { [Trona, Burkeite] }\left(\mathrm{VII}_{\mathrm{c}}\right) \text {, Halite (VIII), } \\
\text { Arcanite (IX) }\end{array}$ & $\begin{array}{l}\text { Calcite does not form in two model runs }(09 c 2 t 4 e \text {, } \\
09 c 2 t 7 e) \text {; natrite does not form at } 40^{\circ} \mathrm{C} \text {, nahcolite } \\
\text { does not form at } 100^{\circ} \mathrm{C} \text { or at } p \mathrm{CO}_{2}=10^{-4} \text {; } \\
\text { arcanite does not form at } 100^{\circ} \mathrm{C} \text {; sellaite only } \\
\text { appears at } p \mathrm{CO}_{2}=10^{-2} ; \text { cryolite, burkeite, and } \\
\text { trona only form at } 40^{\circ} \mathrm{C} \text { and } p \mathrm{CO}_{2}=10^{-4} ; \\
\text { nahcolite, trona, burkeite, niter, sellaite, and } \\
\text { cryolite only form when natrite does not. Trona } \\
\text { and burkeite form when natrite and nahcolite } \\
\text { do not. }\end{array}$ \\
\hline Bin 10 & Calcite, Sepiolite & $\begin{array}{l}\text { Stellerite }(\mathrm{I}), \mathrm{SiO}_{2}(\mathrm{am})(\mathrm{II}), \text { Fluorite } \\
(\mathrm{III}), \text { Erionite }(\mathrm{IV}), \text { Natrite }\left(\mathrm{V}_{\mathrm{a}}\right) \\
{\left[\text { Nahcolite, Sellaite, Cryolite] }\left(\mathrm{V}_{\mathrm{b}}\right)\right.} \\
{\left[\text { Trona, Burkeite, Niter] }\left(\mathrm{V}_{\mathrm{c}}\right),\right.} \\
\text { Thenardite }(\mathrm{VI}), \text { Villiaumite }(\mathrm{VII}) \\
\text { Arcanite (VIII), Halite (IX) }\end{array}$ & $\begin{array}{l}\text { Sepiolite does not form at the start in one model } \\
\text { run }(10 c 4 t 1 e) ; \text { natrite does not form at } 40^{\circ} \mathrm{C} \text {; } \\
\text { nahcolite does not form at } 100^{\circ} \mathrm{C} \text { or at } \\
p \mathrm{CO}_{2}=10^{-4} \text {, sellaite and cryolite only appear at } \\
p \mathrm{CO}_{2}=10^{-2} \text {; nahcolite, trona, burkeite, niter, } \\
\text { sellaite, and cryolite only form when natrite does } \\
\text { not; trona, burkeite, and niter only form when } \\
\text { thenardite does not. }\end{array}$ \\
\hline Bin 11 & $\begin{array}{l}\text { Fluorite, } \mathrm{SiO}_{2}(\mathrm{am}), \\
\text { Stellerite, Sepiolite }\end{array}$ & $\begin{array}{l}\text { Calcite }(\mathrm{I}), \text { Erionite }(\mathrm{II}), \text { Villiaumite } \\
(\mathrm{III}), \text { Thenardite }(\mathrm{IV} \mathrm{a}), \text { [Burkeite, } \\
\text { Trona, Niter] }\left(\mathrm{IV}_{\mathrm{b}}\right), \text { Natrite }\left(\mathrm{V}_{\mathrm{a}}\right), \\
\text { [Sellaite, Cryolite, Nahcolite] }\left(\mathrm{V}_{\mathrm{b}}\right) \text {, } \\
{\left[\text { Sellaite, Nahcolite], }\left(\mathrm{V}_{\mathrm{c}}\right), \text { Nahcolite }\right.} \\
\left(\mathrm{V}_{\mathrm{d}}\right), \text { Halite }(\mathrm{VI}), \text { Arcanite }(\mathrm{VII})\end{array}$ & $\begin{array}{l}\text { Sepiolite does not form at the start in two model } \\
\text { runs }(11 c 2 t 7 e, 11 c 2 t 4 e) ; \text { calcite does not form in } \\
\text { some model runs }(11 c 2 t 4 e, 11 c 4 t 1 e \text {, and } \\
11 c 2 t 7 e) ; \text { burkeite, trona, and niter only form when } \\
\text { thenardite and natrite do not form; Vc and } \mathrm{Vb} \text { only } \\
\text { form when no calcite is present. }\end{array}$ \\
\hline
\end{tabular}

Source: Output DTN: MO0312SPAPCESA.002.

Based on the discussion of chemical divides in Section 6.2, an analysis of the lookup table mineralogy is provided in the following paragraphs, linking each of the bins to the precipitation of a particular sequence of minerals. The analysis is performed by extracting the mineral data from the EQ6 output files listed in Table 6.9-7 into 11 bin mineral assemblage.xls using GETEQDATA (BSC 2002 [DIRS 173680]). This spreadsheet is archived in Output DTN: MO0312SPAPCESA.002. Within the spreadsheet, a simplified paragenetic sequence is constructed for each bin based on the order of mineral appearance, the temperature, and $p \mathrm{CO}_{2}$ for each evaporated brine. This worksheet is the source of the information found in Table 6.13-6.

Using the information in Table 6.13-6, Figure 6.13-14 is constructed to illustrate which precipitating minerals control the trajectory of brine evolution as the seepage waters are evaporated. 


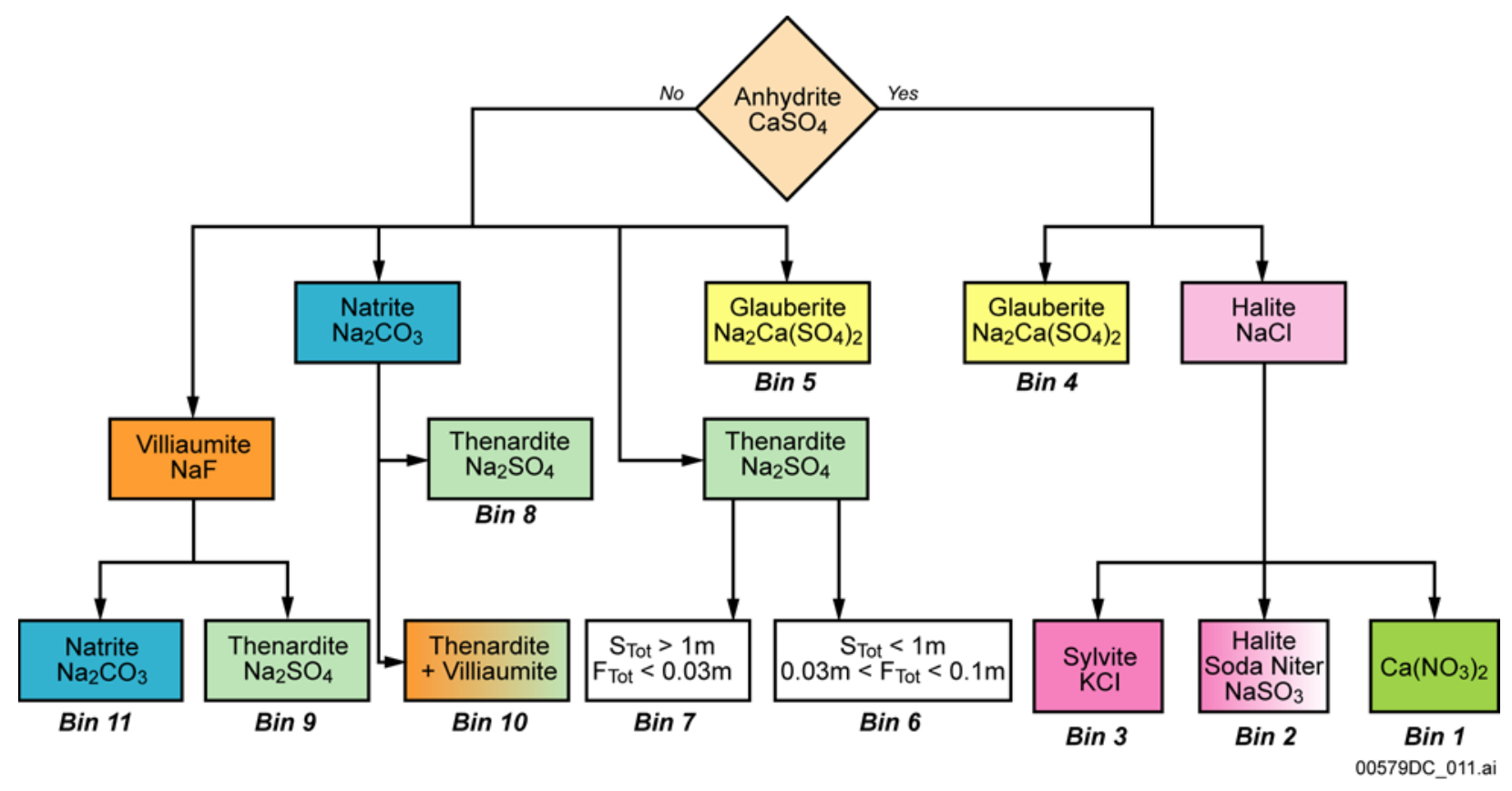

NOTE: Previously precipitating minerals: calcite, flourite, sepiolite, stellerite, erionite, and $\mathrm{SiO}_{2}(\mathrm{am})$. Bins 6 and 7 do not tie directly to a precipitating mineral that defines the bin. The items listed are the binning criteria that differentiate the two bins; see Table 6.6-3.

Figure 6.13-14. Flow Diagram Showing Some of the Precipitating Minerals Associated with Each of the 11 Seepage Bins

Although not directly equivalent to the classical chemical divides, as shown by Drever (1988 [DIRS 118564], p. 236) (Figure 6.2-1), Figure 6.13-14 does show the mineral phases that precipitate as the seepage waters evaporate, and those that are associated with the 11 Bins. The presence or absence of anhydrite in the precipitated mineral assemblage separates the evaporative brine evolution of Bins 1 through 4 from Bins 5 through 11. Combined with the comparative $\mathrm{pH}$ results of all bins shown in Figures 6.13-15 and 6.13-16, three major groupings of brine chemistry and mineral precipitation can be seen, where not only the presence or absence of anhydrite, but the presence or absence of glauberite is associated with the distribution of the $\mathrm{pH}$. In general, the sequencing of natrite, thenardite, and villiaumite characterizes the evolution of Bins 6 through 11. Bins 1 through 3 are characterized by early precipitation of halite and Bins 4 and 5 by the precipitation of glauberite. Bins 6 and 7 are a result of the binning criterion shown in Figure 6.13-14. In no cases do any calcium chloride, magnesium chloride, or calcium-magnesium chloride minerals, such as bischofite and tachyhydrite, precipitate. 


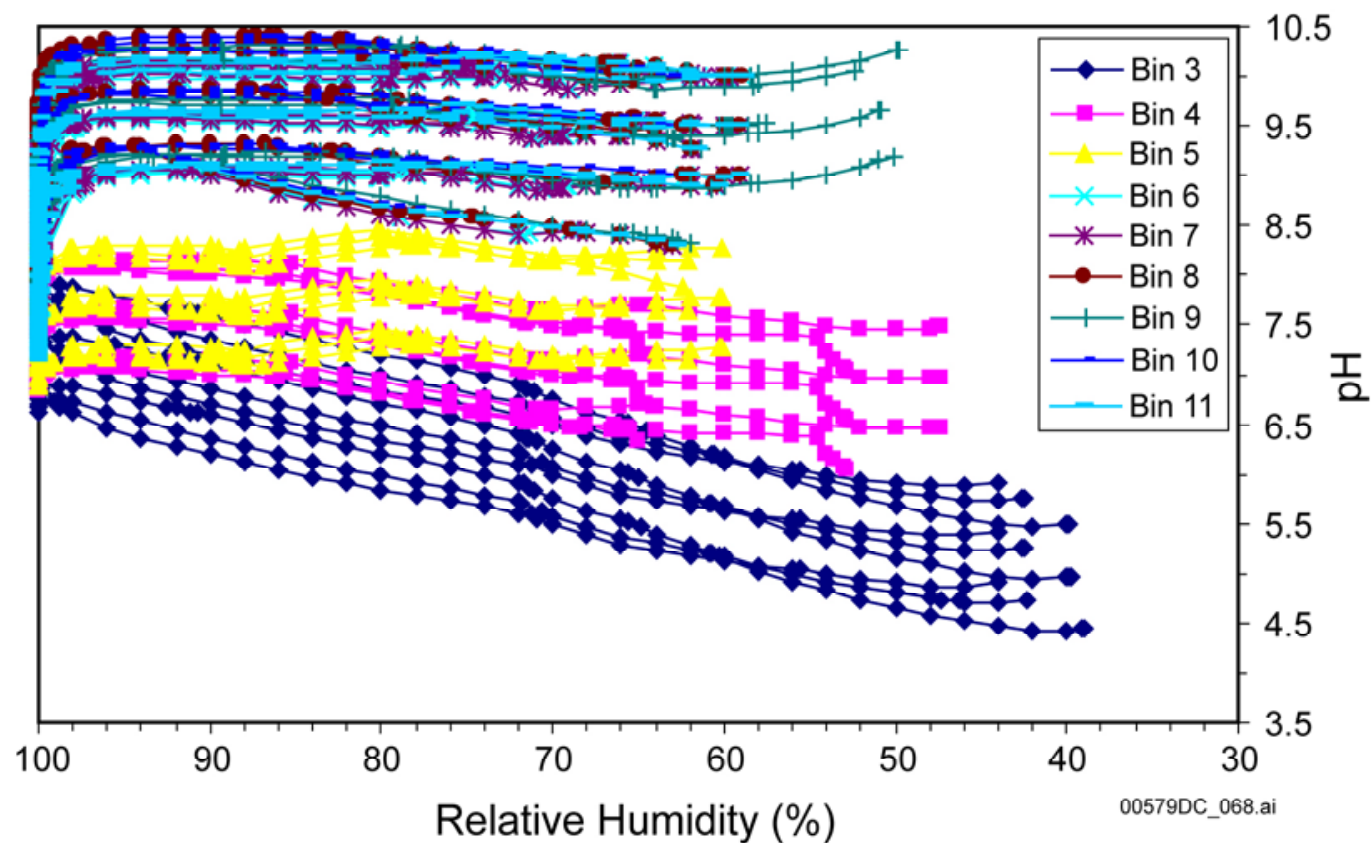

Source: Output DTN: MO0312SPAPCESA.002.

Figure 6.13-15. Range of $\mathrm{pH}$ versus Relative Humidity for the Seepage Evaporation Lookup Tables Representing Bins 3 through 11

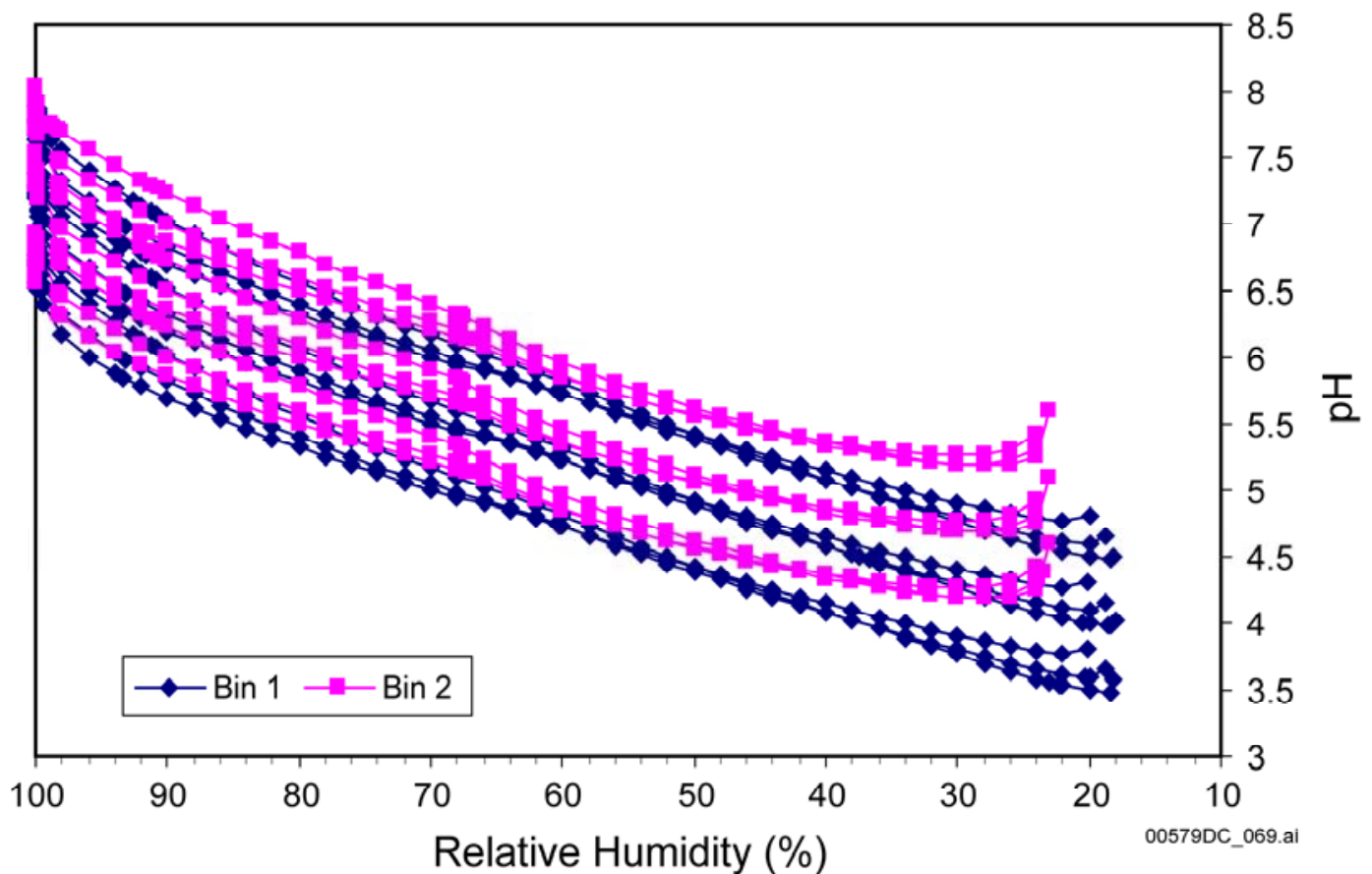

Source: Output DTN: MO0312SPAPCESA.002.

Figure 6.13-16. Range of $\mathrm{pH}$ versus Relative Humidity for the Seepage Evaporation Lookup Tables Representing Bins 1 and 2 


\subsubsection{Lookup Table Interpolation for Seepage}

Aside from the general modeling uncertainty discussed in Section 6.12, this section considers the interpolation requirements associated with implementing the lookup tables within the TSPA-LA. The lookup tables contain two types of parameters, independent and dependent. The independent parameters are relative humidity, temperature, and carbon dioxide pressure. Values for these parameters are needed to determine the values of the dependent parameters, such as the $\mathrm{pH}$, or the total concentration of a dissolved chemical component (chloride, for example).

The independent variables in the lookup tables (i.e., relative humidity, temperature, and $p \mathrm{CO}_{2}$ ) have their own uncertainty in the TSPA-LA realizations. The uncertainties for temperature and relative humidity are defined outside the $\mathrm{P} \& \mathrm{CE}$ model and are not addressed here. As for $p \mathrm{CO}_{2}$, lookup tables are generated from the THC model results in Section 6.7.2. When a given water type is selected for any given TSPA-LA model realization, the $\mathrm{pCO}_{2}$ value at a particular time is derived from lookup time-linear, $\log \left(\mathrm{pCO}_{2}\right)$-linear, interpolation between the previous time step's value and the next time step's value. For example, when using Table 6.7-1 for the time interval from about 200 to 250 years, the drift $p \mathrm{CO}_{2}$ will vary from $5.28 \times 10^{-4}$ bar at 200 years to $4.34 \times 10^{-4}$ bar at 250 years in a log-linear fashion.

The lookup tables provide direct results only for select combinations of independent variables. That is, they provide results at temperatures of $40^{\circ} \mathrm{C}, 70^{\circ} \mathrm{C}, 100^{\circ} \mathrm{C}, \mathrm{pCO}_{2}$ of $10^{-2}, 10^{-3}$, and $10^{-4}$ bar, and relative humidity at intervals up to $2 \%$. Many humidity intervals are less than $2 \%$. The TSPA-LA model is designed to interpolate and extrapolate dependent variable outputs for other combinations of these parameters (ranges defined in Output DTN: MO0505SEPSEEPA.000). By interpolating and extrapolating, the lookup tables provide a set of smooth and continuous response surfaces. Although some error may be introduced by interpolation and extrapolation, this error is negligible compared to model uncertainty and uncertainty in the predicted values of the independent variables (see Section 6.12 for uncertainty analysis and Section 7.3.2 for additional confirmation).

\subsubsection{Chemical Environments on the Drip Shield and Waste Package}

In addition to $\mathrm{pH}$ and ionic strength, the main parameter of interest for drip shield performance is the concentration of $\mathrm{F}^{-}$in the solution, because fluoride has a detrimental influence on titanium corrosion rates. For the waste package environment, the primary aqueous components of concern include $\mathrm{Cl}^{-}, \mathrm{NO}_{3}{ }^{-}$, and $\mathrm{SO}_{4}{ }^{2-}$, and to some extent other halides such as $\mathrm{Br}^{-}$, because these elements may affect corrosion of Alloy 22. These are discussed in terms of the major output of this model, i.e., the composition of in-drift evaporated seepage waters.

In order to develop an argument that supports the use of probabilities and distributions for the THC seepage water inputs, an assumption is carried forward into this report (see Assumption 5.1.4 for basis and further discussion). That is, the five THC starting waters adequately represent all possible seepage waters, and are therefore used to initiate this analysis and their numerical bin distributions (Table 6.6-5), as discussed in Section 6.6. 
In-Drift Evaporated Seepage Waters-As shown in Tables 6.13-1 through 6.13-3, waters from Bins 1 and 2 are not relevant for the waste package or drip shield because they are not composed of crown seepage. For $\mathrm{pH}$, Figure 6.13-15 shows that the seepage $\mathrm{pH}$ range varies from bin to bin as a strong function of relative humidity and $\mathrm{pCO}_{2}$. The entire $\mathrm{pH}$ range, for all waters at all relative humidity conditions, is approximately 10.5 to 4.5 . Bin 3 is responsible for the low $\mathrm{pH}$, its range being from about 8 to 4.5. As shown in Table 6.13-1, the time-integrated occurrence of all of the 368 starting waters represented by Bin 3 is less than $1 \%$. For Bins 4 and 5, the pH range is between 6.5 and 8.5. These two bins account for about $20 \%$ of the numerical locations on the bin history map (Table 6.6-5), but only have a time-integrated occurrence in the first 20,000 years of about 1.5\%. For the remaining waters (Bins 6 through 11), the $\mathrm{pH}$ range is from about 8 to 10.5. Therefore, the most dominant $\mathrm{pH}$ range of evaporated seepage water on the waste package is from approximately 8 to 10.5 . Bins 6 through 11 also represent $98 \%$ of the time-integrated crown seepage water occurrences (for the 20,000-year interval considered).

Figure 6.13-17 shows the predicted concentrations of $\mathrm{F}$ for the lookup tables representing Bins 3 through 11. The figure indicates that the maximum molality that could be present is approximately 1. This occurs at a drift relative humidity above approximately $90 \%$. The maximum values fall within Bins 9 and 6 . Bin 9 has a high frequency of occurrence in the boiling, hot, and cooldown periods. Possible $\mathrm{Cl}$ concentrations are much higher, up to approximately 10 molal at low relative humidity (Figure 6.13-18), and are relatively insensitive to bin choice.

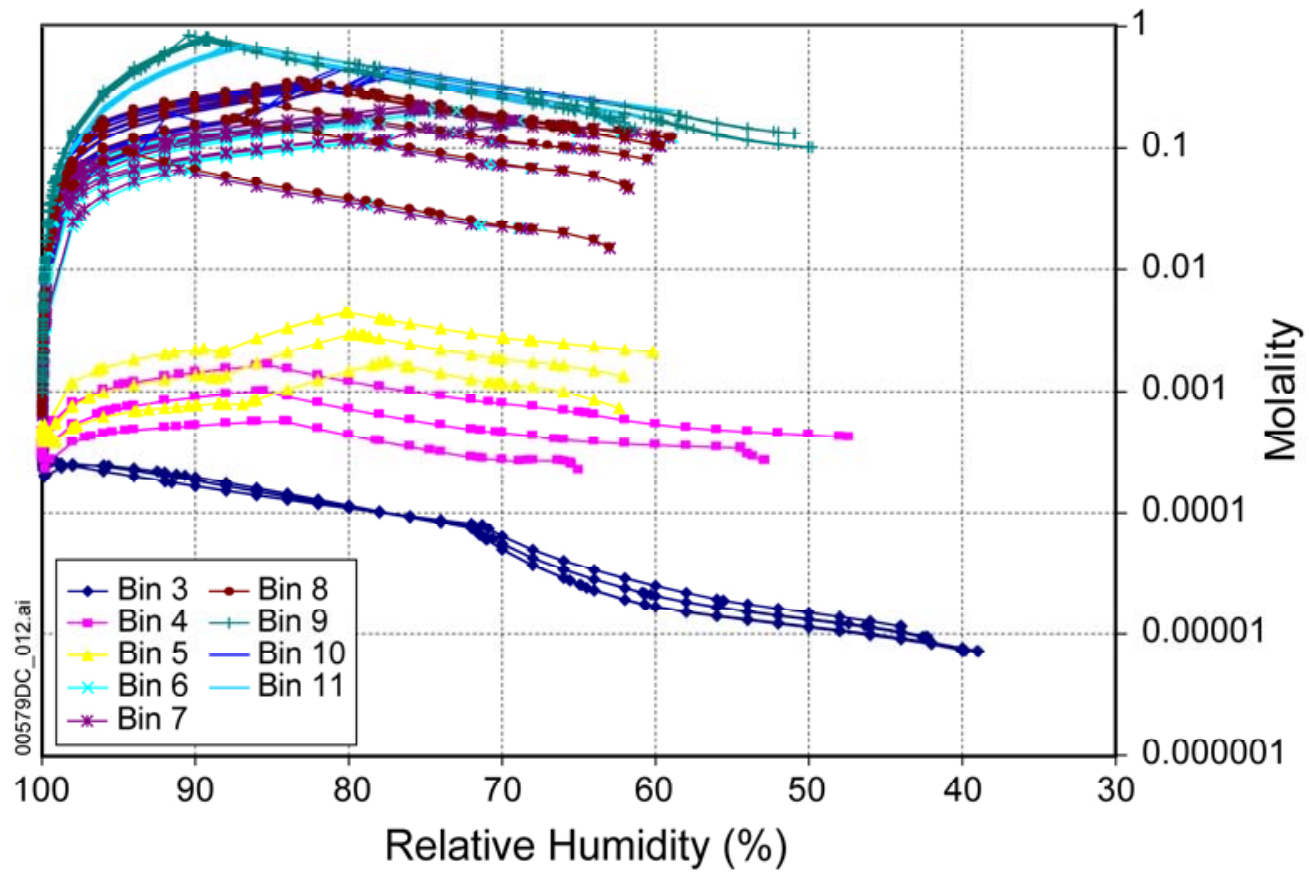

Source: Output DTN: MO0312SPAPCESA.002.

Figure 6.13-17. Range of $F$ versus Relative Humidity for the Seepage Evaporation Lookup Tables Representing Bins 3 through 11 


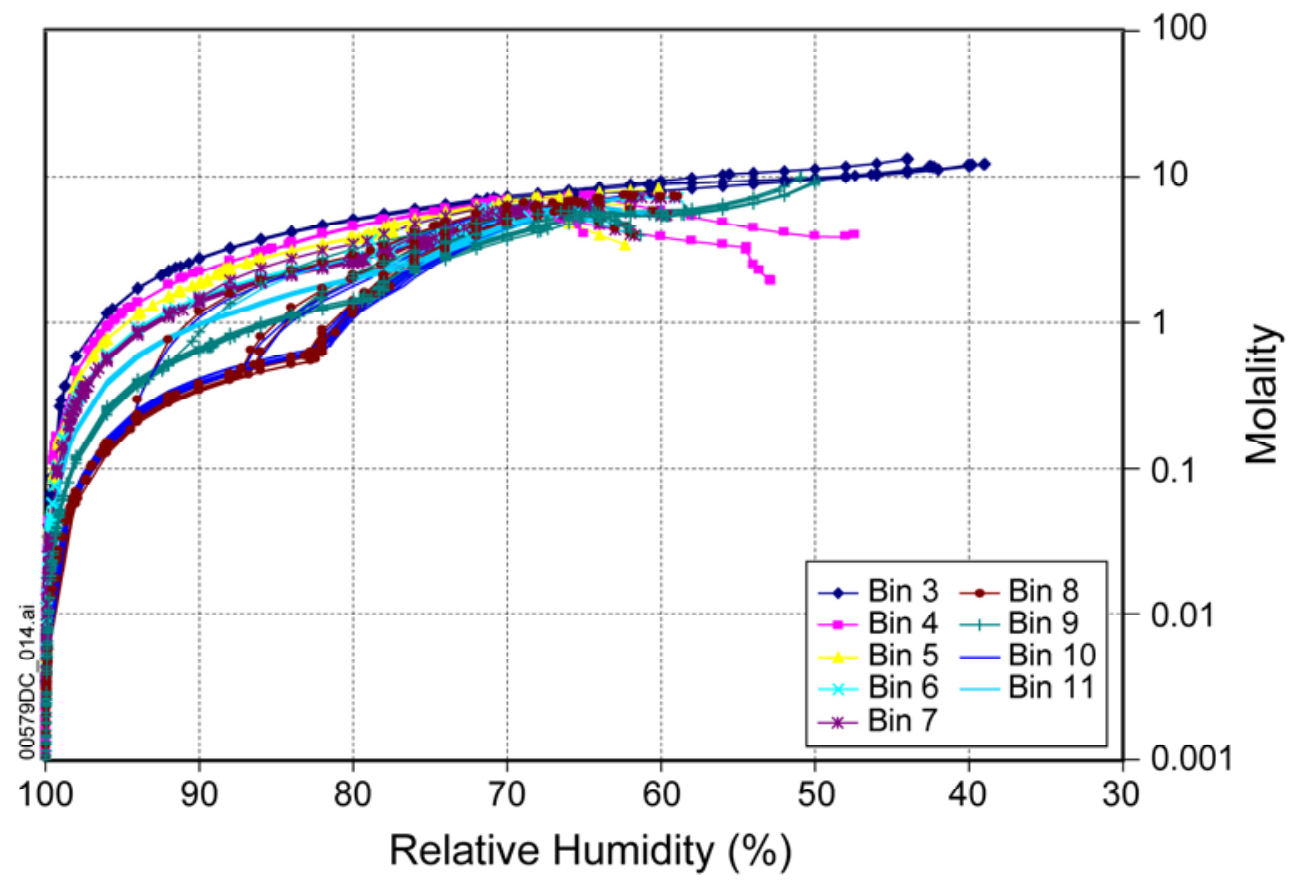

Source: Output DTN: MO0312SPAPCESA.002.

Figure 6.13-18. Range of $\mathrm{Cl}$ versus Relative Humidity for the Seepage Evaporation Lookup Tables Representing Bins 3 through 11

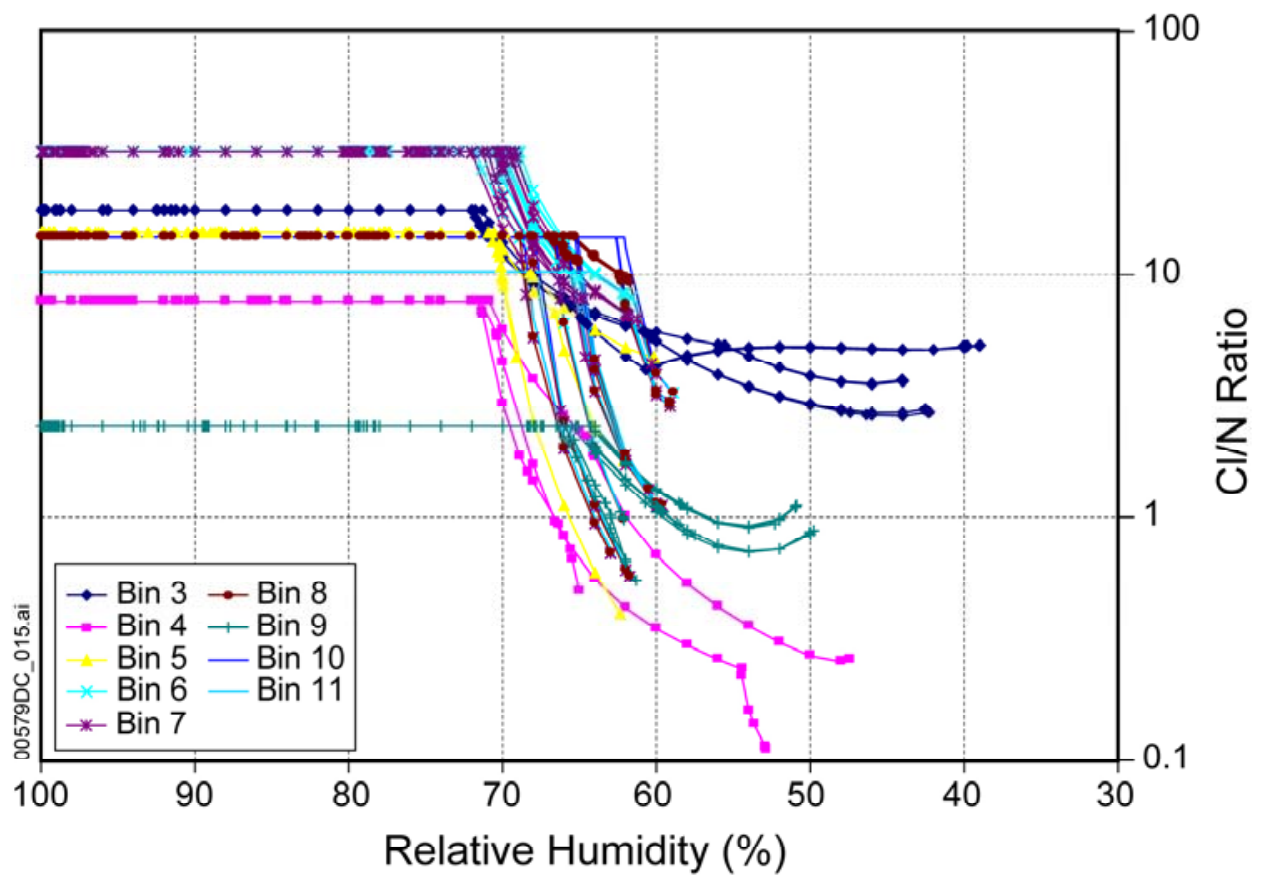

Source: Output DTN: MO0312SPAPCESA.002.

Figure 6.13-19. Range of $\mathrm{Cl}$ to N Molal Ratios for the Seepage Evaporation Lookup Tables Representing Bins 3 through 11 
Table 6.13-7. Engineered Barrier System Seepage Lookup Table End-Point Relative Humidity and Brine Evolution

\begin{tabular}{|c|c|c|c|c|c|c|c|c|c|c|}
\hline $\begin{array}{c}\text { Lookup Table } \\
\text { File Name }\end{array}$ & $\begin{array}{c}\text { Number of } 60 \\
\text { Binning Files } \\
\text { Matching this } \\
\text { Sensitivity Run } \\
\text { (number of waters } \\
\text { in bin) }\end{array}$ & $\begin{array}{c}\% \text { of } 368 \\
\text { Binning } \\
\text { Output } \\
\text { Runs }\end{array}$ & Bin & Temp. & $\mathrm{PcO}_{2}$ & Endpoint RH & $\begin{array}{c}98 \% \text { RH } \\
\text { Brine }\end{array}$ & $\begin{array}{c}85 \% \text { RH } \\
\text { Brine }\end{array}$ & $\begin{array}{c}65 \% \text { RH } \\
\text { Brine }\end{array}$ & $\begin{array}{c}\text { Endpoint } \\
\text { Brine }\end{array}$ \\
\hline 01c2t1e.xls.xls & \multirow{9}{*}{5} & \multirow{9}{*}{$1.4 \%$} & 1 & 100 & $1.00 \mathrm{E}-02$ & $20.0 \%$ & $\mathrm{Ca}-\mathrm{Cl}$ & $\mathrm{Ca}-\mathrm{Cl}$ & $\mathrm{Ca}-\mathrm{Cl}$ & $\mathrm{Ca}-\mathrm{Cl}$ \\
\hline 01c2t4e.xls.xls & & & 1 & 40 & $1.00 \mathrm{E}-02$ & $18.1 \%$ & $\mathrm{Ca}-\mathrm{Cl}$ & $\mathrm{Ca}-\mathrm{Cl}$ & $\mathrm{Ca}-\mathrm{Cl}$ & $\mathrm{Ca}-\mathrm{Cl}$ \\
\hline 01c2t7e.xls.xls & & & 1 & 70 & $1.00 \mathrm{E}-02$ & $18.7 \%$ & $\mathrm{Ca}-\mathrm{Cl}$ & $\mathrm{Ca}-\mathrm{Cl}$ & $\mathrm{Ca}-\mathrm{Cl}$ & $\mathrm{Ca}-\mathrm{Cl}$ \\
\hline 01c3t1e.xls.xls & & & 1 & 100 & $1.00 \mathrm{E}-03$ & $20.0 \%$ & $\mathrm{Ca}-\mathrm{Cl}$ & $\mathrm{Ca}-\mathrm{Cl}$ & $\mathrm{Ca}-\mathrm{Cl}$ & $\mathrm{Ca}-\mathrm{Cl}$ \\
\hline $01 \mathrm{c} 3 \mathrm{t} 4 \mathrm{e} . \mathrm{xls} . \mathrm{xls}$ & & & 1 & 40 & $1.00 \mathrm{E}-03$ & $18.1 \%$ & $\mathrm{Ca}-\mathrm{Cl}$ & $\mathrm{Ca}-\mathrm{Cl}$ & $\mathrm{Ca}-\mathrm{Cl}$ & $\mathrm{Ca}-\mathrm{Cl}$ \\
\hline 01c3t7e.xls.xls & & & 1 & 70 & $1.00 \mathrm{E}-03$ & $18.7 \%$ & $\mathrm{Ca}-\mathrm{Cl}$ & $\mathrm{Ca}-\mathrm{Cl}$ & $\mathrm{Ca}-\mathrm{Cl}$ & $\mathrm{Ca}-\mathrm{Cl}$ \\
\hline 01c4t1e.xls.xls & & & 1 & 100 & $1.00 \mathrm{E}-04$ & $20.0 \%$ & $\mathrm{Ca}-\mathrm{Cl}$ & $\mathrm{Ca}-\mathrm{Cl}$ & $\mathrm{Ca}-\mathrm{Cl}$ & $\mathrm{Ca}-\mathrm{Cl}$ \\
\hline 01c4t4e.xls.xls & & & 1 & 40 & $1.00 \mathrm{E}-04$ & $18.2 \%$ & $\mathrm{Ca}-\mathrm{Cl}$ & $\mathrm{Ca}-\mathrm{Cl}$ & $\mathrm{Ca}-\mathrm{Cl}$ & $\mathrm{Ca}-\mathrm{Cl}$ \\
\hline 01c4t7e.xls.xls & & & 1 & 70 & $1.00 \mathrm{E}-04$ & $18.7 \%$ & $\mathrm{Ca}-\mathrm{Cl}$ & $\mathrm{Ca}-\mathrm{Cl}$ & $\mathrm{Ca}-\mathrm{Cl}$ & $\mathrm{Ca}-\mathrm{Cl}$ \\
\hline 02c2t1e.xls.xls & \multirow{9}{*}{13} & \multirow{9}{*}{$3.5 \%$} & 2 & 100 & $1.00 \mathrm{E}-02$ & $24.0 \%$ & $\mathrm{Na}-\mathrm{Cl}$ & $\mathrm{Na}-\mathrm{Cl}$ & $\mathrm{Na}-\mathrm{Cl}$ & $\mathrm{Ca}-\mathrm{Cl}$ \\
\hline 02c2t4e.xls.xls & & & 2 & 40 & $1.00 \mathrm{E}-02$ & $23.1 \%$ & $\mathrm{Na}-\mathrm{Cl}$ & $\mathrm{Na}-\mathrm{Cl}$ & $\mathrm{Na}-\mathrm{Cl}$ & $\mathrm{Ca}-\mathrm{Cl}$ \\
\hline 02c2t7e.xls.xls & & & 2 & 70 & 1.00E-02 & $23.4 \%$ & $\mathrm{Na}-\mathrm{Cl}$ & $\mathrm{Na}-\mathrm{Cl}$ & $\mathrm{Na}-\mathrm{Cl}$ & $\mathrm{Ca}-\mathrm{Cl}$ \\
\hline 02c3t1e.xls.xls & & & 2 & 100 & $1.00 \mathrm{E}-03$ & $24.0 \%$ & $\mathrm{Na}-\mathrm{Cl}$ & $\mathrm{Na}-\mathrm{Cl}$ & $\mathrm{Na}-\mathrm{Cl}$ & $\mathrm{Ca}-\mathrm{Cl}$ \\
\hline 02c3t4e.xls.xls & & & 2 & 40 & $1.00 \mathrm{E}-03$ & $23.1 \%$ & $\mathrm{Na}-\mathrm{Cl}$ & $\mathrm{Na}-\mathrm{Cl}$ & $\mathrm{Na}-\mathrm{Cl}$ & $\mathrm{Ca}-\mathrm{Cl}$ \\
\hline 02c3t7e.xls.xls & & & 2 & 70 & $1.00 \mathrm{E}-03$ & $24.0 \%$ & $\mathrm{Na}-\mathrm{Cl}$ & $\mathrm{Na}-\mathrm{Cl}$ & $\mathrm{Na}-\mathrm{Cl}$ & $\mathrm{Ca}-\mathrm{Cl}$ \\
\hline 02c4t1e.xls.xls & & & 2 & 100 & $1.00 \mathrm{E}-04$ & $24.0 \%$ & $\mathrm{Na}-\mathrm{Cl}$ & $\mathrm{Na}-\mathrm{Cl}$ & $\mathrm{Na}-\mathrm{Cl}$ & $\mathrm{Ca}-\mathrm{Cl}$ \\
\hline 02c4t4e.xls.xls & & & 2 & 40 & 1.00E-04 & $23.1 \%$ & $\mathrm{Na}-\mathrm{Cl}$ & $\mathrm{Na}-\mathrm{Cl}$ & $\mathrm{Na}-\mathrm{Cl}$ & $\mathrm{Ca}-\mathrm{Cl}$ \\
\hline 02c4t7e.xls.xls & & & 2 & 70 & $1.00 \mathrm{E}-04$ & $24.0 \%$ & $\mathrm{Na}-\mathrm{Cl}$ & $\mathrm{Na}-\mathrm{Cl}$ & $\mathrm{Na}-\mathrm{Cl}$ & $\mathrm{Ca}-\mathrm{Cl}$ \\
\hline 03c2t1e.xls.xls & \multirow{9}{*}{12} & \multirow{9}{*}{$3.3 \%$} & 3 & 100 & $1.00 \mathrm{E}-02$ & $43.9 \%$ & $\mathrm{Na}-\mathrm{Cl}$ & $\mathrm{Na}-\mathrm{Cl}$ & $\mathrm{Na}-\mathrm{Cl}$ & $\mathrm{K}-\mathrm{Cl}$ \\
\hline 03c2t4e.xls.xls & & & 3 & 40 & $1.00 \mathrm{E}-02$ & $38.9 \%$ & $\mathrm{Na}-\mathrm{Cl}$ & $\mathrm{Na}-\mathrm{Cl}$ & $\mathrm{Na}-\mathrm{Cl}$ & $\mathrm{Ca}-\mathrm{Cl}$ \\
\hline 03c2t7e.xls.xls & & & 3 & 70 & $1.00 \mathrm{E}-02$ & $42.3 \%$ & $\mathrm{Na}-\mathrm{Cl}$ & $\mathrm{Na}-\mathrm{Cl}$ & $\mathrm{Na}-\mathrm{Cl}$ & $\mathrm{K}-\mathrm{Cl}$ \\
\hline 03c3t1e.xls.xls & & & 3 & 100 & $1.00 \mathrm{E}-03$ & $44.0 \%$ & $\mathrm{Na}-\mathrm{Cl}$ & $\mathrm{Na}-\mathrm{Cl}$ & $\mathrm{Na}-\mathrm{Cl}$ & $\mathrm{K}-\mathrm{Cl}$ \\
\hline 03c3t4e.xls.xls & & & 3 & 40 & $1.00 \mathrm{E}-03$ & $39.8 \%$ & $\mathrm{Na}-\mathrm{Cl}$ & $\mathrm{Na}-\mathrm{Cl}$ & $\mathrm{Na}-\mathrm{Cl}$ & $\mathrm{Ca}-\mathrm{Cl}$ \\
\hline 03c3t7e.xls.xls & & & 3 & 70 & $1.00 \mathrm{E}-03$ & $42.5 \%$ & $\mathrm{Na}-\mathrm{Cl}$ & $\mathrm{Na}-\mathrm{Cl}$ & $\mathrm{Na}-\mathrm{Cl}$ & $\mathrm{K}-\mathrm{Cl}$ \\
\hline 03c4t1e.xls.xls & & & 3 & 100 & $1.00 \mathrm{E}-04$ & $44.0 \%$ & $\mathrm{Na}-\mathrm{Cl}$ & $\mathrm{Na}-\mathrm{Cl}$ & $\mathrm{Na}-\mathrm{Cl}$ & $\mathrm{K}-\mathrm{Cl}$ \\
\hline 03c4t4e.xls.xls & & & 3 & 40 & $1.00 \mathrm{E}-04$ & $40.0 \%$ & $\mathrm{Na}-\mathrm{Cl}$ & $\mathrm{Na}-\mathrm{Cl}$ & $\mathrm{Na}-\mathrm{Cl}$ & $\mathrm{Ca}-\mathrm{Cl}$ \\
\hline 03c4t7e.xls.xls & & & 3 & 70 & $1.00 \mathrm{E}-04$ & $42.5 \%$ & $\mathrm{Na}-\mathrm{Cl}$ & $\mathrm{Na}-\mathrm{Cl}$ & $\mathrm{Na}-\mathrm{Cl}$ & $\mathrm{K}-\mathrm{Cl}$ \\
\hline 04c2t1e.xls.xls & \multirow{9}{*}{43} & \multirow{9}{*}{$11.7 \%$} & 4 & 100 & $1.00 \mathrm{E}-02$ & $47.4 \%$ & $\mathrm{Na}-\mathrm{Cl}$ & $\mathrm{Na}-\mathrm{Cl}$ & $\mathrm{K}-\mathrm{Cl}$ & $\mathrm{K}-\mathrm{N}$ \\
\hline 04c2t4e.xls.xls & & & 4 & 40 & $1.00 \mathrm{E}-02$ & $65.0 \%$ & $\mathrm{Na}-\mathrm{Cl}$ & $\mathrm{Na}-\mathrm{Cl}$ & $\mathrm{Na}-\mathrm{N}$ & $\mathrm{Na}-\mathrm{N}$ \\
\hline 04c2t7e.xls.xls & & & 4 & 70 & $1.00 \mathrm{E}-02$ & $52.9 \%$ & $\mathrm{Na}-\mathrm{Cl}$ & $\mathrm{Na}-\mathrm{Cl}$ & $\mathrm{Na}-\mathrm{N}$ & $\mathrm{Na}-\mathrm{N}$ \\
\hline 04c3t1e.xls.xls & & & 4 & 100 & $1.00 \mathrm{E}-03$ & $47.4 \%$ & $\mathrm{Na}-\mathrm{Cl}$ & $\mathrm{Na}-\mathrm{Cl}$ & $\mathrm{K}-\mathrm{Cl}$ & $\mathrm{K}-\mathrm{N}$ \\
\hline 04c3t4e.xls.xls & & & 4 & 40 & $1.00 \mathrm{E}-03$ & $65.0 \%$ & $\mathrm{Na}-\mathrm{Cl}$ & $\mathrm{Na}-\mathrm{Cl}$ & $\mathrm{Na}-\mathrm{N}$ & $\mathrm{Na}-\mathrm{N}$ \\
\hline 04c3t7e.xls.xls & & & 4 & 70 & $1.00 \mathrm{E}-03$ & $52.9 \%$ & $\mathrm{Na}-\mathrm{Cl}$ & $\mathrm{Na}-\mathrm{Cl}$ & $\mathrm{Na}-\mathrm{N}$ & $\mathrm{Na}-\mathrm{N}$ \\
\hline 04c4t1e.xls.xls & & & 4 & 100 & $1.00 \mathrm{E}-04$ & $47.4 \%$ & $\mathrm{Na}-\mathrm{Cl}$ & $\mathrm{Na}-\mathrm{Cl}$ & $\mathrm{K}-\mathrm{Cl}$ & $\mathrm{K}-\mathrm{N}$ \\
\hline 04c4t4e.xls.xls & & & 4 & 40 & $1.00 \mathrm{E}-04$ & $65.0 \%$ & $\mathrm{Na}-\mathrm{Cl}$ & $\mathrm{Na}-\mathrm{Cl}$ & $\mathrm{Na}-\mathrm{N}$ & $\mathrm{Na}-\mathrm{N}$ \\
\hline 04c4t7e.xls.xls & & & 4 & 70 & $1.00 \mathrm{E}-04$ & $52.9 \%$ & $\mathrm{Na}-\mathrm{Cl}$ & $\mathrm{Na}-\mathrm{Cl}$ & $\mathrm{Na}-\mathrm{N}$ & $\mathrm{Na}-\mathrm{N}$ \\
\hline 05c2t1e.xls.xls & \multirow{9}{*}{27} & \multirow{9}{*}{$7.3 \%$} & 5 & 100 & $1.00 \mathrm{E}-02$ & $60.1 \%$ & $\mathrm{Na}-\mathrm{Cl}$ & $\mathrm{Na}-\mathrm{Cl}$ & $\mathrm{Na}-\mathrm{Cl}$ & $\mathrm{Na}-\mathrm{Cl}$ \\
\hline 05c2t4e.xls.xls & & & 5 & 40 & $1.00 \mathrm{E}-02$ & $69.1 \%$ & $\mathrm{Na}-\mathrm{Cl}$ & $\mathrm{Na}-\mathrm{Cl}$ & No Brine & $\mathrm{Na}-\mathrm{Cl}$ \\
\hline 05c2t7e.xls.xls & & & 5 & 70 & $1.00 \mathrm{E}-02$ & $62.1 \%$ & $\mathrm{Na}-\mathrm{Cl}$ & $\mathrm{Na}-\mathrm{Cl}$ & $\mathrm{Na}-\mathrm{Cl}$ & $\mathrm{K}-\mathrm{Cl}$ \\
\hline 05c3t1e.xls.xls & & & 5 & 100 & $1.00 \mathrm{E}-03$ & $60.1 \%$ & $\mathrm{Na}-\mathrm{Cl}$ & $\mathrm{Na}-\mathrm{Cl}$ & $\mathrm{Na}-\mathrm{Cl}$ & $\mathrm{Na}-\mathrm{Cl}$ \\
\hline $05 \mathrm{c} 3 \mathrm{t} 4 \mathrm{e} . \mathrm{xls} . \mathrm{xls}$ & & & 5 & 40 & $1.00 \mathrm{E}-03$ & $69.9 \%$ & $\mathrm{Na}-\mathrm{Cl}$ & $\mathrm{Na}-\mathrm{Cl}$ & No Brine & $\mathrm{Na}-\mathrm{Cl}$ \\
\hline 05c3t7e.xls.xls & & & 5 & 70 & $1.00 \mathrm{E}-03$ & $62.1 \%$ & $\mathrm{Na}-\mathrm{Cl}$ & $\mathrm{Na}-\mathrm{Cl}$ & $\mathrm{Na}-\mathrm{Cl}$ & $\mathrm{K}-\mathrm{Cl}$ \\
\hline 05c4t1e.xls.xls & & & 5 & 100 & $1.00 \mathrm{E}-04$ & $60.1 \%$ & $\mathrm{Na}-\mathrm{Cl}$ & $\mathrm{Na}-\mathrm{Cl}$ & $\mathrm{Na}-\mathrm{Cl}$ & $\mathrm{Na}-\mathrm{Cl}$ \\
\hline 05c4t4e.xls.xls & & & 5 & 40 & $1.00 \mathrm{E}-04$ & $62.4 \%$ & $\mathrm{Na}-\mathrm{Cl}$ & $\mathrm{Na}-\mathrm{Cl}$ & $\mathrm{Na}-\mathrm{N}$ & $\mathrm{Na}-\mathrm{N}$ \\
\hline $05 \mathrm{c} 4 \mathrm{t} 7 \mathrm{e} . \mathrm{xls} . \mathrm{xls}$ & & & 5 & 70 & $1.00 \mathrm{E}-04$ & $62.1 \%$ & $\mathrm{Na}-\mathrm{Cl}$ & $\mathrm{Na}-\mathrm{Cl}$ & $\mathrm{Na}-\mathrm{Cl}$ & $\mathrm{K}-\mathrm{Cl}$ \\
\hline 06c2t1e.xls.xls & \multirow{9}{*}{8} & \multirow{9}{*}{$2.2 \%$} & 6 & 100 & $1.00 \mathrm{E}-02$ & $59.1 \%$ & $\mathrm{Na}-\mathrm{Cl}$ & $\mathrm{Na}-\mathrm{Cl}$ & $\mathrm{Na}-\mathrm{Cl}$ & $\mathrm{K}-\mathrm{Cl}$ \\
\hline 06c2t4e.xls.xls & & & 6 & 40 & $1.00 \mathrm{E}-02$ & $63.0 \%$ & $\mathrm{Na}-\mathrm{Cl}$ & $\mathrm{Na}-\mathrm{Cl}$ & $\mathrm{Na}-\mathrm{Cl}$ & $\mathrm{Na}-\mathrm{N}$ \\
\hline 06c2t7e.xls.xls & & & 6 & 70 & $1.00 \mathrm{E}-02$ & $60.5 \%$ & $\mathrm{Na}-\mathrm{Cl}$ & $\mathrm{Na}-\mathrm{Cl}$ & $\mathrm{Na}-\mathrm{Cl}$ & $\mathrm{K}-\mathrm{Cl}$ \\
\hline 06c3t1e.xls.xls & & & 6 & 100 & $1.00 \mathrm{E}-03$ & $59.1 \%$ & $\mathrm{Na}-\mathrm{Cl}$ & $\mathrm{Na}-\mathrm{Cl}$ & $\mathrm{Na}-\mathrm{Cl}$ & $\mathrm{Na}-\mathrm{Cl}$ \\
\hline $06 \mathrm{c} 3 \mathrm{t} 4 \mathrm{e} . \mathrm{xls} . \mathrm{xls}$ & & & 6 & 40 & 1.00E-03 & $61.7 \%$ & $\mathrm{Na}-\mathrm{Cl}$ & $\mathrm{Na}-\mathrm{Cl}$ & $\mathrm{Na}-\mathrm{Cl}$ & $\mathrm{Na}-\mathrm{N}$ \\
\hline 06c3t7e.xls.xls & & & 6 & 70 & $1.00 \mathrm{E}-03$ & $59.7 \%$ & $\mathrm{Na}-\mathrm{Cl}$ & $\mathrm{Na}-\mathrm{Cl}$ & $\mathrm{Na}-\mathrm{Cl}$ & $\mathrm{K}-\mathrm{Cl}$ \\
\hline 06c4t1e.xls.xls & & & 6 & 100 & $1.00 \mathrm{E}-04$ & $58.9 \%$ & $\mathrm{Na}-\mathrm{Cl}$ & $\mathrm{Na}-\mathrm{Cl}$ & $\mathrm{Na}-\mathrm{Cl}$ & $\mathrm{Na}-\mathrm{Cl}$ \\
\hline 06c4t4e.xls.xls & & & 6 & 40 & $1.00 \mathrm{E}-04$ & $64.1 \%$ & $\mathrm{Na}-\mathrm{Cl}$ & $\mathrm{Na}-\mathrm{Cl}$ & $\mathrm{Na}-\mathrm{Cl}$ & $\mathrm{Na}-\mathrm{Cl}$ \\
\hline 06c4t7e.xls.xls & & & 6 & 70 & $1.00 \mathrm{E}-04$ & $59.6 \%$ & $\mathrm{Na}-\mathrm{Cl}$ & $\mathrm{Na}-\mathrm{Cl}$ & $\mathrm{Na}-\mathrm{Cl}$ & $\mathrm{K}-\mathrm{Cl}$ \\
\hline
\end{tabular}


Table 6.13-7. Engineered Barrier System Seepage Lookup Table End Point Relative Humidity and Brine Evolution (Continued)

\begin{tabular}{|c|c|c|c|c|c|c|c|c|c|c|}
\hline 07c2t1e.xls.xls & \multirow{9}{*}{25} & \multirow{9}{*}{$6.8 \%$} & 7 & 100 & $1.00 \mathrm{E}-02$ & $59.1 \%$ & $\mathrm{Na}-\mathrm{Cl}$ & $\mathrm{Na}-\mathrm{Cl}$ & $\mathrm{Na}-\mathrm{Cl}$ & $\mathrm{K}-\mathrm{Cl}$ \\
\hline $07 \mathrm{c} 2 \mathrm{t} 4 \mathrm{e} . \mathrm{xls} . \mathrm{xls}$ & & & 7 & 40 & $1.00 \mathrm{E}-02$ & $63.0 \%$ & $\mathrm{Na}-\mathrm{Cl}$ & $\mathrm{Na}-\mathrm{Cl}$ & $\mathrm{Na}-\mathrm{Cl}$ & $\mathrm{Na}-\mathrm{N}$ \\
\hline 07c2t7e.xls.xls & & & 7 & 70 & $1.00 \mathrm{E}-02$ & $60.5 \%$ & $\mathrm{Na}-\mathrm{Cl}$ & $\mathrm{Na}-\mathrm{Cl}$ & $\mathrm{Na}-\mathrm{Cl}$ & $\mathrm{K}-\mathrm{Cl}$ \\
\hline 07c3t1e.xls.xls & & & 7 & 100 & $1.00 \mathrm{E}-03$ & $59.1 \%$ & $\mathrm{Na}-\mathrm{Cl}$ & $\mathrm{Na}-\mathrm{Cl}$ & $\mathrm{Na}-\mathrm{Cl}$ & $\mathrm{Na}-\mathrm{Cl}$ \\
\hline 07c3t4e.xls.xls & & & 7 & 40 & $1.00 \mathrm{E}-03$ & $61.7 \%$ & $\mathrm{Na}-\mathrm{Cl}$ & $\mathrm{Na}-\mathrm{Cl}$ & $\mathrm{Na}-\mathrm{Cl}$ & $\mathrm{Na}-\mathrm{N}$ \\
\hline 07c3t7e.xls.xls & & & 7 & 70 & $1.00 \mathrm{E}-03$ & $59.7 \%$ & $\mathrm{Na}-\mathrm{Cl}$ & $\mathrm{Na}-\mathrm{Cl}$ & $\mathrm{Na}-\mathrm{Cl}$ & $\mathrm{K}-\mathrm{Cl}$ \\
\hline 07c4t1e.xls.xls & & & 7 & 100 & $1.00 \mathrm{E}-04$ & $60.0 \%$ & $\mathrm{Na}-\mathrm{Cl}$ & $\mathrm{Na}-\mathrm{Cl}$ & $\mathrm{Na}-\mathrm{Cl}$ & $\mathrm{Na}-\mathrm{Cl}$ \\
\hline 07c4t4e.xls.xls & & & 7 & 40 & $1.00 \mathrm{E}-04$ & $66.2 \%$ & $\mathrm{Na}-\mathrm{Cl}$ & $\mathrm{Na}-\mathrm{Cl}$ & No Brine & $\mathrm{Na}-\mathrm{Cl}$ \\
\hline 07c4t7e.xls.xls & & & 7 & 70 & $1.00 \mathrm{E}-04$ & $59.6 \%$ & $\mathrm{Na}-\mathrm{Cl}$ & $\mathrm{Na}-\mathrm{Cl}$ & $\mathrm{Na}-\mathrm{Cl}$ & $\mathrm{K}-\mathrm{Cl}$ \\
\hline 08c2t1e.xls.xls & \multirow{9}{*}{22} & \multirow{9}{*}{$6.0 \%$} & 8 & 100 & $1.00 \mathrm{E}-02$ & $59.1 \%$ & $\mathrm{Na}-\mathrm{C}$ & $\mathrm{Na}-\mathrm{C}$ & $\mathrm{Na}-\mathrm{Cl}$ & $\mathrm{K}-\mathrm{Cl}$ \\
\hline 08c2t4e.xIs.xls & & & 8 & 40 & 1.00E-02 & $63.0 \%$ & $\mathrm{Na}-\mathrm{C}$ & $\mathrm{Na}-\mathrm{Cl}$ & $\mathrm{Na}-\mathrm{N}$ & $\mathrm{Na}-\mathrm{N}$ \\
\hline 08c2t7e.xls.xls & & & 8 & 70 & 1.00E-02 & $60.5 \%$ & $\mathrm{Na}-\mathrm{C}$ & $\mathrm{Na}-\mathrm{C}$ & $\mathrm{Na}-\mathrm{Cl}$ & $\mathrm{K}-\mathrm{Cl}$ \\
\hline 08c3t1e.xls.xls & & & 8 & 100 & $1.00 \mathrm{E}-03$ & $59.1 \%$ & $\mathrm{Na}-\mathrm{C}$ & $\mathrm{Na}-\mathrm{C}$ & $\mathrm{Na}-\mathrm{Cl}$ & $\mathrm{Na}-\mathrm{Cl}$ \\
\hline 08c3t4e.xls.xls & & & 8 & 40 & $1.00 \mathrm{E}-03$ & $61.7 \%$ & $\mathrm{Na}-\mathrm{C}$ & $\mathrm{Na}-\mathrm{C}$ & $\mathrm{Na}-\mathrm{Cl}$ & $\mathrm{Na}-\mathrm{N}$ \\
\hline 08c3t7e.xls.xls & & & 8 & 70 & $1.00 \mathrm{E}-03$ & $59.7 \%$ & $\mathrm{Na}-\mathrm{C}$ & $\mathrm{Na}-\mathrm{C}$ & $\mathrm{Na}-\mathrm{Cl}$ & $\mathrm{K}-\mathrm{Cl}$ \\
\hline 08c4t1e.xls.xls & & & 8 & 100 & $1.00 \mathrm{E}-04$ & $58.9 \%$ & $\mathrm{Na}-\mathrm{C}$ & $\mathrm{Na}-\mathrm{C}$ & $\mathrm{Na}-\mathrm{Cl}$ & $\mathrm{Na}-\mathrm{Cl}$ \\
\hline 08c4t4e.xls.xls & & & 8 & 40 & $1.00 \mathrm{E}-04$ & $62.2 \%$ & $\mathrm{Na}-\mathrm{C}$ & $\mathrm{Na}-\mathrm{C}$ & $\mathrm{Na}-\mathrm{Cl}$ & $\mathrm{Na}-\mathrm{Cl}$ \\
\hline 08c4t7e.xls.xls & & & 8 & 70 & $1.00 \mathrm{E}-04$ & $59.6 \%$ & $\mathrm{Na}-\mathrm{C}$ & $\mathrm{Na}-\mathrm{C}$ & $\mathrm{Na}-\mathrm{Cl}$ & $\mathrm{K}-\mathrm{Cl}$ \\
\hline 09c2t1e.xls.xls & \multirow{9}{*}{58} & \multirow{9}{*}{$15.8 \%$} & 9 & 100 & $1.00 \mathrm{E}-02$ & $50.9 \%$ & $\mathrm{Na}-\mathrm{C}$ & $\mathrm{Na}-\mathrm{C}$ & $\mathrm{Na}-\mathrm{Cl}$ & $\mathrm{K}-\mathrm{Cl}$ \\
\hline 09c2t4e.xls.xls & & & 9 & 40 & $1.00 \mathrm{E}-02$ & $62.0 \%$ & $\mathrm{Na}-\mathrm{C}$ & $\mathrm{Na}-\mathrm{Cl}$ & $\mathrm{Na}-\mathrm{Cl}$ & $\mathrm{K}-\mathrm{N}$ \\
\hline 09c2t7e.xls.xls & & & 9 & 70 & $1.00 \mathrm{E}-02$ & $50.0 \%$ & $\mathrm{Na}-\mathrm{C}$ & $\mathrm{Na}-\mathrm{C}$ & $\mathrm{Na}-\mathrm{Cl}$ & $\mathrm{K}-\mathrm{N}$ \\
\hline 09c3t1e.xls.xls & & & 9 & 100 & $1.00 \mathrm{E}-03$ & $50.9 \%$ & $\mathrm{Na}-\mathrm{C}$ & $\mathrm{Na}-\mathrm{C}$ & $\mathrm{Na}-\mathrm{Cl}$ & $\mathrm{K}-\mathrm{Cl}$ \\
\hline 09c3t4e.xls.xls & & & 9 & 40 & $1.00 \mathrm{E}-03$ & $61.3 \%$ & $\mathrm{Na}-\mathrm{C}$ & $\mathrm{Na}-\mathrm{C}$ & $\mathrm{Na}-\mathrm{Cl}$ & $\mathrm{K}-\mathrm{N}$ \\
\hline 09c3t7e.xls.xls & & & 9 & 70 & $1.00 \mathrm{E}-03$ & $57.5 \%$ & $\mathrm{Na}-\mathrm{C}$ & $\mathrm{Na}-\mathrm{C}$ & $\mathrm{Na}-\mathrm{Cl}$ & K-N \\
\hline 09c4t1e.xls.xls & & & 9 & 100 & $1.00 \mathrm{E}-04$ & $52.3 \%$ & $\mathrm{Na}-\mathrm{Si}$ & $\mathrm{Na}-\mathrm{C}$ & $\mathrm{Na}-\mathrm{Cl}$ & K-N \\
\hline 09c4t4e.xls.xls & & & 9 & 40 & $1.00 \mathrm{E}-04$ & $62.1 \%$ & $\mathrm{Na}-\mathrm{C}$ & $\mathrm{Na}-\mathrm{C}$ & $\mathrm{Na}-\mathrm{Cl}$ & $\mathrm{K}-\mathrm{N}$ \\
\hline 09c4t7e.xls.xls & & & 9 & 70 & $1.00 \mathrm{E}-04$ & $49.8 \%$ & $\mathrm{Na}-\mathrm{C}$ & $\mathrm{Na}-\mathrm{C}$ & $\mathrm{Na}-\mathrm{Cl}$ & $\mathrm{K}-\mathrm{N}$ \\
\hline 10c2t1e.xls.xls & \multirow{9}{*}{10} & \multirow{9}{*}{$2.7 \%$} & 10 & 100 & $1.00 \mathrm{E}-02$ & $59.0 \%$ & $\mathrm{Na}-\mathrm{C}$ & $\mathrm{Na}-\mathrm{C}$ & $\mathrm{Na}-\mathrm{Cl}$ & $\mathrm{Na}-\mathrm{Cl}$ \\
\hline 10c2t4e.xIs.xIs & & & 10 & 40 & $1.00 \mathrm{E}-02$ & $66.1 \%$ & $\mathrm{Na}-\mathrm{C}$ & $\mathrm{Na}-\mathrm{Cl}$ & No Brine & $\mathrm{Na}-\mathrm{Cl}$ \\
\hline 10c2t7e.xls.xls & & & 10 & 70 & $1.00 \mathrm{E}-02$ & $60.3 \%$ & $\mathrm{Na}-\mathrm{C}$ & $\mathrm{Na}-\mathrm{C}$ & $\mathrm{Na}-\mathrm{Cl}$ & $\mathrm{K}-\mathrm{Cl}$ \\
\hline 10c3t1e.xls.xls & & & 10 & 100 & $1.00 \mathrm{E}-03$ & $59.0 \%$ & $\mathrm{Na}-\mathrm{C}$ & $\mathrm{Na}-\mathrm{C}$ & $\mathrm{Na}-\mathrm{Cl}$ & $\mathrm{Na}-\mathrm{Cl}$ \\
\hline 10c3t4e.xls.xls & & & 10 & 40 & $1.00 \mathrm{E}-03$ & $61.5 \%$ & $\mathrm{Na}-\mathrm{C}$ & $\mathrm{Na}-\mathrm{C}$ & $\mathrm{Na}-\mathrm{Cl}$ & $\mathrm{Na}-\mathrm{N}$ \\
\hline 10c3t7e.xls.xls & & & 10 & 70 & $1.00 \mathrm{E}-03$ & $59.6 \%$ & $\mathrm{Na}-\mathrm{C}$ & $\mathrm{Na}-\mathrm{C}$ & $\mathrm{Na}-\mathrm{Cl}$ & $\mathrm{K}-\mathrm{Cl}$ \\
\hline 10c4t1e.xls.xls & & & 10 & 100 & $1.00 \mathrm{E}-04$ & $58.8 \%$ & $\mathrm{Na}-\mathrm{Si}$ & $\mathrm{Na}-\mathrm{C}$ & $\mathrm{Na}-\mathrm{Cl}$ & $\mathrm{Na}-\mathrm{Cl}$ \\
\hline 10c4t4e.xls.xls & & & 10 & 40 & $1.00 \mathrm{E}-04$ & $62.1 \%$ & $\mathrm{Na}-\mathrm{C}$ & $\mathrm{Na}-\mathrm{C}$ & $\mathrm{Na}-\mathrm{Cl}$ & $\mathrm{Na}-\mathrm{N}$ \\
\hline 10c4t7e.xls.xls & & & 10 & 70 & $1.00 \mathrm{E}-04$ & $59.5 \%$ & $\mathrm{Na}-\mathrm{C}$ & $\mathrm{Na}-\mathrm{C}$ & $\mathrm{Na}-\mathrm{Cl}$ & $\mathrm{K}-\mathrm{Cl}$ \\
\hline 11c2t1e.xls.xls & \multirow{9}{*}{145} & \multirow{9}{*}{$39.4 \%$} & 11 & 100 & $1.00 \mathrm{E}-02$ & $59.0 \%$ & $\mathrm{Na}-\mathrm{Cl}$ & $\mathrm{Na}-\mathrm{Cl}$ & $\mathrm{Na}-\mathrm{Cl}$ & $\mathrm{Na}-\mathrm{Cl}$ \\
\hline 11c2t4e.xIs.xIs & & & 11 & 40 & $1.00 \mathrm{E}-02$ & $62.7 \%$ & $\mathrm{Na}-\mathrm{Cl}$ & $\mathrm{Na}-\mathrm{Cl}$ & $\mathrm{Na}-\mathrm{Cl}$ & $\mathrm{Na}-\mathrm{N}$ \\
\hline 11c2t7e.xls.xls & & & 11 & 70 & 1.00E-02 & $60.4 \%$ & $\mathrm{Na}-\mathrm{Cl}$ & $\mathrm{Na}-\mathrm{Cl}$ & $\mathrm{Na}-\mathrm{Cl}$ & $\mathrm{K}-\mathrm{Cl}$ \\
\hline 11c3t1e.xls.xls & & & 11 & 100 & $1.00 \mathrm{E}-03$ & $59.0 \%$ & $\mathrm{Na}-\mathrm{Cl}$ & $\mathrm{Na}-\mathrm{Cl}$ & $\mathrm{Na}-\mathrm{Cl}$ & $\mathrm{Na}-\mathrm{Cl}$ \\
\hline 11c3t4e.xls.xls & & & 11 & 40 & $1.00 \mathrm{E}-03$ & $61.5 \%$ & $\mathrm{Na}-\mathrm{Cl}$ & $\mathrm{Na}-\mathrm{Cl}$ & $\mathrm{Na}-\mathrm{Cl}$ & $\mathrm{Na}-\mathrm{N}$ \\
\hline 11c3t7e.xls.xls & & & 11 & 70 & $1.00 \mathrm{E}-03$ & $59.6 \%$ & $\mathrm{Na}-\mathrm{Cl}$ & $\mathrm{Na}-\mathrm{Cl}$ & $\mathrm{Na}-\mathrm{Cl}$ & $\mathrm{K}-\mathrm{Cl}$ \\
\hline 11c4t1e.xls.xls & & & 11 & 100 & 1.00E-04 & $58.8 \%$ & $\mathrm{Na}-\mathrm{Cl}$ & $\mathrm{Na}-\mathrm{Cl}$ & $\mathrm{Na}-\mathrm{Cl}$ & $\mathrm{Na}-\mathrm{Cl}$ \\
\hline 11c4t4e.xls.xls & & & 11 & 40 & $1.00 \mathrm{E}-04$ & $62.1 \%$ & $\mathrm{Na}-\mathrm{Cl}$ & $\mathrm{Na}-\mathrm{Cl}$ & $\mathrm{Na}-\mathrm{Cl}$ & $\mathrm{Na}-\mathrm{N}$ \\
\hline 11c4t7e.xls.xls & & & 11 & 70 & $1.00 \mathrm{E}-04$ & $59.5 \%$ & $\mathrm{Na}-\mathrm{Cl}$ & $\mathrm{Na}-\mathrm{Cl}$ & $\mathrm{Na}-\mathrm{Cl}$ & $\mathrm{K}-\mathrm{Cl}$ \\
\hline
\end{tabular}

Source: Output DTN: MO0312SPAPCESA.002.

NOTE: Shown in the table is the percentage of all waters the bins represent. To see the time normalized percentages for the crown and invert, consult Tables 6.13-1 and 6.13-2.

Table 6.13-7 shows the brine compositions that develop during evaporative concentration of the seepage waters, as presented in the TSPA-LA lookup tables. Also shown is the endpoint relative humidity of the brines represented by the 11 bins. Under most conditions, the evaporated seepage waters can be classified as one of three brine types: sodium chloride, sodium carbonate, or calcium chloride. Bins 1 through 3 show that the accumulation of $\mathrm{Ca}$ and $\mathrm{Cl}$ is sufficient to make them the dominant cation and anion, respectively, as relative humidity decreases. Under these conditions, the potential for aggressive localized corrosion exists. However, based on the bin history maps (Figure 6.13-1), bins 1 and 2 are not possible as crown seepage and the time integrated occurrence for Bin 3 over the 20,000-year timeframe is $0.22 \%$ (Table 6.13-1). In addition, Bin 3 waters only occur during the first several hundred years (Figure 6.13-1) when drift temperatures are high and liquid water is least likely to be entering the drift. 
With the exception of Bins 8 through 10, the dominant anion is $\mathrm{Cl}$, which could potentially yield localized corrosion (approximately 72\%), yet Bins 4 through 7 and 11 are not expected to be as aggressive as Bin 3 because of the absence of $\mathrm{CaCl}_{2}$ and their higher $\mathrm{pH}$. Also evident from Figure 6.13-19 is the potential for six of the bins to have a $\mathrm{Cl} / \mathrm{N}$ ratio above 10 at relative humidity conditions above about 70\%. In Bins 6 and 7, $\mathrm{Cl} / \mathrm{N}$ ratios above 30 are possible.

Additional plots have been included in the following figures to show the ranges in Bins 3 through 11 for total elemental Ca, S, and C (Figures 6.13-20 through 6.13-22). Plots for elemental $\mathrm{Si}, \mathrm{N}, \mathrm{K}, \mathrm{Mg}$, and $\mathrm{Na}$ are provided in checked MOALT ROd2.xls archived in Output DTN: MO0312SPAPCESA.002.

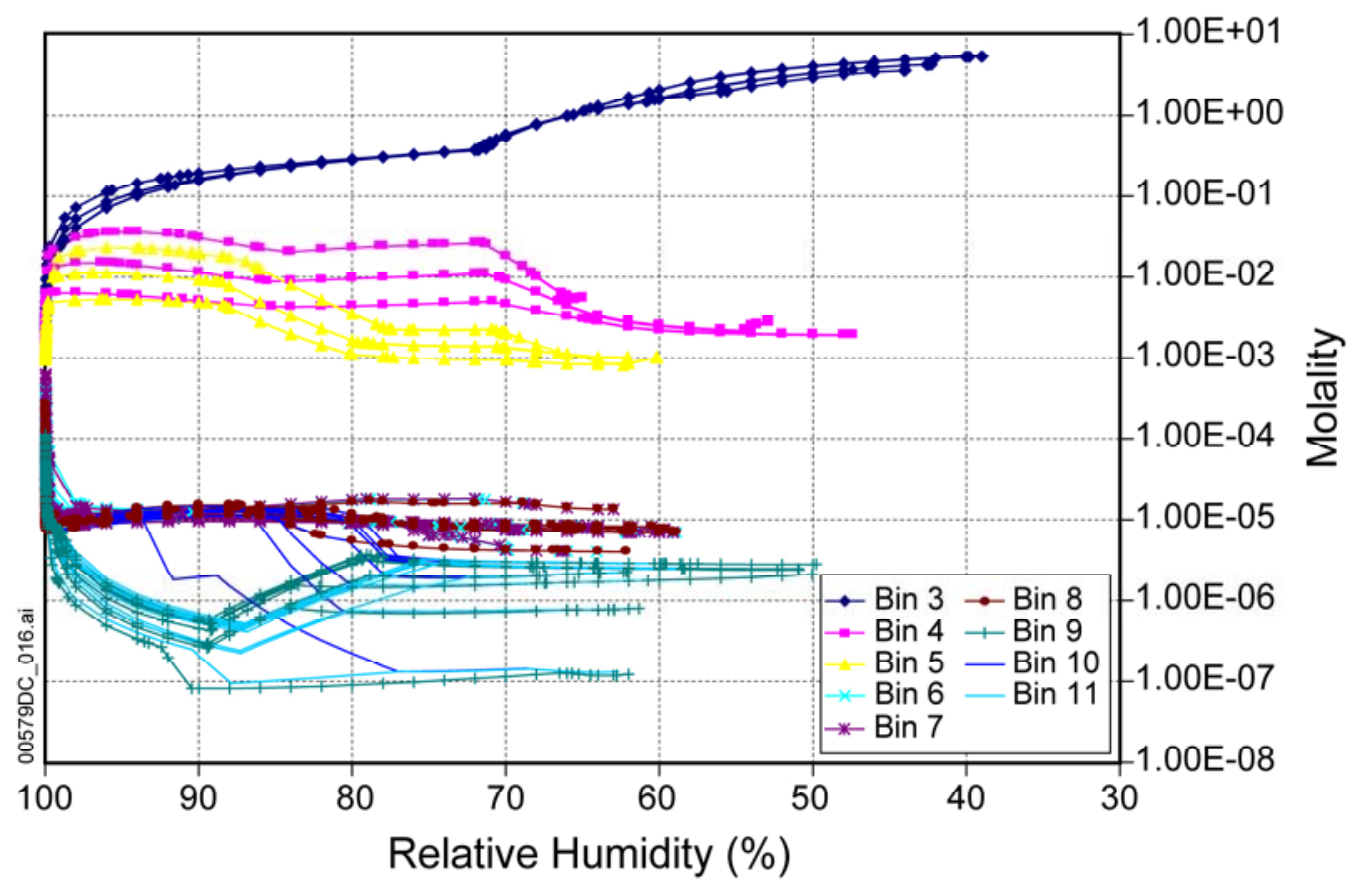

Source: Output DTN: MO0312SPAPCESA.002.

Figure 6.13-20. Range of Total Elemental Ca for the Seepage Evaporation Lookup Tables Representing Bins 3 through 11 


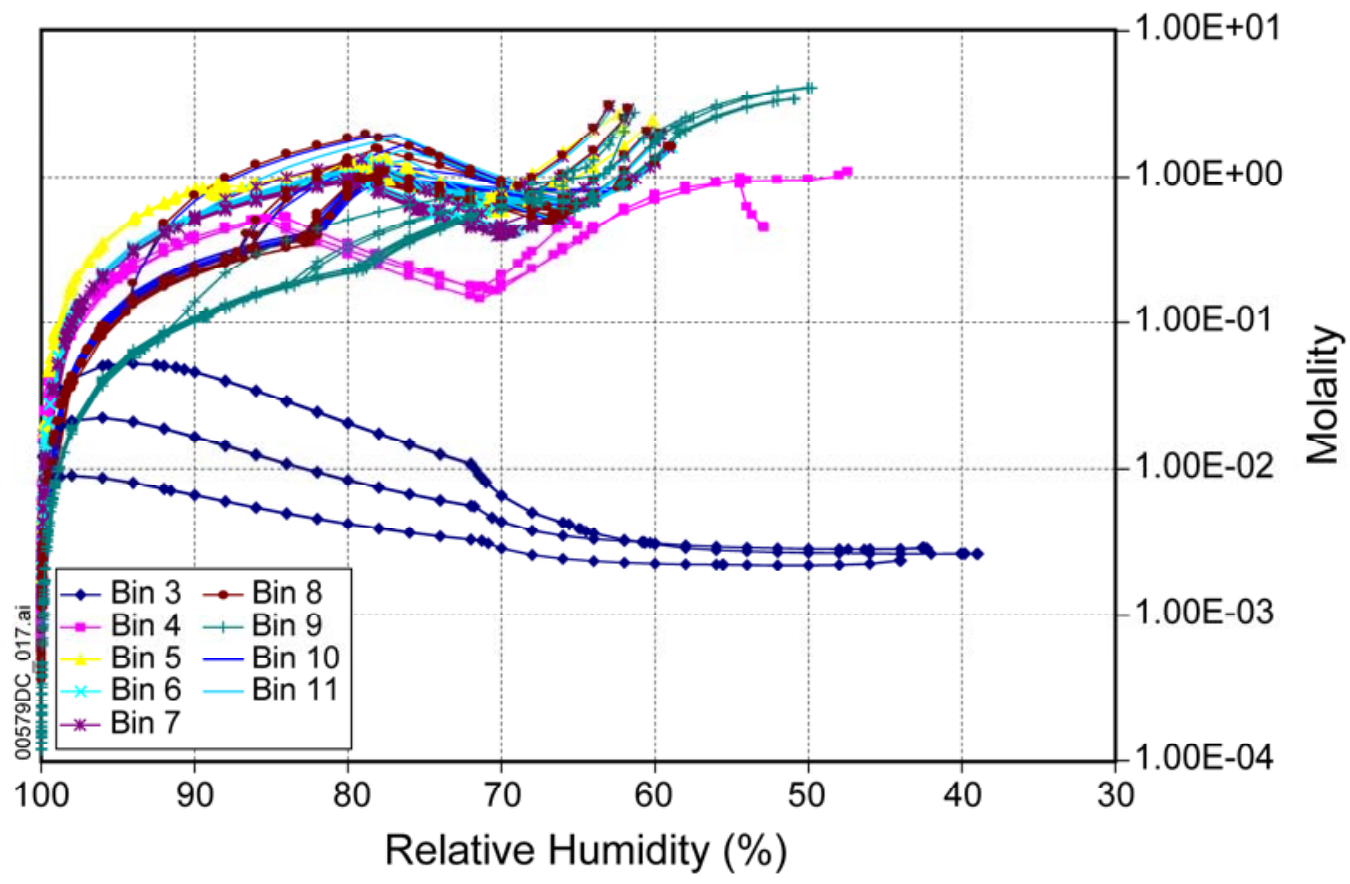

Source: Output DTN: MO0312SPAPCESA.002.

Figure 6.13-21. Range of Total Elemental S for the Seepage Evaporation Lookup Tables Representing Bins 3 through 11

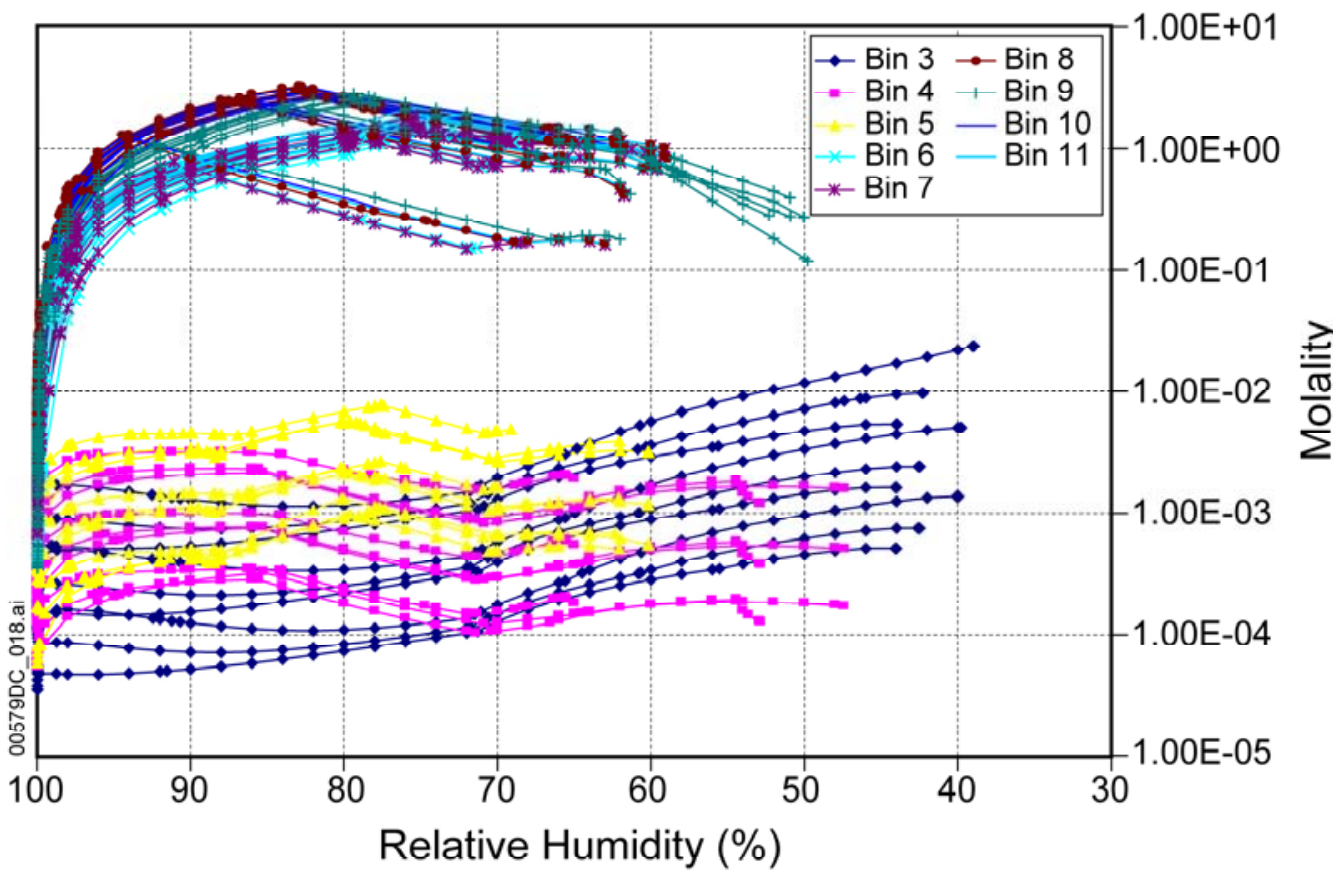

Source: Output DTN: MO0312SPAPCESA.002.

Figure 6.13-22. Range of Total Elemental C for the Seepage Evaporation Lookup Tables Representing Bins 3 through 11 
Between 100 and 95\% relative humidity in the drift, the ionic strength of the evaporating solutions exceeds 1 molal (Figure 6.13-23). At the lower relative humidity conditions, concentrations of well over 10 molal are possible. EQ6 results report the relative loss of water mass through the evaporative process. Figure 6.13-24 plots this water loss against the ionic strength. This figure shows that when the brines are very concentrated, the relative mass of water becomes extremely small. For example, when $1 \mathrm{~kg}$ of unevaporated seepage water is concentrated to an ionic strength of 10 or greater, the mass of remaining water becomes a gram or less. In some cases, the remaining brine is $10^{-4}$ grams or less. This indicates that the area affected by the corrosion capability of the brines reacting with the waste package or drip shield should decrease as evaporation increases due to the substantial reduction in evaporated seepage water mass.

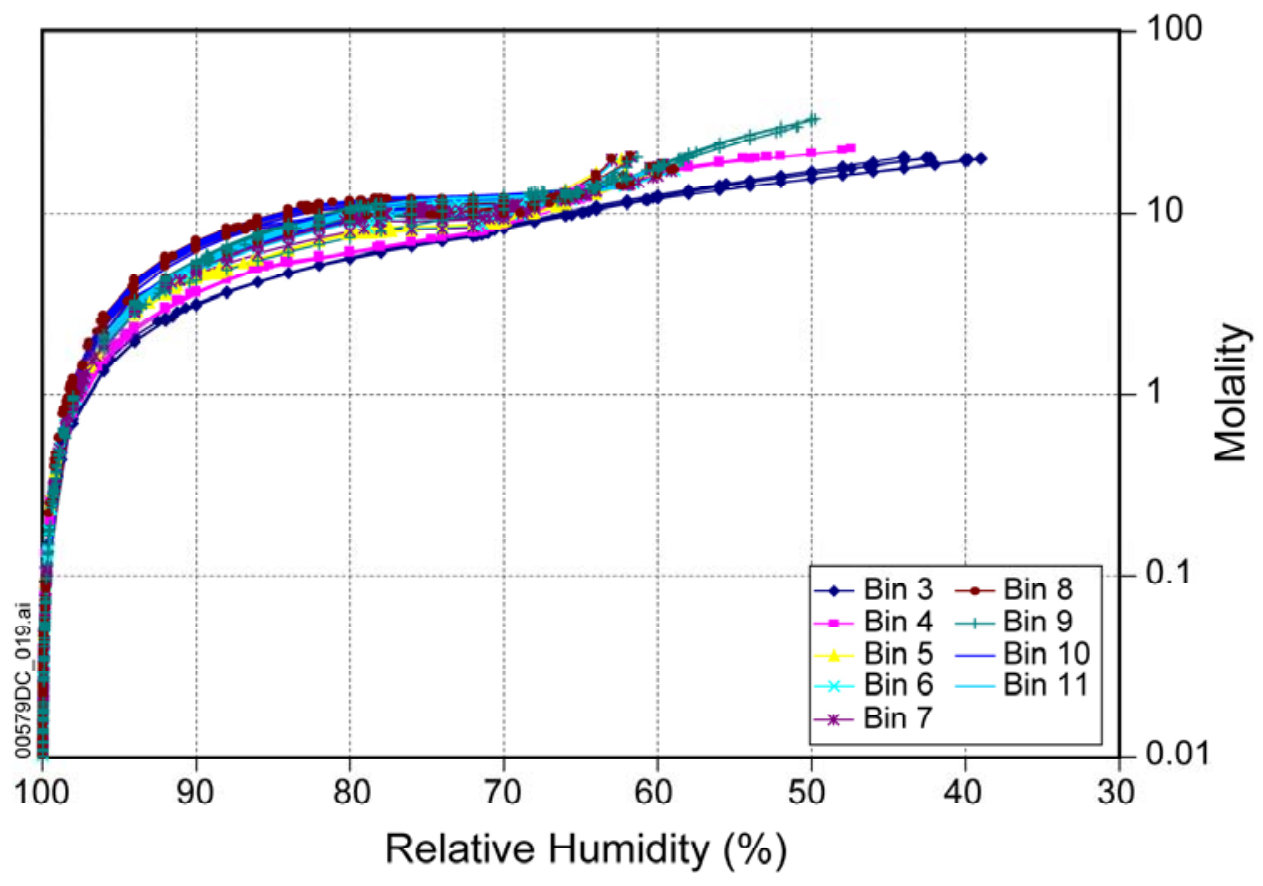

Source: Output DTN: MO0312SPAPCESA.002.

Figure 6.13-23. Range of lonic Strength versus Relative Humidity for the Seepage Evaporation Lookup Tables Representing Bins 3 through 11 


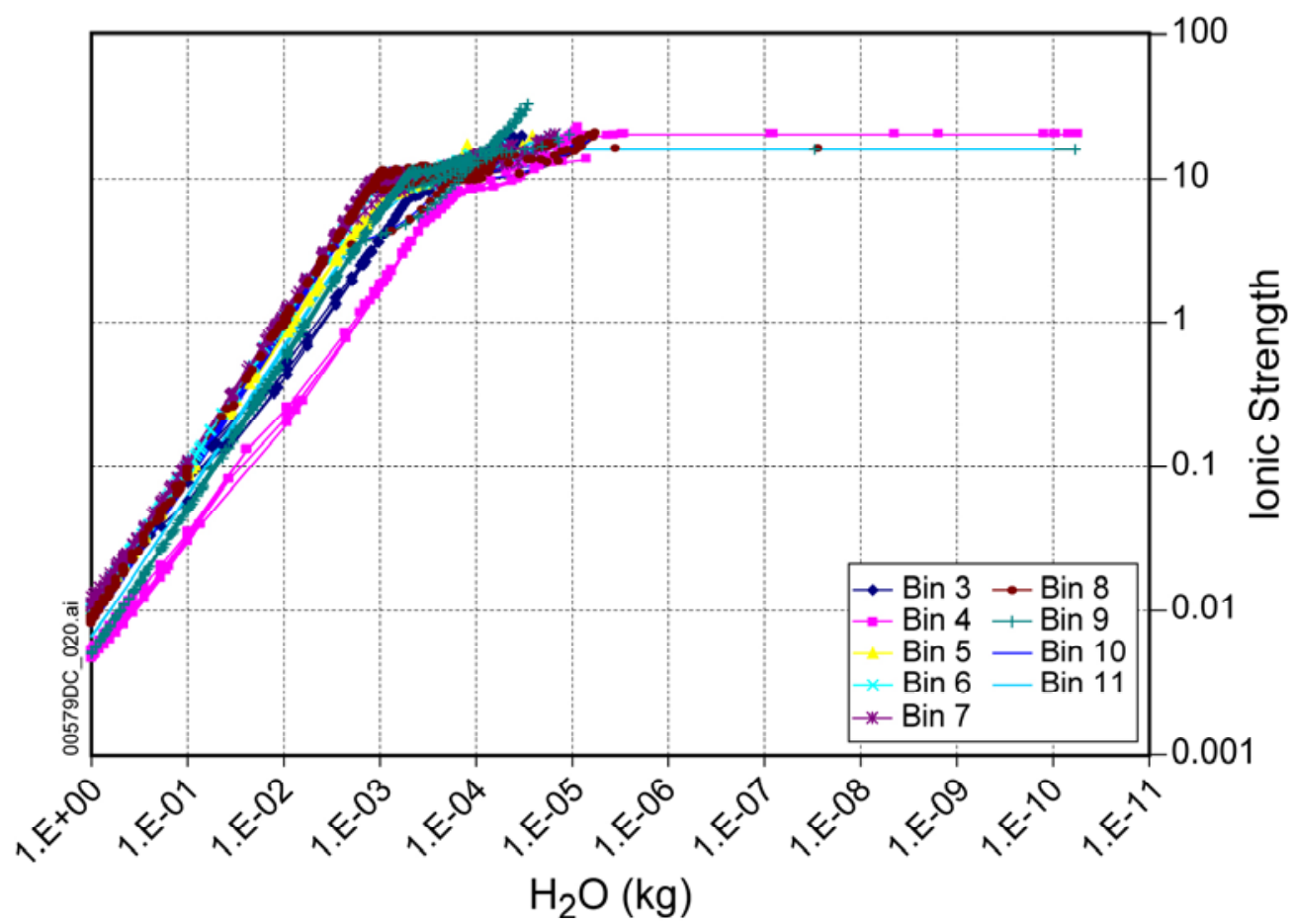

Source: Output DTN: MO0312SPAPCESA.002.

Figure 6.13-24. Mass of Water versus lonic Strength for the Seepage Evaporation Lookup Tables Representing Bins 3 through 11

The mineral assemblages associated with Bins 3 through 11 are provided in Table 6.13-6. These minerals are likely to form on drip shield and waste package surfaces as seepage evaporates.

\subsubsection{Chemical Environment in the Invert}

The chemical environment in the invert is important for two key TSPA-LA parameters: radionuclide solubility and colloid stability. In general, the chemical parameters of interest are $\mathrm{pH}$ and ionic strength. All 11 sets of bin chemistries are possible in the invert, whereas the drip shield and waste package environment discussed in Section 6.13.3 did not consider Bins 1 and 2, as they do not occur in the crown seepage waters. To establish the chemical environment in the invert, multiple sources of water must be considered (Figure 6.13-25). These include waters that have wicked into the invert from below, dripped from the crown, dripped and flowed down from the drip shield or outer surface of the waste package, or exited from a breached waste package after interacting with the waste form.

Figure 6.13-1 shows the bin history maps for each of the five waters in a color-coded scheme. This figure illustrates that the waters being wicked into the invert are chemically distinct from the waters seeping from the crown over significant portions during the early periods (i.e., the boiling and hot periods; Table 6.13-3). In addition, the temperature, $p \mathrm{CO}_{2}$, and relative humidity will not be the same in the drift as in the invert throughout time (Section 6.7.2). This indicates that, even though the waters wicking into the invert and seeping into the invert from the crown of the drift come from the same bin, the chemistry parameters obtained from a given lookup table 
could be different. During certain time periods there is also the possibility that seepage that has entered the waste package, and become chemically modified due to reactions with the waste form and in-package components, can leave the waste package and introduce yet a third type of water into the invert. Figure 6.13-25 shows the potential sources of water that can enter the invert. Three sources of water are discussed independently in the following paragraphs.

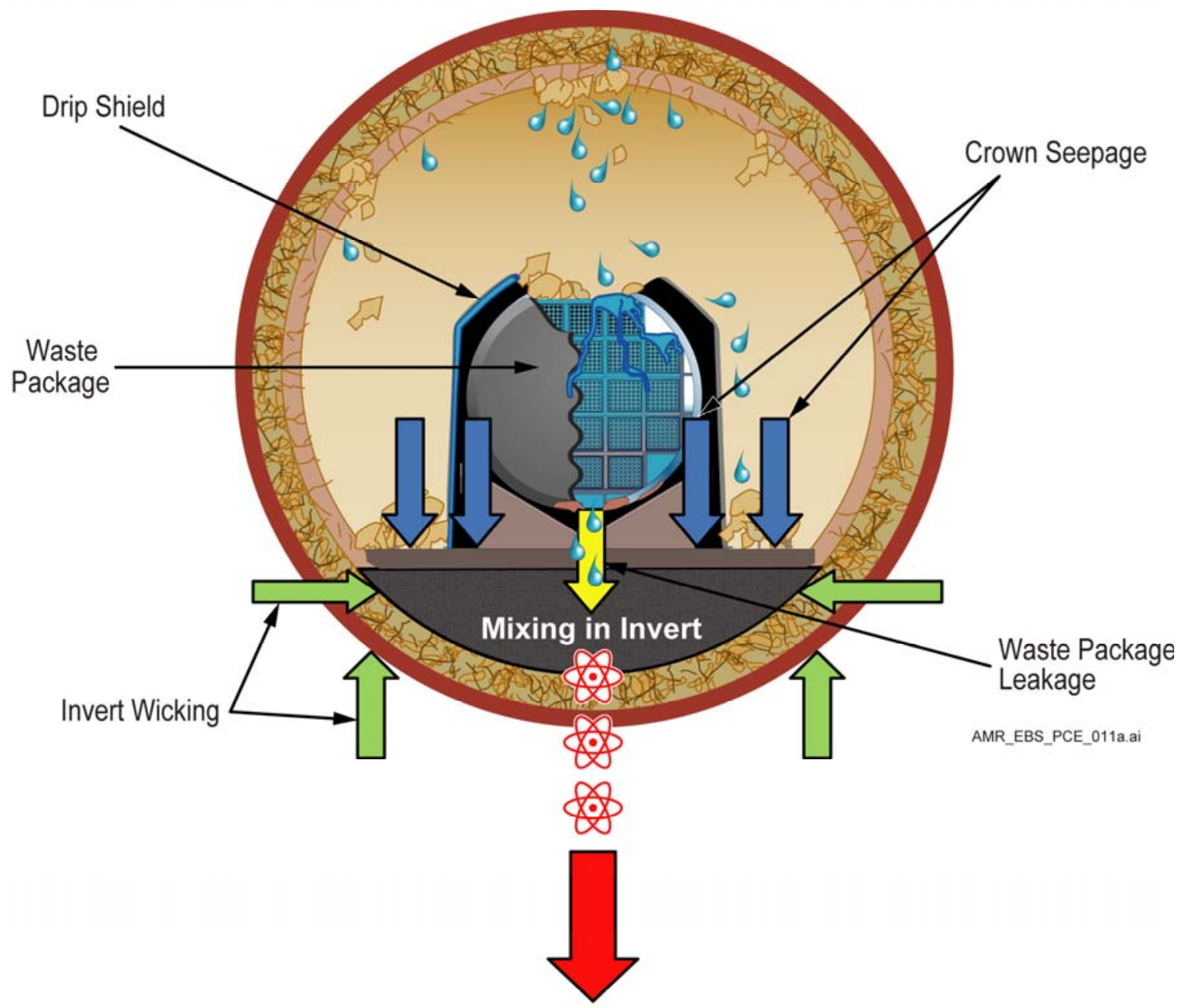

EBS Radionuclide Release

Figure 6.13-25. Schematic Representation of the Sources of Different Chemical Fluxes into the Invert and Subsequent Radionuclide Release from the Engineered Barrier System

\subsubsection{Crown Seepage Chemistry}

Seepage chemistry is discussed in detail in Section 6.13.3, which provides a description of the ranges of crown seepage waters that could enter the invert. 


\subsubsection{Invert Wicking Chemistry}

In addition to the same range of possible water chemistries available from crown seepage previously discussed (Bins 3 through 11), waters entering the invert by wicking include Bins 1 and 2, as shown in Figure 6.13-1. Bins 1 and 2 are only briefly present over the long term (thousands of years), but they are common in the invert during the boiling period, as shown in Table 6.13-3. Figure 6.13-16 and Figures 6.13-26 through 6.13-31 show the compositional (pH, $\mathrm{F}, \mathrm{Cl}, \mathrm{Ca}, \mathrm{S}, \mathrm{C}$, and ionic strength, respectively) evolution of Bin 1 and 2 waters that occurs during evaporation. Plots for $\mathrm{Si}, \mathrm{N}, \mathrm{K}, \mathrm{Mg}, \mathrm{Na}$, and $\mathrm{Cl} / \mathrm{N}$ ratio are not shown here, but are provided in checked MOALT R02d2.xls archived in Output DTN: MO0312SPAPCESA.002.

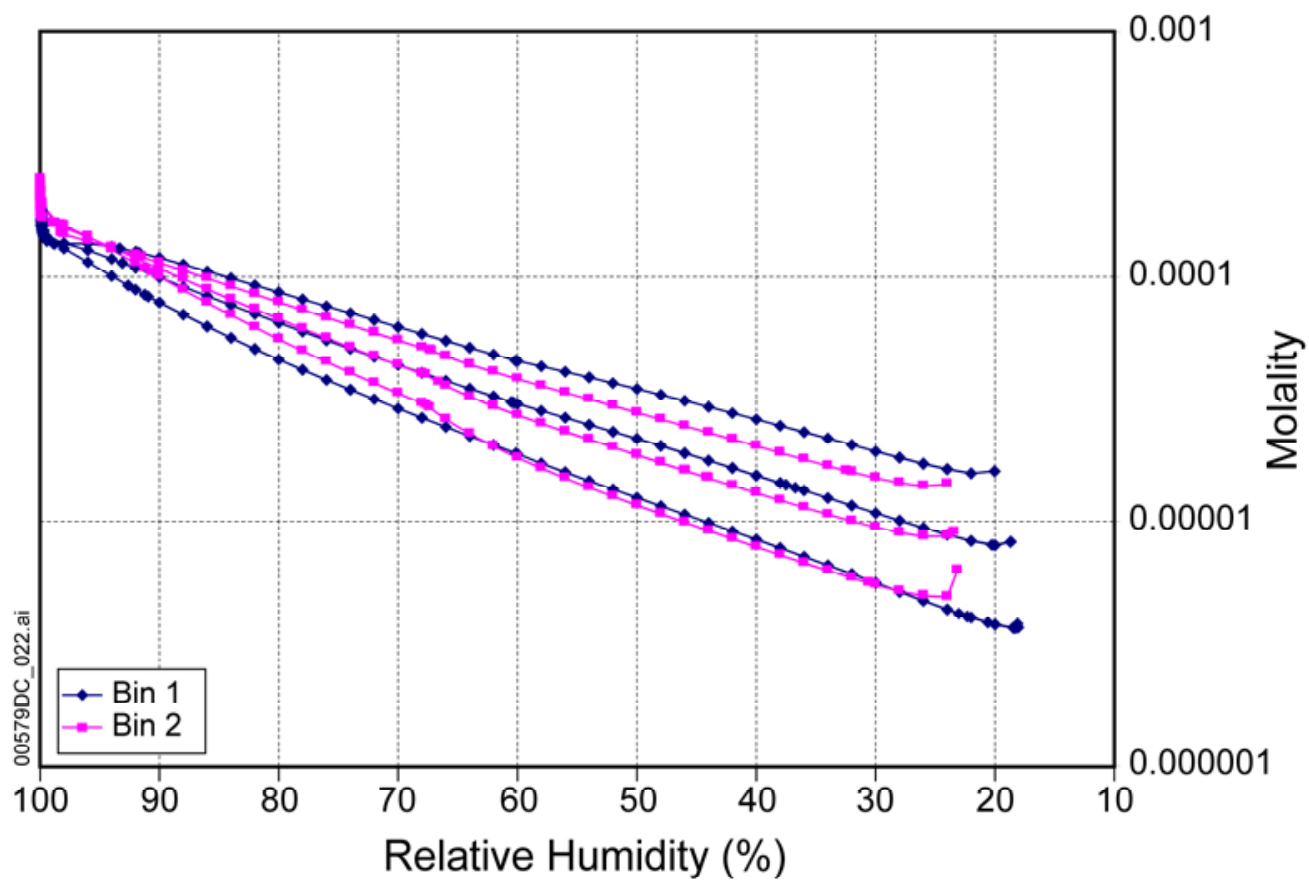

Source: Output DTN: MO0312SPAPCESA.002.

Figure 6.13-26. Range of $F$ versus Relative Humidity for the Seepage Evaporation Lookup Tables Representing Bins 1 and 2 


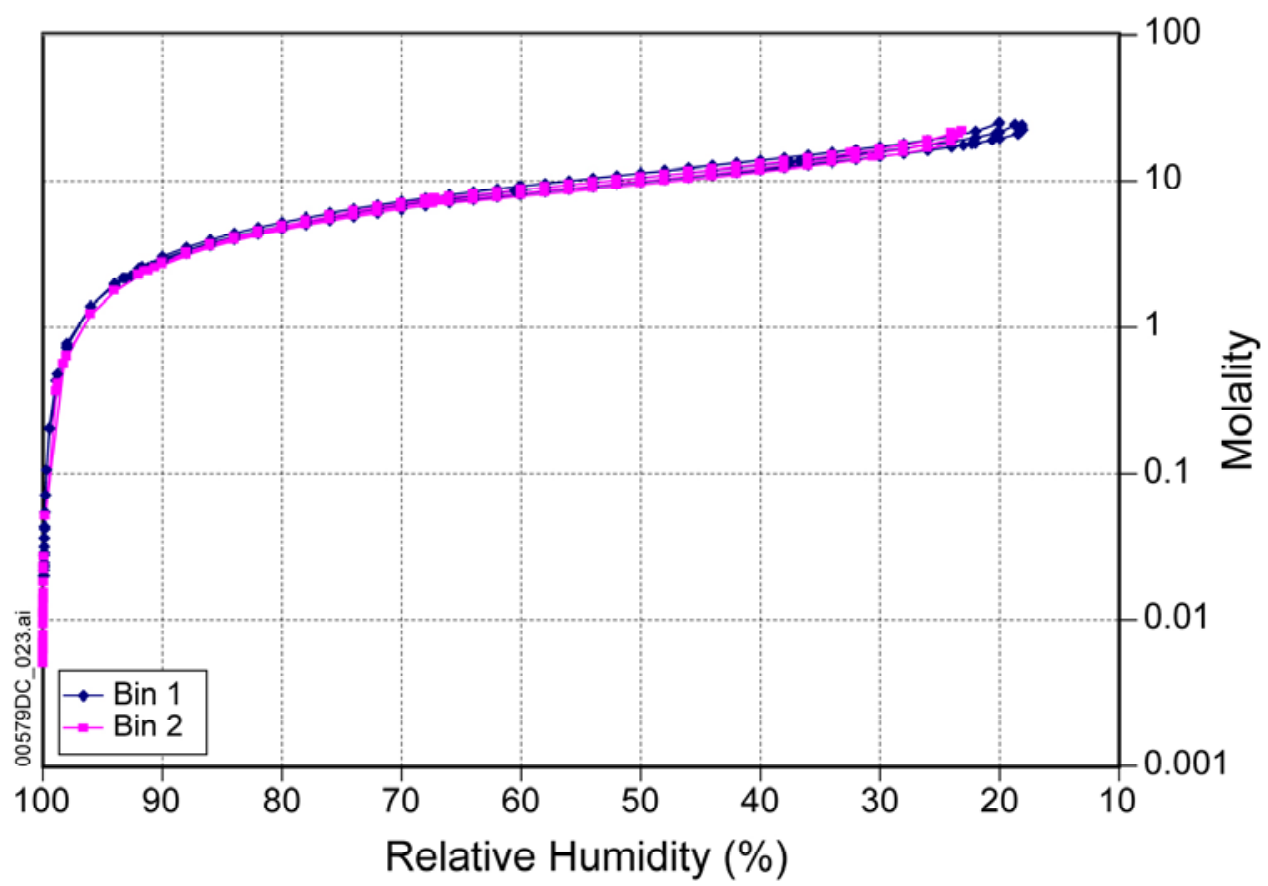

Source: Output DTN: MO0312SPAPCESA.002.

Figure 6.13-27. Range of $\mathrm{Cl}$ versus Relative Humidity for the Seepage Evaporation Lookup Tables Representing Bins 1 and 2

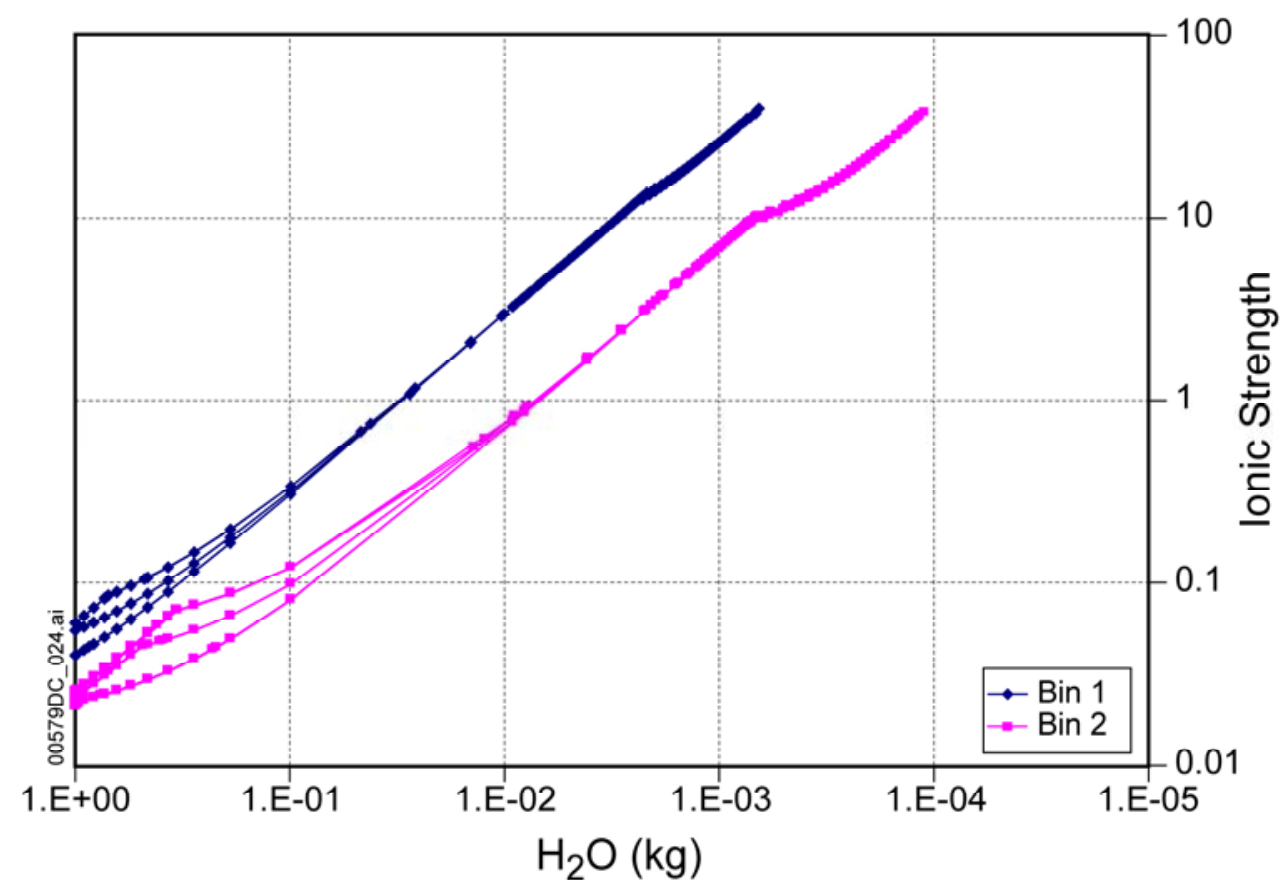

Source: Output DTN: MO0312SPAPCESA.002.

Figure 6.13-28. Range of lonic Strength versus Mass of Water $(\mathrm{kg})$ for the Seepage Evaporation Lookup Tables Representing Bins 1 and 2 


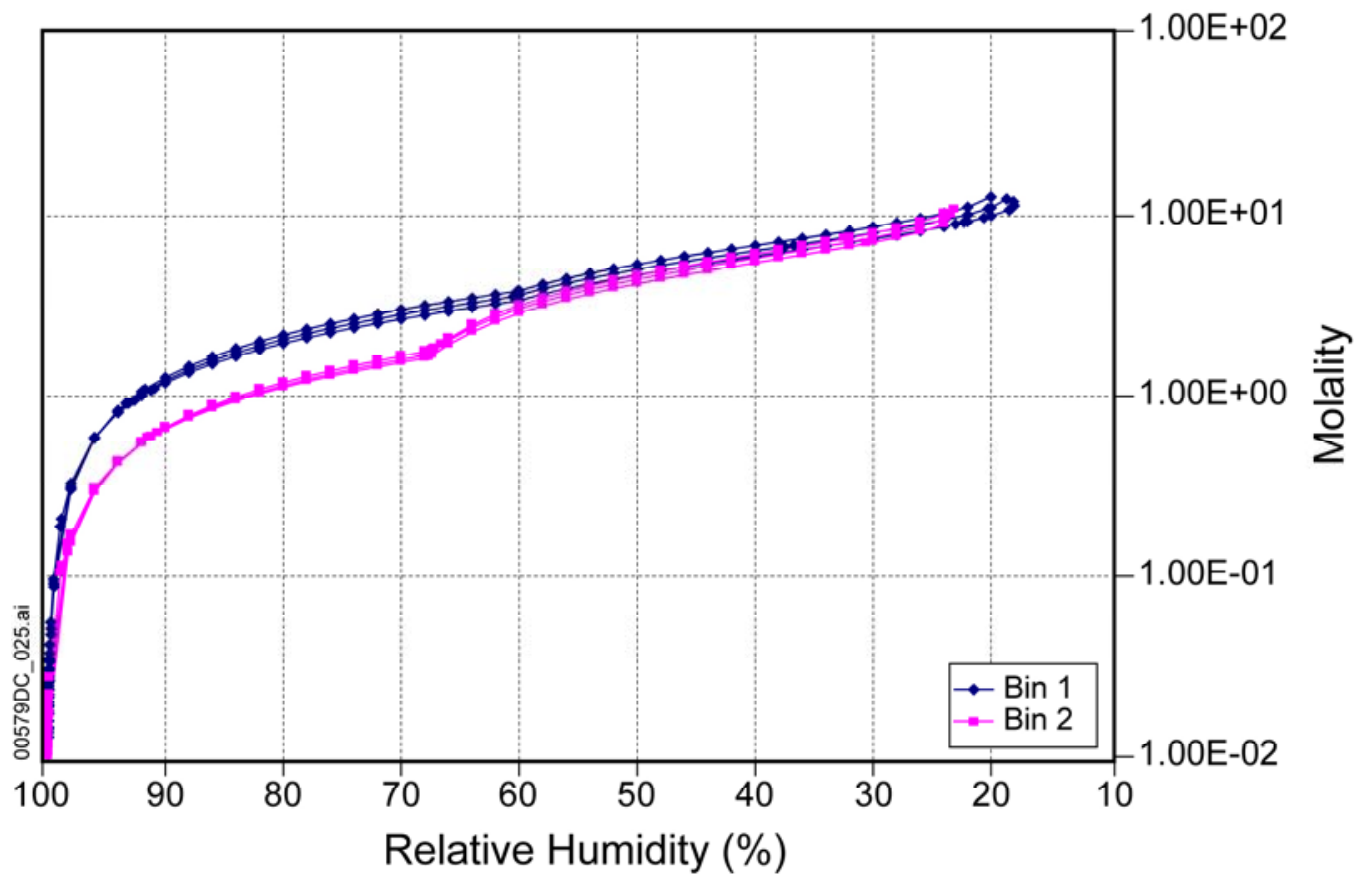

Source: Output DTN: MO0312SPAPCESA.002.

Figure 6.13-29. Range of Total Elemental Ca for the Seepage Evaporation Lookup Tables Representing Bins 1 and 2

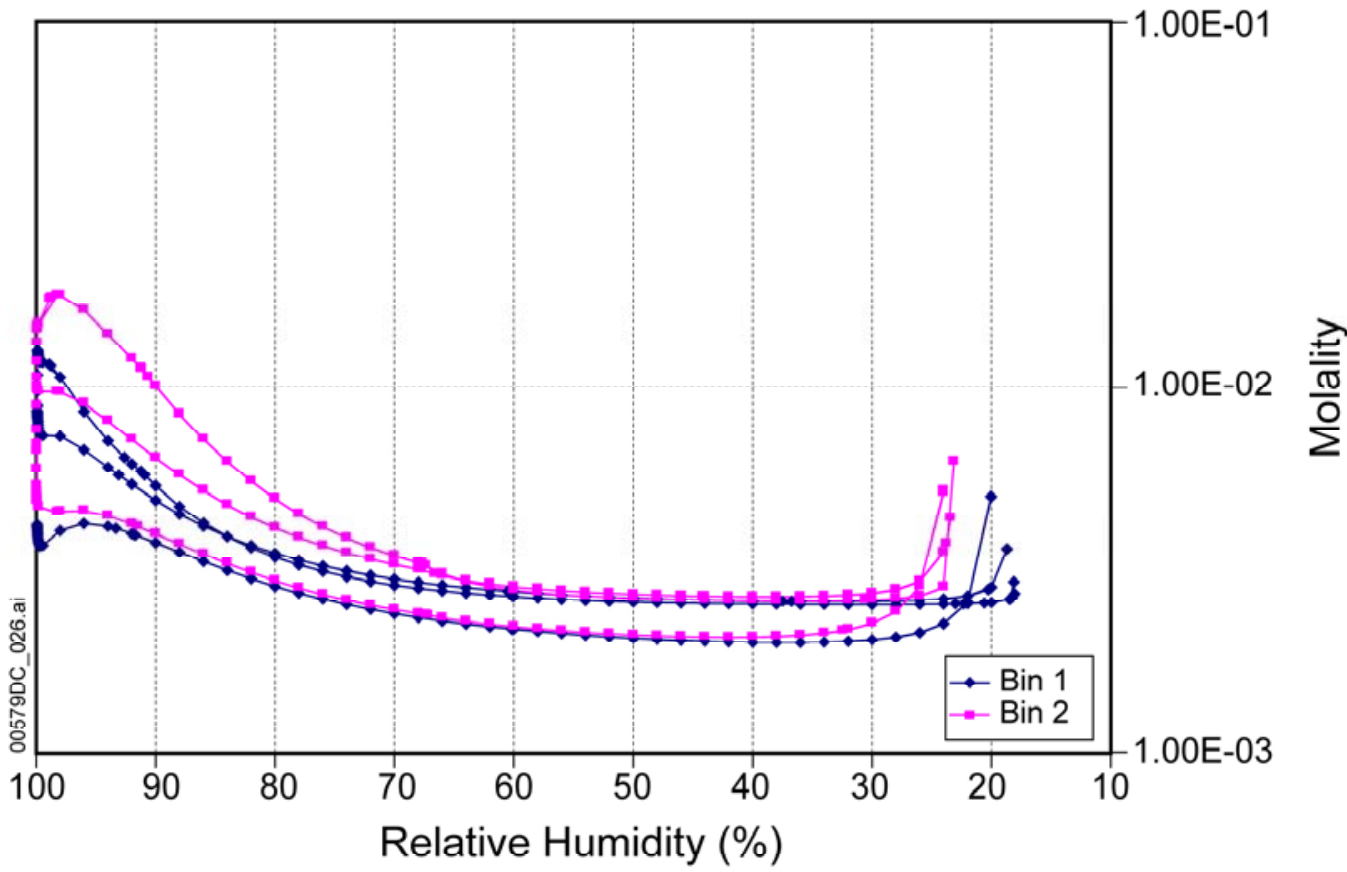

Source: Output DTN: MO0312SPAPCESA.002.

Figure 6.13-30. Range of Total Elemental S for the Seepage Evaporation Lookup Tables Representing Bins 1 and 2 


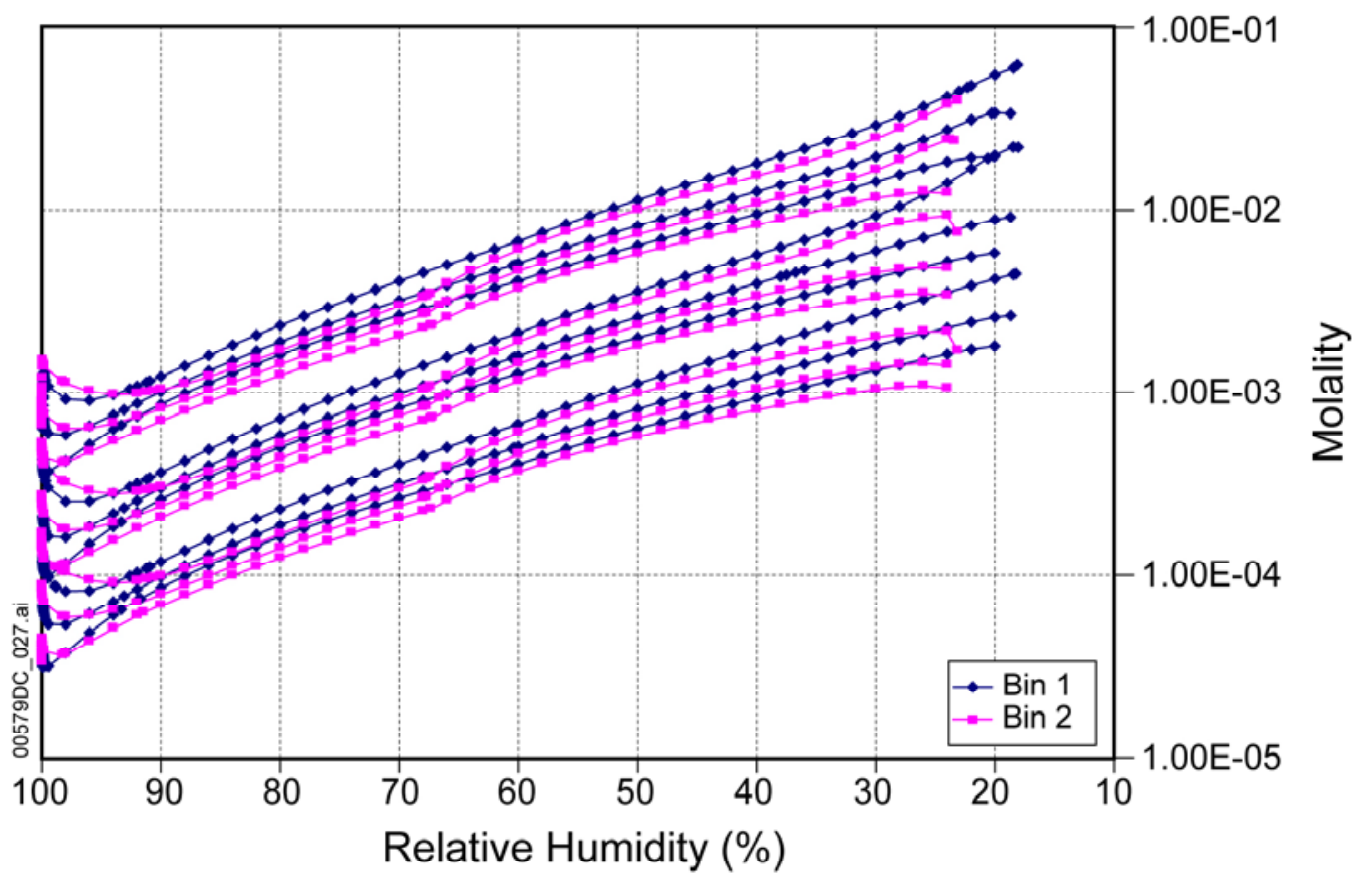

Source: Output DTN: MO0312SPAPCESA.002.

Figure 6.13-31. Range of Total Elemental C for the Seepage Evaporation Lookup Tables Representing Bins 1 and 2

In contrast to crown seepage, during the boiling period the overall $\mathrm{pH}$ range of the waters in the invert bin 1 and 2 waters extends from $~ 8.5$ down to 3.5 (Figure 6.13-16). In the hot period, Bin 4 and 5 waters are more dominant in the invert than in the crown waters and the predicted $\mathrm{pH}$ range extends from 6 to 10.5 , as opposed to approximately 8 to 10.5 for the crown waters. For all other periods, the ranges in $\mathrm{pH}$ and ionic strength in the invert waters are similar to those reported for the evaporated crown seepage waters in Section 6.13 .3 ( $\mathrm{pH}$ approximately 8 to 10.5$)$.

\subsubsection{Chemistry of Waste Package Leakage}

The compositions of water produced in the waste package by interactions of seepage or condensate water with waste package materials and waste is documented in another process model report. That report, In-Package Chemistry Abstraction (BSC 2005 [DIRS 174583]), provides data containing the parameters of interest. A review of Sections 6 and 8 of In-Package Chemistry Abstraction (BSC 2005 [DIRS 174583]) indicates that $\mathrm{pH}$ and ionic strengths through time are generally much different than those reported for the crown seepage and invert wicking chemistries.

\subsubsection{Comparison to Corrosion Testing Chemistries}

Initial corrosion testing environments can be related to three types of natural brines: calcium chloride, carbonate, and sulfate. Initial corrosion test studies focused on the carbonate type brine, based on reasoning that sodium carbonate type waters, as typified by J-13 well water from the saturated zone near Yucca Mountain, were the expected types of waters at the repository 
(Harrar et al. 1990 [DIRS 100814]). A later study (Rosenberg et al. 2001 [DIRS 154862]) showed that evaporative concentration of a water based on a reported analysis (Sonnenthal et al. 1998 [DIRS 118845]) of a pore water from Yucca Mountain resulted in a calcium chloride type brine. The types of aqueous solutions used for corrosion testing will be discussed in the context of the natural brines that follows.

Geochemical literature (e.g., Drever 1997 [DIRS 147480]) establishes the three types of brines that result from the evaporative concentration of dilute natural waters at the Earth's surface: (1) calcium chloride brine, (2) carbonate brine, and (3) sulfate brine. It is important to note that the compositions of brines are dependent on relative humidity, and the dominant ions in solution can and do change as a function of relative humidity.

\subsubsection{Corrosion Test Chemistries}

Table 6.13-8 shows the composition of some of the solutions used for corrosion testing. These solutions were developed based on the evaporative concentration of a carbonate-based water with a composition based on J-13 well water, which is a saturated zone water near Yucca Mountain. The solutions represent various stages of evaporative concentration of this type of water. These aqueous solution compositions were concentrated to about 10 times (for SDW test solutions) to over 45,000 times (for simulated saturated water (SSW) and basic saturated water (BSW) test solutions) to simulate evaporative concentration of the water upon contacting the waste package or the drip shield. $\mathrm{NaCl}$ test solutions were also used where $\mathrm{NaCl}$ concentrations varied from 0.5 to 4.0 molar; $\mathrm{CaCl}_{2}$ and $\mathrm{CaCl}_{2}+\mathrm{Ca}\left(\mathrm{NO}_{3}\right)_{2}$ test solutions were also used with $\mathrm{CaCl}_{2}$ concentrations up to 9 molar.

In all cases, the $\mathrm{NO}_{3}{ }^{-}$component is the most soluble species and would dominate the solution composition at the deliquescent relative humidity or eutectic point of a mineral assemblage at elevated temperatures. It is not until the relative humidity is higher that $\mathrm{Cl}^{-}$could become comparable to $\mathrm{NO}_{3}{ }^{-}$. This is discussed in more detail in Section 6.13.6, where it is related to the transport separation of halite. 
Table 6.13-8. Target Composition of Standard Test Media Based on Evaporative Concentration of a Dilute Carbonate-Type Water

\begin{tabular}{|l|c|c|c|c|c|}
\hline \multicolumn{1}{|c|}{ lon } & $\begin{array}{c}\text { SDW } \\
\text { (mg/L) }\end{array}$ & $\begin{array}{c}\text { SCW } \\
(\mathbf{m g} / \mathbf{L})\end{array}$ & $\begin{array}{c}\text { SAW } \\
(\mathbf{m g} / \mathbf{L})\end{array}$ & $\begin{array}{c}\text { SSW } \\
\text { (mg/L) }\end{array}$ & $\begin{array}{c}\text { BSW-12 } \\
\text { (mg/L) }\end{array}$ \\
\hline $\mathrm{K}^{+}$ & $3.4 \times 10^{1}$ & $3.4 \times 10^{3}$ & $3.4 \times 10^{3}$ & $1.42 \times 10^{5}$ & $6.7101 \times 10^{4}$ \\
\hline $\mathrm{Na}^{+}$ & $4.09 \times 10^{2}$ & $4.09 \times 10^{4}$ & $3.769 \times 10^{4}$ & $4.87 \times 10^{4}$ & $1.05686 \times 10^{5}$ \\
\hline $\mathrm{Mg}^{2+}$ & 1 & $<1$ & $1.00 \times 10^{3}$ & 0 & 0 \\
\hline $\mathrm{Ca}^{2+}$ & $5 \times 10^{-1}$ & $<1$ & $1.00 \times 10^{3}$ & 0 & 0 \\
\hline $\mathrm{F}^{-}$ & $1.4 \times 10^{1}$ & $1.4 \times 10^{3}$ & 0 & 0 & $1.3308 \times 10^{3}$ \\
\hline $\mathrm{Cl}^{-}$ & $6.7 \times 10^{1}$ & $6.7 \times 10^{3}$ & $2.425 \times 10^{4}$ & $1.28 \times 10^{5}$ & $1.31315 \times 10^{5}$ \\
\hline $\mathrm{NO}_{3}{ }^{-}$ & $6.4 \times 10^{1}$ & $6.4 \times 10^{3}$ & $2.30 \times 10^{4}$ & $1.313 \times 10^{6}$ & $1.39466 \times 10^{6}$ \\
\hline $\mathrm{SO}_{4}{ }^{2-}$ & $1.67 \times 10^{2}$ & $1.67 \times 10^{4}$ & $3.86 \times 10^{4}$ & 0 & $1.3924 \times 10^{4}$ \\
\hline $\mathrm{HCO}_{3}{ }^{-}$ & $9.47 \times 10^{2}$ & $7.0 \times 10^{4}$ & 0 & 0 & 0 \\
\hline $\mathrm{Si}^{2}$ & $27\left(60^{\circ} \mathrm{C}\right), 49\left(90^{\circ} \mathrm{C}\right)$ & $27\left(60^{\circ} \mathrm{C}\right), 49\left(90^{\circ} \mathrm{C}\right)$ & $27\left(60^{\circ} \mathrm{C}\right), 49\left(90^{\circ} \mathrm{C}\right)$ & 0 & 0 \\
\hline $\mathrm{pH}$ & 9.8 to 10.2 & 9.8 to 10.2 & 2.7 & 5.5 to 7 & 12 \\
\hline
\end{tabular}

Source: DTN: LL040803112251.117 [DIRS 171362].

NOTES: The basis for the dilute carbonate water was J-13 well water, a saturated zone water near Yucca Mountain. The SDW, SCW, and BSW test solutions correspond to increasing evaporative concentration of the basis water. The SSW test solution contains only $\mathrm{Cl}^{-}$and $\mathrm{NO}_{3}{ }^{-}$and corresponds to the scenario where the other anions have precipitated out of solution, that is, a very low relative humidity condition. The SAW test solution is a moderately acidic solution (hence, no carbonate because of its volatility) with an ionic strength similar to the SCW test solution. The SAW test solution also does not contain fluoride, which was excluded because of its high vapor pressure at the solution $\mathrm{pH}$. $\mathrm{pH}$ is measured for actual solutions at room temperature.

\subsubsection{In-Drift Brine Compared to Test Solutions}

The compositions of evaporated seepage waters were discussed in Sections 6.13.1 and 6.13.2. The following discussion relates those water brine types to the corrosion test solutions.

Table 6.13-9 summarizes the range of environments projected to form within the repository due to water seepage. The conditional frequency of occurrence (if seepage occurs at the drift crown for any particular location) that a water in a particular bin will form is also listed. For each bin, the associated brine and test solution in which corrosion testing was conducted are listed. In terms of brine type the drift crown brines are predominantly the alkaline carbonate brines, although carbonate may not be a dominant component except at higher relative humidity. The composition of each bin water as a function of temperature and relative humidity is given in lookup tables discussed in Section 6.13.1. 
Table 6.13-9. Evaporated Crown Seepage Water and Corresponding Corrosion Test Solutions

\begin{tabular}{|c|c|c|c|c|c|}
\hline Bin Water & $\begin{array}{c}\text { Frequency of } \\
\text { Occurrence } \\
\text { for Crown } \\
\text { Seepage }^{a} \\
\end{array}$ & $\begin{array}{c}\text { Dominant } \\
\text { Constituents in } \\
\text { Bin Water at } \\
98 \% \text { Relative } \\
\text { Humidity }^{\mathbf{b}} \\
\end{array}$ & $\begin{array}{c}\text { Dominant } \\
\text { Constituents in } \\
\text { Endpoint } \\
\text { Brines }^{b}\end{array}$ & Brine Type & $\begin{array}{c}\text { Corresponding } \\
\text { Corrosion Test } \\
\text { Solution } \\
\end{array}$ \\
\hline 1 & 0.00 & $\mathrm{Ca}-\mathrm{Cl}$ & $\mathrm{Ca}-\mathrm{Cl}$ & Calcium chloride & $\begin{array}{l}\mathrm{CaCl}_{2} ; \mathrm{CaCl}_{2}+ \\
\mathrm{Ca}\left(\mathrm{NO}_{3}\right)_{2}\end{array}$ \\
\hline 2 & 0.00 & $\mathrm{Na}-\mathrm{Cl}$ & $\mathrm{Ca}-\mathrm{Cl}$ & Calcium chloride & $\begin{array}{l}\mathrm{CaCl}{ }_{2} ; \mathrm{CaCl}_{2}+ \\
\mathrm{Ca}\left(\mathrm{NO}_{3}\right)_{2}\end{array}$ \\
\hline 3 & 0.22 & $\mathrm{Na}-\mathrm{Cl}$ & $\mathrm{Ca}-\mathrm{Cl}$; K-Cl & Calcium chloride & $\begin{array}{l}\mathrm{CaCl} 2 ; \mathrm{CaCl}_{2}+ \\
\mathrm{Ca}\left(\mathrm{NO}_{3}\right)_{2}\end{array}$ \\
\hline 4 & 1.42 & $\mathrm{Na}-\mathrm{Cl}$ & $\mathrm{K}-\mathrm{NO}_{3} ; \mathrm{Na}-\mathrm{NO}_{3}$ & Sulfate & $\begin{array}{l}\text { SSW, SAW, } \\
\mathrm{NaCl}\end{array}$ \\
\hline 5 & 0.79 & $\mathrm{Na}-\mathrm{Cl}$ & $\mathrm{Na}-\mathrm{Cl} ; \mathrm{K}-\mathrm{Cl}$ & Sulfate & $\begin{array}{l}\text { SSW, SAW, } \\
\mathrm{NaCl}\end{array}$ \\
\hline 6 & 5.46 & $\mathrm{Na}-\mathrm{Cl}$ & $\begin{array}{l}\mathrm{Na}-\mathrm{Cl} ; \mathrm{Na}-\mathrm{NO}_{3} ; \\
\mathrm{K}-\mathrm{Cl}\end{array}$ & Carbonate & $\begin{array}{l}\text { SDW, SCW, } \\
\text { BSW, SSW, } \\
\mathrm{NaCl}\end{array}$ \\
\hline 7 & 27.15 & $\mathrm{Na}-\mathrm{Cl}$ & $\begin{array}{l}\mathrm{Na}-\mathrm{Cl} ; \mathrm{Na}-\mathrm{NO}_{3} ; \\
\mathrm{K}-\mathrm{Cl}\end{array}$ & Carbonate & $\begin{array}{l}\text { SDW, SCW, } \\
\text { BSW, SSW, } \\
\mathrm{NaCl}\end{array}$ \\
\hline 8 & 16.2 & $\mathrm{Na}-\mathrm{CO}_{3}$ & $\begin{array}{l}\mathrm{Na}-\mathrm{Cl} ; \mathrm{Na}-\mathrm{NO}_{3} ; \\
\mathrm{K}-\mathrm{Cl}\end{array}$ & Carbonate & $\begin{array}{l}\text { SDW, SCW, } \\
\text { BSW, SSW, } \\
\mathrm{NaCl}\end{array}$ \\
\hline 9 & 15.55 & $\mathrm{Na}-\mathrm{CO}_{3}$ & $\mathrm{~K}^{-\mathrm{NO}_{3}} ; \mathrm{K}-\mathrm{Cl}$ & Carbonate & $\begin{array}{l}\text { SDW, SCW, } \\
\text { BSW, SSW, } \\
\mathrm{NaCl}\end{array}$ \\
\hline 10 & 11.7 & $\mathrm{Na}-\mathrm{CO}_{3}$ & $\begin{array}{l}\mathrm{Na}-\mathrm{Cl} ; \mathrm{Na}-\mathrm{NO}_{3} ; \\
\mathrm{K}-\mathrm{Cl}\end{array}$ & Carbonate & $\begin{array}{l}\text { SDW, SCW, } \\
\text { BSW, SSW, } \\
\mathrm{NaCl}\end{array}$ \\
\hline 11 & 21.5 & $\mathrm{Na}-\mathrm{Cl}$ & $\begin{array}{l}\mathrm{Na}-\mathrm{Cl} ; \mathrm{Na}^{-\mathrm{NO}_{3}} ; \\
\mathrm{K}-\mathrm{Cl}\end{array}$ & Carbonate & $\begin{array}{l}\text { SDW, SCW, } \\
\text { BSW, SSW, } \\
\mathrm{NaCl}\end{array}$ \\
\hline
\end{tabular}

Source: ${ }^{a}$ Table 6.13-1.

b Table 6.13-7.

NOTE: The frequency of occurrence of crown seepage represents the 20,000-year time-integrated occurrence fraction (in percent) of the representative water for each bin.

\subsubsection{Discussion of the Corrosion Test Solutions}

The brine type name reflects a characteristic of the brine that distinguishes it from the other brines. When evaporation has gone beyond the classic chemical divides shown in Figure 6.2-1, it may no longer reflect dominant species in the brine. This characterization of surface brine types has in part guided the expected range of brine water chemistry in the repository. However, some differences are expected between brines formed at the earth's surface and brines formed in the repository. These differences are mainly due to differences in the chemistry of seepage waters and surface waters giving rise to brines, and differences between the salt chemistry of dust and the dissolved salt content of the surface waters. Two factors specific to the repository brines are the ubiquity of nitrate and more effective mechanisms for the removal of magnesium. It is expected that nitrate will be in these brines because of the multiple potential sources and the 
generally high solubility of nitrate minerals (BSC 2004 [DIRS 161237], Sections 6.7.2.8 and 4.1.7, and Table 4.1-9). It is expected that magnesium will not be significant because of limited sources and multiple removal mechanisms, most of which are enhanced by elevated temperature (BSC 2004 [DIRS 161237], Sections 6.7.2.10 and 6.7.2.11). Table 6.13-10 summarizes the general classification of the brine types that could be in contact with drip shields and waste packages and the probabilities of contact.

Table 6.13-10. General Classification of the Brine Types and the Probabilities of Contact

\begin{tabular}{|l|c|l|}
\hline \multicolumn{1}{|c|}{ Brine Type } & $\begin{array}{c}\text { TSPA-LA Percent Frequency of } \\
\text { Occurrence }\end{array}$ & \multicolumn{1}{c|}{ Comments } \\
\hline Calcium chloride & Seepage at Drift Crown & \multicolumn{1}{c|}{ Comoride, carbonate, sulfate contents are negligible } \\
\hline Sulfate & 0.22 & Near-neutral $\mathrm{pH}$. \\
\hline Carbonate & 2.21 & $\begin{array}{l}\text { High } \mathrm{pH}, \text { no significant calcium or magnesium } \\
\text { content. }\end{array}$ \\
\hline
\end{tabular}

NOTE: The frequency of occurrence of crown seepage represents the 20,000-year time-integrated occurrence fraction of the representative water for each bin; at particular times in the simulation, the bin probabilities may differ (Table 6.13-4). Additionally, the mapping from Table 6.13-7 for the 11 bins is as follows: Bins 1 to 3 are calcium chloride; Bins 4 and 5 are sulfate; and Bins 6 to 11 are carbonate.

Calcium Chloride Brines - Corrosion test solutions corresponding to this calcium chloride type of brine include: calcium chloride, calcium chloride plus calcium nitrate, the simulated saturated water (Table 6.13-8), and sodium chloride aqueous solutions. The SSW and sodium chloride test solutions simulate the moderate relative humidity scenario where calcium is a minor component in the aqueous solution. Numerous electrochemical studies were performed in these test solutions. Thin film studies were also performed using these types of solutions on coupons of Alloy 22 using an environmental thermogravimetric analyzer.

These brines may have acidic to near-neutral $\mathrm{pH}$ and no significant bicarbonate, carbonate, fluoride, or sulfate content. These brines may contain other cations such as $\mathrm{Na}^{+}, \mathrm{K}^{+}$, and $\mathrm{Mg}^{2+}$ and other anions such as $\mathrm{NO}_{3}{ }^{-}$. The endpoint of the evaporative concentration of this type of brine would contain $\mathrm{Ca}-\mathrm{Cl} / \mathrm{NO}_{3}$ or a mixture of $\mathrm{Ca} / \mathrm{Mg}-\mathrm{Cl} / \mathrm{NO}_{3}$. The quantity of $\mathrm{Mg}^{2+}$ and $\mathrm{Ca}^{2+}$ in this type of brine would be limited due to the precipitation of calcium carbonates and sulfates and magnesium silicates. This is consistent with information on saline lakes where $\mathrm{Na}^{+}$is the dominant cation with the percentage of $\mathrm{Ca}^{2+}$ varying from insignificant to about $20 \%$ (Drever 1997 [DIRS 147480]). In the repository, the concentration of $\mathrm{Mg}^{2+}$ in any type of brine is expected to be insignificant. Thus, a magnesium chloride brine is not expected. $\mathrm{NO}_{3}{ }^{-}$is expected to be present, and an end-point brine of this type is likely to be dominated by calcium chloride and calcium nitrate. A brine of the calcium chloride type is expected to have a very limited occurrence in the repository, as indicated in Table 6.13-10.

Relative humidity dependence of the calcium chloride brine is as follows. At low relative humidity, the aqueous solutions will be dominated by $\mathrm{Ca}^{2+}$ cations (very low sodium and potassium), and $\mathrm{Cl}^{-}$and $\mathrm{NO}_{3}{ }^{-}$anions, since both calcium nitrate and calcium chloride are very soluble. At higher relative humidity, chloride and nitrate salts of sodium and potassium become soluble and could dominate the aqueous solution compositions. This would occur at or above the deliquescence relative humidity for salts composed of these ions. 
Carbonate Brines-These brines are alkaline and do not contain significant calcium or magnesium. In the early stages of the evaporative concentration, calcium precipitates predominately as carbonate minerals (calcite or aragonite). Magnesium precipitates as a component in magnesium silicate (BSC 2004 [DIRS 161237], Section 6.7.2.11). In the repository, it is expected that magnesium will be removed efficiently, and potassium may be significant in some of these brines. As shown in Table 6.13-10, the carbonate brine is expected to be the most common type produced by evaporation of seepage waters.

Relative humidity dependence of carbonate brine is as follows. At low relative humidity, the aqueous solutions will be dominated by $\mathrm{Cl}^{-}$and $\mathrm{NO}_{3}{ }^{-}$anions with $\mathrm{NO}_{3}{ }^{-}$ions dominating at the lowest relative humidity. At moderate relative humidity (greater than $70 \%$ relative humidity), $\mathrm{Cl}^{-}$could dominate the solution composition. The $\mathrm{Cl}^{-}-\mathrm{NO}_{3}{ }^{-}$solutions are expected to have slightly elevated $\mathrm{pH}$ due to residual carbonate in solution. Significant amounts of carbonate and $\mathrm{SO}_{4}{ }^{2-}$ are not expected until the relative humidity is greater than $85 \%$.

Corrosion test solutions corresponding to the carbonate type of brine include: the SDW, SCW, BSW, and under certain circumstances SSW and SAW aqueous test solutions (Table 6.13-8). The BSW test solution is a highly concentrated alkaline solution and could be expected under repository conditions where temperatures could be at its measured boiling point (nominally $112^{\circ} \mathrm{C}$ to $113^{\circ} \mathrm{C}$ ) or where the relative humidity is nominally 70 to $75 \%$. The SCW test solution is a moderately concentrated alkaline solution; solutions in this concentration range could be expected to form for relative humidity in the range of 90 to $95 \%$. The SDW test solution is a dilute alkaline solution; solutions in this concentration range could be expected to form for high relative humidity (greater than 99\%). These may have characteristics of solutions at the drift wall, that is, typical of seepage waters.

Under conditions of extreme evaporative concentration (i.e., low relative humidity) the carbonate brine would evolve into a $\mathrm{Cl}^{-}-\mathrm{NO}_{3}{ }^{-}$brine with low carbonate content. The SSW test solution has characteristics of this type of brine. Likewise the SAW test solution has characteristics of low carbonate brine and would have characteristics of solutions in equilibrium with relative humidity of nominally $90 \%$. The calcium and magnesium content of the SAW test solution tends to make it more able to sustain lower $\mathrm{pH}$ values due to the hydrolysis properties of these cations.

Sulfate Brines-These have near-neutral $\mathrm{pH}$ and no significant carbonate or calcium content. Calcium precipitates as carbonates and possibly sulfates. In addition, brines typically have only a small amount of magnesium, though some surface brines have been observed to have high magnesium (Drever 1997 [DIRS 147480], Table 15-1, p. 333, brines 1 to 3). The dominant cation is typically $\mathrm{Na}^{+}$. In the repository brines, $\mathrm{K}^{+}$may be more significant than $\mathrm{Na}^{+}$, and $\mathrm{Mg}^{2+}$ is expected to be insignificant. As shown in Table 6.13-10, the sulfate-brine type is expected to be a minor type produced by evaporation of seepage waters.

Relative humidity dependence of the sulfate brine is as follows. At low relative humidity, the aqueous solutions will be dominated by $\mathrm{Cl}^{-}$and $\mathrm{NO}_{3}{ }^{-}$anions, with $\mathrm{NO}_{3}{ }^{-}$ions dominating at the lowest relative humidity. At moderate relative humidity $(>70 \% \mathrm{RH}) \mathrm{Cl}^{-}$ions could dominate the solution composition. However, unlike the carbonate brines, these brines are expected to have near neutral to slightly acidic $\mathrm{pH}$ because of the lack of a carbonate component. Significant 
amounts of carbonate and $\mathrm{SO}_{4}{ }^{2-}$ are not expected until the relative humidity is greater than $85 \%$ because of the increase in solubility of expected sulfate minerals (sodium and potassium sulfates). (Magnesium sulfate is expected to be present in only insignificant quantities in these repository brines.)

The corrosion test solutions corresponding to the sulfate type of brine include the SAW, SSW, and sodium chloride. This type of brine has near neutral to slightly acidic $\mathrm{pH}$, and as noted above magnesium is not expected to be present in seepage waters to any significant extent. The SAW test solutions have characteristics of solutions in equilibrium with nominally $90 \%$ relative humidity. The SSW has characteristics of water that have undergone evaporative concentration to the extent that sulfate precipitates out of solution (this is for the magnesium free situation). Sodium chloride test solutions simulate the scenario where $\mathrm{Cl}^{-}$is the dominant anion under moderate relative humidity conditions.

\subsubsection{Transport-Affected Salt Assemblages}

The environment on the surface of the drip shield or waste package is subject to thermal-hydrologic conditions that may involve splashing. The surface may be covered with dust and debris on the surface, and may have dents or depressions caused by rockfall. In addition, crevices may form as stress corrosion cracks or where debris contacts the surface, and these may harbor stagnant liquid or immobilized solid phases. Over the long term, the surface of the drip shield and the waste package (depending on local seepage and possible drip shield damage) is subject to cumulative evaporation amounting to hundreds to thousands of liters per waste package.

Interaction of evaporated seepage water with the surfaces of the drip shields or exposed waste packages may produce mineral precipitates because the surface temperature is greater than that of the host rock resulting in a lower local relative humidity. The most volumetrically important of these precipitates are calcite, anhydrite, and forms of silica (Section 6.13). The effect of these processes on the chemical environment for corrosion is the possible accumulation of separated salts as well as inert products that affect hydraulics and chemical heterogeneity (Hall and Walton 2003 [DIRS 170586]). The effects of relatively inert scale (e.g., silica or calcite) are included in the measured data used to develop the corrosion models (BSC 2004 [DIRS 169984], Sections 1.2 and 6.4.4.2); however, the effects from separation of potentially aggressive species such as chloride are addressed explicitly in the seepage evaporation abstraction.

Soluble salts containing chloride may precipitate along flow pathways if the temperature and humidity conditions (e.g., on the drip shield or waste package) are sufficiently different from the conditions at the drift wall. If transport of the residual liquid phase occurs, the chloride-bearing precipitates are separated from the other chemical components of seepage, such as nitrate. The process could be enhanced by the presence of precipitates such as silica or calcite, which could cause ponding or channeling. Dents caused by rockfall or resulting from seismic shaking could cause similar effects on flow. Although this situation may be rare, it is incorporated in the seepage evaporation abstraction model used for TSPA in relation to the potential for localized corrosion of the waste package outer barrier. The drip shield titanium material is not susceptible to localized corrosion under in-drift environmental conditions (BSC 2004 [DIRS 169845], Section 6.3.3). 
Halite Separation-The first mineral to alter chloride during evaporation of the seepage evaporation abstraction bin waters is halite $(\mathrm{NaCl})$. The most cautious approach for modeling deleterious chloride separation is to consider at what point halite begins to precipitate, ignoring the concurrent transport issues. Examination of the evaporated seepage water lookup tables (Output DTN: MO0304SPACSALT.000, Evap_Look-up-Tables.zip) shows in Figure 6.13-32 a range of relative humidity values dependent upon temperature and $p \mathrm{CO}_{2}$. These bin- and condition-dependent values may be used in TSPA-LA to implement this salt separation effect.

For implementation in TSPA-LA, a single cutoff value may be desirable. For this, a bounding value has been determined from examination of two sources of halite precipitation relative humidity at various temperatures. These sources were DTN: LL031106231032.007 ([DIRS 170605], ExptDRHCalcsKracekRev00c.xls), covering $20^{\circ} \mathrm{C}$ to $110^{\circ} \mathrm{C}$, and the article "Humidity Fixed Points of Binary Saturated Aqueous Solutions" (Greenspan 1977 [DIRS 104945], Table 2), covering $20^{\circ} \mathrm{C}$ to $80^{\circ} \mathrm{C}$. The highest relative humidity of these results comes from the report by Greenspan (1977 [DIRS 104945]) at $80^{\circ} \mathrm{C}$ with $76.29( \pm 0.65)$ percent. Given the slight uncertainty on this value, it has been rounded upwards to $77 \% \mathrm{RH}$. For the complete data sets see Output DTN: SN0403T0503404.001. Note that the single-value threshold relative humidity is higher than any value predicted for precipitation of sodium chloride in any of the seepage bins and is a bounding upper limit as determined by pure sodium chloride salt deliquescence experiments.

Therefore, when seepage occurs directly on waste packages and the relative humidity on the waste package surface is less than either the $77 \%$ single cutoff or the condition-dependent RH values, separation of sodium chloride precipitate is allowed to occur. While this halite separation is able to occur, the nitrate concentration should be set to a low value and then the potential for localized corrosion may be evaluated.

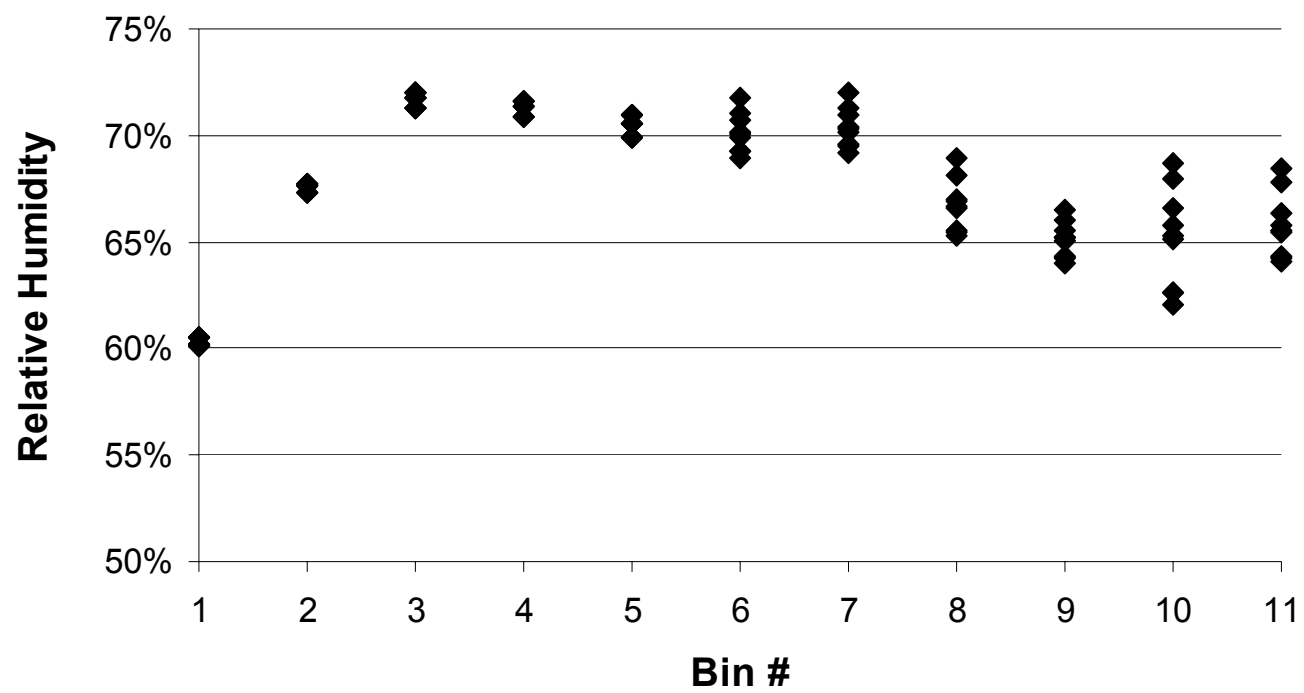

Source: Output DTN: SN0403T0510102.001.

NOTE: Each bin shows data at nine points for all three temperatures $\left(40^{\circ} \mathrm{C}, 70^{\circ} \mathrm{C}, 100^{\circ} \mathrm{C}\right)$ and $p \mathrm{CO}_{2}\left(10^{-4}, 10^{-3}\right.$, and $10^{-4}$ bar).

Figure 6.13-32. Relative Humidity at Initial Precipitation of Halite in Median Bin Waters 


\subsection{EVALUATION OF FEATURES, EVENTS, AND PROCESSES}

Table 2 of the technical work plan (BSC 2005 [DIRS 173782]), lists the features, events, and processes (FEPs) related to the EBS physical and chemical environment as contained within the LA FEP list (DTN: MO0501SEPFEPLA.001 [DIRS 172601]). A deviation from the table of included FEPs presented in the TWP is discussed at the end of Section 1.1. The FEPs that are considered included in TSPA-LA through this in-drift physical and chemical model are listed in Table 6.14-1.

In addition to the EBS FEPs listed here, several other FEPs that are explicitly incorporated in Post-Processing Analysis for THC Seepage (BSC 2004 [DIRS 169858], Table 6.1-1) are implicitly included in this analysis as part of model input (water and gas compositions) or boundary conditions. However, these additional FEPs are adequately addressed in Post-Processing Analysis for THC Seepage (BSC 2004 [DIRS 169858]) and are not repeated here.

FEPs excluded using arguments documented in Engineered Barrier System Features, Events, and Processes (BSC 2005 [DIRS 175014]) are not specifically addressed in this report, although it may provide supporting analyses. 
Table 6.14-1. Included Features, Events, and Processes Addressed in This Report

\begin{tabular}{|c|c|c|c|}
\hline FEP Number & LA FEP Title & Description & $\begin{array}{l}\text { Section(s) Where } \\
\text { Addressed }\end{array}$ \\
\hline 2.1.08.06.0A & $\begin{array}{l}\text { Capillary Effects (Wicking) in } \\
\text { EBS }\end{array}$ & $\begin{array}{l}\text { Capillary rise, or wicking, is a potential mechanism for water to move through the waste } \\
\text { and EBS. }\end{array}$ & $1,6.9,6.13 .5$ \\
\hline 2.1.08.07.0A & Unsaturated flow in the EBS & $\begin{array}{l}\text { Unsaturated flow may occur along preferential pathways in the waste and EBS. Physical } \\
\text { and chemical properties of the EBS and waste form, in both intact and degraded states, } \\
\text { should be considered in evaluating pathways. }\end{array}$ & $6.6,6.9,6.13$ \\
\hline 2.1.09.01.0A & $\begin{array}{l}\text { Chemical characteristics of } \\
\text { water in drifts }\end{array}$ & $\begin{array}{l}\text { When flow in the drifts is reestablished following the peak thermal period, water may have } \\
\text { chemical characteristics influenced by the near-field host rock and EBS. Specifically, the } \\
\text { water chemistry (pH and dissolved species in the groundwater) may be affected by } \\
\text { interactions with cementitious materials or steel used in the disposal region. These point } \\
\text { source contaminated waters may coalesce to form a larger volume of contaminated } \\
\text { water. This altered groundwater is referred to as the carrier plume because dissolution } \\
\text { and transport will occur in this altered chemical environment as contaminants move } \\
\text { through the EBS, and down into the unsaturated zone. }\end{array}$ & $\begin{array}{l}6.4,6.6,6.7,6.8 \\
6.9,6.12,6.13\end{array}$ \\
\hline $2.1 .09 .02 .0 \mathrm{~A}$ & $\begin{array}{l}\text { Chemical interaction with } \\
\text { corrosion products }\end{array}$ & $\begin{array}{l}\text { Corrosion products produced during degradation of the waste form, metallic portions of } \\
\text { the waste package, and metals in the drift (rock bolts, steel in invert, gantry rails) may } \\
\text { affect the mobilization and transport of radionuclides. Corrosion products may facilitate } \\
\text { sorption/desorption and coprecipitation/dissolution processes. Corrosion products may } \\
\text { form a "rind" around the fuel that could (1) restrict the availability of water for dissolution of } \\
\text { radionuclides or (2) inhibit advective or diffusive transport of water and radionuclides from } \\
\text { the waste form to the EBS. Corrosion products also have the potential to retard the } \\
\text { transport of radionuclides to the EBS. Finally, corrosion products may alter the local } \\
\text { chemistry, possibly enhancing dissolution rates for specific waste forms, or altering } \\
\text { radionuclide solubility. }\end{array}$ & $6.7 .1,6.8$ \\
\hline 2.1.09.06.0B & $\begin{array}{l}\text { Reduction-Oxidation } \\
\text { potential in Drifts }\end{array}$ & $\begin{array}{l}\text { The redox potential in the EBS influences the oxidation of the in-drift materials and the in- } \\
\text { drift solubility of radionuclide species. Local variations in the in-drift redox potential can } \\
\text { occur. }\end{array}$ & 6.7 .1 \\
\hline 2.1.09.07.0B & Reaction kinetics in Drifts & $\begin{array}{l}\text { Chemical reactions, such as radionuclide dissolution/precipitation reactions and reactions } \\
\text { controlling the reduction-oxidation state, may not be at equilibrium in the drifts. }\end{array}$ & $\begin{array}{l}6.5,6.6,6.7,6.8 \\
6.9,6.13\end{array}$ \\
\hline 2.1.11.08.0A & $\begin{array}{l}\text { Thermal effects on } \\
\text { chemistry and microbial } \\
\text { activity in the EBS }\end{array}$ & $\begin{array}{l}\text { Temperature changes may affect chemical and microbial processes in the waste and } \\
\text { EBS. }\end{array}$ & $6.4,6.7,6.9$ \\
\hline 2.2.08.04.0A & $\begin{array}{l}\text { Redissolution of precipitates } \\
\text { directs more corrosive fluids } \\
\text { to waste packages }\end{array}$ & $\begin{array}{l}\text { Redissolution of precipitates which have plugged pores as a result of evaporation of } \\
\text { groundwater in the dry-out zone, produces a pulse of fluid reaching the waste packages } \\
\text { when gravity-driven flow resumes, which is more corrosive than the original fluid in the } \\
\text { rock }\end{array}$ & $6.6,6.9,6.13$ \\
\hline
\end{tabular}

\footnotetext{
a There is no defining limit as to what volume of contaminated water constitutes a plume.
} 
FEP 2.1.08.07.0A, Unsaturated flow in the EBS, is considered as included in TSPA-LA from this report because this report contributes the chemistry resulting from differing flow pathways (i.e., either as crown seepage or as capillary or wicking effect).

FEP 2.1.09.02.0A, Chemical interaction with corrosion products, is considered as included in TSPA-LA through the oxygen balance analysis, where in-drift gas composition calculations (Section 6.7.1) are used to evaluate oxygen consumption due to metal degradation in the drift. This determination sets the oxidizing environment used to generate the in-drift seepage chemistry. Additionally, the analysis of the effect of stainless steel ground support (Section 6.8) on seepage chemistry found it to be insignificant, so it was not considered further for the modeling of in-drift chemistry.

FEP 2.2.08.04.0A, Redissolution of precipitates directs more corrosive fluids to waste packages, is considered as included in TSPA-LA from this report. Though this process is explicitly part of the THC seepage model, the results of it are directly fed as input to this model report and are incorporated in the results given to TSPA. If any re-dissolution of precipitates creates more corrosive fluids in the THC seepage model, then a bin chemistry representing that fluid will be called for in the bin history (Figure 6.13-1).

\subsection{IMPLEMENTATION INSTRUCTIONS FOR THE TSPA-LA MODEL}

This section describes how the chemistry and, more specifically, the lookup tables developed in Sections 6.6, 6.7 and 6.9, and uncertainty instructions developed in Sections 6.12, are to be implemented in the TSPA-LA. This section provides roadmap figures for implementation of the lookup tables established in this report for the parameters of interest on the waste package surface and within the invert, during the development of the TSPA-LA model. Although the processes used to ascertain these parameters for the two locations are similar, the resulting chemical environments are different.

A general rule that applies to the seepage scenarios discussed in the following subsection is that once a starting water is selected (i.e., w0, w4, w5, w6, or w7; Section 4.1.3), the associated $p \mathrm{CO}_{2}$ gas lookup tables for that given water should also be selected for that given realization (Section 6.7.2.1). The TSPA-LA model should not select these two tables independently. This also means that the $\mathrm{pCO}_{2}$ lookup table applied in the drift for waste package chemistry should be from the same starting water (e.g., w0, w4, etc.) as the selected unevaporated crown seepage water entering the invert. In addition, the gas applied in the invert should be associated with the same starting water that is specified to select the gas in the drift. The only time that this rule does not apply is where no seepage is present, and in that case, any of the five $p \mathrm{CO}_{2}$ lookup tables can be randomly selected for any given waste package for invert chemistry.

\subsubsection{Implementation of Engineered Barrier System Chemistry on Waste Package Surfaces: Seepage or "Dripping Scenario"}

Only one scenario is envisioned for the TSPA-LA use of the chemical parameters from the lookup tables on the waste package surface:

- When crown seepage is directly dripping onto the drip shields and waste packages. 
This scenario, in which crown seepage drips directly onto the waste package or drip shield surface, is modeled in the TSPA-LA by using the roadmap given in Figure 6.15-1 and described further here.

For each TSPA LA realization, in order to represent the uncertainty of which THC seepage water enters the drift, the starting water (w0, w4, w5, w6, and w7; Section 4.1.3) must be randomly selected. All five of these waters have an equal probability of selection for any given TSPA-LA realization. Therefore, the probability of any given water being selected is 20\% (Output DTN: MO0505SEPSEEPA.000).

Once the starting water is selected, the corresponding "bin history map" tables and associated $p \mathrm{CO}_{2}$ lookup tables are selected. This map gives the bin history across time for that particular starting water (see Section 6.6 for the development of these maps). These "bin history map" tables are archived in Output DTN: MO0508SPAEBSCB.001 and are provided in Tables 6.6-9 through 6.6-13. The $\mathrm{pCO}_{2}$ lookup tables are provided in Tables 6.7-1 through 6.7-5 and are archived in Output DTN: SN0503T0510102.019. Each bin history map table and $p \mathrm{CO}_{2}$ lookup table is unique to the particular starting water.

Next, for any given TSPA-LA model time step, the appropriate evaporated seepage water bin (Table 6.9-8 provides file names of lookup tables) and $\mathrm{pCO}_{2}$ are determined (in the bin history map table, use the column labeled "Bin for Crown Seepage," and in each $p \mathrm{CO}_{2}$ lookup table, use the column labeled "Drift"). Concurrently, temperature and relative humidity values for the same time step are obtained from other process model lookup tables.

The selected in-drift relative humidity value is used to determine whether the evaporation or dilution lookup tables are used. The dilution lookup tables are used if the selected relative humidity is greater than the relative humidity boundary condition values found in Table 6.9-9. In all other cases, the evaporative lookup tables are used. Table 6.9-8 lists the files that are part of Output DTN: MO0304SPACSALT.000, along with the 99 lookup tables for evaporative conditions and 99 lookup tables for dilute conditions. This DTN has been modified slightly for use in the TSPA-LA model (Section 8.2.1), resulting in Output DTN: MO0310SPAPCEGS.000. If the relative humidity is lower than the lowest value in a lookup table, then that lowest $\mathrm{RH}$ information is utilized.

The lookup table file nomenclature is ??c\#t\%\$.xls.xls where:

- "??" is the two-digit bin number $(01,02,03$, etc.)

- "\#” is 2,3 , or 4 for pressure of $\mathrm{CO}_{2}$ (c) equal to $10^{-2}, 10^{-3}$, or $10^{-4}$ bar, respectively

- " $\% "$ is 4,7 , or 1 for temperature $(\mathrm{t})$ equal to $40^{\circ} \mathrm{C}, 70^{\circ} \mathrm{C}$, or $100^{\circ} \mathrm{C}$, respectively

- " $\$$ " is e or c for evaporation or dilution.

The chemistries from the lookup tables are shown in Section 6.9.5 and in Appendix B. 


\section{Waste Package/Drip Shield Surface "Dripping Scenario"}

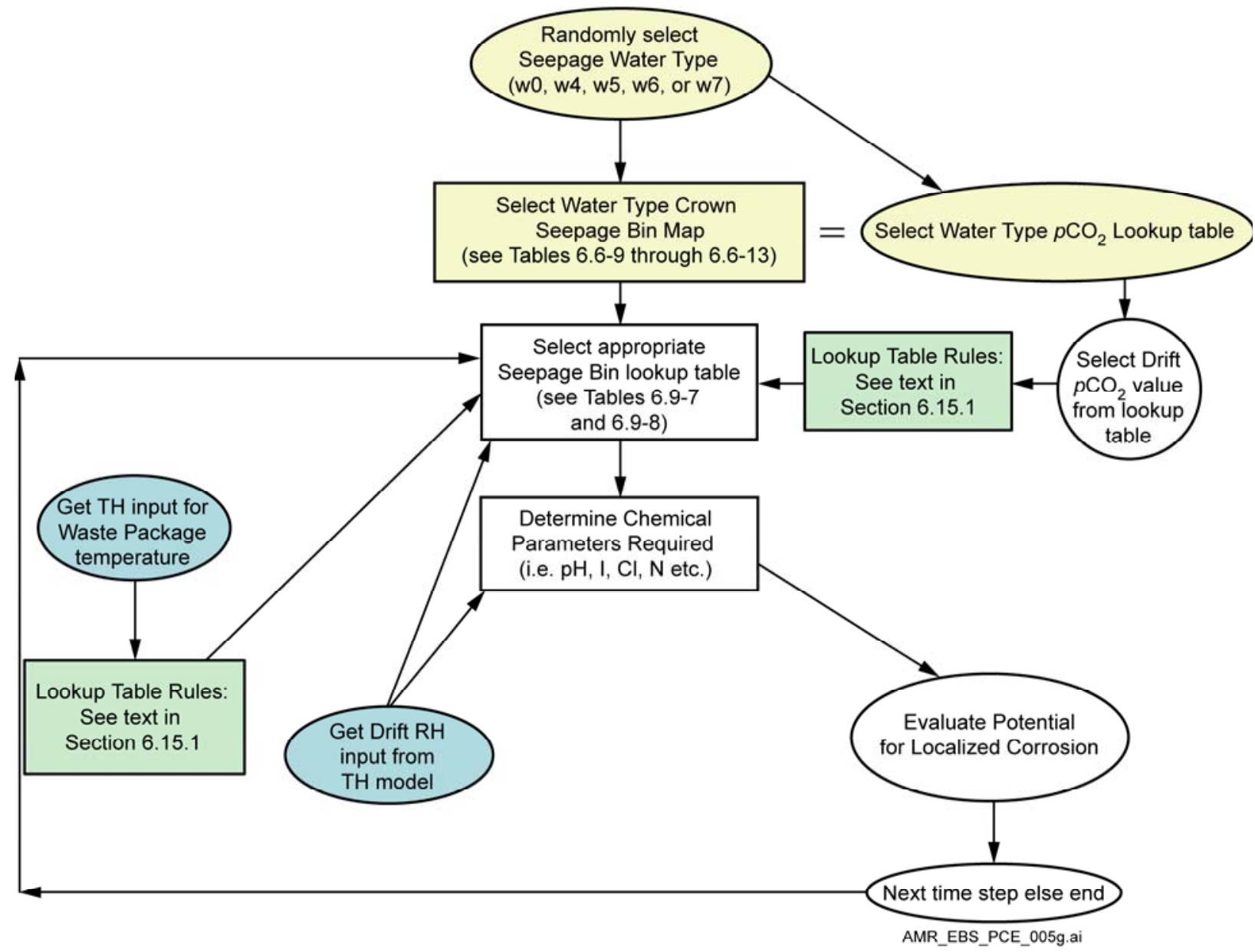

NOTE: $\quad \mathrm{TH}=$ thermal-hydrologic; $\mathrm{WP}=$ waste package. The equal sign indicates that the bin map and $p \mathrm{CO}_{2}$ lookup table have to be associated with the same seepage water type (w0, w4, w5, w6, or w7).

Figure 6.15-1. Roadmap for TSPA-LA Implementation of Engineered Barrier System Chemistry on the Waste Package Surface under the "Dripping Scenario"

To select the appropriate chemistry from a selected lookup table, the nearest drift relative humidity value row is used. When selecting chemical parameters that fall between lookup tables, the parameters should be estimated using linear interpolation on temperature and $\log$ linear for $\mathrm{pCO}_{2}$ parameters. Chemistry values should be extrapolated for $\mathrm{pH}, \mathrm{I}, \mathrm{Cl}^{-}$, and $\mathrm{NO}_{3}{ }^{-}$if the $p \mathrm{CO}_{2}$ exceeds the range of $10^{-4}$ to $10^{-2}$ bar, established in the lookup tables (up to $2 \times 10^{-2}$ and down to $1 \times 10^{-5}$ bar). This is based on the uncertainty results documented in Section 6.12.4.3. For temperatures above $100^{\circ} \mathrm{C}$ and below $40^{\circ} \mathrm{C}$, interpolation cannot be used and values should be extrapolated as the $100^{\circ} \mathrm{C}$ or $40^{\circ} \mathrm{C}$ lookup tables, respectively. Discussion of temperature values to justify this is found in Section 6.7.3. If the $\mathrm{RH}$ is greater than the highest value in the lookup tables, use the highest value; if the RH is lower than the lowest value in the lookup tables, use the lowest value. Additional discussion of the use of interpolation is included in Section 6.13.2. Implementation of uncertainty on any parameter should be done in accordance with the instructions found in Section 6.12.5. 
Nonconvergence-The EQ3/6 calculation runs used to produce the seepage lookup tables did not always converge on the eutectic point associated with the deliquescence or dryout RH value for very low water to solute ratios (at low RH values). An appropriately conservative method to deal with this limitation is to specify that aqueous conditions exist at all times when seepage is occurring, regardless of the in-drift RH. For TSPA-LA purposes, the selection of chemical parameters below the lowest $\mathrm{RH}$ in the lookup tables can be done as described in next paragraph, because the chemistries are conservative with respect to $\mathrm{NO}_{3}{ }^{-}$(i.e., $\mathrm{NO}_{3}{ }^{-}$should only increase with respect to $\mathrm{Cl}^{-}$with decreasing $\mathrm{RH}$ due to the presence of the halite chemical divide). The basis for this modeling decision is illustrated in Figure 6.13-19, where at low $\mathrm{RH}$ the $\mathrm{NO}_{3}{ }^{-}$ concentration climbs in comparison to the $\mathrm{Cl}^{-}$ion concentration, indicating that no matter where the DRH is predicted for the seepage, nitrate will continue to dominate the brine chemistry. The exception to this general rule is bin 1 , where $\mathrm{Ca}\left(\mathrm{NO}_{3}\right)_{2}$ is precipitating and $\mathrm{NO}_{3}{ }^{-}$is being removed from the aqueous system. This occurs around a relative humidity of $20 \%$. However, at lower $\mathrm{RH}$ values, the $\mathrm{Cl}^{-} / \mathrm{NO}_{3}{ }^{-}$ratio remains relatively constant because of the continued precipitation of halite, and the lowest value taken from the lookup table will result in a conservative estimate of the $\mathrm{Cl}^{-} / \mathrm{NO}_{3}{ }^{-}$ratio.

Implementation at or Below the Lowest Relative Humidity Point for Seepage-The TSPA-LA seepage evaporation lookup tables approach, but do not always predict the deliquescence or dryout RH point (see previous paragraph). When seepage chemistry is to be predicted, the conservative modeling decision of always having aqueous conditions present should be made regardless of RH. Therefore, if the feed RH falls below the last RH point in the particular seepage lookup table, the chemistry at that last (lowest RH) point, then the composition for the last value is used.

Salt Separation-As indicated in Section 6.13.6, if the relative humidity on a waste package undergoing seepage should fall below either the $77 \%$ single cutoff or the condition-dependent $\mathrm{RH}$ values, halite salt separation is presumed to occur.

\subsubsection{Implementation of Engineered Barrier System Chemistry in the Invert}

The following instructions are imposed to ensure that the appropriate parameters are selected for lookup tables (crown seepage or invert wicking) that may be used in the invert cell of the TSPA-LA model.

For each TSPA-LA realization, one of the five starting THC seepage waters (w0, w4, w5, w6, | and w7) must be selected randomly. All starting waters are equally probable, and thus the probability of any given water being selected is 20\% (Output DTN: MO0505SEPSEEPA.000).

Once the starting water is selected, the "bin history map" (crown seepage and invert) and $p \mathrm{CO}_{2}$ lookup tables (invert only) are used. There are two separate history maps, one for crown seepage and one for invert wicking (imbibition) water. These "bin history maps" are archived in Output DTN: MO0508SPAEBSCB.001 and can be found in Tables 6.6-9 through 6.6-13. The next set of lookup tables used are the $p \mathrm{CO}_{2}$ lookup tables. The invert $p \mathrm{CO}_{2}$ lookup tables are archived in Output DTN: SN0503T0510102.019 and can be found in Tables 6.7-1 through 6.7-5. Whether the incoming water originates in the crown as seepage or from invert wicking (imbibition), all evaluations of invert chemistry should apply interpolated values from the invert $\mathrm{pCO}_{2}$ tables to 
select appropriate chemical values. The drift $p \mathrm{CO}_{2}$ tables should not be used in the invert. Each bin history map table and $p \mathrm{CO}_{2}$ lookup table is unique to a particular starting water.

The usage of the invert wicking (imbibition) chemistry is applied in the invert if the imbibition rate exceeds the seepage plus condensation rate. Otherwise, the crown seepage chemistry is applied to the invert. If there is advective flow through the waste package, then TSPA will determine whether or not to use the chemistry from In-Package Chemistry Abstraction (BSC 2005 [DIRS 174583]).

Next, for any given TSPA-LA model time step, the appropriate water bin (Table 6.9-8 provides file names of lookup tables) and $\mathrm{pCO}_{2}$ are to be selected. In addition, temperature and relative humidity input for the same time step, which is available from other process models lookup tables, must be selected.

As with crown seepage, if the relative humidity is lower than the lowest value in a lookup table, then that lowest RH information is utilized. In contrast to crown seepage, if the relative humidity exceeds the highest value in the evaporation lookup table the dilution tables are not utilized (Section 6.9.3). Rather, the chemistry that exists at that highest relative humidity available in the evaporation table is used for any greater relative humidity conditions. The same evaporation tables as used for crown seepage are in Output DTN: MO0304SPACSALT.000, along with the 99 lookup tables for evaporative conditions. This DTN has been modified slightly for TSPA-LA use (see Section 8.2.1 for discussion) resulting in a DTN for use in the TSPA-LA model archived in Output DTN: MO0310SPAPCEGS.000.

The lookup table file nomenclature is ??c\#t\%e.xls.xls where:

- "??" is the two-digit bin number $(01,02,03$, etc. $)$

- "\#” is 2,3 , or 4 for pressure of $\mathrm{CO}_{2}$ equal to $10^{-2}, 10^{-3}$, or $10^{-4}$ bar, respectively

- " $\%$ " is 4,7 , or 1 for temperature equal to $40^{\circ} \mathrm{C}, 70^{\circ} \mathrm{C}$, or $100^{\circ} \mathrm{C}$, respectively.

The chemistries from the evaporation lookup tables are shown briefly in Section 6.9 .5 and in Appendix B.

To select the appropriate chemistry from a lookup table, the nearest invert relative humidity value row is used. When selecting chemical parameters that fall between lookup tables, the parameters can be estimated using linear interpolation on temperature and log linear interpolation on $\mathrm{pCO}_{2}$ parameters. Chemistry values can be extrapolated for $\mathrm{pH}, \mathrm{I}, \mathrm{Cl}^{-}$, and $\mathrm{NO}_{3}{ }^{-}$if the $p \mathrm{CO}_{2}$ exceeds the range of $10^{-4}$ to $10^{-2}$ established in the lookup tables (up to $2 \times 10^{-2}$ and down to $1 \times 10^{-5}$ bar). This is based on the analysis documented in Section 6.12.4.3. For temperatures above $100^{\circ} \mathrm{C}$ and below $40^{\circ} \mathrm{C}$, no interpolation is allowed and values should be extrapolated directly as the $100^{\circ} \mathrm{C}$ or $40^{\circ} \mathrm{C}$ lookup tables. If the $\mathrm{RH}$ is greater than the highest value in the evaporation lookup tables, use that highest value and do not use the dilution tables (Section 6.9.3). Additional seepage evaporation abstraction interpolation is discussed in Section 6.13.2 and validated in Section 7.1.1. Implementation of uncertainty on any parameter should be done in accordance with the instructions found in Section 6.12.5. 
Implementation at or Below the Lowest Relative Humidity Point for Seepage-The TSPA-LA seepage evaporation lookup tables approach, but do not always predict, the deliquescence RH point. When seepage chemistry is to be predicted, the conservative modeling decision of always having aqueous conditions present should be made regardless of $\mathrm{RH}$. Therefore, if the feed RH falls below the last RH point in the particular seepage lookup table, the chemistry at that last (lowest RH) point, then the composition for the last value is used. 


\section{INTENTIONALLY LEFT BLANK}




\section{VALIDATION}

This section summarizes the validation of the two in-drift environment abstraction models detailed in Sections 6.7 (gas) and 6.9 (seepage evaporation), and provides additional supporting analyses and information. Section 7.1 describes validation of the in-drift seepage evaporation abstraction, and Section 7.2 describes validation of the in-drift gas abstraction. Section 7.3 provides supplementary information, including a supporting analysis that is not considered model validation, and other analyses performed during development of the seepage evaporation abstraction.

Section 7.1.1 documents the post-development validation of the seepage evaporation abstraction. This consists of a comparison between output from the in-drift precipitates/salts (IDPS) process model and the seepage evaporation abstraction by implementing the interpolation discussed in Sections 6.9, 6.13.2, and 6.15.1. The validation is performed consistent with Level II, for a model of moderate importance to repository system performance, as directed by LP-2.29Q-BSC, Planning for Science Activities, Attachment 3, Section 2.2.2.2. The validation criteria state that the interpolation results are to be within the bounds of the uncertainty range of the IDPS model output. This criterion for adequacy is in accord with the technical work plan (BSC 2005 [DIRS 173782], Section 2.2.2.4), which calls for use of Method 6 (Section 5.3.2(c) of LP-SIII.10Q-BSC):

Meeting Validation Criteria for Post-Development Method 6: Corroboration of abstraction model results to the results of the validated mathematical model(s) from which the abstraction model was derived.

Section 7.2.1 documents the basis for validity of the oxygen fugacity condition selected for the gas abstraction. Section 7.2.2 documents the post-development validation of the gas abstraction model for carbon dioxide by comparison with a more detailed thermal-hydrologic-chemical (THC) reactive transport seepage process model. The validation is performed consistent with Level II, for a model of moderate importance to repository system performance (LP-2.29Q-BSC, Attachment 3, Section 2.2.2.2). The validation criteria state that the interpolation results are to be within a factor of two of the THC model output. This ensures that the abstraction described in Section 6.7.2 represents the original THC model results with sufficient accuracy for modeling carbonate equilibria. This criterion for adequacy is in accord with the technical work plan (BSC 2005 [DIRS 173782], Section 2.2.2.4), which calls for use of Method 6 (Section 5.3.2(c) of LP-SIII.10Q-BSC).

Section 7.3.1 examines a set of pore water chemical analyses from the repository host-rock units to see how they "bin" in comparison with the five starting waters that are the input boundary conditions for the seepage evaporation abstraction. Section 7.3.2 evaluates the evaporated seepage water compositional uncertainty values, focusing on the binning process and its variability (Table 6.12-4), across a range of water activity. Section 7.3.3 contributes to confidence in the IDPS process model by performing a comparison to published data for evaporation of mountain spring water to concentrated alkaline brine. Section 7.3.4 compares the compositions of potential seepage waters calculated by the THC reactive transport seepage process model, with the results of the binning analysis, to evaluate the binning analysis described in Section 6.6. 
No further validation activities are required in accordance with the technical work plan (BSC 2005 [DIRS 173782], Section 2.2.2). The during- and post-development validation activities described below provide sufficient confidence that the models are valid for their intended uses, and that the associated uncertainties are propagated into the total system performance assessment (TSPA).

\subsection{IN-DRIFT SEEPAGE EVAPORATION ABSTRACTION}

Confidence building performed during the development of the models is documented in accordance with the requirements of Section 5.3.2(b) of LP-SIII.10Q-BSC. This confidence building includes the following:

Selection of input parameters and/or input data, and a discussion of how the selection process builds confidence in the model. [Section 5.3.2.(b)(1)]

- Discussion of the input parameters for the seepage evaporation abstraction and the bases for their selection is provided in Section 4.1. For the seepage evaporation abstraction, the rationale for equilibrium modeling, and for including or excluding precipitating minerals and trace elements, is documented in a technically defensible manner (Section 6.5).

- The rationale for equilibrium modeling is documented in Sections 6.5.3 and 6.5.4, which provide background discussion, and 6.5.4.1, which specifies explicit criteria used for selecting minerals for inclusion or exclusion, including criteria based on kinetics.

- Mineral suppressions (i.e., including or excluding precipitating minerals) are documented in Section 6.12.4.4, which specifically evaluates the effects of the minerals cryolite, glaserite, and magnesite on the results of the abstractions. The resulting shifts in output are well within the model uncertainties associated with the IDPS model (changes less than one order of magnitude).

- The framework for evaluation of certain trace elements is documented in Section 6.5.4.2. Analysis of bromide (Section 6.12.4.2) shows that inclusion of bromide in the seepage evaporation abstraction, at concentrations related to the measurements on pore waters, would cause insignificant changes in output from the abstraction.

- The rationale for excluding the chemical effects from ground support material degradation on water composition is documented in Section 6.8, considering additional sensitivity to background water chemistry, $\mathrm{CO}_{2}$ fugacity, and $\mathrm{Cr}$ (VI) speciation provided in Section 6.12.4.1.

- Binning analysis of pore water chemical analyses, for additional samples acquired from the host rock units, is presented in Section 7.3.1. This analysis supports selection of the five different starting pore water compositions for the initial and boundary conditions for the five THC seepage model runs used for TSPA, and thus 
supports the propagation of uncertainty from the THC seepage model, through the seepage evaporation abstraction, to the TSPA.

Description of initial and boundary conditions runs, and/or run convergences, and a discussion of how the activity or activities build confidence in the model. If appropriate, include a discussion of impacts of any non-convergence runs. [Section 5.3.2.(b)(2)]

- Initial and boundary conditions for the seepage evaporation abstraction are discussed in Sections 4.1.3 and 6.6.1. For the seepage evaporation abstraction, nonconvergence of EQ3/6 runs was encountered when calculating dryout (eutectic compositions) at very low water activity values (Section 6.15.1.1). The representation of nitrate and chloride concentrations for these conditions is based on the known solubility behaviors of nitrate and chloride salts, and the abstraction provides a reasonable lower bound on the nitrate/chloride ratio.

Discussion of the impacts of uncertainties to the model results. [Section 5.3.2.(b)(3)]

- For the seepage evaporation abstraction the predictive model uncertainty associated with use of the IDPS model is propagated to TSPA using uncertainty lookup tables, as described in Section 6.12.5. The statistical uncertainty inherent to binning of THC seepage model output waters into the 11 bins, is also propagated to TSPA using uncertainty distributions described in Section 6.12.3. Uncertainty specific to the interpolation of lookup tables, as is done for the abstraction in TSPA, is evaluated in Section 7.2.2 and found to be small, and much less than the model uncertainty from the IDPS model.

- The statistical method used to estimate binning uncertainty (Table 6.12-4), which is based on discrete analysis at three relative humidity points, is evaluated in a comparison of THC seepage model output with median bin water compositions, across a larger range of relative humidity, in Section 7.3.2.

- Predictive uncertainty associated with the IDPS model at up to 1,000-fold evaporative concentration, is confirmed by comparison of model calculations with a classical data set representing evaporation of Sierra Nevada spring water, in Section 7.3.3.

Documentation of the seepage evaporation abstraction includes defensible assumptions (Section 5) and simplifications in model development (addressed in Sections 6.2, 6.5, and 6.12). The seepage evaporation abstraction maintains consistency with physical principles, such as conservation of mass and energy, using EQ3/6 V8.0 software (BSC 2003 [DIRS 162228]) | (Section 6.5.1).

In the following section, the post-development validation comparison uses a set of lookup tables from Section 6.9 and performs interpolation between the lookup tables in a similar manner as described in Section 6.13.2 and 6.15.1 for direct comparison to IDPS process model results. 


\subsubsection{Comparison of Seepage Evaporation Abstraction to IDPS Model}

In accordance with the validation criterion (BSC 2005 [DIRS 173782], Section 2.2.2.4), the seepage evaporation abstraction (i.e., interpolated lookup table results) are compared with specific realizations of the IDPS model output to ensure that the interpolation results represent the process model output, within the bounds of the model uncertainty (from Table 6.12-1). Binning uncertainty, an additive uncertainty that is part of the seepage evaporation abstraction and is used by TSPA (Table 6.12-4), is not applied initially so as to limit the comparison to the abstraction of IDPS process model output.

The inputs selected for this validation calculation are from Bin 11 seepage lookup table EQ6 calculations found in Output DTN: MO0304MWDEBSSA.000. These include the following input and output files:

- $11 c 3 t 4 e .6 i$

- $11 c 3 t 7 e .6 o$

- $11 c 3 t 4 e .60$

- $11 c 4 t 7 e .6 o$

- $11 c 4 t 4 e .6 o$

- 11c2t1e.6o

- $11 c 2 t 7 e .6 o$

- 11c3t1e.6o.

The input file 11c3t4e.6i was modified twice to replace the temperature and $\mathrm{CO}_{2}$ partial pressure and renamed bin11val.6i and bin11val_b.6i. The selected temperature and $\mathrm{pCO}_{2}$ in those two files for these abstraction validation calculation runs were $56^{\circ} \mathrm{C}$ and $10^{-3.2}$ bar, and $95.6^{\circ} \mathrm{C}$ and $10^{-2.4}$ bar, respectively. Additionally, a single relative humidity point is selected for each of these temperature and $\mathrm{pCO}_{2}$ cases; these are 98 and $66 \% \mathrm{RH}$, respectively. The basis for this choice is that during higher temperature conditions, the relative humidity is generally lower, and upon cooling the RH is known to increase.

Software application EQ3/6 V8.0 (BSC 2003 [DIRS 162228]) was used along with the data0.ypf.R0 database (DTN: SN0302T0510102.002 [DIRS 162572]) to create bin11val.6o and bin11val_b.6o. GETEQDATA (BSC 2002 [DIRS 173680]) was then used to extract the results from those output files along with the results of the seven lookup table output files listed above into bin11val-rlj.xls. The relevant files can be found in Output DTN: MO0506SPAPCEIC.001.

In the validation, values for $\mathrm{pH}$, ionic strength, $\mathrm{Cl}^{-}$, and $\mathrm{Cl}^{-} / \mathrm{NO}_{3}{ }^{-}$are first interpolated with respect to $\mathrm{CO}_{2}$ partial pressure, and then the two nearest temperatures in the set of lookup tables. For example, interpolation for $10^{-3.2}$ bar $\mathrm{pCO}_{2}$ is accomplished by linearly interpolating the logarithms of $\mathrm{CO}_{2}$ partial pressure. In this case, the two nearest logarithms of $p \mathrm{CO}_{2}$ in the lookup tables are -3 and -4 . This procedure exactly follows that used for TSPA, as described in Section 6.15. The interpolated values are then plotted at $40^{\circ} \mathrm{C}$ and $70^{\circ} \mathrm{C}$ and connected by a straight line to determine the interpolated value at $56^{\circ} \mathrm{C}$ and $10^{-3.2}$ bar of $\mathrm{CO}_{2}$.

It is noted that for the chloride/nitrate ratio case, the relative humidity of $66 \%$ is below the threshold identified for salt separation (Section 6.13.6). Therefore, although the predicted 
chloride/nitrate ratio may not be used to describe the corrosion environment in TSPA for these conditions (because the salt separation effect would be implemented), the lower $\mathrm{RH}$ is an appropriate validation case for conservative species nitrate and chloride, which are concentrated at these conditions.

Figure 7.1-1, for ionic strength, $\mathrm{pH}, \mathrm{Cl}^{-}$, and $\mathrm{Cl}^{-} / \mathrm{NO}_{3}{ }^{-}$, shows that even with dependence on both $\mathrm{CO}_{2}$ partial pressure and temperature, the exact IDPS values (green squares) are well represented by the interpolated values at $56^{\circ} \mathrm{C}$ (red lines). The IDPS model uncertainties for ionic strength and $\mathrm{pH}$ (from Table 6.12-1) encompass the ranges of lookup values for $\mathrm{CO}_{2}$ partial pressure and temperature.

The uncertainty for $\mathrm{Cl}^{-}$and $\mathrm{Cl}^{-} / \mathrm{NO}_{3}{ }^{-}$are defined as zero in the $\mathrm{RH}$ range that includes $98 \%$ (Table 6.12-1). Therefore, no uncertainty bar is applicable to Figures 7.1-1c and 7.1-1d. It can be seen on the detailed scale shown that the IDPS model $\log \mathrm{Cl}^{-}$concentration is not exactly on the interpolation line. The difference, approximately $0.003 \log$ units, is insignificant in this case when compared to the errors applied to the seepage model abstraction for $\mathrm{Cl}^{-}$, which is $0.43 \log$ units for Bin 11 (see Table 6.12-4). As for the $\mathrm{Cl}^{-} / \mathrm{NO}_{3}{ }^{-}$ratio, the seepage evaporation abstraction and IDPS model numerically agree to beyond the fifth decimal. Accordingly, for the comparisons shown in Figure 7.1-1, the validation criterion is met.

Examination of the second validation case, at $95.6^{\circ} \mathrm{C}, 10^{-2.4}$ bar of $p \mathrm{CO}_{2}$, and $66 \% \mathrm{RH}$, is presented in Figure 7.1-2. Ionic strength is not included in this low-RH example because it is below 85\% RH; this is where the ionic strength is greater than 3 molal (about 10 molal here) and does not support any implementation in the total system performance assessment for the license application (TSPA-LA) (see Table 6.12-1, footnote a). For $\mathrm{pH}, \mathrm{Cl}^{-}$, and $\mathrm{Cl}^{-} / \mathrm{NO}_{3}{ }^{-}$the differences between the seepage evaporation abstraction and the IDPS model are smaller than the uncertainty bars, so for the comparisons shown in Figure 7.1-2 the validation criterion is also met.

These two validation cases indicate that the seepage evaporation abstraction is a valid representation of the IDPS process model for the representation of evaporated seepage water composition, especially when propagation of the model and binning uncertainties is included. Where the IDPS model uncertainty is nonzero, the abstraction model falls within those bounds, and where the IDPS model uncertainty is zero, the differences are quantitatively insignificant. 
a)

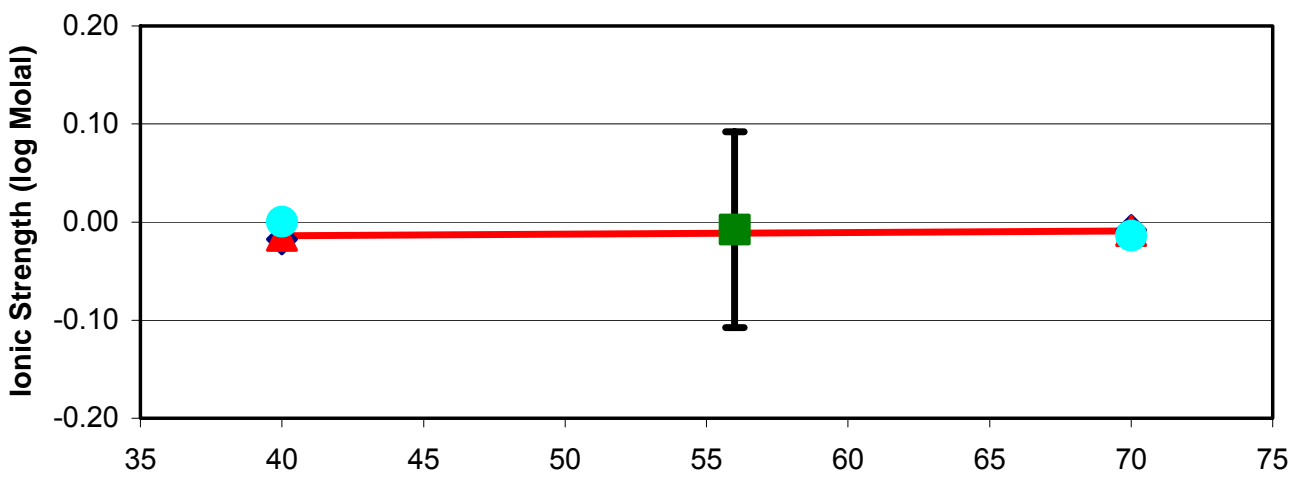

b)

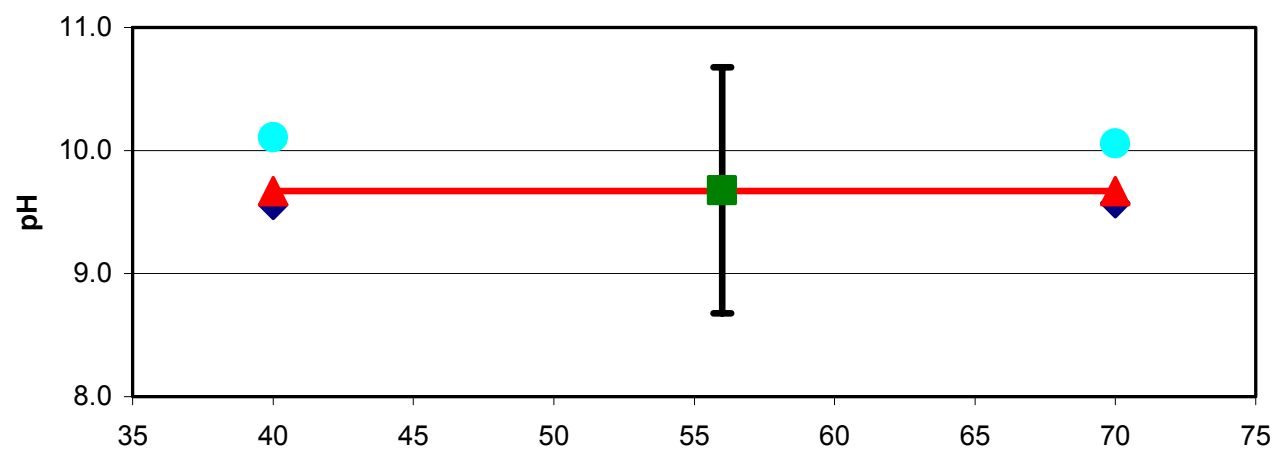

c)

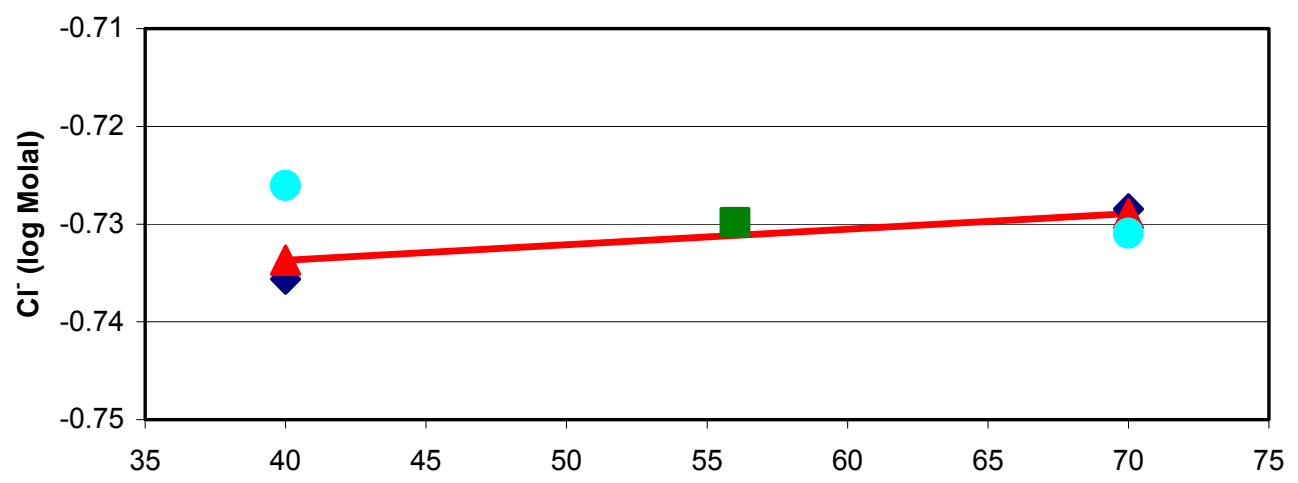

d)

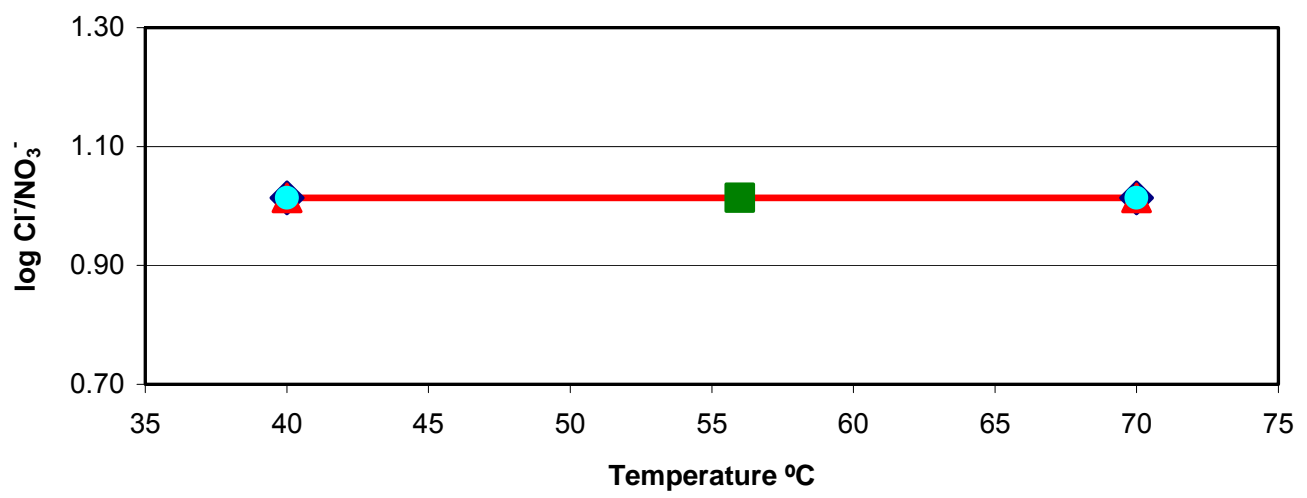

- $\quad \mathrm{pCO} 2=10 \mathrm{E}-3$ Interpolation Points

IDPS model results with uncertainty

-Interpolated Values

- $\mathrm{pCO} 2=10 \mathrm{E}-4$ Interpolation Points

Source: Output DTN: MO0506SPAPCEIC.001.

Figure 7.1-1. Seepage Evaporation Abstraction Validation at $56^{\circ} \mathrm{C}, 10^{-3.2} p \mathrm{CO}_{2}$, and $98 \% \mathrm{RH}$ 
a)

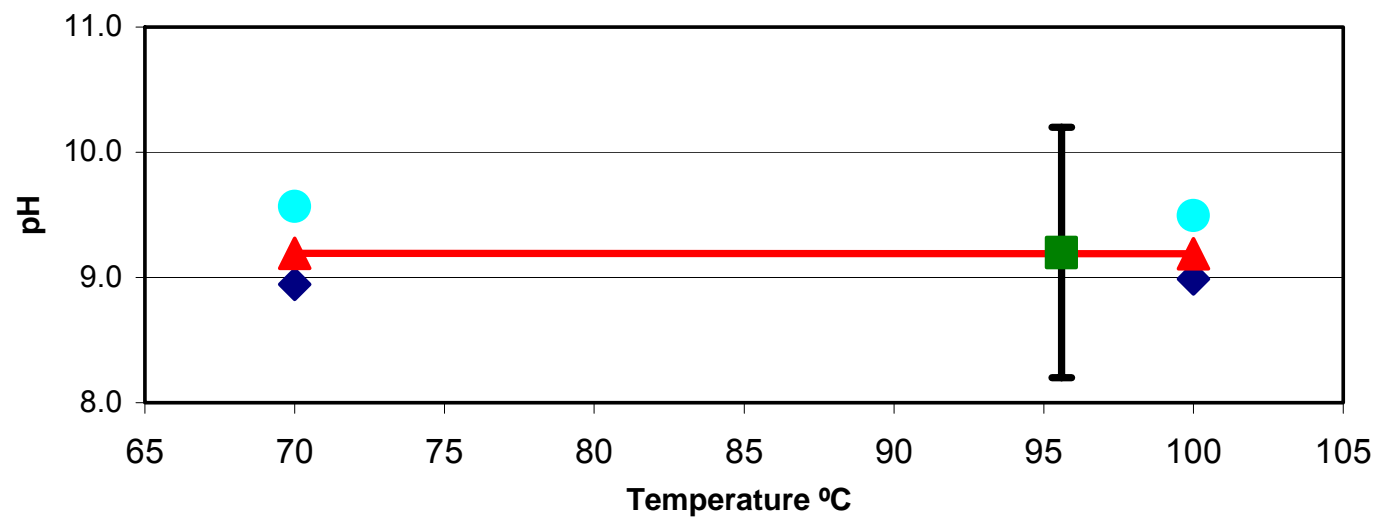

b)

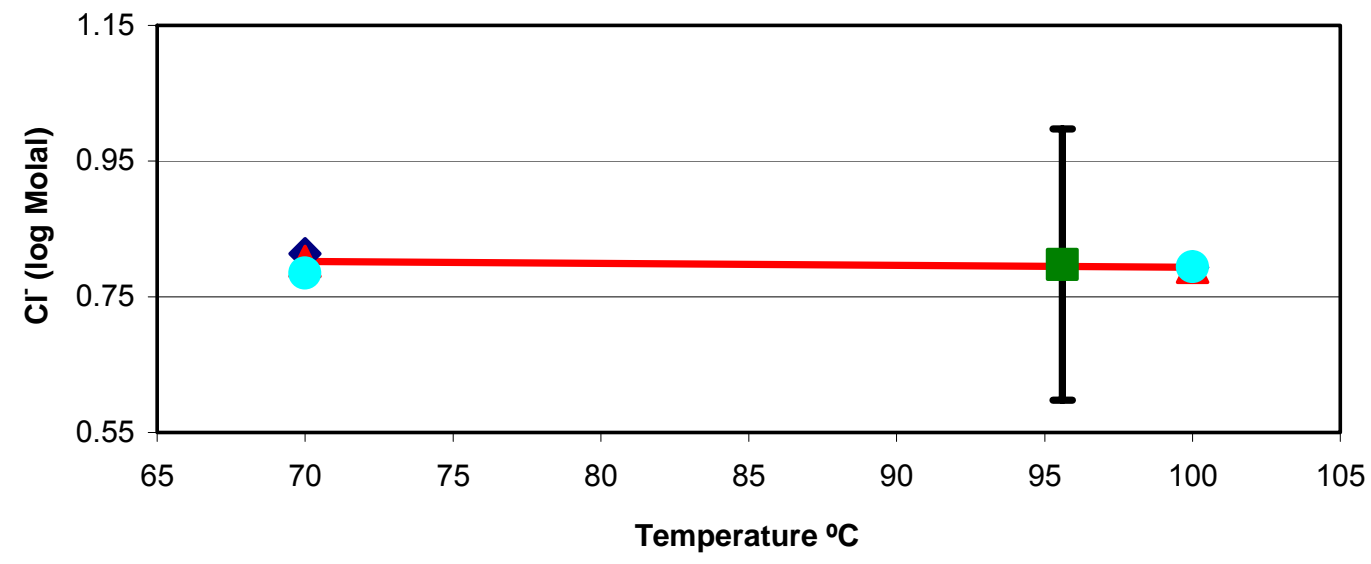

c)

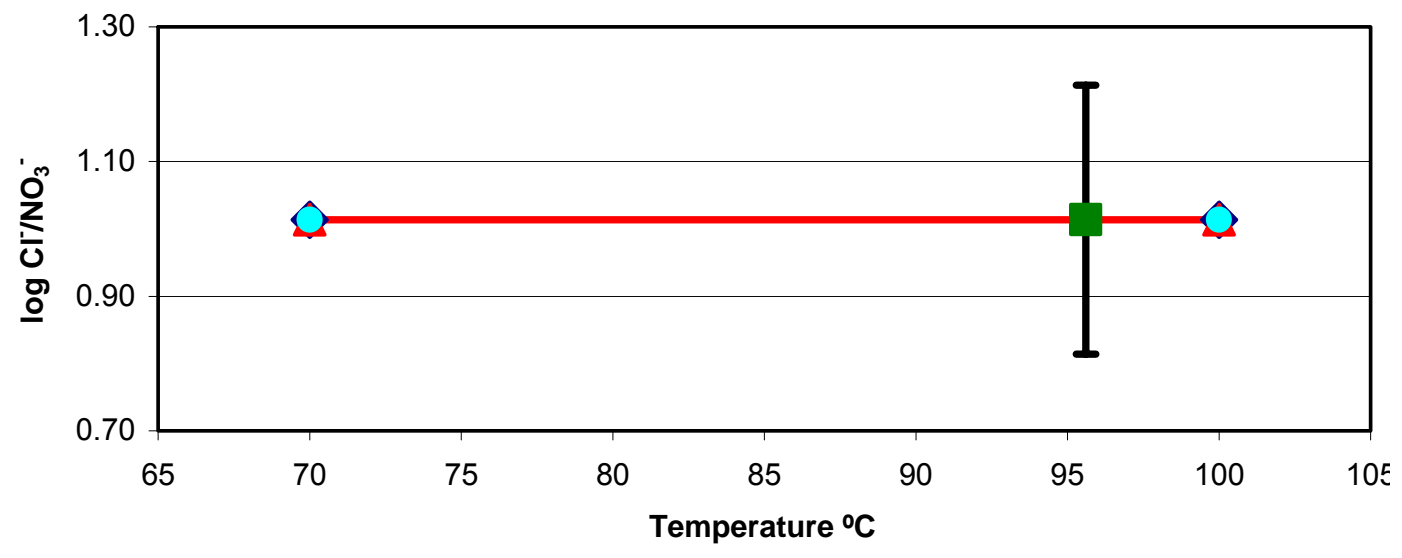

- $\mathrm{pCO} 2=10 \mathrm{E}-02$ Interpolation Points

$\leftarrow$ Interpolated Values
IDPS model results with uncertainty

pCO2 = 10E-03 Interpolation Points

Source: Output DTN: MO0506SPAPCEIC.001.

Figure 7.1-2. Seepage Evaporation Abstraction Validation at $95.6^{\circ} \mathrm{C}, 10^{-2.4} \mathrm{pCO}_{2}$, and $66 \% \mathrm{RH}$ 


\subsection{IN-DRIFT GAS MODEL ABSTRACTION}

Confidence building performed during the development of the model is documented in accordance with the requirements of Section 5.3.2(b) of LP-SIII.10Q-BSC. Confidence building includes the following:

Selection of input parameters and/or input data, and a discussion of how the selection process builds confidence in the model. [Section 5.3.2.(b)(1)]

- Discussion of the input parameters for the gas abstraction, and of the bases for their selection, is provided in Section 4.1. The key gas-phase species that affects the in-drift chemical environment is $\mathrm{CO}_{2}$. Other constituents of the gas phase are either inert for abiotic reactions in the environment (e.g., nitrogen gas, noble gases), or they are involved in reactions that do not significantly affect the bulk chemical environment (e.g., oxygen), or they are too scarce to have a significant effect. As documented in Section 6.7.2, the $\mathrm{CO}_{2}$ partial pressures for the in-drift chemical environment are taken from the THC seepage model, which explicitly represents the coupled chemical processes in the host rock. The amounts of moisture and $\mathrm{CO}_{2}$ in the host rock far exceed the amounts in the drift air and the invert, and there is a continuous exchange flux between them (see Figure 6.7-2), so it is appropriate to select the THC seepage model $\mathrm{CO}_{2}$ partial pressure (from $\mathrm{CO}_{2}$ volume fraction and total pressure) as a direct representation of in-drift $\mathrm{pCO}_{2}$.

Description of initial and boundary conditions runs, and/or run convergences, and a discussion of how the activity or activities build confidence in the model. If appropriate, include a discussion of impacts of any non-convergence runs. [Section 5.3.2.(b)(2)]

- The gas abstraction obtains $\mathrm{pCO}_{2}$ directly from the THC seepage model, which is separately validated (BSC 2005 [DIRS 172862], Section 7). No additional model calculations potentially involving initial or boundary conditions, or nonconvergences, are needed.

Discussion of the impacts of uncertainties to the model results. [Section 5.3.2.(b)(3)]

- The gas abstraction sets the in-drift oxygen fugacity equal to atmospheric $(21 \%$ of the total pressure) as a convenient means of representing oxidizing conditions in the drift, for purposes of simulating the evolution of seepage and imbibed waters in the invert. For this to be representative, the oxygen fugacity must be shown to be great enough that key redox reactions are not significant. The IDPS model defines this lower fugacity limit to be $10^{-9}$ bar (BSC 2004 [DIRS 169863], Section 8.4). Two such comparisons are made: 1) comparison with the partial pressure of oxygen values from the THC seepage model calculations, in which oxygen is not a reactant but is diluted by water vapor or steam (Section 6.7.2); and 2) comparison with a sensitivity analysis of oxygen consumption from degradation of introduced materials in the emplacement drifts (Section 6.7.1). The first comparison is discussed in Section 7.2.1. The results from the second comparison (Section 6.7.2) show that consumption of oxygen by degradation of steel decreases the oxygen fugacity, but 
that it is likely to remain greater than the lower limit stated above in the emplacement drift environment, supporting validation of the abstraction.

Documentation of the gas abstraction includes defensible assumptions (Section 5) and simplifications in model development (addressed in Sections 6.2, 6.5, and 6.12).

Post-developmental validations are described in the following subsections.

\subsubsection{Oxygen Fugacity Submodel}

Development of this submodel is documented in accordance with the requirements of Section 5.3.2(b) of LP-SIII.10Q-BSC. Confidence building includes the following:

- Meeting Validation Criteria for Postdevelopment Method 6: Corroboration of abstraction model results to the results of the validated mathematical model(s) from which the abstraction model was derived.

For the oxygen fugacity submodel of the gas abstraction, the constant fugacity value developed in the abstraction is appropriate because both it and the THC seepage model output fugacity (which varies with time) are substantially greater (by more than 1 order of magnitude) than the oxygen fugacity associated with equivalence of the $\mathrm{Fe}^{2+} / \mathrm{Fe}^{3+}$ couple and of the $\mathrm{NO}_{2}{ }^{-} / \mathrm{NO}_{3}{ }^{-}$couple.

Validation of the constant value of approximately -0.7 for the log oxygen partial pressure (corresponding to 20\% volume fraction of air and in accordance with BSC 2004 [DIRS 169863], Section 4.1.2) is supported by the analyses in Section 6.7.1. Two sensitivity studies are presented: 1) the effect of dilution with water vapor (steam) is documented in Section 6.7.1.1; and 2) the consumption of oxygen by corrosion of steel in the drift environment is addressed in Section 6.7.1.2. In addition, the effects from degradation of carbon and stainless steels in the emplacement drifts are analyzed in Section 6.8.

The analyses show that although oxygen will be consumed by degradation of steel, and diluted by steam, the approach to representing oxygen fugacity (i.e., partial pressure of $\mathrm{O}_{2}$ gas) is appropriate because: 1) the effect of dilution by steam (as represented in the THC seepage model results) is consistent with not including redox behavior in the IDPS model; 2) the in-drift oxygen fugacity that could result from consumptive reactions is consistent with not including redox behavior in the IDPS model; and 3) the chemical reactions that will consume oxygen in the drift will not significantly affect evaporated seepage water chemistry.

The lower limit of oxygen fugacity recognized for applicability of the IDPS model is $10^{-9}$ bar (BSC 2004 [DIRS 169863], Sections 4.1.2 and 8.4). As discussed in Section 6.7.1.3 the oxygen fugacity values associated with equivalence points for the $\mathrm{NO}_{2}{ }^{-} / \mathrm{NO}_{3}{ }^{-}$and $\mathrm{Fe}^{2+} / \mathrm{Fe}^{3+}$ redox couples are much smaller (on the order of $10^{-28}$ bar or less). Accordingly, in the following validation discussion an oxygen fugacity value of $10^{-9}$ bar is used in the comparisons. The equivalence-point condition is appropriate for comparison to the in-drift oxygen fugacity because it occurs when the activity of the reduced species (e.g., $\mathrm{NO}_{2}^{-}$) is equal to that for the species that occurs at oxidizing conditions (e.g., $\mathrm{NO}_{3}{ }^{-}$). 
The smallest value for oxygen fugacity that occurs at the drift wall in any of the THC seepage model runs used for TSPA, has a value of approximately $6 \times 10^{-6}$ bar, which is substantially greater than $10^{-9}$ bar (Section 6.7.1.1). This value represents the maximum dilution effect caused by displacement of air by water vapor at or near the peak of the thermal period, thus the validation criterion is met for dilution effects. It is further noted that the result presented in Section 6.7.1.1 overestimates dilution (i.e., underestimates oxygen fugacity) because the THC seepage model is a two-dimensional cross-sectional model that does not consider movement of air and water vapor in the axial direction within the drift.

The reduction in oxygen fugacity caused by degradation of carbon steel in the invert, and of carbon steel materials inside (breached) waste packages, is estimated in Section 6.7.1.2. The resulting fugacity estimates are also substantially greater than 10-9 bar, thus the validation criterion is also met for oxygen consumption by material degradation. It is noted here also, that the result presented in Section 6.7.1.2 overestimates oxygen consumption (i.e., underestimates oxygen fugacity) because the analysis is two-dimensional and does not consider movement of air and water vapor in the axial direction within the drift. Also, the two-dimensional analysis considers material degradation to occur uniformly along the entire length of an emplacement drift.

These results show that the oxygen fugacity submodel is a valid representation of oxidizing conditions within the emplacement drifts, consistent with the THC seepage model. This result implies that conditions will never exist to generate significant amounts of reduced chemical species through aqueous chemical reactions (Section 6.7.1.3).

\subsubsection{Carbon Dioxide Abstraction}

The abstraction of the THC seepage process model for carbon dioxide partial pressures (i.e., $\mathrm{CO}_{2}$ fugacity, or $p \mathrm{CO}_{2}$ ) involves a log-linear interpolation of the THC model output with respect to time (Section 6.13.2). The $\mathrm{CO}_{2}$ gas abstraction results are compared to more temporally-detailed THC seepage model output results. This analysis demonstrates that the gas abstraction results are within the required factor of two from the THC model, in accordance with the validation criteria in the technical work plan (BSC 2005 [DIRS 173782], Section 2.2.2.4). All data and results from CO2_validation.xls come from Output DTN: SN0505T0510102.022.

For purposes of this validation analysis, the TSPA-LA lookup table data for $p \mathrm{CO}_{2}$ and total pressure are taken directly from Output DTN: SN0502T0510102.018 for crown seepage water based on THC seepage model runs using the w0 water, and placed into the spreadsheet CO2_validation.xls, tab "P\&CE Abstraction." Only one of the five available $\mathrm{THC} p \mathrm{CO}_{2}$ output time series (i.e., for the THC case using w0 water) is examined in this validation, as they all show the same trends (see Figure 6.7-4) and the w0 time series appears to span the greatest range of values. The detailed THC model output "co2(g)" is extracted into this spreadsheet, tab "THC data," from the w0 TIME.DAT file of DTN: LB0506DSCPTHCS.001 [DIRS 174149]. Only grid node " $\mathrm{F} 121$ " is of interest here as it represents the in-drift environment with fracture media at the top of the drift crown; all other grid node data are removed.

These THC "co2(g)" values are expressed as volume fractions. To convert the detailed THC results from volume fraction to a partial pressure of $\mathrm{CO}_{2}$ (i.e., $p \mathrm{CO}_{2}$ ) for direct comparison, the 
total pressure from the THC seepage model is also required. However, it is not available at the detailed level and is therefore approximated by averaging over six time periods from the original THC output results (as contained in Output DTN: SN0503T0510102.019). This reasonable representation of total pressure is color-coded in CO2_validation.xls, tab "P\&CE Abstraction" with standard deviations in each period of $0.05 \%$ or less, as compared to a total-range deviation of about $0.2 \%$ (i.e., the choice of a six-point running average has no significant effect on the comparison presented here for validation). The selection of six time periods for this correction was arbitrary; more periods would produce a smoother result and even greater fidelity of comparison between the abstraction and the process model output.

The comparison of the $\mathrm{CO}_{2}$ gas abstraction, using log-linear interpolation as implemented in the TSPA for $p \mathrm{CO}_{2}$ (see Section 6.15), with the detailed THC seepage model output, is presented in Figure 7.2-1. It shows regular behavior of the $\mathrm{pCO}_{2}$ process model data that is closely represented by the $\mathrm{CO}_{2}$ gas abstraction using log-linear interpolation. This is well within the validation factor of two, or approximately $\log 0.3$ unit difference, thus the validation criterion is met. This finding excludes the transient responses in the THC model output at 600 years and at 2,400 years, which are due to the THC seepage process model being restarted at these time points.

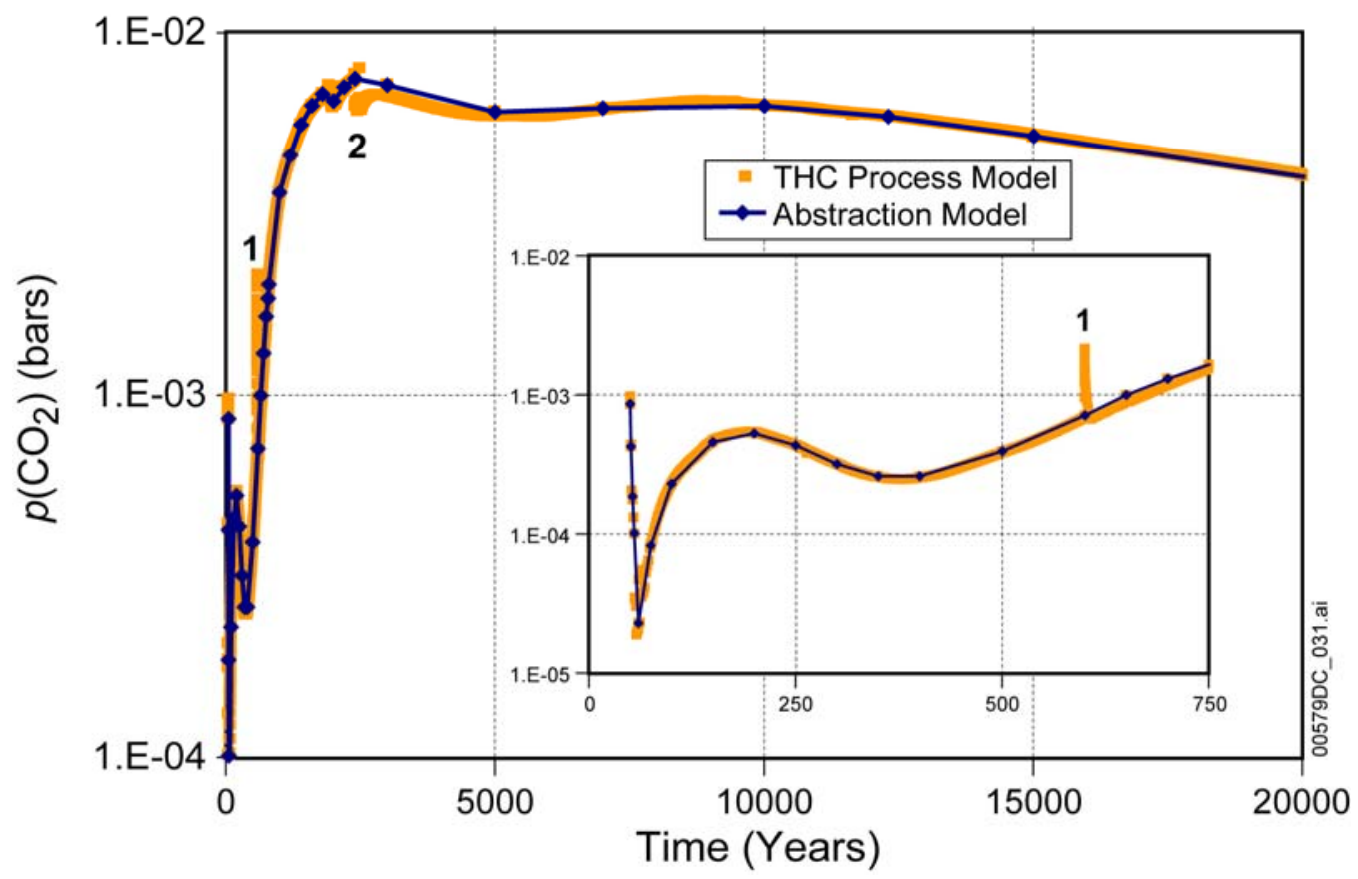

Source: Output DTN: SN0505T0510102.022.

NOTE: Figure indicators "1" at 600 years and "2" at 2,400 years indicate where the THC model undergoes a modeling restart. The large variabilities seen at this point are an artifact of this restart.

Figure 7.2-1. $\mathrm{CO}_{2}$ Gas Abstraction Validation: Log-Linear Interpolation

Importantly, the validity of the gas abstraction is also supported by use of the five $\mathrm{pCO}_{2}$ time series corresponding to the five starting waters used with the THC seepage model. The TSPA samples one of these series for each realization, consistent with the representation of process 
model uncertainty in TSPA (BSC 2004 [DIRS 169858], Section 7); thus, the process model uncertainty associated with $p \mathrm{CO}_{2}$ is propagated into TSPA.

\subsection{SUPPLEMENTARY CONFIDENCE BUILDING INFORMATION}

This section presents supplementary information on additional confidence building efforts in the representation of in-drift seepage evaporation chemistry (and the underlying process models and analysis). This consists of both during-development activities (Section 7.3.1, 7.3.2, and 7.3.4), and a supplementary model-data comparison (Section 7.3.3).

\subsubsection{Binning of Repository-Horizon Pore Waters}

This section examines a set of pore water chemical analyses from the repository host-rock units to evaluate how they "bin" in comparison with the five starting waters that are analyzed for use in TSPA-LA (Section 6.6). This analysis was performed during development of the seepage evaporation abstraction, and supports selection of the five different starting pore water compositions for the initial and boundary conditions for the five THC seepage model runs used for TSPA-LA. Thus, this analysis supports the propagation of uncertainty from the THC seepage model, through the seepage evaporation abstraction, and to the TSPA-LA. The results described below provide additional confidence because they show that the additional pore water compositions fall into "bins" that are similar to those presented in the seepage evaporation abstraction for long-term response (more than 20,000 yr; Section 6.13.1).

A binning analysis, similar to those in Section 6.6, of 40 measured repository-horizon pore waters was carried out to evaluate the range in brine compositions that result from evaporation to $65 \% \mathrm{RH}$ at $25^{\circ} \mathrm{C}$. The resulting outputs for the EQ3/6 evaporation results (to $65 \% \mathrm{RH}$ ) were extracted from the input .6i files (archived in Output DTN: MO0406MWDARHPW.000) using GETEQDATA (BSC 2002 [DIRS 173680]). These outputs are given in Binning of Repository Horizon Pore Waters.xls (archived in Output DTN: MO0406MWDARHPW.000), which were then subjected to the binning analysis method described in Section 6.6.

It is notable that most of the source DTNs for these pore water chemistries state that there are problems with the measured bicarbonate concentrations, indicated by poor charge balance. In at least one instance, measured values were supplemented by values calculated from charge balance, with both values presented. For this analysis, the measured values (including those identified as being of poor quality in DTNs: GS020408312272.003 [DIRS 160899] and GS020808312272.004 [DIRS 166569]) are used as input for the EQ3NR input files, and charge balance is imposed consistently using bicarbonate in the EQ3NR runs, thereby setting the bicarbonate concentration regardless of the input values entered.

One of the 40 waters was deemed inappropriate for modeling due to a lack of data. Specifically, for sample ecrb6 (Table 4.4-2) the value for nitrate was given as exactly 0.0 , whereas for other samples the nitrate value was nonzero, or a detection limit was provided (e.g., $<0.2 \mathrm{mg} / \mathrm{L}$ ). As a zero value for nitrate is unreasonable, and it was not determined if the nitrate analysis was actually performed, this water sample is excluded from this analysis.

The binning analysis was carried out to evaluate whether the five starting waters used in the THC seepage model are a good representation of the 39 water analyses from various host-rock units 
(including the Tptpul, Tptpmn, Tptpll, and Tptpln units only). The five starting waters for the THC model are designated as w0, w4, w5, w6 and w7 in Section 6.6. The 39 starting waters used in binning the repository horizon pore waters are given in Table 4.4-2, along with the associated DTNs where the chemical analysis data are located. The five THC starting waters are included in this binning analysis. Note that the w0 THC starting water is a composite average of two other waters in this binning analysis (Table 4.4-2; BSC 2005 [DIRS 172862], Table 6.2-1).

The numerical evaporations were performed following the same procedure used in the THC seepage water input analysis in Section 6.6.3. Specifically for these pore waters, the temperature was fixed at $25^{\circ} \mathrm{C}$ to represent their ambient condition and charge balancing was done on bicarbonate. Carbon dioxide partial pressure was fixed at the equilibrium value for the original composition, and held constant through the evaporation. The input and output EQ3/6 files are all included in Output DTN: MO0406MWDARHPW.000.

Waters were then chemically grouped into bins based on the criteria given in Section 6.6.4 and Table 6.6-3. The binning analysis results of the 38 repository-horizon pore waters shows that 33 of the 38 pore waters $(86.8 \%)$ are distributed in either Bin 5 or Bin 7 after evaporation to $65 \% \mathrm{RH}$, with Bin 7 being the most frequent (Table 7.3-1). By comparison, four of the five THC starting waters are also distributed in Bins 5 and $7(80 \%)$. This comparison adds confidence that the five THC starting waters utilized in the THC model (BSC 2005 [DIRS 172862]) are a reasonable representation of the range in near-field chemistries that are present.

Note that one THC starting water (w0) is a composite of two measured analyses (one is Bin 2, and the other Bin 3, and they are included in the left-hand columns of Table 7.3-1). The w0 composition is shown as one composition in the right-hand column in Table 7.3-1 (in Bin 2; see Note b). These results show that the predominant trend in pore water binning (Bins 5 and 7 ) is well represented among the five starting waters selected for the THC seepage model, and that the occurrence of Bin 2 or Bin 3 waters is also represented by the composite composition w0. These results build confidence in the propagation of uncertainty from the THC seepage model (BSC 2005 [DIRS 172862]), through the post-processing analysis (BSC 2004 [DIRS 169858]), the binning described in Section 6.6 of this report, and the seepage evaporation abstraction described in Sections 6.9, 6.13, and 6.15.

Table 7.3-1. Binning Distribution of Repository-Horizon Pore Waters

\begin{tabular}{|c|c|c|c|}
\hline Bin Number & $\begin{array}{c}\text { Number of Pore Waters in } \\
\text { Each Bin }\end{array}$ & \% Distribution & $\begin{array}{c}\text { Number of THC Model } \\
\text { Starting Waters }^{\mathbf{a}}\end{array}$ \\
\hline 2 & $2^{\text {b }}$ & 5.3 & 1 \\
\hline 3 & 3 & 7.9 & 0 \\
\hline 5 & 14 & 36.8 & 2 \\
\hline 7 & 19 & 50.0 & 2 \\
\hline
\end{tabular}

Source: Output DTN: MO0406MWDARHPW.000, Binning of Repository Horizon Pore waters.xIs; except values listed in column labeled "\% Distribution," which were derived by hand calculation.

a See Section 6.6 for the five THC starting waters.

b THC model starting water w0 would fall into Bin 2, but since it was developed using the average chemistries of two repository-horizon waters that both included in this analysis, it is not included in columns 2 ("Number of Pore Waters in Each Bin") and 3 (“\% Distribution") to avoid double-counting of this water. 


\subsubsection{Confirmation of Binning Variability}

This section presents an analysis performed during development of the seepage evaporation abstraction, to confirm that the evaporated crown seepage water uncertainty abstraction, focusing on the binning process and its variability (Table 6.12-4), is reasonable across a representative range of water activity. This confirmatory analysis tests the estimated binning uncertainty (Table 6.12-4) that is based on discrete analysis at three relative humidity points, by comparison with the median bin water compositions across a larger range of relative humidity.

The median waters, from Final_Checked_EBS_THC_Seepage_Abstraction_REV_4.xls file archived in Output DTN: MO0508SPAEBSCB.001, are copied and pasted into the spreadsheet top_front_crown_waters.xls within Output DTN: MO0505SPAPCEBV.000.

The method used here first evaporates to dryness (using EQ3/6) the median waters for crown seepage chemistries at randomly chosen $\mathrm{pCO}_{2}$ and temperature conditions (THC starting water chemistries are in Output DTN: MO0303MWDSCMAB.000). No crown seepage waters are present within Bins 1 and 2, based on the binning criteria from Section 6.6.4; thus, only evaporated crown seepage waters in Bins 3 through 11 apply for this validation analysis. The $p \mathrm{CO}_{2}$ and temperature conditions were randomly chosen from within the lookup table ranges (Section 6.7.2.2) by the RAND function of Microsoft Excel. The range for $p \mathrm{CO}_{2}$ is between $10^{-4}$ and $10^{-2}$ bar (logarithmically distributed) and temperature ranges linearly between $40^{\circ} \mathrm{C}$ and $100^{\circ} \mathrm{C}$ (linearly distributed) in the lookup tables. The random selection was carried out within Output DTN: MO0505SPAPCEBV.000 (top_front_crown_waters.xls, tab "Random T and pCO2"). Table 7.3-2 shows the $p \mathrm{CO}_{2}$ and temperature conditions randomly chosen for each individual bin for the evaporation runs.

Table 7.3-2. Temperature and $p \mathrm{CO}_{2}$ Used for Each Bin in the Validation Analysis

\begin{tabular}{|c|c|c|}
\hline Bin Number & $\begin{array}{c}\text { Randomly Selected } \\
\left.\text { Temperature ( }{ }^{\circ} \mathbf{C}\right)\end{array}$ & $\begin{array}{c}\text { Randomly Selected } \\
\log \mathbf{p C O}_{2}\end{array}$ \\
\hline 3 & 57.7 & -2.3 \\
\hline 4 & 78.2 & -4.0 \\
\hline 5 & 48.3 & -2.8 \\
\hline 6 & 96.9 & -3.5 \\
\hline 7 & 65.8 & -3.3 \\
\hline 8 & 72.4 & -2.6 \\
\hline 9 & 88.1 & -3.0 \\
\hline 10 & 55.2 & -4.0 \\
\hline 11 & 65.4 & -3.1 \\
\hline & tab "Random T and pCO2." & \\
\hline
\end{tabular}

The individual THC top-front crown waters used in this analysis were also randomly chosen by the RAND function in Excel within Output DTN: MO0505SPAPCEBV.000 (see spreadsheet top_front_crown_waters.xls, tabs "Bin 3 through Bin 11"). These non-median bin waters were then evaporated by EQ3/6 runs carried out using the randomly chosen THC crown seepage waters at the $\mathrm{pCO}_{2}$ and temperature conditions in Table 7.3-2. The starting water chemistries used for these evaporation runs are also archived in Output DTN: MO0303MWDSCMAB.000. 
The median waters and the randomly chosen THC top-front crown waters used in this analysis, along with the EQ3/6 input files, are identified in Table 7.3-3. The EQ3/6 input files along with the resulting output files are archived within Output DTN: MO0505SPAPCEBV.000.

Table 7.3-3. Identified Waters and EQ3/6 Input Filenames Used in the Analysis

\begin{tabular}{|c|c|c|c|c|}
\hline $\begin{array}{c}\text { Bin } \\
\text { Number }\end{array}$ & Median Water (year) & $\begin{array}{l}\text { EQ3/6 .3i and .6i } \\
\text { Input Filenames }\end{array}$ & $\begin{array}{c}\text { Randomly selected } \\
\text { THC Top-Front Crown } \\
\text { Water (year) }\end{array}$ & $\begin{array}{l}\text { EQ3/6 .3i and .6i } \\
\text { Input Filenames }\end{array}$ \\
\hline 3 & w0bf4 (650) & b3mwPCE & w0tf4 (350) & b3w0tf4 \\
\hline 4 & w4bf4 (600) & b4mwPCE & w0tf4 (500) & b4w0tf4 \\
\hline 5 & w7tf4 (300) & b5mWPCE & w0tf4 (53) & b5w0tf4 \\
\hline 6 & w0tf4 (7004) & b6mwPCE & w0tf4 (10006) & b6w0tf4 \\
\hline 7 & w4bf4 (10006) & b7mwPCE & w4tf4 (12597) & $b 7 w 4 t f 4$ \\
\hline 8 & w5tf4 (20013) & b8mwPCE & w4tf4 (50034) & $b 8 w 4 t f 4$ \\
\hline 9 & w6tf4 (51) & b9mWPCE & w6tf4 (1000) & b9w6tf4 \\
\hline 10 & w5bf4 (10006) & b10mwPCE & w5tf4 (10006) & b10w5tf4 \\
\hline 11 & w4tf4 (300) & b11mwPCE & w5tf4 (2401) & $b 11 w 5 t f 4$ \\
\hline
\end{tabular}

Chemical data of interest were then extracted from both the median water evaporation runs and the randomly selected THC top-front crown waters evaporation runs, using GETEQDATA (BSC 2002 [DIRS 173680]). The extracted chemical data are archived in the spreadsheet PCE_THC_Compare.xls within Output DTN: MO0505SPAPCEBV.000.

Finally, plots for each individual bin were generated for the $\mathrm{pH}, \mathrm{Cl}^{-}$, and $\mathrm{Cl}^{-} / \mathrm{NO}_{3}{ }^{-}$chemical data from Bins 3 through 11 (Figures 7.3-1 to 7.3-9, respectively). Specifically, these plots compare these chemical data during evaporation of the median waters against those of the selected alternate THC crown water from the same bin.

Binning uncertainties, as applied to the median water results represented by the uncertainty bars on the figures, are from Table 6.12-4. The uncertainties are for the binning variability only and do not include model uncertainty from Table 6.12-1. This is appropriate because the purpose of this analysis is to evaluate the treatment of binning uncertainty, and the model uncertainties would simply add to the uncertainty bars shown in Figure 7.3-1 through 7.3-9.

Figures 7.3-1 through 7.3-9 show that within the applied binning uncertainty on the median waters (shown by the uncertainty bars) the randomly chosen THC top-front crown water from each bin falls within the binning uncertainty of the median water. Thus, the binning uncertainty captures the range of variability sampled from THC seepage model output corresponding to each bin. It would be acceptable for as many as five percent of the values to fall outside the uncertainty range, because the binning uncertainty range was based on two-sigma statistics (i.e., two standard deviations or approximately 95\%, see Section 6.12.3).

The results plotted in Figure 7.3-5 are affected by the selection of Bin 7 median water, discussed in Section 6.6.7.3. Comparison of the $\mathrm{Cl}$ (as chloride), $\mathrm{N}$ (as nitrate), and $\mathrm{N} / \mathrm{Cl}$ traces on Figure 6.6-26 for w0-derived and w4-derived waters shows that the w0-derived water has approximately three-fold greater chloride concentration than the w4-derived water in the 
intermediate range of water activity (approximately 0.72 to 0.9 ). Accordingly, if w0-derived water results were plotted in Figure 7.3-5 (which is based on the w4-derived composition), the chloride concentration and the chloride-nitrate ratio would plot at the limit of the uncertainty bars. A symmetric result would have been obtained if the calculations described in this section were performed using the w0-derived water, i.e., in that case the w4-derived median-bin water would plot at the limit of the uncertainty bars. This is consistent with the two-sigma range used above to develop the binning uncertainty bars; the statistics represent the overall behavior of the waters in each bin. Hence the differences between the w0-derived and w4-derived waters as shown on Figure 7.3-5 are consistent with the binning statistics. Other differences between the waters (Figure 6.6-26) such as the $\mathrm{Na}$ and $\mathrm{pH}$ comparisons, and the compositions at water activity less than 0.7 , are smaller and would plot well within the uncertainty bars. 

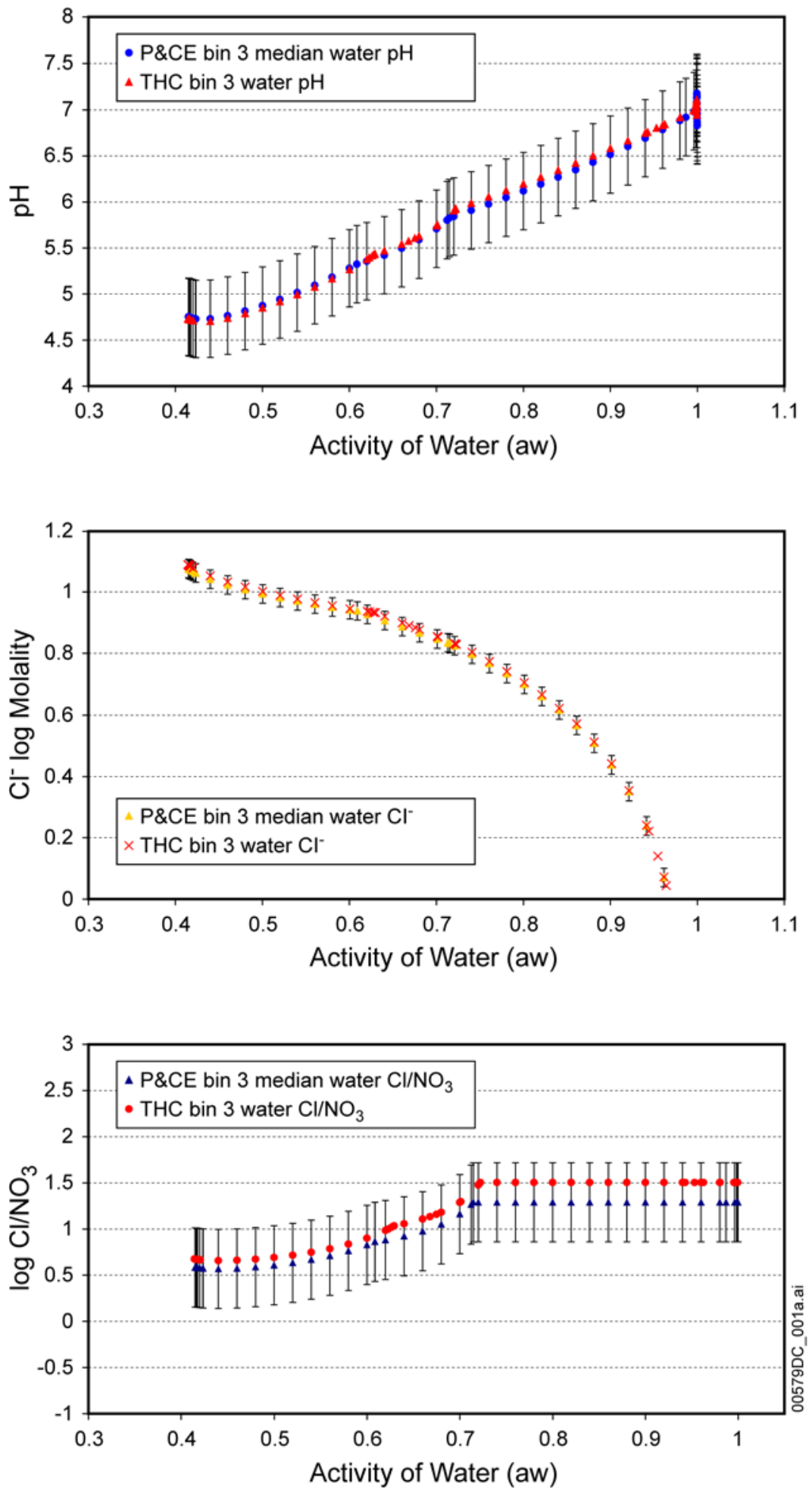

Source: Output DTN: MO0505SPAPCEBV.000.

Figure 7.3-1. Bin $3 \mathrm{pH}, \mathrm{Cl}^{-}$, and $\mathrm{Cl}^{-} / \mathrm{NO}_{3}{ }^{-}$Results 

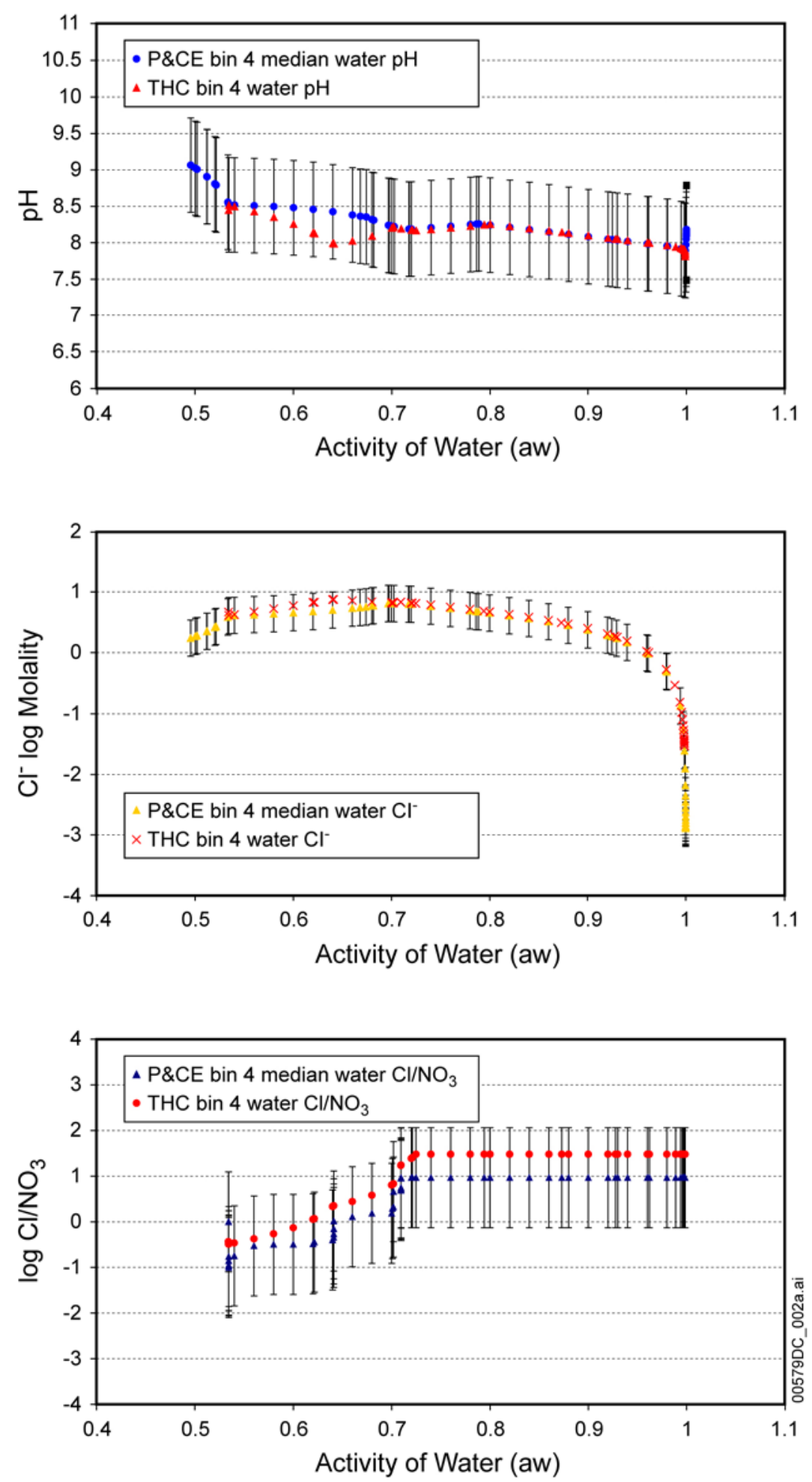

Source: Output DTN: MO0505SPAPCEBV.000.

Figure 7.3-2. Bin $4 \mathrm{pH}, \mathrm{Cl}^{-}$, and $\mathrm{Cl}^{-} / \mathrm{NO}_{3}{ }^{-}$Results 

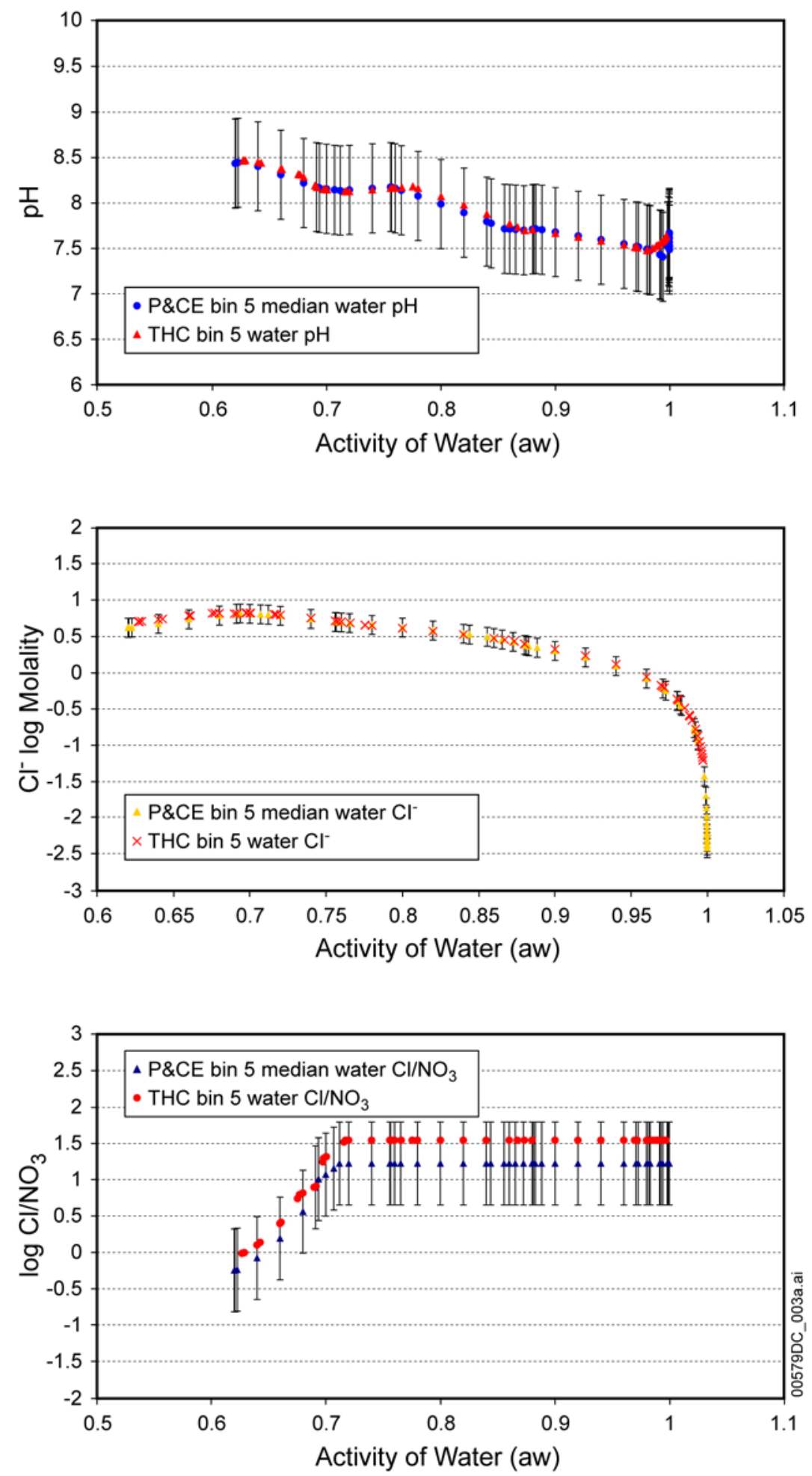

Source: Output DTN: MO0505SPAPCEBV.000.

Figure 7.3-3. Bin $5 \mathrm{pH}, \mathrm{Cl}^{-}$, and $\mathrm{Cl}^{-} / \mathrm{NO}_{3}{ }^{-}$Results 

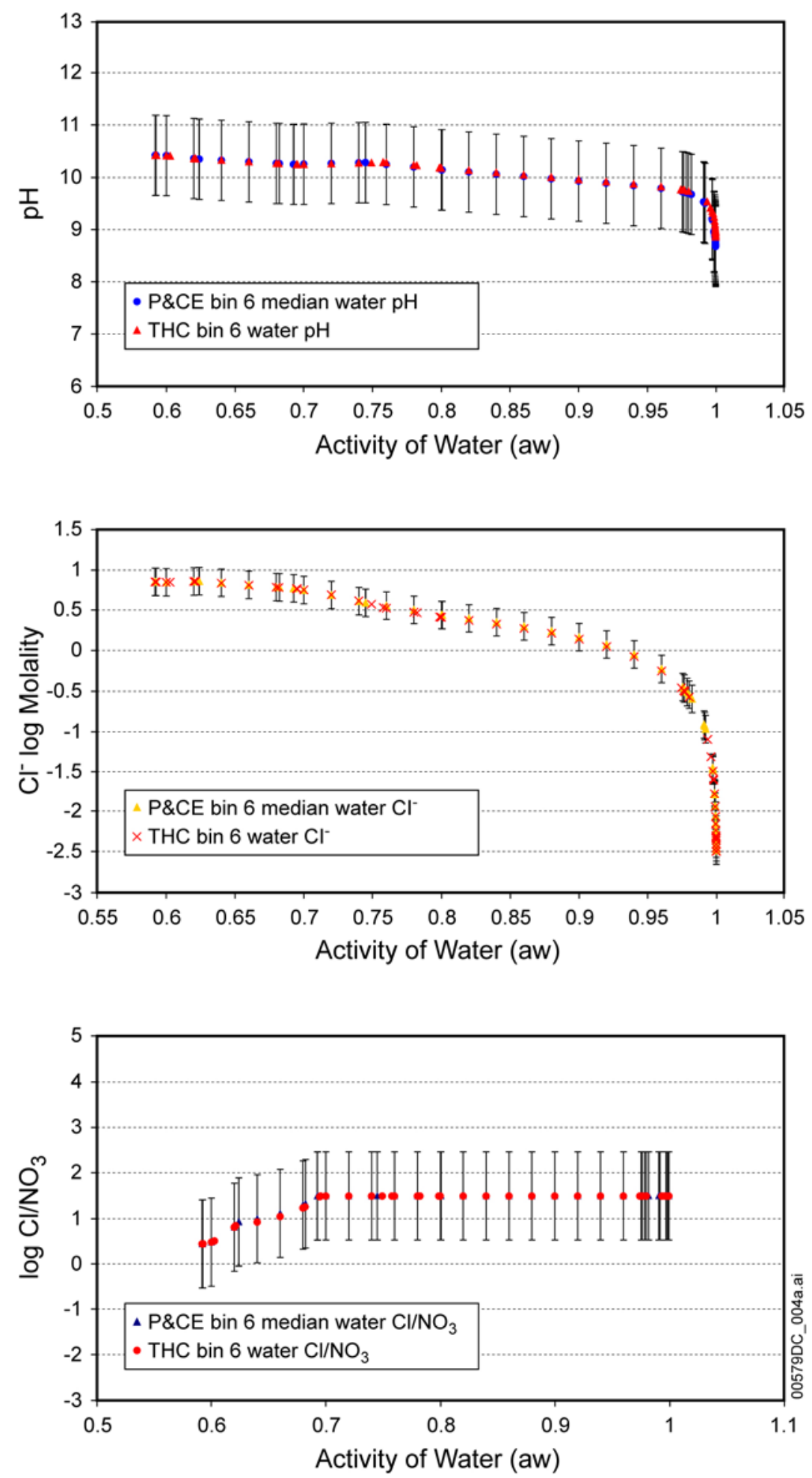

Source: Output DTN: MO0505SPAPCEBV.000.

Figure 7.3-4. Bin $6 \mathrm{pH}, \mathrm{Cl}^{-}$, and $\mathrm{Cl}^{-} / \mathrm{NO}_{3}{ }^{-}$Results 

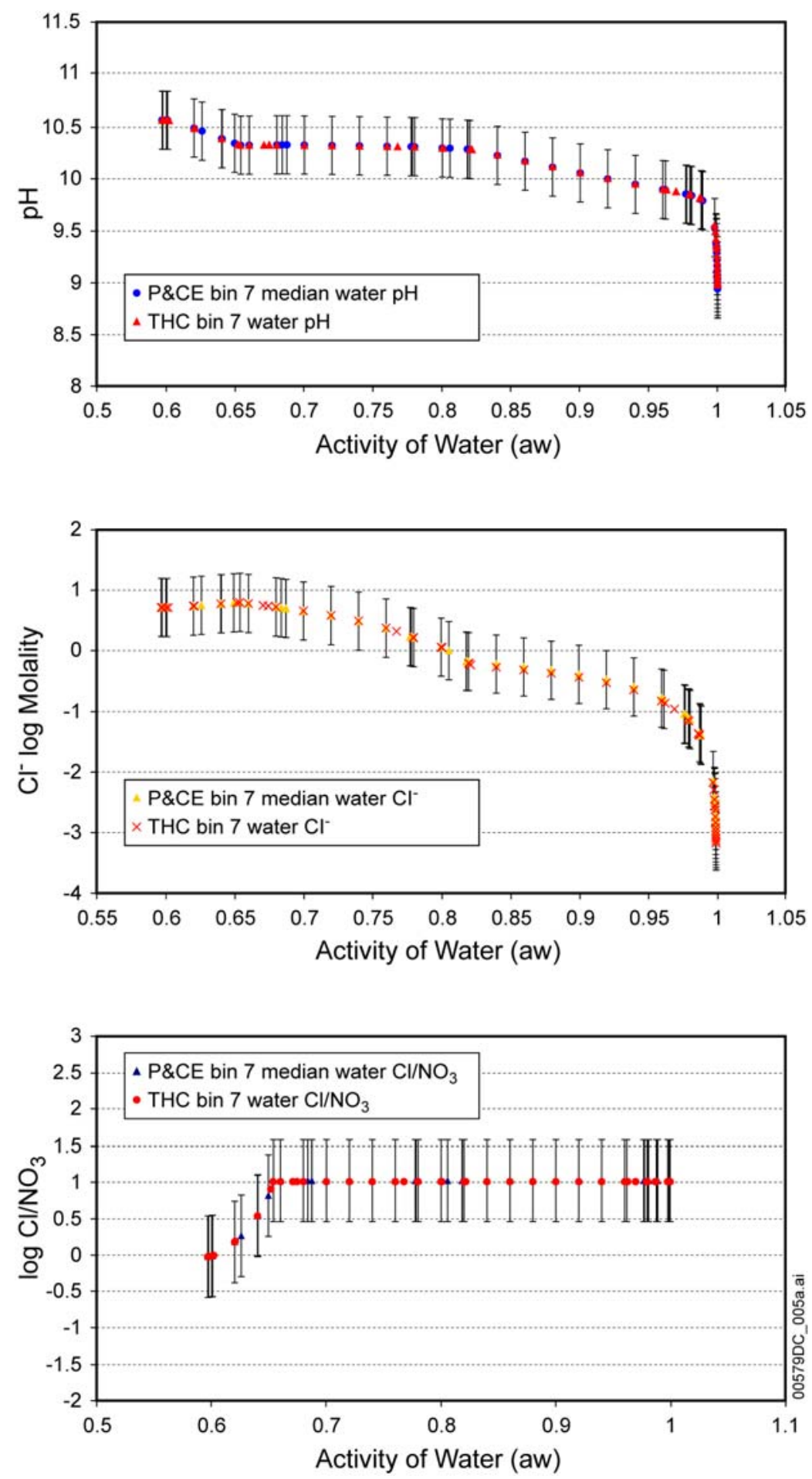

Source: Output DTN: MO0505SPAPCEBV.000.

NOTE: $\quad$ The bin-7 median water data on this figure are based on the THC seepage model output for the w4 starting water (10,000 year base-front). As discussed in Section 6.6.7.3, the bin-7 median water used for TSPA is based on the THC seepage model output for the w0 starting water (10,000 year base-front).

Figure 7.3-5. Bin $7 \mathrm{pH}, \mathrm{Cl}^{-}$, and $\mathrm{Cl}^{-} / \mathrm{NO}_{3}^{-}$Results 

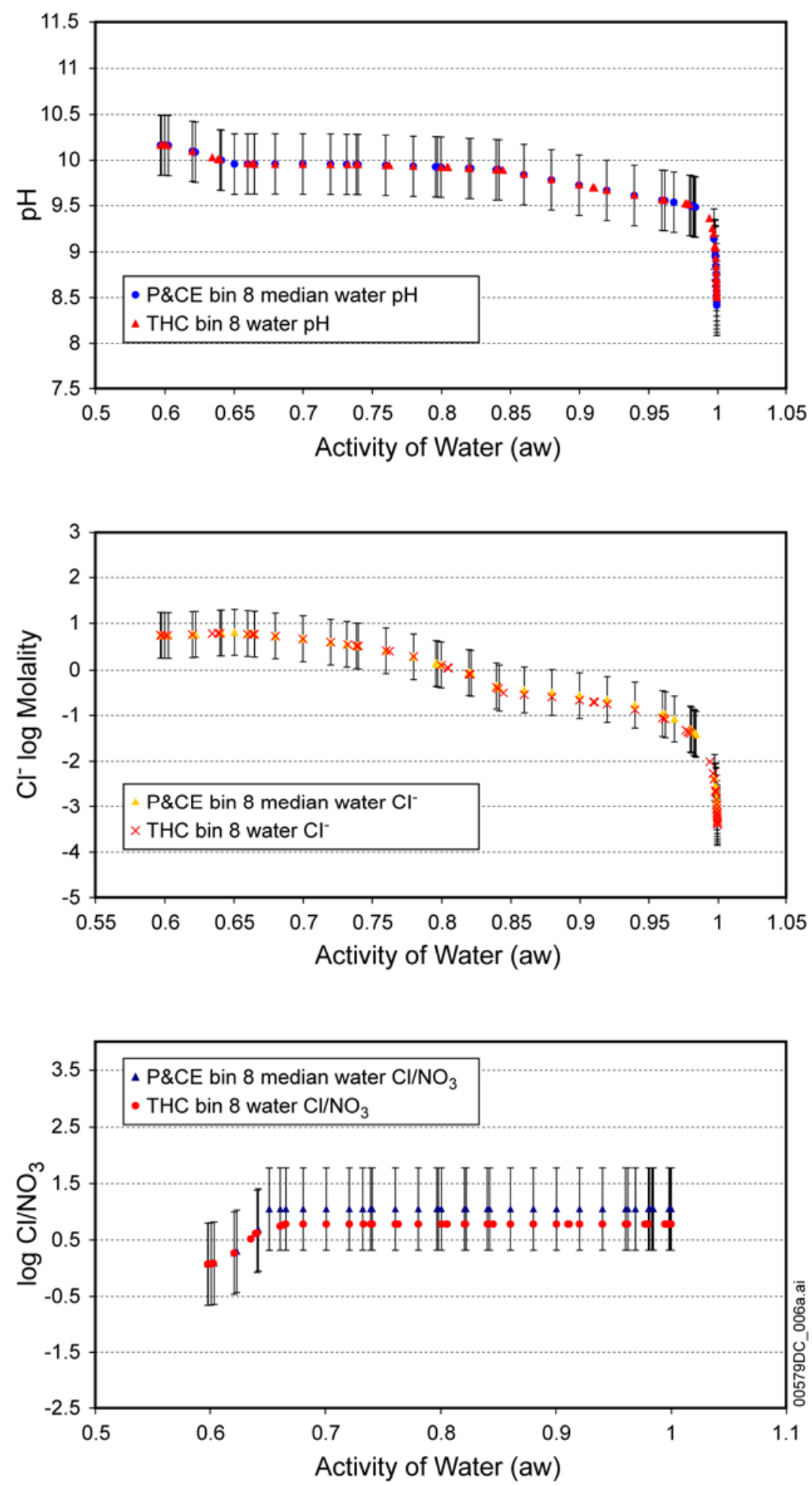

Source: Output DTN: MO0505SPAPCEBV.000.

Figure 7.3-6. Bin $8 \mathrm{pH}, \mathrm{Cl}^{-}$, and $\mathrm{Cl}^{-} / \mathrm{NO}_{3}{ }^{-}$Results 

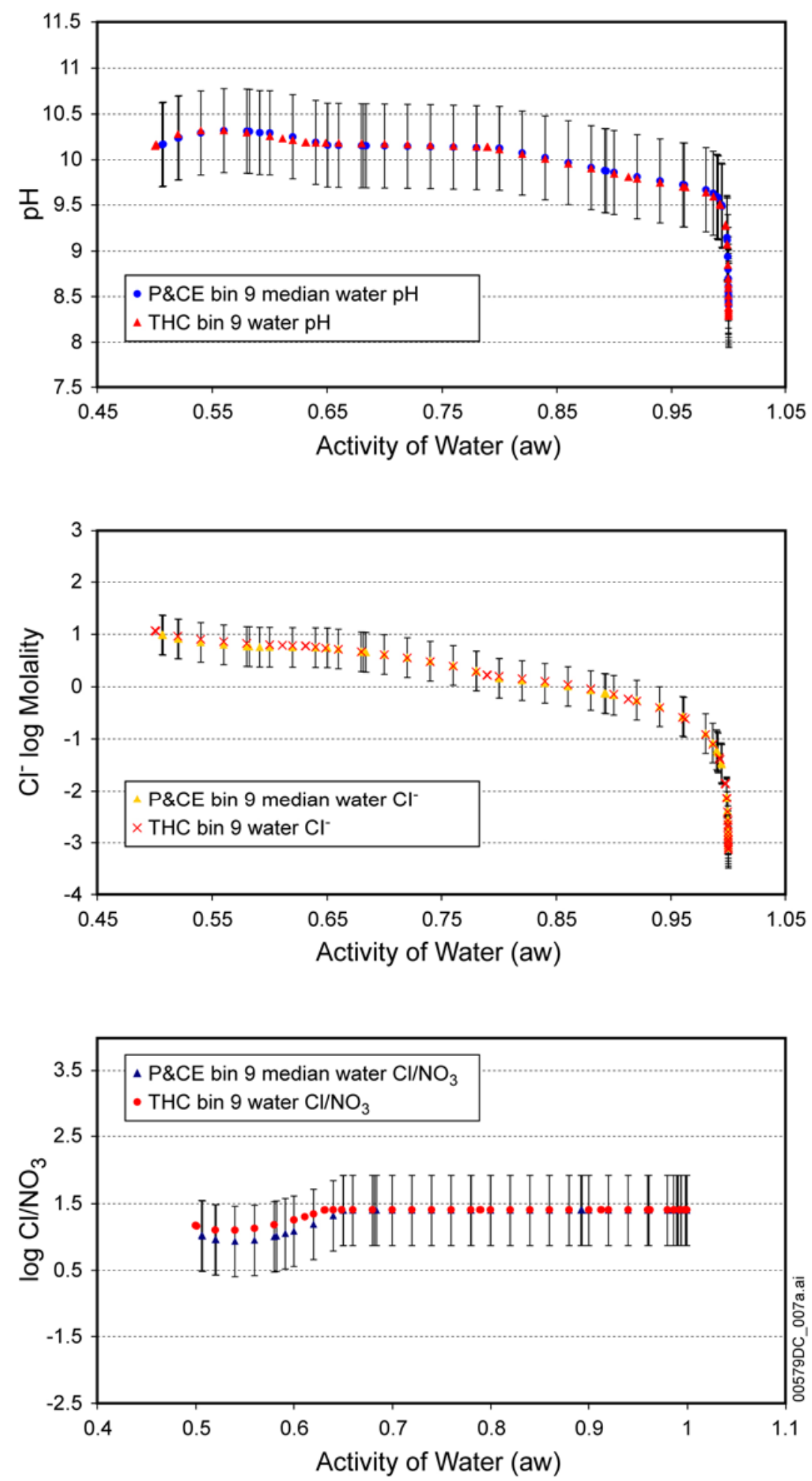

Source: Output DTN: MO0505SPAPCEBV.000.

Figure 7.3-7. Bin $9 \mathrm{pH}, \mathrm{Cl}^{-}$, and $\mathrm{Cl}^{-} / \mathrm{NO}_{3}{ }^{-}$Results 

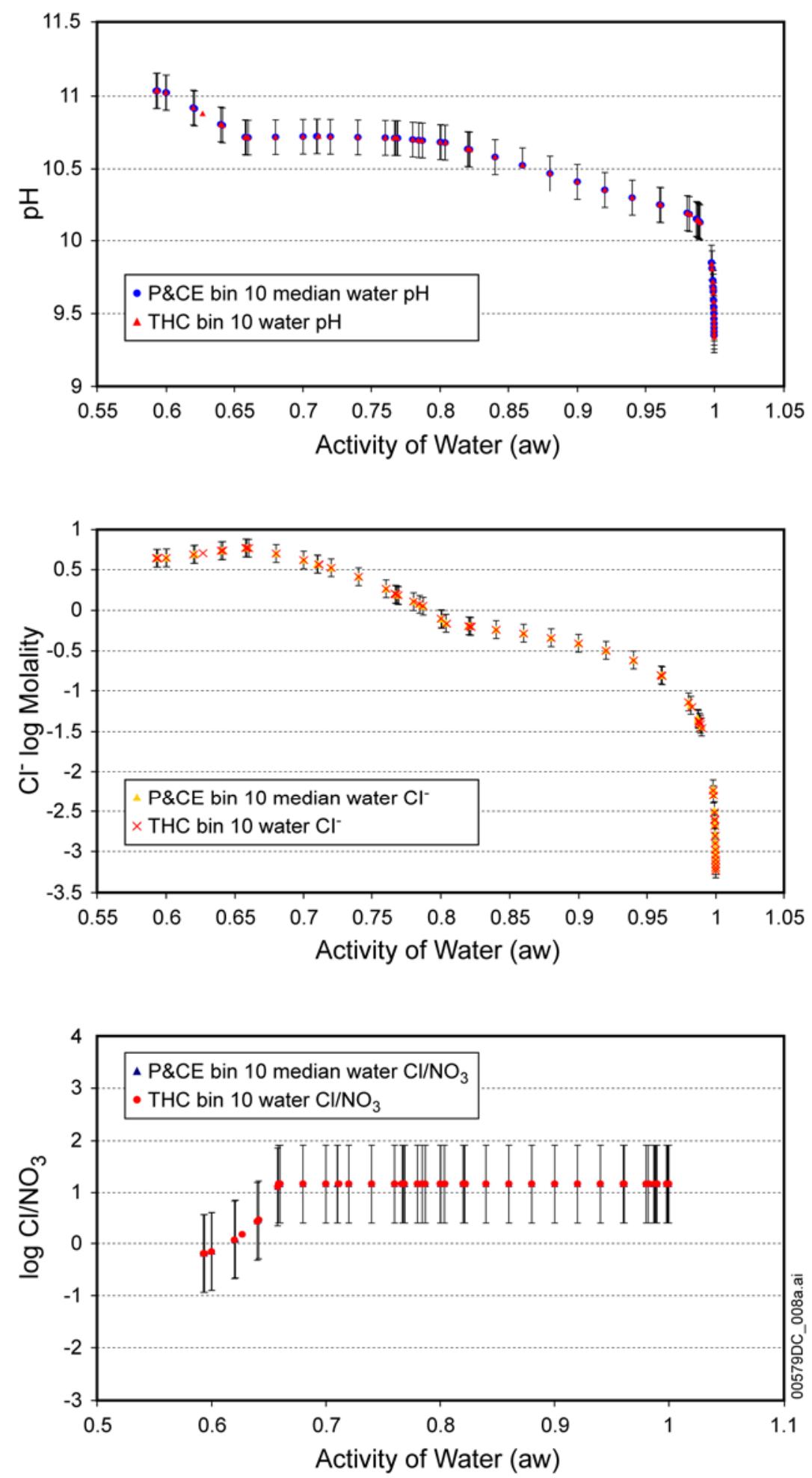

Source: Output DTN: MO0505SPAPCEBV.000.

Figure 7.3-8. Bin $10 \mathrm{pH}, \mathrm{Cl}^{-}$, and $\mathrm{Cl}^{-} / \mathrm{NO}_{3}{ }^{-}$Results 

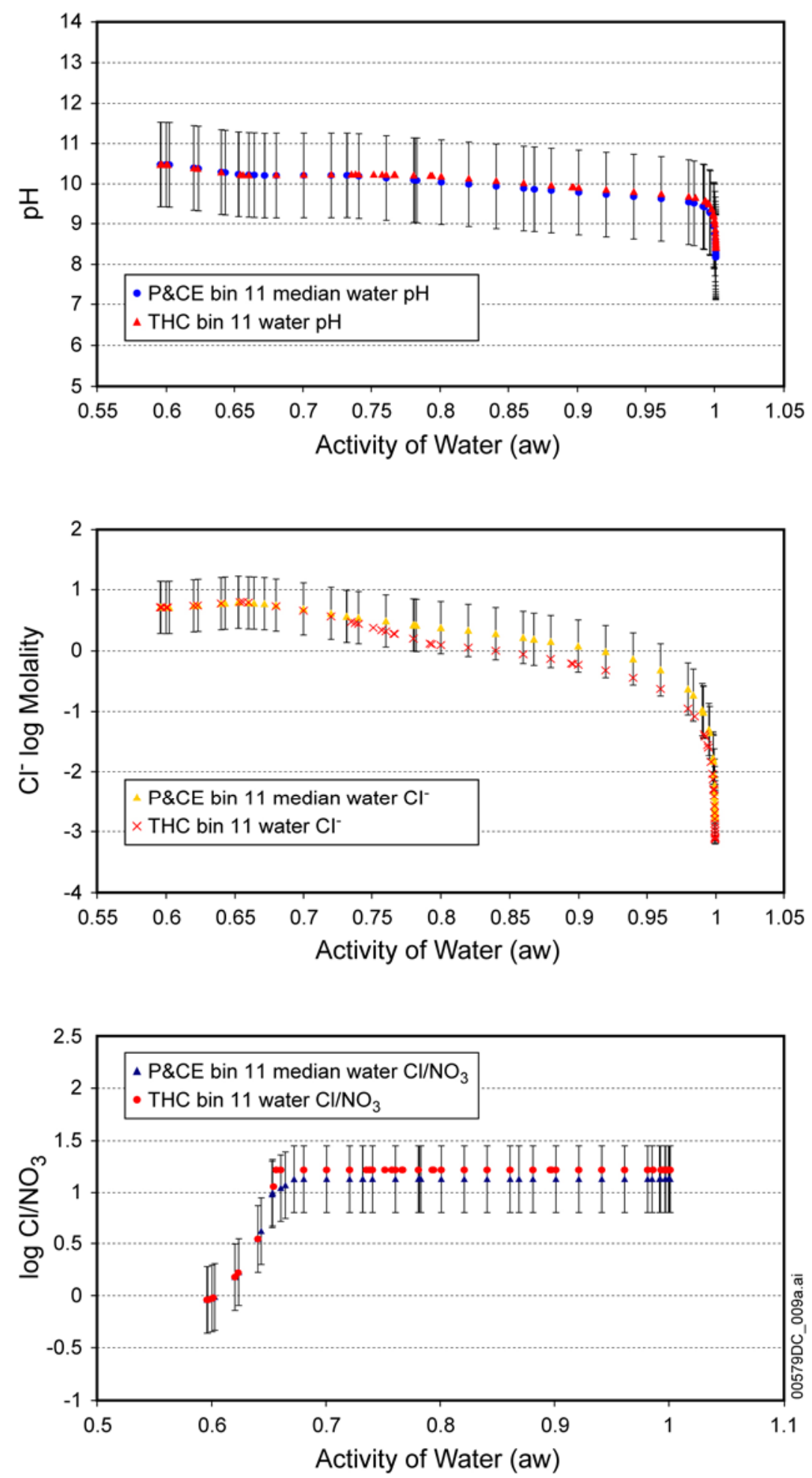

Source: Output DTN: MO0505SPAPCEBV.000.

Figure 7.3-9. Bin $11 \mathrm{pH}, \mathrm{Cl}^{-}$, and $\mathrm{Cl}^{-} / \mathrm{NO}_{3}{ }^{-}$Results 


\subsubsection{Evaporation of Sierra Nevada Spring Waters to Form Concentrated Brines}

This analysis contributes to confidence in the IDPS process model, which is the basis of the seepage evaporation abstraction, by performing a comparison to published data for evaporation concentration of Sierra Nevada mountain spring water. The information presented below is similar to the model-data comparisons provided in In-Drift Precipitates/Salts Model (BSC 2004 [DIRS 169863], Section 7), but uses a published data set that was not included. The results show good agreement, to within the accuracy of model output that could be achieved given the charge balance of the reported measurements used as input, and the definitions of the mineral precipitates used.

The process model underlying the seepage evaporation abstraction is evaluated by comparison with a classical data set that includes evaporative concentration of dissolved species and mineral precipitation. The data set is for the isothermal evaporation, at $25^{\circ} \mathrm{C}$ and $p \mathrm{CO}_{2}=10^{-3.5}$ bar, of Sierra Nevada spring water by Garrels and Mackenzie (1967 [DIRS 123636], pp. 222 to 242), which has been cited by Drever (1988 [DIRS 118564], pp. 232 to 234) as "a simulation of what might happen if streams from the Sierra Nevada flowed out into one of the arid basins of Nevada" to form saline lake water.

Drever (1988 [DIRS 118564], p. 233) suggests that the resulting brine "chemistry of these lakes could be explained by simple evaporation of dilute spring waters whose chemistry was, in turn, controlled by reactions between rainwater and igneous rock." In an analogous way, several Yucca Mountain waters can concentrate into alkaline carbonate brines by evaporation of initial crown seepage, invert wicking, or condensate that has reacted with volcanic tuff. It is useful to compare the $\mathrm{pH}$ and major ion concentrations from this classical study, with up to 1,000-fold evaporative concentration, against the same concentration range developed using the methodology of the present work (Figure 7.3-10).

Before detailing the results of the Sierra Nevada Spring evaporation calculations, the difference in databases, mineral suppression during speciation calculations, and the number of chemical species is addressed. Garrels and Mackenzie (1967 [DIRS 123636], p. 234) originally considered 11 major aqueous species and 7 minerals that could precipitate during evaporative concentration: calcite, gypsum, brucite, magnesite, hydromagnesite, sepiolite, and amorphous silica. In this comparison up to 22 aqueous species with concentrations greater than $10^{-20}$ molal are output (this concentration limit is set in the EQ3/6 input files, sierra.3i and sierra.6i, archived in Output DTN: SN0404T0510102.014). Saturation values for nearly 40 minerals, minus mineral suppressions, are evaluated.

Further, the molecular formula of sepiolite and hydromagnesite has been revised. The common molecular formula for sepiolite has been changed from $\mathrm{MgSi}_{3} \mathrm{O}_{6}(\mathrm{OH})_{2}$ (Garrels and Mackenzie 1967 [DIRS 123636], p. 234) to $\mathrm{Mg}_{4} \mathrm{Si}_{6} \mathrm{O}_{15}(\mathrm{OH})_{2} \cdot 6 \mathrm{H}_{2} \mathrm{O}$. The formula for hydromagnesite has been changed from $\mathrm{Mg}_{4}\left(\mathrm{CO}_{3}\right)_{3}(\mathrm{OH})_{2}$ (Garrels and Mackenzie 1967 [DIRS 123636], p. 234) to $\mathrm{Mg}_{5}\left(\mathrm{CO}_{3}\right)_{4}(\mathrm{OH})_{2} \cdot 4 \mathrm{H}_{2} \mathrm{O}$. The Debye-Hückel activity coefficients used by Garrels and Mackenzie are accurate up to an ionic strength of 0.05 molal (Garrels and Christ 1990 [DIRS 144877], p. 64). However, at the concentration factor of 1,000 the ionic strength is nearly 0.2 molal (sierra.6o at 0.996 activity of water, archived in Output DTN: SN0404T0510102.014). Garrels and Mackenzie (1967 [DIRS 123636], p. 240) were 
aware of the problem in using activity coefficients derived for use in lower ionic strength solutions, and emphasized that their results were increasingly uncertain with greater ionic strength: "Using the Debye-Hückel activity coefficients obviously leads to an increasing

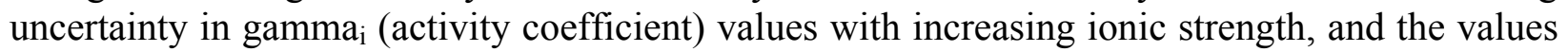
calculated for $1,000 \times$ concentration should be regarded as rough approximations." The Pitzer activity coefficients calculated with the current modeling are accurate to ionic strength well over 1 molal.

Figure 7.3-10 shows close similarity despite the differences in how the results were derived. The evaporative concentration starts with a near-neutral $\mathrm{pH}, \mathrm{Na}-\mathrm{Ca}-\mathrm{HCO}_{3}$ water and concentrates it to alkaline $\mathrm{Na}-\mathrm{HCO}_{3}-\mathrm{CO}_{3}$ water. Calcium and magnesium are removed by early mineral precipitation of calcite and sepiolite, respectively. $\mathrm{Na}^{+}, \mathrm{K}^{+}, \mathrm{Cl}^{-}$, and $\mathrm{SO}_{4}{ }^{2-}$ are conservatively concentrated without forming solids. Bicarbonate and carbonate ions deviate from log-linear concentration due to calcite precipitation and their equilibrium relation. Because the Sierra Spring waters are originally low in $\mathrm{SO}_{4}{ }^{2-}$, gypsum does not precipitate in these data. Aqueous silica is seen to saturate at approximately the same concentration, around 0.002 molal. Many waters in the repository are expected to concentrate by evaporation in a similar manner (Section 6.9).

The only difference lies in the initial concentration of chloride. This occurs because of a difference in charge balancing between the original study and the present work. The present EQ3/6 calculation performed charge balancing on chloride, whereas the literature source used bicarbonate. As chloride is conservatively concentrated in both models (chloride never saturates with respect to any mineral or salt), this has a negligible impact on the comparisons for other species.

The plotted data comparison (Figure 7.3-10) to evaporation data from Garrels and Mackenzie (1967 [DIRS 123636], pp. 222 to 242) provides additional confidence for the validity of the IDPS model (BSC 2004 [DIRS 169863]), for evaporative concentration of $\mathrm{Na}-\mathrm{Ca}-\mathrm{HCO}_{3}$ waters up to approximately 1,000 -fold. 


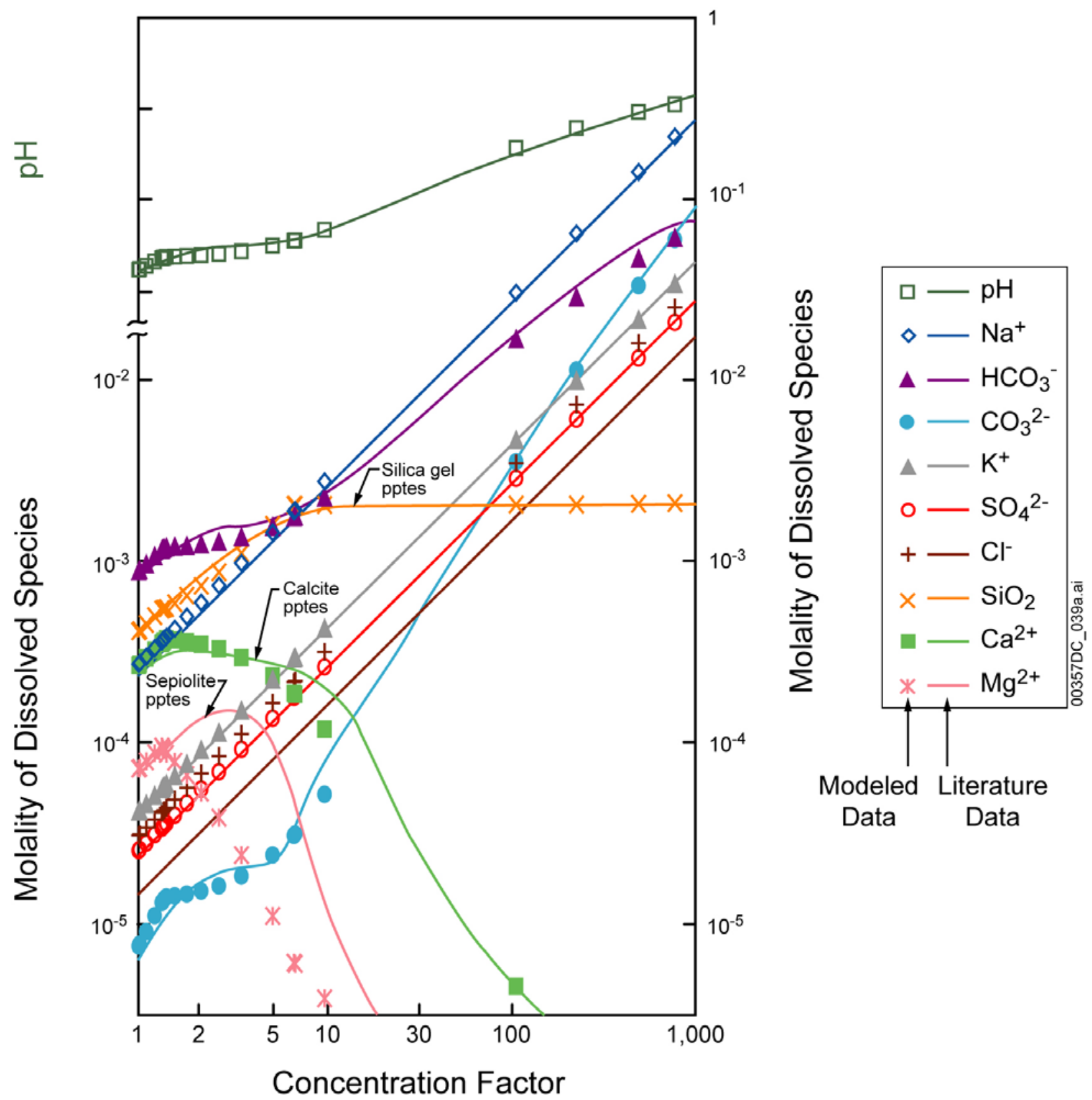

Sources: Modeled data: Output DTN: SN0404T0510102.014; literature data: Garrels and Mackenzie 1967 [DIRS 123636], p. 239.

NOTES: pptes $=$ precipitates .

Mineral pptes labels and associated arrows do not necessarily indicate the location on the figure where precipitation begins, but rather indicate that the specific aqueous species to which an arrow points is controlled by the precipitation of the corresponding mineral that is given next to the arrow.

Figure 7.3-10. Comparison of Results of Evaporation of Typical Sierra Nevada Spring Water at $25^{\circ} \mathrm{C}$ in Equilibrium with Atmospheric $p \mathrm{CO}_{2}$ at $10^{-3.5}$ bar 


\subsubsection{Comparison of THC Seepage Model with Seepage Binning Analysis}

This analysis was performed during development of the seepage evaporation abstraction to compare the compositions of potential seepage waters calculated by the THC seepage process model, with the corresponding time series of median bin waters from the analysis described in Section 6.6. This analysis differs from that in Section 7.3.2 because it compares the binning analysis with THC seepage model output on the basis of time history instead of relative humidity. This comparison provides a check that the original post-processing THC model output for the five model runs (BSC 2004 [DIRS 169858], Section 6.2.3.3) falls within the 95\% uncertainty bounds from the abstraction, over the duration of the simulation. It is not an exact comparison of the seepage analysis with process model output, because median bin waters are used without equilibration to time-dependent environmental conditions. Accordingly, some discrepancies are noted as discussed below, but the process model output generally lies within the range of the median bin waters (plus uncertainty), increasing confidence that the binning analysis has provided reasonable results.

These comparisons are documented in THC Seepage Validation Spreadsheet LOG distributions.xls (Output DTN: MO0312SPAPCESA.002), which contains the output values developed in Section 6.6. This spreadsheet was constructed using the "THC Starting Chemistry Tables" worksheet (copied from Final Checked EBS THC Seepage Binning Abstraction REV 4.xls archived in Output DTN: MO0508SPAEBSCB.001), the "All Data" worksheet, and the 11 bin worksheets copied from New Non Evaporated Binning Statistics.xls archived in Output DTN: MO0310SPAEBSUE.002.

For each comparison (Figures 7.3-11 through 7.3-21), two data series and one set of uncertainty bars are plotted:

- First, for the "THC Seepage" curves, the uncertainty bars represent the range of actual water chemistry found on the "All Data" worksheet. These data are the THC seepage model values for the waters identified (see Section 6.6.2) to potentially seep into the drift from the crown (tf4) or from the invert (bf4) for the various THC model starting waters (w0, w4, w5, w6, and w7). These values change as a function of time.

- Second, for the "Bin Median Water Analysis" curves, the symbols show the median bin water chemistry found on the "THC starting chemistry" tables. These are the median water compositions chosen for each of the 11 bins. The compositions do not change with time; rather, the bin assignment varies with time for each of the five starting waters. Importantly, as plotted in Figures 7.3-11 through 7.3-21, the median bin waters have not been equilibrated to the environmental conditions in the drift (temperature, relative humidity, and $\mathrm{pCO}_{2}$ ), which change with time. The equilibration to environmental conditions would improve the correspondence between the THC seepage waters and the median bin waters. This simplified comparison shows that reasonable agreement is obtained without further equilibration to environment conditions, with a few exceptions discussed below. The differences between the median bin waters (with uncertainty) and the THC model output are not errors, but result mainly from not equilibrating the median waters with the environmental conditions associated with the THC model output. 
- Third, the $\pm 2 \sigma$ uncertainty bars centered on the "Bin Median Water Analysis" points represent the binning uncertainty, i.e., the estimated uncertainty introduced in the binning analysis process. The $2 \sigma$ values used to generate the log-uncertainty bars are twice the standard deviations calculated from the logs of the component concentrations in the THC seepage waters that reside in each bin (Table 6.12-4). This $\pm 2 \sigma$ uncertainty estimate captures approximately $95 \%$ of uncertainty range. These binning uncertainty estimates are bin specific, but do not change as a function of time.

Figures 7.3-11 through 7.3-21 compare the median bin water compositions with the original THC model output. As an example, the bin information for Figure 7.3-16 is mapped in Figure 6.13-1 for water w5 in the invert. The THC seepage water represents the temporal evolution of this water (matrix water at the base of the invert, for the wetting front at node four - w5bf4). To limit the comparisons to a reasonable number, the results for all five waters are shown only for crown seepage $\mathrm{pH}, \mathrm{Cl}^{-}$, and $\mathrm{NO}_{3}{ }^{-}$(Figures 7.3-11, 7.3-15, and 7.3-21), as these are outputs directly used in TSPA-LA. Plots for other solution parameters are provided for specific starting waters, selected as examples (Figures 7.3-12 and 7.3-13, $\mathrm{Ca}^{2+}$ and $\mathrm{Mg}^{2+}$ for starting water w0; Figure 7.3-14, $\mathrm{Na}^{+}$for starting water w4; Figures 7.3-16 and 7.3-17, $\mathrm{SiO}_{2}$ and $\mathrm{HCO}_{3}{ }^{-}$for starting water w5; Figures 7.3-18 and 7.3-19, $\mathrm{SO}_{4}{ }^{-2}$ and $\mathrm{K}^{+}$for starting water w6; and Figure 7.3-20, $\mathrm{F}^{-}$for starting water $\mathrm{w} 7$ ).

The binning analysis, represented by the median bin water time histories and the binning uncertainty, provides a smoothed version of the THC model output. With the exception of a few data, all the THC model output values lie within the $\pm 2 \sigma$ log-uncertainty bars. One exception is the apparent underprediction of $\mathrm{Cl}^{-}$and $\mathrm{NO}_{3}{ }^{-}$concentrations at approximately 53 years (Figures 7.3-15 and 7.3-21) which is due to the evaporative concentration (i.e., lower relative humidity) that is explicitly included in the THC model but not accounted for in the treatment of median bin waters for these figures. Importantly, for the implementation of the seepage evaporation abstraction in TSPA, the median bin waters are equilibrated to the extant conditions of temperature, relative humidity, and carbon dioxide partial pressure.

Another exception is noted in the $\mathrm{pH}$ at about 2,000 years (Figure 7.3-11a through $\mathrm{d}$ ) when the time series of median bin waters does not represent the transient $\mathrm{pH}$ decrease. This occurs because the median bin water for Bin 4 is assigned to this time step, except for water w7 (see Tables 6.6-8 through 6.6-12 at starting year of 1,901). The Bin 4 median water actually originates from the THC model output at 600 years, when $\mathrm{pCO}_{2}$ is relatively low $\left(4.8 \times 10^{-4}\right.$ bar $)$. Comparatively, at 2,000 years, $\mathrm{pCO}_{2}$ is increased significantly to approximately $6.5 \times 10^{-3}$ bar (see Tables 6.7-1 through 6.7-5 at starting year of 1,901.5). The increase in $\mathrm{CO}_{2}$ pressure (approximately one order of magnitude), if used in equilibration of the Bin 4 median water, would decrease the $\mathrm{pH}$ of the Bin 4 median water to a similar extent.

(To obtain this result, a hand-interpolation can be done using the lookup tables for Bin 4 at $100^{\circ} \mathrm{C}$ : files $04 c 2 t 1 c . x l s$ and $04 c 3 t 1 c . x l s$ found in seepage_lookup_cond.zip in Output DTN: MO0310SPAPCEGS.000. For the Bin 4 median water, the $\mathrm{pH}$ is 7.155 and 7.674 for $p \mathrm{CO}_{2}$ at $10^{-2}$ and $10^{-3}$ bar, respectively. Interpolating this by the log-scale value for $p \mathrm{CO}_{2}$ at 2,000 years, $6.5 \times 10^{-3}=10^{-2.2}$, produces a $\mathrm{pH}$ value of 7.26. This is significantly lower than the unadjusted median $\mathrm{pH}$ of 7.90 for Bin 4, and it encompasses the $\mathrm{pH}$ values from the THC model output at 2,000 years in Figure 7.3-11.) 
As stated previously, the comparisons in Figures 7.3-11 through 7.3-21 show that reasonable correspondence with the THC model output is obtained, with a few exceptions, without further detailed calculations. The exceptions would disappear with equilibration of the median bin waters, or if the IDPS model uncertainty (Table 6.12-1) were added to the uncertainty bars (especially for $\mathrm{pH}$ in Figure 7.3-11), to represent how the seepage evaporation abstraction is implemented in TSPA. The magnitude of the IDPS model uncertainty is generally $1 \mathrm{pH}$ unit for temperatures less than boiling, and ranges from zero to $0.2 \log$-units for $\mathrm{Cl}^{-}$concentration and the $\mathrm{Cl}^{-} / \mathrm{NO}_{3}{ }^{-}$molar ratio. Further discussion of uncertainty in the seepage evaporation abstraction, and how it is implemented in TSPA, is presented in Section 6.12.

The results plotted in Figures 7.3-11 to 7.3-21 are affected by the selection of Bin 7 median water, discussed in Section 6.6.7.3. The results shown in the figures were compiled using the w4-derived median water for Bin 7, whereas the w0-derived water is used for the seepage evaporation abstraction. The differences betweens these water compositions are not readily discernible on the figures presented in this section. Firstly, the Bin 7 median waters are only part of the bin histories for the seepage evaporation abstraction (Figure 6.13-1) at early time ( $<50 \mathrm{yr}$ ) and late time (greater than approximately 8,500 yr for invert seepage, and 11,000 yr for crown seepage). Hence only the last few points on these plots could be affected. Secondly, the most potentially significant difference between the w4-derived and w0-derived median bin waters is the chloride concentration, which is approximately 3-fold greater for the w0-derived median water used in the seepage evaporation abstraction (Figure 6.6-26). Accordingly on Figure 7.3-15 the affected points on the plots for w0, w4, w5, and w7 would be those beyond 11,000 yr, and the effect would be to increase the "Bin Median Water Abstraction" points by approximately one-half an order of magnitude. The plot for w6 corresponds to a bin history (Figure 6.13-1) that does not include Bin 7 at late time. In summary, the results presented in this section are not sensitive to the differences between the w4-derived and w0-derived median waters for Bin 7 , because the differences are limited in scope and in effect. 
(a)

wotf4

(b)

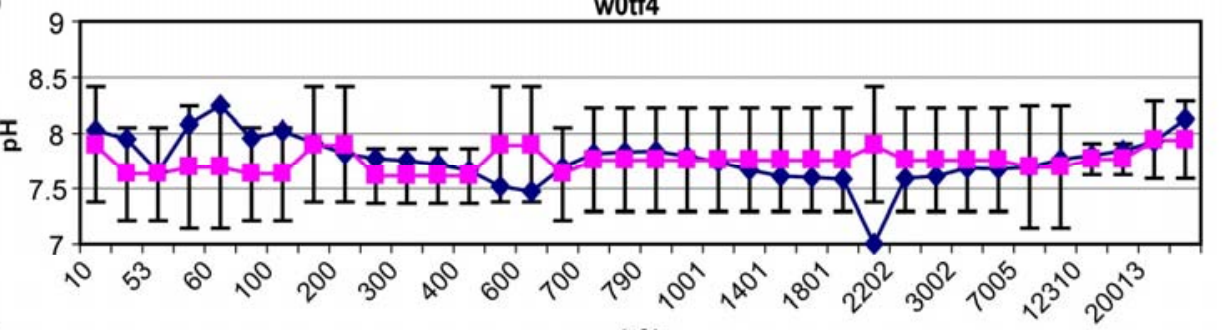

(b)

w4tf4

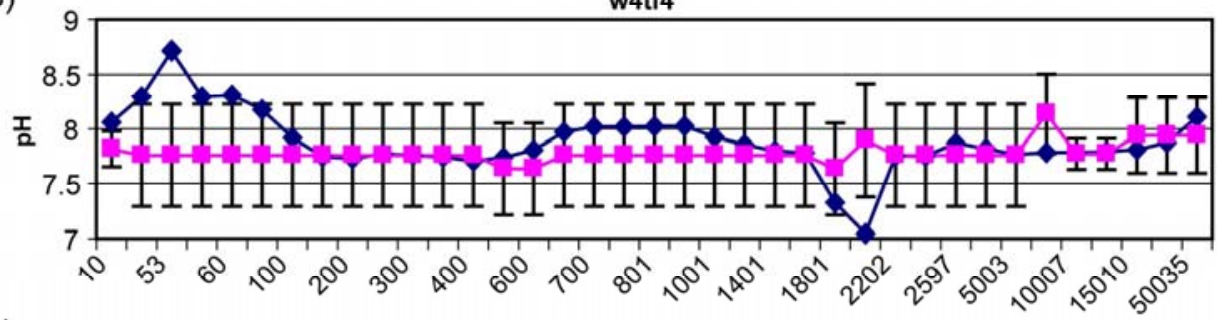

(c)

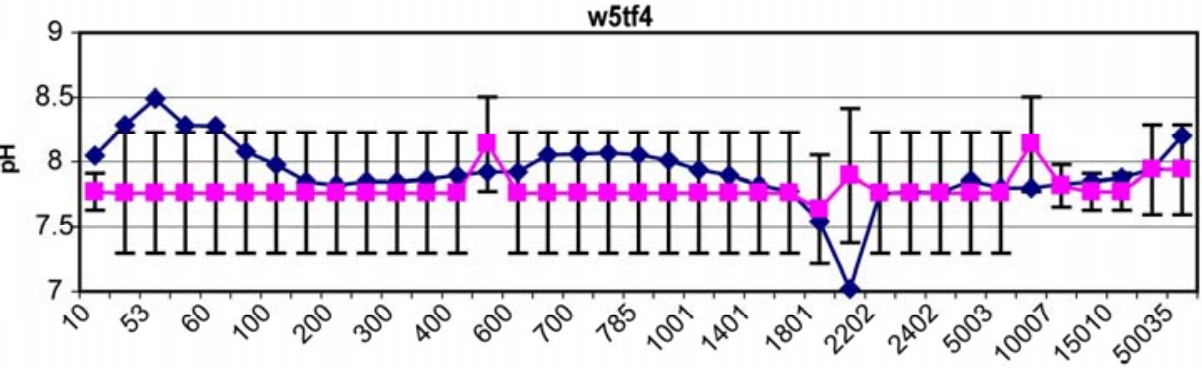

(d)

w6tf4

(e)
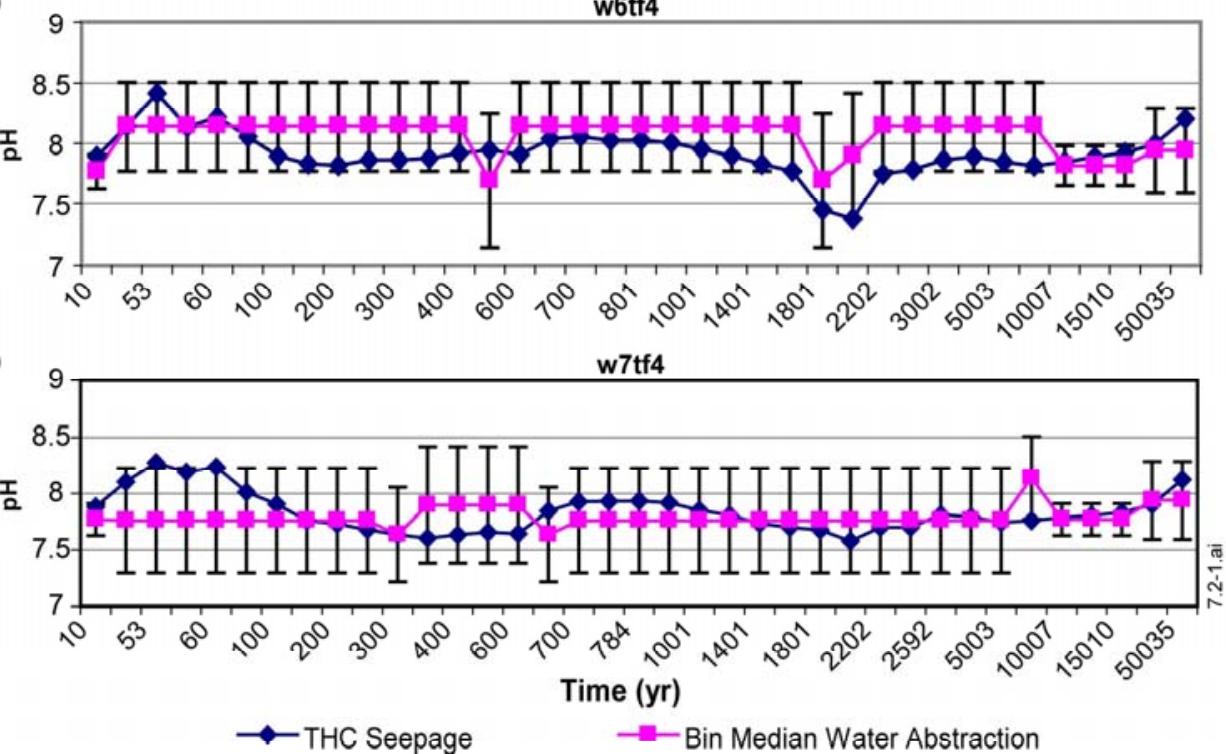

Source: Output DTN: MO0312SPAPCESA.002, THC Seepage Validation Spreadsheet LOG distributions.xls.

NOTE: The median water for bin 7 is plotted among median bin waters in this figure. The composition is based on the THC seepage model output for the w4 starting water (10,000 year base-front). As discussed in Section 6.6.7.3, the bin 7 median water used for TSPA is based on the THC seepage model output for the w0 starting water (10,000 year base-front). The affected points on these plots lie only at early time $(<50 \mathrm{yr})$ and at late time $(>11,000 \mathrm{yr})$.

Figure 7.3-11. Comparison of THC Seepage pH with Crown Seepage Water Binning Analysis 


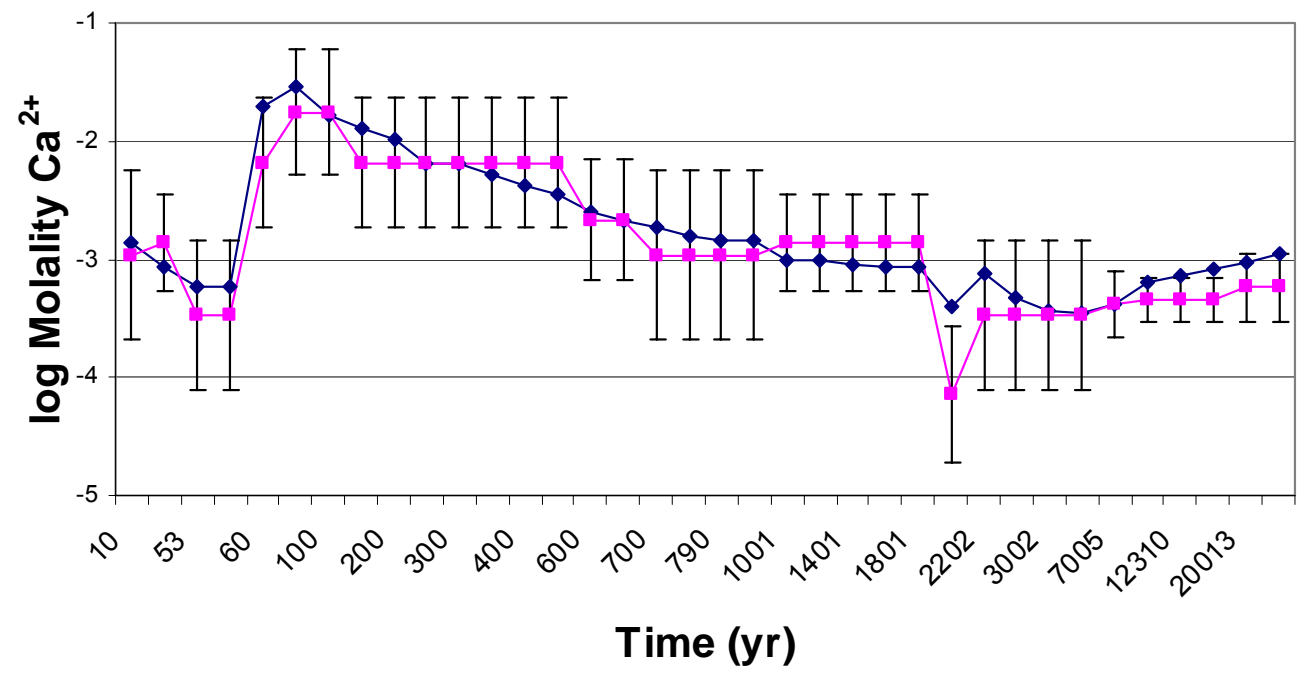

$\multimap$ w0bf4 THC Seepage $\_-$w0bf4 Bin Median Water Abstraction

Source: Output DTN: MO0312SPAPCESA.002, THC Seepage Validation Spreadsheet LOG distributions.xIs.

NOTE: The median water for bin 7 is plotted among median bin waters in this figure. The composition is based on the THC seepage model output for the w4 starting water (10,000 year base-front). As discussed in Section 6.6.7.3, the bin 7 median water used for TSPA is based on the THC seepage model output for the w0 starting water $(10,000$ year base-front). The affected points on these plots lie only at early time $(<50 \mathrm{yr})$ and at late time $(>8,500 \mathrm{yr})$.

Figure 7.3-12. Comparison of THC Seepage $\mathrm{Ca}^{2+}$ with Binning Analysis for w0bf4 Invert Seepage

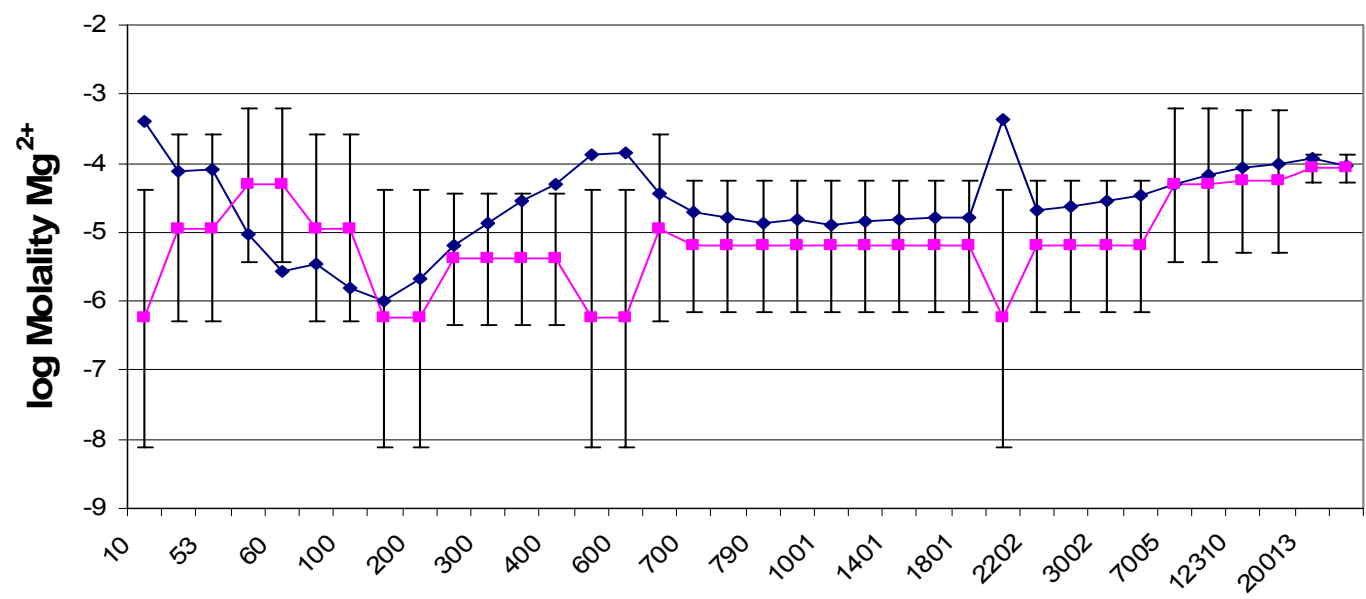

Time (yr)

Source: Output DTN: MO0312SPAPCESA.002, THC Seepage Validation Spreadsheet LOG distributions.xIs.

NOTE: The median water for bin 7 is plotted among median bin waters in this figure. The composition is based on the THC seepage model output for the w4 starting water (10,000 year base-front). As discussed in Section 6.6.7.3, the bin 7 median water used for TSPA is based on the THC seepage model output for the w0 starting water (10,000 year base-front). The affected points on these plots lie only at early time $(<50 \mathrm{yr})$ and at late time $(>11,000 \mathrm{yr})$.

Figure 7.3-13. Comparison of THC Seepage $\mathrm{Mg}^{2+}$ with Binning Analysis for w0tf4 Crown Seepage 


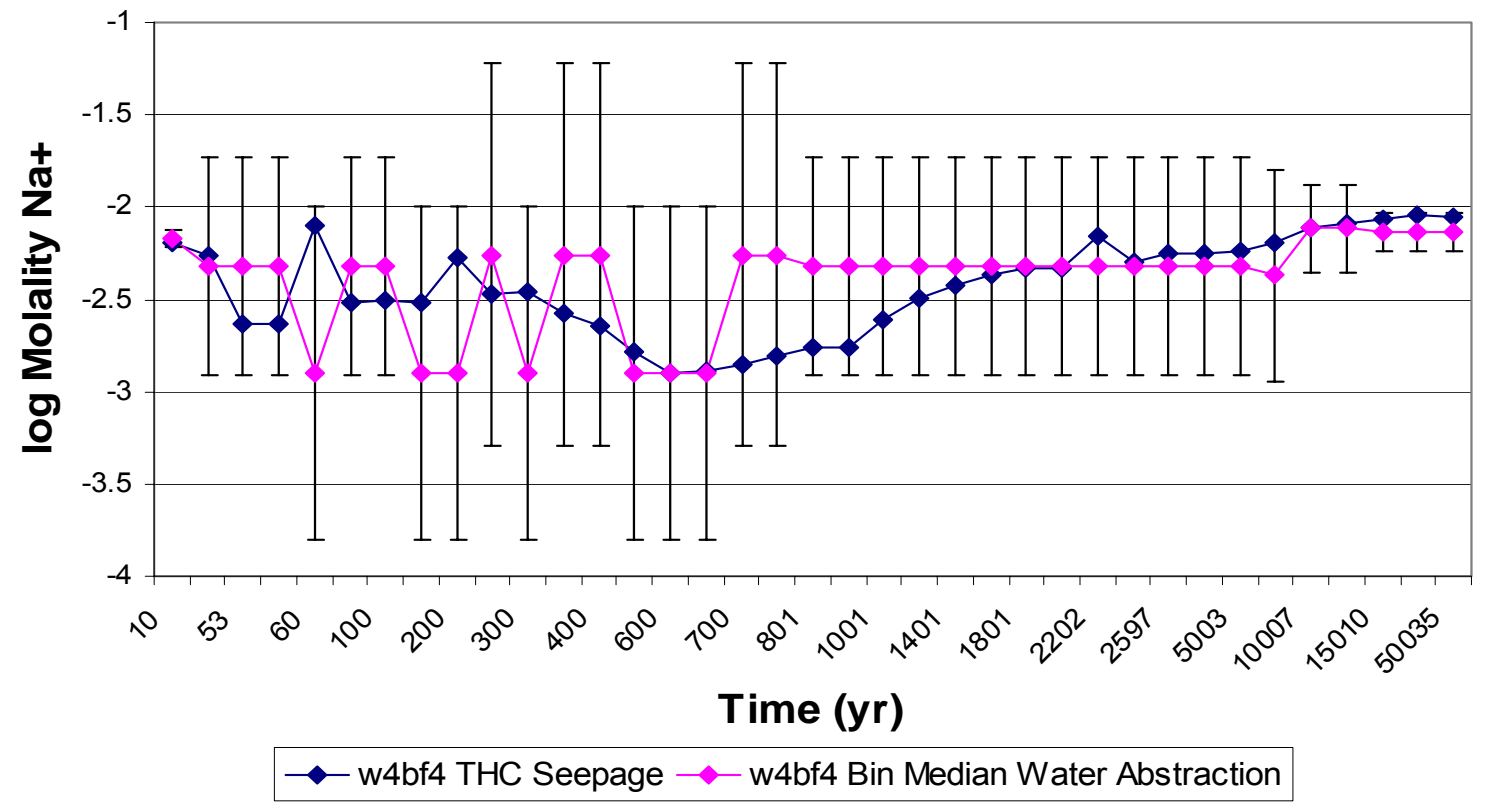

Source: Output DTN: MO0312SPAPCESA.002, THC Seepage Validation Spreadsheet LOG distributions.xIs.

NOTE: The median water for bin 7 is plotted among median bin waters in this figure. The composition is based on the THC seepage model output for the w4 starting water (10,000 year base-front). As discussed in Section 6.6.7.3, the bin 7 median water used for TSPA is based on the THC seepage model output for the w0 starting water (10,000 year base-front). The affected points on these plots lie only at early time $(<50 \mathrm{yr})$ and at late time $(>8,500 \mathrm{yr})$.

Figure 7.3-14. Comparison of THC Seepage $\mathrm{Na}^{+}$with Binning Analysis for w4bf4 Invert Seepage 

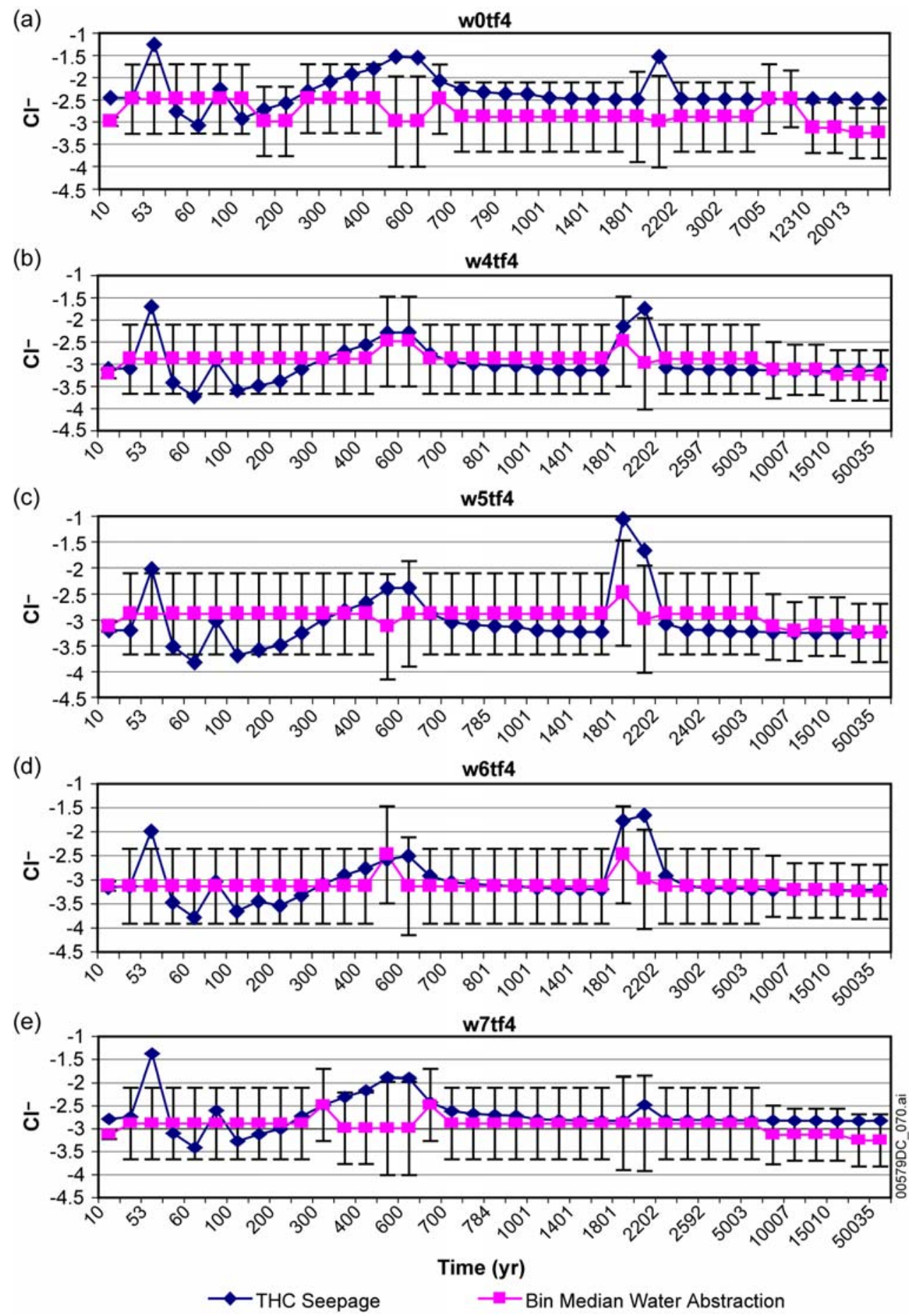

Source: Output DTN: MO0312SPAPCESA.002, THC Seepage Validation Spreadsheet LOG distributions.xIs.

NOTES: $\mathrm{Cl}^{-}$units given as log molality.

The median water for bin 7 is plotted among median bin waters in this figure. The composition is based on the THC seepage model output for the w4 starting water (10,000 year base-front). As discussed in Section 6.6.7.3, the bin 7 median water used for TSPA is based on the THC seepage model output for the w0 starting water (10,000 year base-front). The affected points on these plots lie only at early time $(<50 \mathrm{yr})$ and at late time $(>11,000 \mathrm{yr})$.

Figure 7.3-15. Comparison of THC Seepage $\mathrm{Cl}^{-}$with Crown Seepage Water Binning Analysis 


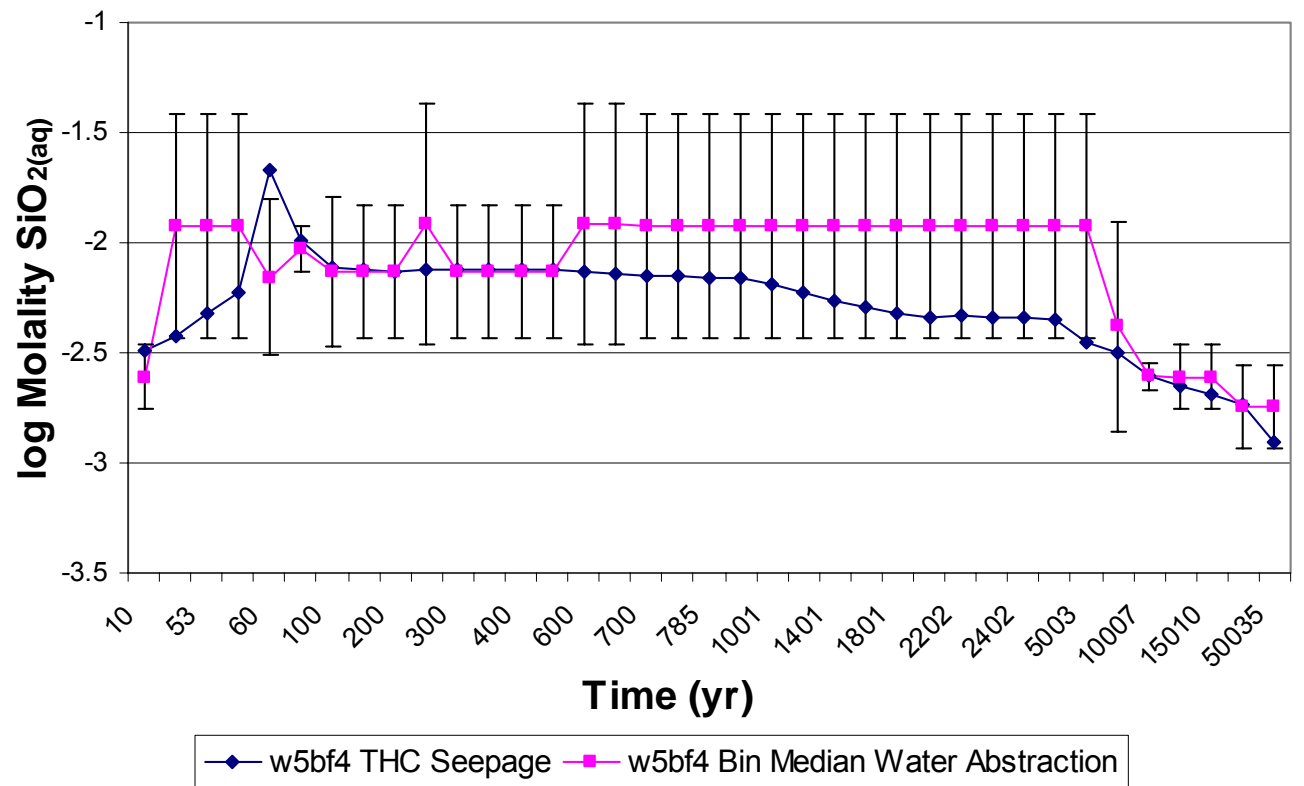

Source: Output DTN: MO0312SPAPCESA.002, THC Seepage Validation Spreadsheet LOG distributions.xls.

NOTE: The median water for bin 7 is plotted among median bin waters in this figure. The composition is based on the THC seepage model output for the w4 starting water (10,000 year base-front). As discussed in Section 6.6.7.3, the bin 7 median water used for TSPA is based on the THC seepage model output for the w0 starting water (10,000 year base-front). The affected points on these plots lie only at early time $(<50 \mathrm{yr})$ and at late time $(>8,500 \mathrm{yr})$.

Figure 7.3-16. Comparison of $\mathrm{THC}$ Seepage $\mathrm{SiO}_{2}(\mathrm{aq})$ with Abstraction Results for w5bf4 Invert Seepage

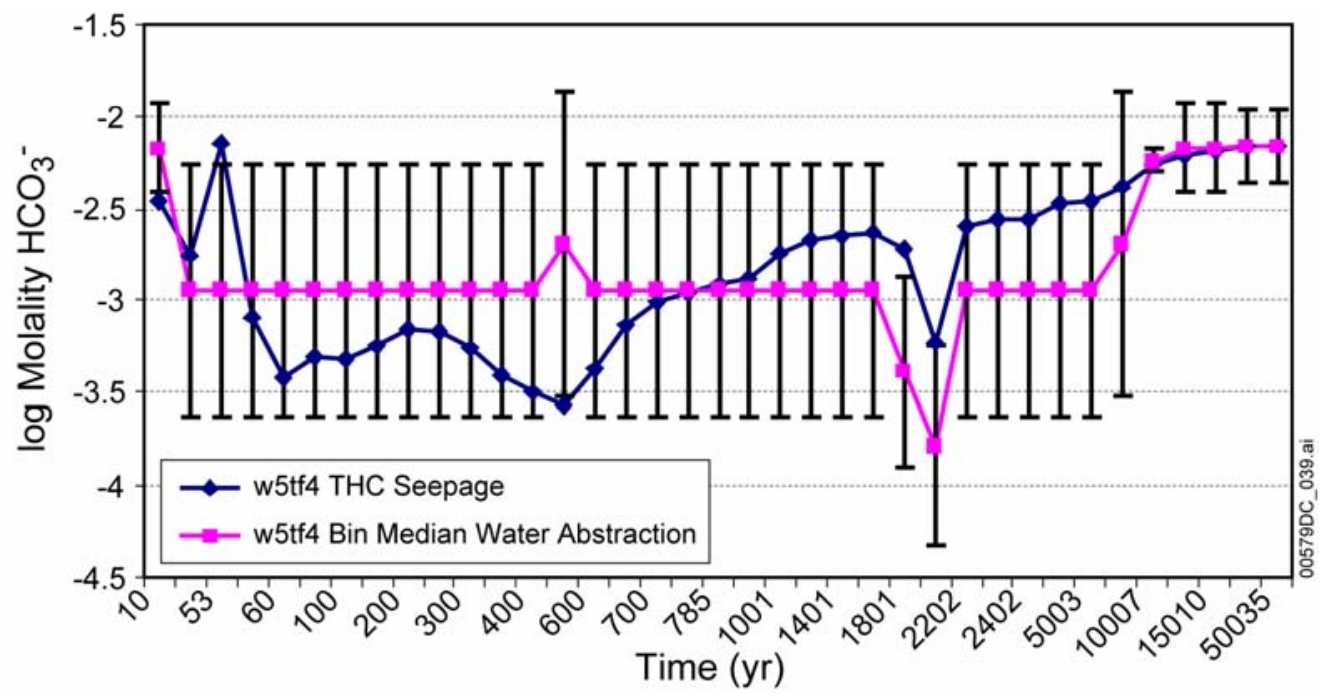

Source: Output DTN: MO0312SPAPCESA.002, THC Seepage Validation Spreadsheet LOG distributions.xIs.

NOTE: The median water for bin 7 is plotted among median bin waters in this figure. The composition is based on the THC seepage model output for the w4 starting water (10,000 year base-front). As discussed in Section 6.6.7.3, the bin 7 median water used for TSPA is based on the THC seepage model output for the w0 starting water (10,000 year base-front). The affected points on these plots lie only at early time $(<50 \mathrm{yr})$ and at late time $(>11,000 \mathrm{yr})$.

Figure 7.3-17. Comparison of $\mathrm{THC}$ Seepage $\mathrm{HCO}_{3}{ }^{-}$with Binning Analysis for w5tf4 Crown Seepage 


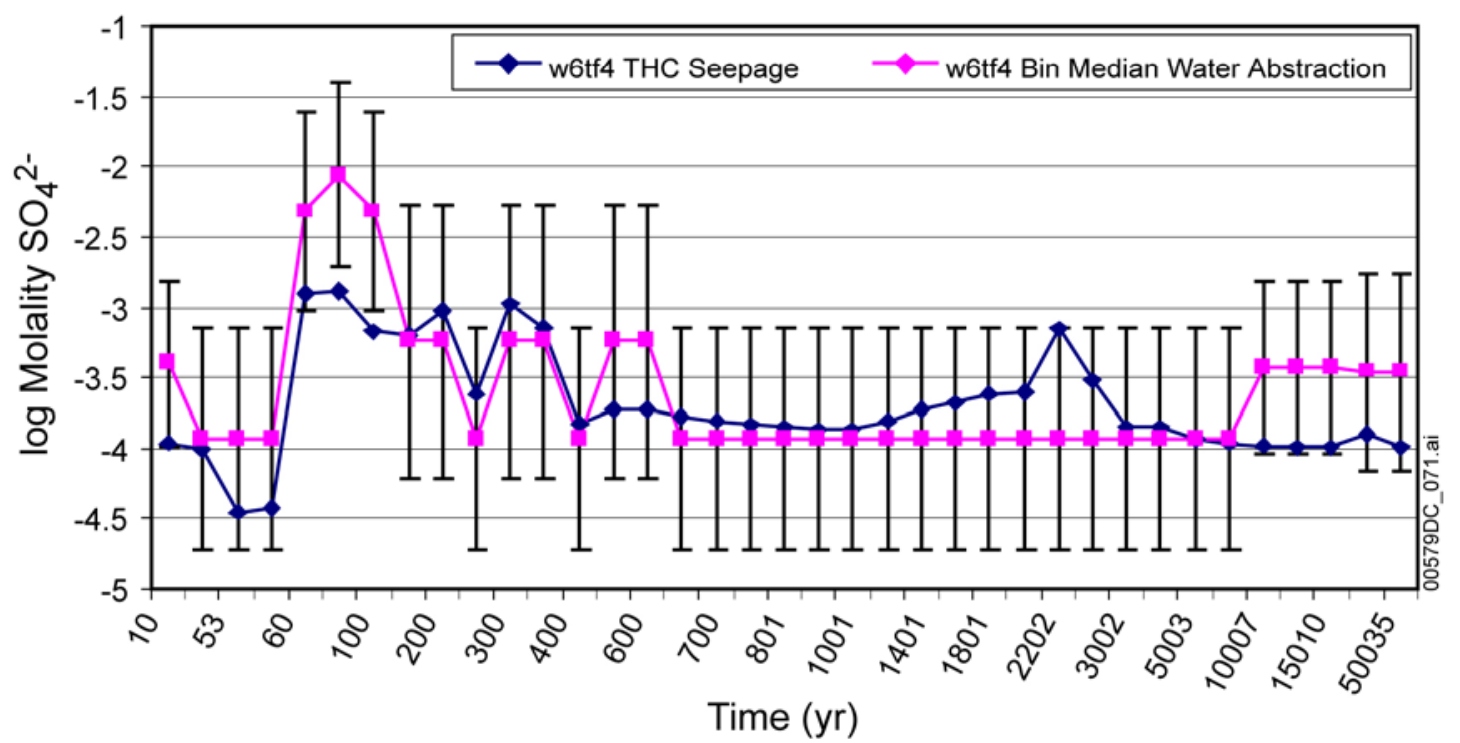

Source: Output DTN: MO0312SPAPCESA.002, THC Seepage Validation Spreadsheet LOG distributions.xIs.

NOTE: The median water for bin 7 is plotted among median bin waters in this figure. The composition is based on the THC seepage model output for the w4 starting water (10,000 year base-front). As discussed in Section 6.6.7.3, the bin 7 median water used for TSPA is based on the THC seepage model output for the w0 starting water (10,000 year base-front). The affected points on these plots lie only at early time $(<50 \mathrm{yr})$ and at late time $(>8,500 \mathrm{yr})$.

Figure 7.3-18. Comparison of THC Seepage $\mathrm{SO}_{4}{ }^{2-}$ with Binning Analysis for w6bf4 Invert Seepage

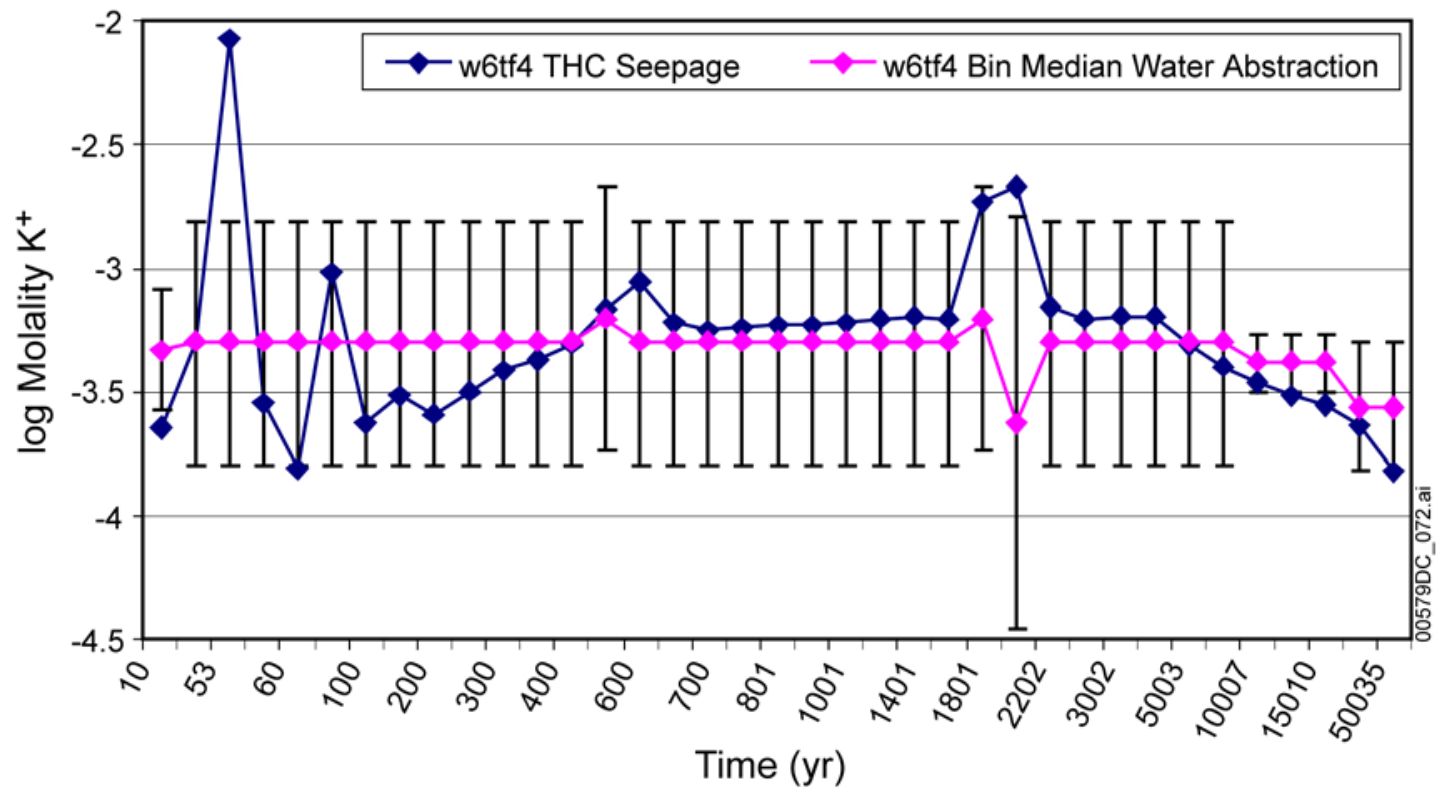

Source: Output DTN: MO0312SPAPCESA.002, THC Seepage Validation Spreadsheet LOG distributions.xIs.

NOTE: The median water for bin 7 is plotted among median bin waters in this figure. The composition is based on the THC seepage model output for the w4 starting water (10,000 year base-front). As discussed in Section 6.6.7.3, the bin 7 median water used for TSPA is based on the THC seepage model output for the w0 starting water (10,000 year base-front). The affected points on these plots lie only at early time $(<50 \mathrm{yr})$ and at late time $(>11,000 \mathrm{yr})$.

Figure 7.3-19. Comparison of THC Seepage $\mathrm{K}^{+}$with Binning Analysis for w6tf4 Crown Seepage 


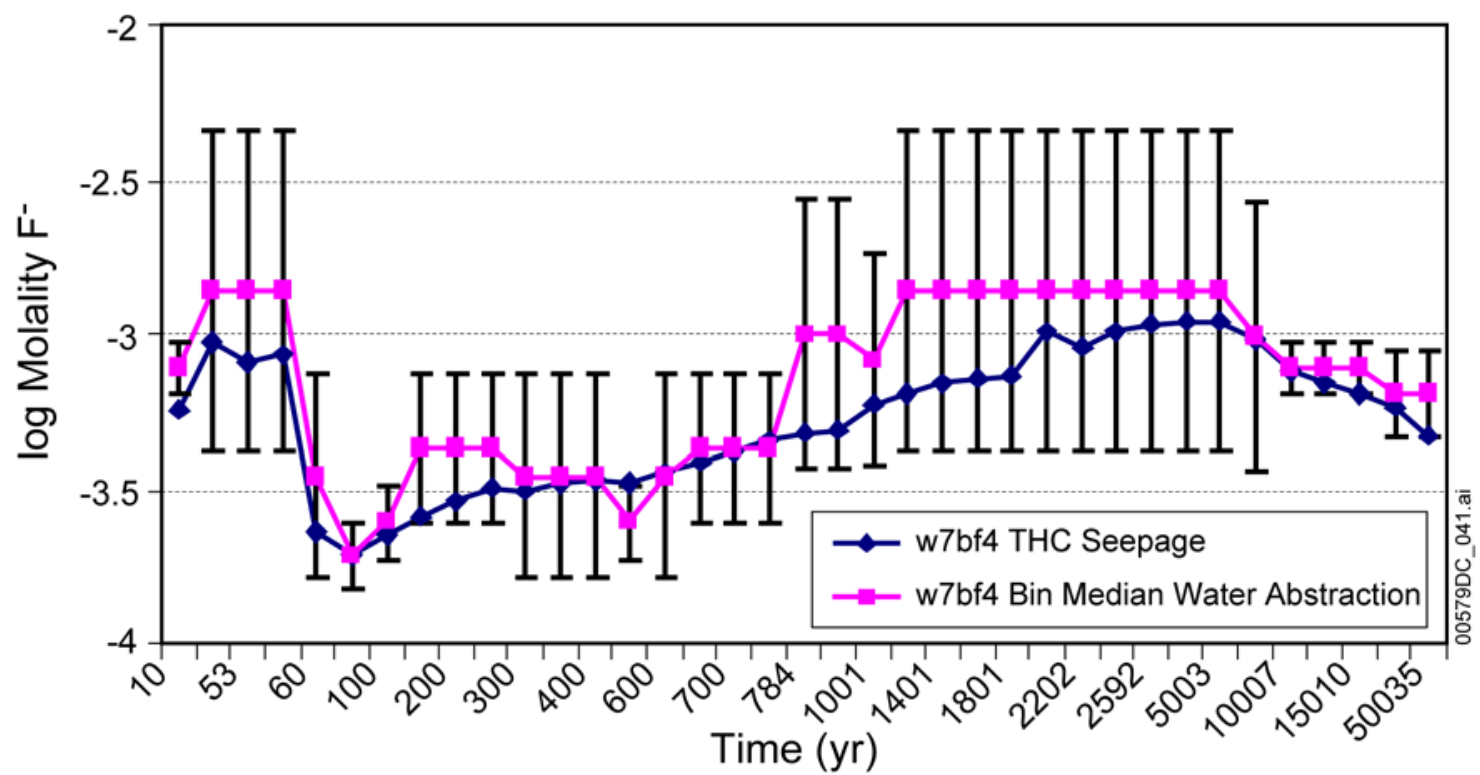

Source: Output DTN: MO0312SPAPCESA.002, THC Seepage Validation Spreadsheet LOG distributions.xls.

NOTE: The median water for bin 7 is plotted among median bin waters in this figure. The composition is based on the THC seepage model output for the w4 starting water (10,000 year base-front). As discussed in Section 6.6.7.3, the bin 7 median water used for TSPA is based on the THC seepage model output for the w0 starting water (10,000 year base-front). The affected points on these plots lie only at early time $(<50 \mathrm{yr})$ and at late time $(>8,500 \mathrm{yr})$.

Figure 7.3-20. Comparison of THC Seepage $\mathrm{F}^{-}$with Binning Analysis for w7bf4 Invert Seepage 
(a)

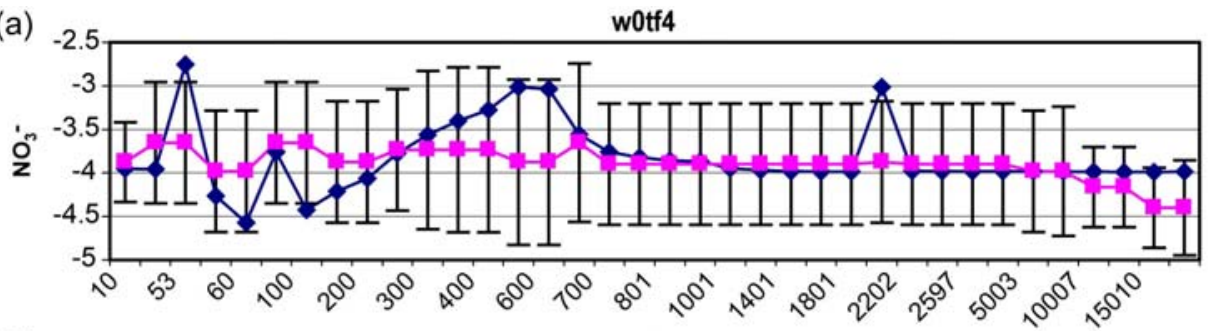

(b)

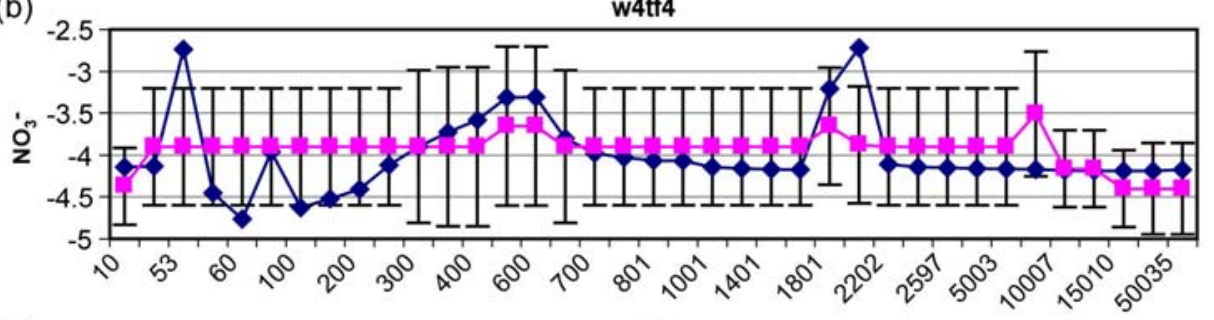

(c)

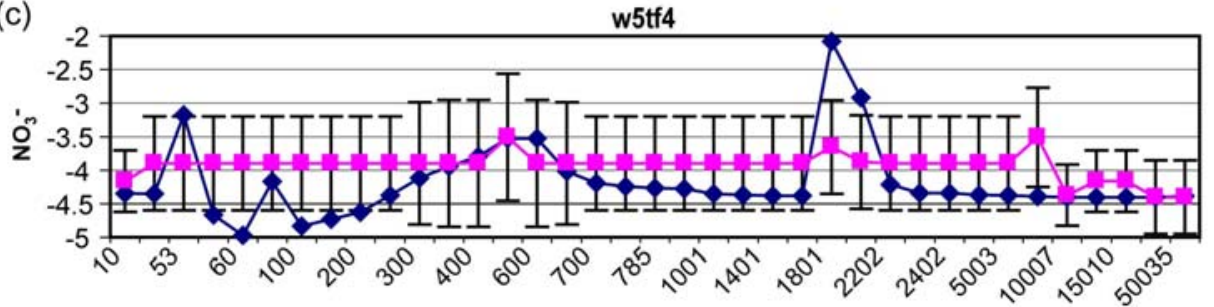

(d)

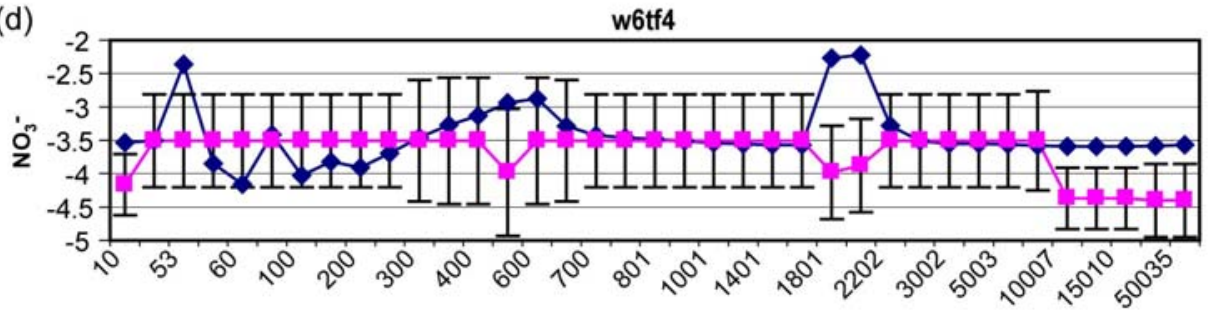

(e)

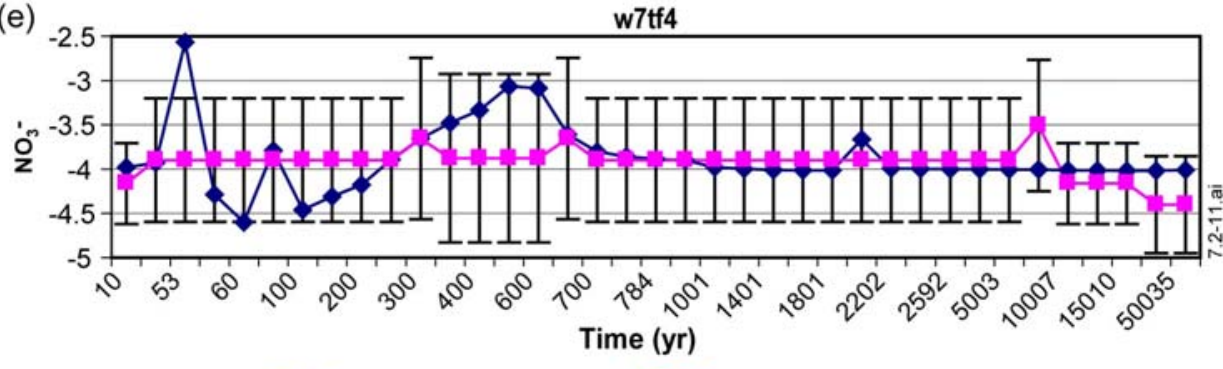

Source: Output DTN: MO0312SPAPCESA.002, THC Seepage Validation Spreadsheet LOG distributions.xls.

NOTES: $\quad \mathrm{NO}_{3}{ }^{-}$units given as log molality.

The median water for bin 7 is plotted among median bin waters in this figure. The composition is based on the THC seepage model output for the w4 starting water (10,000 year base-front). As discussed in Section 6.6.7.3, the bin 7 median water used for TSPA is based on the THC seepage model output for the w0 starting water (10,000 year base-front). The affected points on these plots lie only at early time $(<50 \mathrm{yr})$ and at late time $(>11,000 \mathrm{yr})$.

Figure 7.3-21. Comparison of THC Seepage $\mathrm{NO}_{3}{ }^{-}$with Crown Seepage Water Binning Analysis 


\subsection{VALIDATION SUMMARY}

The two abstraction models (for gas and seepage evaporation) in this report have been validated by applying explicit criteria, which are appropriately based on the model's relative importance to the potential performance of the repository system. Validation requirements defined in the technical work plan (BSC 2005 [DIRS 173782], Sections 2.2.2.2 and 2.2.2.4), including the Level II validation requirement derived from LP-2.29Q-BSC, have been met. Validation is accomplished principally by comparing the abstraction output with results from the process models; the seepage evaporation abstraction is compared with results obtained from the in-drift precipitates/salts model (Section 7.1) and the $\mathrm{CO}_{2}$ gas abstraction is compared with the $p \mathrm{CO}_{2}$ results from the THC seepage model output (Section 7.2).

Importantly, the validity of the gas and seepage evaporation abstractions is supported by the propagation of uncertainty from the process models, through the abstraction, into the TSPA. For the gas abstraction, this is accomplished through the use of five $\mathrm{pCO}_{2}$ time series corresponding to the five starting waters used in the THC seepage model. The TSPA samples one of these series for each realization, consistent with the representation of process model uncertainty in TSPA (BSC 2004 [DIRS 169858], Section 7). For the seepage evaporation abstraction, two types of uncertainty are propagated: the IDPS model uncertainty (Table 6.12-1) and the binning uncertainty associated with analysis of the IDPS model inputs, which are derived from the THC seepage model output (Table 6.12-4).

Additional confidence in the representation of in-drift seepage evaporation chemistry (and the underlying process models and analysis) is obtained using alternative conceptual models (Section 6.11), by supplementary model-data comparison (Section 7.3.3), and by during-development activities including the confirmatory analyses documented in Sections 7.3.1, 7.3.2, and 7.3.4.

Based on the during- and post-development activities documented in Section 7, the abstraction models developed in this report are sufficiently accurate and adequate for their intended uses, and an appropriate level of confidence has been established consistent with the relative importance to repository system performance. 


\section{CONCLUSIONS}

\subsection{SUMMARY AND MODEL FINDINGS}

The engineered barrier system (EBS) chemical environment abstractions provide a quantitative description of the $\mathrm{pH}$, ionic strength $(I)$, and major ionic and elemental compositions of waters in contact with the waste package, drip shield, and the invert. Brines that form by evaporative concentration of the crown seepage can potentially affect corrosion on the waste package and drip shield, and influence radionuclide mobility in the invert. Compositional parameters in the waters contacting the drip shield and waste package, such as $\mathrm{pH}$ or the ratio of chloride to nitrate, are important in assessing potential localized corrosion (BSC 2004 [DIRS 169984], Section 6.4.4; BSC 2004 [DIRS 169845]). Acidic or alkaline $\mathrm{pH}$ values in the water of the invert may affect the solubility of radionuclides. Changes in ionic strength of the water in the invert may reduce the mobility of colloidal particles transporting sorbed radionuclides.

Potential water compositions of crown seepage from the THC seepage model are sorted, and represented by 11 possible waters that represent different brine types upon evaporation (Section 6.6). These waters are used to generate a set of 198 lookup tables to represent evaporated crown seepage and invert waters for TSPA-LA. The lookup tables represent a response surface for each bin covering a range of temperatures $\left(100^{\circ} \mathrm{C}\right.$ to $\left.40^{\circ} \mathrm{C}\right), p \mathrm{CO}_{2}$ $\left(10^{-4}\right.$ to $10^{-2}$ bar) and relative humidity. The generation of these tables is discussed in Section 6.9. The total range in chemistry of the crown seepage and invert waters (e.g., pH, $I$, $\mathrm{Cl}^{-}, \mathrm{NO}_{3}{ }^{-} / \mathrm{Cl}^{-}$), as predicted by the lookup tables, is discussed in Section 6.13.

The physical and chemical environment (P\&CE) seepage evaporation abstraction shows that corrosive calcium and magnesium chloride brines are unlikely to form on waste packages and drip shields (Table 6.13-1), and if they do form, persist for only very short times soon after closure of the repository. The most likely brines to form are sodium chloride- or sodium carbonate-type brines (Table 6.13-7, Bins 7 through 11). Chloride/nitrate ratios for all bins expected to contact drip shields and waste packages are shown in Figure 6.13-19. The mineral assemblages that precipitate during evaporation of the brines in the 99 crown seepage evaporative lookup tables are reported in Table 6.13-6.

Lookup tables that represent both evaporated seepage water and invert water have been provided with instructions (Section 6.15) on how to select the appropriate chemical values from the lookup tables. These lookup tables can be used as source chemistry for waters fluxing into the invert.

Stainless steel ground support and low-alloy or carbon steel committed materials have their chemical composition and corrosion rates compiled in Section 6.4. The short-lived materials, such as low-alloy or carbon steel, corrode rapidly in the high humidity environment of the drift and do not affect crown seepage water because they are located in the invert. Oxygen gas pressure of the in-drift atmosphere is determined to be sufficient to maintain an oxidative environment during the corrosion of the low-alloy or carbon steels (Section 6.7).

The Stainless Steel Type 316L corrosion rate output allows for determination of ground support interactions with seepage. This material comprises the perforated sheet ground support 
component that spans the crown of the drift. Analysis and sensitivity studies of crown seepage interacting with Stainless Steel Type 316L, as calculated in Section 6.8.4, indicate that the effects of the active corrosion of Stainless Steel Type 316L are insignificant near 100 and $98 \%$ relative humidity. Based on these results and the results of the uncertainty calculations presented in Section 6.12.4.1, it is concluded that the active corrosion of ground support will not significantly influence the composition of the seepage at any time.

Dust that settles onto the waste package and drip shield from natural sources and repository construction processes will not affect repository performance with respect to corrosion. During and for a while after the heat pulse, when temperatures are above $100^{\circ} \mathrm{C}$, no liquid water is expected to flow in the drift (Section 6.2). Thus, the only waters that are likely to be present are those formed by deliquescence of the salt within dust, and the effect of those has been screened out with respect to localized corrosion of the waste packages (Section 6.10 and BSC 2005 [DIRS 175058]).

\subsection{SUMMARY OF MODEL ABSTRACTION FOR TOTAL SYSTEM PERFORMANCE ASSESSMENT}

\subsubsection{Summary of the Total System Performance Assessment Lookup Tables}

Figure 8.2-1 summarizes the recommended TSPA-LA usage of the lookup tables for crown seepage developed in Sections 6.6, 6.7, and 6.9 for use in analyses of engineered barrier surfaces. The instructions and restrictions for use of the scenarios depicted by this figure are summarized in Sections 6.13 and 6.15. The figure describes the use of this model by TSPA-LA to determine water chemistries during active seepage on the waste packages and drip shields. Section 6.15.2 gives the instructions for implementing lookup tables to determine chemistry in the invert. Section 8.2.2 lists the lookup table data tracking numbers (DTNs).

During preliminary implementation of the seepage lookup tables in the TSPA, it was discovered that the GoldSim software (BSC 2003 [DIRS 161572]) cannot handle duplicated values for the independent parameter in the tables. This occurs in the lookup tables when mineral precipitation occurs, at which point the exact same activity of water (the independent parameter) is duplicated to include the new mineral. In order to provide a set of lookup tables to the TSPA that could be utilized, the lookup tables in Output DTN: MO0304SPACSALT.000 were modified; in cases where the independent parameter $(R H)$ was repeated, one of the values was modified slightly to eliminate the duplication without removing chemical parameter values from the dataset. The modified versions of the files in Output DTN: MO0304SPACSALT.000 are found in the new Output DTN: MO0310SPAPCEGS.000; modifications are indicated in the lookup table by red text. All other users of data from this report should use the original files archived in Output DTN: MO0304SPACSALT.000. 


\section{CROWN}

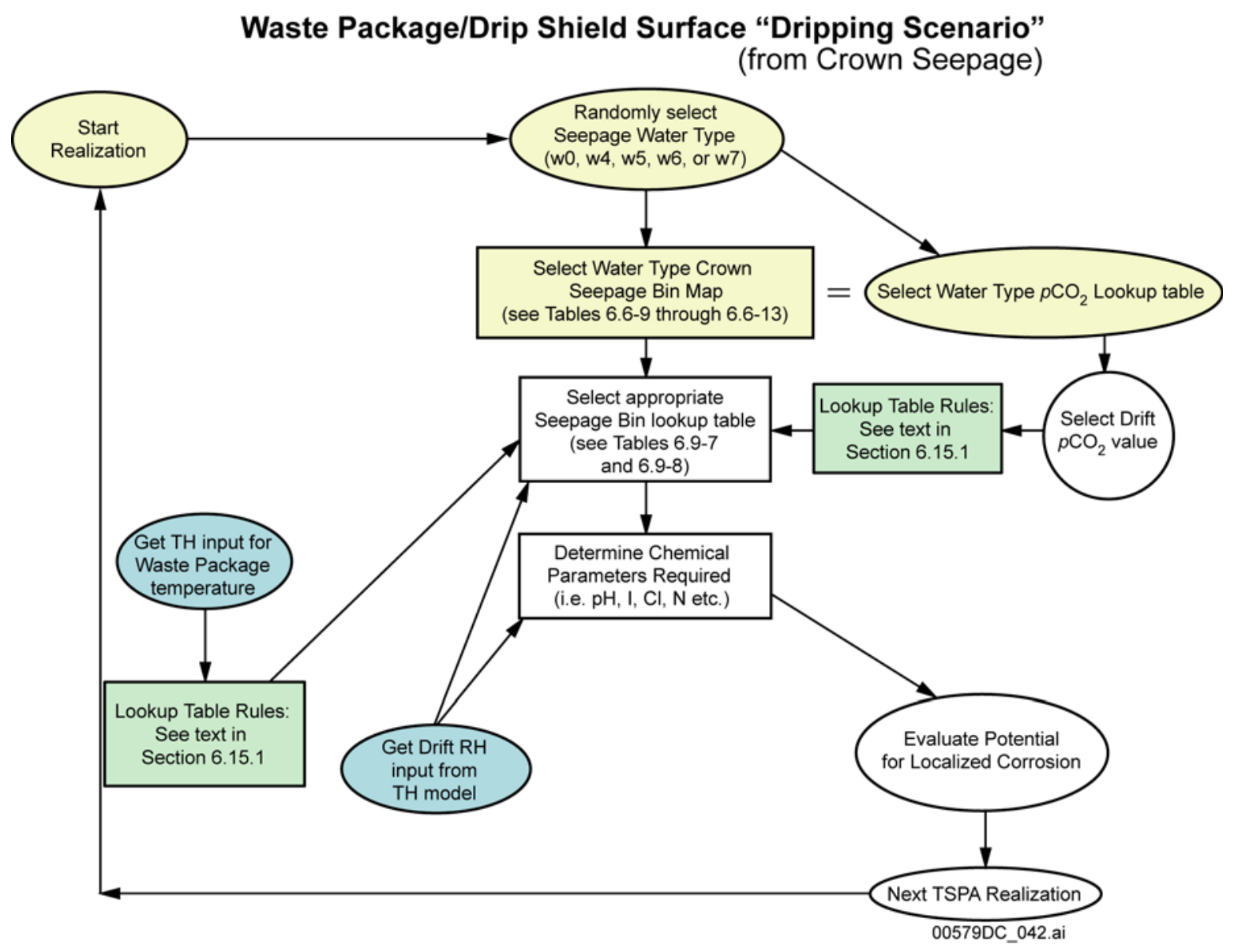

NOTE: $\quad T H=$ thermal-hydrologic; $\mathrm{WP}=$ waste package.

Figure 8.2-1. Recommended TSPA-LA Usage Outline for Crown Seepage Evaporation Abstraction 


\subsubsection{Data Tracking Numbers for Data Generated in This Report}

Tables 8.2-1 and 8.2-2 list the DTNs for data generated in this report. Table 8.2-1 is for data generated to feed the TSPA-LA and Table 8.2-2 is for supporting data used in development of the TSPA-LA data feeds. These data are also summarized in Appendix A.

Table 8.2-1. EBS Physical and Chemical Environment Model Output DTNs Derived for Use in the TSPA-LA Model

\begin{tabular}{|c|c|c|}
\hline Data Tracking Number & Location In Text & Description of TSPA Parameters \\
\hline MO0508SPAEBSCB.001 & $\begin{array}{l}\text { Sections } 6.6 .4 \text { to } 6.6 .6,6.6 .7 .1 \text {, } \\
6.6 .7 .2,6.11 .1 .1,6.12 .3 .1, \\
6.15 .1 .1,6.15 .2 \text {, and } 7.3 .4 \\
\text { Tables } 6.6-3 \text { to } 6.6-14\end{array}$ & $\begin{array}{l}\text { Bin history maps for each of the } 5 \text { starting THC } \\
\text { waters for both crown seepage and invert wicking }\end{array}$ \\
\hline $\begin{array}{l}\text { MO0310SPAPCEGS.000 } \\
\text { These values are for TSPA } \\
\text { Goldsim software } \\
\text { implementation. All other } \\
\text { users should use the lookup } \\
\text { tables archived in } \\
\text { MO0304SPACSALT.000 }\end{array}$ & $\begin{array}{l}\text { Sections } 6.9 .3,6.9 .4,6.12 .5 \text {, } \\
\text { 6.12.5.2, 6.12.5.3, 6.13.6, } \\
\text { 6.15.1.1, 6.15.2, 7.3.4, and } \\
8.2 .1 \\
\text { Tables } 6.9-6 \text { and } 6.9-7\end{array}$ & $\begin{array}{l}198 \text { seepage evaporation abstraction lookup tables } \\
\text { containing pH, } I \text {, and ion concentrations as a } \\
\text { function of drift relative humidity, associated with } \\
\text { the } 11 \text { bins, three starting temperatures }\left(100^{\circ} \mathrm{C} \text {, }\right. \\
\left.70^{\circ} \mathrm{C} \text {, and } 40^{\circ} \mathrm{C}\right) \text { and three } p \mathrm{CO}_{2} \text { values }\left(10^{-4} \text {, }\right. \\
\left.10^{-3} \text {, and } 10^{-2} \text { bar }\right)- \text { in all } 99 \text { tables for } \\
\text { evaporation and } 99 \text { tables for condensation. Also } \\
\text { included is a relative humidity map to interface } \\
\text { between the evaporation lookup tables and the } \\
\text { condensation lookup tables. }\end{array}$ \\
\hline MO0311SPAEPMUT.000 & Tables $6.12-4$ and $6.12-23$ & $\begin{array}{l}\text { Uncertainty values for } \mathrm{pH} \text {, ionic strength, } \mathrm{Cl} \text {, and } \\
\mathrm{Cl}-\mathrm{NO}_{3} \text { parameters }\end{array}$ \\
\hline MO0505SEPSEEPA.000 & $\begin{array}{l}\text { Sections } 6.13 .1 .2,6.13 .2 \text {, } \\
6.15 .1 \text {, and } 6.15 .2\end{array}$ & $\begin{array}{l}\text { Limitation ranges for temperature interpolation and } \\
\mathrm{pCO}_{2} \text { extrapolation; starting water probability. }\end{array}$ \\
\hline SN0403T0503404.001 & Sections 4.1 .5 and 6.13 .6 & $\begin{array}{l}\text { Maximum relative humidity }(R H) \text { of halite } \\
\text { precipitation extracted from P\&CE seepage } \\
\text { evaporation lookup tables }\end{array}$ \\
\hline SN0503T0510102.019 & $\begin{array}{l}\text { Sections } 4.1 .3,6.7 .2 .1,6.7 .2 .2 \text {, } \\
6.12 .5 .3,6.15 .1 \text {, and } 6.15 .2 \\
\text { Tables } 6.7-1 \text { to } 6.7-5\end{array}$ & $\begin{array}{l}p \mathrm{CO}_{2} \text { time-history lookup tables for each of the five } \\
\text { starting THC waters for both crown seepage and } \\
\text { invert wicking }\end{array}$ \\
\hline
\end{tabular}

Table 8.2-2. EBS Physical and Chemical Environment Model Supplemental Output DTNs

\begin{tabular}{|c|c|c|}
\hline Output DTN & Location In Text & Title \\
\hline MO0304SPAA11GC.000 & $\begin{array}{l}\text { Section 6.9.1 } \\
\text { Tables 6.7-6, 6.9-1 and 6.9-2 }\end{array}$ & $\begin{array}{l}\text { EBS THC Seepage Abstraction } 11 \text { Bin EQ3NR3o } \\
\text { File Water and Gas Chemistry Extraction }\end{array}$ \\
\hline MO0304MWDSAB11.001 & $\begin{array}{l}\text { Sections 6.8.2, 6.8.4.1, 6.9.1, } \\
\text { and 6.12.4.1.3 } \\
\text { Tables 6.12-5, 6.9-3 and 6.9-4 }\end{array}$ & $\begin{array}{l}\text { EBS THC Seepage Abstraction } 11 \text { Bin EQ3NR3i, } \\
3 p \text {, and 3o Files }\end{array}$ \\
\hline $\begin{array}{l}\text { MO0304SPACSALT.000 } \\
\text { These values are for users } \\
\text { other than TSPA Goldsim } \\
\text { software implementation. } \\
\text { For TSPA implementation } \\
\text { use lookup tables archived } \\
\text { in MO0310SPAPCEGS.000 }\end{array}$ & $\begin{array}{l}\text { Sections } 6.9 .3,6.12 .5 \\
6.12 .5 .3,6.15 .1 .1 \text {, and } 6.15 .2 \\
\text { Tables } 6.9-6,6.9-7 \text {, and } 8.2-1\end{array}$ & $\begin{array}{l}\text { EBS Chemistry THC Seepage Model Abstraction } \\
\text { Lookup Tables for TSPA-LA }\end{array}$ \\
\hline
\end{tabular}


Table 8.2-2. EBS Physical and Chemical Environment Model Supplemental Output DTNs (Continued)

\begin{tabular}{|c|c|c|}
\hline Output DTN & Location In Text & Title \\
\hline MO0303MWDSCMAB.000 & $\begin{array}{l}\text { Sections } 6.6 .3,6.7 .3 \text {, and } 6.9 .1 \\
\text { Table } 6.6-1\end{array}$ & $\begin{array}{l}\text { THC Seepage Chemistry Model Abstraction } \\
\text { Binning EQ3NR Input, Pickup and Output Files }\end{array}$ \\
\hline MO0303MWDEBSSM.000 & $\begin{array}{l}\text { Sections } 6.6 .3,6.6 .4 \text {, and } 6.7 .3 \\
\text { Tables } 6.6-1,6.6-13 \text { and } \\
6.6-14\end{array}$ & $\begin{array}{l}\text { EBS Abstraction of the THC Seepage Model: } \\
\text { Binning Analysis Evaporation to } 65 \% \text { RH EQ6 } \\
\text { Input and Output Files }\end{array}$ \\
\hline MO0304SPACPSLT.000 & Section 6.13 .1 .2 & $\begin{array}{l}\text { Combined In-Drift Precipitates/Salts Model Lookup } \\
\text { Table for Seepage Evaporation Abstractions for All } \\
\text { Bins }\end{array}$ \\
\hline MO0304MWDEBSSA.000 & $\begin{array}{l}\text { Section } 6.9 .2 \text { and } 7.1 .1 \\
\text { Tables } 6.9-5,6.12-5\end{array}$ & $\begin{array}{l}\text { EBS THC Seepage Abstraction TSPA-LA Lookup } \\
\text { Table EQ6 Input and Output Files }\end{array}$ \\
\hline MO0505MWDEBSPC.000 & $\begin{array}{l}\text { Sections } 6.12 .4 .2 .2,6.12 .4 .2 .3 \text {, } \\
6.12 .4 .3 .1,6.12 .4 .3 .2,6.12 .4 .4 \\
6.12 .4 .4 .1 \text {, and } 6.12 .4 .4 .2 \\
\text { Tables } 6.12-17 \text { to } 6.12-21\end{array}$ & $\begin{array}{l}\text { EBS P\&CE Uncertainty Analyses for } p \mathrm{CO}_{2}, \mathrm{Br} \text {, and } \\
\text { Mineral Suppressions }\end{array}$ \\
\hline MO0310SPAEBSUE.002 & Sections 6.12 .3 .1 and 7.3 .2 & $\begin{array}{l}\text { EBS Chemistry Unevaporated Binning Abstraction } \\
\text { Statistics }\end{array}$ \\
\hline MO0310SPAPCEAC.002 & $\begin{array}{l}\text { Section } 6.11 .1 .1 \\
\text { Tables } 6.11-1 \text { to } 6.11-14\end{array}$ & $\begin{array}{l}\text { EBS P\&CE Alternate Conceptual Model } \\
\text { Calculations }\end{array}$ \\
\hline MO0310SPAEBSSB.002 & Section 6.12.3.1 & $\begin{array}{l}\text { EBS P\&CE Model THC Seepage Bin Uncertainty } \\
\text { Analyses }\end{array}$ \\
\hline MO0312SPAPCESA.002 & $\begin{array}{l}\text { Sections } 6.13,6.13 .1 .3 \text {, } \\
6.13 .4 .1,6.13 .5 .2 \text {, and } 7.3 .4 \\
\text { Tables 6.13-1, 6.13-2, 6.13-6, } \\
\text { and 6.13-7 }\end{array}$ & $\begin{array}{l}\text { EBS P\&CE Model THC Seepage Analysis } \\
\text { Spreadsheets }\end{array}$ \\
\hline MO0406MWDARHPW.000 & $\begin{array}{l}\text { Section } 7.3 .1 \\
\text { Table 7.3-1 }\end{array}$ & $\begin{array}{l}\text { Abstraction of Repository Horizon Porewaters using } \\
\text { EQ3/6. }\end{array}$ \\
\hline MO0407SPAPCEML.005 & $\begin{array}{l}\text { Section } 4.1 .1 \\
\text { Tables 4.1-2, 6.4-6, 6.4-7, and } \\
6.4-8\end{array}$ & $\begin{array}{l}\text { EBS P\&CE Model Longevity of Materials } \\
\text { Evaluation }\end{array}$ \\
\hline MO0506SPAPCEIC.001 & Section 7.1 .1 & $\begin{array}{l}\text { EBS P\&CE Model Validation Interpolation } \\
\text { Calculations }\end{array}$ \\
\hline MO0505SPAPCEBV.000 & $\begin{array}{l}\text { Section } 7.3 .2 \\
\text { Table 7.3-2 } \\
\end{array}$ & P\&CE Binning Validation Analysis Using EQ3/6 \\
\hline SN0312T0510102.013 & $\begin{array}{l}\text { Sections } 6.8 .2,6.8 .3,6.8 .4 .1 \\
6.8 .4 .3 \text {, and } 6.12 .4 .1 \\
\text { Tables } 4.1-12,4.1-13,6.8-2 \text {, } \\
6.8-5 \text {, and } 6.12-6 \text { to } 6.12-15\end{array}$ & EBS P\&CE Model Stainless Steel Abstraction \\
\hline SN0404T0510102.014 & Section 7.3 .3 & $\begin{array}{l}\text { EBS P\&CE Model, Sierra Nevada Spring Water } \\
\text { Validation; EQ3/6 Runs and Results }\end{array}$ \\
\hline SN0505T0510102.020 & $\begin{array}{l}\text { Section } 6.9 .3 \\
\text { Table 6.9-5 }\end{array}$ & Dilute Water-Rock Interaction \\
\hline SN0505T0510102.022 & Section 7.2 .2 & $\mathrm{CO}_{2}$ Abstraction Model Validation \\
\hline SN0508T0510102.023 & $\begin{array}{l}\text { Sections } 4.1 .2,4.1 .3 \text {, and } \\
6.7 .1 .1 \text { to } 6.7 .1 .3 \\
\text { Tables } 4.1-7 \text { and } 4.1-8\end{array}$ & In-Drift Gas Flux And Oxygen Demand \\
\hline SN0508T0510102.024 & $\begin{array}{l}\text { Section } 6.12 .3 \\
\text { Table } 6.12-2\end{array}$ & EBS P\&CE Log Transform Of Uncertainty Data \\
\hline
\end{tabular}




\subsection{ABSTRACTION MODEL UNCERTAINTY AND RESTRICTIONS}

Uncertainties in the output from the EBS physical and chemical environment (P\&CE) model are summarized in this section. Direct inputs to the model are tabulated and discussed in Section 4.1, but the uncertainties associated with those inputs are discussed in the subsections of Section 6 where they are used. The effects of input uncertainties are discussed in more detail in Section 6.12. Limitations and constraints on the use of the model and its outputs are discussed in Section 6.13 with the discussions of the various components and features of the overall P\&CE model. Specific limitations involved in the model are listed in Section 1.3.

The P\&CE model uses four primary inputs, and each has uncertainty associated with it. These inputs are:

- Composition of water entering the drift

- The IDPS model (BSC 2004 [DIRS 169863]) and its associated data bases (thermodynamic data and other technical information not specific to the site used in the geochemical modeling that results in the model output)

- Composition and flux of in-drift gases

- Amounts and characteristics of engineered materials to be placed in the drift (ground support, emplacement rails, etc.).

For evaluating repository performance, four parameters have been identified as output from this model that will be used as direct input to TSPA calculations: 1) chloride ion concentration, 2) chloride/nitrate molar ratio, 3) ionic strength, and 4) $\mathrm{pH}$.

As explained in Section 6.12, of the four inputs, only two were found to have uncertainties that would propagate into the output parameters that feed the TSPA: 1) the IDPS model, and 2) the boundary incoming seepage waters.

An evaluation of the IDPS model was conducted to determine its contribution to error in predicting the parameters of interest as explained in Section 6.12.2. A statistical evaluation of the TSPA parameter feeds (except relative humidity, which was not relevant to this evaluation) in the 11 bins of evaporated seepage water was conducted as explained in Section 6.12.3. This evaluation demonstrated that there is a sufficiently large variability within the bins to warrant the creation of a discretization error band around the median water's values for parameters that need be propagated by the TSPA process.

Uncertainties from these sources are propagated in a realistic and representative way to TSPA. There the process model and binning analysis uncertainties are directly combined to generate total error bands for the parameters of interest to TSPA. Appropriate distribution for the error ranges was selected, and instructions for how to implement the errors were developed in Section 6.12.5.

No confirmatory actions are deemed necessary at this time. 


\subsection{YUCCA MOUNTAIN REVIEW PLAN CRITERIA ASSESSMENT}

This report predicts results that directly pertain to the abstraction of the quantity and chemistry of water contacting engineered barriers and waste forms. This section summarizes the contents of this report as they apply to NRC criteria for a detailed review of that abstraction.

\subsubsection{Acceptance Criteria for Quantity and Chemistry of Water Contacting Engineered Barriers and Waste Forms}

These criteria are from Yucca Mountain Review Plan, Final Report (NRC 2003 [DIRS 163274], Section 2.2.1.3.3.3, which is from 10 CFR 63.114(a)-(c) and (e)-(g) [DIRS 173273]).

\subsubsection{Acceptance Criterion 1-System Description and Model Integration Are Adequate}

(1) TSPA adequately incorporates important design features, physical phenomena, and couplings, and uses consistent and appropriate assumptions throughout the quantity and chemistry of water contacting engineered barriers and waste forms abstraction process;

The effects of coupled processes (Section 6.3) have been considered in part in the development of this model. For example, THC effects on input water compositions are incorporated in the THC model output (Section 4.1.3) used as input to the P\&CE model. Thermal-hydrologicchemical processes are at the heart of the in-drift water chemistry evolution presented in this report. The analyses presented in this report use current design information (Sections 4.1 and 6.4), and are based on physical phenomena expected within repository drifts (Section 6.2). Coupled processes that were considered and screened out from further consideration in this report and their rationale for exclusion, are presented in Engineered Barrier System Features, Events, and Processes (BSC 2005 [DIRS 175014], Section 6.2.60). Assumptions (Section 5) contained in this report are appropriate and are consistent with similar assumptions in related documents. These factors are included in the analyses leading to the output parameters (Section 6.13), which may be used to assess engineered barrier and waste form degradation.

(2) The abstraction of the quantity and chemistry of water contacting engineered barriers and waste forms uses assumptions, technical bases, data, and models that are appropriate and consistent with other related DOE abstractions. For example, the assumptions used for the quantity and chemistry of water contacting engineered barriers and waste forms are consistent with the abstractions of "Degradation of Engineered Barriers" (Section 2.2.1.3.1); "Mechanical Disruption of Engineered Barriers" (Section 2.2.1.3.2); "Radionuclide Release Rates and Solubility Limits" (Section 2.2.1.3.4); "Climate and Infiltration" (Section 2.2.1.3.5); and "Flow Paths in the Unsaturated Zone” (Section 2.2.1.3.6). The descriptions and technical bases provide transparent and traceable support for the abstraction of quantity and chemistry of water contacting engineered barriers and waste forms;

This report uses the same technical bases and other information used in other LA-supporting documents concerned with engineered barrier and waste form performance. The conceptual 
model that forms the basis for this report (Section 6.2), and its assumptions (Section 5), are consistent with other engineered system models and repository design. Primary input (Section 4.1) is taken from the unsaturated zone (UZ) THC model to develop both the in-drift water and gas chemistries. The IDPS model is used in conjunction with the THC model output to generate in-drift water chemistry. Section 6.2 provides details of these model interfaces. Input water fluxes are dealt with in Seepage Model for PA Including Drift Collapse (BSC 2003 [DIRS 167652]). The descriptions and technical bases are recorded to provide inherently transparent and traceable support for the abstraction of in-drift water chemistry.

(3) Important design features, such as waste package design and material selection, backfill, drip shield, ground support, thermal loading strategy, and degradation processes, are adequate to determine the initial and boundary conditions for calculations of the quantity and chemistry of water contacting engineered barriers and waste forms;

Initial and boundary conditions for this model are based on descriptions of design features (Section 6.4) and predicted behavior of the EBS (Section 6.2) as documented in YMP design documents and in other barrier-specific models and abstractions. This model includes consideration of the chemical effects of corrosion on engineered materials (Sections 6.7 and 6.8).

(4) Spatial and temporal abstractions appropriately address physical couplings (thermal-hydrologic-mechanical-chemical). For example, the DOE evaluates the potential for focusing of water flow into drifts, caused by coupled thermal-hydrologic-mechanical-chemical processes;

The abstractions in the P\&CE model incorporate the effects of a number of different coupled processes in its evaluation of in-drift water chemistry. For example, THC physical couplings are included implicitly through the THC model output as well as through the temporal water-type methodology (i.e., bin history mapping, Section 6.6.6). Another example is the analysis addressing the impact of corrosion of ground support materials. This analysis takes into account various thermal-hydrological-mechanical-chemical effects, as do the corrosion rates used in the analysis. Coupled processes formally classified as features, events, or processes (FEPs) are discussed briefly in Section 6.14 and documented in more detail in various FEPs reports such as Engineered Barrier System Features, Events, and Processes (BSC 2005 [DIRS 175014], Section 6.2.60). These reports contain straightforward screening arguments if the FEP is excluded from further consideration and a description of the TSPA disposition if it is included. The master list of FEPs is contained in DTN: MO0501SEPFEPLA.001 [DIRS 172601].

(5) Sufficient technical bases and justification are provided for total system performance assessment assumptions and approximations for modeling coupled thermal-hydrological-mechanical-chemical effects on seepage and flow, the waste package chemical environment, and the chemical environment for radionuclide release. The effects of distribution of flow on the amount of water contacting the engineered barriers and waste forms are consistently addressed, in all relevant abstractions; 
Assumptions (Section 5) and approximations pertaining to coupled processes in the P\&CE model, as well as their technical bases and justification, are provided throughout the report. FEPs involving coupled processes are discussed with their technical bases in Section 6.14. The seepage evaporation abstraction is consistent with the THC seepage model and the TSPA-LA lookup tables are designed to couple the thermal hydrology of the drift with the chemical environment in drift. This model report is not concerned with distribution of flow within the drift.

(6) The expected ranges of environmental conditions within the waste package emplacement drifts, inside of breached waste packages, and contacting the waste forms and their evolution with time are identified. These ranges may be developed to include:

(i) Effects of the drip shield and backfill on the quantity and chemistry of water (e.g., the potential for condensate formation and dripping from the underside of the shield)

(ii) Conditions that promote corrosion of engineered barriers and degradation of waste forms;

(iii) Irregular wet and dry cycles;

(iv) Gamma-radiolysis; and

(v) Size and distribution of penetrations of engineered barriers;

This report develops and presents the expected ranges of environmental conditions within the drifts (Section 6.7, 6.9, and 6.10). Although this model does characterize conditions that affect corrosion of engineered barriers (Section 6.13), it does not consider the effect of the drip shield or backfill (current design does not include backfill) on the quantity and chemistry of water. Wet and dry cycles, gamma radiolysis, and size and distribution of engineered barriers are not the subject of this report, although information from it may be used to assess those factors.

(7) The model abstraction for quantity and chemistry of water contacting engineered barriers and waste forms is consistent with the detailed information on engineered barrier design and other engineered features. For example, consistency is demonstrated for:

(i) Dimensionality of the abstractions;

(ii) Various design features and site characteristics; and

(iii) Alternative conceptual approaches.

Analyses are adequate to demonstrate that no deleterious effects are caused by design or site features that the DOE does not take into account in this abstraction; 
The chemistry of water contacting engineered barriers was developed using detailed information on various designed (engineered) features and site characteristics (Section 4.1), although this report does not address dimensionality of the abstractions as they relate to water contacting engineered barriers. This report includes consideration of potential impacts from engineered materials: for example, the effect of stainless steel ground support on in-drift water composition (Section 6.8) and the effect of evaporative concentration coupled with transport on the chemical environment at the surface of the waste package (Section 6.13.6). In addition, treatment of alternative conceptual approaches (Section 6.11) is consistent with engineered barrier design and other engineered features. For those design or site features not incorporated in the P\&CE model, analyses were done to ensure that there were no adverse impacts caused by their exclusion (see Section 6.14, as well as the relevant FEPs report for further details).

(8) Adequate technical bases are provided, including activities such as independent modeling, laboratory or field data, or sensitivity studies, for inclusion of any thermal-hydrologic-mechanical-chemical couplings and features, events, and processes;

This report summarizes the inclusion of coupled processes by use of the THC seepage model output. In addition, this report includes a brief evaluation of Onsager coupled processes, which are dominated by direct processes that are appropriately represented in the abstractions (Section 6.3). This report also includes sensitivity analyses that address the effects from engineered materials on the in-drift chemical environment (Sections 6.7 and 6.8).

(9) Performance-affecting processes that have been observed in thermal-hydrologic tests and experiments are included into the performance assessment. For example, the U.S. Department of Energy either demonstrates that liquid water will not reflux into the underground facility or incorporates refluxing water into the performance assessment calculation, and bounds the potential adverse effects of alteration of the hydraulic pathway that result from refluxing water;

The effects observed in thermal-hydrologic tests and experiments (from the drift scale test) are used for validation purposes in Drift-Scale THC Seepage Model (BSC 2005 [DIRS 172862], Section 7.1). Results from this thermal-hydrological validated model that include refluxing are used in this report (Section 6.6) to generate results used by TSPA-LA (Sections 6.12 and 6.13).

(10) Likely modes for container corrosion (Section 2.2.1.3.1 of the Yucca Mountain Review Plan) are identified and considered in determining the quantity and chemistry of water entering the engineered barriers and contacting waste forms. For example, the model abstractions consistently address the role of parameters, such as $\mathrm{pH}$, carbonate concentration, and the effect of corrosion on the quantity and chemistry of water contacting engineered barriers and waste forms;

As indicated in Section 1.2, one of the intended uses of this model is to provide TSPA-LA with quantified inputs for ionic strength, chloride and nitrate concentrations, and $\mathrm{pH}$ as functions of $\mathrm{RH}, \mathrm{pCO}_{2}$, and temperature. This information is then used in conjunction with another model 
supplying the $R H$ and temperature information to then implement a third model - that developed in General Corrosion and Localized Corrosion of Waste Package Outer Barrier (BSC 2004 [DIRS 169984], Sections 6.3.1 and 6.3.2) - to determine if localized corrosion is occurring on the waste packages.
Guidance in NUREG-1297 (Altman et al. 1988
[DIRS 103597]) and NUREG-1298 (Altman et al. 1988 [DIRS 103750]), or other acceptable approaches, is followed.

Inputs were selected and documented according to applicable BSC procedures, which comply with NUREG-1297 and -1298 (Section 4.1).

\subsubsection{Acceptance Criterion 2-Data Are Sufficient for Model Justification}

(1) Geological, hydrological, and geochemical values used in the license application are adequately justified. Adequate description of how the data were used, interpreted, and appropriately synthesized into the parameters is provided;

The selection and justification of geological, hydrological, and geochemical values for use, along with sources of input data, are contained in Section 4.1 and tabulated in the Document Input Reference System. Further details of model development as related to the use, interpretation, and synthesis of data into parameters are presented throughout Section 6, especially in Section 6.6. The model was developed using water chemistry data collected in the Exploratory Studies Facility (ESF) and adjoining facilities. The geochemical analyses presented in this report are based on a chemical thermodynamic database developed for this use from internationally accepted thermodynamic data (Sections 6.2 and 6.5).

(2) Sufficient data were collected on the characteristics of the natural system and engineered materials to establish initial and boundary conditions for conceptual models of thermal-hydrological-mechanical-chemical coupled processes, that affect seepage and flow and the engineered barrier chemical environment;

Data and technical information collected from field and experimental sources, and from literature searches for this model, are discussed for engineered materials in Section 4.1 (engineered components) and Section 6.4 (design features), and for natural system characteristics in Section 6.5 (mineralogical information) and Section 6.6 (THC model). Natural system data are used to develop the THC model, which is a major input to this model (Section 6.6). The natural system data are used to establish initial and boundary conditions that affect seepage and flow and are discussed in Section 6.6. The discussion of the initial and boundary conditions that affect seepage and flow for the engineered material data is discussed in Section 6.8. The effects on the chemical environment in the waste package from collected data are discussed in In-Package Chemistry Abstraction (BSC 2005 [DIRS 174583]).

(4) Sufficient information to formulate the conceptual approach(es) for analyzing water contact with the drip shield, engineered barriers, and waste forms is provided; 
The conceptual approaches of this report's modeling of evaporated seepage waters are supported. This support comes both from other reports (e.g., BSC 2004 [DIRS 169863] and BSC 2005 [DIRS 172862] for support in Section 6.2; BSC 2005 [DIRS 175058] for support in | Section 6.10), and from the analyses presented within this report: e.g., mineral inclusion or suppression (Section 6.5.5), oxygen availability (Section 6.7), and crown seepage interaction with the stainless steel ground support (Section 6.8).

\subsubsection{Acceptance Criterion 3-Data Uncertainty Is Characterized and Propagated Through the Model Abstraction}

(1) Models use parameter values, assumed ranges, probability distributions, and bounding assumptions that are technically defensible, reasonably account for uncertainties and variabilities, and do not result in an under-representation of the risk estimate;

The model parameter values were selected based on the characteristics of the input and are considered representative of the natural and engineered systems (Sections 4.1, 6.4, 6.5, 6.6, and 6.10). Ranges, probability distributions, and bounding assumptions were considered in assessing boundary conditions and input uncertainties and variabilities, which were propagated through the model as described in Section 6.12. Further propagation through TSPA-LA implementation is described in Section 6.15. When modeling decisions were necessary, the choices were made to result in conservative outcomes that avoid dilution of overall risk (Sections 6.9, 6.10, and 6.12).

(2) Parameter values, assumed ranges, probability distributions, and bounding assumptions used in the total system performance assessment calculations of quantity and chemistry of water contacting engineered barriers and waste forms are technically defensible and reasonable, based on data from the Yucca Mountain region (e.g., results from large block and drift-scale heater and niche tests), and a combination of techniques that may include laboratory experiments, field measurements, natural analog research, and process-level modeling studies;

The parameter values, assumed ranges, probability distributions, and bounding assumptions developed by other models based on site-specific data are discussed in Sections 6.6 and 6.11 . Values, ranges, and distributions obtained from other techniques mentioned above include such information as the thermodynamic databases, discussed in Section 4.1.4 with additional discussion in In-Drift Precipitates/Salts Model (BSC 2004 [DIRS 169863]); corrosion data, discussed in Sections 6.4 and 6.8; and mineralogy data discussed in Appendix C. The pore water data founding model development was collected in the ESF and adjoining facilities. Environmental conditions imposed on model development (temperatures, $R H$, and moisture contents) were consistent with data collected from the drift scale test and other related tests. The validation for the seepage evaporation abstraction has been performed by comparison against results directly from the IDPS process model. Other laboratory and natural analogue information were used for additional confidence-building for this model (Section 7.3). 
(3) Input values used in the total system performance assessment calculations of quantity and chemistry of water contacting engineered barriers (e.g., drip shield and waste package) are consistent with the initial and boundary conditions and the assumptions of the conceptual models and design concepts for the Yucca Mountain site. Correlations between input values are appropriately established in the U.S. Department of Energy total system performance assessment. Parameters used to define initial conditions, boundary conditions, and computational domain in sensitivity analyses involving coupled thermal-hydrological-mechanical-chemical effects on seepage and flow, the waste package chemical environment, and the chemical environment for radionuclide release, are consistent with available data. Reasonable or conservative ranges of parameters or functional relations are established;

The input values (Section 4.1) were developed using initial and boundary conditions and assumptions (Section 5) common to other conceptual models and compatible with design concepts. Sensitivity studies involving coupled effects on the chemical environment were conducted (e.g., Section 6.12). The initial and boundary conditions and computational domain for these sensitivity analyses were determined using parameters that are consistent with available data. This report uses the same technical bases and other information used in other TSPA-LA-supporting documents concerned with engineered barrier and waste form performance. The conceptual model that forms the basis for this report is consistent with other engineered system models and repository design. Primary input is taken from the UZ THC model and the IDPS model is used to generate in-drift water chemistry. Sections 6.2 and 6.6 provide details of these model interfaces.

Correlations between input values were established and used at various points in the P\&CE model (Sections 6.6, 6.7, and 6.13). For example, the THC input water and gas chemistries through time are correlated to each other, to temperature, and to relative humidity. Additionally, the correlation of chloride and nitrate are accounted for in the way their uncertainties are determined (Section 6.12.3.1) and implemented (Section 6.12.5.3).

The ranges of parameters and functional relations developed in this report, primarily as lookup tables (Section 6.13), are considered reasonable or conservative. Section 6.15 discusses the appropriate use of these tables, which are response surfaces that relate water chemistry to relative humidity, temperature, $p \mathrm{CO}_{2}$, and time.

(4) Adequate representation of uncertainties in the characteristics of the natural system and engineered materials is provided in parameter development for conceptual models, process-level models, and alternative conceptual models. The U.S. Department of Energy may constrain these uncertainties using sensitivity analyses or conservative limits. For example, the U.S. Department of Energy demonstrates how parameters used to describe flow through the EBS bound the effects of backfill and excavation-induced changes;

Uncertainties in natural system characteristics are included in the THC model output, which is used as direct input to this model. Uncertainties in the Pitzer (natural system) and the 
data0.ymp.R2 (engineered systems) thermodynamic databases used as direct input to this model are discussed in Section 6.12, with additional mineralogy discussion in Appendix C. Engineered materials uncertainties are specifically considered in Section 6.12, and discussions on the effects of dust in Section 6.10. Those uncertainties are evaluated using sensitivity analyses as discussed in Sections 4.1.7 and 6.12. Section 6.12 discusses five key uncertainties including engineered materials and natural systems parameters.

\subsubsection{Acceptance Criterion 4-Model Uncertainty Is Characterized and Propagated Through the Model Abstraction}

(1) Alternative modeling approaches of features, events, and processes are considered and are consistent with available data and current scientific understanding, and the results and limitations are appropriately considered in the abstraction;

The evaluation of FEPs documented in Section 6.14 is based on the model results developed in this report, including the alternative modeling discussed in Section 6.11. This alternative modeling is consistent with available data and scientific understanding. The results and limitations of the alternative FEP modeling and their impact on the engineered barrier chemical environment are presented in Section 6.14.

(2) Alternative modeling approaches are considered and the selected modeling approach is consistent with available data and current scientific understanding. A description that includes a discussion of alternative modeling approaches not considered in the final analysis and the limitations and uncertainties of the chosen model is provided;

Section 6.11 describes several alternative modeling approaches considered for various P\&CE submodels. One submodel, the in-drift gas abstraction, was deemed to not need an explicit alternative conceptual model (also see Section 6.11 for this screening rationale). None of the alternative models were selected for further use. For all model alternatives, brief descriptions and the rationale for exclusion are included as well as references to other reports and sections within this report for further detail. These references also contain information about the models that were selected, including their technical bases, limitations, and uncertainties.

Section 6.11 also provides an extensive investigation of a single model involving an alternative method for clustering waters during the data reduction analysis of the THC seepage waters. The exclusion rationale is based upon a comparison of results from the alternative model with those from the selected approach (Section 6.6). The selected approach is consistent with available data and current scientific understanding. The uncertainties and limitations of various selected approaches are discussed throughout the report (Sections 1.3, 6.6, 6.12, and 8.3).

(3) Consideration of conceptual model uncertainty is consistent with available site characterization data, laboratory experiments, field measurements, natural analog information and process-level modeling studies; and the treatment of conceptual model uncertainty does not result in an under-representation of the risk estimate; 
Uncertainties in inputs and in analytical methodology are considered in the development of the conceptual model (Section 6.2) and output parameters (Section 6.15). Discussion of uncertainty in the conceptual model appears in various places throughout the report. One example is Section 6.12.1, where quotations from Drift-Scale THC Seepage Model (BSC 2005 [DIRS 172862], Sections 6.2.2.1, 6.6.2, and 8.1) discuss the uncertainty of model conceptualizations involving the THC model outputs. The uncertainty evaluation is consistent with available site-specific data, laboratory experiments, field studies, natural analogue data and process-level modeling studies. In addition, model validation is based on available site characterization data, laboratory experiments, and natural analogues (Section 7). The treatment of conceptual model uncertainty described in this report does not under represent risk.

(4) Adequate consideration is given to effects of thermal-hydrologicalmechanical-chemical coupled processes in the assessment of alternative conceptual models. These effects may include:

(i) Thermal-hydrologic effects on gas, water, and mineral chemistry;

(ii) Effects of microbial processes on the engineered barrier chemical environment and the chemical environment for radionuclide release;

(iii) Changes in water chemistry that may result from the release of corrosion products from the waste package and interactions between engineered materials and ground water; and

(iv) Changes in boundary conditions (e.g., drift shape and size) and hydrologic properties, relating to the response of the geomechanical system to thermal loading;

The effects of coupled processes were considered during the assessment of alternative conceptual models (Section 6.11). The descriptions in Section 6.11 are brief because the primary evaluation of most of these alternative models (e.g., effects of microbial processes on the in-drift chemical environment) was outside the scope of this report. References are provided to the other pertinent reports. However, Section 6.11 provides details on an investigation of an alternative method for clustering waters during the analysis of THC seepage waters. This alternative method incorporates coupled thermal-hydrologic-chemical processes.

\subsubsection{Acceptance Criterion 5-Model Abstraction Output Is Supported by Objective Comparisons}

(1) The models implemented in this total system performance assessment abstraction provide results consistent with output from detailed process-level models and/or empirical observations (laboratory and field testings and/or natural analogs);

Information provided to the TSPA-LA was developed using detailed process-level models (Section 6.2). The resulting abstracted model output provided for implementation in the TSPA-LA is consistent with the related process-level model output (Section 7). For appropriate cases, validation against empirical observation is also provided (Section 7). 
(2) Abstracted models for coupled thermal-hydrological-mechanical-chemical effects on seepage and flow and the engineered barrier chemical environment, as well as on the chemical environment for radionuclide release, are based on the same assumptions and approximations demonstrated to be appropriate for process-level models or closely analogous natural or experimental systems. For example, abstractions of processes, such as thermally induced changes in hydrological properties, or estimated diversion of percolation away from the drifts, are adequately justified by comparison to results of process-level modeling, that are consistent with direct observations and field studies;

The abstracted model is based on the same assumptions and approximations demonstrated to be appropriate for process-level models. Coupled thermal-hydrologic-chemical considerations are the dominant factor in the development of this model abstraction. The output of this model is a tabulation of chemical conditions as a function of physical environmental conditions that is consistent with process-level modeling as demonstrated by model validation results (Section 7), which are in turn consistent with direct observations from laboratory and field studies.

(3) Accepted and well-documented procedures are used to construct and test the numerical models that simulate coupled thermal-hydrological-mechanicalchemical effects on seepage and flow, engineered barrier chemical environment, and the chemical environment for radionuclide release. Analytical and numerical models are appropriately supported. Abstracted model results are compared with different mathematical models, to judge robustness of results.

Accepted and well-documented procedures contained in the Quality Assurance Program (Section 2) governed the development of this report and the work it documents. The PC\&E model was constructed, supported, and documented according to LP-SIII.10Q-BSC. Test and validation methods (Section 7), including comparison of abstracted output with that of other relevant models, also comply with LP-SIII.10Q-BSC, as well as with applicable written guidance. This report was generated according to the requirements of Technical Work Plan for: Near-Field Environment and Transport In-Drift Geochemistry Model Report Integration (BSC 2005 [DIRS 173782]), as directed by LP-2.29Q-BSC. 


\section{INPUTS AND REFERENCES}

\subsection{DOCUMENTS CITED}

162265 Alexander, A.L.; Southwell, C.R.; and Forgeson, B.W. 1961. "Corrosion of Metals in Tropical Environments." Corrosion, 17, 97-104. Houston, Texas: National Association of Corrosion Engineers. TIC: 223352.

103597 Altman, W.D.; Donnelly, J.P.; and Kennedy, J.E. 1988. Peer Review for High-Level Nuclear Waste Repositories: Generic Technical Position.

NUREG-1297. Washington, D.C.: U.S. Nuclear Regulatory Commission. TIC: 200651.

103750 Altman, W.D.; Donnelly, J.P.; and Kennedy, J.E. 1988. Qualification of Existing Data for High-Level Nuclear Waste Repositories: Generic Technical Position. NUREG-1298. Washington, D.C.: U.S. Nuclear Regulatory Commission. TIC: 200652.

105701 Amonette, J.E. and Rai, D. 1990. "Identification of Noncrystalline (Fe,Cr)(OH)3 by Infrared Spectroscopy." Clays and Clay Minerals, 38, (2), 129-136. Boulder, Colorado: Clay Minerals Society. TIC: 243615.

172858 Apted, M.; King, F.; Langmuir, D.; Arthur, R.; and Kessler, J. 2005. “The Unlikelihood of Localized Corrosion of Nuclear Waste Packages Arising from Deliquescent Brine Formation.” Journal of Metals, 57, (1), 43-48. Warrendale, Pennsylvania: The Minerals, Metals \& Materials Society. TIC: 257253.

157860 Baes, C.F., Jr. and Mesmer, R.E. 1976. The Hydrolysis of Cations. Pages 1, 6, 7, 176, 177, 180, 181, 184-191. New York, New York: John Wiley \& Sons. TIC: 217440.

163015 Ball, J.W. and Nordstrom, D.K. 1998. "Critical Evaluation and Selection of Standard State Thermodynamic Properties for Chromium Metal and its Aqueous Ions, Hydrolysis Species, Oxides, and Hydroxides." Journal of Chemical \& Engineering Data, 43, (6), 895-918. Washington, D.C.: American Chemical Society. TIC: 254015.

105730 Baron, D. and Palmer, C.D. 1996. "Solubility of KFe3(CrO4)2(OH)6 at 4 to $35^{\circ}$ C." Geochimica et Cosmochimica Acta, 60, (20), 3815-3824. New York, New York: Elsevier. TIC: 243731.

162270 Bethke, C.M. 1996. Geochemical Reaction Modeling, Concepts and Applications. New York, New York: Oxford University Press. TIC: 252884. 
163699 Bomberger, H.B.; Cambourelis, P.J.; and Hutchinson, G.E. 1954. "Corrosion Properties of Titanium in Marine Environments." Journal of the Electrochemical Society, 101, (9), 442-447. New York, New York: Electrochemical Society. TIC: 254366.

156639 Borchardt, G. 1995. "Smectites." Chapter 14 of Minerals in Soil Environments. 2nd Edition. Dixon J.B. and Weed, S.B., eds. SSSA Book Series, No. 1. Madison, Wisconsin: Soil Science Society of America. TIC: 237222.

100883 Brasher, D.M. and Mercer, A.D. 1968. "Comparative Study of Factors Influencing the Action of Corrosion Inhibitors for Mild Steel in Neutral Solution, I. Sodium Benzoate." British Corrosion Journal, 3, 120-129. London, England: British Joint Corrosion Group. TIC: 236434.

105092 Brookins, D.G. 1988. Eh-pH Diagrams for Geochemistry. New York, New York: Springer-Verlag. TIC: 237943.

110969 Bruno, J.; Duro, L.; de Pablo, J.; Casas, I.; Ayora, C.; Delgado, J.; Gimeno, M.J.; Peña, J.; Linklater, C.; Pérez del Villar, L.; and Gómez, P. 1998. "Estimation of the Concentrations of Trace Metals in Natural Systems. The Application of Codissolution and Coprecipitation Approaches to El Berrocal (Spain) and Poços de Caldas (Brazil)." Chemical Geology, 151, 277-291. Amsterdam, The Netherlands: Elsevier. TIC: 246492.

164101 BSC (Bechtel SAIC Company) 2003. Repository Design Project, Repository/PA IED Emplacement Drift Committed Materials (2). 800-IED-WIS0-00302-000-00A. Las Vegas, Nevada: Bechtel SAIC Company. ACC: ENG.20030627.0004.

168489 BSC 2004. D\&E / PA/C IED Emplacement Drift Configuration and Environment. 800-IED-MGR0-00201-000-00B. Las Vegas, Nevada: Bechtel SAIC Company. ACC: ENG.20040326.0001.

169058 BSC 2004. D\&E / PA/C IED Subsurface Facilities Committed Materials. 800-IED-WIS0-00302-000-00B. Las Vegas, Nevada: Bechtel SAIC Company. ACC: ENG.20040318.0031.

161237 BSC 2004. Environment on the Surfaces of the Drip Shield and Waste Package Outer Barrier. ANL-EBS-MD-000001 REV 01. Las Vegas, Nevada: Bechtel SAIC Company. ACC: DOC.20041116.0005.

169991 BSC 2004. Evaluation of Potential Impacts of Microbial Activities on Drift Chemistry. ANL-EBS-MD-000038 REV 01. Las Vegas, Nevada: Bechtel SAIC Company. ACC: DOC.20041118.0005.

169845 BSC 2004. General Corrosion and Localized Corrosion of the Drip Shield. ANL-EBS-MD-000004 REV 02. Las Vegas, Nevada: Bechtel SAIC Company. ACC: DOC.20040921.0002. 
169984 BSC 2004. General Corrosion and Localized Corrosion of Waste Package Outer Barrier. ANL-EBS-MD-000003 REV 02. Las Vegas, Nevada: Bechtel SAIC Company. ACC: DOC.20041004.0001.

168405 BSC 2004. Geochemistry Model Abstraction and Sensitivity Studies for the 21 PWR CSNF Waste Packages. MDL-DSU-MD-000001 REV 00 Errata 001. Las Vegas, Nevada: Bechtel SAIC Company. ACC: MOL.20021107.0154; DOC.20040225.0005.

169863 BSC 2004. In-Drift Precipitates/Salts Model. ANL-EBS-MD-000045 REV 02. Las Vegas, Nevada: Bechtel SAIC Company. ACC: DOC.20041111.0002.

169858 BSC 2004. Post-Processing Analysis for THC Seepage. ANL-NBS-HS-000045 REV 00. Las Vegas, Nevada: Bechtel SAIC Company.

ACC: DOC.20040929.0002; DOC.20050606.0006.

171916 BSC 2004. Qualification of Thermodynamic Data for Geochemical Modeling of Mineral-Water Interactions in Dilute Systems. ANL-WIS-GS-000003 REV 00. Las Vegas, Nevada: Bechtel SAIC Company. ACC: DOC.20041129.0006.

169776 BSC 2004. Repository Subsurface Emplacement Drifts Steel Invert Structure Sect. \& Committed Materials. 800-SS0-SSE0-00102-000-00B. Las Vegas, Nevada: Bechtel SAIC Company. ACC: ENG.20040520.0005.

167652 BSC 2004. Seepage Model for PA Including Drift Collapse. MDL-NBS-HS-000002 REV 03. Las Vegas, Nevada: Bechtel SAIC Company. ACC: DOC.20040922.0008.

169862 BSC 2004. Ventilation Model and Analysis Report. ANL-EBS-MD-000030 REV 04. Las Vegas, Nevada: Bechtel SAIC Company.

ACC: DOC.20041025.0002.

169996 BSC 2004. WAPDEG Analysis of Waste Package and Drip Shield Degradation. ANL-EBS-PA-000001 REV 02. Las Vegas, Nevada: Bechtel SAIC Company. ACC: DOC.20041004.0005.

170025 BSC 2004. Waste Form and In-Drift Colloids-Associated Radionuclide Concentrations: Abstraction and Summary. MDL-EBS-PA-000004 REV 01. Las Vegas, Nevada: Bechtel SAIC Company. ACC: DOC.20041028.0007; DOC.20050425.0003.

175058 BSC 2005. Analysis of Dust Deliquescence for FEP Screening. ANL-EBS-MD-000074 REV 01. Las Vegas, Nevada: Bechtel SAIC Company.

174566 BSC 2005. Dissolved Concentration Limits of Radioactive Elements. ANL-WIS-MD-000010 REV 05. Las Vegas, Nevada: Bechtel SAIC Company. ACC: DOC.20050713.0006. 
172862 BSC 2005. Drift-Scale THC Seepage Model. MDL-NBS-HS-000001 REV 04. Las Vegas, Nevada: Bechtel SAIC Company. ACC: DOC.20050218.0001.

173433 BSC 2005. EBS Radionuclide Transport Abstraction. ANL-WIS-PA-000001 REV 02. Las Vegas, Nevada: Bechtel SAIC Company. ACC: DOC.20050825.0008.

175014 BSC 2005. Engineered Barrier System Features, Events, and Processes. ANL-WIS-PA-000002 REV 05. Las Vegas, Nevada: Bechtel SAIC Company, LLC.

173498 BSC 2005. IED Subsurface Facilities Ground Support Configuration [Sheet 1 of 1]. 800-IED-WIS0-01601-000-00A. Las Vegas, Nevada: Bechtel SAIC Company. ACC: ENG.20050406.0003.

173501 BSC 2005. IED Waste Package Configuration [Sheet 1 of 1]. 800-IED-WIS0-00601-000-00A. Las Vegas, Nevada: Bechtel SAIC Company. ACC: ENG.20050406.0005.

174583 BSC 2005. In-Package Chemistry Abstraction. ANL-EBS-MD-000037 REV 04. Las Vegas, Nevada: Bechtel SAIC Company. ACC: DOC.20050714.0003.

173944 BSC 2005. Multiscale Thermohydrologic Model. ANL-EBS-MD-000049 REV 03. Las Vegas, Nevada: Bechtel SAIC Company. ACC: DOC.20050711.0001.

174269 BSC 2005. Q-List. 000-30R-MGR0-00500-000-002. Las Vegas, Nevada: Bechtel SAIC Company. ACC: ENG.20050805.0006.

173782 BSC 2005. Technical Work Plan for: Near-Field Environment and Transport InDrift Geochemistry Model Report Integration. TWP-MGR-PA-000016 REV 03. Las Vegas, Nevada: Bechtel SAIC Company. ACC: DOC.20050518.0004.

163753 Bühn B. and Rankin A.H. 1999. "Composition of Natural, Volatile-Rich $\mathrm{Na}-\mathrm{Ca}$-REE-Sr Carbonatitic Fluids Trapped in Fluid Inclusions." Geochimica et Cosmochimica Acta, 63, (22), 3781-3797. New York, New York: Pergamon.

TIC: 254299.

166275 Canori, G.F. and Leitner, M.M. 2003. Project Requirements Document. TER-MGR-MD-000001 REV 02. Las Vegas, Nevada: Bechtel SAIC Company. ACC: DOC.20031222.0006.

105213 Carlos, B.A.; Chipera, S.J.; Bish, D.L.; and Raymond, R. 1995. "Distribution and Chemistry of Fracture-Lining Zeolites at Yucca Mountain, Nevada." Natural Zeolites '93: Occurrence, Properties, Use, Proceedings of the 4th International Conference on the Occurrence, Properties, and Utilization of Natural Zeolites, June 20-28, 1993, Boise, Idaho. Ming, D.W. and Mumpton, F.A., eds. Pages 547-563. Brockport, New York: International Committee on Natural Zeolites. TIC: 243086. 
138706 Carnahan, C.L. 1987. Effects of Coupled Thermal, Hydrological and Chemical Processes on Nuclide Transport. LBL-23186. Berkeley, California: Lawrence Berkeley National Laboratory. TIC: 232514.

105732 Cotton, F.A. and Wilkinson, G. 1988. Advanced Inorganic Chemistry. 5th Edition. New York, New York: John Wiley \& Sons. TIC: 236867.

162482 Davies, C.W. 1962. Ion Association. Washington, D.C.: Butterworths. TIC: 244840.

117493 Davis, J.R., ed. 1996. ASM Specialty Handbook: Carbon and Alloy Steels. Materials Park, Ohio: ASM International. TIC: 246396.

162338 Deer, W.A.; Howie, R.A.; and Zussman, J. 1967. An Introduction to the Rock-Forming Minerals. New York, New York: John Wiley and Sons. TIC: 234769.

163286 Deer, W.A.; Howie, R.A.; and Zussman, J. 1992. An Introduction to the Rock-Forming Minerals. 2nd Edition. New York, New York: Prentice Hall. TIC: 221918.

151392 Dellien, I.; Hall, F.M.; and Hepler, L.G. 1976. "Chromium, Molybdenum, and Tungsten: Thermodynamic Properties, Chemical Equilibria, and Standard Potentials." Chemical Reviews, 76, (3), 283-310. Washington, D.C.: American Chemical Society. TIC: 248458.

105778 Deng, Y.; Stjernstrom, M.; and Banwart S. 1996. "Accumulation and Remobilization of Aqueous Chromium (VI) at Iron Oxide Surfaces: Application of a Thin-film Continuous Flow-through Reactor." Journal of Contaminant Hydrology, 21, 141-151. Amsterdam, The Netherlands: Elsevier. TIC: 243062.

118564 Drever, J.I. 1988. The Geochemistry of Natural Waters. 2nd Edition. Englewood Cliffs, New Jersey: Prentice-Hall. TIC: 242836.

147480 Drever, J.I. 1997. "Evaporation and Saline Waters.” Chapter 15 of The Geochemistry of Natural Waters: Surface and Groundwater Environments. 3rd Edition. Upper Saddle River, New Jersey: Prentice Hall. TIC: 246732.

105780 Eary, L.E. and Rai, D. 1987. "Kinetics of Chromium(III) Oxidation to Chromium(VI) by Reaction with Manganese Dioxide." Environmental Science \& Technology, 21, (12), 1187-1193. Washington, D.C.: American Chemical Society. TIC: 243224.

105784 Eary, L.E. and Rai, D. 1988. "Chromate Removal from Aqueous Wastes by Reduction with Ferrous Ion." Environmental Science \& Technology, 22, (8), 972-977. Washington, D.C.: American Chemical Society. TIC: 243600. 
105788 Eary, L.E. and Rai, D. 1989. "Kinetics of Chromate Reduction by Ferrous Ions Derived from Hematite and Biotite at 25C." American Journal of Science, 289, 180-213. New Haven, Connecticut: Yale University. TIC: 243614.

100743 Eugster, H.P. and Hardie, L.A. 1978. "Saline Lakes." Lakes, Chemistry, Geology, Physics. Lerman, A., ed. Pages 237-293. New York, New York: Springer-Verlag. TIC: 240782.

162282 Faust, G.T. 1953. "Huntite, $\mathrm{Mg}_{3} \mathrm{Ca}\left(\mathrm{CO}_{3}\right)_{4}$, a New Mineral." American Mineralogist, 38, (1-2), 4-24. Washington, D.C.: Mineralogical Society of America. TIC: 252888.

105795 Fitzpatrick, R.W.; Le Roux, J.; and Schwertmann, U. 1978. “Amorphous and Crystalline Titanium and Iron-Titanium Oxides in Synthetic Preparations, at Near Ambient Conditions, and in Soil Clays." Clays and Clay Minerals, 26, (3), 189-201. Boulder, Colorado: Clay Minerals Society. TIC: 242847.

162312 Fleischer, M. and Efremov, N. 1954. "New Mineral Names." American Mineralogist, 39, (3-4), 402-408. Washington, D.C.: Mineralogical Society of America. TIC: 252897.

162284 Fleischer, M. and Pabst, A. 1983. "New Mineral Names." Journal of the Mineralogical Society of America, 68, (1-2), 281-283. Washington, D.C.: Mineralogical Society of America. TIC: 252898.

100033 Flint, L.E. 1998. Characterization of Hydrogeologic Units Using Matrix Properties, Yucca Mountain, Nevada. Water-Resources Investigations Report 97-4243. Denver, Colorado: U.S. Geological Survey.

ACC: MOL.19980429.0512.

159343 Forgeson, B.W.; Southwell, C.R.; Alexander, A.L.; Mundt, H.W.; and Thompson, L.J. 1958. "Corrosion of Metals in Tropical Environments, (Part 1-Five Non-Ferrous Metals and a Structural Steel)." Corrosion, 14, (2), 73t-81t. Houston, Texas: National Association of Corrosion Engineers. TIC: 223373.

161804 Frye, K. 1981. Encyclopedia of Mineralogy. Encyclopedia of Earth Sciences, Volume 4B. Stroudsburg, Pennsylvania: Hutchinson Ross. TIC: 252977.

144877 Garrels, R.M. and Christ, C.L. 1990. Solutions, Minerals, and Equilibria. Boston, Massachusetts: Jones and Bartlett Publishers. TIC: 223483.

123636 Garrels, R.M. and Mackenzie, F.T. 1967. "Origin of the Chemical Compositions of Some Springs and Lakes?" Equilibrium Concepts in Natural Water Systems. American Chemical Society Advances in Chemistry Series 67. Pages 222-242. Washington, D.C.: American Chemical Society. TIC: 246519. 
163705 Gilbert, R.O. 1987. Statistical Methods for Environmental Pollution Monitoring. New York, New York: John Wiley \& Sons. TIC: 252619.

104945 Greenspan, L. 1977. "Humidity Fixed Points of Binary Saturated Aqueous Solutions." Journal of Research of the National Bureau of Standards, 81A, (1), 89-96. Washington, D.C.: U.S. Department of Commerce. TIC: 241138.

170586 Hall, D. and Walton, J. 2003. "Physical Separation Processes and EBS Water Chemistry - A Modeling Study." Proceedings of the 10th International High-Level Radioactive Waste Management Conference (IHLRWM), March 30-April 2, 2003, Las Vegas, Nevada. Pages 624-628. La Grange Park, Illinois: American Nuclear Society. TIC: 254559.

100814 Harrar, J.E.; Carley, J.F.; Isherwood, W.F.; and Raber, E. 1990. Report of the Committee to Review the Use of J-13 Well Water in Nevada Nuclear Waste Storage Investigations. UCID-21867. Livermore, California: Lawrence Livermore National Laboratory. ACC: NNA.19910131.0274.

105965 Hay, R.L. 1966. Zeolites and Zeolitic Reactions in Sedimentary Rocks. Special Paper 85. Boulder, Colorado: Geological Society of America. TIC: 238294.

162281 Hay, R.L. and Wiggins, B. 1980. "Pellets, Ooids, Sepiolite and Silica in Three Calcretes of the Southwestern United States." Sedimentology, 27, 559-576. Malden, Massachusetts: Blackwell Publishing. TIC: 222806.

137246 Helgeson, H.C. 1969. "Thermodynamics of Hydrothermal Systems at Elevated Temperatures and Pressures." American Journal of Science, 267, (6), 729-804. New Haven, Connecticut: Scholarly Publications. TIC: 241817.

115670 Hem, J.D. 1985. Study and Interpretation of the Chemical Characteristics of Natural Water. 3rd Edition. Geological Survey Water-Supply Paper 2254. Washington, D.C.: U.S. Government Printing Office. ACC: NNA.19940427.0181.

105854 Hem, J.D.; Lind, C.J.; and Roberson, C.E. 1989. "Coprecipitation and Redox Reactions of Manganese Oxides with Copper and Nickel." Geochimica et Cosmochimica Acta, 53, 2811-2822. New York, New York: Pergamon Press. TIC: 243113.

163031 Hrma, P.; Piepel, G.F.; Vienna, J.D.; Cooley, S.K.; Kim, D.S.; and Russell, R.L. 2001. Database and Interim Glass Property Models for Hanford HLW Glasses. PNNL-13573. Richland, Washington: Pacific Northwest National Laboratory. TIC: 254061. 
158974 HydroGeoLogic and Allison Geoscience Consultants. 1999. MINTEQA2/PRODEFA2, A Geochemical Assessment Model for Environmental Systems: User Manual Supplement for Version 4.0. Athens, Georgia: U.S. Environmental Protection Agency, National Exposure Research Laboratory. TIC: 252456.

169567 Jarek, R.L. 2002. GetEQData Version 1.0.1, Software Management Report. Software Document Number: 10809-SMR-1.0.1-00. Albuquerque, New Mexico: Sandia National Laboratories. ACC: MOL.20030127.0064.

162479 Jenne, E.A. 1981. Waste/Rock Interactions Technology Program, Geochemical Modeling: A Review. PNL-3574. Richland, Washington: Pacific Northwest Laboratory. TIC: 229656.

105878 Johnson, C.A. and Xyla, A.G. 1991. "The Oxidation of Chromium (III) to Chromium (VI) on the Surface of Manganite (MnOOH)." Geochimica et Cosmochimica Acta, 55, 2861-2866. New York, New York: Pergamon Press. TIC: 243616.

168509 Jovancicevic, V. and Bockris, J.O’M. 1986. “The Mechanism of Oxygen Reduction on Iron in Neutral Solutions." Journal of the Electrochemical Society, 133, (9), 1797-1807. Manchester, New Hampshire: Electrochemical Society. TIC: 255668.

161606 Kerr, P.F. 1977. Optical Mineralogy. 4th Edition. New York, New York: McGraw-Hill. TIC: 252886.

105907 Klein, C. and Hurlbut, C.S., Jr. 1985. Manual of Mineralogy. 20th Edition. New York, New York: John Wiley \& Sons. TIC: 242818.

125329 Koorevaar, P.; Menelik, G.; and Dirksen, C. 1983. Elements of Soil Physics. Developments in Soil Science 13. New York, New York: Elsevier. TIC: 246286.

100909 Kotra, J.P.; Lee, M.P.; Eisenberg, N.A.; and DeWispelare, A.R. 1996. Branch Technical Position on the Use of Expert Elicitation in the High-Level Radioactive Waste Program. NUREG-1563. Washington, D.C.: U.S. Nuclear Regulatory Commission. TIC: 226832.

105909 Krauskopf, K.B. 1979. Introduction to Geochemistry. 2nd Edition. New York, New York: McGraw-Hill. TIC: 242816.

100051 Langmuir, D. 1997. Aqueous Environmental Geochemistry. Upper Saddle River, New Jersey: Prentice Hall. TIC: 237107. 
159034 Li, G.; Peacor, D.R.; Coombs, D.S.; and Kawachi, Y. 1997. "Solid Solution in the Celadonite Family: The New Minerals Ferroceladonite, $\mathrm{K}_{2} \mathrm{Fe}_{2}{ }_{2}+\mathrm{Fe}^{3}{ }_{2}+\mathrm{Si}_{8} \mathrm{O}_{20}(\mathrm{OH})_{4}$, and Ferroaluminoceladonite, $\mathrm{K}_{2} \mathrm{Fe}_{2}{ }_{2}+\mathrm{Al}_{2} \mathrm{Si}_{8} \mathrm{O}_{20}(\mathrm{OH})_{4}$." American Mineralogist, 82, (5-6), 503-511. Washington, D.C.: Mineralogical Society of America.

TIC: 252472.

114637 McCright, R.D. 1998. Corrosion Data and Modeling, Update for Viability Assessment. Volume 3 of Engineered Materials Characterization Report.

UCRL-ID-119564, Rev. 1.1. Livermore, California: Lawrence Livermore National Laboratory. ACC: MOL.19980806.0177.

108954 McLean, J.E. and Bledsoe, B.E. 1992. Behavior of Metals in Soils.

EPA/540/S-92/018. Washington, D.C.: U.S. Environmental Protection Agency.

TIC: 243412.

163728 Niki, K. 1985. "Chromium.” In Standard Potentials in Aqueous Solution, Monographs in Electroanalytical Chemistry and Electrochemistry. Bard, A.J.; Parsons, R.; and Jordan, J.; eds. New York, New York: Marcel Dekker. TIC: 254232.

$162480 \quad$ Nordstrom, D.K. and Jenne, E.A. 1977. "Fluorite Solubility Equilibria in Selected Geothermal Waters." Geochimica et Cosmochimica Acta, 41, (2), 175-188.

New York, New York: Pergamon Press. TIC: 253587.

162508 Nordstrom, D.K.; Jenne, E.A.; and Ball, J.W. 1979. "Redox Equilibria of Iron in Acid Mine Waters." Chapter 3 of Chemical Modeling in Aqueous Systems, Specification, Sorption, Solubility, and Kinetics. Jenne, E.A., ed. ACS Symposium Series 93. Washington, D.C.: American Chemical Society. TIC: 208922.

163274 NRC (U.S. Nuclear Regulatory Commission) 2003. Yucca Mountain Review Plan, Final Report. NUREG-1804, Rev. 2. Washington, D.C.: U.S. Nuclear Regulatory Commission, Office of Nuclear Material Safety and Safeguards. TIC: 254568.

162280 Palache, C.; Berman, H.; and Frondel, C. 1951. Halides, Nitrates, Borates, Carbonates, Sulfates, Phosphates, Arsenates, Tungstates, Molybdates, Etc. Volume II of The System of Mineralogy of James Dwight Dana and Edward Salisbury Dana, Yale University 1837-1892. 7th Edition. New York, New York: John Wiley \& Sons. TIC: 209332.

108991 Palmer, C.D. and Puls, R.W. 1994. Natural Attenuation of Hexavalent Chromium in Ground Water and Soils. EPA/540/S-94/505. Washington, D.C.: U.S. Environmental Protection Agency. TIC: 243413.

105952 Pankow, J.F. 1991. Aquatic Chemistry Concepts. Chelsea, Michigan: Lewis Publishers. TIC: 242999. 
162274 Papke, K.G. 1976. Evaporites and Brines in Nevada Playas. Nevada Bureau of Mines and Geology Bulletin 87. Reno, Nevada: University of Nevada, Reno, Mackay School of Mines. TIC: 211869.

142177 Parkhurst, D.L. 1995. User's Guide to PHREEQC-A Computer Program for Speciation, Reaction-Path, Advective-Transport, and Inverse Geochemical Calculations. Water-Resources Investigations Report 95-4227. Lakewood, Colorado: U.S. Geological Survey. TIC: 248314.

103896 Parrington, J.R.; Knox, H.D.; Breneman, S.L.; Baum, E.M.; and Feiner, F. 1996. Nuclides and Isotopes, Chart of the Nuclides. 15th Edition. San Jose, California: General Electric Company and KAPL, Inc. TIC: 233705.

163030 Perez, J.M., Jr.; Bickford, D.F.; Day, D.E.; Kim, D.S.; Lambert, S.L.; Marra, S.L.; Peeler, D.K.; Strachan, D.M.; Triplett, M.B.; Vienna, J.D.; and Wittman, R.S. 2001. High-Level Waste Melter Study Report. PNNL-13582. Richland, Washington: Pacific Northwest National Laboratory. TIC: 254062.

162576 Peterman, Z.E. and Cloke, P.L. 2002. "Geochemistry of Rock Units at the Potential Repository Level, Yucca Mountain, Nevada (includes Erratum).” Applied Geochemistry, 17, (6, 7), 683-698, 955-958. New York, New York: Pergamon. TIC: $252516 ; 252517$.

105955 Pettine, M.; D’Ottone, L.; Campanella, L.; Millero, F.J.; and Passino, R. 1998. "The Reduction of Chromium(VI) by Iron(II) in Aqueous Solutions." Geochimica et Cosmochimica Acta, 62, (9), 1509-1519. New York, New York: Pergamon Press. TIC: 243059.

$162481 \quad$ Pitzer, K.S. 1987. "A Thermodynamic Model for Aqueous Solutions of Liquid-Like Density." Thermodynamic Modeling of Geological Materials: Minerals, Fluids and Melts. Carmichael, I.S.E. and Eugster, H.P., eds. Reviews in Mineralogy Volume 17. Pages 97-142. Washington, D.C.: Mineralogical Society of America. TIC: 253653.

152738 Pitzer, K.S. 1973. "Thermodynamics of Electrolytes. I. Theoretical Basis and General Equations.” Journal of Physical Chemistry, 77, (2), 268-277. Washington, D.C.: American Chemical Society. TIC: 239503.

152740 Pitzer, K.S. 1975. "Thermodynamics of Electrolytes. V. Effects of Higher-Order Electrostatic Terms." Journal of Solution Chemistry, 4, (3), 249-265. New York, New York: Plenum Publishing. TIC: 248997.

119530 Pitzer, K.S. 1979. "Theory: Ion Interaction Approach." Volume 1, Chapter 7 of Activity Coefficients in Electrolyte Solutions. Pytkowicz, R.M., ed. Boca Raton, Florida: CRC Press. TIC: 239527. 
107060 Rai, D. and Zachara, J.M. 1984. A Critical Review. Volume 1 of Chemical Attenuation Rates, Coefficients, and Constants in Leachate Migration. EPRI EA-3356. Palo Alto, California: Electric Power Research Institute. TIC: 237846.

163369 Rai, D.; Sass, B.M.; and Moore, D.A. 1987. "Chromium(III) Hydrolysis Constants and Solubility of Chromium(III) Hydroxide." Inorganic Chemistry, 26, (3), 345-349. Washington, D.C.: American Chemical Society. TIC: 254060.

163132 Reheis, M.C.; Budahn, J.R.; and Lamothe, P.J. 2002. "Geochemical Evidence for Diversity of Dust Sources in the Southwestern United States." Geochimica et Cosmochimica Acta, 66, (9), 1569-1587. New York, New York: Pergamon. TIC: 254213

159370 Revie, R.W., ed. 2000. Uhlig’s Corrosion Handbook. 2nd Edition. New York, New York: John Wiley \& Sons. TIC: 248360.

107105 Roberts, W.L.; Campbell, T.J.; and Rapp, G.R., Jr. 1990. Encyclopedia of Minerals. 2nd Edition. New York, New York: Van Nostrand Reinhold. TIC: 242976.

154862 Rosenberg, N.D.; Gdowski, G.E.; and Knauss, K.G. 2001. "Evaporative Chemical Evolution of Natural Waters at Yucca Mountain, Nevada." Applied Geochemistry, 16, (9-10), 1231-1240. New York, New York: Pergamon. TIC: 249879.

105957 Sass, B.R. and Rai, D. 1987. "Solubility of Amorphous Chromium(III)-Iron(III) Hydroxide Solid Solutions.” Inorganic Chemistry, 26, (13), 2228-2232. Washington, D.C.: American Chemical Society. TIC: 243717.

105959 Schwertmann, U. and Taylor, R.M. 1995. "Iron Oxides." Chapter 8 of Minerals in Soil Environments. 2nd Edition. Dixon, J.B. and Weed, S.B., eds. SSSA Book Series, No. 1. Madison, Wisconsin: Soil Science Society of America. TIC: 237222.

105964 Sedlak, D.L. and Chan, P.G. 1997. "Reduction of Hexavalent Chromium by Ferrous Iron." Geochimica et Cosmochimica Acta, 61, (11), 2185-2192. New York, New York: Elsevier. TIC: 243064.

162970 Sequeira, C.A.C. 2000. "Corrosion of Copper and Copper Alloys.” Chapter 42 of Uhlig's Corrosion Handbook. 2nd Edition. Revie, R.W., ed. New York, New York: John Wiley \& Sons. TIC: 248360.

127953 Shock, E.L.; Sassani, D.C.; Willis, M.; and Sverjensky, D.A. 1997. "Inorganic Species in Geologic Fluids: Correlations Among Standard Molal Thermodynamic Properties of Aqueous Ions and Hydroxide Complexes." Geochimica et Cosmochimica Acta, 61, (5), 907-950. New York, New York: Pergamon Press. TIC: 246451. 
162976 Smith, W.H. and Purdy, G.M. 1995. "Chromium in Aqueous Nitrate Plutonium Process Streams: Corrosion of 316 Stainless Steel and Chromium Speciation.” Waste Management, 15, (7), 477-484. New York, New York: Pergamon.

TIC: 254034.

161602 Smith, W.R. and Missen, R.W. 1991. Chemical Reaction Equilibrium Analysis: Theory and Algorithms. Malabar, Florida: Krieger Publishing Company. TIC: 252885.

162494 SNL (Sandia National Laboratories) 2003. Software User's Manual, EQ3/6, Version 8.0. SDN: 10813-UM-8.0-00. Albuquerque, New Mexico: Sandia National Laboratories. ACC: MOL.20030312.0084.

118845 Sonnenthal, E.; Spycher, N.; Apps, J.; and Simmons, A. 1998. Thermo-Hydro-Chemical Predictive Analysis for the Drift-Scale Heater Test. Milestone SPY289M4. Version 1.0. Berkeley, California: Lawrence Berkeley National Laboratory. ACC: MOL.19980812.0268.

100928 Southwell, C.R. and Bultman, J.D. 1982. "Atmospheric Corrosion Testing in the Tropics." Chapter 64 of Atmospheric Corrosion. The Corrosion Monograph Series. Ailor, W.H., ed. New York, New York: John Wiley and Sons. TIC: 240907.

100927 Southwell, C.R.; Bultman, J.D.; and Alexander, A.L. 1976. "Corrosion of Metals in Tropical Environments - Final Report of 16-Year Exposures." Materials Performance, 15, (7), 9-25. Houston, Texas: National Association of Corrosion Engineers. TIC: 224022.

161956 Steinborn, T.L.; Wolery, T.J.; Alcorn, S.R.; Arthur, S.E.; Bernot, P.A.; Brady, P.V.; Chen, Y.; Domski, P.S.; Jolley, D.M.; Metcalf, R.C.; and Thomas, E. 2003. Data Qualification: Update and Revision of the Geochemical Thermodynamic Database, Data0.ymp. TDR-EBS-MD-000022 REV 00. Las Vegas, Nevada: Bechtel SAIC Company. ACC: DOC.20030331.0003.

100829 Stumm, W. and Morgan, J.J. 1981. Aquatic Chemistry, An Introduction Emphasizing Chemical Equilibria in Natural Waters. 2nd Edition. New York, New York: John Wiley \& Sons. TIC: 208448.

105960 Tebo, B.M.; Ghiorse, W.C.; van Wassbergen, L.G.; Siering, P.L.; and Caspi, R. 1997. "Bacterially Mediated Mineral Formation: Insights into Manganese(II) Oxidation from Molecular Genetic and Biochemical Studies." Chapter 7 of Geomicrobiology: Interactions Between Microbes and Minerals. Banfield, J.F. and Nealson, K.H., eds. Reviews in Mineralogy, Volume 35. Washington, D.C.: Mineralogical Society of America. TIC: 236757.

161603 Van Zeggeren, F. and Storey, S.H. 1970. The Computation of Chemical Equilibria. New York, New York: Cambridge University Press. TIC: 252891. 
107066 Vaniman, D.T.; Ebinger, M.H.; Bish, D.L.; and Chipera, S. 1992. "Precipitation of Calcite, Dolomite, Sepiolite, and Silica from Evaporated Carbonate and Tuffaceous Waters of Southern Nevada, USA." Proceedings of the 7th International Symposium on Water-Rock Interaction, Park City, Utah, July 13-18, 1992. Kharaka, Y.K. and Maest, A., eds. 1, 687-691. Brookfield, Vermont: A.A. Balkema. TIC: 208527.

162283 Walling, E.M.; Rock, P.A.; and Casey, W.H. 1995. "The Gibbs Energy of Formation of Huntite, $\mathrm{CaMg}_{3}\left(\mathrm{CO}_{3}\right)_{4}$, at $298 \mathrm{~K}$ and 1 Bar from Electrochemical Cell Measurements." American Mineralogist, 80, (3-4), 355-360. Washington, D.C.: Mineralogical Society of America. TIC: 252890.

127454 Walton, J.C. 1994. "Influence of Evaporation on Waste Package Environment and Radionuclide Release from a Tuff Repository." Water Resources Research, 30, (12), 3479-3487. Washington, D.C.: American Geophysical Union. TIC: 246921.

102865 Weast, R.C. and Astle, M.J., eds. 1979. CRC Handbook of Chemistry and Physics. 60th Edition. 2nd Printing 1980. Boca Raton, Florida: CRC Press. TIC: 245312.

106170 Weast, R.C., ed. 1984. CRC Handbook of Chemistry and Physics. 65th Edition. Boca Raton, Florida: CRC Press. TIC: 206666.

100836 Wolery, T.J. 1992. EQ3NR, A Computer Program for Geochemical Aqueous Speciation-Solubility Calculations: Theoretical Manual, User's Guide, and Related Documentation (Version 7.0). UCRL-MA-110662 PT III. Livermore, California: Lawrence Livermore National Laboratory. ACC: MOL.19980717.0626.

100097 Wolery, T.J. and Daveler, S.A. 1992. EQ6, A Computer Program for Reaction Path Modeling of Aqueous Geochemical Systems: Theoretical Manual, User's Guide, and Related Documentation (Version 7.0). UCRL-MA-110662 PT IV. Livermore, California: Lawrence Livermore National Laboratory.

ACC: MOL.19980701.0459.

105963 Zachara, J.M.; Girvin, D.C.; Schmidt, R.L.; and Resch, C.T. 1987. "Chromate Adsorption on Amorphous Iron Oxyhydroxide in the Presence of Major Groundwater Ions.” Environmental Science \& Technology, 21, (6), 589-594. Easton, Pennsylvania: American Chemical Society. TIC: 243613.

\subsection{CODES, STANDARDS, REGULATIONS, AND PROCEDURES}

17327310 CFR 63. 2005 Energy: Disposal of High-Level Radioactive Wastes in a Geologic Repository at Yucca Mountain, Nevada. ACC: MOL.20050405.0118.

107536 AISC (American Institute of Steel Construction) 1989. Manual of Steel Construction, Allowable Stress Design. 9th Edition. Chicago, Illinois: American Institute of Steel Construction. TIC: 205770. 
101992 ASM International. 1987. Corrosion. Volume 13 of ASM Handbook. 9th Edition. Materials Park, Ohio: ASM International. TIC: 240704.

103753 ASM International. 1987. Corrosion. Volume 13 of Metals Handbook. 9th Edition. Metals Park, Ohio: ASM International. TIC: 209807.

151765 ASME (American Society of Mechanical Engineers) 1995. "Specification for General Requirements for Steel Plates for Pressure Vessels." SA-20/SA-20M. Section II: Materials, Part A - Ferrous Material Specifications. 1995 ASME Boiler and Pressure Vessel Code. New York, New York: American Society of Mechanical Engineers. TIC: 245287.

170256 ASTM (American Society for Testing and Materials) 1968. "Corrosiveness of Various Atmospheric Test Sites as Measured by Specimens of Steel and Zinc." Metal Corrosion in the Atmosphere, A Symposium Presented at the Seventieth Annual Meeting, Boston, Massachusetts, 25-30 June, 1967. ASTM Special Technical Publication No. 435. Pages 360-391. Philadelphia, Pennsylvania: American Society for Testing and Materials. TIC: 239410.

162720 ASTM A 240/A 240M-02a. 2002. Standard Specification for Chromium and Chromium-Nickel Stainless Steel Plate, Sheet, and Strip for Pressure Vessels and for General Applications. West Conshohocken, Pennsylvania: American Society for Testing and Materials. TIC: 253994.

165006 ASTM A 276-03. 2003. Standard Specification for Stainless Steel Bars and Shapes. West Conshohocken, Pennsylvania: American Society for Testing and Materials. TIC: 254842.

162723 ASTM A 516/A 516M-01. 2001. Standard Specification for Pressure Vessel Plates, Carbon Steel, for Moderate- and Lower-Temperature Service.

West Conshohocken, Pennsylvania: American Society for Testing and Materials. TIC: 253997.

162724 ASTM A 588/A 588M-01. 2001. Standard Specification for High-Strength Low-Alloy Structural Steel with 50 ksi [345 MPa] Minimum Yield Point to 4-in. [100-mm] Thick. West Conshohocken, Pennsylvania: American Society for Testing and Materials. TIC: 253998.

159971 ASTM A 759-00. 2001. Standard Specification for Carbon Steel Crane Rails. West Conshohocken, Pennsylvania: American Society for Testing and Materials. TIC: 253176.

103515 ASTM G 1-90 (Reapproved 1999). 1999. Standard Practice for Preparing, Cleaning, and Evaluating Corrosion Test Specimens. West Conshohocken, Pennsylvania: American Society for Testing and Materials. TIC: 238771. 
LP-2.29Q-BSC, Rev. 0 ICN 0. Planning for Science Activities. Washington, D.C.: U.S. Department of Energy, Office of Civilian Radioactive Waste Management. ACC: DOC.20050114.0001.

LP-SIII.2Q-BSC, Rev. 0 ICN 0. Qualification of Unqualified Data. Washington, D.C.: U.S. Department of Energy, Office of Civilian Radioactive Waste Management. ACC: DOC.20050119.0002.

LP-SIII.10Q-BSC, Rev. 0 ICN 1. Models. Washington, D.C.: U.S. Department of Energy, Office of Civilian Radioactive Waste Management.

ACC: DOC.20050623.0001.

\subsection{SOURCE DATA, LISTED BY DATA TRACKING NUMBER}

160899 GS020408312272.003. Collection and Analysis of Pore Water Samples for the Period from April 2001 to February 2002. Submittal date: 04/24/2002.

166569 GS020808312272.004. Analysis of Water-Quality Samples for the Period from July 1999 to July 2002. Submittal date: 09/18/2002.

165226 GS030408312272.002. Analysis of Water-Quality Samples for the Period from July 2002 to November 2002. Submittal date: 05/07/2003.

166570 GS031008312272.008. Analysis of Pore Water and Miscellaneous Water Samples for the Period from December 2002 to July 2003. Submittal date: 11/13/2003.

161976 LB0302DSCPTHCS.002. Drift-Scale Coupled Processes (THC Seepage) Model: Data Summary. Submittal date: 02/11/2003.

174149 LB0506DSCPTHCS.001. THC Seepage Model-THC Simulation Output Files. Submittal date: 06/15/2005.

170605 LL031106231032.007. High Temperature Solubility and Vapor Pressure (Relative Humidity) Data for Aqueous Systems Containing Single and Multiple Salts. Submittal date: 11/19/2003.

171362 LL040803112251.117. Target Compositions of Aqueous Solutions Used for Corrosion Testing. Submittal date: 08/14/2004.

147298 LL980704605924.035. Engineering Material Characterization Report, Volume 3. Submittal date: 07/17/1998.

150930 MO0005PORWATER.000. Perm-Sample Pore Water Data. Submittal date: 05/04/2000.

161756 MO0302SPATHDYN.000. Thermodynamic Data Input Files - Data0.YMP.R2. Submittal date: 02/05/2003. 
162841 MO0303MWDIOJ13.000. Example EQ3/6 In-Drift Precipitates/Salts Model Input/Output Files for In Situ J-13 Well Water. Submittal date: 03/04/2003.

162549 MO0303SPAMEQ36.000. General Formats of In-Drift Precipitates/Salts Model EQ3/6 Input Files. Submittal date: 03/04/2003.

166329 MO0312SPAESMUN.002. Estimated Model Uncertainties in IDPS Model Outputs. Submittal date: $12 / 03 / 2003$.

167409 MO0312SPAPCEML.003. EBS P\&CE Model Longevity of Materials Evaluation. Submittal date: 12/18/2003.

170616 MO0406SEPTVDST.000. Temperature and Volume Water Content for Drift Scale Test (DST) Heating Phase for Boreholes 79 and 80. Submittal date: 06/29/2004.

171714 MO0409MWDUGCMW.000. Updated General Corrosion Model of the Waste Package Outer Barrier. Submittal date: 09/17/2004.

172059 MO0409SPAACRWP.000. Aqueous Corrosion Rates For Non-Waste Form Waste Package Materials. Submittal date: 09/16/2004.

172601 MO0501SEPFEPLA.001. LA FEP List and Screening. Submittal date: $01 / 17 / 2005$.

162572 SN0302T0510102.002. Pitzer Thermodynamic Database (data0.ypf.r0, Formerly data0.ypf, Revision 1). Submittal date: 02/06/2003.

\subsection{OUTPUT DATA, LISTED BY DATA TRACKING NUMBER}

MO0303MWDEBSSM.000. EBS Abstraction of the THC Seepage Model: Binning Analysis Evaporation to 65\% RH EQ6 Input and Output Files. Submittal date: 03/12/2003.

MO0303MWDSCMAB.000. THC Seepage Chemistry Model Abstraction Binning EQ3NRInput, Pickup and Output Files. Submittal date: 03/06/2003.

MO0304MWDEBSSA.000. EBS THC Seepage Abstraction TSPA-LA Lookup Table EQ6 Input and Output Files. Submittal date: 04/01/2003.

MO0304MWDSAB11.001. EBS THC Seepage Abstraction 11 Bin EQ3NR3i, 3p, and 3o Files. Submittal date: 04/08/2003.

MO0304SPAA11GC.000. EBS THC Seepage Abstraction 11 Bin EQ3NR3o File Water and Gas Chemistry Extraction. Submittal date: 04/10/2003.

MO0304SPACPSLT.000. Combined In-Drift Precipitates/Salts Model Lookup Table for Seepage Evaporation Abstractions for All Bins. Submittal date: 04/18/2003. 
MO0304SPACSALT.000. EBS Chemistry THC Seepage Model Abstraction Lookup Tables for TSPA-LA. Submittal date: 04/14/2003.

MO0310SPAEBSSB.002. EBS P\&CE Model THC Seepage Within and Without Bin Uncertainty Analyses. Submittal date: 10/15/2003.

MO0310SPAEBSUE.002. EBS Chemistry Unevaporated Binning Abstraction Statistics. Submittal date: 10/15/2003.

MO0310SPAPCEAC.002. EBS P\&CE Alternate Conceptual Model Calculations. Submittal date: $10 / 15 / 2003$.

MO0310SPAPCEGS.000. EBS P\&CE “Goldsim Friendly” THC Seepage Look-Up Tables for TSPA-LA. Submittal date: 10/16/2003.

MO0311SPAEPMUT.000. EBS P\&CE Model Uncertainty Tables For TSPA-LA. Submittal date: $11 / 05 / 2003$.

MO0312SPAPCESA.002. EBS P\&CE Model THC Seepage Analysis Spreadsheets. Submittal date: $12 / 10 / 2003$.

MO0406MWDARHPW.000. Abstraction of Repository Horizon Pore Waters using EQ3/6.

Submittal date: 06/18/2004.

MO0407SPAPCEML.005. EBS P\&CE Model Longevity of Materials Evaluation. Submittal date: $06 / 22 / 2004$.

MO0505MWDEBSPC.000. Uncertainty Analyses for pCO2, Br, and Mineral Suppressions. Submittal date: 05/10/2005.

MO0505SPAPCEBV.000. P\&CE Binning Validation Analysis using EQ3/6. Submittal date: $05 / 9 / 2005$.

MO0505SEPSEEPA.000. Seepage Abstraction Instructions for TSPA-LA: Limitation Ranges and Starting Water Probability. Submittal date: 05/12/2005.

MO0506SPAPCEIC.001. EBS P\&CE Model Validation of Interpolation Calculations. Submittal date: 06/22/2005.

MO0508SPAEBSCB.001. EBS Chemistry Binning Abstraction Results of the THC Seepage Model. Submittal date: 08/26/2005.

SN0312T0510102.013. EBS P\&CE Model Stainless Steel Abstraction. Submittal date: $12 / 15 / 2003$.

SN0403T0503404.001. Maximum Relative Humidity (RH) of Halite Precipitation Extracted from P\&CE Seepage Evaporation Look-Up Tables. Submittal date: 03/24/2004. 
SN0404T0510102.014. Sierra Nevada Spring Water Validation; EQ3/6 Runs and Results. Submittal date: 04/19/2004.

SN0503T0510102.019. Near Field Environment In-Drift CO2 Gas Look-up Tables for TSPA-LA. Submittal date: 03/10/2005.

SN0505T0510102.020. Dilute Water-Rock Interaction. Submittal date: 05/3/2005.

SN0505T0510102.022. $\mathrm{CO}_{2}$ Abstraction Model Validation. Submittal date: 05/20/2005.

SN0508T0510102.023. EBS P\&CE Model Gas Flux Evaluation. Submittal date: 08/25/2005.

SN0508T0510102.024. EBS P\&CE Log Transform of Uncertainty Data. Submittal date: $08 / 26 / 2005$.

\subsection{SOFTWARE CODES}

173680 BSC (Bechtel SAIC Company) 2002. GetEQData. 1.0.1. PC w/ Windows 2000. STN: 10809-1.0.1-00.

162228 BSC 2003. Software Code: EQ3/6. V8.0. PC w/ Windows 95/98/2000/NT 4.0. 10813-8.0-00.

161572 BSC 2003. Software Code: GoldSim. V7.50.100. PC. 10344-7.50.100-00. 
APPENDIX A

SUPPORTING FILES 


\section{INTENTIONALLY LEFT BLANK}


Table A-1 documents the output DTNs created by this document and lists the data files and the locations citing these DTNs.

Table A-1. Traceability of Output DTNs Developed in the Report, and Their Associated Files

\begin{tabular}{|c|c|c|c|}
\hline Output DTN & $\begin{array}{l}\text { Associated File } \\
\text { Traceability } \\
\text { Table or Section }\end{array}$ & File Name(s) & $\begin{array}{c}\text { Bin-7 Status } \\
\text { (see Section 6.6.7.3) }\end{array}$ \\
\hline MO0303MWDEBSSM.000 & $\begin{array}{l}\text { Table } 6.6-1 \\
\text { Tables } 6.6-10 \\
\text { and } 6.6-11 \\
\text { Sections } 6.6 .3 \text { and } \\
6.6 .4 \\
\text { Section } 6.7 .3 \\
\text { Table } 8.2-2 \\
\end{array}$ & $\begin{array}{l}\text { W0_THCabstractionRH65_6i_6o_files.zip } \\
\text { W4_THCabstractionRH65_6i_6o_files.zip } \\
\text { W5_THCabstractionRH65_6i_6o_files.zip } \\
\text { W6_THCabstractionRH65_6i_6o_files.zip } \\
\text { W7_THCabstractionRH65_6i_6o_files.zip } \\
\text { Readme.doc }\end{array}$ & $\begin{array}{l}\text { No impact (files } \\
\text { contain THC seepage } \\
\text { model output) }\end{array}$ \\
\hline MO0303MWDSCMAB.000 & $\begin{array}{l}\text { Table } 6.6-1 \\
\text { Section } 6.6 .3 \\
\text { Section } 6.7 .3 \\
\text { Section } 6.9 .1 \\
\text { Table } 8.2-2\end{array}$ & $\begin{array}{l}\text { W0_THCabstraction3i3o3pfiles.zip } \\
\text { W4_THCabstraction3i3o3pfiles.zip } \\
\text { W5_THCabstraction3i3o3pfiles.zip } \\
\text { W6_THCabstraction3i3o3pfiles.zip } \\
\text { W7_THCabstraction3i3o3pfiles.zip } \\
\text { Readme.doc }\end{array}$ & $\begin{array}{l}\text { No impact (files } \\
\text { contain THC seepage } \\
\text { model output) }\end{array}$ \\
\hline MO0304MWDEBSSA.000 & $\begin{array}{l}\text { Table } 6.9-6 \\
\text { Table } 6.12-5 \\
\text { Section } 6.9 .2 \\
\text { Section } 7.1 .1 \\
\text { Table } 8.2-2\end{array}$ & $\begin{array}{l}\text { EQ6_Cond.zip } \\
\text { EQ6_EVAP.zip } \\
\text { Readme.doc }\end{array}$ & $\begin{array}{l}\text { Bin } 7 \text { median water is } \\
\text { based on THC model } \\
\text { output for w0 starting } \\
\text { water (base-front) at } \\
10 \text { kyr, consistent with } \\
\text { output for TSPA. }\end{array}$ \\
\hline MO0304MWDSAB11.001 & $\begin{array}{l}\text { Tables } 6.9-3 \text { and } \\
6.9-4 \\
\text { Table 6.12-9 } \\
\text { Section } 6.8 .2 \\
\text { Section } 6.8 .4 .1 \\
\text { Section } 6.9 .1 \\
\text { Section } 6.12 .4 .1 .3 \\
\text { Table } 8.2-2\end{array}$ & $\begin{array}{l}\text { 11_Bin3i3p3o_files.zip } \\
\text { Readme.doc }\end{array}$ & $\begin{array}{l}\text { Bin } 7 \text { median water is } \\
\text { based on THC model } \\
\text { output for w0 starting } \\
\text { water (base-front) at } \\
10 \text { kyr, consistent with } \\
\text { output for TSPA. }\end{array}$ \\
\hline MO0304SPAA11GC.000 & $\begin{array}{l}\text { Tables 6.7-6 } \\
\text { Tables 6.9-1 } \\
\text { and 6.9-2 } \\
\text { Section 6.9.1 } \\
\text { Table 8.2-2 }\end{array}$ & 11_bin_EQ3_file_dataExtract.zip & $\begin{array}{l}\text { Bin } 7 \text { median water is } \\
\text { based on THC model } \\
\text { output for w0 starting } \\
\text { water (base-front) at } \\
10 \mathrm{kyr} \text {, consistent with } \\
\text { output for TSPA. }\end{array}$ \\
\hline MO0304SPACPSLT.000 & $\begin{array}{l}\text { Section } 6.13 .1 .2 \\
\text { Table 8.2-2 }\end{array}$ & checked_MOALT_r1.zip & $\begin{array}{l}\text { Bin } 7 \text { median water is } \\
\text { based on THC model } \\
\text { output for w0 starting } \\
\text { water (base-front) at } \\
10 \text { kyr, consistent with } \\
\text { output for TSPA. }\end{array}$ \\
\hline MO0304SPACSALT.000 & $\begin{array}{l}\text { Table } 6.9-6 \\
\text { Table } 6.9-7 \\
\text { Section } 6.9 .3 \\
\text { Section } 6.12 .5 \\
\text { Section } 6.12 .5 .3 \\
\text { Section } 6.15 .1 .1 \\
\text { Section } 6.15 .2 \\
\text { Table } 8.2-1 \\
\text { Section } 8.2 .1 \\
\end{array}$ & $\begin{array}{l}\text { Cond_Look-up-Tables.zip } \\
\text { Evap_Look-up-Tables.zip } \\
\text { Readme.doc }\end{array}$ & $\begin{array}{l}\text { Bin } 7 \text { median water is } \\
\text { based on THC model } \\
\text { output for w0 starting } \\
\text { water (base-front) at } \\
10 \mathrm{kyr} \text {, consistent with } \\
\text { output for TSPA. }\end{array}$ \\
\hline MO0310SPAEBSUE.002 & $\begin{array}{l}\text { Section } 6.12 .3 .1 \\
\text { Section } 7.3 .4 \\
\text { Table } 8.2-2\end{array}$ & $\begin{array}{l}\text { New_Non_Evaporated_Binning_Statistics } \\
\text { 02.zip }\end{array}$ & $\begin{array}{l}\text { No impact (files do } \\
\text { not identify or use } \\
\text { median bin waters) }\end{array}$ \\
\hline
\end{tabular}


Table A-1. Traceability of Output DTNs Developed in the Report, and Their Associated Files (Continued)

\begin{tabular}{|c|c|c|c|}
\hline Output DTN & $\begin{array}{l}\text { Associated File } \\
\text { Traceability } \\
\text { Table or Section }\end{array}$ & File Name(s) & $\begin{array}{c}\text { Bin-7 Status } \\
\text { (see Section 6.6.7.3) }\end{array}$ \\
\hline MO0508SPAEBSCB.001 & $\begin{array}{l}\text { Table } 6.6-3 \\
\text { Tables } 6.6-5 \text { to } \\
6.6-15 \\
\text { Sections } 6.6 .4 \text { to } \\
6.6 .6 \\
\text { Sections 6.6.7.1 } \\
\text { and } 6.6 .7 .2 \\
\text { Section } 6.11 .1 .1 \\
\text { Section } 6.12 .3 .1 \\
\text { Section } 6.15 .1 .1 \\
\text { Section } 6.15 .2 \\
\text { Section } 7.3 .4 \\
\text { Table } 8.2-1 \\
\end{array}$ & $\begin{array}{l}\text { Incomplete_65\%_RH_EQ6_files.zip } \\
\text { pCO2and65percentRHBinAbstraction } \\
\text { Reruns.zip } \\
\text { Final_Checked_EBS_THC_Seepage_- } \\
\text { Binning_Abstraction_REV_4.zip }\end{array}$ & $\begin{array}{l}\text { Bin } 7 \text { median water is } \\
\text { based on THC model } \\
\text { output for w0 starting } \\
\text { water (base-front) at } \\
10 \text { kyr, consistent with } \\
\text { output for TSPA. }\end{array}$ \\
\hline MO0310SPAEBSSB.002 & $\begin{array}{l}\text { Section } 6.12 .3 \\
\text { Table 8.2-2 }\end{array}$ & $\begin{array}{l}\text { RH98andRH85EQ6filesW0.zip } \\
\text { RH98andRH85EQ6filesW4.zip } \\
\text { RH98andRH85EQ6filesW5.zip } \\
\text { RH98andRH85EQ6filesW6.zip } \\
\text { RH98andRH85EQ6filesW7.zip } \\
\text { THC_Seepage_Bin_Uncertainty.zip }\end{array}$ & $\begin{array}{l}\text { No impact (files do } \\
\text { not identify or use } \\
\text { median bin waters) }\end{array}$ \\
\hline MO0310SPAPCEAC.002 & $\begin{array}{l}\text { Tables } 6.11-1 \text { to } \\
6.11-14 \\
\text { Section } 6.11 .1 .1 \\
\text { Table } 8.2-2\end{array}$ & $\begin{array}{l}\text { Alternative_Conceptual_Model_Statistics } \\
\text {.zip }\end{array}$ & $\begin{array}{l}\text { Bin } 7 \text { median water is } \\
\text { based on THC model } \\
\text { output for w0 starting } \\
\text { water (base-front) at } \\
10 \text { kyr, consistent with } \\
\text { output for TSPA. }\end{array}$ \\
\hline MO0310SPAPCEGS.000 & $\begin{array}{l}\text { Tables } 6.9-7 \text { and } \\
6.9-8 \\
\text { Sections } 6.9 .3 \text { and } \\
6.9 .4 \\
\text { Section } 6.13 .6 \\
\text { Section } 6.12 .5 \\
\text { Sections } 6.12 .5 .2 \\
\text { and 6.12.5.3 } \\
\text { Section 6.15.1.1 } \\
\text { Section 6.15.2 } \\
\text { Section } 7.3 .4 \\
\text { Section } 8.2 .1 \\
\text { Section } 8.2 .1\end{array}$ & $\begin{array}{l}\text { seepage_lookup_cond.zip } \\
\text { seepage_lookup_evap.zip } \\
\text { Readme_cond.doc } \\
\text { Readme_evap.doc }\end{array}$ & $\begin{array}{l}\text { Bin } 7 \text { median water is } \\
\text { based on THC model } \\
\text { output for w0 starting } \\
\text { water (base-front) at } \\
10 \mathrm{kyr} \text {, consistent with } \\
\text { output for TSPA. }\end{array}$ \\
\hline MO0311SPAEPMUT.000 & $\begin{array}{l}\text { Table } 6.12-4 \\
\text { Table } 6.12-23 \\
\text { Table } 8.2-1\end{array}$ & MO0311SPAEPMUT.000.zip & $\begin{array}{l}\text { Bin } 7 \text { median water is } \\
\text { based on THC model } \\
\text { output for w0 starting } \\
\text { water (base-front) at } \\
10 \text { kyr, consistent with } \\
\text { output for TSPA. }\end{array}$ \\
\hline MO0312SPAPCESA.002 & $\begin{array}{l}\text { Tables 6.13-1, } \\
6.13-2,6.13-6, \\
\text { and 6.13-7 } \\
\text { Section } 6.13 \\
\text { Sections } 6.13 .1 .3 \text {, } \\
6.13 .4 .1 \text {, and } \\
6.13 .5 .2 \\
\text { Section } 7.3 .4 \\
\text { Table } 8.2-2 \\
\end{array}$ & THCSeepageModelAnalysis.zip & $\begin{array}{l}\text { Bin } 7 \text { median water is } \\
\text { based on THC model } \\
\text { output for w4 starting } \\
\text { water (base-front) at } \\
10 \mathrm{kyr} \text {, similar to, but } \\
\text { not the same as } \\
\text { output for TSPA (see } \\
\text { Section } 6.6 .7 .3 \text { for } \\
\text { details). }\end{array}$ \\
\hline MO0406MWDARHPW.000 & $\begin{array}{l}\text { Section } 7.3 .1 \\
\text { Table } 7.3-1 \\
\text { Table } 8.2-2\end{array}$ & RepositoryHorizonPoreWaters.zip & $\begin{array}{l}\text { No impact (files do } \\
\text { not identify or use } \\
\text { median bin waters) }\end{array}$ \\
\hline
\end{tabular}


Table A-1. Traceability of Output DTNs Developed in the Report, and Their Associated Files (Continued)

\begin{tabular}{|c|c|c|c|}
\hline Output DTN & $\begin{array}{l}\text { Associated File } \\
\text { Traceability } \\
\text { Table or Section }\end{array}$ & File Name(s) & $\begin{array}{c}\text { Bin-7 Status } \\
\text { (see Section 6.6.7.3) }\end{array}$ \\
\hline MO0407SPAPCEML.005 & $\begin{array}{l}\text { Table } 4.1-2 \\
\text { Tables 6.4-6, } \\
6.4-7 \text {, and } 6.4-8 \\
\text { Section } 4.1 .1 \\
\text { Table } 8.2-2\end{array}$ & Longevity.zip & $\begin{array}{l}\text { No impact (files do } \\
\text { not identify or use } \\
\text { median bin waters) }\end{array}$ \\
\hline MO0505MWDEBSPC.000 & $\begin{array}{l}\text { Tables } 6.12-17 \text { to } \\
6.12-21 \\
\text { Sections } \\
6.12 .4 .2 .2, \\
6.12 .4 .2 .3, \\
6.12 .4 .3 .1 \\
6.12 .4 .3 .2, \\
6.12 .4 .4, \\
6.12 .4 .4 .1 \text {, and } \\
6.12 .4 .4 .2 \\
\text { Table } 8.2-2\end{array}$ & $\begin{array}{l}\text { MineralSuppressions.zip } \\
\text { seepage_pco2uncertcalcs.zip } \\
\text { SeepageBrSensitivityStudy.zip }\end{array}$ & $\begin{array}{l}\text { No impact (files do } \\
\text { not identify or use } \\
\text { median bin waters) }\end{array}$ \\
\hline MO0505SPAPCEBV.000 & $\begin{array}{l}\text { Table } 7.3-2 \\
\text { Section } 7.3 .2 \\
\text { Table } 8.2-2\end{array}$ & $\begin{array}{l}\text { Validation_of_PandCE_Binning.zip } \\
\text { Readme.doc }\end{array}$ & $\begin{array}{l}\text { Bin } 7 \text { median water is } \\
\text { based on THC model } \\
\text { output for w4 starting } \\
\text { water (base-front) at } \\
10 \text { kyr, similar to, but } \\
\text { not the same as } \\
\text { output for TSPA (see } \\
\text { Section } 6.6 .7 .3 \text { for } \\
\text { details). }\end{array}$ \\
\hline MO0505SEPSEEPA.000 & Table 8.2-1 & $\begin{array}{l}\text { MO0505SEPSEEPA.000.zip } \\
\text { Readme.doc }\end{array}$ & $\begin{array}{l}\text { No impact (files do } \\
\text { not identify or use } \\
\text { median bin waters) }\end{array}$ \\
\hline MO0506SPAPCEIC.001 & $\begin{array}{l}\text { Section } 7.1 .1 \\
\text { Table } 8.2-2\end{array}$ & Interpolation.zip & $\begin{array}{l}\text { No impact (files do } \\
\text { not identify or use } \\
\text { median bin waters) }\end{array}$ \\
\hline SN0312T0510102.013 & $\begin{array}{l}\text { Tables } 4.1-11 \text { and } \\
4.1-13 \\
\text { Tables } 6.8-2 \text { and } \\
6.8-5 \\
\text { Tables } 6.12-6 \text { to } \\
6.12-15 \\
\text { Sections } 6.8 .2 \\
\text { and } 6.8 .3 \\
\text { Sections } 6.8 .4 .1 \\
\text { and 6.8.4.3, } \\
\text { Section } 6.12 .4 .1 \\
\text { Table } 8.2-2\end{array}$ & $\begin{array}{l}\text { Base case.zip } \\
\text { DegradationMolality.zip } \\
\text { Cr-database.zip } \\
\text { Cr-validation.zip } \\
\text { Uncertainties.zip } \\
\text { readme.txt }\end{array}$ & $\begin{array}{l}\text { Bin } 7 \text { median water is } \\
\text { based on THC model } \\
\text { output for w0 starting } \\
\text { water (base-front) at } \\
10 \mathrm{kyr} \text {, consistent with } \\
\text { output for TSPA. }\end{array}$ \\
\hline SN0403T0503404.001 & $\begin{array}{l}\text { Section } 4.1 .5 \\
\text { Section } 6.13 .6 \\
\text { Table } 8.2-1\end{array}$ & Halite_RH.zip & $\begin{array}{l}\text { Bin } 7 \text { median water is } \\
\text { based on THC model } \\
\text { output for w0 starting } \\
\text { water (base-front) at } \\
10 \mathrm{kyr} \text {, consistent with } \\
\text { output for TSPA. }\end{array}$ \\
\hline SN0404T0510102.014 & $\begin{array}{l}\text { Section } 7.3 .1 \\
\text { Table } 8.2-2\end{array}$ & sierra.zip & $\begin{array}{l}\text { No impact (files do } \\
\text { not identify or use } \\
\text { median bin waters) }\end{array}$ \\
\hline
\end{tabular}


Table A-1. Traceability of Output DTNs Developed in the Report, and Their Associated Files (Continued)

\begin{tabular}{|c|c|c|c|}
\hline Output DTN & $\begin{array}{l}\text { Associated File } \\
\text { Traceability } \\
\text { Table or Section }\end{array}$ & File Name(s) & $\begin{array}{c}\text { Bin-7 Status } \\
\text { (see Section 6.6.7.3) }\end{array}$ \\
\hline SN0503T0510102.019 & $\begin{array}{l}\text { Tables 6.7-1 to } \\
6.7-5 \\
\text { Section } 4.1 .3 \\
\text { Sections } 6.7 .2 .1 \\
\text { and 6.7.2.2 } \\
\text { Section } 6.12 .5 .3 \\
\text { Section } 6.15 .1 \\
\text { Section } 6.15 .2 \\
\text { Table } 8.2-1\end{array}$ & THC_CO2_Look-up.zip & $\begin{array}{l}\text { No impact (files do } \\
\text { not identify or use } \\
\text { median bin waters) }\end{array}$ \\
\hline SN0505T0510102.020 & Section 6.9.3 & $\begin{array}{l}\text { Water-Rock.zip } \\
\text { readme.txt }\end{array}$ & $\begin{array}{l}\text { No impact (files do } \\
\text { not identify or use } \\
\text { median bin waters) }\end{array}$ \\
\hline SN0508T0510102.024 & $\begin{array}{l}\text { Tables } 6.12-2 \\
\text { Section } 6.12 .3 \\
\text { Table 8.2-2 }\end{array}$ & LogTransform.zip & $\begin{array}{l}\text { Bin } 7 \text { median water is } \\
\text { based on THC model } \\
\text { output for w0 starting } \\
\text { water (base-front) at } \\
10 \text { kyr, consistent with } \\
\text { output for TSPA. }\end{array}$ \\
\hline SN0505T0510102.022 & $\begin{array}{l}\text { Section } 7.2 .2 \\
\text { Table } 8.2-2\end{array}$ & CO2_validation.zip & $\begin{array}{l}\text { No impact (files do } \\
\text { not identify or use } \\
\text { median bin waters) }\end{array}$ \\
\hline SN0508T0510102.023 & $\begin{array}{l}\text { Table } 4.1-7 \\
\text { Sections } 4.1 .2 \\
\text { and } 4.1 .3 \\
\text { Sections } 6.7 .1 .1 \\
\text { to } 6.7 .1 .3 \\
\text { Table } 8.2-2\end{array}$ & Oxygen_Evaluation.zip & $\begin{array}{l}\text { No impact (files do } \\
\text { not identify or use } \\
\text { median bin waters) }\end{array}$ \\
\hline
\end{tabular}




\section{APPENDIX B}

THC SEEPAGE LOOKUP TABLE RESULTS 


\section{INTENTIONALLY LEFT BLANK}


The graphs presented in this appendix are representative of the information available in Output DTN: MO0304SPACSALT.000. Two graphs from each Excel file are shown here; they are: "Aqueous Composition Evaporation Predictions vs. Relative Humidity" and "Mineral Precipitation Evaporation Predictions vs. Relative Humidity." Also available in Output DTN: MO0304SPACSALT.000 is the condensation information: "Aqueous Composition Condensation Predictions vs. Relative Humidity," "Aqueous Composition Condensation Predictions vs. Concentration Factor," "ANC Species Concentration Condensation Predictions vs. Relative Humidity," and "ANC Species Concentration Condensation Predictions vs. Concentration Factor." This information is provided for each respective bin and parameter setting. Also available in the respective excel files, but not shown here, are: "ANC Species Concentration Evaporation Predictions vs. Relative Humidity," “ANC Species Concentration Evaporation Predictions vs. Concentration Factor," "Aqueous Composition Evaporation Predictions vs. Concentration Factor," and "Mineral Precipitation Evaporation Predictions vs. Concentration.”

The graphs given in this appendix are referenced only by the bin number and parameter settings. Table B-1 gives the associated excel source file name for the graphs in this document. Each excel file header contains the traceability back to the specific input data used in the calculation. The file nomenclature is $d$ ? $\mathrm{c} \# t \% \$ . x l s$, where $d$ represents the dust bin, ? is the 1-digit bin number $\left(01,02\right.$, etc.), $\#=2,3$, or 4 (for $p \mathrm{CO}_{2}=10^{-\#}$ ), $\%=4,7$, or 1 (for temp $=40^{\circ} \mathrm{C}, 70^{\circ} \mathrm{C}$, or $100^{\circ} \mathrm{C}$, respectively). For example, the file name d1c2t1.xls designates dust bin 01 at a $p \mathrm{CO}_{2}$ of $10^{-2}$ at $100^{\circ} \mathrm{C}$.

For the figures shown below, two terms need to be defined:

1. IS = ionic strength

2. $\mathrm{RH}=$ relative humidity.

The values in Table B-2 correspond to the given parameters extracted from the Excel files in Output DTN: MO0304SPACSALT.000. Given in this table are deliquescence point relative humidity and the associated chemical parameters of interest to TSPA. 
Table B-1. Excel File Names for Each Lookup Table in DTN: MO0304SPACSALT.000

\begin{tabular}{|c|c|c|}
\hline Bin & Evaporation Lookup Tables & Condensation Lookup Tables \\
\hline 1 & 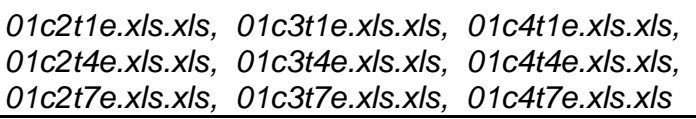 & $\begin{array}{l}01 c 2 t 1 c . x I s . x I s, 01 c 3 t 1 c . x I s . x I s, 01 c 4 t 1 c . x I s . x I s, \\
01 c 2 t 4 c . x I s . x I s, 01 c 3 t 4 c . x I s . x I s, 01 c 4 t 4 c . x I s . x I s, \\
01 c 2 t 7 c . x I s . x I s, 01 c 3 t 7 c . x I s . x I s, 01 c 4 t 7 c . x I s . x I s\end{array}$ \\
\hline 2 & 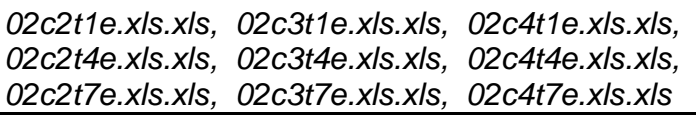 & $\begin{array}{lll}02 c 2 t 1 c . x I s . x I s, & 02 c 3 t 1 c . x I s . x I s, & 02 c 4 t 1 c . x I s . x I s, \\
02 c 2 t 4 c . x I s . x I s, & 02 c 3 t 4 c . x I s . x I s, & 02 c 4 t 4 c . x I s . x I s, \\
02 c 2 t 7 c . x I s . x I s, & 02 c 3 t 7 c . x I s . x I s, & 02 c 4 t 7 c . x I s . x I s \\
\end{array}$ \\
\hline 3 & 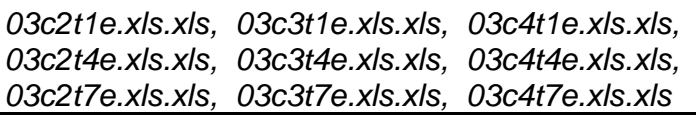 & $\begin{array}{lll}03 c 2 t 1 c . x I s . x I s, & 03 c 3 t 1 c . x I s . x I s, & 03 c 4 t 1 c . x I s . x I s, \\
03 c 2 t 4 c . x I s . x I s, & 03 c 3 t 4 c . x I s . x I s, & 03 c 4 t 4 c . x I s . x I s, \\
03 c 2 t 7 c . x I s . x I s, & 03 c 3 t 7 c . x I s . x I s, & 03 c 4 t 7 c . x I s . x I s \\
\end{array}$ \\
\hline 4 & 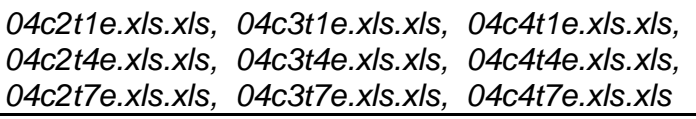 & 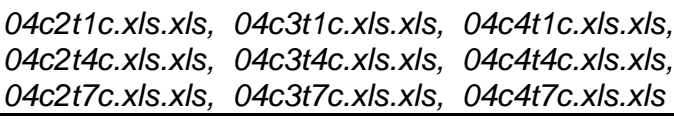 \\
\hline 5 & 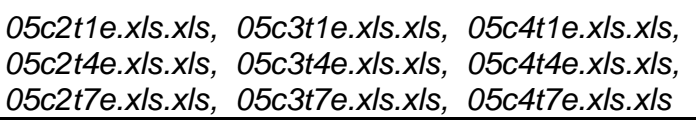 & $\begin{array}{lll}05 c 2 t 1 c . x I s . x I s, & 05 c 3 t 1 c . x I s . x I s, & 05 c 4 t 1 c . x I s . x I s, \\
05 c 2 t 4 c . x I s . x I s, & 05 c 3 t 4 c . x 1 s . x I s, & 05 c 4 t 4 c . x I s . x I s, \\
05 c 2 t 7 c . x I s . x I s, & 05 c 3 t 7 c . x I s . x I s, & 05 c 4 t 7 c . x I s . x I s \\
\end{array}$ \\
\hline 6 & 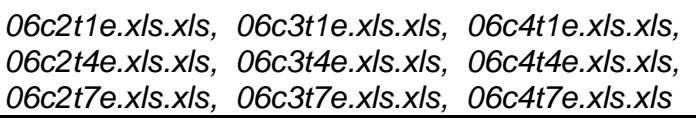 & $\begin{array}{lll}06 c 2 t 1 c . x I s . x I s, & 06 c 3 t 1 c . x I s . x I s, & 06 c 4 t 1 c . x I s . x I s, \\
06 c 2 t 4 c . x I s . x I s, & 06 c 3 t 4 c . x I s . x I s, & 06 c 4 t 4 c . x I s . x I s, \\
06 c 2 t 7 c . x I s . x I s, & 06 c 3 t 7 c . x I s . x I s, & 06 c 4 t 7 c . x I s . x I s \\
\end{array}$ \\
\hline 7 & 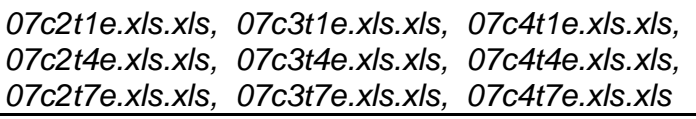 & 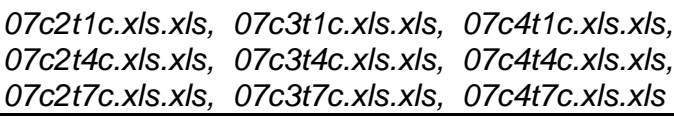 \\
\hline 8 & 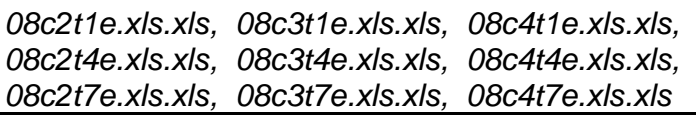 & 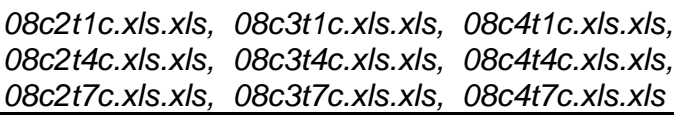 \\
\hline 9 & 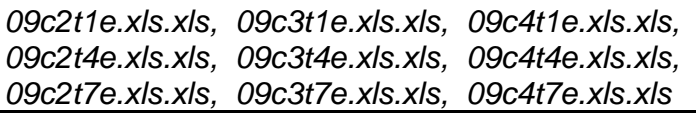 & 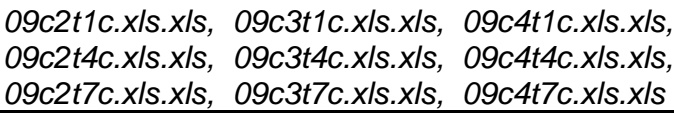 \\
\hline 10 & $\begin{array}{l}\text { 10c2t1e.xIs.xIs, 10c3t1e.xIs.xIs, 10c4t1e.xIs.xIs, } \\
\text { 10c2t4e.xIs.xIs, 10c3t4e.xls.xls, 10c4t4e.xIs.xIs, } \\
\text { 10c2t7e.xIs.xIs, 10c3t7e.xIs.xIs, 10c4t7e.xIs.xIs }\end{array}$ & 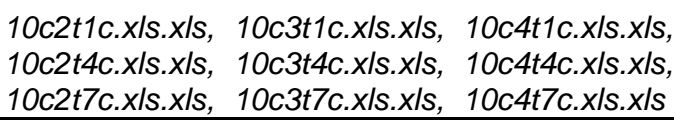 \\
\hline 11 & 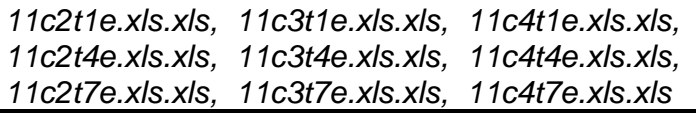 & 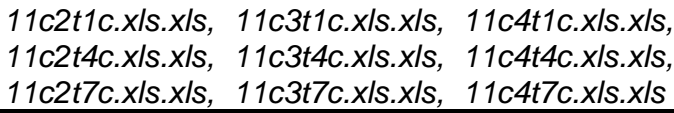 \\
\hline
\end{tabular}

Source: Output DTN: MO0304SPACSALT.000. 
Engineered Barrier System: Physical and Chemical Environment

Table B-2. Deliquescence Point Relative Humidity and Associated Chemical Parameters Taken from the THC Seepage Lookup Tables in Output DTN: MO0304SPACSALT.000

\begin{tabular}{|c|c|c|c|c|c|c|c|}
\hline Bin & $\begin{array}{c}\text { Temperature } \\
\left({ }^{\circ} \mathrm{C}\right)\end{array}$ & $\begin{array}{l}\mathrm{pCO}_{2} \\
\text { (bar) }\end{array}$ & $\begin{array}{c}\text { Deliquescence } \\
\text { Point Relative } \\
\text { Humidity (\%) }\end{array}$ & $\mathrm{pH}$ & $\begin{array}{c}\text { Ionic } \\
\text { Strength } \\
\left(\mathrm{M} / \mathrm{kg} \mathrm{H}_{2} \mathrm{O}\right)\end{array}$ & $\begin{array}{c}\mathrm{Cl} \\
\left(\mathrm{M} / \mathrm{kg} \mathrm{H} \mathrm{H}_{2} \mathrm{O}\right)\end{array}$ & $\begin{array}{c}\mathrm{NO}_{3} \\
\left(\mathrm{M} / \mathrm{kg} \mathrm{H}_{2} \mathrm{O}\right)\end{array}$ \\
\hline \multirow{9}{*}{1} & 100 & \multirow{3}{*}{0.0100} & 20.037 & 3.817 & 3.985E+01 & 2.513E+01 & 1.989E-00 \\
\hline & 40 & & 18.119 & 3.572 & $3.736 E+01$ & $2.406 \mathrm{E}+01$ & 1.313E-00 \\
\hline & 70 & & 18.692 & 3.646 & $3.864 \mathrm{E}+01$ & $2.431 \mathrm{E}+01$ & $1.938 \mathrm{E}-00$ \\
\hline & 100 & \multirow{3}{*}{0.0010} & 20.038 & 4.317 & 3.985E+01 & $2.512 \mathrm{E}+01$ & 1.990E-00 \\
\hline & 40 & & 18.062 & 4.018 & $3.556 \mathrm{E}+01$ & $2.266 \mathrm{E}+01$ & 1.485E-00 \\
\hline & 70 & & 18.704 & 4.146 & $3.866 \mathrm{E}+01$ & $2.432 \mathrm{E}+01$ & 1.937E-00 \\
\hline & 100 & \multirow{3}{*}{0.0001} & 20.013 & 4.816 & 3.984E+01 & $2.511 \mathrm{E}+01$ & $1.989 \mathrm{E}-00$ \\
\hline & 40 & & 18.245 & 4.493 & $3.441 \mathrm{E}+01$ & $2.174 \mathrm{E}+01$ & 1.607E-00 \\
\hline & 70 & & 18.685 & 4.645 & 3.864E+01 & $2.430 \mathrm{E}+01$ & 1.937E-00 \\
\hline \multirow{9}{*}{2} & 100 & \multirow{3}{*}{0.0100} & 24.000 & 4.423 & $3.624 \mathrm{E}+01$ & $2.126 \mathrm{E}+01$ & 4.690E-00 \\
\hline & 40 & & 23.135 & 4.597 & 3.763E+01 & $2.192 \mathrm{E}+01$ & 4.904E-00 \\
\hline & 70 & & 23.412 & 4.381 & $3.540 E+01$ & $2.066 \mathrm{E}+01$ & 4.619E-00 \\
\hline & 100 & \multirow{3}{*}{0.0010} & 24.000 & 4.921 & $3.620 E+01$ & $2.123 E+01$ & 4.684E-00 \\
\hline & 40 & & 23.137 & 5.096 & $3.762 E+01$ & $2.191 \mathrm{E}+01$ & $4.905 \mathrm{E}-00$ \\
\hline & 70 & & 24.000 & 4.806 & 3.358E+01 & 1.959E+01 & 4.383E-00 \\
\hline & 100 & \multirow{3}{*}{0.0001} & 24.000 & 5.420 & $3.618 \mathrm{E}+01$ & $2.122 \mathrm{E}+01$ & 4.682E-00 \\
\hline & 40 & & 23.141 & 5.596 & 3.763E+01 & 2.191E+01 & 4.902E-00 \\
\hline & 70 & & 24.000 & 5.306 & 3.358E+01 & $1.958 \mathrm{E}+01$ & $4.382 \mathrm{E}-00$ \\
\hline \multirow{9}{*}{3} & 100 & \multirow{3}{*}{0.0100} & 43.947 & 4.906 & $2.038 \mathrm{E}+01$ & 1.317E+01 & $3.620 \mathrm{E}-00$ \\
\hline & 40 & & 38.942 & 4.441 & 2.000E+01 & $1.221 \mathrm{E}+01$ & $2.382 \mathrm{E}-00$ \\
\hline & 70 & & 42.259 & 4.736 & 2.024E+01 & 1.166E+01 & 4.312E-00 \\
\hline & 100 & \multirow{3}{*}{0.0010} & 44.004 & 5.415 & $2.039 \mathrm{E}+01$ & 1.323E+01 & $3.597 \mathrm{E}-00$ \\
\hline & 40 & & 39.781 & 4.972 & $1.975 \mathrm{E}+01$ & $1.208 \mathrm{E}+01$ & $2.373 \mathrm{E}-00$ \\
\hline & 70 & & 42.471 & 5.265 & 2.024E+01 & 1.180E+01 & 4.237E-00 \\
\hline & 100 & \multirow{3}{*}{0.0001} & 44.020 & 5.915 & 2.039E+01 & 1.323E+01 & 3.595E-00 \\
\hline & 40 & & 39.953 & 5.488 & $1.973 \mathrm{E}+01$ & $1.209 \mathrm{E}+01$ & $2.373 \mathrm{E}-00$ \\
\hline & 70 & & 42.492 & 5.767 & $2.024 \mathrm{E}+01$ & 1.181E+01 & $4.230 \mathrm{E}-00$ \\
\hline \multirow{9}{*}{4} & 100 & \multirow{3}{*}{0.0100} & 47.411 & 6.473 & $2.239 \mathrm{E}+01$ & 3.936E-00 & $1.523 \mathrm{E}+01$ \\
\hline & 40 & & 65.012 & 6.325 & 1.346E+01 & 3.994E-00 & 8.100E-00 \\
\hline & 70 & & 52.860 & 6.049 & $2.029 \mathrm{E}+01$ & 1.904E-00 & 1.705E+01 \\
\hline & 100 & \multirow{3}{*}{0.0010} & 47.412 & 6.973 & $2.239 \mathrm{E}+01$ & 3.937E-00 & $1.523 \mathrm{E}+01$ \\
\hline & 40 & & 65.014 & 6.825 & $1.346 \mathrm{E}+01$ & 3.994E-00 & $8.101 \mathrm{E}-00$ \\
\hline & 70 & & 52.861 & 6.549 & $2.029 \mathrm{E}+01$ & $1.902 \mathrm{E}-00$ & 1.705E+01 \\
\hline & 100 & \multirow{3}{*}{0.0001} & 47.414 & 7.473 & $2.239 \mathrm{E}+01$ & $3.936 \mathrm{E}-00$ & $1.523 \mathrm{E}+01$ \\
\hline & 40 & & 65.014 & 7.325 & $1.346 \mathrm{E}+01$ & 3.994E-00 & $8.101 \mathrm{E}-00$ \\
\hline & 70 & & 52.861 & 7.048 & $2.029 \mathrm{E}+01$ & $1.900 \mathrm{E}-00$ & $1.705 \mathrm{E}+01$ \\
\hline \multirow{9}{*}{5} & 100 & \multirow{3}{*}{0.0100} & 60.130 & 7.270 & 1.727E+01 & 8.186E-00 & $1.802 \mathrm{E}-00$ \\
\hline & 40 & & 69.130 & 7.119 & $1.001 \mathrm{E}+01$ & $5.998 \mathrm{E}-00$ & $1.321 \mathrm{E}-00$ \\
\hline & 70 & & 62.053 & 7.136 & $1.660 \mathrm{E}+01$ & $6.375 \mathrm{E}-00$ & $3.728 \mathrm{E}-00$ \\
\hline & 100 & \multirow{3}{*}{0.0010} & 60.129 & 7.770 & $1.728 \mathrm{E}+01$ & 8.186E-00 & $1.801 \mathrm{E}-00$ \\
\hline & 40 & & 69.943 & 7.637 & $9.368 \mathrm{E}-00$ & $6.267 \mathrm{E}-00$ & $7.024 \mathrm{E}-01$ \\
\hline & 70 & & 62.066 & 7.636 & $1.658 \mathrm{E}+01$ & $6.375 \mathrm{E}-00$ & $3.726 \mathrm{E}-00$ \\
\hline & 100 & \multirow{3}{*}{0.0001} & 60.131 & 8.269 & 1.727E+01 & $8.182 \mathrm{E}-00$ & 1.801E-00 \\
\hline & 40 & & 62.351 & 7.880 & 1.996E+01 & 3.406E-00 & $8.532 \mathrm{E}-00$ \\
\hline & 70 & & 62.059 & 8.136 & 1.659E+01 & 6.376E-00 & $3.726 \mathrm{E}-00$ \\
\hline
\end{tabular}


Engineered Barrier System: Physical and Chemical Environment

Table B-2. Deliquescence Point Relative Humidity and Associated Chemical Parameters Taken from the THC Seepage Lookup Tables in Output DTN: MO0304SPACSALT.000 (Continued)

\begin{tabular}{|c|c|c|c|c|c|c|c|}
\hline Bin & $\begin{array}{c}\text { Temperature } \\
\left({ }^{\circ} \mathrm{C}\right)\end{array}$ & $\begin{array}{l}p \mathrm{CO}_{2} \\
\text { (bar) }\end{array}$ & $\begin{array}{c}\text { Deliquescence } \\
\text { Point Relative } \\
\text { Humidity (\%) } \\
\end{array}$ & $\mathrm{pH}$ & $\begin{array}{c}\text { lonic } \\
\text { Strength } \\
\left(\mathrm{M} / \mathrm{kg} \mathrm{H}_{2} \mathrm{O}\right)\end{array}$ & $\begin{array}{c}\mathrm{Cl} \\
\left(\mathrm{M} / \mathrm{kg} \mathrm{H}_{2} \mathrm{O}\right)\end{array}$ & $\begin{array}{c}\mathrm{NO}_{3} \\
\left(\mathrm{M} / \mathrm{kg} \mathrm{H}_{2} \mathrm{O}\right) \\
\end{array}$ \\
\hline \multirow{9}{*}{6} & 100 & \multirow{3}{*}{0.0100} & 59.117 & 8.999 & $1.719 \mathrm{E}+01$ & $7.213 \mathrm{E}-00$ & $2.518 \mathrm{E}-00$ \\
\hline & 40 & & 62.976 & 8.298 & $1.979 \mathrm{E}+01$ & 4.304E-00 & $6.088 \mathrm{E}-00$ \\
\hline & 70 & & 60.500 & 8.910 & $1.782 \mathrm{E}+01$ & $5.750 \mathrm{E}-00$ & $4.430 \mathrm{E}-00$ \\
\hline & 100 & \multirow{3}{*}{0.0010} & 59.123 & 9.503 & $1.717 \mathrm{E}+01$ & $7.269 \mathrm{E}-00$ & $2.440 \mathrm{E}-00$ \\
\hline & 40 & & 61.745 & 9.266 & $2.055 \mathrm{E}+01$ & $3.930 \mathrm{E}-00$ & $6.918 \mathrm{E}-00$ \\
\hline & 70 & & 59.703 & 9.510 & $1.854 \mathrm{E}+01$ & $5.458 \mathrm{E}-00$ & $5.018 \mathrm{E}-00$ \\
\hline & 100 & \multirow{3}{*}{0.0001} & 58.888 & 9.999 & $1.730 \mathrm{E}+01$ & $7.200 \mathrm{E}-00$ & $2.207 \mathrm{E}-00$ \\
\hline & 40 & & 64.071 & 10.096 & $1.404 \mathrm{E}+01$ & $5.033 \mathrm{E}-00$ & $2.567 \mathrm{E}-00$ \\
\hline & 70 & & 59.630 & 10.010 & $1.856 \mathrm{E}+01$ & $5.458 \mathrm{E}-00$ & 4.897E-00 \\
\hline \multirow{9}{*}{7} & 100 & \multirow{3}{*}{0.0100} & 59.108 & 8.999 & $1.720 \mathrm{E}+01$ & $7.215 \mathrm{E}-00$ & $2.519 \mathrm{E}-00$ \\
\hline & 40 & & 62.976 & 8.298 & $1.979 \mathrm{E}+01$ & $4.304 \mathrm{E}-00$ & $6.088 \mathrm{E}-00$ \\
\hline & 70 & & 60.501 & 8.910 & $1.781 \mathrm{E}+01$ & $5.750 \mathrm{E}-00$ & $4.430 \mathrm{E}-00$ \\
\hline & 100 & \multirow{3}{*}{0.0010} & 59.123 & 9.503 & $1.717 \mathrm{E}+01$ & $7.269 \mathrm{E}-00$ & $2.440 \mathrm{E}-00$ \\
\hline & 40 & & 61.745 & 9.266 & $2.054 \mathrm{E}+01$ & $3.930 \mathrm{E}-00$ & $6.918 \mathrm{E}-00$ \\
\hline & 70 & & 59.704 & 9.510 & $1.854 \mathrm{E}+01$ & $5.458 \mathrm{E}-00$ & $5.018 \mathrm{E}-00$ \\
\hline & 100 & \multirow{3}{*}{0.0001} & 60.000 & 9.992 & $1.607 \mathrm{E}+01$ & $7.120 \mathrm{E}-00$ & $1.835 \mathrm{E}-00$ \\
\hline & 40 & & 66.234 & 10.126 & $1.237 \mathrm{E}+01$ & $5.606 \mathrm{E}-00$ & $7.012 \mathrm{E}-01$ \\
\hline & 70 & & 59.634 & 10.010 & $1.855 \mathrm{E}+01$ & $5.457 \mathrm{E}-00$ & $4.896 \mathrm{E}-00$ \\
\hline \multirow{9}{*}{8} & 100 & \multirow{3}{*}{0.0100} & 59.112 & 8.999 & $1.720 \mathrm{E}+01$ & $7.214 \mathrm{E}-00$ & $2.518 \mathrm{E}-00$ \\
\hline & 40 & & 62.977 & 8.298 & $1.978 \mathrm{E}+01$ & $4.304 \mathrm{E}-00$ & $6.088 \mathrm{E}-00$ \\
\hline & 70 & & 60.498 & 8.910 & $1.782 \mathrm{E}+01$ & $5.751 \mathrm{E}-00$ & $4.430 \mathrm{E}-00$ \\
\hline & 100 & \multirow{3}{*}{0.0010} & 59.116 & 9.503 & $1.718 \mathrm{E}+01$ & $7.270 \mathrm{E}-00$ & $2.441 \mathrm{E}-00$ \\
\hline & 40 & & 61.744 & 9.266 & $2.055 \mathrm{E}+01$ & $3.930 \mathrm{E}-00$ & $6.918 \mathrm{E}-00$ \\
\hline & 70 & & 59.701 & 9.510 & $1.854 \mathrm{E}+01$ & $5.458 \mathrm{E}-00$ & $5.019 \mathrm{E}-00$ \\
\hline & 100 & \multirow{3}{*}{0.0001} & 58.884 & 9.999 & $1.730 \mathrm{E}+01$ & $7.200 \mathrm{E}-00$ & $2.208 \mathrm{E}-00$ \\
\hline & 40 & & 62.162 & 10.061 & $1.594 \mathrm{E}+01$ & $4.489 \mathrm{E}-00$ & $4.609 \mathrm{E}-00$ \\
\hline & 70 & & 59.624 & 10.010 & $1.857 \mathrm{E}+01$ & $5.459 \mathrm{E}-00$ & $4.898 \mathrm{E}-00$ \\
\hline \multirow{9}{*}{9} & 100 & \multirow{3}{*}{0.0100} & 50.935 & 9.157 & $3.012 \mathrm{E}+01$ & $9.899 \mathrm{E}-00$ & $8.991 \mathrm{E}-00$ \\
\hline & 40 & & 62.013 & 8.327 & $1.923 \mathrm{E}+01$ & $4.532 \mathrm{E}-00$ & $6.774 \mathrm{E}-00$ \\
\hline & 70 & & 50.023 & 9.191 & $3.284 \mathrm{E}+01$ & $9.339 \mathrm{E}-00$ & $1.075 \mathrm{E}+01$ \\
\hline & 100 & \multirow{3}{*}{0.0010} & 50.905 & 9.661 & $3.017 \mathrm{E}+01$ & $9.977 \mathrm{E}-00$ & $8.948 \mathrm{E}-00$ \\
\hline & 40 & & 61.329 & 9.270 & $2.041 \mathrm{E}+01$ & $3.934 \mathrm{E}-00$ & $7.178 \mathrm{E}-00$ \\
\hline & 70 & & 57.507 & 9.530 & $2.168 \mathrm{E}+01$ & $5.656 \mathrm{E}-00$ & $6.710 \mathrm{E}-00$ \\
\hline & 100 & \multirow{3}{*}{0.0001} & 52.305 & 10.061 & $2.794 \mathrm{E}+01$ & $8.008 \mathrm{E}-00$ & $8.526 \mathrm{E}-00$ \\
\hline & 40 & & 62.119 & 10.060 & $1.593 \mathrm{E}+01$ & $4.479 \mathrm{E}-00$ & $4.590 \mathrm{E}-00$ \\
\hline & 70 & & 49.783 & 10.274 & $3.307 \mathrm{E}+01$ & $9.401 \mathrm{E}-00$ & $1.070 \mathrm{E}+01$ \\
\hline \multirow{9}{*}{10} & 100 & \multirow{3}{*}{0.0100} & 58.991 & 8.997 & $1.724 \mathrm{E}+01$ & $7.175 \mathrm{E}-00$ & $2.556 \mathrm{E}-00$ \\
\hline & 40 & & 66.105 & 8.399 & $1.247 \mathrm{E}+01$ & $5.578 \mathrm{E}-00$ & $2.558 \mathrm{E}-00$ \\
\hline & 70 & & 60.345 & 8.907 & $1.787 \mathrm{E}+01$ & $5.704 \mathrm{E}-00$ & $4.485 \mathrm{E}-00$ \\
\hline & 100 & \multirow{3}{*}{0.0010} & 59.008 & 9.501 & $1.721 \mathrm{E}+01$ & $7.229 \mathrm{E}-00$ & $2.477 \mathrm{E}-00$ \\
\hline & 40 & & 61.525 & 9.262 & $2.061 \mathrm{E}+01$ & $3.879 \mathrm{E}-00$ & $7.010 \mathrm{E}-00$ \\
\hline & 70 & & 59.598 & 9.508 & $1.857 \mathrm{E}+01$ & $5.428 \mathrm{E}-00$ & $5.056 \mathrm{E}-00$ \\
\hline & 100 & \multirow{3}{*}{0.0001} & 58.844 & 9.996 & $1.725 E+01$ & $7.147 \mathrm{E}-00$ & $2.235 \mathrm{E}-00$ \\
\hline & 40 & & 62.119 & 10.060 & $1.593 \mathrm{E}+01$ & $4.480 \mathrm{E}-00$ & $4.589 \mathrm{E}-00$ \\
\hline & 70 & & 59.542 & 10.008 & $1.856 \mathrm{E}+01$ & $5.424 \mathrm{E}-00$ & $4.932 \mathrm{E}-00$ \\
\hline
\end{tabular}


Table B-2. Deliquescence Point Relative Humidity and Associated Chemical Parameters Taken from the THC Seepage Lookup Tables in Output DTN: MO0304SPACSALT.000 (Continued)

\begin{tabular}{|c|c|c|c|c|c|c|c|}
\hline Bin & $\begin{array}{c}\text { Temperature } \\
\left({ }^{\circ} \mathrm{C}\right)\end{array}$ & $\begin{array}{c}\mathrm{pCO}_{2} \\
\text { (bar) }\end{array}$ & $\begin{array}{c}\text { Deliquescence } \\
\text { Point Relative } \\
\text { Humidity (\%) }\end{array}$ & $\mathrm{pH}$ & $\begin{array}{c}\text { Ionic } \\
\text { Strength } \\
\left(\mathrm{M} / \mathrm{kg} \mathrm{H} \mathrm{H}_{2} \mathrm{O}\right)\end{array}$ & $\begin{array}{c}\mathrm{Cl} \\
\left(\mathrm{M} / \mathrm{kg} \mathrm{H}_{2} \mathrm{O}\right)\end{array}$ & $\begin{array}{c}\mathrm{NO}_{3} \\
\left(\mathrm{M} / \mathrm{kg} \mathrm{H}_{2} \mathrm{O}\right)\end{array}$ \\
\hline \multirow{9}{*}{11} & 100 & \multirow{3}{*}{0.0100} & 58.995 & 8.997 & 1.723E+01 & 7.174E-00 & $2.555 \mathrm{E}-00$ \\
\hline & 40 & & 62.683 & 8.292 & 1.995E+01 & 4.227E-00 & $6.213 \mathrm{E}-00$ \\
\hline & 70 & & 60.351 & 8.907 & $1.786 \mathrm{E}+01$ & 5.703E-00 & 4.484E-00 \\
\hline & 100 & \multirow{3}{*}{0.0010} & 59.004 & 9.501 & $1.721 \mathrm{E}+01$ & 7.229E-00 & 2.477E-00 \\
\hline & 40 & & 61.524 & 9.262 & $2.062 \mathrm{E}+01$ & 3.879E-00 & 7.011E-00 \\
\hline & 70 & & 59.596 & 9.508 & 1.858E+01 & $5.428 \mathrm{E}-00$ & $5.056 \mathrm{E}-00$ \\
\hline & 100 & \multirow{3}{*}{0.0001} & 58.768 & 9.997 & $1.734 \mathrm{E}+01$ & 7.160E-00 & $2.245 \mathrm{E}-00$ \\
\hline & 40 & & 62.119 & 10.060 & 1.593E+01 & 4.476E-00 & 4.593E-00 \\
\hline & 70 & & 59.511 & 10.008 & 1.862E+01 & $5.430 \mathrm{E}-00$ & 4.936E-00 \\
\hline
\end{tabular}

Source: Output DTN: MO0304SPACSALT.000.

NOTE: Deliquescence-point relative humidity can not be confirmed in all cases (Table 6.12-1). 


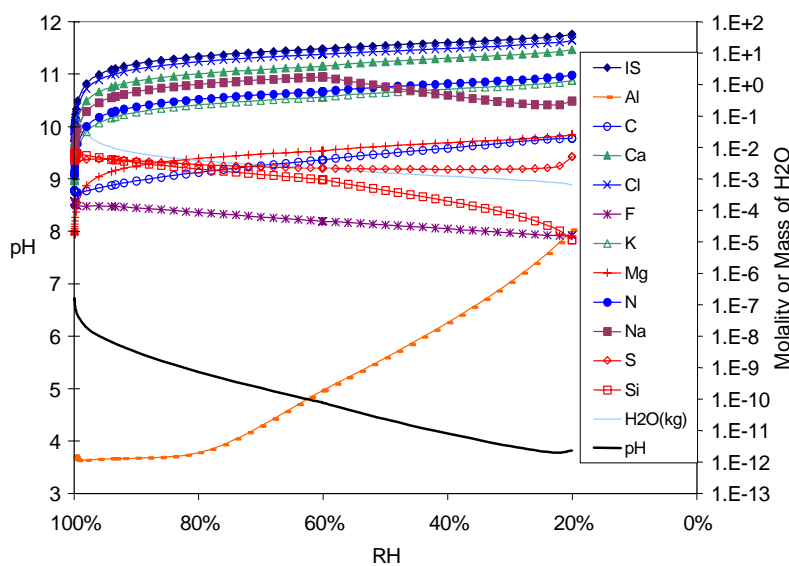

Source: DTN: M00304SPACSALT.000, 01c2t1e.xIs.xIs.

Figure B-01-1. Bin 01 Aqueous Composition Evaporation Predictions vs. Relative Humidity at $100^{\circ} \mathrm{C}$ and $10^{-2}$ bar $\mathrm{CO}_{2}$ Fugacity

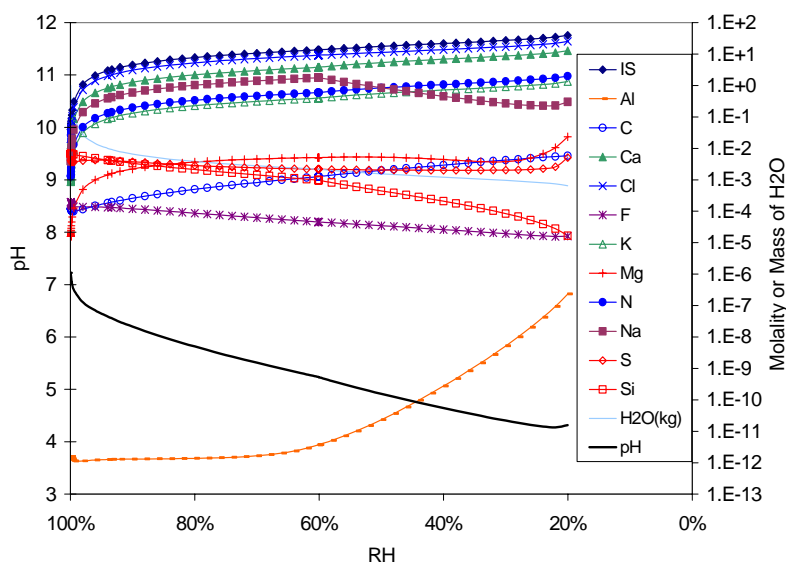

Source: DTN: M00304SPACSALT.000, 01c3t1e.xIs.xIs.

Figure B-01-3. Bin 01 Aqueous Composition Evaporation Predictions vs. Relative Humidity at $100^{\circ} \mathrm{C}$ and $10^{-3}$ bar $\mathrm{CO}_{2}$ Fugacity

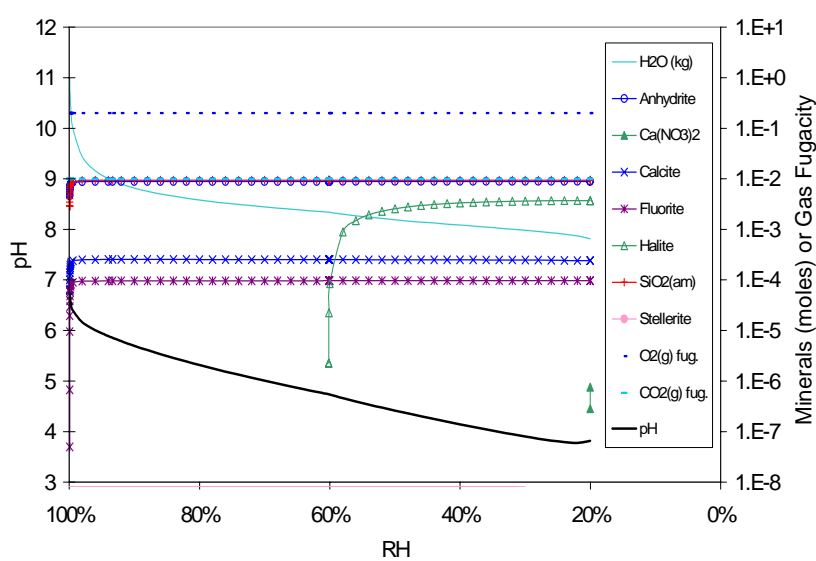

Source: DTN: MO0304SPACSALT.000, 01c2t1e.xls.xls.

Figure B-01-2. Bin 01 Mineral Precipitation Evaporation Predictions vs. Relative Humidity at $100^{\circ} \mathrm{C}$ and $10^{-2}$ bar $\mathrm{CO}_{2}$ Fugacity

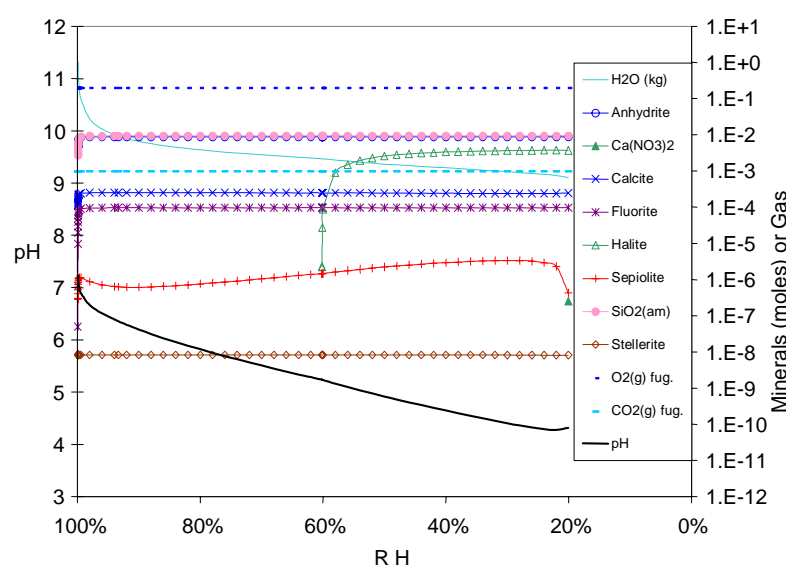

Source: DTN: M00304SPACSALT.000, 01c3t1e.xIs.xls.

Figure B-01-4. Bin 01 Mineral Precipitation Evaporation Predictions vs. Relative Humidity at $100^{\circ} \mathrm{C}$ and $10^{-3}$ bar $\mathrm{CO}_{2}$ Fugacity 


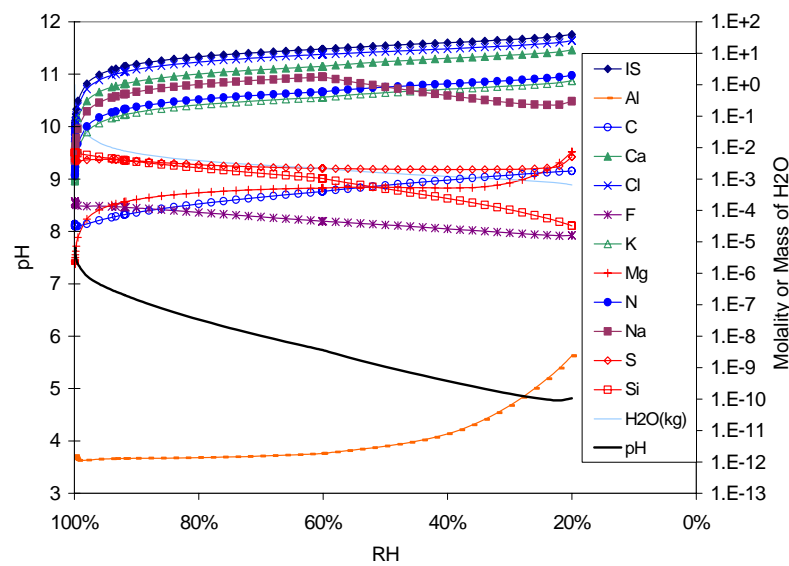

Source: DTN: M00304SPACSALT.000, 01c4t1e.xIs.xIs.

Figure B-01-5. Bin 01 Aqueous Composition Evaporation Predictions vs. Relative Humidity at $100^{\circ} \mathrm{C}$ and $10^{-4}$ bar $\mathrm{CO}_{2}$ Fugacity

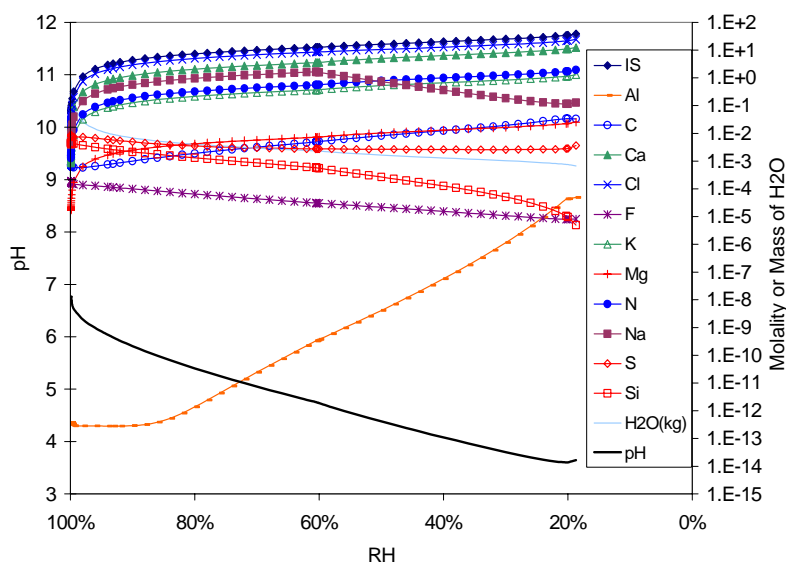

Source: DTN: M00304SPACSALT.000, 01c2t7e.xIs.xIs.

Figure B-01-7. Bin 01 Aqueous Composition Evaporation Predictions vs. Relative Humidity at $70^{\circ} \mathrm{C}$ and $10^{-2}$ bar $\mathrm{CO}_{2}$ Fugacity

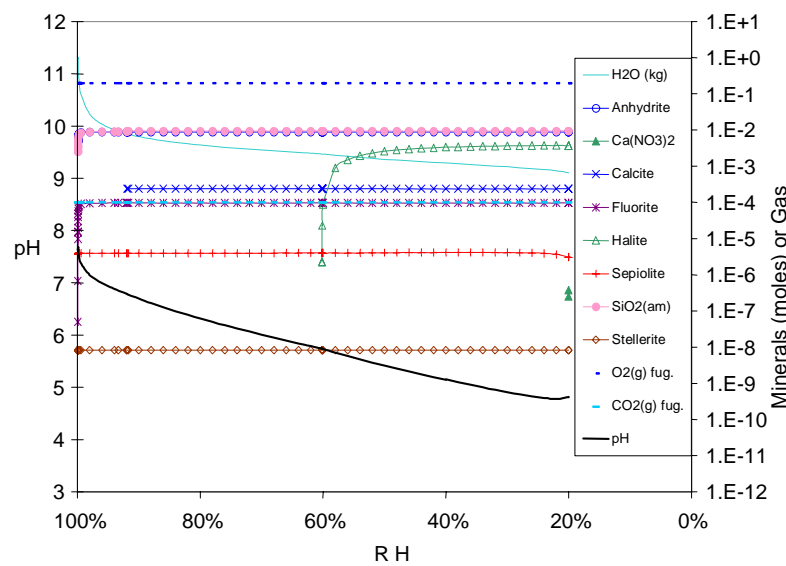

Source: DTN: MO0304SPACSALT.000, 01c4t1e.xIs.xIs.

Figure B-01-6. Bin 01 Mineral Precipitation Evaporation Predictions vs. Relative Humidity at $100^{\circ} \mathrm{C}$ and $10^{-4}$ bar $\mathrm{CO}_{2}$ Fugacity

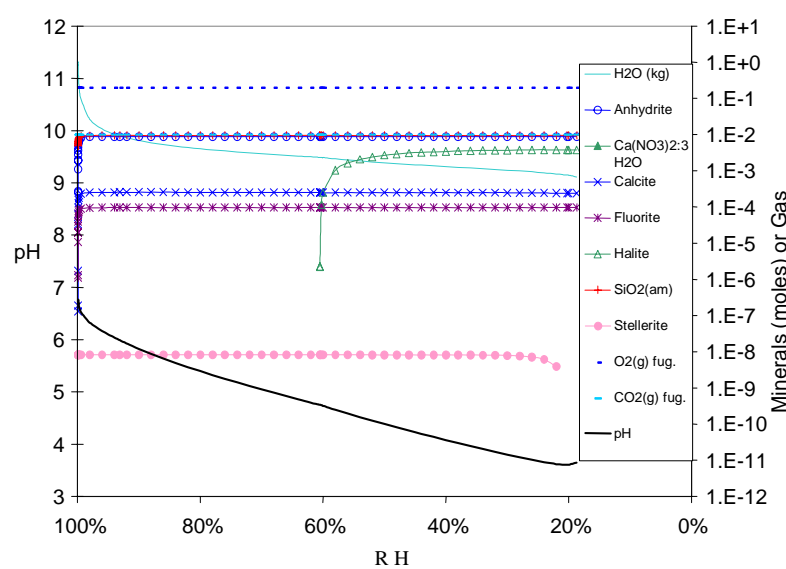

Source: DTN: MO0304SPACSALT.000, 01c2t7e.xIs.xIs.

Figure B-01-8. Bin 01 Mineral Precipitation Evaporation Predictions vs. Relative Humidity at $70^{\circ} \mathrm{C}$ and $10^{-2}$ bar $\mathrm{CO}_{2}$ Fugacity 


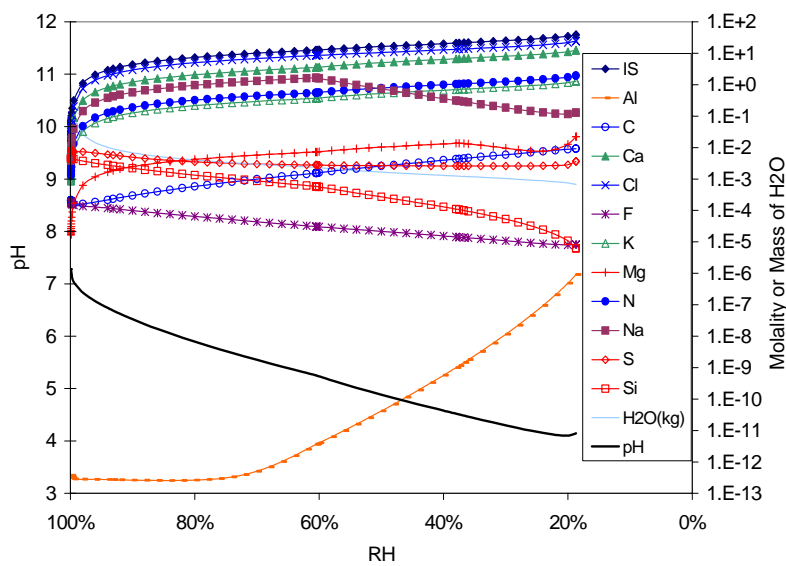

Source: DTN: M00304SPACSALT.000, 01c3t7e.xIs.xIs.

Figure B-01-9. Bin 01 Aqueous Composition Evaporation Predictions vs. Relative Humidity at $70^{\circ} \mathrm{C}$ and $10^{-3}$ bar $\mathrm{CO}_{2}$ Fugacity

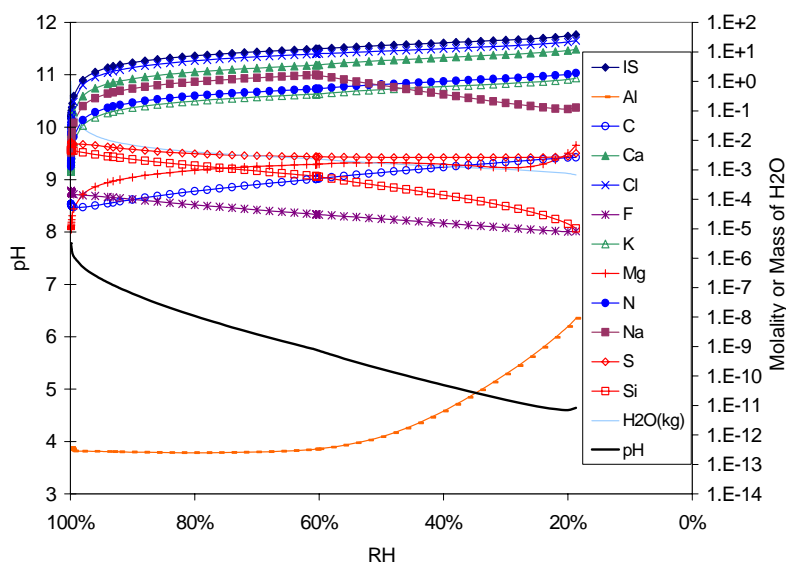

Source: DTN: MO0304SPACSALT.000, 01c4t7e.xIs.xls.

Figure B-01-11. Bin 01 Aqueous Composition Evaporation Predictions vs. Relative Humidity at $70^{\circ} \mathrm{C}$ and $10^{-4}$ bar $\mathrm{CO}_{2}$ Fugacity

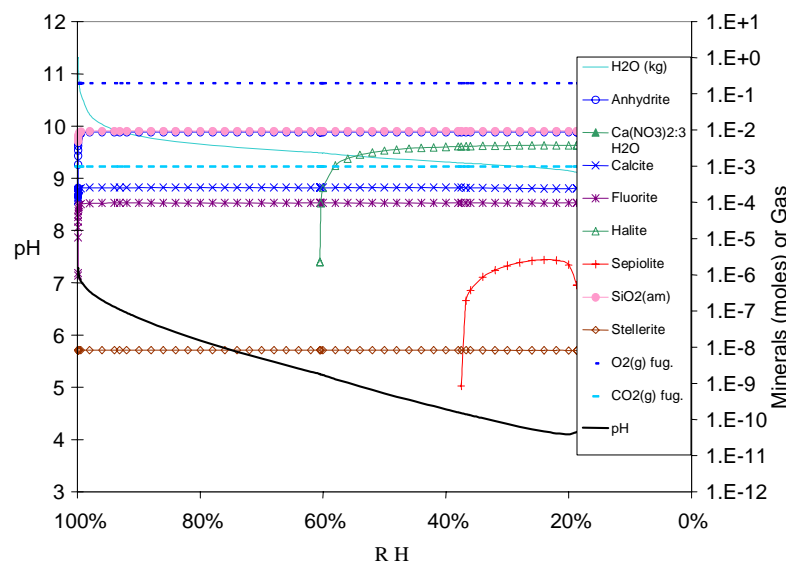

Source: DTN: MO0304SPACSALT.000, 01c3t7e.xIs.xIs.

Figure B-01-10. Bin 01 Mineral Precipitation Evaporation Predictions vs. Relative Humidity at $70^{\circ} \mathrm{C}$ and $10^{-3}$ bar $\mathrm{CO}_{2}$ Fugacity

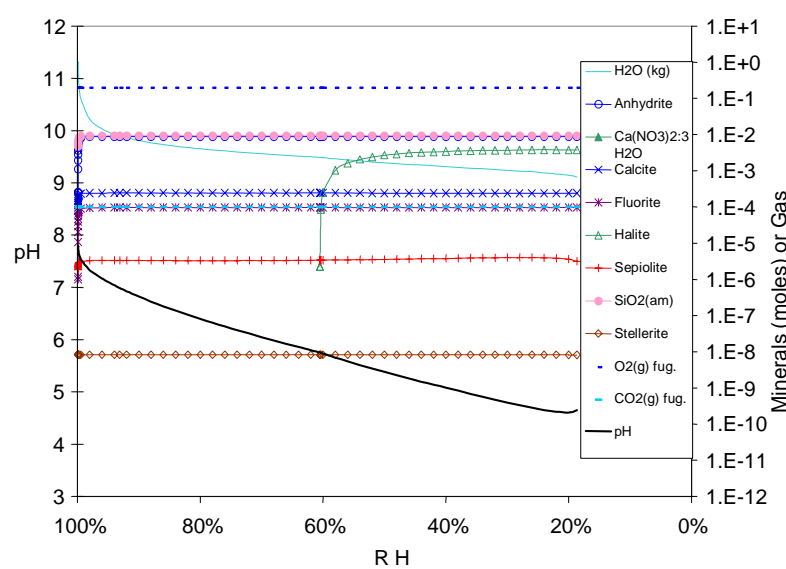

Source: DTN: MO0304SPACSALT.000, 01c4t7e.xIs.xIs.

Figure B-01-12. Bin 01 Mineral Precipitation Evaporation Predictions vs. Relative Humidity at $70^{\circ} \mathrm{C}$ and $10^{-4}$ bar $\mathrm{CO}_{2}$ Fugacity 


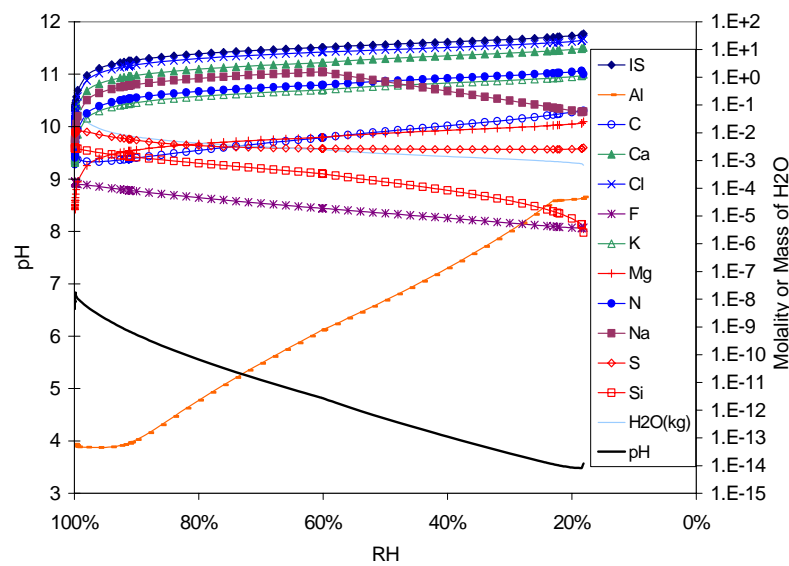

Source: DTN: M00304SPACSALT.000, 01c2t4e.xIs.xIs.

Figure B-01-13. Bin 01 Aqueous Composition Evaporation Predictions vs. Relative Humidity at $40^{\circ} \mathrm{C}$ and $10^{-2}$ bar $\mathrm{CO}_{2}$ Fugacity

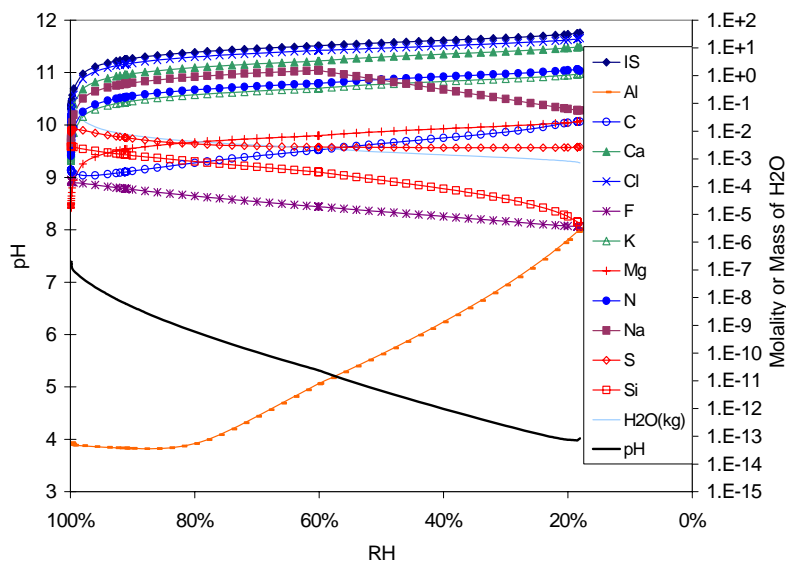

Source: DTN: M00304SPACSALT.000, 01c3t4e.xIs.xls.

Figure B-01-15. Bin 01 Aqueous Composition Evaporation Predictions vs. Relative Humidity at $40^{\circ} \mathrm{C}$ and $10^{-3}$ bar $\mathrm{CO}_{2}$ Fugacity

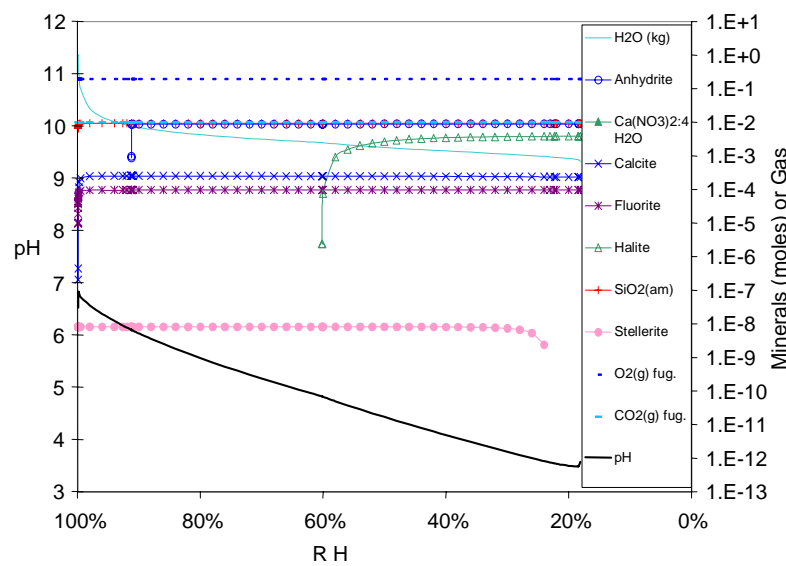

Source: DTN: MO0304SPACSALT.000, 01c2t4e.xls.xls.

Figure B-01-14. Bin 01 Mineral Precipitation Evaporation Predictions vs. Relative Humidity at $40^{\circ} \mathrm{C}$ and $10^{-2}$ bar $\mathrm{CO}_{2}$ Fugacity

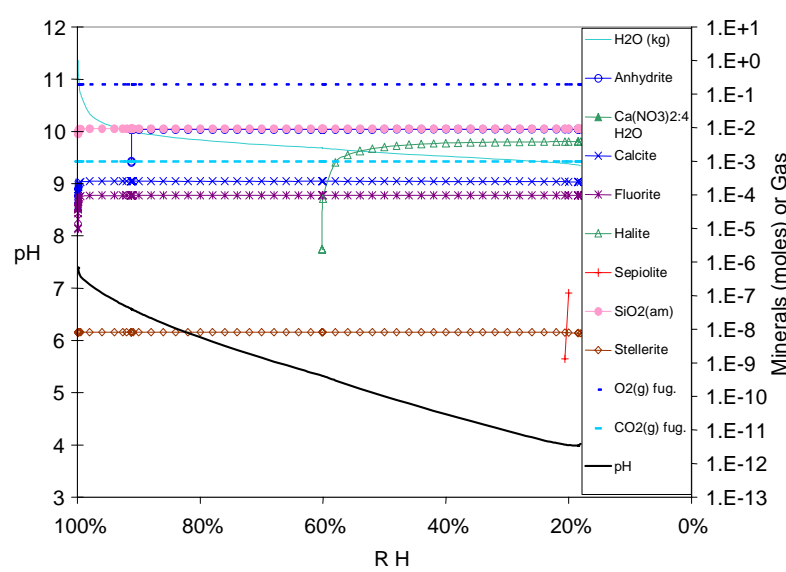

Source: DTN: MO0304SPACSALT.000, 01c3t4e.xIs.x/s.

Figure B-01-16. Bin 01 Mineral Precipitation Evaporation Predictions vs. Relative Humidity at $40^{\circ} \mathrm{C}$ and $10^{-3}$ bar $\mathrm{CO}_{2}$ Fugacity 


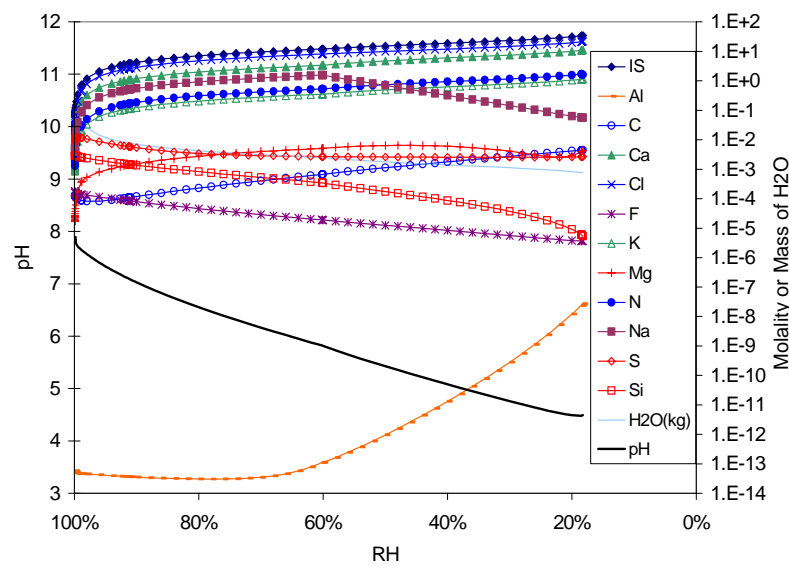

Source: DTN: M00304SPACSALT.000, 01c4t4e.xIs.xIs.

Figure B-01-17. Bin 01 Aqueous Composition Evaporation Predictions vs. Relative Humidity at $40^{\circ} \mathrm{C}$ and $10^{-4}$ bar $\mathrm{CO}_{2}$ Fugacity

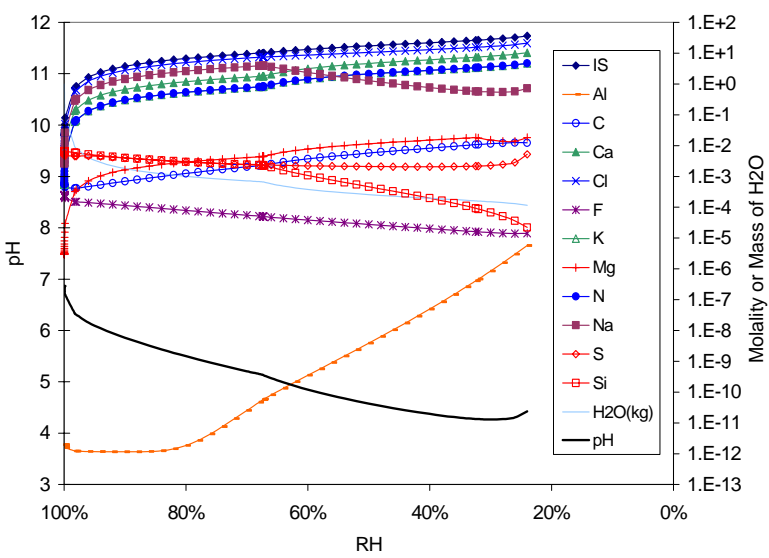

Source: DTN: MO0304SPACSALT.000, 02c2t1e.xIs.xls.

Figure B-02-1. Bin 02 Aqueous Composition Evaporation Predictions vs. Relative Humidity at $100^{\circ} \mathrm{C}$ and $10^{-2}$ bar $\mathrm{CO}_{2}$ Fugacity

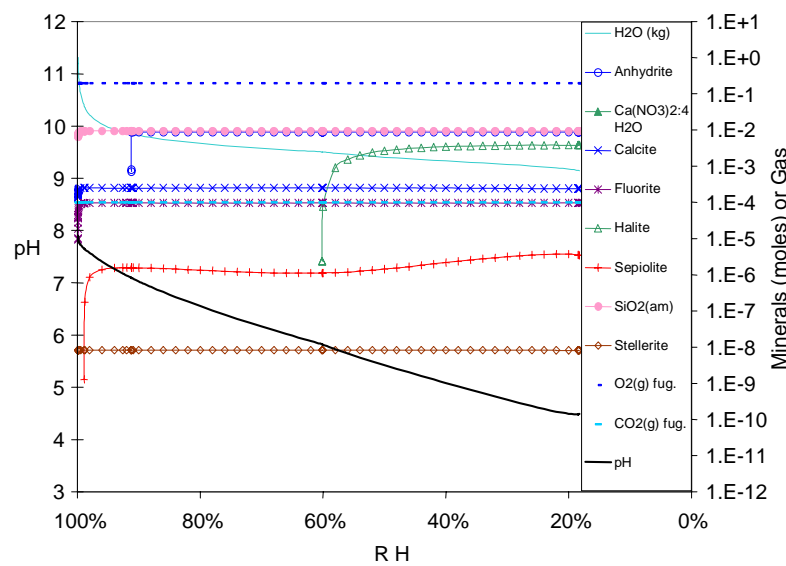

Source: DTN: MO0304SPACSALT.000, 01c4t4e.xIs.x/s.

Figure B-01-18. Bin 01 Mineral Precipitation Evaporation Predictions vs. Relative Humidity at $40^{\circ} \mathrm{C}$ and $10^{-4}$ bar $\mathrm{CO}_{2}$ Fugacity

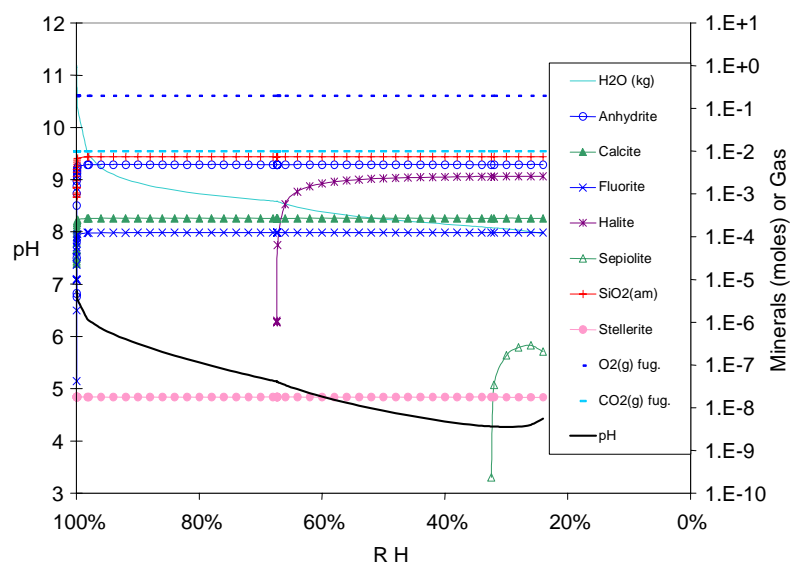

Source: DTN: MO0304SPACSALT.000, 02c2t1e.xIs.x/s.

Figure B-02-2. Bin 02 Mineral Precipitation Evaporation Predictions vs. Relative Humidity at $100^{\circ} \mathrm{C}$ and $10^{-2}$ bar $\mathrm{CO}_{2}$ Fugacity 


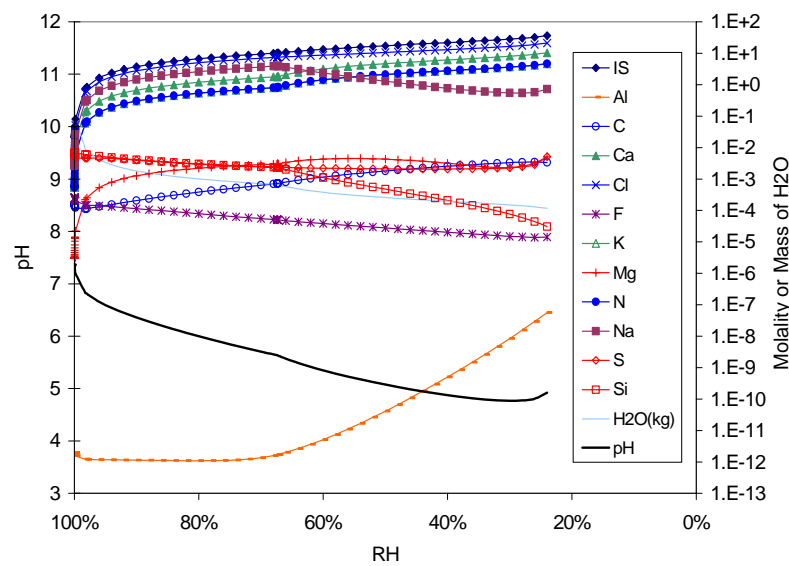

Source: DTN: MO0304SPACSALT.000, 02c3t1e.xIs.xIs.

Figure B-02-3. Bin 02 Aqueous Composition Evaporation Predictions vs. Relative Humidity at $100^{\circ} \mathrm{C}$ and $10^{-3}$ bar $\mathrm{CO}_{2}$ Fugacity

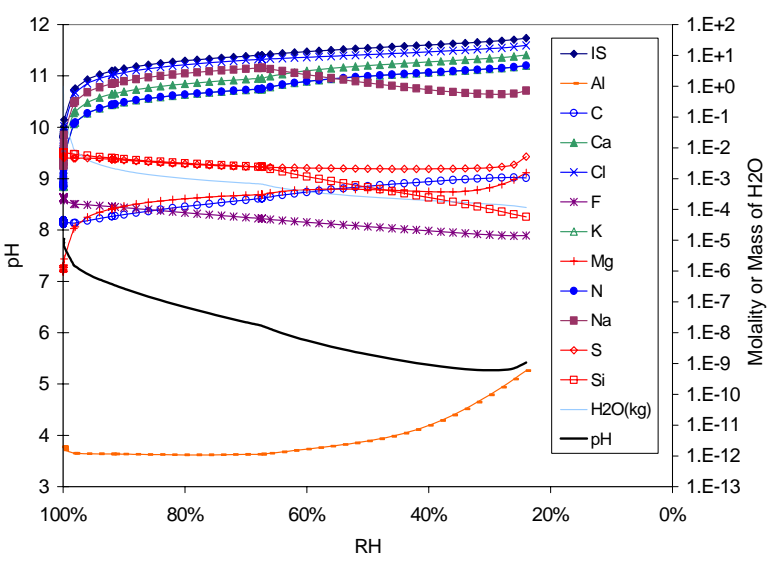

Source: DTN: MO0304SPACSALT.000, 02c4t1e.xls.xls.

Figure B-02-5. Bin 02 Aqueous Composition Evaporation Predictions vs. Relative Humidity at $100^{\circ} \mathrm{C}$ and $10^{-4}$ bar $\mathrm{CO}_{2}$ Fugacity

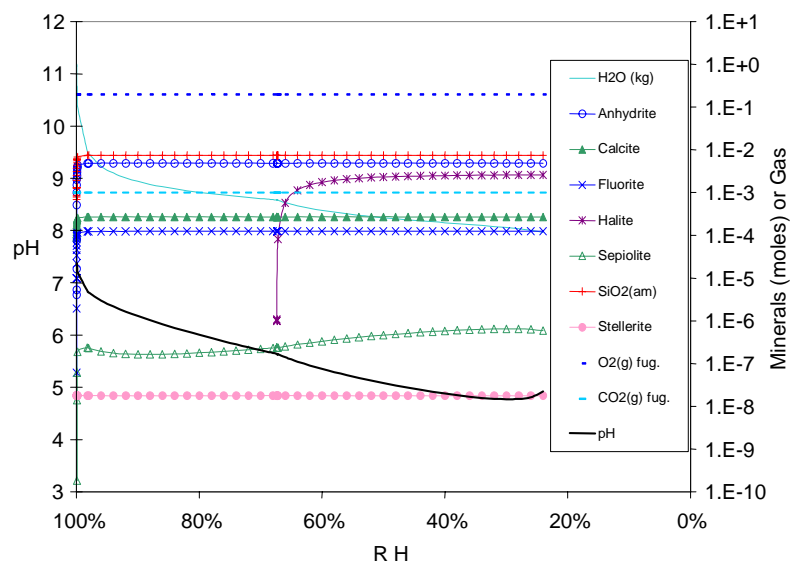

Source: DTN: MO0304SPACSALT.000, 02c3t1e.xIs.xIs.

Figure B-02-4. Bin 02 Mineral Precipitation Evaporation Predictions vs. Relative Humidity at $100^{\circ} \mathrm{C}$ and $10^{-3}$ bar $\mathrm{CO}_{2}$ Fugacity

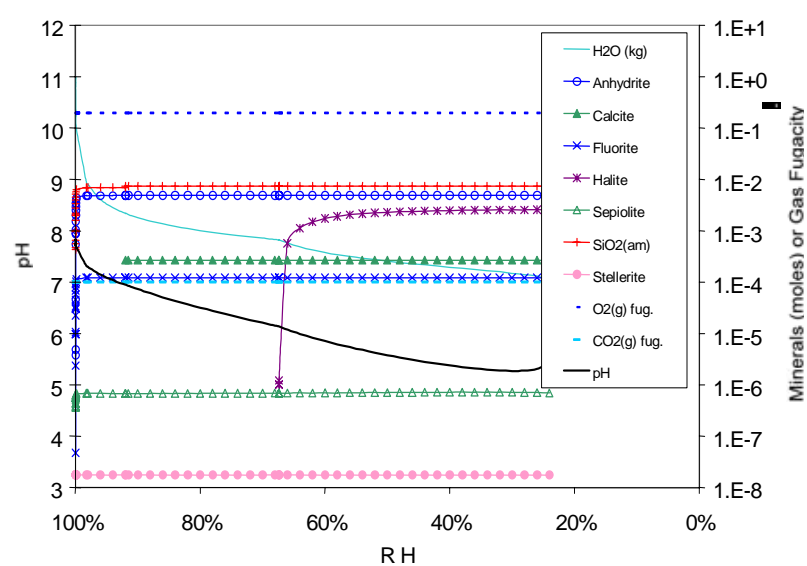

Source: DTN: MO0304SPACSALT.000, 02c4t1e.xIs.xIs.

Figure B-02-6. Bin 02 Mineral Precipitation Evaporation Predictions vs. Relative Humidity at $100^{\circ} \mathrm{C}$ and $10^{-4}$ bar $\mathrm{CO}_{2}$ Fugacity 


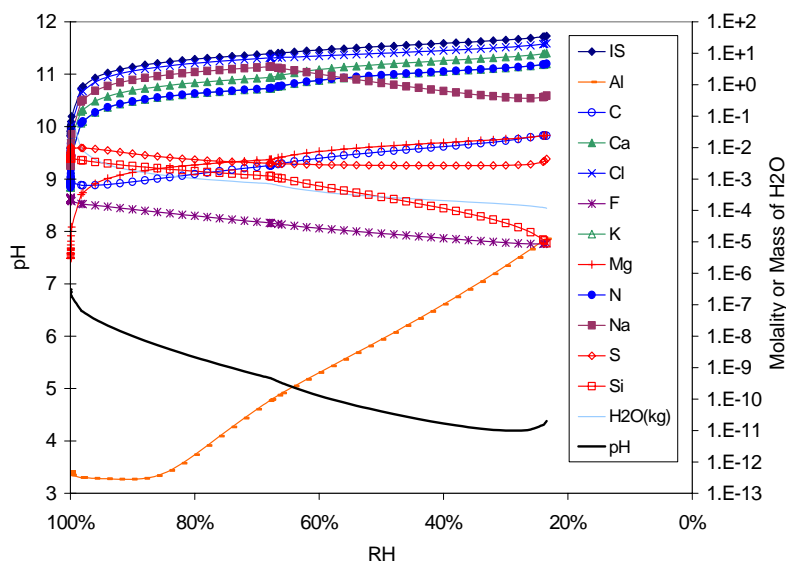

Source: DTN: MO0304SPACSALT.000, 02c2t7e.xIs.xIs.

Figure B-02-7. Bin 02 Aqueous Composition Evaporation Predictions vs. Relative Humidity at $70^{\circ} \mathrm{C}$ and $10^{-2}$ bar $\mathrm{CO}_{2}$ Fugacity

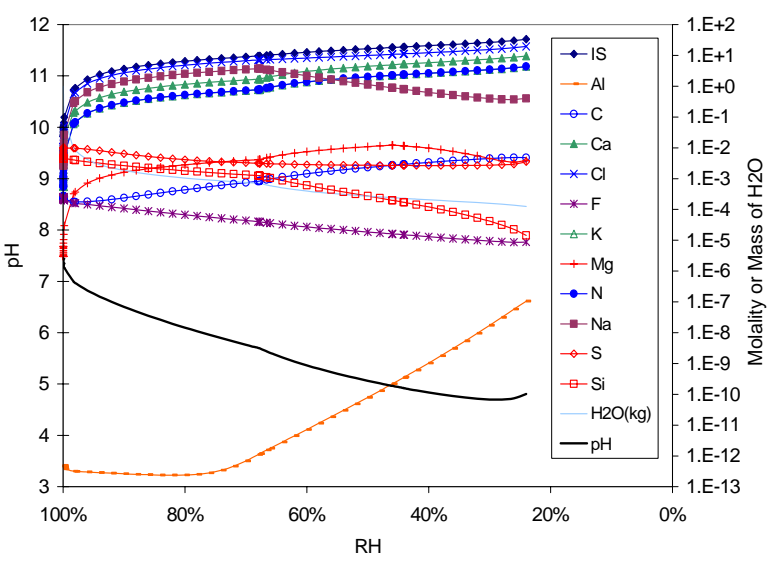

Source: DTN: MO0304SPACSALT.000, 02c3t7e.xIs.xls.

Figure B-02-9. Bin 02 Aqueous Composition Evaporation Predictions vs. Relative Humidity at $70^{\circ} \mathrm{C}$ and $10^{-3}$ bar $\mathrm{CO}_{2}$ Fugacity

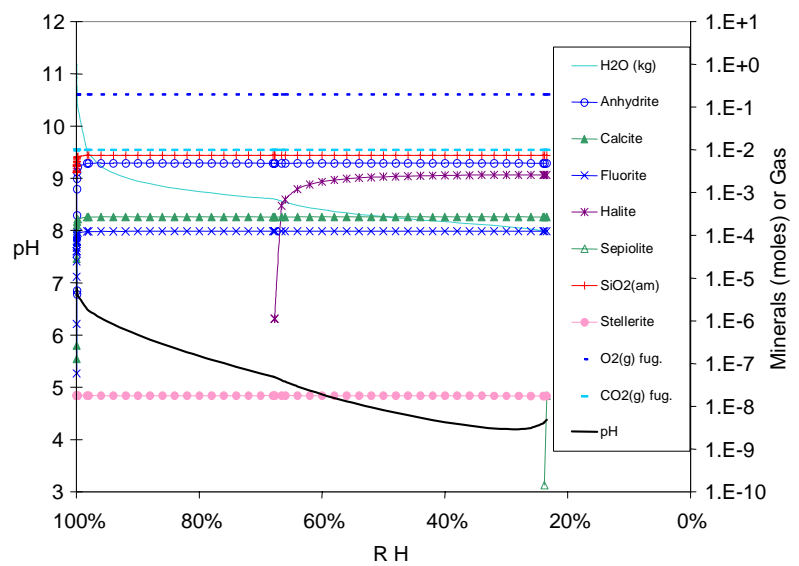

Source: DTN: MO0304SPACSALT.000, 02c2t7e.xls.xIs.

Figure B-02-8. Bin 02 Mineral Precipitation Evaporation Predictions vs. Relative Humidity at $70^{\circ} \mathrm{C}$ and $10^{-2}$ bar $\mathrm{CO}_{2}$ Fugacity

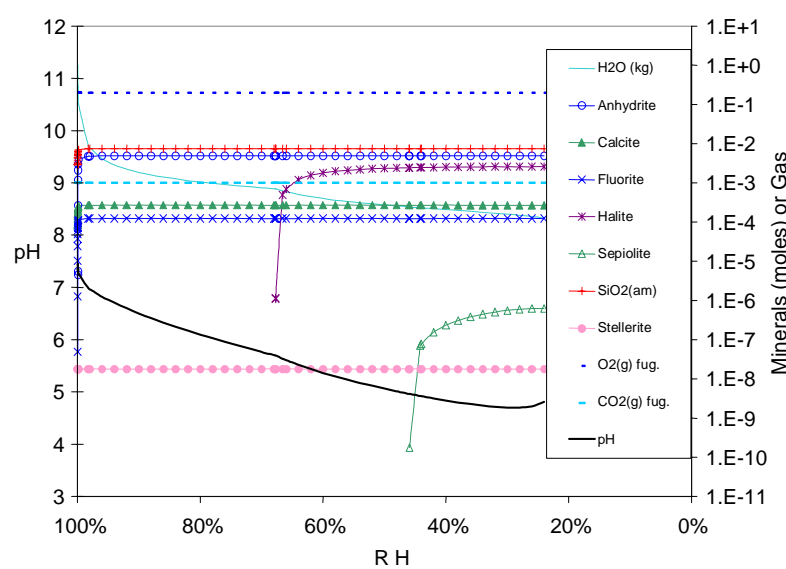

Source: DTN: MO0304SPACSALT.000, 02c3t7e.xIs.x/s.

Figure B-02-10. Bin 02 Mineral Precipitation Evaporation Predictions vs. Relative Humidity at $70^{\circ} \mathrm{C}$ and $10^{-3}$ bar $\mathrm{CO}_{2}$ Fugacity 


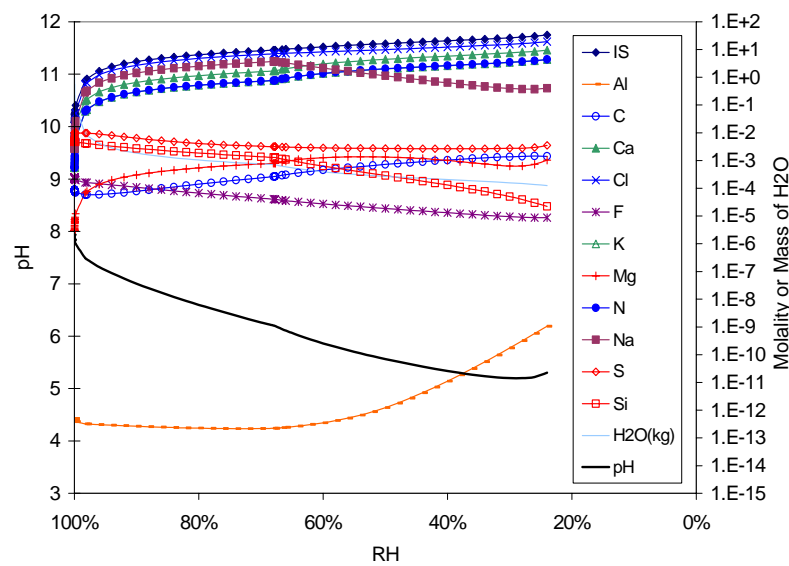

Source: DTN: MO0304SPACSALT.000, 02c4t7e.xIs.xIs.

Figure B-02-11. Bin 02 Aqueous Composition Evaporation Predictions vs. Relative Humidity at $70^{\circ} \mathrm{C}$ and $10^{-4}$ bar $\mathrm{CO}_{2}$ Fugacity

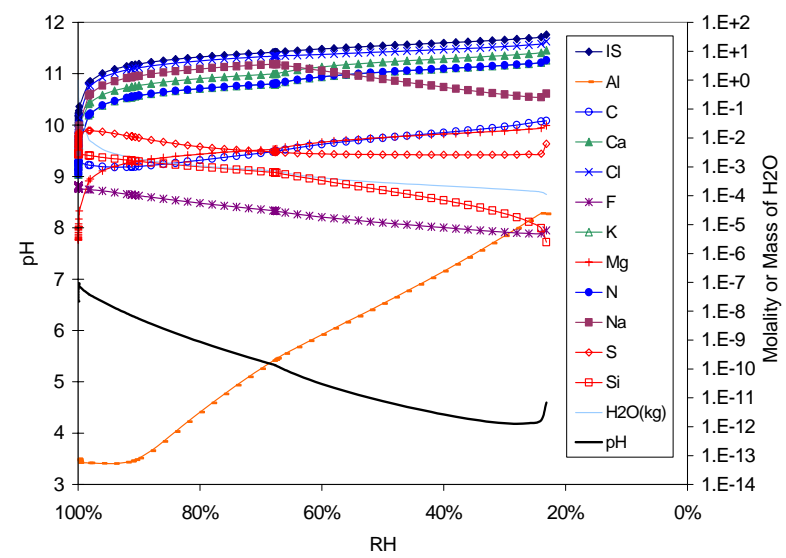

Source: DTN: MO0304SPACSALT.000, 02c2t4e.xIs.xls.

Figure B-02-13. Bin 02 Aqueous Composition Evaporation Predictions vs. Relative Humidity at $40^{\circ} \mathrm{C}$ and $10^{-2}$ bar $\mathrm{CO}_{2}$ Fugacity

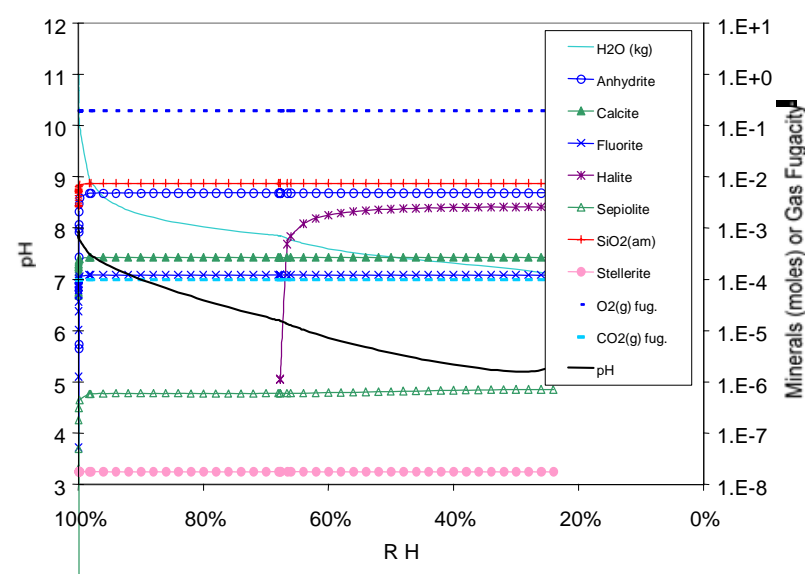

Source: DTN: MO0304SPACSALT.000, 02c4t7e.xIs.xls.

Figure B-02-12. Bin 02 Mineral Precipitation Evaporation Predictions vs. Relative Humidity at $70^{\circ} \mathrm{C}$ and $10^{-4}$ bar $\mathrm{CO}_{2}$ Fugacity

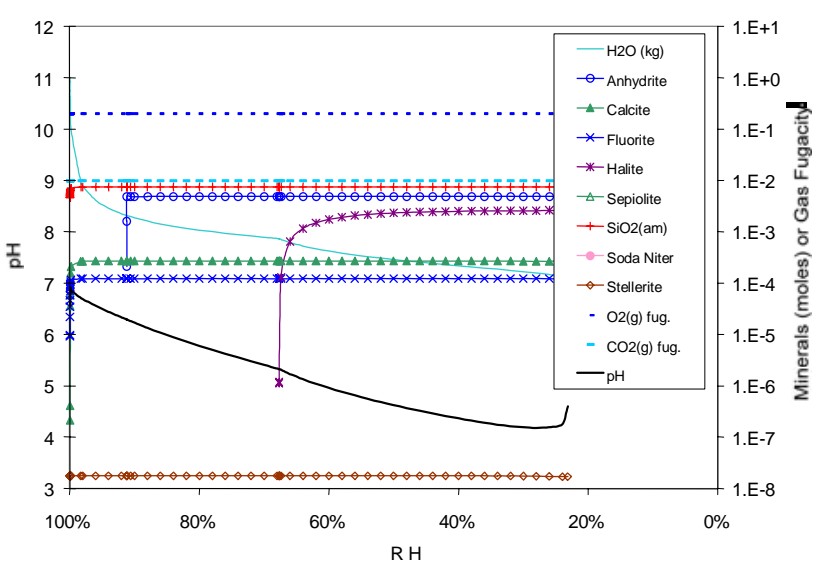

Source: DTN: MO0304SPACSALT.000, 02c2t4e.xIs.xls.

Figure B-02-14. Bin 02 Mineral Precipitation Evaporation Predictions vs. Relative Humidity at $40^{\circ} \mathrm{C}$ and $10^{-2}$ bar $\mathrm{CO}_{2}$ Fugacity 


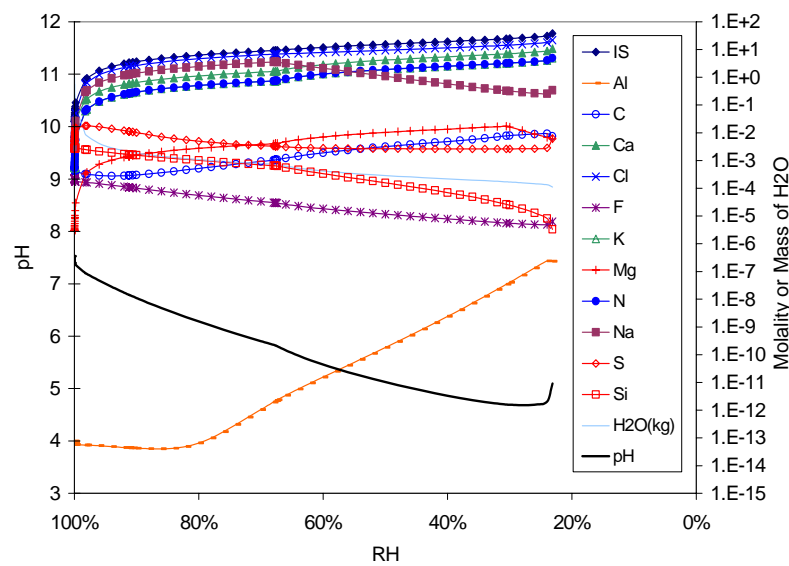

Source: DTN: MO0304SPACSALT.000, 02c3t4e.xIs.xIs.

Figure B-02-15. Bin 02 Aqueous Composition Evaporation Predictions vs. Relative Humidity at $40^{\circ} \mathrm{C}$ and $10^{-3}$ bar $\mathrm{CO}_{2}$ Fugacity

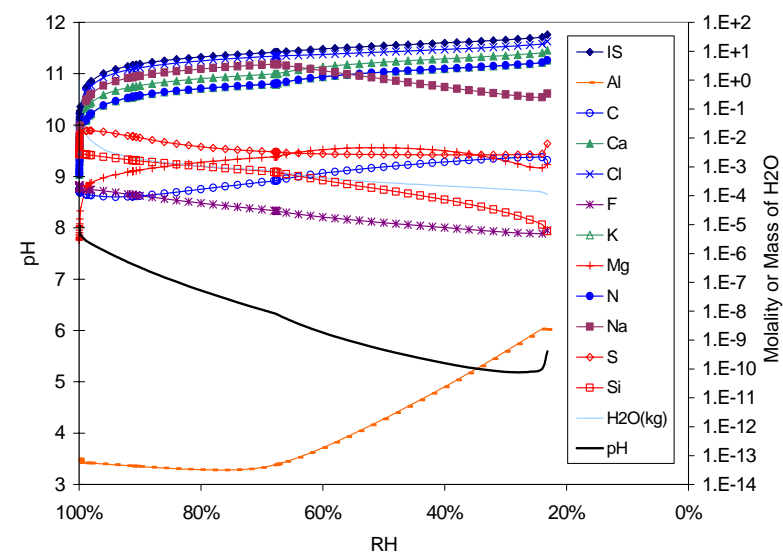

Source: DTN: MO0304SPACSALT.000, 02c4t4e.xIs.xls.

Figure B-02-17. Bin 02 Aqueous Composition Evaporation Predictions vs. Relative Humidity at $40^{\circ} \mathrm{C}$ and $10^{-4}$ bar $\mathrm{CO}_{2}$ Fugacity

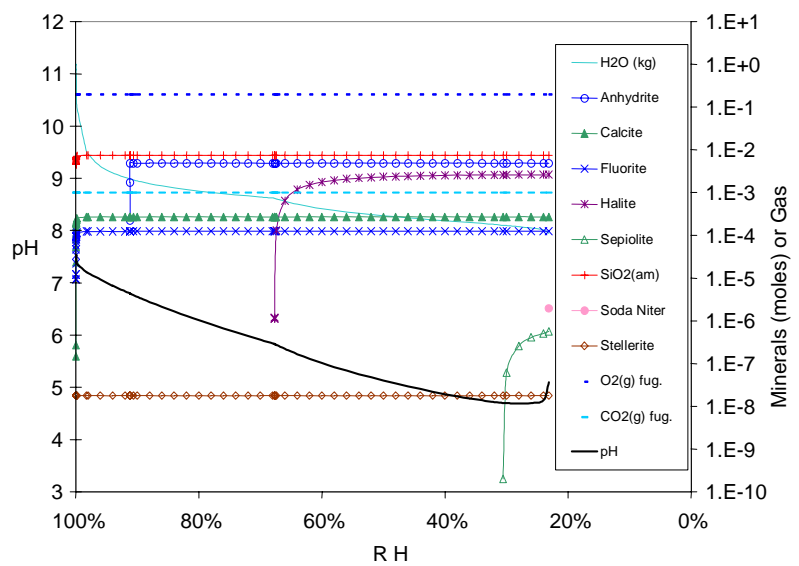

Source: DTN: MO0304SPACSALT.000, 02c3t4e.xIs.xIs.

Figure B-02-16. Bin 02 Mineral Precipitation Evaporation Predictions vs. Relative Humidity at $40^{\circ} \mathrm{C}$ and $10^{-3}$ bar $\mathrm{CO}_{2}$ Fugacity

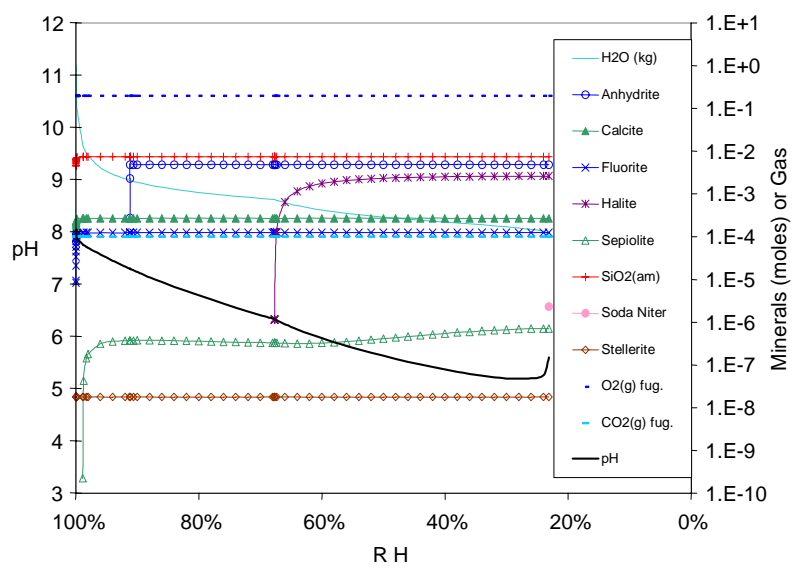

Source: DTN: MO0304SPACSALT.000, 02c4t4e.xIs.xIs.

Figure B-02-18. Bin 02 Mineral Precipitation Evaporation Predictions vs. Relative Humidity at $40^{\circ} \mathrm{C}$ and $10^{-4}$ bar $\mathrm{CO}_{2}$ Fugacity 


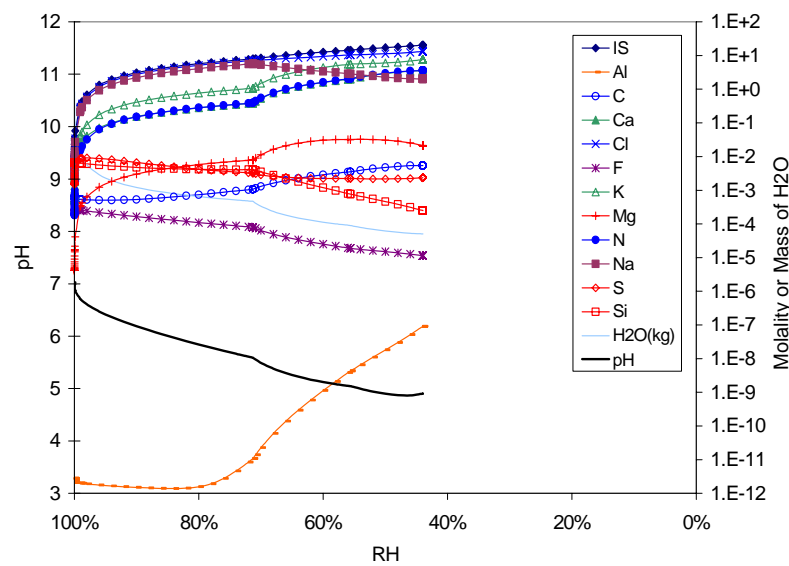

Source: DTN: M00304SPACSALT.000, 03c2t1e.xIs.xIs.

Figure B-03-1. Bin 03 Aqueous Composition Evaporation Predictions vs. Relative Humidity at $100^{\circ} \mathrm{C}$ and $10^{-2}$ bar $\mathrm{CO}_{2}$ Fugacity

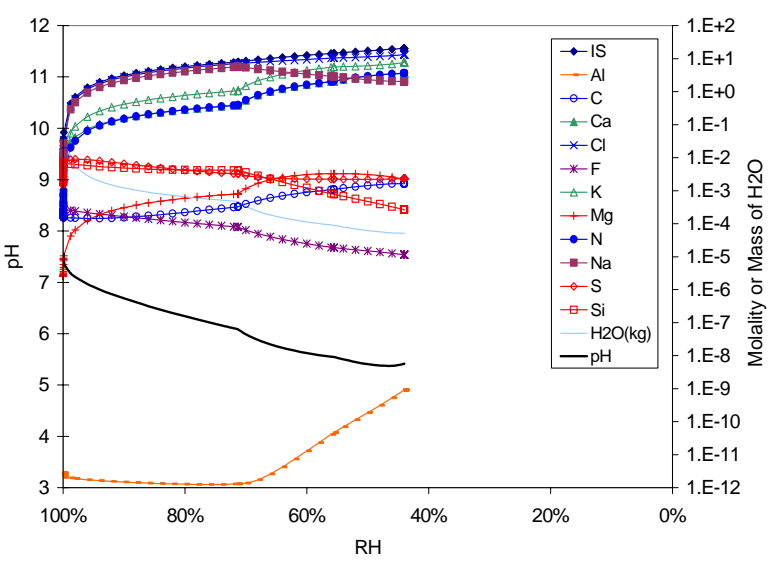

Source: DTN: M00304SPACSALT.000, 03c3t1e.xIs.xls.

Figure B-03-3. Bin 03 Aqueous Composition Evaporation Predictions vs. Relative Humidity at $100^{\circ} \mathrm{C}$ and $10^{-3}$ bar $\mathrm{CO}_{2}$ Fugacity

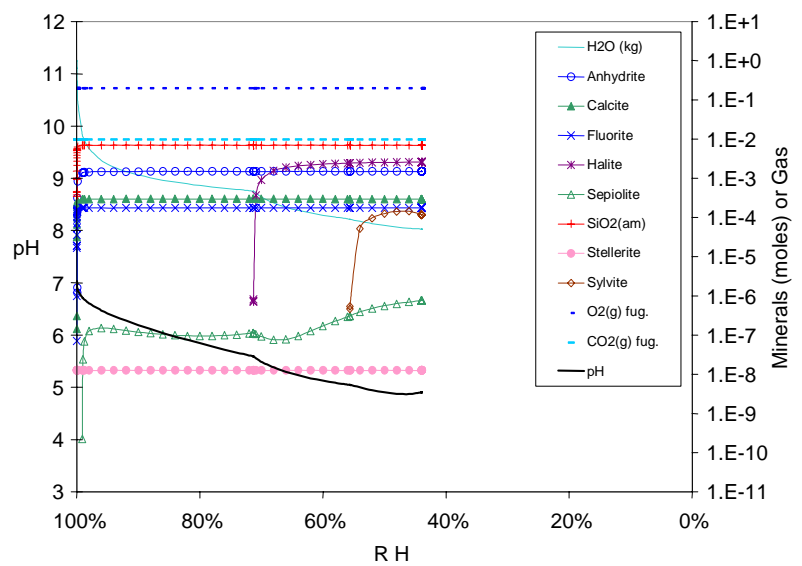

Source: DTN: MO0304SPACSALT.000, 03c2t1e.xls.xls.

Figure B-03-2. Bin 03 Mineral Precipitation Evaporation Predictions vs. Relative Humidity at $100^{\circ} \mathrm{C}$ and $10^{-2}$ bar $\mathrm{CO}_{2}$ Fugacity

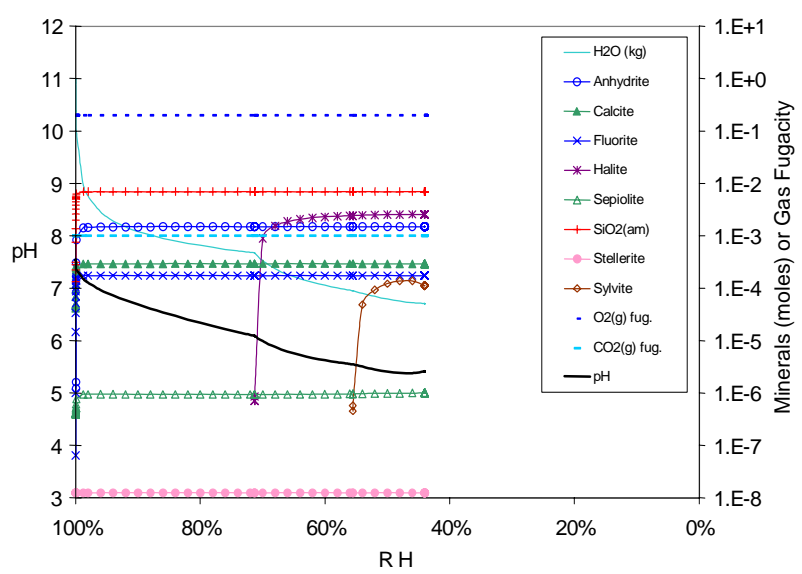

Source: DTN: MO0304SPACSALT.000, 03c3t1e.xIs.xIs.

Figure B-03-4. Bin 03 Mineral Precipitation Evaporation Predictions vs. Relative Humidity at $100^{\circ} \mathrm{C}$ and $10^{-3}$ bar $\mathrm{CO}_{2}$ Fugacity 


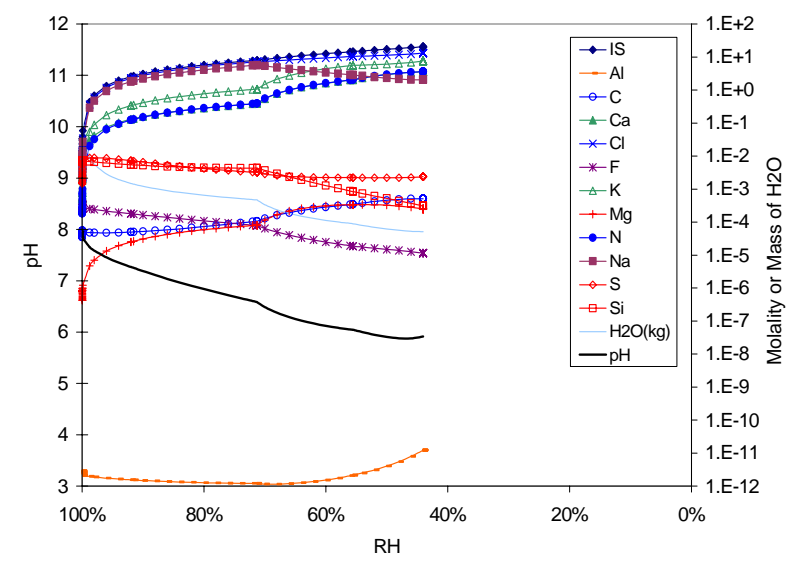

Source: DTN: MO0304SPACSALT.000, 03c4t1e.xIs.xIs.

Figure B-03-5. Bin 03 Aqueous Composition Evaporation Predictions vs. Relative Humidity at $100^{\circ} \mathrm{C}$ and $10^{-4}$ bar $\mathrm{CO}_{2}$ Fugacity

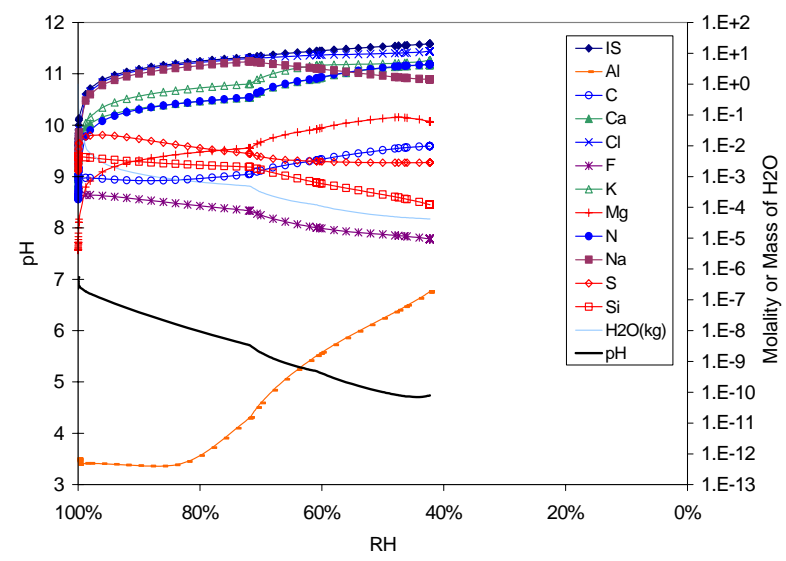

Source: DTN: MO0304SPACSALT.000, 03c2t7e.xls.xls.

Figure B-03-7. Bin 03 Aqueous Composition Evaporation Predictions vs. Relative Humidity at $70^{\circ} \mathrm{C}$ and $10^{-2}$ bar $\mathrm{CO}_{2}$ Fugacity

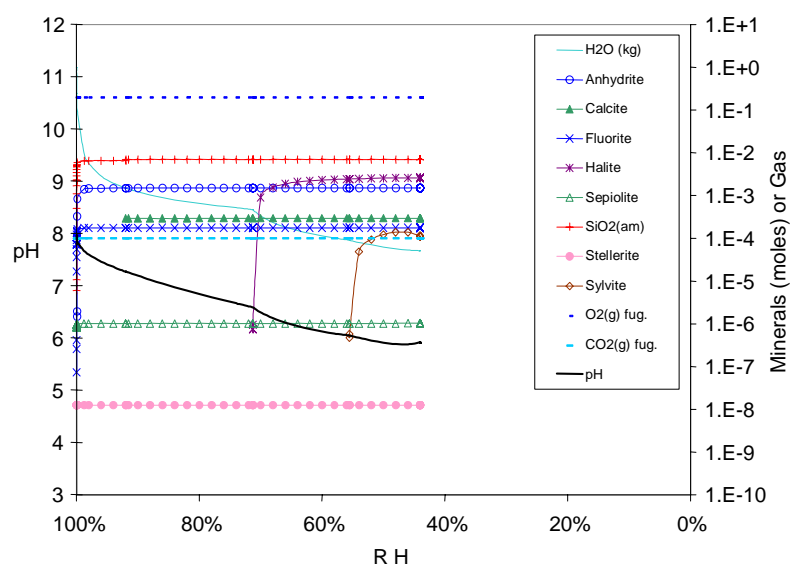

Source: DTN: MO0304SPACSALT.000, 03c4t1e.xIs.xls.

Figure B-03-6. Bin 03 Mineral Precipitation Evaporation Predictions vs. Relative Humidity at $100^{\circ} \mathrm{C}$ and $10^{-4}$ bar $\mathrm{CO}_{2}$ Fugacity

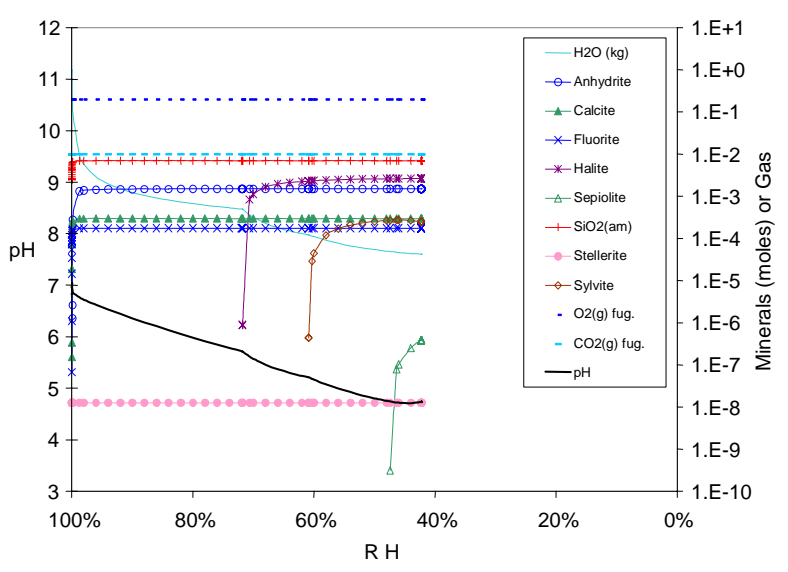

Source: DTN: MO0304SPACSALT.000, 03c2t7e.xIs.xls.

Figure B-03-8. Bin 03 Mineral Precipitation Evaporation Predictions vs. Relative Humidity at $70^{\circ} \mathrm{C}$ and $10^{-2}$ bar $\mathrm{CO}_{2}$ Fugacity 


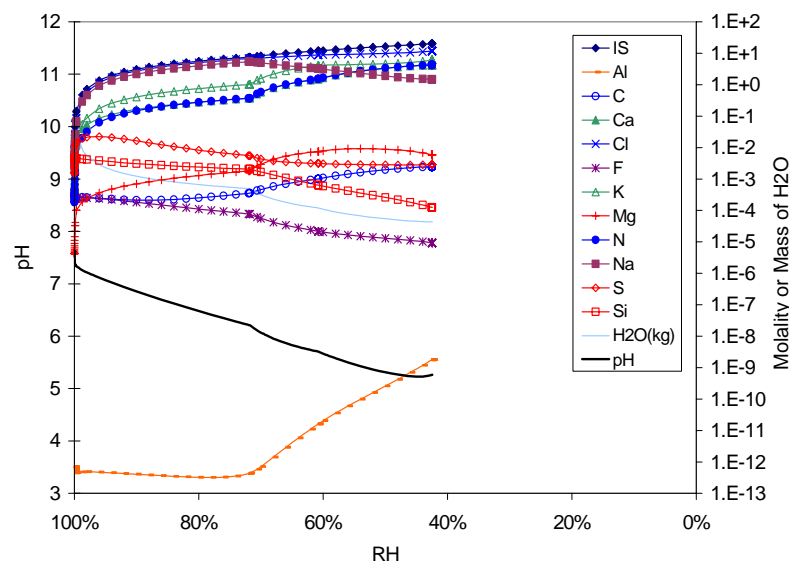

Source: DTN: MO0304SPACSALT.000, 03c3t7e.xIs.xIs.

Figure B-03-9. Bin 03 Aqueous Composition Evaporation Predictions vs. Relative Humidity at $70^{\circ} \mathrm{C}$ and $10^{-3}$ bar $\mathrm{CO}_{2}$ Fugacity

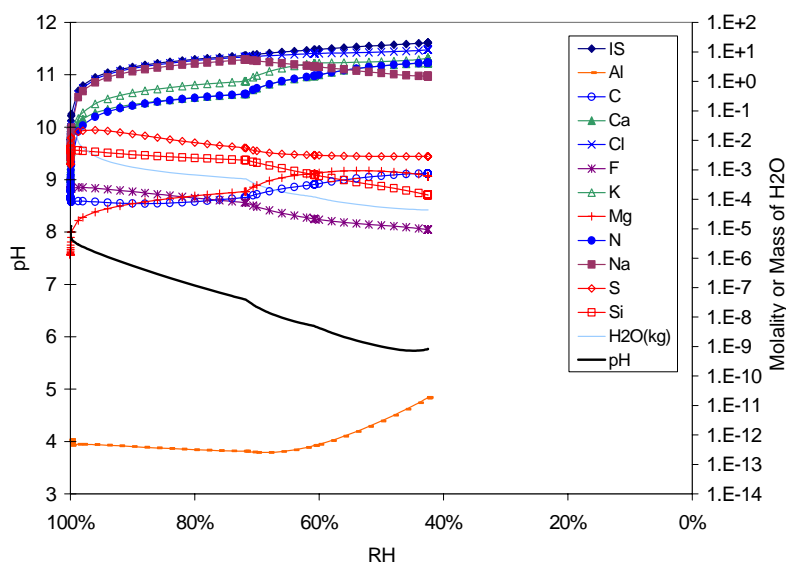

Source: DTN: M00304SPACSALT.000, 03c4t7e.xls.xls.

Figure B-03-11. Bin 03 Aqueous Composition Evaporation Predictions vs. Relative Humidity at $70^{\circ} \mathrm{C}$ and $10^{-4}$ bar $\mathrm{CO}_{2}$ Fugacity

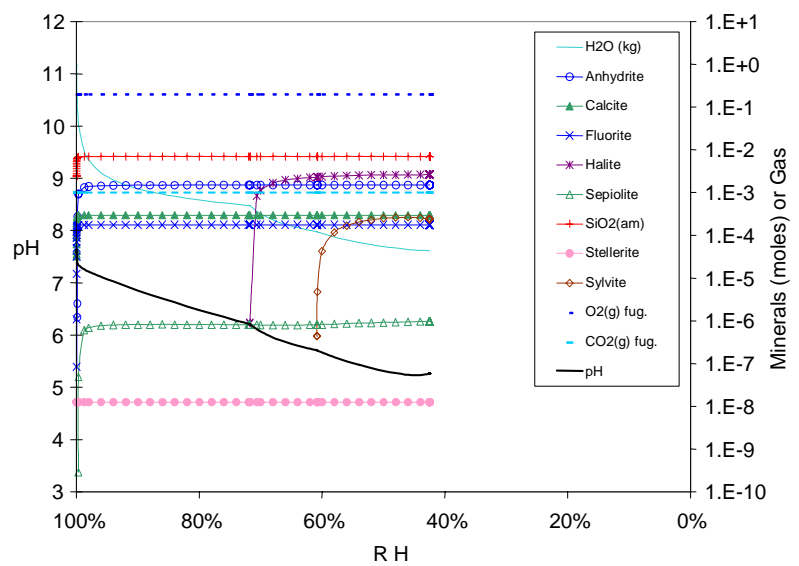

Source: DTN: MO0304SPACSALT.000, 03c3t7e.xIs.x/s.

Figure B-03-10. Bin 03 Mineral Precipitation Evaporation Predictions vs. Relative Humidity at $70^{\circ} \mathrm{C}$ and $10^{-3}$ bar $\mathrm{CO}_{2}$ Fugacity

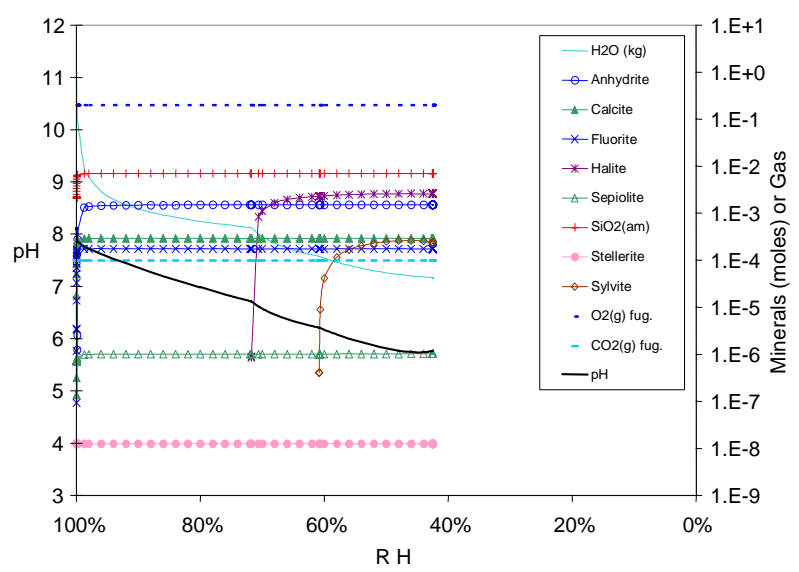

Source: DTN: M00304SPACSALT.000, 03c4t7e.xIs.x/s.

Figure B-03-12. Bin 03 Mineral Precipitation Evaporation Predictions vs. Relative Humidity at $70^{\circ} \mathrm{C}$ and $10^{-4}$ bar $\mathrm{CO}_{2}$ Fugacity 


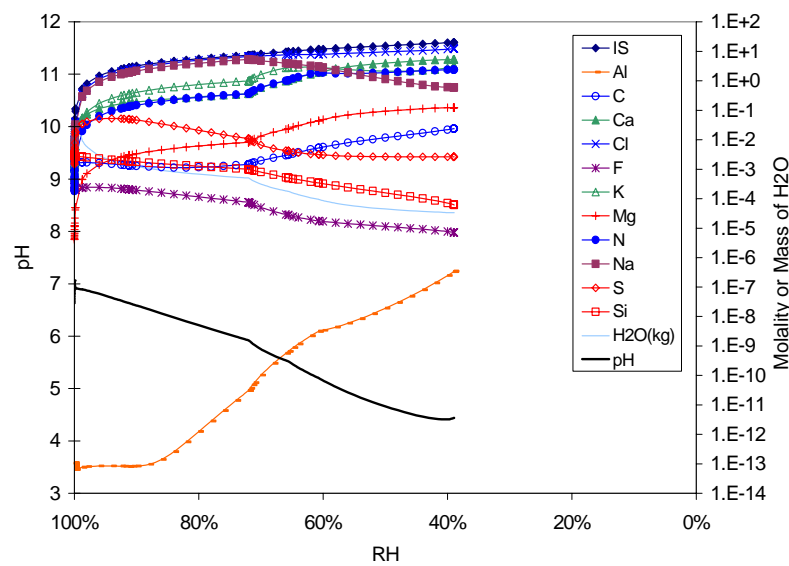

Source: DTN: MO0304SPACSALT.000, 03c2t4e.xIs.xIs.

Figure B-03-13. Bin 03 Aqueous Composition Evaporation Predictions vs. Relative Humidity at $40^{\circ} \mathrm{C}$ and $10^{-2}$ bar $\mathrm{CO}_{2}$ Fugacity

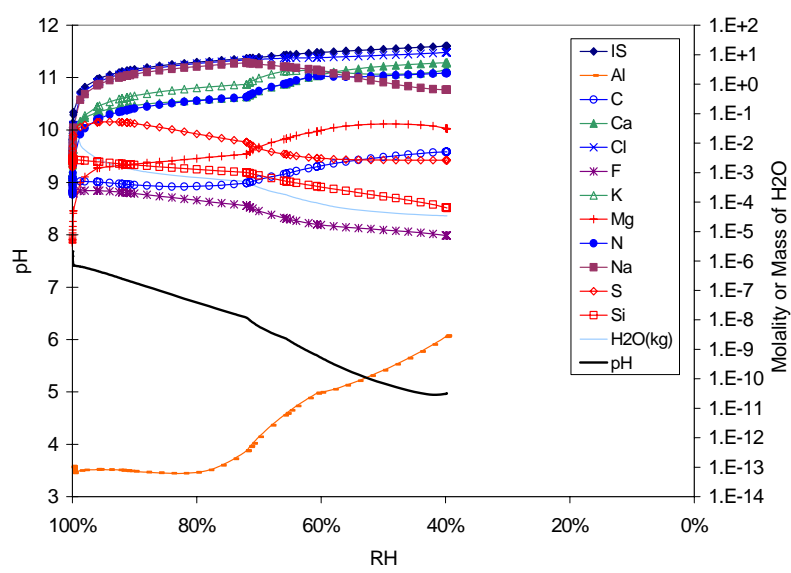

Source: DTN: MO0304SPACSALT.000, 03c3t4e.xIs.xls.

Figure B-03-15. Bin 03 Aqueous Composition Evaporation Predictions vs. Relative Humidity at $40^{\circ} \mathrm{C}$ and $10^{-3}$ bar $\mathrm{CO}_{2}$ Fugacity

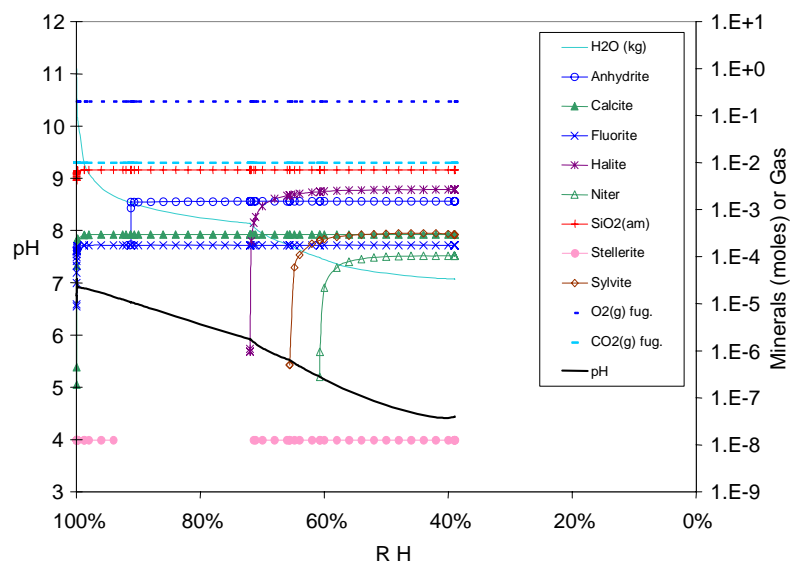

Source: DTN: MO0304SPACSALT.000, 03c2t4e.xIs.xIs.

Figure B-03-14. Bin 03 Mineral Precipitation Evaporation Predictions vs. Relative Humidity at $40^{\circ} \mathrm{C}$ and $10^{-2}$ bar $\mathrm{CO}_{2}$ Fugacity

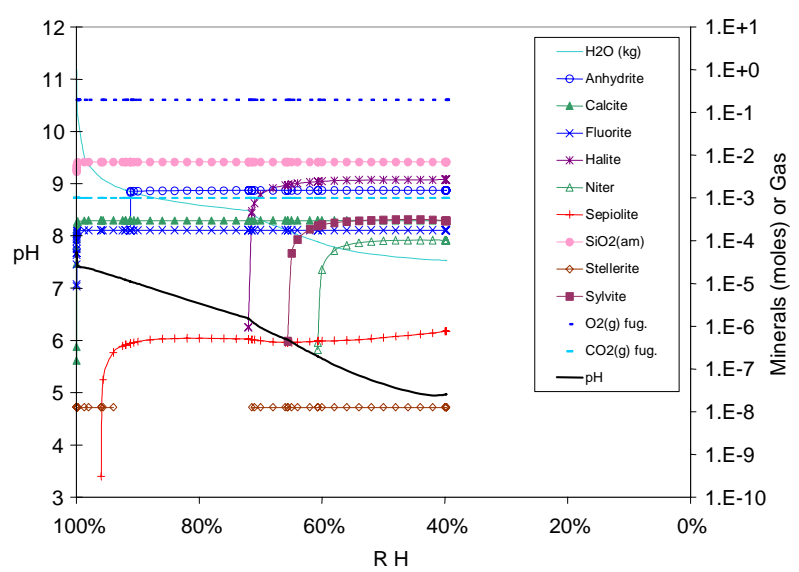

Source: DTN: MO0304SPACSALT.000, 03c3t4e.xIs.xIs.

Figure B-03-16. Bin 03 Mineral Precipitation Evaporation Predictions vs. Relative Humidity at $40^{\circ} \mathrm{C}$ and $10^{-3}$ bar $\mathrm{CO}_{2}$ Fugacity 


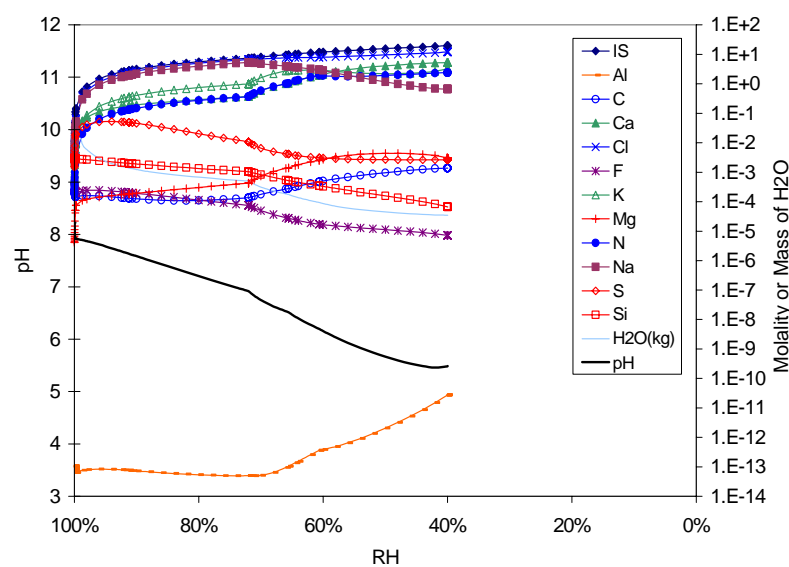

Source: DTN: M00304SPACSALT.000, 03c4t4e.xIs.xIs.

Figure B-03-17. Bin 03 Aqueous Composition Evaporation Predictions vs. Relative Humidity at $40^{\circ} \mathrm{C}$ and $10^{-4}$ bar $\mathrm{CO}_{2}$ Fugacity

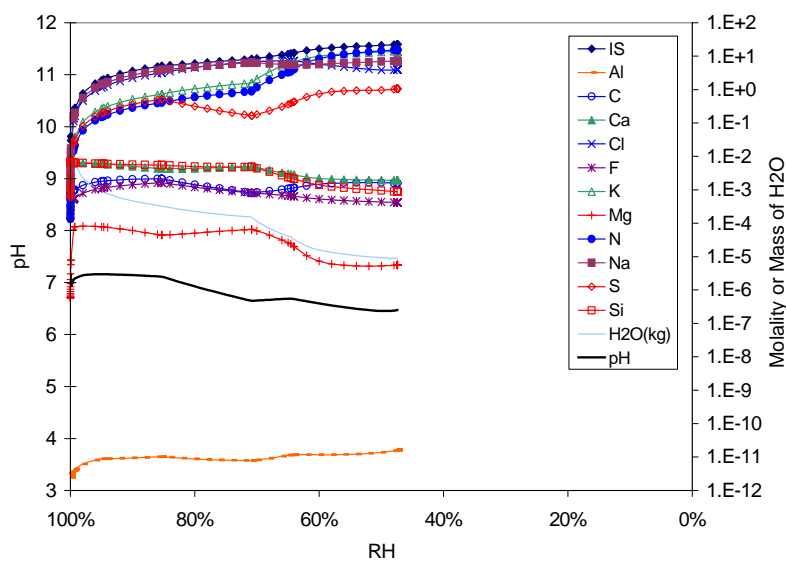

Source: DTN: MO0304SPACSALT.000, 04c2t1e.xIs.xls.

Figure B-04-1. Bin 04 Aqueous Composition Evaporation Predictions vs. Relative Humidity at $100^{\circ} \mathrm{C}$ and $10^{-2}$ bar $\mathrm{CO}_{2}$ Fugacity

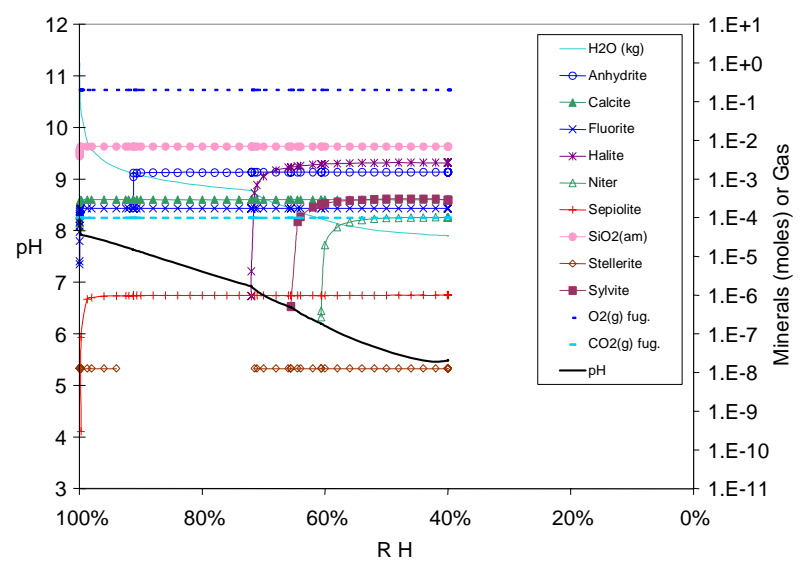

Source: DTN: MO0304SPACSALT.000, 03c4t4e.xIs.xls.

Figure B-03-18. Bin 03 Mineral Precipitation Evaporation Predictions vs. Relative Humidity at $40^{\circ} \mathrm{C}$ and $10^{-4}$ bar $\mathrm{CO}_{2}$ Fugacity

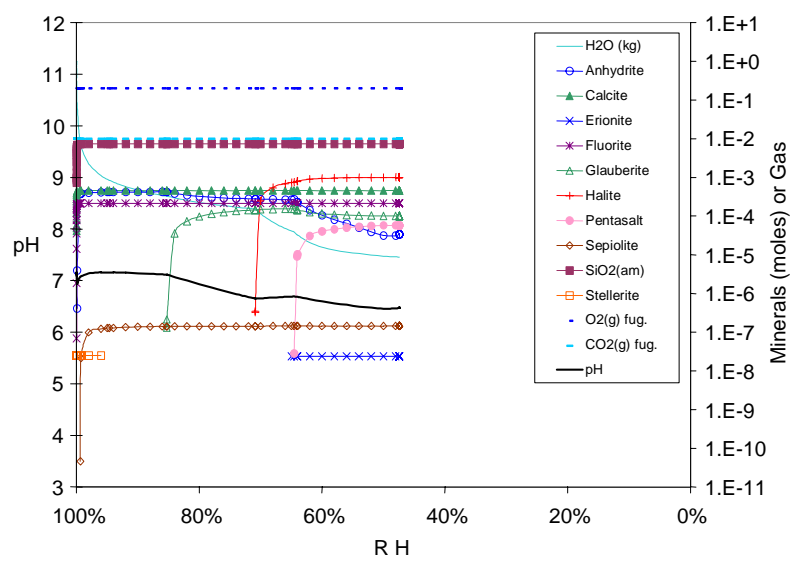

Source: DTN: MO0304SPACSALT.000, 04c2t1e.xIs.xls.

Figure B-04-2. Bin 04 Mineral Precipitation Evaporation Predictions vs. Relative Humidity at $100^{\circ} \mathrm{C}$ and $10^{-2}$ bar $\mathrm{CO}_{2}$ Fugacity 


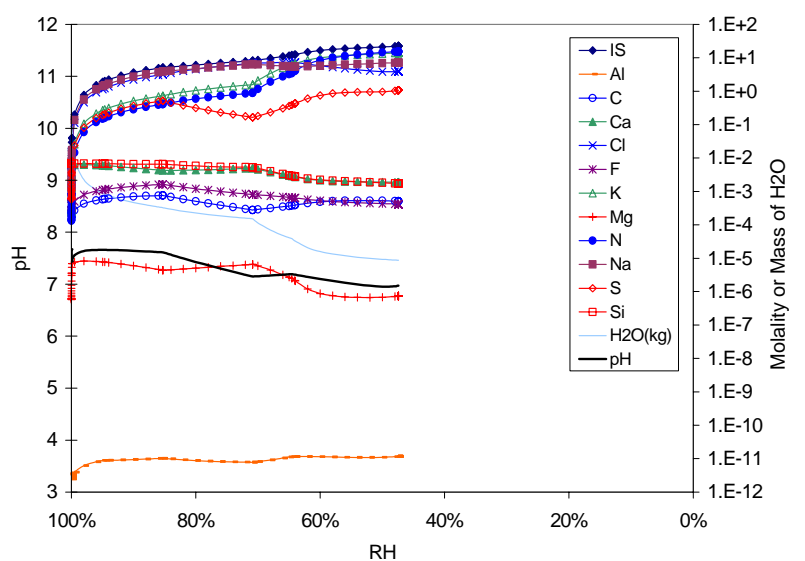

Source: DTN: MO0304SPACSALT.000, 04c3t1e.xls.xls.

Figure B-04-3. Bin 04 Aqueous Composition Evaporation Predictions vs. Relative Humidity at $100^{\circ} \mathrm{C}$ and $10^{-3}$ bar $\mathrm{CO}_{2}$ Fugacity

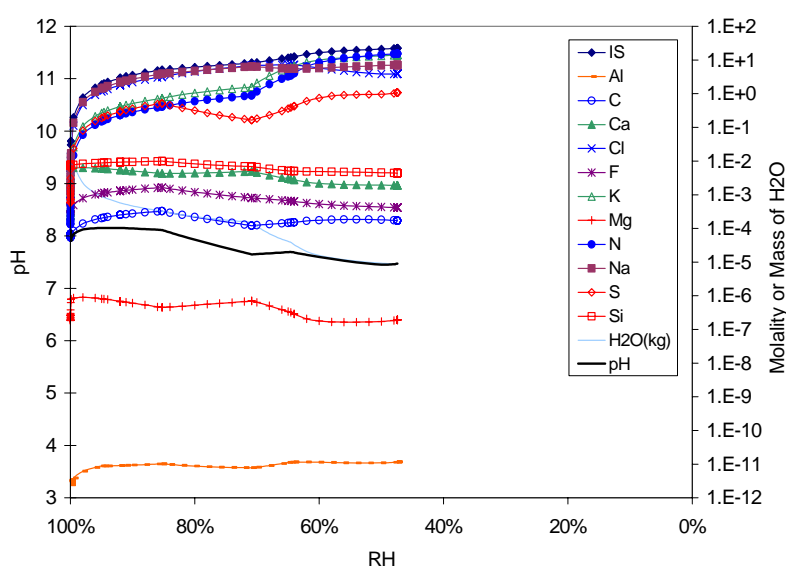

Source: DTN: MO0304SPACSALT.000, 04c4t1e.xIs.xIs.

Figure B-04-5. Bin 04 Aqueous Composition Evaporation Predictions vs. Relative Humidity at $100^{\circ} \mathrm{C}$ and $10^{-4}$ bar $\mathrm{CO}_{2}$ Fugacity

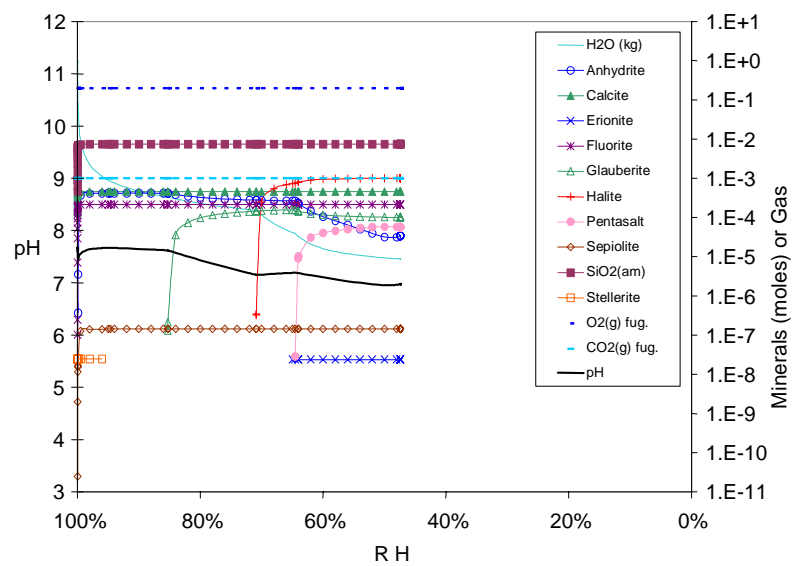

Source: DTN: MO0304SPACSALT.000, 04c3t1e.xIs.xIs.

Figure B-04-4. Bin 04 Mineral Precipitation Evaporation Predictions vs. Relative Humidity at $100^{\circ} \mathrm{C}$ and $10^{-3}$ bar $\mathrm{CO}_{2}$ Fugacity

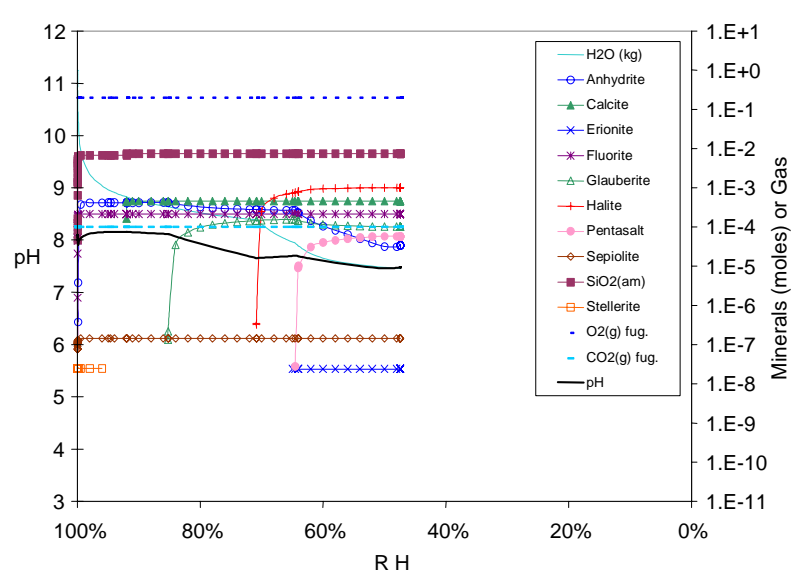

Source: DTN: MO0304SPACSALT.000, 04c4t1e.xIs.xls.

Figure B-04-6. Bin 04 Mineral Precipitation Evaporation Predictions vs. Relative Humidity at $100^{\circ} \mathrm{C}$ and $10^{-4}$ bar $\mathrm{CO}_{2}$ Fugacity 


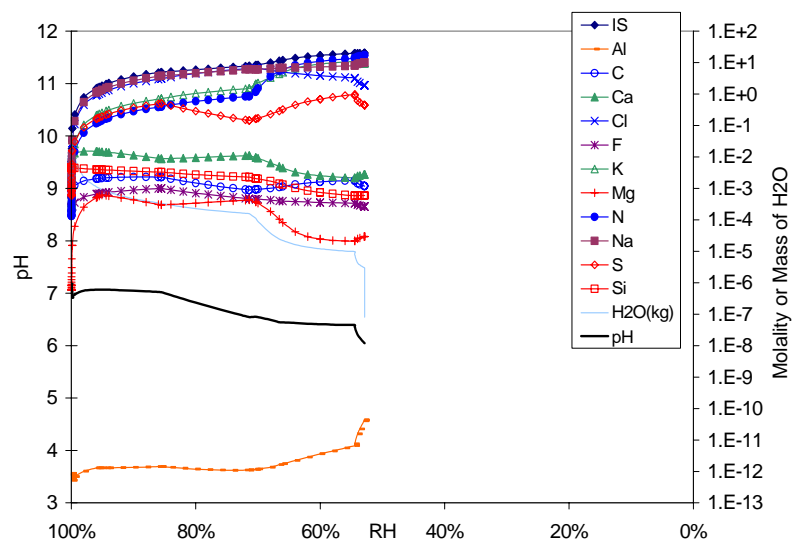

Source: DTN: MO0304SPACSALT.000, 04c2t7e.xIs.xIs.

Figure B-04-7. Bin 04 Aqueous Composition Evaporation Predictions vs. Relative Humidity at $70^{\circ} \mathrm{C}$ and $10^{-2}$ bar $\mathrm{CO}_{2}$ Fugacity

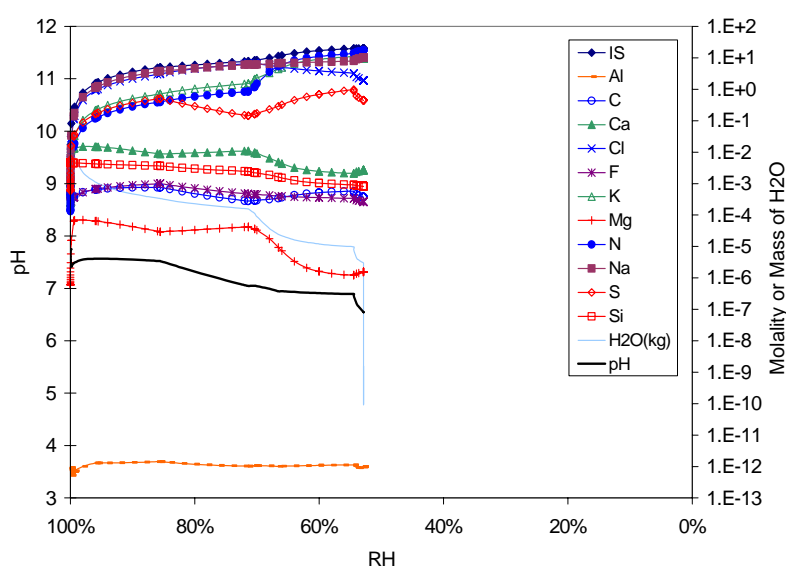

Source: DTN: MO0304SPACSALT.000, 04c3t7e.xls.xls.

Figure B-04-9. Bin 04 Aqueous Composition Evaporation Predictions vs. Relative Humidity at $70^{\circ} \mathrm{C}$ and $10^{-3}$ bar $\mathrm{CO}_{2}$ Fugacity

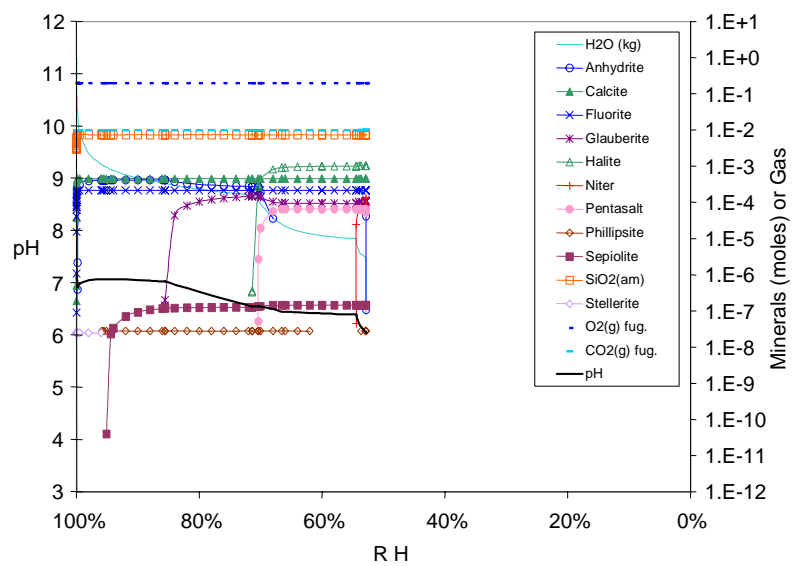

Source: DTN: MO0304SPACSALT.000, 04c2t7e.xIs.xIs.

Figure B-04-8. Bin 04 Mineral Precipitation Evaporation Predictions vs. Relative Humidity at $70^{\circ} \mathrm{C}$ and $10^{-2}$ bar $\mathrm{CO}_{2}$ Fugacity

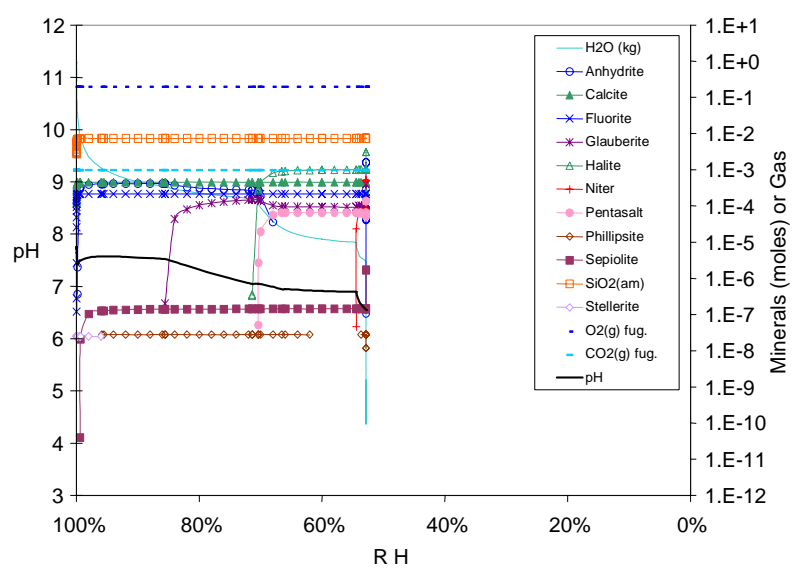

Source: DTN: MO0304SPACSALT.000, 04c3t7e.xls.xls.

Figure B-04-10. Bin 04 Mineral Precipitation Evaporation Predictions vs. Relative Humidity at $70^{\circ} \mathrm{C}$ and $10^{-3}$ bar $\mathrm{CO}_{2}$ Fugacity 


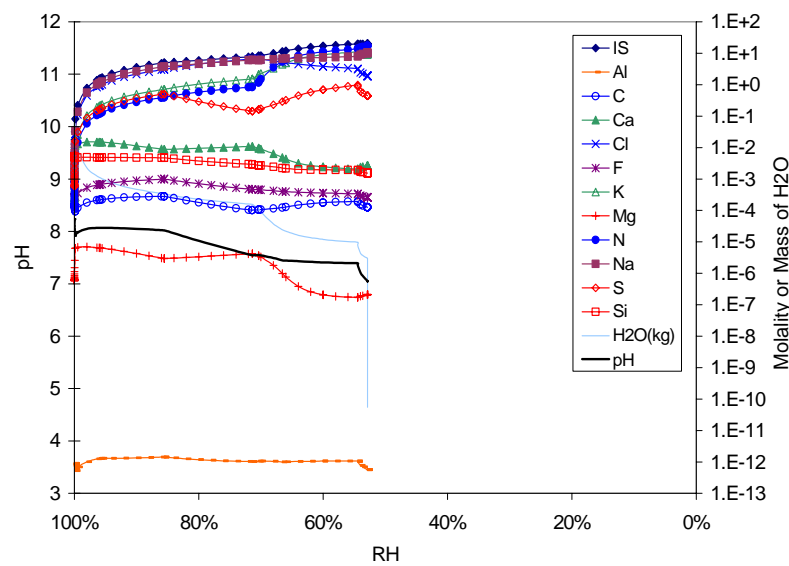

Source: DTN: MO0304SPACSALT.000, 04c4t7e.xIs.xIs.

Figure B-04-11. Bin 04 Aqueous Composition Evaporation Predictions vs. Relative Humidity at $70^{\circ} \mathrm{C}$ and $10^{-4}$ bar $\mathrm{CO}_{2}$ Fugacity

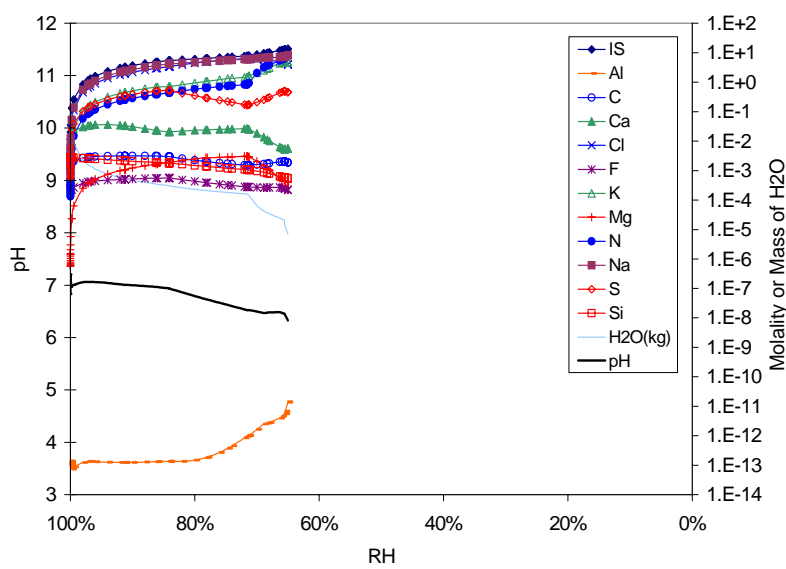

Source: DTN: MO0304SPACSALT.000, 04c2t4e.xIs.xls.

Figure B-04-13. Bin 04 Aqueous Composition Evaporation Predictions vs. Relative Humidity at $40^{\circ} \mathrm{C}$ and $10^{-2}$ bar $\mathrm{CO}_{2}$ Fugacity

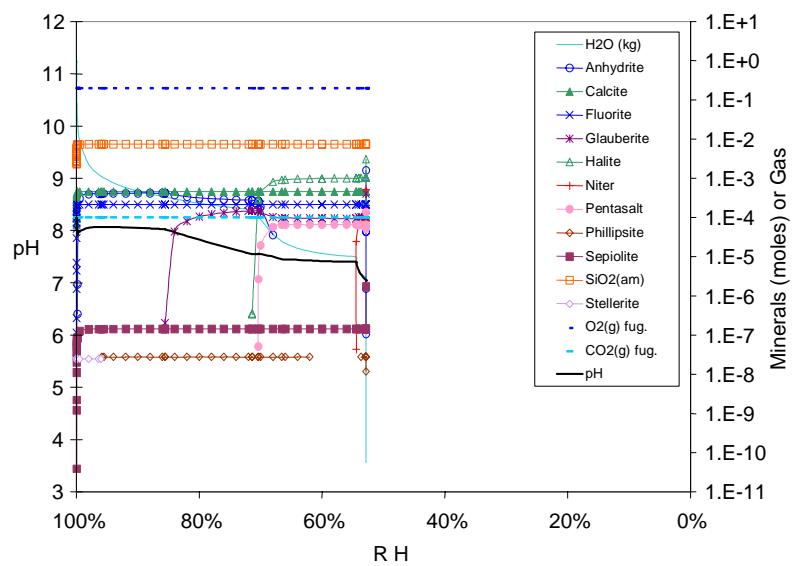

Source: DTN: MO0304SPACSALT.000, 04c4t7e.xIs.xIs.

Figure B-04-12. Bin 04 Mineral Precipitation Evaporation Predictions vs. Relative Humidity at $70^{\circ} \mathrm{C}$ and $10^{-4}$ bar $\mathrm{CO}_{2}$ Fugacity

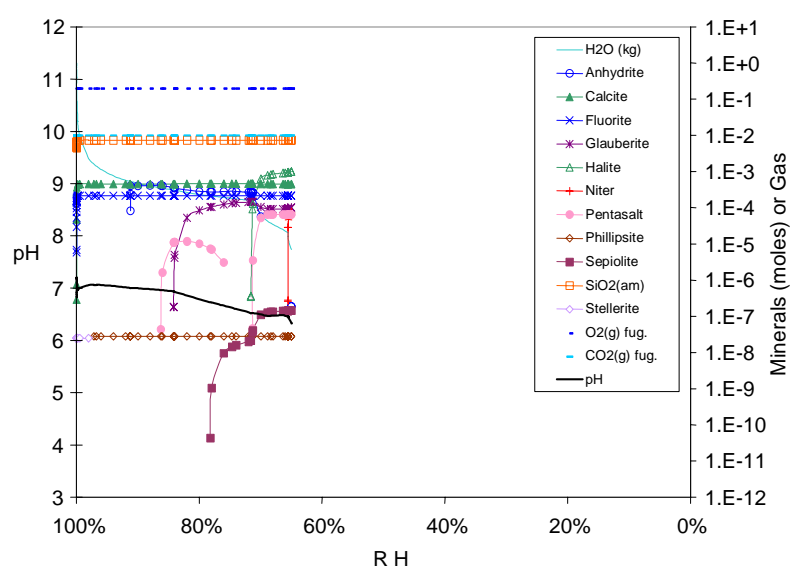

Source: DTN: MO0304SPACSALT.000, 04c2t4e.xIs.xIs.

Figure B-04-14. Bin 04 Mineral Precipitation Evaporation Predictions vs. Relative Humidity at $40^{\circ} \mathrm{C}$ and $10^{-2}$ bar $\mathrm{CO}_{2}$ Fugacity 


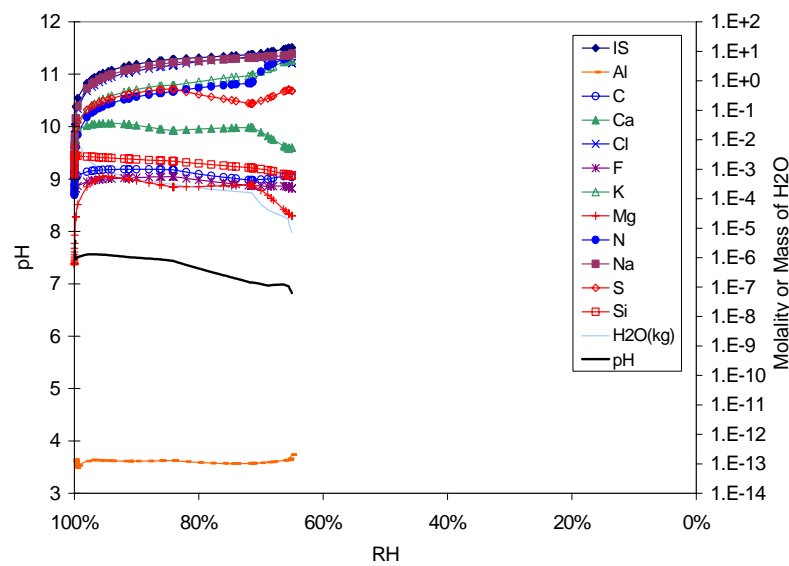

Source: DTN: MO0304SPACSALT.000, 04c3t4e.xIs.xIs.

Figure B-04-15. Bin 04 Aqueous Composition Evaporation Predictions vs. Relative Humidity at $40^{\circ} \mathrm{C}$ and $10^{-3}$ bar $\mathrm{CO}_{2}$ Fugacity

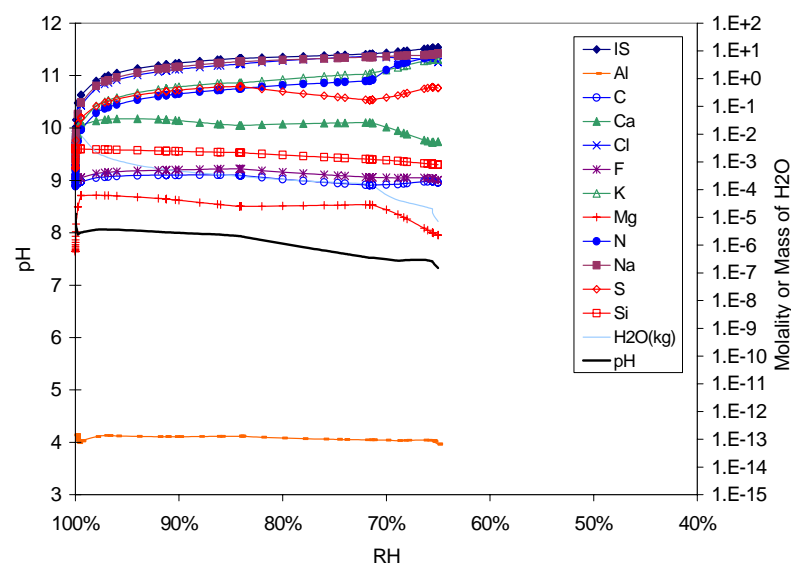

Source: DTN: MO0304SPACSALT.000, 04c4t4e.xIs.xls.

Figure B-04-17. Bin 04 Aqueous Composition Evaporation Predictions vs. Relative Humidity at $40^{\circ} \mathrm{C}$ and $10^{-4}$ bar $\mathrm{CO}_{2}$ Fugacity

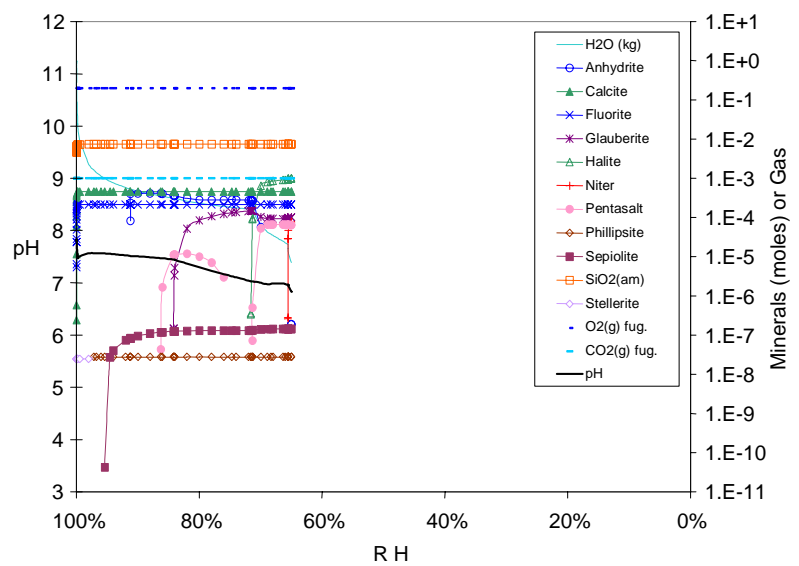

Source: DTN: MO0304SPACSALT.000, 04c3t4e.xIs.xIs.

Figure B-04-16. Bin 04 Mineral Precipitation Evaporation Predictions vs. Relative Humidity at $40^{\circ} \mathrm{C}$ and $10^{-3}$ bar $\mathrm{CO}_{2}$ Fugacity

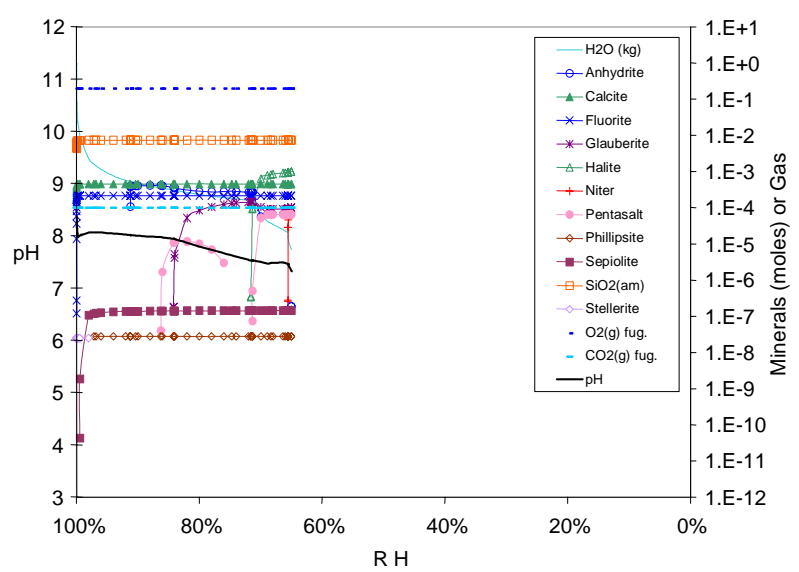

Source: DTN: MO0304SPACSALT.000, 04c4t4e.xIs.xIs.

Figure B-04-18. Bin 04 Mineral Precipitation Evaporation Predictions vs. Relative Humidity at $40^{\circ} \mathrm{C}$ and $10^{-4}$ bar $\mathrm{CO}_{2}$ Fugacity 


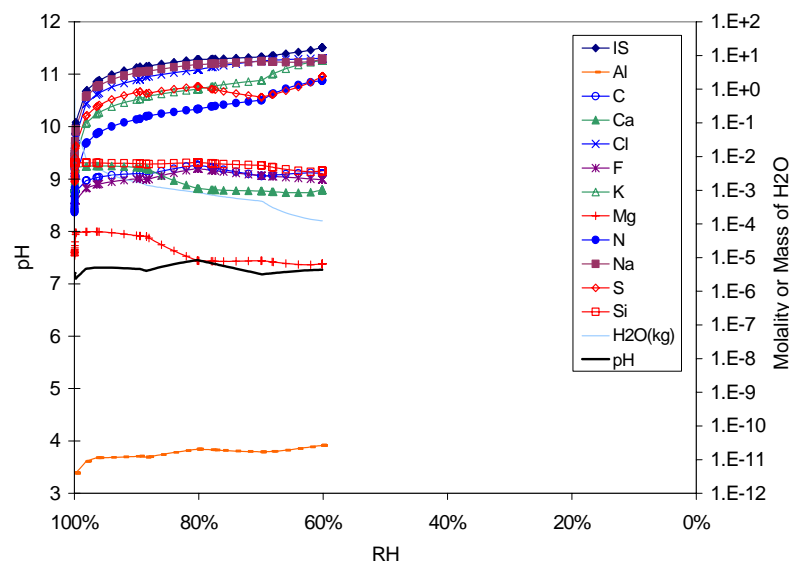

Source: DTN: MO0304SPACSALT.000, 05c2t1e.xIs.xIs.

Figure B-05-1. Bin 05 Aqueous Composition Evaporation Predictions vs. Relative Humidity at $100^{\circ} \mathrm{C}$ and $10^{-2}$ bar $\mathrm{CO}_{2}$ Fugacity

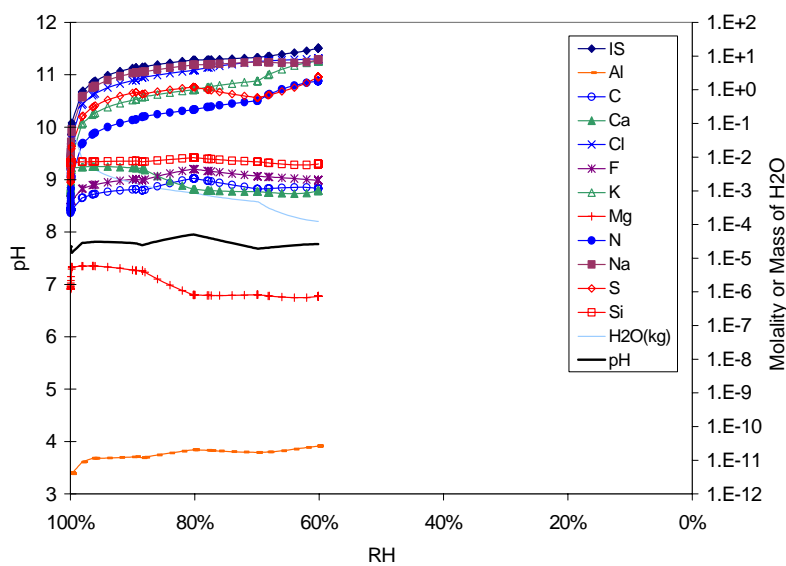

Source: DTN: MO0304SPACSALT.000, 05c3t1e.xIs.xIs.

Figure B-05-3. Bin 05 Aqueous Composition Evaporation Predictions vs. Relative Humidity at $100^{\circ} \mathrm{C}$ and $10^{-3}$ bar $\mathrm{CO}_{2}$ Fugacity

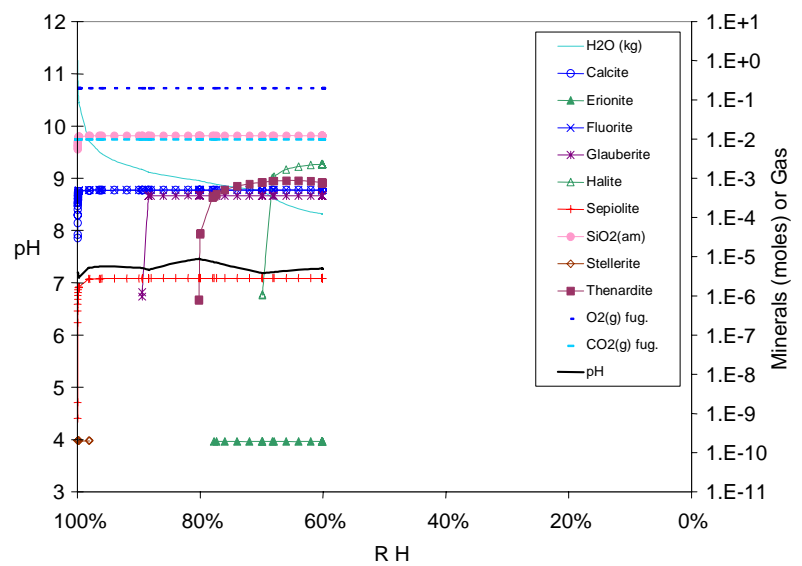

Source: DTN: MO0304SPACSALT.000, 05c2t1e.xIs.x/s.

Figure B-05-2. Bin 05 Mineral Precipitation Evaporation Predictions vs. Relative Humidity at $100^{\circ} \mathrm{C}$ and $10^{-2}$ bar $\mathrm{CO}_{2}$ Fugacity

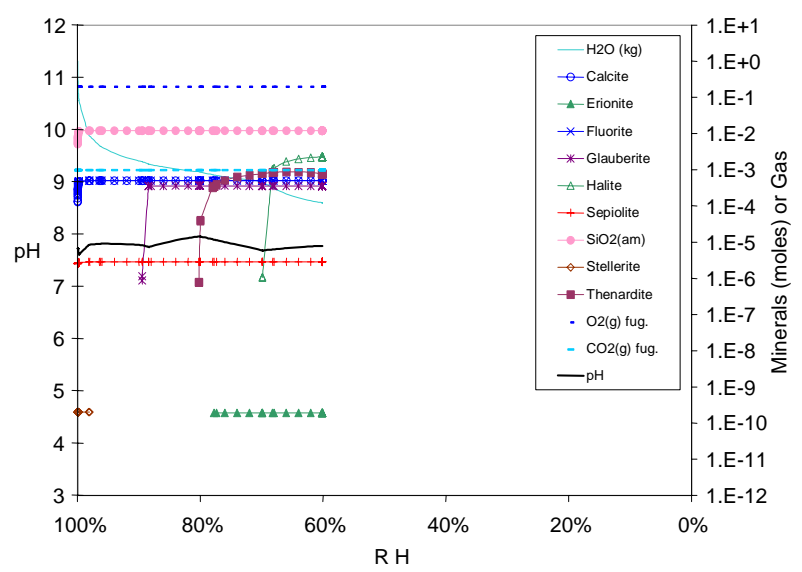

Source: DTN: MO0304SPACSALT.000, 05c3t1e.xls.xls.

Figure B-05-4. Bin 05 Mineral Precipitation Evaporation Predictions vs. Relative Humidity at $100^{\circ} \mathrm{C}$ and $10^{-3}$ bar $\mathrm{CO}_{2}$ Fugacity 


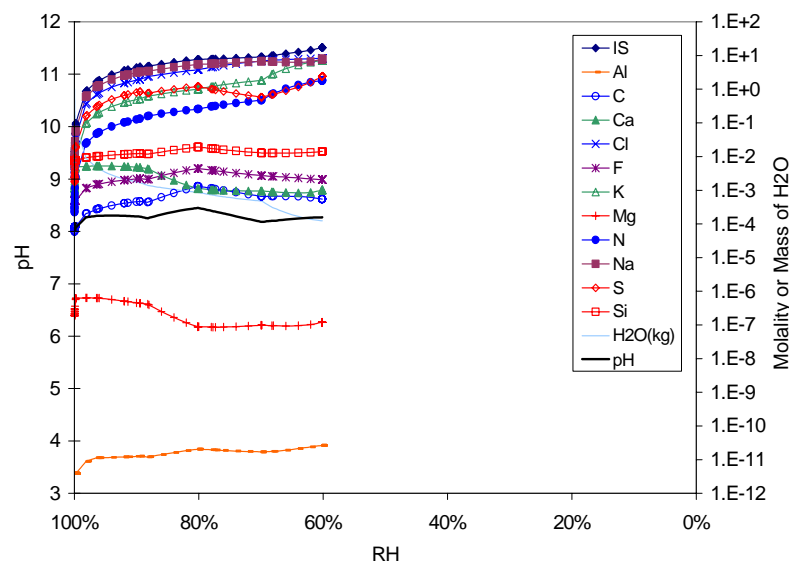

Source: DTN: MO0304SPACSALT.000, 05c4t1e.xIs.xIs.

Figure B-05-5. Bin 05 Aqueous Composition Evaporation Predictions vs. Relative Humidity at $100^{\circ} \mathrm{C}$ and $10^{-4}$ bar $\mathrm{CO}_{2}$ Fugacity

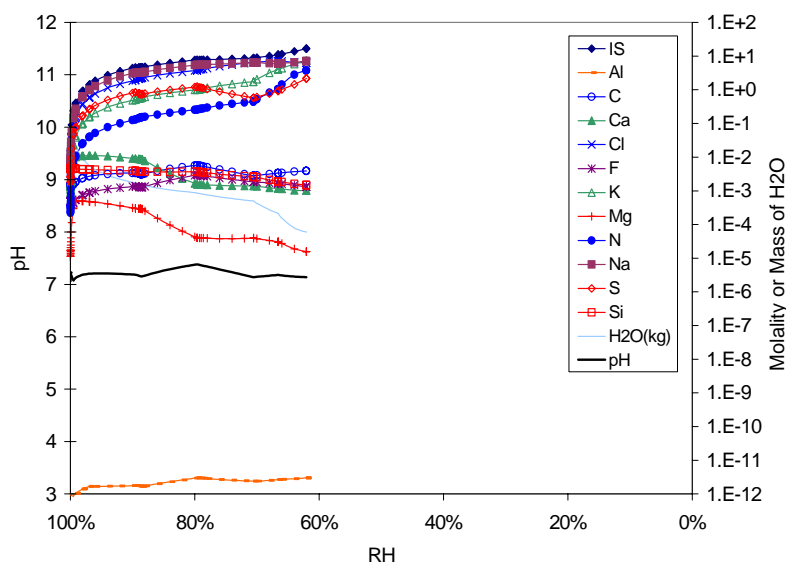

Source: DTN: MO0304SPACSALT.000, 05c2t7e.xIs.xIs.

Figure B-05-7. Bin 05 Aqueous Composition Evaporation Predictions vs. Relative Humidity at $70^{\circ} \mathrm{C}$ and $10^{-2}$ bar $\mathrm{CO}_{2}$ Fugacity

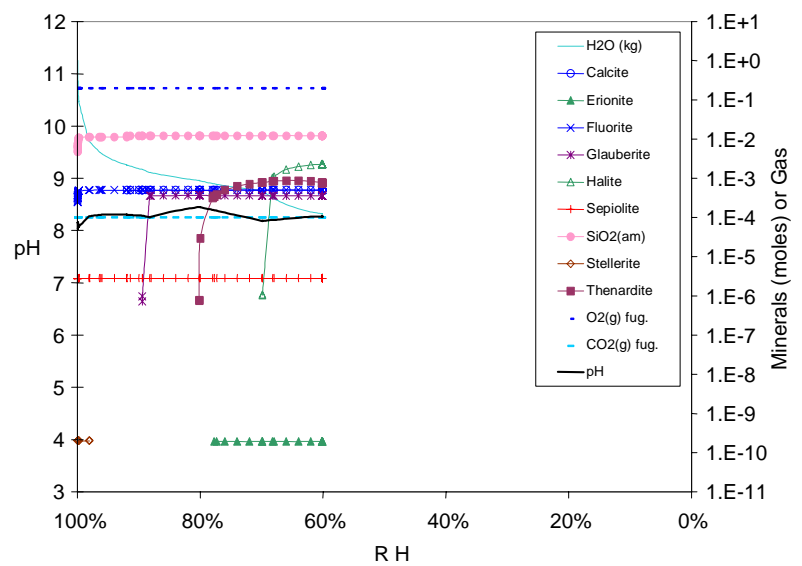

Source: DTN: MO0304SPACSALT.000, 05c4t1e.xIs.xIs.

Figure B-05-6. Bin 05 Mineral Precipitation Evaporation Predictions vs. Relative Humidity at $100^{\circ} \mathrm{C}$ and $10^{-4}$ bar $\mathrm{CO}_{2}$ Fugacity

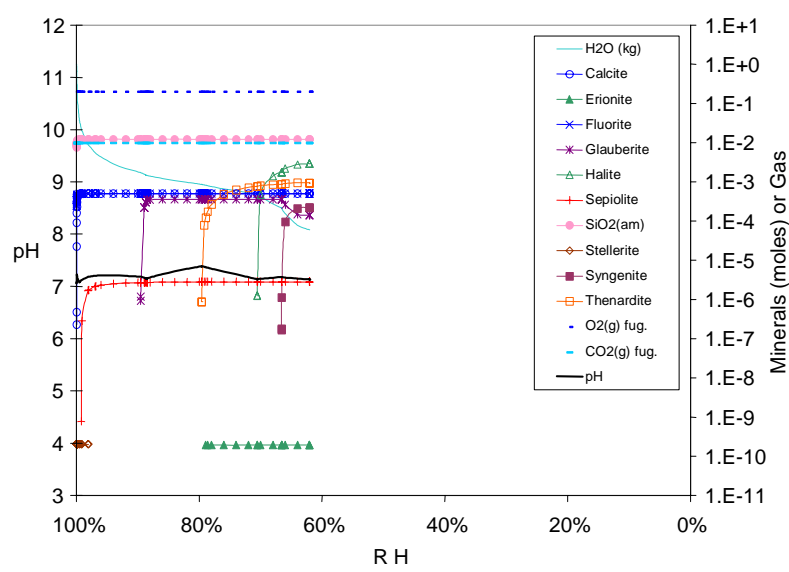

Source: DTN: MO0304SPACSALT.000, 05c2t7e.xIs.xIs.

Figure B-05-8. Bin 05 Mineral Precipitation Evaporation Predictions vs. Relative Humidity at $70^{\circ} \mathrm{C}$ and $10^{-2}$ bar $\mathrm{CO}_{2}$ Fugacity 


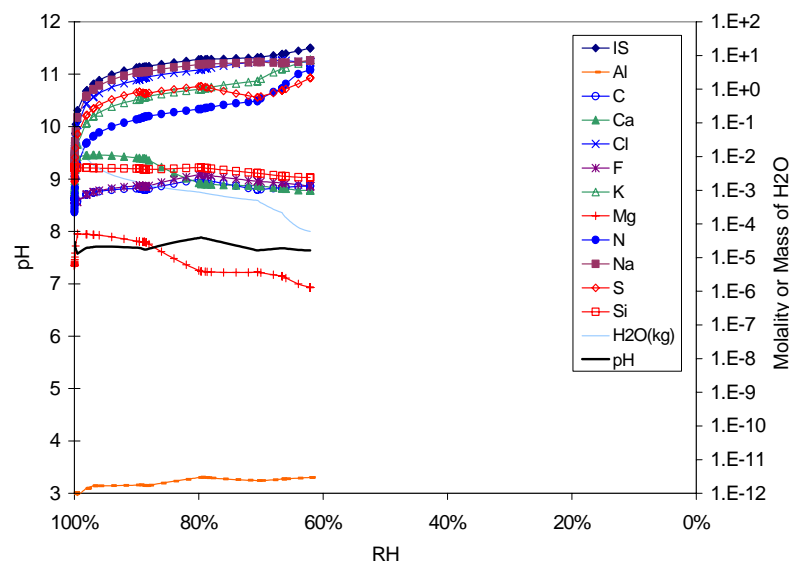

Source: DTN: MO0304SPACSALT.000, 05c3t7e.xls.xls.

Figure B-05-9. Bin 05 Aqueous Composition Evaporation Predictions vs. Relative Humidity at $70^{\circ} \mathrm{C}$ and $10^{-3}$ bar $\mathrm{CO}_{2}$ Fugacity

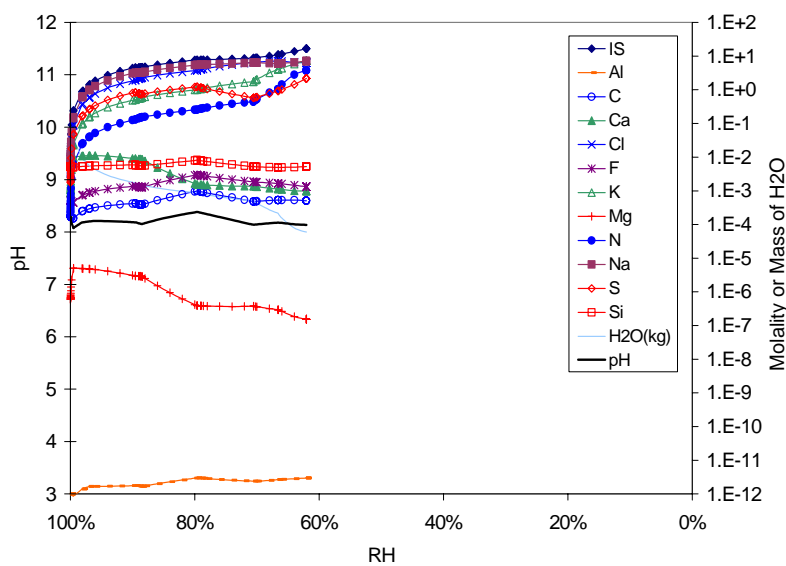

Source: DTN: MO0304SPACSALT.000, 05c4t7e.xIs.xls.

Figure B-05-11. Bin 05 Aqueous Composition Evaporation Predictions vs. Relative Humidity at $70^{\circ} \mathrm{C}$ and $10^{-4}$ bar $\mathrm{CO}_{2}$ Fugacity

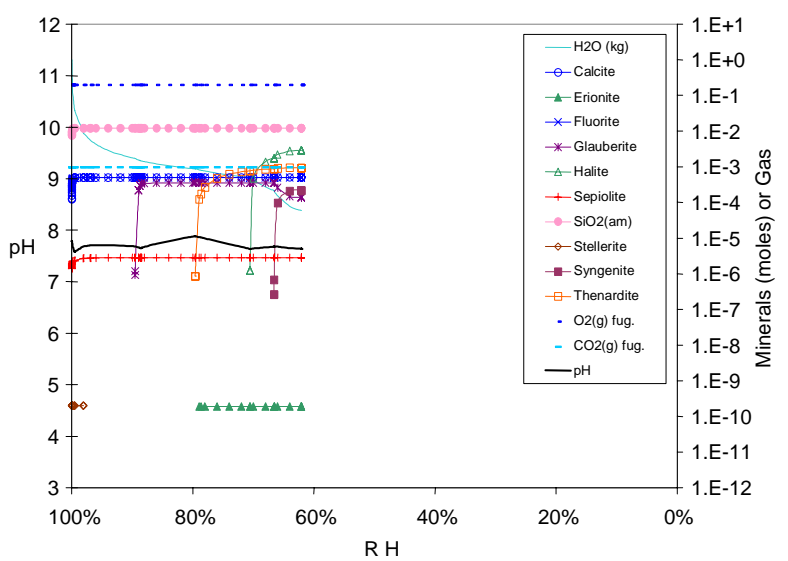

Source: DTN: MO0304SPACSALT.000, 05c3t7e.xls.xls.

Figure B-05-10. Bin 05 Mineral Precipitation Evaporation Predictions vs. Relative Humidity at $70^{\circ} \mathrm{C}$ and $10^{-3}$ bar $\mathrm{CO}_{2}$ Fugacity

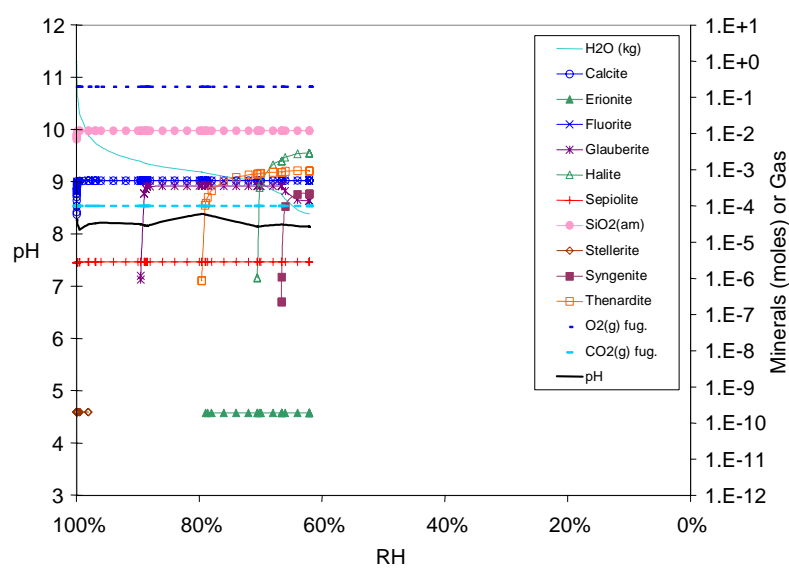

Source: DTN: MO0304SPACSALT.000, 05c4t7e.xls.xls.

Figure B-05-12. Bin 05 Mineral Precipitation Evaporation Predictions vs. Relative Humidity at $70^{\circ} \mathrm{C}$ and $10^{-4}$ bar $\mathrm{CO}_{2}$ Fugacity 


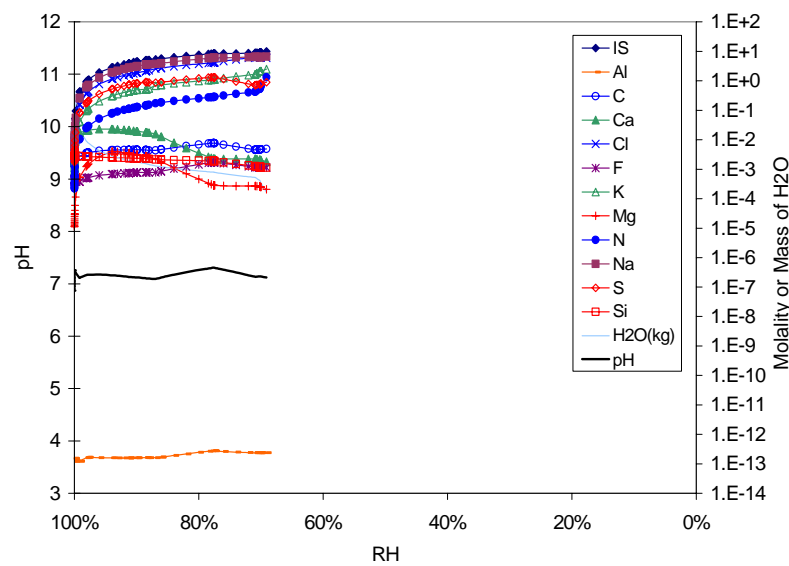

Source: DTN: MO0304SPACSALT.000, 05c2t4e.xIs.xIs.

Figure B-05-13. Bin 05 Aqueous Composition Evaporation Predictions vs. Relative Humidity at $40^{\circ} \mathrm{C}$ and $10^{-2}$ bar $\mathrm{CO}_{2}$ Fugacity

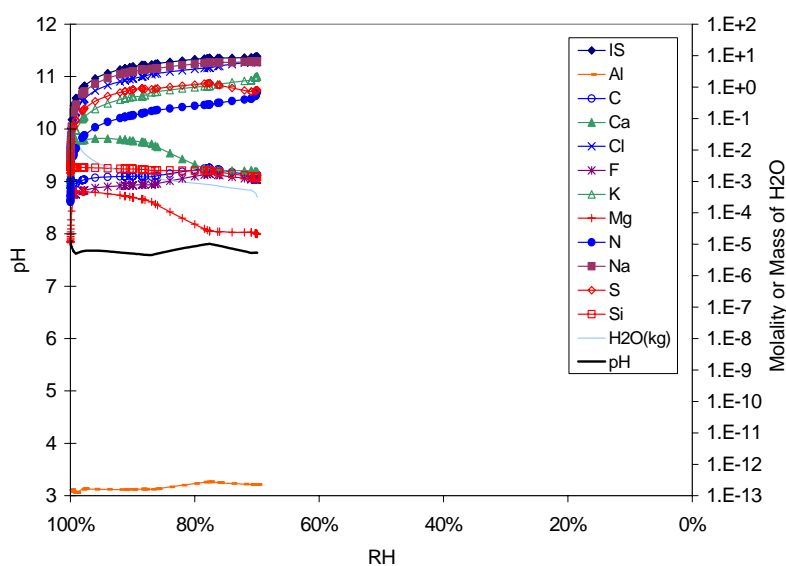

Source: DTN: M00304SPACSALT.000, 05c3t4e.xIs.xls.

Figure B-05-15. Bin 05 Aqueous Composition Evaporation Predictions vs. Relative Humidity at $40^{\circ} \mathrm{C}$ and $10^{-3}$ bar $\mathrm{CO}_{2}$ Fugacity

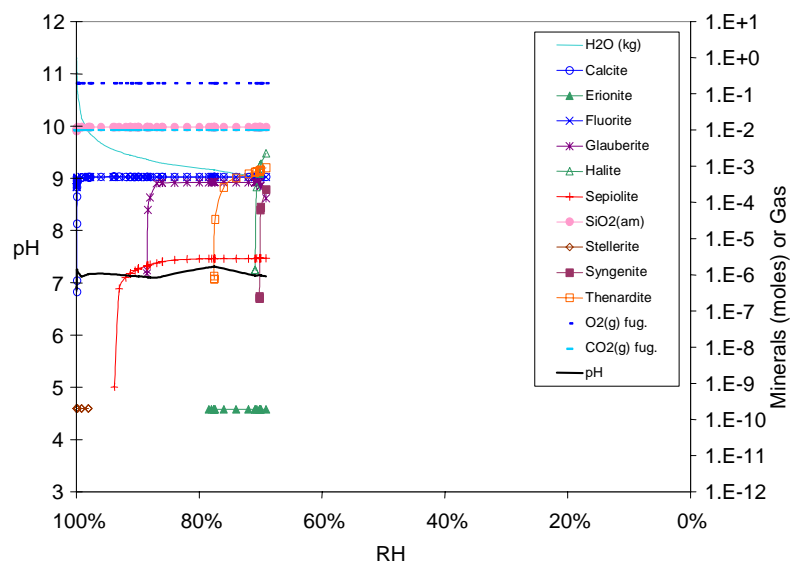

Source: DTN: MO0304SPACSALT.000, 05c2t4e.xIs.xIs.

Figure B-05-14. Bin 05 Mineral Precipitation Evaporation Predictions vs. Relative Humidity at $40^{\circ} \mathrm{C}$ and $10^{-2}$ bar $\mathrm{CO}_{2}$ Fugacity

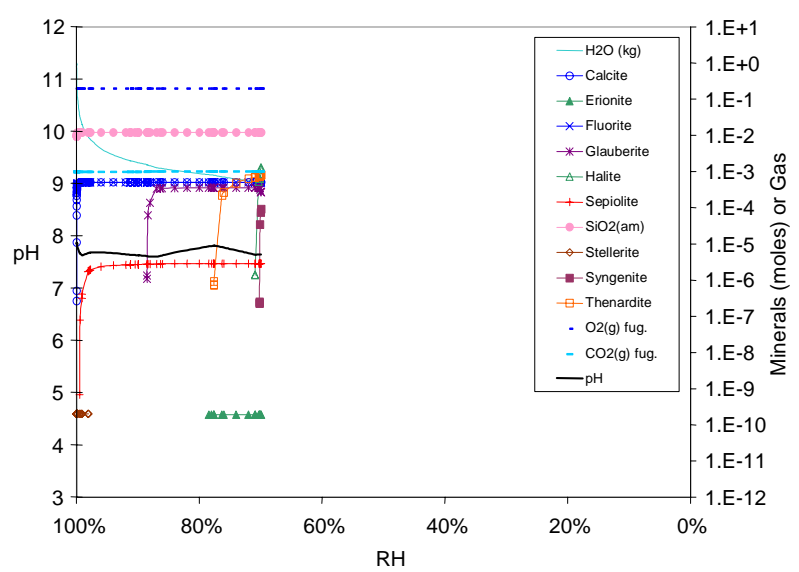

Source: DTN: MO0304SPACSALT.000, 05c3t4e.xIs.xIs.

Figure B-05-16. Bin 05 Mineral Precipitation Evaporation Predictions vs. Relative Humidity at $40^{\circ} \mathrm{C}$ and $10^{-3}$ bar $\mathrm{CO}_{2}$ Fugacity 


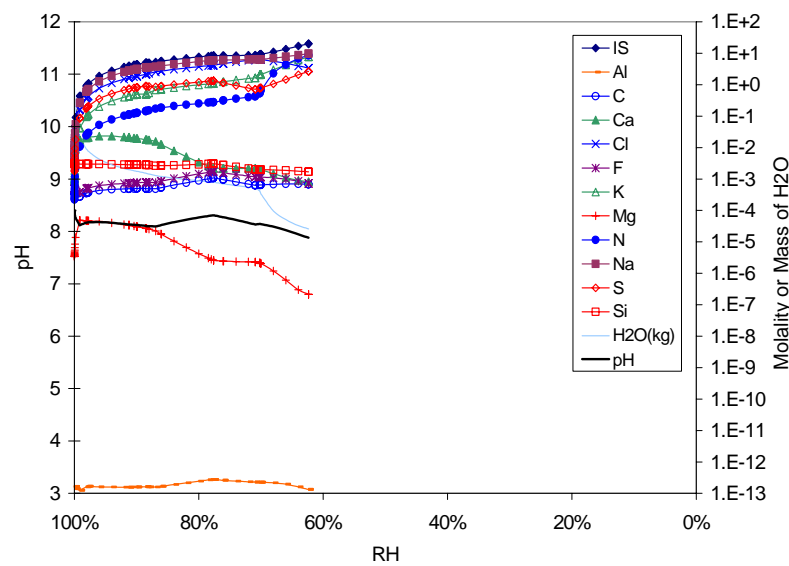

Source: DTN: MO0304SPACSALT.000, 05c4t4e.xIs.xIs.

Figure B-05-17. Bin 05 Aqueous Composition Evaporation Predictions vs. Relative Humidity at $40^{\circ} \mathrm{C}$ and $10^{-4}$ bar $\mathrm{CO}_{2}$ Fugacity

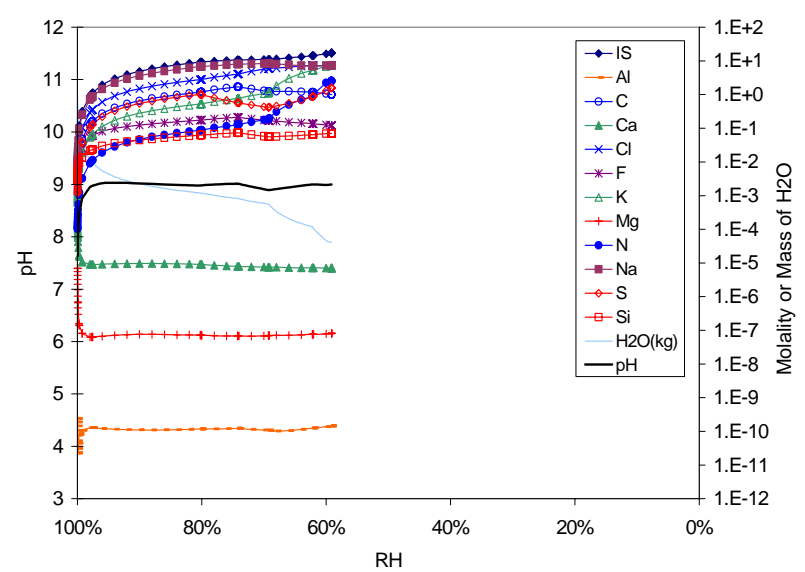

Source: DTN: MO0304SPACSALT.000, 06c2t1e.xls.xls.

Figure B-06-1. Bin 06 Aqueous Composition Evaporation Predictions vs. Relative Humidity at $100^{\circ} \mathrm{C}$ and $10^{-2}$ bar $\mathrm{CO}_{2}$ Fugacity

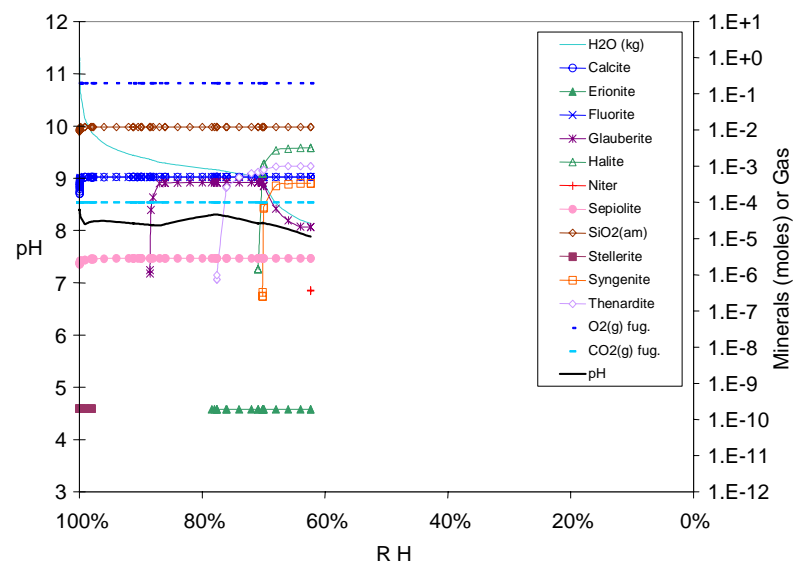

Source: DTN: MO0304SPACSALT.000, 05c4t4e.xIs.xIs.

Figure B-05-18. Bin 05 Mineral Precipitation Evaporation Predictions vs. Relative Humidity at $40^{\circ} \mathrm{C}$ and $10^{-4}$ bar $\mathrm{CO}_{2}$ Fugacity

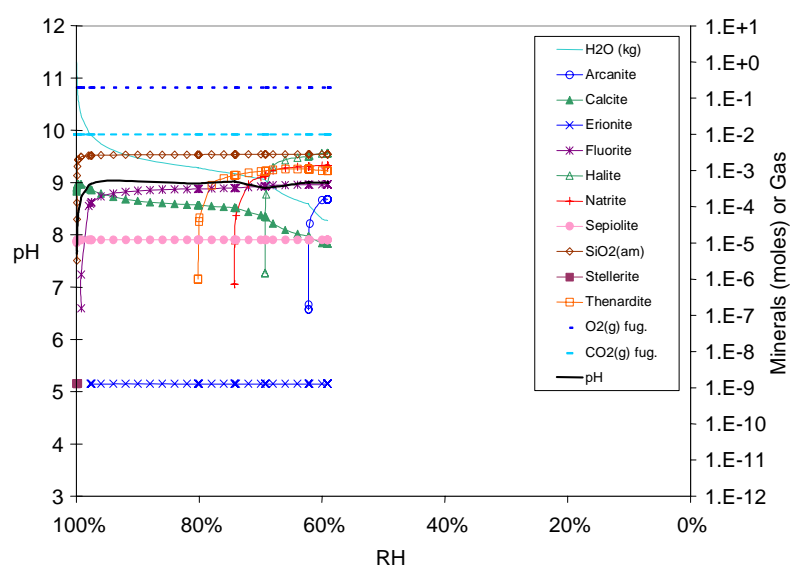

Source: DTN: MO0304SPACSALT.000, 06c2t1e.xIs.xIs.

Figure B-06-2. Bin 06 Mineral Precipitation Evaporation Predictions vs. Relative Humidity at $100^{\circ} \mathrm{C}$ and $10^{-2}$ bar $\mathrm{CO}_{2}$ Fugacity 


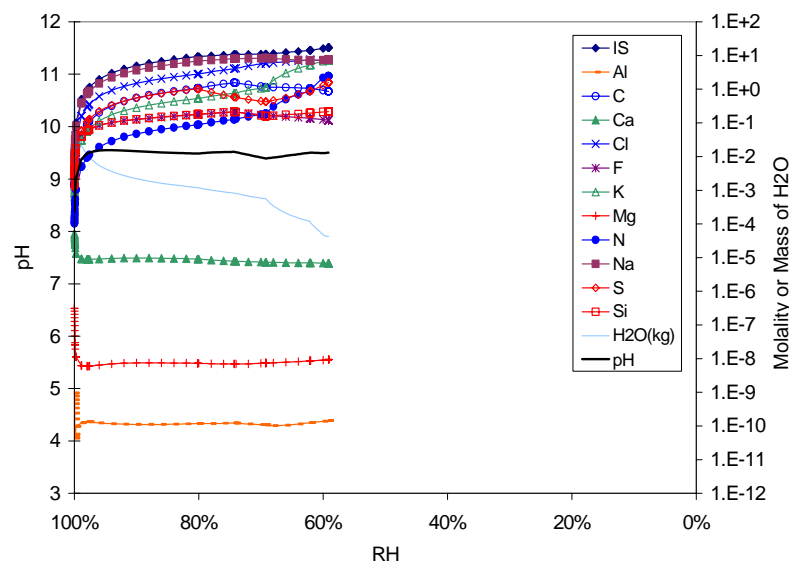

Source: DTN: MO0304SPACSALT.000, 06c3t1e.xIs.xIs.

Figure B-06-3. Bin 06 Aqueous Composition Evaporation Predictions vs. Relative Humidity at $100^{\circ} \mathrm{C}$ and $10^{-3}$ bar $\mathrm{CO}_{2}$ Fugacity

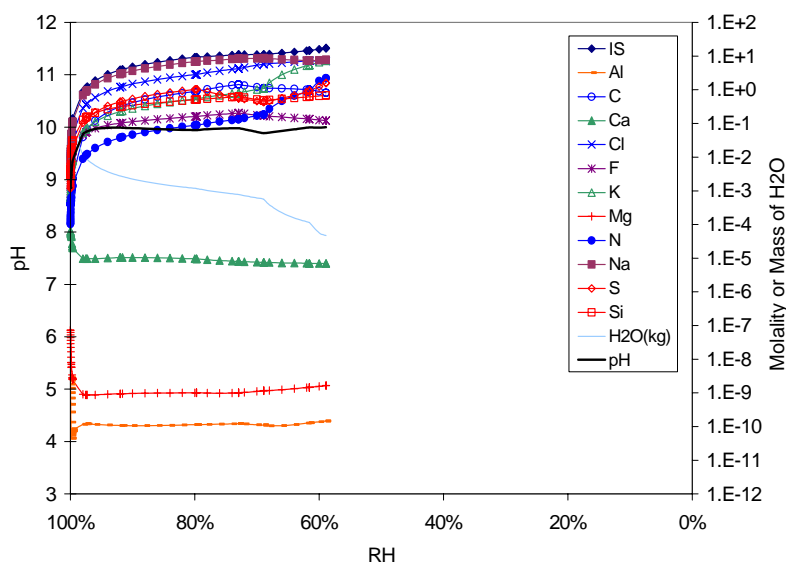

Source: DTN: MO0304SPACSALT.000, 06c4t1e.xIs.xIs.

Figure B-06-5. Bin 06 Aqueous Composition Evaporation Predictions vs. Relative Humidity at $100^{\circ} \mathrm{C}$ and $10^{-4}$ bar $\mathrm{CO}_{2}$ Fugacity

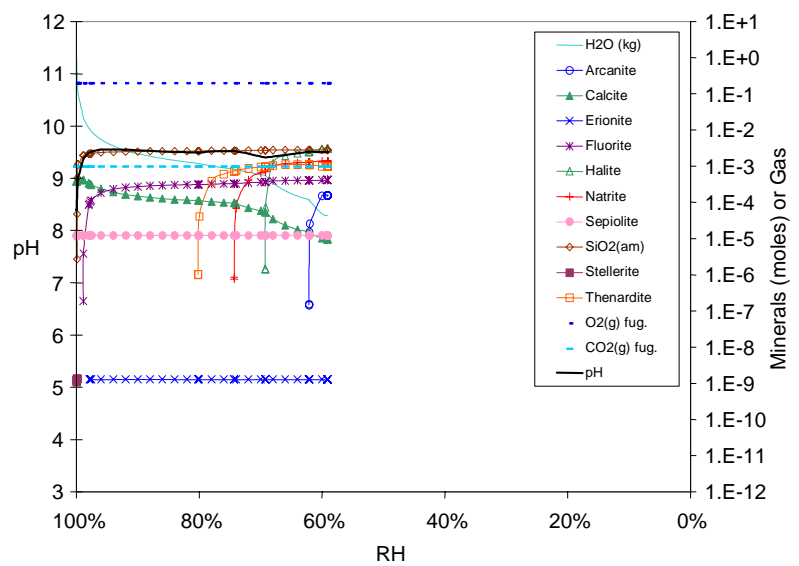

Source: DTN: MO0304SPACSALT.000, 06c3t1e.xIs.xIs.

Figure B-06-4. Bin 06 Mineral Precipitation Evaporation Predictions vs. Relative Humidity at $100^{\circ} \mathrm{C}$ and $10^{-3}$ bar $\mathrm{CO}_{2}$ Fugacity

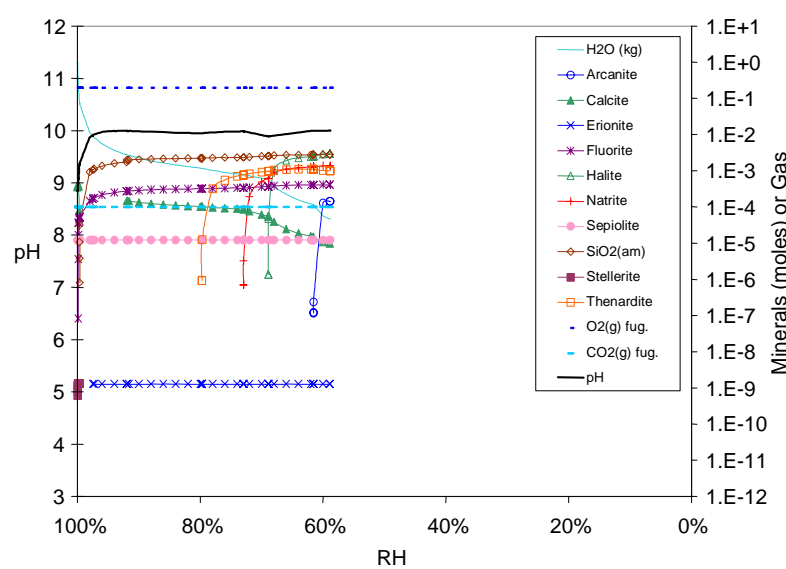

Source: DTN: MO0304SPACSALT.000, 06c4t1e.xIs.xIs.

Figure B-06-6. Bin 06 Mineral Precipitation Evaporation Predictions vs. Relative Humidity at $100^{\circ} \mathrm{C}$ and $10^{-4}$ bar $\mathrm{CO}_{2}$ Fugacity 


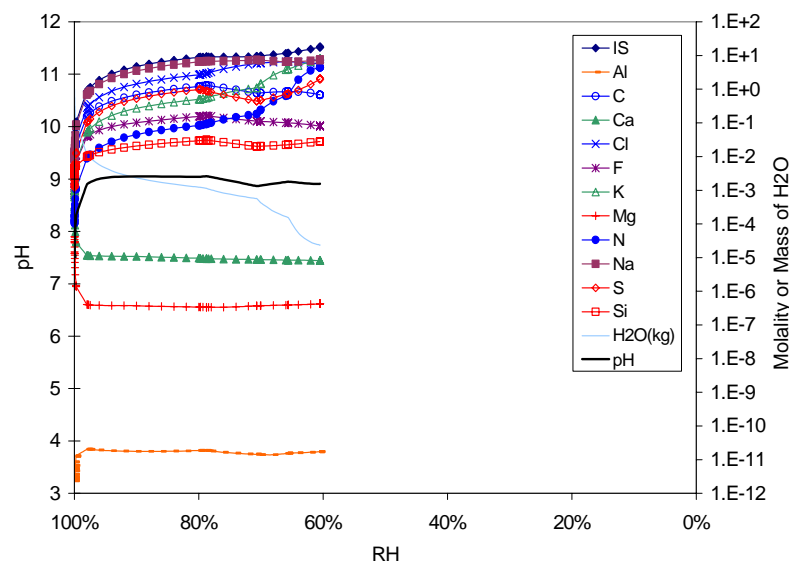

Source: DTN: MO0304SPACSALT.000, 06c2t7e.xIs.xIs.

Figure B-06-7. Bin 06 Aqueous Composition Evaporation Predictions vs. Relative Humidity at $70^{\circ} \mathrm{C}$ and $10^{-2}$ bar $\mathrm{CO}_{2}$ Fugacity

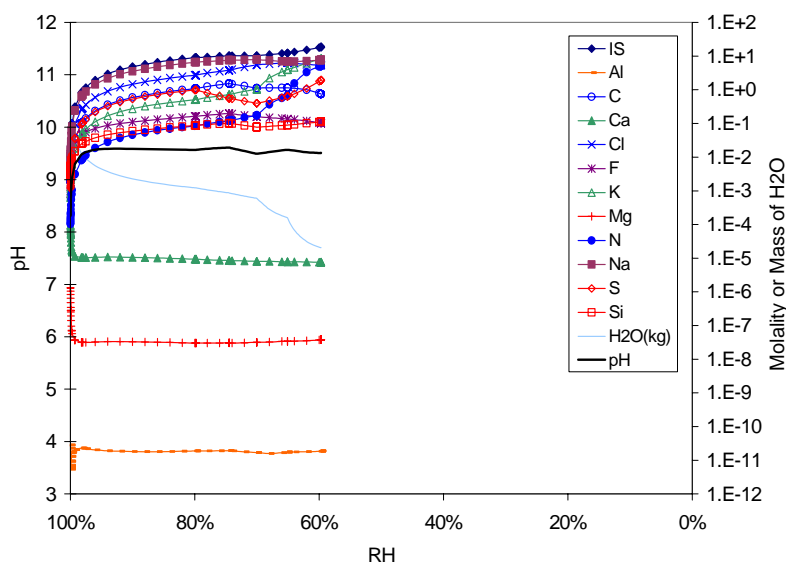

Source: DTN: MO0304SPACSALT.000, 06c3t7e.xIs.xIs.

Figure B-06-9. Bin 06 Aqueous Composition Evaporation Predictions vs. Relative Humidity at $70^{\circ} \mathrm{C}$ and $10^{-3}$ bar $\mathrm{CO}_{2}$ Fugacity

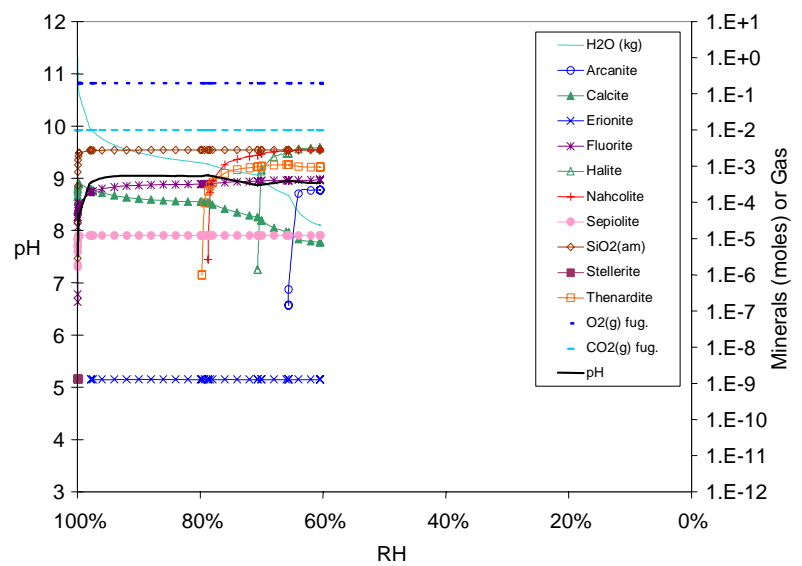

Source: DTN: MO0304SPACSALT.000, 06c2t7e.xIs.xIs.

Figure B-06-8. Bin 06 Mineral Precipitation Evaporation Predictions vs. Relative Humidity at $70^{\circ} \mathrm{C}$ and $10^{-2}$ bar $\mathrm{CO}_{2}$ Fugacity

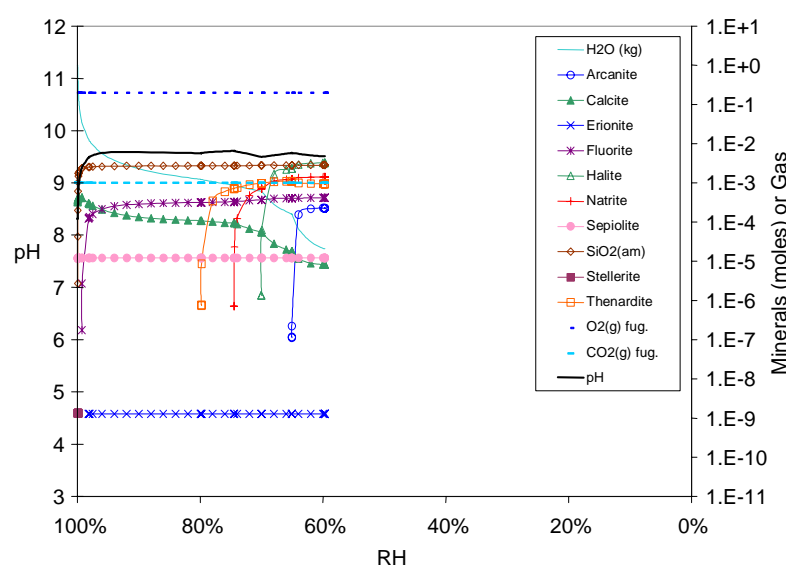

Source: DTN: MO0304SPACSALT.000, 06c3t7e.xIs.xIs.

Figure B-06-10. Bin 06 Mineral Precipitation Evaporation Predictions vs. Relative Humidity at $70^{\circ} \mathrm{C}$ and $10^{-3}$ bar $\mathrm{CO}_{2}$ Fugacity 


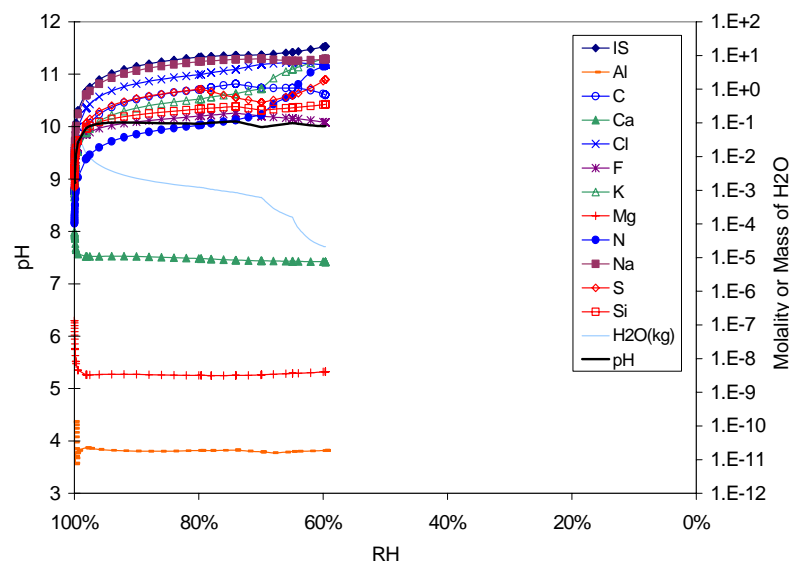

Source: DTN: MO0304SPACSALT.000, 06c4t7e.xIs.xIs.

Figure B-06-11. Bin 06 Aqueous Composition Evaporation Predictions vs. Relative Humidity at $70^{\circ} \mathrm{C}$ and $10^{-4}$ bar $\mathrm{CO}_{2}$ Fugacity

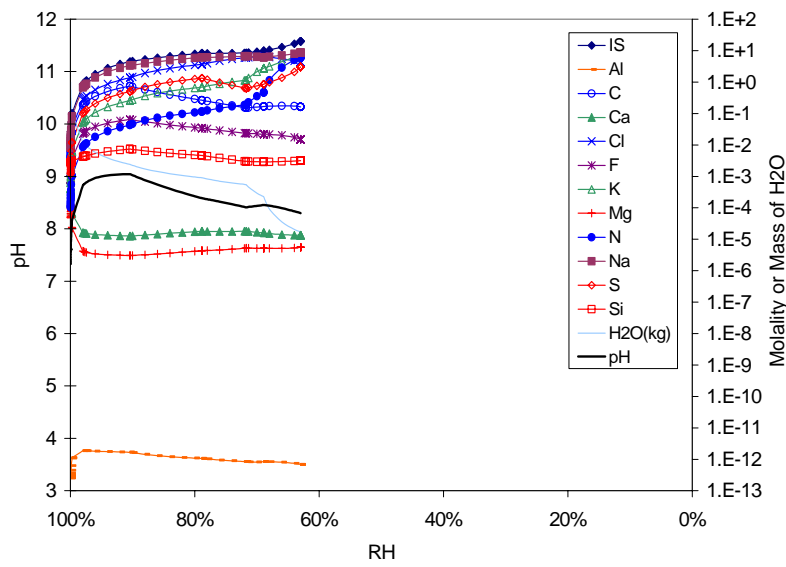

Source: DTN: M00304SPACSALT.000, 06c2t4e.xIs.xls.

Figure B-06-13. Bin 06 Aqueous Composition Evaporation Predictions vs. Relative Humidity at $40^{\circ} \mathrm{C}$ and $10^{-2}$ bar $\mathrm{CO}_{2}$ Fugacity

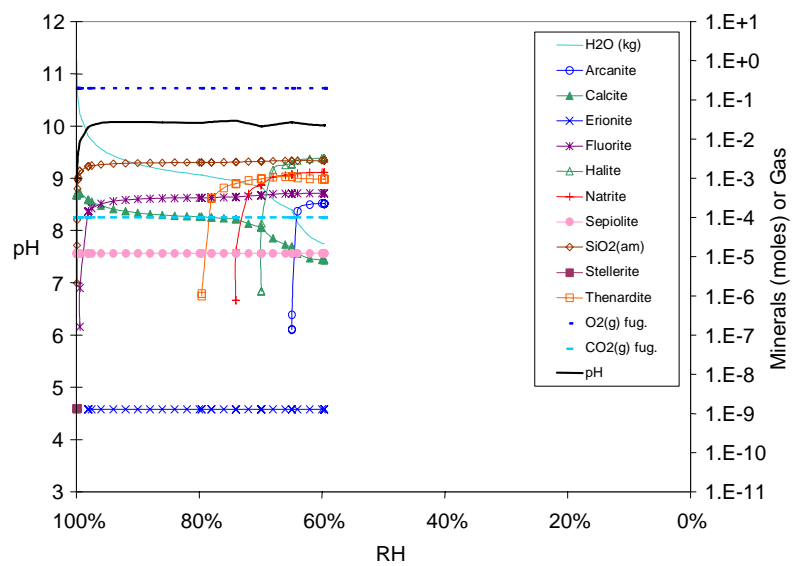

Source: DTN: MO0304SPACSALT.000, 06c4t7e.xIs.xIs.

Figure B-06-12. Bin 06 Mineral Precipitation Evaporation Predictions vs. Relative Humidity at $70^{\circ} \mathrm{C}$ and $10^{-4}$ bar $\mathrm{CO}_{2}$ Fugacity

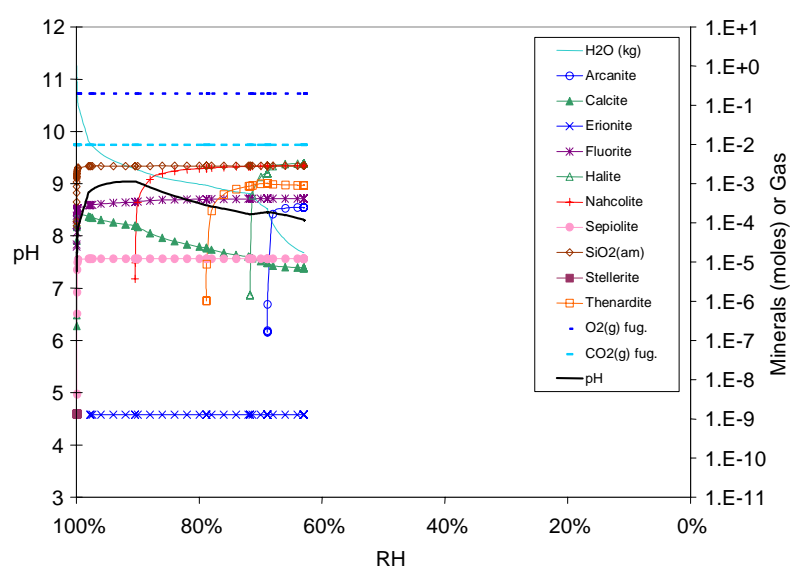

Source: DTN: MO0304SPACSALT.000, 06c2t4e.xIs.xIs.

Figure B-06-14. Bin 06 Mineral Precipitation Evaporation Predictions vs. Relative Humidity at $40^{\circ} \mathrm{C}$ and $10^{-2}$ bar $\mathrm{CO}_{2}$ Fugacity 


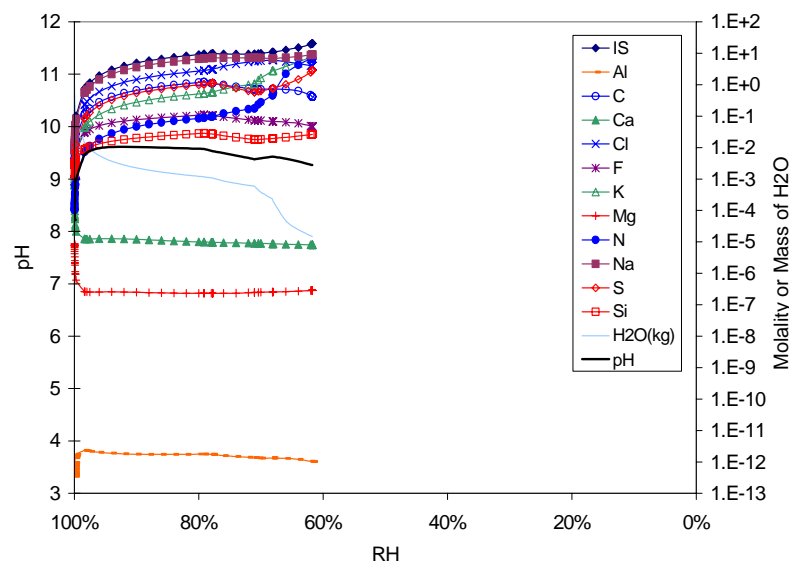

Source: DTN: MO0304SPACSALT.000, 06c3t4e.xIs.xIs.

Figure B-06-15. Bin 06 Aqueous Composition Evaporation Predictions vs. Relative Humidity at $40^{\circ} \mathrm{C}$ and $10^{-3}$ bar $\mathrm{CO}_{2}$ Fugacity

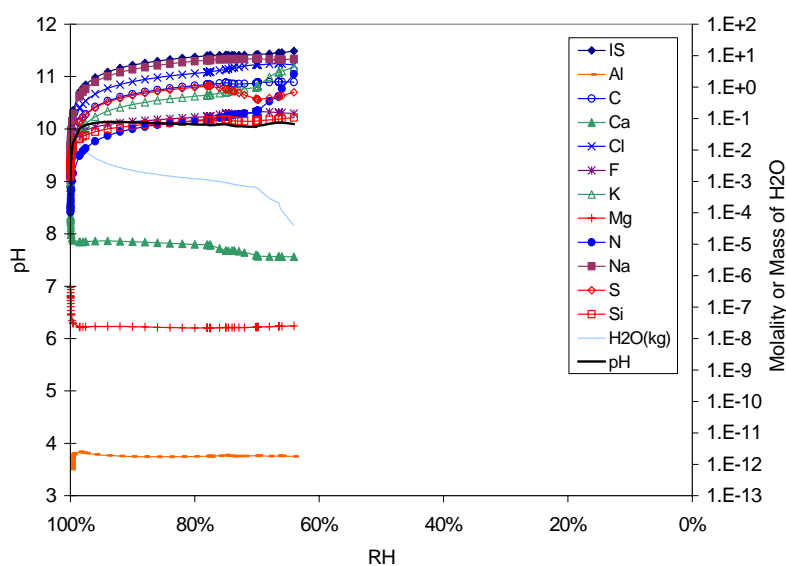

Source: DTN: M00304SPACSALT.000, 06c4t4e.xIs.xIs.

Figure B-06-17. Bin 06 Aqueous Composition Evaporation Predictions vs. Relative Humidity at $40^{\circ} \mathrm{C}$ and $10^{-4}$ bar $\mathrm{CO}_{2}$ Fugacity

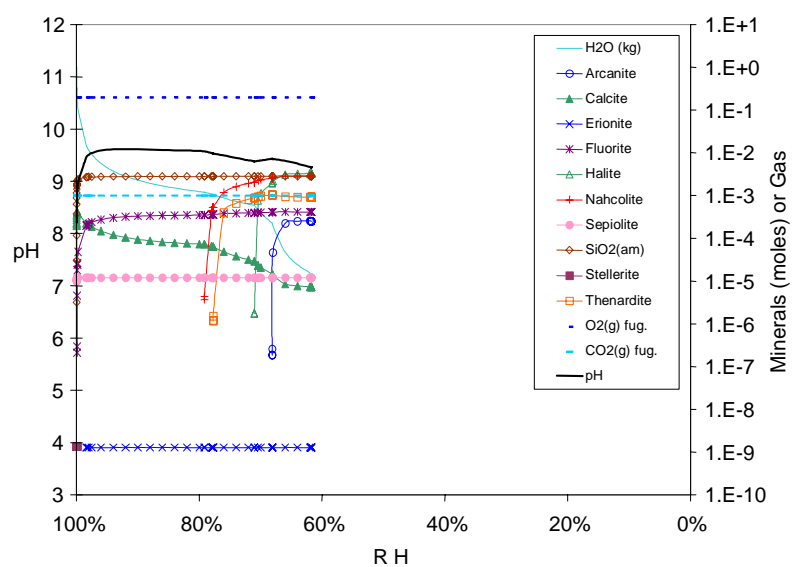

Source: DTN: MO0304SPACSALT.000, 06c3t4e.xIs.xIs.

Figure B-06-16. Bin 06 Mineral Precipitation Evaporation Predictions vs. Relative Humidity at $40^{\circ} \mathrm{C}$ and $10^{-3}$ bar $\mathrm{CO}_{2}$ Fugacity

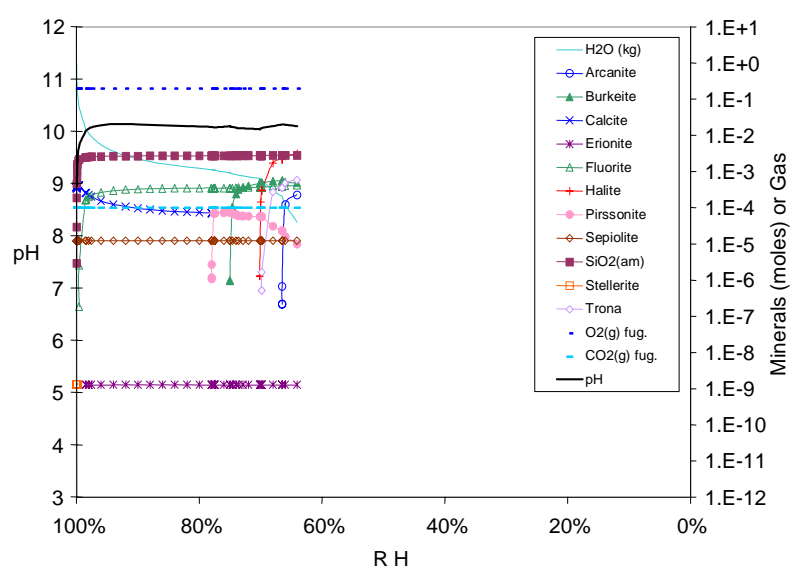

Source: DTN: MO0304SPACSALT.000, 06c4t4e.xIs.xls.

Figure B-06-18. Bin 06 Mineral Precipitation Evaporation Predictions vs. Relative Humidity at $40^{\circ} \mathrm{C}$ and $10-4$ bar $\mathrm{CO}_{2}$ Fugacity 


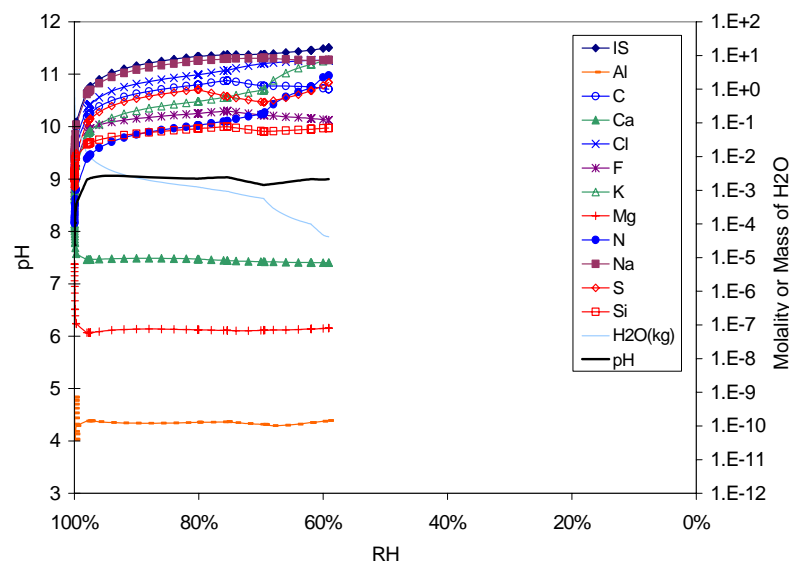

Source: DTN: M00304SPACSALT.000, 07c2t1e.xIs.xIs.

Figure B-07-1. Bin 07 Aqueous Composition Evaporation Predictions vs. Relative Humidity at $100^{\circ} \mathrm{C}$ and $10^{-2}$ bar $\mathrm{CO}_{2}$ Fugacity

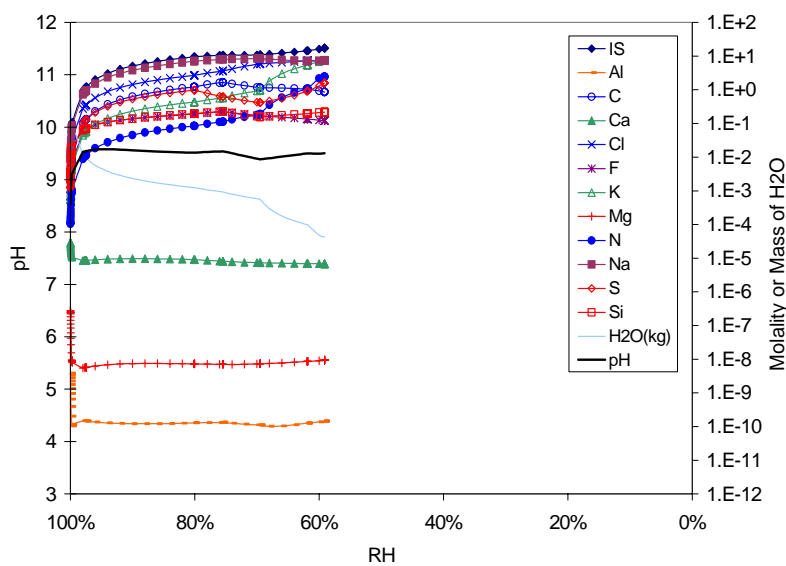

Source: DTN: M00304SPACSALT.000, 07c3t1e.xIs.xIs.

Figure B-07-3. Bin 07 Aqueous Composition Evaporation Predictions vs. Relative Humidity at $100^{\circ} \mathrm{C}$ and $10^{-3}$ bar $\mathrm{CO}_{2}$ Fugacity

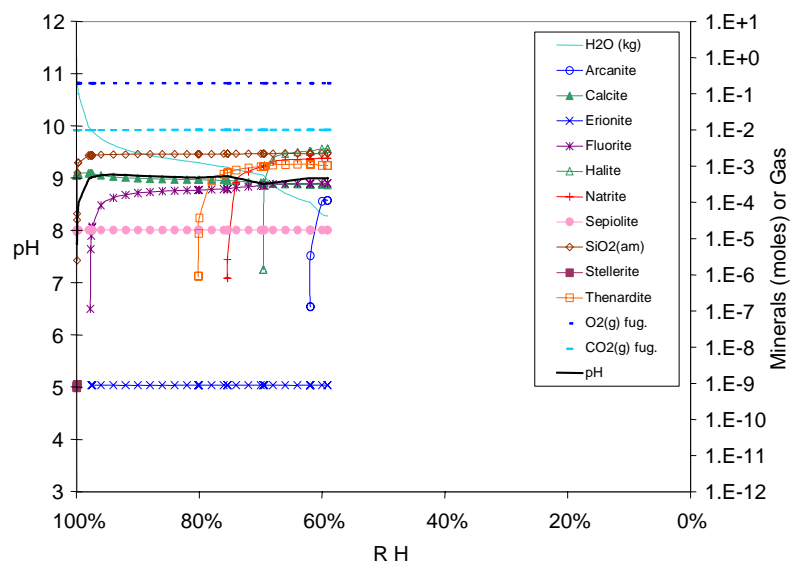

Source: DTN: MO0304SPACSALT.000, 07c2t1e.xls.xIs.

Figure B-07-2. Bin 07 Mineral Precipitation Evaporation Predictions vs. Relative Humidity at $100^{\circ} \mathrm{C}$ and $10^{-2}$ bar $\mathrm{CO}_{2}$ Fugacity

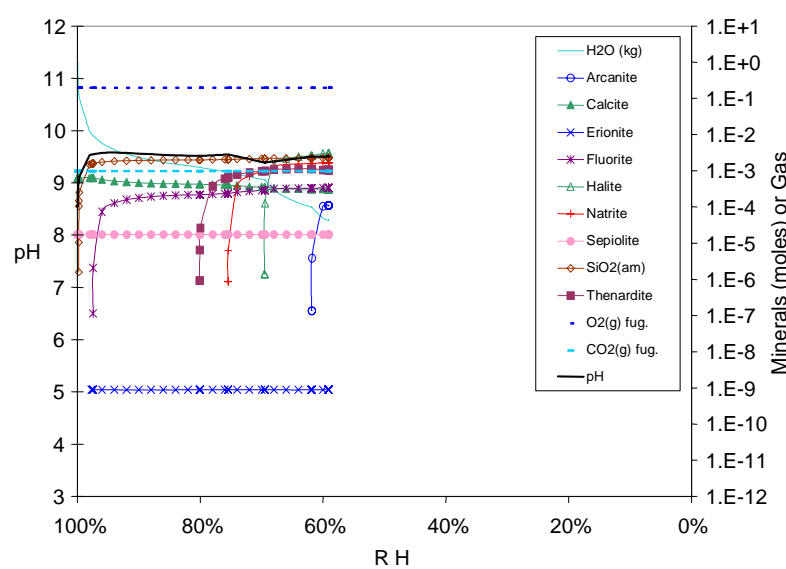

Source: DTN: MO0304SPACSALT.000, 07c3t1e.xIs.xIs.

Figure B-07-4. Bin 07 Mineral Precipitation Evaporation Predictions vs. Relative Humidity at $100^{\circ} \mathrm{C}$ and $10^{-3}$ bar $\mathrm{CO}_{2}$ Fugacity 


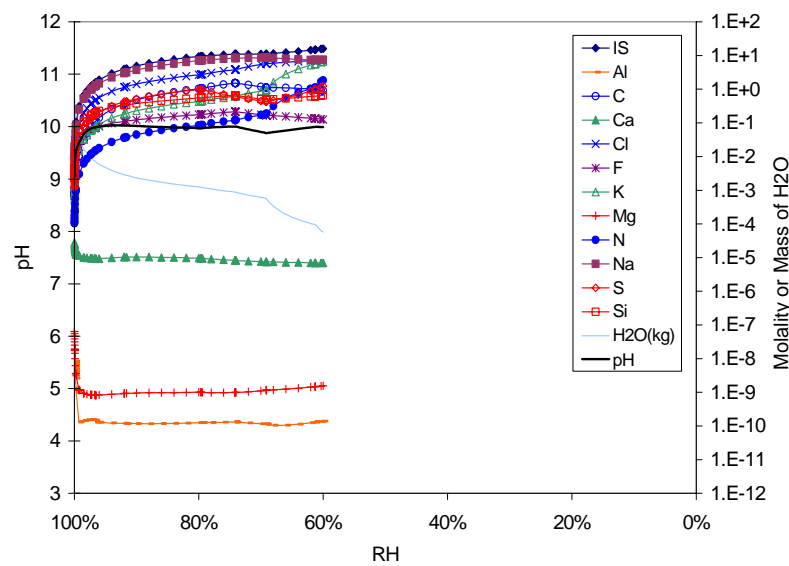

Source: DTN: M00304SPACSALT.000, 07c4t1e.xIs.xIs.

Figure B-07-5. Bin 07 Aqueous Composition Evaporation Predictions vs. Relative Humidity at $100^{\circ} \mathrm{C}$ and $10^{-4}$ bar $\mathrm{CO}_{2}$ Fugacity

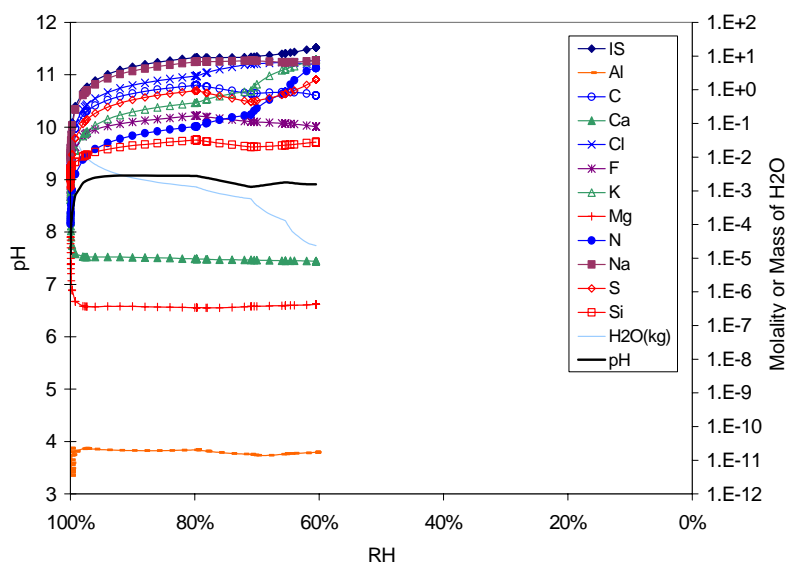

Source: DTN: MO0304SPACSALT.000, 07c2t7e.xIs.xIs.

Figure B-07-7. Bin 07 Aqueous Composition Evaporation Predictions vs. Relative Humidity at $70^{\circ} \mathrm{C}$ and $10^{-2}$ bar $\mathrm{CO}_{2}$ Fugacity

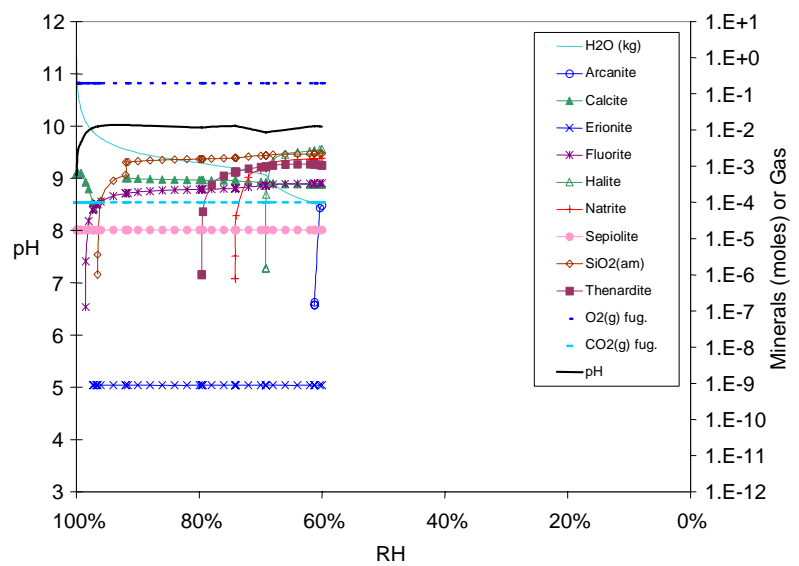

Source: DTN: MO0304SPACSALT.000, 07c4t1e.xIs.xIs.

Figure B-07-6. Bin 07 Mineral Precipitation Evaporation Predictions vs. Relative Humidity at $100^{\circ} \mathrm{C}$ and $10^{-4}$ bar $\mathrm{CO}_{2}$ Fugacity

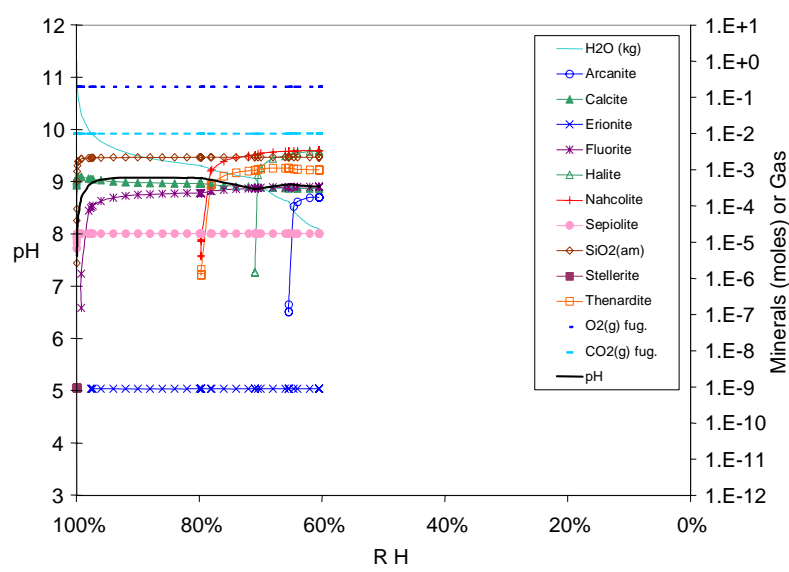

Source: DTN: MO0304SPACSALT.000, 07c2t7e.xIs.xIs.

Figure B-07-8. Bin 07 Mineral Precipitation Evaporation Predictions vs. Relative Humidity at $70^{\circ} \mathrm{C}$ and $10^{-2}$ bar $\mathrm{CO}_{2}$ Fugacity 


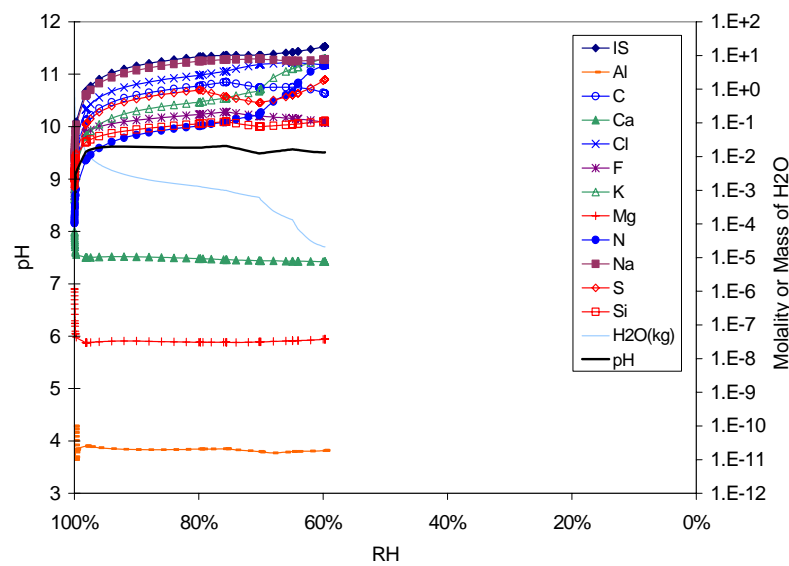

Source: DTN: M00304SPACSALT.000, 07c3t7e.xIs.xIs.

Figure B-07-9. Bin 07 Aqueous Composition Evaporation Predictions vs. Relative Humidity at $70^{\circ} \mathrm{C}$ and $10^{-3}$ bar $\mathrm{CO}_{2}$ Fugacity

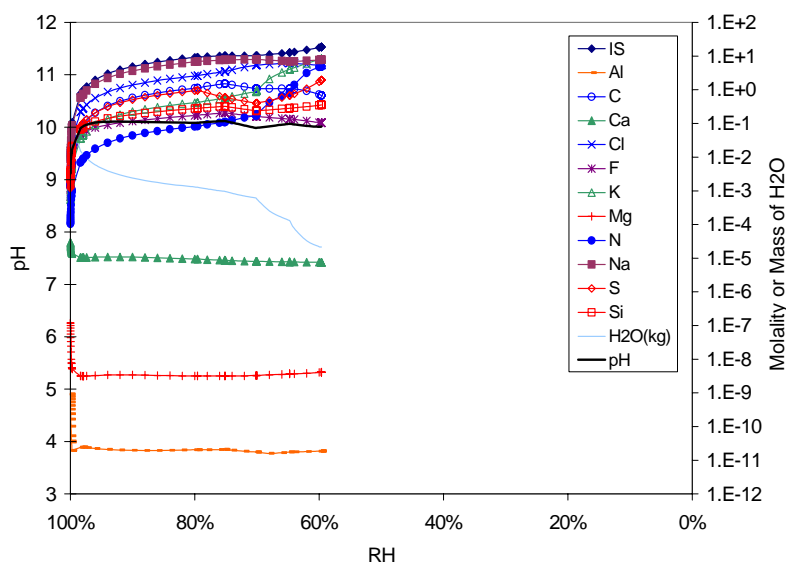

Source: DTN: MO0304SPACSALT.000, 07c4t7e.xIs.xIs.

Figure B-07-11. Bin 07 Aqueous Composition Evaporation Predictions vs. Relative Humidity at $70^{\circ} \mathrm{C}$ and $10^{-4}$ bar $\mathrm{CO}_{2}$ Fugacity

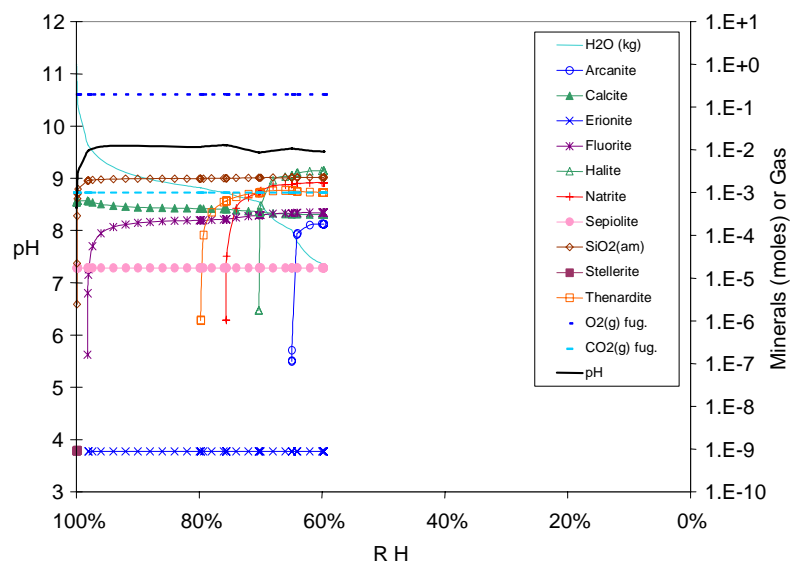

Source: DTN: MO0304SPACSALT.000, 07c3t7e.xIs.xIs.

Figure B-07-10. Bin 07 Mineral Precipitation Evaporation Predictions vs. Relative Humidity at $70^{\circ} \mathrm{C}$ and $10^{-3}$ bar $\mathrm{CO}_{2}$ Fugacity

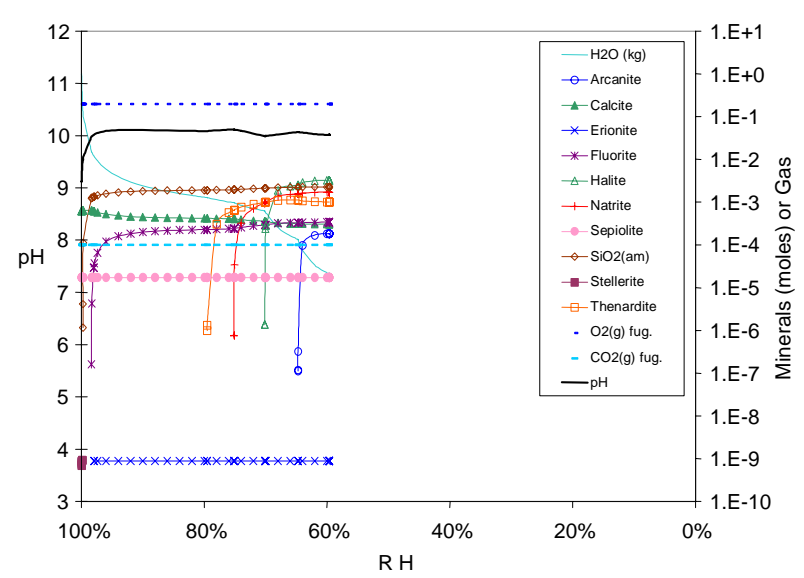

Source: DTN: M00304SPACSALT.000, 07c4t7e.xIs.xIs.

Figure B-07-12. Bin 07 Mineral Precipitation Evaporation Predictions vs. Relative Humidity at $70^{\circ} \mathrm{C}$ and $10^{-4}$ bar $\mathrm{CO}_{2}$ Fugacity 


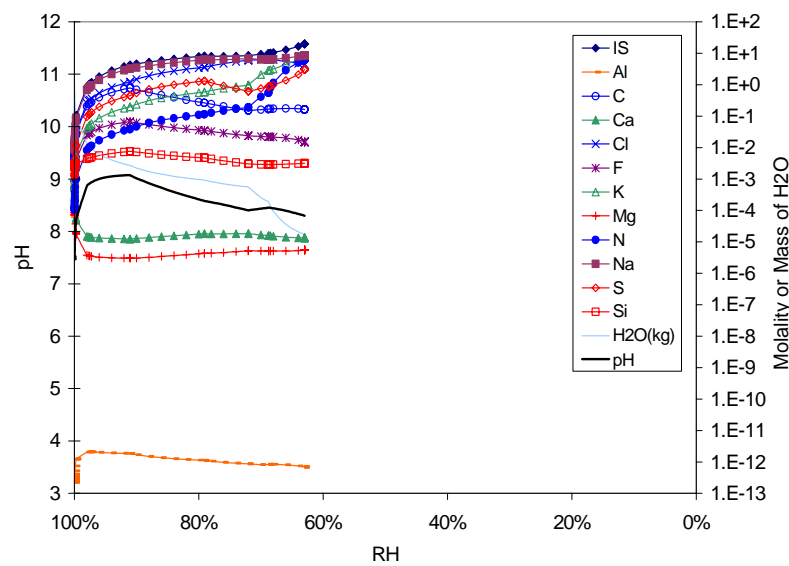

Source: DTN: MO0304SPACSALT.000, 07c2t4e.xIs.xIs.

Figure B-07-13. Bin 07 Aqueous Composition Evaporation Predictions vs. Relative Humidity at $40^{\circ} \mathrm{C}$ and $10^{-2}$ bar $\mathrm{CO}_{2}$ Fugacity

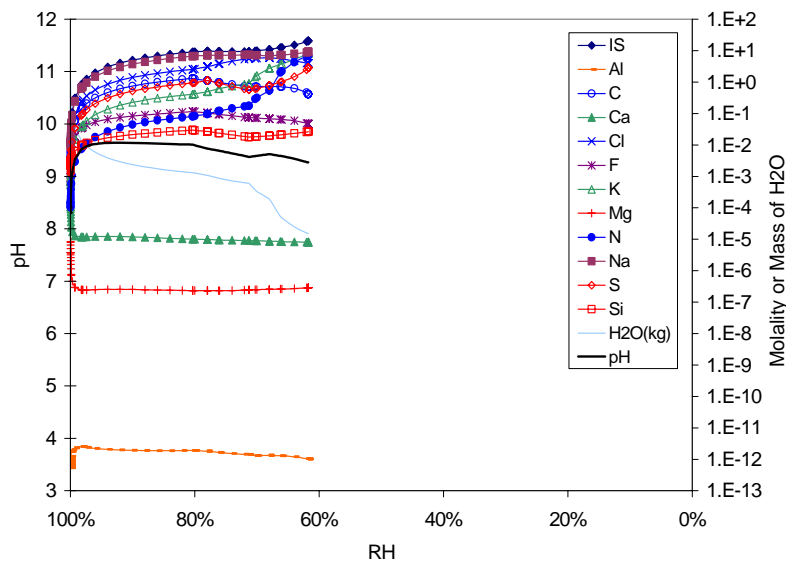

Source: DTN: M00304SPACSALT.000, 07c3t4e.xIs.xls.

Figure B-07-15. Bin 07 Aqueous Composition Evaporation Predictions vs. Relative Humidity at $40^{\circ} \mathrm{C}$ and $10^{-3}$ bar $\mathrm{CO}_{2}$ Fugacity

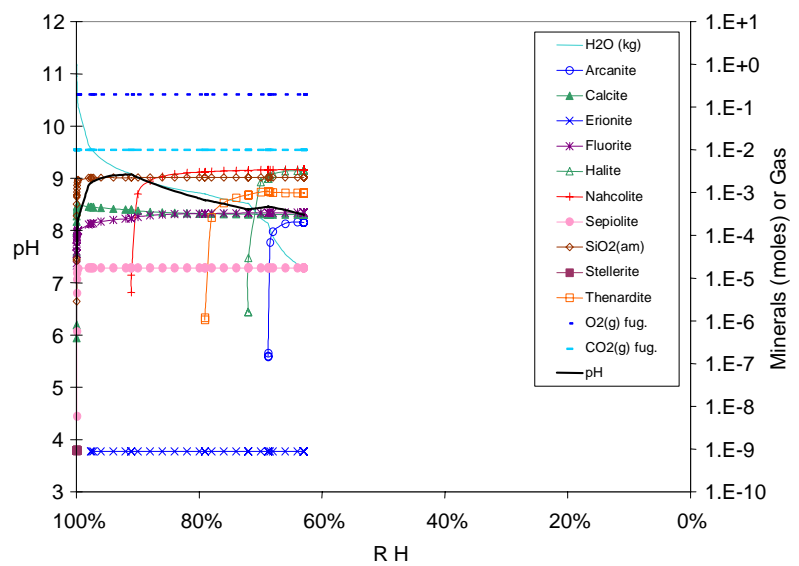

Source: DTN: MO0304SPACSALT.000, 07c2t4e.xIs.xIs.

Figure B-07-14. Bin 07 Mineral Precipitation Evaporation Predictions vs. Relative Humidity at $40^{\circ} \mathrm{C}$ and $10^{-2}$ bar $\mathrm{CO}_{2}$ Fugacity

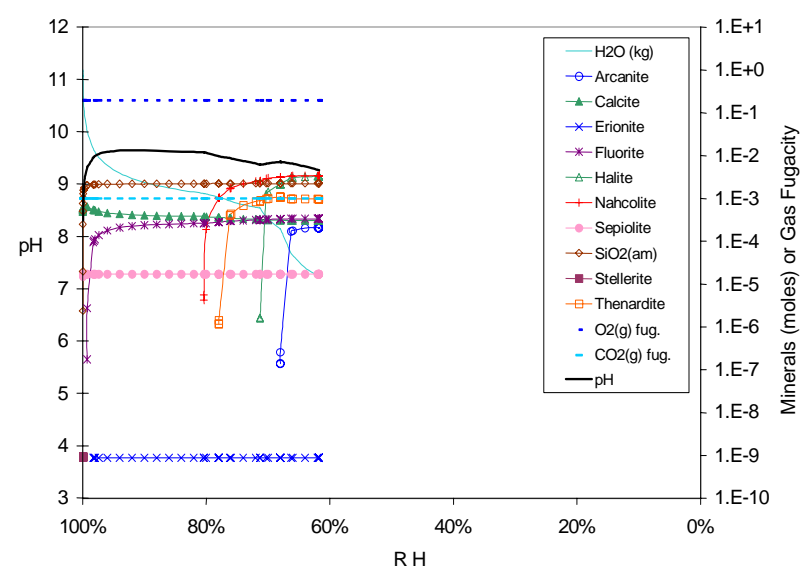

Source: DTN: MO0304SPACSALT.000, 07c3t4e.xIs.xls.

Figure B-07-16. Bin 07 Mineral Precipitation Evaporation Predictions vs. Relative Humidity at $40^{\circ} \mathrm{C}$ and $10^{-3}$ bar $\mathrm{CO}_{2}$ Fugacity 


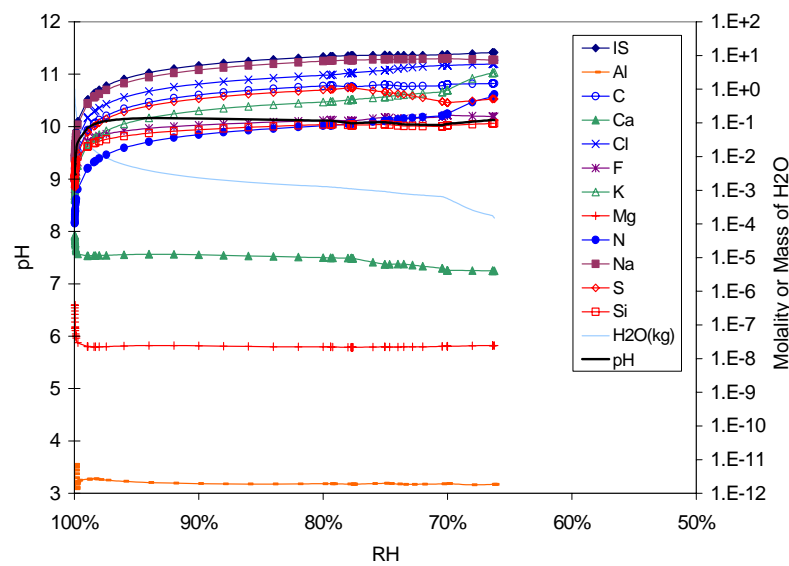

Source: DTN: MO0304SPACSALT.000, 07c4t4e.xIs.xIs.

Figure B-07-17. Bin 07 Aqueous Composition Evaporation Predictions vs. Relative Humidity at $40^{\circ} \mathrm{C}$ and $10^{-4}$ bar $\mathrm{CO}_{2}$ Fugacity

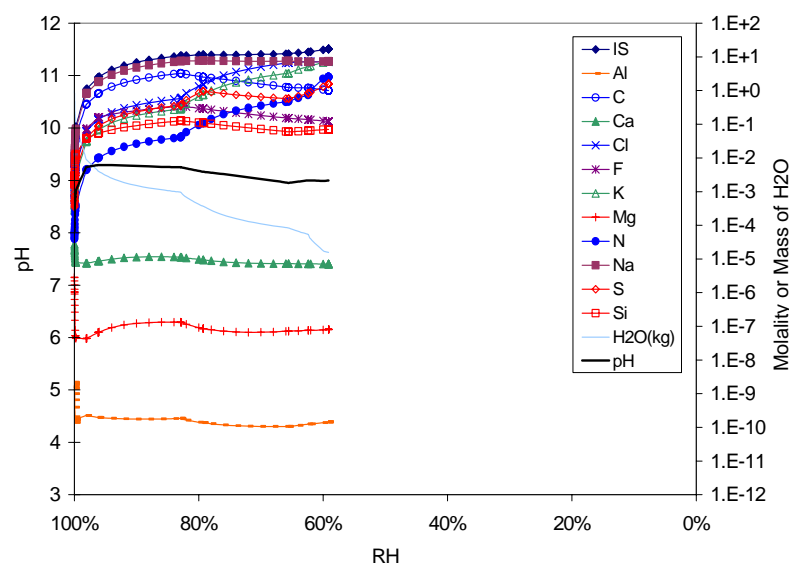

Source: DTN: M00304SPACSALT.000, 08c2t1e.xIs.xls.

Figure B-08-1. Bin 08 Aqueous Composition Evaporation Predictions vs. Relative Humidity at $100^{\circ} \mathrm{C}$ and $10^{-2}$ bar $\mathrm{CO}_{2}$ Fugacity

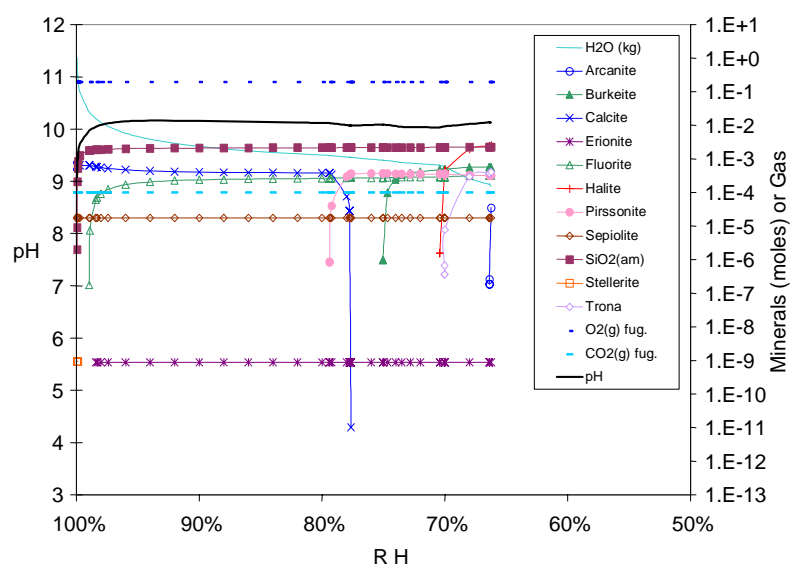

Source: DTN: MO0304SPACSALT.000, 07c4t4e.xIs.xIs.

Figure B-07-18. Bin 07 Mineral Precipitation Evaporation Predictions vs. Relative Humidity at $40^{\circ} \mathrm{C}$ and $10^{-4}$ bar $\mathrm{CO}_{2}$ Fugacity

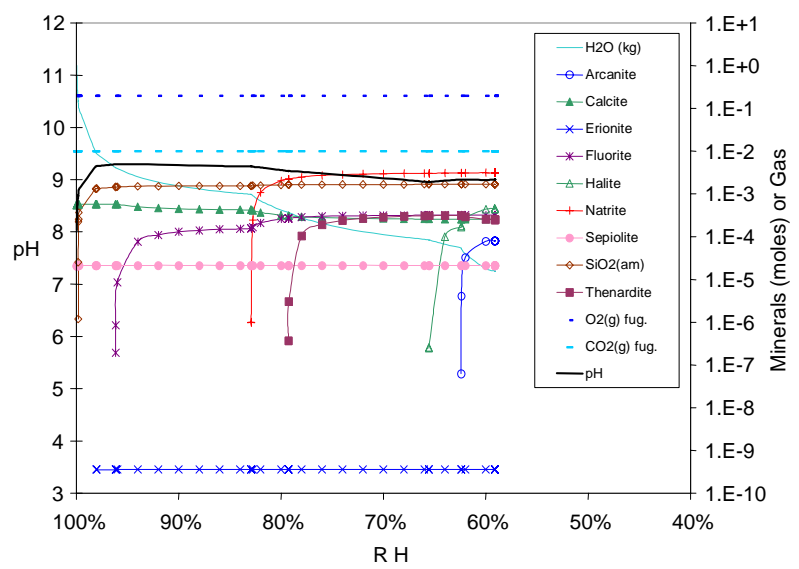

Source: DTN: MO0304SPACSALT.000, 08c2t1e.xIs.xIs.

Figure B-08-2. Bin 08 Mineral Precipitation Evaporation Predictions vs. Relative Humidity at $100^{\circ} \mathrm{C}$ and $10^{-2}$ bar $\mathrm{CO}_{2}$ Fugacity 


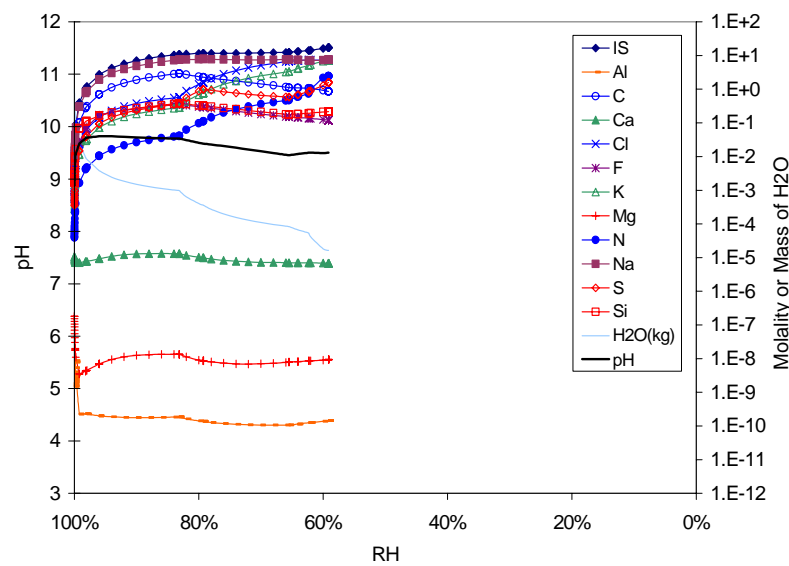

Source: DTN: M00304SPACSALT.000, 08c3t1e.xIs.x/s.

Figure B-08-3. Bin 08 Aqueous Composition Evaporation Predictions vs. Relative Humidity at $100^{\circ} \mathrm{C}$ and $10^{-3}$ bar $\mathrm{CO}_{2}$ Fugacity

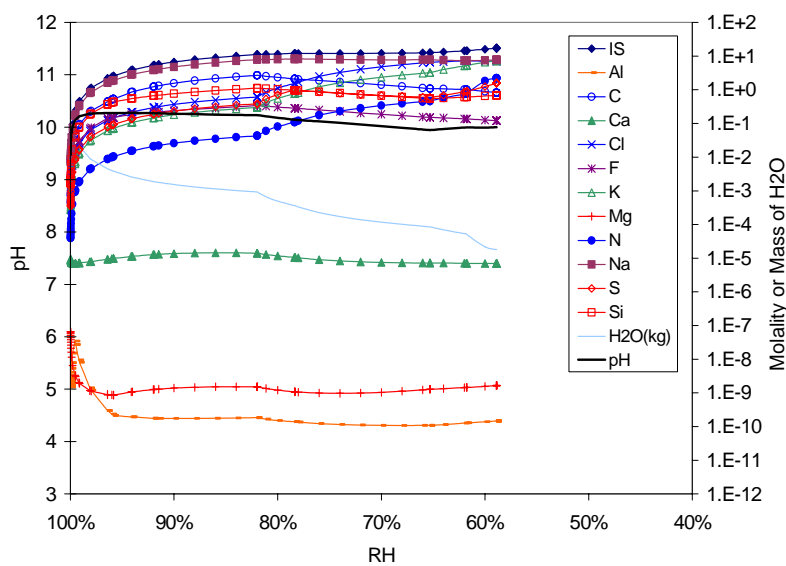

Source: DTN: M00304SPACSALT.000, 08c4t1e.xIs.xIs.

Figure B-08-5. Bin 08 Aqueous Composition Evaporation Predictions vs. Relative Humidity at $100^{\circ} \mathrm{C}$ and $10^{-4}$ bar $\mathrm{CO}_{2}$ Fugacity

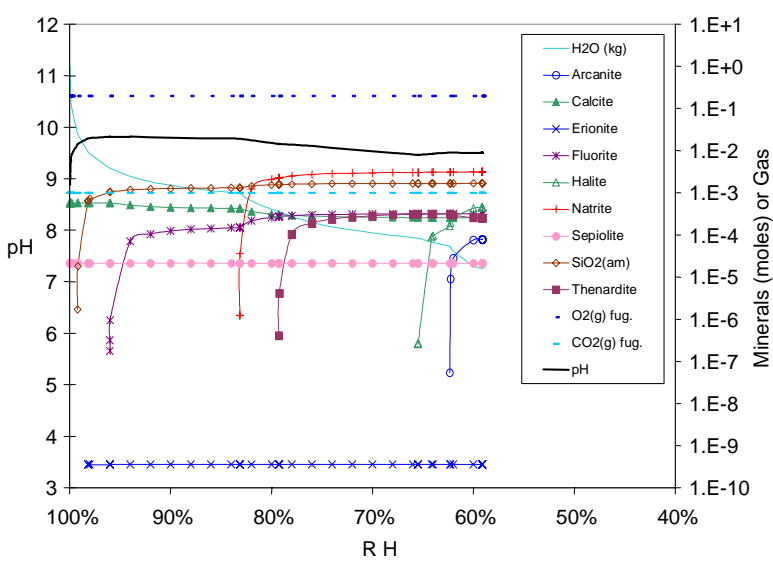

Source: DTN: MO0304SPACSALT.000, 08c3t1e.xIs.xls.

Figure B-08-4. Bin 08 Mineral Precipitation Evaporation Predictions vs. Relative Humidity at $100^{\circ} \mathrm{C}$ and $10^{-3}$ bar $\mathrm{CO}_{2}$ Fugacity

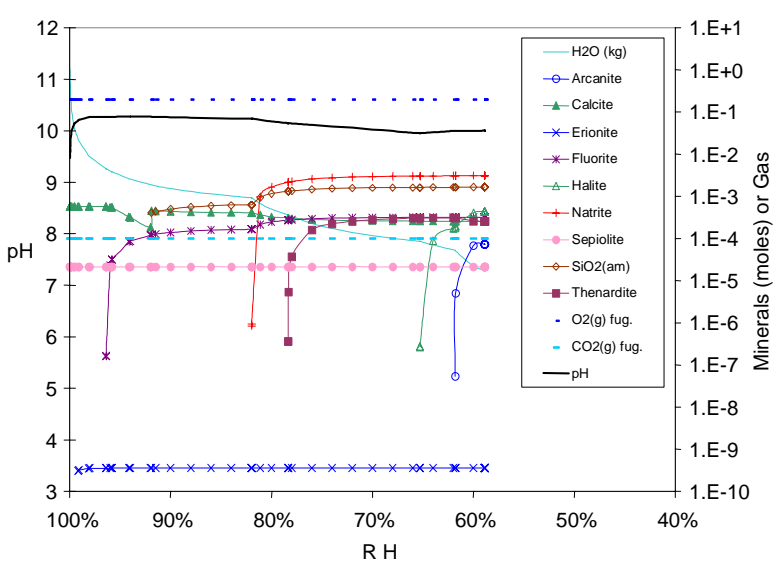

Source: DTN: MO0304SPACSALT.000, 08c4t1e.xIs.xls.

Figure B-08-6. Bin 08 Mineral Precipitation Evaporation Predictions vs. Relative Humidity at $100^{\circ} \mathrm{C}$ and $10^{-4}$ bar $\mathrm{CO}_{2}$ Fugacity 


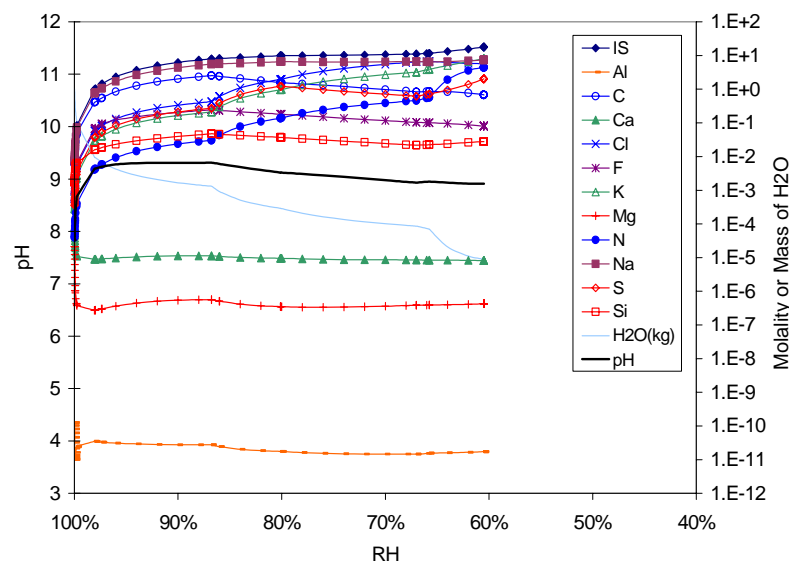

Source: DTN: MO0304SPACSALT.000, 08c2t7e.xIs.xIs.

Figure B-08-7. Bin 08 Aqueous Composition Evaporation Predictions vs. Relative Humidity at $70^{\circ} \mathrm{C}$ and $10^{-2}$ bar $\mathrm{CO}_{2}$ Fugacity

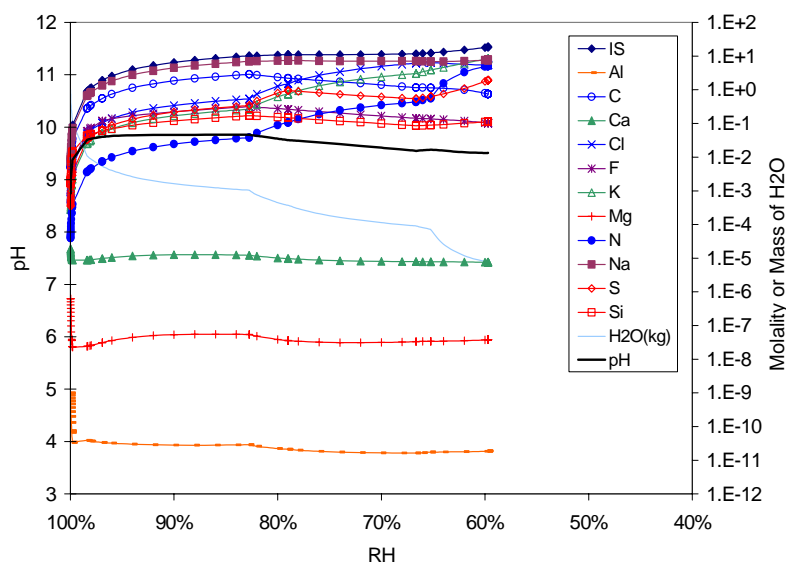

Source: DTN: MO0304SPACSALT.000, 08c3t7e.xIs.xIs.

Figure B-08-9. Bin 08 Aqueous Composition Evaporation Predictions vs. Relative Humidity at $70^{\circ} \mathrm{C}$ and $10^{-3}$ bar $\mathrm{CO}_{2}$ Fugacity

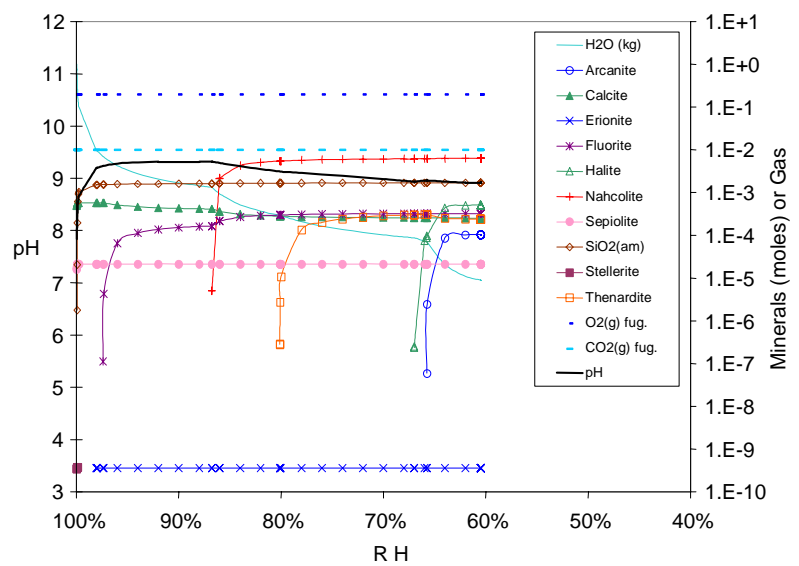

Source: DTN: MO0304SPACSALT.000, 08c2t7e.xls.xIs.

Figure B-08-8. Bin 08 Mineral Precipitation Evaporation Predictions vs. Relative Humidity at $70^{\circ} \mathrm{C}$ and $10^{-2}$ bar $\mathrm{CO}_{2}$ Fugacity

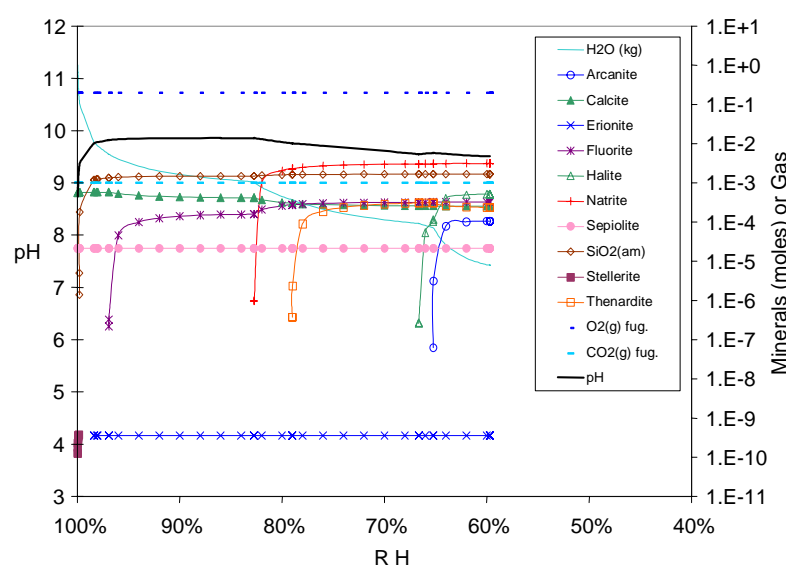

Source: DTN: MO0304SPACSALT.000, 08c3t7e.xIs.xIs.

Figure B-08-10. Bin 08 Mineral Precipitation Evaporation Predictions vs. Relative Humidity at $70^{\circ} \mathrm{C}$ and $10^{-3}$ bar $\mathrm{CO}_{2}$ Fugacity 


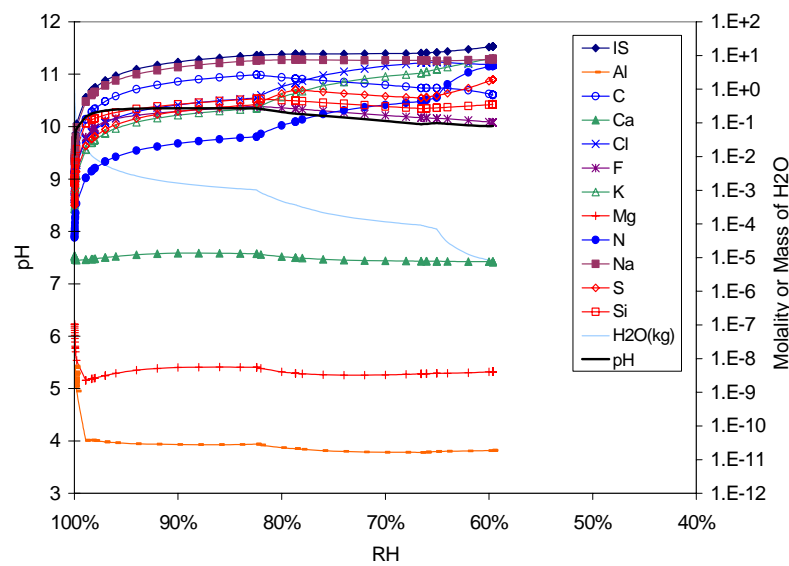

Source: DTN: MO0304SPACSALT.000, 08c4t7e.xIs.xIs.

Figure B-08-11. Bin 08 Aqueous Composition Evaporation Predictions vs. Relative Humidity at $70^{\circ} \mathrm{C}$ and $10^{-4}$ bar $\mathrm{CO}_{2}$ Fugacity

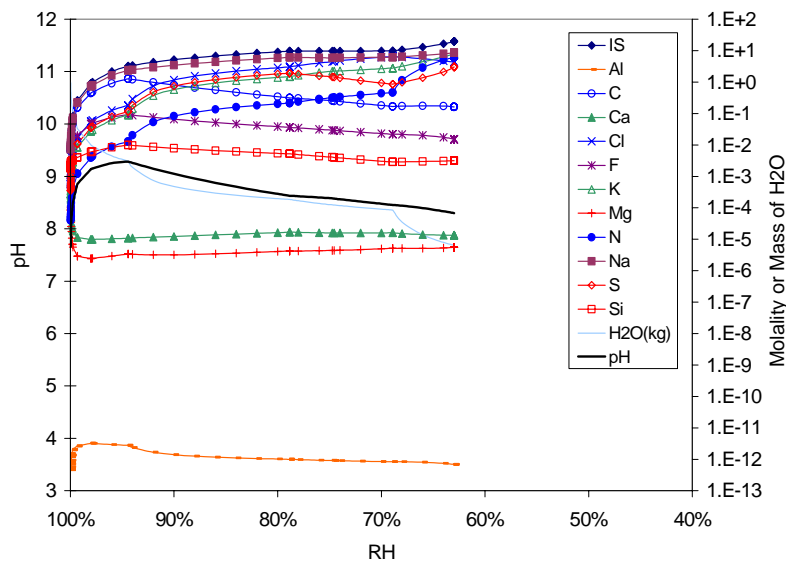

Source: DTN: M00304SPACSALT.000, 08c2t4e.xIs.xls.

Figure B-08-13. Bin 08 Aqueous Composition Evaporation Predictions vs. Relative Humidity at $40^{\circ} \mathrm{C}$ and $10^{-2}$ bar $\mathrm{CO}_{2}$ Fugacity

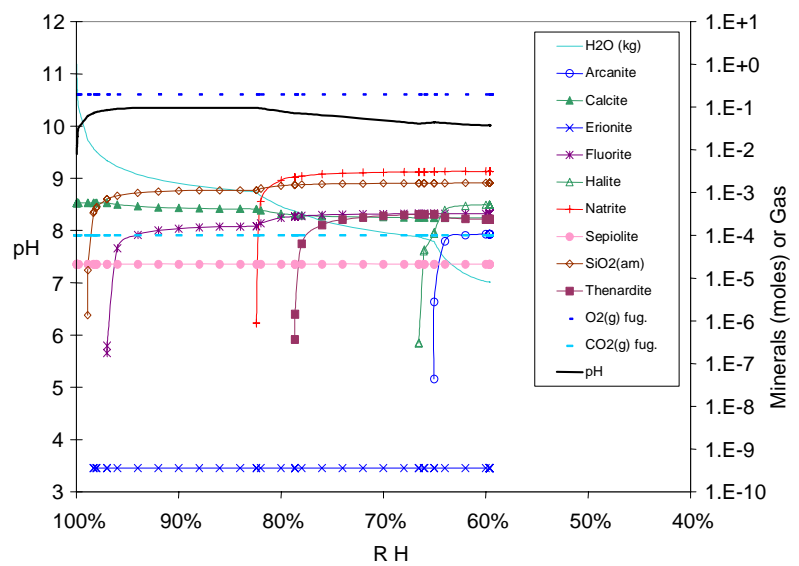

Source: DTN: MO0304SPACSALT.000, 08c4t7e.xls.xls.

Figure B-08-12. Bin 08 Mineral Precipitation Evaporation Predictions vs. Relative Humidity at $70^{\circ} \mathrm{C}$ and $10^{-4}$ bar $\mathrm{CO}_{2}$ Fugacity

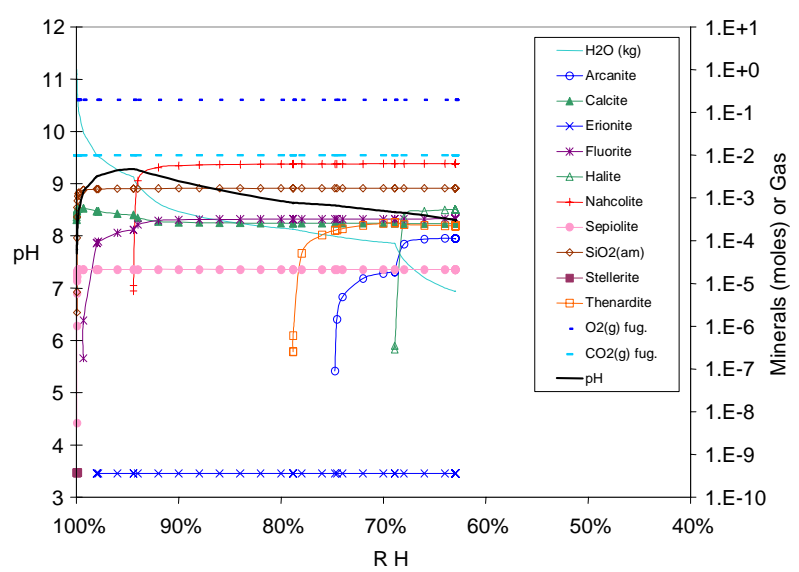

Source: DTN: MO0304SPACSALT.000, 08c2t4e.xIs.xIs.

Figure B-08-14. Bin 08 Mineral Precipitation Evaporation Predictions vs. Relative Humidity at $40^{\circ} \mathrm{C}$ and $10^{-2}$ bar $\mathrm{CO}_{2}$ Fugacity 


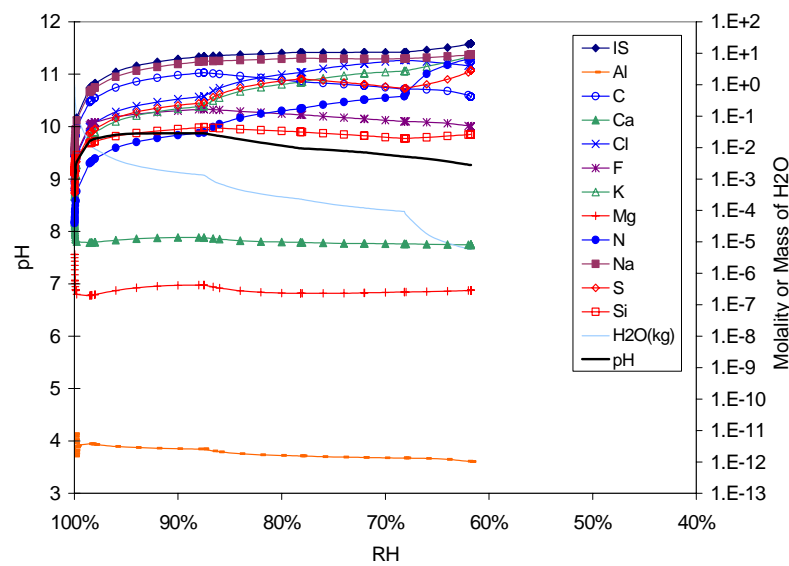

Source: DTN: MO0304SPACSALT.000, 08c3t4e.xIs.xIs.

Figure B-08-15. Bin 08 Aqueous Composition Evaporation Predictions vs. Relative Humidity at $40^{\circ} \mathrm{C}$ and $10^{-3}$ bar $\mathrm{CO}_{2}$ Fugacity

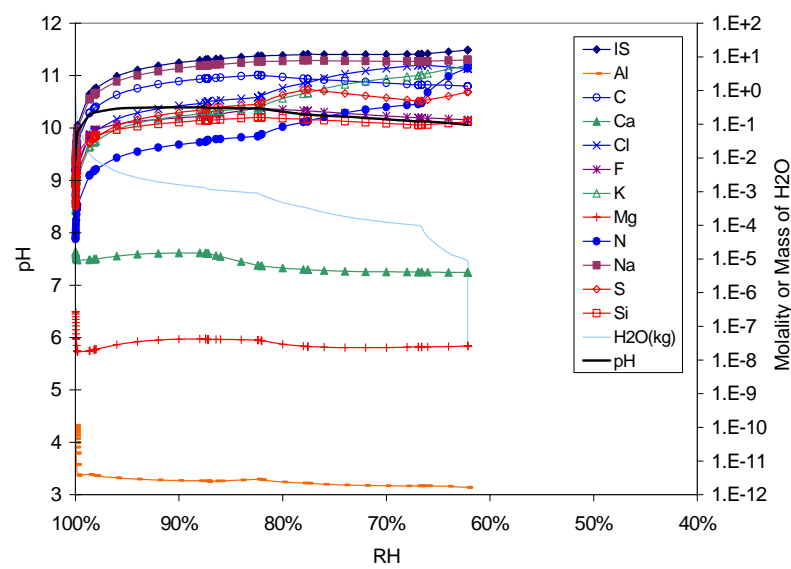

Source: DTN: M00304SPACSALT.000, 08c4t4e.xIs.xls.

Figure B-08-17. Bin 08 Aqueous Composition Evaporation Predictions vs. Relative Humidity at $40^{\circ} \mathrm{C}$ and $10^{-4}$ bar $\mathrm{CO}_{2}$ Fugacity

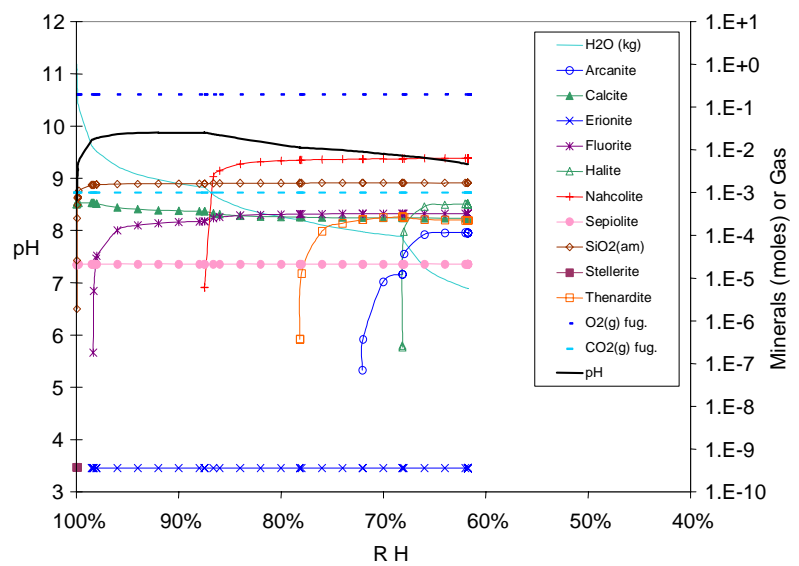

Source: DTN: MO0304SPACSALT.000, 08c3t4e.xls.xls.

Figure B-08-16. Bin 08 Mineral Precipitation Evaporation Predictions vs. Relative Humidity at $40^{\circ} \mathrm{C}$ and $10^{-3}$ bar $\mathrm{CO}_{2}$ Fugacity

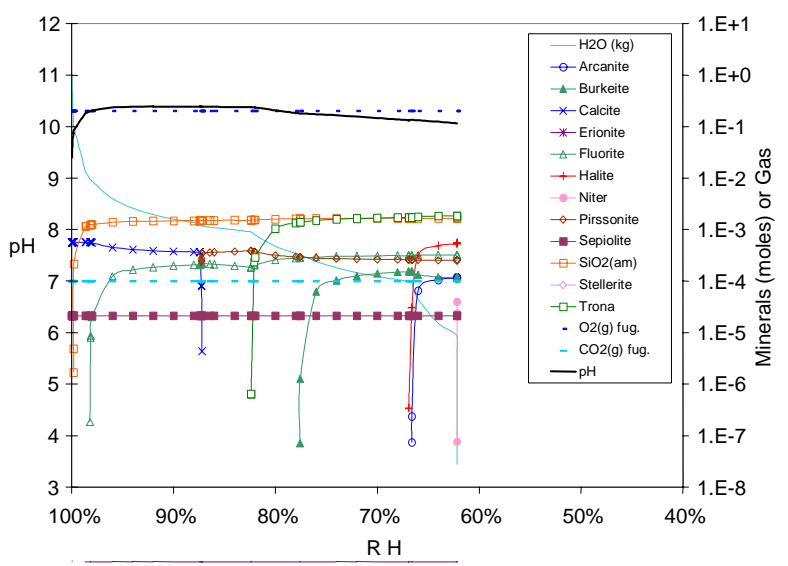

Source: DTN: MO0304SPACSALT.000, 08c4t4e.xls.xls.

Figure B-08-18. Bin 08 Mineral Precipitation Evaporation Predictions vs. Relative Humidity at $40^{\circ} \mathrm{C}$ and $10^{-4}$ bar $\mathrm{CO}_{2}$ Fugacity 


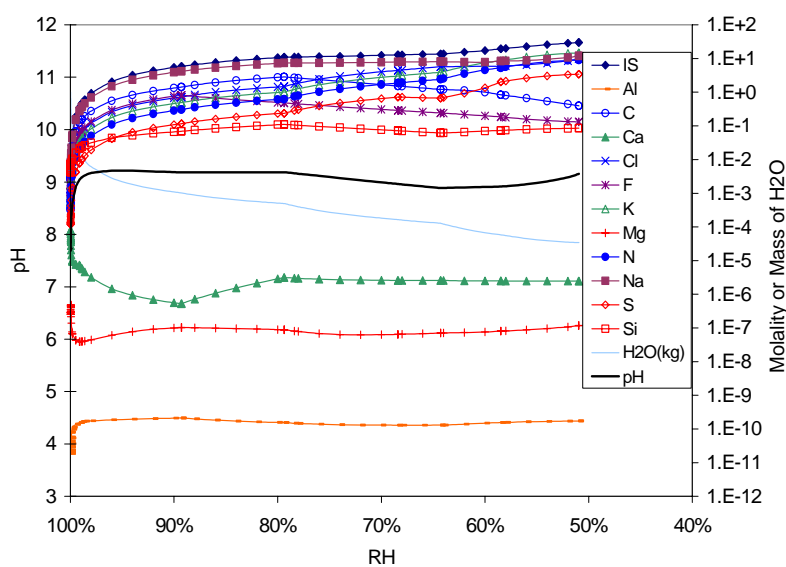

Source: DTN: M00304SPACSALT.000, 09c2t1e.xIs.xIs.

Figure B-09-1. Bin 09 Aqueous Composition Evaporation Predictions vs. Relative Humidity at $100^{\circ} \mathrm{C}$ and $10^{-2}$ bar $\mathrm{CO}_{2}$ Fugacity

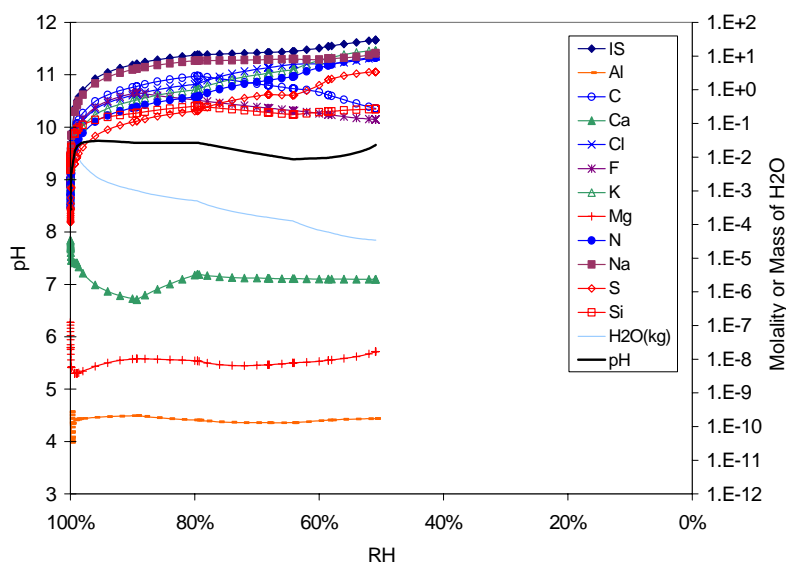

Source: DTN: M00304SPACSALT.000, 09c3t1e.xIs.xIs.

Figure B-09-3. Bin 09 Aqueous Composition Evaporation Predictions vs. Relative Humidity at $100^{\circ} \mathrm{C}$ and $10^{-3}$ bar $\mathrm{CO}_{2}$ Fugacity

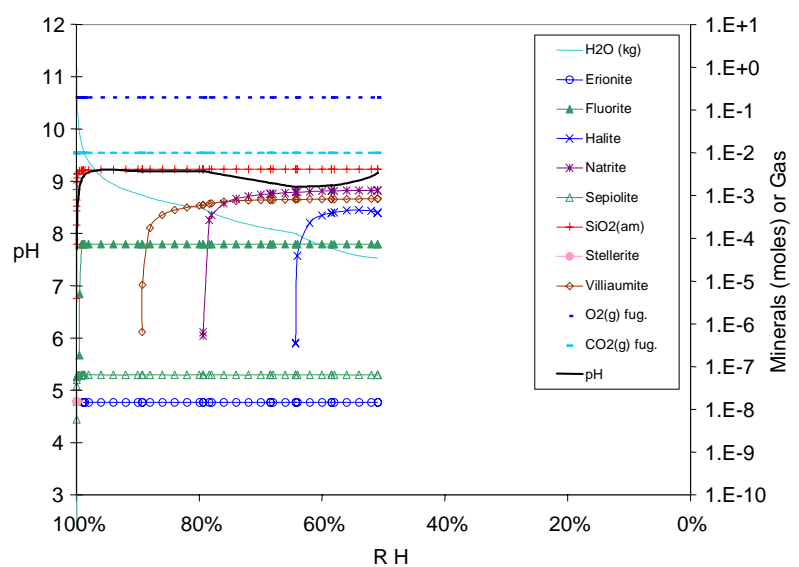

Source: DTN: MO0304SPACSALT.000, 09c2t1e.xls.xls.

Figure B-09-2. Bin 09 Mineral Precipitation Evaporation Predictions vs. Relative Humidity at $100^{\circ} \mathrm{C}$ and $10^{-2}$ bar $\mathrm{CO}_{2}$ Fugacity

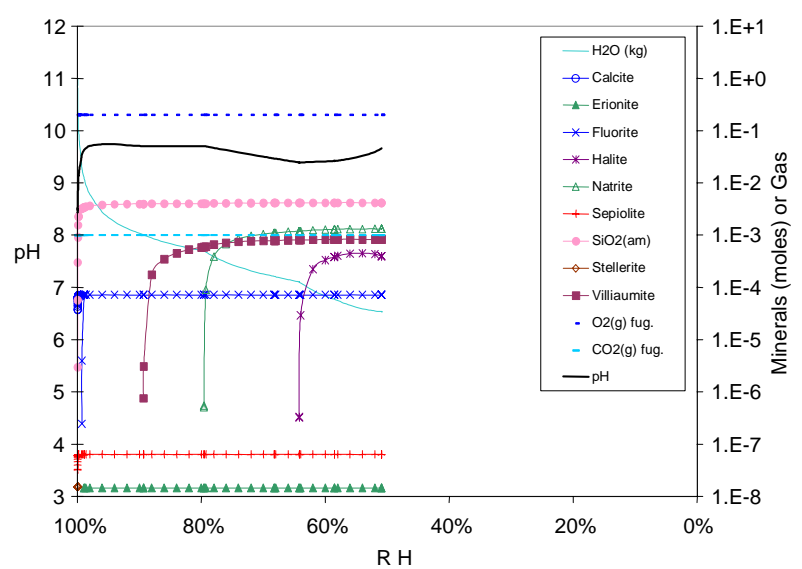

Source: DTN: MO0304SPACSALT.000, 09c3t1e.xIs.xIs.

Figure B-09-4. Bin 09 Mineral Precipitation Evaporation Predictions vs. Relative Humidity at $100^{\circ} \mathrm{C}$ and $10^{-3}$ bar $\mathrm{CO}_{2}$ Fugacity 


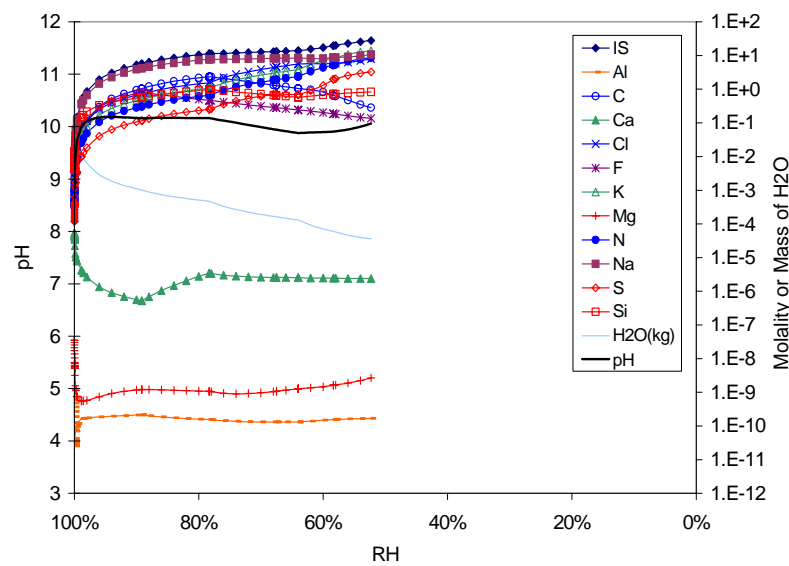

Source: DTN: M00304SPACSALT.000, 09c4t1e.xIs.xIs.

Figure B-09-5. Bin 09 Aqueous Composition Evaporation Predictions vs. Relative Humidity at $100^{\circ} \mathrm{C}$ and $10^{-4}$ bar $\mathrm{CO}_{2}$ Fugacity

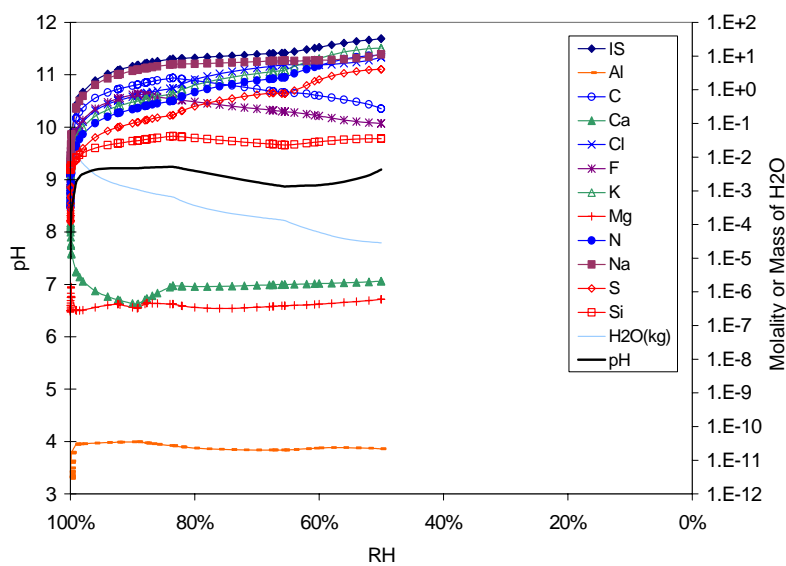

Source: DTN: MO0304SPACSALT.000, 09c2t7e.xIs.xIs.

Figure B-09-7. Bin 09 Aqueous Composition Evaporation Predictions vs. Relative Humidity at $70^{\circ} \mathrm{C}$ and $10^{-2}$ bar $\mathrm{CO}_{2}$ Fugacity

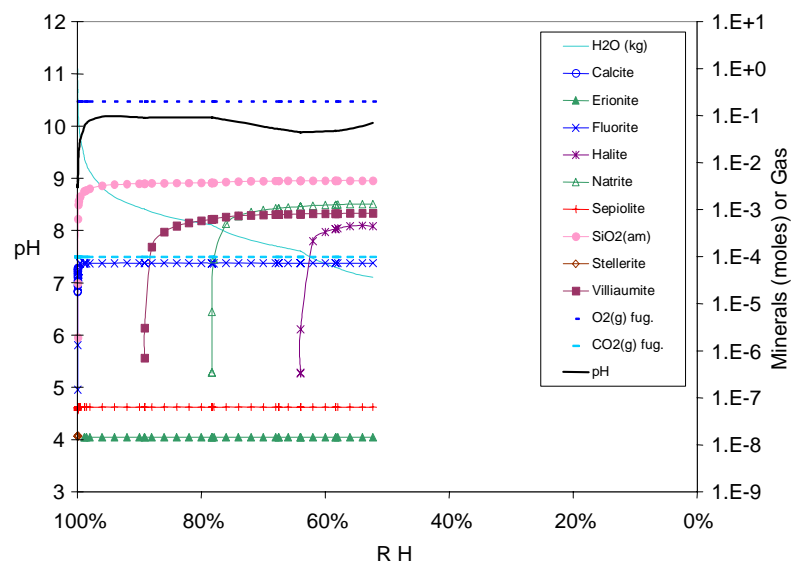

Source: DTN: MO0304SPACSALT.000, 09c4t1e.xIs.xIs.

Figure B-09-6. Bin 09 Mineral Precipitation Evaporation Predictions vs. Relative Humidity at $100^{\circ} \mathrm{C}$ and $10^{-4}$ bar $\mathrm{CO}_{2}$ Fugacity

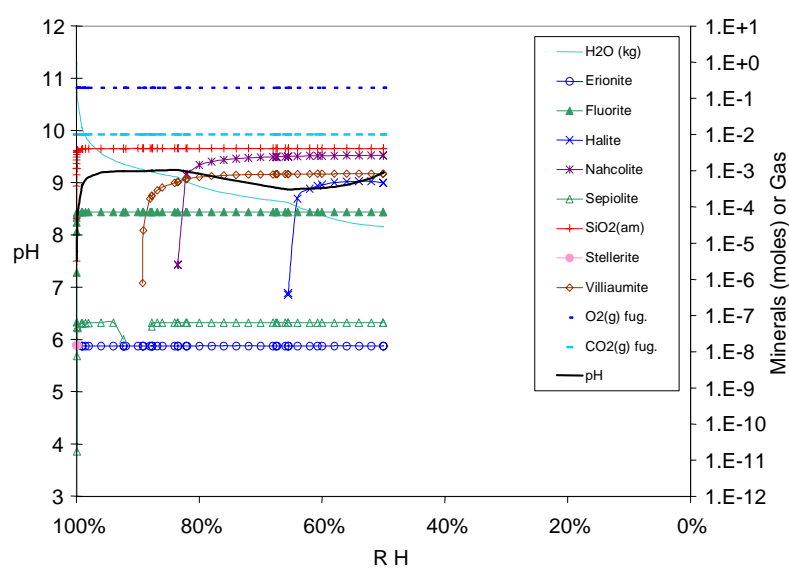

Source: DTN: MO0304SPACSALT.000, 09c2t7e.xIs.xIs.

Figure B-09-8. Bin 09 Mineral Precipitation Evaporation Predictions vs. Relative Humidity at $70^{\circ} \mathrm{C}$ and $10^{-2}$ bar $\mathrm{CO}_{2}$ Fugacity 


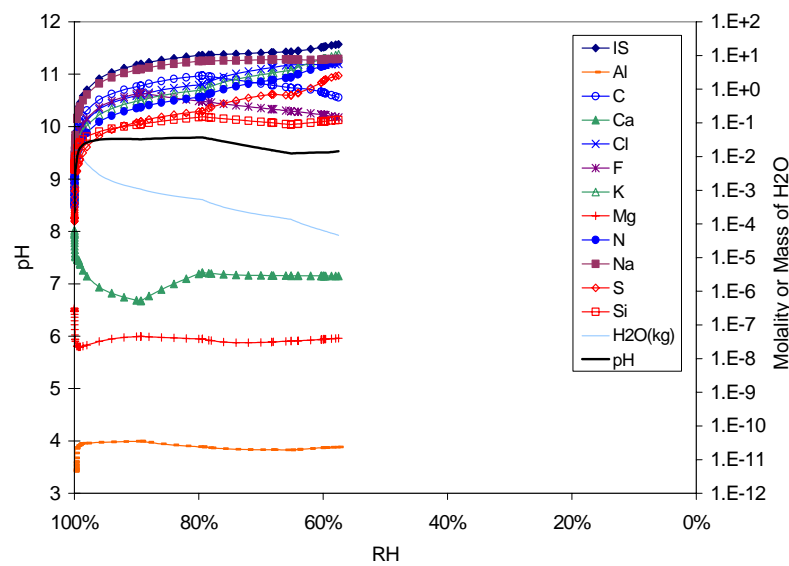

Source: DTN: MO0304SPACSALT.000, 09c3t7e.xIs.xIs.

Figure B-09-9. Bin 09 Aqueous Composition Evaporation Predictions vs. Relative Humidity at $70^{\circ} \mathrm{C}$ and $10^{-3}$ bar $\mathrm{CO}_{2}$ Fugacity

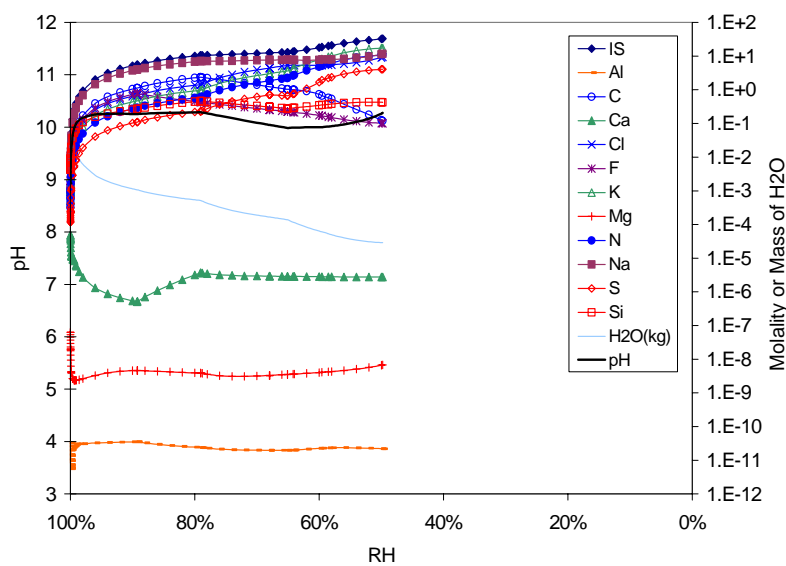

Source: DTN: MO0304SPACSALT.000, 09c4t7e.xIs.xIs.

Figure B-09-11. Bin 09 Aqueous Composition Evaporation Predictions vs. Relative Humidity at $70^{\circ} \mathrm{C}$ and $10^{-4}$ bar $\mathrm{CO}_{2}$ Fugacity

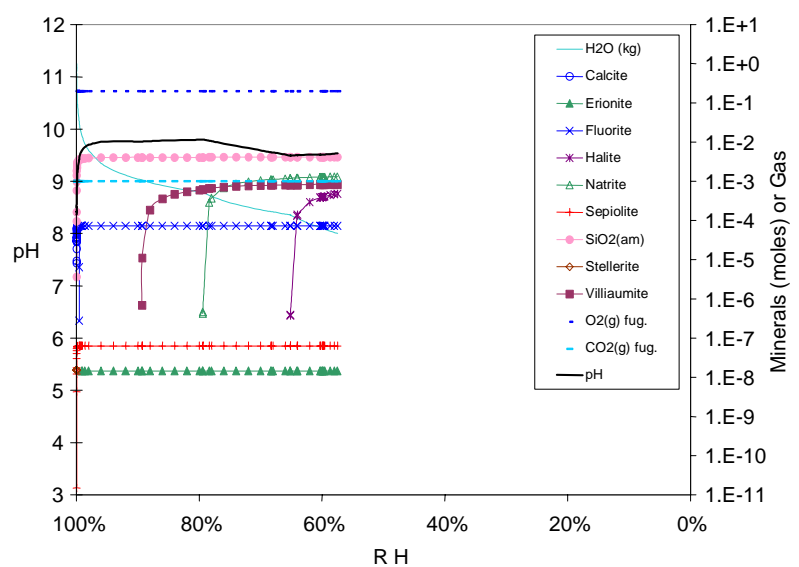

Source: DTN: MO0304SPACSALT.000, 09c3t7e.xIs.xIs.

Figure B-09-10. Bin 09 Mineral Precipitation Evaporation Predictions vs. Relative Humidity at $70^{\circ} \mathrm{C}$ and $10-3$ bar CO2 Fugacity

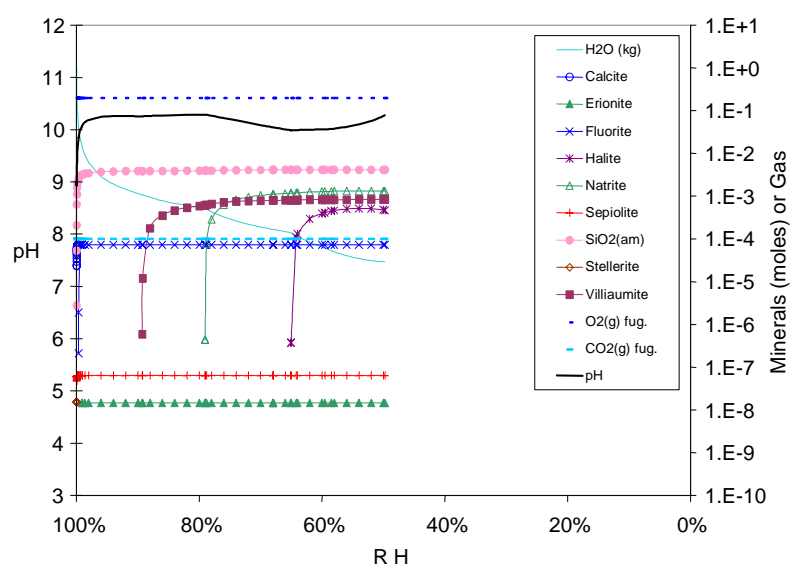

Source: DTN: MO0304SPACSALT.000, 09c4t7e.xIs.xIs.

Figure B-09-12. Bin 09 Mineral Precipitation Evaporation Predictions vs. Relative Humidity at $70^{\circ} \mathrm{C}$ and $10^{-4}$ bar $\mathrm{CO}_{2}$ Fugacity 


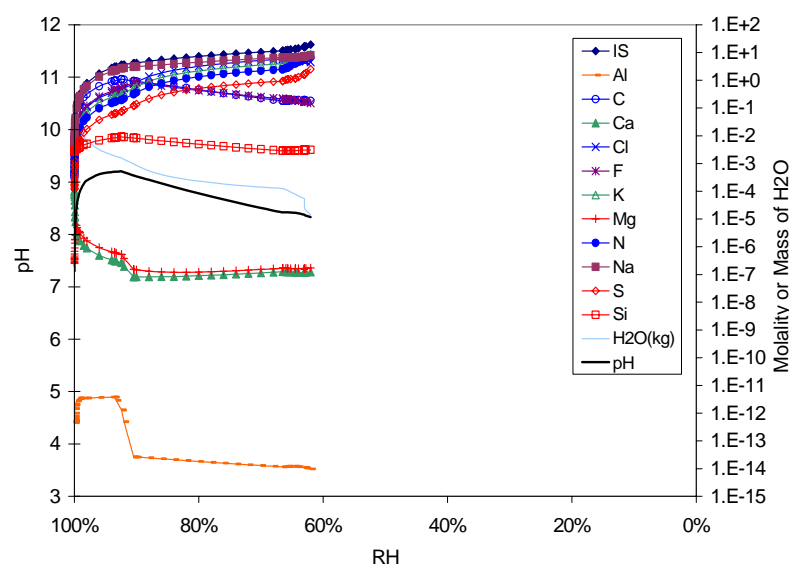

Source: DTN: MO0304SPACSALT.000, 09c2t4e.xIs.xIs.

Figure B-09-13. Bin 09 Aqueous Composition Evaporation Predictions vs. Relative Humidity at $40^{\circ} \mathrm{C}$ and $10^{-2}$ bar $\mathrm{CO}_{2}$ Fugacity

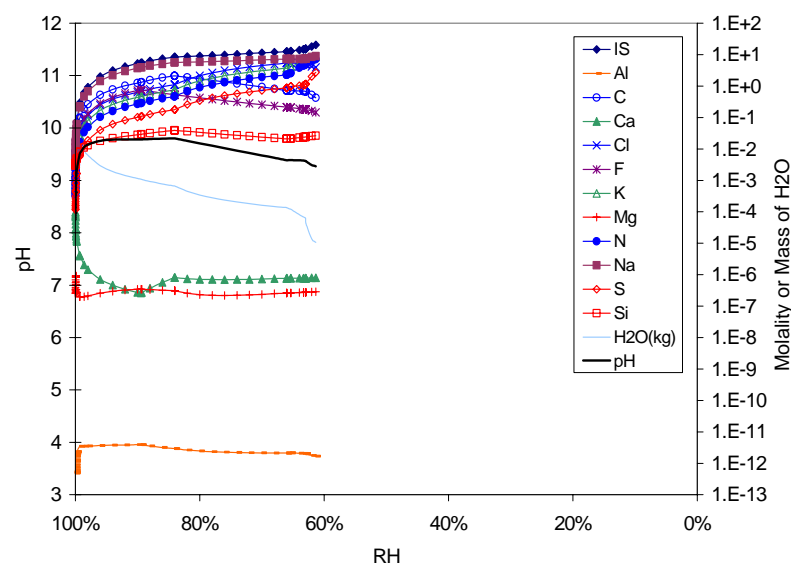

Source: DTN: M00304SPACSALT.000, 09c3t4e.xIs.xls.

Figure B-09-15. Bin 09 Aqueous Composition Evaporation Predictions vs. Relative Humidity at $40^{\circ} \mathrm{C}$ and $10^{-3}$ bar $\mathrm{CO}_{2}$ Fugacity

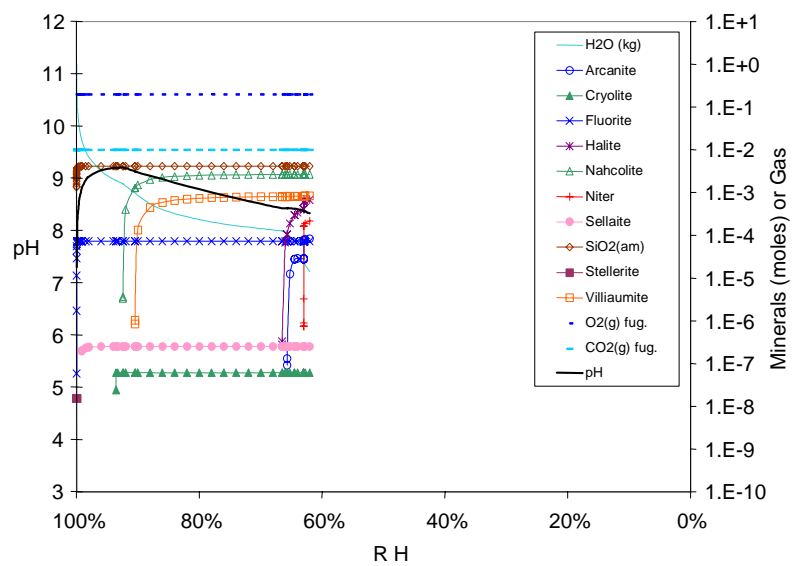

Source: DTN: MO0304SPACSALT.000, 09c2t4e.xIs.xIs.

Figure B-09-14. Bin 09 Mineral Precipitation Evaporation Predictions vs. Relative Humidity at $40^{\circ} \mathrm{C}$ and $10^{-2}$ bar $\mathrm{CO}_{2}$ Fugacity

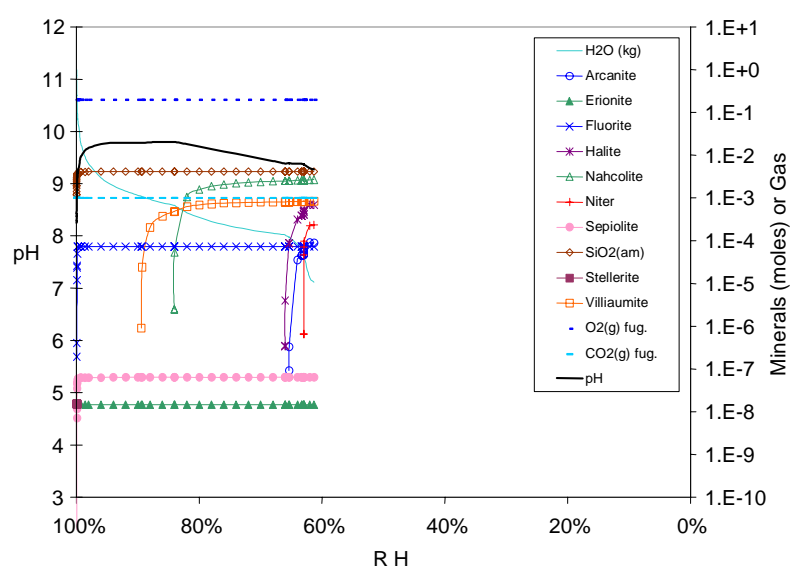

Source: DTN: MO0304SPACSALT.000, 09c3t4e.xIs.xIs.

Figure B-09-16. Bin 09 Mineral Precipitation Evaporation Predictions vs. Relative Humidity at $40^{\circ} \mathrm{C}$ and $10^{-3}$ bar $\mathrm{CO}_{2}$ Fugacity 


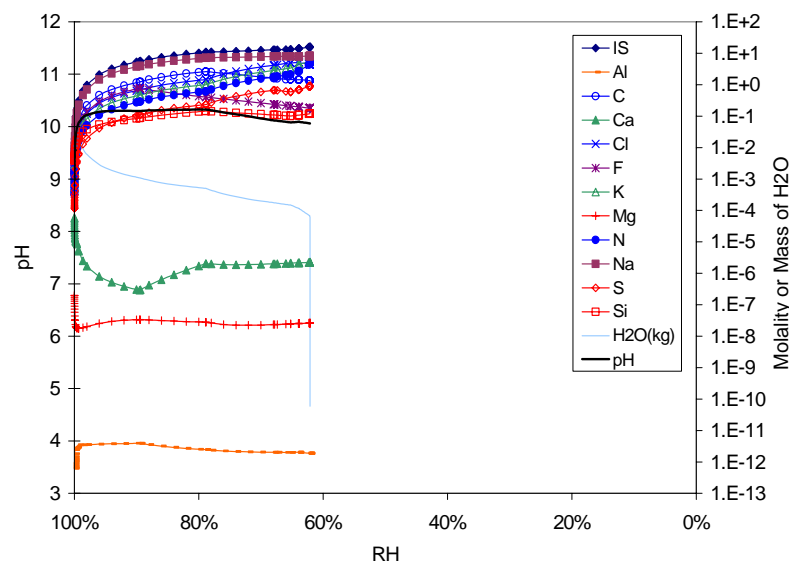

Source: DTN: MO0304SPACSALT.000, 09c4t4e.xIs.xIs.

Figure B-09-17. Bin 09 Aqueous Composition Evaporation Predictions vs. Relative Humidity at $40^{\circ} \mathrm{C}$ and $10^{-4}$ bar $\mathrm{CO}_{2}$ Fugacity

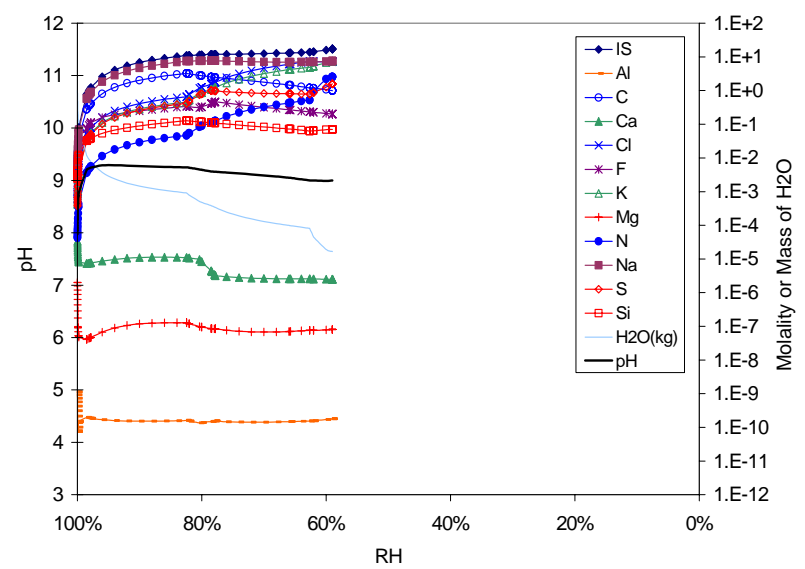

Source: DTN: MO0304SPACSALT.000, 10c2t1e.xIs.xls.

Figure B-10-1. Bin 10 Aqueous Composition Evaporation Predictions vs. Relative Humidity at $100^{\circ} \mathrm{C}$ and $10^{-2}$ bar $\mathrm{CO}_{2}$ Fugacity

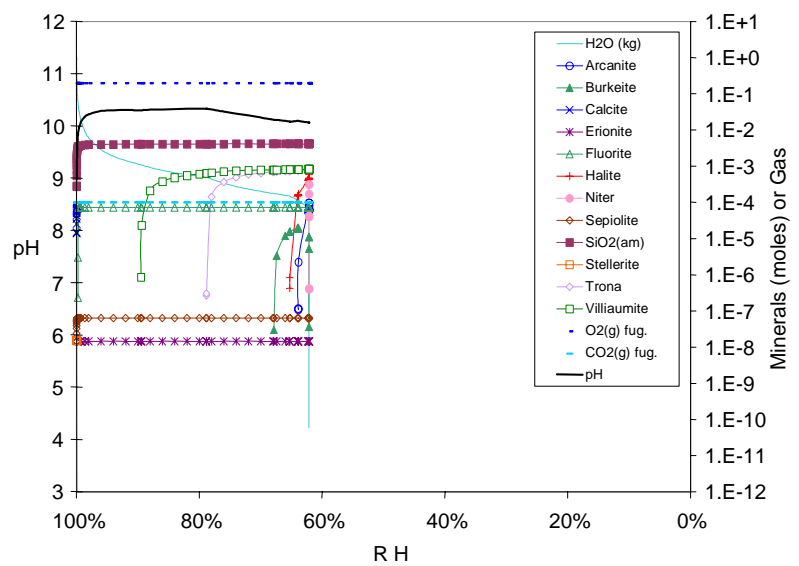

Source: DTN: M00304SPACSALT.000, 09c4t4e.xIs.xIs.

Figure B-09-18. Bin 09 Mineral Precipitation Evaporation Predictions vs. Relative Humidity at $40^{\circ} \mathrm{C}$ and $10^{-4}$ bar $\mathrm{CO}_{2}$ Fugacity

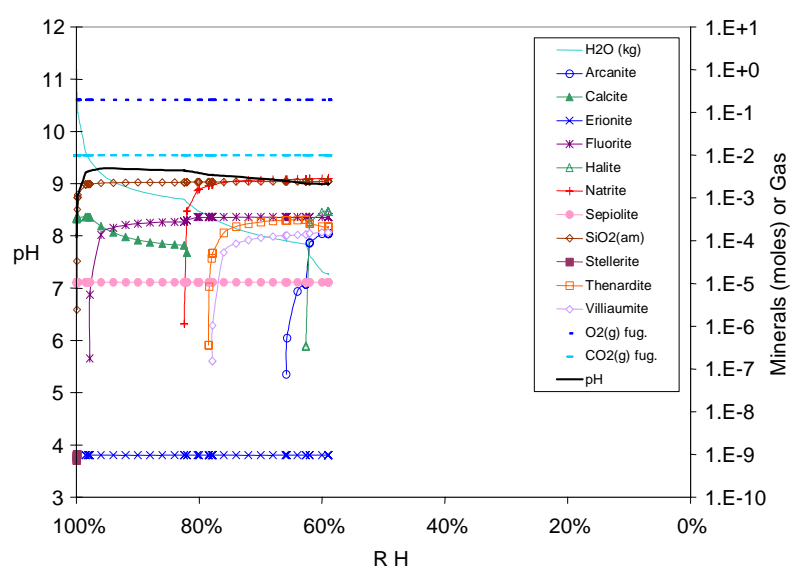

Source: DTN: MO0304SPACSALT.000, 10c2t1e.xIs.xIs.

Figure B-10-2. Bin 10 Mineral Precipitation Evaporation Predictions vs. Relative Humidity at $100^{\circ} \mathrm{C}$ and $10^{-2}$ bar $\mathrm{CO}_{2}$ Fugacity 


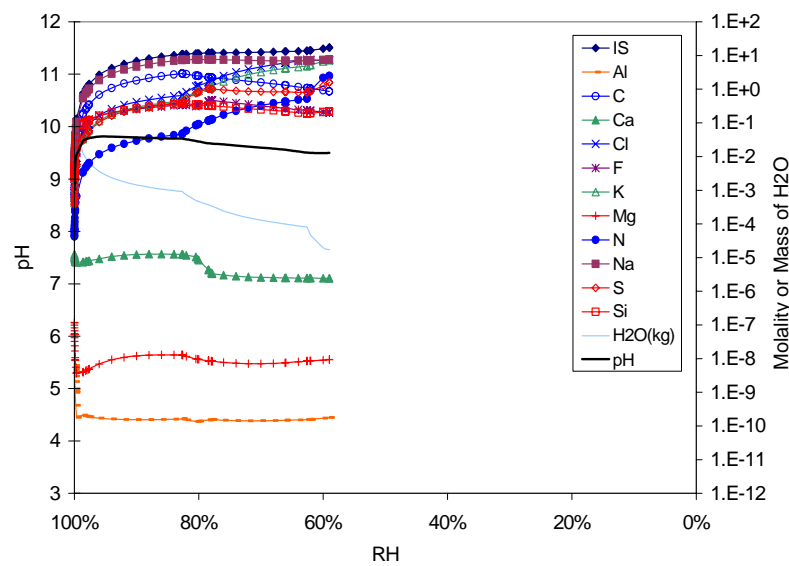

Source: DTN: MO0304SPACSALT.000, 10c3t1e.xIs.x/s.

Figure B-10-3. Bin 10 Aqueous Composition Evaporation Predictions vs. Relative Humidity at $100^{\circ} \mathrm{C}$ and $10^{-3}$ bar $\mathrm{CO}_{2}$ Fugacity

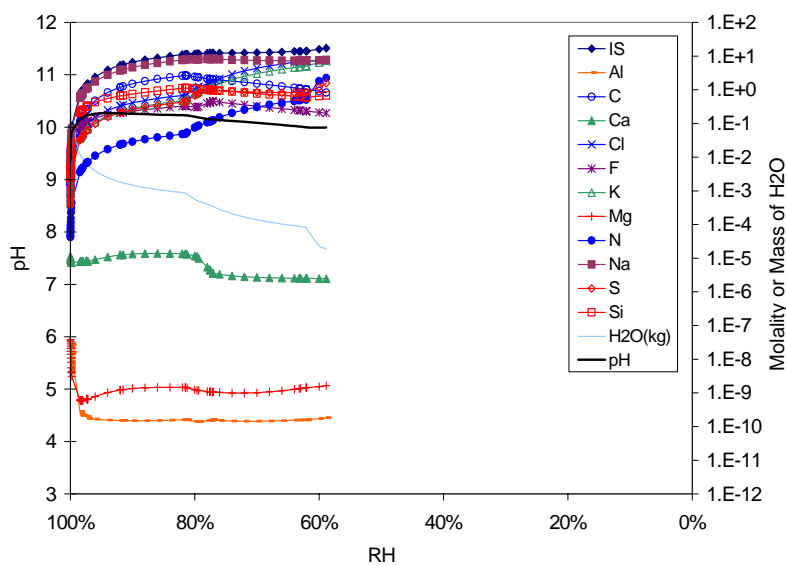

Source: DTN: MO0304SPACSALT.000, 10c4t1e.xIs.xIs.

Figure B-10-5. Bin 10 Aqueous Composition Evaporation Predictions vs. Relative Humidity at $100^{\circ} \mathrm{C}$ and $10^{-4}$ bar $\mathrm{CO}_{2}$ Fugacity

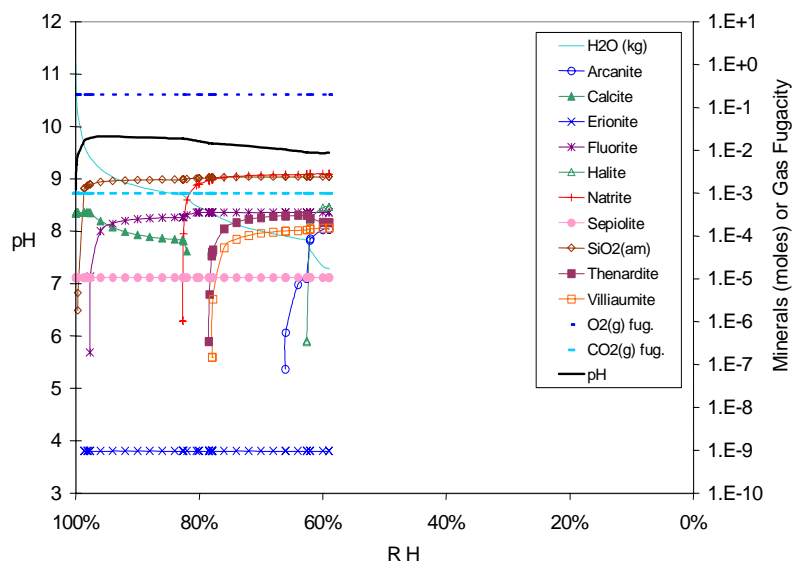

Source: DTN: MO0304SPACSALT.000, 10c3t1e.xIs.xls.

Figure B-10-4. Bin 10 Mineral Precipitation Evaporation Predictions vs. Relative Humidity at $100^{\circ} \mathrm{C}$ and $10^{-3}$ bar $\mathrm{CO}_{2}$ Fugacity

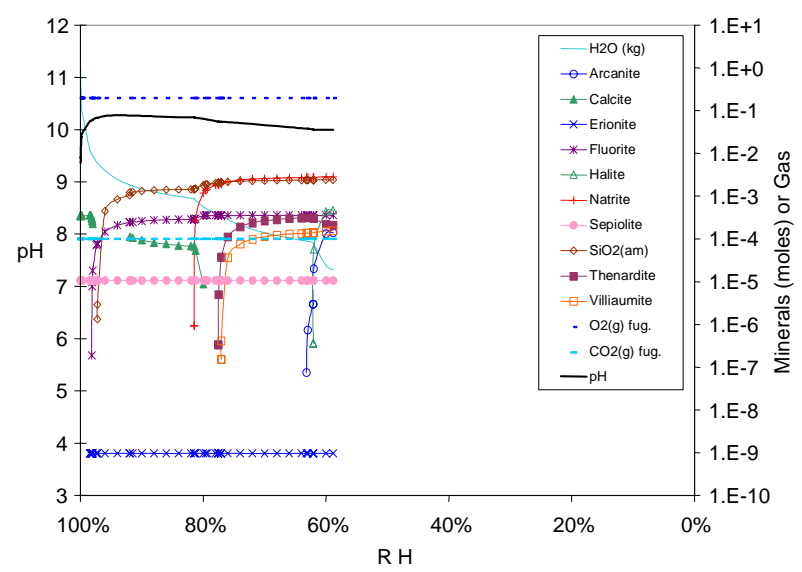

Source: DTN: MO0304SPACSALT.000, 10c4t1e.xIs.xIs.

Figure B-10-6. Bin 10 Mineral Precipitation Evaporation Predictions vs. Relative Humidity at $100^{\circ} \mathrm{C}$ and $10^{-4}$ bar $\mathrm{CO}_{2}$ Fugacity 


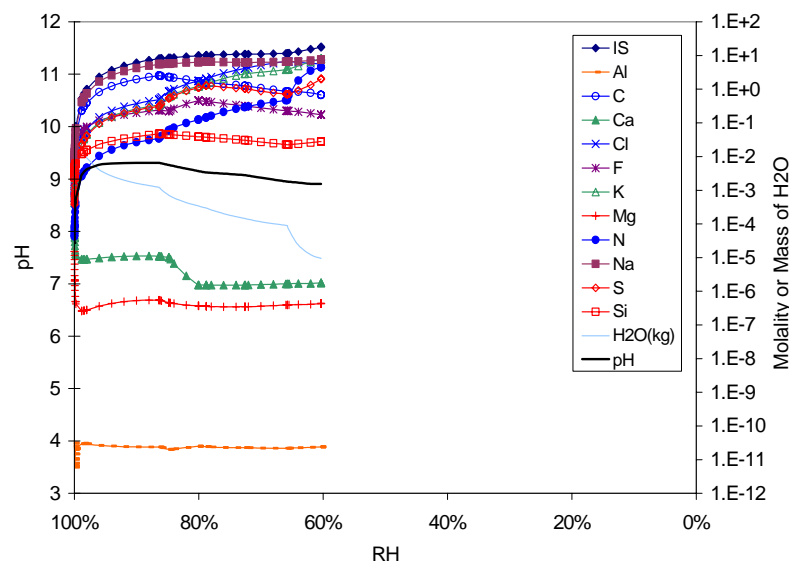

Source: DTN: MO0304SPACSALT.000, 10c2t7e.xIs.xIs.

Figure B-10-7. Bin 10 Aqueous Composition Evaporation Predictions vs. Relative Humidity at $70^{\circ} \mathrm{C}$ and $10^{-2}$ bar $\mathrm{CO}_{2}$ Fugacity

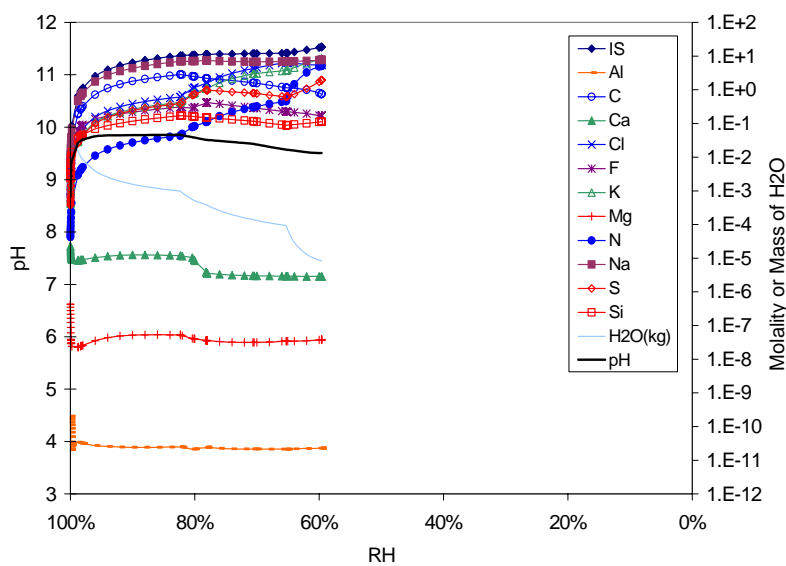

Source: DTN: MO0304SPACSALT.000, 10c3t7e.xIs.xIs.

Figure B-10-9. Bin 10 Aqueous Composition Evaporation Predictions vs. Relative Humidity at $70^{\circ} \mathrm{C}$ and $10^{-3}$ bar $\mathrm{CO}_{2}$ Fugacity

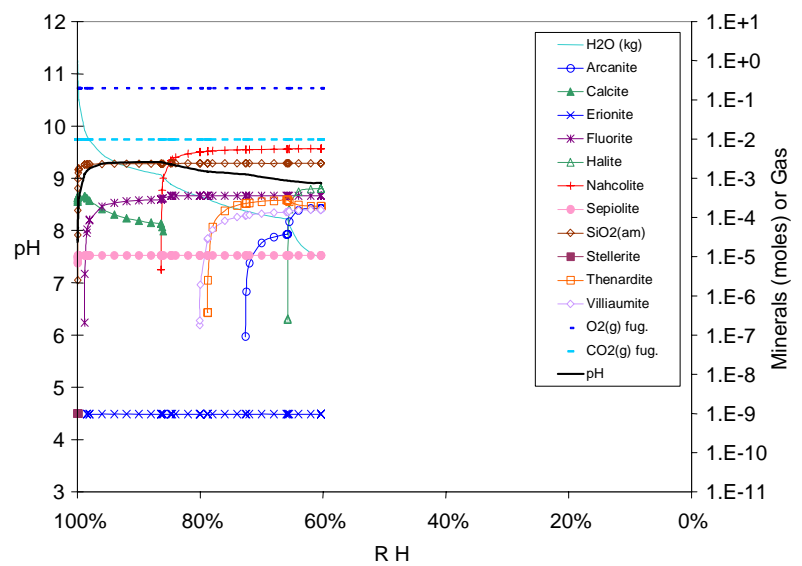

Source: DTN: MO0304SPACSALT.000, 10c2t7e.xIs.xIs.

Figure B-10-8. Bin 10 Mineral Precipitation Evaporation Predictions vs. Relative Humidity at $70^{\circ} \mathrm{C}$ and $10^{-2}$ bar $\mathrm{CO}_{2}$ Fugacity

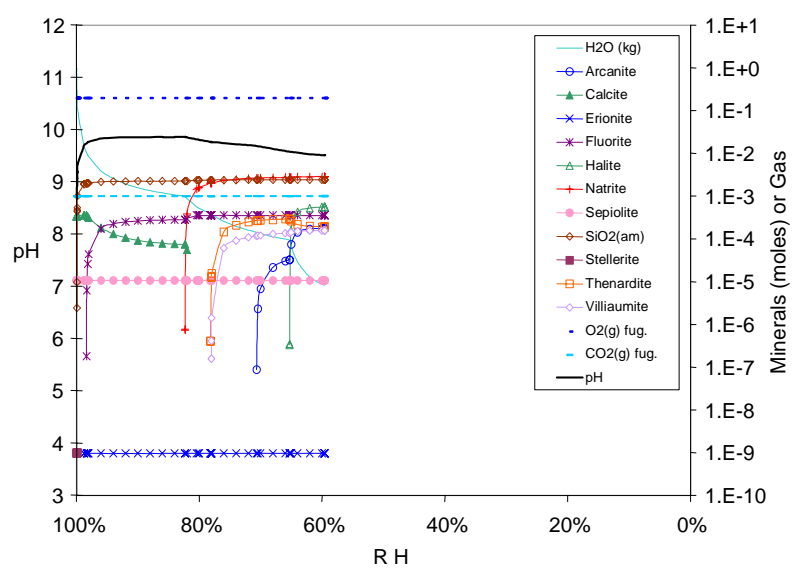

Source: DTN: MO0304SPACSALT.000, 10c3t7e.xIs.xIs.

Figure B-10-10. Bin 10 Mineral Precipitation Evaporation Predictions vs. Relative Humidity at $70^{\circ} \mathrm{C}$ and $10^{-3}$ bar $\mathrm{CO}_{2}$ Fugacity 


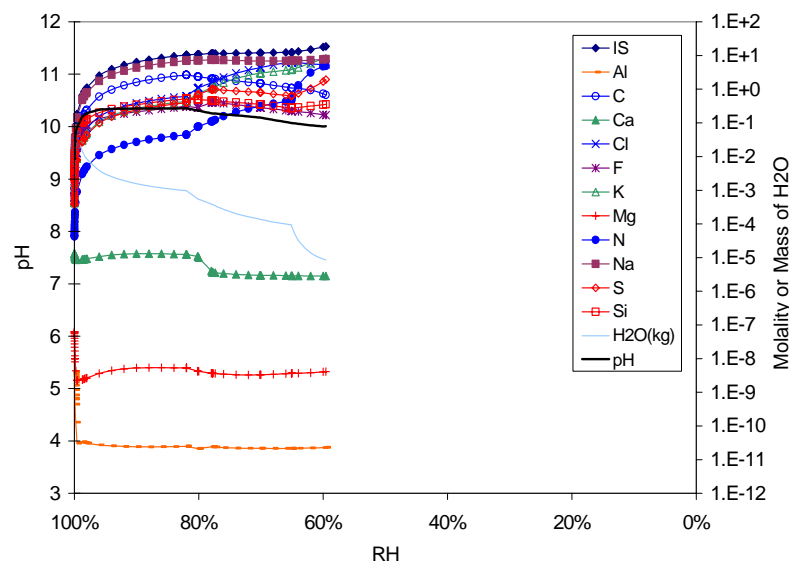

Source: DTN: MO0304SPACSALT.000, 10c4t7e.xIs.xIs.

Figure B-10-11. Bin 10 Aqueous Composition Evaporation Predictions vs. Relative Humidity at $70^{\circ} \mathrm{C}$ and $10^{-4}$ bar $\mathrm{CO}_{2}$ Fugacity

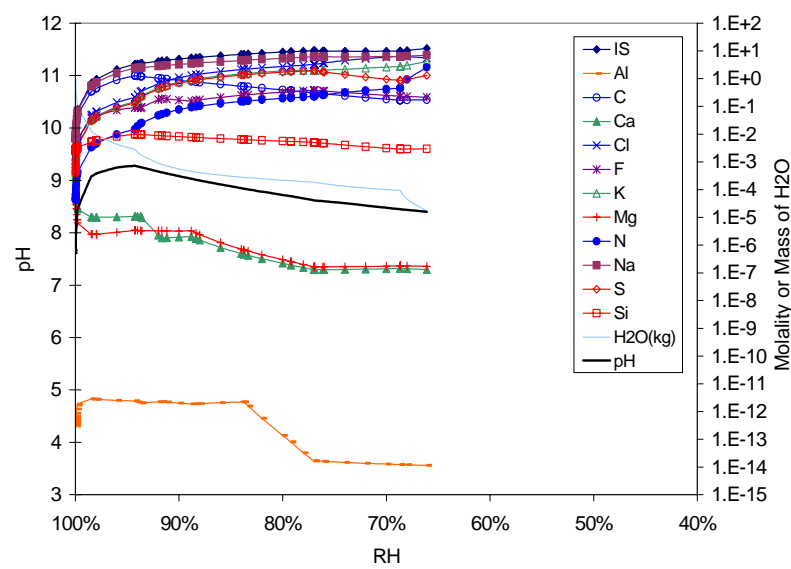

Source: DTN: MO0304SPACSALT.000, 10c2t4e.xIs.xls.

Figure B-10-13. Bin 10 Aqueous Composition Evaporation Predictions vs. Relative Humidity at $40^{\circ} \mathrm{C}$ and $10^{-2}$ bar $\mathrm{CO}_{2}$ Fugacity

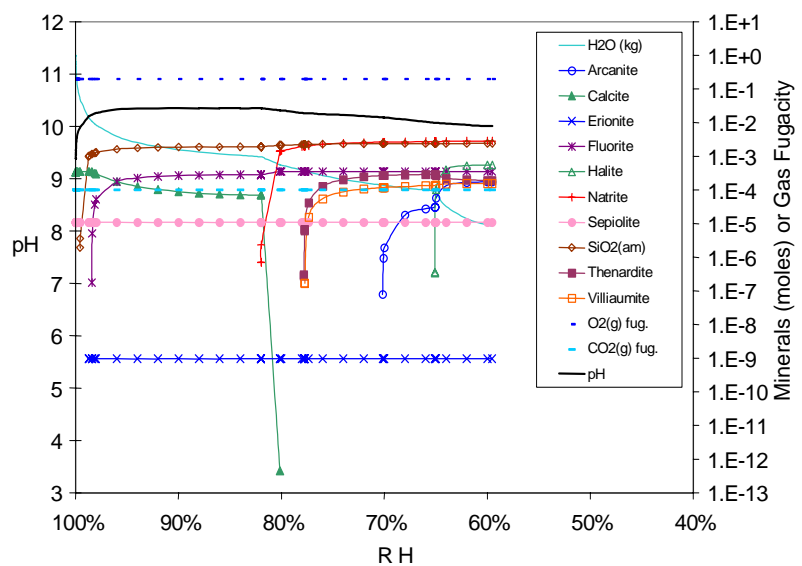

Source: DTN: MO0304SPACSALT.000, 10c4t7e.xIs.xls.

Figure B-10-12. Bin 10 Mineral Precipitation Evaporation Predictions vs. Relative Humidity at $70^{\circ} \mathrm{C}$ and $10^{-4}$ bar $\mathrm{CO}_{2}$ Fugacity

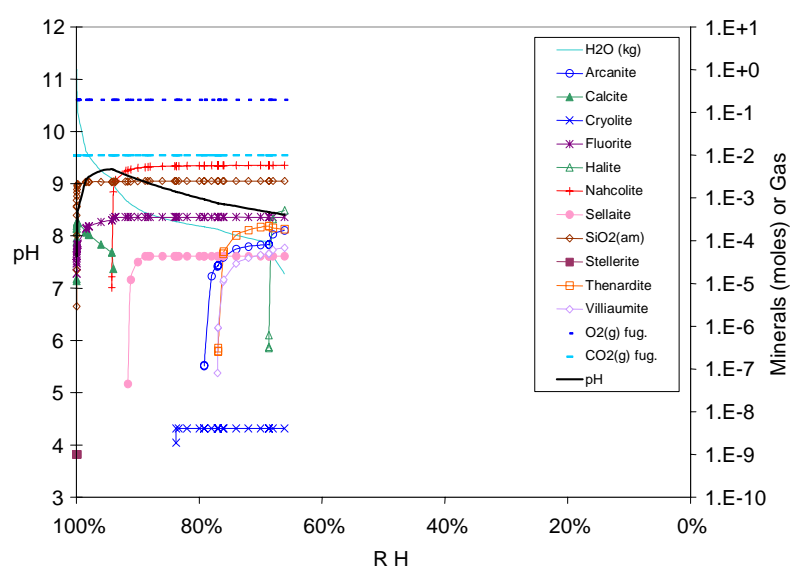

Source: DTN: MO0304SPACSALT.000, 10c2t4e.xIs.xIs.

Figure B-10-14. Bin 10 Mineral Precipitation Evaporation Predictions vs. Relative Humidity at $40^{\circ} \mathrm{C}$ and $10^{-2}$ bar $\mathrm{CO}_{2}$ Fugacity 


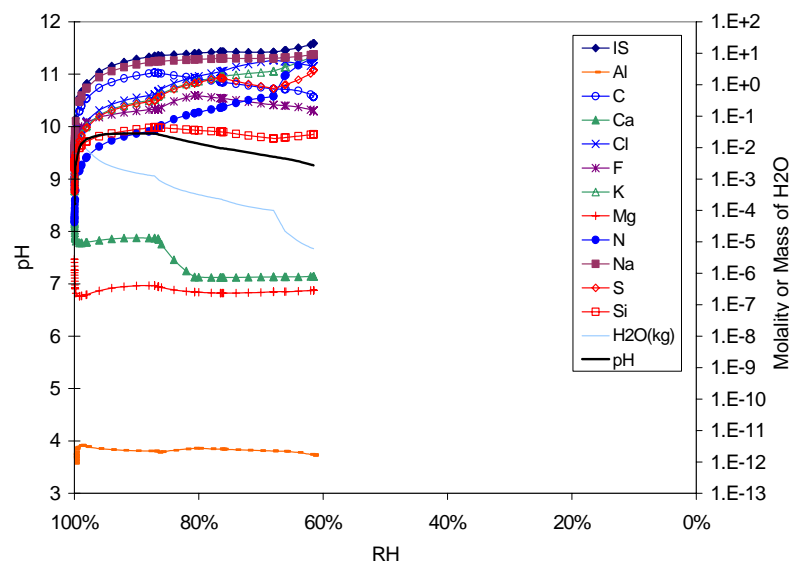

Source: DTN: MO0304SPACSALT.000, 10c3t4e.xIs.xIs.

Figure B-10-15. Bin 10 Aqueous Composition Evaporation Predictions vs. Relative Humidity at $40^{\circ} \mathrm{C}$ and $10^{-3}$ bar $\mathrm{CO}_{2}$ Fugacity

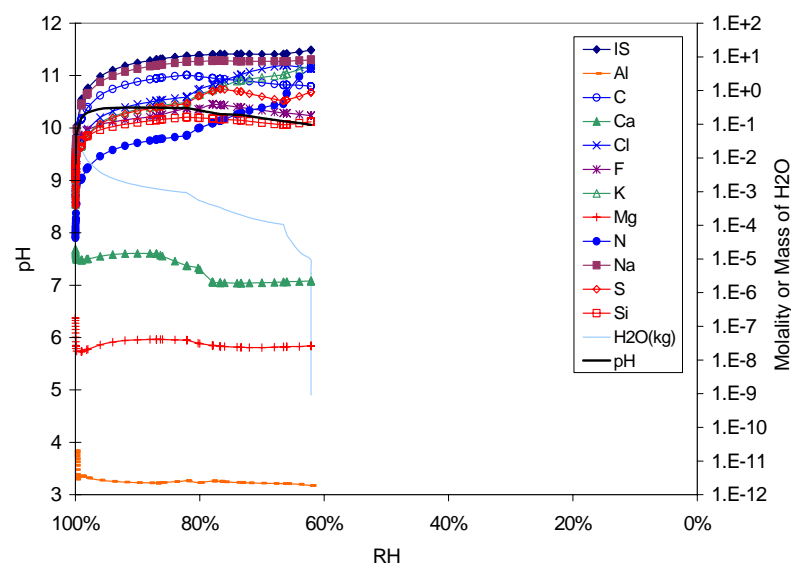

Source: DTN: MO0304SPACSALT.000, 10c4t4e.xls.xIs.

Figure B-10-17. Bin 10 Aqueous Composition Evaporation Predictions vs. Relative Humidity at $40^{\circ} \mathrm{C}$ and $10^{-4}$ bar $\mathrm{CO}_{2}$ Fugacity

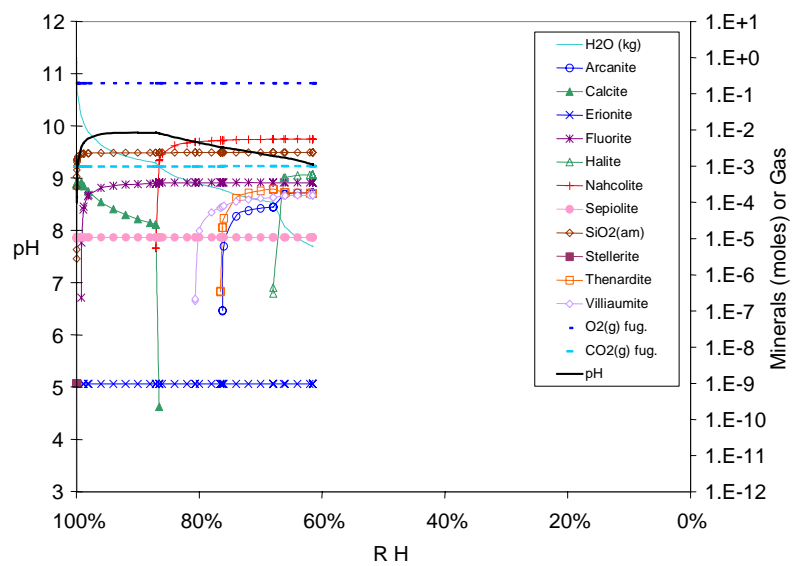

Source: DTN: MO0304SPACSALT.000, 10c3t4e.xIs.xIs.

Figure B-10-16. Bin 10 Mineral Precipitation Evaporation Predictions vs. Relative Humidity at $40^{\circ} \mathrm{C}$ and $10^{-3}$ bar $\mathrm{CO}_{2}$ Fugacity

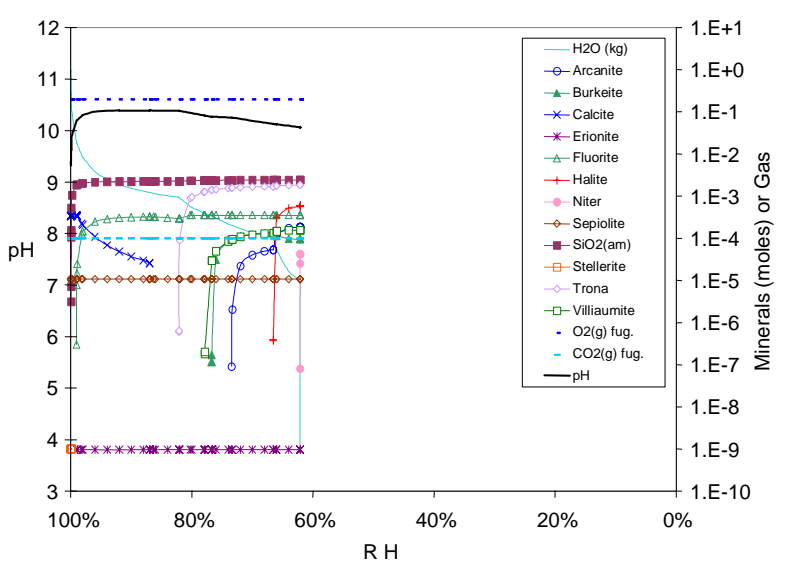

Source: DTN: MO0304SPACSALT.000, 10c4t4e.xIs.xIs.

Figure B-10-18. Bin 10 Mineral Precipitation Evaporation Predictions vs. Relative Humidity at $40^{\circ} \mathrm{C}$ and $10^{-4}$ bar $\mathrm{CO}_{2}$ Fugacity 


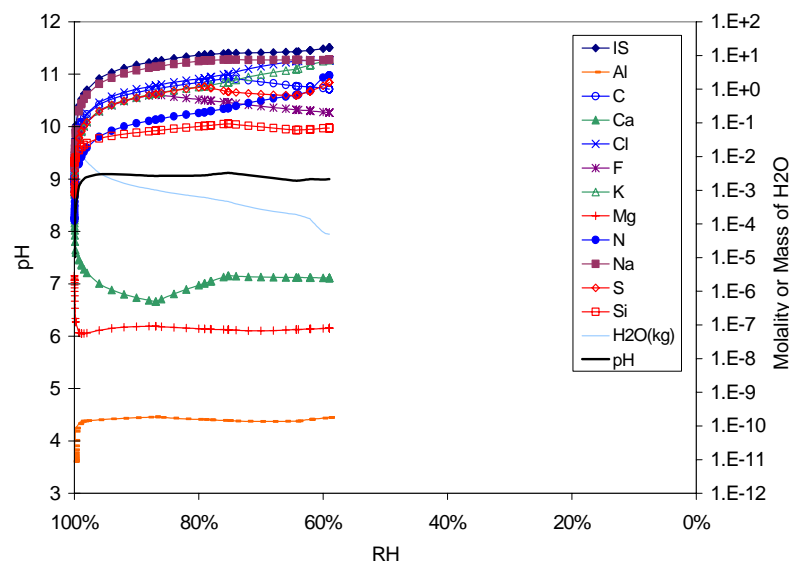

Source: DTN: MO0304SPACSALT.000, 11c2t1e.xIs.xIs.

Figure B-11-1. Bin 11 Aqueous Composition Evaporation Predictions vs. Relative Humidity at $100^{\circ} \mathrm{C}$ and $10^{-2}$ bar $\mathrm{CO}_{2}$ Fugacity

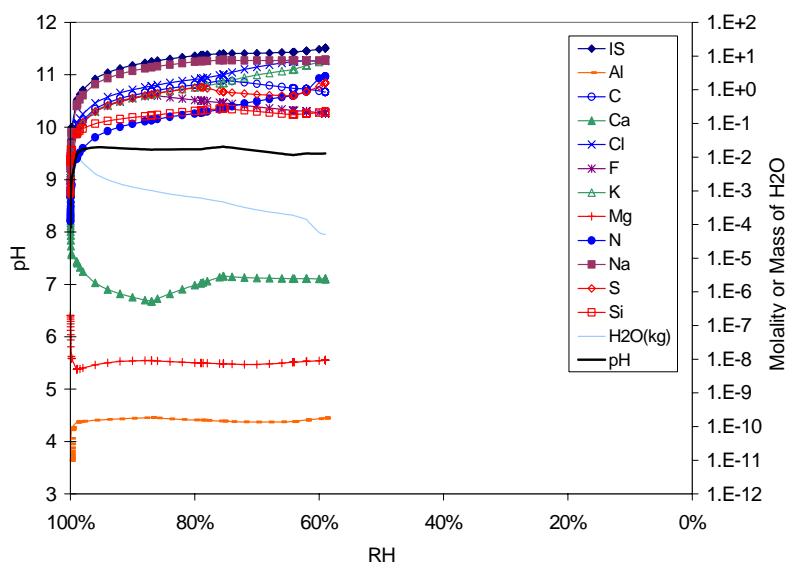

Source: DTN: MO0304SPACSALT.000, 11c3t1e.xIs.x/s.

Figure B-11-3. Bin 11 Aqueous Composition Evaporation Predictions vs. Relative Humidity at $100^{\circ} \mathrm{C}$ and $10^{-3}$ bar $\mathrm{CO}_{2}$ Fugacity

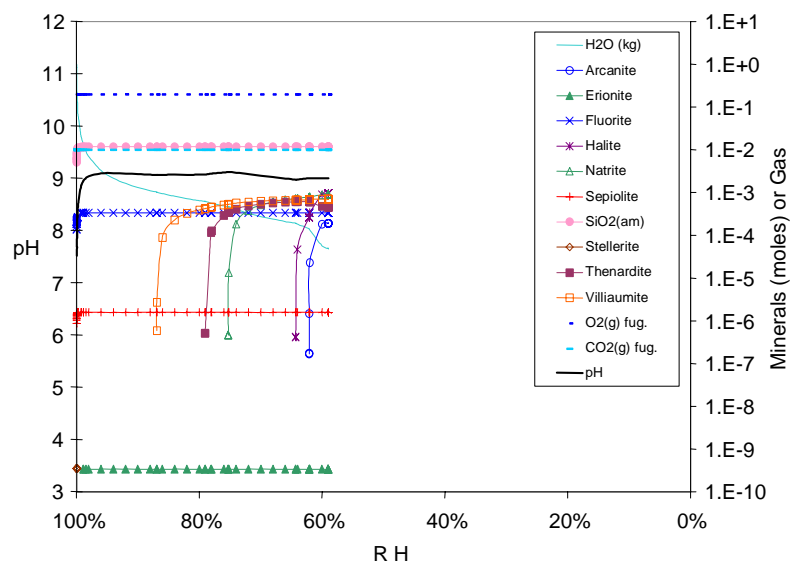

Source: DTN: MO0304SPACSALT.000, 11c2t1e.xls.xIs.

Figure B-11-2. Bin 11 Mineral Precipitation Evaporation Predictions vs. Relative Humidity at $100^{\circ} \mathrm{C}$ and $10^{-2}$ bar $\mathrm{CO}_{2}$ Fugacity

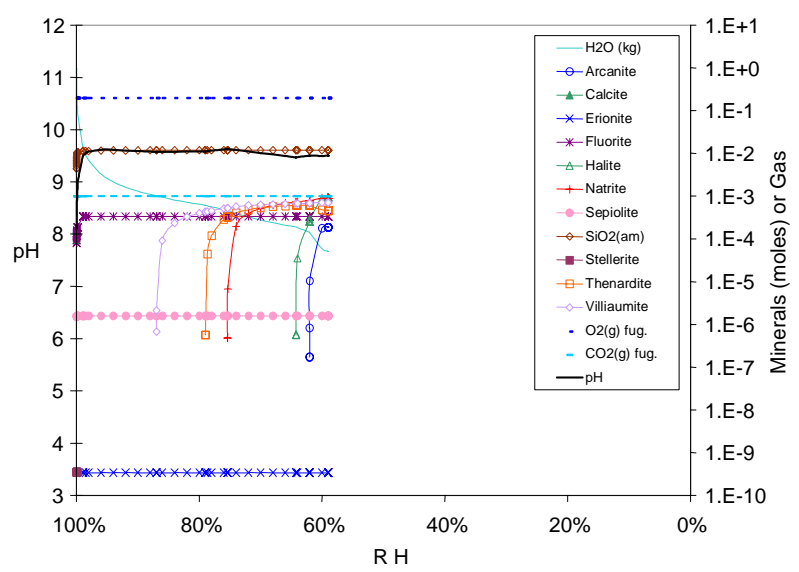

Source: DTN: MO0304SPACSALT.000, 11c3t1e.xIs.xIs.

Figure B-11-4. Bin 11 Mineral Precipitation Evaporation Predictions vs. Relative Humidity at $100^{\circ} \mathrm{C}$ and $10^{-3}$ bar $\mathrm{CO}_{2}$ Fugacity 


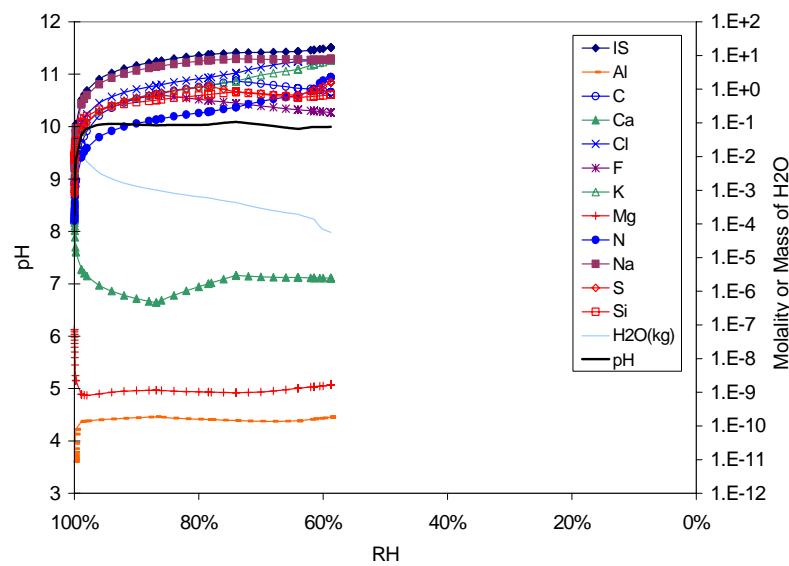

Source: DTN: MO0304SPACSALT.000, 11c4t1e.xIs.xIs.

Figure B-11-5. Bin 11 Aqueous Composition Evaporation Predictions vs. Relative Humidity at $100^{\circ} \mathrm{C}$ and $10^{-4}$ bar $\mathrm{CO}_{2}$ Fugacity

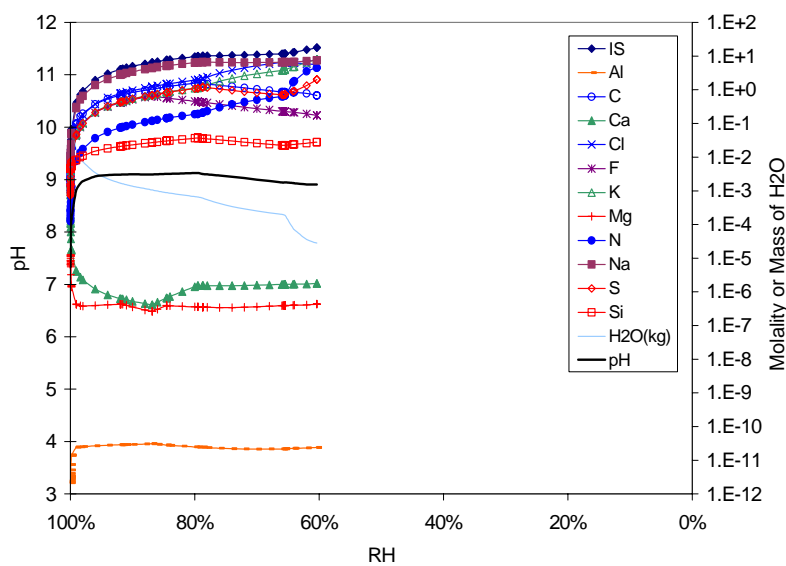

Source: DTN: MO0304SPACSALT.000, 11c2t7e.xIs.x/s.

Figure B-11-7. Bin 11 Aqueous Composition Evaporation Predictions vs. Relative Humidity at $70^{\circ} \mathrm{C}$ and $10^{-2}$ bar $\mathrm{CO}_{2}$ Fugacity

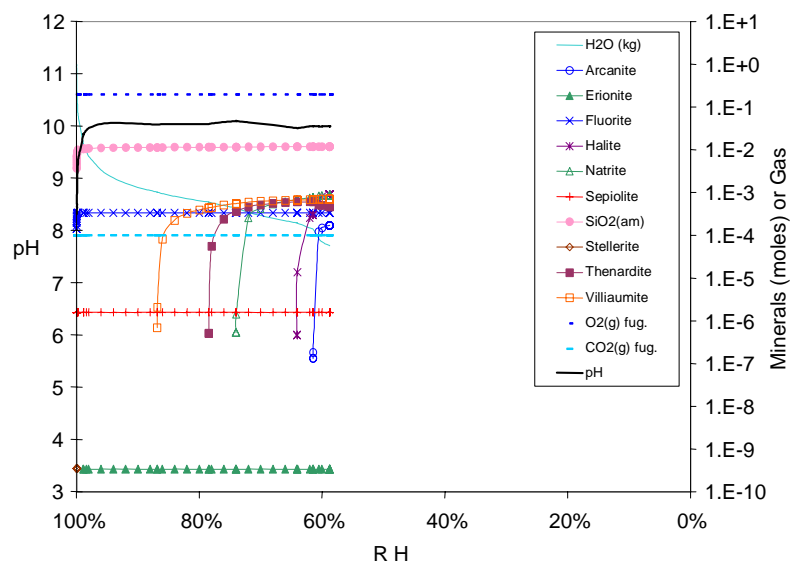

Source: DTN: MO0304SPACSALT.000, 11c4t1e.xIs.xIs.

Figure B-11-6. Bin 11 Mineral Precipitation Evaporation Predictions vs. Relative Humidity at $100^{\circ} \mathrm{C}$ and $10^{-4}$ bar $\mathrm{CO}_{2}$ Fugacity

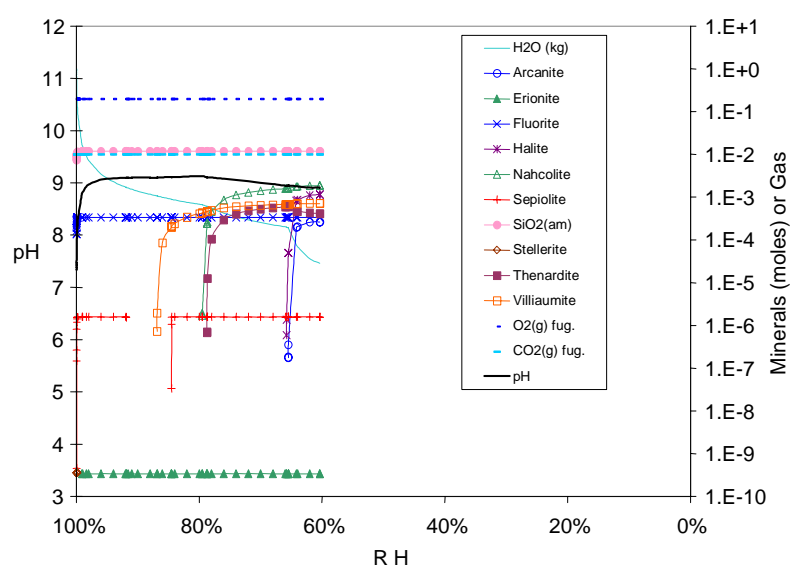

Source: DTN: MO0304SPACSALT.000, 11c2t7e.xIs.xIs.

Figure B-11-8. Bin 11 Mineral Precipitation Evaporation Predictions vs. Relative Humidity at $70^{\circ} \mathrm{C}$ and $10^{-2}$ bar $\mathrm{CO}_{2}$ Fugacity 


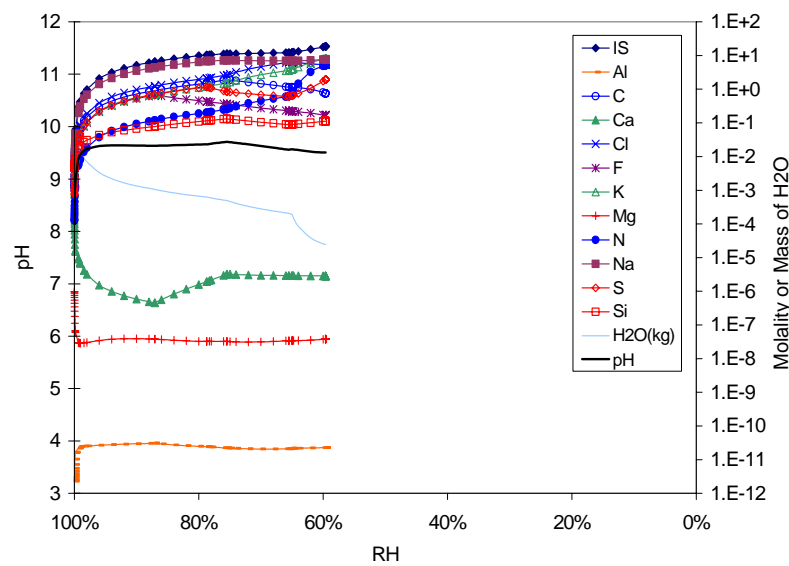

Source: DTN: MO0304SPACSALT.000, 11c3t7e.xIs.x/s.

Figure B-11-9. Bin 11 Aqueous Composition Evaporation Predictions vs. Relative Humidity at $70^{\circ} \mathrm{C}$ and $10^{-3}$ bar $\mathrm{CO}_{2}$ Fugacity

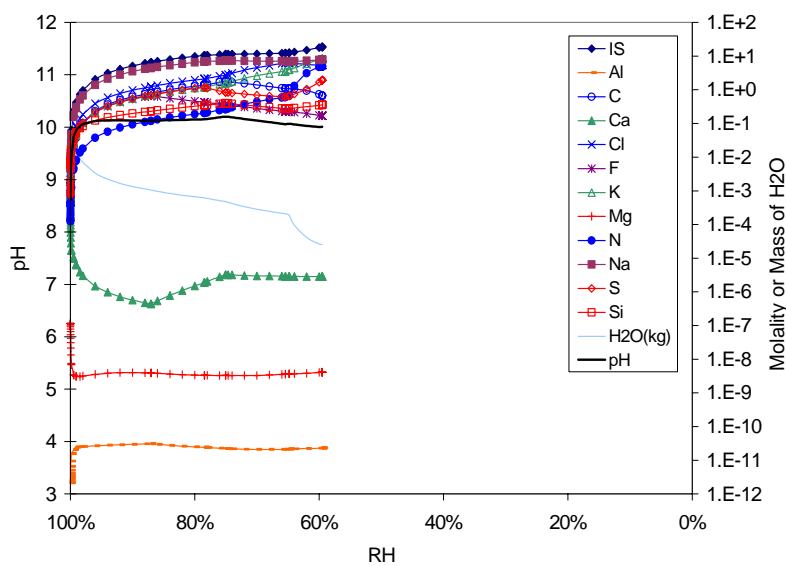

Source: DTN: MO0304SPACSALT.000, 11c4t7e.xIs.xIs.

Figure B-11-11. Bin 11 Aqueous Composition Evaporation Predictions vs. Relative Humidity at $70^{\circ} \mathrm{C}$ and $10^{-4}$ bar $\mathrm{CO}_{2}$ Fugacity

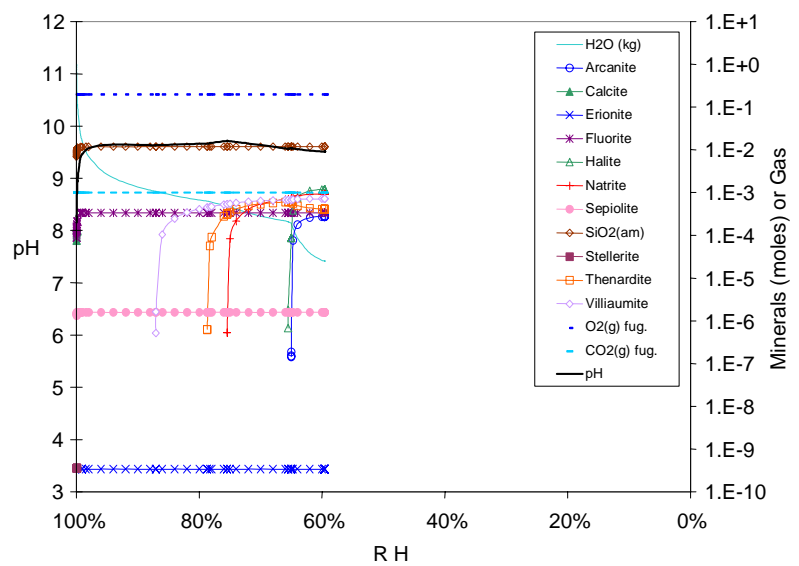

Source: DTN: MO0304SPACSALT.000, 11c3t7e.xIs.xIs.

Figure B-11-10. Bin 11 Mineral Precipitation Evaporation Predictions vs. Relative Humidity at $70^{\circ} \mathrm{C}$ and $10^{-3}$ bar $\mathrm{CO}_{2}$ Fugacity

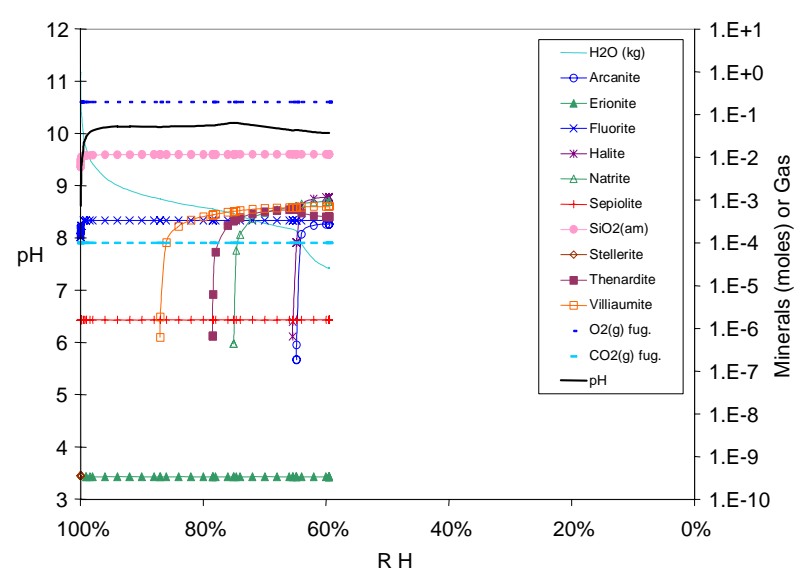

Source: DTN: MO0304SPACSALT.000, 11c4t7e.xls.xls.

Figure B-11-12. Bin 11 Mineral Precipitation Evaporation Predictions vs. Relative Humidity at $70^{\circ} \mathrm{C}$ and $10^{-4}$ bar $\mathrm{CO}_{2}$ Fugacity 


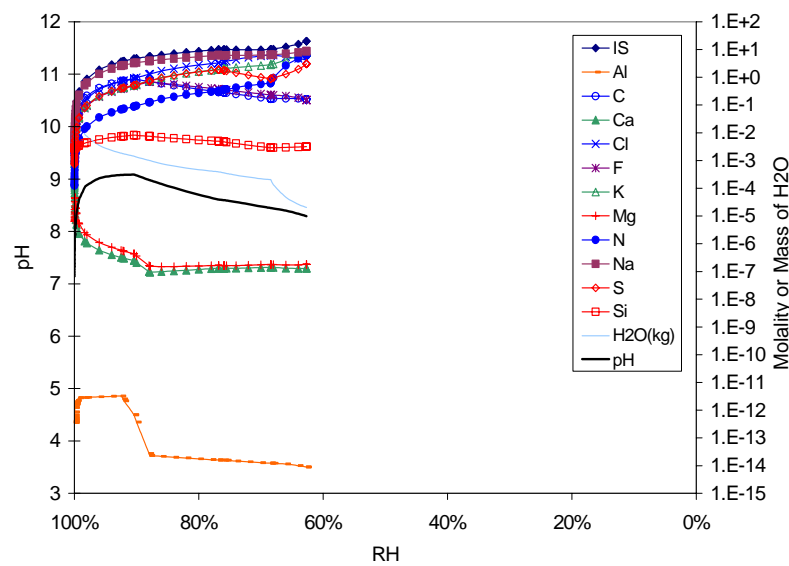

Source: DTN: MO0304SPACSALT.000, 11c2t4e.xIs.xIs.

Figure B-11-13. Bin 11 Aqueous Composition Evaporation Predictions vs. Relative Humidity at $40^{\circ} \mathrm{C}$ and $10^{-2}$ bar $\mathrm{CO}_{2}$ Fugacity

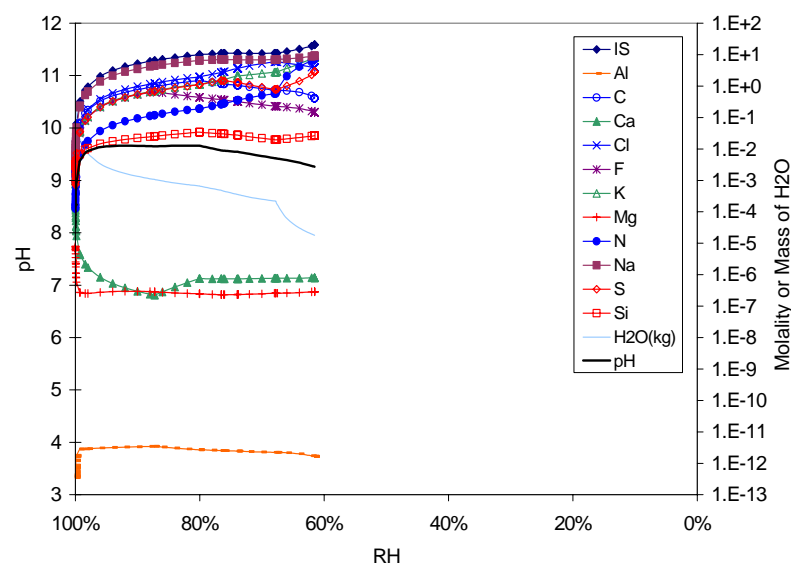

Source: DTN: M00304SPACSALT.000, 11c3t4e.xIs.xls.

Figure B-11-15. Bin 11 Aqueous Composition Evaporation Predictions vs. Relative Humidity at $40^{\circ} \mathrm{C}$ and $10^{-3}$ bar $\mathrm{CO}_{2}$ Fugacity

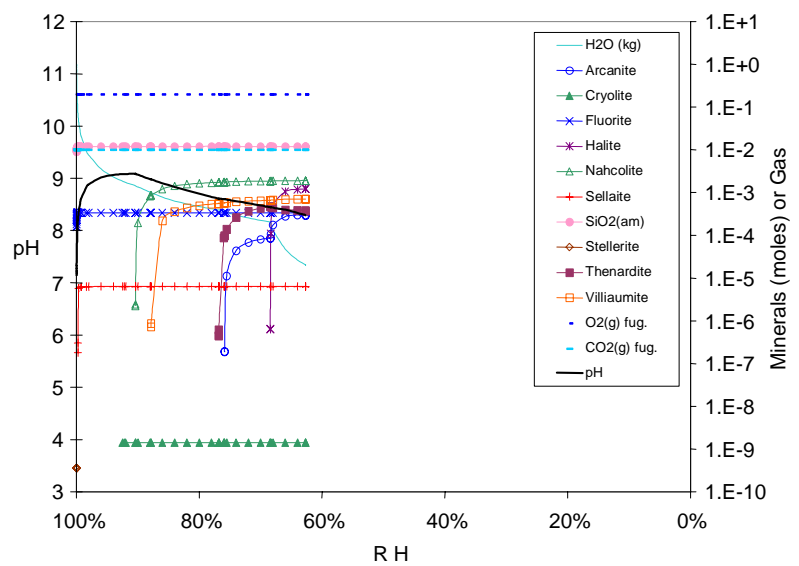

Source: DTN: MO0304SPACSALT.000, 11c2t4e.xIs.x/s.

Figure B-11-14. Bin 11 Mineral Precipitation Evaporation Predictions vs. Relative Humidity at $40^{\circ} \mathrm{C}$ and $10^{-2}$ bar $\mathrm{CO}_{2}$ Fugacity

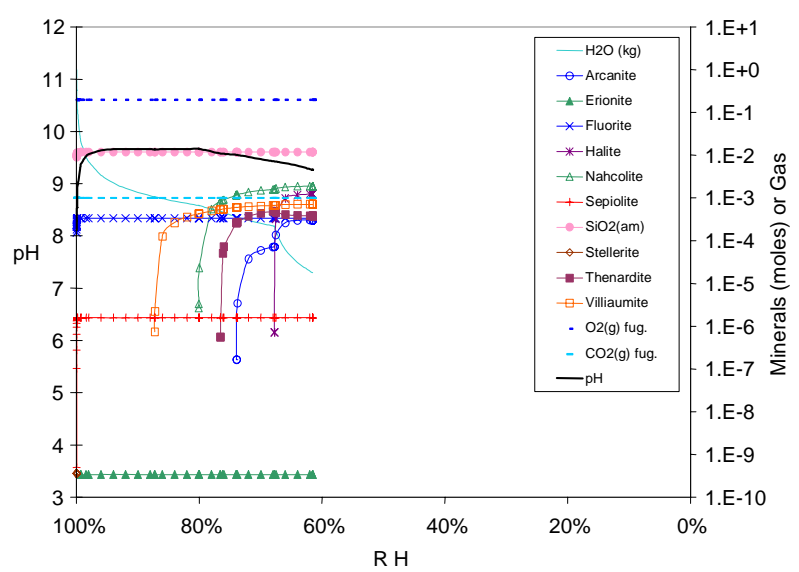

Source: DTN: MO0304SPACSALT.000, 11c3t4e.xIs.xIs.

Figure B-11-16. Bin 11 Mineral Precipitation Evaporation Predictions vs. Relative Humidity at $40^{\circ} \mathrm{C}$ and $10^{-3}$ bar $\mathrm{CO}_{2}$ Fugacity 


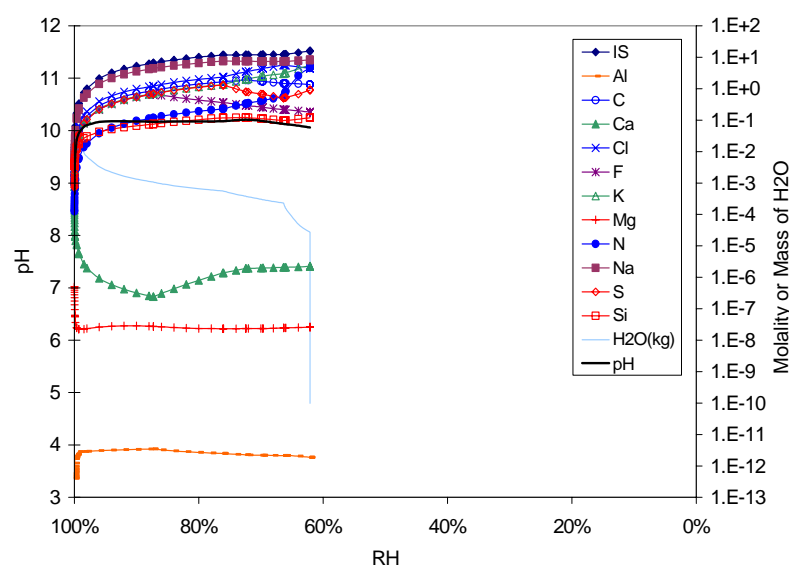

Source: DTN: MO0304SPACSALT.000, 11c4t4e.xIs.xls.

Figure B-11-17. Bin 11 Aqueous Composition Evaporation Predictions vs. Relative Humidity at $40^{\circ} \mathrm{C}$ and $10^{-4}$ bar $\mathrm{CO}_{2}$ Fugacity

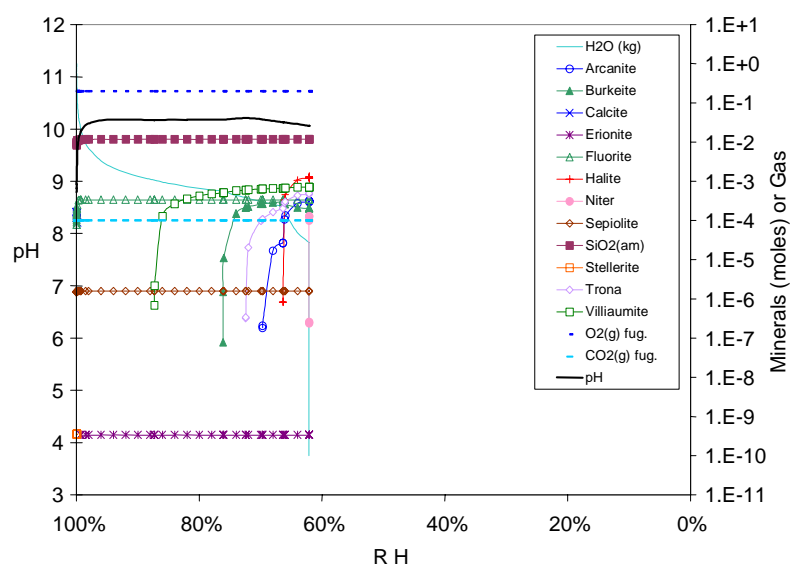

Source: DTN: MO0304SPACSALT.000, 11c4t4e.xls.xIs

Figure B-11-18. Bin 11 Mineral Precipitation Evaporation Predictions vs. Relative Humidity at $40^{\circ} \mathrm{C}$ and $10^{-4}$ bar $\mathrm{CO}_{2}$ Fugacity 


\section{INTENTIONALLY LEFT BLANK}




\section{APPENDIX C}

\section{CRITIQUE OF EXCLUDED MINERALS}




\section{INTENTIONALLY LEFT BLANK}


To evaluate as comprehensively as possible what solids need to be included in the database entries, all minerals in Encyclopedia of Minerals, 2nd Ed. (Roberts et al. 1990 [DIRS 107105]) have been examined with respect to the anticipated physicochemical system. Table $\mathrm{C}-1$ provides the results of this evaluation. Minerals known to form only at temperatures outside the anticipated range of temperature for seepage to enter the drift $\left(0^{\circ} \mathrm{C}\right.$ to $100^{\circ} \mathrm{C}$; Section 6.2 .2 .5$)$ are excluded from the table. Specifically, this means that, if the only occurrences noted by Roberts et al. (1990 [DIRS 107105]) are for hydrothermal, metamorphic, or igneous conditions, the mineral is not included in the table. Similarly, minerals that form only at elevated pressure are omitted. Limits have been placed on chemical conditions. Specifically, the minerals that contain $\mathrm{Na}, \mathrm{Mg}, \mathrm{Al}, \mathrm{Si}, \mathrm{K}, \mathrm{Ca}, \mathrm{Mn}$, and Fe were included if they did not also contain $\mathrm{Li}, \mathrm{Be}, \mathrm{B}$, $\mathrm{Sc}, \mathrm{V}, \mathrm{Cr}$, or elements heavier than Fe, and if they were not already included in data0.ymp.R2 or in data0.ypf.R0. This excludes minerals that contain ferroalloy metals other than iron. To the extent that they will occur in the repository, these minerals are included in analyses and models of metal corrosion and need not be included here. Similarly, the various elements of concern in respect to radioactivity are considered separately. The scope of the chemical range for minerals included in Table $\mathrm{C}-1$ does not include: reducing conditions; the oxidizing zone of ore deposits (especially sulfide ore bodies); those minerals that formed within the range $0^{\circ} \mathrm{C}$ to $100^{\circ} \mathrm{C}$, and which form only as weathering products on mafic and ultramafic rocks, pegmatites, or metamorphic rocks; environments in which the rocks consist largely or dominantly of iron, manganese, or phosphate minerals; meteorites; deep sea minerals; or minerals that are known to form, by alteration or epitaxial growth, only on preexisting minerals that are unexpected to be present or to form in the repository (often in Table C-1 the comment "precursor absent" is used to designate this situation). Training in mineralogy and petrology is required in making these evaluations. For the purposes of Table $\mathrm{C}-1$, metamorphic rocks include those formed by regional metamorphism, contact metamorphism, and metasomatism. Serpentine is considered metamorphic rather than igneous. Pegmatites are considered igneous, and in many cases minerals formed by alteration of pegmatite minerals are also; it is often not clear whether these minerals formed during late-stage hydrothermal alteration or by weathering.

Many igneous and metamorphic minerals vary in chemical composition and include varieties that are unusually rich in $\mathrm{Fe}, \mathrm{Mn}, \mathrm{Mg}$, or $\mathrm{Na}$. The occurrences of these enriched minerals have been examined and generally excluded from the listing in Table $\mathrm{C}-1$ because their conditions of formation were either essentially the same as for the corresponding non-enriched varieties or would be excluded on other bases. Thus, most minerals beginning with the prefixes ferri-, ferromagnesio-, magnesium- mangan-, natro-, and sodium- were not included. In similar fashion, minerals that differ only slightly (e.g., in amount of water of hydration, or small differences in structure, prefixes meta-, ortho-, and para-) were excluded. Minerals identified as consisting of interstratified sheet silicates with intercalated layers characteristic of different minerals have been excluded, as well as a few inadequately described rare minerals.

Except for the exclusions noted above, all minerals listed by Roberts et al. (1990 [DIRS 107105]) are included in Table C-1. 
The criteria used to construct Table C-1 resemble those given for suppression of minerals in Section 6.5.4, but some either differ slightly or are not used. They are:

Criterion 1-The conditions for formation of the mineral lie outside the defined physicochemical system.

Criterion 2-There is evidence that the precipitation of the mineral in nature is likely slow within the defined temperature range. For example, authigenic minerals, which typically form very slowly, fall in this category.

Criterion 3-Another mineral with the same, or nearly the same, chemical composition is in one of the databases (e.g., one with a difference only in the degree of hydration).

Criterion 4-The mineral is not needed to test uncertainty or sensitivity. Not evaluated.

Criterion 5-Exclusion of the mineral does not make the model less conservative. Used only for rare minerals.

Criterion 6-Other minerals that are in a database provide an adequate surrogate or proxy for the mineral.

This last criterion is used globally for those lacustrine borate evaporate minerals not included in data0.ymp.R2. A large number of minerals containing boron occur in lacustrine evaporites. If those that also contain $\mathrm{Al}, \mathrm{As}, \mathrm{Be}, \mathrm{Ce}, \mathrm{Cu}, \mathrm{Cs}, \mathrm{Fe}, \mathrm{La}, \mathrm{Mn}, \mathrm{Nb}, \mathrm{NH} 4, \mathrm{Ni}, \mathrm{Si}, \mathrm{Sn}$, or Sr are excluded, because all are expected to have very low concentrations in solution either due to their rarity or their insolubility, the only remaining cations in these borate minerals are $\mathrm{Ca}, \mathrm{Na}$, and $\mathrm{Mg}$. Some of these minerals also contain carbonate, chloride, sulfate, or phosphate. Consequently, the minerals borax, colemanite, hydroboracite, calcite, gypsum, apatite, and halite, which are incorporated into data0.ymp.R2, include all the elements in any of the borate minerals that might reasonably be expected to form as a consequence of evaporation of water in the repository. Because these minerals (and others in the database, including boehmite for $\mathrm{Al}$, $\mathrm{SiO}_{2}(\mathrm{am})$ for $\mathrm{Si}$, and goethite for $\mathrm{Fe}$ ) in one proportion or another encompass the anticipated compositional range in respect to boron, there is no need to include the approximately 85 additional borate minerals in the database and they are not further evaluated in Table C-1.

The first column in Table $\mathrm{C}$-1 gives the mineral name and the second the corresponding chemical formula. The third states whether the mineral is known to form in nature within the temperature range $0^{\circ} \mathrm{C}$ to $100^{\circ} \mathrm{C}$. The fourth uniformly states that these minerals are not needed for the geochemical models on the basis of the criteria in column 5 and comments in column 7. Column 6 provides a more general evaluation of whether or not the mineral is known to, or may, form within both the chemical and physical scopes applicable to the repository. So long as a suitable surrogate is available within the databases in the form or one or more minerals, a "yes" in this column does not mean that the mineral must be in a database. In all cases, such surrogates appear adequate.

For those minerals whose conditions for formation lie within the physicochemical system for the repository, but are not in a database, one or more minerals are listed or referred to by category, in the comments section for that mineral. These minerals are in data0.ymp.R2 or data0.ypf.R0, 
include all or most of the elements in the mineral, and tend to precipitate under conditions resembling those for formation of the mineral in question. These lists are not intended to be comprehensive, but merely to show that minerals of the same general nature are in at least one of the databases. During geochemical modeling, a combination of these minerals, possibly including others not listed, that corresponds approximately to the composition of the mineral may precipitate. If instead the mineral should have precipitated, the modeled result will leave more of at least some of the elements involved in solution than would be the case, if the mineral itself precipitated. Because the concentrations would be higher, the modeled results are more conservative. In any event, the evolution of the water chemistry would be similar because the amounts and proportions of precipitated components would largely correspond.

The principal reference for all entries is Encyclopedia of Minerals, 2nd Ed. (Roberts et al. 1990 [DIRS 107105]). In addition, Aquatic Chemistry, An Introduction Emphasizing Chemical Equilibria in Natural Waters, 2nd Edition, (Stumm and Morgan 1981 [DIRS 100829], pp. 284 to 285) is used for the mineral carbonate-apatite. 
Table C-1. Critique of Minerals Not Included in Project Databases

\begin{tabular}{|c|c|c|c|c|c|c|}
\hline Mineral & Chemical Formula & $\begin{array}{c}\text { Precipitates } \\
\text { from } 0 \text { to } 100^{\circ} \mathrm{C} \\
\text { and at } 1 \mathrm{ATM}\end{array}$ & Needed & Criterion & $\begin{array}{l}\text { Within Defined } \\
\text { Physico- } \\
\text { Chemical } \\
\text { System } \\
\end{array}$ & $\begin{array}{c}\text { Comments on Occurrence } \\
\text { or Formation }\end{array}$ \\
\hline actinolite & $\mathrm{Ca}_{2}\left(\mathrm{Mg}, \mathrm{Fe}^{2+}\right)_{5} \mathrm{Si}_{8} \mathrm{O}_{22}(\mathrm{OH})_{2}$ & No & No & 1 & No & Metamorphic mineral \\
\hline aegirine(Acmite) & $\mathrm{NaFe}^{3+} \mathrm{Si}_{2} \mathrm{O}_{6}$ & Yes & No & 2 & Yes & $\begin{array}{l}\text { Igneous, metamorphic and } \\
\text { authigenic mineral. Not } \\
\text { needed because authigenic } \\
\text { minerals form very slowly. }\end{array}$ \\
\hline aenigmatite & $\mathrm{Na}_{2} \mathrm{Fe}_{5} \mathrm{TiSi}_{6} \mathrm{O}_{20}$ & No & No & 1 & No & Igneous mineral \\
\hline afghanite & $(\mathrm{Na}, \mathrm{Ca}, \mathrm{K})_{8}(\mathrm{Si}, \mathrm{Al})_{12} \mathrm{O}_{24}\left(\mathrm{Cl}, \mathrm{SO}_{4}, \mathrm{CO}_{3}\right)_{3-4} \bullet \mathrm{H}_{2} \mathrm{O}$ & No & No & 1 & No & Igneous mineral \\
\hline afwillite & $\mathrm{Ca}_{3} \mathrm{Si}_{2} \mathrm{O}_{4}(\mathrm{OH})_{6}$ & No & No & 1 & No & $\begin{array}{l}\text { Igneous or metamorphic } \\
\text { mineral }\end{array}$ \\
\hline agrellite & $\mathrm{NaCa}_{2} \mathrm{Si}_{4} \mathrm{O}_{10} \mathrm{~F}$ & No & No & 1 & No & Metamorphic mineral \\
\hline akaganéite & $\beta-\mathrm{FeO}(\mathrm{OH}, \mathrm{Cl})$ & $?$ & No & 6 & Yes & $\begin{array}{l}\text { Other FeOOH minerals suffice } \\
\text { for conservatism }\end{array}$ \\
\hline akatoreite & $\mathrm{Mn}_{9}(\mathrm{Si}, \mathrm{Al})_{10} \mathrm{O}_{23}(\mathrm{OH})_{9}$ & No & No & 1 & No & Metamorphic mineral \\
\hline akdalaite & $4 \mathrm{Al}_{2} \mathrm{O}_{3} \cdot \mathrm{H}_{2} \mathrm{O}$ & No & No & 1 & No & $\begin{array}{l}\text { Hydrothermal and } \\
\text { metasomatic }\end{array}$ \\
\hline aldermanite & $\mathrm{Mg}_{5} \mathrm{Al}_{12}\left(\mathrm{PO}_{4}\right)_{8}(\mathrm{OH})_{22} \cdot 32 \mathrm{H}_{2} \mathrm{O}$ & Yes? & No & 1 & No & $\begin{array}{l}\text { Associated with phosphate } \\
\text { deposits }\end{array}$ \\
\hline alleghanyite & $\mathrm{Mn}_{5} \mathrm{Si}_{2} \mathrm{O}_{8}(\mathrm{OH})_{2}$ & No & No & 1 & No & $\begin{array}{l}\text { Metamorphic mineral, occurs } \\
\text { in } \mathrm{Mn} \text { deposits }\end{array}$ \\
\hline allophane & $\mathrm{Al}_{2} \mathrm{SiO}_{5} \bullet \mathrm{nH}_{2} \mathrm{O}$ & No & No & 1 & No & $\begin{array}{l}\text { Hydrothermal mineral and in } \\
\text { coal }\end{array}$ \\
\hline alluaudite & $(\mathrm{Na}, \mathrm{Ca}) \mathrm{Fe}^{2+}\left(\mathrm{Mn}, \mathrm{Fe}^{2+}, \mathrm{Fe}^{3+}, \mathrm{Mg}\right)_{2}\left(\mathrm{PO}_{4}\right)_{3}$ & No & No & 1 & No & Igneous mineral \\
\hline almandine & $\mathrm{Fe}_{3}^{2+}{ }_{3} \mathrm{Al}_{2}\left(\mathrm{SiO}_{4}\right)_{3}$ & No & No & 1 & No & $\begin{array}{l}\text { Igneous and metamorphic } \\
\text { mineral }\end{array}$ \\
\hline alstonite & $\mathrm{CaBa}\left(\mathrm{CO}_{3}\right)_{2}$ & No & No & 1 & No & Hydrothermal mineral \\
\hline althausite & $\mathrm{Mg}_{2}\left(\mathrm{PO}_{4}\right)(\mathrm{OH}, \mathrm{F}, \mathrm{O})$ & No & No & 1 & No & $\begin{array}{l}\text { Igneous or hydrothermal } \\
\text { mineral }\end{array}$ \\
\hline aluminite & $\mathrm{Al}_{2}\left(\mathrm{SO}_{4}\right)(\mathrm{OH})_{4} \cdot 7 \mathrm{H}_{2} \mathrm{O}$ & Yes & No & 5 & Possibly & $\begin{array}{l}\text { Rare, in limestone. Other } \\
\text { minerals (e.g., alum-K, } \\
\text { gypsum, boehmite) provide } \\
\text { adequate conservatism for } \\
\text { elements in this mineral. }\end{array}$ \\
\hline
\end{tabular}


Table C-1. Critique of Minerals not Included in Project Databases (Continued)

\begin{tabular}{|c|c|c|c|c|c|c|}
\hline Mineral & Chemical Formula & $\begin{array}{c}\text { Precipitates } \\
\text { from } 0 \text { to } 100^{\circ} \mathrm{C} \\
\text { and at } 1 \mathrm{ATM}\end{array}$ & Needed & Criterion & $\begin{array}{c}\text { Within Defined } \\
\text { Physico- } \\
\text { Chemical } \\
\text { System } \\
\end{array}$ & $\begin{array}{c}\text { Comments on Occurrence } \\
\text { or Formation }\end{array}$ \\
\hline aluminocopiapite & $\mathrm{AlFe}_{4}^{3+}{ }_{4}\left(\mathrm{SO}_{4}\right)_{6} \mathrm{O}(\mathrm{OH}) \cdot 2 \mathrm{H}_{2} \mathrm{O}$ & Yes & No & 5 & Possibly & $\begin{array}{l}\text { Rare. Other minerals (e.g., } \\
\text { ettringite, jarosite) provide } \\
\text { adequate conservatism for } \\
\text { elements in this mineral }\end{array}$ \\
\hline alumohydrocalcite & $\mathrm{CaAl}_{2}\left(\mathrm{CO}_{3}\right)_{2}(\mathrm{OH})_{4} \cdot 3 \mathrm{H}_{2} \mathrm{O}$ & Yes & No & 5 & No & $\begin{array}{l}\text { Rare, alteration of allophane, } \\
\text { precursor absent. Other } \\
\text { solids (e.g., cement phases } \\
\text { hemi- and mono- } \\
\text { carboaluminate in } \\
\text { dataO.ypf.RO, as well as } \\
\text { boehmite and calcite) provide } \\
\text { adequate conservatism for } \\
\text { elements in this mineral. }\end{array}$ \\
\hline alunogen & $\mathrm{Al}_{2}\left(\mathrm{SO}_{4}\right)_{3} \cdot 17 \mathrm{H}_{2} \mathrm{O}$ & Yes & No & 1 & No & $\begin{array}{l}\text { Uncommon in shale, slate, } \\
\text { coal }\end{array}$ \\
\hline amakinite & $\left(\mathrm{Fe}^{2+}, \mathrm{Mg}\right)(\mathrm{OH})_{2}$ & No? & No & 5 & No & Rare, in kimberlite \\
\hline amarantite & $\mathrm{Fe}^{3+}\left(\mathrm{SO}_{4}\right)(\mathrm{OH}) \cdot 3 \mathrm{H}_{2} \mathrm{O}$ & Yes & No & 1 & No & $\begin{array}{l}\text { Forms in sulfide mines and } \\
\text { dumps }\end{array}$ \\
\hline amarillite & $\mathrm{NaFe}^{3+}\left(\mathrm{SO}_{4}\right)_{2} \cdot 6 \mathrm{H}_{2} \mathrm{O}$ & Yes & No & 1 & No & $\begin{array}{l}\text { Forms in sulfide mines and } \\
\text { dumps }\end{array}$ \\
\hline amicite & $\mathrm{K}_{2} \mathrm{Na}_{2} \mathrm{Al}_{4} \mathrm{Si}_{4} \mathrm{O}_{16} \cdot 5 \mathrm{H}_{2} \mathrm{O}$ & No & No & 1 & No & $\begin{array}{l}\text { Igneous or hydrothermal } \\
\text { mineral }\end{array}$ \\
\hline ammoniojarosite & $\left(\mathrm{NH}_{4}\right) \mathrm{Fe}^{3+}{ }_{3}\left(\mathrm{SO}_{4}\right)_{2}(\mathrm{OH})_{6}$ & $?$ & No & 1 & No & $\begin{array}{l}\text { Associated with geysers and } \\
\text { hot springs, requires reducing } \\
\text { conditions. }\end{array}$ \\
\hline ammonioleucite & $\left(\mathrm{NH}_{4}\right) \mathrm{AlSi}_{2} \mathrm{O}_{6}$ & Yes? & No & 1 & No & $\begin{array}{l}\text { Occurs in dolomitized schist, } \\
\text { requires reducing conditions. }\end{array}$ \\
\hline anapaite & $\mathrm{Ca}_{2} \mathrm{Fe}^{2+}\left(\mathrm{PO}_{4}\right)_{2} \bullet 4 \mathrm{H}_{2} \mathrm{O}$ & $?$ & No & 1 & No & $\begin{array}{l}\text { Associated with phosphates, } \\
\text { iron ore, clay, in pegmatite }\end{array}$ \\
\hline andradite & $\mathrm{Ca}_{3} \mathrm{Fe}^{3+}{ }_{2}\left(\mathrm{SiO}_{4}\right)_{3}$ & No & No & 1 & No & $\begin{array}{l}\text { Igneous and metamorphic } \\
\text { mineral }\end{array}$ \\
\hline
\end{tabular}




\begin{tabular}{|c|c|c|c|c|c|c|}
\hline Mineral & Chemical Formula & $\begin{array}{c}\text { Precipitates } \\
\text { from } 0 \text { to } 100^{\circ} \mathrm{C} \\
\text { and at } 1 \mathrm{ATM}\end{array}$ & Needed & Criterion & $\begin{array}{l}\text { Within Defined } \\
\text { Physico- } \\
\text { Chemical } \\
\text { System }\end{array}$ & $\begin{array}{c}\text { Comments on Occurrence } \\
\text { or Formation }\end{array}$ \\
\hline ankerite & $\mathrm{Ca}\left(\mathrm{Fe}^{2+}, \mathrm{Mg}\right)\left(\mathrm{CO}_{3}\right)_{2}$ & No & No & 1 & No & Hydrothermal mineral \\
\hline anthophyllite & $\left(\mathrm{Mg}, \mathrm{Fe}^{2+}\right)_{7} \mathrm{Si}_{8} \mathrm{O}_{22}(\mathrm{OH})_{2}$ & No & No & 1 & No & Metamorphic mineral \\
\hline antigorite & $\left(\mathrm{Mg}, \mathrm{Fe}^{2+}\right)_{3} \mathrm{Si}_{2} \mathrm{O}_{5}(\mathrm{OH})_{4}$ & No? & No & 1 & No & $\begin{array}{l}\text { Associated with ultramafic } \\
\text { rocks }\end{array}$ \\
\hline apjohnite & $\mathrm{Mn}^{2+} \mathrm{Al}_{2}\left(\mathrm{SO}_{4}\right)_{4} \cdot 22 \mathrm{H}_{2} \mathrm{O}$ & Yes & No & 5 & No & $\begin{array}{l}\text { Rare. Probably requires high } \\
\text { Mn content in environment. }\end{array}$ \\
\hline archerite & $\left(\mathrm{K}, \mathrm{NH}_{4}\right) \mathrm{H}_{2} \mathrm{PO}_{4}$ & Yes & No & 1 & No & Requires reducing conditions \\
\hline arctite & $\mathrm{Na}_{2} \mathrm{Ca}_{4}\left(\mathrm{PO}_{4}\right)_{3} \mathrm{~F}$ & No & No & 1 & No & Igneous mineral \\
\hline ardealite & $\mathrm{Ca}_{2} \mathrm{HPO}_{4} \mathrm{SO}_{4} \bullet 4 \mathrm{H}_{2} \mathrm{O}$ & $?$ & No & 1 & No & Occurs in phosphate rocks \\
\hline arfvedsonite & $\mathrm{Na}_{3}\left(\mathrm{Fe}^{2+}, \mathrm{Mg}\right)_{4} \mathrm{Fe}^{3+} \mathrm{Si}_{8} \mathrm{O}_{22}(\mathrm{OH})_{2}$ & No & No & 1 & No & Igneous mineral \\
\hline armalcolite & $\left(\mathrm{Mg}, \mathrm{Fe}^{2+}\right) \mathrm{Ti}_{2} \mathrm{O}_{5}$ & No & No & 1 & No & $\begin{array}{l}\text { Igneous mineral and in } \\
\text { meteorites }\end{array}$ \\
\hline arrojadite & $\mathrm{KNa}_{4} \mathrm{CaMn}^{2+}{ }_{4} \mathrm{Fe}^{2+}{ }_{10} \mathrm{Al}\left(\mathrm{PO}_{4}\right)_{12}(\mathrm{OH}, \mathrm{F})_{2}$ & No & No & 1 & No & Igneous mineral \\
\hline astrophyllite & $(\mathrm{K}, \mathrm{Na})_{3}(\mathrm{Fe}, \mathrm{Mn})_{7} \mathrm{Ti}_{2} \mathrm{Si}_{8} \mathrm{O}_{24}(\mathrm{O}, \mathrm{OH})_{7}$ & No & No & 1 & No & Igneous mineral \\
\hline attakolite & $(\mathrm{Ca}, \mathrm{Mn}, \mathrm{Sr})_{3} \mathrm{Al}_{6}\left(\mathrm{PO}_{4}, \mathrm{SiO}_{4}\right)_{7} \cdot 3 \mathrm{H}_{2} \mathrm{O}$ & No? & No & 1 & No & Occurs in an iron mine \\
\hline augelite & $\mathrm{Al}_{2}\left(\mathrm{PO}_{4}\right)(\mathrm{OH})_{3}$ & No & No & 1 & No & $\begin{array}{l}\text { Igneous and metamorphic } \\
\text { mineral }\end{array}$ \\
\hline augite & $(\mathrm{Ca}, \mathrm{Na})(\mathrm{Mg}, \mathrm{Fe}, \mathrm{Al})(\mathrm{Si}, \mathrm{Al})_{2} \mathrm{O}_{6}$ & No & No & 1 & No & $\begin{array}{l}\text { Igneous and metamorphic } \\
\text { mineral }\end{array}$ \\
\hline babingtonite & $\mathrm{Ca}_{2} \mathrm{Fe}^{2+} \mathrm{Fe}^{3+} \mathrm{Si}_{5} \mathrm{O}_{14}(\mathrm{OH})$ & No? & No & 1 & No & $\begin{array}{l}\text { Secondary mineral in cavities } \\
\text { and fractures in igneous and } \\
\text { metamorphic rocks }\end{array}$ \\
\hline balangeroite & $\left(\mathrm{Mg}, \mathrm{Fe}^{2+}, \mathrm{Fe}^{3+}, \mathrm{Mn}^{2+}\right)_{42} \mathrm{Si}_{16} \mathrm{O}_{54}(\mathrm{OH})_{40}$ & No & No & 1 & No & $\begin{array}{l}\text { Igneous or metamorphic } \\
\text { mineral }\end{array}$ \\
\hline bannisterite & $\begin{array}{l}\mathrm{Ca}(\mathrm{K}, \mathrm{Na})\left(\mathrm{Mn}, \mathrm{Fe}^{2+}\right)_{21}(\mathrm{Si}, \mathrm{Al})_{32} \mathrm{O}_{76}(\mathrm{OH})_{16} \\
\cdot 12 \mathrm{H}_{2} \mathrm{O}\end{array}$ & No & No & 1 & No & Metamorphic mineral \\
\hline bararite & $\left(\mathrm{NH}_{4}\right)_{2} \mathrm{SiF}_{6}$ & No & No & 1 & No & Fumarolic mineral \\
\hline barbosalite & $\mathrm{Fe}^{2+} \mathrm{Fe}_{2}^{3+}{ }_{2}\left(\mathrm{PO}_{4}\right)_{2}(\mathrm{OH})_{2}$ & No & No & 1 & No & Igneous mineral \\
\hline barentsite & $\mathrm{Na}_{7} \mathrm{AlH}_{2}\left(\mathrm{CO}_{3}\right)_{4} \mathrm{~F}_{4}$ & No & No & 1 & No & Hydrothermal mineral \\
\hline baricite & $\left(\mathrm{Mg}, \mathrm{Fe}^{2+}\right)_{3}\left(\mathrm{PO}_{4}\right)_{2} \bullet 8 \mathrm{H}_{2} \mathrm{O}$ & $?$ & No & 1 & No & Associated with iron formation \\
\hline
\end{tabular}


Table C-1. Critique of Minerals not Included in Project Databases (Continued)

\begin{tabular}{|c|c|c|c|c|c|c|}
\hline Mineral & Chemical Formula & $\begin{array}{l}\text { Precipitates } \\
\text { from } 0 \text { to } 100^{\circ} \mathrm{C} \\
\text { and at } 1 \mathrm{ATM}\end{array}$ & Needed & Criterion & $\begin{array}{l}\text { Within Defined } \\
\text { Physico- } \\
\text { Chemical } \\
\text { System }\end{array}$ & $\begin{array}{c}\text { Comments on Occurrence } \\
\text { or Formation }\end{array}$ \\
\hline barrerite & $(\mathrm{Na}, \mathrm{K}, \mathrm{Ca})_{2} \mathrm{Al}_{2} \mathrm{Si}_{7} \mathrm{O}_{18^{\bullet}} 7 \mathrm{H}_{2} \mathrm{O}$ & $?$ & No & 5 & $?$ & $\begin{array}{l}\text { Rare zeolite. Other zeolites } \\
\text { provide adequate } \\
\text { conservatism for elements in } \\
\text { this mineral. }\end{array}$ \\
\hline barringtonite & $\mathrm{MgCO}_{3} \cdot 2 \mathrm{H}_{2} \mathrm{O}(?)$ & Yes & No & 1 & No & $\begin{array}{l}\text { Alteration from basalt, } \\
\text { precursor absent in repository. }\end{array}$ \\
\hline bartonite & $\mathrm{K}_{3} \mathrm{Fe}_{10} \mathrm{~S}_{14}$ & No & No & 1 & No & Requires reducing conditions \\
\hline basaluminite & $\mathrm{Al}_{4} \mathrm{SO}_{4}(\mathrm{OH})_{10} \cdot 5 \mathrm{H}_{2} \mathrm{O}$ & Yes & No & 1 & No & $\begin{array}{l}\text { Associated with coal, gypsum, } \\
\text { siderite }\end{array}$ \\
\hline bassanite & $\mathrm{CaSO}_{4} \bullet 1 / 2 \mathrm{H}_{2} \mathrm{O}$ & No & No & 1 & No & Igneous or fumarolic mineral \\
\hline bayerite & $\mathrm{Al}(\mathrm{OH})_{3}$ & Yes & No & 6 & Yes & $\begin{array}{l}\text { Gibbsite provides adequate } \\
\text { substitute. Occurs with calcite, } \\
\text { gypsum, portlandite }\end{array}$ \\
\hline baylissite & $\mathrm{K}_{2} \mathrm{Mg}\left(\mathrm{CO}_{3}\right) \cdot 4 \mathrm{H}_{2} \mathrm{O}$ & $?$ & No & 5 & No? & $\begin{array}{l}\text { Rare mineral. Other minerals } \\
\text { (e.g., kalicinite, } \\
\text { hydromagnesite) provide } \\
\text { adequate conservatism for } \\
\text { elements in this mineral. }\end{array}$ \\
\hline bementite & $\mathrm{Mn}_{8} \mathrm{Si}_{6} \mathrm{O}_{15}(\mathrm{OH})_{10}$ & Yes? & No & 1 & No & Occurs in Mn ore deposits \\
\hline beraunite & $\mathrm{Fe}^{2+} \mathrm{Fe}^{3+}{ }_{5}\left(\mathrm{PO}_{4}\right)_{4}(\mathrm{OH})_{5} \bullet 4 \mathrm{H}_{2} \mathrm{O}$ & Yes & No & 1 & No & $\begin{array}{l}\text { Alteration product in } \\
\text { phosphatic rocks and of iron } \\
\text { phosphate minerals }\end{array}$ \\
\hline berlinite & $\mathrm{AlPO}_{4}$ & No? & No & 1 & No? & Associated with iron formation \\
\hline bermanite & $\mathrm{Mn}^{2+} \mathrm{Mn}^{3+}{ }_{2}\left(\mathrm{PO}_{4}\right)_{2}(\mathrm{OH})_{2} \bullet 4 \mathrm{H}_{2} \mathrm{O}$ & No & No & 1 & No & Igneous mineral \\
\hline berthierine & $\left(\mathrm{Fe}^{2+}, \mathrm{Fe}^{3+}, \mathrm{Mg}\right)_{2-3}(\mathrm{Si}, \mathrm{Al})_{2} \mathrm{O}_{5}(\mathrm{OH})_{4}$ & Yes? & No & 6 & Possibly & $\begin{array}{l}\text { Other Fe-Mg aluminosilicates } \\
\text { provide adequate } \\
\text { conservatism for elements in } \\
\text { this mineral. }\end{array}$ \\
\hline beusite & $(\mathrm{Mn}, \mathrm{Fe}, \mathrm{Ca}, \mathrm{Mg})_{3}\left(\mathrm{PO}_{4}\right)_{2}$ & No & No & 1 & No & Igneous mineral \\
\hline bicchulite & $\mathrm{Ca}_{2} \mathrm{Al}_{2} \mathrm{SiO}_{6}(\mathrm{OH})_{2}$ & No & No & 1 & No & Metamorphic mineral \\
\hline bilinite & $\mathrm{Fe}^{2+} \mathrm{Fe}^{3+}{ }_{2}\left(\mathrm{SO}_{4}\right)_{4} \cdot 22 \mathrm{H}_{2} \mathrm{O}$ & Yes & No & 1 & No & $\begin{array}{l}\text { Alters from sulfides, absent in } \\
\text { repository }\end{array}$ \\
\hline biphosphammite & $\left(\mathrm{NH}_{4}, \mathrm{~K}\right) \mathrm{H}_{2} \mathrm{PO}_{4}$ & Yes & No & 1 & No & Occurs in bat guano \\
\hline
\end{tabular}


Table C-1. Critique of Minerals not Included in Project Databases (Continued)

\begin{tabular}{|c|c|c|c|c|c|c|}
\hline Mineral & Chemical Formula & $\begin{array}{l}\text { Precipitates } \\
\text { from } 0 \text { to } 100^{\circ} \mathrm{C} \\
\text { and at } 1 \mathrm{ATM}\end{array}$ & Needed & Criterion & $\begin{array}{l}\text { Within Defined } \\
\text { Physico- } \\
\text { Chemical } \\
\text { System } \\
\end{array}$ & $\begin{array}{c}\text { Comments on Occurrence } \\
\text { or Formation }\end{array}$ \\
\hline birnessite & $\mathrm{Na}_{4} \mathrm{Mn}_{14} \mathrm{O}_{27} \cdot 9 \mathrm{H}_{2} \mathrm{O}$ & Yes & No & 1 & No & $\begin{array}{l}\text { Probably requires high Mn } \\
\text { content in environment. Other } \\
\text { Mn minerals provide adequate } \\
\text { conservatism for elements in } \\
\text { this mineral. }\end{array}$ \\
\hline bobfergusonite & $\mathrm{Na}_{2} \mathrm{Mn}_{5} \mathrm{Fe}^{3+} \mathrm{Al}\left(\mathrm{PO}_{4}\right)_{6}$ & No & No & 1 & No & Igneous mineral \\
\hline bobierrite & $\mathrm{Mg}_{3}\left(\mathrm{PO}_{4}\right)_{2} \bullet 8 \mathrm{H}_{2} \mathrm{O}$ & Yes & No & 1 & No & $\begin{array}{l}\text { Rare, in guano, etc., also in } \\
\text { pegmatite }\end{array}$ \\
\hline bolivarite & $\mathrm{Al}_{2}\left(\mathrm{PO}_{4}\right)(\mathrm{OH})_{3} \bullet 4-5 \mathrm{H}_{2} \mathrm{O}$ & Yes & No & 1 & No & $\begin{array}{l}\text { Occurs in weathered } \\
\text { phosphatic pegmatite, granite }\end{array}$ \\
\hline bonshtedtite & $\mathrm{Na}_{3} \mathrm{Fe}\left(\mathrm{PO}_{4}\right)\left(\mathrm{CO}_{3}\right)$ & No & No & 1 & No & $\begin{array}{l}\text { Igneous or metamorphic } \\
\text { mineral }\end{array}$ \\
\hline borcarite & $\mathrm{Ca}_{4} \mathrm{MgH}_{6}\left(\mathrm{BO}_{3}\right)_{4}\left(\mathrm{CO}_{3}\right)_{2}$ & No & No & 1 & No & Metamorphic mineral \\
\hline borickite & $\mathrm{CaFe}_{3}\left(\mathrm{PO}_{4}\right)_{2}(\mathrm{OH})_{11} \cdot 3 \mathrm{H}_{2} \mathrm{O}$ & $?$ & No & 6 & Unknown & $\begin{array}{l}\text { Other minerals (e.g., apatite, } \\
\text { goethite) provide adequate } \\
\text { conservatism for elements in } \\
\text { this mineral. }\end{array}$ \\
\hline bostwickite & $\mathrm{CaMn}^{3+}{ }_{6} \mathrm{Si}_{3} \mathrm{O}_{16} \cdot 7 \mathrm{H}_{2} \mathrm{O}$ & No & No & 1 & No & Hydrothermal mineral \\
\hline botryogen & $\mathrm{MgFe}^{3+}\left(\mathrm{SO}_{4}\right)_{2}(\mathrm{OH}) \cdot 7 \mathrm{H}_{2} \mathrm{O}$ & $?$ & No & 1 & No & $\begin{array}{l}\text { Associated with oxidized } \\
\text { sulfides }\end{array}$ \\
\hline boussingaultite & $\left(\mathrm{NH}_{4}\right)_{2} \mathrm{Mg}\left(\mathrm{SO}_{4}\right)_{2} \cdot 6 \mathrm{H}_{2} \mathrm{O}$ & Yes? & No & 1 & No & $\begin{array}{l}\text { Associated with hot springs, } \\
\text { shale, coal }\end{array}$ \\
\hline bradleyite & $\mathrm{Na}_{3} \mathrm{Mg}\left(\mathrm{PO}_{4}\right)\left(\mathrm{CO}_{3}\right)$ & Yes & No & 1 & No & Found in oil shale \\
\hline brammallite & $\left(\mathrm{Na}, \mathrm{H}_{3} \mathrm{O}\right)(\mathrm{Al}, \mathrm{Mg}, \mathrm{Fe})_{2}(\mathrm{Si}, \mathrm{Al})_{4} \mathrm{O}_{10}\left[(\mathrm{OH})_{2}, \mathrm{H}_{2} \mathrm{O}\right]$ & Yes? & No & 1 & No & Occurs in shale overlying coal \\
\hline braunite & $\mathrm{Mn}^{2+} \mathrm{Mn}^{3+}{ }_{6} \mathrm{SiO}_{12}$ & Yes & No & 1 & No & Occurs in Mn ore deposits \\
\hline brazilianite & $\mathrm{NaAl}_{3}\left(\mathrm{PO}_{4}\right)_{2}(\mathrm{OH})_{4}$ & No & No & 1 & No & $\begin{array}{l}\text { Pegmatitic and hydrothermal } \\
\text { mineral }\end{array}$ \\
\hline bredigite & $(\mathrm{Ca}, \mathrm{Ba}) \mathrm{Ca}_{13} \mathrm{Mg}_{2} \mathrm{Si}_{8} \mathrm{O}_{32}$ & No & No & 1 & No & Contact metamorphic mineral \\
\hline brenkite & $\mathrm{Ca}_{2}\left(\mathrm{CO}_{3}\right) \mathrm{F}_{2}$ & ? & No & 6 & ? & $\begin{array}{l}\text { Other minerals (e.g., calcite, } \\
\text { fluorite) provide adequate } \\
\text { conservatism for elements in } \\
\text { this mineral }\end{array}$ \\
\hline
\end{tabular}


Table C-1. Critique of Minerals not Included in Project Databases (Continued)

\begin{tabular}{|c|c|c|c|c|c|c|}
\hline Mineral & Chemical Formula & $\begin{array}{l}\text { Precipitates } \\
\text { from } 0 \text { to } 100^{\circ} \mathrm{C} \\
\text { and at } 1 \mathrm{ATM}\end{array}$ & Needed & Criterion & $\begin{array}{c}\text { Within Defined } \\
\text { Physico- } \\
\text { Chemical } \\
\text { System } \\
\end{array}$ & $\begin{array}{c}\text { Comments on Occurrence } \\
\text { or Formation }\end{array}$ \\
\hline brianite & $\mathrm{Na}_{2} \mathrm{CaMg}\left(\mathrm{PO}_{4}\right)_{2}$ & No & No & 1 & No & Found in a meteorite \\
\hline brownmillerite & $\mathrm{Ca}_{2}(\mathrm{Al}, \mathrm{Fe})_{2} \mathrm{O}_{5}$ & No & No & 1 & No & Metamorphic mineral \\
\hline brugnatellite & $\mathrm{Mg}_{6} \mathrm{FeCO}_{3}(\mathrm{OH})_{13} \cdot 4 \mathrm{H}_{2} \mathrm{O}$ & No & No & 1 & No & $\begin{array}{l}\text { Hydrothermal mineral in } \\
\text { serpentine; in igneous rock }\end{array}$ \\
\hline buchwaldite & $\mathrm{NaCaPO}_{4}$ & No & No & 1 & No & Found in a meteorite \\
\hline buddingtonite & $\left(\mathrm{NH}_{4}\right) \mathrm{AlSi}_{3} \mathrm{O}_{8} \cdot 0.5 \mathrm{H}_{2} \mathrm{O}$ & No & No & 1 & No & $\begin{array}{l}\text { Hydrothermal mineral, } \\
\text { reducing condition }\end{array}$ \\
\hline buergerite & $\mathrm{NaFe}^{3+}{ }_{3} \mathrm{Al}_{6} \mathrm{Si}_{6} \mathrm{~B}_{3} \mathrm{O}_{30} \mathrm{~F}$ & No & No & 1 & No & Igneous mineral \\
\hline buetschliite & $\mathrm{K}_{2} \mathrm{Ca}\left(\mathrm{CO}_{3}\right)_{2}$ & No & No & 1 & No & $\begin{array}{l}\text { Occurs as clinkers in wood } \\
\text { ash }\end{array}$ \\
\hline bultfonteinite & $\mathrm{Ca}_{2} \mathrm{SiO}_{2}(\mathrm{OH}, \mathrm{F})_{4}$ & ? & No & 1 & No & Rare, metamorphic mineral \\
\hline burangaite & $(\mathrm{Na}, \mathrm{Ca})_{2}\left(\mathrm{Fe}^{2+}, \mathrm{Mg}_{2} \mathrm{Al}_{10}\left(\mathrm{PO}_{4}\right)_{8}(\mathrm{OH}, \mathrm{O})_{12} \cdot 4 \mathrm{H}_{2} \mathrm{O}\right.$ & No & No & 1 & No & Igneous mineral \\
\hline bustamite & $(\mathrm{Ca}, \mathrm{Mn}) \mathrm{Si}_{2} \mathrm{O}_{6}$ & No & No & 1 & No & Metamorphic mineral \\
\hline butlerite & $\mathrm{Fe}^{3+} \mathrm{SO}_{4}(\mathrm{OH}) \cdot 2 \mathrm{H}_{2} \mathrm{O}$ & $?$ & No & 1 & No & $\begin{array}{l}\text { Associated with oxidized } \\
\text { sulfides }\end{array}$ \\
\hline cacoxenite & $\mathrm{Fe}^{3+}{ }_{4}\left(\mathrm{PO}_{4}\right)_{3}(\mathrm{OH})_{3} \cdot 12 \mathrm{H}_{2} \mathrm{O}$ & Yes & No & 1 & No & In phosphatic rocks \\
\hline cadwaladerite & $\mathrm{Al}(\mathrm{OH})_{2} \mathrm{Cl} \cdot 4 \mathrm{H}_{2} \mathrm{O}$ & Yes? & No & 6 & Possibly & $\begin{array}{l}\text { Occurs in a sulfate deposit. } \\
\text { Other evaporite minerals and } \\
\text { boehmite provide adequate } \\
\text { conservatism for elements in } \\
\text { this mineral. }\end{array}$ \\
\hline cafetite & $\mathrm{Ca}\left(\mathrm{Fe}^{3+}, \mathrm{Al}\right)_{2} \mathrm{Ti}_{4} \mathrm{O}_{12} \bullet 4 \mathrm{H}_{2} \mathrm{O}$ & No & No & 1 & No & Igneous mineral \\
\hline calciocopiapite & $\mathrm{CaFe}_{4}\left(\mathrm{SO}_{4}\right)_{6}(\mathrm{OH})_{2} \cdot 19 \mathrm{H}_{2} \mathrm{O}$ & Yes & No & 1 & No & $\begin{array}{l}\text { Weathering product of pyritic } \\
\text { magnetite }\end{array}$ \\
\hline calcioferrite & $\mathrm{Ca}_{4} \mathrm{Fe}^{2+}\left(\mathrm{Fe}^{3+}, \mathrm{Al}\right)_{4}\left(\mathrm{PO}_{4}\right)_{6}(\mathrm{OH})_{4} \cdot 12 \mathrm{H}_{2} \mathrm{O}$ & Yes & No & 1 & No & Nodules in clay \\
\hline calclacite & $\mathrm{CaC}_{2} \mathrm{H}_{3} \mathrm{ClO}_{2} \cdot 5 \mathrm{H}_{2} \mathrm{O}$ & Yes & No & 1 & No & $\begin{array}{l}\text { Occurs on pottery and } \\
\text { museum specimens in oak } \\
\text { cabinets }\end{array}$ \\
\hline
\end{tabular}


Table C-1. Critique of Minerals not Included in Project Databases (Continued)

\begin{tabular}{|c|c|c|c|c|c|c|}
\hline Mineral & Chemical Formula & $\begin{array}{l}\text { Precipitates } \\
\text { from } 0 \text { to } 100^{\circ} \mathrm{C} \\
\text { and at } 1 \mathrm{ATM}\end{array}$ & Needed & Criterion & \begin{tabular}{|c|} 
Within Defined \\
Physico- \\
Chemical \\
System
\end{tabular} & $\begin{array}{c}\text { Comments on Occurrence } \\
\text { or Formation }\end{array}$ \\
\hline calderite & $\left(\mathrm{Mn}^{2+}, \mathrm{Ca}\right)_{3}\left(\mathrm{Fe}^{3+}, \mathrm{Al}_{2}\right)_{2}\left(\mathrm{SiO}_{4}\right)_{3}$ & ? & No & 1 & $?$ & $\begin{array}{l}\text { A garnet, hence, likely } \\
\text { metamorphic. Other minerals, } \\
\text { (e.g., wollastonite, fayalite) } \\
\text { provide adequate } \\
\text { conservatism for elements in } \\
\text { this mineral. }\end{array}$ \\
\hline canaphite & $\mathrm{CaNa}_{2} \mathrm{H}_{2}\left(\mathrm{PO}_{4}\right)_{2} \cdot 3 \mathrm{H}_{2} \mathrm{O}$ & ? & No & 5 & ? & $\begin{array}{l}\text { Rare, on stilbite. Zeolites and } \\
\text { apatite provide adequate } \\
\text { conservatism for elements in } \\
\text { this mineral. }\end{array}$ \\
\hline canasite & $(\mathrm{Na}, \mathrm{K})_{6} \mathrm{Ca}_{5} \mathrm{Si}_{12} \mathrm{O}_{30}(\mathrm{OH}, \mathrm{F})_{4}$ & No & No & 1 & No & Igneous mineral \\
\hline cancrinite & $\mathrm{Na}_{6} \mathrm{Ca}_{2} \mathrm{Al}_{6} \mathrm{Si}_{6} \mathrm{O}_{24}\left(\mathrm{CO}_{3}\right)_{2}$ & No? & No & 1 & No & $\begin{array}{l}\text { Igneous mineral or alteration } \\
\text { of nepheline }\end{array}$ \\
\hline carbonate-hydroxylapatite & $\mathrm{Ca}_{5}\left(\mathrm{PO}_{4}, \mathrm{CO}_{3}\right)_{3}(\mathrm{OH}, \mathrm{F})$ & Yes & No & 6 & No? & $\begin{array}{l}\text { Replacement of calcite, } \\
\text { probably absent in repository. } \\
\text { Other minerals (e.g., } \\
\text { hydroxylapatite, calcite) } \\
\text { provide adequate } \\
\text { conservatism for elements in } \\
\text { this mineral. } \\
\end{array}$ \\
\hline carletonite & $\mathrm{KNa}_{4} \mathrm{Ca}_{4} \mathrm{Si}_{8} \mathrm{O}_{18}\left(\mathrm{CO}_{3}\right)_{4}(\mathrm{OH}, \mathrm{F}) \cdot \mathrm{H}_{2} \mathrm{O}$ & No & No & 1 & No & $\begin{array}{l}\text { Metamorphosed inclusions in } \\
\text { igneous rock }\end{array}$ \\
\hline carlhintzeite & $\mathrm{Ca}_{2} \mathrm{AlF}_{7} \cdot \mathrm{H}_{2} \mathrm{O}$ & No & No & 1 & No & Igneous mineral \\
\hline carpholite & $\mathrm{MnAl}_{2} \mathrm{Si}_{2} \mathrm{O}_{6}(\mathrm{OH})_{4}$ & ? & No & 1 & No & $\begin{array}{l}\text { Probably requires high } \mathrm{Mn} \\
\text { content in environment. }\end{array}$ \\
\hline caryopilite & $(\mathrm{Mn}, \mathrm{Mg})_{3} \mathrm{Si}_{2} \mathrm{O}_{5}(\mathrm{OH})_{4}$ & Yes? & No & 1 & No & $\begin{array}{l}\text { Probably requires high } \mathrm{Mn} \\
\text { content in environment. } \\
\text { Replacement of rhodonite, } \\
\text { which is absent in the } \\
\text { repository. }\end{array}$ \\
\hline cebollite & $\mathrm{Ca}_{4} \mathrm{Al}_{2} \mathrm{Si}_{3} \mathrm{O}_{12}(\mathrm{OH})_{2}$ & Yes? & No & 1 & No & $\begin{array}{l}\text { Alters from melilite, precursor } \\
\text { absent in repository. Also, } \\
\text { igneous mineral. }\end{array}$ \\
\hline
\end{tabular}


Table C-1. Critique of Minerals not Included in Project Databases (Continued)

\begin{tabular}{|c|c|c|c|c|c|c|}
\hline Mineral & Chemical Formula & $\begin{array}{l}\text { Precipitates } \\
\text { from } 0 \text { to } 100^{\circ} \mathrm{C} \\
\text { and at } 1 \text { ATM }\end{array}$ & Needed & Criterion & $\begin{array}{l}\text { Within Defined } \\
\text { Physico- } \\
\text { Chemical } \\
\text { System } \\
\end{array}$ & $\begin{array}{c}\text { Comments on Occurrence } \\
\text { or Formation }\end{array}$ \\
\hline cesanite & $\mathrm{Na}_{3} \mathrm{Ca}_{2}\left(\mathrm{SO}_{4}\right)_{3}(\mathrm{OH})$ & $?$ & No & 1 & Possibly & $\begin{array}{l}\text { Other minerals (e.g. } \\
\text { glauberite) provide adequate } \\
\text { conservatism for elements in } \\
\text { this mineral }\end{array}$ \\
\hline chantalite & $\mathrm{CaAl}_{2} \mathrm{SiO}_{4}(\mathrm{OH})_{4}$ & No & No & 1 & No & Igneous mineral \\
\hline charoite & $\mathrm{K}(\mathrm{Ca}, \mathrm{Na})_{2} \mathrm{Si}_{4} \mathrm{O}_{10}(\mathrm{OH}, \mathrm{F}) \cdot \mathrm{H}_{2} \mathrm{O}$ & No & No & 1 & No & Contact metamorphic mineral \\
\hline chesterite & $\left(\mathrm{Mg}, \mathrm{Fe}^{2+}\right)_{17} \mathrm{Si}_{20} \mathrm{O}_{54}(\mathrm{OH})_{6}$ & No & No & 1 & No & Metamorphic mineral \\
\hline childrenite & $(\mathrm{Fe}, \mathrm{Mn}) \mathrm{AlPO}_{4}(\mathrm{OH})_{2} \cdot \mathrm{H}_{2} \mathrm{O}$ & No & No & 1 & No & $\begin{array}{l}\text { Hydrothermal and igneous } \\
\text { mineral }\end{array}$ \\
\hline chiolite & $\mathrm{Na}_{5} \mathrm{Al}_{3} \mathrm{~F}_{14}$ & No & No & 1 & No & Igneous mineral \\
\hline chloraluminite & $\mathrm{AlCl}_{3} \cdot 6 \mathrm{H}_{2} \mathrm{O}$ & No & No & 1 & No & Igneous or fumarolic mineral \\
\hline chlorapatite & $\mathrm{Ca}_{5}\left(\mathrm{PO}_{4}\right)_{3} \mathrm{Cl}$ & No & No & 1 & No & $\begin{array}{l}\text { Igneous or metamorphic } \\
\text { mineral }\end{array}$ \\
\hline chloritoid & $\left(\mathrm{Fe}^{2+}, \mathrm{Mg}, \mathrm{Mn}\right)_{2} \mathrm{Al}_{4} \mathrm{Si}_{2} \mathrm{O}_{10}(\mathrm{OH})_{4}$ & No & No & 1 & No & $\begin{array}{l}\text { Metamorphic and } \\
\text { hydrothermal mineral }\end{array}$ \\
\hline chlormagaluminite & $\left(\mathrm{Mg}, \mathrm{Fe}^{2+}\right)_{4} \mathrm{Al}_{2}(\mathrm{OH})_{12}\left(\mathrm{Cl}_{2}, \mathrm{CO}_{3}\right)_{2} \cdot 2 \mathrm{H}_{2} \mathrm{O}$ & No & No & 1 & No & Metamorphic mineral \\
\hline chlormanganokalite & $\mathrm{K}_{4} \mathrm{MnCl}_{6}$ & No? & No & 1 & No & $\begin{array}{l}\text { Fumarolic mineral and } \\
\text { associated with halite, sylvite, } \\
\text { and hematite }\end{array}$ \\
\hline chondrodite & $\mathrm{Mg}_{5}\left(\mathrm{SiO}_{4}\right)_{2}(\mathrm{~F}, \mathrm{OH})_{2}$ & No & No & 1 & No & $\begin{array}{l}\text { Metamorphic or igneous } \\
\text { mineral }\end{array}$ \\
\hline clairite & $\left(\mathrm{NH}_{4}\right)_{2} \mathrm{Fe}_{3}\left(\mathrm{SO}_{4}\right)_{4}(\mathrm{OH})_{3} \cdot 3 \mathrm{H}_{2} \mathrm{O}$ & Yes & No & 1 & No & $\begin{array}{l}\text { Altered from pyrite under } \\
\text { reducing conditions }\end{array}$ \\
\hline clinohumite & $(\mathrm{Mg}, \mathrm{Fe})_{9}\left(\mathrm{SiO}_{4}\right)_{4}(\mathrm{~F}, \mathrm{OH})_{2}$ & No & No & 1 & No & Metamorphic mineral \\
\hline clinojimthompsonite & $\left(\mathrm{Mg}, \mathrm{Fe}^{2+}\right)_{5} \mathrm{Si}_{6} \mathrm{O}_{16}(\mathrm{OH})_{2}$ & No & No & 1 & No & Metamorphic mineral \\
\hline clinophosinaite & $\mathrm{Na}_{3} \mathrm{CaPSiO}{ }_{7}$ & No & No & 1 & No & Igneous mineral \\
\hline clinoungemachite & probably near $\mathrm{K}_{3} \mathrm{Na}_{9} \mathrm{Fe}\left(\mathrm{SO}_{4}\right)_{6}(\mathrm{OH})_{3} \cdot 9 \mathrm{H}_{2} \mathrm{O}$ & Yes & No & 1 & No & $\begin{array}{l}\text { Oxidation product at copper } \\
\text { mine. Jarosite and } \\
\text { natrojarosite provide adequate } \\
\text { conservatism. }\end{array}$ \\
\hline clintonite & $\mathrm{Ca}(\mathrm{N}$ & No & No & 1 & No & etamorphic mine \\
\hline
\end{tabular}


Table C-1. Critique of Minerals not Included in Project Databases (Continued)

\begin{tabular}{|c|c|c|c|c|c|c|}
\hline Mineral & Chemical Formula & $\begin{array}{l}\text { Precipitates } \\
\text { from } 0 \text { to } 100^{\circ} \mathrm{C} \\
\text { and at } 1 \mathrm{ATM}\end{array}$ & Needed & Criterion & \begin{tabular}{|c|} 
Within Defined \\
Physico- \\
Chemical \\
System
\end{tabular} & $\begin{array}{c}\text { Comments on Occurrence } \\
\text { or Formation }\end{array}$ \\
\hline coalingite & $\mathrm{Mg}_{10} \mathrm{Fe}^{3+}{ }_{2}\left(\mathrm{CO}_{3}\right)(\mathrm{OH})_{24} \cdot 2 \mathrm{H}_{2} \mathrm{O}$ & Yes & No & 1 & No & $\begin{array}{l}\text { Weathering product of } \\
\text { serpentine, which is absent in } \\
\text { repository }\end{array}$ \\
\hline coesite & $\mathrm{SiO}_{2}$ & No & No & 1 & No & In meteorite craters \\
\hline collinsite & $\mathrm{Ca}_{2}(\mathrm{Mg}, \mathrm{Fe})\left(\mathrm{PO}_{4}\right)_{2} \cdot 2 \mathrm{H}_{2} \mathrm{O}$ & Yes? & No & 5 & No & $\begin{array}{l}\text { Rare; associated with } \\
\text { phosphate nodules or } \\
\text { asphaltum, pegmatites }\end{array}$ \\
\hline combeite & $\mathrm{Na}_{2} \mathrm{Ca}_{2} \mathrm{Si}_{3} \mathrm{O}_{9}$ & No & No & 1 & No & Igneous mineral \\
\hline copiapite & $\left(\mathrm{Fe}^{2+}, \mathrm{Mg} \mathrm{Fe}^{3+}{ }_{4}\left(\mathrm{SO}_{4}\right)_{6}(\mathrm{OH})_{2} \cdot 2 \mathrm{OH}_{2} \mathrm{O}\right.$ & Yes & No & 1 & No & $\begin{array}{l}\text { Alters from sulfides, absent in } \\
\text { repository }\end{array}$ \\
\hline coquimbite & $\mathrm{Fe}_{2}^{3+}\left(\mathrm{SO}_{4}\right)_{3} \cdot 9 \mathrm{H}_{2} \mathrm{O}$ & Yes & No & 1 & No & $\begin{array}{l}\text { Alters from sulfides, absent in } \\
\text { repository }\end{array}$ \\
\hline cordierite & $\left(\mathrm{Mg}, \mathrm{Fe}^{3+}\right)_{2} \mathrm{Al}_{4} \mathrm{Si}_{5} \mathrm{O}_{18}$ & No & No & 1 & No & $\begin{array}{l}\text { Igneous and metamorphic } \\
\text { mineral }\end{array}$ \\
\hline cowlesite & $\mathrm{CaAl}_{2} \mathrm{Si}_{3} \mathrm{O}_{10} \cdot 5-6 \mathrm{H}_{2} \mathrm{O}$ & Yes? & No & 1 & No & $\begin{array}{l}\text { Associated with zeolites in } \\
\text { basalt }\end{array}$ \\
\hline crandallite & $\mathrm{CaAl}_{3}\left(\mathrm{PO}_{4}\right)(\mathrm{OH})_{5} \cdot \mathrm{H}_{2} \mathrm{O}$ & Yes & No & 1 & No & $\begin{array}{l}\text { Associated with phosphate } \\
\text { deposits }\end{array}$ \\
\hline creedite & $\mathrm{Ca}_{3} \mathrm{Al}_{2}\left(\mathrm{SO}_{4}\right)(\mathrm{F}, \mathrm{OH})_{10} \cdot 2 \mathrm{H}_{2} \mathrm{O}$ & No & No & 1 & No & Hydrothermal mineral \\
\hline crossite & $\mathrm{Na}_{2}\left(\mathrm{Mg}, \mathrm{Fe}^{2+}\right)_{3}\left(\mathrm{Al}, \mathrm{Fe}^{3+}\right)_{2} \mathrm{Si}_{8} \mathrm{O}_{22}(\mathrm{OH})_{2}$ & No & No & 1 & No & Metamorphic mineral \\
\hline cryptohalite & $\left(\mathrm{NH}_{4}\right)_{2} \mathrm{SiF}_{6}$ & No & No & 1 & No & $\begin{array}{l}\text { Fumarolic mineral or } \\
\text { sublimation product }\end{array}$ \\
\hline cryptomelane & $\mathrm{K}\left(\mathrm{Mn}^{2+}, \mathrm{Mn}^{4+}\right)_{8} \mathrm{O}_{16}$ & Yes & No & 6 & No & $\begin{array}{l}\text { Other minerals (e.g., } \\
\text { pyrolusite) provide adequate } \\
\text { conservatism for elements in } \\
\text { this mineral }\end{array}$ \\
\hline cummingtonite & $\left(\mathrm{Mg}, \mathrm{Fe}^{2+}\right)_{7} \mathrm{Si}_{8} \mathrm{O}_{22}(\mathrm{OH})_{2}$ & No & No & 1 & No & Metamorphic mineral \\
\hline cuspidine & $\mathrm{Ca}_{4} \mathrm{Si}_{2} \mathrm{O}_{7}(\mathrm{~F}, \mathrm{OH})_{2}$ & No & No & 1 & No & Metamorphic mineral \\
\hline cyrilovite & $\mathrm{NaFe}^{3+}{ }_{3}\left(\mathrm{PO}_{4}\right)_{2}(\mathrm{OH})_{4} \cdot 2 \mathrm{H}_{2} \mathrm{O}$ & Yes? & No & 1 & No & $\begin{array}{l}\text { Alteration mineral in } \\
\text { pegmatites and in phosphate } \\
\text { deposit }\end{array}$ \\
\hline dachiardite & $\left(\mathrm{Ca}, \mathrm{Na}_{2}, \mathrm{~K}_{2}\right)_{5} \mathrm{Al}_{10} \mathrm{Si}_{38} \mathrm{O}_{96} \cdot 25 \mathrm{H}_{2} \mathrm{O}$ & No? & No & 1 & No & Found in pegmatites \\
\hline
\end{tabular}


Table C-1. Critique of Minerals not Included in Project Databases (Continued)

\begin{tabular}{|c|c|c|c|c|c|c|}
\hline Mineral & Chemical Formula & $\begin{array}{l}\text { Precipitates } \\
\text { from } 0 \text { to } 100^{\circ} \mathrm{C} \\
\text { and at } 1 \text { ATM }\end{array}$ & Needed & Criterion & \begin{tabular}{|c|} 
Within Defined \\
Physico- \\
Chemical \\
System
\end{tabular} & $\begin{array}{c}\text { Comments on Occurrence } \\
\text { or Formation }\end{array}$ \\
\hline dannemorite & $\mathrm{Mn}_{2}\left(\mathrm{Fe}^{2+}, \mathrm{Mg}\right)_{5} \mathrm{Si}_{8} \mathrm{O}_{22}(\mathrm{OH})_{2}$ & No & No & 1 & No & $\begin{array}{l}\text { Metamorphic or igneous } \\
\text { mineral }\end{array}$ \\
\hline d'Ansite & $\mathrm{Na}_{21} \mathrm{Mg}\left(\mathrm{SO}_{4}\right)_{10} \mathrm{Cl}_{3}$ & Yes & No & 6 & Yes & $\begin{array}{l}\text { Other minerals (e.g. bloedite, } \\
\text { halite) provide adequate } \\
\text { conservatism for elements in } \\
\text { this mineral }\end{array}$ \\
\hline davanite & $\mathrm{K}_{2} \mathrm{TiSi}_{6} \mathrm{O}_{15}$ & No & No & 1 & No & Contact metamorphic mineral \\
\hline davreuxite & $\mathrm{Mn}_{2} \mathrm{Al}_{12}\left(\mathrm{SiO}_{4}\right)_{7} \mathrm{O}_{3}(\mathrm{OH})_{6}$ & $?$ & No & 1 & No & Hydrothermal mineral \\
\hline davyne & $(\mathrm{Na}, \mathrm{Ca}, \mathrm{K})_{8} \mathrm{Al}_{6} \mathrm{Si}_{6} \mathrm{O}_{24}\left(\mathrm{Cl}, \mathrm{SO}_{4}, \mathrm{CO}_{3}\right)_{2}{ }^{3-}$ & No & No & 1 & No & Igneous mineral \\
\hline deerite & $\left(\mathrm{Fe}^{2+}, \mathrm{Mn}\right)_{6}\left(\mathrm{Fe}^{3+}, \mathrm{Al}_{3}\right)_{3} \mathrm{Si}_{6} \mathrm{O}_{20}(\mathrm{OH})_{5}$ & No & No & 1 & No & Metamorphic mineral \\
\hline defernite & $\mathrm{Ca}_{6}\left(\mathrm{CO}_{3}\right)_{2}(\mathrm{OH}, \mathrm{Cl})_{8} \bullet \mathrm{nH}_{2} \mathrm{O}$ & No & No & 1 & No & Contact metamorphic mineral \\
\hline delhayelite & $(\mathrm{Na}, \mathrm{K})_{10} \mathrm{Ca}_{5} \mathrm{Al}_{6} \mathrm{Si}_{32} \mathrm{O}_{80}\left(\mathrm{Cl}_{2}, \mathrm{~F}_{2}, \mathrm{SO}_{4}\right)_{3} \cdot 18 \mathrm{H}_{2} \mathrm{O}$ & No & No & 1 & No & Igneous mineral \\
\hline dellaite & $\mathrm{Ca}_{6} \mathrm{Si}_{3} \mathrm{O}_{11}(\mathrm{OH})_{2}$ & No & No & 1 & No & Hydrothermal mineral \\
\hline delvauxite & $\begin{array}{l}(\mathrm{Ca}, \mathrm{Mg})\left(\mathrm{Fe}^{3+}, \mathrm{Al}_{3}\left(\mathrm{PO}_{4}, \mathrm{SO}_{4}, \mathrm{CO}_{3}\right)_{2}(\mathrm{OH})_{8}\right. \\
-4-6 \mathrm{H}_{2} \mathrm{O}\end{array}$ & Yes? & No & 6 & Possibly & $\begin{array}{l}\text { Other minerals (e.g., } \\
\text { hydroxylapatite, strengite) } \\
\text { provide adequate } \\
\text { conservatism for elements in } \\
\text { this mineral } \\
\end{array}$ \\
\hline denisovite & $(\mathrm{K}, \mathrm{Na}) \mathrm{Ca}_{2} \mathrm{Si}_{3} \mathrm{O}_{8}(\mathrm{~F}, \mathrm{OH})$ & No & No & 1 & No & $\begin{array}{l}\text { Igneous or metamorphic } \\
\text { mineral }\end{array}$ \\
\hline desautelsite & $\mathrm{Mg}_{6} \mathrm{Mn}^{3+}{ }_{2}\left(\mathrm{CO}_{3}\right)(\mathrm{OH})_{16} \bullet 4 \mathrm{H}_{2} \mathrm{O}$ & No? & No & 6 & No? & $\begin{array}{l}\text { Other minerals (e.g., } \\
\text { hydromagnesite, } \\
\text { rhodochrosite) provide } \\
\text { adequate conservatism for } \\
\text { elements in this mineral. } \\
\end{array}$ \\
\hline despujolsite & $\mathrm{Ca}_{3} \mathrm{Mn}^{4+}\left(\mathrm{SO}_{4}\right)_{2}(\mathrm{OH})_{6} \cdot 3 \mathrm{H}_{2} \mathrm{O}$ & Yes? & No & 1 & No & $\begin{array}{l}\text { Associated only with other } \mathrm{Mn} \\
\text { minerals }\end{array}$ \\
\hline diadochite & $\mathrm{Fe}^{3+}{ }_{9}\left(\mathrm{PO}_{4}\right)\left(\mathrm{SO}_{4}\right)(\mathrm{OH}) \cdot 5 \mathrm{H}_{2} \mathrm{O}$ & Yes & No & 1 & No & $\begin{array}{l}\text { Associated with (sulfide?) } \\
\text { mine workings }\end{array}$ \\
\hline
\end{tabular}


Table C-1. Critique of Minerals not Included in Project Databases (Continued)

\begin{tabular}{|c|c|c|c|c|c|c|}
\hline Mineral & Chemical Formula & $\begin{array}{l}\text { Precipitates } \\
\text { from } 0 \text { to } 100^{\circ} \mathrm{C} \\
\text { and at } 1 \mathrm{ATM}\end{array}$ & Needed & Criterion & \begin{tabular}{|c|} 
Within Defined \\
Physico- \\
Chemical \\
System \\
\end{tabular} & $\begin{array}{c}\text { Comments on Occurrence } \\
\text { or Formation }\end{array}$ \\
\hline dickite & $\mathrm{Al}_{2} \mathrm{Si}_{2} \mathrm{O}_{5}(\mathrm{OH})_{4}$ & No? & No & 3 & No & $\begin{array}{l}\text { Hydrothermal mineral; } \\
\text { properties close to kaolinite, } \\
\text { which provides adequate } \\
\text { conservatism for this mineral }\end{array}$ \\
\hline dittmarite & $\left(\mathrm{NH}_{4}\right) \mathrm{Mg}\left(\mathrm{PO}_{4}\right) \cdot \mathrm{H}_{2} \mathrm{O}$ & Yes & No & 1 & No & Occurs in guano, etc. \\
\hline donpeacorite & $(\mathrm{Mn}, \mathrm{Mg}) \mathrm{MgSi}_{2} \mathrm{O}_{6}$ & No & No & 1 & No & Metamorphic mineral \\
\hline dorfmanite & $\mathrm{Na}_{2} \mathrm{H}\left(\mathrm{PO}_{4}\right) \cdot 2 \mathrm{H}_{2} \mathrm{O}$ & Yes & No & 1 & No & $\begin{array}{l}\text { Alteration mineral in alkalic } \\
\text { pegmatite }\end{array}$ \\
\hline douglasite & $\mathrm{K}_{2} \mathrm{Fe}^{2+} \mathrm{Cl}_{4} \cdot 2 \mathrm{H}_{2} \mathrm{O}$ & Yes? & No & 1 & No & $\begin{array}{l}\text { Occurs in marine evaporites; } \\
\text { ferous iron requires reducing } \\
\text { conditions }\end{array}$ \\
\hline doyleite & $\mathrm{Al}(\mathrm{OH})_{3}$ & No & No & 1 & No & $\begin{array}{l}\text { Igneous (and metamorphic?) } \\
\text { mineral }\end{array}$ \\
\hline dufrenite & $\mathrm{Fe}^{2+} \mathrm{Fe}^{3+}{ }_{4}\left(\mathrm{PO}_{4}\right)_{3}(\mathrm{OH})_{5} \cdot 2 \mathrm{H}_{2} \mathrm{O}$ & Yes? & No & 1 & No & $\begin{array}{l}\text { Associated with pegmatites } \\
\text { and phosphate deposits }\end{array}$ \\
\hline dypingite & $\mathrm{Mg}_{5}\left(\mathrm{CO}_{3}\right)_{4}(\mathrm{OH})_{2} \cdot 5 \mathrm{H}_{2} \mathrm{O}$ & Yes? & No & 1 & No & $\begin{array}{l}\text { Metamorphic mineral (and on } \\
\text { serpentine) }\end{array}$ \\
\hline earlandite & $\mathrm{Ca}_{3}\left(\mathrm{C}_{6} \mathrm{H}_{5} \mathrm{O}_{7}\right)_{2} \cdot 4 \mathrm{H}_{2} \mathrm{O}$ & Yes & No & 1 & No & $\begin{array}{l}\text { In oceanic bottom sediments, } \\
\text { Antarctica }\end{array}$ \\
\hline earlshannonite & $\mathrm{MnFe}^{3+}{ }_{2}\left(\mathrm{PO}_{4}\right)_{2}(\mathrm{OH})_{2} \bullet 4 \mathrm{H}_{2} \mathrm{O}$ & No & No & 1 & No & Igneous mineral \\
\hline eckermannite & $\mathrm{Na}_{3}\left(\mathrm{Mg}_{1} \mathrm{Fe}^{2+}\right)_{4}\left(\mathrm{Al}_{1} \mathrm{Fe}^{3+}\right) \mathrm{Si}_{8} \mathrm{O}_{22}(\mathrm{OH})_{2}$ & No & No & 1 & No & Igneous mineral \\
\hline edenite & $\mathrm{NaCa}_{2}\left(\mathrm{Mg}, \mathrm{Fe}^{2+}\right)_{5} \mathrm{Si}_{7} \mathrm{AlO}_{22}(\mathrm{OH})_{2}$ & No & No & 1 & No & $\begin{array}{l}\text { Igneous and metamorphic } \\
\text { mineral }\end{array}$ \\
\hline eggletonite & $(\mathrm{Na}, \mathrm{K}, \mathrm{Ca})_{2}(\mathrm{Mn}, \mathrm{Fe})_{8}(\mathrm{Si}, \mathrm{Al})_{12} \mathrm{O}_{29}(\mathrm{OH})_{7} \cdot 11 \mathrm{H}_{2} \mathrm{O}$ & No & No & 1 & No & $\begin{array}{l}\text { Occurs in cavities in igneous } \\
\text { rock }\end{array}$ \\
\hline eifelite & $\mathrm{KNa}_{3} \mathrm{Mg}_{4} \mathrm{Si}_{12} \mathrm{O}_{30}$ & No & No & 1 & No & Metamorphic mineral \\
\hline eitelite & $\mathrm{Na}_{2} \mathrm{Mg}\left(\mathrm{CO}_{3}\right)_{2}$ & Yes? & No & 6 & Yes & $\begin{array}{l}\text { Associated with lacustrine } \\
\text { evaporites. Other minerals } \\
\text { (e.g., natron, hydromagnesite) } \\
\text { provide adequate } \\
\text { conservatism for elements in } \\
\text { this mineral. }\end{array}$ \\
\hline elpasolite & $\mathrm{K}_{2} \mathrm{NaAlF}_{6}$ & No & No & 1 & No & Igneous mineral \\
\hline
\end{tabular}


Table C-1. Critique of Minerals not Included in Project Databases (Continued)

\begin{tabular}{|c|c|c|c|c|c|c|}
\hline Mineral & Chemical Formula & $\begin{array}{c}\text { Precipitates } \\
\text { from } 0 \text { to } 100^{\circ} \mathrm{C} \\
\text { and at } 1 \mathrm{ATM}\end{array}$ & Needed & Criterion & \begin{tabular}{|c|} 
Within Defined \\
Physico- \\
Chemical \\
System \\
\end{tabular} & $\begin{array}{c}\text { Comments on Occurrence } \\
\text { or Formation }\end{array}$ \\
\hline endellite & $\mathrm{Al}_{2} \mathrm{Si}_{2} \mathrm{O}_{5}(\mathrm{OH})_{4} \cdot 2 \mathrm{H}_{2} \mathrm{O}$ & Yes? & No & 3 & No & $\begin{array}{l}\text { Resembles kaolinite, which } \\
\text { suffices for conservatism }\end{array}$ \\
\hline englishite & $\mathrm{K}_{3} \mathrm{Na}_{2} \mathrm{Ca}_{10} \mathrm{Al}_{15}\left(\mathrm{PO}_{4}\right)_{21}(\mathrm{OH})_{7} \cdot 26 \mathrm{H}_{2} \mathrm{O}$ & Yes? & No & 1 & No & $\begin{array}{l}\text { Igneous or in phosphate } \\
\text { deposits }\end{array}$ \\
\hline eosphorite & $(\mathrm{Mn}, \mathrm{Fe}) \mathrm{Al}\left(\mathrm{PO}_{4}\right)(\mathrm{OH})_{2} \bullet \mathrm{H}_{2} \mathrm{O}$ & No & No & 1 & No & Igneous mineral \\
\hline epistilbite & $\mathrm{CaAl}_{2} \mathrm{Si}_{6} \mathrm{O}_{16} \cdot 5 \mathrm{H}_{2} \mathrm{O}$ & No? & No & 1 & No & $\begin{array}{l}\text { Cavities in basalt; in } \\
\text { pegmatites }\end{array}$ \\
\hline erdite & $\mathrm{NaFeS}_{2} \cdot 2 \mathrm{H}_{2} \mathrm{O}$ & No & No & 1 & No & $\begin{array}{l}\text { Igneous or hydrothermal } \\
\text { mineral }\end{array}$ \\
\hline ernstite & $\left(\mathrm{Mn}_{1-x} \mathrm{Fe}_{x}\right) \mathrm{Al}\left(\mathrm{PO}_{4}\right)(\mathrm{OH})_{2-x} \mathrm{O}_{x}$ & Yes & No & 1 & No & $\begin{array}{l}\text { Alters from eosphorite, } \\
\text { precursor absent }\end{array}$ \\
\hline ertixiite & $\mathrm{Na}_{2} \mathrm{Si}_{4} \mathrm{O}_{9}$ & No & No & 1 & No & Igneous mineral \\
\hline erythrosiderite & $\mathrm{K}_{2} \mathrm{Fe}^{3+} \mathrm{Cl}_{5} \bullet \mathrm{H}_{2} \mathrm{O}$ & Yes & No & 6 & No & $\begin{array}{l}\text { Efflorescence on marine } \\
\text { evaporites. Other minerals } \\
\text { (e.g., sylvite, molysite) provide } \\
\text { adequate conservatism for } \\
\text { elements in this mineral. }\end{array}$ \\
\hline essenite & $\mathrm{CaFe}^{3+} \mathrm{AlSiO}_{6}$ & No & No & 1 & No & $\begin{array}{l}\text { Occurs in fused sedimentary } \\
\text { rock }\end{array}$ \\
\hline eugsterite & $\mathrm{Na}_{4} \mathrm{Ca}\left(\mathrm{SO}_{4}\right)_{3} \cdot 2 \mathrm{H}_{2} \mathrm{O}$ & Yes & No & 6 & Yes & $\begin{array}{l}\text { Occurs in lacustrine } \\
\text { evaporites. Other minerals } \\
\text { (e.g., glauberite) provide } \\
\text { adequate conservatism for } \\
\text { elements in this mineral }\end{array}$ \\
\hline evansite & $\mathrm{Al}_{3}\left(\mathrm{PO}_{4}\right)(\mathrm{OH})_{6} \cdot 6 \mathrm{H}_{2} \mathrm{O}(?)$ & Yes & No & 1 & No & $\begin{array}{l}\text { In Al and phosphate-rich } \\
\text { settings }\end{array}$ \\
\hline fairchildite & $\mathrm{K}_{2} \mathrm{Ca}\left(\mathrm{CO}_{3}\right)_{2}$ & No & No & 1 & No & In clinkers in wood ash \\
\hline fairfieldite & $\mathrm{Ca}_{2}\left(\mathrm{Mn}^{2+}, \mathrm{Fe}^{2+}\right)\left(\mathrm{PO}_{4}\right)_{2} \cdot 2 \mathrm{H}_{2} \mathrm{O}$ & No & No & 1 & No & Igneous mineral \\
\hline farringtonite & $\mathrm{Mg}_{3}\left(\mathrm{PO}_{4}\right)_{2}$ & No & No & 1 & No & In a meteorite \\
\hline faujasite & $\left(\mathrm{Na}_{2}, \mathrm{Ca}\right) \mathrm{Al}_{2} \mathrm{Si}_{4} \mathrm{O}_{12} \cdot 8 \mathrm{H}_{2} \mathrm{O}$ & No? & No & 1 & No & $\begin{array}{l}\text { Associated with augite and } \\
\text { other zeolites }\end{array}$ \\
\hline fedorite & $(\mathrm{K}, \mathrm{Na})_{2}(\mathrm{Ca}, \mathrm{Na})_{7} \mathrm{Si}_{16} \mathrm{O}_{38}(\mathrm{OH}, \mathrm{F})_{2} \bullet \mathrm{H}_{2} \mathrm{O}$ & No & No & 1 & No & Metasomatic mineral \\
\hline
\end{tabular}


Table C-1. Critique of Minerals not Included in Project Databases (Continued)

\begin{tabular}{|c|c|c|c|c|c|c|}
\hline Mineral & Chemical Formula & $\begin{array}{c}\text { Precipitates } \\
\text { from } 0 \text { to } 100^{\circ} \mathrm{C} \\
\text { and at } 1 \mathrm{ATM}\end{array}$ & Needed & Criterion & \begin{tabular}{|} 
Within Defined \\
Physico- \\
Chemical \\
System \\
\end{tabular} & $\begin{array}{c}\text { Comments on Occurrence } \\
\text { or Formation }\end{array}$ \\
\hline feitknechtite & $\beta-\mathrm{MnO}(\mathrm{OH})$ & Yes & No & 1 & No & $\begin{array}{l}\text { Alters from pyrochroite, } \\
\text { precursor absent }\end{array}$ \\
\hline felsöbanyaite & $\mathrm{Al}_{4}\left(\mathrm{SO}_{4}\right)(\mathrm{OH})_{10} \cdot 5 \mathrm{H}_{2} \mathrm{O}$ & No & No & 1 & No & Hydrothermal mineral \\
\hline fenaksite & $(\mathrm{K}, \mathrm{Na}, \mathrm{Ca})_{4}\left(\mathrm{Fe}^{2+}, \mathrm{Fe}^{3+}, \mathrm{Mn}\right)_{2} \mathrm{Si}_{8} \mathrm{O}_{20}(\mathrm{OH}, \mathrm{F})$ & No & No & 1 & No & Igneous mineral \\
\hline ferdisilicite & $\mathrm{FeSi}_{2}$ & No & No & 1 & No & $\begin{array}{l}\text { Found in amphibolite and } \\
\text { placers }\end{array}$ \\
\hline feroxyhyte & $\delta-\mathrm{Fe}^{3+} \mathrm{O}(\mathrm{OH})$ & Yes & No & 1 & No & $\begin{array}{l}\text { Occurs in Fe-Mn deep-sea } \\
\text { nodules }\end{array}$ \\
\hline ferrierite & $(\mathrm{Na}, \mathrm{K})_{2} \mathrm{MgAl}_{3} \mathrm{Si}_{15} \mathrm{O}_{36}(\mathrm{OH}) \cdot 9 \mathrm{H}_{2} \mathrm{O}$ & No? & No & 1 & No & $\begin{array}{l}\text { Associated with andesites and } \\
\text { basalt }\end{array}$ \\
\hline ferrihydrite & $5 \mathrm{Fe}^{3+}{ }_{2} \mathrm{O}_{3} \cdot 9 \mathrm{H}_{2} \mathrm{O}$ & Yes & No & 1 & Possibly & $\begin{array}{l}\text { Goethite and } \mathrm{Fe}(\mathrm{OH})_{3} \text { provide } \\
\text { adequate conservatism for } \\
\text { this mineral. }\end{array}$ \\
\hline ferrinatrite & $\mathrm{Na}_{3} \mathrm{Fe}^{3+}\left(\mathrm{SO}_{4}\right)_{3} \cdot 3 \mathrm{H}_{2} \mathrm{O}$ & Yes & No & 6 & Possibly & $\begin{array}{l}\text { With other sulfates in } \\
\text { Atacama desert and in } \\
\text { furmaroles. Other minerals } \\
\text { (e.g., natrojarosite) provide } \\
\text { adequate conservatism for } \\
\text { elements in this mineral. }\end{array}$ \\
\hline ferrohexahydrite & $\mathrm{Fe}^{2+} \mathrm{SO}_{4} \cdot 6 \mathrm{H}_{2} \mathrm{O}$ & Yes & No & 6 & No & $\begin{array}{l}\text { Alters from melanterite, which, } \\
\text { while unlikely to occur in the } \\
\text { repository, provides adequate } \\
\text { conservatism. Also a } \\
\text { fumarolic mineral. }\end{array}$ \\
\hline ferrohornblende & $\mathrm{Ca}_{2}\left(\mathrm{Fe}^{2+}, \mathrm{Mg}\right)_{4} \mathrm{Al}\left(\mathrm{Si}_{7} \mathrm{Al}\right) \mathrm{O}_{22}(\mathrm{OH}, \mathrm{F})_{2}$ & No & No & 1 & No & $\begin{array}{l}\text { Igneous and metamorphic } \\
\text { mineral }\end{array}$ \\
\hline fersilicite & FeSi & No & No & 1 & No & $\begin{array}{l}\text { Found in amphibolite and } \\
\text { placers }\end{array}$ \\
\hline fibroferrite & $\mathrm{Fe}^{3+}\left(\mathrm{SO}_{4}\right)(\mathrm{OH}) \cdot 5 \mathrm{H}_{2} \mathrm{O}$ & Yes & No & 1 & No & $\begin{array}{l}\text { Alters from sulfides, absent in } \\
\text { repository }\end{array}$ \\
\hline fillowite & $\mathrm{Na}_{2} \mathrm{Ca}\left(\mathrm{Mn}, \mathrm{Fe}^{2+}\right)_{7}\left(\mathrm{PO}_{4}\right)_{6}$ & No & No & 1 & No & Igneous mineral \\
\hline fluellite & $\mathrm{Al}_{2}\left(\mathrm{PO}_{4}\right) \mathrm{F}_{2}(\mathrm{OH}) \cdot 7 \mathrm{H}_{2} \mathrm{O}$ & No & No & 1 & No & $\begin{array}{l}\text { Igneous and, possibly, } \\
\text { hydrothermal mineral }\end{array}$ \\
\hline
\end{tabular}


Table C-1. Critique of Minerals not Included in Project Databases (Continued)

\begin{tabular}{|c|c|c|c|c|c|c|}
\hline Mineral & Chemical Formula & $\begin{array}{c}\text { Precipitates } \\
\text { from } 0 \text { to } 100^{\circ} \mathrm{C} \\
\text { and at } 1 \mathrm{ATM}\end{array}$ & Needed & Criterion & \begin{tabular}{|} 
Within Defined \\
Physico- \\
Chemical \\
System \\
\end{tabular} & $\begin{array}{c}\text { Comments on Occurrence } \\
\text { or Formation }\end{array}$ \\
\hline fluorapophyllite & $\mathrm{KCa}_{4} \mathrm{Si}_{8} \mathrm{O}_{20}(\mathrm{~F}, \mathrm{OH}) \bullet 8 \mathrm{H}_{2} \mathrm{O}$ & No & No & 1 & No? & $\begin{array}{l}\text { Associated with basalts or } \\
\text { low-temperature hydrothermal } \\
\text { deposits }\end{array}$ \\
\hline fluorellestadite & $\mathrm{Ca}_{5}\left(\mathrm{SiO}_{4}, \mathrm{PO}_{4}, \mathrm{SO}_{4}\right)_{3}(\mathrm{~F}, \mathrm{OH}, \mathrm{Cl})$ & No & No & 1 & No & Contact metamorphic mineral \\
\hline foggite & $\mathrm{CaAl}\left(\mathrm{PO}_{4}\right)(\mathrm{OH})_{2} \cdot \mathrm{H}_{2} \mathrm{O}$ & No & No & 1 & No & Igneous mineral \\
\hline foshagite & $\mathrm{Ca}_{4} \mathrm{Si}_{3} \mathrm{O}_{9}(\mathrm{OH})_{2}$ & No & No & 1 & No & Hydrothermal mineral \\
\hline foshallasite & $\mathrm{Ca}_{3} \mathrm{Si}_{2} \mathrm{O}_{7} \cdot 3 \mathrm{H}_{2} \mathrm{O}(?)$ & No & No & 1 & No & Hydrothermal mineral \\
\hline francoanellite & $\mathrm{H}_{6}(\mathrm{~K}, \mathrm{Na})_{3}\left(\mathrm{Al}, \mathrm{Fe}^{3+}\right)_{5}\left(\mathrm{PO}_{4}\right)_{8} \cdot 13 \mathrm{H}_{2} \mathrm{O}$ & Yes & No & 1 & No & Associated with bat guano \\
\hline franzinite & $(\mathrm{Na}, \mathrm{Ca})_{7}(\mathrm{Si}, \mathrm{Al})_{12} \mathrm{O}_{24}\left(\mathrm{SO}_{4}, \mathrm{CO}_{3}, \mathrm{OH}, \mathrm{Cl}\right)_{3} \cdot \mathrm{H}_{2} \mathrm{O}$ & No & No & 1 & No & Occurs in pumice in Italy \\
\hline friedelite & $(\mathrm{Mn}, \mathrm{Fe})_{8} \mathrm{Si}_{6} \mathrm{O}_{15}(\mathrm{OH}, \mathrm{Cl})_{10}$ & No & No & 1 & No & Hydrothermal mineral \\
\hline frondelite & $\left(\mathrm{Mn}^{2+}, \mathrm{Fe}^{2+}\right) \mathrm{Fe}^{3+}{ }_{4}\left(\mathrm{PO}_{4}\right)_{3}(\mathrm{OH})_{5}$ & Yes & No & 1 & No & $\begin{array}{l}\text { Alters from triphylite in } \\
\text { pegmatites, precursor absent }\end{array}$ \\
\hline fukalite & $\mathrm{Ca}_{4} \mathrm{Si}_{2} \mathrm{O}_{6}\left(\mathrm{CO}_{3}\right)(\mathrm{OH}, \mathrm{F})_{2}$ & No & No & 1 & No & Metamorphic mineral \\
\hline galaxite & $\left(\mathrm{Mn}, \mathrm{Fe}^{2+}, \mathrm{Mg}\right)\left(\mathrm{Al}, \mathrm{Fe}^{3+}\right)_{2} \mathrm{O}_{4}$ & $?$ & No & 1 & No & $\begin{array}{l}\text { Occurs in vein with other } \mathrm{Mn} \\
\text { minerals }\end{array}$ \\
\hline galeite & $\mathrm{Na}_{15}\left(\mathrm{SO}_{4}\right)_{5} \mathrm{~F}_{4} \mathrm{Cl}$ & Yes? & No & 6 & Possibly & $\begin{array}{l}\text { Occurs in lacustrine } \\
\text { evaporites. Other minerals } \\
\text { (e.g., thenardite, halite, } \\
\text { villiaumite) provide adequate } \\
\text { conservatism for elements in } \\
\text { this mineral }\end{array}$ \\
\hline ganophyllite & $(\mathrm{Na}, \mathrm{K})\left(\mathrm{Mn}, \mathrm{Fe}^{2+}, \mathrm{Al}\right)_{5}(\mathrm{Si}, \mathrm{Al})_{6} \mathrm{O}_{15}(\mathrm{OH})_{5} \cdot 2 \mathrm{H}_{2} \mathrm{O}$ & No & No & 1 & No & Hydrothermal mineral \\
\hline garronite & $\mathrm{Na}_{2} \mathrm{Ca}_{5} \mathrm{Al}_{12} \mathrm{Si}_{20} \mathrm{O}_{64} \cdot 27 \mathrm{H}_{2} \mathrm{O}$ & No? & No & 1 & No & Zeolite found in basalts \\
\hline garyansellite & $\left(\mathrm{Mg}, \mathrm{Fe}^{3+}\right)_{6}\left(\mathrm{PO}_{4}\right)_{4}(\mathrm{OH})_{3} \cdot 3 \mathrm{H}_{2} \mathrm{O}$ & No? & No & 1 & No & Occurs in iron formation \\
\hline gatumbaite & $\mathrm{CaAl} 2\left(\mathrm{PO}_{4}\right)_{2}(\mathrm{OH})_{2} \bullet \mathrm{H}_{2} \mathrm{O}$ & No & No & 1 & No & Igneous mineral \\
\hline gearksutite & $\mathrm{CaAlF}_{4}(\mathrm{OH}) \cdot \mathrm{H}_{2} \mathrm{O}$ & No & No & 1 & No & Hydrothermal mineral \\
\hline gedrite & $\left(\mathrm{Mg}, \mathrm{Fe}^{2+}\right)_{5} \mathrm{Al}_{2}\left(\mathrm{Si}_{6} \mathrm{Al}_{2}\right) \mathrm{O}_{22}(\mathrm{OH})_{2}$ & No & No & 1 & No & Metamorphic \\
\hline geikielite & $\mathrm{MgTiO}_{3}$ & No & No & 1 & No & Metamorphic \\
\hline giniite & $\mathrm{Fe}^{2+} \mathrm{Fe}^{3+}{ }_{4}\left(\mathrm{PO}_{4}\right)_{4}(\mathrm{OH})_{2} \cdot 2 \mathrm{H}_{2} \mathrm{O}$ & No & No & 1 & No & Igneous mineral \\
\hline giorgiosite & $\mathrm{Mg}_{5}\left(\mathrm{CO}_{3}\right)_{4}(\mathrm{OH})_{2} \cdot 5 \mathrm{H}_{2} \mathrm{O}$ & Yes & No & 1 & Possibly & Weathering product on lava \\
\hline
\end{tabular}


Table C-1. Critique of Minerals not Included in Project Databases (Continued)

\begin{tabular}{|c|c|c|c|c|c|c|}
\hline Mineral & Chemical Formula & $\begin{array}{l}\text { Precipitates } \\
\text { from } 0 \text { to } 100^{\circ} \mathrm{C} \\
\text { and at } 1 \mathrm{ATM}\end{array}$ & Needed & Criterion & $\begin{array}{l}\text { Within Defined } \\
\text { Physico- } \\
\text { Chemical } \\
\text { System }\end{array}$ & $\begin{array}{c}\text { Comments on Occurrence } \\
\text { or Formation }\end{array}$ \\
\hline giuseppettite & $(\mathrm{Na}, \mathrm{K}, \mathrm{Ca})_{7-8}(\mathrm{Si}, \mathrm{Al})_{12} \mathrm{O}_{24}\left(\mathrm{SO}_{4}, \mathrm{Cl}\right)_{1-2}$ & No & No & 1 & No & $\begin{array}{l}\text { Veinlets in feldspar-rich } \\
\text { igneous rock }\end{array}$ \\
\hline glaucochroite & $\mathrm{CaMnSiO}_{4}$ & No & No & 1 & No & Metamorphic mineral \\
\hline glauconite & $(\mathrm{K}, \mathrm{Na})\left(\mathrm{Fe}^{3+}, \mathrm{Al}, \mathrm{Mg}\right)_{2}(\mathrm{Si}, \mathrm{Al})_{4} \mathrm{O}_{10}(\mathrm{OH})_{2}$ & Yes & No & 1 & No & $\begin{array}{l}\text { Forms in marine sands and } \\
\text { sedimentary rocks }\end{array}$ \\
\hline glaucophane & $\mathrm{Na}_{2}\left(\mathrm{Mg}, \mathrm{Fe}^{2+}\right)_{3} \mathrm{Al}_{2} \mathrm{Si}_{8} \mathrm{O}_{22}(\mathrm{OH})_{2}$ & No & No & 1 & No & Metamorphic \\
\hline glushinskite & $\mathrm{MgC}_{2} \mathrm{O}_{4} \cdot 2 \mathrm{H}_{2} \mathrm{O}$ & Yes & No & 1 & No & Occurs with lichen \\
\hline gmelinite & $\left(\mathrm{Na}_{2}, \mathrm{Ca}\right) \mathrm{Al}_{2} \mathrm{Si}_{4} \mathrm{O}_{12} \cdot 6 \mathrm{H}_{2} \mathrm{O}$ & No? & No & 1 & No & Zeolite found in basalts \\
\hline goldichite & $\mathrm{KFe}^{3+}\left(\mathrm{SO}_{4}\right)_{2} \bullet 4 \mathrm{H}_{2} \mathrm{O}$ & Yes & No & 1 & No & In talus below a pyritic deposit \\
\hline gonnardite & $\mathrm{Na}_{2} \mathrm{CaAl}{ }_{4} \mathrm{Si}_{6} \mathrm{O}_{20} \cdot 7 \mathrm{H}_{2} \mathrm{O}$ & No? & No & 1 & No & $\begin{array}{l}\text { Zeolite found in basalts and in } \\
\text { pyritic metamorphic rock }\end{array}$ \\
\hline gonyerite & $(\mathrm{Mn}, \mathrm{Mg})_{5} \mathrm{Fe}^{3+}\left(\mathrm{Si}_{3} \mathrm{Fe}^{3+}\right) \mathrm{O}_{10}(\mathrm{OH})_{8}$ & No & No & 1 & No & Hydrothermal mineral \\
\hline goosecreekite & $\mathrm{CaAl}_{2} \mathrm{Si}_{6} \mathrm{O}_{16} \cdot 10 \mathrm{H}_{2} \mathrm{O}$ & No? & No & 1 & No & Associated with diabase \\
\hline gordonite & $\mathrm{MgAl}_{2}\left(\mathrm{PO}_{4}\right)_{2}(\mathrm{OH})_{2} \bullet 8 \mathrm{H}_{2} \mathrm{O}$ & $?$ & No & 1 & No & Associated with variscite \\
\hline görgeyite & $\mathrm{K}_{2} \mathrm{Ca}_{5}\left(\mathrm{SO}_{4}\right)_{6} \cdot \mathrm{H}_{2} \mathrm{O}$ & Yes? & No & 6 & No & $\begin{array}{l}\text { In marine evaporite. } \\
\text { Syngenite provides adequate } \\
\text { conservatism for this mineral. }\end{array}$ \\
\hline gormanite & $\mathrm{Fe}^{2+}{ }_{3} \mathrm{Al}_{4}\left(\mathrm{PO}_{4}\right)_{4}(\mathrm{OH})_{6} \cdot 2 \mathrm{H}_{2} \mathrm{O}$ & $?$ & No & 1 & No & $\begin{array}{l}\text { Associated with phosphate } \\
\text { deposits }\end{array}$ \\
\hline graftonite & $\left(\mathrm{Fe}^{2+}, \mathrm{Mn}^{2+}, \mathrm{Ca}\right)_{3}\left(\mathrm{PO}_{4}\right)_{2}$ & Yes & No & 1 & No & Igneous mineral \\
\hline gregoryite & $\left(\mathrm{Na}_{2}, \mathrm{~K}_{2}, \mathrm{Ca}\right) \mathrm{CO}_{3}$ & No & No & 1 & No & Igneous mineral \\
\hline greigite & $\mathrm{Fe}^{2+} \mathrm{Fe}_{2}^{3+} \mathrm{S}_{4}$ & Yes & No & 1 & No & $\begin{array}{l}\text { Forms under reducing } \\
\text { conditions }\end{array}$ \\
\hline groutite & $\mathrm{Mn}^{3+} \mathrm{O}(\mathrm{OH})$ & $?$ & No & 1 & No & $\begin{array}{l}\text { Occurs in Fe and talc } \\
\text { deposits, probably } \\
\text { metamorphic }\end{array}$ \\
\hline grunerite & $(\mathrm{Fe}, \mathrm{Mg})_{7} \mathrm{Si}_{8} \mathrm{O}_{22}(\mathrm{OH})_{2}$ & No & No & 1 & No & Metamorphic \\
\hline gupeiite & $\mathrm{Fe}_{3} \mathrm{Si}$ & No & No & 1 & No & Probably extraterrestrial \\
\hline hagendorfite & $(\mathrm{Na}, \mathrm{Ca}) \mathrm{Mn}\left(\mathrm{Fe}^{2+}, \mathrm{Fe}^{3+}, \mathrm{Mg}\right)_{2}\left(\mathrm{PO}_{4}\right)_{3}$ & No & No & 1 & No & Igneous mineral \\
\hline halloysite & $\mathrm{Al}_{2} \mathrm{Si}_{2} \mathrm{O}_{5}(\mathrm{OH})_{4}$ & Yes & No & 3 & Yes & $\begin{array}{l}\text { Kaolinite provides adequate } \\
\text { proxy for this mineral }\end{array}$ \\
\hline
\end{tabular}


Table C-1. Critique of Minerals not Included in Project Databases (Continued)

\begin{tabular}{|c|c|c|c|c|c|c|}
\hline Mineral & Chemical Formula & $\begin{array}{c}\text { Precipitates } \\
\text { from } 0 \text { to } 100^{\circ} \mathrm{C} \\
\text { and at } 1 \mathrm{ATM}\end{array}$ & Needed & Criterion & $\begin{array}{l}\text { Within Defined } \\
\text { Physico- } \\
\text { Chemical } \\
\text { System } \\
\end{array}$ & $\begin{array}{c}\text { Comments on Occurrence } \\
\text { or Formation }\end{array}$ \\
\hline halotrichite & $\mathrm{Fe}^{2+} \mathrm{Al}_{2}\left(\mathrm{SO}_{4}\right)_{4} \cdot 22 \mathrm{H}_{2} \mathrm{O}$ & Yes & No & 1 & No & $\begin{array}{l}\text { Alteration product of pyrite, } \\
\text { precursor absent. Also, a } \\
\text { fumarolic and hydrothermal } \\
\text { mineral. }\end{array}$ \\
\hline hanksite & $\mathrm{KNa}_{22}\left(\mathrm{SO}_{4}\right)_{9}\left(\mathrm{CO}_{3}\right)_{2} \mathrm{Cl}$ & Yes? & No & 6 & Possibly & $\begin{array}{l}\text { Occurs in lacustrine } \\
\text { evaporites. Other minerals } \\
\text { (e.g., glaserite, burkeite, } \\
\text { sylvite) provide adequate } \\
\text { conservatism for elements in } \\
\text { this mineral. }\end{array}$ \\
\hline hannayite & $\left(\mathrm{NH}_{4}\right)_{2} \mathrm{Mg}_{3} \mathrm{H}_{4}\left(\mathrm{PO}_{4}\right)_{4} \cdot 8 \mathrm{H}_{2} \mathrm{O}$ & Yes & No & 1 & No & Occurs with bat guano \\
\hline hastingsite & $\mathrm{NaCa}_{2}\left(\mathrm{Fe}^{2+}, \mathrm{Mg}\right)_{4} \mathrm{Fe}^{+3}\left(\mathrm{Al}_{2} \mathrm{Si}_{6}\right) \mathrm{O}_{22}(\mathrm{OH})_{2}$ & No & No & 1 & No & $\begin{array}{l}\text { Igneous and metamorphic } \\
\text { mineral }\end{array}$ \\
\hline hatrurite & $\mathrm{Ca}_{3} \mathrm{SiO}_{5}$ & No & No & 1 & No & Metamorphic mineral \\
\hline hauerite & $\mathrm{MnS}_{2}$ & Yes & No & 1 & No & $\begin{array}{l}\text { Sulfide mineral, requires } \\
\text { reducing conditions }\end{array}$ \\
\hline haüyne & $(\mathrm{Na}, \mathrm{Ca})_{4-8} \mathrm{Al}_{6} \mathrm{Si}_{6}(\mathrm{O}, \mathrm{S})_{24}\left(\mathrm{SO}_{4}, \mathrm{Cl}\right)_{1-2}$ & No & No & 1 & No & Igneous mineral \\
\hline henritermierite & $\mathrm{Ca}_{3}\left(\mathrm{Mn}^{3+}, \mathrm{Al}\right)_{2}\left(\mathrm{SiO}_{4}\right)_{2}(\mathrm{OH})_{4}$ & No? & No & 1 & No & Occurs in Mn deposits \\
\hline herschelite & $(\mathrm{Na}, \mathrm{Ca}, \mathrm{K}) \mathrm{AlSi}_{2} \mathrm{O}_{6} \cdot 3 \mathrm{H}_{2} \mathrm{O}$ & No? & No & 1 & No & Occurs in cavities in basalt \\
\hline heterosite & $\left(\mathrm{Fe}^{3+}, \mathrm{Mn}^{3+}\right) \mathrm{PO}_{4}$ & Yes? & No & 1 & No & $\begin{array}{l}\text { Alters from triphylite, } \\
\text { precursor absent }\end{array}$ \\
\hline hieratite & $\mathrm{K}_{2} \mathrm{SiF}_{6}$ & No & No & 1 & No & Fumarolic mineral \\
\hline hillebrandite & $\mathrm{Ca}_{2} \mathrm{SiO}_{3}(\mathrm{OH})_{2}$ & No & No & 1 & No & Metamorphic mineral \\
\hline hisingerite & $\mathrm{Fe}^{3+}{ }_{2} \mathrm{Si}_{2} \mathrm{O}_{5}(\mathrm{OH})_{4} \cdot 2 \mathrm{H}_{2} \mathrm{O}$ & Yes & No & 6 & Possibly & $\begin{array}{l}\text { Weathering product, but may } \\
\text { be slow to form. Greenalite } \\
\text { provides a reasonable proxy } \\
\text { for this mineral. }\end{array}$ \\
\hline högbomite & $\mathrm{Mg}(\mathrm{Al}, \mathrm{Fe}, \mathrm{Ti})_{4} \mathrm{O}_{7}$ & No? & No & 1 & No & $\begin{array}{l}\text { Occurs with emery, magnetite, } \\
\text { and corundum; hence, is } \\
\text { metamorphic }\end{array}$ \\
\hline hohmannite & $\mathrm{Fe}_{2}^{3+}{ }_{2}\left(\mathrm{SO}_{4}\right)_{2}(\mathrm{OH})_{2} \cdot 7 \mathrm{H}_{2} \mathrm{O}$ & No & No & 1 & No & $\begin{array}{l}\text { Hydrothermal or alteration } \\
\text { product at sulfide mines }\end{array}$ \\
\hline
\end{tabular}


Table C-1. Critique of Minerals not Included in Project Databases (Continued)

\begin{tabular}{|c|c|c|c|c|c|c|}
\hline Mineral & Chemical Formula & $\begin{array}{c}\text { Precipitates } \\
\text { from } 0 \text { to } 100^{\circ} \mathrm{C} \\
\text { and at } 1 \mathrm{ATM}\end{array}$ & Needed & Criterion & \begin{tabular}{|} 
Within Defined \\
Physico- \\
Chemical \\
System \\
\end{tabular} & $\begin{array}{c}\text { Comments on Occurrence } \\
\text { or Formation }\end{array}$ \\
\hline holtedahlite & $\mathrm{Mg}_{2}\left(\mathrm{PO}_{4}\right)(\mathrm{OH})$ & No & No & 1 & No & $\begin{array}{l}\text { Igneous or metamorphic } \\
\text { mineral }\end{array}$ \\
\hline hotsonite & $\mathrm{Al}_{11}\left(\mathrm{PO}_{4}\right)_{2}\left(\mathrm{SO}_{4}\right)_{3}(\mathrm{OH})_{21} \cdot 16 \mathrm{H}_{2} \mathrm{O}$ & No & No & 1 & No & Metamorphic mineral \\
\hline howieite & $\mathrm{Na}\left(\mathrm{Fe}^{2+}, \mathrm{Mn}\right)_{10}\left(\mathrm{Fe}^{+3}, \mathrm{Al}_{2}\right)_{2} \mathrm{Si}_{12} \mathrm{O}_{31}(\mathrm{OH})_{13}$ & No & No & 1 & No & Metamorphic mineral \\
\hline humberstonite & $\mathrm{Na}_{7} \mathrm{~K}_{3} \mathrm{Mg}_{2}\left(\mathrm{SO}_{4}\right)_{6}\left(\mathrm{NO}_{3}\right)_{2} \cdot 6 \mathrm{H}_{2} \mathrm{O}$ & Yes & No & 6 & No & $\begin{array}{l}\text { Associated with nitrates in } \\
\text { Atacama desert. Other } \\
\text { minerals (e.g., bloedite, } \\
\text { picromerite, niter, soda niter) } \\
\text { provide adequate } \\
\text { conservatism for elements in } \\
\text { this mineral. }\end{array}$ \\
\hline humboldtine & $\mathrm{Fe}^{2+} \mathrm{C}_{2} \mathrm{O}_{4} \cdot 2 \mathrm{H}_{2} \mathrm{O}$ & Yes & No & 1 & No & $\begin{array}{l}\text { Associated with coal, outside } \\
\text { redox range }\end{array}$ \\
\hline humite & $\left(\mathrm{Mg}, \mathrm{Fe}^{2+}\right)_{7}\left(\mathrm{SiO}_{4}\right)_{3}(\mathrm{~F}, \mathrm{OH})_{2}$ & No & No & 1 & No & Metamorphic mineral \\
\hline hureaulite & $\mathrm{Mn}_{5}\left(\mathrm{PO}_{4}\right)_{2}\left[\mathrm{PO}_{3}(\mathrm{OH})\right]_{2} \bullet 4 \mathrm{H}_{2} \mathrm{O}$ & No & No & 1 & No & $\begin{array}{l}\text { Alters from triphylite in } \\
\text { pegmatites, precursor absent }\end{array}$ \\
\hline hydroastrophyllite & $\left(\mathrm{H}_{3} \mathrm{O}, \mathrm{K}, \mathrm{Ca}\right)_{3}\left(\mathrm{Fe}^{2+}, \mathrm{Mn}\right)_{5-6} \mathrm{Ti}_{2} \mathrm{Si}_{6}(\mathrm{O}, \mathrm{OH})_{31}$ & Yes & No & 1 & No & $\begin{array}{l}\text { Weathering product in an } \\
\text { alkalic pegmatite }\end{array}$ \\
\hline hydrobasaluminite & $\mathrm{Al}_{4}\left(\mathrm{SO}_{4}\right)(\mathrm{OH})_{10} \cdot 12-36 \mathrm{H}_{2} \mathrm{O}$ & Yes & No & 1 & No & $\begin{array}{l}\text { Weathering product in siderite } \\
\text { and clay deposits }\end{array}$ \\
\hline hydrocalumite & $\mathrm{Ca}_{2} \mathrm{Al}(\mathrm{OH})_{6}\left[\mathrm{Cl}_{1-\mathrm{x}}(\mathrm{OH})_{\mathrm{x}}\right] \cdot 3 \mathrm{H}_{2} \mathrm{O}$ & No & No & 1 & No & In vugs in a metamorphic rock \\
\hline hydroglauberite & $\mathrm{Na}_{4} \mathrm{Ca}\left(\mathrm{SO}_{4}\right)_{3} \cdot 2 \mathrm{H}_{2} \mathrm{O}$ & Yes & No & 6 & Yes & $\begin{array}{l}\text { Other minerals, notably } \\
\text { glauberite, provide adequate } \\
\text { conservatism for elements in } \\
\text { this mineral. }\end{array}$ \\
\hline hydrogrossular & $\mathrm{Ca}_{3} \mathrm{Al}_{2}\left(\mathrm{SiO}_{4}\right)_{3-\mathrm{x}}(\mathrm{OH})_{4 \mathrm{x}}$ & No? & No & 1 & No? & $\begin{array}{l}\text { Dominantly a metamorphic } \\
\text { mineral. Grossular provides } \\
\text { adequate conservatism. }\end{array}$ \\
\hline hydrohalite & $\mathrm{NaCl} \cdot 2 \mathrm{H}_{2} \mathrm{O}$ & No & No & 1 & No & Stable only below $0^{\circ} \mathrm{C}$. \\
\hline hydromolysite & $\mathrm{FeCl}_{3} \cdot 6 \mathrm{H}_{2} \mathrm{O}$ & Yes & No & 1 & No & $\begin{array}{l}\text { Alteration of pyrite, precursor } \\
\text { absent }\end{array}$ \\
\hline hydronium jarosite & $\left(\mathrm{H}_{3} \mathrm{O}\right) \mathrm{Fe}^{3+}{ }_{3}\left(\mathrm{SO}_{4}\right)_{2}(\mathrm{OH})_{6}$ & Yes & No & 1 & No & $\begin{array}{l}\text { Alteration of pyrite, precursor } \\
\text { absent, or in similar settings }\end{array}$ \\
\hline
\end{tabular}


Table C-1. Critique of Minerals not Included in Project Databases (Continued)

\begin{tabular}{|c|c|c|c|c|c|c|}
\hline Mineral & Chemical Formula & $\begin{array}{c}\text { Precipitates } \\
\text { from } 0 \text { to } 100^{\circ} \mathrm{C} \\
\text { and at } 1 \mathrm{ATM}\end{array}$ & Needed & Criterion & $\begin{array}{l}\text { Within Defined } \\
\text { Physico- } \\
\text { Chemical } \\
\text { System } \\
\end{array}$ & $\begin{array}{c}\text { Comments on Occurrence } \\
\text { or Formation }\end{array}$ \\
\hline hydroscarbroite & $\mathrm{Al}_{14}\left(\mathrm{CO}_{3}\right)_{3}(\mathrm{OH})_{36} \bullet \mathrm{nH}_{2} \mathrm{O}$ & $?$ & No & 1 & Unlikely & $\begin{array}{l}\text { Little detail available; } \\
\text { formation would require } \\
\text { unusual conditions, such as } \\
\text { repression of gibbsite } \\
\text { precipitation. }\end{array}$ \\
\hline hydrotalcite & $\mathrm{Mg}_{6} \mathrm{Al}_{2}\left(\mathrm{CO}_{3}\right)(\mathrm{OH})_{16} \bullet 4 \mathrm{H}_{2} \mathrm{O}$ & $?$ & No & 6 & No & $\begin{array}{l}\text { Occurs in rocks with high } \mathrm{Mg} \text {, } \\
\text { such as serpentine. Other } \\
\text { minerals provide adequate } \\
\text { conservatism for elements in } \\
\text { this mineral. }\end{array}$ \\
\hline hydrougrandite & $\left(\mathrm{Ca}, \mathrm{Mg}, \mathrm{Fe}^{2+}\right)_{3}\left(\mathrm{Fe}^{3+}, \mathrm{Al}\right)_{2}\left(\mathrm{SiO}_{4}\right)_{3-\mathrm{x}}(\mathrm{OH})_{4 \mathrm{x}}$ & No & No & 1 & No & Igneous mineral \\
\hline hydroxyapophyllite & $\mathrm{KCa}_{4} \mathrm{Si}_{8} \mathrm{O}_{20}(\mathrm{OH}, \mathrm{F}) \cdot 8 \mathrm{H}_{2} \mathrm{O}$ & No? & No & 1 & No? & $\begin{array}{l}\text { Reported occurrences in } \\
\text { mines. Probably similar } \\
\text { settings as fluorapophyllite. }\end{array}$ \\
\hline hydroxylellestadite & $\mathrm{Ca}_{10}\left(\mathrm{SiO}_{4}\right)_{3}\left(\mathrm{SO}_{4}\right)_{3}(\mathrm{OH}, \mathrm{Cl}, \mathrm{F})_{2}$ & No & No & 1 & No & Occurs in metamorphic rocks \\
\hline ikaite & $\mathrm{CaCO}_{3} \cdot 6 \mathrm{H}_{2} \mathrm{O}$ & No? & No & 1 & No & Occurs in a fjord in Greenland \\
\hline ilvaite & $\mathrm{CaFe}_{2}^{2+}{ }_{2} \mathrm{Fe}^{3+}\left(\mathrm{SiO}_{4}\right)_{2}(\mathrm{OH})$ & No & No & 1 & No & $\begin{array}{l}\text { Igneous and metamorphic } \\
\text { mineral }\end{array}$ \\
\hline imandrite & $\mathrm{Na}_{12} \mathrm{Ca}_{3} \mathrm{Fe}^{3+}{ }_{2}\left(\mathrm{Si}_{6} \mathrm{O}_{18}\right)_{2}$ & No & No & 1 & No & Igneous mineral \\
\hline indialite & $(\mathrm{Mg}, \mathrm{Fe})_{2} \mathrm{Al}_{4} \mathrm{Si}_{5} \mathrm{O}_{18}$ & No & No & 1 & No & $\begin{array}{l}\text { Metamorphic mineral (e.g., in } \\
\text { fused rock) }\end{array}$ \\
\hline indigirite & $\mathrm{Mg}_{2} \mathrm{Al}_{2}\left(\mathrm{CO}_{3}\right)_{4}(\mathrm{OH})_{2} \cdot 15 \mathrm{H}_{2} \mathrm{O}$ & Yes & No & 1 & No & $\begin{array}{l}\text { Occurs in oxidized zone of a } \\
\mathrm{Au}-\mathrm{Sb} \text { deposit }\end{array}$ \\
\hline inesite & $\mathrm{Ca}_{2} \mathrm{Mn}_{7} \mathrm{Si}_{10} \mathrm{O}_{28}(\mathrm{OH})_{2} \cdot 5 \mathrm{H}_{2} \mathrm{O}$ & No & No & 1 & No & Occurs in Mn ore deposits \\
\hline iowaite & $\mathrm{Mg}_{4} \mathrm{Fe}^{3+}(\mathrm{OH})_{8} \mathrm{OCl} \cdot 2-4 \mathrm{H}_{2} \mathrm{O}$ & No & No & 1 & No & Occurs in ultramafic rocks \\
\hline iron & $\mathrm{Fe}$ & No & Yes & 2 & Yes & $\begin{array}{l}\text { Iron needed as a component } \\
\text { of reactants in geochemical } \\
\text { models. }\end{array}$ \\
\hline isoclasite & $\mathrm{Ca}_{2}\left(\mathrm{PO}_{4}\right)(\mathrm{OH}) \cdot 2 \mathrm{H}_{2} \mathrm{O}$ & $?$ & No & 6 & Possibly & $\begin{array}{l}\text { Other minerals (e.g., apatite) } \\
\text { provide adequate } \\
\text { conservatism for elements in } \\
\text { this mineral. }\end{array}$ \\
\hline isokite & $\mathrm{CaMg}\left(\mathrm{PO}_{4}\right) \mathrm{F}$ & No & No & 1 & No & Igneous mineral \\
\hline
\end{tabular}


Table C-1. Critique of Minerals not Included in Project Databases (Continued)

\begin{tabular}{|c|c|c|c|c|c|c|}
\hline Mineral & Chemical Formula & $\begin{array}{l}\text { Precipitates } \\
\text { from } 0 \text { to } 100^{\circ} \mathrm{C} \\
\text { and at } 1 \mathrm{ATM}\end{array}$ & Needed & Criterion & $\begin{array}{l}\text { Within Defined } \\
\text { Physico- } \\
\text { Chemical } \\
\text { System }\end{array}$ & $\begin{array}{c}\text { Comments on Occurrence } \\
\text { or Formation }\end{array}$ \\
\hline iwakiite & $\mathrm{Mn}^{2+}\left(\mathrm{Fe}^{3+}, \mathrm{Mn}^{3+}\right)_{2} \mathrm{O}_{4}$ & No? & No & 1 & No & Occurs in Mn ores \\
\hline jacobsite & $\left(\mathrm{Mn}^{2+}, \mathrm{Fe}^{2+}, \mathrm{Mg}\right)\left(\mathrm{Fe}^{3+}, \mathrm{Mn}^{3+}\right)_{2} \mathrm{O}_{4}$ & No & No & 1 & No & Associated with Mn minerals \\
\hline jahnsite & $\mathrm{CaMn}\left(\mathrm{Mg}, \mathrm{Fe}^{2+}\right)_{2} \mathrm{Fe}_{2}^{3+}{ }_{2}\left(\mathrm{PO}_{4}\right)_{4}(\mathrm{OH})_{2} \cdot 8 \mathrm{H}_{2} \mathrm{O}$ & No & No & 1 & No & $\begin{array}{l}\text { Igneous and metamorphic } \\
\text { mineral }\end{array}$ \\
\hline janggunite & $\mathrm{Mn}^{4+}{ }_{5-\mathrm{x}}\left(\mathrm{Mn}^{2+}, \mathrm{Fe}^{3+}\right)_{1+\mathrm{x}} \mathrm{O}_{8}(\mathrm{OH})_{6}$ & Yes & No & 1 & No & Supergene Mn mineral \\
\hline jasmundite & $\mathrm{Ca}_{11}\left(\mathrm{SiO}_{4}\right)_{4} \mathrm{O}_{2} \mathrm{~S}$ & No & No & 1 & No & Metamorphic mineral \\
\hline jennite & $\mathrm{Ca}_{9} \mathrm{H}_{2} \mathrm{Si}_{6} \mathrm{O}_{18}(\mathrm{OH})_{8} \cdot 6 \mathrm{H}_{2} \mathrm{O}$ & No & No & 1 & No & Metamorphic mineral \\
\hline jerrygibbsite & $\mathrm{Mn}_{9}\left(\mathrm{SiO}_{4}\right)_{4}(\mathrm{OH})_{2}$ & No & No & 1 & No & Hydrothermal mineral \\
\hline jimthompsonite & $\left(\mathrm{Mg}, \mathrm{Fe}^{2+}\right)_{5} \mathrm{Si}_{6} \mathrm{O}_{16}(\mathrm{OH})_{2}$ & No & No & 1 & No & Metamorphic mineral \\
\hline johannsenite & $\mathrm{Ca}\left(\mathrm{Mn}, \mathrm{Fe}^{2+}\right) \mathrm{Si}_{2} \mathrm{O}_{6}$ & No & No & 1 & No & $\begin{array}{l}\text { Metasomatic mineral; } \\
\text { associated with Mn minerals }\end{array}$ \\
\hline johnsomervilleite & $\mathrm{Na}_{10} \mathrm{Ca}_{6} \mathrm{Mg}_{18}(\mathrm{Fe}, \mathrm{Mn})_{25}\left(\mathrm{PO}_{4}\right)_{36}$ & No & No & 1 & No & Metamorphic mineral \\
\hline jokokuite & $\mathrm{MnSO}_{4} \cdot 5 \mathrm{H}_{2} \mathrm{O}$ & Yes & No & 1 & Yes & $\begin{array}{l}\text { Occurs in caves. Associated } \\
\text { minerals indicate a reducing } \\
\text { environment, outside of redox } \\
\text { range }\end{array}$ \\
\hline jouravskite & $\mathrm{Ca}_{3} \mathrm{Mn}^{4+}\left(\mathrm{SO}_{4}\right)\left(\mathrm{CO}_{3}\right)(\mathrm{OH})_{6} \cdot 13 \mathrm{H}_{2} \mathrm{O}$ & No? & No & 1 & No & $\begin{array}{l}\text { Associated with Mn minerals } \\
\text { on mine dump }\end{array}$ \\
\hline juanite & $\mathrm{Ca}_{10} \mathrm{Mg}_{4} \mathrm{Al}_{2} \mathrm{Si}_{11} \mathrm{O}_{39} \bullet 4 \mathrm{H}_{2} \mathrm{O}(?)$ & Yes & No & 1 & No & $\begin{array}{l}\text { Alters from melilite, precursor } \\
\text { absent }\end{array}$ \\
\hline julgoldite & $\mathrm{Ca}_{2} \mathrm{Fe}^{2+}\left(\mathrm{Fe}^{3+}, \mathrm{Al}\right)_{2}\left(\mathrm{SiO}_{4}\right)\left(\mathrm{Si}_{2} \mathrm{O}_{7}\right)(\mathrm{OH})_{2} \bullet \mathrm{H}_{2} \mathrm{O}$ & No? & No & 1 & No & Occurs in Fe ore \\
\hline jurbanite & $\mathrm{Al}\left(\mathrm{SO}_{4}\right)(\mathrm{OH}) \cdot 5 \mathrm{H}_{2} \mathrm{O}$ & Yes & No & 6 & No & $\begin{array}{l}\text { Post-mining deposit in a Cu } \\
\text { mine. Other minerals (e.g., } \\
\text { alum-K, gypsum, boehmite) } \\
\text { provide adequate } \\
\text { conservatism for elements in } \\
\text { this mineral. }\end{array}$ \\
\hline kaersutite & 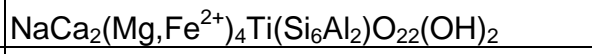 & No & No & 1 & No & Igneous mineral \\
\hline kafehydrocyanite & $\mathrm{K}_{4} \mathrm{Fe}^{2+}(\mathrm{CN})_{6} \cdot 3 \mathrm{H}_{2} \mathrm{O}$ & No & No & 1 & No & Metamorphic mineral \\
\hline
\end{tabular}


Table C-1. Critique of Minerals not Included in Project Databases (Continued)

\begin{tabular}{|c|c|c|c|c|c|c|}
\hline Mineral & Chemical Formula & $\begin{array}{l}\text { Precipitates } \\
\text { from } 0 \text { to } 100^{\circ} \mathrm{C} \\
\text { and at } 1 \text { ATM }\end{array}$ & Needed & Criterion & $\begin{array}{l}\text { Within Defined } \\
\text { Physico- } \\
\text { Chemical } \\
\text { System } \\
\end{array}$ & $\begin{array}{c}\text { Comments on Occurrence } \\
\text { or Formation }\end{array}$ \\
\hline kalinite & $\mathrm{KAI}\left(\mathrm{SO}_{4}\right)_{2} \cdot 11 \mathrm{H}_{2} \mathrm{O}$ & $?$ & No & 6 & $?$ & $\begin{array}{l}\text { Alum-K and other K-Al } \\
\text { sulfates in dataO.ypf.RO } \\
\text { provide adequate } \\
\text { conservatism for elements in } \\
\text { this mineral }\end{array}$ \\
\hline kaliophilite & $\mathrm{KAISiO}_{4}$ & No & No & 1 & No & Igneous mineral \\
\hline kalsilite & $\mathrm{KAISiO}_{4}$ & No & No & 1 & No & Igneous mineral \\
\hline kamaishilite & $\mathrm{Ca}_{2} \mathrm{Al}_{2} \mathrm{SiO}_{6}(\mathrm{OH})_{2}$ & No & No & 1 & No & Metamorphic mineral \\
\hline kanemite & $\mathrm{NaHSi}_{2} \mathrm{O}_{4}(\mathrm{OH})_{2} \cdot 2 \mathrm{H}_{2} \mathrm{O}$ & Yes & No & 6 & Yes & $\begin{array}{l}\text { Occurs in lacustrine } \\
\text { evaporites. Other minerals } \\
\text { (e.g., nahcolite, trona, } \\
\left.\mathrm{SiO}_{2(\text { am })}\right) \text { provide adequate } \\
\text { conservatism for elements in } \\
\text { this mineral. }\end{array}$ \\
\hline kanoite & $\left(\mathrm{Mn}^{2+}, \mathrm{Mg}\right)_{2} \mathrm{Si}_{2} \mathrm{O}_{6}$ & No & No & 6 & No & $\begin{array}{l}\text { A pyroxene, hence, probably } \\
\text { metamorphic or igneous. } \\
\text { Other solids (e.g., } \mathrm{SiO}_{2(\mathrm{am})} \text {, } \\
\mathrm{Mn}(\mathrm{OH})_{2}, \text { boehmite, } \\
\text { manganite) provide adequate } \\
\text { conservatism for elements in } \\
\text { this mineral. } \\
\end{array}$ \\
\hline kanonaite & $\left(\mathrm{Mn}^{3+}, \mathrm{Al}\right) \mathrm{AlSiO}_{5}$ & No & No & 1 & No & Metamorphic mineral \\
\hline kassite & $\mathrm{CaTi}_{2} \mathrm{O}_{4}(\mathrm{OH})_{2}$ & No & No & 1 & No & Igneous mineral \\
\hline katoite & $\mathrm{Ca}_{3} \mathrm{Al}_{2}\left(\mathrm{SiO}_{4}\right)_{3-\mathrm{x}}(\mathrm{OH})_{4 \mathrm{x}}$ & No & No & 1 & No & Igneous mineral \\
\hline kazakovite & $\mathrm{Na}_{6}\left(\mathrm{Mn}, \mathrm{H}_{2}\right) \mathrm{TiSi}_{6} \mathrm{O}_{18}$ & No & No & 1 & No & Igneous mineral \\
\hline kellyite & $\left(\mathrm{Mn}^{2+}, \mathrm{Mg}, \mathrm{Al}\right)_{3}(\mathrm{Si}, \mathrm{Al})_{2} \mathrm{O}_{5}(\mathrm{OH})_{4}$ & No? & No & 1 & No & $\begin{array}{l}\text { Occurs with sulfides in a Mn } \\
\text { mine. Requires reducing } \\
\text { conditions }\end{array}$ \\
\hline kempite & $\mathrm{Mn}_{2} \mathrm{Cl}(\mathrm{OH})_{3}$ & $?$ & No & 5 & No & $\begin{array}{l}\text { Rare. Found in a Mn-rich } \\
\text { boulder }\end{array}$ \\
\hline kennedyite & $\mathrm{MgFe}_{2}^{3+}{ }_{2} \mathrm{Ti}_{3} \mathrm{O}_{10}$ & No & No & 1 & No & Igneous mineral \\
\hline
\end{tabular}


Table C-1. Critique of Minerals not Included in Project Databases (Continued)

\begin{tabular}{|c|c|c|c|c|c|c|}
\hline Mineral & Chemical Formula & $\begin{array}{c}\text { Precipitates } \\
\text { from } 0 \text { to } 100^{\circ} \mathrm{C} \\
\text { and at } 1 \mathrm{ATM}\end{array}$ & Needed & Criterion & \begin{tabular}{|c|} 
Within Defined \\
Physico- \\
Chemical \\
System
\end{tabular} & $\begin{array}{c}\text { Comments on Occurrence } \\
\text { or Formation }\end{array}$ \\
\hline kenyaite & $\mathrm{Na}_{2} \mathrm{Si}_{22} \mathrm{O}_{41}(\mathrm{OH})_{8} \cdot 6 \mathrm{H}_{2} \mathrm{O}$ & Yes & No & 6 & Yes & $\begin{array}{l}\text { Occurs in lacustrine } \\
\text { evaporites. Other minerals } \\
\text { (e.g., nahcolite, trona, } \\
\left.\mathrm{SiO}_{2(\mathrm{am})}\right) \text { provide adequate } \\
\text { conservatism for elements in } \\
\text { this mineral. }\end{array}$ \\
\hline kidwellite & $\mathrm{NaFe}^{3+}{ }_{9}\left(\mathrm{PO}_{4}\right)_{6}(\mathrm{OH})_{10} \cdot 5 \mathrm{H}_{2} \mathrm{O}$ & $?$ & No & 6 & No? & $\begin{array}{l}\text { Found in a few mines, but } \\
\text { reference provides no other } \\
\text { data on type of occurrence. } \\
\text { Other minerals (e.g., strengite, } \\
\text { nahcolite, natron) provide } \\
\text { adequate conservatism for } \\
\text { elements in this mineral. } \\
\end{array}$ \\
\hline kilchoanite & $\mathrm{Ca}_{3} \mathrm{Si}_{2} \mathrm{O}_{7}$ & No & No & 1 & No & Metamorphic mineral \\
\hline killalaite & $\mathrm{Ca}_{6}\left(\mathrm{Si}_{2} \mathrm{O}_{7}\right)_{2} \bullet \mathrm{H}_{2} \mathrm{O}$ & No & No & 1 & No & Metamorphic mineral \\
\hline kingite & $\mathrm{Al}_{3}\left(\mathrm{PO}_{4}\right)_{2}(\mathrm{OH}, \mathrm{F})_{3} \cdot 9 \mathrm{H}_{2} \mathrm{O}$ & No? & No & 1 & No & $\begin{array}{l}\text { Associated with a } \\
\text { metamorphic, } \mathrm{Fe} \text {, and } \\
\text { phosphate minerals }\end{array}$ \\
\hline kingsmountite & $\left(\mathrm{Ca}, \mathrm{Mn}^{2+}\right)_{4}\left(\mathrm{Fe}^{2+}, \mathrm{Mn}^{2+}\right) \mathrm{Al}_{4}\left(\mathrm{PO}_{4}\right)_{6}(\mathrm{OH})_{4} \cdot 12 \mathrm{H}_{2} \mathrm{O}$ & No & No & 1 & No & Igneous mineral \\
\hline kirschsteinite & $\mathrm{CaFe}^{2+} \mathrm{SiO}_{4}$ & No & No & 1 & No & Igneous mineral \\
\hline kittatinnyite & $\mathrm{Ca}_{4} \mathrm{Mn}^{3+}{ }_{4} \mathrm{Mn}^{2+}{ }_{2} \mathrm{Si}_{4} \mathrm{O}_{16}(\mathrm{OH})_{8} \cdot 18 \mathrm{H}_{2} \mathrm{O}$ & No & No & 1 & No & Hydrothermal mineral \\
\hline kleberite & $\mathrm{FeTi}_{6} \mathrm{O}_{13} \cdot 4 \mathrm{H}_{2} \mathrm{O}(?)$ & $?$ & No & 5,6 & Unlikely & $\begin{array}{l}\text { Rare. Found in Tertiary } \\
\text { sediments, Germany. Other } \\
\text { minerals (e.g., rutile, goethite) } \\
\text { provide adequate } \\
\text { conservatism for elements in } \\
\text { this mineral. }\end{array}$ \\
\hline koashvite & $\mathrm{Na}_{6}(\mathrm{Ca}, \mathrm{Mn})(\mathrm{Ti}, \mathrm{Fe}) \mathrm{Si}_{6} \mathrm{O}_{18} \bullet \mathrm{H}_{2} \mathrm{O}$ & No & No & 1 & No & Igneous mineral \\
\hline koenenite & $\mathrm{Na}_{4} \mathrm{Mg}_{9} \mathrm{Al}_{4} \mathrm{Cl}_{12}(\mathrm{OH})_{22}$ & Yes & No & 6 & Yes? & $\begin{array}{l}\text { Marine evaporite. Other } \\
\text { minerals (e.g., bischofite, } \\
\text { halite, gibbsite) provide } \\
\text { adequate conservatism for } \\
\text { elements in this mineral. }\end{array}$ \\
\hline
\end{tabular}


Table C-1. Critique of Minerals not Included in Project Databases (Continued)

\begin{tabular}{|c|c|c|c|c|c|c|}
\hline Mineral & Chemical Formula & $\begin{array}{l}\text { Precipitates } \\
\text { from } 0 \text { to } 100^{\circ} \mathrm{C} \\
\text { and at } 1 \mathrm{ATM}\end{array}$ & Needed & Criterion & $\begin{array}{l}\text { Within Defined } \\
\text { Physico- } \\
\text { Chemical } \\
\text { System } \\
\end{array}$ & $\begin{array}{c}\text { Comments on Occurrence } \\
\text { or Formation }\end{array}$ \\
\hline kogarkoite & $\mathrm{Na}_{3}\left(\mathrm{SO}_{4}\right) \mathrm{F}$ & No & No & 1 & No & $\begin{array}{l}\text { Igneous and sublimated } \\
\text { mineral }\end{array}$ \\
\hline koktaite & $\left(\mathrm{NH}_{4}\right)_{2} \mathrm{Ca}\left(\mathrm{SO}_{4}\right)_{2} \cdot \mathrm{H}_{2} \mathrm{O}$ & Yes & No & 1 & No & Requires reducing conditions \\
\hline koninckite & $\mathrm{Fe}^{3+} \mathrm{PO}_{4} \cdot 3 \mathrm{H}_{2} \mathrm{O}(?)$ & Yes & No & 6 & Yes & $\begin{array}{l}\text { Other minerals (e.g., } \\
\text { strengite) provide adequate } \\
\text { conservatism for elements in } \\
\text { this mineral. }\end{array}$ \\
\hline konyaite & $\mathrm{Na}_{2} \mathrm{Mg}\left(\mathrm{SO}_{4}\right)_{2} \cdot 5 \mathrm{H}_{2} \mathrm{O}$ & Yes & No & 6 & Yes & $\begin{array}{l}\text { Other minerals (e.g., bloedite) } \\
\text { provide adequate } \\
\text { conservatism for elements in } \\
\text { this mineral. }\end{array}$ \\
\hline kornelite & $\mathrm{Fe}_{2}^{3+}\left(\mathrm{SO}_{4}\right)_{3} \cdot 7 \mathrm{H}_{2} \mathrm{O}$ & Yes & No & 6 & No? & $\begin{array}{l}\text { Oxidation product at } \mathrm{Cu} \\
\text { mines. Other minerals (e.g., } \\
\text { jarosite) provide adequate } \\
\text { conservatism for elements in } \\
\text { this mineral. }\end{array}$ \\
\hline korshunovskite & $\mathrm{Mg}_{2} \mathrm{Cl}(\mathrm{OH})_{3} \bullet \mathrm{nH}_{2} \mathrm{O}$ & No? & No & 1 & No & $\begin{array}{l}\text { Found in a veinlet in } \\
\text { metamorphic rock in Fe ore }\end{array}$ \\
\hline kovdorskite & $\mathrm{Mg}_{5}\left(\mathrm{PO}_{4}\right)_{2}\left(\mathrm{CO}_{3}\right)(\mathrm{OH})_{2} \cdot 9 / 2 \mathrm{H}_{2} \mathrm{O}$ & No & No & 1 & No & Igneous mineral \\
\hline kozulite & $\mathrm{Na}_{3} \mathrm{Mn}_{4}\left(\mathrm{Fe}^{3+}, \mathrm{Al}\right) \mathrm{Si}_{8} \mathrm{O}_{22}(\mathrm{OH}, \mathrm{F})_{2}$ & No & No & 1 & No & Metamorphic mineral \\
\hline krausite & $\mathrm{KFe}^{3+}\left(\mathrm{SO}_{4}\right)_{2} \cdot \mathrm{H}_{2} \mathrm{O}$ & Yes? & No & 6 & Possibly & $\begin{array}{l}\text { Other minerals (e.g., jarosite) } \\
\text { provide adequate } \\
\text { conservatism for elements in } \\
\text { this mineral. }\end{array}$ \\
\hline kremersite & $\left(\mathrm{NH}_{4}, \mathrm{~K}\right)_{2} \mathrm{Fe}^{3+} \mathrm{Cl}_{5} \bullet \mathrm{H}_{2} \mathrm{O}$ & No & No & 1 & No & Fumarolic mineral \\
\hline kribergite & $\mathrm{Al}_{5}\left(\mathrm{PO}_{4}\right)_{3}\left(\mathrm{SO}_{4}\right)(\mathrm{OH})_{4} \cdot 2 \mathrm{H}_{2} \mathrm{O}(?)$ & No? & No & 1 & No & $\begin{array}{l}\text { Occurs within a sulfide, } \\
\text { outside redox range }\end{array}$ \\
\hline kryzhanovskite & $\mathrm{MnFe}_{2}^{3+}{ }_{2}\left(\mathrm{PO}_{4}\right)_{2}(\mathrm{OH})_{2} \bullet \mathrm{H}_{2} \mathrm{O}$ & No & No & 1 & No & $\begin{array}{l}\text { Alters from pegmatitic } \\
\text { phosphates, which are absent }\end{array}$ \\
\hline kulkeite & $\mathrm{Mg}_{8} \mathrm{Al}\left(\mathrm{AlSi}_{7}\right) \mathrm{O}_{20}(\mathrm{OH})_{10}$ & No & No & 1 & No & Metamorphic mineral \\
\hline kutnohorite & $\mathrm{Ca}\left(\mathrm{Mn}, \mathrm{Mg}, \mathrm{Fe}^{2+}\right)\left(\mathrm{CO}_{3}\right)_{2}$ & No & No & 1 & No & Metamorphic mineral \\
\hline kvanefjeldite & $\mathrm{Na}_{4}(\mathrm{Ca}, \mathrm{Mn}) \mathrm{Si}_{6} \mathrm{O}_{14}(\mathrm{OH})_{2}$ & No & No & 1 & No & Igneous mineral \\
\hline
\end{tabular}


Table C-1. Critique of Minerals not Included in Project Databases (Continued)

\begin{tabular}{|c|c|c|c|c|c|c|}
\hline Mineral & Chemical Formula & $\begin{array}{l}\text { Precipitates } \\
\text { from } 0 \text { to } 100^{\circ} \mathrm{C} \\
\text { and at } 1 \mathrm{ATM}\end{array}$ & Needed & Criterion & \begin{tabular}{|} 
Within Defined \\
Physico- \\
Chemical \\
System \\
\end{tabular} & $\begin{array}{c}\text { Comments on Occurrence } \\
\text { or Formation }\end{array}$ \\
\hline lacroixite & $\mathrm{NaAl}\left(\mathrm{PO}_{4}\right)(\mathrm{F}, \mathrm{OH})$ & No & No & 1 & No & Igneous mineral \\
\hline laihunite & $\mathrm{Fe}^{2+} \mathrm{Fe}^{3+}{ }_{2}\left(\mathrm{SiO}_{4}\right)_{2}$ & No & No & 1 & No & Metamorphic mineral \\
\hline landesite & $(\mathrm{Mn}, \mathrm{Mg})_{9} \mathrm{Fe}^{3+}{ }_{3}\left(\mathrm{PO}_{4}\right)_{8}(\mathrm{OH})_{3} \cdot 9 \mathrm{H}_{2} \mathrm{O}$ & No & No & 1 & No & Igneous mineral \\
\hline langbeinite & $\mathrm{K}_{2} \mathrm{Mg}_{2}\left(\mathrm{SO}_{4}\right)_{3}$ & Yes? & No & 6 & Yes? & $\begin{array}{l}\text { In marine evaporites. Other } \\
\text { minerals (e.g., picromerite) } \\
\text { provide adequate } \\
\text { conservatism for elements in } \\
\text { this mineral. }\end{array}$ \\
\hline lannonite & $\mathrm{HCa}_{4} \mathrm{Mg}_{2} \mathrm{Al}_{4}\left(\mathrm{SO}_{4}\right)_{8} \mathrm{~F}_{9} \cdot 32 \mathrm{H}_{2} \mathrm{O}$ & Yes & No & 1 & No & $\begin{array}{l}\text { Most mine product with other } \\
\text { F minerals }\end{array}$ \\
\hline latiumite & $(\mathrm{Ca}, \mathrm{K})_{8}(\mathrm{Al}, \mathrm{Mg}, \mathrm{Fe})(\mathrm{Si}, \mathrm{Al})_{10} \mathrm{O}_{25}\left(\mathrm{SO}_{4}\right)$ & No & No & 1 & No & Metamorphic mineral \\
\hline laubmannite & $\mathrm{Fe}^{2+}{ }_{3} \mathrm{Fe}^{3+}{ }_{6}\left(\mathrm{PO}_{4}\right)_{4}(\mathrm{OH})_{12}$ & Yes & No & 6 & No? & $\begin{array}{l}\text { Found in gossan. Other } \\
\text { minerals (e.g., strengite) } \\
\text { provide adequate } \\
\text { conservatism for elements in } \\
\text { this mineral. }\end{array}$ \\
\hline laueite & $\mathrm{Mn}^{2+} \mathrm{Fe}_{2}^{3+}\left(\mathrm{PO}_{4}\right)_{2}(\mathrm{OH})_{2} \cdot 8 \mathrm{H}_{2} \mathrm{O}$ & No & No & 1 & No & Igneous mineral \\
\hline lausenite & $\mathrm{Fe}^{3+}{ }_{2}\left(\mathrm{SO}_{4}\right)_{3} \cdot 6 \mathrm{H}_{2} \mathrm{O}$ & No & No & 1 & No & Occurs in fire zone in a mine \\
\hline lazulite & $\left(\mathrm{Mg}, \mathrm{Fe}^{2+}\right) \mathrm{Al}_{2}\left(\mathrm{PO}_{4}\right)_{2}(\mathrm{OH})_{2}$ & No & No & 1 & No & $\begin{array}{l}\text { Igneous, metamorphic, and } \\
\text { hydrothermal mineral }\end{array}$ \\
\hline lazurite & $(\mathrm{Na}, \mathrm{Ca})_{8}(\mathrm{Al}, \mathrm{Si})_{12}(\mathrm{O}, \mathrm{S})_{24}\left[\left(\mathrm{SO}_{4}\right), \mathrm{Cl}_{2},(\mathrm{OH})_{2}\right]$ & No & No & 1 & No & Metamorphic mineral \\
\hline lechatelierite & $\mathrm{SiO}_{2}$ & No & No & 1 & No & Natural fused silica \\
\hline lecontite & $\mathrm{Na}\left(\mathrm{NH}_{4}, \mathrm{~K}\right)\left(\mathrm{SO}_{4}\right) \cdot 2 \mathrm{H}_{2} \mathrm{O}$ & Yes & No & 1 & No & Occurs in bat guano \\
\hline lepidocrocite & $\gamma-\mathrm{FeO}(\mathrm{OH})$ & Yes & No & 3 & Yes & $\begin{array}{l}\text { Goethite provides adequate } \\
\text { conservatism for this mineral }\end{array}$ \\
\hline letovicite & $\left(\mathrm{NH}_{4}\right)_{3} \mathrm{H}\left(\mathrm{SO}_{4}\right)_{2}$ & No? & No & 1 & No & $\begin{array}{l}\text { Rare. Found as product in } \\
\text { burning coal mine and at a hot } \\
\text { spring. }\end{array}$ \\
\hline leucite & $\mathrm{KAISi}_{2} \mathrm{O}_{6}$ & No & No & 1 & No & Igneous mineral \\
\hline leucophoenicite & $\mathrm{Mn}_{7}\left(\mathrm{SiO}_{4}\right)_{3}(\mathrm{OH})_{2}$ & No & No & 1 & No & $\begin{array}{l}\text { Hydrothermal and } \\
\text { metamorphic mineral }\end{array}$ \\
\hline leucophosphite & $\mathrm{KFe}_{2}^{3+}{ }_{2}\left(\mathrm{PO}_{4}\right)_{2}(\mathrm{OH}) \cdot 2 \mathrm{H}_{2} \mathrm{O}$ & No & No & 1 & No & Igneous mineral \\
\hline
\end{tabular}


Table C-1. Critique of Minerals not Included in Project Databases (Continued)

\begin{tabular}{|c|c|c|c|c|c|c|}
\hline Mineral & Chemical Formula & $\begin{array}{c}\text { Precipitates } \\
\text { from } 0 \text { to } 100^{\circ} \mathrm{C} \\
\text { and at } 1 \mathrm{ATM}\end{array}$ & Needed & Criterion & $\begin{array}{l}\text { Within Defined } \\
\text { Physico- } \\
\text { Chemical } \\
\text { System }\end{array}$ & $\begin{array}{c}\text { Comments on Occurrence } \\
\text { or Formation }\end{array}$ \\
\hline levyne & $\left(\mathrm{Ca}, \mathrm{Na}_{2}, \mathrm{~K}_{2}\right)_{3} \mathrm{Al}_{6} \mathrm{Si}_{12} \mathrm{O}_{36} \cdot 18 \mathrm{H}_{2} \mathrm{O}$ & No & No & 1 & No & Occurs in cavities in basalt \\
\hline liottite & $(\mathrm{Ca}, \mathrm{Na}, \mathrm{K})_{8}(\mathrm{Si}, \mathrm{Al})_{12} \mathrm{O}_{24}\left(\mathrm{SO}_{4}, \mathrm{CO}_{3}, \mathrm{Cl}, \mathrm{OH}\right)_{4} \bullet \mathrm{H}_{2} \mathrm{O}$ & No? & No & 1 & No & $\begin{array}{l}\text { Member of cancrinite group, } \\
\text { all members of which are } \\
\text { related to alkalic igneous or } \\
\text { metamorphic rocks }\end{array}$ \\
\hline lipscombite & $\left(\mathrm{Fe}^{2+}, \mathrm{Mn}\right) \mathrm{Fe}_{2}^{3+}\left(\mathrm{PO}_{4}\right)_{2}(\mathrm{OH})_{2}$ & No & No & 1 & No & Igneous mineral \\
\hline lithosite & $\mathrm{K}_{6} \mathrm{Al}_{4} \mathrm{Si}_{8} \mathrm{O}_{25} \cdot 2 \mathrm{H}_{2} \mathrm{O}$ & No & No & 1 & No & Igneous mineral \\
\hline lizardite & $\mathrm{Mg}_{3} \mathrm{Si}_{2} \mathrm{O}_{5}(\mathrm{OH})_{4}$ & No & No & 1 & No & Metamorphic mineral \\
\hline loeweite & $\mathrm{Na}_{12} \mathrm{Mg}_{7}\left(\mathrm{SO}_{4}\right)_{13} \cdot 15 \mathrm{H}_{2} \mathrm{O}$ & Yes? & No & 6 & Yes? & $\begin{array}{l}\text { Other minerals (e.g., bloedite) } \\
\text { provide adequate } \\
\text { conservatism for elements in } \\
\text { this mineral. }\end{array}$ \\
\hline lomonosovite & $\mathrm{Na}_{2} \mathrm{Ti}_{2} \mathrm{Si}_{2} \mathrm{O}_{9} \cdot \mathrm{Na}_{3} \mathrm{PO}_{4}$ & No & No & 1 & No & Igneous mineral \\
\hline lonecreekite & $\left.\left(\mathrm{NH}_{4}\right) \mathrm{FeSO}_{4}\right)_{2} \cdot 2 \mathrm{H}_{2} \mathrm{O}$ & Yes & No & 1 & No & $\begin{array}{l}\text { Found as alteration of pyrite in } \\
\text { presence of organics. } \\
\text { Requires reducing conditions. }\end{array}$ \\
\hline Iorenzenite & $\mathrm{Na}_{2} \mathrm{Ti}_{2} \mathrm{Si}_{2} \mathrm{O}_{9}$ & No & No & 1 & No & Igneous mineral \\
\hline loughlinite & $\mathrm{Na}_{2} \mathrm{Mg}_{3} \mathrm{Si}_{6} \mathrm{O}_{16} \bullet 8 \mathrm{H}_{2} \mathrm{O}$ & No & No & 1 & No & $\begin{array}{l}\text { Hydrothermal (?) mineral; } \\
\text { occurs in veins in oil shale }\end{array}$ \\
\hline Iudlamite & $\left(\mathrm{Fe}^{2+}\right)_{3}\left(\mathrm{PO}_{4}\right)_{2} \cdot 4 \mathrm{H}_{2} \mathrm{O}$ & Yes & No & 1 & No & $\begin{array}{l}\text { Occurs in oxidation zone of } \\
\text { ore deposits and in igneous } \\
\text { rocks (pegmatites; alteration } \\
\text { of Fe phosphates) }\end{array}$ \\
\hline lun'okite & $(\mathrm{Mn}, \mathrm{Ca})(\mathrm{Mg}, \mathrm{Fe}, \mathrm{Mn}) \mathrm{Al}\left(\mathrm{PO}_{4}\right)_{2}(\mathrm{OH}) \cdot 4 \mathrm{H}_{2} \mathrm{O}$ & No & No & 1 & No & Igneous mineral \\
\hline macaulayite & $\left(\mathrm{Fe}^{3+}, \mathrm{Al}\right)_{24} \mathrm{Si}_{4} \mathrm{O}_{43}(\mathrm{OH})_{2}$ & Yes & No & 5,6 & Unlikely & $\begin{array}{l}\text { Very rare in deeply weathered } \\
\text { granite. Other minerals (e.g., } \\
\text { hematite, kaolinite) provide } \\
\text { adequate conservatism for } \\
\text { elements in this mineral. }\end{array}$ \\
\hline macfallite & $\mathrm{Ca}_{2} \mathrm{Mn}_{3}^{3+}\left(\mathrm{SiO}_{4}\right)\left(\mathrm{Si}_{2} \mathrm{O}_{7}\right)(\mathrm{OH})_{3}$ & Yes? & No & 1 & No & $\begin{array}{l}\text { Associated with replacement } \\
\text { of calcite in fissures in basalt. } \\
\text { Rare. }\end{array}$ \\
\hline
\end{tabular}


Table C-1. Critique of Minerals not Included in Project Databases (Continued)

\begin{tabular}{|c|c|c|c|c|c|c|}
\hline Mineral & Chemical Formula & $\begin{array}{c}\text { Precipitates } \\
\text { from } 0 \text { to } 100^{\circ} \mathrm{C} \\
\text { and at } 1 \mathrm{ATM}\end{array}$ & Needed & Criterion & $\begin{array}{l}\text { Within Defined } \\
\text { Physico- } \\
\text { Chemical } \\
\text { System } \\
\end{array}$ & $\begin{array}{c}\text { Comments on Occurrence } \\
\text { or Formation }\end{array}$ \\
\hline magadiite & $\mathrm{NaSi}_{7} \mathrm{O}_{13}(\mathrm{OH})_{3} \cdot 4 \mathrm{H}_{2} \mathrm{O}$ & Yes & No & 6 & Yes & $\begin{array}{l}\text { Occurs in lacustrine } \\
\text { evaporites. Other minerals } \\
\text { (e.g., nahcolite, trona, } \\
\mathrm{SiO}_{2(\mathrm{am}) \text { ) provide adequate }} \\
\text { conservatism for elements in } \\
\text { this mineral. }\end{array}$ \\
\hline maghagendorfite & $\mathrm{NaMgMn}\left(\mathrm{Fe}^{2+}, \mathrm{Fe}^{3+}\right)_{3}\left(\mathrm{PO}_{4}\right)_{3}$ & No? & No & 6 & No? & $\begin{array}{l}\text { Other minerals (e.g., strengite, } \\
\text { nahcolite, natron, manganite) } \\
\text { provide adequate } \\
\text { conservatism for elements in } \\
\text { this mineral. Mineral contains } \\
\text { reduced Fe and Mn, implying } \\
\text { reducing conditions needed. }\end{array}$ \\
\hline maghemite & $\gamma-\mathrm{Fe}_{2} \mathrm{O}_{3}$ & Yes & No & 6 & Possibly & $\begin{array}{l}\text { Found in gossans. Other } \\
\text { minerals (e.g., goethite, } \\
\text { hematite) provide adequate } \\
\text { conservatism for elements in } \\
\text { this mineral. }\end{array}$ \\
\hline magnesiohornblende & $\mathrm{Ca}_{2}\left(\mathrm{Mg}, \mathrm{Fe}^{2+}\right)_{4} \mathrm{Al}\left(\mathrm{Si}{ }_{7} \mathrm{Al}\right) \mathrm{O}_{22}(\mathrm{OH}, \mathrm{F})_{2}$ & No & No & 1 & No & $\begin{array}{l}\text { Igneous and metamorphic } \\
\text { mineral }\end{array}$ \\
\hline magnesioriebeckite & $\mathrm{Na}_{2}\left(\mathrm{Mg}, \mathrm{Fe}^{2+}\right)_{3} \mathrm{Fe}^{3+}{ }_{2} \mathrm{Si}_{8} \mathrm{O}_{22}(\mathrm{OH})_{2}$ & No & No & 1 & No & $\begin{array}{l}\text { Igneous and metamorphic } \\
\text { mineral }\end{array}$ \\
\hline magniotriplite & $\left(\mathrm{Mg}, \mathrm{Fe}^{2+}, \mathrm{Mn}\right)_{2}\left(\mathrm{PO}_{4}\right) \mathrm{F}$ & No & No & 1 & No & Igneous mineral \\
\hline majorite & $\mathrm{Mg}_{3}(\mathrm{Fe}, \mathrm{Al}, \mathrm{Si})_{2}\left(\mathrm{SiO}_{4}\right)_{3}$ & No & No & 1 & No & Found in meteorites \\
\hline makatite & $\mathrm{Na}_{2} \mathrm{Si}_{4} \mathrm{O}_{8}(\mathrm{OH})_{2} \bullet 4 \mathrm{H}_{2} \mathrm{O}$ & Yes & No & 6 & Yes & $\begin{array}{l}\text { Evaporite mineral. Other } \\
\text { minerals }\left(\mathrm{e} . \mathrm{g} ., \text { trona, } \mathrm{SiO}_{2(\mathrm{am})}\right) \\
\text { provide adequate } \\
\text { conservatism for elements in } \\
\text { this mineral. }\end{array}$ \\
\hline malladrite & $\mathrm{Na}_{2} \mathrm{SiF}_{6}$ & No & No & 1 & No & Igneous mineral (fumarolic?) \\
\hline mallardite & $\mathrm{MnSO}_{4} \cdot 7 \mathrm{H}_{2} \mathrm{O}$ & Yes & No & 1 & No & Oxidation product in mines \\
\hline manasseite & $\mathrm{Mg}_{6} \mathrm{Al}_{2}\left(\mathrm{CO}_{3}\right)(\mathrm{OH})_{16} \cdot 4 \mathrm{H}_{2} \mathrm{O}$ & No & No & 1 & No & Metamorphic mineral \\
\hline manganpyrosmalite & $\left(\mathrm{Mn}, \mathrm{Fe}^{2+}\right)_{8} \mathrm{Si}_{6} \mathrm{O}_{15}(\mathrm{OH}, \mathrm{Cl})_{10}$ & No & No & 1 & No & Hydrothermal mineral \\
\hline
\end{tabular}


Table C-1. Critique of Minerals not Included in Project Databases (Continued)

\begin{tabular}{|c|c|c|c|c|c|c|}
\hline Mineral & Chemical Formula & $\begin{array}{l}\text { Precipitates } \\
\text { from } 0 \text { to } 100^{\circ} \mathrm{C} \\
\text { and at } 1 \mathrm{ATM}\end{array}$ & Needed & Criterion & \begin{tabular}{|c|} 
Within Defined \\
Physico- \\
Chemical \\
System
\end{tabular} & $\begin{array}{c}\text { Comments on Occurrence } \\
\text { or Formation }\end{array}$ \\
\hline manjiroite & $(\mathrm{Na}, \mathrm{K})\left(\mathrm{Mn}^{4+}, \mathrm{Mn}^{2+}\right)_{8} \mathrm{O}_{16} \bullet \mathrm{nH}_{2} \mathrm{O}$ & Yes & No & 1 & No & $\begin{array}{l}\text { Found in oxidation zone of } \mathrm{Mn} \\
\text { deposits }\end{array}$ \\
\hline mantienneite & $\mathrm{KMg}_{2} \mathrm{Al}_{2} \mathrm{Ti}\left(\mathrm{PO}_{4}\right)_{4}(\mathrm{OH})_{3} \cdot 15 \mathrm{H}_{2} \mathrm{O}$ & Yes & No & 1 & No & $\begin{array}{l}\text { In black shales. Requires } \\
\text { reducing conditions }\end{array}$ \\
\hline marcasite & $\mathrm{FeS}_{2}$ & Yes & No & 1 & No & $\begin{array}{l}\text { Occurs under acidic } \\
\text { conditions. Pyrite provides } \\
\text { adequate conservatism }\end{array}$ \\
\hline marialite & $3 \mathrm{NaAlSi}_{3} \mathrm{O}_{8} \cdot \mathrm{NaCl}$ & No & No & 1 & No & Metamorphic mineral \\
\hline maricite & $\mathrm{NaFePO}_{4}$ & Yes & No & 1 & No & $\begin{array}{l}\text { Occurs in shales with pyrite, } \\
\text { etc. Requires reducing } \\
\text { conditions }\end{array}$ \\
\hline marokite & $\mathrm{CaMn}_{2} \mathrm{O}_{4}$ & No & No & 1 & No & Hydrothermal mineral \\
\hline marsturite & $\mathrm{NaCaMn}_{3} \mathrm{Si}_{5} \mathrm{O}_{14}(\mathrm{OH})$ & No & No & 1 & No & Metamorphic mineral \\
\hline matteuccite & $\mathrm{NaHSO}_{4} \cdot \mathrm{H}_{2} \mathrm{O}$ & Yes? & No & 1 & No & $\begin{array}{l}\text { In stalactites from } 1933 \\
\text { Vesuvius eruption }\end{array}$ \\
\hline matulaite & $\mathrm{CaAl}_{18}\left(\mathrm{PO}_{4}\right)_{12}(\mathrm{OH})_{20} \cdot 28 \mathrm{H}_{2} \mathrm{O}$ & No? & No & 1 & No & $\begin{array}{l}\text { Occurs in an Fe-phosphate } \\
\text { mine and a pegmatite }\end{array}$ \\
\hline maufite & $(\mathrm{Mg}, \mathrm{Ni}) \mathrm{Al}_{4} \mathrm{Si}_{3} \mathrm{O}_{13} \bullet 4 \mathrm{H}_{2} \mathrm{O}(?)$ & No & No & 1 & No & Metamorphic mineral \\
\hline mazzite & $\mathrm{K}_{2} \mathrm{CaMg}_{2}(\mathrm{Al}, \mathrm{Si})_{36} \mathrm{O}_{72} \cdot 28 \mathrm{H}_{2} \mathrm{O}$ & No? & No & 1 & No & Occurs in cavities in basalt \\
\hline mcgillite & $\mathrm{Mn}_{8} \mathrm{Si}_{6} \mathrm{O}_{15}(\mathrm{OH})_{8} \mathrm{Cl}_{2}$ & No & No & 1 & No & Hydrothermal mineral \\
\hline meionite & $3 \mathrm{CaAl}_{2} \mathrm{Si}_{2} \mathrm{O}_{8} \cdot \mathrm{CaCO}_{3}$ & No & No & 1 & No & Metamorphic mineral \\
\hline meixnerite & $\mathrm{Mg}_{6} \mathrm{Al}_{2}(\mathrm{OH})_{18} \bullet 4 \mathrm{H}_{2} \mathrm{O}$ & No & No & 1 & No & Metamorphic mineral \\
\hline melanophlogite & $\mathrm{SiO}_{2}$ & No? & No & 1 & No & $\begin{array}{l}\text { Occurs with sulfur or as a } \\
\text { metamorphic mineral }\end{array}$ \\
\hline mellite & $\mathrm{Al}_{2}\left(\mathrm{C}_{6}(\mathrm{COO})_{6}\right) \cdot 18 \mathrm{H}_{2} \mathrm{O}$ & Yes & No & 1 & No & $\begin{array}{l}\text { Secondary mineral in coal and } \\
\text { lignite }\end{array}$ \\
\hline melonjosephite & $\mathrm{Ca}\left(\mathrm{Fe}^{2+}, \mathrm{Mg}\right) \mathrm{Fe}^{3+}\left(\mathrm{PO}_{4}\right)_{2}(\mathrm{OH})$ & No & No & 1 & No & Igneous mineral \\
\hline mendozite & $\mathrm{NaAl}\left(\mathrm{SO}_{4}\right)_{2} \cdot 11 \mathrm{H}_{2} \mathrm{O}$ & $?$ & No & 6 & $?$ & $\begin{array}{l}\text { Other solids (e.g., } \mathrm{Na}_{2} \mathrm{SO}_{4}, \\
\text { alunite) provide adequate } \\
\text { conservatism for elements in } \\
\text { this mineral. }\end{array}$ \\
\hline merrihueite & $(\mathrm{K}, \mathrm{Na})_{2}(\mathrm{Fe}, \mathrm{Mg})_{5} \mathrm{Si}_{12} \mathrm{O}_{30}$ & No & No & 1 & No & Found in meteorites \\
\hline
\end{tabular}


Table C-1. Critique of Minerals not Included in Project Databases (Continued)

\begin{tabular}{|c|c|c|c|c|c|c|}
\hline Mineral & Chemical Formula & $\begin{array}{l}\text { Precipitates } \\
\text { from } 0 \text { to } 100^{\circ} \mathrm{C} \\
\text { and at } 1 \mathrm{ATM}\end{array}$ & Needed & Criterion & $\begin{array}{l}\text { Within Defined } \\
\text { Physico- } \\
\text { Chemical } \\
\text { System } \\
\end{array}$ & $\begin{array}{c}\text { Comments on Occurrence } \\
\text { or Formation }\end{array}$ \\
\hline messelite & $\mathrm{Ca}_{2}\left(\mathrm{Fe}^{2+}, \mathrm{Mn}^{2+}\right)\left(\mathrm{PO}_{4}\right)_{2} \cdot 2 \mathrm{H}_{2} \mathrm{O}$ & No & No & 1 & No & $\begin{array}{l}\text { Igneous mineral (late } \\
\text { hydrothermal stage) }\end{array}$ \\
\hline microsommite & $(\mathrm{Na}, \mathrm{Ca}, \mathrm{K})_{7-8}(\mathrm{Si}, \mathrm{Al})_{12} \mathrm{O}_{24}\left(\mathrm{Cl}, \mathrm{SO}_{4}, \mathrm{CO}_{3}\right)_{2-3}$ & No & No & 1 & No & Igneous mineral \\
\hline millisite & $(\mathrm{Na}, \mathrm{K}) \mathrm{CaAl} \mathrm{I}_{6}\left(\mathrm{PO}_{4}\right)_{4}(\mathrm{OH})_{9} \cdot 3 \mathrm{H}_{2} \mathrm{O}$ & Yes? & No & 1 & No & Occurs in phosphate rocks \\
\hline millosevichite & $\left(\mathrm{Al}, \mathrm{Fe}^{3+}\right)_{2}\left(\mathrm{SO}_{4}\right)_{3}$ & $?$ & No & 1 & No & $\begin{array}{l}\text { Single occurrence noted, } \\
\text { evidently under reducing } \\
\text { conditions, as color changes } \\
\text { on exposure to air }\end{array}$ \\
\hline minamiite & $(\mathrm{Na}, \mathrm{K}, \mathrm{Ca}) \mathrm{Al}_{3}\left(\mathrm{SO}_{4}\right)_{2}(\mathrm{OH})_{6}$ & No & No & 1 & No & $\begin{array}{l}\text { Hydrothermal or igneous } \\
\text { mineral }\end{array}$ \\
\hline minguzzite & $\mathrm{K}_{2} \mathrm{Fe}^{3+}\left(\mathrm{C}_{2} \mathrm{O}_{4}\right)_{3} \cdot 3 \mathrm{H}_{2} \mathrm{O}$ & Yes? & No & 1 & No & $\begin{array}{l}\text { Found in limonite. Organic } \\
\text { radical implies reducing } \\
\text { conditions. }\end{array}$ \\
\hline minyulite & $\mathrm{KAl}_{2}\left(\mathrm{PO}_{4}\right)_{2}(\mathrm{OH}, \mathrm{F}) \cdot 4 \mathrm{H}_{2} \mathrm{O}$ & Yes? & No & 1 & No & Occurs in phosphate deposits \\
\hline mitridatite & $\mathrm{Ca}_{3} \mathrm{Fe}^{3+}{ }_{4}\left(\mathrm{PO}_{4}\right)_{4}(\mathrm{OH})_{6} \cdot 3 \mathrm{H}_{2} \mathrm{O}$ & No & No & 1 & No & Igneous mineral \\
\hline mohrite & $\left(\mathrm{NH}_{4}\right)_{2} \mathrm{Fe}^{2+}\left(\mathrm{SO}_{4}\right)_{2} \cdot 6 \mathrm{H}_{2} \mathrm{O}$ & No & No & 1 & No & Sulfataric mineral \\
\hline moissanite & $\mathrm{SiC}$ & No? & No & 1 & No & $\begin{array}{l}\text { Found in a meteorite, } \\
\text { bituminous rocks, with } \\
\text { metamorphic minerals }\end{array}$ \\
\hline monetite & $\mathrm{CaHPO}_{4}$ & Yes & No & 6 & No? & $\begin{array}{l}\text { Mostly occurs in high } \\
\text { phosphate settings. Other } \\
\text { minerals (e.g., apatite) provide } \\
\text { adequate conservatism for } \\
\text { elements in this mineral. }\end{array}$ \\
\hline montdorite & $(\mathrm{K}, \mathrm{Na})_{2}\left(\mathrm{Fe}^{2+}, \mathrm{Mn}, \mathrm{Mg}\right)_{5} \mathrm{Si}_{8} \mathrm{O}_{20}(\mathrm{~F}, \mathrm{OH})_{4}$ & No & No & 1 & No & Igneous mineral \\
\hline montgomeryite & $\mathrm{Ca}_{4} \mathrm{Al}_{4} \mathrm{Mg}\left(\mathrm{PO}_{4}\right)_{6}(\mathrm{OH})_{4} \cdot 12 \mathrm{H}_{2} \mathrm{O}$ & No? & No & 1 & No & $\begin{array}{l}\text { Igneous mineral, or } \\
\text { component of phosphate } \\
\text { nodules }\end{array}$ \\
\hline morinite & $\mathrm{NaCa}_{2} \mathrm{Al}_{2}\left(\mathrm{PO}_{4}\right)_{2}(\mathrm{~F}, \mathrm{OH})_{5} \cdot 2 \mathrm{H}_{2} \mathrm{O}$ & No & No & 1 & No & Igneous mineral \\
\hline
\end{tabular}


Table C-1. Critique of Minerals not Included in Project Databases (Continued)

\begin{tabular}{|c|c|c|c|c|c|c|}
\hline Mineral & Chemical Formula & $\begin{array}{l}\text { Precipitates } \\
\text { from } 0 \text { to } 100^{\circ} \mathrm{C} \\
\text { and at } 1 \text { ATM }\end{array}$ & Needed & Criterion & $\begin{array}{l}\text { Within Defined } \\
\text { Physico- } \\
\text { Chemical } \\
\text { System }\end{array}$ & $\begin{array}{c}\text { Comments on Occurrence } \\
\text { or Formation }\end{array}$ \\
\hline motukoreaite & $\mathrm{Na}_{2} \mathrm{Mg}_{38} \mathrm{Al}_{24}\left(\mathrm{CO}_{3}\right)_{13}\left(\mathrm{SO}_{4}\right)_{8}(\mathrm{OH})_{108} \cdot 56 \mathrm{H}_{2} \mathrm{O}$ & Yes & No & 6 & No & $\begin{array}{l}\text { Found as cement in a beach } \\
\text { containing basalt. Cement } \\
\text { phases included in } \\
\text { dataO.ypf. } R O \text { have similar } \\
\text { compositions. }\end{array}$ \\
\hline mountainite & $\left(\mathrm{Ca}, \mathrm{Na}_{2}, \mathrm{~K}_{2}\right)_{2} \mathrm{Si}_{4} \mathrm{O}_{10} \cdot 3 \mathrm{H}_{2} \mathrm{O}$ & ? & No & 6 & $?$ & $\begin{array}{l}\text { Other minerals (e.g., afwillite, } \\
\left.\text { nahcolite, } \mathrm{SiO}_{2(\mathrm{am})}\right) \text { provide } \\
\text { adequate conservatism for } \\
\text { elements in this mineral. }\end{array}$ \\
\hline mullite & $\mathrm{Al}_{6} \mathrm{Si}_{2} \mathrm{O}_{13}$ & No & No & 1 & No & $\begin{array}{l}\text { Found in fused argillaceous } \\
\text { inclusions }\end{array}$ \\
\hline mundrabillaite & $\left(\mathrm{NH}_{4}\right)_{2} \mathrm{Ca}\left(\mathrm{HPO}_{4}\right)_{2} \cdot \mathrm{H}_{2} \mathrm{O}$ & Yes & No & 1 & No & Requires reducing conditions \\
\hline muskoxite & $\mathrm{Mg}_{7} \mathrm{Fe}^{3+}{ }_{4} \mathrm{O}_{13} \cdot 10 \mathrm{H}_{2} \mathrm{O}$ & No & No & 1 & No & Metamorphic mineral \\
\hline nacaphite & $\mathrm{Na}_{2} \mathrm{Ca}\left(\mathrm{PO}_{4}\right) \mathrm{F}$ & No & No & 1 & No & Igneous mineral \\
\hline nacrite & $\mathrm{Al}_{2} \mathrm{Si}_{2} \mathrm{O}_{5}(\mathrm{OH})_{4}$ & No & No & 1 & No & Hydrothermal mineral \\
\hline nagelschmidtite & $\mathrm{Ca}_{3}\left(\mathrm{PO}_{4}\right)_{2} \cdot 2\left(\alpha-\mathrm{Ca}_{2} \mathrm{SiO}_{4}\right)$ & No & No & 1 & No & Metamorphic mineral \\
\hline nahpoite & $\mathrm{Na}_{2} \mathrm{H}\left(\mathrm{PO}_{4}\right)$ & Yes & No & 1 & No & $\begin{array}{l}\text { Occurs in shales with pyrite, } \\
\text { etc. Requires reducing } \\
\text { conditions }\end{array}$ \\
\hline narsarsukite & $\mathrm{Na}_{2}\left(\mathrm{Ti}, \mathrm{Fe}^{3+}\right) \mathrm{Si}_{4}(\mathrm{O}, \mathrm{F})_{11}$ & No & No & 1 & No & $\begin{array}{l}\text { Igneous or metamorphic } \\
\text { mineral }\end{array}$ \\
\hline nasinite & $\mathrm{Na}_{2} \mathrm{~B}_{5} \mathrm{O}_{8}(\mathrm{OH}) \cdot 2 \mathrm{H}_{2} \mathrm{O}$ & No & No & 1 & No & $\begin{array}{l}\text { Occurs as encrustation on } \\
\text { geothermal well tubing }\end{array}$ \\
\hline natisite & $\mathrm{Na}_{2}\left(\mathrm{TiO} \mathrm{SiO}_{4}\right.$ & No & No & 1 & No & $\begin{array}{l}\text { Igneous or metamorphic } \\
\text { mineral }\end{array}$ \\
\hline natroalunite & $\mathrm{NaAl}_{3}\left(\mathrm{SO}_{4}\right)_{2}(\mathrm{OH})_{6}$ & No & No & 1 & No & $\begin{array}{l}\text { Solfataric or metamorphic } \\
\text { mineral }\end{array}$ \\
\hline natrojarosite & $\mathrm{NaFe}^{3+}\left(\mathrm{SO}_{4}\right)_{2}(\mathrm{OH})_{6}$ & Yes & No & 6 & No? & $\begin{array}{l}\text { Alteration mineral of ores. } \\
\text { Other minerals (e.g., jarosite, } \\
\text { thenardite) provide adequate } \\
\text { conservatism for elements in } \\
\text { this mineral. }\end{array}$ \\
\hline natrophilite & $\mathrm{NaMn}\left(\mathrm{PO}_{4}\right)$ & No & No & 1 & No & Igneous mineral \\
\hline
\end{tabular}


Table C-1. Critique of Minerals not Included in Project Databases (Continued)

\begin{tabular}{|c|c|c|c|c|c|c|}
\hline Mineral & Chemical Formula & $\begin{array}{l}\text { Precipitates } \\
\text { from } 0 \text { to } 100^{\circ} \mathrm{C} \\
\text { and at } 1 \mathrm{ATM}\end{array}$ & Needed & Criterion & $\begin{array}{l}\text { Within Defined } \\
\text { Physico- } \\
\text { Chemical } \\
\text { System } \\
\end{array}$ & $\begin{array}{c}\text { Comments on Occurrence } \\
\text { or Formation }\end{array}$ \\
\hline natrophosphate & $\mathrm{Na}_{7} \mathrm{H}\left(\mathrm{PO}_{4}\right)_{2} \mathrm{~F} \cdot 19 \mathrm{H}_{2} \mathrm{O}$ & No & No & 1 & No & Igneous mineral \\
\hline naujakasite & $(\mathrm{Na}, \mathrm{K})_{6}\left(\mathrm{Fe}^{+2}, \mathrm{Mn}\right) \mathrm{Al}_{4} \mathrm{Si}_{8} \mathrm{O}_{26}$ & No & No & 1 & No & Metamorphic mineral \\
\hline nefedovite & $\mathrm{Na}_{5} \mathrm{Ca}_{4}\left(\mathrm{PO}_{4}\right)_{4} \mathrm{~F}$ & No & No & 1 & No & Igneous mineral \\
\hline neighborite & $\mathrm{NaMgF}_{3}$ & Yes & No & 1 & No & $\begin{array}{l}\text { Found in dolomitic "oil shale," } \\
\text { and igneous or metamorphic } \\
\text { rocks }\end{array}$ \\
\hline nekoite & $\mathrm{Ca}_{3} \mathrm{Si}_{6} \mathrm{O}_{15} \cdot 7 \mathrm{H}_{2} \mathrm{O}$ & Yes? & No & 6 & No? & $\begin{array}{l}\text { Other minerals (e.g., afwillite, } \\
\text { foshagite) provide adequate } \\
\text { conservatism for elements in } \\
\text { this mineral. }\end{array}$ \\
\hline neltnerite & $\mathrm{CaMn}_{6} \mathrm{SiO}_{12}$ & No? & No & 1 & No & $\begin{array}{l}\text { Occurs with } \mathrm{Cu} \text { and } \mathrm{Mn} \\
\text { minerals }\end{array}$ \\
\hline neotocite & $\left(\mathrm{Mn}, \mathrm{Fe}^{2+}\right) \mathrm{SiO}_{3} \cdot \mathrm{H}_{2} \mathrm{O}(?)$ & Yes & No & 1 & No & $\begin{array}{l}\text { Occurs as alteration of } \mathrm{Mn} \\
\text { silicates, precursors absent }\end{array}$ \\
\hline newberyite & $\mathrm{MgHPO}_{4} \cdot 3 \mathrm{H}_{2} \mathrm{O}$ & Yes & No & 1 & No & Occurs in bat guano \\
\hline niahite & $\left(\mathrm{NH}_{4}\right) \mathrm{Mn}\left(\mathrm{PO}_{4}\right) \cdot \mathrm{H}_{2} \mathrm{O}$ & Yes & No & 1 & No & Occurs in bat guano \\
\hline niningerite & $(\mathrm{Mg}, \mathrm{Fe}, \mathrm{Mn}) \mathrm{S}$ & No & No & 1 & No & Found in meteorites \\
\hline nitromagnesite & $\mathrm{Mg}\left(\mathrm{NO}_{3}\right)_{2} \cdot 6 \mathrm{H}_{2} \mathrm{O}$ & Yes & No & 1 & Yes & $\begin{array}{l}\mathrm{Mg}\left(\mathrm{NO}_{3}\right)_{2} \text {, included in } \\
\text { dataO.ypf. } \mathrm{RO} \text {, provides } \\
\text { adequate conservatism. }\end{array}$ \\
\hline norbergite & $\mathrm{Mg}_{3}\left(\mathrm{SiO}_{4}\right)(\mathrm{F}, \mathrm{OH})_{2}$ & No & No & 1 & No & $\begin{array}{l}\text { Metamorphic and } \\
\text { hydrothermal mineral }\end{array}$ \\
\hline nordstrandite & $\mathrm{Al}(\mathrm{OH})_{3}$ & Yes & No & 3 & No? & $\begin{array}{l}\text { Mostly in igneous rocks. } \\
\text { Other minerals (e.g., gibbsite) } \\
\text { provide adequate } \\
\text { conservatism for elements in } \\
\text { this mineral. }\end{array}$ \\
\hline northupite & $\mathrm{Na}_{3} \mathrm{Mg}\left(\mathrm{CO}_{3}\right)_{2} \mathrm{Cl}$ & Yes & No & 6 & Yes & $\begin{array}{l}\text { Other minerals (e.g., natron, } \\
\text { hydromagnesite, halite) } \\
\text { provide adequate } \\
\text { conservatism for elements in } \\
\text { this mineral. }\end{array}$ \\
\hline nosean & $\mathrm{Na}_{8} \mathrm{Al}_{6} \mathrm{Si}_{6} \mathrm{O}_{24}\left(\mathrm{SO}_{4}\right)$ & No & No & 1 & No & Igneous mineral \\
\hline
\end{tabular}


Table C-1. Critique of Minerals not Included in Project Databases (Continued)

\begin{tabular}{|c|c|c|c|c|c|c|}
\hline Mineral & Chemical Formula & $\begin{array}{c}\text { Precipitates } \\
\text { from } 0 \text { to } 100^{\circ} \mathrm{C} \\
\text { and at } 1 \mathrm{ATM}\end{array}$ & Needed & Criterion & $\begin{array}{l}\text { Within Defined } \\
\text { Physico- } \\
\text { Chemical } \\
\text { System } \\
\end{array}$ & $\begin{array}{l}\text { Comments on Occurrence } \\
\text { or Formation }\end{array}$ \\
\hline nsutite & $\mathrm{Mn}^{2+}{ }_{x} \mathrm{Mn}^{4+}{ }_{1-x} \mathrm{O}_{2-2 x}(\mathrm{OH})_{2 \mathrm{x}}(\mathrm{x}$ is small $)$ & Yes? & No & 1 & No & Occurs in Mn deposits \\
\hline nyböite & $\mathrm{NaNa}_{2} \mathrm{Mg}_{3} \mathrm{Al}_{2}\left(\mathrm{Si}_{7} \mathrm{Al}\right) \mathrm{O}_{22}(\mathrm{OH})_{2}$ & No & No & 1 & No & Metamorphic mineral \\
\hline nyerereite & $\mathrm{Na}_{2} \mathrm{Ca}\left(\mathrm{CO}_{3}\right)_{2}$ & No & No & 1 & No & Igneous mineral \\
\hline offretite & $\left(\mathrm{K}_{2}, \mathrm{Ca}\right)_{5} \mathrm{Al}_{10} \mathrm{Si}_{26} \mathrm{O}_{72} \cdot 30 \mathrm{H}_{2} \mathrm{O}$ & No? & No & 1 & No & Associated with basalt \\
\hline okenite & $\mathrm{Ca}_{10} \mathrm{Si}_{18} \mathrm{O}_{46} \cdot 18 \mathrm{H}_{2} \mathrm{O}$ & No? & No & 1 & No & Associated with basalt \\
\hline oldhamite & $(\mathrm{Ca}, \mathrm{Mn}) \mathrm{S}$ & No & No & 1 & No & Found in meteorites \\
\hline olympite & $\mathrm{Na}_{3} \mathrm{PO}_{4}$ & No & No & 1 & No & Igneous mineral \\
\hline omphacite & $(\mathrm{Ca}, \mathrm{Na})\left(\mathrm{Mg}, \mathrm{Fe}^{2+}, \mathrm{Fe}^{3+}, \mathrm{Al}\right) \mathrm{Si}_{2} \mathrm{O}_{6}$ & No & No & 1 & No & Metamorphic mineral \\
\hline opal & $\mathrm{SiO}_{2} \bullet \mathrm{nH}_{2} \mathrm{O}$ & Yes & No & 6 & Yes & $\begin{array}{l}\mathrm{SiO}_{2(\text { am) }} \text { provides adequate } \\
\text { conservatism }\end{array}$ \\
\hline orientite & $\mathrm{Ca}_{2} \mathrm{Mn}^{2+} \mathrm{Mn}^{3+}{ }_{2} \mathrm{Si}_{3} \mathrm{O}_{10}(\mathrm{OH})_{4}$ & No? & No & 1 & No & $\begin{array}{l}\text { Occurs in Mn deposits and Mn } \\
\text { ores }\end{array}$ \\
\hline osumilite & $(\mathrm{K}, \mathrm{Na})\left(\mathrm{Fe}^{2+}, \mathrm{Mg}\right)_{2}\left(\mathrm{Al}, \mathrm{Fe}^{3+}\right)_{3}(\mathrm{Si}, \mathrm{Al})_{12} \mathrm{O}_{30} \bullet \mathrm{H}_{2} \mathrm{O}$ & No? & No & 1 & No & $\begin{array}{l}\text { Occurs in vugs in mafic } \\
\text { igneous rocks }\end{array}$ \\
\hline osumilite-(Mg) & $(\mathrm{K}, \mathrm{Na})(\mathrm{Mg}, \mathrm{Fe})_{2}\left(\mathrm{Al}, \mathrm{Fe}^{3+}\right)_{3}(\mathrm{Si}, \mathrm{Al})_{12} \mathrm{O}_{30} \bullet \mathrm{H}_{2} \mathrm{O}$ & No & No & 1 & No & Metamorphic mineral \\
\hline ottrelite & $\left(\mathrm{Mn}, \mathrm{Fe}^{2+}, \mathrm{Mg}\right)_{2} \mathrm{Al}_{4} \mathrm{Si}_{2} \mathrm{O}_{10}(\mathrm{OH})_{4}$ & No & No & 1 & No & Metamorphic mineral \\
\hline overite & $\mathrm{CaMgAl}\left(\mathrm{PO}_{4}\right)_{2}(\mathrm{OH}) \cdot 2-4 \mathrm{H}_{2} \mathrm{O}$ & Yes? & No & 1 & No & Occurs in phosphate rocks \\
\hline pachnolite & $\mathrm{NaCaAlF}_{6} \bullet \mathrm{H}_{2} \mathrm{O}$ & No? & No & 1 & No & $\begin{array}{l}\text { Igneous mineral or alteration } \\
\text { product of cryolite }\end{array}$ \\
\hline palygorskite & $(\mathrm{Mg}, \mathrm{Al})_{2} \mathrm{Si}_{4} \mathrm{O}_{10}(\mathrm{OH}) \cdot 4 \mathrm{H}_{2} \mathrm{O}$ & No? & No & 6 & No? & $\begin{array}{l}\text { Mainly a hydrothermal } \\
\text { mineral. Mg-montmorillonite } \\
\text { provides adequate } \\
\text { conservatism. }\end{array}$ \\
\hline panasquieraite & $\mathrm{CaMg}\left(\mathrm{PO}_{4}\right)(\mathrm{OH}, \mathrm{F})$ & No & No & 1 & No & Hydrothermal mineral \\
\hline panethite & $(\mathrm{Na}, \mathrm{Ca}, \mathrm{K})_{2}(\mathrm{Mg}, \mathrm{Fe}, \mathrm{Mn})_{2}\left(\mathrm{PO}_{4}\right)_{2}$ & No & No & 1 & No & Found in meteorites \\
\hline parsettensite & $\mathrm{KMn}_{10} \mathrm{Si}_{12} \mathrm{O}_{30}(\mathrm{OH})_{12}$ & No? & No & 1 & No & Occurs in Mn deposits \\
\hline partheite & $\mathrm{CaAl}_{2} \mathrm{Si}_{2} \mathrm{O}_{8} \cdot 2 \mathrm{H}_{2} \mathrm{O}$ & No? & No & 1 & No & $\begin{array}{l}\text { Occurs in cavities in ultramafic } \\
\text { rock }\end{array}$ \\
\hline paulkerrite & $\begin{array}{l}\mathrm{KTi}(\mathrm{Mg}, \mathrm{Mn})_{2}\left(\mathrm{Fe}^{2+}, \mathrm{Al}, \mathrm{Ti}, \mathrm{Mg}\right)_{2}\left(\mathrm{PO}_{4}\right)_{4}(\mathrm{OH})_{3} \\
\left.\cdot 15 \mathrm{H}_{2} \mathrm{O}\right)\end{array}$ & No & No & 1 & No & Occurs in phosphate rocks \\
\hline
\end{tabular}


Table C-1. Critique of Minerals not Included in Project Databases (Continued)

\begin{tabular}{|c|c|c|c|c|c|c|}
\hline Mineral & Chemical Formula & $\begin{array}{c}\text { Precipitates } \\
\text { from } 0 \text { to } 100^{\circ} \mathrm{C} \\
\text { and at } 1 \mathrm{ATM}\end{array}$ & Needed & Criterion & \begin{tabular}{|c|} 
Within Defined \\
Physico- \\
Chemical \\
System
\end{tabular} & $\begin{array}{c}\text { Comments on Occurrence } \\
\text { or Formation }\end{array}$ \\
\hline pectolite & $\mathrm{NaCa}_{2} \mathrm{Si}_{3} \mathrm{O}_{8}(\mathrm{OH})$ & No & No & 1 & No & Associated with basalt \\
\hline peisleyite & $\mathrm{Na}_{3} \mathrm{Al}_{16}\left(\mathrm{SO}_{4}\right)_{2}\left(\mathrm{PO}_{4}\right)_{10}(\mathrm{OH})_{17} \cdot 2 \mathrm{OH}_{2} \mathrm{O}$ & Yes? & No & 1 & No & Occurs in phosphate rocks \\
\hline penkvilksite & $\mathrm{Na}_{4} \mathrm{Ti}_{2} \mathrm{Si}_{8} \mathrm{O}_{22} \cdot 5 \mathrm{H}_{2} \mathrm{O}$ & No & No & 1 & No & Igneous mineral \\
\hline pennantite & $\mathrm{Mn}_{5} \mathrm{Al}\left(\mathrm{Si}_{3} \mathrm{Al}\right) \mathrm{O}_{10}(\mathrm{OH})_{8}$ & No? & No & 1 & No & Occurs in Mn deposits \\
\hline perhamite & $\mathrm{Ca}_{3} \mathrm{Al}_{7}\left(\mathrm{SiO}_{4}\right)_{3}\left(\mathrm{PO}_{4}\right)_{4}(\mathrm{OH})_{3} \cdot 33 / 2 \mathrm{H}_{2} \mathrm{O}$ & No & No & 1 & No & Igneous mineral \\
\hline phosphoferrite & $\left(\mathrm{Fe}^{+2}, \mathrm{Mn}\right)_{3}\left(\mathrm{PO}_{4}\right)_{2} \cdot 3 \mathrm{H}_{2} \mathrm{O}$ & No? & No & 1 & No & $\begin{array}{l}\text { Hydrothermal alteration in } \\
\text { pegmatites }\end{array}$ \\
\hline phosphorrösslerite & $\mathrm{MgHPO}_{4} \cdot 7 \mathrm{H}_{2} \mathrm{O}$ & Yes & No & 6 & $?$ & $\begin{array}{l}\text { Other minerals (e.g., apatite, } \\
\text { brucite) provide adequate } \\
\text { conservatism for elements in } \\
\text { this mineral; found in an } \\
\text { abandoned mine. }\end{array}$ \\
\hline phosphosiderite & $\mathrm{Fe}^{3+} \mathrm{PO}_{4} \cdot 2 \mathrm{H}_{2} \mathrm{O}$ & No & No & 1 & No & Igneous mineral \\
\hline pianlinite & $\mathrm{Al}_{2} \mathrm{Si}_{2} \mathrm{O}_{6}(\mathrm{OH})_{2}$ & Yes? & No & 6 & No? & $\begin{array}{l}\text { Occurs as a monomineralic } \\
\text { clay bed. Other minerals } \\
\text { (e.g., kaolinite) provide } \\
\text { adequate conservatism for } \\
\text { elements in this mineral. }\end{array}$ \\
\hline pickeringite & $\mathrm{MgAl}_{2}\left(\mathrm{SO}_{4}\right)_{4} \cdot 22 \mathrm{H}_{2} \mathrm{O}$ & Yes & No & 1 & No & $\begin{array}{l}\text { Oxidation product in mines, } \\
\text { caves, and coal beds }\end{array}$ \\
\hline piemontite & $\mathrm{Ca}_{2}\left(\mathrm{Al}, \mathrm{Mn}, \mathrm{Fe}^{3+}\right)_{3} \mathrm{Si}_{3} \mathrm{O}_{12}(\mathrm{OH})$ & No & No & 1 & No & $\begin{array}{l}\text { Igneous and metamorphic } \\
\text { mineral }\end{array}$ \\
\hline pigeonite & $(\mathrm{Mg}, \mathrm{Fe}, \mathrm{Ca})(\mathrm{Mg}, \mathrm{Fe}) \mathrm{Si}_{2} \mathrm{O}_{6}$ & No & No & 1 & No & $\begin{array}{l}\text { Igneous mineral (and in } \\
\text { meteorites) }\end{array}$ \\
\hline plombierite & $\mathrm{Ca}_{5} \mathrm{H}_{2} \mathrm{Si}_{6} \mathrm{O}_{18} \cdot 6 \mathrm{H}_{2} \mathrm{O}(?)$ & $?$ & No & 6 & $?$ & $\begin{array}{l}\text { Other solids (e.g., cement } \\
\text { phases included in } \\
\text { dataO.ypf.RO) provide } \\
\text { adequate conservatism for } \\
\text { this mineral. }\end{array}$ \\
\hline pokrovskite & $\mathrm{Mg}_{2}\left(\mathrm{CO}_{3}\right)(\mathrm{OH})_{2} \cdot 1 / 2 \mathrm{H}_{2} \mathrm{O}$ & No? & No & 1 & No & Vein in ultramafic rock \\
\hline preiswerkite & $\mathrm{NaMg}_{2} \mathrm{Al}_{3} \mathrm{Si}_{2} \mathrm{O}_{10}(\mathrm{OH})_{2}$ & No? & No & 1 & No & $\begin{array}{l}\text { Occurs in cavities in ultramafic } \\
\text { rock }\end{array}$ \\
\hline
\end{tabular}


Table C-1. Critique of Minerals not Included in Project Databases (Continued)

\begin{tabular}{|c|c|c|c|c|c|c|}
\hline Mineral & Chemical Formula & $\begin{array}{l}\text { Precipitates } \\
\text { from } 0 \text { to } 100^{\circ} \mathrm{C} \\
\text { and at } 1 \text { ATM }\end{array}$ & Needed & Criterion & $\begin{array}{c}\text { Within Defined } \\
\text { Physico- } \\
\text { Chemical } \\
\text { System }\end{array}$ & $\begin{array}{c}\text { Comments on Occurrence } \\
\text { or Formation }\end{array}$ \\
\hline prosopite & $\mathrm{CaAl}_{2}(\mathrm{~F}, \mathrm{OH})_{8}$ & No & No & 1 & No & $\begin{array}{l}\text { Igneous and metamorphic } \\
\text { mineral }\end{array}$ \\
\hline pseudobrookite & $\left(\mathrm{Fe}^{3+}, \mathrm{Fe}^{2+}\right)_{2}\left(\mathrm{Fe}^{+3}, \mathrm{Ti}\right) \mathrm{O}_{5}$ & No & No & 1 & No & $\begin{array}{l}\text { Igneous mineral and in } \\
\text { cavities in basalt }\end{array}$ \\
\hline pseudolaueite & $\mathrm{Mn}^{2+} \mathrm{Fe}^{3+}{ }_{2}\left(\mathrm{PO}_{4}\right)_{2}(\mathrm{OH})_{2} \cdot 8 \mathrm{H}_{2} \mathrm{O}$ & No & No & 1 & No & Igneous mineral \\
\hline pseudorulite & $\mathrm{Fe}^{3+}{ }_{2} \mathrm{Ti}_{3} \mathrm{O}_{9}(?)$ & Yes & No & 1 & No & $\begin{array}{l}\text { Alteration product of ilmenite, } \\
\text { precursor absent }\end{array}$ \\
\hline pumpellyite & $\mathrm{Ca}_{2} \mathrm{MgAl}_{2}\left(\mathrm{SiO}_{4}\right)\left(\mathrm{Si}_{2} \mathrm{O}_{7}\right)(\mathrm{OH})_{2} \cdot \mathrm{H}_{2} \mathrm{O}$ & No? & No & 1 & No & $\begin{array}{l}\text { Occurs in cavities in basalt } \\
\text { and metamorphic mineral }\end{array}$ \\
\hline purpurite & $\left(\mathrm{Mn}^{3+}, \mathrm{Fe}^{3+}\right) \mathrm{PO}_{4}$ & Yes & No & 1 & No & $\begin{array}{l}\text { Alteration product of } \\
\text { lithiophilite, precursor absent }\end{array}$ \\
\hline pyroaurite & $\mathrm{Mg}_{6} \mathrm{Fe}^{3+}{ }_{2}\left(\mathrm{CO}_{3}\right)(\mathrm{OH})_{16} \bullet 4 \mathrm{H}_{2} \mathrm{O}$ & No & No & 1 & No & $\begin{array}{l}\text { Metamorphic or hydrothermal } \\
\text { mineral }\end{array}$ \\
\hline pyrochroite & $\mathrm{Mn}(\mathrm{OH})_{2}$ & No & No & 1 & No & Hydrothermal mineral \\
\hline pyrope & $\mathrm{Mg}_{3} \mathrm{Al}_{2}\left(\mathrm{SiO}_{4}\right)_{3}$ & No & No & 1 & No & $\begin{array}{l}\text { Igneous and metamorphic } \\
\text { mineral }\end{array}$ \\
\hline pyrophanite & $\mathrm{MnTiO}_{3}$ & No & No & 1 & No & Metamorphic mineral \\
\hline pyrosmalite & $(\mathrm{Fe}, \mathrm{Mn})_{8} \mathrm{Si}_{6} \mathrm{O}_{15}(\mathrm{OH}, \mathrm{Cl})_{10}$ & No? & No & 1 & No & Occurs in Fe deposits \\
\hline pyroxferroite & $(\mathrm{Fe}, \mathrm{Mn}, \mathrm{Ca}) \mathrm{SiO}_{3}$ & No & No & 1 & No & Occurs in lunar rocks \\
\hline pyroxmangite & $(\mathrm{Mn}, \mathrm{Fe}) \mathrm{SiO}_{3}$ & No & No & 1 & No & Metamorphic mineral \\
\hline qandilite & $\mathrm{Mg}_{2} \mathrm{TiO}_{4}$ & No? & No & 1 & No & $\begin{array}{l}\text { Occurs in a metamorphic Mn } \\
\text { deposit }\end{array}$ \\
\hline qingheiite & $\mathrm{Na}_{2} \mathrm{NaMn}_{2} \mathrm{Mg}_{2}\left(\mathrm{Al}, \mathrm{Fe}^{3+}\right)_{2}\left(\mathrm{PO}_{4}\right)_{6}$ & No & No & 1 & No & Igneous mineral \\
\hline quenstedtite & $\mathrm{Fe}^{3+}{ }_{2}\left(\mathrm{SO}_{4}\right)_{3} \cdot 10 \mathrm{H}_{2} \mathrm{O}$ & Yes & No & 1 & No & Oxidation product in mines \\
\hline raite & $\mathrm{Na}_{4} \mathrm{Mn}_{3} \mathrm{Si}_{8}(\mathrm{O}, \mathrm{OH})_{24} \cdot 9 \mathrm{H}_{2} \mathrm{O}(?)$ & No & No & 1 & No & Igneous mineral \\
\hline ralstonite & $\mathrm{Na}_{x} \mathrm{Mg}_{x} \mathrm{Al}_{2-\mathrm{x}}(\mathrm{F}, \mathrm{OH})_{6} \cdot \mathrm{H}_{2} \mathrm{O}$ & No & No & 1 & No & $\begin{array}{l}\text { Igneous or metamorphic } \\
\text { mineral }\end{array}$ \\
\hline ramsdellite & $\mathrm{MnO}_{2}$ & Yes & No & 1 & No & Occurs in Mn deposits \\
\hline rancieite & $\left(\mathrm{Ca}, \mathrm{Mn}^{2+}\right) \mathrm{Mn}^{4+}{ }_{4} \mathrm{O}_{9} \cdot 3 \mathrm{H}_{2} \mathrm{O}$ & Yes & No & 1 & No & $\begin{array}{l}\text { Occurs in Fe and Mn deposits } \\
\text { and on a bauxite-limestone } \\
\text { contact }\end{array}$ \\
\hline
\end{tabular}


Table C-1. Critique of Minerals not Included in Project Databases (Continued)

\begin{tabular}{|c|c|c|c|c|c|c|}
\hline Mineral & Chemical Formula & $\begin{array}{l}\text { Precipitates } \\
\text { from } 0 \text { to } 100^{\circ} \mathrm{C} \\
\text { and at } 1 \mathrm{ATM}\end{array}$ & Needed & Criterion & $\begin{array}{l}\text { Within Defined } \\
\text { Physico- } \\
\text { Chemical } \\
\text { System }\end{array}$ & $\begin{array}{c}\text { Comments on Occurrence } \\
\text { or Formation }\end{array}$ \\
\hline rapidcreekite & $\mathrm{Ca}_{2}\left(\mathrm{SO}_{4}\right)\left(\mathrm{CO}_{3}\right) \cdot 4 \mathrm{H}_{2} \mathrm{O}$ & Yes & No & 1 & No & Occurs in Fe deposits \\
\hline rasvumite & $\mathrm{KFe}_{2} \mathrm{~S}_{3}$ & No & No & 1 & No & Igneous mineral \\
\hline reddingite & $(\mathrm{Mn}, \mathrm{Fe})_{3}\left(\mathrm{PO}_{4}\right)_{2} \cdot 3 \mathrm{H}_{2} \mathrm{O}$ & Yes & No & 1 & No & $\begin{array}{l}\text { Secondary phosphate in } \\
\text { pegmatites }\end{array}$ \\
\hline reinhardbraunsite & $\mathrm{Ca}_{5}\left(\mathrm{SiO}_{4}\right)_{2}(\mathrm{OH}, \mathrm{F})_{2}$ & No & No & 1 & No & $\begin{array}{l}\text { Igneous or metamorphic } \\
\text { mineral }\end{array}$ \\
\hline revdite & $\mathrm{Na}_{2} \mathrm{Si}_{2} \mathrm{O}_{5} \cdot 5 \mathrm{H}_{2} \mathrm{O}$ & No & No & 1 & No & $\begin{array}{l}\text { Igneous or hydrothermal } \\
\text { mineral }\end{array}$ \\
\hline reyerite & $(\mathrm{Na}, \mathrm{K})_{4} \mathrm{Ca}_{14}(\mathrm{Si}, \mathrm{Al})_{24} \mathrm{O}_{60}(\mathrm{OH})_{5} \cdot 5 \mathrm{H}_{2} \mathrm{O}$ & No & No & 1 & No & $\begin{array}{l}\text { Occurs in cavities in basalt or } \\
\text { within mafic tuffs }\end{array}$ \\
\hline rhodesite & $\left(\mathrm{Ca}, \mathrm{Na}_{2}, \mathrm{~K}_{2}\right)_{8} \mathrm{Si}_{16} \mathrm{O}_{40} \bullet 11 \mathrm{H}_{2} \mathrm{O}$ & No? & No & 6 & No? & $\begin{array}{l}\text { Other minerals (e.g., afwillite, } \\
\text { nahcolite, } \mathrm{SiO}_{2(\mathrm{am})} \text { ) provide } \\
\text { adequate conservatism for } \\
\text { elements in this mineral. }\end{array}$ \\
\hline rhomboclase & $\mathrm{HFe}^{3+}\left(\mathrm{SO}_{4}\right)_{2} \bullet 4 \mathrm{H}_{2} \mathrm{O}$ & Yes & No & 1 & No & Oxidation product in mines \\
\hline rhönite & $\mathrm{Ca}_{2}\left(\mathrm{Fe}^{2+}, \mathrm{Fe}^{3+}, \mathrm{Mg}, \mathrm{Ti}\right)_{6}(\mathrm{Si}, \mathrm{Al})_{6} \mathrm{O}_{20}$ & No & No & 1 & No & Igneous mineral \\
\hline ribbeite & $\mathrm{Mn}_{5}\left(\mathrm{SiO}_{4}\right)_{2}(\mathrm{OH})_{2}$ & No? & No & 1 & No & Occurs in Mn pods in dolomite \\
\hline richellite & $\mathrm{Ca}_{3} \mathrm{Fe}^{3+}{ }_{10}\left(\mathrm{PO}_{4}\right)_{8}(\mathrm{OH}, \mathrm{F})_{12} \bullet \mathrm{nH}_{2} \mathrm{O}(?)$ & Yes & No & 6 & No? & $\begin{array}{l}\text { Other minerals (e.g., apatite, } \\
\text { goethite) provide adequate } \\
\text { conservatism for elements in } \\
\text { this mineral. }\end{array}$ \\
\hline richterite & $\mathrm{Na}_{2} \mathrm{Ca}\left(\mathrm{Mg}, \mathrm{Fe}^{2+}\right)_{5} \mathrm{Si}_{8} \mathrm{O}_{22}(\mathrm{OH})_{2}$ & No & No & 1 & No & $\begin{array}{l}\text { Igneous and metamorphic } \\
\text { mineral }\end{array}$ \\
\hline riebeckite & $\mathrm{Na}_{2}\left(\mathrm{Fe}^{2+}, \mathrm{Mg}\right)_{3} \mathrm{Fe}^{3+}{ }_{2} \mathrm{Si}_{8} \mathrm{O}_{22}(\mathrm{OH})_{2}$ & No & No & 1 & No & $\begin{array}{l}\text { Igneous and metamorphic } \\
\text { mineral }\end{array}$ \\
\hline ringwoodite & $\left(\mathrm{Mg}, \mathrm{Fe}^{2+}\right)_{2} \mathrm{SiO}_{4}$ & No & No & 1 & No & $\begin{array}{l}\text { Found in meteorites and } \\
\text { veins. }\end{array}$ \\
\hline rinneite & $\mathrm{K}_{3} \mathrm{NaFe}^{2+} \mathrm{Cl}_{6}$ & Yes & No & 6 & Yes & $\begin{array}{l}\text { Other minerals (e.g., molysite, } \\
\text { sylvite, halite) provide } \\
\text { adequate conservatism for } \\
\text { elements in this mineral. }\end{array}$ \\
\hline roaldite & $\mathrm{Fe}_{4} \mathrm{~N}$ & No & No & 1 & No & Found in meteorites \\
\hline
\end{tabular}


Table C-1. Critique of Minerals not Included in Project Databases (Continued)

\begin{tabular}{|c|c|c|c|c|c|c|}
\hline Mineral & Chemical Formula & $\begin{array}{l}\text { Precipitates } \\
\text { from } 0 \text { to } 100^{\circ} \mathrm{C} \\
\text { and at } 1 \mathrm{ATM}\end{array}$ & Needed & Criterion & $\begin{array}{l}\text { Within Defined } \\
\text { Physico- } \\
\text { Chemical } \\
\text { System } \\
\end{array}$ & $\begin{array}{c}\text { Comments on Occurrence } \\
\text { or Formation }\end{array}$ \\
\hline robertsite & $\mathrm{Ca}_{3} \mathrm{Mn}^{3+}{ }_{4}\left(\mathrm{PO}_{4}\right)_{4}(\mathrm{OH})_{6} \cdot 3 \mathrm{H}_{2} \mathrm{O}$ & No & No & 1 & No & Igneous mineral \\
\hline rockbridgeite & $\left(\mathrm{Fe}^{2+}, \mathrm{Mn}\right) \mathrm{Fe}^{3+}{ }_{4}\left(\mathrm{PO}_{4}\right)_{3}(\mathrm{OH})_{5}$ & Yes? & No & 1 & No & $\begin{array}{l}\text { Occurs mostly in pegmatites, } \\
\text { also in novaculite }\end{array}$ \\
\hline roedderite & $(\mathrm{Na}, \mathrm{K})_{2}\left(\mathrm{Mg}, \mathrm{Fe}^{2+}\right)_{5} \mathrm{Si}_{12} \mathrm{O}_{30}$ & No & No & 1 & No & Found in meteorites \\
\hline roggianite & $\mathrm{Ca}_{8} \mathrm{Al}_{8} \mathrm{Si}_{16} \mathrm{O}_{44}(\mathrm{OH})_{16} \cdot 13 \mathrm{H}_{2} \mathrm{O}$ & No & No & 1 & No & Igneous mineral \\
\hline rokühnite & $\mathrm{Fe}^{2+} \mathrm{Cl}_{2} \cdot 2 \mathrm{H}_{2} \mathrm{O}$ & Yes? & No & 1 & No & $\begin{array}{l}\text { Ferrous iron; requires } \\
\text { reducing conditions }\end{array}$ \\
\hline römerite & $\mathrm{Fe}^{2+} \mathrm{Fe}_{2}^{3+}{ }_{2}\left(\mathrm{SO}_{4}\right)_{4} \cdot 14 \mathrm{H}_{2} \mathrm{O}$ & Yes & No & 1 & No & $\begin{array}{l}\text { Oxidation product in mines } \\
\text { and associated with } \\
\text { phosphates }\end{array}$ \\
\hline rosemaryite & $\begin{array}{l}\left(\mathrm{Na}, \mathrm{Ca}, \mathrm{Mn}^{2+}\right)\left(\mathrm{Mn}^{2+}, \mathrm{Fe}^{2+}\right)\left(\mathrm{Fe}^{3+}, \mathrm{Fe}^{2+}, \mathrm{Mg}\right) \mathrm{Al} \\
\left(\mathrm{PO}_{4}\right)_{3}\end{array}$ & No & No & 1 & No & Igneous mineral \\
\hline rosenhahnite & $\mathrm{Ca}_{3} \mathrm{Si}_{3} \mathrm{O}_{8}(\mathrm{OH})_{2}$ & No & No & 1 & No & Metamorphic mineral \\
\hline rostite & $\mathrm{Al}\left(\mathrm{SO}_{4}\right)(\mathrm{OH}) \cdot 5 \mathrm{H}_{2} \mathrm{O}$ & No & No & 1 & No & Found on burning coal dumps \\
\hline rozenite & $\mathrm{Fe}^{2+} \mathrm{SO}_{4} \cdot 4 \mathrm{H}_{2} \mathrm{O}$ & Yes & No & 1 & No & Oxidation product in mines \\
\hline ruizite & $\mathrm{CaMn}^{3+} \mathrm{Si}_{2} \mathrm{O}_{6}(\mathrm{OH}) \cdot 2 \mathrm{H}_{2} \mathrm{O}$ & No & No & 1 & No & Metamorphic mineral \\
\hline rustumite & $\mathrm{Ca}_{10}\left(\mathrm{Si}_{2} \mathrm{O}_{7}\right)_{2}\left(\mathrm{SiO}_{4}\right) \mathrm{Cl}_{2}(\mathrm{OH})_{2}$ & No & No & 1 & No & Metamorphic mineral \\
\hline sabieite & $\left(\mathrm{NH}_{4}\right) \mathrm{Fe}^{3+}\left(\mathrm{SO}_{4}\right)_{2}$ & Yes & No & 1 & No & Requires reducing conditions \\
\hline sacrofanite & $\begin{array}{l}(\mathrm{Na}, \mathrm{Ca}, \mathrm{K})_{9}(\mathrm{Si}, \mathrm{Al})_{12} \mathrm{O}_{24}\left[(\mathrm{OH})_{2},\left(\mathrm{SO}_{4}\right),\left(\mathrm{CO}_{3}\right),\right. \\
\left.\mathrm{Cl}_{2}\right]_{3} \bullet \mathrm{nH}_{2} \mathrm{O}\end{array}$ & No & No & 1 & No & $\begin{array}{l}\text { Igneous or metamorphic } \\
\text { mineral }\end{array}$ \\
\hline sadanagaite & $\begin{array}{l}(\mathrm{K}, \mathrm{Na}) \mathrm{Ca}_{2}\left(\mathrm{Fe}^{2+}, \mathrm{Mg}, \mathrm{Al}, \mathrm{Fe}^{3+}, \mathrm{Ti}\right)_{5}(\mathrm{Si}, \mathrm{Al})_{8} \mathrm{O}_{22} \\
(\mathrm{OH})_{2}\end{array}$ & No & No & 1 & No & Metamorphic mineral \\
\hline samuelsonite & $(\mathrm{Ca}, \mathrm{Ba}) \mathrm{Fe}^{2+}{ }_{2} \mathrm{Mn}^{2+}{ }_{2} \mathrm{Ca}_{8} \mathrm{Al}_{2}\left(\mathrm{PO}_{4}\right)_{10}(\mathrm{OH})_{2}$ & No & No & 1 & No & $\begin{array}{l}\text { Igneous mineral and in Fe and } \\
\text { Mn oxides }\end{array}$ \\
\hline sanderite & $\mathrm{MgSO}_{4} \cdot 2 \mathrm{H}_{2} \mathrm{O}$ & Yes & No & 6 & Yes & $\begin{array}{l}\text { Other minerals (e.g., kieserite } \\
\text { and leonhardtite) provide } \\
\text { adequate conservatism for } \\
\text { this mineral. }\end{array}$ \\
\hline sanjuanite & $\mathrm{Al}_{2}\left(\mathrm{PO}_{4}\right)\left(\mathrm{SO}_{4}\right)(\mathrm{OH}) \cdot 9 \mathrm{H}_{2} \mathrm{O}$ & Yes? & No & 5 & No & $\begin{array}{l}\text { Rare; in some slates in } \\
\text { Argentina }\end{array}$ \\
\hline
\end{tabular}


Table C-1. Critique of Minerals not Included in Project Databases (Continued)

\begin{tabular}{|c|c|c|c|c|c|c|}
\hline Mineral & Chemical Formula & $\begin{array}{c}\text { Precipitates } \\
\text { from } 0 \text { to } 100^{\circ} \mathrm{C} \\
\text { and at } 1 \mathrm{ATM}\end{array}$ & Needed & Criterion & $\begin{array}{l}\text { Within Defined } \\
\text { Physico- } \\
\text { Chemical } \\
\text { System }\end{array}$ & $\begin{array}{c}\text { Comments on Occurrence } \\
\text { or Formation }\end{array}$ \\
\hline santaclaraite & $\mathrm{CaMn}^{2+}{ }_{4} \mathrm{Si}_{5} \mathrm{O}_{14}(\mathrm{OH})_{2} \cdot \mathrm{H}_{2} \mathrm{O}$ & No & No & 1 & No & $\begin{array}{l}\text { Hydrothermal mineral in } \mathrm{Cu} \\
\text { sulfide deposit }\end{array}$ \\
\hline sapphirine & $(\mathrm{Mg}, \mathrm{Al})_{8}(\mathrm{Al}, \mathrm{Si})_{6} \mathrm{O}_{20}$ & No & No & 1 & No & Metamorphic mineral \\
\hline sarcolite & $(\mathrm{Ca}, \mathrm{Na})_{9} \mathrm{Al}_{4} \mathrm{Si}_{6} \mathrm{O}_{26} \mathrm{~F}$ & No & No & 1 & No & Igneous mineral \\
\hline sarcopside & $\left(\mathrm{Fe}^{2+}, \mathrm{Mn}, \mathrm{Mg}\right)_{3}\left(\mathrm{PO}_{4}\right)_{2}$ & No & No & 1 & No & Igneous mineral \\
\hline sasaite & $\left(\mathrm{Al}, \mathrm{Fe}^{3+}\right)_{14}\left(\mathrm{PO}_{4}\right)_{11}\left(\mathrm{SO}_{4}\right)(\mathrm{OH})_{7} \bullet 83 \mathrm{H}_{2} \mathrm{O}$ & Yes & No & 1 & No & Occurs in bat guano \\
\hline satterlyite & $\left(\mathrm{Fe}^{2+}, \mathrm{Mg}, \mathrm{Fe}^{3+}\right)_{2}\left(\mathrm{PO}_{4}\right)(\mathrm{OH})$ & Yes? & No & 1 & No & $\begin{array}{l}\text { Occurs in shale with pyrite, } \\
\text { etc. }\end{array}$ \\
\hline scarbroite & $\mathrm{Al}_{5}\left(\mathrm{CO}_{3}\right)(\mathrm{OH})_{13} \cdot 5 \mathrm{H}_{2} \mathrm{O}$ & Yes & No & 6 & No? & $\begin{array}{l}\text { Found in sandstone. May be } \\
\text { hydrothermal. Other solids } \\
\text { (e.g., boehmite, gibbsite) } \\
\text { provide adequate } \\
\text { conservatism for this mineral. }\end{array}$ \\
\hline scawtite & $\mathrm{Ca}_{7} \mathrm{Si}_{6}\left(\mathrm{CO}_{3}\right) \mathrm{O}_{18} \cdot 2 \mathrm{H}_{2} \mathrm{O}$ & No & No & 1 & No & Metamorphic mineral \\
\hline schairerite & $\mathrm{Na}_{2}\left(\mathrm{SO}_{4}\right)_{7} \mathrm{~F}_{6} \mathrm{Cl}$ & Yes & No & 6 & Yes & $\begin{array}{l}\text { Other minerals (e.g., } \\
\text { thenardite, halite, villiaumite) } \\
\text { provide adequate } \\
\text { conservatism for elements in } \\
\text { this mineral. }\end{array}$ \\
\hline schertelite & $\left(\mathrm{NH}_{4}\right)_{2} \mathrm{MgH}_{2}\left(\mathrm{PO}_{4}\right)_{2} \cdot 4 \mathrm{H}_{2} \mathrm{O}$ & Yes & No & 1 & No & Occurs in bat guano \\
\hline schorlomite & $\mathrm{Ca}_{3} \mathrm{Ti}^{4+}{ }_{2}\left(\mathrm{Fe}^{3+}{ }_{2} \mathrm{Si}\right) \mathrm{O}_{12}$ & No & No & 1 & No & $\begin{array}{l}\text { Igneous and metamorphic } \\
\text { mineral }\end{array}$ \\
\hline scorzalite & $\left(\mathrm{Fe}^{2+}, \mathrm{Mg}\right) \mathrm{Al}_{2}\left(\mathrm{PO}_{4}\right)_{2}(\mathrm{OH})_{2}$ & No & No & 1 & No & $\begin{array}{l}\text { Igneous or metamorphic } \\
\text { mineral }\end{array}$ \\
\hline segelerite & $\mathrm{CaMgFe}^{3+}\left(\mathrm{PO}_{4}\right)_{2}(\mathrm{OH}) \cdot 4 \mathrm{H}_{2} \mathrm{O}$ & No & No & 1 & No & Igneous mineral \\
\hline sekaninaite & $(\mathrm{Fe}, \mathrm{Mg})_{2} \mathrm{Al}_{4} \mathrm{Si}_{5} \mathrm{O}_{18}$ & No & No & 1 & No & Igneous mineral \\
\hline senegalite & $\mathrm{Al}_{2}\left(\mathrm{PO}_{4}\right)(\mathrm{OH})_{3} \cdot \mathrm{H}_{2} \mathrm{O}$ & Yes & No & 1 & No & Oxidation zone in a mine \\
\hline serandite & $\mathrm{Mn}_{2} \mathrm{NaSi}_{3} \mathrm{O}_{8}(\mathrm{OH})$ & No & No & 1 & No & Igneous mineral \\
\hline serendibite & $\mathrm{Ca}_{2}(\mathrm{Mg}, \mathrm{Al})_{6}(\mathrm{Si}, \mathrm{Al}, \mathrm{B})_{6} \mathrm{O}_{20}$ & No & No & 1 & No & Metamorphic mineral \\
\hline
\end{tabular}


Table C-1. Critique of Minerals not Included in Project Databases (Continued)

\begin{tabular}{|c|c|c|c|c|c|c|}
\hline Mineral & Chemical Formula & $\begin{array}{c}\text { Precipitates } \\
\text { from } 0 \text { to } 100^{\circ} \mathrm{C} \\
\text { and at } 1 \mathrm{ATM}\end{array}$ & Needed & Criterion & \begin{tabular}{|c|} 
Within Defined \\
Physico- \\
Chemical \\
System \\
\end{tabular} & $\begin{array}{c}\text { Comments on Occurrence } \\
\text { or Formation }\end{array}$ \\
\hline sergeevite & $\mathrm{Ca}_{2} \mathrm{Mg}_{11}\left(\mathrm{CO}_{3}\right)_{9}\left(\mathrm{HCO}_{3}\right)_{4}(\mathrm{OH})_{4} \cdot 6 \mathrm{H}_{2} \mathrm{O}$ & ? & No & 6 & Possibly & $\begin{array}{l}\text { Other minerals (e.g., huntite) } \\
\text { provide adequate } \\
\text { conservatism for elements in } \\
\text { this mineral. }\end{array}$ \\
\hline shafranovskite & $(\mathrm{Na}, \mathrm{K})_{6}\left(\mathrm{Mn}^{2+}, \mathrm{Fe}^{2+}\right)_{3} \mathrm{Si}_{9} \mathrm{O}_{24} \cdot 6 \mathrm{H}_{2} \mathrm{O}$ & No & No & 1 & No & Igneous mineral \\
\hline shigaite & $\mathrm{Al}_{4} \mathrm{Mn}_{7}\left(\mathrm{SO}_{4}\right)_{2}(\mathrm{OH})_{22} \cdot 8 \mathrm{H}_{2} \mathrm{O}$ & No? & No & 1 & No & Occurs in Mn deposits \\
\hline shortite & $\mathrm{Na}_{2} \mathrm{Ca}_{2}\left(\mathrm{CO}_{3}\right)_{3}$ & No & No & 6 & No & $\begin{array}{l}\text { Occurs in the Green River } \\
\text { "oil" shale and in igneous } \\
\text { rocks. Natron and calcite } \\
\text { provide adequate } \\
\text { conservatism for this mineral. }\end{array}$ \\
\hline siderazot & $\mathrm{Fe}_{5} \mathrm{~N}_{2}$ & No? & No & 1 & No & $\begin{array}{l}\text { Coating on lava } \\
\text { (Mt. Vesuvius) }\end{array}$ \\
\hline sideronatrite & $\mathrm{Na}_{2} \mathrm{Fe}^{3+}\left(\mathrm{SO}_{4}\right)_{2}(\mathrm{OH}) \cdot 3 \mathrm{H}_{2} \mathrm{O}$ & Yes & No & 1 & No & Oxidation product in mines \\
\hline siderophyllite & $\mathrm{KFe}^{2+}{ }_{2} \mathrm{Al}\left(\mathrm{Al}_{2} \mathrm{Si}_{2}\right) \mathrm{O}_{10}(\mathrm{~F}, \mathrm{OH})$ & $?$ & No & 6 & No? & $\begin{array}{l}\text { No occurrence data in } \\
\text { reference. A mica. Other } \\
\text { minerals (e.g., annite) provide } \\
\text { adequate conservatism for } \\
\text { elements in this mineral. }\end{array}$ \\
\hline siderotil & $\mathrm{Fe}^{2+} \mathrm{SO}_{4} \cdot 5 \mathrm{H}_{2} \mathrm{O}$ & Yes & No & 6 & Yes? & $\begin{array}{l}\text { Other minerals (e.g., } \\
\text { melanterite) provide adequate } \\
\text { conservatism for this mineral. }\end{array}$ \\
\hline sidorenkite & $\mathrm{Na}_{3} \mathrm{Mn}\left(\mathrm{PO}_{4}\right)\left(\mathrm{CO}_{3}\right)$ & No & No & 1 & No & Igneous mineral \\
\hline sigloite & $\left(\mathrm{Fe}^{3+}, \mathrm{Fe}^{2+}\right) \mathrm{Al}_{2}\left(\mathrm{PO}_{4}\right)_{2}(\mathrm{OH})_{3} \cdot 5 \mathrm{H}_{2} \mathrm{O}$ & No & No & 1 & No & Hydrothermal mineral \\
\hline silhydrite & $3 \mathrm{SiO}_{2} \cdot \mathrm{H}_{2} \mathrm{O}$ & Yes & No & 6 & No? & $\begin{array}{l}\text { Alters from magadiite, which } \\
\text { is likely absent. } \mathrm{SiO}_{2(\mathrm{am})} \\
\text { provides adequate } \\
\text { conservatism. }\end{array}$ \\
\hline sinjarite & $\mathrm{CaCl}_{2} \cdot 2 \mathrm{H}_{2} \mathrm{O}$ & Yes & No & 1 & Yes & $\begin{array}{l}\text { Same as } \mathrm{CaCl}_{2} \cdot \mathrm{H}_{2} \mathrm{O} \text { in } \\
\text { dataO.ypf.RO }\end{array}$ \\
\hline sinkankasite & $\mathrm{H}_{2} \mathrm{MnAl}\left(\mathrm{PO}_{4}\right)_{2}(\mathrm{OH}) \cdot 6 \mathrm{H}_{2} \mathrm{O}$ & No & No & 1 & No & $\begin{array}{l}\text { Igneous mineral (secondary in } \\
\text { pegmatite) }\end{array}$ \\
\hline sinoite & $\mathrm{Si}_{2} \mathrm{~N}_{2} \mathrm{O}$ & No & No & 1 & No & Found in meteorites \\
\hline
\end{tabular}


Table C-1. Critique of Minerals not Included in Project Databases (Continued)

\begin{tabular}{|c|c|c|c|c|c|c|}
\hline Mineral & Chemical Formula & $\begin{array}{c}\text { Precipitates } \\
\text { from } 0 \text { to } 100^{\circ} \mathrm{C} \\
\text { and at } 1 \mathrm{ATM}\end{array}$ & Needed & Criterion & \begin{tabular}{|} 
Within Defined \\
Physico- \\
Chemical \\
System \\
\end{tabular} & $\begin{array}{c}\text { Comments on Occurrence } \\
\text { or Formation }\end{array}$ \\
\hline sjögrenite & $\mathrm{Mg}_{6} \mathrm{Fe}_{2}^{3+}{ }_{2}\left(\mathrm{CO}_{3}\right)(\mathrm{OH})_{16} \cdot 4 \mathrm{H}_{2} \mathrm{O}$ & No & No & 1 & No & $\begin{array}{l}\text { Hydrothermal mineral and } \\
\text { epitactic on pyroaurite }\end{array}$ \\
\hline Slavikite & $\mathrm{NaMg}_{2} \mathrm{Fe}_{5}^{3+}{ }_{5}\left(\mathrm{SO}_{4}\right)_{7}(\mathrm{OH})_{6} \cdot 33 \mathrm{H}_{2} \mathrm{O}$ & Yes & No & 1 & No & Oxidation product in mines \\
\hline sobolevite & $\mathrm{Na}_{14} \mathrm{Ca}_{2} \mathrm{MnTi}_{3} \mathrm{P}_{4} \mathrm{Si}_{4} \mathrm{O}_{34}$ & No & No & 1 & No & Igneous mineral \\
\hline sobotkite & $\left.(\mathrm{K}, \mathrm{Ca} /)_{2}\right)_{0.3}\left(\mathrm{Mg}_{2}, \mathrm{Al}\right)\left(\mathrm{Si}_{3} \mathrm{Al}\right) \mathrm{O}_{10}(\mathrm{OH})_{2} \cdot 5 \mathrm{H}_{2} \mathrm{O}$ & Yes & No & 6 & No & $\begin{array}{l}\text { Occurs in weathered } \\
\text { serpentinite. Montmorillonite } \\
\text { provides adequate } \\
\text { conservatism. }\end{array}$ \\
\hline sodalite & $\mathrm{Na}_{4} \mathrm{Al}_{3} \mathrm{Si}_{3} \mathrm{O}_{12} \mathrm{Cl}$ & No & No & 1 & No & $\begin{array}{l}\text { Igneous and metamorphic } \\
\text { mineral }\end{array}$ \\
\hline sodium_alum & $\mathrm{NaAl}\left(\mathrm{SO}_{4}\right)_{2} \cdot 12 \mathrm{H}_{2} \mathrm{O}$ & Yes & No & 6 & Yes? & $\begin{array}{l}\text { Reported occurrences not } \\
\text { authenticated. Other minerals } \\
\text { (e.g., alum-K, thenardite) } \\
\text { provide adequate } \\
\text { conservatism for elements in } \\
\text { this mineral. }\end{array}$ \\
\hline sonolite & $\mathrm{Mn}_{9}\left(\mathrm{SiO}_{4}\right)_{4}(\mathrm{OH}, \mathrm{F})_{2}$ & No? & No & 1 & No & Occurs in Mn deposits \\
\hline souzalite & $\left(\mathrm{Mg}, \mathrm{Fe}^{2+}\right)_{3}\left(\mathrm{Al}, \mathrm{Fe}^{3+}\right)_{4}\left(\mathrm{PO}_{4}\right)_{4}(\mathrm{OH})_{6} \cdot 2 \mathrm{H}_{2} \mathrm{O}$ & No & No & 1 & No & $\begin{array}{l}\text { Igneous mineral (secondary in } \\
\text { pegmatite) }\end{array}$ \\
\hline spadaite & $\mathrm{MgSiO}_{2}(\mathrm{OH})_{2} \cdot \mathrm{H}_{2} \mathrm{O}(?)$ & No & No & 1 & No & $\begin{array}{l}\text { Found in sulfide ores, igneous } \\
\text { and metamorphic rocks }\end{array}$ \\
\hline spessartine & $\mathrm{Mn}_{3} \mathrm{Al}_{2}\left(\mathrm{SiO}_{4}\right)_{3}$ & No & No & 1 & No & $\begin{array}{l}\text { Igneous and metamorphic } \\
\text { mineral }\end{array}$ \\
\hline spheniscidite & $\left(\mathrm{NH}_{4}, \mathrm{~K}\right)\left(\mathrm{Fe}^{3+}, \mathrm{Al}\right)_{2}\left(\mathrm{PO}_{4}\right)_{2}(\mathrm{OH}) \cdot 2 \mathrm{H}_{2} \mathrm{O}$ & Yes & No & 1 & No & Occurs in penguin guano \\
\hline spurrite & $\mathrm{Ca}_{5}\left(\mathrm{SiO}_{4}\right)_{2}\left(\mathrm{CO}_{3}\right)$ & No & No & 1 & No & Metamorphic mineral \\
\hline srebrodolskite & $\mathrm{Ca}_{2} \mathrm{Fe}^{3+}{ }_{2} \mathrm{O}_{3}$ & No & No & 1 & No & $\begin{array}{l}\text { Found in petrified wood baked } \\
\text { by burning coal }\end{array}$ \\
\hline stanfieldite & $\mathrm{Ca}_{4}(\mathrm{Mg}, \mathrm{Fe}, \mathrm{Mn})_{5}\left(\mathrm{PO}_{4}\right)_{6}$ & No & No & 1 & No & $\begin{array}{l}\text { Found in meteorites and in } \\
\text { veinlets in olivine }\end{array}$ \\
\hline staurolite & $\mathrm{Fe}_{2} \mathrm{Al}_{9}(\mathrm{Si}, \mathrm{Al})_{4} \mathrm{O}_{22}(\mathrm{OH})_{2}$ & No & No & 1 & No & Metamorphic mineral \\
\hline stepanovite & $\mathrm{NaMgFe}^{3+}\left(\mathrm{C}_{2} \mathrm{O}_{4}\right)_{3} \bullet 8-9 \mathrm{H}_{2} \mathrm{O}$ & Yes & No & 1 & No & Occurs in coal \\
\hline stercorite & $\mathrm{Na}\left(\mathrm{NH}_{4}\right) \mathrm{H}\left(\mathrm{PO}_{4}\right) \cdot 4 \mathrm{H}_{2} \mathrm{O}$ & Yes & No & 1 & No & Occurs in bat guano \\
\hline
\end{tabular}


Table C-1. Critique of Minerals not Included in Project Databases (Continued)

\begin{tabular}{|c|c|c|c|c|c|c|}
\hline Mineral & Chemical Formula & $\begin{array}{c}\text { Precipitates } \\
\text { from } 0 \text { to } 100^{\circ} \mathrm{C} \\
\text { and at } 1 \mathrm{ATM}\end{array}$ & Needed & Criterion & $\begin{array}{l}\text { Within Defined } \\
\text { Physico- } \\
\text { Chemical } \\
\text { System }\end{array}$ & $\begin{array}{c}\text { Comments on Occurrence } \\
\text { or Formation }\end{array}$ \\
\hline stevensite & $\mathrm{Mg}_{3} \mathrm{Si}_{4} \mathrm{O}_{10}(\mathrm{OH})_{2}$ & No? & No & 1 & No & Occurs in basalt and dunite \\
\hline stewartite & $\mathrm{MnFe}^{3+}{ }_{2}\left(\mathrm{PO}_{4}\right)_{2}(\mathrm{OH})_{2} \bullet 8 \mathrm{H}_{2} \mathrm{O}$ & No & No & 1 & No & Igneous mineral \\
\hline stilpnomelane & $\mathrm{K}\left(\mathrm{Fe}^{2+}, \mathrm{Fe}^{3+}, \mathrm{Al}\right)_{10} \mathrm{Si}_{12} \mathrm{O}_{30}(\mathrm{OH})_{12}$ & No & No & 1 & No & Metamorphic mineral \\
\hline stishovite & $\mathrm{SiO}_{2}$ & No & No & 1 & No & Forms from meteorite impacts \\
\hline strätlingite & $\mathrm{Ca}_{2} \mathrm{Al}_{2} \mathrm{SiO}_{7} \cdot 8 \mathrm{H}_{2} \mathrm{O}$ & No & No & 1 & No & Metamorphic mineral \\
\hline strunzite & $\mathrm{MnFe}_{2}^{3+}\left(\mathrm{PO}_{4}\right)_{2}(\mathrm{OH})_{2} \bullet 8 \mathrm{H}_{2} \mathrm{O}$ & No & No & 1 & No & $\begin{array}{l}\text { Igneous mineral (weathering } \\
\text { product in pegmatites), and in } \\
\text { phosphorite }\end{array}$ \\
\hline struvite & $\left(\mathrm{NH}_{4}\right) \mathrm{MgPO}_{4} \cdot 6 \mathrm{H}_{2} \mathrm{O}$ & Yes & No & 1 & No & Occurs in bat guano \\
\hline sudoite & $\mathrm{Mg}_{2}\left(\mathrm{Al}, \mathrm{Fe}^{3+}\right)_{3} \mathrm{Si}_{3} \mathrm{AlO}_{10}(\mathrm{OH})_{8}$ & No? & No & 1 & No & $\begin{array}{l}\text { Occurs in Fe deposits, and as } \\
\text { hydrothermal mineral }\end{array}$ \\
\hline suessite & $\mathrm{Fe}_{3} \mathrm{Si}$ & No & No & 1 & No & Found in meteorites \\
\hline sulphohalite & $\mathrm{Na}_{6}\left(\mathrm{SO}_{4}\right)_{2} \mathrm{FCl}$ & Yes & No & 6 & Yes & $\begin{array}{l}\text { Other minerals (e.g., } \\
\text { thenardite, halite, villiaumite) } \\
\text { provide adequate } \\
\text { conservatism for elements in } \\
\text { this mineral. }\end{array}$ \\
\hline suolunite & $\mathrm{Ca}_{2} \mathrm{Si}_{2} \mathrm{O}_{5}(\mathrm{OH})_{2} \bullet \mathrm{H}_{2} \mathrm{O}$ & No & No & 6 & No & $\begin{array}{l}\text { Occurs in veins in mafic and } \\
\text { ultramafic rocks. Afwillite } \\
\text { provides adequate } \\
\text { conservatism. }\end{array}$ \\
\hline sursassite & $\mathrm{Mn}_{2} \mathrm{Al}_{3}\left(\mathrm{SiO}_{4}\right)\left(\mathrm{Si}_{2} \mathrm{O}_{7}\right)(\mathrm{OH})_{3}$ & No? & No & 1 & No & Occurs in Mn and Fe deposits \\
\hline sveite & $\mathrm{KAl}_{7}\left(\mathrm{NO}_{3}\right)_{4} \mathrm{Cl}_{2}(\mathrm{OH})_{16} \cdot 8 \mathrm{H}_{2} \mathrm{O}$ & Yes & No & 6 & Possibly & $\begin{array}{l}\text { Occurs in a cave. Other } \\
\text { minerals (e.g., niter, sylvite, } \\
\text { boehmite) provide adequate } \\
\text { conservatism for elements in } \\
\text { this mineral. }\end{array}$ \\
\hline svetlozarite & $\left(\mathrm{Ca}, \mathrm{K}_{2}, \mathrm{Na}_{2}\right) \mathrm{Al}_{2}(\mathrm{Si}, \mathrm{Al})_{12} \mathrm{O}_{28} \bullet 6 \mathrm{H}_{2} \mathrm{O}$ & Yes? & No & 1 & No & Found as veinlets in andesite \\
\hline svyazhinite & $(\mathrm{Mg}, \mathrm{Mn}, \mathrm{Ca})\left(\mathrm{Al}, \mathrm{Fe}^{3+}\right)\left(\mathrm{SO}_{4}\right)_{2} \mathrm{~F} \cdot 14 \mathrm{H}_{2} \mathrm{O}$ & ? & No & 1 & No & $\begin{array}{l}\text { Occurs in a mafic fenite } \\
\text { (low-silica igneous rock) }\end{array}$ \\
\hline switzerite & $(\mathrm{Mn}, \mathrm{Fe})_{3}\left(\mathrm{PO}_{4}\right)_{2} \cdot 7 \mathrm{H}_{2} \mathrm{O}$ & No & No & 1 & No & Igneous mineral \\
\hline
\end{tabular}


Table C-1. Critique of Minerals not Included in Project Databases (Continued)

\begin{tabular}{|c|c|c|c|c|c|c|}
\hline Mineral & Chemical Formula & $\begin{array}{c}\text { Precipitates } \\
\text { from } 0 \text { to } 100^{\circ} \mathrm{C} \\
\text { and at } 1 \mathrm{ATM}\end{array}$ & Needed & Criterion & $\begin{array}{l}\text { Within Defined } \\
\text { Physico- } \\
\text { Chemical } \\
\text { System }\end{array}$ & $\begin{array}{c}\text { Comments on Occurrence } \\
\text { or Formation }\end{array}$ \\
\hline szmikite & $\mathrm{MnSO}_{4} \cdot \mathrm{H}_{2} \mathrm{O}$ & Yes & No & 1 & No & $\begin{array}{l}\text { Oxidation product in mines } \\
\text { (efflorescence) }\end{array}$ \\
\hline szomolnokite & $\mathrm{Fe}^{2+} \mathrm{SO}_{4} \cdot \mathrm{H}_{2} \mathrm{O}$ & Yes & No & 1 & No & Oxidation product in mines \\
\hline tacharanite & $\mathrm{Ca}_{12} \mathrm{Al}_{2} \mathrm{Si}_{18} \mathrm{O}_{51} \cdot 18 \mathrm{H}_{2} \mathrm{O}$ & No? & No & 1 & No & $\begin{array}{l}\text { Occurs in cavities in basalt } \\
\text { and metagabbro }\end{array}$ \\
\hline takanelite & $\left(\mathrm{Mn}^{2+}, \mathrm{Ca}\right) \mathrm{Mn}^{4+}{ }_{4} \mathrm{O}_{9} \cdot 1.3 \mathrm{H}_{2} \mathrm{O}$ & No? & No & 1 & No & Occurs in Mn deposits \\
\hline tamarugite & $\mathrm{NaAl}\left(\mathrm{SO}_{4}\right)_{2} \cdot 6 \mathrm{H}_{2} \mathrm{O}$ & Yes & No & 1 & No? & $\begin{array}{l}\text { Oxidation product in mines. } \\
\text { Thenardite and alunite provide } \\
\text { conservatism. }\end{array}$ \\
\hline taneyamalite & $(\mathrm{Na}, \mathrm{Ca})\left(\mathrm{Mn}^{2+}, \mathrm{Mg}, \mathrm{Fe}^{3+}, \mathrm{Al}\right)_{12} \mathrm{Si}_{12}(\mathrm{O}, \mathrm{OH})_{24}$ & No? & No & 1 & No & Occurs in Mn deposits \\
\hline taramite & $\mathrm{Na}_{2} \mathrm{Ca}\left(\mathrm{Fe}^{2+}, \mathrm{Mg}_{3}\right)_{3} \mathrm{Al}_{2}\left(\mathrm{Si}_{6} \mathrm{Al}_{2}\right) \mathrm{O}_{22}(\mathrm{OH})_{2}$ & No & No & 1 & No & Igneous mineral \\
\hline taranakite & $\left(\mathrm{K}, \mathrm{NH}_{4}\right) \mathrm{Al}_{3}\left(\mathrm{PO}_{4}\right)_{3}(\mathrm{OH}) \cdot 9 \mathrm{H}_{2} \mathrm{O}$ & Yes & No & 1 & No & Occurs in bat guano \\
\hline tatarskite & $\mathrm{Ca}_{6} \mathrm{Mg}_{2}\left(\mathrm{SO}_{4}\right)_{2}\left(\mathrm{CO}_{3}\right)_{2} \mathrm{Cl}_{4}(\mathrm{OH})_{4} \cdot 7 \mathrm{H}_{2} \mathrm{O}$ & Yes & No & 6 & Yes & $\begin{array}{l}\text { Other minerals (e.g., } \\
\text { tachyhydrite, polyhalite, } \\
\text { calcite) provide adequate } \\
\text { conservatism for elements in } \\
\text { this mineral. }\end{array}$ \\
\hline tauriscite & $\mathrm{FeSO}_{4} \cdot 7 \mathrm{H}_{2} \mathrm{O}$ & Yes & No & 6 & No & $\begin{array}{l}\text { Requires reducing conditions. } \\
\text { Melanterite provides adequate } \\
\text { conservatism for this mineral. }\end{array}$ \\
\hline tetrakalsilite & $(\mathrm{K}, \mathrm{Na}) \mathrm{AlSiO}_{4}$ & No & No & 1 & No & Igneous mineral \\
\hline tetranatrolite & $\mathrm{Na}_{2} \mathrm{Al}_{2} \mathrm{Si}_{3} \mathrm{O}_{10} \cdot 2 \mathrm{H}_{2} \mathrm{O}$ & No? & No & 1 & No & $\begin{array}{l}\text { Occurs as epitactic } \\
\text { overgrowth on natrolite, } \\
\text { natrolite absent }\end{array}$ \\
\hline thadeuite & $\mathrm{Mg}(\mathrm{Ca}, \mathrm{Mn})(\mathrm{Mg}, \mathrm{Fe}, \mathrm{Mn})_{2}\left(\mathrm{PO}_{4}\right)_{2}(\mathrm{OH}, \mathrm{F})_{2}$ & No & No & 1 & No & Hydrothermal mineral \\
\hline thaumasite & $\mathrm{Ca}_{3} \mathrm{Si}\left(\mathrm{CO}_{3}\right)\left(\mathrm{SO}_{4}\right)(\mathrm{OH})_{6} \cdot 12 \mathrm{H}_{2} \mathrm{O}$ & No & No & 1 & No & $\begin{array}{l}\text { Metamorphic mineral, or } \\
\text { associated with basalts }\end{array}$ \\
\hline thomsenolite & $\mathrm{NaCaAlF}_{6} \bullet \mathrm{H}_{2} \mathrm{O}$ & Yes & No & 1 & No & Alteration product of cryolite \\
\hline thomsonite & $\mathrm{NaCa}_{2} \mathrm{Al}_{5} \mathrm{Si}_{5} \mathrm{O}_{20} \cdot 6 \mathrm{H}_{2} \mathrm{O}$ & No? & No & 1 & No & $\begin{array}{l}\text { Occurs in cavities in basalt } \\
\text { and as metamorphic mineral }\end{array}$ \\
\hline tilleyite & $\mathrm{Ca}_{5} \mathrm{Si}_{2} \mathrm{O}_{7}\left(\mathrm{CO}_{3}\right)_{2}$ & No & No & 1 & No & Metamorphic mineral \\
\hline
\end{tabular}


Table C-1. Critique of Minerals not Included in Project Databases (Continued)

\begin{tabular}{|c|c|c|c|c|c|c|}
\hline Mineral & Chemical Formula & $\begin{array}{c}\text { Precipitates } \\
\text { from } 0 \text { to } 100^{\circ} \mathrm{C} \\
\text { and at } 1 \mathrm{ATM}\end{array}$ & Needed & Criterion & $\begin{array}{l}\text { Within Defined } \\
\text { Physico- } \\
\text { Chemical } \\
\text { System }\end{array}$ & $\begin{array}{c}\text { Comments on Occurrence } \\
\text { or Formation }\end{array}$ \\
\hline tinaksite & $\mathrm{NaK}_{2} \mathrm{Ca}_{2} \mathrm{TiSi}_{7} \mathrm{O}_{19}(\mathrm{OH})$ & No & No & 1 & No & Metamorphic mineral \\
\hline tinsleyite & $\mathrm{KAl}_{2}\left(\mathrm{PO}_{4}\right)_{2}(\mathrm{OH}) \cdot 2 \mathrm{H}_{2} \mathrm{O}$ & No & No & 1 & No & Igneous mineral \\
\hline tinticite & $\mathrm{Fe}_{6}^{3+}\left(\mathrm{PO}_{4}\right)_{4}(\mathrm{OH})_{6} \cdot 7 \mathrm{H}_{2} \mathrm{O}$ & Yes & No & 6 & Yes & $\begin{array}{l}\text { Other minerals (e.g., } \\
\text { strengite) provide adequate } \\
\text { conservatism for elements in } \\
\text { this mineral. }\end{array}$ \\
\hline tirodite & $\mathrm{Mn}_{2}^{2+}\left(\mathrm{Mg}, \mathrm{Fe}^{2+}\right)_{5} \mathrm{Si}_{8} \mathrm{O}_{22}(\mathrm{OH})_{2}$ & No? & No & 1 & No & $\begin{array}{l}\text { Occurs in deposits high in } \mathrm{Mn} \text {, } \\
\mathrm{Fe} \text {, or } \mathrm{Mg}\end{array}$ \\
\hline tisinalite & $\mathrm{Na}_{3} \mathrm{H}_{3}(\mathrm{Mn}, \mathrm{Ca}, \mathrm{Fe}) \mathrm{TiSi}_{6}(\mathrm{O}, \mathrm{OH})_{18} \cdot 2 \mathrm{H}_{2} \mathrm{O}$ & No & No & 1 & No & Igneous mineral \\
\hline tobelite & $\left(\mathrm{NH}_{4}, \mathrm{~K}\right) \mathrm{Al}_{2}\left(\mathrm{Si}_{3} \mathrm{Al}\right) \mathrm{O}_{10}(\mathrm{OH})_{2}$ & No? & No & 1 & No & $\begin{array}{l}\text { Metamorphic (and } \\
\text { hydrothermal?). Requires } \\
\text { reducing conditions. }\end{array}$ \\
\hline tobermorite & $\mathrm{Ca}_{5} \mathrm{Si}_{6} \mathrm{O}_{16}(\mathrm{OH})_{2} \bullet 4 \mathrm{H}_{2} \mathrm{O}$ & No? & No & 6 & No? & $\begin{array}{l}\text { Other minerals (e.g., zeolites) } \\
\text { provide adequate } \\
\text { conservatism for this mineral. }\end{array}$ \\
\hline tochilinite & $6 \mathrm{Fe}_{0.9} \mathrm{~S} \cdot 5(\mathrm{Mg}, \mathrm{Fe})(\mathrm{OH})_{2}$ & No & No & 1 & No & $\begin{array}{l}\text { Igneous and metamorphic } \\
\text { mineral }\end{array}$ \\
\hline todorokite & $(\mathrm{Mn}, \mathrm{Ca}, \mathrm{Mg}) \mathrm{Mn}^{4+}{ }_{3} \mathrm{O}_{7} \cdot \mathrm{H}_{2} \mathrm{O}$ & Yes & No & 1 & No & $\begin{array}{l}\text { Alteration product of } \mathrm{Mn} \\
\text { deposits }\end{array}$ \\
\hline tokkoite & $\mathrm{K}_{4} \mathrm{Ca}_{4} \mathrm{Si}_{7} \mathrm{O}_{17}(\mathrm{O}, \mathrm{OH}, \mathrm{F})_{4}$ & No & No & 1 & No & Igneous mineral \\
\hline topaz & $\mathrm{Al}_{2} \mathrm{SiO}_{4}(\mathrm{~F}, \mathrm{OH})_{2}$ & No & No & 1 & No & $\begin{array}{l}\text { Igneous, metamorphic, and } \\
\text { hydrothermal mineral }\end{array}$ \\
\hline trikalsilite & $(\mathrm{K}, \mathrm{Na}) \mathrm{AlSiO}_{4}$ & No & No & 1 & No & Igneous mineral \\
\hline triplite & $\left(\mathrm{Mn}^{2+}, \mathrm{Fe}^{2+}, \mathrm{Mg}, \mathrm{Ca}\right)_{2}\left(\mathrm{PO}_{4}\right)(\mathrm{F}, \mathrm{OH})$ & No & No & 1 & No & $\begin{array}{l}\text { Igneous and hydrothermal } \\
\text { mineral }\end{array}$ \\
\hline triploidite & $\left(\mathrm{Mn}^{2+}, \mathrm{Fe}^{2+}\right)_{2}\left(\mathrm{PO}_{4}\right)(\mathrm{OH})$ & No & No & 1 & No & $\begin{array}{l}\text { Igneous mineral and as } \\
\text { alteration of triplite }\end{array}$ \\
\hline trolleite & $\mathrm{Al}_{4}\left(\mathrm{PO}_{4}\right)_{3}(\mathrm{OH})_{3}$ & No? & No & 1 & No & $\begin{array}{l}\text { Found in deposits high in } \\
\text { phosphate and at a } \\
\text { phosphatic iron mine }\end{array}$ \\
\hline
\end{tabular}


Table C-1. Critique of Minerals not Included in Project Databases (Continued)

\begin{tabular}{|c|c|c|c|c|c|c|}
\hline Mineral & Chemical Formula & $\begin{array}{l}\text { Precipitates } \\
\text { from } 0 \text { to } 100^{\circ} \mathrm{C} \\
\text { and at } 1 \mathrm{ATM}\end{array}$ & Needed & Criterion & $\begin{array}{l}\text { Within Defined } \\
\text { Physico- } \\
\text { Chemical } \\
\text { System } \\
\end{array}$ & $\begin{array}{c}\text { Comments on Occurrence } \\
\text { or Formation }\end{array}$ \\
\hline truscottite & $(\mathrm{Ca}, \mathrm{Mn})_{14} \mathrm{Si}_{24} \mathrm{O}_{58}(\mathrm{OH})_{8} \cdot 2 \mathrm{H}_{2} \mathrm{O}$ & No? & No & 6 & No? & $\begin{array}{l}\text { Hydrothermal (only?) mineral. } \\
\text { Other solids (e.g., zeolites, Mn } \\
\text { minerals, and cement phases) } \\
\text { provide adequate } \\
\text { conservatism for elements in } \\
\text { this mineral. }\end{array}$ \\
\hline tschermakite & $\mathrm{Ca}_{2}\left(\mathrm{Mg}, \mathrm{Fe}^{2+}\right)_{3} \mathrm{Al}_{2}\left(\mathrm{Si}_{6} \mathrm{Al}_{2}\right) \mathrm{O}_{22}(\mathrm{OH})_{2}$ & No & No & 1 & No & $\begin{array}{l}\text { Igneous and metamorphic } \\
\text { mineral }\end{array}$ \\
\hline tschermigite & $\left(\mathrm{NH}_{4}\right) \mathrm{Al}\left(\mathrm{SO}_{4}\right)_{2} \cdot 12 \mathrm{H}_{2} \mathrm{O}$ & No & No & 1 & No & $\begin{array}{l}\text { Hydrothermal mineral and } \\
\text { with coal. Requires reducing } \\
\text { conditions. }\end{array}$ \\
\hline tuhualite & $(\mathrm{Na}, \mathrm{K}) \mathrm{Fe}^{2+} \mathrm{Fe}^{3+} \mathrm{Si}_{6} \mathrm{O}_{15}$ & No & No & 1 & No & Igneous mineral \\
\hline tungusite & $\mathrm{Ca}_{4} \mathrm{Fe}^{2+}{ }_{2} \mathrm{Si}_{6} \mathrm{O}_{15}(\mathrm{OH})_{6}$ & No? & No & 1 & No & Occurs in cavities in basalt \\
\hline tunisite & $\mathrm{NaCa}_{2} \mathrm{Al}_{4}\left(\mathrm{CO}_{3}\right)_{4}(\mathrm{OH})_{8} \mathrm{Cl}$ & No & No & 1 & No & Hydrothermal mineral \\
\hline tuperssuatsiaite & $\mathrm{NaFe}_{3}^{3+} \mathrm{Si}_{8} \mathrm{O}_{20}(\mathrm{OH})_{2} \cdot 5 \mathrm{H}_{2} \mathrm{O}$ & Yes? & No & 2 & Yes? & $\begin{array}{l}\text { Hydrothermal (?). Association } \\
\text { with aegirine indicates slow } \\
\text { rate of formation. }\end{array}$ \\
\hline tuscanite & $\mathrm{K}(\mathrm{Ca}, \mathrm{Na})_{6}(\mathrm{Si}, \mathrm{Al})_{10} \mathrm{O}_{22}\left(\mathrm{SO}_{4}, \mathrm{CO}_{3},(\mathrm{OH})_{2}\right) \cdot \mathrm{H}_{2} \mathrm{O}$ & No & No & 1 & No & $\begin{array}{l}\text { Igneous or metamorphic } \\
\text { mineral }\end{array}$ \\
\hline tychite & $\mathrm{Na}_{6} \mathrm{Mg}_{2}\left(\mathrm{SO}_{4}\right)\left(\mathrm{CO}_{3}\right)_{4}$ & Yes & No & 6 & Yes & $\begin{array}{l}\text { Other minerals (e.g., burkeite, } \\
\text { kieserite) provide adequate } \\
\text { conservatism for elements in } \\
\text { this mineral. }\end{array}$ \\
\hline uklonskovite & $\mathrm{NaMg}\left(\mathrm{SO}_{4}\right)(\mathrm{OH}) \cdot 2 \mathrm{H}_{2} \mathrm{O}$ & Yes? & No & 6 & Yes? & $\begin{array}{l}\text { Occurs in marine evaporites. } \\
\text { Other minerals (e.g., } \\
\text { thenardite, kieserite, } \\
\text { villiaumite) provide adequate } \\
\text { conservatism for elements in } \\
\text { this mineral. }\end{array}$ \\
\hline ulvöspinel & $\mathrm{Fe}_{2}^{2+} \mathrm{TiO}_{4}$ & No & No & 1 & No & Igneous mineral \\
\hline ungemachite & $\mathrm{K}_{3} \mathrm{Na}_{8} \mathrm{Fe}^{3+}\left(\mathrm{SO}_{4}\right)_{6}(\mathrm{OH})_{2} \cdot 6 \mathrm{H}_{2} \mathrm{O}$ & Yes & No & 1 & No & Oxidation product in mines \\
\hline ushkovite & $\mathrm{MgFe}_{2}^{3+}{ }_{2}\left(\mathrm{PO}_{4}\right)_{2}(\mathrm{OH})_{2} \bullet 8 \mathrm{H}_{2} \mathrm{O}$ & Yes & No & 1 & No & $\begin{array}{l}\text { Alteration of triplite, not } \\
\text { present }\end{array}$ \\
\hline
\end{tabular}


Table C-1. Critique of Minerals not Included in Project Databases (Continued)

\begin{tabular}{|c|c|c|c|c|c|c|}
\hline Mineral & Chemical Formula & $\begin{array}{l}\text { Precipitates } \\
\text { from } 0 \text { to } 100^{\circ} \mathrm{C} \\
\text { and at } 1 \mathrm{ATM}\end{array}$ & Needed & Criterion & $\begin{array}{l}\text { Within Defined } \\
\text { Physico- } \\
\text { Chemical } \\
\text { System }\end{array}$ & $\begin{array}{c}\text { Comments on Occurrence } \\
\text { or Formation }\end{array}$ \\
\hline ussingite & $\mathrm{Na}_{2} \mathrm{AlSi}_{3} \mathrm{O}_{8}(\mathrm{OH})$ & No & No & 1 & No & Igneous mineral \\
\hline vanthoffite & $\mathrm{Na}_{6} \mathrm{Mg}\left(\mathrm{SO}_{4}\right)_{4}$ & Yes? & No & 6 & Yes? & $\begin{array}{l}\text { Occurs in marine evaporites. } \\
\text { Other minerals (e.g., } \\
\text { thenardite, natron, kieserite) } \\
\text { provide adequate } \\
\text { conservatism for elements in } \\
\text { this mineral. } \\
\end{array}$ \\
\hline variscite & $\mathrm{AlPO}_{4} \cdot 2 \mathrm{H}_{2} \mathrm{O}$ & Yes & No & 1 & No & $\begin{array}{l}\text { Forms from phosphatic waters } \\
\text { altering aluminous rocks }\end{array}$ \\
\hline varulite & $(\mathrm{Na}, \mathrm{Ca}) \mathrm{Mn}\left(\mathrm{Mn}, \mathrm{Fe}^{2+}, \mathrm{Fe}^{3+}\right)_{2}\left(\mathrm{PO}_{4}\right)_{3}$ & No & No & 1 & No & Igneous mineral \\
\hline vashegyite & $\mathrm{Al}_{6}\left(\mathrm{PO}_{4}\right)_{5}(\mathrm{OH})_{3} \cdot 23 \mathrm{H}_{2} \mathrm{O}$ & Yes & No & 1 & No & $\begin{array}{l}\text { Forms from phosphatic waters } \\
\text { altering aluminous rocks }\end{array}$ \\
\hline vaterite & $\mathrm{CaCO}_{3}$ & Yes & No & 1 & No & $\begin{array}{l}\text { Alters from larnite, which is } \\
\text { absent }\end{array}$ \\
\hline vauxite & $\mathrm{Fe}^{2+} \mathrm{Al}_{2}\left(\mathrm{PO}_{4}\right)_{2}(\mathrm{OH})_{2} \cdot 6 \mathrm{H}_{2} \mathrm{O}$ & No & No & 1 & No & $\begin{array}{l}\text { Occurs in hydrothermal tin } \\
\text { deposits }\end{array}$ \\
\hline vernadite & $\mathrm{Mn}(\mathrm{OH})_{4}$ & Yes & No & 6 & Yes & $\begin{array}{l}\text { Pyrolusite provides adequate } \\
\text { conservatism for this mineral. }\end{array}$ \\
\hline vertumnite & $\mathrm{Ca}_{4} \mathrm{Al}_{4} \mathrm{Si}_{4} \mathrm{O}_{6}(\mathrm{OH})_{24} \cdot 3 \mathrm{H}_{2} \mathrm{O}$ & $?$ & No & 6 & No & $\begin{array}{l}\text { Found in a geode in igneous } \\
\text { rock. Various zeolites provide } \\
\text { adequate conservatism. }\end{array}$ \\
\hline vesuvianite & $\mathrm{Ca}_{10} \mathrm{Mg}_{2} \mathrm{Al}_{4}\left(\mathrm{SiO}_{4}\right)_{5}\left(\mathrm{Si}_{2} \mathrm{O}_{7}\right)_{2}(\mathrm{OH})_{4}$ & No & No & 1 & No & $\begin{array}{l}\text { Igneous and metamorphic } \\
\text { mineral }\end{array}$ \\
\hline viitaniemiite & $\mathrm{Na}\left(\mathrm{Ca}, \mathrm{Mn}^{2+}\right) \mathrm{Al}\left(\mathrm{PO}_{4}\right)(\mathrm{F}, \mathrm{OH})_{3}$ & No & No & 1 & No & Igneous mineral \\
\hline vinogradovite & $(\mathrm{Na}, \mathrm{Ca}, \mathrm{K})_{4} \mathrm{Ti}_{4} \mathrm{AlSi}_{6} \mathrm{O}_{23}(\mathrm{OH}) \cdot 2 \mathrm{H}_{2} \mathrm{O}$ & No & No & 1 & No & $\begin{array}{l}\text { Igneous or metamorphic } \\
\text { mineral (or altered there from) } \\
\text { at alkalic pegmatite contacts }\end{array}$ \\
\hline viseite & $\mathrm{NaCa}_{2} \mathrm{Al}_{10}\left(\mathrm{SiO}_{4}\right)_{3}\left(\mathrm{PO}_{4}\right)_{5}(\mathrm{OH})_{14} \cdot 10 \mathrm{H}_{2} \mathrm{O}(?)$ & Yes? & No & 6 & Possibly & $\begin{array}{l}\text { Other minerals (e.g., zeolites } \\
\text { and apatite) provide adequate } \\
\text { conservatism for elements in } \\
\text { this mineral. }\end{array}$ \\
\hline vishnevite & $(\mathrm{Na}, \mathrm{Ca}, \mathrm{K})_{6}(\mathrm{Si}, \mathrm{Al})_{12} \mathrm{O}_{24}\left(\mathrm{SO}_{4}, \mathrm{CO}_{3}, \mathrm{Cl}\right)_{2-4} \bullet \mathrm{nH}_{2} \mathrm{O}$ & No & No & 1 & No & Igneous mineral \\
\hline vivianite & $\mathrm{Fe}^{2+}{ }_{3}\left(\mathrm{PO}_{4}\right)_{2} \bullet 8 \mathrm{H}_{2} \mathrm{O}$ & Yes & No & 1 & No & Requires reducing conditions \\
\hline
\end{tabular}


Table C-1. Critique of Minerals not Included in Project Databases (Continued)

\begin{tabular}{|c|c|c|c|c|c|c|}
\hline Mineral & Chemical Formula & $\begin{array}{c}\text { Precipitates } \\
\text { from } 0 \text { to } 100^{\circ} \mathrm{C} \\
\text { and at } 1 \mathrm{ATM}\end{array}$ & Needed & Criterion & $\begin{array}{l}\text { Within Defined } \\
\text { Physico- } \\
\text { Chemical } \\
\text { System }\end{array}$ & $\begin{array}{c}\text { Comments on Occurrence } \\
\text { or Formation }\end{array}$ \\
\hline voltaite & $\mathrm{K}_{2} \mathrm{Fe}_{5}^{2+} \mathrm{Fe}_{4}^{3+}\left(\mathrm{SO}_{4}\right)_{12} \cdot 18 \mathrm{H}_{2} \mathrm{O}$ & Yes & No & 1 & Yes & $\begin{array}{l}\text { Igneous mineral or sulfide ore } \\
\text { oxidation product }\end{array}$ \\
\hline vuagnatite & $\mathrm{CaAlSiO}{ }_{4}(\mathrm{OH})$ & No & No & 1 & No & Igneous mineral \\
\hline wadsleyite & $\beta-\left(\mathrm{Mg}, \mathrm{Fe}^{2+}\right)_{2} \mathrm{SiO}_{4}$ & No & No & 1 & No & Found in meteorites \\
\hline wagnerite & $\left(\mathrm{Mg}, \mathrm{Fe}^{2+}\right)_{2} \mathrm{PO}_{4} \mathrm{~F}$ & No & No & 1 & No & $\begin{array}{l}\text { Igneous, metamorphic, and } \\
\text { hydrothermal mineral }\end{array}$ \\
\hline wardite & $\mathrm{NaAl}_{3}\left(\mathrm{PO}_{4}\right)_{2}(\mathrm{OH})_{4} \cdot 2 \mathrm{H}_{2} \mathrm{O}$ & Yes? & No & 1 & No & $\begin{array}{l}\text { Occurs in phosphate rocks } \\
\text { and pegmatites }\end{array}$ \\
\hline wattevillite & $\mathrm{Na}_{2} \mathrm{Ca}\left(\mathrm{SO}_{4}\right)_{2} \bullet 4 \mathrm{H}_{2} \mathrm{O}(?)$ & Yes & No & 1 & No & $\begin{array}{l}\text { Occurs in pyritic lignite; } \\
\text { hence, likely an oxidation } \\
\text { product of the pyrite }\end{array}$ \\
\hline wavellite & $\mathrm{Al}_{3}\left(\mathrm{PO}_{4}\right)_{2}(\mathrm{OH}, \mathrm{F})_{3} \cdot 5 \mathrm{H}_{2} \mathrm{O}$ & Yes & No & 1 & No & $\begin{array}{l}\text { Occurs in phosphate, } \\
\text { hydrothermal, and } \\
\text { metamorphic rocks }\end{array}$ \\
\hline weberite & $\mathrm{Na}_{2} \mathrm{MgAlF}_{7}$ & No & No & 1 & No & $\begin{array}{l}\text { Igneous and metamorphic } \\
\text { mineral }\end{array}$ \\
\hline weddellite & $\mathrm{Ca}\left(\mathrm{C}_{2} \mathrm{O}_{4}\right) \cdot 2 \mathrm{H}_{2} \mathrm{O}$ & No? & No & 1 & No & Requires reducing conditions \\
\hline wegscheiderite & $\mathrm{Na}_{5}\left(\mathrm{CO}_{3}\right)\left(\mathrm{HCO}_{3}\right)_{3}$ & Yes & No & 6 & Yes & $\begin{array}{l}\text { Occurs in lacustrine } \\
\text { evaporites. Other minerals } \\
\text { (e.g., nahcolite, natron) } \\
\text { provide adequate } \\
\text { conservatism for elements in } \\
\text { this mineral. } \\
\end{array}$ \\
\hline wermlandite & $\mathrm{Ca}_{2} \mathrm{Mg}_{14} \mathrm{Al}_{4}\left(\mathrm{CO}_{3}\right)(\mathrm{OH})_{42} \cdot 29 \mathrm{H}_{2} \mathrm{O}$ & No & No & 6 & No & $\begin{array}{l}\text { Occurs in an Fe deposit. } \\
\text { Calcite, hydromagnesite, } \\
\text { boehmite provide adequate } \\
\text { conservatism. }\end{array}$ \\
\hline whewellite & $\mathrm{CaC}_{2} \mathrm{O}_{4} \cdot \mathrm{H}_{2} \mathrm{O}$ & Yes & No & 1 & No & $\begin{array}{l}\text { Occurs in coal. Requires } \\
\text { reducing conditions. }\end{array}$ \\
\hline whiteite & $\mathrm{Ca}\left(\mathrm{Fe}, \mathrm{Mn}^{2+}\right) \mathrm{Mg}_{2} \mathrm{Al}_{2}\left(\mathrm{PO}_{4}\right)_{4}(\mathrm{OH})_{2} \bullet 8 \mathrm{H}_{2} \mathrm{O}$ & No & No & 1 & No & Igneous mineral \\
\hline whitmoreite & $\mathrm{Fe}^{2+} \mathrm{Fe}_{2}^{3+}{ }_{2}\left(\mathrm{PO}_{4}\right)_{2}(\mathrm{OH})_{2} \bullet 4 \mathrm{H}_{2} \mathrm{O}$ & No & No & 1 & No & Igneous mineral \\
\hline wicksite & $\mathrm{NaCa}_{2}\left(\mathrm{Fe}^{2+}, \mathrm{Mn}^{2+}\right)_{4} \mathrm{MgFe}^{3+}\left(\mathrm{PO}_{4}\right)_{6} \cdot 2 \mathrm{H}_{2} \mathrm{O}$ & $?$ & No & 1 & No & $\begin{array}{l}\text { Occurs in nodules with pyrite. } \\
\text { Requires reducing conditions }\end{array}$ \\
\hline
\end{tabular}


Table C-1. Critique of Minerals not Included in Project Databases (Continued)

\begin{tabular}{|c|c|c|c|c|c|c|}
\hline Mineral & Chemical Formula & $\begin{array}{l}\text { Precipitates } \\
\text { from } 0 \text { to } 100^{\circ} \mathrm{C} \\
\text { and at } 1 \mathrm{ATM}\end{array}$ & Needed & Criterion & \begin{tabular}{|c|} 
Within Defined \\
Physico- \\
Chemical \\
System \\
\end{tabular} & $\begin{array}{c}\text { Comments on Occurrence } \\
\text { or Formation }\end{array}$ \\
\hline wilcoxite & $\mathrm{MgAl}\left(\mathrm{SO}_{4}\right)_{2} \mathrm{~F} \cdot 18 \mathrm{H}_{2} \mathrm{O}$ & Yes & No & 1 & No & Oxidation product in mines \\
\hline willhendersonite & $\mathrm{KCaAl}_{3} \mathrm{Si}_{3} \mathrm{O}_{12} \cdot 5 \mathrm{H}_{2} \mathrm{O}$ & No? & No & 1 & No & Occurs in cavities in basalt \\
\hline winchite & $\mathrm{NaCa}\left(\mathrm{Mg}, \mathrm{Fe}^{2+}\right)_{4} \mathrm{AlSi}_{8} \mathrm{O}_{22}(\mathrm{OH})_{2}$ & No? & No & 1 & No & Occurs in Mn deposits \\
\hline wolfeite & $\left(\mathrm{Fe}^{2+}, \mathrm{Mn}\right)_{2}\left(\mathrm{PO}_{4}\right)(\mathrm{OH})$ & No & No & 1 & No & $\begin{array}{l}\text { Igneous and hydrothermal } \\
\text { mineral }\end{array}$ \\
\hline wonesite & $(\mathrm{Na}, \mathrm{K})(\mathrm{Mg}, \mathrm{Fe}, \mathrm{Al})_{6}(\mathrm{Si}, \mathrm{Al})_{8} \mathrm{O}_{20}(\mathrm{OH}, \mathrm{F})_{4}$ & No & No & 1 & No & Metamorphic mineral \\
\hline woodhouseite & $\mathrm{CaAl}_{3}\left(\mathrm{PO}_{4}\right)\left(\mathrm{SO}_{4}\right)(\mathrm{OH})_{6}$ & Yes & No & 6 & Yes? & $\begin{array}{l}\text { Metamorphic, and cave, } \\
\text { mineral. Other minerals (e.g., } \\
\text { apatite and gypsum) provide } \\
\text { adequate conservatism for } \\
\text { elements in this mineral. }\end{array}$ \\
\hline wyllieite & $\begin{array}{l}\left(\mathrm{Na}, \mathrm{Ca}, \mathrm{Mn}^{2+}\right)\left(\mathrm{Mn}^{2+}, \mathrm{Fe}^{2+}\right)\left(\mathrm{Fe}^{2+}, \mathrm{Fe}^{3+}, \mathrm{Mg}\right) \mathrm{Al} \\
\left(\mathrm{PO}_{4}\right)_{3}\end{array}$ & $?$ & No & 1 & $?$ & $\begin{array}{l}\text { Mineral is high in Fe and Mn. } \\
\text { Reference provides very little } \\
\text { data on occurrence, but, in } \\
\text { view of the locality, the mine is } \\
\text { likely in a pegmatite. }\end{array}$ \\
\hline xanthoxenite & $\mathrm{Ca}_{4} \mathrm{Fe}_{2}^{3+}{ }_{2}\left(\mathrm{PO}_{4}\right)_{4}(\mathrm{OH})_{2} \cdot 3 \mathrm{H}_{2} \mathrm{O}$ & No & No & 1 & No & $\begin{array}{l}\text { Alters from igneous mineral, } \\
\text { triplite }\end{array}$ \\
\hline xifengite & $\mathrm{Fe}_{5} \mathrm{Si}_{3}$ & No & No & 1 & No & Extraterrestrial origin \\
\hline xitieshanite & $\mathrm{Fe}^{3+}\left(\mathrm{SO}_{4}\right)(\mathrm{OH}) \cdot 7 \mathrm{H}_{2} \mathrm{O}$ & Yes & No & 1 & No & Oxidation product in mines \\
\hline yagiite & $(\mathrm{Na}, \mathrm{K})_{3} \mathrm{Mg}_{4}(\mathrm{Al}, \mathrm{Mg})_{6}(\mathrm{Si}, \mathrm{Al})_{24} \mathrm{O}_{60}$ & No & No & 1 & No & Found in meteorites \\
\hline yaroslavite & $\mathrm{Ca}_{3} \mathrm{Al}_{2} \mathrm{~F}_{10}(\mathrm{OH})_{2} \bullet \mathrm{H}_{2} \mathrm{O}$ & Yes & No & 1 & No & Oxidation product in mines \\
\hline yavapaiite & $\mathrm{KFe}^{3+}\left(\mathrm{SO}_{4}\right)_{2}$ & Yes & No & 1 & No & Oxidation product in mines \\
\hline ye'elimite & $\mathrm{Ca}_{4} \mathrm{Al}_{6} \mathrm{O}_{12}\left(\mathrm{SO}_{4}\right)$ & No & No & 1 & No & Metamorphic mineral \\
\hline yoderite & $(\mathrm{Al}, \mathrm{Mg}, \mathrm{Fe})_{2} \mathrm{Si}(\mathrm{O}, \mathrm{OH})_{5}$ & No & No & 1 & No & Metamorphic mineral \\
\hline yofortierite & $(\mathrm{Mn}, \mathrm{Mg})_{5} \mathrm{Si}_{8} \mathrm{O}_{20}(\mathrm{OH})_{2} \bullet 4-5 \mathrm{H}_{2} \mathrm{O}$ & No & No & 1 & No & Igneous mineral \\
\hline yugawaralite & $\mathrm{CaAl}_{2} \mathrm{Si}_{6} \mathrm{O}_{16} \bullet 4 \mathrm{H}_{2} \mathrm{O}$ & No & No & 1 & No & Hydrothermal mineral \\
\hline yuksporite & $\mathrm{KNaCa}_{2}(\mathrm{Si}, \mathrm{Ti})_{4} \mathrm{O}_{11} \mathrm{~F} \bullet \mathrm{nH}_{2} \mathrm{O}$ & $?$ & No & 6 & $?$ & $\begin{array}{l}\text { No data on occurrence in } \\
\text { reference. Other minerals } \\
\text { (e.g., zeolites, rutile) provide } \\
\text { adequate conservatism for } \\
\text { elements in this mineral. }\end{array}$ \\
\hline
\end{tabular}


Table C-1. Critique of Minerals not Included in Project Databases (Continued)

\begin{tabular}{|c|c|c|c|c|c|c|}
\hline Mineral & Chemical Formula & $\begin{array}{l}\text { Precipitates } \\
\text { from } 0 \text { to } 100^{\circ} \mathrm{C} \\
\text { and at } 1 \mathrm{ATM}\end{array}$ & Needed & Criterion & \begin{tabular}{|c|} 
Within Defined \\
Physico- \\
Chemical \\
System \\
\end{tabular} & $\begin{array}{c}\text { Comments on Occurrence } \\
\text { or Formation }\end{array}$ \\
\hline zaherite & $\mathrm{Al}_{12}\left(\mathrm{SO}_{4}\right)_{5}(\mathrm{OH})_{26} \cdot 2 \mathrm{OH}_{2} \mathrm{O}$ & Yes? & No & 6 & No & $\begin{array}{l}\text { Occurs with other Al minerals. } \\
\text { Kaolinite and boehmite } \\
\text { provide adequate } \\
\text { conservatism for this mineral. }\end{array}$ \\
\hline zakharovite & $\mathrm{Na}_{4} \mathrm{Mn}^{2+}{ }_{5} \mathrm{Si}_{10} \mathrm{O}_{24}(\mathrm{OH})_{6} \cdot 6 \mathrm{H}_{2} \mathrm{O}$ & No & No & 1 & No & $\begin{array}{l}\text { Igneous or metamorphic } \\
\text { mineral }\end{array}$ \\
\hline zeophyllite & $\mathrm{Ca}_{4} \mathrm{Si}_{3} \mathrm{O}_{8}(\mathrm{OH}, \mathrm{F})_{4} \cdot 2 \mathrm{H}_{2} \mathrm{O}$ & No? & No & 1 & No & Occurs in cavities in basalt \\
\hline zhemchuzhnikovite & $\mathrm{NaMg}\left(\mathrm{Al}, \mathrm{Fe}^{3+}\right)\left(\mathrm{C}_{2} \mathrm{O}_{4}\right)_{3} \cdot 8 \mathrm{H}_{2} \mathrm{O}$ & Yes & No & 1 & No & $\begin{array}{l}\text { Requires reducing conditions, } \\
\text { occurs in coal. }\end{array}$ \\
\hline zirklerite & $(\mathrm{Fe}, \mathrm{Mg}, \mathrm{Ca})_{9} \mathrm{Al}_{4} \mathrm{Cl}_{18}(\mathrm{OH})_{12} \cdot 14 \mathrm{H}_{2} \mathrm{O}(?)$ & Yes? & No & 6 & Yes? & $\begin{array}{l}\text { Occurs in marine evaporites. } \\
\text { Other solids (e.g., bischofite, } \\
\text { sinjarite, portlandite, } \mathrm{Fe}(\mathrm{OH})_{2} \text {, } \\
\text { molysite) provide adequate } \\
\text { conservatism for elements in } \\
\text { this mineral. }\end{array}$ \\
\hline zorite & $\mathrm{Na}_{3}(\mathrm{Ti}, \mathrm{Al})_{2} \mathrm{Si}_{4}(\mathrm{O}, \mathrm{OH})_{14} \bullet 3 \mathrm{H}_{2} \mathrm{O}$ & No & No & 1 & No & Igneous mineral \\
\hline zunyite & $\mathrm{Al}_{13} \mathrm{Si}_{5} \mathrm{O}_{20}(\mathrm{OH}, \mathrm{F})_{18} \mathrm{Cl}$ & No & No & 1 & No & $\begin{array}{l}\text { Occurs in igneous, } \\
\text { hydrothermal, and highly } \\
\text { aluminous deposits }\end{array}$ \\
\hline zussmanite & $\mathrm{K}\left(\mathrm{Fe}^{2+}, \mathrm{Mg}, \mathrm{Mn}\right)_{13}(\mathrm{Si}, \mathrm{Al})_{18} \mathrm{O}_{42}(\mathrm{OH})_{14}$ & No & No & 1 & No & Metamorphic mineral \\
\hline zwieselite & $\left(\mathrm{Fe}^{2+}, \mathrm{Mn}^{2+}, \mathrm{Mg}, \mathrm{Ca}\right)_{2}\left(\mathrm{PO}_{4}\right)(\mathrm{F}, \mathrm{OH})$ & No & No & 1 & No & Igneous mineral \\
\hline
\end{tabular}

NOTE: The "?" indicates that there is not enough information in the listing by Roberts et al. (1990 [DIRS 107105]) to infer or deduce the conditions under which the mineral occurs. In such cases, a conservative approach is taken that it could occur under repository conditions. "No?" means that there is enough information to conclude that the answer is probably no, but that the data given are not definitive. This is similar for "yes?" The (?) after the chemical formula indicates that the waters of hydration may vary from the stated formula. 
APPENDIX D

QUALIFICATION OF DATA FROM DTN: LL980704605924.035

FOR INTENDED USE PER LP-SIII.2Q-BSC 


\section{INTENTIONALLY LEFT BLANK}


This appendix documents the qualification of corrosion rate data for low-alloy carbon steel listed in DTN: LL980704605924.035 ([DIRS 147298], Supplemental Table S98217_016), and serves as the data qualification report for the specified set of data within this DTN. This data qualification effort was carried out as described in the Data Qualification Plan that is included in the records package for this model report. A facsimile of the Data Qualification Plan is included in Section D.7 of this appendix.

\section{D.1 PURPOSE OF DATA QUALIFICATION}

The data set to be qualified for intended use, located within DTN: LL980704605924.035 ([DIRS 147298], Supplemental Table S98217_016) was developed by McCright (1998 [DIRS 114637]) and is pre-PVAR YMP data. Therefore, it must be justified for intended use per the guidance and requirements of LP-SIII.2Q-BSC, Qualification of Unqualified Data. The corrosion rate data to be qualified is presented in Table D-1 and Table 4.1-2 of this report.

Table D-1. Low-Alloy Carbon Steel Corrosion Rates from DTN: LL980704605924.035 [DIRS 147298], Supplemental Table S98217_016, to Be Qualified

\begin{tabular}{|c|c|c|c|}
\hline Material & Corrosion Rate $(\mu \mathrm{m} / \mathbf{y r})$ & Material & Corrosion Rate $(\mu \mathrm{m} / \mathbf{y r})$ \\
\hline Carbon Steel Type A516 & 241.82 & A27 Grade 70-40 & 150.33 \\
\hline A516 Grade 55 & 321.66 & A27 Grade 70-40 & 210.6 \\
\hline A516 Grade 55 & 257.97 & A27 Grade 70-40 & 313.05 \\
\hline A516 Grade 55 & 238.11 & A27 Grade 70-40 & 166.22 \\
\hline A516 Grade 55 & 195.23 & A27 Grade 70-40 & 261.61 \\
\hline A516 Grade 55 & 192.02 & A27 Grade 70-40 & 203.28 \\
\hline A516 Grade 55 & 185.47 & A27 Grade 70-40 & 75.29 \\
\hline A516 Grade 55 & 228.28 & A27 Grade 70-40 & 93.33 \\
\hline A516 Grade 55 & 228.04 & A27 Grade 70-40 & 102.31 \\
\hline A516 Grade 55 & 276.51 & A27 Grade 70-40 & 129.12 \\
\hline A516 Grade 55 & 175.85 & A27 Grade 70-40 & 180.84 \\
\hline A516 Grade 55 & 269.12 & A27 Grade 70-40 & 218.57 \\
\hline A516 Grade 55 & 342.99 & A27 Grade 70-40 & 212.81 \\
\hline A516 Grade 55 & 363.36 & A27 Grade 70-40 & 193.28 \\
\hline A516 Grade 55 & 358.68 & A27 Grade 70-40 & 272.06 \\
\hline A516 Grade 55 & 423.06 & A27 Grade 70-40 & 80.15 \\
\hline A516 Grade 55 & 190.72 & A27 Grade 70-40 & 120.81 \\
\hline A516 Grade 55 & 139.58 & A27 Grade 70-40 & 168.75 \\
\hline A516 Grade 55 & 133.91 & A27 Grade 70-40 & 72.96 \\
\hline A516 Grade 55 & 121.31 & A27 Grade 70-40 & 85.05 \\
\hline A516 Grade 55 & 144.45 & A27 Grade 70-40 & 87.64 \\
\hline A516 Grade 55 & 132 & A27 Grade 70-40 & 113.86 \\
\hline A516 Grade 55 & 146.48 & A27 Grade 70-40 & 146.72 \\
\hline & & A27 Grade 70-40 & 220.08 \\
\hline
\end{tabular}

NOTE: All corrosion rates determined for atmospheric vapor phase and simulated concentrated well water (SCW) at $90^{\circ} \mathrm{C}$. 
Table D-2. Summary of Low-Alloy Carbon Steel Corrosion Rates from DTN: LL980704605924.035

\begin{tabular}{|c|c|}
\hline Summary Result & Corrosion Rate $(\mu \mathrm{m} / \mathrm{yr})^{\mathrm{a}}$ \\
\hline Maximum Corrosion Rate & 423.06 \\
\hline Mean Corrosion Rate & $195.44^{b}$ \\
\hline Minimum Corrosion Rate & 72.96 \\
\hline
\end{tabular}

\section{D.2 PURPOSE OF DATA BEING QUALIFIED}

The data being qualified provide corrosion rates for low-alloy carbon steel under temperature conditions intended to simulate those expected in the in-drift environment. Specifically, the mean corrosion rate of $195.44 \mu \mathrm{m} / \mathrm{yr}$ (Table D-2) was calculated within Output DTN: MO0407SPAPCEML.005 (tab "mild-structural-carbon steel") from these unqualified corrosion rate data listed in Table D-1, and then used as direct input in Section 6.4.2 (Table 6.4-18) to calculate the estimated in-drift corrosion rates for low-alloy carbon steel. The mean corrosion rate of $195.44 \mu \mathrm{m} / \mathrm{yr}$ within Output DTN: MO0407SPAPCEML.005 was determined using unqualified corrosion rate data that originates in DTN: LL980704605924.035 within Supplemental Table S98217_016. Furthermore, the mean corrosion rate of $195.44 \mu \mathrm{m} /$ year was used as direct input for calculating the availability of oxygen in Section 6.7.1. Calculations to determine the availability of oxygen are archived in the spreadsheet Oxygen Demand.xls (Output DTN: SN0407T0510102.017).

\section{D.3 QUALIFICATION METHODS}

Consistent with LP-SIII.2Q-BSC, the method selected to qualify these data is Method 2 in Attachment 3 of the procedure:

Corroborating Data - The data to be qualified are compared with an independent data set from ASTM Special Technical Publication No. 335 [DIRS 170256]. The data to be qualified given in Table D-1 comes specifically from experiments of McCright (1998 [DIRS 114637]). Data from ASTM Special Technical Publication No. 335 (ASTM 1968 [DIRS 170256]) is used as corroborating data.

\section{D.4 QUALIFICATION PROCESS ATTRIBUTES}

Consistent with LP-SIII.2Q-BSC from Attachment 4, the attributes associated with this data qualification include:

(3) The extent to which the data demonstrate the properties of interest (e.g., physical, chemical, geologic, mechanical).

This attribute is justified for application here because the data being qualified were specifically developed to determine corrosion rates of low-alloy carbon steels (Carbon Steel Types A516 
Grade 55 and A27 Grade 70-40). The mean corrosion rate was then determined and was used as direct input into the model.

(10) Extent and quality of corroborating data or confirmatory testing results.

The extent of corrosion rate data for low-alloy carbon steels is abundant in the literature but very limited at temperature above ambient conditions $\left(>25^{\circ} \mathrm{C}\right)$. In fact, most studies concerning corrosion rates of various metals are performed below $25^{\circ} \mathrm{C}$. Furthermore, corroborating data (independent of McCright 1998 [DIRS 114637]) at atmospheric temperatures of $90^{\circ} \mathrm{C}$ (i.e., temperature that is similar to in-drift environment) that determine corrosion rates of low-alloy carbon steel is lacking and none could be located for this qualification effort. Therefore, lower temperature corrosion rate data specified in Table D-3 is presented as corroborating data.

The quality of corroborating data given in Table D-3 from ASTM Special Technical Publication No. 335 (ASTM 1968 [DIRS 170256]) is considered sufficient because publications by ASTM follow their own stringent ASTM standards for experimental methodology involving data collection. Much of the data results issued by ASTM involve contributions of many of the country's leading technical experts from industry, scientific agencies, and government. Additionally, the corroborating data in Table D-3 has been cited in many publications since it was presented at Metal Corrosion in the Atmosphere, A Symposium Presented at the Seventieth Annual Meeting, Boston, Massachusetts, 25-30 June, 1967. The following three publications are examples of technical handbooks that have cited the corroborating data in Table D-3:

- Davis, J.R., ed. 1996. ASM Specialty Handbook: Carbon and Alloy Steels. Materials Park, Ohio: ASM International. TIC: 246396 [DIRS 117493].

- ASM International 1987. Corrosion. Volume 13 of ASM Handbook. 9th Edition. Materials Park, Ohio: ASM International. TIC: 240704 [DIRS 101992].

- Matsushima, I. 2000. "Carbon Steel-Atmospheric Corrosion.” Chapter 30 of Uhlig's Corrosion Handbook. 2nd Edition. Revie, R.W., ed. New York, New York: John Wiley \& Sons. TIC: 248360 [DIRS 159370].

\section{D.5 CORROBORATING DATA}

Table D-3 contains the corroborating data from ASTM Special Technical Publication No. 335 (ASTM 1968 [DIRS 170256], Table 9, pp. 371 and 372). The model input corrosion rate of $195.44 \mu \mathrm{m} / \mathrm{yr}$ (Table D-2) can be compared to column 3 (loss $\mu \mathrm{m} / \mathrm{yr}$ ) in Table D-3. 
Table D-3. Corroborating Ambient Temperature Corrosion Rate Data for Low-Alloy Carbon Steels from ASTM Special Technical Publication No. 335 (ASTM 1968 [DIRS 170256], Table 16)

\begin{tabular}{|l|c|c|}
\hline \multicolumn{1}{|c|}{ Location } & 2-Year Mass Loss $(\mathbf{g})$ & Loss $(\mu \mathrm{m} / \mathrm{yr})$ \\
\hline Cape Kennedy, 55 m (60 yd) from ocean, 60 ft elevation & 64.0 & 132 \\
\hline Kure Beach, NC, 250 m (800 ft) lot & 71.0 & 146 \\
\hline Cape Kennedy, 55 m (60 yd) from ocean, 9 m (30 ft) elevation & 80.2 & 165 \\
\hline Daytona Beach, FL & 144 & 296 \\
\hline Widness, England & 174 & 358 \\
\hline Cape Kennedy, 55 m (60 yd) from ocean, ground level & 215 & 442 \\
\hline Dungeness, England & 238 & 490 \\
\hline Point Reyes, Ca & 244 & 502 \\
\hline Kure Beach, NC, 25 m (80 ft) lot & 260 & 534 \\
\hline Galeta Point Beach, Panama, C.Z. & 336 & 691 \\
\hline
\end{tabular}

NOTE: The source reference (ASTM 1968 [DIRS 170256]) gives corrosion rates as two-year mass loss (g)(column 2). Loss (column 3 ) is calculated first by determining the area of the plate of the experiments in $\mathrm{cm}^{2}\left(10.16 \mathrm{~cm} \times 15.24 \mathrm{~cm}=154.8 \mathrm{~cm}^{2}\right)$; then, multiplying $154.8 \mathrm{~cm}^{2}$ by 2 to account for both sides of the plate, the total area of both sides of the plate becomes $309.6 \mathrm{~cm}^{2}$. Next, the two-year mass loss ( $\mathrm{g}$ ) in column 2 is divided by $309.6 \mathrm{~cm}^{2}$ divided by time (2 years). This result is then divided by the density of the low-alloy steel plate $\left(7.85 \mathrm{~g} / \mathrm{cm}^{3}\right)$ and multiplied by 10,000 (conversion of $\mathrm{cm}$ to $\mu \mathrm{m}$ ).

\section{D.6 EVALUATION OF DATA QUALIFICATION EFFORT}

Corrosion rates of low-alloy carbon steel from the independent data set (Table D-3) at or near ambient temperatures $\left(<25^{\circ} \mathrm{C}\right)$ give a range from $132 \mu \mathrm{m} / \mathrm{yr}$ to $691 \mu \mathrm{m} / \mathrm{yr}$. The direct input corrosion rate of $195.44 \mu \mathrm{m} / \mathrm{yr}$ (mean value from Table D-2) is within this range of the corroborating independent corrosion rate data. A mean corrosion rate was not calculated for the independent data set in Table D-3 because these data comes from many different experimental test locations.

Environmental conditions under which the corroborating corrosion rates (Table D-3) were collected reasonably simulate the conditions of the data to be qualified. This is an important factor for the qualification of the data because the data to be qualified were collected under experimental conditions prepared to simulate the in-drift environment. The data to be qualified from McCright (1998 [DIRS 114637]) involved experiments that measured the corrosion rate of low-alloy carbon steel exposed to atmospheric vapor phase above $\mathrm{SCW}$ at $90^{\circ} \mathrm{C}$. The corroborating independent corrosion rates (Table D-3) were also determined under atmospheric vapor-phase conditions and were performed near seawater. The SCW water used in the McCright (1998 [DIRS 114637]) experiments (J-13 well water concentrated to 1000×) is similar to seawater in major ion contents $\left(\mathrm{K}^{+}, \mathrm{Na}^{+}, \mathrm{NO}_{3}{ }^{-}\right.$, and $\left.\mathrm{Cl}^{-}\right)$, and thus the basic conditions are similar.

Therefore, based on the above assessment that experimental physical conditions of the data to be qualified were reasonably similar to the experimental conditions of the corroborating data, and that the comparison of the model input corrosion rate is within an acceptable range of corroborating data, the input data given in Table D-1 have been demonstrated to be justified and qualified for their intended use. 


\section{D.7 DATA QUALIFICATION PLAN}

\begin{tabular}{c|c|c} 
BSC & $\begin{array}{c}\text { Data Qualification Plan } \\
\text { Complete only applicable items. }\end{array}$ & $\begin{array}{l}\text { QA: QA } \\
\text { Page 1 of 1 }\end{array}$
\end{tabular}

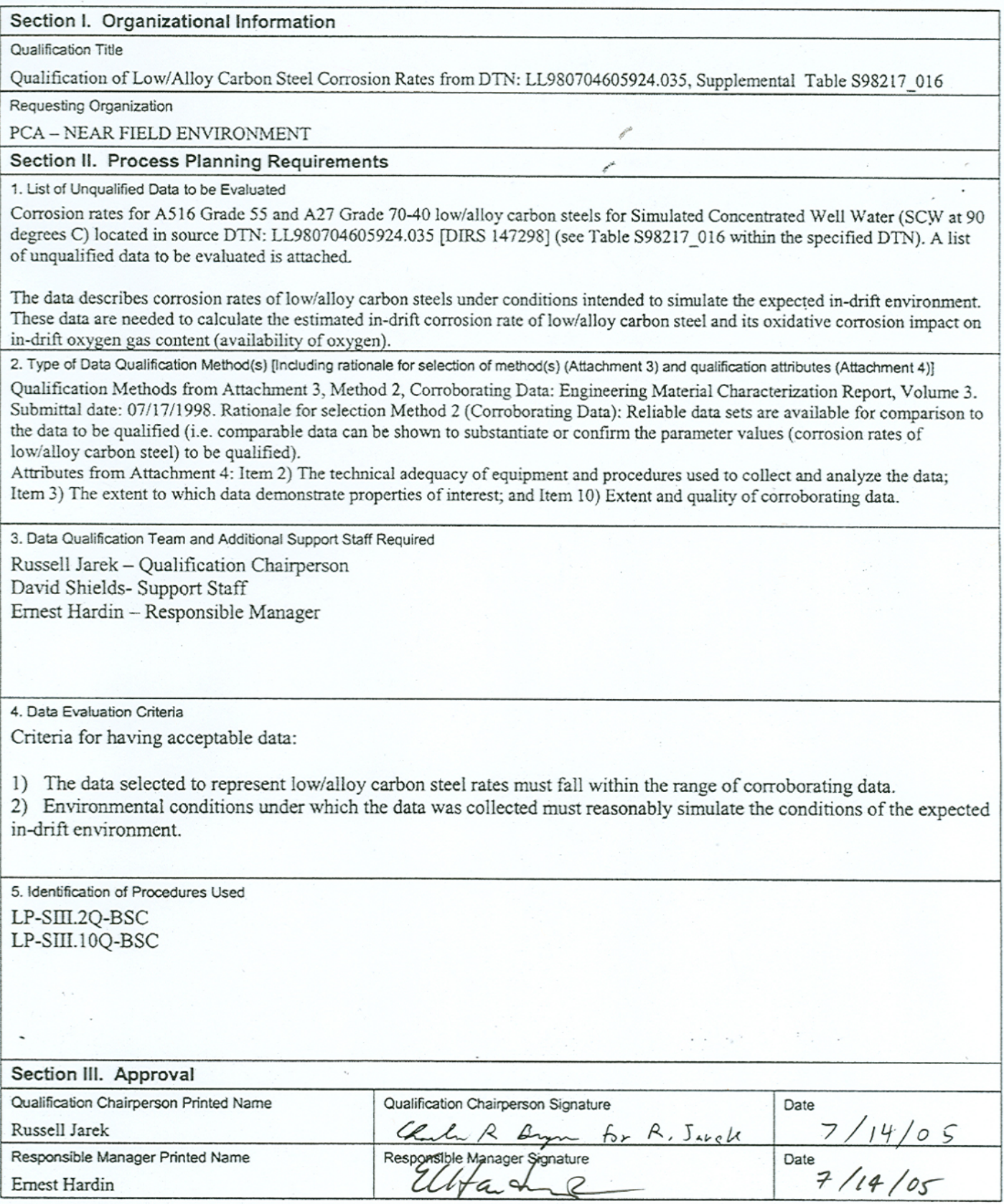

LP.SIII.2Q-BSC 


\section{INTENTIONALLY LEFT BLANK}

